Tierärztliches Institut

der Georg-August-Universität Göttingen

\title{
Handbuch der monogenen Erbmerkmale beim Hund
}

\author{
Dissertation \\ zur Erlangung des Doktorgrades \\ der Fakultät für Agrarwissenschaften \\ der Georg-August-Universität Göttingen
}

vorgelegt von

Sibylle Hahn

geboren in Göttingen

Göttingen, Januar 2008 
D 7

1. Referentin/Referent: Prof. Dr. Dr. Bertram Brenig

2. Korreferentin/Korreferent: Prof. Dr. Christoph Knorr

Tag der mündlichen Prüfung: 21.01.2008 


\section{Inhalt}

Verzeichnis der Abbildungen $\quad$ xxi

Verzeichnis der Tabellen $\quad$ xxvii

1

Einleitung 1

$1.1 \quad$ Literatur 4

$2 \quad$ Erläuterungen zu grundlegenden Begriffen und Methoden

$2.1 \quad$ Typen von Mutationen 6

$2.2 \quad$ Mögliche Auswirkungen von Mutationen 9

2.3 Methodisches Handwerkszeug für die Genotypisierung 11

2.3.1 Isolierung von DNA 11

2.3.2 Polymerasekettenreaktion (PCR) 12

$\begin{array}{lll}\text { 2.3.3 Elektrophorese } & 13\end{array}$

$2.4 \quad$ Genotypisierungsverfahren 14

2.4.1 Allelspezifische PCR (ASP) 14

$\begin{array}{lll}2.4 .2 & \text { Sequenzierung } & 14\end{array}$

2.4.3 Pyrosequenzierung 16

2.4.4 Heteroduplexanalyse 17

2.4.5 Restriktionsfragmentlängenpolymorphismus 18

2.4.6 SSCP-Analyse (single strand conformation polymorphism) 19

2.4.7 Allelspezifische Oligonukleotidhybridisierung (ASO) 19

2.4.8 Oligonukleotid-Ligations-Assay (OLA) 21

2.4.9 Mikrosatellitenanalyse 21

2.5 Strategien zur Identifizierung molekulargenetischer Ursachen von Erbkrankheiten oder morphologischen Merkmalen 22

$2.6 \quad$ Literatur 26 
3.1 Genetisch bedingte Störungen der Hämostase

3.1.1 Thrombozytenerkrankungen 32

I. Krankheitsbild

I.a+b Thrombozytische Thrombasthenie der Otterhunde und Thrombopathie der Pyrenäenberghunde

I.c Thrombopathie (Bernard Soulier's Disease) der Otterhunde 35

I.d Thrombopathie der Bassets 36

II. Genetischer Hintergrund 36

III.a Ursächliche Mutation für Thrombopathie bei Pyrenäenberghunden 38

IV.a Genotypisierung für Thrombopathie bei Pyrenäenberghunden 39

III.b Ursächliche Mutation für Thrombozytische Thrombasthenie bei Otterhunden

von Willebrand Disease (vWD)

I. Krankheitsbild

I.a von Willebrand Disease I

I.b von Willebrand Disease II 43

I.c von Willebrand Disease III 43

II. Genetischer Hintergrund $\quad 44$

III.a Ursächliche Mutation für vWD I bei Dobermännern, Manchester Terriern und Pudeln $\quad 46$

IV.a Genotypisierung für vWD I bei Dobermännern, Manchester Terriern und Pudeln

III.b Ursächliche Mutation für vWD II bei Deutsch Drahthaar und Deutsch Kurzhaar Vorstehhunden

IV.b Genotypisierung für vWD II bei Deutsch Drahthaar und Deutsch Kurzhaar Vorstehhunden 
III.c Ursächliche Mutation für vWD III bei Holländischen Kooiker Hunden

IV.c Genotypisierung für vWD III bei Holländischen Kooiker Hunden

III.d Ursächliche Mutation für vWD III bei Scottish Terriern

IV.d Genotypisierung für vWD III bei Scottish Terriern

III.e Ursächliche Mutation für vWD III bei Shetland

Schäferhunden

IV.e Genotypisierung für vWD III bei Shetland Schäferhunden

3.1.3 Hämophilie A und B

I. Krankheitsbild

II.a+b Genetischer Hintergrund der Hämophilie A

III.a Ursächliche Mutation der schweren Hämophilie A bei Irischen Settern, Schnauzern und Redbone Coonhounds

IV.a Genotypisierung für schwere Hämophilie A bei Irischen Settern, Schnauzern und Redbone Coonhunds

III.b Assoziation eines Polymorphismus des Mikrosatelliten F8C mit mittelschwerer Hämophilie A bei Golden Retrievern

II.c-h Genetischer Hintergrund der Hämophilie B

III.c Ursächliche Mutation für Hämophilie B bei Cairn Terriern

IV.c Genotypisierung für Hämophilie B bei Cairn Terriern

III.d Ursächliche Mutation für Hämophilie B bei Lhasa Apsos

IV.d Genotypisierung für Hämophilie B bei Lhasa Apso Hunden

III.e Ursächliche Mutation für Hämophilie B bei Labrador Retrievern

IV.f Genotypisierung für Hämophilie B bei Airdale Terriern

III.g Ursächliche Mutation für Hämophilie B bei Pit-BullMischlingen

III.h Ursächliche Mutation für Hämophilie B bei Deutsch Drahthaar Vorstehhunden 
IV.h Genotypisierung für Hämophilie B bei Deutsch Drahthaar Vorstehhunden

3.1.4 Weitere Faktormangelerkrankungen 73

$\begin{array}{lll}\text { 3.1.5 Faktor-XI-Defizienz } & 73\end{array}$

$\begin{array}{ll}\text { I. Krankheitsbild } & 73\end{array}$

II. Genetischer Hintergrund 73

III. Ursächliche Mutation für Faktor-XI-Defizienz bei Kerry Blue Terriern

$\begin{array}{lll}\text { 3.1.6 Faktor-VII-Defizienz } & 75\end{array}$

$\begin{array}{ll}\text { I. Krankheitsbild } & 75\end{array}$

II. Genetischer Hintergrund 76

III. Ursächliche Mutation der Faktor VII Defizienz bei Beagles 77

IV. Genotypisierung für Faktor-VII-Defizienz bei Beagles $\quad 78$

$\begin{array}{lll}\text { 3.1.7 Primerliste } & 79\end{array}$

$\begin{array}{lll}\text { 3.1.8 Literatur } & 81\end{array}$

$\begin{array}{lll}3.2 & \text { Hereditäre Erkrankungen des Immunsystems } & 87\end{array}$

$\begin{array}{lll}\text { 3.2.1 Canine zyklische Neutropenie (CN) } & 87\end{array}$

$\begin{array}{ll}\text { I. Krankheitsbild } & 87\end{array}$

II. Genetischer Hintergrund 88

III. Ursächliche Mutation für zyklische Neutropenie bei Collies $\quad 91$

IV. Genotypisierung für zyklische Neutropenie 92

3.2.2 Canine Leukozytenadhäsionsdefizienz (CLAD) 93

I. Krankheitsbild 93

II. Genetischer Hintergrund 95

III. Ursächliche Mutation für CLAD bei Irischen Settern und Irischen Rot-Weißen Settern $\quad 96$

IV. Genotypisierung für CLAD bei Irischen Settern und Irischen Rot-Weißen Settern 
3.2.3 Schwere kombinierte Immundefizienz (Severe Combined Immunodeficiency, SCID) 99

I. Krankheitsbild 99

I.a+b SCID bei Bassets und Cardigan Welsh Corgis 100

$\begin{array}{ll}\text { I.c SCID bei Jack Russell Terrier } & 101\end{array}$

II.a+b Genetischer Hintergrund der SCID bei Bassets und Cardigan Welsh Corgis

103

III.a Ursächliche Mutation für SCID bei Bassets 104

III.b Ursächliche Mutation bei Cardigan Welsh Corgis 105

$\begin{array}{ll}\text { IV.a Genotypisierung für SCID bei Bassets } & 107\end{array}$

IV.b Genotypisierung für SCID bei Cardigan Welsh Corgis 107

II.c Genetischer Hintergrund von SCID bei Jack Russell Terriern 107

III.c Ursächliche Mutation für SCID bei Jack Russel Terriern 108

IV.c Genotypisierung für SCID bei Jack Russell Terriern 109

$\begin{array}{lll}3.2 .4 & 110\end{array}$

$\begin{array}{ll}\text { I. Krankheitsbild } & 110\end{array}$

II. Genetischer Hintergrund 111

III. Ursächliche Mutation der C3-Defizienz bei Bretonischen Spaniels 112

IV. Genotypisierung für C3-Defizienz bei Bretonischen Spaniels 113

$\begin{array}{lll}3.2 .5 & \text { Primerliste } & 114\end{array}$

$\begin{array}{lll}\text { 3.2.6 Literatur } & 115\end{array}$

3.3 Hereditäre Speicherdefekte $\quad 121$

$\begin{array}{lll}\text { 3.3.1 } & \text { Lysosomale Speicherdefekte } & 121\end{array}$

$\begin{array}{lll}\text { 3.3.1.1 Lysosomale Saccharidosen } & 125\end{array}$ 
$\begin{array}{lll}\text { 3.3.1.1.1 Mucopolysaccharidose I } & 128\end{array}$

$\begin{array}{ll}\text { I. Krankheitsbild } & 128\end{array}$

II. Genetischer Hintergrund 129

III. Ursächliche Mutation für MPS I bei Plotthounds 131

IV. Genotypisierung für MPS I bei Plotthounds 131

3.3.1.1.2 Mucopolysaccharidose III 132

3.3.1.1.2.1 Mucopolysaccharidose IIIA 132

I. Krankheitsbild 132

II. Genetischer Hintergrund 134

III.a Ursächliche Mutation für MPS IIIA bei Rauhaardackeln 134

III.b Ursächliche Mutation der MPS IIIA bei Neuseeländischen Huntaways 135

IV.b Genotypisierung für MPS IIIA bei Neuseeländischen Huntaways 136

$\begin{array}{lll}\text { 3.3.1.1.2.2 } & \text { Mucopolysaccharidose III B } & 137\end{array}$

$\begin{array}{ll}\text { I. Krankheitsbild } & 137\end{array}$

II. Genetischer Hintergrund 137

III. Ursächliche Mutation für MPS III B bei Belgischen Schifferspitzen 138

$\begin{array}{lll}\text { 3.3.1.1.3 Mucopolysaccharidose VI } & 139\end{array}$

$\begin{array}{ll}\text { I. Krankheitsbild } & 139\end{array}$

II. Genetischer Hintergrund 140

III.a Ursächliche Mutation der MPS VI bei Zwergschnauzern $\quad 140$

III.b Ursächliche Mutation der MPS VI bei Zwergpinschern $\quad 141$

$\begin{array}{lll}\text { 3.3.1.1.4 Mucopolysaccharidose VII } & 141\end{array}$

$\begin{array}{ll}\text { I. Krankheitsbild } & 141\end{array}$

II. Genetischer Hintergrund 143

III. Ursächliche Mutation für Mucopolysaccharidose VII 144

IV. Genotypisierung für MPS VII 144 
$\begin{array}{lll}\text { 3.3.1.1.5 } & \text { Fukosidose } & 145\end{array}$

I. Krankheitsbild 145

II. Genetischer Hintergrund 146

III. Ursächliche Mutation der Fukosidose bei Englischen Springer Spaniels

IV. Genotypisierung für Fukosidose bei Englischen Springer Spaniels

3.3.1.1.6 Lafora-Krankheit 149

$\begin{array}{ll}\text { I. Krankheitsbild } & 149\end{array}$

II. Genetischer Hintergrund 150

III. Ursächliche Mutation für die Lafora Krankheit bei $\begin{array}{ll}\text { Zwergrauhaardackeln und Bassets } & 151\end{array}$

IV. Genotypisierung für die Lafora-Krankheit bei Zwergrauhaardackeln und Bassets 152

3.3.1.2 Lysosomale Proteinosen: Ceroid-Lipofuscinosen 153

3.3.1.2.1 Frühadult-akute Form 156

I. Krankheitsbild 156

II. Genetischer Hintergrund 159

II.a Genetischer Hintergrund bei Englischen Settern 159

II.b Genetischer Hintergrund bei Border Collies 160

II.c Genetischer Hintergrund bei Langhaardackeln 161

III.a Ursächliche Mutation der CL bei Englischen Settern 162

IV.a Genotypisierung für CL bei Englischen Settern 163

III.b Ursächliche Mutation für CL bei Border Collies 164

IV.b Genotypisierung für CL bei Border Collies 165

III.c Ursächliche Mutation für CL bei Langhaardackeln 165

IV.c Genotypisierung für CL bei Langhaardackeln 166

3.3.1.2.2 Präpubertär-langwierige Form 166 
$\begin{array}{lll}\text { 3.3.1.2.3 Adulte Form } & 167\end{array}$

$\begin{array}{lr}\text { I. Krankheitsbild } & 167\end{array}$

II. Genetischer Hintergrund 167

III. Ursächliche Mutation bei American Bulldogs 168

IV. Genotypisierung für CL bei American Bulldogs 170

$\begin{array}{lll}\text { 3.3.1.3 Lysosomale Sphingolipidosen } & 171\end{array}$

$\begin{array}{lll}\text { 3.3.1.3.1 GM1-Gangliosidose } & 172\end{array}$

$\begin{array}{ll}\text { I. Krankheitsbild } & 172\end{array}$

II. Genetischer Hintergrund 173

III.a Ursächliche Mutation für GM1-Gangliosidose bei

Portugiesischen Wasserhunden 175

IV.a Genotypisierung für GM1-Gangliosidose bei Portugiesischen Wasserhunden

III.b Ursächliche Mutation der GM1-Gangliosidose bei Shiba Hunden 176

IV.b Genotypisierung für GM1-Gangliosidose bei Shiba Hunden $\quad 177$

3.3.1.3.2 Globoidzell-Leukodystrophie (Krabbe Disease) 177

$\begin{array}{ll}\text { I. Krankheitsbild } & 177\end{array}$

II. Genetischer Hintergrund 183

III.a Ursächliche Mutation für Globoidzell-Leukodystrophie bei West Highland White Terriern und Cairn Terriern 184

IV.a Genotypisierung für Globoidzell-Leukodystrophie bei West Highland White Terriern und Cairn Terriern 184

III.b Ursächliche Mutation für Globoidzell-Leukodystrophie bei Irischen Settern

IV.b Genotypisierung für Globoidzell-Leukodystrophie bei Irischen Settern

3.3.2 Nicht lysosomale Speicherdefekte: Störungen des Glukose- und Glykogenstoffwechsels 
$\begin{array}{lll}\text { 3.3.2.1 } & \text { Erythrozytäre Pyruvatkinase Defizienz } & 188\end{array}$

I. Krankheitsbild 188

II. Genetischer Hintergrund 190

III.a Ursächliche Mutation für PK-Defizienz bei Basenjis 192

IV.a Genotypisierung für PK-Defizienz bei Basenjis 192

III.b Ursächliche Mutation für PK-Defizienz bei West Highland White Terriern 193

IV.b Genotypisierung für PK-Defizienz bei West Highland White Terriern

$\begin{array}{lll}\text { 3.3.2.2 Phosphofruktokinase-Defizienz } & 194\end{array}$

$\begin{array}{ll}\text { I. Krankheitsbild } & 194\end{array}$

II. Genetischer Hintergrund 195

III. Ursächliche Mutation der PFK-Defizienz bei Englischen Springer Spaniels 196

IV. Genotypisierung für PFK-Defizienz bei Englischen Springer Spaniels

$\begin{array}{lll}\text { 3.3.2.3 Pyruvatdehydrogenase-Defizienz } & 197\end{array}$

$\begin{array}{ll}\text { I. Krankheitsbild } & 197\end{array}$

II. Genetischer Hintergrund 199

III. Ursächliche Mutation für Pyruvatdehydrogenase-Defizienz bei Clumber und Sussex Spaniels 200

IV. Genotypisierung für Pyruvatdehydrogenase-Defizienz bei Clumber und Sussex Spaniels

3.3.2.4 Glukose-6-Phosphatase-Defizienz 201

I. Krankheitsbild 201

II. Genetischer Hintergrund 202

III. Ursächliche Mutation für Glucose-6-Phosphatase-Defizienz bei Maltesern

IV. Genotypisierung für Glukose-6-Phosphatase-Defizienz bei Maltesern 205

$\begin{array}{lll}\text { 3.3.3 Primerliste } & 206\end{array}$ 
3.4 Genetische Dispositionen für Vergiftungen oder

$\begin{array}{lll}3.4 .1 & \text { Kupfertoxikose } & 224\end{array}$

I. Krankheitsbild 224

II. Genetischer Hintergrund 228

III.a Assoziation eines Mikrosatellitenpolymorphismus mit Kupfertoxikose bei Bedlington Terriern 231

IV.a Genotypisierung für den mit Kupfertoxikose bei Bedlington Terriern assoziierten Mikrosatellitenpolymorphismus 233

III.b Ursächliche Mutation für Kupfertoxikose bei Bedlington Terriern

IV.b Genotypisierung für Kupfertoxikose bei Bedlington Terriern 235

3.4.2 Erythrozytäre Hypokatalasie 236

I. Krankheitsbild 236

II. Genetischer Hintergrund 237

3.4.3 Ivermectin-Unverträglichkeit 237

$\begin{array}{ll}\text { I. Krankheitsbild } & 237\end{array}$

II. Genetischer Hintergrund 239

III. Ursächliche Mutation für Ivermectin-Unverträglichkeit in neun Rassen

IV. Genotypisierung für Ivermectin-Unverträglichkeit in neun Rassen

3.4.4 Varianten des caninen Arzneimittelstoffwechsels: CYP1A2Polymorphismus

I. Phänotyp 242

II. Genetischer Hintergrund 243

III. Stoffwechselwirksame Mutation des Isoenzyms CYP1A2 244

IV. Genotypisierung für den stoffwechselwirksamen CYP1A2Polymorphismus 245

$\begin{array}{lll}3.4 .5 & \text { Primerliste } & 246\end{array}$ 
3.4.6 Literatur

3.5 Hereditäre Erkrankungen innerer und äußerer Organe

3.5.1 Erkrankungen der Haut 253

3.5.1.1 Ektodermale Dysplasie 253

I. Krankheitsbild 253

II. Genetischer Hintergrund 254

III. Ursächliche Mutation für ektodermale Dysplasie bei Deutschen Schäferhunden 255

3.5.1.2 Epidermolysis bullosa 257

3.5.1.2.1 Junktionale Epidermolysis bullosa 258

I. Krankheitsbild der junktionalen Epidermolysis bullosa bei Deutsch Kurzhaar Vorstehhunden 258

II. Genetischer Hintergrund 259

III. Ursächliche Mutation für Epidermolysis bullosa bei Deutsch Kurzhaar Vorstehhunden 261

3.5.1.2.2 Dystrophische Epidermolysis bullosa 262

I. Krankheitsbild 262

II. Genetischer Hintergrund 264

III. Ursächliche Mutation der dystrophischen Epidermolysis bullosa bei Golden Retrievern 265

IV. Genotypisierung für dystrophische Epidermolysis bullosa bei Golden Retrievern 266

3.5.1.3 Epidermolytische Hyperkeratose 267

$\begin{array}{ll}\text { I. Krankheitsbild } & 267\end{array}$

II. Genetischer Hintergrund 269

III. Ursächliche Mutation für Epidermolytische Hyperkeratose bei Norfolk Terriern

IV. Genotypisierung für epidermolytische Hyperkeratose bei Norfolk Terriern 270

3.5.2 Hereditäre ophthalmologische Defekte 271 
3.5.2.1 Photorezeptor-PRAs 274

3.5.2.1.1 Photorezeptordysplasie bei Irischen Settern und Sloughis 277

I.a Krankheitsbild bei Irischen Settern 277

$\begin{array}{ll}\text { I.b Krankheitsbild bei Sloughis } & 278\end{array}$

II. Genetischer Hintergrund 279

III.a Ursächliche Mutation für PRA bei Irischen Settern 281

IV.a Genotypisierung für PRA bei Irischen Settern 282

III.b Ursächliche Mutation für PRA bei Sloughis 282

IV.b Genotypisierung für PRA bei Sloughis 283

3.5.2.1.2 Photorezeptordysplasie bei Cardigan Welsh Corgis 284

I. Krankheitsbild 284

II. Genetischer Hintergrund 284

III. Ursächliche Mutation für PRA bei Cardigan Welsh Corgis 285

IV. Genotypisierung für PRA bei Cardigan Welsh Corgis 286

3.5.2.1.3 Photorezeptordysplasie bei Zwergschnauzern 286

I. Krankheitsbild 286

II. Genetischer Hintergrund 287

III. Ursächliche Mutation für PRA bei Zwergschnauzern 289

IV. Genotypisierung für PRA bei Zwergschnauzern 290

3.5.2.1.4 X-chromosomal gekoppelte PRA 1 und 2

I. Krankheitsbild 291

II. Genetischer Hintergrund 292

III. Ursächliche Mutation der XLPRA1 bei Sibirischen Huskys und Samoyeden und XLPRA2 293

IV. Genotypisierung für XLPRA 1 und 2 
3.5.2.1.5 Fortschreitende Stäbchen-Zapfen-Degenerations-PRA (PRCDPRA)

I. Krankheitsbild

II. Genetischer Hintergrund 296

III. Ursächliche Mutation für PRCD PRA in 34 Rassen 299

IV. Genotypisierung 301

3.5.2.1.6 Degenerative PRA bei Schapendoes 303

I. Krankheitsbild 303

II./III. Genetischer Hintergrund und assoziierter Haplotyp 303

IV. Haplotypisierung 304

3.5.2.1.7 Multifokale PRA bei Englischen Mastiffs und Bullmastiffs 306

I. Krankheitsbild 306

II. Genetischer Hintergrund 306

III. Ursächliche Mutation für PRA bei Englischen Mastiffs und Bullmastiff

IV. Genotypisierung für PRA bei Englischen Mastiffs und Bullmastiff 309

3.5.2.1.8 Primäre Zapfenphotorezeptoratrophie bei Zwerglanghaardackeln 310

$\begin{array}{ll}\text { I. Krankheitsbild } & 310\end{array}$

II. Genetischer Hintergrund 312

III. Ursächliche Mutation für primäre Zapfenphotorezeptoratrophie bei Zwerglanghaardackeln 314

3.5.2.2 Achromatopsie/Hemeralopie 315

I. Krankheitsbild 315

II. Genetischer Hintergrund 317

III.a Ursächliche Mutation für Achromatopsie bei Alaskan 319 Malamutes

III.b Ursächliche Mutation bei Deutsch Kurzhaar Vorstehhunden 320

IV.b Genotypisierung für Achromatopsie bei Deutsch Kurzhaar Vorstehhunden 
3.5.2.3 Defekte des Retinapigmentepithels

3.5.2.3.1 Kongenitale Stationäre Nachtblindheit / Hereditäre Retinadystrophie bei Briards

I. Krankheitsbild

II. Genetischer Hintergrund

III. Ursächliche Mutation für kongenitale Nachtblindheit bei Briards

IV. Genotypisierung für kongenitale Nachtblindheit bei Briards

I. Krankheitsbild 327

II. Genetischer Hintergrund

III.a Ursächliche Mutation der Multifokalen Retinopathie bei Pyrenäenberghunden, English Mastiffs und Bullmastiffs

IV.a Genotypisierung für Multifokale Retinopathie bei Pyrenäenberghunden, Englischen Mastiffs und Bullmastiffs

III.b Ursächliche Mutation der Multifokalen Retinopathie bei Coton de Tulear

IV.b Genotypisierung für Multifokale Retinopathie bei Coton de Tulear

3.5.2.4 Aderhautdefekt: Collie Eye Anomalie (CEA) 332

I. Krankheitsbild

II. Genetischer Hintergrund

III. Ursächliche Mutation für CEA bei Langhaarcollies, Kurzhaarcollies, Border Collies, Australischen Schäferhunden, Lancashire Heelers, Shetland Schäferhunden, Nova Scotia Duck Tolling Retrievern und Langhaarwhippets

IV. Genotypisierung für CEA bei Langhaarcollies, Kurzhaarcollies, Border Collies, Australischen Schäferhunden, Lancashire Heelers, Shetland Schäferhunden, Nova Scotia Duck Tolling Retrievern und Langhaarwhippets 
3.5.2.5 Linsendefekt: Die Katarakt 335

I. Krankheitsbild 335

II. Genetischer Hintergrund 337

III. Ursächliche Mutation für Katarakt bei Staffordshire Bullterriern, Boston Terriern und Australischen 338 Schäferhunden

IV. Genotypisierung für Katarakt bei Boston Terriern, Staffordshire Bullterriern und Australischen Schäferhunden 341

3.5.3 Hereditäre Nierenfunktionsstörungen 342

3.5.3.1 Cystinurie 342

I. Krankheitsbild 342

II. Genetischer Hintergrund der Cystinurie 345

III. Ursächliche Mutation für Cystinurie bei Neufundländern 347

IV. Genotypisierung für Cystinurie bei Neufundländern 347

3.5.3.2 Nierenzystadenokarzinom und nodulare Dermatofibrose des Deutschen Schäferhundes 348

I. Krankheitsbild 348

II. Genetischer Hintergrund 350

III. Ursächliche Mutation für Nierenzystadenokarzinome beim Deutschen Schäferhund 351

IV. Genotypisierung für Nierenzystadenokarzinom beim Deutschen Schäferhund 353

3.5.4 X-chromosmal gekoppelte Nephritis 353

I. Krankheitsbild 353

II. Genetischer Hintergrund 357

III.a Ursächliche Mutation bei Samoyeden 361

IV.a Genotypisierung bei Samoyeden 361

III.b Ursächliche Mutation bei Navasota Hunden 361 
3.5.5 Hereditäre Schilddrüsenunterfunktion 363

I.a Krankheitsbild allgemein 363

II.a Genetischer Hintergrund der hereditären

Schilddrüsenunterfunktion bei Dobermännern 366

I.b Krankheitsbild der hereditären Schilddrüsenunterfunktion bei Toy Foxterriern

II.b Genetischer Hintergrund der hereditären Schilddrüsenunterfunktion bei Toy Foxterriern

III.b Ursächliche Mutation für hereditäre Schilddrüsenunterfunktion bei Toy Foxterriern

IV.b Genotypisierung für hereditäre Schilddrüsenunterfunktion bei Toy Foxterriern

$\begin{array}{lll}3.5 .6 & \text { Primer } & 373\end{array}$

3.5.7 Literatur

3.6 Hereditäre Erkrankungen des Skelettsystems, der Muskulatur und des Nervensystems

3.6.1 Erkrankungen des Skelettsystems 397

3.6.1.1 Osteogenesis imperfecta 397

I. Krankheitsbild 397

II. Genetischer Hintergrund der Osteogenesis imperfecta beim Golden Retriever und beim Beagle $\quad 400$

III.a Ursächliche Mutation der Osteogenesis imperfecta bei Golden Retrievern $\quad 402$

III.b Ursächliche Mutation für Osteogenesis imperfecta beim $\quad 403$ Beagle

3.6.1.2 Brachyury (Kurzschwänzigkeit) 405

I. Krankheitsbild 405

II. Genetischer Hintergrund 405

III. Ursächliche Mutation für Brachyury bei Pembroke Welsh Corgis 
3.6.2 Erkrankungen des Nervensystems 409

$\begin{array}{lll}\text { 3.6.2.1 Narkolepsie } & 409\end{array}$

I. Krankheitsbild 409

II. Genetischer Hintergrund 412

III.a Ursächliche Mutation für Narkolepsie bei Dobermännern 415

IV.a Genotypisierung für Narkolepsie bei Dobermännern 416

III.b Ursächliche Mutation für Narkolepsie bei Labrador $\quad 416$ Retrievern

IV.b Genotypisierung für Narkolepsie bei Labrador Retrievern $\quad 417$

III.c Ursächliche Mutation für Narkolepsie bei Dackeln 417

IV.c Genotypisierung für Narkolepsie bei Dackeln 418

$\begin{array}{lll}\text { 3.6.2.2 Spongiforme Leukoenzephalomyelopathie } & 418\end{array}$

I. Krankheitsbild 418

II. Genetischer Hintergrund 420

III. Ursächliche Mutation für Spongiforme Leukoenzephalomyelopathie bei Australian Cattle Dogs und Shetland Schäferhunden

IV. Genotypisierung für Spongiforme Leukoenzephalomyelopathie bei Australian Cattle Dogs und Shetland Schäferhunden

3.6.2.3 X-chromosomal gekoppelter Tremor (shaking pup) 424

I. Krankheitsbild $\quad 424$

II. Genetischer Hintergrund 429

III. Ursächliche Mutation für X-chromosomal gekoppelten Tremor bei Englischen Springer Spaniels 430

IV. Genotypisierung für X-chromosomal gekoppelten Tremor bei Englischen Springer Spaniels 
3.6.3 Muskelerkrankungen 433

3.6.3.1 Das Maligne Hyperthermie Syndrom (MHS) 433

I. Krankheitsbild 433

II. Genetischer Hintergrund 434

III. Ursächliche Mutation für MHS bei Dobermann-DeutscherSchäferhund-Mischlingen $\quad 435$

IV. Genotypisierung für Maligne Hyperthermie bei DobermannDeutscher-Schäferhund Mischlingen 437

3.6.3.2 Muskeldystrophie 438

I. Krankheitsbild 438

II. Genetischer Hintergrund 440

III.a Ursächliche Mutation für Muskeldystrophie bei Golden Retrievern 443

IV.a Genotypisierung für Muskeldystrophie bei Golden Retrievern 444

III.b Ursächliche Mutation für Muskeldystrophie bei Deutsch Kurzhaar Vorstehhunden 445

3.6.3.3 Kongenitale Myotonie 445

I. Krankheitsbild 445

II. Genetischer Hintergrund 446

III. Ursächliche Mutation für Kongenitale Myotonie bei Zwergschnauzern $\quad 447$

IV. Genotypisierung für Kongenitale Myotonie bei Zwergschnauzern 
3.6.3.4 Zentronukleäre Myopathie $\quad 449$

I. Krankheitsbild 449

II. Genetischer Hintergrund 450

III. Ursächliche Mutation für kongenitale Zentronukleäre Myopathie bei Labrador Retrievern 452

IV. Genotypisierung für zentronukleäre Myopathie bei Labrador Retrievern

454

3.6.4 Primerliste

455

$\begin{array}{lll}\text { 3.6.5 Literatur } & 456\end{array}$

$\begin{array}{lll}3.7 & \text { Farbvarianten } & 467\end{array}$

3.7.1 Varianten des MC1R-Gens $\quad 469$

I.a Der Polymorphismus R306ter $\quad 471$

I.b Der Polymorphismus M264V 472

I.c Der Polymorphismus S90G 473

II.a Genotypisierung für den Polymorphismus R306ter 474

II.b Genotypisierung für den Polymorphismus M264V 474

II.c Genotypisierung für den Polymorphismus S90G 474

3.7.2 Varianten des Agouti-Gens 474

I.a Das angestammte Agouti-Allel 476

I.b Der Polymorphismus R96C 477

I.c Der Polymorphismus A82S+R83H 478

II.b Genotypisierung für den Polymorphismus R96C 479

II.c Genotypisierung für den Polymorphismus A82S+R83H 479 
3.7.3 Varianten des TYRP1-Gens 480

I.a Die Polymorphismen Q331ter, P345del und S41C 481

I.b Der Polymorphismus C336S 484

II.a Genotypisierung für die Polymorphismen Q331ter und $\quad 485$ P345del

3.7.4 Der Aufhellungsfaktor (Dilute-Faktor) 485

I. Phänotyp 485

II. Genetischer Hintergrund 486

III. Potentiell ursächliche Mutation für den Farbaufhellungsphänotyp in mindestens sieben Rassen 488

$\begin{array}{lll}\text { 3.7.5 Die Merlefärbung } & 489\end{array}$

I. Phänotyp 489

II. Genetischer Hintergrund 490

III. Ursächliche Mutation für den Merle-Phänotyp in mindestens zwölf Rassen 492

IV. Genotypisierung für die Merle-Mutation in mindestens zwölf Rassen 493

$\begin{array}{lll}\text { 3.7.6 Primerliste } & 495\end{array}$

$\begin{array}{lll}3.7 .7 & \text { Literatur } & 496\end{array}$

4 Zusammenfassung/Abstract $\quad 501$

$\begin{array}{lll}4.1 & \text { Zusammenfassung } & 501\end{array}$

$\begin{array}{lll}4.2 & \text { Abstract } & 503\end{array}$ 
Verzeichnis der Abbildungen

Abb. 1 Schematische Darstellung des ITGA2B-Gens (Glykoprotein IIb des caninen Fibrinogenrezeptorkomplexes Integrin $\alpha \mathrm{IIb} \beta 3)$ und der bekannten funktionellen Mutationen.

Abb. 2 Exon 13 und angrenzende Intronsequenz des ITGA2B-Gens.

Abb. 3 Exon 12 und angrenzende Intronsequenzen des caninen GlykoproteinIIb-Gens.

Abb. 4 Schematische Darstellung des für den vWF codierenden Gens und der bekannten funktionellen Mutationen.

Abb. 5 Exon 43 und angrenzende Intronsequenz des vWF-Gens.

Abb. 6 Exon 28 des vWF-Gens.

Abb. 7 Sequenzabschnitte des vWF-Gens von Exon 16 (53 letzte Nukleotide) bis Exon 17.

Abb. 8

Intron 4 und angrenzende Exonsequenzen des vWF-Gens.

Abb. 9 Exon 7 des vWF codierenden Gens von Nukleotid 658 bis 874 in der codierenden Sequenz (NCBI-GenBank: AF099154).

Abb. 10 Schematische Darstellung des Faktor-VIII-Gens und der bisher identifizierten Mutationen.

Abb. 11 Exon 22 bis Anfang Exon 23 des Faktor VIII Gens. 59

Abb. 12 Nukleotide 6301 bis 6725 des caninen BAC-Klons 291 M9. 60

Abb. 13 F8C Mikrosatellitenregion im Intron 21 des Faktor-VIII-Gens. 61

Abb. 14 Schematische Darstellung des Faktor-IX-Gens und der bekannten funktionellen Mutationen.

Abb. 15 133-bp-Fragment aus Exon 8 des Faktor IX Gens. $\quad 64$

Abb. 16 Sequenzfragment aus Exon 6 des Faktor-IX-Gens. 65

Abb. 17 Exon 8 des Faktor IX Gens mit 3'UTR. 68

Abb. 18 Faktor-IX-Gensequenz von Exon 5 bis Anfang Exon 6.

Abb. 19 Schematische Darstellung des für den caninen Faktor XI codierenden Gens.

Abb. 20 Schematische Darstellung des caninen Faktor VII-Gens und Lage der bisher identifizierten Mutationen.

Abb. 21 Exon 5 des caninen Faktor-VII-Gens und angrenzende Intronsequenzen. 78

Abb. 22 Schematische Darstellung des caninen AP3B1-Gens und Lage der bisher identifizierten Mutationen.

Abb. 23 Exon 21 des caninen AP3B1-Gens und vorausgehende Intronsequenz.

Abb. 24 Schematische Darstellung des caninen ITGB2-Gens und Lage der bisher identifizierten Mutationen.

Abb. 25

Exon 2 des caninen ITGB2 Gens.

Abb. 26 Exon 2 des caninen ITGB2-Gens.

Abb. 27 Schematische Darstellung des caninen IL-2R $\gamma$ Gens und Lage der bisher identifizierten Mutationen.

Abb. 28 5'UTR, Exon 1 und anschließende Intronsequenz des IL-2R $\gamma$-Gens. 105

Abb. 29 Exon 4 bis Exon 5 des caninen Il-2R $\gamma$-Gens. 
Abb. 30 Schematische Darstellung des caninen DNA-PKcs-Gens und Lage der bisher identifizierten Mutationen.

Abb. 31 Exon 76 des DNA-PKcs-Gens (PRKDC).

Abb. 32 Schematische Darstellung des caninen C3-Gens und Lage der bisher identifizierten Mutationen.

Abb. 33 Exon 17 des caninen C3 Gens.

Abb. 34 Schematische Darstellung des caninen IDUA-Gens und Lage der bisher identifizierten Mutationen.

Abb. 35 Exons 1-2 des caninen IDUA Gens und angrenzende Intronsequenzen (EMBL-EBI ID: L01065).

Abb. 36 Schematische Darstellung des caninen Heparansulfat-Sulfamidase-Gens und Lage der bisher identifizierten Mutationen.

Abb. 37 Exon 6 des caninen Heparansulfat-Sulfamidase-Gens und angrenzende Intronsequenzen.

Abb. 38 Intron 5, Exon 6 und angrenzende Exon- bzw. Intronsequenzen des caninen Heparansulfat-Sulfamidase-Gens.

Abb. 39 Schematische Darstellung des caninen Naglu-Gens und Lage der bisher identifizierten Mutationen.

Abb. 40 Exon 6 des caninen Naglu-Gens.

Abb. 41 Schematische Darstellung des caninen ASB-Gens und Lage der bisher identifizierten Mutationen.

Abb. 42 Exon 1 des caninen Arylsulfatase B Gens und angrenzende 5'UTR- und Intronsequenz (NCBI-GeneID: 610364).

Abb. 43 Schematische Darstellung des caninen GUSB-Gens und Lage der bisher identifizierten Mutationen.

Abb. 44 Exon 3 des caninen $\beta$-Glukuronidase-Gens.

Abb. 45 Exon 3 des caninen $\beta$-Glukuronidase-Gens.

Abb. 46 Schematische Darstellung des caninen $\alpha$-L-Fukosidase-Gens und Lage der bisher identifizierten Mutationen.

Abb. 47 Exon 1, Intron 1 und 5'-Bereich des Exons 2 des caninen $\alpha$-L-FukosidaseGens.

Abb. 48 Exon 1 des caninen Epm2b Gens.

Abb. 49 Schematische Darstellung des caninen CLN8-Gens und Lage der bisher identifizierten Mutationen.

Abb. 50 Schematische Darstellung des caninen CLN5-Gens und Lage der bisher identifizierten Mutationen.

Abb. 51 Schematische Darstellung des caninen TPP1-Gens und Lage der bisher identifizierten Mutationen.

Abb. 52 Sequenzabschnitt aus Exon 2 des caninen CLN8 Gens.

Abb. 53 Exon 4 des caninen CLN5-Gens und angrenzende Intron- bzw. UTR-

Sequenz.

Abb. 54 Exon 4 und angrenzende Intronsequenz des caninen TPP1 Gens.

Abb. 55 Schematische Darstellung des caninen CTSD-Gens und Lage der bisher identifizierten Mutationen.

Abb. 56 Exon 5 des caninen Cathepsin D Gens. 
Abb. 57 Schematische Darstellung des caninen $\beta$-Galaktosidase-Gens und Lage der bisher identifizierten Mutationen.

Abb. 58 Exon 2 des caninen $\beta$-Galaktosidase-Gens und angrenzende Intronsequenz.

Abb. 59 Exon 15 Intron 15 und Exon 16 des caninen $\beta$-Galaktosidase-Gens. 177

Abb. 60 Aktuelles Modell des pathogenen Mechanismus bei GloboidzellLeukodystrophie (vereinfacht nach Suzuki 2003).

Abb. 61 Schematische Darstellung des caninen Galaktosylcerebrosidase-Gens und Lage der bisher identifizierten Mutationen.

Abb. 62 Exon 6 des caninen Galaktosylceramid- $\beta$-Galaktosidase Gens und flankierende Intronsequenzen.

Abb. 63 Exon 9 des caninen Galaktosylceramid- $\beta$-Galaktosidase-Gens mit angrenzender Intronsequenz (Ensembl-GeneID: ENSCAFG00000017337). 185

Abb. 64 Schematische Darstellung des caninen PKLR-Gens und Lage der bisher identifizierten Mutationen.

Abb. 65 Exon 4 des PKLR-Gens und angrenzende Intronsequenzen. 192

Abb. 66 3'Ende des Exons 9 und angrenzende Intronsequenz.

Abb. 67 Schematische Darstellung des caninen Phosphofruktokinase-Gens und Lage der bisher identifizierten Mutationen.

Abb. 68

Exon 23-24 des caninen Muskeltyp PFK-Gens.

Exon 1 des caninen PDP1-Gens und angrenzende Sequenz.

Abb. 70 Schematische Darstellung des caninen G6PC-Gens und Lage der bisher identifizierten Mutationen.

Abb. 71 Exon 3 des caninen G6PC-Gens mit flankierender Intronsequenz.

Abb. 72 Schematische Darstellung des caninen MURR1-Gens und Lage der bisher identifizierten Mutationen.

Abb. 73 Exon 2 des MURR1-Gens umgeben von Sequenzabschnitten aus Intron 1, beginnend beim C04107-Mikrosatellitenmarker, und Intron 2.

Abb. 74 Schematische Darstellung des caninen MDR1-Gens und bisher identifizierte Mutationen.

Abb. 75 Exon 4 des caninen MDR1 Gens und angrenzende Intronsequenzen.

Abb. 76 Schematische Darstellung des caninen CYP1A2-Gens und Lage der bisher identifizierten Mutationen.

Abb. 77 Exon 5 des caninen CYP1A2-Gens und angrenzende Intronsequenzen. 245

Abb. 78 Schematische Darstellung des caninen EDA-Gens und Lage der bisher identifizierten Mutationen.

Abb. 79 Exon 8 und Exon 9 des caninen EDA-Gens mit angrenzenden Intronsequenzen und 3'-UTR.

Abb. 80 Schematische Darstellung der ersten 38 Exons des caninen LAMA3-Gens und Lage der bisher identifizierten Mutationen.

Abb. 81 Exon 35, Intron 35 und 5'-Sequenz von Exon 36 des caninen lama3-Gens.

Abb. 82 Schematische Darstellung des caninen COL7A1-Gens und Lage der bisher identifizierten Mutationen.

Abb. 83 Exon 69 des caninen Kollagen-Typ-VII-Gens und angrenzende Intronsequenzen. 
Abb. 84 Schematische Darstellung des caninen Keratin-10-Gens und Lage der bisher identifizierten Mutationen.

Abb. 85 Intron 5 des caninen Keratin-10-Gens und angrenzende Exonsequenzen. 270

Abb. 86 Schematische Darstellung des caninen PDE6B-Gens und Lage der bisher identifizierten Mutationen.

Abb. 87

Exon 21 des canine cGMP-PDE $\beta$-Gens.

Exon 21 des caninen cGMP-PDE $\beta-G e n s$.

Abb. 89 Schematische Darstellung des caninen PDE6A-Gens und Lage der bisher identifizierten Mutationen.

Abb. 90 Exon 15 und Intron 15 sowie angrenzende Intron- und Exonsequenzen des caninen cGMP-PDE $\alpha$-Gens.

Abb. 91 Schematische Darstellung des caninen Phosducin-Gens und Lage der bisher identifizierten Mutationen.

Abb. 92 Exon 4 des caninen Phosducin Gens.

Abb. 93 Gegenüberstellung der genomischen Struktur des caninen RPGR-Gens

Abb. 94 Exon ORF15 des caninen RPGR-Gens.

Abb. 95 Schematische Darstellung des caninen PRCD-Gens und Lage der bisher identifizierten Mutationen.

Abb. 96 5'-UTR, aufwärts angrenzende Sequenz und Sequenzanfang von Exon 1 des caninen PRCD-Gens.

Abb. 97 Marker des PRA-Haplotyps bei Schapendoes (Ensembl Dog Contig View Release 44 - April 2007 - Chromosom 20).

Abb. 98 Schematische Darstellung des caninen Rhodopsin-Gens und Lage der bisher identifizierten Mutationen.

Abb. 99 Sequenzabschnitt aus Exon 1 des caninen Rhodopsin-Gens und der angrenzende 5' UTR.

Abb. 100 Exons 2 und 3 des caninen RPGRIP1-Gens (Mellersh et al. 2006a).

Abb. 101 Schematische Darstellung des caninen CNGB3-Gens und bisher identifizierte Mutationen.

Abb. 102 Schematische Darstellung des caninen RPE65-Gens und Lage der bisher identifizierten Mutationen.

Abb. 103 Exon 5 und 6, sowie Exon 14 des caninen RPE65-Gens.

Abb. 104 Schematische Darstellung des caninenVMD2-Gens und Lage der bisher identifizierten Mutationen.

Abb. 105 Exon 2 des caninen VMD2-Gens und angrenzende Intronsequenzen.

Abb. 106 Exon 4, Intron 4 und Exon 5 des caninen VMD2-Gens und angrenzende Intronsequenzen.

Abb. 107 Sequenzabschnitt des caninen FLJ12610-Gens (UCSC-WGS-Assembly v.1.0, Juli 2004: Chr.37 28685294 - 28677118).

Abb. 108 Schematische Darstellung des caninen HSF4-Gens und Lage der bisher identifizierten Mutationen.

Abb. 109 Exon 9-11 des caninen HSF-Gens und angrenzende Intronsequenzen. 339

Abb. 110 Schematische Darstellung des caninen SLC3A1-Gens und Lage der bisher identifizierten Mutationen.

Abb. 111 Exon 2 des caninen SLC3A1 Gens und angrenzende Intronsequenzen. 
Abb. 112 Schematische Darstellung des caninen BHD-Gens und Lage der bisher identifizierten Mutationen.

Abb. 113 Exon 4 des caninen BHD-Gens und angrenzende Intronsequenzen (Ensembl GeneID: ENSCAFG00000018469 entspricht Exon 7 und angrenzenden Intronsequenzen bei Lingaas et al. (Lingaas et al. 2003)).

Abb. 114 Schematische Darstellung des caninen COL4A5-Gens (Exon 2-53) und Lage der bisher identifizierten Mutationen.

Abb. 115 Exon 34 des caninen COL4A5-Gens und angrenzende Intronsequenzen.

Abb. 116 Exon 9 und 10 des caninen COL4A5 Gens und angrenzende Intronsequenzen (GeneID 403466).

Abb. 117 Schematische Darstellung des caninen TPO-Gens (Exon 2-Exon 17) und Lage der bisher identifizierten Mutationen.

Abb. 118 Exon 4 des caninen TPO-Gens und angrenzende Intronsequenzen.

Abb. 119 Schematische Darstellung des caninen COL1A1-Gens und Lage der bisher identifizierten Mutationen.

Abb. 120 Schematische Darstellung des caninen COL1A2-Gens und Lage der bisher identifizierten Mutationen.

Abb. 121 cDNA-Abschnitt von Exon 17 bis Exon 22 des caninen COL1A1 Gens.

Abb. 122 Exon 51 des COL1A2 Gens.

Abb. 123 Schematische Darstellung des caninen T-Gens und Lage der bisher identifizierten Mutationen.

Abb. 124 Exon 1 des caninen T-Gens.

Abb. 125 Schematische Darstellung des caninen HCRTR2-Gens und Lage der bisher dentifizierten Mutationen.

Abb. 126 Intron 3, Exon 4, Intron 4 und angrenzende Exonsequenzen des caninen HCRTR2-Gens.

Abb. 127 Intron 5, Exon 6, Intron 6 und angrenzende Exonsequenzen des caninen HCRTR2 Gens.

Abb. 128 5'UTR, Exon 1 und angrenzende genomische Sequenz bzw. Intronsequenz des caninen HCRTR2 Gens.

Abb. 129 Sequenz des caninen Cytochrom-b-Gens.

Abb. 130 Schematische Darstellung des caninen PLP-Gens und Lage der bisher identifizierten Mutationen.

Abb. 131 Exon 2 des caninen PLP-Gens und angrenzende Intronsequenz.

Abb. 132 cDNA-Abschnitt des caninen RYR1-Gens (GenBank AF302128: 1262-1592, entspricht Exon 15 und Teilen von Exon 14 und 16).

Abb. 133 Schematische Darstellung des caninen Dystrophin-Gens (Exon 3-80) und Lage der bisher identifizierten Mutationen.

Abb. 134 Exon 6 bis Exon 8 des caninen Dystrophin-Gens und angrenzende Intronsequenzen.

Abb. 135 Schematische Darstellung des caninen CLCN1-Gens und Lage der bisher identifizierten Mutationen.

Abb. 136 Exon 6 und 7 des caninen $\mathrm{ClC}-1$ Gens und angrenzende Intronsequenzen. 
Abb. 137 Schematische Darstellung des caninen PTPLA-Gens und Lage der bisher identifizierten Mutationen.

Abb. 138 Exon 1-3 des caninen PTPLA-Gens und angrenzende Intronsequenzen.

Abb. 139 MC1R-Gen und flankierende Sequenzen.

Abb. 140 Schematische Darstellung des caninen Agoutigens und Lage der bisher identifizierten Mutationen.

Abb. 141 Exons 1-4 des caninen Agoutigens und angrenzende Intronsequenzen.

Abb. 142 Schematische Darstellung des caninen TYRP1-Gens und Lage der bisher identifizierten Mutationen.

Abb. 143 Exon 5 des caninen TYRP1-Gens und angrenzende Intronsequenzen.

Abb. 144 Exon 2 des caninen TYRP1-Gens und angrenzende Intronsequenzen.

Abb. 145 Schematische Darstellung des caninen MLPH-Gens und Lage der bisher identifizierten Mutationen.

Abb. 146 5'-UTR und Exon 2 des caninen MLPH-Gens und angrenzende Sequenzen.

Abb. 147 Schematische Darstellung des caninen SILV-Gens und Lage der bisher identifizierten Mutationen.

Abb. 148 Exon 11 und 3'-UTR des caninen SILV-Gens und angrenzende Intronsequenz. 
Verzeichnis der Tabellen

Tabelle 1: Typische Befunde, betroffene Rassen und ursächliche Gendefekte verschiedener Thrombopathieformen

Tabelle 2: Wesentliche Merkmale der drei vWD-Typen und betroffene Rassen mit bekannten Mutationen

Tabelle 3: Anteil der einzelnen vWD-I-Genotypen in fünf Hunderassen (http://www.vetgen.com)

Tabelle 4: Liste der in Kapitel 3.1 genannten Primer

Tabelle 5: Liste der in Kapitel 3.2 genannten Primer

Tabelle 6: Saccharidose: betroffene Rassen, klinische und pathologische Erscheinungen

Tabelle 7: Saccharidosen: Enzymdefekt, eingelagertes Material und histologische Befunde

Tabelle 8: Ceroid-Lipofuscinose: wesentliche Merkmale des frühadult-akuten Typs gegenüber der adulten Form

Tabelle 9: Klinische, pathologische, histopathologische und biochemische Merkmale der caninen GM1Gangliosidose

Tabelle 10: Klinische, pathologische, histopathologische und biochemische Merkmale der caninen Globoidzell-Leukodystrophie

Tabelle 11: Liste der in Kapitel 3.3 genannten Primer

Tabelle 12: Liste der Wirkstoffe, die bei Hunden mit Ivermectinüberempfindlichkeit zu unerwünschten Nebenwirkungen führen können 238

Tabelle 13: Liste der in Kapitel 3.4 genannten Primer

Tabelle 14: Typen hereditärer ophthalmologischer Erkrankungen, betroffene Rassen und assoziierte Defektgene

Tabelle 15: Photorezeptoratrophien: Übersicht über zugrunde liegende Gendefekte, klinische, elektroretinographische, biochemische und histolopathologische Befunde

Tabelle 16: Häufigkeit der PRCD-PRA bei verschiedenen Rassen

Tabelle 17: Häufigkeit autoimmuner Thyroiditis in verschiedenen Rassen (leicht abgewandelt nach http://www.offa.org/thystatbreed.html 2006)

Tabelle 18: Liste der in Kapitel 3.5 genannten Primer

Tabelle 19: Sequenz der Primer für die Amplifikation mitochondrialer DNA, Lage der Primer in der mitochondrialen DNA, Länge des amplifizierten Fragments, nicht amplifizierter DNA-Bereich

Tabelle 20: Liste der in Kapitel 3.6 genannten Primer

Tabelle 21: Liste der bisher identifizierten Mutationen mit Einfluss auf die Fellfarbe

Tabelle 22: TYRP1-Genotypen, die mit einer braunen Fell- und Nasenfarbe assoziiert sind

Tabelle 23: Effekte der Polymorphismen Q131ter, P345del und S41C des TYRP1Gens in unterschiedlichen Rassen

Tabelle 24: Liste der in Kapitel 3.7 genannten Primer 


\section{Einleitung}

Auf dem Gebiet der Genomanalyse beim Hund ist im Verlauf der letzten zehn Jahre eine rasante Entwicklung zu verzeichnen. Auf die Veröffentlichung der ersten caninen Kopplungskarte (Mellersh et al. 1997) folgten in kurzen Abständen Erweiterungen in Form einer Radiation-Hybrid-Karte (Priat et al. 1998) und schließlich einer ersten integrierten Kopplungs-Radiation-Hybrid-Karte (Mellersh et al. 2000), die durch zusätzliche Erkenntnisse aus zytogenetischen Untersuchungen ergänzt wurde (Breen et al. 2001). Diese ergänzte Kopplungs-Radiation-Hybrid-Karte basiert auf einer Kopplungskarte von 354 Markern mit einem mittleren Abstand von $9 \mathrm{Mb}$ und einer Radiation-HybridKarte von 1500 Markern mit einem mittleren Abstand von 1,7 Mb. Seit Juli 2004 ist eine Assemblierung der Sequenz des gesamten caninen Genoms verfügbar (CanFam1.0), die bereits ein Mal aktualisiert wurde (CanFam2.0, Mai 2005). Grundlage der aktuellen Version ist die 7,6-fache „Whole Genome Shotgun“ (WGS)-Sequenz eines weiblichen Boxers. Die Koordinierung des „Dog Genome Sequencing Poject“ (Hundegenomprojekt) erfolgte im Broad Institute, Cambridge, MA. Der aktuelle Stand des Hundegenomprojektes ist stets öffentlich zugänglich (http://www.broad.mit.edu/mammals/dog/). Die aktuelle Version deckt über $98 \%$ des euchromatischen Genoms ab und umfasst 2,5 Millionen kartierte SNPs (Single Nucleotide Polymorphism).

In der OMIA-Datenbank (Online Mendelian Inheritance in Animals (http://omia.angis.org.au/)) steht das Begleittier Hund bezüglich der Anzahl der molekulargenetisch entschlüsselten Erbmerkmale mit 58 Merkmalen deutlich vor Nutztieren wie Rindern (36 molekulargenetisch entschlüsselte Merkmale) und Schweinen (13 molekulargenetisch entschlüsselte Merkmale).

Als wichtigste Triebfeder der enormen Forschungsaktivität auf dem Gebiet der Genomanalyse beim Hund wirkte unter anderem das große Interesse an Hunden als Modell für die Erforschung humaner Erbkrankheiten. Dabei spielen sowohl die Gewinnung neuer Erkenntnisse im Bereich der Pathogenese als auch die Entwicklung von Therapien einschließlich der Möglichkeit der Gentherapie eine Rolle. Die besondere Eignung domestizierter Hunde in diesem Zusammenhang ist in der einmaligen genetischen 
Struktur dieser als Canis familiaris oder Canis lupus familiaris bezeichneten Unterart aus der Familie der Canidae begründet. Durch die Existenz von etwa 400 verschiedenen Rassen herrscht innerhalb der Unterart eine sehr hohe genetische Variabilität. Auf der anderen Seite besteht zwischen den einzelnen Individuen derselben Rasse durch die gezielte Selektion für wenige, eng definierte Merkmale ein hohes Maß an genetischer Übereinstimmung. Die relativ hohe Inzucht innerhalb von Rassen führt zum Auftreten zahlreicher monogener Erbkrankheiten, die phänotypisch und, wie die Forschungsergebnisse der letzten Jahre zeigen, häufig auch genotypisch homolog zu Erkrankungen des Menschen sind.

Die hohe genetische Homogenität innerhalb von Rassen beinhaltet zudem eine relativ geringe Rekombinationsrate und demzufolge das Auftreten von Haplotypen die sich über sehr lange Distanzen erstrecken. Bruchstücke dieser Haplotypen mit einer Länge von ca. 100000 Basenpaaren stimmen oft in mehreren Rassen überein. Über die vergleichende Analyse einer definierten Zusammenstellung von Markern an reinrassigen Hunden und Kreuzungshunden lässt sich die Länge der mit dem Merkmal oder der Erkrankung assoziierten Haplotypen auf einige 1000 Basenpaare eingrenzen. Innerhalb dieses Bereiches kann anschließend per Sequenzanalyse und durch Vergleiche mit homologen DNA-Regionen bei anderen Spezies nach möglichen Kandidatengenen und nach Mutationen gesucht werden (Holmes 1994; Lindblad-Toh et al. 2005; Parker und Ostrander 2005).

Die Zahl der beim Hund im Zusammenhang mit Erbkrankheiten oder bestimmten morphologischen Merkmalen identifizierten Genmutationen ist in den letzten Jahren rapide angestiegen. Die Nutzung der ständig wachsenden Menge an Daten, die sich aus der beschriebenen Entwicklung ergeben, ist nicht nur für die humanmedizinische Forschung von Interesse, sondern bietet Hundezüchtern die Möglichkeit, über den Einsatz molekulargenetischer Genotypisierungsmethoden mit einer hohen Effizienz gegen Erbkrankheiten und unerwünschte morphologische Merkmale zu selektieren.

Trotz zahlreicher Quellen (OMIA, Liste der Universität Bern: „Gentests beim Hund“, Internetseiten verschiedener Firmen und Einrichtungen, die Gentests anbieten und Patentschriften) sind die wesentlichen Detailinformationen oft erst nach längeren Recherchen auffindbar. Die vorliegende Arbeit bietet die Grundlage für die Erstellung 
eines Handbuches, um Tierärzten und Hundezüchtern den Zugang zu verfügbaren DNA-Tests bei Hunden zu erleichtern. 


\subsection{Literatur}

Breen, M., Jouquand, S., Renier, C., Mellersh, C.S., Hitte, C., Holmes, N.G., Cheron, A., Suter, N., Vignaux, F., Bristow, A.E., Priat, C., McCann, E., Andre, C., Boundy, S., Gitsham, P., Thomas, R., Bridge, W.L., Spriggs, H.F., Ryder, E.J., Curson, A., Sampson, J., Ostrander, E.A., Binns, M.M. und Galibert, F. (2001): Chromosome-specific single-locus FISH probes allow anchorage of an 1800marker integrated radiation-hybrid/linkage map of the domestic dog genome to all chromosomes. Genome Res, 11 (10), 1784-95.

Holmes, N.G. (1994): Microsatellite markers and the analysis of genetic disease. $\mathrm{Br} \mathrm{Vet}$ J, 150 (5), 411-21.

http://omia.angis.org.au/: aufgerufen am 30. November 2007

http://www.broad.mit.edu/mammals/dog/: aufgerufen am 30. November 2007

Lindblad-Toh, K., Wade, C.M., Mikkelsen, T.S., Karlsson, E.K., Jaffe, D.B., Kamal, M., Clamp, M., Chang, J.L., Kulbokas, E.J., 3rd, Zody, M.C., Mauceli, E., Xie, X., Breen, M., Wayne, R.K., Ostrander, E.A., Ponting, C.P., Galibert, F., Smith, D.R., DeJong, P.J., Kirkness, E., Alvarez, P., Biagi, T., Brockman, W., Butler, J., Chin, C.W., Cook, A., Cuff, J., Daly, M.J., DeCaprio, D., Gnerre, S., Grabherr, M., Kellis, M., Kleber, M., Bardeleben, C., Goodstadt, L., Heger, A., Hitte, C., Kim, L., Koepfli, K.P., Parker, H.G., Pollinger, J.P., Searle, S.M., Sutter, N.B., Thomas, R., Webber, C., Baldwin, J., Abebe, A., Abouelleil, A., Aftuck, L., Ait-Zahra, M., Aldredge, T., Allen, N., An, P., Anderson, S., Antoine, C., Arachchi, H., Aslam, A., Ayotte, L., Bachantsang, P., Barry, A., Bayul, T., Benamara, M., Berlin, A., Bessette, D., Blitshteyn, B., Bloom, T., Blye, J., Boguslavskiy, L., Bonnet, C., Boukhgalter, B., Brown, A., Cahill, P., Calixte, N., Camarata, J., Cheshatsang, Y., Chu, J., Citroen, M., Collymore, A., Cooke, P., Dawoe, T., Daza, R., Decktor, K., DeGray, S., Dhargay, N., Dooley, K., Dorje, P., Dorjee, K., Dorris, L., Duffey, N., Dupes, A., Egbiremolen, O., Elong, R., Falk, J., Farina, A., Faro, S., Ferguson, D., Ferreira, P., Fisher, S., FitzGerald, M., Foley, K., Foley, C., Franke, A., Friedrich, D., Gage, D., Garber, M., Gearin, G., Giannoukos, G., Goode, T., Goyette, A., Graham, J., Grandbois, E., Gyaltsen, K., Hafez, N., Hagopian, D., Hagos, B., Hall, J., Healy, C., Hegarty, R., Honan, T., Horn, A., Houde, N., Hughes, L., Hunnicutt, L., Husby, M., Jester, B., Jones, C., Kamat, A., Kanga, B., Kells, C., Khazanovich, D., Kieu, A.C., Kisner, P., Kumar, M., Lance, K., Landers, T., Lara, M., Lee, W., Leger, J.P., Lennon, N., Leuper, L., LeVine, S., Liu, J., Liu, X., Lokyitsang, Y., Lokyitsang, T., Lui, A., Macdonald, J., Major, J., Marabella, R., Maru, K., Matthews, C., McDonough, S., Mehta, T., Meldrim, J., Melnikov, A., Meneus, L., Mihalev, A., Mihova, T., Miller, K., Mittelman, R., Mlenga, V., Mulrain, L., Munson, G., Navidi, A., Naylor, J., Nguyen, T., Nguyen, N., Nguyen, C., Nicol, R., Norbu, N., Norbu, C., Novod, N., Nyima, T., Olandt, P., O'Neill, B., O'Neill, K., Osman, S., Oyono, L., Patti, C., Perrin, D., Phunkhang, P., Pierre, F., Priest, M., Rachupka, A., Raghuraman, S., Rameau, R., Ray, V., Raymond, C., Rege, F., Rise, C., Rogers, J., Rogov, P., Sahalie, J., Settipalli, S., Sharpe, T., Shea, T., Sheehan, M., Sherpa, N., Shi, J., Shih, D., Sloan, J., Smith, C., Sparrow, T., Stalker, J., Stange-Thomann, N., Stavropoulos, S., Stone, C., Stone, S., Sykes, 
S., Tchuinga, P., Tenzing, P., Tesfaye, S., Thoulutsang, D., Thoulutsang, Y., Topham, K., Topping, I., Tsamla, T., Vassiliev, H., Venkataraman, V., Vo, A., Wangchuk, T., Wangdi, T., Weiand, M., Wilkinson, J., Wilson, A., Yadav, S., Yang, S., Yang, X., Young, G., Yu, Q., Zainoun, J., Zembek, L., Zimmer, A. und Lander, E.S. (2005): Genome sequence, comparative analysis and haplotype structure of the domestic dog. Nature, 438 (7069), 803-19.

Mellersh, C.S., Langston, A.A., Acland, G.M., Fleming, M.A., Ray, K., Wiegand, N.A., Francisco, L.V., Gibbs, M., Aguirre, G.D. und Ostrander, E.A. (1997): A linkage map of the canine genome. Genomics, 46 (3), 326-36.

Mellersh, C.S., Hitte, C., Richman, M., Vignaux, F., Priat, C., Jouquand, S., Werner, P., Andre, C., DeRose, S., Patterson, D.F., Ostrander, E.A. und Galibert, F. (2000): An integrated linkage-radiation hybrid map of the canine genome. Mamm Genome, 11 (2), 120-30.

Parker, H.G. und Ostrander, E.A. (2005): Canine genomics and genetics: running with the pack. PLoS Genet, 1 (5), e58.

Priat, C., Hitte, C., Vignaux, F., Renier, C., Jiang, Z., Jouquand, S., Cheron, A., Andre, C. und Galibert, F. (1998): A whole-genome radiation hybrid map of the dog genome. Genomics, 54 (3), 361-78. 


\section{Erläuterungen zu grundlegenden Begriffen und Methoden}

Dieses Kapitel beinhaltet Hintergrundinformationen zu den verschiedenen Typen von Mutationen, die in den folgenden Kapiteln beschrieben werden, und zu den üblichen Methoden, die beim Nachweis dieser Mutationen eingesetzt werden. In einem letzten Abschnitt werden grundlegende Strategien zur Identifizierung von Gendefekten kurz vorgestellt. Die Erläuterungen sind bewusst möglichst knapp gehalten. Für ausführlichere Informationen sei auf entsprechende Lehrbücher der Genetik verwiesen.

Zweck dieses Kapitels ist nicht, einen umfassenden Überblick über Methoden der Genotypisierung zu bieten, sondern die in den folgenden Kapiteln häufig auftretenden Begriffe und Methoden vorab zu erläutern, um eine Wiederholung von Erklärungen zu vermeiden. Methoden und Begriffe, die im Text nur einmal auftauchen, werden in dieser Übersicht nicht behandelt, sondern direkt an der Stelle im Text erklärt, an der sie erwähnt werden.

\subsection{Typen von Mutationen}

Der Begriff Mutation bezieht sich auf jede dauerhafte, stabil vererbte Veränderung der DNA eines Lebewesens, durch die sich das betreffende Individuum von einer Referenzpopulation unterscheidet. Der Begriff wird unabhängig davon verwendet, ob die jeweilige Mutation zur Veränderung von Genfunktionen führt oder folgenlos bleibt. Die Veränderung lediglich eines einzelnen Nukleotids wird als Punktmutation bezeichnet. Tritt eine Mutation bzw. Punktmutation innerhalb einer bestimmten Population mit einer Häufigkeit von $>1 \%$ auf, handelt es sich um einen Polymorphismus bzw. Einzelbasenpolymorphismus (SNP - Single Nucleotide Polymorphism) (Knippers 2001).

Bei den ursächlichen Mutationen für die in dieser Arbeit beschriebenen caninen Erbmerkmale (Erbkrankheiten und morphologische Varianten) handelt es sich überwiegend um Genmutationen. Darunter versteht man ein einzelnes Gen betreffende Veränderungen in Form von Substitutionen, Deletionen und Insertionen. 
Eine Substitution oder ein Basenaustausch bezeichnet einen Vorgang, bei dem ein Nukleotid oder eine Sequenz an einer bestimmten Position in der DNA durch ein anderes Nukleotid oder eine andere Sequenz ersetzt wird. Meistens betreffen Substitutionen nur ein einzelnes Nukleotid. Bei einer Deletion handelt es sich um den Verlust eines Sequenzabschnitts. Die Größe der gelöschten Sequenz ist sehr variabel. Unter einer Insertion versteht man den Einbau von einem oder mehreren zusätzlichen Nukleotiden in eine DNA-Sequenz. Dabei kann es sich sowohl um eine einzelne Base als auch um längere DNA-Abschnitte handeln.

Eine Sonderform der Insertion ist die Transposition. Darunter versteht man den Einbau eines DNA-Abschnitts oder der Kopie eines DNA-Abschnitts an einer anderen Stelle im Genom. Das humane Genom besteht zu ca. 45 \% aus transponiblen Sequenzelementen (Ostertag und Kazazian 2001). Im caninen Genom liegt der Anteil transponibler Elemente bei 34 \% (Lindblad-Toh et al. 2005). Die transponiblen Elemente der Säugetiere lassen sich in Transposons und Retroposons unterteilen. Transposons enthalten an den Enden invertierte Wiederholungssequenzen (darunter versteht man Duplikationen, deren Richtung im Verhältnis zur ursprünglichen Sequenz um $180^{\circ}$ gedreht ist) und codieren für eine Transposase. Durch die Aktivität der Transposase erfolgt die Bewegung der Transposons im Genom, indem die betreffenden DNA-Fragmente ausgeschnitten und anschließend an einer anderen Stelle im Genom eingefügt werden. Das humane Genom besteht zu etwa 3 \% aus DNA-Transposons. Dabei handelt es sich jedoch nach der allgemeinen Überzeugung um evolutionsgeschichtlich sehr alte Elemente, die nicht mehr transpositionell aktiv sind. Auch ein großer Teil der Retroposons, die etwa $42 \%$ des humanen Genoms ausmachen, scheint nicht mehr aktiv zu sein. Im Unterschied zu Transposons entstehen Retroposons, indem aus RNA-Zwischenstufen durch die Aktivität des Enzyms Reverse Transkriptase neue DNA-Fragmente synthetisiert und an unterschiedlichen Stellen im Genom eingefügt werden (Ostertag und Kazazian 2001).

Innerhalb der Gruppe der Retroposons wird weiterhin unterschieden zwischen autonomen und nicht autonomen Elementen. Autonome Retroposons bewegen sich eigenständig im Genom, indem sie offene Leseraster enthalten, die für die erforderlichen Proteine codieren. Im Gegensatz dazu kann bei nicht autonomen Elementen eine Transposition nur gesteuert durch die Proteine autonomer Elemente stattfinden. Die 
häufigsten Retroposons im Säugetiergenom sind LINEs (long interspersed nuclear elements) und SINEs (short interspersed nuclear elements) (Ostertag und Kazazian 2001).

LINEs sind autonome Retroposons von mehren kb Länge. Je nach Ursprungssequenz und Ähnlichkeiten untereinander sind einzelne LINEs zu Familien zusammengefasst. Der überwiegende Teil der im caninen Genom identifizierten LINEs stammt von einer Unterfamilie der jüngsten, säugetierspezifischen LINE-Familie L1MA oder kurz L1 ab. Es handelt sich um die Unterfamilie L1MA9, die innerhalb der L1MA Unterfamilien die zweitälteste ist (Kirkness et al. 2003). Der typische Aufbau von L1-Elementen beinhaltet zwei offene Leseraster, die für die erforderlichen Proteine zur Retroposition codieren, eine 5'- und eine 3'-UTR (untranslated region) sowie ein Poly-Adenin-Ende. Die transponierten Elemente werden stets von so genannten target site duplications (Zielortduplikationen) flankiert. Dabei handelt es sich um die Duplikation des direkt vor der Insertion lokalisierten Sequenzabschnitts (Ostertag und Kazazian 2001).

Die Sequenzen von SINEs umfassen zwischen 100 und 500 Nukleotide, enthalten stets zwei gleiche Monomere und ein Poly-Adenin-Ende und werden wie L1MA Elemente von target site duplications flankiert. Im caninen Genom ist eine karnivorenspezifische SINE-Familie besonders aktiv (Minnick et al. 1992). Diese SINE-Familie stellt $7 \%$ des caninen Genoms und stammt vermutlich von einer Transfer-RNA (tRNA-Lys) ab. Eine Unterfamilie der karnivorenspezifischen SINE-Familie (bezeichnet als SINEC_Cf) liegt in einer geschätzten Häufigkeit von 230.000 Kopien im caninen Genom vor, die durchschnittlich lediglich in 4,8 \% ihrer Sequenz von der Konsensussequenz abweichen. Aus diesen Beobachtungen lässt sich auf eine entwicklungsgeschichtlich junge, starke Verbreitung dieser SINE-Familie im caninen Genom schließen (Kirkness et al. 2003). An vielen Insertionsorten hat sich noch keine Stabilisierung eingestellt und es liegen immer noch Polymorphismen vor. Das im Zuge des Dog Genome Projects vollständig sequenzierte Genom eines Boxers enthält ca. 87.000 junge SINEC_Cf Elemente, von denen $8 \%$ heterozygot vorliegen (Lindblad-Toh et al. 2005).

Neben den oben beschriebenen Genmutationen gibt es Chromosomenmutationen, die in strukturelle und numerische Mutationen unterteilt sind, und Genommutationen. Formen der strukturellen Chromosomenmutationen sind Brüche, Deletionen und Defizienzen, Inversionen, Translokationen, Zentromerfusionen sowie Fissionen. Unter einem 
Bruch versteht man das Abbrechen eines Chromosomenabschnitts im Verlauf der Zellteilung. Dieser Vorgang bildet die Voraussetzung für alle weiteren Formen struktureller Chromosomenmutationen. In den meisten Fällen werden Bruchstücke in der Originalform wiedervereinigt. Der Verlust eines Bruchstücks am Ende eins Chromosoms wird als Deletion bezeichnet. Unter einer Defizienz versteht man den Verlust eines Abschnitts innerhalb eines Chromosoms. Dazu kommt es, wenn bei einem doppelten Bruch das Bruchstück aus dem Chromosom entfernt wird und die übrigen Abschnitte wieder zusammengefügt werden. Bei einer Inversion wird ein Bruchstück nach einem doppelten Bruch in umgekehrter Richtung wieder in das Chromosom eingefügt. Eine Translokation beschreibt allgemein die Veränderung der Position eines Chromosomenabschnitts innerhalb eins Chromosoms oder den Austausch von Chromosomenabschnitten zwischen homologen oder nicht homologen Chromosomen. Bei einer reziproken Translokation handelt es sich um den Austausch von Chromosomenabschnitten zwischen nicht homologen Chromosomen. Eine Sonderform der Translokation ist die Zentromerfusion, auch bezeichnet als Fusionstyp-Translokation oder Robertsonsche Translokation. Dabei kommt es zur Verschmelzung zweier Chromosomen im Bereich ihrer Zentromere. Dabei entsteht aus zwei Chromosomen ein neues Chromosom. Bei einer Fission liegt ein Bruch innerhalb des Zentromers eines Chromosoms vor. Dabei entstehen aus einem metzentrischen Chromosom zwei akrozentrische Chromosomen. Unter numerischen Chromosomenmutationen versteht man die das Vorliegen überzähliger Chromosomen oder das Fehlen eines Chromosoms. Bei der Genommutation ist die Gesamtheit eines Chromosomensatzes einer Mutation unterworfen (Kräußlich 1997).

\subsection{Mögliche Auswirkungen von Mutationen}

Die Auswirkungen der genannten Mutationen sind abhängig von ihrer Lage im Genom und von der Größe des betroffenen Bereiches. In codierenden Bereichen können Mutationen zur Änderung des genetischen Codes und damit zu Aminosäurensubstitutionen führen. Dabei muss nicht jede Änderung der Basenabfolge eine Aminosäurensubstitution verursachen, da mit Ausnahme von Methionin jeweils mindestens zwei verschiedene Basenabfolgen für dieselbe Aminosäure codieren. Eine weitere mögliche Folge ist die Entstehung eines verfrühten Stoppsignals. Deletionen oder Insertionen, deren Längen 
nicht ein Vielfaches von drei Nukleotiden betragen, können eine Leserasterverschiebung nach sich ziehen.

Als weitere Folge von Mutationen kann es zur Entstehung neuer Spleißstellen sowie zu Veränderung oder zum Verlust von Spleißkonsensussequenzen kommen, die sowohl durch Mutationen in codierenden Bereichen als auch durch Mutationen der Intronsequenz verursacht werden können. Die Wahrscheinlichkeit, mit der an einer bestimmten Stelle der mRNA ein Spleißereignis stattfindet, hängt vom Vorhandensein bestimmter funktioneller Sequenzabschnitte ab. Dazu gehören eine 5'- und eine 3'- Spleißstelle, eine Folge von Pyrimidinnukleotiden stromaufwärts der 3'-Spleißstelle des Introns sowie eine Verzweigungsstelle ca. 20-40 Nukleotide stromaufwärts der 3'-Spleißstelle des Introns. Bei der funktionellen Sequenz an den Spleißstellen handelt es sich um die konservierte Akzeptorsequenz GT am 5'-Ende eines Introns und die konservierte Donorsequenz AG am 3'-Ende eines Introns. In seltenen Ausnahmen kann die Akzeptorsequenz auch AC und die Donorsequenz AT lauten. Die Konsensussequenz der Verzweigungsstelle umfasst sieben Nukleotide und ist bei Säugetieren bis auf einen Adenosinbaustein an Position 6 wenig konserviert. Die Basenabfolge lautet beim Säugetier YNCURAC. Für Y kann sowohl Uracil als auch Cytosin eingesetzt werden. R steht für Guanin oder Adenin. Anstelle von N kann jedes der vier Nukleotide Adenin, Guanin, Cytosin oder Uracil stehen. (Passarge 1994; Knippers 2001). Eine von Shapiro und Senapathy (1987) entwickelte Methode ermöglicht die Berechnung der Wahrscheinlichkeit für ein Spleißereignis an einer bestimmten Position anhand der Ähnlichkeit der zu untersuchenden Sequenz mit den oben genannten Konsensussequenzen. Sequenzänderungen durch Mutationen können diese Wahrscheinlichkeit erhöhen oder reduzieren. Infolgedessen kann es zum Verlust von Exons oder zur Integration von Intronsequenzen in die codierende Sequenz und damit zur Codierung zusätzlicher Aminosäuren kommen. In vielen Fällen zieht ein verändertes Spleißmuster außerdem eine Leserasterverschiebung nach sich. Sowohl durch die Leserasterverschiebung als auch durch die Integration intronischer Sequenz kann zudem ein verfrühtes Stoppcodon erzeugt werden.

In nichtcodierenden DNA-Abschnitten können Mutationen die Steuerung der Transkription beeinflussen. Beispielsweise kommt es durch Mutationen in Promotorbereichen 
von Genen unter Umständen zu einer gestörten Genexpression (Passarge 1994; Knippers 2001).

\subsection{Methodisches Handwerkszeug für die Genotypisierung}

Am Anfang jeder molekularbiologischen Genotypisierung steht die Isolierung genomischer DNA, die die gesamte genetische Information des zu untersuchenden Individuums enthält. Für den Nachweis einer bestimmten Mutation ist in der Regel lediglich ein wenige hundert Basenpaare (bp) umfassender Abschnitt von Interesse. Um diesen Abschnitt näher zu untersuchen muss die DNA sichtbar gemacht werden. Die kleinste in einem mit Ethidiumbromid gefärbten Agarosegel sichtbare Menge an DNA beträgt 1020 ng. Das entspricht mindestens $18 \times 10^{12}$ Nukleotiden bzw. $9 \times 10^{12}$ bp. Um ein wenige hundert Basenpaare langes DNA-Fragment sichtbar zu machen, muss es also stark vervielfältigt werden. Dazu dient die Polymerasekettenreaktion (engl. Polymerase Chain Reaction, PCR). Für eine weitere Untersuchung ist in der Regel eine Vereinzelung der $\mathrm{zu}$ untersuchenden DNA-Abschnitte und deren Trennung vom Rest der genomischen DNA erforderlich. Dieser Schritt erfolgt durch eine Elektrophorese. Für die Sichtbarmachung der $\mathrm{zu}$ untersuchenden DNA-Fragmente stehen verschiedene Markierungsmethoden zu Verfügung.

\subsubsection{Isolierung von DNA}

Jede einzelne kernhaltige Zelle eines Organismus enthält das vollständige Genom, also die Gesamtheit der genetischen Information eines Organismus. Das haploide canine Genom umfasst laut Schätzungen $2,4 \times 10^{9}$ bp (Lindblad-Toh et al. 2005). Der überwiegende Anteil des Genoms ist im Zellkern lokalisiert, allerdings enthalten auch Mitochondrien DNA. Das mitochondriale Genom des Hundes ist vollständig sequenziert und umfasst 16728 bp (NCBI-Sequence: NC_002008) (Kim et al. 1998).

Als Ausgangsmaterial für die Isolierung genomischer DNA sind grundsätzlich alle Präparate geeignet, die kernhaltige Zellen enthalten. Typische Materialien sind Gewebeproben, Schleimhautabstriche, Blut, Sperma oder Haare. Üblicherweise werden zunächst durch Inkubation des Ausgangsmaterials mit geeigneten Enzymen oder Reagenzien alle Substanzen außer der DNA lysiert. So werden Zellwände und Kernmembranen zerstört und die DNA befindet sich frei im Medium. Die Isolierung der 
DNA von den übrigen Substanzen des Mediums erfolgt unter Nutzung spezifischer Zentrifugations- und Bindungseigenschaften von Nukleinsäuren gegenüber anderen Verbindungen. Geeignete Protokolle finden sich bei Schrimpf (2002) und bei Ausubel et al. (1993).

Für den Nachweis einer Mutation in mitochondrialer DNA ist es unter Umständen von Interesse, reine Mitochondrien-DNA zu isolieren. Die DNA des Zellkerns enthält einzelne gleichmäßig verteilte mitochondriale Sequenzfragmente (mitochondriale Pseudogene) (Woischnik und Moraes 2002). Dadurch besteht das Risiko, bei einer PCR mit dem Ziel der Amplifikation eines bestimmten Abschnitts mitochondrialer DNA ungewollt Teile der Zellkern-DNA zu amplifizieren. Um dieses Problem zu umgehen, kann entweder die Länge des zu amplifizierenden DNA-Abschnitts erweitert werden (Li et al. 2006), oder man arbeitet mit reiner mitochondrialer DNA.

Die Isolierung mitochondrialer DNA erfolgt per Zerstörung der Zellwände, beispielsweise durch den Einsatz von Zymolase in Verbindung mit mechanischer Bearbeitung durch Schütteln und gegebenenfalls Ultraschallbehandlung, und anschließende Trennung der Mitochondrien von Zellmaterial und Zellkernen. Dabei macht man sich die spezifischen Zentrifugationseigenschaften von Mitochondrien zunutze. Die anschließende Isolierung der DNA aus den Mitochondrien erfolgt mit ähnlichen Methoden wie bei der Isolierung genomischer DNA (Defontaine et al. 1991).

\subsubsection{Polymerasekettenreaktion (PCR)}

Das Prinzip der Polymerasekettenreaktion (PCR), einem um die Mitte der 80er Jahre entwickelten Verfahren zur Vervielfältigung spezifischer DNA-Fragmente (Saiki et al. 1985; Mullis und Faloona 1987), beruht auf der Nachahmung der Vorgänge bei der natürlichen Replikation. Es werden Oligonukleotide (Primer) konstruiert, die an die ersten Basen des Matrizenstranges des zu amplifiziernden Fragments in Leserichtung bzw. an die letzten Basen des Fragments in revers komplementärer Richtung binden.

Eine DNA-Menge zwischen 0,1-1,0 $\mu \mathrm{g}$ wird mit einer entsprechenden Menge Primer, einer entsprechenden Menge der vier Desoxynukleotide (kurz: dNTPs), aus denen die DNA zusammengesetzt ist (Desoxyadenosintriphosphat, Desoxyguanosintriphosphat, Desoxycytosintriphosphat und Desoxythymintriphosphat), und DNA-Polymerase in 
einem Puffer inkubiert. Die Amplifikation erfolgt im Verlauf von zyklisch wiederholten, gezielten Temperaturwechseln. In einem Denaturierungsschritt bei einer Temperatur zwischen $90^{\circ} \mathrm{C}$ und $94^{\circ} \mathrm{C}$ werden die Doppelstränge der DNA denaturiert. Für den anschließenden Hybridisierungsschritt wird die Reaktion in auf eine Temperatur von $\geq 50^{\circ} \mathrm{C}$ abgekühlt. Dabei richtet sich die Temperatur nach der Sequenz der verwendeten Primer mit dem Ziel, optimale Bedingungen für die Anlagerung der Primer am Matrizenstrang und am revers komplementären Strang zu schaffen. Dieser Vorgang wird auch als Annealing bezeichnet. Im Extensionsschritt bei einer Temperatur von üblicherweise $72^{\circ} \mathrm{C}$ werden, katalysiert durch die Polymerase, die hybridisierten Primer durch Anlagerung von komplementären Nukleotiden am Matrizen- bzw. am revers komplementären Strang entlang verlängert. Der Ablauf dieser drei Schritte wird als PCR-Zyklus bezeichnet. Es werden so viele Zyklen durchgeführt, bis die erwünschte Anzahl an Kopien hergestellt ist (Schrimpf 2002).

Die genaue Menge der einzelnen Komponenten des PCR-Ansatzes, die genaue Annealingtemperatur, die Dauer der einzelnen Schritte und die Anzahl benötigter Zyklen hängt unter anderem von bestimmten Eigenschaften des zu amplifiziernden Fragments und der Primer, von der Art der verwendeten Polymerase und zahlreichen weiteren Voraussetzungen $\mathrm{ab}$ und muss daher stets an die jeweiligen Bedingungen angepasst werden.

\subsubsection{Elektrophorese}

Die Elektrophorese dient der Bestimmung der Größe einzelner DNA-Fragmente und der Sortierung von unterschiedlich großen Fragmenten in einer Probe. Bei der Gelelektrophorese, dem gebräuchlichsten Verfahren, werden die zu untersuchenden Proben nebeneinander in die Taschen eines porösen Gels aus Agarose oder Polyacrylamid geladen. Das Gel befindet sich in einer Elektrophoresekammer und wird von einem geeigneten flüssigen Medium, meist TBE- (Tris-Borat-EDTA-) Puffer, umgeben. An das so vorbereitete Gel wird ein elektrisches Feld angelegt. Da DNA-Moleküle negativ geladen sind, wandern sie innerhalb dieses Feldes durch die Poren des Gels zur Kathode. Die Geschwindigkeit der einzelnen Moleküle hängt dabei von ihrer Größe im Verhältnis zur Porengröße ab: kleine Moleküle wandern schneller als große Moleküle. Moleküle derselben Größe wandern mit derselben Geschwindigkeit und bilden im Gel 
Banden. Wird die Wanderung nach einer gewissen Zeit durch Aufhebung des elektrischen Feldes unterbrochen, befinden sich größere Moleküle in Banden in der Nähe der Anode, während kleinere Moleküle in Banden in der Nähe der Kathode lokalisiert sind. Durch den Zusatz von Ethidiumbromid, das sich an die Wasserstoffbrücken zwischen den Basenpaaren anlagert und unter UV-Licht fluoresziert, lassen sich die einzelnen Banden visualisieren. Die Größenbestimmung der Banden erfolgt anhand von bekannten Standardmarkern, die mit auf das Gel aufgetragen werden (Mülhardt 2000; Schrimpf 2002).

\subsection{Genotypisierungsverfahren}

\subsubsection{Allelspezifische PCR (ASP)}

Bei diesem Verfahren werden zwei Primerpaare konstruiert, von denen eines nur an das mutierte und das andere nur an das Wildtypallel bindet. Diese Spezifität der Primer beruht auf dem letzten Nukleotid am 3'-Ende der Primer. Die zu untersuchenden Proben werden in zwei verschiedenen Ansätzen unter Verwendung jeweils eines der Primerpaare amplifiziert. Bei Proben von homozygot normalen Individuen wird nur bei Einsatz des für das Wildtypallel spezifischen Primerpaares ein Fragment amplifiziert. Bei Proben von homozygot mutierten Individuen wird nur unter Verwendung des für das mutierte Allel spezifischen Primerpaares ein Fragment amplifiziert. Bei heterozygoten Individuen erfolgt mit beiden Primerpaaren eine erfolgreiche Amplifikation. Weitere Bezeichnungen für dieses Verfahren sind ARMS (amplification refractory mutation system - System der amplifizierungsresistenten Mutation), PASA (PCR-Amplifikation spezifischer Allele) oder ASA (allelspezifische Amplifikation) (Newton und Graham 1997).

\subsubsection{Sequenzierung}

Eine Möglichkeit zur Genotypisierung ist die Amplifikation des zu untersuchenden DNA-Abschnitts mit anschließender Sequenzierung. Für die Aufbereitung der zu sequenzierenden Proben sind in den gängigen Laborhandbüchern unterschiedliche Methoden beschrieben worden. 
Die verschiedenen Methoden zur Sequenzierung beruhen auf der Erzeugung einer hohen Anzahl von unterschiedlich vollständigen Kopien des $\mathrm{zu}$ sequenzierenden Fragments. Ein geringer Teil dieser Kopien entspricht dem gesamten zu sequenzierenden DNA-Abschnitt. Die Sequenz der übrigen Kopien beginnt stets am ersten Nukleotid des 5'-Endes und endet an unterschiedlichen Positionen innerhalb des zu sequenzierenden Fragments, so dass ein Gemisch von Fragmenten vorliegt, die jede mögliche Länge zwischen der Gesamtlänge des zu sequenzierenden Fragments und weinigen Nukleotiden repräsentieren. Per Elektrophorese gelingt es, die einzelnen Fragmente dieses Gemischs auf eine Basenlänge genau nach Größe geordnet in diskreten Banden zu separieren. Mit unterschiedlichen Methoden wird sichergestellt, dass die jeweils letzten Nukleotide am 3'-Ende der einzelnen Fragmente eindeutig bestimmt werden können. So lässt sich die Sequenz des gesamten DNA-Abschnitts von der kürzesten über die jeweils um ein Nukleotid längeren Fragmente bis zum längsten Fragment ablesen (Gassen und Minol 1996).

Zur Erzeugung der unterschiedlich langen Fragmente und zur Bestimmung der Nukleotide am 3'-Ende der Fragmente sind verschiedene Vorgehensweisen beschreiben worden, die in chemische und enzymatische Verfahren unterteilt werden können. Bei chemischen Sequenzierungsmethoden nach Maxam und Gilbert (Maxam und Gilbert 1977; Maxam und Gilbert 1980) werden ${ }^{32}$ P-markierte Einzelstränge des zu sequenzierenden Fragments hergestellt und in vier Aliquots aufgeteilt. Jedes dieser Aliquots wird mit einer Chemikalie behandelt, die spezifisch an einem der vier Nukleotide der DNA eine Spaltung herbeiführt. So wird sichergestellt, dass die unterschiedlich langen Spaltprodukte des zu sequenzierenden Fragments in jedem der vier Aliquots jeweils mit demselben Nukleotid enden. Die Aliquots werden nebeneinander auf ein Elektrophoresegel geladen, elektrophoretisch nach Größen sortiert und per Autoradiographie visualisiert (Gassen und Minol 1996).

Eine weitere, zur selben Zeit entwickelte Methode ist die Kettenabbruchmethode nach Sanger (Sanger et al. 1977), die die Basis aller heutzutage üblichen Sequenzierverfahren darstellt. Die zu sequenzierende DNA wird denaturiert, mit einem Primer hybridisiert und dieser mit Hilfe einer Polymerase verlängert, ähnlich wie bei der PCR. Zusätzlich zu den vier üblichen 2'-Desoxynukleotiden enthält der Ansatz allerdings auch noch eine gewisse Menge eines fünften Nukleotids, das sich insofern von den anderen unterschei- 
det, als ihm am dritten C-Atom der Ribose die notwendige Hydroxylgruppe fehlt, an die üblicherweise das nächste Nukleotid geknüpft wird. Wird statt eines dNTPs ein solches 2',3'-Didesoxynukleotid (ddNTP) eingebaut, kann der Strang nicht weiter verlängert werden. Der Einbau von dNTPs und ddNTPs erfolgt zufällig. Die neuen DNA-Stränge, die in diesem Ansatz synthetisiert werden, haben folglich sehr unterschiedliche Längen. Das Didesoxynukleotid, das eingesetzt wird (ddATP, ddCTP, ddGTP, ddTTP), bestimmt, mit welcher Base die neu synthetisierten DNA-Fragmente enden.

Um bei den einzelnen synthetisierten DNA-Strängen zu unterscheiden, welches der vier möglichen Nukleotide am 3'-Ende vorliegt, existieren verschiedene Methoden. Eine Möglichkeit ist die Aufteilung jeder zu untersuchenden Probe in vier Aliquots und der Zusatz von jeweils einem der vier ddNTPs je Aliquot. Die Detektion der Fragmente erfolgt per radioaktiver Markierung oder alternativ mittels Silberfärbung oder über die Markierung mit Digoxigenin (Mülhardt 2000).

Bei neueren automatischen Sequenzierverfahren erfolgt eine Markierung der vier Didesoxynukleotide mit vier unterschiedlichen Fluorophoren. Im Anschluss an die Sequenzierungs-PCR wird eine Kapillarelektrophorese durchgeführt. Die Kapillaren sind mit einem Polymer gefüllt und in einen Stromkreis eingeschlossen, so dass wie bei der Gelelektrophorese eine Wanderung der einzelnen PCR-Fragmente durch die Poren des Polymers herbeigeführt wird. Per Laserbestrahlung werden die Fluorophoren an den einzelnen PCR-Fragmenten angeregt und emittieren Licht einer spezifischen Wellenlänge. Während der Elektrophorese passieren die fluoreszenzmarkierten PCRFragmente ein Photometer, das die Abfolge der unterschiedlichen Fluoreszenzemissionen detektiert. Mit einer geeigneten Software zur Datenaufbereitung wird anhand dieser Informationen ein Chromatogramm erstellt, aus dem unter Verwendung spezieller Analysesoftware schließlich die Basensequenz der Matrizen-DNA berechnet wird (Mülhardt 2000).

\subsubsection{Pyrosequenzierung}

Diese Methode basiert auf der Detektion von während der DNA-Synthese freigesetzten Pyrophosphaten. Dazu wird das per PCR amplifizierte zu sequenzierende DNAFragment in einzelsträngiger Form mit den vier Enzymen DNA-Polymerase, ATP- 
Sulfurylase, Luciferase und Apyrase sowie den Substraten Adenosin-5'-Phosphosulfat und Luciferin inkubiert. Im ersten Schritt wird eine begrenzte Menge eines bestimmten Desoxynukleotidtriphosphates zugegeben. Die Polymerase katalysiert den Einbau des Desoxynukleotids in den neuen DNA-Strang, sofern die zugegebene Base komplementär zur Base des Matrizenstranges ist. Bei jedem Einbauvorgang wird eine bestimmte Menge an Pyrophosphat freigesetzt, die proportional zur Anzahl an eingebauten Nukleotiden ist. Das freigesetzte Pyrophosphat reagiert unter der katalytischen Einwirkung von ATP-Sulfurylase mit Adenosin-5'-Phosphosulfat zu Adenosintriphosphat (ATP). ATP setzt eine luciferasegesteuerte Umwandlung von Luciferin zu Oxyluciferin in Gang. Bei diesem Prozess wird Energie in Form von sichtbarem Licht freigesetzt. Die Menge des emittierten Lichtes ist proportional zur Menge des generierten ATP und damit zur Menge an eingebauten Nukleotiden. Die Menge an emittiertem Licht lässt sich mithilfe einer speziellen Kamera in einem Pyrogramm aufzeichnen. Erfolgt kein Einbau des zugegebenen Nukleotids, wird kein Licht emittiert. Überschüssiges ATP und nichteingebaute Nukleotide werden durch Apyrase abgebaut. Nach vollständigem Abbau wird das nächste Nukleotid zugegeben und die beschriebenen Vorgänge wiederholen sich. Durch wechselweise Zugabe der vier verschiedenen Nukleotide, aus denen die DNA zusammengesetzt ist, lässt sich anhand des Pyrogramms Anzahl und Art der eingebauten Nukleotide und damit die Sequenz des zu untersuchenden DNA-Fragments bestimmen. Um falsch positive Signale bei Zugabe von Desoxyadenosintriphosphat zu vermeiden, wird ersatzweise Desoxyadenosin-alpha-Thiotriphosphat verwendet, das zwar durch die Polymerase effizient in die DNA eingebaut wird, von der Luciferase jedoch nicht genutzt werden kann (Ronaghi et al. 1996).

\subsubsection{Heteroduplexanalyse}

Bei dieser Methode wird durch spezielle PCR-Bedingungen die Formation von Heteroduplices aus einem mutierten und einem normalen DNA-Strang begünstigt. Diese DNA-Moleküle weisen aufgrund der Fehlpaarung in der mutierten Region eine abweichende Konformation auf und migrieren daher in einer Elektrophorese deutlich langsamer als mutierte oder normale Homoduplices. Bei der Konformationsänderung handelt es sich nach einer Theorie von Ganguly et al. (1993) um einen Knick, der durch eine asymmetrische Verschiebung der fehlgepaarten Basen entsteht, indem eine der Basen in der Helix verbleibt, während die andere aus der Helix herausgedreht wird. Da 
Heteroduplices nur bei heterozygoten Individuen entstehen können, ist diese Methode zur Identifizierung heterozygoter Defektträger geeignet, nicht aber zur Unterscheidung zwischen homozygot normalen und homozygot mutierten Individuen. Eine solche Unterscheidung kann durch die Untersuchung dreier Aliquots je Probe erreicht werden. Dabei wird das erste Aliquot mit der Probe eines homozygot defekten Individuums vermischt und das zweite Aliquot mit der Probe eines homozygot normalen Individuums. Das dritte Aliquot wird pur analysiert. Bei homozygot normalen Individuen ergibt die Untersuchung des ersten Aliquots Heteroduplices, beim homozygot defekten Individuum treten hingegen im zweiten Aliquot Heteroduplices auf.

\subsubsection{Restriktionsfragmentlängenpolymorphismus (RFLP)}

Restriktionsenzyme sind in der Lage, kurze DNA-Sequenzen spezifisch zu erkennen und die DNA an einer definierten Stelle innerhalb oder kurz vor oder nach dieser Sequenz zu spalten. Diese Eigenschaft lässt sich für den Nachweis von Sequenzunterschieden nutzen. Für die Entwicklung einer Genotypisierungsmethode unter Nutzung von Restriktionsenzymen muss eine Restriktionserkennungssequenz gefunden werden, die entweder nur im Wildtypallel oder nur im mutierten Allel vorliegt. Die Erfüllung dieser Voraussetzung wird als Restriktionsfragmentlängenpolymorphismus (RFLP) bezeichnet (Knippers 2001). Nach geeigneten Enzymen zum Spalten eines bestimmten DNA-Fragments kann beispielsweise unter Eingabe der zu spaltenden Sequenz in der REBASE-Datenbank gesucht werden (Roberts et al. 2007). Zum Nachweis eines RFLP wird der zu untersuchende DNA-Abschnitt amplifiziert und anschließend mit dem jeweiligen Restriktionsenzym inkubiert. Die einzelnen Genotypen unterscheiden sich, indem sich aus der Restriktionsspaltung unterschiedliche Anzahlen und Größen von Restriktionsfragmenten ergeben (Knippers 2001).

In manchen Fällen liegt weder im Wildtyp- noch im mutierten Allel eine geeignete Restriktionserkennungssequenz vor. Dann besteht unter Umständen die Möglichkeit, durch die gezielte Veränderung eines Nukleotids oder weniger Nukleotide im zu untersuchenden DNA-Fragment eine entsprechende Sequenz im Wildtyp- oder im mutierten Allel zu konstruieren. Eine solche Veränderung kann durch den Einsatz eines so genannten mismatch-Primers bewirkt werden. Das Verfahren wird als Primer-Mutagenese bezeichnet (Schrimpf 2002). Bedingung für ein Gelingen der Mutagenese ist unter 
anderem eine ausreichende Länge des Primers (zwischen 20 und 35 bp), um spezifisch mit der Zielsequenz zu hybridisieren. Die einzuführende mutierte Sequenz muss innerhalb des Primers so lokalisiert sein, dass zu beiden Seiten der mismatch-Sequenz mindestens 10 bis 15 bp homologer Sequenz vorhanden sind (Kuipers et al. 1991).

\subsubsection{SSCP-Analyse (single strand conformation polymorphism)}

Bei der Genotypisierung per SSCP-Analyse (single strand conformation polymorphism) wird das Amplifikat eines zu untersuchenden DNA-Abschnitts in alkalischer Lösung denaturiert und anschließend einer Elektrophorese unterzogen. Bei Vorliegen einer Mutation bilden die bei der Denaturierung erzeugten Einzelstrang-DNA-Moleküle eine andere Sekundärstruktur aus als die Einzelstrang-DNA-Moleküle des Wildtypallels. Eine abweichende Sekundärstruktur verändert die Migrationseigenschaften der DNAMoleküle in der Elektrophorese. Dadurch lassen sich mutierte und Wildtypallele voneinander unterscheiden (Orita et al. 1989).

Eine Sonderform der SSCP-Analyse ist der snapback-SSCP-Test. Durch die Verwendung eines so genannten snapback (Rückschnapp)-Primers wird im resultierenden PCRProdukt an die Matrizensequenz ein Sequenzabschnitt angehängt, der zu dem von der Mutation betroffenen Bereich des normalen Allels komplementär ist. Bei einer Denaturierung der Doppelstränge kommt es im normalen Allel durch Hybridisierung der komplementären Abschnitte $\mathrm{zu}$ einer spezifischen Konformation. Im defekten Allel bleibt die Konformation der Einzelstränge hingegen unverändert, da hier für das angefügte normale Sequenzfragment aufgrund der Mutation kein komplementäres Fragment für eine Hybridisierung verfügbar ist. Anhand des unterschiedlichen Laufverhaltens hybridisierter und nichthybridisierter Einzelstränge in der Elektrophorese lässt sich bestimmen, ob in einer Probe nur das normale, nur das defekte oder beide Allele vorliegen, also ob das zu untersuchende Individuum einen homozygot normalen, homozygot mutierten oder heterozygoten Genotyp aufweist (Wilton et al. 1998).

\subsubsection{Allelspezifische Oligonukleotidhybridisierung (ASO)}

Für die Analyse per allelspezifischer Oligonukleotidhybridisierung (ASO) werden die einzelnen zu untersuchenden Proben in zwei Aliquots aufgeteilt. Anschließend werden die Proben auf zwei Nylonmembranen übertragen, und zwar so, dass auf jeder Memb- 
ran jeweils ein Aliquot von jeder Probe vorhanden ist und zwei identische Membranen vorliegen. Die Nylonmembranen sind positiv geladen, so dass die in der Probe enthaltene, negativ geladene DNA an der Nylonmembran bindet. Diese Methode wird als Blotting bezeichnet. Zum Blotten wird ein Slot-Blot-Gerät eingesetzt, mithilfe dessen einzelne DNA-Proben durch einen per Vakuum erzeugten Sog auf bestimmte Bereiche der Nylonmembran überführt werden können.

Für die Hybridisierung werden zwei unterschiedliche Oligonukleotide konstruiert, von denen eines $\left(\mathrm{O}_{N}\right)$ spezifisch mit der normalen Sequenz hybridisiert und das andere $\left(\mathrm{O}_{\mathrm{D}}\right)$ spezifisch mit der defekten Sequenz hybridisiert. Die Oligonukleotide werden mit einer geeigneten Substanz markiert. Anschließend werden zwei Hybridisierungsansätze hergestellt, mit denen die beiden Blots vorhybridisiert werden. Für die eigentliche Hybridisierung wird einem der beiden Ansätze $\mathrm{O}_{\mathrm{N}}$, dem anderen $\mathrm{O}_{\mathrm{D}}$ zugesetzt. Nach Abschluss der Hybridisierung werden mehrere Waschschritte durchgeführt. Daran schließt sich je nach Art der Markierung die Detektion der Proben an, die mit $\mathrm{O}_{\mathrm{N}}$ bzw. $\mathrm{O}_{\mathrm{D}}$ oder beiden Oligonukleotiden hybridisiert sind.

Diese Methode basiert auf einem erstmals von Saiki et al. (1986) beschriebenen Verfahren. Bei den in dieser Arbeit zitierten Studien, in denen ASO als Genotypisierungsmethode eingesetzt wurde, wurden die Oligonukleotide radioaktiv markiert. In diesem Fall erfolgt der Nachweis per Inkubation der gewaschenen Membranen mit einem Röntgenfilm. Bei der Auswertung zeigen Proben von homozygot normalen Individuen nur auf der mit $\mathrm{O}_{\mathrm{N}}$ hybridisierten Membran ein Signal. Proben von homozygot defekten Individuen zeigen nur auf der mit $\mathrm{O}_{\mathrm{D}}$ hybridisierten Membran ein Signal. Heterozygote Proben zeigen auf beiden Membranen ein Signal, dessen Intensität jeweils etwa der Hälfte der typischen Signalstärke einer homozygoten Probe entspricht.

Aufgrund der hohen Sicherheitsauflagen bei der Arbeit mit radioaktiven Substanzen werden jedoch üblicherweise nicht-radioaktive Markierungsmethoden, beispielsweise unter Verwendung von Biotin oder Digoxigenin, bevorzugt. Entsprechende Protokolle finden sich beispielsweise bei Schrimpf (2002). 


\subsubsection{Oligonukleotid-Ligations-Assay (OLA)}

Für einen Nachweis von Mutationen per Oligonukleotid-Ligations-Assay (OLA) nach Landgren et al. (1988) wird ein $\mathrm{zu}$ analysierendes Fragment zunächst amplifiziert. Anschließend wird eine „Hybridisierungs-Ligations-Reaktion“ durchgeführt, bei der drei unterschiedliche Oligonukleotide eingesetzt werden. Ein Oligonukleotid (A) hybridisiert spezifisch mit dem Wildtypallel und ist mit HEX markiert. Ein weiteres Oligonukleotid (B) hybridisiert im selben Fragmentabschnitt, wie das erste Oligonukleotid spezifisch mit dem Defektallel, ist jedoch am 5'-Ende um ein Nukleotid länger und ist mit ROX markiert. Das dritte Oligonukleotid (C) hybridisiert direkt im Anschluss an die beiden anderen Oligonukleotide sowohl mit dem Wildtyp- als auch mit dem Defektallel. Der Reaktionsansatz enthält die drei Oligonukleotide, thermostabile Ligase, Reaktionspuffer und das PCR-Produkt. Die Reaktion erfolgt in einem Thermocycler. Jeder Zyklus setzt sich aus drei Schritten zusammen. Im ersten Schritt werden die Doppelstränge des PCR-Produktes denaturiert. Im zweiten Schritt hybridisieren die Oligonukleotide. Im dritten Schritt werden die Oligonukleotide A und B mit dem angrenzenden Oligonukleotid C ligiert. Nach Abschluss der Reaktion erfolgt eine Denaturierung, bei der die ligierten Oligonukleotide von der Matritzen-DNA gelöst werden, und eine elektrophoretische Auftrennung der einzelnen Ligationsprodukte unter denaturierenden Bedingungen. Mithilfe eines automatischen Sequenziergerätes lassen sich die einzelnen Ligationsprodukte anhand ihrer Größe und ihrer spezifischen Fluoreszenzmarkierung voneinander unterscheiden.

\subsubsection{Mikrosatellitenanalyse}

Für einige Erbkrankheiten und -merkmale kann eine Genotypisierung über die Analyse polymorpher Mikrosatellitenmarker erfolgen. Der Begriff Mikrosatellit beschreibt eine Aneinanderreihung von Wiederholungen kurzer Sequenzabschnitte. Dabei beträgt die Länge des wiederholten Sequenzabschnitts in der Regel zwischen 1 und 6 bp. Die Anzahl der Wiederholungseinheiten liegt zwischen 10 und 50. Bei Säugern sind Mikrosatellitensequenzen mit einem durchschnittlichen Abstand von 4 bis 5 kb gleichmäßig im Genom verteilt. Eine Besonderheit von Mikrosatelliten ist die hohe Mutationsrate, die vor allem mit der Neigung zur Haarnadelstrukturbildung bei der Replikation begründet wird. Da Mikrosatelliten in der Regel in nicht codierenden Se- 
quenzbereichen lokalisiert sind, haben Veränderungen in der Anzahl der Wiederholungseinheiten nur selten Einfluss auf die Überlebensfähigkeit der betroffenen Individuen. Dadurch kommt es zu einer starken Variabilität in der Anzahl der Wiederholungseinheiten in einer Mikrosatellitensequenz (Knippers 2001). Voraussetzung für eine Genotypisierung per Mikrosatellitenanalyse ist die Identifizierung bestimmter Polymorphismen, die stets mit der nachzuweisenden Erkrankung oder dem nachzuweisenden Merkmal zusammen vorliegen. Die Gültigkeit dieses Zusammenhangs muss an einer ausreichend großen Population überprüft werden. Die Analyse von Mikrosatellitenpolymorphismen erfolgt per Amplifikation des betreffenden Sequenzabschnitts und anschließende Größenbestimmung mittels Elektrophorese. Aufgrund der gleichmäßigen Verteilung im Genom, der hohen Variabilität und der unkomplizierten Analyse von Polymorphismen eignen sich Mikrosatelliten besonders gut als DNAMarker (Litt und Luty 1989; Tautz 1989; Weber und May 1989). Neben klassischen Verfahren der Detektion einzelner amplifizierter Fragmente wie Ethidiumbromidfärbung, Silberfärbung und Radiomarkierung kommen heute überwiegend automatisierte Verfahren auf der Basis von Kapillarelektrophorese und Fluoreszenzmarkierung zum Einsatz. Dabei wird während der Elektrophorese bei der Passage der einzelnen fluoreszenzmarkierten PCR-Fragmente durch die Kapillaren an einem bestimmten Punkt per Photometer die durch eine Laseranregung ausgelöste Fluoreszenz der Fragmente detektiert. Fragmente unterschiedlicher Größen passieren diesen Messpunkt in unterschiedlichen Zeitabständen. Die Stärke des Signals lässt Rückschlüsse auf die Anzahl der Fragmente einer bestimmten Größe zu. Liegt ein Allel des zu untersuchenden Mikrosatelliten homozygot vor, ist das Signal im Optimalfall doppelt so stark wie das Signal der Probe eines heterozygoten Individuums. Mithilfe einer entsprechenden Software werden anhand der aufgezeichneten Fluoreszenzsignale der zu untersuchenden Fragmente und eines definierten DNA-Fragmentgrößenmarkers die Größen und damit die jeweils vorliegenden Allele der untersuchten Mikrosatelliten bestimmt (Mayrand et al. 1992; Ziegle et al. 1992).

\subsection{Strategien zur Identifizierung molekulargenetischer Ursachen von Erbkrankheiten oder morphologischen Merkmalen}

Für die Suche nach ursächlichen Mutationen für bestimmte morphologische Merkmale oder für Erbkrankheiten haben sich verschiedene Herangehensweisen etabliert, die 
grundsätzlich entweder auf einem positionellen oder auf einem funktionalen Ansatz basieren.

Voraussetzung für den funktionalen Ansatz sind Kenntnisse über möglicherweise an der Ausprägung eines Merkmals oder einer Krankheit beteiligte Proteine und Kenntnis der für diese Proteine codierenden Gene. Die auf diesem Weg identifizierten Kandidatengene können dann mit entsprechenden Methoden auf Mutationen untersucht werden.

Der positionelle Ansatz beruht auf der Eingrenzung eines Genom-Bereiches, innerhalb dessen die Mutation mit einer hohen Wahrscheinlichkeit zu finden ist. Üblicherweise erfolgt diese Eingrenzung über die Identifizierung bestimmter Markersequenzen, die innerhalb einer Rasse mit dem Merkmal oder der Erkrankung gekoppelt vererbt werden. Mögliche Markersequenzen sind kartierte Mikrosatelliten oder SNPs. Bei Hunden sind Rekombinationen innerhalb von Rassen äußerst selten. So lassen sich mit der beschriebenen Methode Haplotypen mit drei bis fünf Allelen je Genort identifizieren, die sich teilweise über sehr lange Entfernungen erstrecken. Bruchstücke dieser Haplotypen mit einer Länge von ca. 100000 Basenpaaren stimmen oft in mehreren Rassen überein. Über die vergleichende Analyse einer definierten Zusammenstellung von Markern an reinrassigen Hunden und Kreuzungshunden lässt sich die Länge der mit dem Merkmal oder der Erkrankung assoziierten Haplotypen auf einige 1000 Basenpaare eingrenzen. Innerhalb dieses Bereiches kann anschließend per Sequenzanalyse und durch Vergleiche mit homologen DNA-Regionen bei anderen Spezies nach möglichen Kandidatengenen und nach Mutationen gesucht werden (Holmes 1994; Lindblad-Toh et al. 2005; Parker und Ostrander 2005).

Ein weiteres Verfahren, das am ehesten zu den funktionellen Strategien gezählt werden kann, ist die Identifizierung von Genombereichen, die Mutationen enthalten könnten, mithilfe von Subtraktionsbibliotheken. Unter Anwendung einer als SSH (suppression subtractive hybridization) bezeichneten Methode (Diatchenko et al. 1996) werden zwei Subtraktionsbibliotheken erstellt. Eine der Bibliotheken enthält cDNA-Fragmente, die bei Merkmalsträgern in größerer Häufigkeit vorliegen als bei Nichtmerkmalsträgern. Die zweite Subtraktionsbibliothek enthält cDNA-Fragmente, die bei Nichtmerkmalsträgern in größerer Häufigkeit vorliegen als bei Merkmalsträgern (Zhang et al. 1998). Vereinfacht umfassen die einzelnen Schritte zur Erstellung von Subtraktionsbibliothe- 
ken

- die Generierung von cDNA aus einer geeigneten Gewebeprobe eines Merkmalsträgers und eines Nichtmerkmalsträgers (besonders geeignet sind Gewebe, in denen eine mit dem zu untersuchenden Merkmal zusammenhängende unterschiedliche Expression von mRNA bei Merkmalsträger und Nichtmerkmalsträger zu erwarten ist),

- eine anschließende Restriktionsspaltung zur Herstellung von cDNA-Fragmenten von einer amplifizierbaren Größe,

- die Ligation eines Aliquots A der cDNA-Fragmente des Merkmalsträgers mit einem Adapter 1 sowie eines zweiten Aliquots B der cDNA-Fragmente des Merkmalsträgers mit einem Adapter 2,

- die Mischung von Aliquot A1 mit Aliquot B2 und einem Aliquot C der cDNAFragmente des Nichtmerkmalsträgers

- sowie eine Denaturierung und anschließende Hybridisierung der cDNAEinzelstränge.

Bei dieser Hybridisierung ergeben sich verschiedene Typen von cDNA-Molekülen, untere A1 und B1 Einzelstränge hybridisieren mit oberen A1 und B2 Einzelsträngen sowie mit oberen C Einzelsträngen, die übereinstimmende Sequenzen aufweisen. Durch die übereinstimmenden oberen C-Einzelstränge werden obere A1 und B2 Einzelstränge derjenigen cDNA-Fragmente verdrängt, die bei Merkmals- und Nichtmerkmalsträgern übereinstimmen. Eine Hybridisierung von A1 mit B2 Einzelsträngen findet bei cDNAFragmenten des Merkmalsträgers, die keine Übereinstimmung mit Fragmenten des Nichtmerkmalsträgers aufweisen häufiger statt als bei cDNA-Fragmenten, die Übereinstimmungen mit Fragmenten des Nichtmerkmalsträgers aufweisen. Bei einer Amplifikation mit Primern, die spezifisch mit Adapter 1 bzw. Adapter 2 hybridisieren, werden also überwiegend cDNA-Fragmente amplifiziert, für die keine übereinstimmenden Hybridisierungspartner in der cDNA des Nichtmerkmalsträgers vorliegen, und die daher eine erhöhte Wahrscheinlichkeit für das Vorliegen relevanter Mutationen aufweisen. Auf diesem Weg lassen sich nur abweichende cDNA-Fragmente aus tatsächlich exprimierten Transkripten identifizieren. Eine Mutation, die zur vollständigen Deletion eines Transkriptes führt, bleibt bei diesem Vorgehen unerkannt. Solche Mutationen 
können bei einer Umkehrung der Vorgehensweise identifiziert werden, indem die Adapter an zwei Aliquots der normalen cDNA-Fragmente ligiert werden und bei einer PCR mit den entsprechenden Primern vorrangig cDNA-Fragmente amplifiziert werden, für die keine übereinstimmenden Hybridisierungspartner aus der cDNA des kranken Hundes existieren.

Die mit dieser Methode amplifizierten Fragmente werden kloniert und in Subtraktionsbibliotheken archiviert. Durch systematische Sequenzierung der einzelnen DNAAbschnitte und Vergleich mit der entsprechenden Sequenz normaler Vergleichshunde können Mutationen gefunden werden. 


\subsection{Literatur}

Ausubel, F., Brent, R., Kingston, R., Moore, D., Seidman, J., Smith, J. und Struhl, K., Eds. (1993). Current protocols in molecular biology, John Wiley \& Sons, Inc.

Defontaine, A., Lecocq, F.M. und Hallet, J.N. (1991): A rapid miniprep method for the preparation of yeast mitochondrial DNA. Nucleic Acids Res, 19 (1), 185.

Diatchenko, L., Lau, Y.F., Campbell, A.P., Chenchik, A., Moqadam, F., Huang, B., Lukyanov, S., Lukyanov, K., Gurskaya, N., Sverdlov, E.D. und Siebert, P.D. (1996): Suppression subtractive hybridization: a method for generating differentially regulated or tissue-specific cDNA probes and libraries. Proc Natl Acad Sci U S A, 93 (12), 6025-30.

Ganguly, A., Rock, M.J. und Prockop, D.J. (1993): Conformation-sensitive gel electrophoresis for rapid detection of single-base differences in double-stranded PCR products and DNA fragments: evidence for solvent-induced bends in DNA heteroduplexes. Proc Natl Acad Sci U S A, 90 (21), 10325-9.

Gassen, H. und Minol, K. (1996): Gentechnik. (4. neubearbeitete Auflage) Gustav Fischer Verlag, Stuttgart Jena 1996.

Holmes, N.G. (1994): Microsatellite markers and the analysis of genetic disease. Br Vet J, $150(5), 411-21$.

Kim, K.S., Lee, S.E., Jeong, H.W. und Ha, J.H. (1998): The complete nucleotide sequence of the domestic dog (Canis familiaris) mitochondrial genome. Mol Phylogenet Evol, 10 (2), 210-20.

Kirkness, E.F., Bafna, V., Halpern, A.L., Levy, S., Remington, K., Rusch, D.B., Delcher, A.L., Pop, M., Wang, W., Fraser, C.M. und Venter, J.C. (2003): The dog genome: survey sequencing and comparative analysis. Science, 301 (5641), 1898-903.

Knippers, R. (2001): Molekulare Genetik. (8., neubearbeitete Auflage) Georg Thieme Verlag, Stuttgart New York 2001.

Kräußlich, H. (1997): Tierzüchtungslehre. (4., völlig neubearbeitete Auflage) Verlag Eugen Ulmer, Stuttgart 1997.

Kuipers, O.P., Boot, H.J. und de Vos, W.M. (1991): Improved site-directed mutagenesis method using PCR. Nucleic Acids Res, 19 (16), 4558.

Landegren, U., Kaiser, R., Sanders, J. und Hood, L. (1988): A ligase-mediated gene detection technique. Science, 241 (4869), 1077-80.

Li, F.Y., Cuddon, P.A., Song, J., Wood, S.L., Patterson, J.S., Shelton, G.D. und Duncan, I.D. (2006): Canine spongiform leukoencephalomyelopathy is associated with a missense mutation in cytochrome b. Neurobiol Dis, 21 (1), 35-42. 
Lindblad-Toh, K., Wade, C.M., Mikkelsen, T.S., Karlsson, E.K., Jaffe, D.B., Kamal, M., Clamp, M., Chang, J.L., Kulbokas, E.J., 3rd, Zody, M.C., Mauceli, E., Xie, X., Breen, M., Wayne, R.K., Ostrander, E.A., Ponting, C.P., Galibert, F., Smith, D.R., DeJong, P.J., Kirkness, E., Alvarez, P., Biagi, T., Brockman, W., Butler, J., Chin, C.W., Cook, A., Cuff, J., Daly, M.J., DeCaprio, D., Gnerre, S., Grabherr, M., Kellis, M., Kleber, M., Bardeleben, C., Goodstadt, L., Heger, A., Hitte, C., Kim, L., Koepfli, K.P., Parker, H.G., Pollinger, J.P., Searle, S.M., Sutter, N.B., Thomas, R., Webber, C., Baldwin, J., Abebe, A., Abouelleil, A., Aftuck, L., Ait-Zahra, M., Aldredge, T., Allen, N., An, P., Anderson, S., Antoine, C., Arachchi, H., Aslam, A., Ayotte, L., Bachantsang, P., Barry, A., Bayul, T., Benamara, M., Berlin, A., Bessette, D., Blitshteyn, B., Bloom, T., Blye, J., Boguslavskiy, L., Bonnet, C., Boukhgalter, B., Brown, A., Cahill, P., Calixte, N., Camarata, J., Cheshatsang, Y., Chu, J., Citroen, M., Collymore, A., Cooke, P., Dawoe, T., Daza, R., Decktor, K., DeGray, S., Dhargay, N., Dooley, K., Dorje, P., Dorjee, K., Dorris, L., Duffey, N., Dupes, A., Egbiremolen, O., Elong, R., Falk, J., Farina, A., Faro, S., Ferguson, D., Ferreira, P., Fisher, S., FitzGerald, M., Foley, K., Foley, C., Franke, A., Friedrich, D., Gage, D., Garber, M., Gearin, G., Giannoukos, G., Goode, T., Goyette, A., Graham, J., Grandbois, E., Gyaltsen, K., Hafez, N., Hagopian, D., Hagos, B., Hall, J., Healy, C., Hegarty, R., Honan, T., Horn, A., Houde, N., Hughes, L., Hunnicutt, L., Husby, M., Jester, B., Jones, C., Kamat, A., Kanga, B., Kells, C., Khazanovich, D., Kieu, A.C., Kisner, P., Kumar, M., Lance, K., Landers, T., Lara, M., Lee, W., Leger, J.P., Lennon, N., Leuper, L., LeVine, S., Liu, J., Liu, X., Lokyitsang, Y., Lokyitsang, T., Lui, A., Macdonald, J., Major, J., Marabella, R., Maru, K., Matthews, C., McDonough, S., Mehta, T., Meldrim, J., Melnikov, A., Meneus, L., Mihalev, A., Mihova, T., Miller, K., Mittelman, R., Mlenga, V., Mulrain, L., Munson, G., Navidi, A., Naylor, J., Nguyen, T., Nguyen, N., Nguyen, C., Nicol, R., Norbu, N., Norbu, C., Novod, N., Nyima, T., Olandt, P., O'Neill, B., O'Neill, K., Osman, S., Oyono, L., Patti, C., Perrin, D., Phunkhang, P., Pierre, F., Priest, M., Rachupka, A., Raghuraman, S., Rameau, R., Ray, V., Raymond, C., Rege, F., Rise, C., Rogers, J., Rogov, P., Sahalie, J., Settipalli, S., Sharpe, T., Shea, T., Sheehan, M., Sherpa, N., Shi, J., Shih, D., Sloan, J., Smith, C., Sparrow, T., Stalker, J., Stange-Thomann, N., Stavropoulos, S., Stone, C., Stone, S., Sykes, S., Tchuinga, P., Tenzing, P., Tesfaye, S., Thoulutsang, D., Thoulutsang, Y., Topham, K., Topping, I., Tsamla, T., Vassiliev, H., Venkataraman, V., Vo, A., Wangchuk, T., Wangdi, T., Weiand, M., Wilkinson, J., Wilson, A., Yadav, S., Yang, S., Yang, X., Young, G., Yu, Q., Zainoun, J., Zembek, L., Zimmer, A. und Lander, E.S. (2005): Genome sequence, comparative analysis and haplotype structure of the domestic dog. Nature, 438 (7069), 803-19.

Litt, M. und Luty, J.A. (1989): A hypervariable microsatellite revealed by in vitro amplification of a dinucleotide repeat within the cardiac muscle actin gene. Am J Hum Genet, 44 (3), 397-401.

Maxam, A.M. und Gilbert, W. (1977): A new method for sequencing DNA. Proc Natl Acad Sci U S A, 74 (2), 560-4.

Maxam, A.M. und Gilbert, W. (1980): Sequencing end-labeled DNA with base-specific chemical cleavages. Methods Enzymol, 65 (1), 499-560. 
Mayrand, P.E., Corcoran, K.P., Ziegle, J.S., Robertson, J.M., Hoff, L.B. und Kronick, M.N. (1992): The use of fluorescence detection and internal lane standards to size PCR products automatically. Appl Theor Electrophor, 3 (1), 1-11.

Minnick, M.F., Stillwell, L.C., Heineman, J.M. und Stiegler, G.L. (1992): A highly repetitive DNA sequence possibly unique to canids. Gene, 110 (2), 235-8.

Mülhardt, C. (2000): Der Eperimentator: Molekularbiologie. (2. Auflage) Spektrum Akademischer Verlag GmbH, Heidelberg Berlin 2000.

Mullis, K.B. und Faloona, F.A. (1987): Specific synthesis of DNA in vitro via a polymerase-catalyzed chain reaction. Methods Enzymol, 155, 335-50.

Newton, C. und Graham, A. (1997): PCR. (2. Auflage) Spektrum Akademischer Verlag, Heidelberg Berlin Oxford 1997.

Orita, M., Iwahana, H., Kanazawa, H., Hayashi, K. und Sekiya, T. (1989): Detection of polymorphisms of human DNA by gel electrophoresis as single-strand conformation polymorphisms. Proc Natl Acad Sci U S A, 86 (8), 2766-70.

Ostertag, E.M. und Kazazian, H.H., Jr. (2001): Biology of mammalian L1 retrotransposons. Annu Rev Genet, 35, 501-38.

Parker, H.G. und Ostrander, E.A. (2005): Canine genomics and genetics: running with the pack. PLoS Genet, 1 (5), e58.

Passarge, E. (1994): Taschenatlas der Genetik. Georg Thieme Verlag, Stuttgart New York 1994.

Roberts, R.J., Vincze, T., Posfai, J. und Macelis, D. (2007): REBASE--enzymes and genes for DNA restriction and modification. Nucleic Acids Res, 35 (Database issue), D269-70.

Ronaghi, M., Karamohamed, S., Pettersson, B., Uhlen, M. und Nyren, P. (1996): Realtime DNA sequencing using detection of pyrophosphate release. Anal Biochem, $242(1), 84-9$.

Saiki, R.K., Bugawan, T.L., Horn, G.T., Mullis, K.B. und Erlich, H.A. (1986): Analysis of enzymatically amplified beta-globin and HLA-DQ alpha DNA with allelespecific oligonucleotide probes. Nature, 324 (6093), 163-6.

Saiki, R.K., Scharf, S., Faloona, F., Mullis, K.B., Horn, G.T., Erlich, H.A. und Arnheim, N. (1985): Enzymatic amplification of beta-globin genomic sequences and restriction site analysis for diagnosis of sickle cell anemia. Science, 230 (4732), $1350-4$.

Sanger, F., Nicklen, S. und Coulson, A.R. (1977): DNA sequencing with chainterminating inhibitors. Proc Natl Acad Sci U S A, 74 (12), 5463-7. 
Schrimpf, G. (2002): Gentechnische Methoden: Eine Sammling von Arbeitsanleitungen für das molekularbiologische Labor. (3. Auflage) Spektrum Akademischer Verlag, Heidelberg Berlin 2002.

Shapiro, M.B. und Senapathy, P. (1987): RNA splice junctions of different classes of eukaryotes: sequence statistics and functional implications in gene expression. Nucleic Acids Res, 15 (17), 7155-74.

Tautz, D. (1989): Hypervariability of simple sequences as a general source for polymorphic DNA markers. Nucleic Acids Res, 17 (16), 6463-71.

Weber, J.L. und May, P.E. (1989): Abundant class of human DNA polymorphisms which can be typed using the polymerase chain reaction. Am J Hum Genet, 44 (3), 388-96.

Wilton, S.D., Honeyman, K., Fletcher, S. und Laing, N.G. (1998): Snapback SSCP analysis: engineered conformation changes for the rapid typing of known mutations. Hum Mutat, 11 (3), 252-8.

Woischnik, M. und Moraes, C.T. (2002): Pattern of organization of human mitochondrial pseudogenes in the nuclear genome. Genome Res, 12 (6), 885-93.

Zhang, Q., Acland, G.M., Parshall, C.J., Haskell, J., Ray, K. und Aguirre, G.D. (1998): Characterization of canine photoreceptor phosducin cDNA and identification of a sequence variant in dogs with photoreceptor dysplasia. Gene, 215 (2), 231-9.

Ziegle, J.S., Su, Y., Corcoran, K.P., Nie, L., Mayrand, P.E., Hoff, L.B., McBride, L.J., Kronick, M.N. und Diehl, S.R. (1992): Application of automated DNA sizing technology for genotyping microsatellite loci. Genomics, 14 (4), 1026-31. 


\section{Monogene Erbmerkmale des Hundes: Phänotyp, genetischer Hintergrund, ursächliche Mutationen und Genotypisierungsmethoden}

Dieses Kapitel bietet einen Überblick über Gendefekte und -varianten sowie die damit zusammenhängenden Erkrankungen bzw. morphologischen Eigenschaften und liefert detaillierte Informationen $\mathrm{zu}$ den jeweiligen verfügbaren Genotypisierungsmethoden. Die einzelnen Defekte oder Varianten sind in die sieben Kategorien

„Störungen der Hämostase“, Abschnitt 3.1,

„Störungen des Immunsystems“, Abschnitt 3.2,

„Speicherdefekte“, Abschnitt 3.3,

„Vergiftungen und Unverträglichkeiten“, Abschnitt 3.4,

„Erkrankungen der inneren und äußeren Organe“, Abschnitt 3.5,

„Erkrankungen von Skelettsystem, Muskulatur oder Nervensystem“, Abschnitt 3.6 und

„Morphologische Varianten“, Abschnitt 3.7

eingeteilt und werden innerhalb dieser sieben Kategorien nach Untergruppen geordnet abgehandelt.

Die Abhandlung einzelner Erkrankungen bzw. morphologischer Varianten erfolgt jeweils in drei Abschnitten. Zuerst wird eine kurze Übersicht über die wesentlichen Krankheitserscheinungen bzw. die Merkmalsvarianten gegeben. Dabei werden gegebenenfalls Besonderheiten einzelner Rassen in Unterkapiteln besprochen. Daran schließt sich eine Zusammenfassung der genetischen Hintergründe an, in der der Erbgang sowie die Eigenschaften des jeweils betroffenen Gens beschrieben werden.

Im letzten Abschnitt werden nach Mutationen und jeweils betroffenen Rassen geordnet einzelne Gendefekte behandelt. Sofern bekannt, wird an dieser Stelle der Zusammenhang zwischen der Mutation und den Krankheitserscheinungen kurz erläutert. In Fällen, in denen ein ursächlicher Zusammenhang zwischen der Mutation und dem Merkmal oder der Erkrankung nicht eindeutig hergestellt werden kann, wird gegebenenfalls auf 
das Verfahren zur Identifizierung der Mutation näher eingegangen. Anhand dieser Informationen kann der Grad der Assoziation zwischen der Mutation und dem zu untersuchenden Merkmal eingeschätzt werden.

In einem gesonderten Unterkapitel in direktem Anschluss an die Beschreibung der jeweiligen Mutationen wird auf mögliche Nachweismethoden eingegangen, die in der Originalveröffentlichung oder in Folgeveröffentlichungen beschrieben wurden. Sofern verschiedene Verfahren veröffentlicht sind, wird lediglich eine Auswahl vorgestellt. In einigen Fällen sind die in der Originalveröffentlichung beschriebenen Verfahren nicht mehr zeitgemäß, so zum Beispiel Verfahren, bei denen radioaktive Substanzen eingesetzt werden. Der Vollständigkeit halber werden diese Verfahren dennoch erwähnt. Detaillierte Informationen werden lediglich zum Ablauf seltener spezieller Verfahren aufgeführt. Der Ablauf von Standardverfahren wurde in Kapitel 2 besprochen und wird im Folgenden nicht mehr im Einzelnen erläutert. 


\subsection{Genetisch bedingte Störungen der Hämostase}

Es existiert eine Vielzahl erblicher Bluterkrankheiten bei Hunden, die fast alle enge Parallelen zu humanen Blutererkrankungen aufweisen. Je nach betroffenem Hämostasemechanismus und betroffener Komponente des Gerinnungssystems weichen die klinischen Erscheinungen und die hämatologischen Laborbefunde bei den einzelnen Erkrankungen voneinander $\mathrm{ab}$. Wie schwerwiegend die klinischen Anzeichen in Erscheinung treten hängt vom molekulargenetischen Status ab. Die genetischen Ursachen einer bestimmten Erkrankung, die in mehreren Rassen auftritt, können sich zwischen den einzelnen Rassen aber auch zwischen einzelnen Linien innerhalb einer Rasse unterscheiden und zu unterschiedlich starken Beeinträchtigungen führen.

Inzwischen (Stand: Oktober 2007) kennt man insgesamt 13 Gendefekte, die in unterschiedlichen Rassen und Familien für Defekte der Thrombozytenagglutination, verschiedene Unterformen der drei Typen der von Willebrand Disease (vWD) sowie Formen der Hämophilie A und B verantwortlich sind.

\subsubsection{Thrombozytenerkrankungen}

\begin{tabular}{|ll|}
\hline Chromosom: & CFA9 \\
Gen: & ITGA2B (Glykoprotein IIb, Untereinheit des \\
& Fibrinogenrezeptors Integrin $\alpha$ IIb $\beta 3$ ) \\
NCBI: & GeneID: 403789, GenBank: AF153316 \\
DNA-Sequenz: & NW_876332, Position 862415-877075 \\
Mutationen: & 14-bp-Insertion (Duplikation der Basen 153-167), \\
& Basset \\
& G1193C, Otterhund \\
\hline
\end{tabular}

\section{Krankheitsbild}

Die bei Hunden bekannten ererbten Thrombozytenerkrankungen sind ausschließlich qualitativer Art. Betroffen sind die drei Rassen Otterhunde (Dodds 1967; Boudreaux und Lipscomb 2001), Pyrenäenberghunde (Boudreaux et al. 1996) und Bassets (Patterson et al. 1985; Mattson et al. 1986; Patterson et al. 1989). Offenbar liegen in den einzelnen Rassen unterschiedliche genetische Ursachen vor, die zu rassenspezifischen Besonderheiten des Krankheitsbildes führen. Zudem treten innerhalb der Rasse der Otterhunde zwei unterschiedliche Formen der Thrombopathie auf, so dass insgesamt 
vier verschiedene Ausprägungen erblicher caniner Thrombopathien beschrieben wurden.

Tabelle 1: Typische Befunde, betroffene Rassen und ursächliche Gendefekte verschiedener Thrombopathieformen

\begin{tabular}{|c|c|c|c|c|c|}
\hline Bezeichnung & Rasse & Symptome & $\begin{array}{l}\text { Typspezifische } \\
\text { Besonderheiten }\end{array}$ & Gen & Mutation \\
\hline Thrombopathie & $\begin{array}{l}\text { Pyrenäenberg- } \\
\text { hunde }\end{array}$ & $\begin{array}{l}\text { Blutungen der } \\
\text { Schleimhäute, } \\
\text { Nasenbluten, } \\
\text { verlängerte } \\
\text { Blutungszeiten } \\
\text { nach chir. } \\
\text { Eingriffen }\end{array}$ & $\begin{array}{l}\text { Zahl + Morphologie der } \\
\text { Thrombozyten normal, } \\
\text { Adhäsionsfähigkeit } \\
\text { normal, Agglutination } \\
\text { und Retraktion stark } \\
\text { gestört bis defizient, } \\
\text { GPIIb und GPIIIa auf } \\
\text { Thrombozytenmembran } \\
\text { deutlich reduziert }\end{array}$ & $\begin{array}{l}\text { Glykoprotein IIb } \\
\text { des Fibrinogen- } \\
\text { rezeptorkomplexes } \\
\text { Integrin } \alpha 2 b \beta_{3}\end{array}$ & SNP in Exon 12 \\
\hline $\begin{array}{l}\text { Thrombozytische } \\
\text { Thrombasthenie }\end{array}$ & Otterhunde & $"$ & ” & $"$ & $\begin{array}{l}\text { 14-bp-Insertion in } \\
\text { Exon } 13\end{array}$ \\
\hline $\begin{array}{l}\text { Thrombopathie } \\
\text { (Bernard } \\
\text { Soulier's } \\
\text { Disease) }\end{array}$ & Otterhunde & $"$ & $\begin{array}{l}\text { s.o., zus. Auftreten } \\
\text { morphologisch } \\
\text { veränderter Riesen- } \\
\text { thrombozyten ( } \varnothing 3-4 \\
\mu \mathrm{m})\end{array}$ & nicht bekannt & nicht bekannt \\
\hline $\begin{array}{l}\text { Basset } \\
\text { Thrombopathie }\end{array}$ & $\begin{array}{l}\text { Bassets, } \\
\text { Spitze }\end{array}$ & ” & $\begin{array}{l}\text { Adhäsionsfähigkeit } \\
\text { deutlich reduziert, } \\
\text { Retraktion verzögert, } \\
\text { aber quantitativ normal, } \\
\text { GPIIb und GPIIIa auf } \\
\text { Thrombozytenmembran } \\
\text { normal, normales } \\
\text { Fibrinogenbindungs- } \\
\text { vermögen }\end{array}$ & nicht bekannt & nicht bekannt \\
\hline
\end{tabular}

Nur eine der beiden Thrombopathieformen bei Otterhunden und die Thrombopathie der Pyrenäenberghunde konnten bisher auf bestimmte Mutationen zurückgeführt werden. Beiden Formen liegt eine Funktionsstörung des Fibrinogenrezeptors Integrin $\alpha \operatorname{IIb} \beta_{3}$ zugrunde, die in beiden Rassen durch Mutationen der Rezeptorkomplexuntereinheit Glykoprotein IIb verursacht wird (Boudreaux et al. 1996; Boudreaux und Catalfamo 2001).

Die Thrombopathie der Bassets wird nach bisherigem Kenntnisstand durch andere Ursachen hervorgerufen, auch wenn Angaben in der OMIA-Datenbank auf den ersten Blick eine Übereinstimmung anzudeuten scheinen. Unter den Quellenangaben zum ursächlichen Gendefekt für thrombozytische Thrombasthenie bei Otterhunden werden auch Quellen zur Thrombopathie der Bassetts aufgelistet. Außerdem wird irritierenderweise unter dem Punkt „Cross Species Summary" angegeben, die durch den 
genannten Gendefekt verursachte Thrombopathie sei auf ein Unvermögen der Adenosindiphosphat (ADP)-Freisetzung durch die Thrombozyten bei Stimulierung durch verschiedene Aggregationsfaktoren wie Thromboplastin zurückzuführen. Diese Aussage trifft für die Erkrankung der Otterhunde definitiv nicht $\mathrm{zu}$ und wird für die Thrombopathie der Bassets durch keine der angegebenen Quellen belegt (Patterson et al. 1989; Boudreaux et al. 1994; Boudreaux und Lipscomb 2001). Der molekulargenetische Hintergrund der Basset-Thrombopathie ist bis heute nicht bekannt.

Die äußerlichen Anzeichen sind bei allen Rassen dieselben und umfassen vor allem Blutungen der Schleimhäute und Nasenbluten sowie verlängerte Blutungszeit nach chirurgischen Eingriffen. Der Grad der Blutungstendenz variiert rassenunabhängig von leicht bis schwer. Tabelle 1 gibt einen Überblick über betroffene Rassen, ursächliche Gendefekte und rassentypische Befunde bei den einzelnen Thrombopathieformen.

\section{I.a+b Thrombozytische Thrombasthenie der Otterhunde und Thrombopathie der Pyrenäenberghunde}

Bezüglich der hämatologischen Befunde liegt eine hohe Übereinstimmung zwischen der gegen Ende der 80er Jahre erstmals aufgetretenen Erscheinungsform der Thrombopathie bei Otterhunden (thrombozytische Thrombasthenie) (Boudreaux und Lipscomb 2001) und der Thrombopathie der Pyrenäenberghunde (Boudreaux et al. 1996) vor. Beide Erkrankungen sind eindeutig auf Defekte des Fibrinogenrezeptors Integrin $\alpha \operatorname{IIb} \beta_{3}$ zurückzuführen. Dieser Rezeptor wird durch einen Komplex aus den Glykoproteinen IIb und IIIa gebildet. In hämatologischen Untersuchungen zeigen betroffene Hunde als typisches Anzeichen für eine Störung der primären Hämostase verlängerte Blutungszeiten. Sowohl Anzahl und Morphologie der Thrombozyten als auch die Retention bei der Passage einer Glasperlensäule (ein Maß für die Adhäsionsfähigkeit der Thrombozyten an der Gefäßwand) entsprechen der Norm. Hingegen ist die Agglutination in Reaktion auf die einschlägigen Stimuli (ADP, Kollagen, Thrombin) stark gestört bis nicht vorhanden. Ebenso liegt eine erhebliche Störung der Retraktion vor. Ein weiterer Hinweis auf eine Schädigung des Fibrinogenrezeptors ist der Nachweis reduzierter Fibrinogengehalte der Thrombozytenmembranen und -granula sowie des Thrombozytenzytosols (Boudreaux et al. 1996; Boudreaux und Lipscomb 2001). Eine densitometrische Untersuchung elektrophoretisch separierter, PAS(periodic acid Schiff, Perjodsäure-Schiff-Reagenz) reaktiver Thrombozytenmembran- 
Glykoproteine zeigt eine starke Reduzierung der Glykoproteine IIb und IIIa (Raymond und Dodds 1979; Boudreaux und Catalfamo 2001). Mittels Durchflußzytometrie können jedoch unter Verwendung eines monoklonalen Antikörpers gegen humanes Glykoprotein IIIa geringe Mengen von Glykoprotein IIIa in den Thrombozyten betroffener Otterhunde detektiert werden. Ein Nachweis des Glykoproteins IIb konnte mit dieser Methode nicht durchgeführt werden, da kein geeigneter Antikörper zur Verfügung stand (Boudreaux et al. 1996; Boudreaux und Catalfamo 2001). Diese Ergebnisse werden als Hinweis darauf interpretiert, dass die Ursachen der Thrombopathie eher in einem Defekt des Glykoproteins IIb zu suchen sind. Bezüglich der beschriebenen Befunde entsprechen die bei Otterhunden und Pyrenäenberghunden beobachteten Thrombopathien der humanen Glanzmann Thrombasthenie Typ I (Boudreaux et al. 1996; Boudreaux und Lipscomb 2001).

Die Häufigkeiten der beschriebenen Thrombopathieformen bezogen auf die gesamte Population der Otterhunde und Pyrenäenberghunde sind nicht angegeben. Bei Pyrenäenberghunden wurde der erste Fall einer Thrombopathie 1996 beschrieben (Boudreaux et al. 1996). Später traten auch Fälle bei mehreren weiteren, nicht verwandten Pyrenäenberghunden auf (Boudreaux und Catalfamo 2001; Boudreaux und Lipscomb 2001). Bei Otterhunden konnten während einer klinischen Studie in einem 38 Tiere aus mehreren Generationen umfassenden Pedigree fünf betroffene und 13 obligate Defektträger. In einer Gruppe von 27 weiteren Otterhunden, deren verwandtschaftliche Beziehungen untereinander sowie zu den 38 Otterhunden des erwähnten Pedigrees nicht bekannt waren, wurde bei acht Hunden eine Thrombopathie diagnostiziert (Boudreaux und Catalfamo 2001).

\section{I.c Thrombopathie (Bernard Soulier's Disease) der Otterhunde}

Die erste Beschreibung einer caninen Thrombopathie, die 1967 bei Otterhunden auftrat, ähnelt den oben beschrieben Erkrankungen in den meisten Punkten. Im Gegensatz zur thrombozytischen Thrombasthenie der Otterhunde und zur Thrombopathie der Pyrenäenberghunde kommt es jedoch bei dieser Thrombopathie der Otterhunde zum Auftreten von 30-80\% morphologisch veränderter Riesenthrombozyten (3-4 $\mu \mathrm{m})$. Aufgrund dieser charakteristischen Erscheinung erfolgt eine Einstufung als Kombination aus der oben beschriebenen caninen Form der Glanzmann Thrombasthenie und einer caninen Form der humanen Bernard Soulier's Disease, die 
ebenfalls durch das Auftreten von Riesenthrombozyten gekennzeichnet ist (Raymond und Dodds 1979). Diese nur bei Otterhunden beschriebene Erscheinung konnte jedoch durch züchterische Maßnahmen im Verlauf der 70er Jahre nahezu eliminiert werden (Boudreaux und Lipscomb 2001).

\section{I.d Thrombopathie der Bassets}

Die bei Bassets beschriebene Thrombopathie unterscheidet sich klar von den in den beiden anderen Rassen beschriebenen Erkrankungen. Die deutlich verringerte Retention von Thrombozyten bei Passage einer Glasperlensäule zeigt Störungen der Adhäsion. Die Aggregation hingegen ist bei Thrombinstimulierung zwar zeitlich verzögert, findet jedoch in normaler Quantität statt. Bei Stimulierung durch Kollagen und ADP ist die Aggregation wie bei den anderen Rassen stark gestört. Eine weitere Abweichung von den Befunden bei Otterhunden und Pyrenäenberghunden ist, dass die Glykoproteine IIb und IIIa auf der Thrombozytenmembran in normaler Quantität vorhanden sind. Hämatologische Untersuchungen zeigen das Vorliegen eines normalen Fibrinogenbindungsvermögens der Thrombozyten betroffener Bassets (Patterson et al. 1989). Auch Vergleiche der Fibrinogenrezeptor-cDNA zwischen erkrankten Bassetts und gesunden Hunden zeigen in den codierenden Bereichen keinerlei Unterschiede (Boudreaux und Lipscomb 2001). Als Ursache der gestörten Blutgerinnung wird ein Defekt des auf die Interaktion von Fibrinogen mit dem Rezeptorkomplex Integrin $\alpha \mathrm{IIb} \beta_{3}$ folgenden intrazellulären Signalmechanismus vermutet. Abgesehen von einem der Bassett-Thrombopathie entsprechenden Hämostasedefekt bei zwei Spitzen (Boudreaux et al. 1994), scheint ein vergleichbarer Defekt weder in weiteren Rassen noch in weiteren Spezies aufzutreten. Weder die physiologischen noch die molekulargenetischen Ursachen dieser autosomal rezessiv vererbten Thrombozytenerkrankung (Bell et al. 1984) sind bisher abschließend geklärt worden (Boudreaux und Lipscomb 2001).

\section{Genetischer Hintergrund}

Sowohl die thrombozytische Thrombasthenie der Otterhunde als auch die Thrombopathie bei Pyrenäenberghunden beruht auf Defekten der Untereinheit Glykoprotein IIb des Fibrinogenrezeptors Integrin $\alpha \operatorname{IIb} \beta_{3}$. 
Die cDNA-Sequenz des caninen Glykoproteins IIb (NCBI-GenBank: AF153316) hat eine Länge von 3111 Nukleotiden und ist in 30 Exons unterteilt (Boudreaux und Lipscomb 2001). Die genomische Sequenz ist innerhalb des genomischen Contigs NW_876332 auf Chromosom 9 zwischen Position 862415 und 877075 lokalisiert (NCBI-GeneID: 403789). In Abb. 1 ist die genomische Struktur des caninen Glykoproteins IIb schematisiert dargestellt und die Lage der bisher bekannten funktionellen Mutationen eingezeichnet.

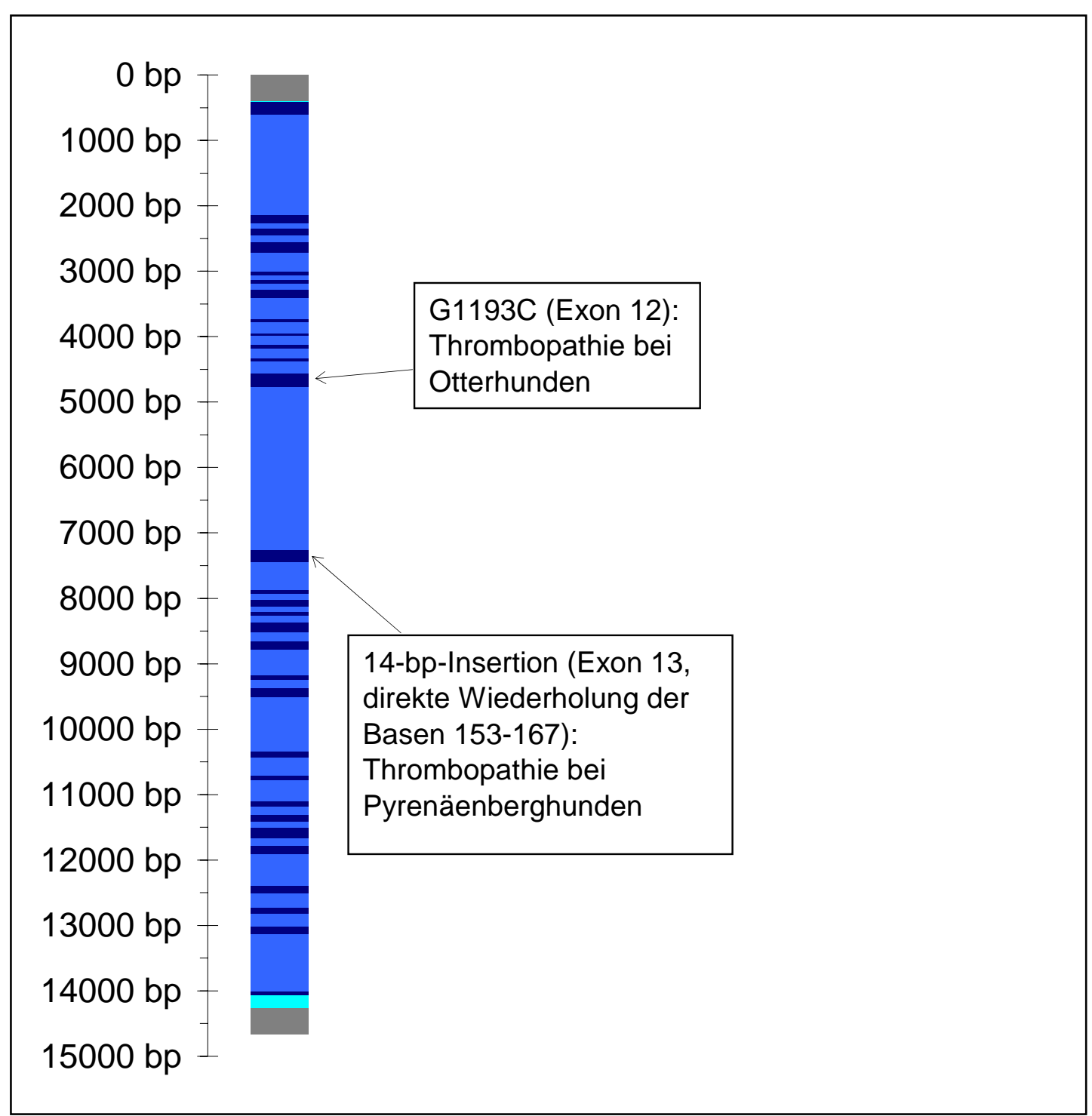

Abb. 1 Schematische Darstellung des ITGA2B-Gens (Glykoprotein IIb des caninen Fibrinogenrezeptorkomplexes Integrin $\alpha \mathrm{IIb} \beta 3$ ) und der bekannten funktionellen Mutationen. Grau: intergenischer Bereich, türkis: 5'- und 3'-UTR, dunkelblau: codierende Sequenz, hellblau: Intron. 


\section{III.a Ursächliche Mutation für Thrombopathie bei Pyrenäenberghunden}

Ein Vergleich der Glykoprotein-IIb-cDNA-Sequenz eines betroffenen Pyrenäenberghundrüden mit den Sequenzen zweier gesunder Mischlingshunde sowie der gesamten Gensequenz des oben erwähnten und eines weiteren betroffenen Pyrenäenberghundrüden und sechs gesunder Wurfgeschwister führte zur Entdeckung einer 14-bp-Insertion nach Nukleotid 1373 der codierenden Sequenz in Exon 13 in der Sequenz der beiden betroffenen Pyrenäenberghundrüden (Lipscomb et al. 2000).

Die Insertion stellt eine direkte Wiederholung der vorhergehenden Sequenz von Nukleotid 1360-1373 dar. Die dadurch bedingte Verschiebung des Leserasters führt zu einer abweichenden Aminosäurensequenz, zum abweichenden Spleißen von Exon 13 und zum verfrühten Abbruch der Transkription aufgrund der Entstehung eines Stoppcodons (Abb. 2). Zwar ist die bei gesunden Kontrollhunden aktive Spleißerkennungssequenz nach Nukleotid 1392 auch bei mutierten Hunden vorhanden. Bei Vorliegen der Insertion wird an dieser Stelle jedoch nicht gespleißt, so dass Exon 13 mit den anschließenden Basen aus Intron 13 fortgesetzt wird. Nach der Insertionsstelle an Nukleotidposition 1373 werden 35 weitere Aminosäuren codiert, bis nach Aminosäure 468 ein Stoppcodon für den Abbruch der Proteinsynthese sorgt.

Die beschriebene Mutation ist in dem Bereich lokalisiert, der für die vierte CaBindungsdomäne codiert. Durch die frühzeitige Terminierung der Proteinsynthese gehen der IIb-Untereinheit des Fibrinogenrezeptorkomplexes alle transmembranen und cytoplasmatischen Domänen sowie ein großer Bereich der extrazellulären Domäne einschließlich der vierten Ca-Bindungsdomäne verloren. Diese Ca-Bindungsdomäne spielt sowohl für die intrazelluläre Prozessierung des IIbIIIa-Komplexes als auch für dessen Transport zur Thrombozytenoberfläche eine wesentliche Rolle. Es ist zu vermuten, dass es entweder schon vor der Bildung des IIbIIIa-Komplexes zum Abbau der abnormen IIb-Untereinheit kommt oder dass zwar ein instabiler Komplex gebildet wird, dieser jedoch vor Expression auf der Thrombozytenoberfläche abgebaut wird (Lipscomb et al. 2000). 


\section{IV.a Genotypisierung für Thrombopathie bei Pyrenäenberghunden}

Der Nachweis der Mutation kann durch die Amplifikation eines 345- bzw. 359-bpAbschnitts aus genomischer DNA und anschließender Analyse per Sequenzierung erfolgen (Lipscomb et al. 2000).

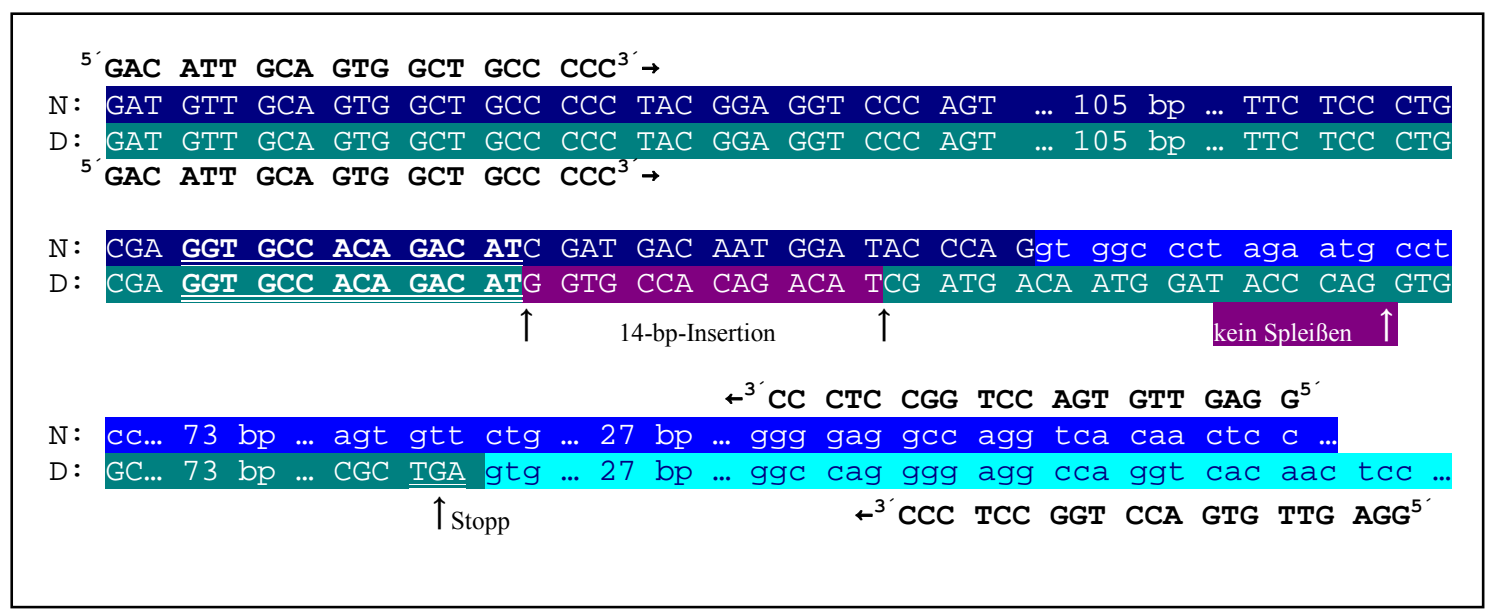

Abb. 2 Exon 13 und angrenzende Intronsequenz des ITGA2B-Gens. N: normale Sequenz, D: defekte Sequenz, dunkelblau: Exon normale Sequenz, hellblau: Intron normale Sequenz, dunkelgrün: Exon defekte Sequenz, türkis: Intron defekte Sequenz, Insertion in der defekten Sequenz violett unterlegt und durch Pfeil gekennzeichnet, ungenutzte Spleißerkennungssequenz und verfrühtes Stoppcodon in defekter Sequenz durch Pfeil gekennzeichnet.

\section{III.b Ursächliche Mutation für Thrombozytische Thrombasthenie bei Otterhunden}

Die veröffentlichten cDNA-Sequenzen der IIb- (Boudreaux und Lipscomb 2001) und der IIIa- (Lipscomb et al. 1999) Untereinheiten des Fibrinogenrezeptorkomplexes dienten als Referenzsequenzen bei der Suche nach dem verantwortlichen Gendefekt für die Ende der 80er Jahre bei Otterhunden aufgetretene Thrombopathie. Ein Vergleich der cDNA-Sequenzen der Glykoproteine IIb und IIIa betroffener Otterhunde mit den normalen Referenzsequenzen (NCBI-GenBank: AF153316 bzw. AF116270) deckte zwei SNP auf, die jeweils Aminosäurensubstitutionen zur Folge haben (Boudreaux und Catalfamo 2001).

Nach derzeitigem Kenntnisstand gilt als Ursache des Hämostasedefektes der Otterhunde eine Substitution von Guanin durch Cytosin in Exon 12 an Position 1193 der codierenden Sequenz. Diese Mutation ist in einer hochkonservierten CaBindungsdomäne lokalisiert und führt zu einem Austausch von Asparaginsäure durch Histidin an Aminosäurenposition 398 (Abb. 3). Aufgrund der starken Konservierung dieses Sequenzbereiches ist als Folge des Aminosäurenaustauschs eine Destabilisierung 
des IIbIIIa-Komplexes zu erwarten. Für einen pathogenen Effekt der Substitution sprechen außerdem Genotypisierungsergebnisse. Bei allen untersuchten betroffen Otterhunden liegt der Defekt homozygot vor. Bei einem obligat heterozygoten Defektträger lautete das Ergebnis der molekulargenetischen Typisierung ebenfalls heterozygot. Sowohl bei den vier gesunden Hunden aus anderen Rassen als auch bei den zwei gesunden Otterhunden liegen homozygot die Wildtypallele vor (Boudreaux und Catalfamo 2001).

Eine weitere Mutation, ein Basenaustausch von Cytosin durch Thymin, ist in Exon 17 an Position 1601 lokalisiert und führt zu einer Substitution von Prolin durch Serin an Position 534. Bei zwei betroffenen Otterhunden liegt die Substitution homozygot vor, bei vier klinisch normalen Hunden aus mehreren anderen Rassen konnte die Mutation nicht nachgewiesen werden. Allerdings waren sowohl der obligat heterozygote Defektträger-Otterhund als auch die zwei gesunden Otterhunde heterozygot für diese Substitution. Die Autoren schließen daraus, dass es sich um einen rassenspezifischen Polymorphismus handelt, der nicht ursächlich für die Thrombopathie ist (Boudreaux und Catalfamo 2001), zumal auch bei dem normalen humanen Glykoprotein IIb an der entsprechenden Position Serin vorliegt, das offenbar keinen nachteiligen Effekt auf die Stabilität des IIbIIIa-Komplexes hat (Poncz et al. 1987).

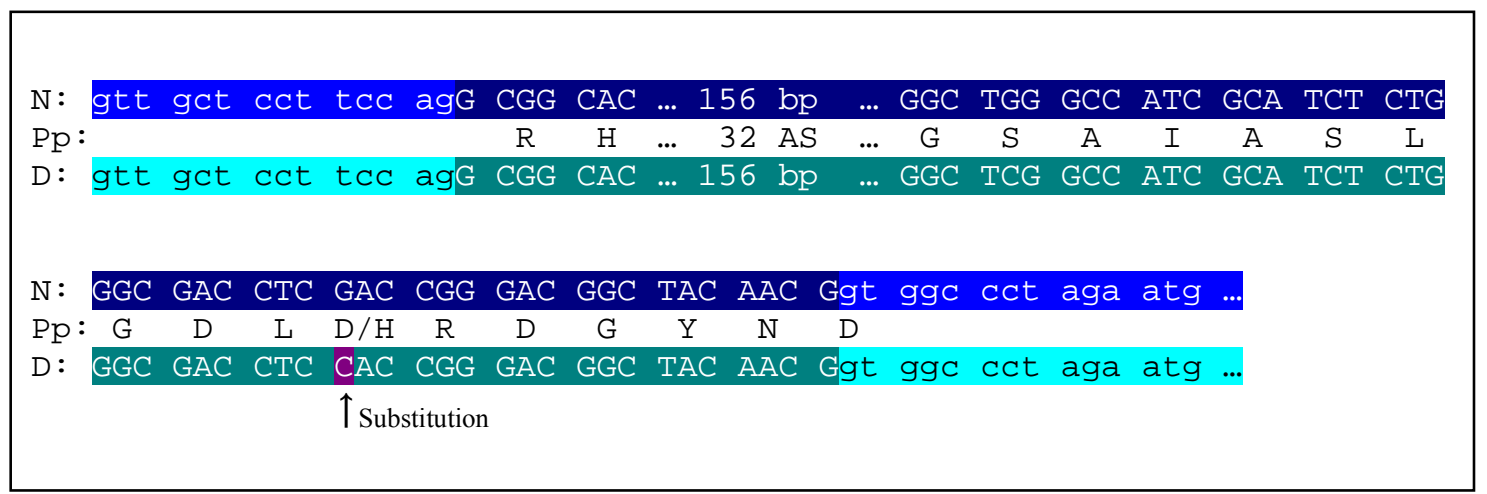

Abb. 3 Exon 12 und angrenzende Intronsequenzen des caninen Glykoprotein-IIb-Gens. N: normale Sequenz, Pp: Polypeptidsequenz, D: defekte Sequenz, dunkelblau: Exons normale Sequenz, dunkelgrün: Exons defekte Sequenz, hellblau: Intron normale Sequenz, hellgrün: Intron defekte Sequenz, Substitution violett hinterlegt und durch Pfeil gekennzeichnet.

Wie bei den Pyrenäenberghunden betrifft auch die bei Otterhunden identifizierte Mutation eine hochkonservierte Ca-Bindungsdomäne, die der humanen dritten CaBindungsdomäne entspricht und lässt ähnliche Effekte vermuten wie die Mutation bei Pyrenäenberghunden (Boudreaux und Catalfamo 2001). 


\subsection{2 von Willebrand Disease (vWD)}

\begin{tabular}{|ll|}
\hline Chromosom: & CFA27 \\
Gen: & vWF-Gen \\
NCBI: & GeneID: 399544, GenBank: AF099154, U66246, \\
DNA-Sequenz: & NW_876284, Position 38864633-39002564 \\
Mutationen: & DelC255, Typ III, Scottish Terrier \\
& DelT736, Typ III, Shetland Schäferhund \\
& G2186A, Typ III, Holländischer Kooiker Hund \\
& A4937G, Typ II, Deutsch Kurzhaar und Deutsch \\
& Drahthaar Vorstehhund \\
& G7437A, Typ I, Dobermann Pinscher, Manchester \\
& Terrier, Pudel
\end{tabular}

\section{Krankheitsbild}

Die von Willebrand Disease (vWD) umfasst eine Gruppe von Blutererkrankungen, die auf verschiedenartigen Defekten des für die primäre Hämostase entscheidenden von Willebrand Faktors (vWF) beruhen. Bereits 1926 entdeckte von Willebrand den nach ihm benannten Faktor und den Zusammenhang zwischen einem Faktormangel und einer bisher unbekannten Bluterkrankheit (von Willebrand 1926). Die canine vWD, die erstmals 1970 beim Deutschen Schäferhund beschrieben (Dodds 1970) und bis 1989 bereits in mehr als 54 verschiedenen Rassen diagnostiziert wurde, gilt allgemein als die häufigste Bluterkrankheit bei Hunden (Kraus und Johnson 1989).

Den verschiedenen heute bekannten zumeist quantitativen zum Teil aber auch qualitativen Defekten des vWF liegt eine Vielzahl unterschiedlicher Mutationen zugrunde, die in den jeweils betroffenen Rassen zu unterschiedlich schwerwiegenden Formen der vWD führen. In einigen Rassen können auch mehrere verschiedene vWDFormen auftreten. Die einzelnen Erscheinungsformen der caninen vWD werden in Anlehnung an die Klassifizierung der humanen vWD je nach vWFPlasmakonzentration, funktionellen und strukturellen Eigenschaften in drei Typen unterteilt. Eine weitere Unterteilung in Subtypen, wie sie in der Humanmedizin vorgenommen wird, erfolgt bei Hunden nicht. Stattdessen wird eine Unterteilung nach betroffenen Rassen vorgenommen, da davon ausgegangen wird, dass in den meisten Fällen die Erkrankung innerhalb einer Rasse oder einer Gruppe von Rassen auf einen spezifischen genetischen Defekt zurückzuführen ist (Johnson et al. 1988). 
Tabelle 2: Wesentliche Merkmale der drei vWD-Typen und betroffene Rassen mit bekannten Mutationen

\begin{tabular}{|c|c|c|c|c|c|c|}
\hline Typ & \multicolumn{2}{|l|}{ I } & II & \multicolumn{3}{|l|}{ III } \\
\hline Rassen & $\begin{array}{l}\text { Dobermann, } \\
\text { Manchester } \\
\text { Terrier, Pudel }\end{array}$ & $\begin{array}{l}\text { Pinscher, Berner } \\
\text { Sennenhund, } \\
\text { Drent'scher } \\
\text { Hühnerhund, Kerry } \\
\text { Blue Terrier, } \\
\text { Papillon, Pembroke } \\
\text { Welsh Corgi }\end{array}$ & $\begin{array}{l}\text { Deutsch Drahthaar, } \\
\text { Deutsch Kurzhaar }\end{array}$ & $\begin{array}{l}\text { Shetland } \\
\text { Schäferhund }\end{array}$ & $\begin{array}{l}\text { Holländischer } \\
\text { Kooiker }\end{array}$ & $\begin{array}{l}\text { Scottish } \\
\text { Terrier }\end{array}$ \\
\hline Symptome & \multicolumn{6}{|c|}{ lange Blutungszeiten, Faktor VIII leicht reduziert, Adhäsionsfähigkeit gestört Aggregation normal } \\
\hline $\begin{array}{l}\text { Typspezifische } \\
\text { Besonderheiten }\end{array}$ & \multicolumn{2}{|c|}{$\begin{array}{l}\text { alle Multimere des vWF sind } \\
\text { gleichermaßen leicht reduziert, leicht } \\
\text { verlängerte Gerinnungszeiten, leichte } \\
\text { Erkrankung }\end{array}$} & $\begin{array}{l}\text { qualitativer Defekt: } \\
\text { hoch-molekulare } \\
\text { Multimere stark } \\
\text { reduziert, nieder- } \\
\text { molekulare in } \\
\text { normaler Quantität, } \\
\text { Gerinnungszeit } \\
\text { normal, schwere } \\
\text { Erkrankung }\end{array}$ & \multicolumn{3}{|c|}{ kein vWF vorhanden, schwere Erkrankung } \\
\hline Mutation & $\begin{array}{l}\text { SNP in Exon } \\
43\end{array}$ & $\begin{array}{l}\text { eine oder mehrere } \\
\text { Mutationen } \\
\text { bekannt aber nicht } \\
\text { veröffentlicht }\end{array}$ & SNP in Exon 28 & $\begin{array}{l}\text { Deletion in } \\
\text { Exon } 7\end{array}$ & $\begin{array}{l}\text { SNP in } \\
\text { Exon } 16\end{array}$ & $\begin{array}{l}\text { Deletion } \\
\text { in Exon } \\
4\end{array}$ \\
\hline
\end{tabular}

Tabelle 2 gibt einen Überblick über die wesentlichen Merkmale der caninen vWDTypen und die bisher identifizierten funktionellen Mutationen in den einzelnen betroffenen Rassen.

\section{I.a Von Willebrand Disease I}

Die von Willebrand Disease Typ I ist, wie beim Menschen auch, bei Hunden die häufigste Form der vWD. Tabelle 3 gibt eine Übersicht über die Häufigkeit von vWD I Gendefekten in fünf verschiedenen Rassen. Datengrundlage sind Untersuchungsergebnisse der Firma VetGen. Über die Anzahl untersuchter Hunde werden keine Angaben gemacht (http://www.vetgen.com).

Über klinische und hämatologische Merkmale der vWD I liegen zahlreiche Untersuchungen vor (Dodds 1970; Dodds 1975; Dodds 1984; Johnson et al. 1985; Johnson et al. 1986). Die wesentlichen Punkte sind in Tabelle 2 zusammengefasst. 


\begin{tabular}{lclc}
\hline Rasse & Frei & $\begin{array}{l}\text { Heterozygote } \\
\text { Defektträger }\end{array}$ & Betroffen \\
\hline Berner Sennenhund & $83 \%$ & $16 \%$ & $1 \%$ \\
Dobermann & $25 \%$ & $49 \%$ & $26 \%$ \\
Manchester Terrier & $59 \%$ & $37 \%$ & $4 \%$ \\
Pembroke Welsh Corgi & $57 \%$ & $37 \%$ & $6 \%$ \\
Pudel & $90 \%$ & $9 \%$ & $1 \%$ \\
\hline
\end{tabular}

Die vWD I äußert sich in meist vergleichsweise geringer Blutungsneigung. Bei einigen Patienten können allerdings auch extrem starke Blutungen auftreten. So kommt es bei Anpaarungen von heterozygoten Schäferhunden auffallend häufig zu Totgeburten. Zudem werden bei Schäferhunden gelegentliche Fälle mit extrem starken, lebensbedrohlichen Blutungsepisoden beobachtet (Dodds 1975). Bei von vWD betroffenen Dobermännern sind stärkere Blutungen häufig durch das zusätzliche Vorliegen einer Schilddrüsenunterfunktion begünstigt (Dodds 1984).

\section{I.b von Willebrand Disease II}

Der relativ seltene Typ II ist vor allem bei Deutsch Kurzhaar Vorstehhunden (Johnson et al. 1988; Kramer et al. 2004) und Deutsch Drahthaar Vorstehhunden (Brooks et al. 1996; Brooks et al. 2001) beschrieben worden. Einzelne Fälle wurden außerdem in den Rassen Deutscher Schäferhund, Shetland Schäferhund, Pembroke Welsh Corgi und Miniaturpinscher beobachtet (Johnstone 1999). Die wesentlichen Merkmale der Erkrankung sind in Tabelle 2 zusammengefasst. Die Häufigkeit der vWD II innerhalb der betroffenen Rassen wird nicht ausdrücklich genannt. In einer Fünfjahresstudie an 331 Deutsch Drahthaar Vorstehhunden wurden anhand der vWF:Ag-Konzentrationen im Plasma Frequenzen von 2,56 \% betroffenen Hunden, 26,88 \% obligaten Defektträgern und 70,56 \% vWF-Defekt-freier Hunde berechnet (Brooks et al. 2001).

\section{I.c von Willebrand Disease III}

Die vWD Typ III hat einen schweren Verlauf und ist durch einen kompletten Mangel an vWF im Plasma gekennzeichnet. Die wesentlichen Merkmale der Erkrankung sind in Tabelle 2 zusammengefasst. Die Prävalenz wird bei Scottish Terriern einschließlich der 
heterozygoten Defektträger auf 27 \% (Stokol und Parry 1993) bzw. 23 \% heterozygote und $2 \%$ homozygote Defektträger (Venta et al. 2000) geschätzt. Weitere betroffene Rassen, bei denen die ursächlichen Mutationen für vWD III identifiziert wurden, sind Shetland Schäferhunde und Holländischen Kooiker Hunde. Bei Holländischen Kooiker Hunden wird die vWD III als ein „ernsthaftes Problem“ bezeichnet (van Oost et al. 2004). Genaue Zahlen zur Häufigkeit der Erkrankung innerhalb dieser Rasse werden jedoch nicht genannt. Bei Shetland Schäferhunden wird der Anteil der heterozygoten vWD-III-Defektträger anhand einer molekulargenetischen Typisierung von 103 Hunden mit 13,6 \% angegeben (US-Patent 6780583). In einer zehn Jahre zuvor durchgeführten epidemiologischen Untersuchung ergab sich anhand von Messungen der vWF:AgKonzentrationen eine Frequenz der heterozygoten Defektträger von 28 \%, wobei ein Drittel dieser heterozygoten Hunde als Träger einer vWD-I-Erkrankung eingestuft werden, so dass die Träger der vWD-III-Mutation 18,7 \% der untersuchten Population ausmachen (Brooks et al. 1992). Als Ursache für diese unterschiedlichen Ergebnisse wird sowohl die unterschiedliche Diagnosemethode angeführt als auch die Möglichkeit eines tatsächlichen Rückgangs der vWD-III-Häufigkeit bei Shetland Schäferhunden in Betracht gezogen. Das Vorliegen einer oder mehrerer weiterer vWD-III-verursachenden Mutationen innerhalb der Rasse wird als weitere mögliche Erklärung für die niedrigere Frequenz diskutiert. Vor dem Hintergrund des bei Hunden üblicherweise starken Einflusses weniger beliebter Zuchtrüden auf die genetische Zusammensetzung einer Population (Founder-Effekt), wird jedoch der Anteil an möglichen weiteren vWD-IIIMutationen als äußerst gering eingeschätzt (US-Patent 6780583).

\section{Genetischer Hintergrund}

Die für den vWF codierende cDNA wurde inzwischen unabhängig voneinander von drei Arbeitsgruppen sequenziert (Montgomery et al. 1996; Stoy et al. 1996; Venta et al. 2000) (NCBI-GenBank: U66246, L76227 und AF099154). Das vWF-Gen (NCBIGeneID: 399544) ist im genomischen Contig NW_876284.1 des Chromosoms 27 zwischen Position 38864633 bis 39002564 lokalisiert und enthält 52 Exons. 


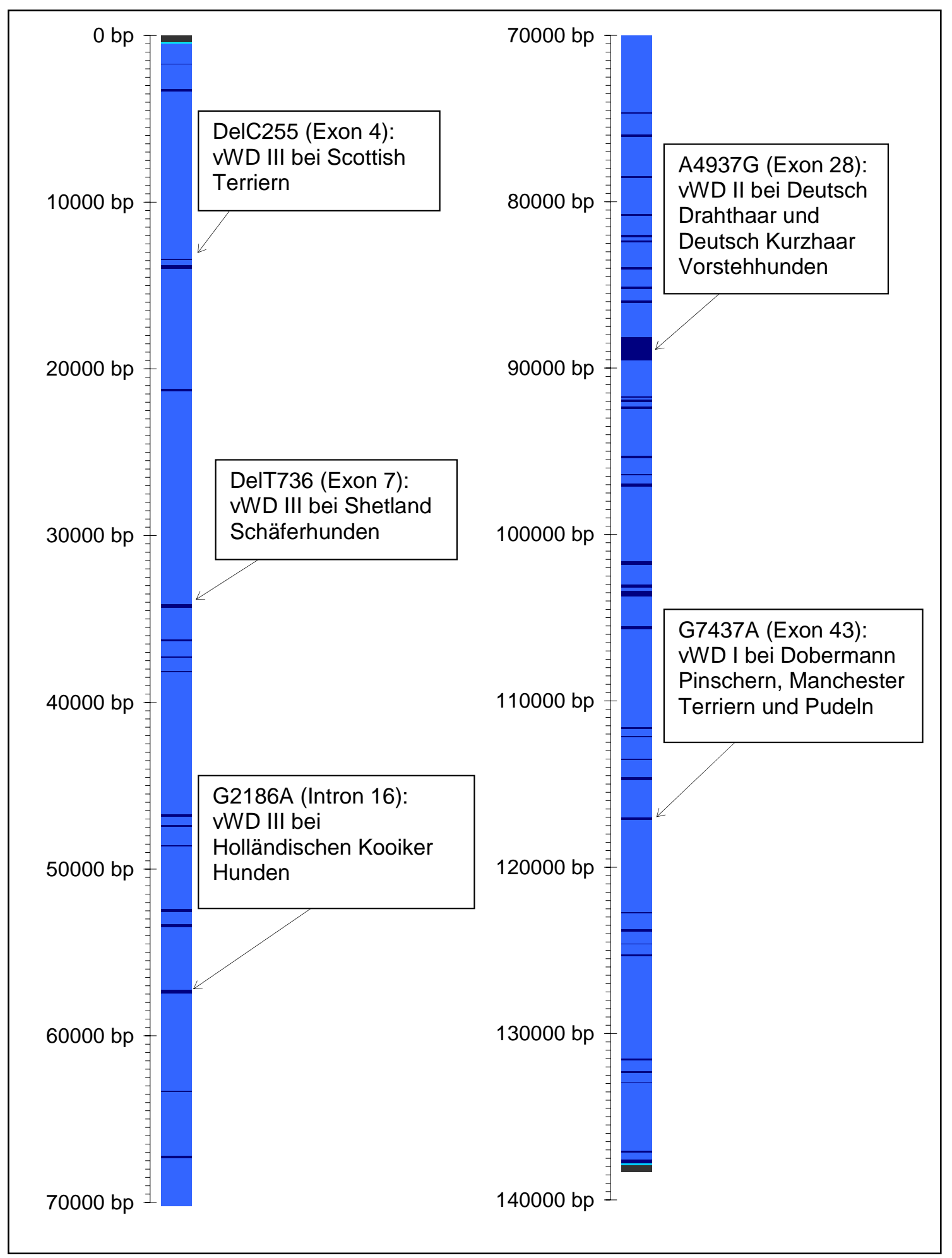

Abb. 4 Schematische Darstellung des für den vWF codierenden Gens und der bekannten funktionellen Mutationen. Grau: intergenische Seqzenz, türkis: 5'- und 3'-UTR, dunkelblau: codierende Sequenz, hellblau: Intron.

Insgesamt sind bisher mindestens fünf offensichtlich funktionelle Mutationen des caninen vWD-Gens bekannt. Der Erbgang ist in den meisten Rassen autosomal rezessiv. Lediglich für vWD III bei Shetland Schäferhunden scheint ein dominanter Erbgang 
vorzuliegen (Stokol und Parry 1993). Ausführliche Veröffentlichungen von Gendefekten beziehen sich auf Typ-II-vWD in den Rassen Deutsch Kurzhaar und Deutsch Drahthaar Vorstehhund (Kramer et al. 2004) und Typ-III-vWD in den Rassen Holländischer Kooikerhund (Rieger et al. 1998) und Scottish Terrier (Venta et al. 2000). Des Weiteren sind Informationen über eine Mutation bei Shetland Schäferhunden mit vWD III und eine weitere bei Dobermännern, Manchester Terriern und Pudeln mit vWD I veröffentlicht (US-Patent 6780583). Die ursächliche Mutation bzw. ursächlichen Mutationen für vWD I in den Rassen Berner Sennenhunde, Drent'scher Hühnerhund, Deutscher Pinscher, Kerry Blue Terrier, Papillon und Pembroke Welsh Corgi scheinen ebenfalls bekannt zu sein, da die US amerikanische Firma VetGen für Hunde dieser Rassen eine vWD-Genotypisierung anbietet (http://www.vetgen.com). Ob die vWD I in einigen oder allen genannten Rassen auf dieselbe Mutation zurückzuführen ist wie bei den Dobermännern, oder ob eine oder mehrere andere Mutationen vorliegen, ist nicht ersichtlich. In Abb. 4 ist die genomische Struktur des caninen vWF-Gens schematisiert dargestellt und die Lage der bisher bekannten funktionellen Mutationen eingezeichnet.

\section{III.a Ursächliche Mutation für vWD I bei Dobermännern, Manchester Terriern und Pudeln}

Eine eindeutig als rezessiv vererbte vWD I identifizierte Erkrankung bei Dobermännern, Pudeln und Manchester Terriern lässt sich auf eine Substitution des letzten Nukleotids in Exon 43 von Guanin durch Adenin an Position 7437 der codierenden Sequenz (Aminosäurenposition Serin 2479) zurückführen (Abb. 5) (Brewer et al. 1998; US-Patent 6780583). 


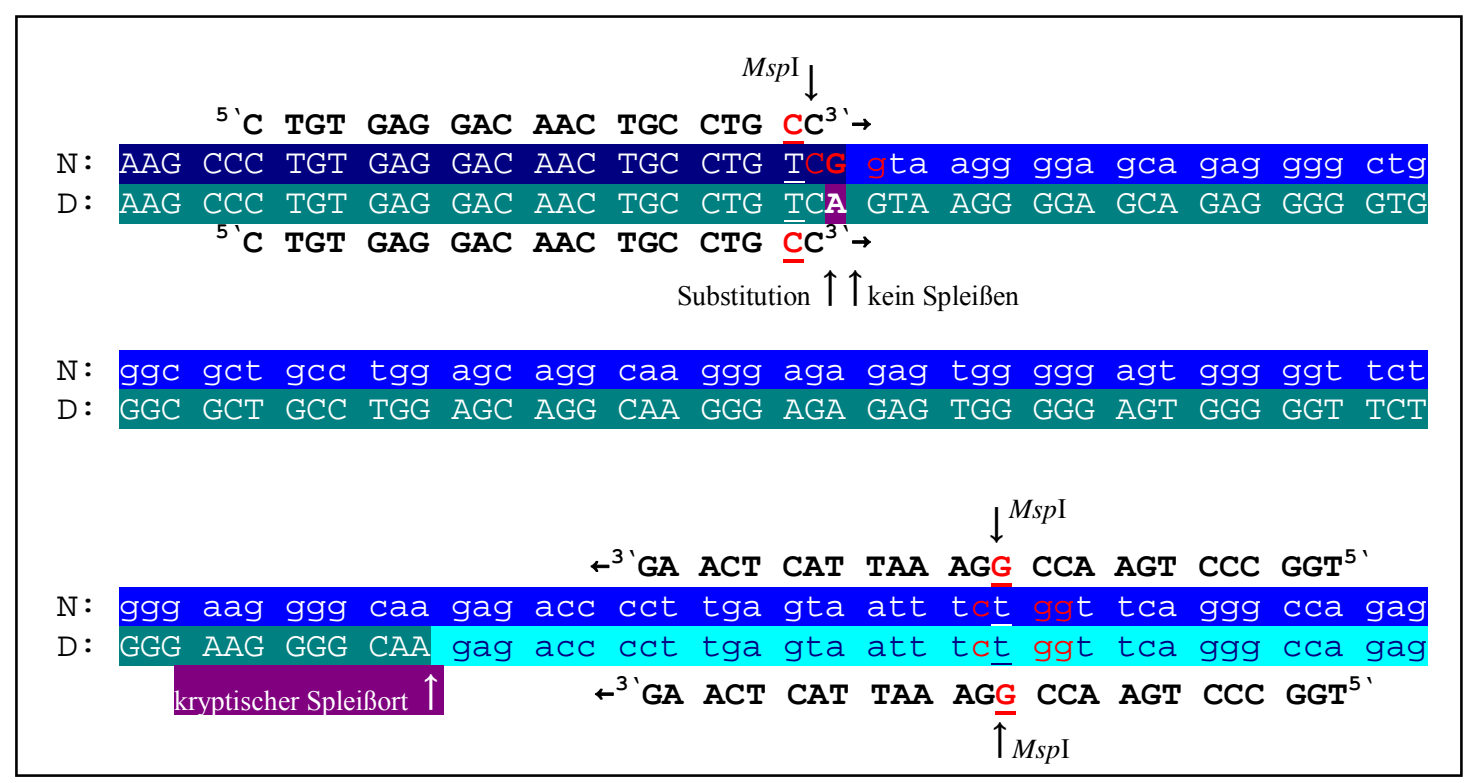

Abb. 5 Exon 43 und angrenzende Intronsequenz des vWF-Gens. N: normale Sequenz, D: defekte Sequenz, Exons normale Sequenz: dunkelblau, Exons defekte Sequenz: dunkelgrün, Introns normale Sequenz: hellblau, Introns defekte Sequenz: türkis, substituiertes Nukleotid fett gedruckt und violett unterlegt, normale Spleißposition durch Pfeil gekennzeichnet, kryptische Spleißposition violett unterlegt, MspI-Erkennungssequenz: rote Schrift, abweichende Primernukleotide zur Konstruktion der MspISchnittstellen rot und unterstrichen, MspI-Schnittstellen durch Pfeile gekennzeichnet.

Die Folge ist eine Verringerung der Wahrscheinlichkeit für ein Spleißereignis an der ursprünglichen Spleißposition und eine Erhöhung der Wahrscheinlichkeit für ein Spleißereignis an der kryptischen Spleißposition 7536. Nach der Shapiro-SenapathyMethode zur Berechnung der Wahrscheinlichkeit eines Spleißvorgangs an den betreffenden Positionen (Shapiro und Senapathy 1987) ergibt sich bei Zugrundelegen der nicht mutierten Sequenz eine Wahrscheinlichkeit von 89,9 \% für ein Spleißen am ursprünglichen Spleißort und von 60,6 \% am kryptischen Spleißort. Demgegenüber beträgt die Wahrscheinlichkeit bei Zugrundelegen der mutierten Sequenz für ein Spleißen am ursprüngliche Spleißort 72,2 \% und für ein Spleißen am kryptischen Spleißort 70,5\%.

Durch die beschriebenen Veränderungen der Wahrscheinlichkeit für ein korrektes Spleißen kommt es zu einer Reduzierung der Genfunktion des vWF-Gens auf 5-10 \% seiner normalen Funktion.

\section{IV.a Genotypisierung für vWD I bei Dobermännern, Manchester Terriern und Pudeln}

Der Nachweis der Mutation kann per Amplifikation eines 136-bp-Fragments unter Verwendung von mismatch-Primern und anschließender RFLP-Typisierung erfolgen. 
Nach der Amplifikation liegen im mutierten Allel eine, im Wildtypallel zwei Erkennungssequenzen für das Restriktionsenzym MspI vor (US-Patent 6780583).

\section{III.b Ursächliche Mutation für vWD II bei Deutsch Drahthaar und Deutsch Kurzhaar Vorstehhunden}

Sowohl bei Deutsch Drahthaar als auch bei Deutsch Kurzhaar Vorstehhunden liegt ein autosomal rezessiver Erbgang zugrunde. In beiden Rassen ist die Erkrankung auf eine Mutation in Exon 28 zurückzuführen (Kramer et al. 2004).

Der Vergleich des Exons 28 eines von vWD Typ II betroffenen Deutsch Kurzhaar Vorstehhundes mit den bekannten normalen Sequenzen der vWF codierenden caninen cDNA (NCBI-GenBank: AF099154, L76227, U66246) bzw. der caninen cDNA des Exons 28 (L16903) zeigte beim Deutsch Kurzhaar einen Basenaustausch an Nukleotidposition 4937 von Adenin durch Guanin. Die Folge ist eine Aminosäurensubstitution von Asparagin durch Serin an Aminosäurenposition 1647 (Abb. 6).

Zur Untersuchung der Verbreitung dieses Polymorphismus wurden DNA Proben von verwandten klinisch gesunden $(n=34)$ und betroffenen $(n=2)$ Deutsch Kurzhaar sowie 14 nicht verwandten Deutsch Kurzhaar und 71 Hunden aus zehn weiteren Rassen auf den Polymorphismus hin untersucht. Nur die vWD betroffenen Hunde waren homozygot für den gefundenen Basenaustausch. Alle untersuchten Defektträger $(n=13)$ waren heterozygot. Bei keinem der anderen untersuchten Hunde konnte der Basenaustausch nachgewiesen werden. Unabhängig von der Untersuchung an Deutsch Kurzhaar Vorstehhunden konnte eine andere Arbeitsgruppe dieselbe Mutation mit vWD Typ II bei Deutsch Drahthaar identifizieren (Kramer et al. 2004).

Als Folge dieser Substitution kommt es nach Vermutungen der Autoren zu einer Schädigung der von Exon 28 codierten Glykoprotein Ib/IX Bindungsdomäne und damit zu einer schwerwiegenden Beeinträchtigung der Funktion des vWF-Proteins. Auch bei der humanen Typ II vWD sind die meisten der bisher identifizierten verantwortlichen Mutationen im Exon 28 lokalisiert (Mancuso et al. 1993; Kramer et al. 2004). 


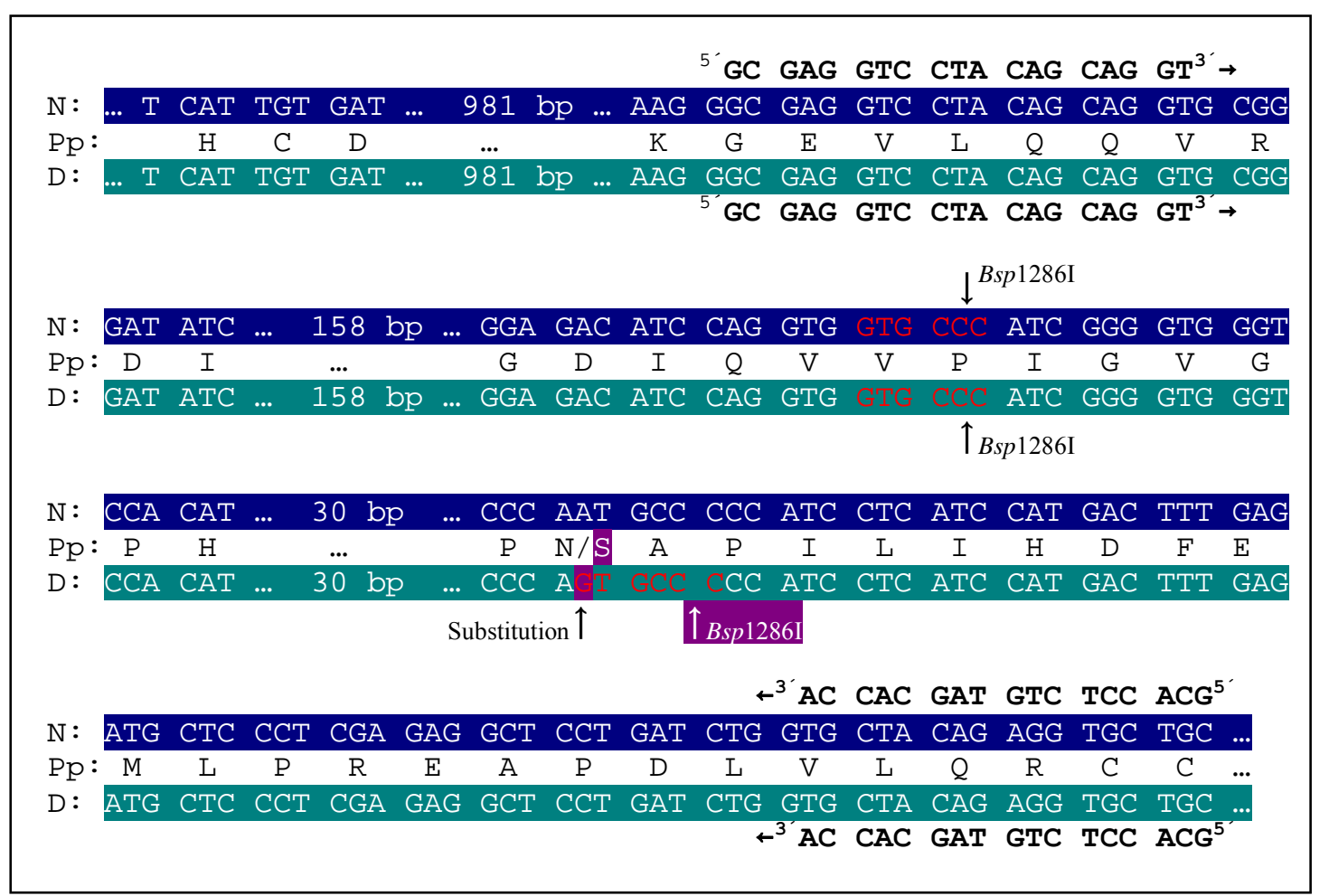

Abb. 6 Exon 28 des vWF-Gens. N: normale Sequenz, D: defekte Sequenz, Pp: Polypeptidsequenz, Exon normale Sequenz: dunkelblau, Exon defekte Sequenz: dunkelgrün, substituiertes Nukleotid und abweichende Aminosäure sowie neue Bsp1286I-Schnittstelle violett markiert, normale Bsp1286ISchnittstellen durch Pfeile gekennzeichnet, Bsp1286I-Erkennungssequenz: rote Schrift.

\section{IV.b Genotypisierung für vWD II bei Deutsch Drahthaar und Deutsch Kurzhaar Vorstehhunden}

Die Genotypisierung kann per Amplifikation eines 333-bp-Fragments aus Exon 28 und anschließender RFLP-Analyse mit Bsp1286I erfolgen. Der RFLP beruht auf der Entstehung einer zusätzlichen Restriktionsschnittstelle, die durch die Substitution im Defektallel entsteht (Kramer et al. 2004).

\section{III.c Ursächliche Mutation für vWD III bei Holländischen Kooiker Hunden}

Bei Holländischen Kooiker Hunden mit rezessiv vererbter Typ III vWD liegt sowohl ein SNP in Exon 3 als auch ein SNP an der Donor-Spleißerkennungssequenz in Exon 16 vor (Rieger et al. 1998).

Bei dem SNP in Exon 3 handelt es sich um eine Substitution von Guanin durch Adenin an Position 208 der codierenden Sequenz, mit der Folge einer Aminosäurensubstitution von Valin durch Isoleucin an Position 70 (Rieger et al. 1998). Neueren Untersuchungen zufolge scheint der beschriebene SNP jedoch nicht spezifisch für vWD III bei Holländischen Kooiker Hunden zu sein, da dieselbe Mutation auch bei einem Beagle 
(van Oost et al. 2004) sowie einem gesunden und einem von vWD III betroffenen Scottish Terrier (Venta et al. 2000) nachgewiesen werden konnte.

Demgegenüber sprechen die schwerwiegenden Einflüsse des SNP in Exon 16 auf die resultierende mRNA deutlich für einen ursächlichen Zusammenhang mit der vWD III bei Holländischen Kooiker Hunden. Es handelt sich um eine Substitution von Guanin durch Adenin an der ersten Position der Donor-Spleißerkennungssequenz, die zur Entstehung eines verfrühten Stoppcodons an Aminosäurenposition 729 des Propeptids führt (Abb. 7). Außerdem wird bei Vorliegen der Substitution an dieser Stelle nicht gespleißt und die resultierende mRNA wird mit zusätzlichen Basen aus Intron 16 fortgesetzt. 46 Nukleotide in 3' Richtung liegt im ursprünglichen Intron 16 eine alternative Donor-Spleißerkennungssequenz. An dieser Stelle wird die mutierte mRNA mit Exon 17 fortgesetzt (Rieger et al. 1998; Venta et al. 2000; van Oost et al. 2004).

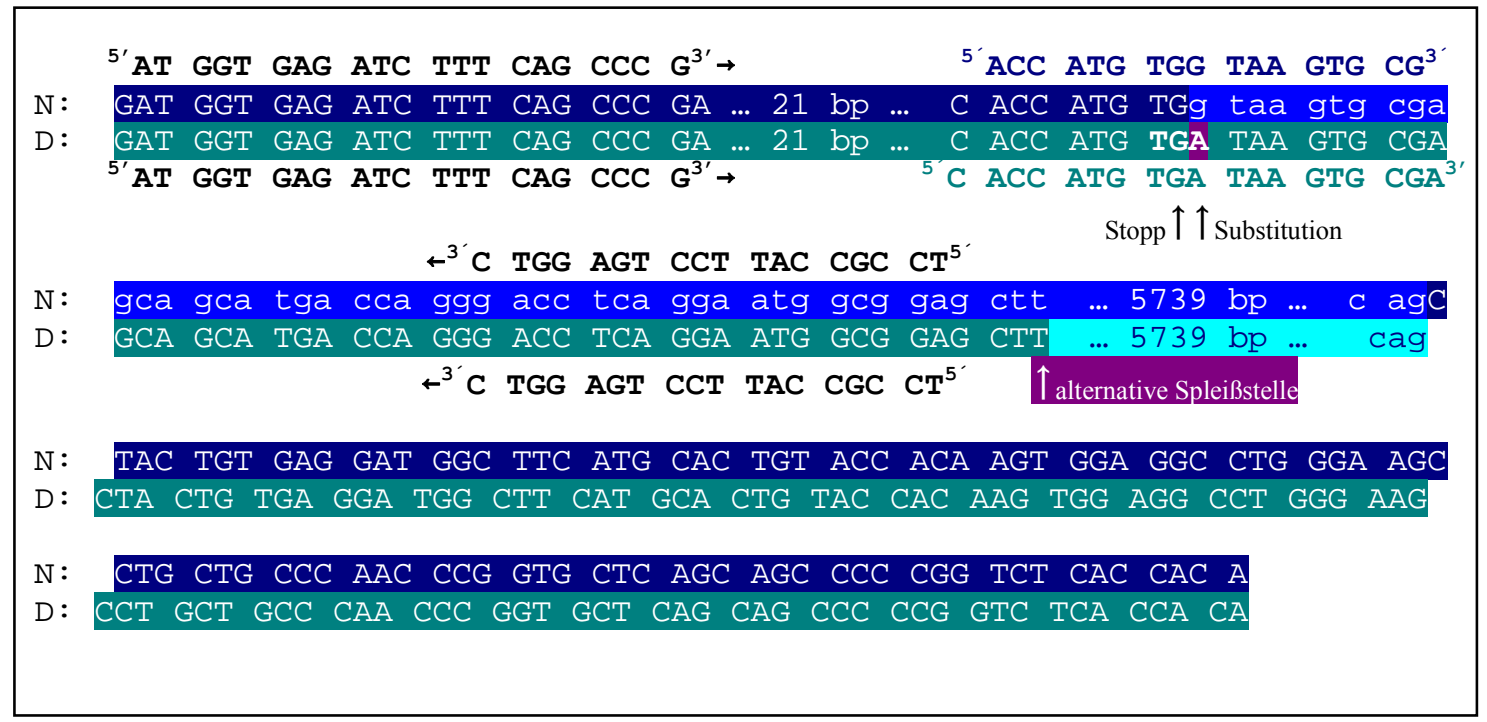

Abb. 7 Sequenzabschnitte des vWF-Gens von Exon 16 (53 letzte Nukleotide) bis Exon 17. N: normale Sequenz, D: defekte Sequenz, dunkelblau: Exon normale Sequenz, dunkelgrün: Exon defekte Sequenz, hellblau: Intron normale Sequenz, türkis: Intron defekte Sequenz, alternative Spleißstelle in defekter Sequenz durch Pfeile gekennzeichnet, substituiertes Nukleotid und resultierendes Stoppcodon violett markiert, dunkelblaue Schrift: wildtypallelspezifisches Oligonukleotid (DK9), dunkelgrüne Schrift: defektallelspezifisches Oligonukleotid (DK10).

\section{IV.c Genotypisierung für vWD III bei Holländischen Kooiker Hunden}

Unabhängig von Rieger et al. (1998) konnte eine weitere Arbeitsgruppe über einen anderen Ansatz dieselben Mutationen in Intron 16 und in Exon 3 bei betroffenen Holländischen Kooiker Hunden finden (Slappendel et al. 1998) und entwickelte einen Test auf Basis von genomischer DNA (van Oost et al. 2004). Dazu wird zunächst ein 94-bp-Fragment aus dem Grenzbereich zwischen Exon 16 und Intron 16 amplifiziert. 
Die Unterscheidung zwischen mutierten und normalen Allelen kann entweder über eine Sequenzierung oder per ASO erfolgen.

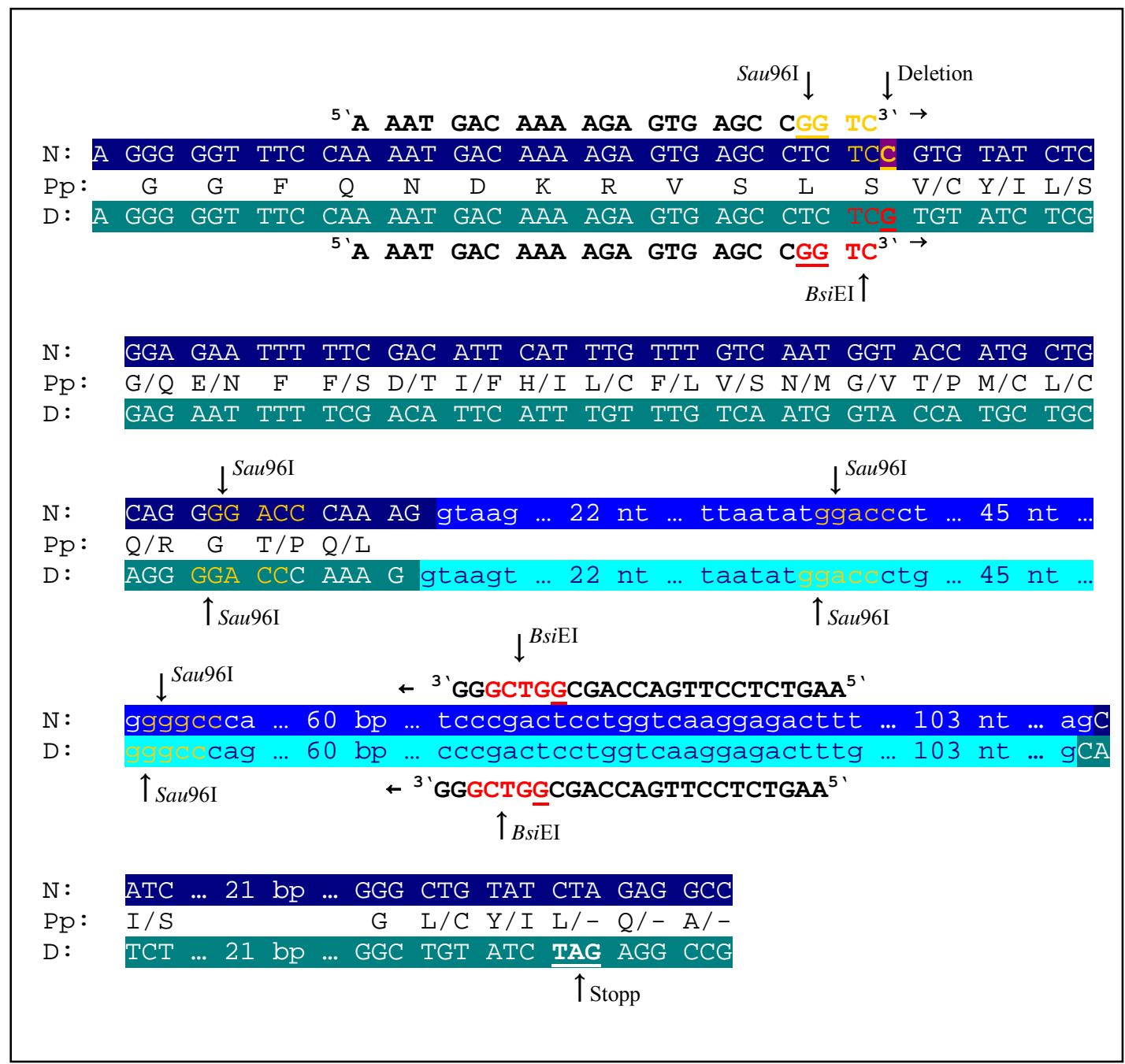

Abb. 8 Intron 4 und angrenzende Exonsequenzen des vWF-Gens. N: normale Sequenz, D: defekte Sequenz, dunkelblau: Exon normale Sequenz, dunkelgrün: Exon defekte Sequenz, hellblau: Intron normale Sequenz, türkis: Intron defekte Sequenz, von Deletion betroffenes Nukleotid in der normalen Sequenz violett unterlegt, verfrühtes Stoppcodon fett gedruckt, unterstrichen und durch Pfeil gekennzeichnet, rote Schrift: BsiEI-Erkennungssequenz, orange Schrift: Sau96I-Erkennungssequenz, Restriktionsschnittstellen jeweils durch Pfeile gekennzeichnet.

\section{III.d Ursächliche Mutation für vWD III bei Scottish Terriern}

Bei Scottish Terriern ist eine Deletion in Exon 4 an Position 3 des Codons 88 mit der vWD III verknüpft, die 103 bp abwärts der Deletion ein neues Stoppcodon erzeugt (Abb. 8). Das generierte Protein ist mit lediglich 119 Aminosäuren gegenüber dem normalen Protein stark verkürzt und stimmt in keiner Region mit dem normalen, reifen vWF überein (Venta et al. 2000). 


\section{IV.d Genotypisierung für vWD III bei Scottish Terriern}

Der Nachweis der Mutation kann per Amplifikation eines 272 bzw. beim vWD-Hund 271 Basenpaare umfassenden DNA-Abschnitts beginnend in Exon 4 und endend in Intron 4 unter Einsatz von mismatch-Primern und anschließender RFLP-Analyse erfolgen. Dafür stehen zwei Restriktionsenzyme (BsiEI oder Sau96I) zur Auswahl. Nach der Amplifikation enthält das Wildtypallel eine Erkennungssequenz für BsiEI und vier Erkennungssequenzen für Sau96I, während das Defektallel zwei Erkennungssequenzen für BsiEI und drei Erkennungssequenzen für Sau96I enthält (USPatent 6780583).

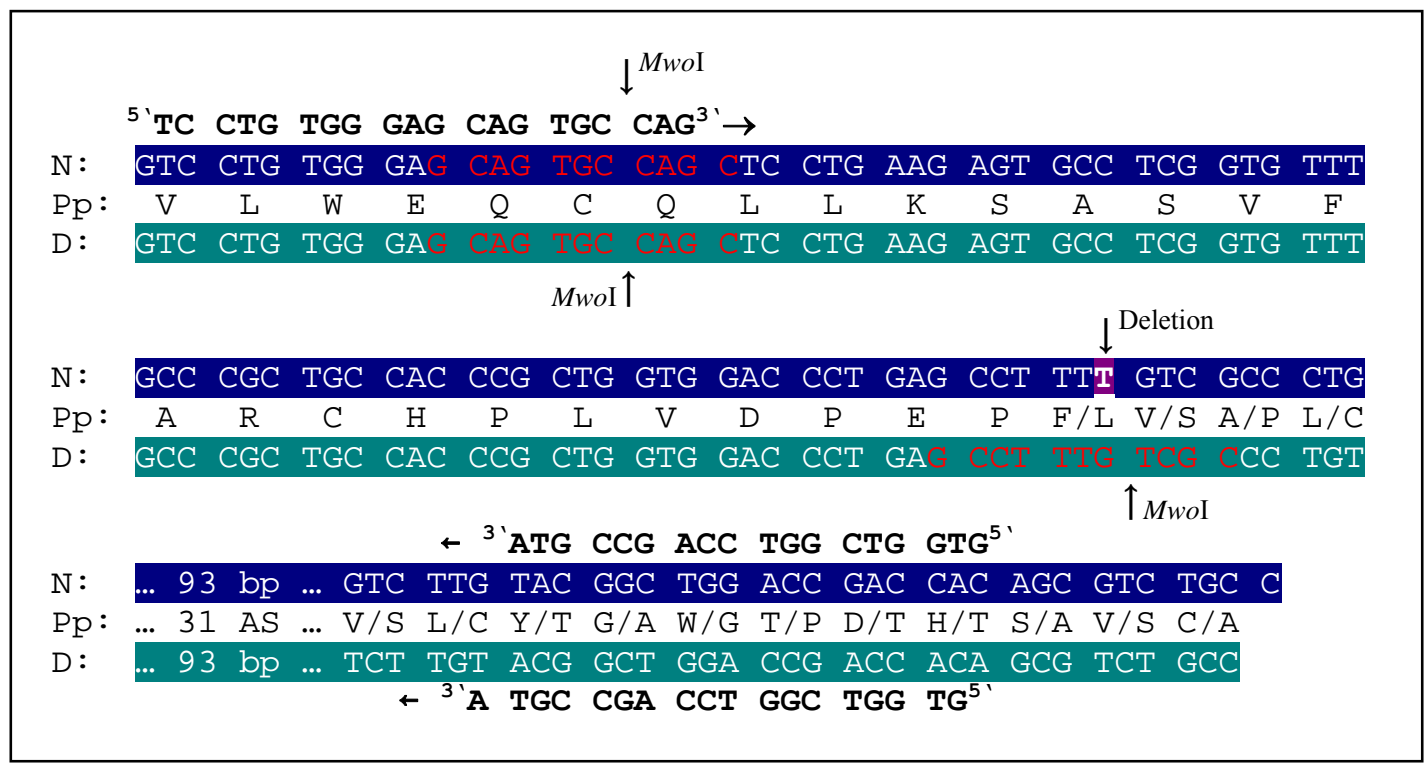

Abb. 9 Exon 7 des vWF codierenden Gens von Nukleotid 658 bis 874 in der codierenden Sequenz (NCBI-GenBank: AF099154). N: normale Sequenz, D: defekte Sequenz, von Deletion betroffenes Nukleotid in der normalen Sequenz fett gedruckt und violett markiert, MwoI-Schnittstellen durch Pfeil gekennzeichnet, rote Schrift: MwoI-Erkennungssequenzen.

\section{III.e Ursächliche Mutation für vWD III bei Shetland Schäferhunden}

Bei Shetland Schäferhunden, die von einer rezessiv vererbten vWD III betroffen sind, liegt eine $1 \mathrm{bp}$ umfassende Deletion in Exon 7 nach Nukleotid Position 735 der codierenden Sequenz (NCBI-GenBank: AF099154) vor, die eine Verschiebung des Leserasters zur Folge hat, so dass das resultierende Protein stark verkürzt ist (Abb. 9) (US-Patent 6780583). Auf die genauen Auswirkungen der Deletion auf das resultierende Protein wird in der Veröffentlichung nicht weiter eingegangen. 


\section{IV.e Genotypisierung für vWD III bei Shetland Schäferhunden}

Der Defekt lässt sich über die Amplifikation eines 206-bp-Fragments und anschließende Restriktionsanalyse nachweisen. Eine Restriktionsspaltung mit MwoI ergibt beim normalen Allel zwei Fragmente, während das defekte Allel in drei Fragmente gespalten wird (US-Patent 6780583). 


\subsubsection{Hämophilie A und B}

\begin{tabular}{ll|}
\hline Chromosom: & CFAX \\
Gen: & F8 (Faktor 8) \\
NCBI: & GeneID: 403875, GenBank: AF016234 \\
DNA-Sequenz: & NW_879563, Position 74395733-74248802 \\
Mutationen: & F8C-Mikrosatellitenpolymorphismus (Intron 21), \\
& mittelschwere Hämophilie A, Golden Retriever \\
& ch8-Insertion (Intron 22), schwere Hämophilie, \\
& Irischer Setter, Zwergschnauzer, Redbone Coonhound
\end{tabular}

\begin{tabular}{|ll|}
\hline Chromosom: & CFAX \\
Gen: & F9 (Faktor 9) \\
NCBI: & GeneID: 404015, GenBank: M21757 \\
DNA-Sequenz: & NW_879563, Position 60900897-60933951 \\
Mutationen: & vollständige Deletion des Gens, Häophilie B, Labrador \\
& Retriever \\
& Deletion der Exons 1-6, beginnend in 5'-UTR, endend \\
& zwischen Exons 6 und 7, nicht abschließend \\
& charakterisiert, Pit Bull Terrier \\
& 1,5-kb-LINE1-Insertion nach Position 2071, Deutsch \\
& Drahthaar Vorstehhund \\
& Del772-776+C777T, Lhasa Apso \\
& G1477A, Cairn Terrier \\
& 5-kb-Insertion nach Position 1471, Airdale Terrier
\end{tabular}

\section{Krankheitsbild}

Die Hämophilien A und B sind Störungen der sekundären Hämostase, die auf quantitativen oder qualitativen Defekten des Faktors VIII bei Hämophilie A und des Faktors IX bei Hämophilie B beruhen. Anhand der äußerlichen Anzeichen sind die beiden Erkrankungen kaum zu unterscheiden. In beiden Fällen handelt es sich um Störungen des intrinsischen oder intravascularen Gerinnungssystems. Die Ausprägung der Symptome ist bei beiden Erkrankungen abhängig von Grad und Art der Gerinnungsfaktorstörungen, denen zahlreiche verschiedene Mutationen zugrunde liegen.

Die Hämophilie gilt als der häufigste erbliche Gerinnungsdefekt bei Hunden und ist in zahlreichen Rassen beschrieben worden. Zur Häufigkeit der Erkrankungen innerhalb der einzelnen Rassen sind keine Zahlen veröffentlicht. Allerdings scheint Hämophilie A etwa drei bis viermal häufiger zu sein als Hämophilie B. Es wird unterschieden 
zwischen Rassen mit sporadischen Fällen, die lediglich einzelne Individuen oder einzelne Würfe betreffen und Rassen mit familiären Fällen, mit mehr als einer betroffenen Generation innerhalb eines Pedigrees oder mehr als drei neuen Fällen pro Jahr.

Rassen in denen eine Form der Hämophilie A sporadisch auftritt sind Basenji, Basset, Bichon Frise, Blue Heeler, Bretonischer Spaniel, Cairn Terrier, Chihuahua, Chow Chow, Irischer Setter, Labrador Retriever (eine von drei verschiedenen Formen), Manchester Terrier, Pit Bull Terrier, Pembroke Welsh Corgi, Shetland Schäferhund, Shiba Inu, Toy Pudel West Highland White Terrier und Yorkshire Terrier. Rassen mit familiär auftretender Hämophilie A sind Akita, Australischer Schäferhund, Beagle, Boxer, Boykin Spaniel, Cocker Spaniel (zwei verschiedene Formen), Englische Bulldogge, Englischer Springer Spaniel, Deutscher Schäferhund (zwei verschiedene Formen), Deutsch Kurzhaar, Golden Retriever, Husky, Labrador Retriever (zwei von drei verschiedenen Formen), Lhasa Apso, Zwergdackel, Zwergschnauzer, Portugiesischer Wasserhund, Rottweiler, Rauhaarcollie, Scottish Terrier (zwei verschiedene Formen), Shar Pei, Shi Tzu und Viszla.

Rassen, in denen eine Form der Hämophilie B sporadisch auftritt sind Beagle, Bichon Frise, Chow Chow, Dobermann Pinscher, Golden Retriever, Jack Russel Terrier, Pit Bull Terrier, Scottish Terrier, Sealyham Terrier, Weimaraner und Drahthaarfoxterrier. Rassen mit familärer Hämophilie B sind Airdale Terrier, Deutscher Schäferhund, Deutsch Drahthaar Vorstehhund, Labrador Retriever (zwei verschiedene Formen), Malteser, Rottweiler, Bernhardiner und Shi Tzu (Brooks 1999).

In Abhängigkeit von der Faktor-VIII-Aktivität wurden für die humane Hämophilie A drei Krankheitskategorien entwickelt (Barthels und Poliwoda 1993), die auf die canine Erkrankung übertragbar sind. Nach einer Darstellung von Mischke et al. (1996) fallen Hunde mit Faktor-VIII-Aktivitäten von $<1 \%$ in die Kategorie schwere Hämophilie, Hunde mit Faktor-VIII-Aktivitäten zwischen $1 \%$ und $4 \%$ leiden an mittelschwerer Hämophilie, Faktor-VIII-Aktivitäten von 5-30 \% liegen bei milder Hämophilie vor. In anderen Darstellungen sind die Untergrenzen der einzelnen Kategorien um einen Prozentpunkt nach oben verschoben (Brooks et al. 2005). 
Bei Hämophilie B liegt die Faktor-IX-Aktivität bei den meisten beschriebenen Hunden $<2 \%$. Einige betroffene Hunde mit weniger schweren Symptomen weisen jedoch auch Faktor-IX-Aktivitäten von bis zu $9 \%$ auf (Littlewood et al. 1986).

Klassische Symptome einer Hämophilie wie Lahmheit, Schmerzen und Gelenkschwellungen aufgrund von Hämarthrosen treten bereits im Alter von sechs Wochen bis drei Monaten auf. Diese Erscheinungen können leicht als Rachitis fehlgedeutet werden. Zusätzlich $\mathrm{zu}$ den aufgezählten Symptomen treten durch subkutane Hämatome plötzlich große Schwellungen in unterschiedlichen Körperzonen auf, die sich nur langsam zurückbilden. In einigen Fällen fallen betroffene Hunde bereits direkt nach der Geburt durch lange anhaltende Blutungen aus der Nabelschnur auf (Hutt et al. 1948; Mustard et al. 1960; Rowsell et al. 1960). Beim Zahnwechsel oder nach chirurgischen Eingriffen kommt es zu langen Blutungen oder Hämatomen (Brooks et al. 2005). Je nach Grad der Hämophilie sind oft schon leichte Verletzungen oder Stöße beim normalen Spiel ausreichend, um anhaltende Blutungen, blutverlustbedingte Anämien und die Entstehung großer Hämatome zu provozieren (Hutt et al. 1948). Mildere Formen der Erkrankung werden oft nur bei chirurgischen Eingriffen und Zahnwechsel offenbar, sonstige Anzeichen sind oft weniger eindeutig als bei schwerer Hämophilie (Horvath und Elodi 1991; Brooks et al. 2005).

Hämatologische Untersuchungen ergeben normale Blutungszeiten, extrem verlängerte Gerinnungszeiten, normale Thromboplastinzeiten, normale Fibrinogen- und Prothrombingehalte im Plasma (Hutt et al. 1948; Mischke et al. 1996; Brooks et al. 2005). Die aktivierte partielle Thromboplastinzeit (aPTT) ist in den meisten Fällen von Hämophilie A und B verlängert (Peterson und Dodds 1979; Parry et al. 1988; Mischke et al. 1996; Brooks et al. 2005). Einige von der milden Form betroffene Hunde zeigen jedoch normale aPTT, so dass dieser Wert nicht als eindeutiges Kriterium für das Vorliegen einer Hämophilie herangezogen werden kann (Fitch und Wardrop 1992; Brooks et al. 2005). Im Gegensatz zur Hämophilie A lässt sich die verlängerte aPTT bei Hämophilie B durch Zugabe von normalem Serum aufheben, da Serum zwar den aktivierten Faktor IX, nicht aber den aktivierten Faktor VIII enthält (Fitch und Wardrop 1992). 


\section{II.a+b Genetischer Hintergrund der Hämophilie A}

Pedigreeanalysen zeigen einen X-chromosomalen, rezessiven Erbgang (Hutt et al. 1948). Die Erkrankung taucht also im Normalfall nur bei Rüden auf. Heterozygote weibliche Träger des Gendefektes zeigen keine Symptome, haben aber häufig auf 40-60 \% verringerte FVIII-Konzentrationen im Plasma. Jedoch ist sowohl auf Basis der FVIIIKonzentration als auch auf Basis von Pedigreeanalysen eine eindeutige Detektion weiblicher Defektträger nicht möglich (Tennant 1996; Brooks et al. 2005).

Das canine Faktor-VIII-Gen konnte mittels FISH auf Xq28 lokalisiert werden (Dutra et al. 1996). Die cDNA-Sequenz des caninen Faktor-VIII-Gens umfasst 7029 Nukleotide, die für insgesamt 2343 Aminosäuren codieren (NCBI-GenBank: AF016234) (Cameron et al. 1998). Innerhalb des Contigs NW_879563 sind die 26 Exons des Faktor-VIIIGens in revers komplementärer Richtung von Nukleotid 74395733 bis Nukleotid 74248802 angeordnet. Die Leserichtung des Faktor-VIII-Gens läuft von Telomer Richtung Centromer. Abb. 10 stellt die Lage der einzelnen Exons innerhalb der genomischen Sequenz schematisch dar.

Bisher ist erst eine Mutation des caninen Faktor-VIII-Gens gefunden worden, die eine Hämophilie-A-Erkrankung verursacht (Hough et al. 2002; Lozier et al. 2002). Diese Mutation konnte in zwei genetisch voneinander unabhängigen Forschungskolonien, in die das defekte Allel durch heterozygote Irische Setterhündinnen (Graham et al. 1949; Lozier et al. 2002) bzw. durch Kreuzungen aus beteroffenen Zwergschnauzerrüden und heterozygoten Schnauzer-Bretonen-Spaniel Mischlingshündinnen eingeführt wurde, sowie bei zwei Redbone Coonhounds nachgewiesen werden (Hough et al. 2002).

Des Weiteren ist in der Rasse Golden Retriever ein Mikrosatellitenpolymorphismus identifiziert worden, der eng mit mittelschwerer Hämophilie A gekoppelt ist (Mellersh et al. 1997; Brooks et al. 2005). Die ursächliche Mutation für die Erkrankung bei Golden Retrievern ist nicht bekannt. 


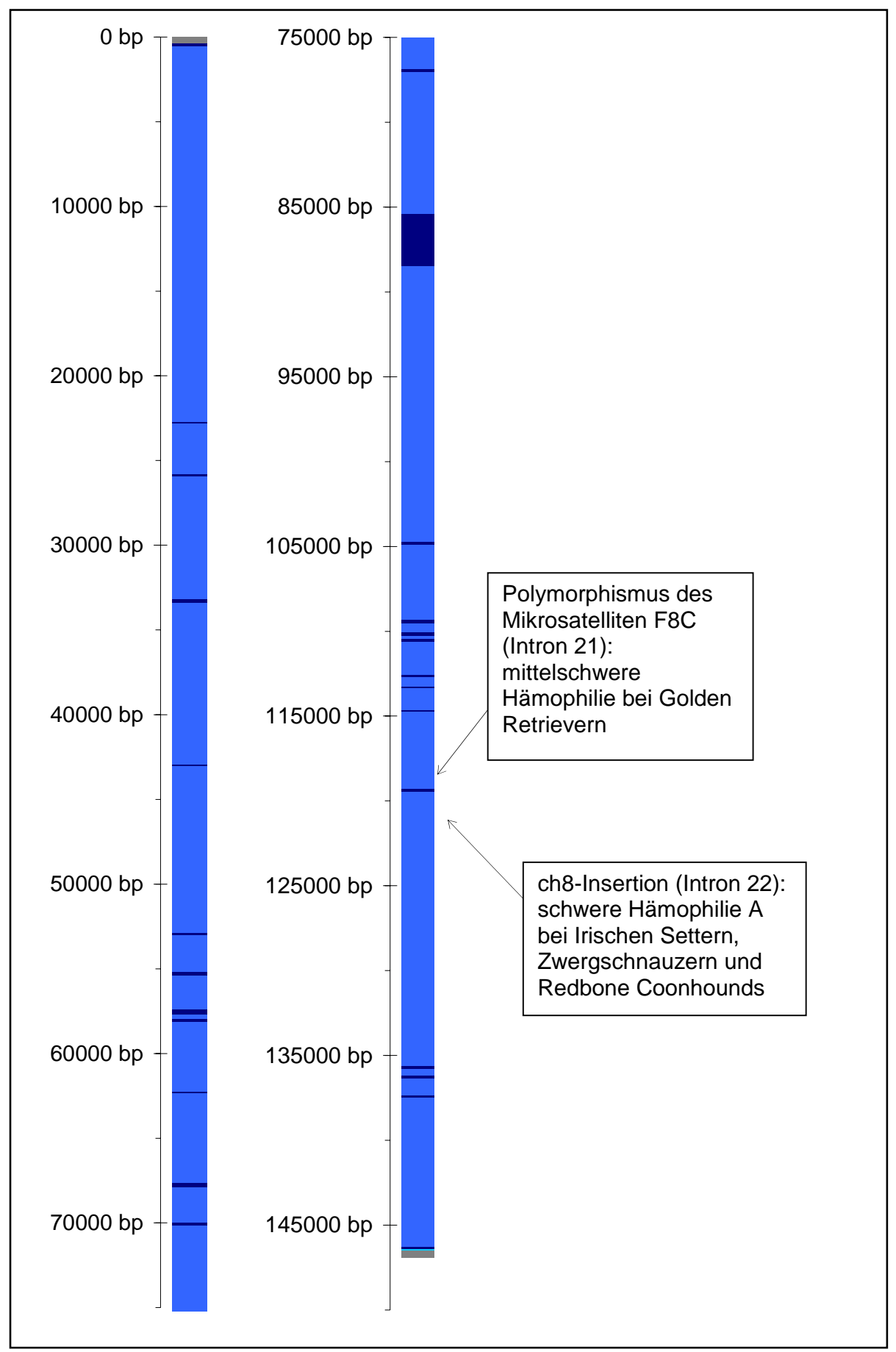

Abb. 10 Schematische Darstellung des Faktor-VIII-Gens und der bisher identifizierten Mutationen. Grau: intergenische Sequenz, türkis: 3'-UTR, dunkelblau: codierende Sequenz, hellblau: Intron.

\section{III.a Ursächliche Mutation der schweren Hämophilie A bei Irischen Settern, Schnauzern und Redbone Coonhounds}

Eine schwere Form der Hämophilie A, die in zwei genetisch voneinander unabhängigen Forschungskolonien untersucht (Hough et al. 2002; Lozier et al. 2002) und zudem bei zwei Redbone Coonhound Wurfgeschwistern beobachtet wurde (Hough et al. 2002), ist auf die Insertion eines 429-bp-Fragments in Intron 22 zurückzuführen (Hough et al. 
2002; Lozier et al. 2002). Die Einführung des defekten Allels geschah in einer der beiden Kolonien durch die Kreuzung heterozygoter Irischer Setterhündinnen mit Rüden aus unterschiedlichen Rassen (Graham et al. 1949; Lozier et al. 2002), in der anderen Forschungskolonie durch die Anpaarung betroffener Zwergschnauzerrüden mit heterozygoten Schnauzer-Bretonen-Spaniel Mischlingshündinnen. Des Weiteren ließ sich die beschriebene Mutation bei zwei Redbone Coonhounds mit schwerer Hämophilie A nachweisen (Hough et al. 2002).

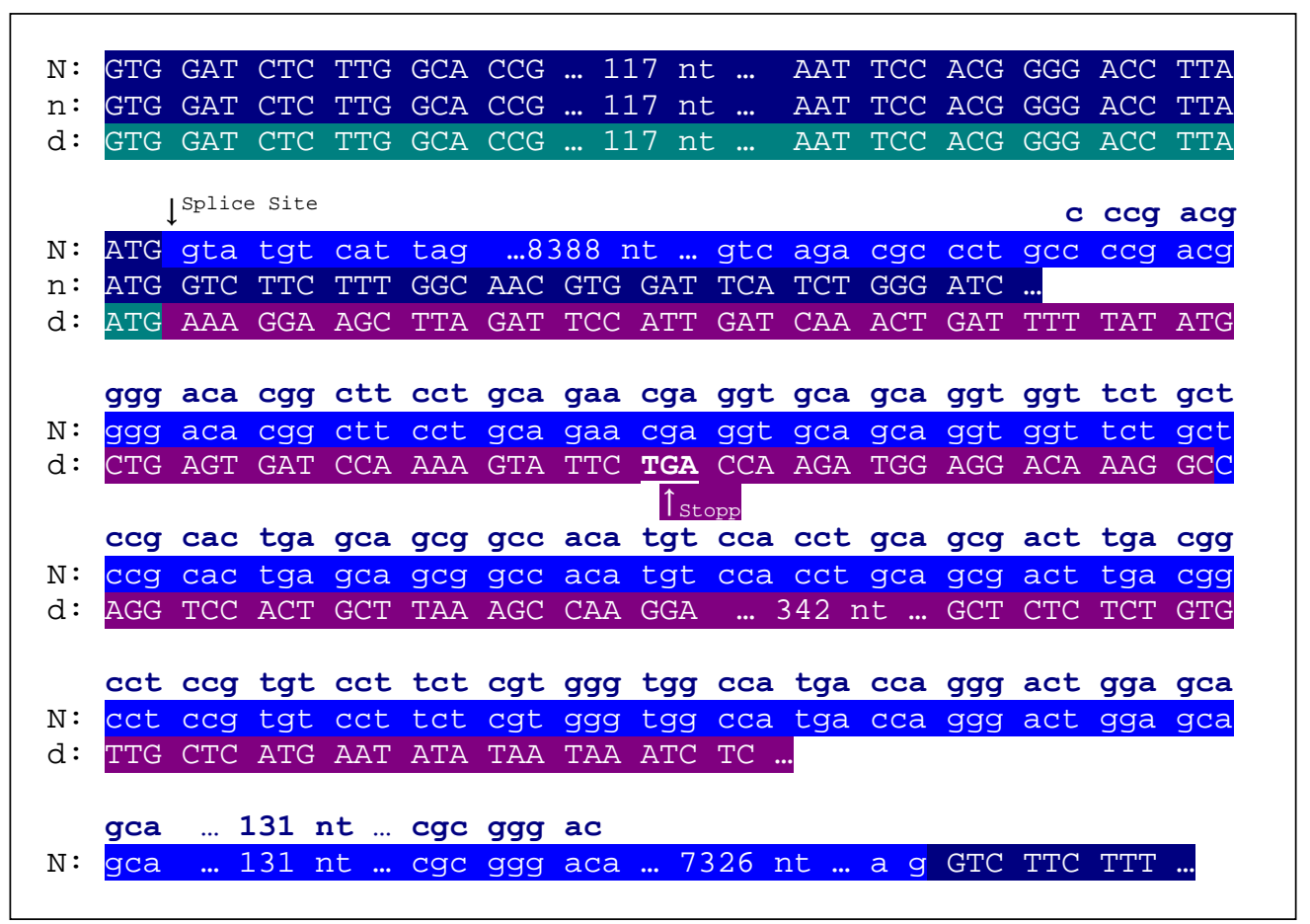

Abb. 11 Exon 22 bis Anfang Exon 23 des Faktor VIII Gens. N: normale genomische DNA Sequenz, n: normale mRNA Sequenz, d: defekte mRNA Sequenz, dunkelblau unterlegt: Exon normale Sequenz, dunkelgrün unterlegt: Exon defekte Sequenz, hellblau unterlegt: Intron normale Sequenz, violett unterlegt: ch8 - Insertion, verfrühtes Stoppcodon in defekter Sequenz durch Pfeil markiert, dunkelblaue Schrift: F8A-Sonde.

Bei der Insertion handelt es sich um eine als "ch8" bezeichnete Sequenz (NCBISequence: AF361485), die bei betroffenen Hunden direkt an Exon 22 anschließt. Nach 63 bp der Insertionssequenz folgt ein Stoppcodon, nach Base 425 der ch8-Sequenz folgt ein Polyadenylierungssignal. Die Insertion führt also zur Codierung von 21 abweichenden Aminosäuren nach Exon 22 und zur vorzeitigen Terminierung der Translation sowie der Transkription (Abb. 11) (Lozier et al. 2002).

Im gesamten caninen Genom liegen mindestens fünf Kopien der ch8-Sequenz vor. Eine dieser Kopien konnte mittels FISH auf dem caninen X-Chromosom in telomerer Orientierung zum Faktor-VIII-Gen nachgewiesen werden. In der Nähe dieser ch8-Kopie 
ist eine mit F8A bezeichnete Sequenz lokalisiert, die auch in Intron 22 des caninen Faktor-VIII-Gens nachgewiesen werden kann. Diese Beobachtungen sprechen für das Vorliegen einer homologen Rekombination der F8A-Sequenz aus Intron 22 und der außerhalb des Faktor-VIII-Gens gelegenen F8A-Sequenz bei Hunden mit der ch8Insertion (Lozier et al. 2002). Eine zu F8A homologe Sequenz ist auch bei einer verbreiteten Insertion im humanen Faktor-VIII-Gen beteiligt, die zu einer schweren Form der Hämophilie A führt (Lakich et al. 1993).

\section{IV.a Genotypisierung für schwere Hämophilie A bei Irischen Settern, Schnauzern und Redbone Coonhunds}

Die Insertion kann beispielsweise anhand eines RFLP nachgewiesen werden, der geeignet ist, heterozygote Defektträger, gesunde und kranke Hunde zu differenzieren. Genomische DNA mit HindIII gespalten zeigt im Southern Blot bei Hybridisierung mit einer caninen F8A-Sonde (Abb. 12) bei normalen Hunden zwei Banden von je 28 und $13 \mathrm{~kb}$, bei kranken Hunden zwei Banden von 21 und $23 \mathrm{~kb}$. Bei heterozygoten Defektträgern sind alle vier Banden präsent (Lozier et al. 2002).

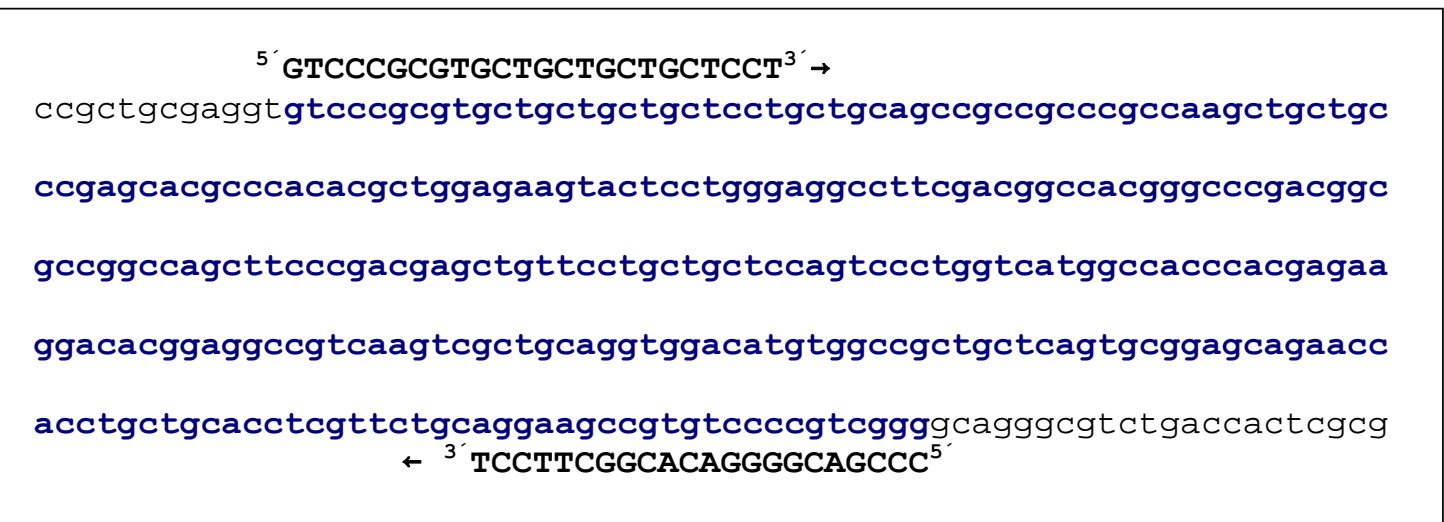

Abb. 12 Nukleotide 6301 bis 6725 des caninen BAC-Klons 291 M9 (Children's Hospital of Oakland Research Institute, Oakland, CA, zu erwerben über http://bacpac.chori.org) (NCBI-GenBank: AF523316). dunkelblaue Schrift: F8A-Sonde.

\section{III.b Assoziation eines Polymorphismus des Mikrosatelliten F8C mit mittelschwerer Hämophilie A bei Golden Retrievern}

Die ursächliche Mutation des Faktor-VIII-Gens für mittelschwere Hämophilie A bei Golden Retrievern ist nicht bekannt. Zur Genotypisierung steht allerdings ein Test auf der Basis einer Mikrosatellitenanalyse zu Verfügung (Brooks et al. 2005). Die Methode basiert auf einem Polymorphismus des bereits 1997 entdeckten Mikrosatelliten Markers F8C (Mellersh et al. 1997). Im genomischen Contig NW_879563 liegt die 360 
Nukleotide umfassende F8C-Sequenz (NCBI-GenBank: U94339) zwischen Nukleotid 74278934 und 74278376, bzw. auf dem revers komplementären Strang. Dieser Bereich ist in Intron 21 des Faktor-VIII-Gens lokalisiert (Abb. 13).

Bei insgesamt 25 untersuchen Golden Retrievern konnten am F8C-Lokus insgesamt 5 Allele von 265, 290, 296, 300 und 305 bp Länge unterschieden werden. Alle erkrankten Hunde waren homozygot für das 300-bp-Allel, alle Überträger der Erkrankung waren Träger des 300-bp-Allels. Bei keinem der untersuchten gesunden Hunde konnte das 300-bp-Allel nachgewiesen werden. Eine Analyse der F8C-Sequenz verspricht demnach eine relativ sichere Bestimmung des Faktor-VIII-Genotyps. Das bei Markertests stets gegebene Risiko einer Rekombination und in Folge dessen eines Verlusts der Aussagefähigkeit wird in diesem Fall aufgrund der Lage des Markers innerhalb des Gens als gering eingeschätzt. Für die Bestimmung von heterozygoten Defektträgern ist dieser Test in jedem Fall anderen Methoden, die auf Bestimmung der Faktor VIII Konzentration oder Aktivität in Verbindung mit Pedigreeanalysen beruhen überlegen (Brooks et al. 2005).

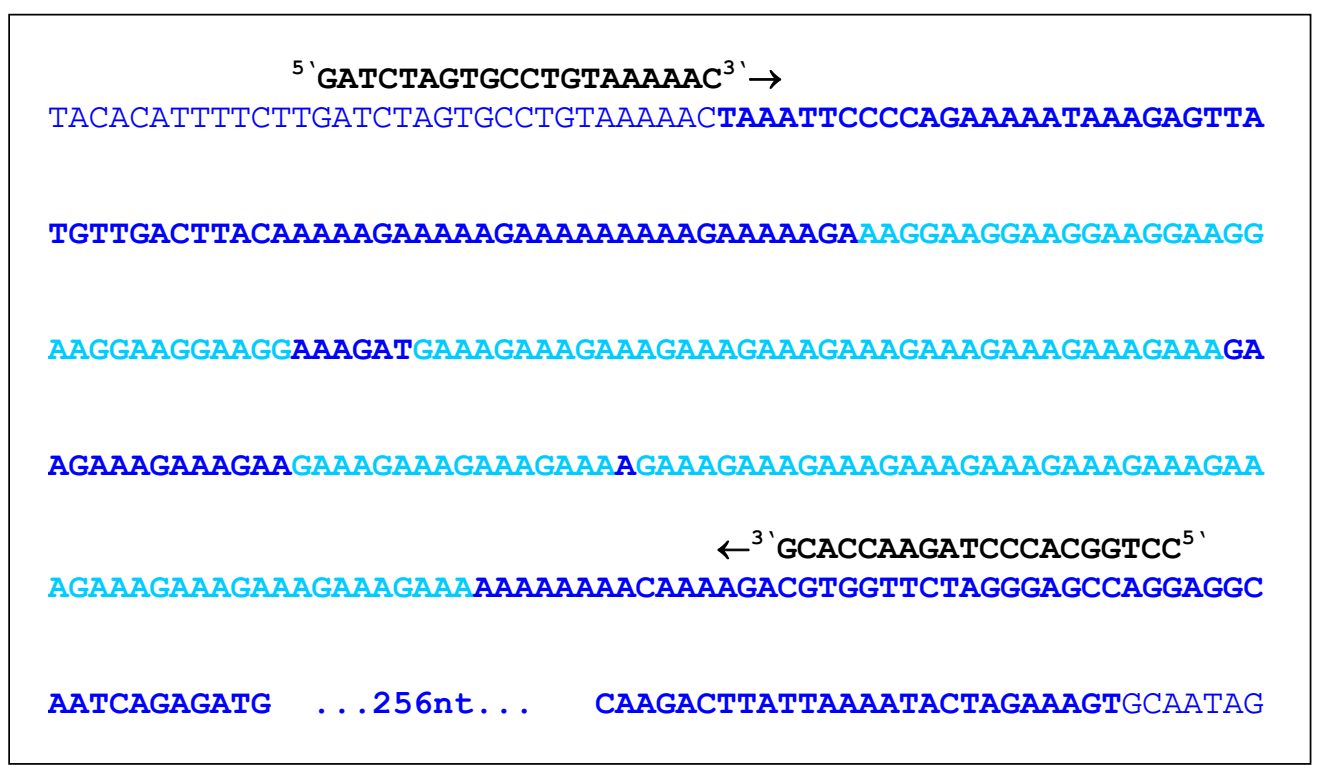

Abb. 13 F8C Mikrosatellitenregion im Intron 21 des Faktor-VIII-Gens. Fett gedruckt: F8C Sequenz (NCBI-GenBank: U94339), normal gedruckt: anschließende Sequenz; blau: normale Intronsequenz, türkis: eine (AAGG)n-Multiplikationsregion und drei (GAAA)n-Multiplikationsregionen.

\section{II.c-h Genetischer Hintergrund der Hämophilie B}

Auch die Vererbung der Hämophilie B verläuft X-chromosomal (Mustard et al. 1960; Rowsell et al. 1960). Ursache der Erkrankung sind verschiedene Mutationen des Faktor- 
IX-Gens, das im genomischen Contig NW_879563 zwischen Position 60900897 und 60933951 lokalisiert ist.

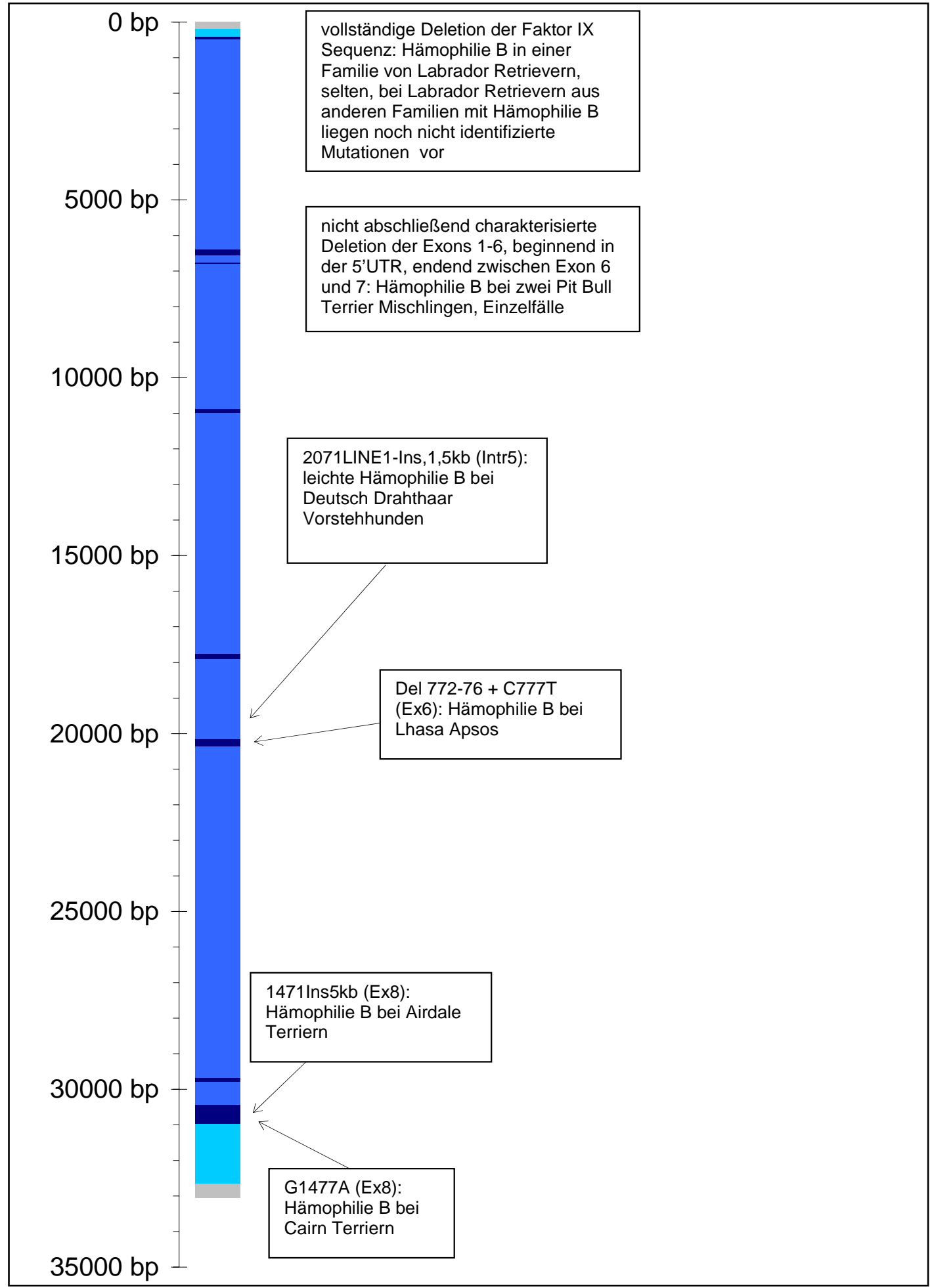

Abb. 14 Schematische Darstellung des Faktor-IX-Gens und der bekannten funktionellen Mutationen. grau: intergenische Sequenz, türkis: UTR, dunkelblau: codierende Sequenz, hellblau: Intron.

Die Länge der für den caninen Faktor IX codierenden mRNA beträgt 2869 Nukleotide (NCBI-GenBank: M21757) (Evans et al. 1989b). Es wird davon ausgegangen, dass das 
canine Faktor-IX-Gen viele strukturelle Gemeinsamkeiten mit dem humanen Faktor-IXGen aufweist, das sich aus acht Exons zusammensetzt, die grob mit funktionellen Domänen des Proteins in Verbindung gebracht werden können (Yoshitake et al. 1985).

Abb. 14 zeigt die auf Kenntnis der humanen Faktor-IX-Genstruktur basierende Vorstellung vom Aufbau des caninen Faktor-IX-Gens und die Lage der zurzeit bekannten sechs pathogenen Mutationen innerhalb dieses Modells.

\section{III.c Ursächliche Mutation für Hämophilie B bei Cairn Terriern}

Ein Vergleich der cDNA-Sequenzen von gesunden Hunden mit den Sequenzen von homozygoten und heterozygoten Hämophilie B Defektträgern führte zur Entdeckung einer Punktmutation von G zu A an Nukleotid 1477 in der katalytischen Domäne des Faktor IX-Gens (Abb. 15) (Evans et al. 1989a). Die untersuchten Hunde stammten aus einer Forschungskolonie, in die das Defektallel durch Einkreuzung betroffener Cairn Terrier eingeführt wurde (Brinkhous et al. 1973). Die Folge der beschriebenen Mutation ist ein Aminosäurenaustausch von Glycin zu Glutamin an Position 379 des caninen Faktor-IX-Proteins. Die physiologischen Effekte der beschriebenen Mutation sind ungewöhnlich, denn obwohl mittels Northern Blot Faktor-IX-mRNA in normaler Menge nachgewiesen werden konnte, ist im Plasma der Hämophilie-B-Hunde Faktor IX nicht nachweisbar. Mögliche Gründe sind eine reduzierte Translation, eine gestörte Sekretion oder eine Instabilität des mutierten Polypeptids. Anhand bekannter Informationen über verwandte Trypsin- und Serin- Proteasen lassen sich Rückschlüsse auf die Tertiärstruktur des Faktor-IX-Proteins ziehen, die dafür sprechen, dass die Mutation zu einer deutlich abweichenden Tertiärstruktur des mutierten Proteins und damit zu struktureller Instabilität führt. Aufgrund dieser Annahme und da innerhalb der untersuchten cDNA keine weiteren Mutationen gefunden werden konnten, schließen die Autoren, dass die beschriebene Mutation die Ursache für Hämophilie B bei den untersuchten Hunden ist (Evans et al. 1989a). 


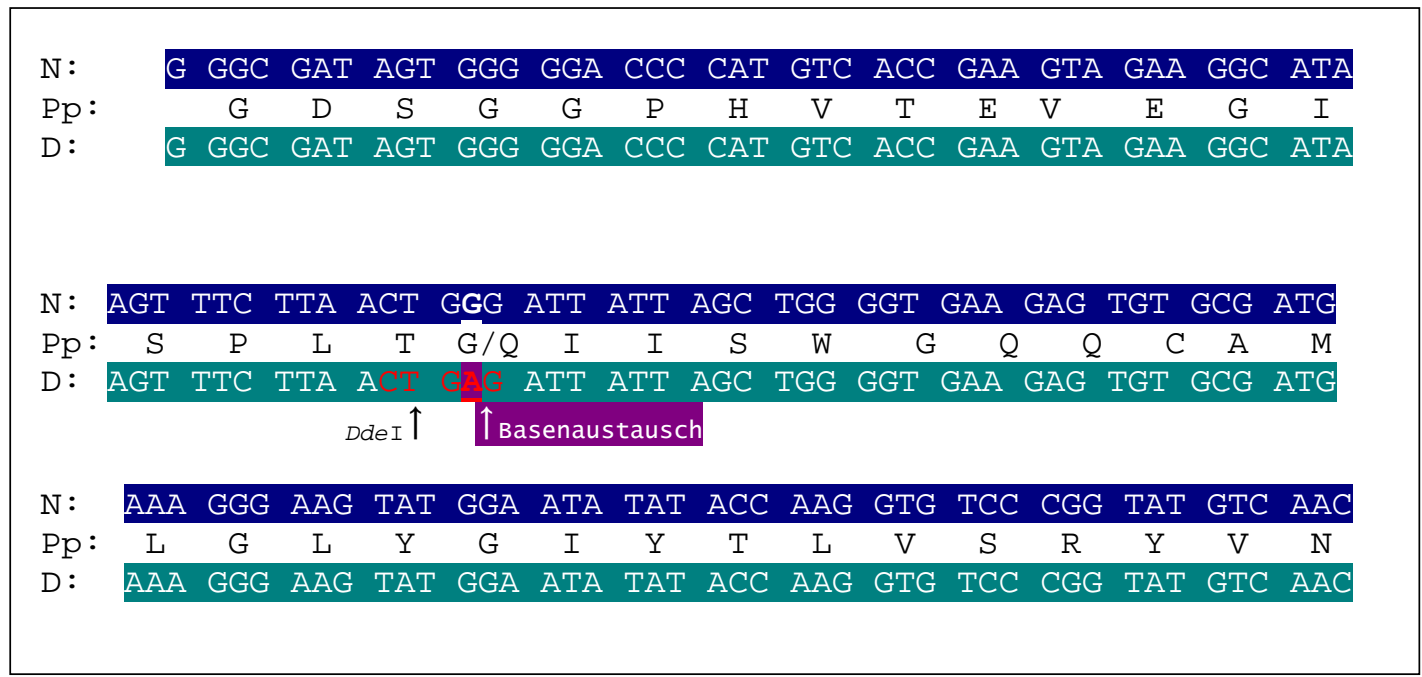

Abb. 15 133-bp-Fragment aus Exon 8 des Faktor IX Gens. N: normale Sequenz, D: defekte Sequenz, von Substitution betroffenes Nukleotid fett gedruckt und violett markiert, rote Schrift: durch Substitution entstandene DdeI-Erkennungssequenz, Restriktionsschnittstelle durch Pfeil gekennzeichnet.

\section{IV.c Genotypisierung für Hämophilie B bei Cairn Terriern}

Der Nachweis der beschriebenen Substitution kann per Amplifikation eines 133-bpFragments aus Exon 8 und anschließende RFLP-Typisierung erfolgen. Der RFLP beruht auf einer Erkennungssequenz für DdeI im Defektallel, die durch die Substitution entsteht (Evans et al. 1989a)(Evans et al. 1989a)(Evans et al. 1989a)(Evans et al. 1989a)(Evans et al. 1989a)(Evans et al. 1989a)(Evans et al. 1989a)(Evans et al. 1989a)(Evans et al. 1989a)(Evans et al. 1989a)(Evans et al. 1989a).

\section{III.d Ursächliche Mutation für Hämophilie B bei Lhasa Apsos}

In einer Hämophilie-B-Lhasa-Apso-Kolonie konnte die Cairn-Terrier-Mutation (Evans et al. 1989a) als Ursache der Hämophilie B ausgeschlossen werden (Mauser et al. 1996). Stattdessen liegt eine Deletion der Nukleotide 772-776 und ein Basenaustausch von Cytosin durch Thymin an Nukleotidposition 777 der codierenden Sequenz vor (Abb. 16), der zu einem verfrühten Stoppcodon an Aminosäurenposition 146 des prozessierten inaktivierten Proteins führt. Bei der Prozessierung von Faktor IX werden die ersten 39 Aminosäuren abgespalten. Die resultierende mRNA unterscheidet sich zwar im Northern Blot bezüglich ihrer Größe nicht von normaler mRNA, die Mutation scheint jedoch zu Instabilität zu führen, da die Menge an detektierter mRNA von Hämophilie-B-Hunden gegenüber normaler mRNA deutlich reduziert ist. 


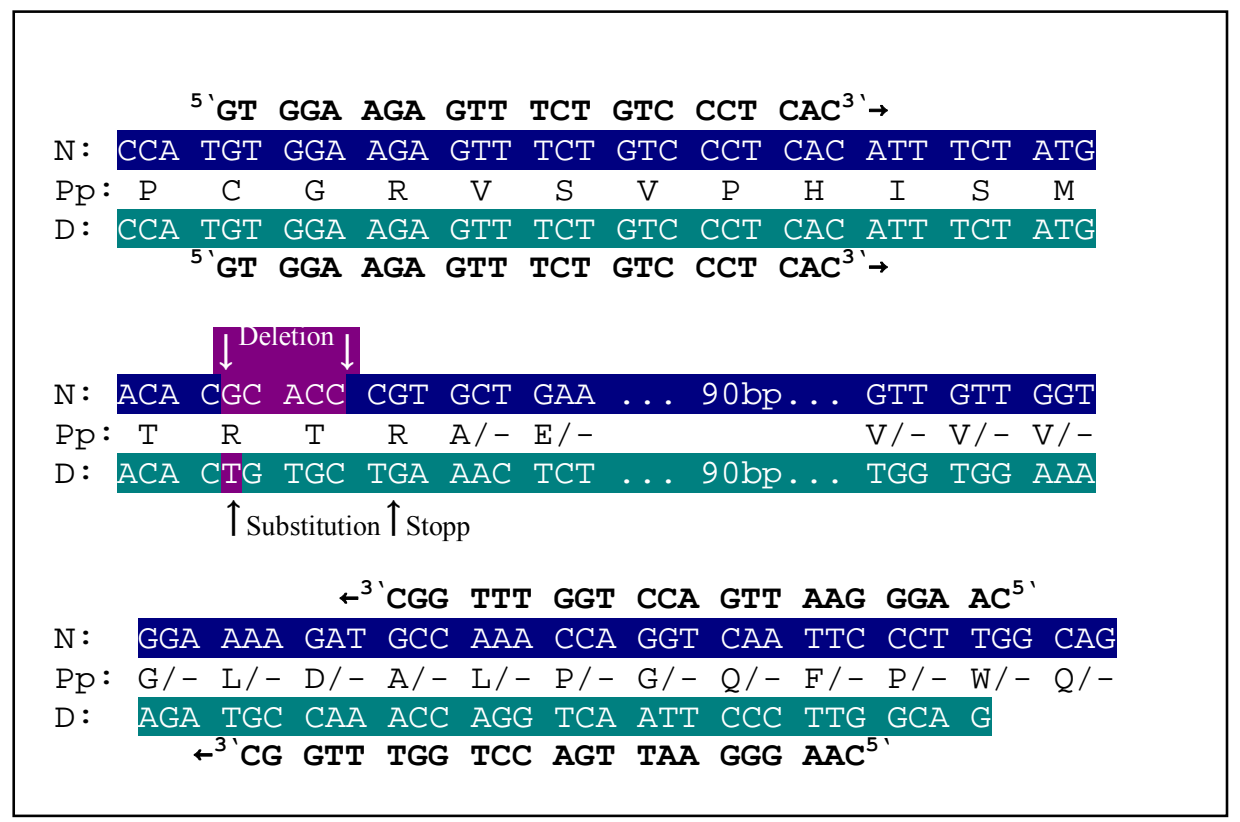

Abb. 16 Sequenzfragment aus Exon 6 des Faktor-IX-Gens. N: normale Sequenz, D: defekte Sequenz, Pp: Polypeptidsequenz, von Deletion betroffener Bereich violett markiert und durch Pfeile gekennzeichnet, von Substitution $\mathrm{C}$ zu $\mathrm{T}$ betroffenes Nukleotid violett markiert und durch Pfeile gekennzeichnet, verfrühtes Stoppcodon fett gedruckt unterstrichen und violett gekennzeichnet.

\section{IV.d Genotypisierung für Hämophilie B bei Lhasa Apso Hunden}

Heterozygote Defektträger können beispielsweise mittels einer Heteroduplexanalyse identifiziert werden. Dabei wird vom Wildtypallel ein 181-bp-Fragment und vom Defektallel ein 176-bp-Fragment amplifiziert. Bei Vorliegen beider Allele entstehen Heteroduplices von 225 bp Länge (Mauser et al. 1996).

\section{III.e Ursächliche Mutation für Hämophilie B bei Labrador Retrievern}

Bei einem Labrador Retriever aus einer Familie mit gehäuftem Auftreten von Hämophilie B wurde eine vollständige Deletion des Faktor-IX-Gens nachgewiesen (Brooks et al. 1997).

Das Ergebnis einer Southern-Blot-Hybridisierung von EcoRI-gespaltener, genomischer DNA mit einer aus caniner Faktor-IX-cDNA hergestellten Sonde deutet auf eine große, die gesamte codierende Sequenz des Faktor IX betreffende Deletion hin. Während bei der Probe eines normalen Kontrollhundes vier Fragmente detektiert werden, liefert die Probe eines Hämophilie-B-Labradors kein einziges Hybridisierungssignal. Für eine genauere Eingrenzung der deletierten Bereiche wurden anhand der humanen Sequenz homologe Primer für die Amplifikation der Exons 1 und 8 generiert. Während aus der DNA eines normalen Kontrollhundes zwei Fragmente in der erwarteten Größe 
amplifiziert wurden, konnte aus der DNA-Probe eines betroffenen Labradors mit dem Primerpaar für Exon 1 gar kein Amplifikat erzielt werden. Mit dem für Exon 8 entwickelten Primerpaar wurde ein um ca. 100 bp zu großes Fragment amplifiziert, das in Southern Blot Untersuchungen als das Ergebnis eines unspezifischen Primerannealings identifiziert werden konnte. Das so ermittelte Vorliegen einer vollständigen Deletion des Faktor-IX-Gens steht mit dem diagnostizierten vollständigen Verlust der Faktor-IX-Aktivität bei betroffenen Labradoren in Einklang. Es scheint sich bei dieser Mutation jedoch nicht um einen bei Labradoren weit verbreiteten Defekt zu handeln, denn bei einem fünf Jahre nach dem untersuchten Labrador eingelieferten Labrador mit Hämophilie B konnte diese Mutation als Ursache der Erkrankung ausgeschlossen werden (Brooks et al. 1997).

\section{III.f Ursächliche Mutation für Hämophilie B bei Airdale Terriern}

Bei sechs Airdale Terriern (einem Hämophilie-B-Rüden und fünf seiner aus Verpaarungen mit Defektträger-Hündinnen hervorgegangenen Nachkommen) konnte eine ca. $5 \mathrm{~kb}$ große Insertion in Exon 8 als Ursache der Erkrankung identifiziert werden (Gu et al. 1999).

Ergebnisse von Southern-Blot-Vergleichen zwischen EcoRI-gespaltener und mit einer caninen Faktor-IX-cDNA-Sonde hybridisierter genomischer DNA von normalen und Hämophilie-B-Airdale-Terriern deuteten auf das Vorliegen einer großen Genstrukturänderung hin. Während bei normalen Hunden vier Banden in Größen zwischen 5,6 und 2,6 kb nachzuweisen waren, fehlte die 2,6-kb-Bande bei betroffenen Airdale Terriern, die stattdessen zwei neue Banden von 0,5 kb und >5,6 kb aufwiesen. Zur Bestimmung des mutierten Genbereiches wurden verschiedene PCRs mit dem Ziel der Amplifizierung der einzelnen Exons durchgeführt. Die dabei eingesetzten Primer wurden auf Basis von caniner Faktor-IX-cDNA entwickelt. Die Amplifikation der Exons 1-7 erbrachte für normale und betroffene Hunde übereinstimmend die erwarteten Ergebnisse. Exon 8 ließ sich unter normalen PCR-Bedingungen bei betroffenen Airdale Terriern im Gegensatz zu gesunden Airdale Terriern nicht amplifizieren. Eine Optimierung der Bedingungen für die Amplifikation großer Fragmente erbrachte ein PCR-Produkt von $7 \mathrm{~kb}$. Durch Sequenzierung konnte ermittelt werden, dass bei betroffenen Hunden eine ca. 5 kb große Insertion nach Nukleotid 1471 vorliegt (Basis für Numerierung: NCBI-Sequence: M21757). Die Insertion beginnt am 5'-Ende mit 
einer Poly-Thyminsequenz und endet am 3'-Ende mit der Sequenz GGCATAAGTTTCTT, die eine direkte Wiederholung der 15-bp-Sequenz unmittelbar vor der Insertion darstellt.

Die Größe der Insertion und das Vorliegen einer Multiplikationssequenz sprechen dafür, dass der Mechanismus der vorliegenden Mutation in der Retroposition eines LINE-1Elementes besteht. Die Insertion führt zur Entstehung einer neuen Spleißerkennungssequenz, wobei die Donorposition 5' der Insertion und die Akzeptorposition in der 3'-UTR lokalisiert ist. Dadurch gehen beim Spleißen mehr als 150 Basen des Exons 8 und der größte Teil der 3'-UTR verloren. Die resultierende mRNA codiert eine abnormale Sequenz nach Glycin 355 bestehend aus Substitutionen von Lysin 356 und Asparaginsäure 357 durch Glutamin und Valin und einem anschließenden Stoppcodon (Abb. 16). Aminosäure 357 entspricht der humanen Aminosäure 359, die an der spezifischen Interaktion mit einer Seitenkette des Faktors X beteiligt ist. Die Wirkung einer Mutation an dieser Position oder die aufgrund des Stoppcodons fehlende Fortsetzung der restlichen katalytischen Region des Exons 8 werden als ausreichend schwerwiegend eingeschätzt, um die schweren klinischen Anzeichen und die vollständige Faktor-IX-Defizienz bei betroffenen Airdale Terriern zu verursachen (Gu et al. 1999).

\section{IV.f Genotypisierung für Hämophilie B bei Airdale Terriern}

Der Nachweis kann über eine ASP erfolgen (Abb. 17). Der Vorwärtsprimer F9-8f hybridisiert in der 5'-Region des Exons 8. Der reverse Primer F9-8r3 hybridisiert beim Wildtypallel in der 3'-UTR, beim Defektallel in Intron 8. Vom Wildtypallel wird durch die Kombination der Primer F9-8f und F9-8r3 ein 907-bp-Fragment amplifiziert. Durch die 5-kb-Insertion ist im mutierten Allel der Abstand zwischen den Primern zu groß, so dass mit dieser Kombination keine Amplifikation möglich ist. Der Vorwärtsprimer F924 hybridisiert in der Insertion und amplifiziert mit dem reversen Primer F9-8r3 vom mutierten Allel ein 569-bp-Fragment (Gu et al. 1999). 


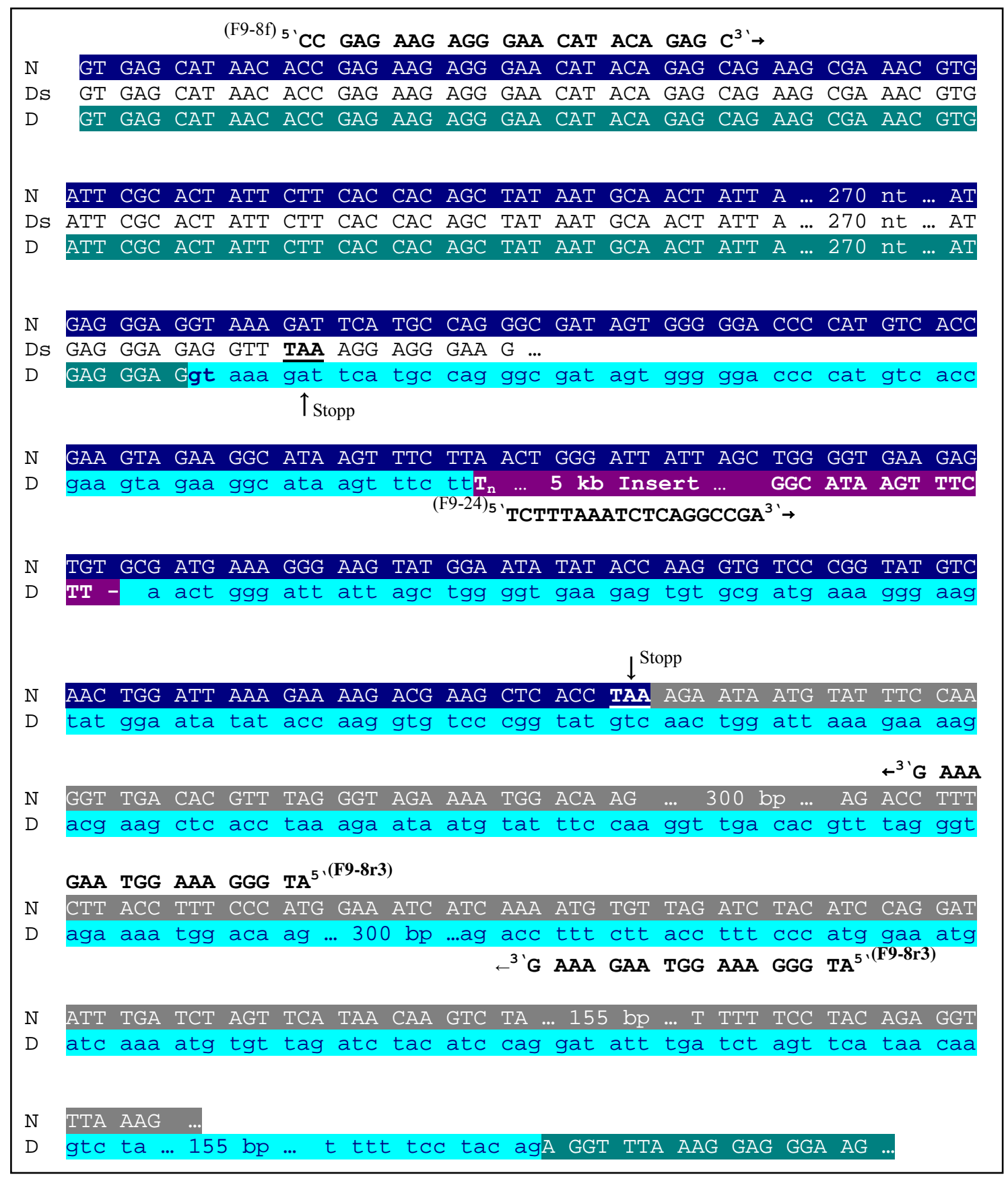

Abb. 17 Exon 8 des Faktor IX Gens mit 3'UTR. N: normale Sequenz, D: defekte Sequenz, Ds: defekte Sequenz nach dem Spleißen, dunkelblau: Exon normale Sequenz, grau: 3'UTR normale Sequenz, dunkelgrün: Exon defekte Sequenz, türkis: Intron defekte Sequenz, violett: Insertion, F9-8f: Vorwärtsprimer für die Amplifikation des intakten Exons 8, F9-24: insertionsspezifischer Vorwärtsprimer für die Amplifikation eines Fragments der mutierten Sequenz, F9-8r3: reverser Primer für beide Amplifikationen, Stoppcodons und Spleißorte durch Pfeile bezeichnet, bzw. in der Ds Sequenz unterstrichen und fett gedruckt.

\section{III.g Ursächliche Mutation für Hämophilie B bei Pit-Bull-Mischlingen}

Bei zwei von Hämophilie B betroffenen Pit-Bull-Mischlingswurfgeschwistern wurde eine Deletion der Exons 1-6 des Faktor-IX-Gens nachgewiesen (Gu et al. 1999). 
Im Southern Blot unter Verwendung einer Faktor-IX-cDNA Sonde ergab sich für die Proben der betroffenen Pit-Bull-Mischlinge im Unterschied zu den DNA-Proben eines Hämophilie-B-Airdale-Terriers und eines normalen Hundes nur eine einzelne Bande von 2,6 kb. Die Folgerung daraus ist das Vorliegen einer schweren Genstrukturänderung, die sich von der beim Airdale Terrier gefundenen Mutation unterscheidet. Verschiedene PCRs, die nach dem oben beschriebenen Muster zur Amplifikation der einzelnen Exons entwickelt wurden, erbrachten keinerlei PCRProdukte für die Exons 1-6, während die Amplifikation der Exons 7 und 8 zu Fragmenten von der erwarteten Größe führte. Demnach liegt bei den betroffenen PitBull-Mischlingen eine Deletion der Exons 1-6 vor. Zur genaueren Bestimmung der deletierten Region wurde eine weitere PCR unter Verwendung von Vorwärtsprimern für die 5'- und die 3'-Region des Exons 6 und des für die Amplifikation von Exon 7 konstruierten reversen Primers durchgeführt. Bei DNA-Proben von normalen Hunden ergaben sich Amplifikate, die Intron 6 enthielten. Bei den betroffenen Pit-BullMischlingen wurde mit dieser Primerkombination keine Amplifikation erreicht. Die Deletion schließt demnach die Exons 1-6 vollständig ein und endet an einer nicht näher definierten Position zwischen Intron 6 und der Position des Primers F9-7f $\left({ }^{5}\right.$ CCTTTTGAATGGGAAAGTTGATGC $\left.{ }^{3}\right)$, des Vorwärtsprimers für die Amplifikation von Exon 7. Bis Ergebnisse aus aktuellen Studien zur Charakterisierung des caninen Faktor-IX-Gens verfügbar sind, ist die von der Deletion betroffene Region als beginnend bei der 5'-UTR des Faktor-IX-Gens und wahrscheinlich mehr als $30 \mathrm{~kb}$ umfassend zu beschreiben. Wie zu erwarten führt diese Deletion dazu, dass Faktor IX bei den betroffenen Pit-Bull-Mischlingen nicht nachweisbar ist. Da keine weiteren verwandten Hunde der betroffenen zwei Pit-Bull-Mischlinge zu Verfügung standen, wurden keine weiterführenden Untersuchungen der Mutation durchgeführt ( $\mathrm{Gu}$ et al. 1999).

\section{III.h Ursächliche Mutation für Hämophilie B bei Deutsch Drahthaar Vorstehhunden}

Bei Deutsch Drahthaar Vorstehhunden segregiert eine LINE-1-Insertion in Intron 5 des caninen Faktor-IX-Gens (Abb. 18) mit einem milden Phänotyp der Hämophilie B, der sich bei hemizygoten männlichen Defektträgern in einer Faktor-IX-Aktivität von ca. $5 \%$ manifestiert (Brooks et al. 2003). 
In einem 50 Deutsch Drahthaar Vorstehhunde umfassenden Pedigree, bestehend aus 19 gesunden und sechs Hämophilie-B-Rüden sowie neun sicheren und 16 möglichen Defektträgerhündinnen, konnten bezüglich der beschriebenen Mutation die folgenden Genotypen ermittelt werden: Die neun sicheren und eine der 16 möglichen Defektträgerhündinnen sowie alle sechs Defektträgerrüden sind Träger der Insertion. Bei den weiteren untersuchten gesunden Rüden und möglichen Defektträgerhündinnen ist die Insertion nicht nachzuweisen. Nach dem bereits bei den oben beschriebenen Untersuchungen von Airdale Terriern und Pit-Bull-Mischlingen angewendeten Muster wurde ein Southern Blot Vergleich zwischen EcoRI-gespaltener genomischer DNA von normalen Mischlingshunden und Hämophilie-B-Deutsch-Drahthaar-Vorstehhunden durchgeführt. Wie in der oben beschriebenen Studie ergab die Hybridisierung mit caniner Faktor-IX-cDNA bei DNA-Proben von normalen Hunden vier Banden mit Größen von 2,6, 4,3, 4,8 und 5,6 kb. Das Bandenmuster bei Hämophilie-B-Hunden unterscheidet sich von dem normalen Muster durch das Fehlen der 4,3-kb-Bande und die abnormale Hybridisierung einer 5-kb-Bande. Dieses Ergebnis ist als Hinweis auf das Vorliegen einer weiteren großen Insertion oder Deletion zu deuten, die von bisher bekannten großräumigen Mutationen bei Airdales und Pit-Bull-Mischlingen abweicht (Gu et al. 1999). Nach demselben Schema und unter Verwendung derselben Primer wie in der oben zusammengefassten Studie von Gu et al. (1999) wurde zur Eingrenzung des von der Mutation betroffenen Bereiches die systematische Amplifikation der einzelnen Exons des Faktor-IX-Gens vorgenommen. Da bezüglich der Größe der amplifizierten Fragmente zwischen normalen und Hämophilie-B-Hunden keinerlei Unterschiede erkennbar waren, wurde die Suche nach der betroffenen Genregion mittels Amplifikation der Introns fortgesetzt. Hier ergab sich bei der Amplifikation von Intron 5 unter Verwendung des Primerpaares 5f/6r (Gu et al. 1999) bei Hämophilie-B-Hunden ein ca. 3,5-4 kb großes PCR-Produkt, während von DNA-Proben gesunder Hunde ein 2,5-kb-Fragment amplifiziert wird. Das mutierte Fragment weist Sequenzparallelen zu Exon 5 und 6 der caninen cDNA (NCBI-GenBank: M21757) sowie zu Intron 5 (NCBIGenBank: U94338) auf. Die Parallelen zu den Exons 5 und 6 entsprechen den Sequenzbereichen zwischen Nukleotid 647-722 bzw. 874-897 der caninen Faktor-IXcDNA. Die Intron-5-Sequenz des mutierten Fragments unterscheidet sich von der normalen Sequenz durch eine 1,5 kb Insertion nach Nukleotidposition 2071. Die Sequenz der Insertion weist auffallende Ähnlichkeiten mit dem ORF2 der caninen 
LINE-1-Sequenz (L1) (NCBI-Sequenz: AB012223) auf, die insbesondere die Nukleotide 1-351 und Nukleotide 349-1041 des Inserts betreffen. Im Einzelnen handelt es sich um eine 96 \%ige Übereinstimmung mit der reversen komplementären Sequenz der LINE-1-Nukleotide 3167-3517 bzw. eine 97 \%ige Übereinstimmung mit den Nukleotiden 3505-4198 der LINE-1-Sequenz. Im Vergleich zur LINE-1 Sequenz ist das Insert am 5'-Ende angeschnitten. Die lange Polyadenylierungssequenz am 3'-Ende und die 15-bp-Duplikation zu beiden Seiten der Insertion sind typische Merkmale einer LINE-1-Integration nach Kazazian (2000). Die Sequenz des Introns ist unter NCBI (GenBank: AY266086) veröffentlicht.

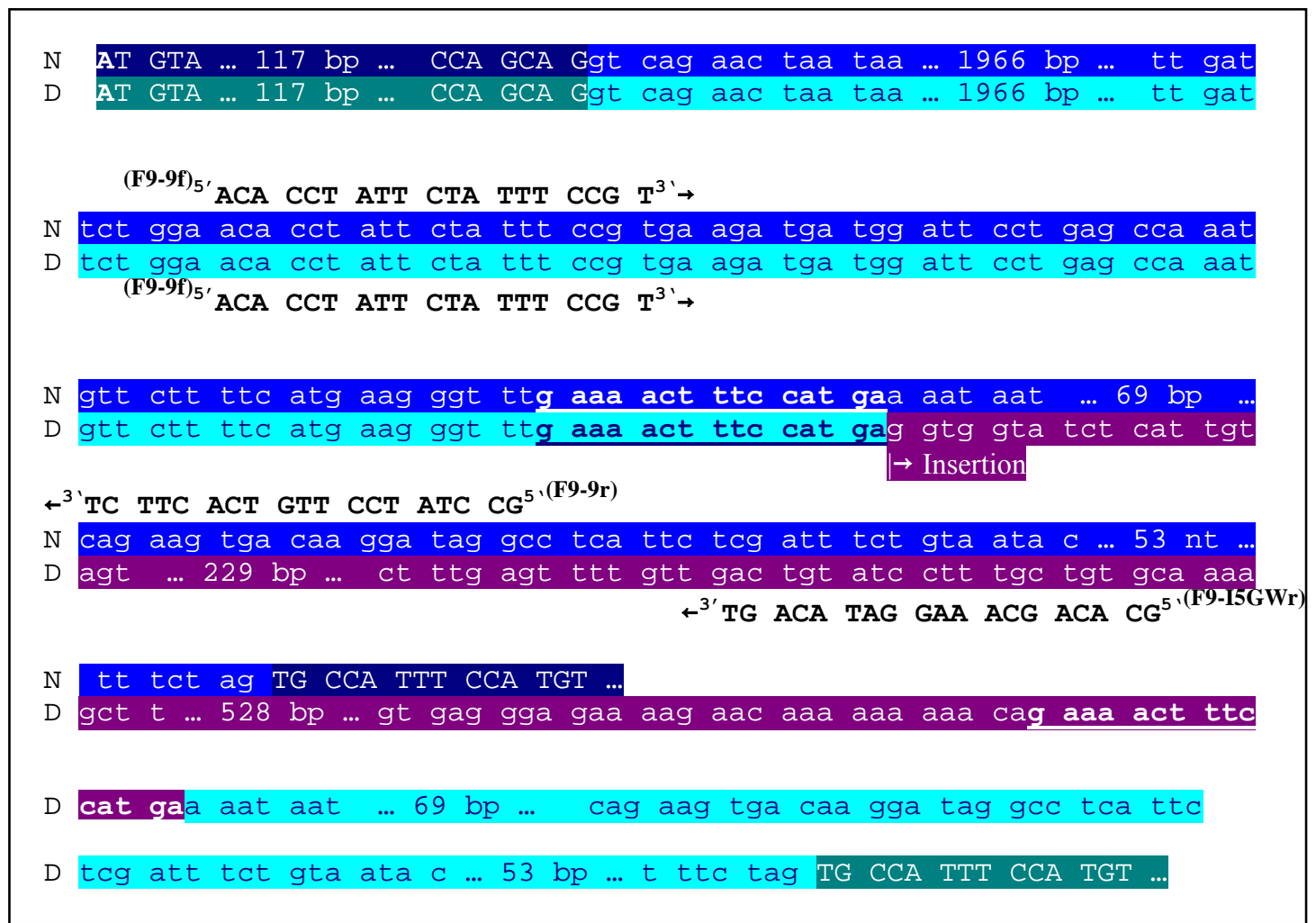

Abb. 18 Faktor-IX-Gensequenz von Exon 5 bis Anfang Exon 6. N: normale Sequenz, D: defekte Sequenz, dunkelblau: Exon normale Sequenz, dunkelgrün: Exon defekte Sequenz, hellblau: Intron normale Sequenz, türkis: Intron defekte Sequenz, LINE-1 Insertion violett markiert, Insert flankierender 15-bp-Duplikation: fett gedruckt und unterstrichen, Intron-Exon- bzw. Intron-Insert-Grenzen durch Pfeile markiert F9-9f: Vorwärtsprimer, F9-I5GWr: insertspezifischer Reversprimer zur Amplifikation eines 362-bp-Fragments von Hämophilie B DNA, F9-9r: Reversprimer zur Amplifikation eines 187-bpFragments aus Intron 5 von normaler DNA.

Da bisher noch keine mRNA-Untersuchung stattgefunden hat, konnte der Effekt der Insertion auf das Transkript nicht untersucht werden. Da die codierende Sequenz des Faktor-IX-Gens bei betroffenen Drahthaar Vorstehhunden nicht verändert ist, die Insertionsstelle etwa 180 bp von der Exon-6-Spleißposition entfernt ist und das Polyadeninsignal der Insertion als schwach eingeschätzt wird, ist eine in die 
flankierende 3'-DNA hinein reichende RNA-Transkription nicht unwahrscheinlich. So ist kein vollständiger Verlust des codierten Proteins zu erwarten. Diese Überlegungen passen zu der bei betroffenen Hunden gemessenen Faktor-IX:C-Aktivität von $5 \%$.

\section{IV.h Genotypisierung für Hämophilie B bei Deutsch Drahthaar Vorstehhunden}

Die Identifizierung heterozygoter Defektträger kann über eine Multiplex-PCR erfolgen, die aus genomischer DNA bei normalen Hunden ein 187-bp-Fragment und bei betroffenen Hunden ein 362-bp-Fragment amplifiziert. Bei heterozygoten Defektträgern werden beide Fragmente amplifiziert. Verwendete Primer sind der Vorwärtsprimer F99f und der reverse Primer F9-9r sowie als zweiter reverser Primer, der in der Insertion hybridisiert und daher spezifisch für das Defektallel ist, der Primer F9-I5GWr (Abb. 18) (Brooks et al. 2003). 


\subsubsection{Weitere Faktormangelerkrankungen}

Als weitere Gerinnungsfaktormangelerkrankungen kommen bei Hunden Faktor-VIIund Faktor-XI-Mangel vor. Während beim Faktor-XI-Mangel wie bei der Hämophilie das intrinsische Gerinnungssystem gestört ist, ist beim Faktor-VII-Mangel das extrinsische oder Gewebe-Gerinnungssystem betroffen.

\subsubsection{Faktor-XI-Defizienz}

\begin{tabular}{|ll|}
\hline Chromosom: & CFA16 \\
Gen: & F11 (Faktor 11) \\
Ensembl: & GeneID: ENSCAFG00000007348 \\
DNA-Sequenz: & CFA16, Position 47430949-47447575 \\
Mutationen: & 90-bp-SINE-Insertion, Exon 7, Kerry Blue Terrier \\
\hline
\end{tabular}

\section{Krankheitsbild}

Die Symptome der Faktor-XI-Defizienz sind den Erscheinungen bei milderen Formen der beiden oben beschriebenen Störungen des intrinsischen Gerinnungssystems sehr ähnlich. Bei betroffenen Hunden kommt es zu späten posttraumatischen oder postoperativen Blutungen. Außerdem können Linsentrübungen auftreten. Es liegen verlängerte partielle Thromboplastinzeiten vor, während die Prothrombinzeiten im Referenzbereich liegen (Knowler et al. 1994; Tcherneva et al. 2006). Die Werte für Faktor-XI-Aktivität schwanken zwischen den einzelnen Hunden stark, heterozygote Träger des Defektallels können auf dieser Basis nicht eindeutig identifiziert werden. Betroffen sind vor allem Kerry Blue Terrier (Dodds 1988; Knowler et al. 1994). In dieser Rasse wurde ein hoher Anteil an betroffenen Hunden beobachtet. Zahlen zur Häufigkeit der Erkrankung werden nicht genannt (Knowler et al. 1994). Einzelne Fälle von Faktor-XI-Defizienz traten außerdem bei Englischen Springer Spaniels (Dodds und Kull 1971) und Pyrenäenberghunden auf (Dodds 1988).

\section{Genetischer Hintergrund}

Die Vererbung der Faktor-XI-Defizienz erfolgt autosomal rezessiv (Tcherneva et al. 2006). Laut der ENSEMBL Datenbank (Ensembl-GeneID: ENSCAFG00000007348) und in Übereinstimmung mit Tcherneva et al. (2006) umfasst das canine Faktor-XI-Gen auf einer Gesamtlänge von 16455 bp 14 Exons. Die cDNA ist 1901 bp lang. Das 
resultierende Protein umfasst 625 Aminosäuren. Das Gen ist auf Chromosom 16 zwischen Position 47430949 und 47447575 lokalisiert. Die Lage der einzelnen Exons innerhalb der genomischen Sequenz ist in Abb. 19 schematisch dargestellt.

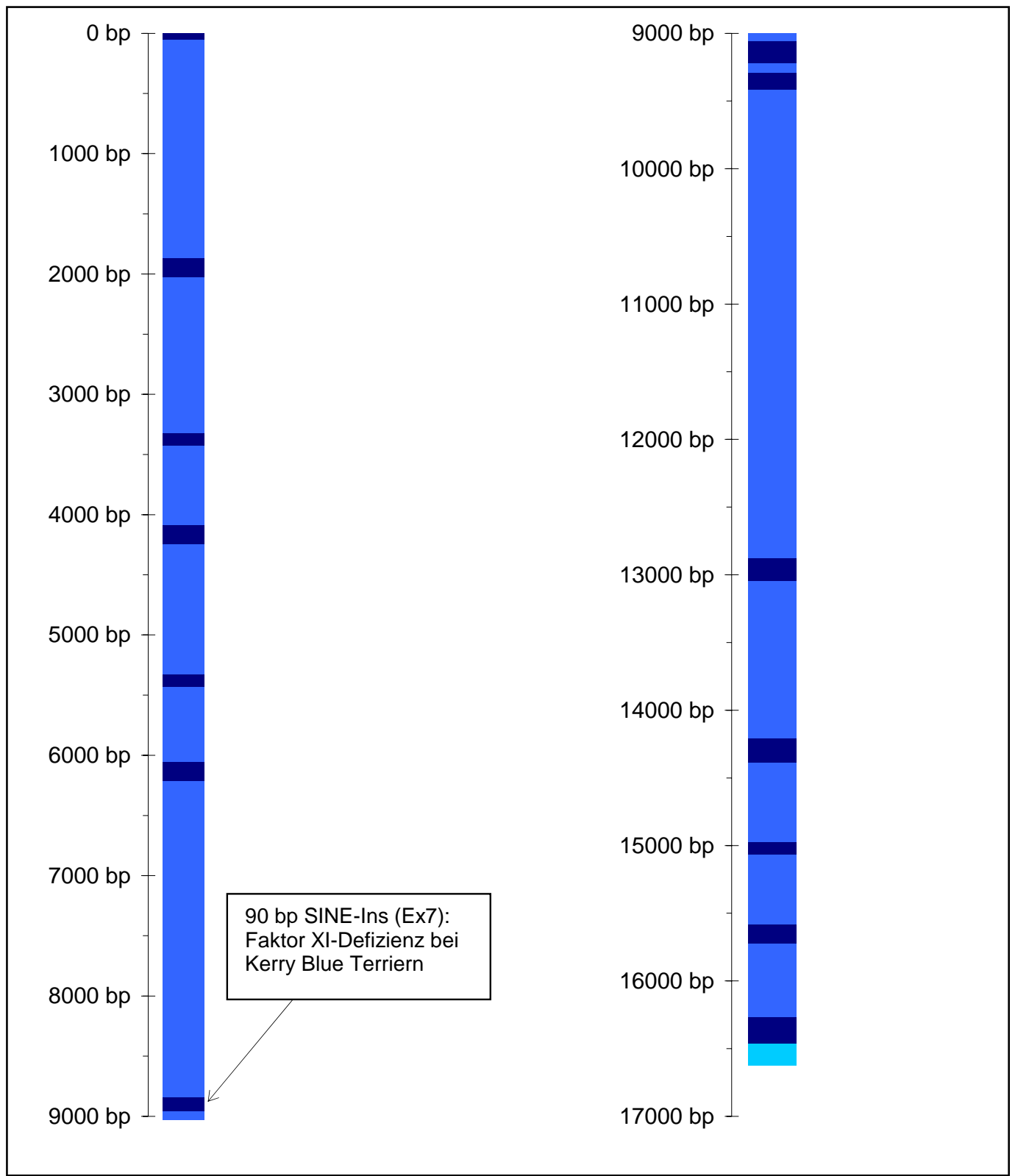

Abb. 19 Schematische Darstellung des für den caninen Faktor XI codierenden Gens. Dunkelblau: codierende Sequenz, hellblau: Intron, türkis: 3'-UTR.

\section{Ursächliche Mutation für Faktor-XI-Defizienz bei Kerry Blue Terriern}

Die molekulargenetischen Grundlagen der Faktor-XI-Defizienz bei Kerry Blue Terriern sind geklärt, aber noch nicht detailliert veröffentlicht. Es handelt sich um eine 90-bpSINE-Insertion im siebten Exon, die hauptsächlich aus Lysin codierenden Adeninen 
besteht. Möglicherweise beeinflusst diese Insertion die dritte von insgesamt vier so genannten Apple-Domänen des FXI-Gens. Der Effekt auf die Faktor-XI-Funktion muss noch näher untersucht werden (Tcherneva et al. 2006).

\subsubsection{Faktor-VII-Defizienz}

\begin{tabular}{|ll|}
\hline Chromosom: & CFA22 \\
Gen: & F7 (Faktor 7) \\
NCBI: & GeneID: 607661 \\
DNA-Sequenz: & NW_876275, Position 4919328-4929521 \\
Mutationen: & G452A, Beagle \\
\hline
\end{tabular}

\section{Krankheitsbild}

Bei der caninen Faktor-VII-Defizienz handelt es sich um eine Störung des extrinsischen Gerinnungssystems. Betroffen sind vor allem stark ingezüchtete Linien aus der Rasse Beagle. Zahlen zur Häufigkeit der Erkrankung innerhalb dieser Rasse werden nicht genannt (Mustard et al. 1962a; Garner et al. 1967). Einzelne Fälle traten auch bei Alaskan Malamutes (Dodds 1974; Mills et al. 1997) und Mischlingshunden (Landi und Higson 1982; Macpherson et al. 1999) auf.

Betroffene Beagles zeigen unter normalen Umständen keine Blutungstendenz und keines der weiteren für Bluterkrankheiten typischen Symptome. Die betroffenen Tiere fallen in den meisten Fällen bei Blutuntersuchungen durch verlängerte Prothrombinzeiten auf und zeigen bei eingehenderen Untersuchungen eine Faktor-VIIAktivität zwischen 1-4 \% der bei normalen Hunden gemessenen Werte. Alle weiteren untersuchten Parameter liegen im Normbereich (Mustard et al. 1962a; Garner et al. 1967; Garner und Conning 1970; Spurling et al. 1972). In einzelnen Fällen kommt es bei betroffenen, pluriparen Beaglehündinnen $\mathrm{zu}$ Komplikationen während der Trächtigkeit in Form von schweren Blutungen aus der Scheide (Spurling et al. 1974; Wheeler et al. 1984). Warum es bei den betroffenen Hündinnen nach mehreren komplikationslosen Trächtigkeiten zu den beschriebenen schweren Blutungen kommt, konnte nicht geklärt werden. In einem Fall lagen eine Entzündung von Plazentagewebe und einige geschwürartig veränderte Bereiche in der Vagina vor, durch die das Auftreten der Blutungen möglicherweise begünstigt wurde (Wheeler et al. 1984). Ebenso wie bei Beagles sind auch bei den meisten Mischlingshunden mit Faktor-VIIMangel unter normalen Umständen keine klinischen Anzeichen zu beobachten (Landi 
und Higson 1982). Lediglich bei einem der betroffenen Mischlingshunde wurde die Hämostasestörung bereits im Alter von fünf Monaten diagnostiziert. Der Rüde wurde aufgrund starker Blutungen während und nach einer Orchiektomie auffällig. Blutuntersuchungen ergaben wie bei den betroffenen Beagles eine verlängerte Prothrombinzeit und eine auf 1,6 \% des Normwertes herabgesetzte Faktor-VIIAktivität. Bemerkenswerterweise beschränkte sich bei dem beschriebenen Rüden die Blutungsneigung auf den unteren Urogenitaltrakt. Bei einer zur selben Zeit durchgeführten Entfernung eines Milchzahnes traten keinerlei Komplikationen auf. Die Ursache für diese lokalisierte Blutungstendenz ist möglicherweise ein in bestimmten Bereichen des Kreislaufs gestörtes Gleichgewicht zwischen Fibrinogenbildung und auflösung (Macpherson et al. 1999). Die bekannten Fälle bei Alaskan Malamutes haben einen schwereren Verlauf. Betroffene Hunde zeigen mittelschwere Blutungsepisoden, deren Verlauf im ersten beschriebenen Fall durch das zusätzliche Vorliegen einer Hundestaupeerkrankung erschwert wurde (Dodds 1974), sowie Blutergüsse in den Beinen und im Leistenbereich, Zahnfleischbluten und subkutane Blutungen (Mills et al. 1997).

\section{Genetischer Hintergrund}

Der Erbgang der Faktor-VII-Defizienz bei Beagles ist autosomal rezessiv (Mustard et al. 1962b). Das canine Faktor-VII-Gen setzt sich aus 8 Exons zusammen (Callan et al. 2005) und ist auf Chromosom 22 lokalisiert (NCBI-GeneID: 607661, NW_876275: Position 4919328 - 4929521). Die Lage der einzelnen Exons innerhalb der genomischen Sequenz ist in Abb. 20 schematisch dargestellt. 


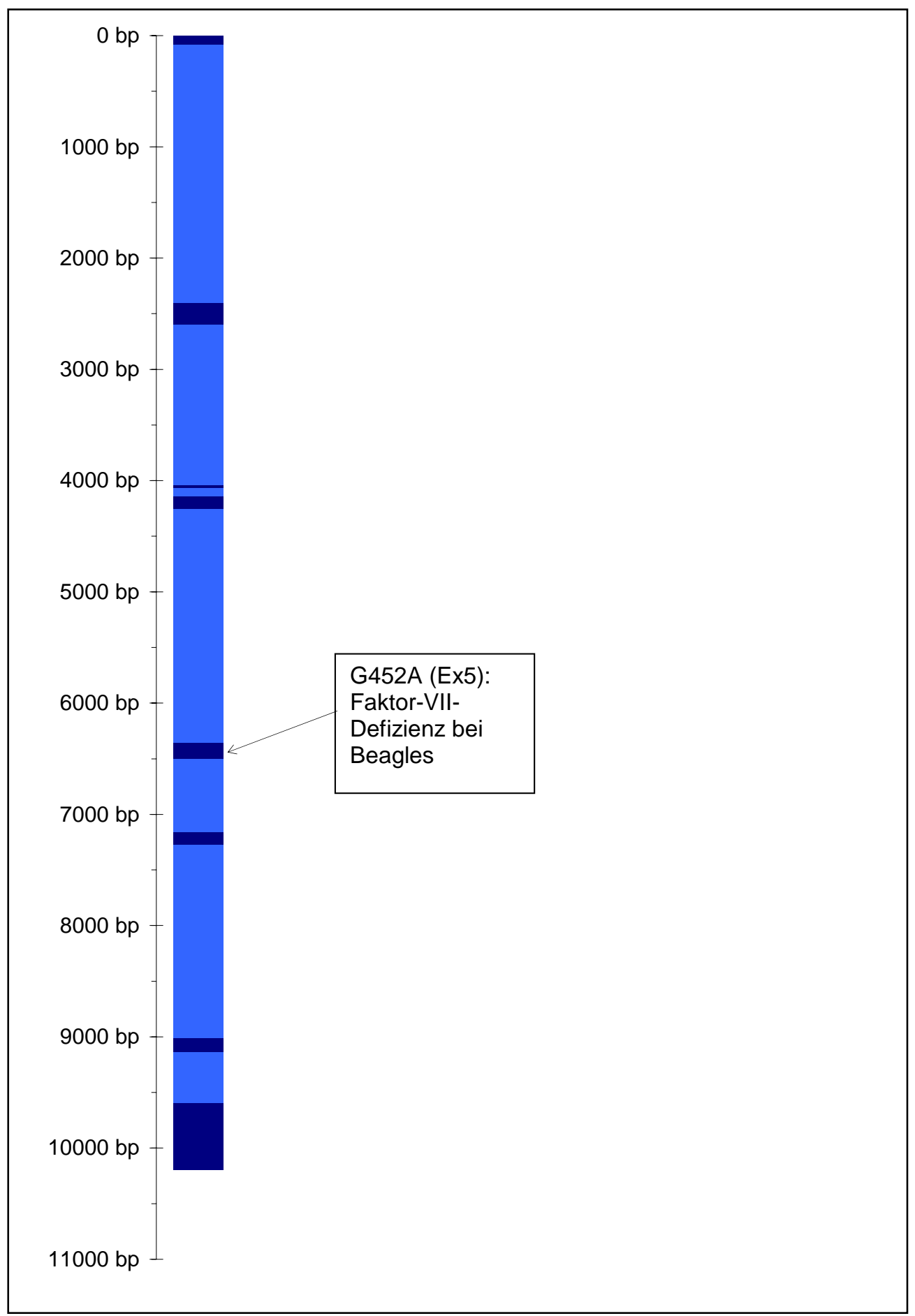

Abb. 20 Schematische Darstellung des caninen Faktor VII-Gens und Lage der bisher identifizierten Mutationen. Dunkelblau: codierende Sequenz, hellblau: Intronsequenz.

\section{Ursächliche Mutation der Faktor VII Defizienz bei Beagles}

Bei Faktor-VII-defizienten Beagles ist die dem Defekt zugrunde liegende Mutation in Exon 5 lokalisiert (Abb. 21). Es handelt sich um die Substitution eines Guanins durch Adenin an Position 452 der mRNA, die eine Substitution der Aminosäure Glycin durch Glutamat nach sich zieht (Callan et al. 2005). Bei Expressionsversuchen mit 
transfizierten HEK-Zellen ist nach 48 Stunden in den Überständen von Zellen, die mutierten Faktor VII exprimieren, eine wesentlich geringere Faktor-VII-Aktivität nachzuweisen als in Überständen von Zellen, die normalen Faktor VII exprimieren.

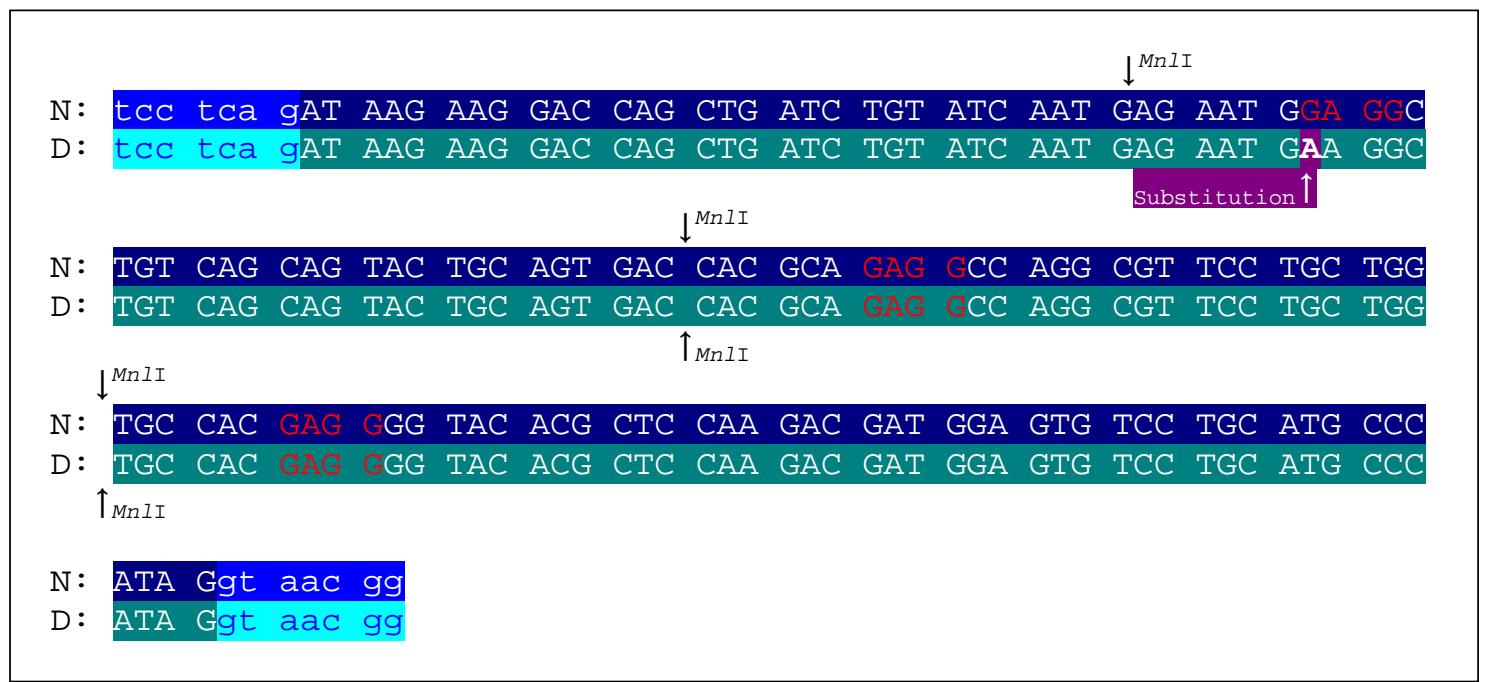

Abb. 21 Exon 5 des caninen Faktor-VII-Gens und angrenzende Intronsequenzen. N: normale Sequenz, D: defekte Sequenz, dunkelblau: Exon normale Sequenz, dunkelgrün: Exon defekte Sequenz, hellblau: Intron normale Sequenz, türkis: Intron defekte Sequenz, Substitution in defekter Sequenz violett unterlegt und durch Pfeil gekennzeichnet, MnlI-Schnittstellen durch Pfeile gekennzeichnet, rote Schrift: MnlIErkennungssequenz.

\section{Genotypisierung für Faktor-VII-Defizienz bei Beagles}

Der Nachweis der Mutation kann per Amplifikation eines Fragments des Exons 5 und anschließender Restriktionsspaltung mit MnlI erfolgen. Im Defektallel ist, verursacht durch die Substitution, im Gegensatz zum Wildtypallel keine MnlI-Erkennungssequenz vorhanden (Callan et al. 2005). 


\subsubsection{Primerliste}

Tabelle 4: Liste der in Kapitel 3.1 genannten Primer

\begin{tabular}{|c|c|c|c|c|}
\hline $\begin{array}{l}\text { Krankheit/ } \\
\text { Merkmal }\end{array}$ & Zweck & Primer & $\begin{array}{l}\text { PCR- } \\
\text { Produk } \\
\mathrm{t}[\mathrm{bp}]\end{array}$ & Quelle \\
\hline $\begin{array}{l}\text { Thrombopathie bei } \\
\text { Pyrenäenberghund } \\
\text { en }\end{array}$ & $\begin{array}{l}\text { diagnostische } \\
\text { Sequenzierung }\end{array}$ & $\begin{array}{l}\text { V: }{ }^{5^{\prime}} \text { GACATTGCAGTGGCTGCCCCC }{ }^{3} \\
\text { r: }{ }^{3^{\prime}} \text { ccctccggtccagtgttgagg }{ }^{5^{\prime}}\end{array}$ & 345 & $\begin{array}{l}\text { (Lipscomb } \\
\text { et al. 2000) }\end{array}$ \\
\hline $\begin{array}{l}\text { vWD I bei } \\
\text { Dobermännern, } \\
\text { Manchester } \\
\text { Terriern und } \\
\text { Pudeln }\end{array}$ & RFLP, patentiert & $\begin{array}{l}\text { V: }{ }^{5} \text { CTGTGAGGACAACTGCCTGCC }{ }^{3^{*}} \\
\text { r: }{ }^{3^{*}} \text { GAACTCATTAAAGGCCAAGTCCCGGT }\end{array}$ & 136 & $\begin{array}{l}\text { (US-Patent } \\
6780583 \text { ) }\end{array}$ \\
\hline $\begin{array}{l}\text { vWD II bei } \\
\text { Deutsch Kurzhaar } \\
\text { und Deutsch } \\
\text { Drahthaar }\end{array}$ & RFLP & $\begin{array}{l}\text { V: }:^{5^{\prime}} \text { GCGAGGTCCTACAGCAGGT }^{3^{\prime}} \\
\mathrm{r:}{ }^{3^{\prime}} \text { ACCACGATGTCTCCACG }^{5^{\prime}}\end{array}$ & 333 & $\begin{array}{l}\text { (Kramer et } \\
\text { al. 2004) }\end{array}$ \\
\hline $\begin{array}{l}\text { vWD III bei } \\
\text { Holländischen } \\
\text { Kooiker Hunden }\end{array}$ & ASO & $\begin{array}{l}\text { V: }{ }^{5} \text { ATGGTGAGATCTTTCAGCCCG }{ }^{3 \prime} \\
\text { r: }{ }^{3} \text { CTGGAGTCCTTACCGCCT }{ }^{5} \\
\text { ASO-Wt: }{ }^{5} \text { ACCATGTGGTAAGTGCG }{ }^{3 \prime} \\
\text { ASO-D: }{ }^{5^{\prime}} \text { CACCATGTGATAAGTGCGA }{ }^{3 \prime}\end{array}$ & 94 & $\begin{array}{l}\text { (van Oost et } \\
\text { al. 2004) }\end{array}$ \\
\hline $\begin{array}{l}\text { vWD III bei } \\
\text { Scottish Terriern }\end{array}$ & RFLP, patentiert & $\begin{array}{l}\text { V: }:^{5^{\prime}} \text { AAATGACAAAAGAGTGAGCCGGTC }{ }^{3^{\circ}} \\
\mathrm{r:}{ }^{3^{\circ}} \text { GGGCTGGCGACCAGTTCCTCTGAA }{ }^{5^{\circ}}\end{array}$ & 272 & $\begin{array}{l}\text { (US-Patent } \\
6780583 \text { ) }\end{array}$ \\
\hline $\begin{array}{l}\text { vWD III bei } \\
\text { Shetland } \\
\text { Schäferhunden }\end{array}$ & RFLP, patentiert & $\begin{array}{l}\text { V: }{ }^{5 \prime} \text { TCCTGTGGGAGCAGTGCCAG }{ }^{3} \\
\text { r: }{ }^{3 .} \text { ATGCCGACCTGGCTGGTG }^{5 *}\end{array}$ & 206 & $\begin{array}{l}\text { (US-Patent } \\
6780583 \text { ) }\end{array}$ \\
\hline $\begin{array}{l}\text { Hämophilie A bei } \\
\text { Redbone } \\
\text { Coonhounds, } \\
\text { Irischen Settern } \\
\text { und Schnauzern }\end{array}$ & $\begin{array}{l}\text { Amplifikation der } \\
\text { F8A-Sonde aus } \\
\text { BAC291M9 (zu } \\
\text { erwerben über: } \\
\text { http://bacpac.chor } \\
\text { i.org/) }\end{array}$ & $\begin{array}{l}\text { V: }{ }^{5^{\prime}} \text { GTCCCGCGTGCTGCTGCTGCTCCT }{ }^{3^{\prime}} \\
\text { r: }{ }^{3^{\prime}} \text { TCCTTCGGCACAGGGGCAGCCC }{ }^{5^{\prime}}\end{array}$ & 284 & $\begin{array}{l}\text { (Lozier et } \\
\text { al. 2002) }\end{array}$ \\
\hline $\begin{array}{l}\text { Hämophilie A bei } \\
\text { Golden Retrievern }\end{array}$ & Mikrosatellit F8C & $\begin{array}{l}\text { V: }:^{5^{*}} \text { GATCTAGTGCCTGTAAAAAC }{ }^{3^{*}} \\
\mathrm{r:}^{3^{*}} \text { GCACCAAGATCCACGTCC }^{5^{*}}\end{array}$ & $\begin{array}{l}265 \\
290 \\
296 \\
300 \\
305\end{array}$ & $\begin{array}{l}\text { (Brooks et } \\
\text { al. 2005) }\end{array}$ \\
\hline $\begin{array}{l}\text { Hämophilie B bei } \\
\text { Lhasa Apsos }\end{array}$ & $\begin{array}{l}\text { Heteroduplex- } \\
\text { analyse }\end{array}$ & $\begin{array}{l}\text { V: }{ }^{5 *} \text { GATCTAGTGCCTGTAAAAAC }{ }^{3 *} \\
\text { r: }{ }^{3 *} \text { GCACCAAGATCCCACGGTCC }{ }^{5 *}\end{array}$ & 181 & $\begin{array}{l}\text { (Mauser et } \\
\text { al. 1996) }\end{array}$ \\
\hline
\end{tabular}


Fortsetzung Tabelle 4: Liste der in Kapitel 3.1 genannten Primer

\begin{tabular}{|c|c|c|c|c|}
\hline $\begin{array}{l}\text { Krankheit/ } \\
\text { Merkmal }\end{array}$ & Zweck & Primer & $\begin{array}{l}\text { PCR- } \\
\text { Produkt } \\
\text { [bp] }\end{array}$ & Quelle \\
\hline \multirow{3}{*}{$\begin{array}{l}\text { Hämophilie B bei } \\
\text { Airdale Terriern }\end{array}$} & \multirow{3}{*}{ ASP } & $\begin{array}{l}\text { V (F98f): } \\
{ }^{5} \text { CCGAGAAGAGGGAACATACAGAG C }{ }^{3}\end{array}$ & \multirow[t]{2}{*}{907} & \multirow{3}{*}{$\begin{array}{l}\text { (Gu et al. } \\
\text { 1999) }\end{array}$} \\
\hline & & r (F9-8r3): ${ }^{34}$ GAAAGAATGGAAAGGGTA ${ }^{5}$ & & \\
\hline & & $\begin{array}{l}\text { V(F9-24): }:^{5^{4}} \text { TCTTTAAATCTCAGGCCGA }{ }^{3} \\
\text { r (F9-8r3): }:^{3^{*}} \text { GAAAGAATGGAAAGGGTA }{ }^{5}\end{array}$ & 569 & \\
\hline \multicolumn{2}{|c|}{$\begin{array}{l}\text { Vorwärtsprimer für die Amplifikation } \\
\text { von Exon } 7 \text { des Faktors IX }\end{array}$} & \multicolumn{2}{|l|}{$\begin{array}{l}\text { V (F9-7f): } \\
{ }^{5} \text { CCTTTTGAATGGGAAAGTTGATGC }{ }^{3} \text {, }\end{array}$} & $\begin{array}{l}\text { (Gu et al. } \\
1999)\end{array}$ \\
\hline \multicolumn{2}{|l|}{$\begin{array}{l}\text { Hämophilie B bei } \\
\text { Deutsch Drahthaar } \\
\text { Vorstehhunden }\end{array}$} & $\begin{array}{l}\text { V (F9-9f): ' }{ }^{\prime} \text { ACACCTATTCTATTTCCGT }{ }^{3}, \\
\text { r (F9-5GWr): }{ }^{3 \prime} \text { TGACATAGGAAACGACACG }{ }^{5}\end{array}$ & 187 & $\begin{array}{l}\text { (Brooks } \\
\text { et al. } \\
\text { 2003) }\end{array}$ \\
\hline
\end{tabular}

V: Vorwärtsprimer, 5'-3'-Richtung, r: reverser Primer: 3'-5'-Richtung, ASO-Wt: wildtypallelspezifisches Oligonukleotid, ASO-D: defektallelspezifisches Oligonukleotid 


\subsubsection{Literatur}

Barthels, M. und Poliwoda, H. (1993): Gerinnungsanalysen: Interpretation Schnellorientierung - Therapiekontrollen. Thieme, Stuttgart, New York 1993.

Bell, T., Leader, R., Olson, P., Padgett, G., Penner, J. und Patterson, W. (1984): Basset Hound hereditary Thrombopathy: an autosomally recessively inherited platelet dysfunction. In Byrd, M. (Herausgeber): One Medicine. Springer-Verlag, Berlin 1984, S. 335-344.

Boudreaux, M.K., Crager, C., Dillon, A.R., Stanz, K. und Toivio-Kinnucan, M. (1994): Identification of an intrinsic platelet function defect in Spitz dogs. $J$ Vet Intern Med, 8 (2), 93-8.

Boudreaux, M.K., Kvam, K., Dillon, A.R., Bourne, C., Scott, M., Schwartz, K.A. und Toivio-Kinnucan, M. (1996): Type I Glanzmann's thrombasthenia in a Great Pyrenees dog. Vet Pathol, 33 (5), 503-11.

Boudreaux, M.K. und Catalfamo, J.L. (2001): Molecular and genetic basis for thrombasthenic thrombopathia in otterhounds. Am J Vet Res, 62 (11), 1797-804.

Boudreaux, M.K. und Lipscomb, D.L. (2001): Clinical, biochemical, and molecular aspects of Glanzmann's thrombasthenia in humans and dogs. Vet Pathol, 38 (3), 249-60.

Brewer, G., Venta, P., Schall, W., Yuzbasiyan-Gurkan, V. und Li, J. (1998): DNA Tests for Von Willebrand's Disease in Dobermans, Scotties, Shelties, and Manchester Terriers. Canine Practice, 23 (1), 45.

Brinkhous, K.M., Davis, P.D., Graham, J.B. und Dodds, W.J. (1973): Expression and linkage of genes for X-linked hemophilias A and B in the dog. Blood, 41 (4), 577-85.

Brooks, M., Dodds, W.J. und Raymond, S.L. (1992): Epidemiologic features of von Willebrand's disease in Doberman pinschers, Scottish terriers, and Shetland sheepdogs: 260 cases (1984-1988). J Am Vet Med Assoc, 200 (8), 1123-7.

Brooks, M., Raymond, S. und Catalfamo, J. (1996): Plasma von Willebrand factor antigen concentration as a predictor of von Willebrand's disease status in German Wirehaired Pointers. J Am Vet Med Assoc, 209 (5), 930-3.

Brooks, M. (1999): A review of canine inherited bleeding disorders: biochemical and molecular strategies for disease characterization and carrier detection. $J$ Hered, 90 (1), 112-118.

Brooks, M.B., Gu, W. und Ray, K. (1997): Complete deletion of factor IX gene and inhibition of factor IX activity in a labrador retriever with hemophilia B. J Am Vet Med Assoc, 211 (11), 1418-21.

Brooks, M.B., Castillo-Juarez, H. und Oltenacu, P. (2001): Heritability of plasma von Willebrand factor antigen concentration in German Wirehaired pointers. Vet $Q$, 23 (3), 126-8.

Brooks, M.B., Gu, W., Barnas, J.L., Ray, J. und Ray, K. (2003): A Line 1 insertion in the Factor IX gene segregates with mild hemophilia B in dogs. Mamm Genome, 14 (11), 788-95. 
Brooks, M.B., Barnas, J.L., Fremont, J. und Ray, J. (2005): Cosegregation of a factor VIII microsatellite marker with mild hemophilia A in Golden Retriever dogs. $J$ Vet Intern Med, 19 (2), 205-10.

Callan, M., Aljamali, M., Griot-Wenk, M., Pollak, E., Werner, P., Giger, U. und High, K. (2005): Molecular characterization of hereditary factor VII deficientcy in the Beagle. J Vet Intern Med, 19, 448-449.

Cameron, C., Notley, C., Hoyle, S., McGlynn, L., Hough, C., Kamisue, S., Giles, A. und Lillicrap, D. (1998): The canine factor VIII cDNA and 5' flanking sequence. Thromb Haemost, 79 (2), 317-22.

Dodds, W.J. (1967): Familial canine thrombocytopathy. Thromb Diath Haemorrh Suppl, 26, 241-248.

Dodds, W.J. (1970): Clinical and experimental Canine von Willebrand's disease. J Lab Clin Med, 76 (5), 713-721.

Dodds, W.J. und Kull, J.E. (1971): Canine factor XI (plasma thromboplastin antecedent) deficiency. J Lab Clin Med, 78 (5), 746-52.

Dodds, W.J. (1974): Herditary and acquired Hemorrhagic Disorders in Animals. In Spaet, T. (Herausgeber): Progress in Hemostasis and Thrombosis $\left(2^{\text {nd }}\right.$ edn.). Grune and Stratton, New York 1974, S. 215-247.

Dodds, W.J. (1975): Further studies of canine von Willebrand's disease. Blood, 45 (2), 221-30.

Dodds, W.J. (1984): Von Willebrand's disease in dogs. Mod Vet Pract, 65 (9), 681-6.

Dodds, W.J. (1988): Third international registry on animal models of thrombosis and haemorrhagic diseases. ILAR news / Institute of Laboratory Animal Resources National Academy of Sciences, 130, R3-R32.

Dutra, A.S., Mignot, E. und Puck, J.M. (1996): Gene localization and syntenic mapping by FISH in the dog. Cytogenet Cell Genet, 74 (1-2), 113-7.

Evans, J.P., Brinkhous, K.M., Brayer, G.D., Reisner, H.M. und High, K.A. (1989a): Canine hemophilia $\mathrm{B}$ resulting from a point mutation with unusual consequences. Proc Natl Acad Sci U S A, 86 (24), 10095-9.

Evans, J.P., Watzke, H.H., Ware, J.L., Stafford, D.W. und High, K.A. (1989b): Molecular cloning of a cDNA encoding canine factor IX. Blood, 74 (1), 207-12.

Fitch, R. und Wardrop, J. (1992): Hemophilia A in a German Shepherd Dog. Canine Practice, 17, 19-23.

Garner, R., Hermoso-Perez, C. und Conning, D.M. (1967): Factor VII deficiency in beagle dog plasma and its use in the assay of human factor VII. Nature, 216 (5120), 1130-1.

Garner, R. und Conning, D.M. (1970): The assay of human factor VII by means of modified factor VII deficient dog plasma. Br J Haematol, 18 (1), 57-66.

Graham, J.B., Buckwalter, J.A., Hartley, L.J. und Brinkhous, K. (1949): Canine Hemophilia. Journal of Experimental Medicine, 90 (2), 97-111.

Gu, W., Brooks, M., Catalfamo, J., Ray, J. und Ray, K. (1999): Two distinct mutations cause severe hemophilia B in two unrelated canine pedigrees. Thromb Haemost, 82 (4), 1270-5.

Horvath, L. und Elodi, Z. (1991): Hereditary Haemophilia (Haemophilia-A) in a German Shepherd Dog. Magyar Allatorvosok Lapja, 46, 29-32. 
Hough, C., Kamisue, S., Cameron, C., Notley, C., Tinlin, S., Giles, A. und Lillicrap, D. (2002): Aberrant splicing and premature termination of transcription of the FVIII gene as a cause of severe canine hemophilia A: similarities with the intron 22 inversion mutation in human hemophilia. Thromb Haemost, 87 (4), 659-65.

http://bacpac.chori.org/: aufgerufen am 28. April 2007

http://www.vetgen.com/vwddobs.html: vWD Type I. (Fa.VetGen), aufgerufen am 27. April 2007

Hutt, F., Rickard, C. und Field, R. (1948): Sex-linked Hemophilia in Dogs. The Journal of Heredity, 39, 2-9.

Johnson, G., Turrentine, M. und Kraus, K. (1986): Unpublished Data zitiert bei Johnson, GS, Turrentine, MA, Kraus, KH. in Veterinary Clinics of North America: Small Animal Practice, 18 (1), 195-229.

Johnson, G.S., Schlink, G.T., Fallon, R.K. und Moore, C.P. (1985): Hemorrhage from the cosmetic otoplasty of Doberman Pinschers with von Willebrand's disease. Am $J$ Vet Res, 46 (6), 1335-40.

Johnson, G.S., Turrentine, M.A. und Kraus, K.H. (1988): Canine von Willebrand's disease. A heterogeneous group of bleeding disorders. Vet Clin North Am Small Anim Pract, 18 (1), 195-229.

Johnstone, I.B. (1999): Plasma von Willebrand factor-collagen binding activity in normal dogs and in dogs with von Willebrand's disease. $J$ Vet Diagn Invest, 11 (4), 308-13.

Kazazian, H.H., Jr. (2000): Genetics. L1 retrotransposons shape the mammalian genome. Science, 289 (5482), 1152-3.

Knowler, C., Giger, U., Dodds, W.J. und Brooks, M. (1994): Factor XI deficiency in Kerry Blue Terriers. J Am Vet Med Assoc, 205 (11), 1557-61.

Kramer, J.W., Venta, P.J., Klein, S.R., Cao, Y., Schall, W.D. und Yuzbasiyan-Gurkan, V. (2004): A von Willebrand's factor genomic nucleotide variant and polymerase chain reaction diagnostic test associated with inheritable type-2 von Willebrand's disease in a line of german shorthaired pointer dogs. Vet Pathol, 41 (3), 221-8.

Kraus, K. und Johnson, G. (1989): Von Willebrand's Disease in dogs. In Kirk, R. (Herausgeber): Current Veterinary Therapy X Small Animal Practice. WB Saunders Co, Philadelphia, 1989, S. 446.

Lakich, D., Kazazian, H.H., Jr., Antonarakis, S.E. und Gitschier, J. (1993): Inversions disrupting the factor VIII gene are a common cause of severe haemophilia A. Nat Genet, 5 (3), 236-41.

Landi, M. und Higson, J. (1982): Factor VII Deficiency in Colony Bred Mongrels. Lab Anim Sci, 32, 429.

Lipscomb, D.L., Bourne, C. und Boudreaux, M.K. (1999): DNA sequence of the canine platelet beta3 gene from cDNA: comparison of canine and mouse beta3 to segments that encode alloantigenic sites and functional domains of beta 3 in human beings. J Lab Clin Med, 134 (3), 313-21.

Lipscomb, D.L., Bourne, C. und Boudreaux, M.K. (2000): Two genetic defects in alphaIIb are associated with type I Glanzmann's thrombasthenia in a Great Pyrenees dog: a 14-base insertion in exon 13 and a splicing defect of intron 13. Vet Pathol, 37 (6), 581-8. 
Littlewood, J.D., Matic, S.E. und Smith, N. (1986): Factor IX deficiency (haemophilia B, Christmas disease) in a crossbred dog. Vet Rec, 118 (14), 400-1.

Lozier, J.N., Dutra, A., Pak, E., Zhou, N., Zheng, Z., Nichols, T.C., Bellinger, D.A., Read, M. und Morgan, R.A. (2002): The Chapel Hill hemophilia A dog colony exhibits a factor VIII gene inversion. Proc Natl Acad Sci U S A, 99 (20), 129916.

Macpherson, R., Scherer, J., Ross, M.L. und Gentry, P.A. (1999): Factor VII deficiency in a mixed breed dog. Can Vet J, 40 (7), 503-5.

Mancuso, D., Christopherson, P., Kroner, P. und Montgomery, R. (1993): The canine von Willebrand factor gene: Sequence and expression of a region encoding the glycoprotein $\mathrm{Ib} / \mathrm{IX}$ binding domain, Unpublished.

Mattson, J.C., Estry, D.W., Bell, T.G. und Patterson, W.R. (1986): Defective contact activation of platelets from dogs with basset hound hereditary thrombopathy. Thromb Res, 44 (1), 23-38.

Mauser, A.E., Whitlark, J., Whitney, K.M. und Lothrop, C.D., Jr. (1996): A deletion mutation causes hemophilia B in Lhasa Apso dogs. Blood, 88 (9), 3451-5.

Mellersh, C.S., Langston, A.A., Acland, G.M., Fleming, M.A., Ray, K., Wiegand, N.A., Francisco, L.V., Gibbs, M., Aguirre, G.D. und Ostrander, E.A. (1997): A linkage map of the canine genome. Genomics, 46 (3), 326-36.

Mills, J.N., Labuc, R.H. und Lawley, M.J. (1997): Factor VII deficiency in an Alaskan malamute. Aust Vet J, 75 (5), 320-2.

Mischke, R., Rivera Ramirez, P.A., Deniz, A., Hanies, R. und Otto, K. (1996): [Hemophilia A in the dog: symptoms, blood coagulation analysis and treatment]. Berl Munch Tierarztl Wochenschr, 109 (8), 279-87.

Montgomery, R., Fahs, S., Montgomery, M. und Mancuso, D. (1996): Cloning and sequencing of canine von Willebrand factor. Blood, 88 (Suppl. 1), 1295.

Mustard, J., Secord, D., Hoeksema, T., Downie, H. und Rowsell, H. (1962a): Canine Faktor-VII Deficiency. British Journal of Haematology, 8, 43-47.

Mustard, J.F., Rowsell, H.C., Robinson, G.A., Hoeksema, T.D. und Downie, H.G. (1960): Canine haemophilia B (Christmas disease). Br J Haematol, 6, 259-66.

Mustard, J.F., Secord, D., Hoeksema, T.D., Downie, H.G. und Rowsell, H.C. (1962b): Canine Faktor-VII Deficiency. British Journal of Haematology, 8, 43-47.

Parry, B.W., Howard, M.A., Mansell, P.D. und Holloway, S.A. (1988): Haemophilia A in German shepherd dogs. Aust Vet J, 65 (9), 276-9.

Patterson, W.R., Padgett, G.A. und Bell, T.G. (1985): Abnormal release of storage pool adenine nucleotides from platelets of dogs affected with basset hound hereditary thrombopathy. Thromb Res, 37 (1), 61-71.

Patterson, W.R., Estry, D.W., Schwartz, K.A., Borchert, R.D. und Bell, T.G. (1989): Absent platelet aggregation with normal fibrinogen binding in basset hound hereditary thrombopathy. Thromb Haemost, 62 (3), 1011-5.

Peterson, M.E. und Dodds, W.J. (1979): Factor IX deficiency in an Alaskan Malamute. J Am Vet Med Assoc, 174 (12), 1326-7.

Poncz, M., Eisman, R., Heidenreich, R., Silver, S.M., Vilaire, G., Surrey, S., Schwartz, E. und Bennett, J.S. (1987): Structure of the platelet membrane glycoprotein IIb. Homology to the alpha subunits of the vitronectin and fibronectin membrane receptors. J Biol Chem, 262 (18), 8476-82. 
Raymond, S.L. und Dodds, W.J. (1979): Platelet membrane glycoproteins in normal dogs and dogs with hemostatic defects. J Lab Clin Med, 93 (4), 607-13.

Rieger, M., Schwarz, H.P., Turecek, P.L., Dorner, F., van Mourik, J.A. und Mannhalter, C. (1998): Identification of mutations in the canine von Willebrand factor gene associated with type III von Willebrand disease. Thromb Haemost, 80 (2), 332-7.

Rowsell, H.C., Downie, H.G., Mustard, J.F., Leeson, J.E. und Archibald, J.A. (1960): A disorder resembling hemophilia B (Christmas disease) in dogs. J Am Vet Med Assoc, 137, 247-50.

Shapiro, M.B. und Senapathy, P. (1987): RNA splice junctions of different classes of eukaryotes: sequence statistics and functional implications in gene expression. Nucleic Acids Res, 15 (17), 7155-74.

Slappendel, R., Versteeg, S., van Zon, P., Rothuizen, J. und van Oost, B. (1998): DNA analysis in diagnosis of von Willebrand disease in dogs. Veterinary Quarterly, 20 (Suppl 1), S90-1.

Spurling, N., Burton, L., Peacock, R. und Pilling, T. (1972): Hereditary Factor-VII Deficiency in the Beagle. British Journal of Haematology, 23, 59-67.

Spurling, N.W., Peacock, R. und Pilling, T. (1974): The clinical aspects of canine factor-VII deficiency including some case histories. J Small Anim Pract, 15 (4), 229-39.

Stokol, T. und Parry, B. (1993): Canine von Willebrand Disease: A Review. Aust Vet Practit, 23 (2), 94-103.

Stoy, S., Shibuya, H., Nonnemann, D., Holzhauer, J., Mohammed, I. und Johnson, G. (1996): Canine vWF cDNA sequence. Unpublished, GenBank accession: L76227,

Tcherneva, E., Huff, A. und Giger, U. (2006): Coagulation factor XI deficiency in Kerry blue terrier dogs is caused by an exonic SINE insertion. $J$ Vet Intern Med, 20, 767.

Tennant, B. (1996): The problem of inherited diseases. 3: Haemophilia in the German Shepherd. J Small Anim Pract, 37 (8), 405-6.

US-Patent (6780583): DNA encoding canine von willebrand factor and methods of use. US Patent \& Trademark Office: Patent Full-Text and Image Database, http://patft1.uspto.gov/netacgi/nph-

Parser?Sect $1=$ PTO1 $\&$ Sect $2=$ HITOFF $\& d=$ PALL $\& p=1 \& u=\% 2 F n e t a h t m l \% 2 F P T$ $\mathrm{O} \% 2 \mathrm{Fsrchnum} . \mathrm{htm} \& \mathrm{r}=1 \& \mathrm{f}=\mathrm{G} \& \mathrm{l}=50 \& \mathrm{~s} 1=6780583 . \mathrm{PN} . \& \mathrm{OS}=\mathrm{PN} / 6780583 \& \mathrm{RS}$ $=\mathrm{PN} / 6780583$

van Oost, B.A., Versteeg, S.A. und Slappendel, R.J. (2004): DNA testing for type III von Willebrand disease in Dutch Kooiker dogs. J Vet Intern Med, 18 (3), 282-8.

Venta, P.J., Li, J., Yuzbasiyan-Gurkan, V., Brewer, G.J. und Schall, W.D. (2000): Mutation causing von Willebrand's disease in Scottish Terriers. $J$ Vet Intern Med, 14 (1), 10-9.

von Willebrand, E. (1926): Hereditar pseudohamophili. Finska läk sällsk, Handl, 68, 87.

Wheeler, S.L., Weingand, K.W., Thrall, M.A., Berg, R.J., Schwarz, P.D. und Olson, P.N. (1984): Persistent uterine and vaginal hemorrhage in a beagle with factor VII deficiency. J Am Vet Med Assoc, 185 (4), 447-8. 
Yoshitake, S., Schach, B.G., Foster, D.C., Davie, E.W. und Kurachi, K. (1985): Nucleotide sequence of the gene for human factor IX (antihemophilic factor B). Biochemistry, 24 (14), 3736-50. 


\subsection{Hereditäre Erkrankungen des Immunsystems}

Angeborene Immunerkrankungen werden bei Hunden meist im Alter von sechs bis acht Wochen symptomatisch, da zu diesem Zeitpunkt die maternalen Antikörper im Blut der Welpen rapide abnehmen. Die deutlichsten Anzeichen sind ständig wiederkehrende, schwere Infektionen und je nach Defekt mehr oder weniger deutliche Wachstumsdepressionen. Bisher sind die molekulargenetischen Ursachen für vier verschiedene Immunerkrankungen identifiziert worden. Während die Canine Zyklische Neutropenie $(\mathrm{CN})$ durch die Störung eines Enzymtransportmechanismus der neutrophilen Leukozyten verursacht wird, sind bei der Caninen Leukozytenadhäsionsdefizienz (CLAD) und bei der Schweren Kombinierten Immundefizienz (SCID) die Lymphozyten betroffen. Bei CLAD betrifft der Defekt Lymphozytenmembranglykoproteine. Den verschiedenen Formen von SCID liegen Störungen der Lymphozytenentwicklung zugrunde. Die C3-Defizienz betrifft eine Komponente des Komplementsystems.

\subsubsection{Canine zyklische Neutropenie (CN)}

\begin{tabular}{ll|}
\hline Chromosom: & CFA3 \\
Gen: & AP3B1 \\
NCBI: & GeneID: 403459, GenBank: AY 221640 \\
DNA-Sequenz: & NW_876308, Position 28369113-28636011 \\
Mutationen: & 2525InsA2526, Collie \\
\hline
\end{tabular}

\section{Krankheitsbild}

Bei Hunden ist die zyklische Neutropenie oder zyklische Hämatopoese vor allem bei Collies als das so genannte „Gray Collie Syndrome“ bekannt, da es stets gekoppelt mit einer Graufärbung des Fells auftritt (Ford 1956). Neben Collies zählen möglicherweise auch Groenendaels (Belgische Schäferhunde) zu den betroffenen Rassen (Lienhart 1954, zitiert bei Ford 1969). Auch hier ist das Auftreten einer grauen Fellfärbung offenbar gekoppelt mit einem Letalfaktor. Einzelheiten über die Natur dieses Letalfaktors sind nicht beschrieben. So ist nicht klar, ob es sich bei der Erkrankung der Belgischen Schäferhunde tatsächlich um eine Form der zyklischen Neutropenie handelt. 
Es wird angedeutet, dass die beschriebene Graufärbung des Fells auch bei anderen Rassen auftritt. Auf Einzelheiten wird dabei nicht eingegangen.

Der Name zyklische Hämatopoese bezieht sich auf den mit dieser Erkrankung einhergehenden zyklischen Verlauf der Blutbildung. In einem regelmäßigen Wechsel von acht bis zwölf Tagen findet ein extremes Absinken der Anzahl der neutrophilen Granulozyten (Neutropenie) (Lund et al. 1967) aber auch der Retikulozyten (Dale et al. 1995) und in geringerem Maße der Blutplättchen statt (Patt et al. 1973). Typische Symptome sind das bereits im ersten Lebensmonat beginnende, zyklisch wiederkehrende Auftreten schwerer Entzündungen, wie schmerzhafter Hautgeschwüre, Geschwüre der Mundschleimhaut und Enteritis, begleitet von allgemeiner Schwäche, Appetitlosigkeit und Gelenkschmerzen (Ford 1956; Lund et al. 1967; Ford 1969).

Werden bei der Behandlung lediglich die Folgeerscheinungen, nicht aber die Neutropenie selbst bekämpft, überleben die betroffenen Hunde selten den ersten Lebensmonat. Fast alle sterben spätestens innerhalb des ersten Lebensjahres an den Folgen schwerer Entzündungen (Ford 1969). Der Neutropenie kann mit regelmäßigen Lithium- oder Endotoxingaben (Hammond et al. 1979; Hammond et al. 1987) oder regelmäßigen Gaben von G-CSF (Granulozytenkolonienbildung stimulierender Faktor) entgegengewirkt werden (Hammond et al. 1990; Dale et al. 1995; Yanay et al. 2006). Eine dauerhafte Normalisierung des Neutrophilenspiegels lässt sich durch Transplantation von Knochenmarkszellen gesunder Wurfgeschwister (Weiden et al. 1974) oder die Injektion eines Lentivirus-Vektors, der G-CSF codierende cDNA enthält (Yanay et al. 2006), erreichen.

\section{Genetischer Hintergrund}

Erste sichere Hinweise darauf, dass das „Gray Collie Syndrome“ wie vermutet (Lund et al. 1967) auf einen autosomal rezessiv vererbten genetischen Defekt zurückzuführen ist, finden sich in einer Pedigreestudie an 39 Würfen bestehend aus 286 Welpen, davon 92 graue, 177 zobelfarbene 14 dreifarbige und drei weiße. Keiner der 92 grauen Collies überlebte viel länger als ein Jahr. Die meisten $(n=62)$ starben bereits im Verlauf der ersten Lebenswoche. Anhand dieser Daten wurde geschätzt, dass ca. $32 \%$ der US- 
amerikanischen Colliepopulation Träger des Defektallels für zyklische Neutropenie sind (Ford 1969).

Die Entdeckung von Parallelen der caninen zyklischen Neutropenie zu bereits genauer untersuchten humanen Erkrankungen wie der schweren zyklischen Neutropenie (Severe Cyclic Neutropenia, SCN) (Lund et al. 1967) und dem Hermansky-Pudlak Syndrom Typ 2 (HPS2) ermöglichte die Bestimmung von Kandidatengenen (Benson et al. 2003). Durch Isolation und vergleichende Sequenzierung der caninen cDNA für die Adapterproteinkomplex-3- $\beta$-Untereinheit (AP3B1) von kranken und gesunden Hunden konnte die verantwortliche Mutation im Exon 21 des caninen AP3B1-Gens lokalisiert werden. Das insgesamt 27 Exons umfassende Gen liegt auf dem caninen Chromosom 3 im genomischen Contig NW_876308 zwischen Position 28369113 und 28636011 (NCBI-GeneID: 403459). Die Länge der cDNA beträgt 3964 bp (NCBI-GenBank: AY 221640). In der ersten Veröffentlichung der cDNA-Sequenz (Benson et al. 2003) wird die Mutation in Exon 20 des 26 Exons umfassenden caninen AP3B1-Gens lokalisiert. Die Autoren korrigieren sich jedoch in einer Folgeveröffentlichung selber und kommen auf Grundlage einer Überarbeitung des Dog Genome Browsers (http://genome.ucsc.edu) zu den oben angegebenen Daten (Benson et al. 2004). Abb. 22 stellt die Struktur des caninen AP3B1-Gens schematisch dar. 


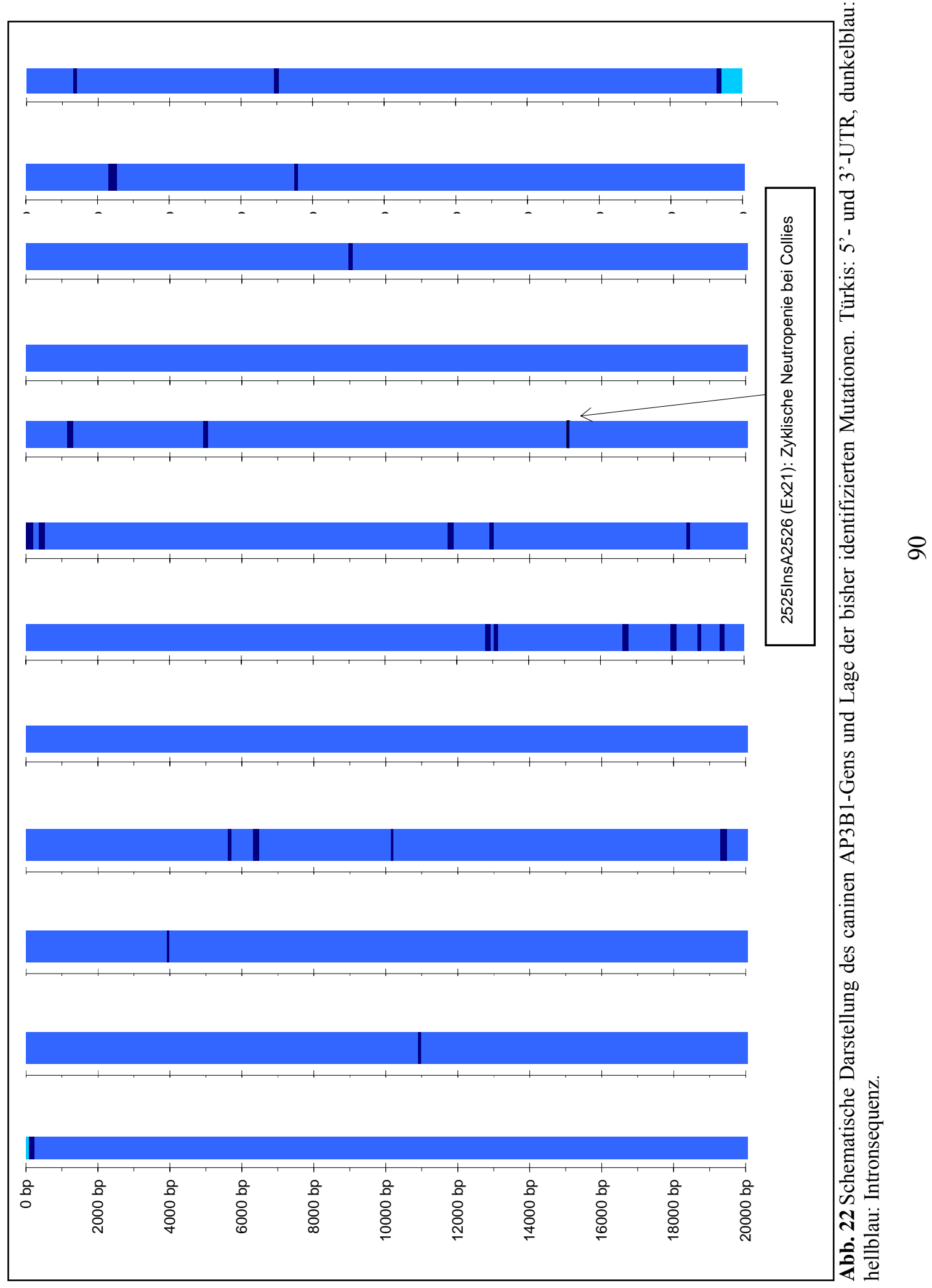




\section{Ursächliche Mutation für zyklische Neutropenie bei Collies}

Bei der Mutation handelt es sich um die Insertion eines Adenins in einer Region mit 9 Adeninen zwischen den Basen 2525 und 2526 (Benson et al. 2003; Benson et al. 2004) mit der Folge einer Leserasterverschiebung und dadurch eines verfrühten Proteinterminierungssignals (Abb. 23).

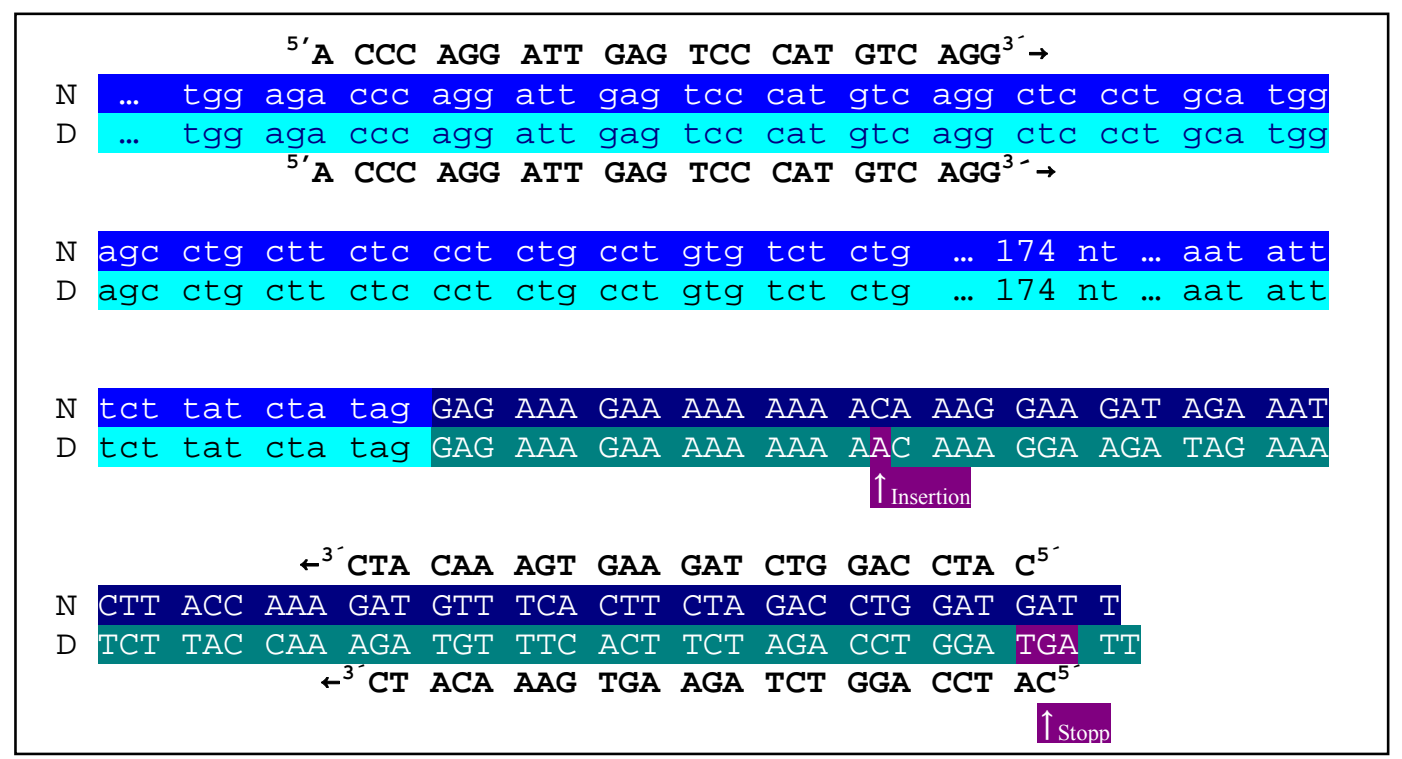

Abb. 23 Exon 21 des caninen AP3B1-Gens und vorausgehende Intronsequenz. N: normale Sequenz, D: defekte Sequenz, hellblau: Intron normale Sequenz, türkis: Intron defekte Sequenz, dunkelblau: Exon normale Sequenz, dunkelgrün: Exon defekte Sequenz, Insertion und verfrühtes Stoppcodon violett markiert und durch Pfeil gekennzeichnet.

Mutationen des dem caninen AP3B1-Gen homologen humanen Gens sind die Ursache des Hermansky-Pudlak Syndroms Typ 2 (Dell'Angelica et al. 1999), dessen Hauptsymptome, fehlende Pigmentierung und zyklische Neutropenie in Verbindung mit Immunschwäche (Huizing et al. 2002; Clark et al. 2003), den Symptomen der caninen zyklischen Neutropenie entsprechen. Eine Erklärung der Auswirkungen des für HPS2 verantwortlichen Gendefektes liefern Ergebnisse von Huizing et al. (2001). Demnach ist AP3 für den Transport bestimmter Proteine in Lysosomen (Dell'Angelica et al. 1999) oder lysosomenverwandten Zellorganellen wie z.B. Melanosomen oder verschiedenen Granula zuständig (Dell'Angelica et al. 2000). Eine Mutation des AP3B1 Gens führt zur Fehllokalisation oder zur Unterbrechung des Transports dieser Proteine. So fanden Huizing et al. (2001) in AP3-defizienten Melanozyten das an der Pigmentbildung beteiligte Protein Tyrosinase nur in perinuklearen Kompartimenten, während es bei normalen Melanozyten außerdem in den Verzweigungsbereichen zu finden ist. Diese 
Fehlleitung wird als Ursache für die fehlende Pigmentierung bei HPS2-Patienten gewertet und könnte auch der Grund für die Graufärbung der „Gray Collies“ sein. Als weiterer Effekt der AP3B1 Mutation wird eine Fehlleitung des Transmembranproteins Neutrophile Elastase beschrieben, das in AP3-defizienten Neutrophilen vorwiegend in Membranen lokalisiert ist, während es in normalen Zellen vorrangig in den Granula lokalisiert ist (Benson et al. 2003). Einzelheiten zu den Auswirkungen dieser Fehllokalisation von Neutrophiler Elastase vor allem bezüglich ihres Effekts auf die typischen Schwankungen der Neutrophilenkonzentration bei der zyklischen Neutropenie sind noch nicht geklärt. Es liegt jedoch auch bei der humanen SCN eine genetisch bedingte Fehllokalisation von neutrophiler Elastase vor (Li und Horwitz 2001). Es wird angenommen, dass dieser Defekt zur Störung eines Rückkopplungsmechanismus zwischen Neutrophilen und Knochenmark führt, der bei gesunden Individuen für eine angepasste Differenzierung und Proliferation neutrophiler Granulozyten sorgt.

\section{Genotypisierung für zyklische Neutropenie}

Um der Vererbung der zyklischen Neutropenie vorzubeugen, ist bei Verdacht auf Defektträgerstatus eines Zuchthundes die Durchführung eines Gentests zu empfehlen. Durch diagnostische Sequenzierung eines 341-bp-Fragmentes, das beginnend in Intron 20 und endend in Exon 21 den von der Insertion betroffenen Bereich umspannt, kann überprüft werden, ob eine Adenininsertion zwischen den Basen 26 und 27 des Exons 21 vorliegt. Passende Primer wurden von Benson et al. (2004) entwickelt (Abb. 23). 


\subsubsection{Canine Leukozytenadhäsionsdefizienz (CLAD)}

\begin{tabular}{|ll|}
\hline Chromosom: & CFA31 \\
Gen: & ITGB2 \\
NCBI: & GeneID: 403770, GenBank: AF181965 \\
DNA-Sequenz: & NW_876295, Position 37896682-37862968 \\
Mutationen: & G107C, Irischer Setter, Irischer Rot-Weißer Setter \\
\hline
\end{tabular}

\section{Krankheitsbild}

Die Canine Leukozytenadhäsionsdefizienz (CLAD) wurde erstmals 1987 beschrieben (Giger et al. 1987). Es handelt sich um eine Störung der Immunantwort, die sich durch tiefe Infektionen von Hautwunden, Lederhautinfektionen an den Pfoten, eine geschwürartige Hauterkrankung (Pyoderma), Entzündungen der Mundschleimhaut, Lungenentzündungen, Entzündungen der oberflächlichen Venen (Thrombophlebitis), Knochenmarksentzündungen (Osteomyelitis), lokalisierte Cellulitis mit beeinträchtigter Eiterbildung, zeitweilig hohes Fieber $\left(40,6^{\circ} \mathrm{C}\right)$, zeitweilige Schwellungen der Lymphknoten, Anorexie und schlechte Wundheilung auch bei leichten Verletzungen manifestiert (Giger et al. 1987). Eine bei Irischen Settern zwischen 1975 und 1979 beschriebene Granulozytenerkrankung (Renshaw et al. 1975; Renshaw et al. 1977; Renshaw und Davis 1979) weist ähnliche Symptome auf, wurde jedoch nicht als Leukozytenadhäsionsdefizienz klassifiziert.

Betroffene Rassen sind Irische Setter (Giger et al. 1987) und Irische Rot-Weiße Setter (Debenham et al. 2002; Foureman et al. 2002). Die Frequenz des Defektallels beträgt in der deutschen Zuchtpopulation Irischer Setter etwa 11 \% (Pfeiffer und Brenig 2005).

Routineblut- und Knochenmarksuntersuchungen ergeben eine deutliche Myeloidhyperplasie und eine extreme bis moderate Leukozytose, die überwiegend von einer Neutrophilie, begleitet von einer variablen Lymphozytose und Myozytose herrührt. Auch die Eosinophilen sind leicht erhöht (Giger et al. 1987). Detailliertere Untersuchungen zeigen eine deutlich reduzierte Adhäsionsfähigkeit, die eine Beeinträchtigung weiterer Leukozytenfunktionen nach sich zieht. Diese Beeinträchtigung betrifft die zufällige Migration und Chemotaxis, die Aggregationsreaktion auf PMA-Stimulierung (Phorbol-Myristat-Acetat) und die lymphozytäre Blastogenese als Reaktion auf mitogene Stimulierung (Giger et al. 1987). 
Nicht beeinträchtigt sind die Immunglobulinkonzentrationen und der so genannte respiratorische Burst, das heißt die nach Aktivierung der Neutrophilen einsetzende, massenhafte Produktion reaktiver Sauerstoffverbindungen wie $\mathrm{O}_{2}, \mathrm{H}_{2} \mathrm{O}_{2}$ und $\mathrm{HOCl}$, die eine wesentliche Bedeutung für die mikrobiziden Fähigkeiten aber auch für die gewebeschädigende Wirkung der Neutrophilen haben. Diese Befunde, die auf der Untersuchung eines einzelnen Falls basieren, decken sich bis auf wenige, höchstwahrscheinlich methodisch bedingte Ausnahmen mit Ergebnissen einer Untersuchung von zwölf Irischen Settern aus sechs verschieden Würfen (Trowald-Wigh et al. 1992; Trowald-Wigh et al. 2000).

An der Steuerung der Adhäsionsfähigkeit sind unter anderem die drei strukturell verwandten Leukozytenmembranglykoproteine Mo1 (Monozytenadhäsionsfaktor, auch bezeichnet als Integrin alpha $\mathrm{M}$ oder Mac-1, Makrophagenantigen), LFA-1 (Lymphozytenfunktionsassoziiertes Antigen, auch bezeichnet als Integrin alpha L) und LeuM5 (Leukozytenadhäsionsglykoprotein, auch bezeichnet als Integrin alpha X oder p150,95) beteiligt. Sie sind aus einer einheitlichen $\beta$-Untereinheit und spezifischen $\alpha-$ Untereinheiten zusammengesetzt, deren Sequenzen $\mathrm{zu} 33-50 \%$ identisch sind. Mo1 wird von Monozyten, Granulozyten und großen, granulären Lymphozyten exprimiert und wirkt neben seiner Funktion als Rezeptor für Komplementsystemkomponenten als Promotor der Adhäsion von Neutrophilen und Monozyten. LFA-1 wird von allen Leukozyten exprimiert und verstärkt die adhäsive Interaktion von Lymphozyten und Killerzellen. LeuM5 ist auf der Zelloberfläche von Monozyten, Makrophagen und Granulozyten zu finden und spielt eine Rolle bei der Adhäsion und Aggregation von Granulozyten (zusammengefasst bei Anderson und Springer 1987). In immunologischen Untersuchungen zeigen die Leukozyten von betroffenen Irischen Settern im Gegensatz zu den Leukozyten gesunder Hunde keine Reaktion auf Antikörper, die spezifisch gegen die $\alpha$-Untereinheit des humanen Glykoproteins Mo1 und gegen die gemeinsame $\beta$-Untereinheit der humanen Glykoproteine Mo1, LFA-1 und LeuM5 gerichtet sind (Giger et al. 1987).

In der Humanmedizin lässt sich die analoge Erkrankung in eine schwere Form, bei der eine komplette Defizienz der Moleküle Mo1, LFA-1 und LeuM5 vorliegt, und eine leichtere Form, bei der eine starke Reduzierung der Expression der drei Glykoproteine vorliegt, unterteilen (Anderson et al. 1985). Aufgrund des nachgewiesenen absoluten 
Mangels an Mo1 lässt sich die bei Irischen Settern beschriebene Erkrankung als schwere CLAD klassifizieren (Giger et al. 1987).

\section{Genetischer Hintergrund}

Anpaarungsstudien ergeben bei betroffenen Irischen Settern und Irischen Rot-Weißen Settern deutliche Hinweise auf einen autosomal rezessiven Erbgang (Renshaw und Davis 1979).

Der genetische Defekt ist bei Irischen Settern und Irischen Rot-Weißen Settern in Europa (Kijas et al. 1999; Kijas et al. 2000; Debenham et al. 2002; Verfaillie et al. 2004; Pfeiffer und Brenig 2005), den USA (Foureman et al. 2002) und Australien (Jobling et al. 2003) derselbe. Es handelt sich um einen SNP im Integrin-beta-2-Gen (ITGB2), das auf Chromosom 31 lokalisiert ist und für die einheitliche $\beta$-2-Untereinheit der Membranglykoproteine Mo1, LFA-1 und Leu M5 codiert. Die Lage der insgesamt 16 Exons in der genomischen Sequenz scheint noch nicht abschließend geklärt zu sein. Ein vollständiges Modell ist nicht veröffentlicht. Im NCBI-Contig NW_876295 ist das canine ITGB2 zwischen Position 37896682 und 37862968 lokalisiert. Die Lagebestimmung der ersten 11 Exons (NCBI-GeneID: 403770) erfolgte per Anordnung mRNA-Sequenz (NCBI-GenBank: AF181965) innerhalb des genomischen Contigs. Das erste dieser 11 Exons ist im Vergleich zu der bei Kijas et al. (1999) veröffentlichten Version unvollständig. Die NCBI-Version (NCBI-GeneID: 403770) ist Grundlage der in Abb. 24 dargestellten Genstruktur des caninen ITGB2-Gens. 


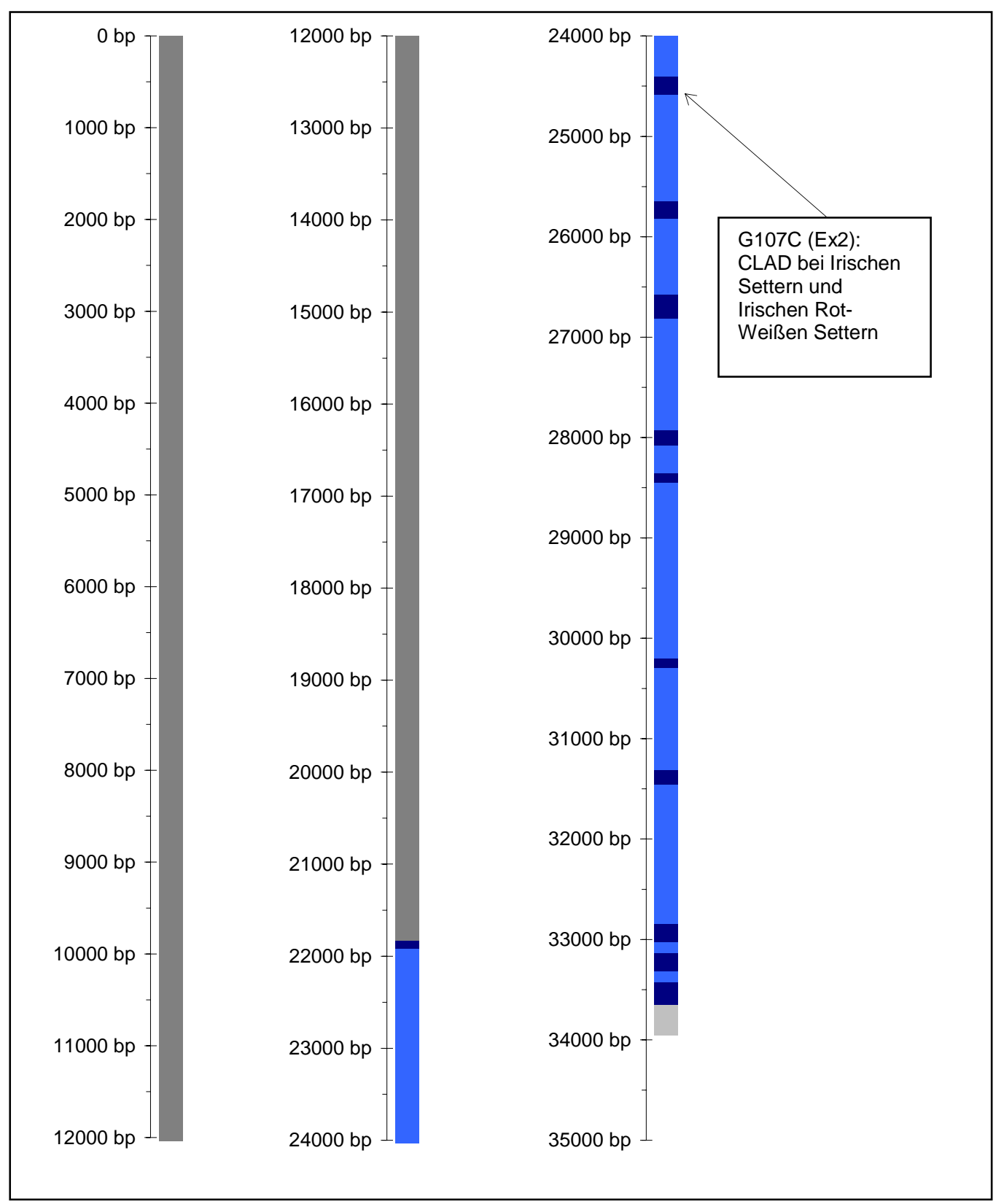

Abb. 24 Schematische Darstellung des caninen ITGB2-Gens und Lage der bisher identifizierten Mutationen. Dunkelblau: codierende Sequenz, hellblau: Intronsequenz, grau: intergenische Sequenz.

\section{Ursächliche Mutation für CLAD bei Irischen Settern und Irischen Rot- Weißen Settern}

Im Einzelnen handelt es sich bei der genannten Mutation um einen Basenaustausch von Guanin durch Cytosin an Position 107 der cDNA in Exon 2 (Abb. 25) (Kijas et al. 1999; Kijas et al. 2000; Debenham et al. 2002; Foureman et al. 2002; Jobling et al. 2003; Verfaillie et al. 2004; Pfeiffer und Brenig 2005). Die Folge der Substitution ist ein Austausch von Cystein durch Serin an Aminosäurenposition 36 (Kijas et al. 1999).

Dieser Cysteinrest ist in den $\beta-1, \beta-2$ - und $\beta$-3-Integrinen bei allen Säugetieren 
konserviert. Die $\beta$-3 Untereinheit ist durch 28 Disulfidbrücken stark quervernetzt (Calvete et al. 1991). Da alle 56 Cysteinreste bei den $\beta$-2- und den $\beta$-3-Integrinen konserviert sind, ist eine identische Disulfidbrückenstruktur $\mathrm{zu}$ erwarten. Der beschriebene Basenaustausch führt daher sehr wahrscheinlich zum Verlust einer Disulfidbrücke und damit zu einer abweichenden Proteinstruktur.

\section{Genotypisierung für CLAD bei Irischen Settern und Irischen Rot-Weißen Settern}

Der erste Gentest zum Nachweis dieser Mutation (Kijas et al. 1999) basierte auf der OLA-Methode (Oligonukleotid-Ligations-Assay) von Landegren et al. (1988) (Abb. 25). Weitere beschriebene Verfahren zur Genotypisierung für CLAD basieren auf einem RFLP (Verfaillie et al. 2004) (Abb. 26), auf einer Sequenzierung (Debenham et al. 2002) oder einer Pyrosequenzierung (Kijas et al. 2000; Pfeiffer und Brenig 2005).

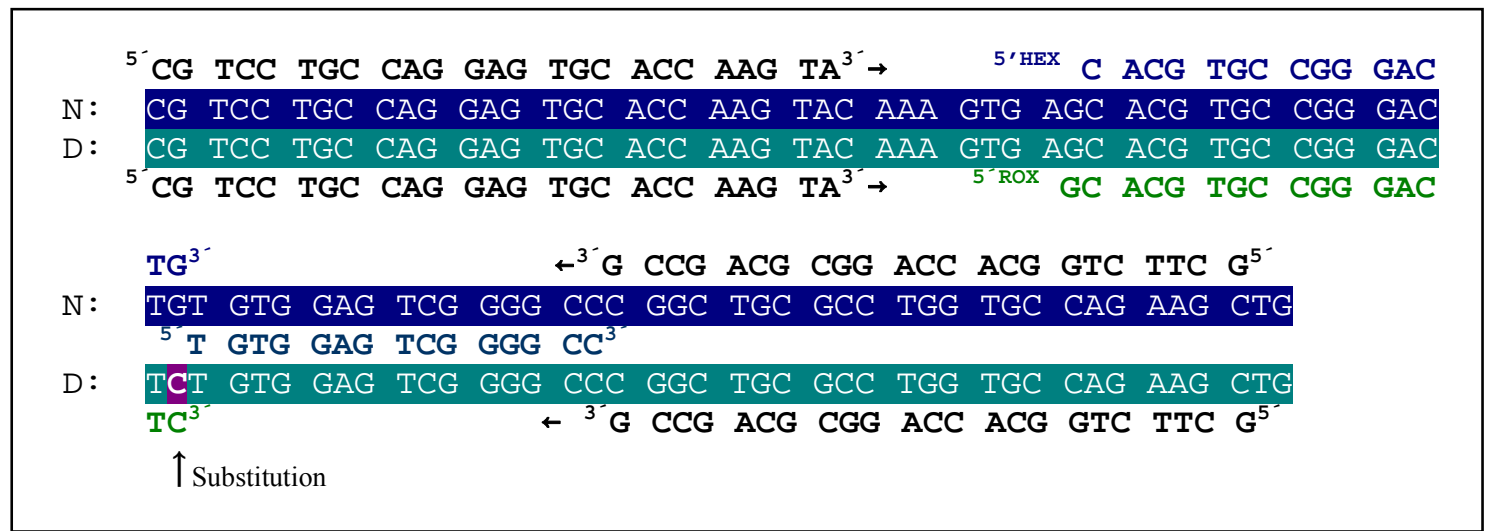

Abb. 25 Exon 2 des caninen ITGB2 Gens. N: normale Sequenz, D: defekte Sequenz, dunkelblau: Exon normale Sequenz, dunkelgrün: Exon defekte Sequenz, von Substitution betroffene Base in defekter Sequenz fett gedruckt, violett markiert und durch Pfeil gekennzeichnet, dunkelblaue Schrift: wildtypallelspezifisches Oligonukleotid, dunkelgrüne Schrift: defektallelspezifisches Oligonukleotid, blaugrüne Schrift: Oligonukleotid für beide Allele.

Die Genotypisierung per RFLP (Verfaillie et al. 2004) basiert auf der Amplifikation eines 87-bp-Fragments aus Exon 2 und anschließender Restriktionsspaltung mit HpyCH4III oder Bst4CI. Das Wildtypallel enthält eine Restriktionserkennungssequenz für diese beiden Enzyme. Im Defektallel ist keine Restriktionserkennungssequenz für die beiden Restriktionsenzyme enthalten. 


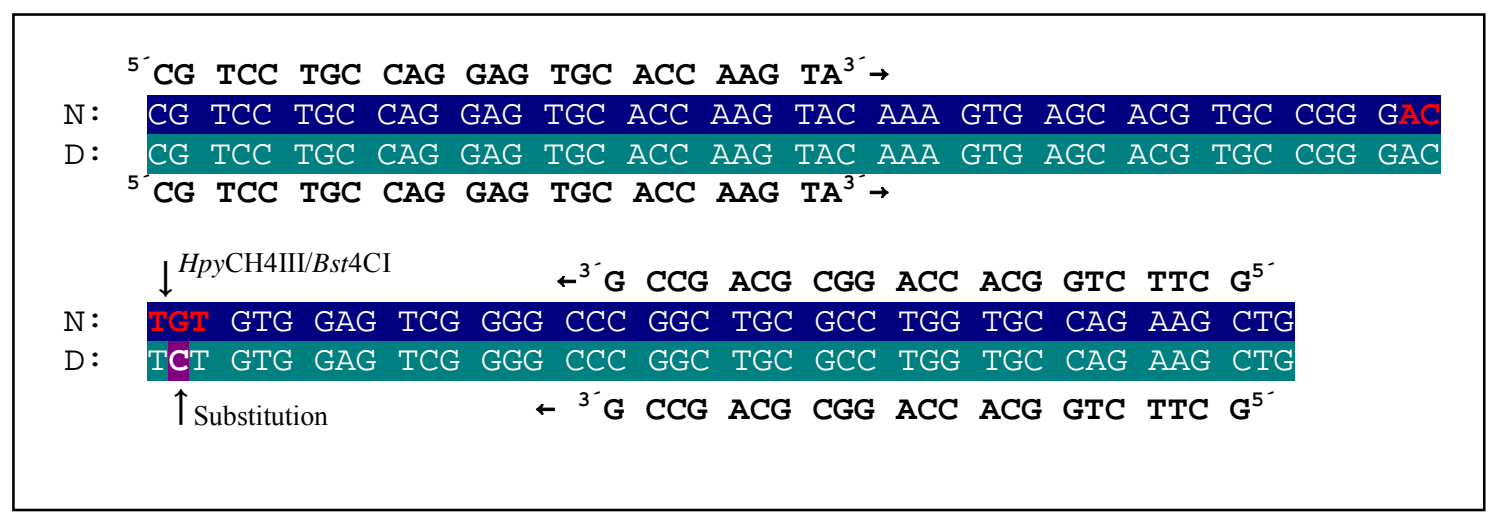

Abb. 26 Exon 2 des caninen ITGB2-Gens. N: normale Sequenz, D: defekte Sequenz, dunkelblau: Exon normale Sequenz, dunkelgrün: Exon defekte Sequenz, von Substitution betroffene Base in defekter Sequenz fett gedruckt, violett markiert und durch Pfeil gekennzeichnet, rote Schrift: Restriktionserkennungssequenz für HpyCH4III oder Bst4CI, Restriktionsschnittstelle im Wildtypallel durch Pfeil gekennzeichnet. 


\subsubsection{Schwere kombinierte Immundefizienz (Severe Combined Immunodeficiency, SCID)}

\begin{tabular}{ll}
\hline Chromosom: & CFAX \\
Gen: & IL-2R $\gamma$ \\
Ensembl: & GeneID: ENSCAFG00000016927 \\
DNA-Sequenz: & CFAX, Position 58274064-58270467 \\
Mutationen: & Del30-33, X-SCID, Basset \\
& Ins582C, X-SCID, Cardigan Welsh Corgi
\end{tabular}

\begin{tabular}{ll}
\hline Chromosom: & CFA29 \\
Gen: & DNA-PKcs \\
NCBI: & GeneID: 474176, GenBank: AF448227 \\
DNA-Sequenz: & NW_876288, Position 246335-26053 \\
Mutationen: & G10879T, SCID, Jack Russel Terrier \\
\hline
\end{tabular}

\section{Krankheitsbild}

Die schwere kombinierte Immundefizienz (Severe Combined Immunodeficiency, SCID) bezeichnet eine Gruppe von Erkrankungen, die durch schwere Beeinträchtigungen sowohl der humoralen als auch der zellgesteuerten Immunantwort gekennzeichnet sind. Es können vier Formen von SCID unterschieden werden: SCID mit Abwesenheit von Lymph- und Myeloidzellen, SCID mit Abwesenheit von B- und T-Lymphozyten, SCID mit Adenosindesaminase (ADA)- oder Purinnukleosidphosphatase (PNP)-Defizienz, SCID mit B-Zellen und funktionsgestörten T-Zellen. Eine X-chromosomal vererbte Form von SCID wurde bei Hunden erstmals 1982 bei Bassets beschrieben (Patterson et al. 1982). Zur Verbreitung der Erkrankung innerhalb der Rasse Basset sind keine Zahlen veröffentlicht. Eine bezüglich der Symptome und des Erbgangs mit der Basset-SCID übereinstimmende Form konnte außerdem in einer Familie bei Cardigan Welsh Corgis diagnostiziert werden. Über die Verbreitung von SCID innerhalb dieser Rasse sind keine Zahlen veröffentlicht (Somberg et al. 1995; Pullen et al. 1997). Eine weitere Form von SCID mit autosomal rezessivem Erbgang tritt bei Jack Russell Terriern auf (Meek et al. 2001; Bell et al. 2002). Die Frequenz des Defektallels in dieser Rasse wird auf weniger als $1,1 \%$ geschätzt (Ding et al. 2002). 


\section{I.a+b SCID bei Bassets und Cardigan Welsh Corgis}

Die bei Bassets diagnostizierte Form zeichnet sich durch nur teilweise funktionelle BZellen und unreife, funktionsgestörte T-Zellen aus (Jezyk et al. 1989). Typische Erscheinungen bei SCID sind Pyoderma, papulöse oder pustulöse Dermatitis, Ohrenentzündung, eitriger Ausfluss aus Auge und Nase, schwere Diarrhöen aufgrund einer Cryptosporidium-spp.-Infektion, Lungenentzündung und Hundestaupe. Auslöser für den Ausbruch einer dieser Erkrankungen sind unter anderem Lebendimpfungen, z.B. mit einer modifizierten Lebendvirus Staupe-Hepatitis-Vakzine. SCID-Hunde sind deutlich kleiner als ihre Wurfgeschwister. Die peripheren Lymphknoten sind nicht ertastbar. In Blutuntersuchungen weisen einkernige Zellen überwiegend eine atypische, bruchstückhafte Form auf. Die betroffenen Tiere werden meist nicht älter als drei bis vier Monate (Jezyk et al. 1989; Felsburg et al. 1992). Bei Sektionen finden sich Veränderungen im Thymus, in den Lymphknoten und in der Milz. Der Thymus ist unterentwickelt, bei einigen Hunden sogar nur auf einen grau-braunen Gewebestreifen reduziert und weist eine lymphoide Hypoplasie auf. Die Lobuli sind sehr klein mit graduell variierender Hypoplasie und Dysplasie. Ferner fehlen bestimmte Lymphknoten vollständig (mandibulare, präscapulare, axillare, mediastinale, hilare, mesenterale, inguinale und popliteale), andere sind stark verkleinert oder unterentwickelt (Patterson et al. 1982; Jezyk et al. 1989; Snyder et al. 1993). Bei immunologischen Untersuchungen ergeben sich hohe bis normale IgM-Werte, während IgG und $\operatorname{IgA}$ in stark reduzierter bis nicht nachweisbarer Menge vorliegen. Die blastogene Reaktion auf mitogene Stimuli (z.B. Phytohämagglutinin) ist unzureichend. Ursache ist die signifikant reduzierte Bindung von Interleukin 2 (IL-2), die bei Phytohämagglutinin (PHA) aktivierten T-Zellen von betroffenen Hunden zu beobachten ist (Somberg et al. 1994). Durch entsprechende Stimuli wird in der T-Zelle die Sekretion von IL-2 sowie die Expression eines IL-2-Rezeptors an der Zelloberfläche ausgelöst. Diese Vorgänge leiten eine intrazellulare Signalkaskade ein, an deren Ende eine mitotische Teilung der T-Zelle steht. Der Ablauf dieser Vorgänge ist den Untersuchungen von Somberg et al (1994) zufolge bei SCID-Hunden gestört. 
Der prozentuale Anteil von B-Lymphozyten im peripheren Blut ist normal, während der T-Lymphozyten Anteil bei SCID-Hunden zwar an den normalen Bereich heranreichen kann, gegenüber normalen Hunden jedoch deutlich reduziert ist. Das Verhältnis zwischen den T-Zell-Subtypen CD4:CD8 ist im Vergleich zu gesunden Hunden deutlich in Richtung CD4-Zellen verschoben (15:1 bei SCID-Hunden gegenüber 2:1 bei gesunden Hunden) (Somberg et al. 1994). Im Verlauf der Differenzierung der TLymphozyten kommt es zur Ausprägung der Subtypen CD4 und CD8, die durch die Expression eines bestimmten Korezeptortyps charakterisiert sind. Zellen, die den Korezeptor CD8 (CD: cluster of differentiation) exprimieren wirken zytotoxisch. Im Gegensatz dazu wirken T-Zellen, die den Korezeptor CD4 exprimieren inflammatorisch (Löffler 1998). Häufig sind große, bruchstückartige Zellen zu finden, die unspezifisch esterasenegativ reagieren. Vermutlich handelt es sich hierbei um unreife Lymphozyten (Somberg et al. 1994).

Auch die Adenosindesaminase (ADA)- und die Purinnukleosidphosphorylase (PNP)Aktivität liegt im normalen Bereich (Jezyk et al. 1989; Felsburg et al. 1992). Eine gestörte Funktion dieser Enzyme ist die Ursache für einige humane SCID-Formen (Hirschhorn 1993; Nyhan 2005). Leicht erhöhte Werte von Inosin und Deoxyinosin deuten jedoch auf eine Verschiebung im Purinbasenhaushalt hin (Jezyk et al. 1989; Felsburg et al. 1992).

Die Symptome und Befunde bei an SCID erkrankten Cardigan Welsh Corgis stimmen mit den Beobachtungen bei SCID-Bassets überein (Somberg et al. 1995; Pullen et al. 1997).

\section{I.c SCID bei Jack Russell Terrier}

Bei SCID-Jack-Russell-Terriern sind im Gegensatz zu Bassets und Cardigan Welsh Corgis nicht nur die T-Zellen, sondern auch die B-Zellen betroffen (Bell et al. 2002). Es liegt eine deutliche bis absolute Lymphopenie vor. Zudem sind keine messbaren Konzentrationen der Immunglobuline IgM, IgG und IgA im peripheren Blut vorhanden. Neutrophile- und Makrophagenkonzentrationen sind leicht erhöht. Der Thymus ist wie bei Bassets und Corgis deutlich unterentwickelt. Es besteht keine erkennbare Differenzierung zwischen Kortex und Medulla. Im kortikalen Bereich des Thymus sind 
weinige C3- (T-Zell-Marker) positive Zellen nachweisbar. Auch die Lymphknoten und die Milz sind bei betroffenen Jack Russell Terriern unterentwickelt. Zudem liegt in Milz, Lymphknoten sowie in den lymphatischen Geweben des Verdauungstrakts und der Bronchien eine lymphoide Aplasie vor. In den Lymphknoten liegen weder C3- noch C79a- (B-Zell-Marker) positive Zellen vor. Dafür sind in betroffenen Lymphknoten lysozympositive Makrophagen besonders deutlich zu erkennen (Bell et al. 2002). Die ADA- und PNP-Aktivität liegt bei SCID-Jack-Russell-Terriern im normalen Bereich (Meek et al. 2001).

Auffälligkeiten liegen bezüglich der Rekombination von V(D)J (variable (V) diversity (D) joining (J)) Elementen der Immunglobulin- sowie der T-Zell-Rezeptor-Gene vor. Die Rekombination dieser Elemente im Verlauf der B- und T-Lymphozytenentwicklung stellt die Anpassung der Immunglobuline und T-Zell-Rezeptoren an das breite, sich ständig verändernde Spektrum von Antigenen sicher. Dieser Mechanismus wird unter anderem von den rekombinationsaktivierenden Genen RAG1 und RAG2 gesteuert, die Enzyme für die Durchführung der spezifischen DNA Spaltung im variablen Bereich der Ig- (Immunglobulin)- und TCR- (T-Zell-Rezeptor)-DNA codieren. Die Spaltprodukte lassen sich mittels ligasegesteuerter (ligase mediated) PCR (LMPCR) sowohl in normaler als auch in SCID-Thymus-DNA nachweisen. Ein Defekt von RAG1 und RAG2, der eine typische Ursache für autosomal rezessive SCID bei Menschen darstellt, liegt demnach bei SCID-Jack-Russell-Terriern nicht vor (Meek et al. 2001). Bei den Spaltungen entstehen jeweils drei Produkte, von denen die beiden äußeren zu einem codierenden DNA-Strang (coding joint) und die beiden Enden des mittleren Spaltproduktes zu einem DNA-Ring (signal joint) ligieren. Zudem entstehen bei diesem Prozess durch fehlerhaften Aufschluss der Spaltproduktenden so genannte Hybridstränge (hybrid joints), die durch Ligation des coding joints eines Gens mit dem signal joint eines anderen Gens entstehen. Bezüglich der signal joints sowie der hybrid joints bestehen Unterschiede zwischen normalen und SCID-Jack-Russell-Terriern, indem sowohl signal joints als auch hybrid joints in SCID-Thymozyten-DNA gegenüber normaler Thymozyten-DNA stark bzw. leicht reduziert sind. Bei der Steuerung der Ligation der Spaltprodukte spielt DNA-PK (DNA-abhängige Proteinkinase) eine wesentliche Rolle. Dabei hanelt es sich um einen extrem großer Multiproteinkomplex, der aus einer regulatorischen Untereinheit, dem heterodimeren 
Ku-Protein (benannt nach den ersten zwei Buchstaben des Namens des Patienten, bei dem dieses Protein erstmals entdeckt wurde (Mimori et al. 1981)), und einer katalytischen Untereinheit (DNA-PKcs) zusammengesetzt ist. Untersuchungen an Fibroblasten ergeben bei SCID Jack Russell Terriern keinerlei messbare DNA-PKAktivität, während bei normalen Jack Russell Terriern die Werte für DNA-PK-Aktivität etwa mittig zwischen den bei Pferden und Mäusen gemessenen Werten liegen. Mittels Immunoblot lässt sich ermitteln, dass bezüglich der regulatorischen Ku-ProteinUntereinheit keinerlei Konzentrationsunterschiede zwischen normalen und SCIDFibroblasten bestehen, währen die katalytische Untereinheit DNA-PKcs in Fibroblasten von SCID-Jack-Russel-Terriern nicht nachweisbar ist. Demnach führen die Autoren SCID bei Jack Russell Terriern auf einen Defekt der Untereinheit DNA-PKcs zurück, der einen gestörten Ablauf der V(D)J Rekombination von T-Zell-Rezeptor- und IgDNA und damit eine Störung der Entwicklung von B- und T-Lymphozyten zur Folge hat.

\section{II.a+b Genetischer Hintergrund der SCID bei Bassets und Cardigan Welsh Corgis}

Sowohl bei Bassets als auch bei Cardigan Welsh Corgis liegt ein X-chromosomaler Erbgang vor (Jezyk et al. 1989; Somberg et al. 1995). Kopplungsanalysen bei Bassets ergaben bezüglich der physikalischen Lokalisation Übereinstimmungen zwischen dem humanen SCIDX1-Lokus (assoziiert mit Typ1 der X-chromosomal gekoppelten SCIDFormen), der an Position Xq13,1 lokalisiert ist, mit dem caninen SCIDX1-Lokus. Die Vererbung von X-SCID beim Hund erfolgt eng gekoppelt an dieselben Gene, die auch beim Menschen mit dem SCIDX1-Lokus gekoppelt sind (Markiewicz et al. 1993; Puck et al. 1993; Deschenes et al. 1994).

Die für die Ausbildung von X-SCID bei Bassets und Cardigan Welsh Corgis verantwortliche Mutation betrifft wie bei humaner X-SCID das IL-2R $\gamma$-Gen, das für die $\gamma$-Kette des IL-2-Rezeptors codiert (Henthorn et al. 1994). Das canine IL-2R $\gamma$-Gen (Interleukin-2-Rezeptor-gamma-Untereinheit) ist auf dem X-Chromosom zwischen Position 58274064 und 58270467 lokalisiert und enthält 8 Exons, die auf einer cDNA Länge von 1204 bp für ein 373 Aminosäuren langes Polypeptid codieren (EnsemblGeneID: ENSCAFG00000016927). Diese Sequenz ist Grundlage der Abb. 27, die eine 
schematische Darstellung des caninen IL-R $\gamma$ Gens und der Lage der bisher identifizierten Mutationen beinhaltet.

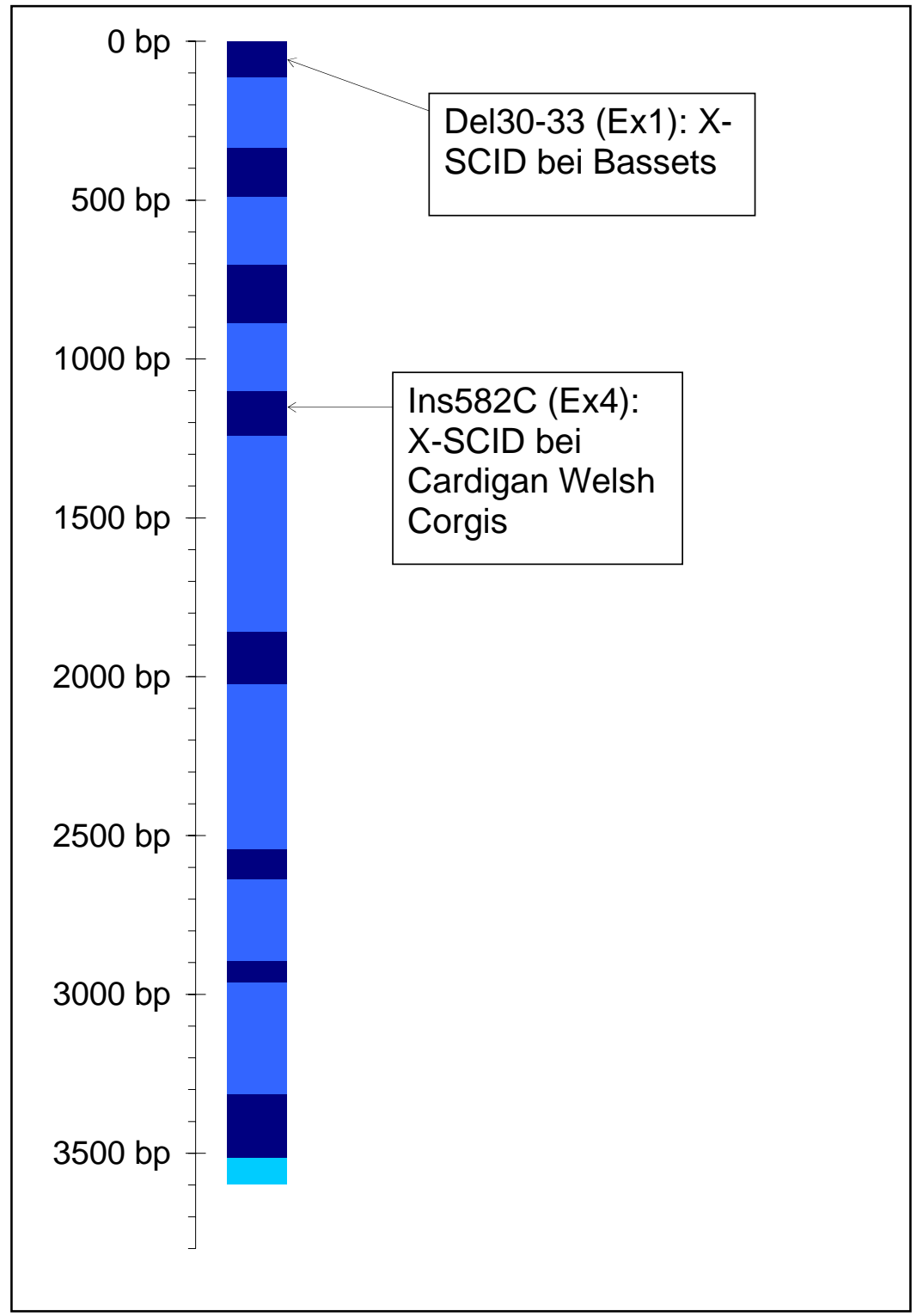

Abb. 27 Schematische Darstellung des caninen IL-2R $\gamma$ Gens und Lage der bisher identifizierten Mutationen. Dunkelblau: codierende Sequenz, hellblau, Intronsequenz, türkis: 3'-UTR.

\section{III.a Ursächliche Mutation für SCID bei Bassets}

Bei X-SCID Bassets liegt eine 4-bp-Deletion in Exon 1 des IL-2R $\gamma$-Gens vor, durch die ein neues Stoppcodon entsteht (Abb. 28). Das theoretisch zu erwartende Genprodukt hat eine Länge von 21 Aminosäuren, von denen nur zehn mit der normalen Polypeptidsequenz übereinstimmen (Henthorn et al. 1994). Diese Überlegung passt zu der signifikant reduzierten Bindung und der mangelhaften Reaktion auf IL-2, die bei 
PHA-aktivierten T-Zellen von betroffenen Hunden zu beobachten ist (Somberg et al. 1994).

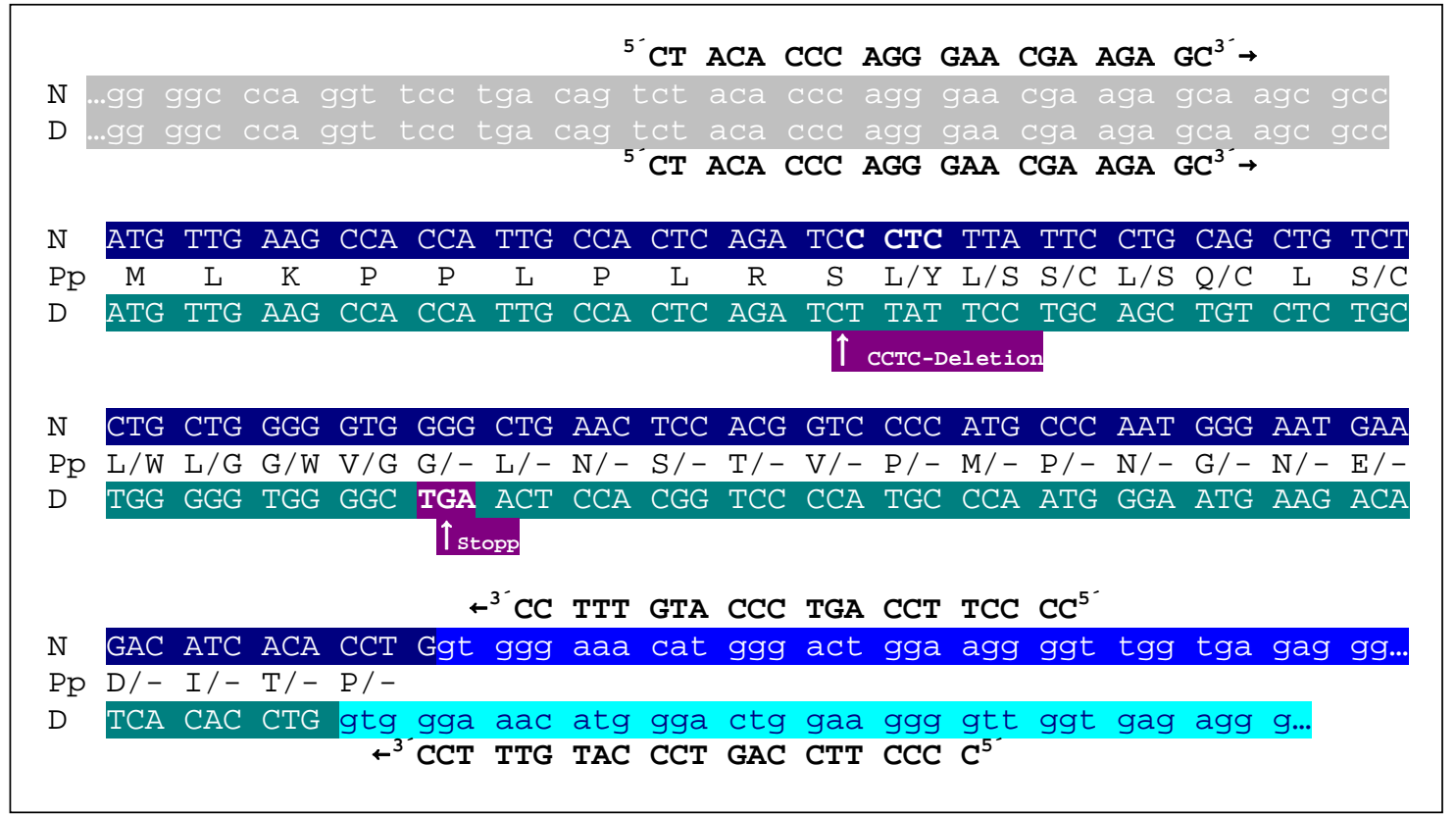

Abb. 28 5'UTR, Exon 1 und anschließende Intronsequenz des IL-2R $\gamma$-Gens. N: normale Sequenz, D: defekte Sequenz, Pp: Polypeptidsequenz, grau: UTR, dunkelblau: Exon normale Sequenz, hellblau: Intron normale Sequenz, dunkelgrün: Exon defekte Sequenz, türkis: Intron defekte Sequenz, deletierter Sequenzabschnitt in der normalen Sequenz fett gedruckt, Ort der Deletion in der defekten Sequenz sowie verfrühtes Stoppcodon durch Pfeil gekennzeichnet und violett markiert.

\section{III.b Ursächliche Mutation bei Cardigan Welsh Corgis}

Die IL-2R $\gamma$-cDNA von an X-SCID leidenden Cardigan Welsh Corgis unterscheidet sich von normaler caniner cDNA durch die Insertion einer einzelnen Base (C) an Nukleotidposition 582 in Exon 4 des IL-2R $\gamma$-Gens (Somberg et al. 1995). Die Folgen sind eine Leserasterverschiebung und ein daraus resultierendes, elf Basen in 3'Richtung von der Insertion gelegenes, neues Stoppcodon (Abb. 29). 


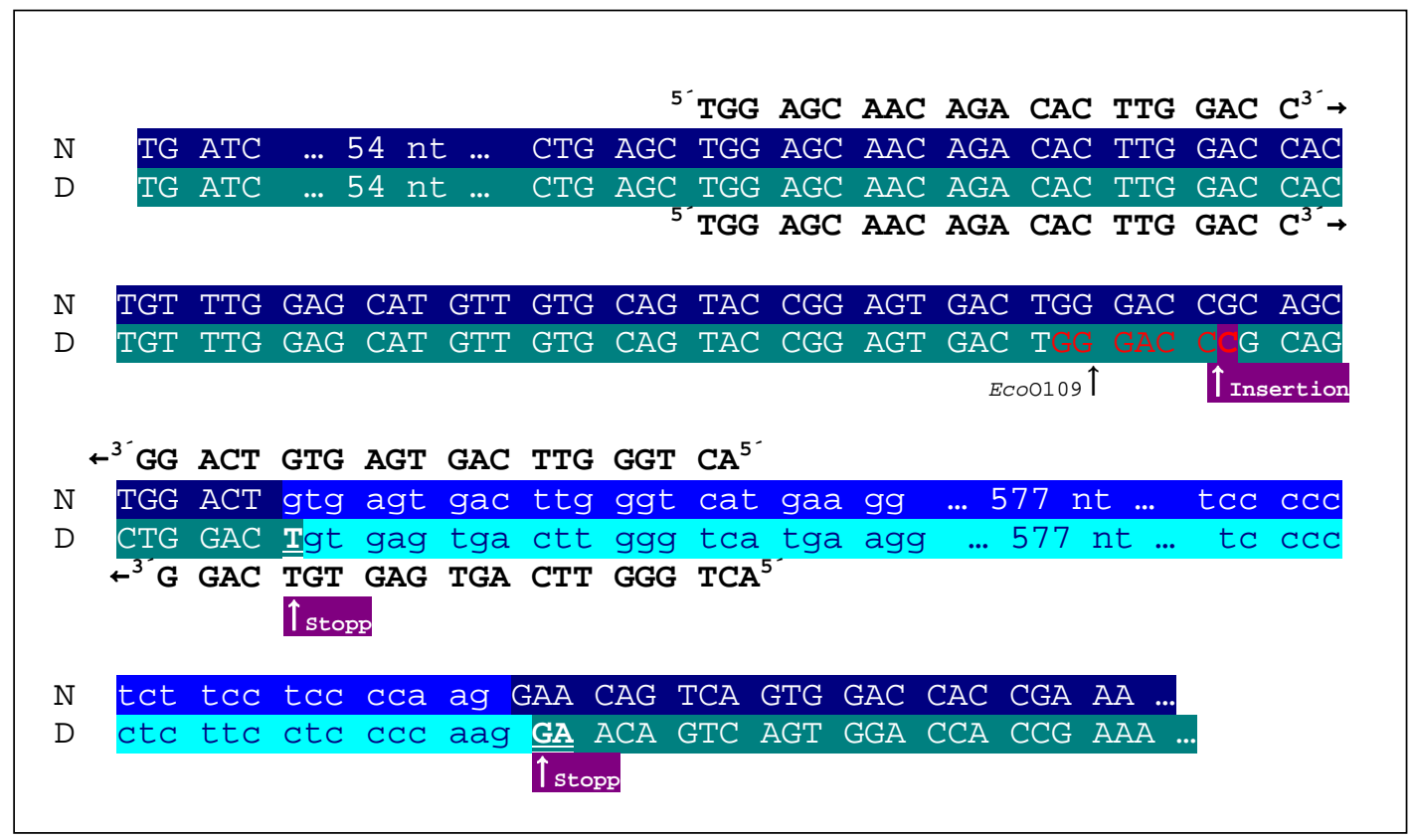

Abb. 29 Exon 4 bis Exon 5 des caninen Il-2R $\gamma$-Gens. N: normale Sequenz, D: defekte Sequenz, dunkelblau: Exon normale Sequenz, dunkelgrün: Exon defekte Sequenz, hellblau: Intron normale Sequenz, türkis: Intron defekte Sequenz, Insertion und verfrühtes Stoppcodon (gebildet durch die letzte Base in Exon 4 und die ersten beiden Basen in Exon 5) violett und durch Pfeile markiert, rote Schrift: EcoO109-Erkennungssequenz, EcoO109 Schnittstelle durch Pfeil markiert.

Sowohl bei Bassets als auch bei Cardigan Welsh Corgis ist die von mutierten XChromosomen transkribierte mRNA nicht instabil, denn in beiden Fällen ist die Synthese von cDNA in voller Länge möglich (Henthorn et al. 1994; Somberg et al. 1995). Trotzdem kommt es weder bei Bassets noch bei Cardigan Welsh Corgis mit SCID zur Expression der IL-2R $\gamma$ Kette auf der T-Lymphozyten Zellmembran, da die Mutationen zu verfrühten Stoppcodons führen. Bei Bassetts liegt die Deletion innerhalb der für das Signalpeptid codierenden Sequenz (Henthorn et al. 1994). Die Insertion und das neue Stoppcodon bei Cardigan Welsh Corgis liegen $5^{\prime}$ der für das konservierte Tryptophan-Serin-Xaa-Tryptophan-Serin-Motiv (WSXWS-Motiv mit Xaa=jede beliebige Aminosäure), das ein wesentliches Kennzeichen von Cytokin-Rezeptoren ist und eine entscheidende Rolle für die Funktionsfähigkeit der Rezeptoren spielt, sowie für die Transmembrandomäne codierenden Sequenzbereiche (Somberg et al. 1995). Damit sind in beiden Fällen entscheidende Bereiche des resultierenden Polypeptids nicht vorhanden. 


\section{IV.a Genotypisierung für SCID bei Bassets}

Der Nachweis der Mutation kann per Amplifikation eines 165-bp-Fragments vom Defektallel bzw. 169-bp-Fragments vom Wildtypallel aus genomischer DNA und anschließender Fragmentgrößenanalyse per Elektrophorese erfolgen (Henthorn et al. 1994).

\section{IV.b Genotypisierung für SCID bei Cardigan Welsh Corgis}

Der Nachweis der Mutation kann per RFLP-Typisierung erfolgen. Der zugrunde liegende RFLP basiert auf dem Vorhandensein einer EcoO109-Erkennungssequenz im Wildtypallel, die im Defektallel aufgrund der Mutation nicht enthalten ist (Somberg et al. 1995).

\section{II.c Genetischer Hintergrund von SCID bei Jack Russell Terriern}

Der Erbgang von SCID bei Jack Russell Terriern ist autosomal rezessiv. Beim Menschen sind verschiedene Formen von autosomal rezessiv vererbbarer SCID bekannt. In allen Fällen sind sowohl B- als auch T-Zellen betroffen. Genetische Ursachen können ADA- oder PNP-Defizienz, Defekte von Genen zur Aktivierung von Rekombinationsereignissen (RAG-1, RAG-2) oder Defekte des an der Steuerung des DNA-Reparations-Mechanismus beteiligten DNA-PK-Gens sein. ADA- und PNPDefizienz führen zur Akkumulation von Nukleotidmetaboliten, die toxisch auf die Entwicklung von Lymphozyten einwirken. RAG-1- und RAG-2-Gendefekte sowie Defekte des DNA-PK Gens stören die Rekombination von Ig- und T-Zell-RezeptorDNA und hemmen damit die Lymphozytenentwicklung.

SCID bei Jack Russell Terriern konnte mittels immunologischer Untersuchungen auf einen Defekt der katalytischen Untereinheit der DNA-abhängigen Proteinkinase (DNAPKcs, cs = catalytic subunit) zurückgeführt werden (Meek et al. 2001). Das canine DNA-PKcs-Gen ist auf Chromosom 29 lokalisiert (Ding et al. 2002) und enthält auf einer Gesamtlänge von 220283 bp 86 Exons, deren Lage innerhalb der genomischen Sequenz in Abb. 30 dargestellt ist. Im genomischen GenBank Contig NW_876288 reicht das DNA-PKcs-Gen von Nukleotid 246335 bis 26053 (NCBI-GeneID: 474176, 
Stand: 04.10.2007). Die mRNA (NCBI-GenBank: AF448227) codiert auf einer Länge von 12435 bp ein 4144 Aminosäuren langes Protein.

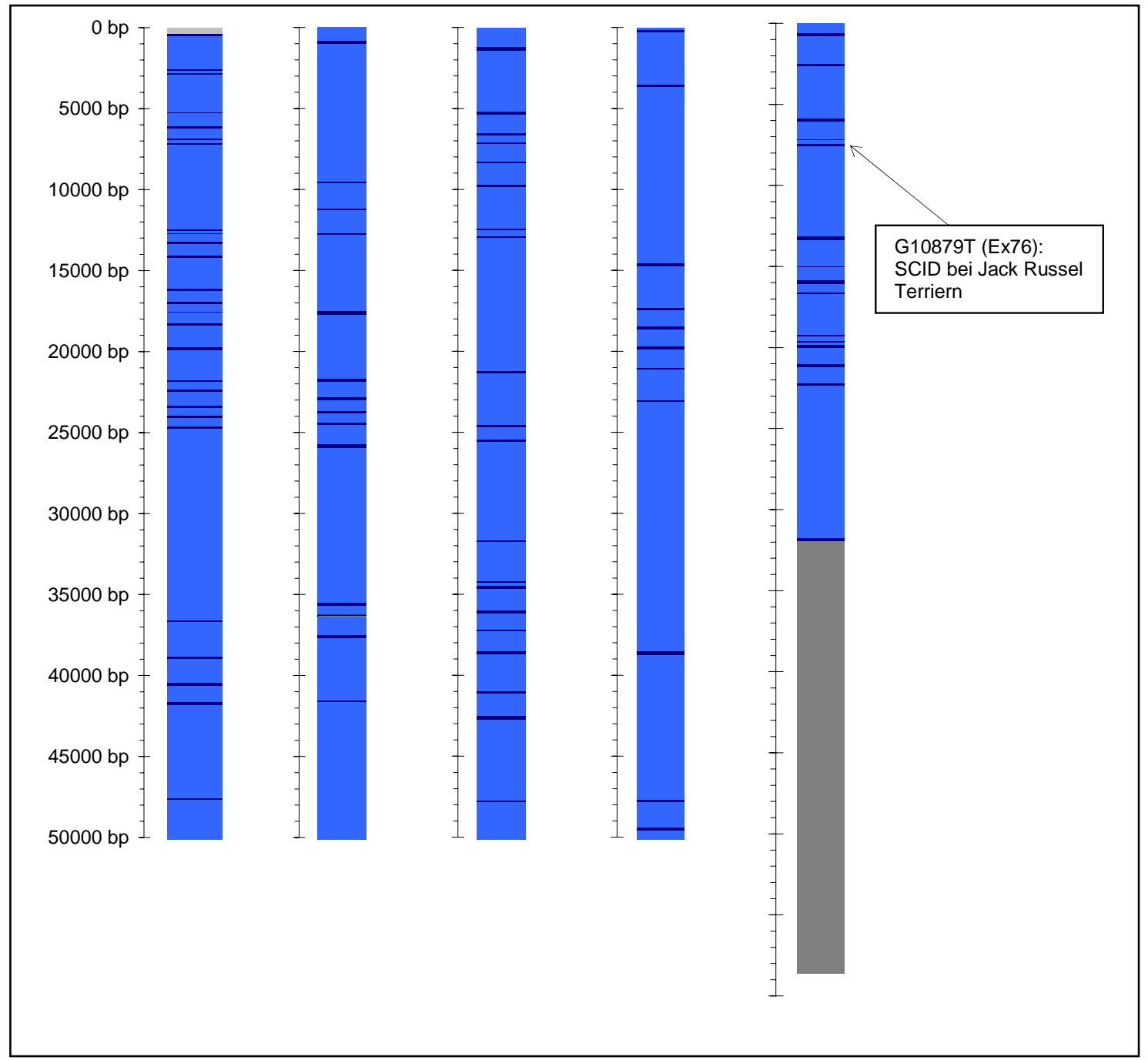

Abb. 30 Schematische Darstellung des caninen DNA-PKcs-Gens und Lage der bisher identifizierten Mutationen. Dunkelblau: codierende Sequenz, hellblau: Intronsequenz, grau: intergenische Sequenz.

\section{III.c Ursächliche Mutation für SCID bei Jack Russel Terriern}

Die für SCID bei Jack Russel Terriern verantwortliche Mutation besteht in einer Substitution an Position 10879 der cDNA und führt an Aminosäurenposition $3627 \mathrm{zu}$ einem Stoppcodon anstelle des bei normalen Hunden an dieser Stelle stehenden Glutamats (Abb. 31) (Ding et al. 2002). 


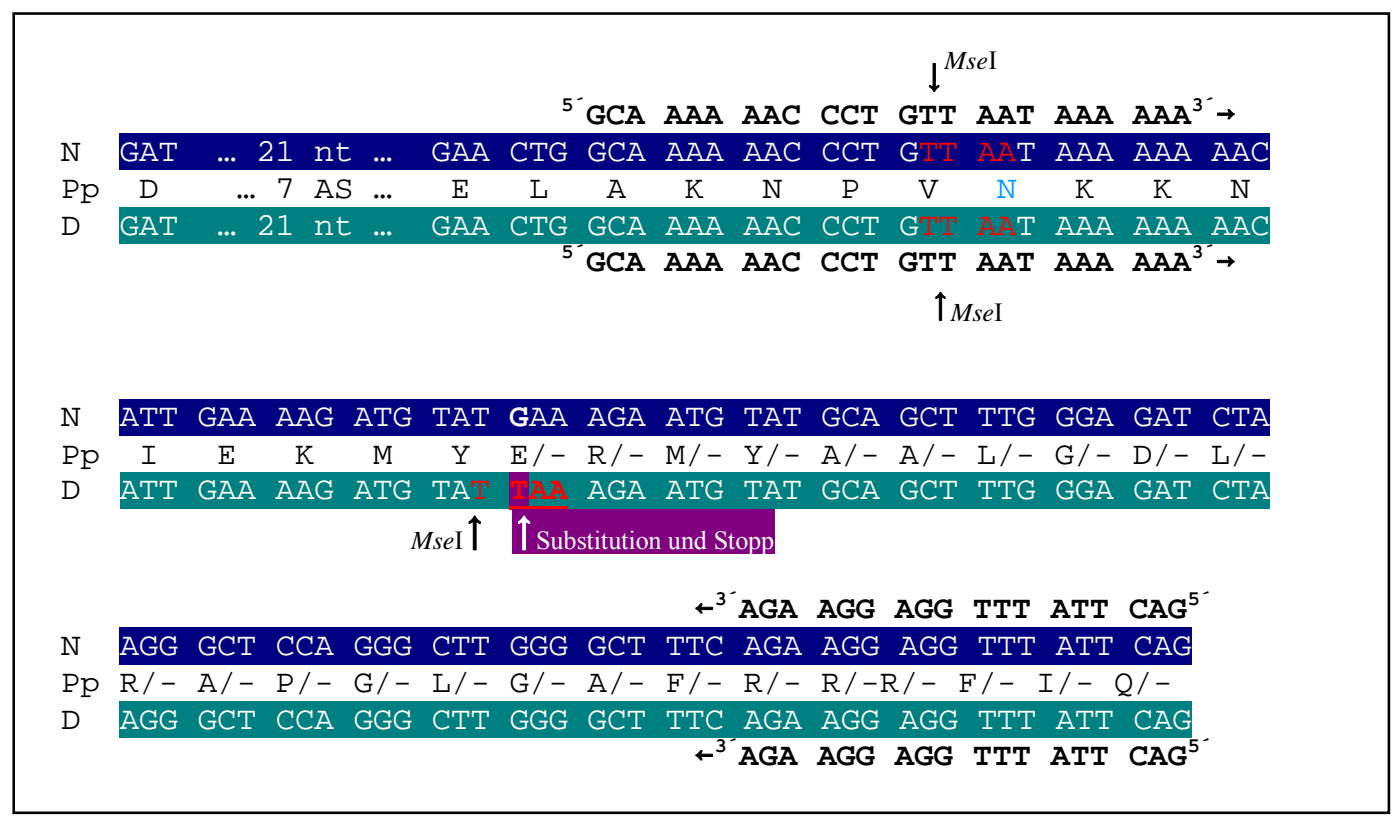

Abb. 31 Exon 76 des DNA-PKes-Gens (PRKDC). N: normale Sequenz, D: defekte Sequenz, Pp: Polypeptidsequenz, dunkelblau: Exon normale Sequenz, dunkelgrün: Exon defekte Sequenz, Substitution und resultierendes Stoppcodon violett markiert, rote Schrift: MseI-Erkennungssequenz, MseISchnittstellen durch Pfeile bezeichnet.

\section{IV.c Genotypisierung für SCID bei Jack Russell Terriern}

Der Nachweis der Substitution kann per Amplifikation eines 117-bp-Fragments aus Exon 76 und anschließender Restriktionsspaltung mit MseI erfolgen. Der FLP beruht auf einer zusätzlichen, durch die Mutation entstehenden MseI-Erkennungssequenz im Defektallel (Ding et al. 2002). 


\subsubsection{C3-Defizienz}

\begin{tabular}{|ll|}
\hline Chromosom: & CFA20 \\
Gen: & C3 \\
Ensembl: & GeneID:ENSCAFG00000018625 \\
DNA-Sequenz: & CFA20, Position 56409675-56440977 \\
Mutationen: & DelC163, Bretonischer Spaniel \\
\hline
\end{tabular}

\section{Krankheitsbild}

Alle Berichte über canine C3-Defizienz beziehen sich auf Hunde aus einer Linie Bretonischer Spaniels, die einer Zuchtkolonie zur Erforschung der caninen erblichen Muskelatrophie angehört, in der unabhängig von der erblichen Muskelatrophie erstmals 1981 Fälle von C3-Defizienz auftraten (Winkelstein et al. 1981). Über die Verbreitung der Erkrankung innerhalb der gesamten Rasse sind keine Zahlen veröffentlicht.

C3 ist die Komponente des Komplementsystems mit der höchsten Plasmakonzentration und spielt eine wichtige Rolle bei der Einleitung des alternativen Wegs zur Aktivierung des Komplementsystems und damit der Aktivierung der Immunzytolyse. Daneben sorgt C3 durch die Interaktion mit zahlreichen verschiedenen Serumkomponenten auch für eine Erhöhung der Gefäßdurchlässigkeit, leichte Muskelkontraktionen, Opsonisierung, Freisetzung von nichtzytotoxischen Enzymen der Granulozyten sowie Aufschluss und Beseitigung von Immunkomplexen und ist zudem an der Proliferation der B-Zellen beteiligt (Becherer et al. 1990). Die Synthese von C3 findet hauptsächlich in der Leber statt. Aber auch in anderen Zelltypen wird C3 exprimiert, so in einkernigen Phagozyten, polymorphkernigen Neutrophilen, Fibroblasten, im Uterusepithel, im Epithel der Nierengänge, im Kapillar- und Gefäßendothel, in Typ-II-Alveolarzellen, in Lungenzellen, in aktivierten T-Zellen, in Bindegewebszellen, in Fettzellen und in Astroglia (zusammengefasst bei Singer et al. 1994).

Die Erkrankung äußert sich in schweren bakteriellen Infektionen wie Lungenentzündung, Gebärmutterentzündung und Sepsis. Zum Teil starben die Hunde ohne äußere klinische Anzeichen. In diesen Fällen zeigten histopathologische Untersuchungen E.coli-Infektionen in Lunge, Nieren, Prostata und Blase. Von 15 C3defizienten Hunden, die an einer sechsjährigen Studie beteiligt waren, konnten nur fünf länger als vier Wochen am Leben gehalten werden (Blum et al. 1985). Ein weiterer 
wesentlicher Effekt der C3-Defizienz bei Hunden ist die Neigung zur Glomerulonephritis verursacht durch Amyloidablagerungen in der mesangialen Matrix, die zu einer stetigen Verdickung der Kapillarwände der Glomeruli führen (Cork et al. 1991). Bei diesen Amyloiden handelt es sich vor allem um IgG und IgM, die sich vermutlich aufgrund einer unvollständigen Clearance zirkulierender Immunkomplexe in der Niere ablagern.

Immunologische Serumuntersuchungen zeigen bei betroffenen Hunden eine totale Defizienz von C3 (Winkelstein et al. 1981). Auch mit sensitiveren immunologischen Methoden zur Bestimmung des C3-Gehaltes im Serum konnte bei sechs von neun C3defizienten Hunden kein C3 gefunden werden. Lediglich drei der C3-defizienten Hunde wiesen in einer 1:10 verdünnten Serumlösung eine C3-Konzentration auf, die der Konzentration in einer 1/300000 verdünnten Serumlösung von normalen Hunden entspricht (Winkelstein et al. 1981). Trotzdem weisen alle C3-defizienten Hunde eine C3-artige hämolytische Aktivität auf, die etwa 3-10\% der normalen hämolytischen Aktivität beträgt (Winkelstein et al. 1981).

Der C3-Mangel hat bei allen C3-defizienten Hunden eine starke Reduzierung der chemotaktischen und opsonisierenden Serumaktivität zur Folge (Winkelstein et al. 1981). Daraus lässt sich eine wichtige Rolle von C3 bei der spezifischen humoralen Immunantwort ableiten. Am deutlichsten ist der Effekt einer C3-Defizienz auf die Antikörperreaktion nach einer primären Immunisierung. Es erfolgt eine quantitativ normale Reaktion, die IgG-Werte sind jedoch deutlich reduziert. Diese abnorme Reaktion ist nicht auf T-Zellen-abhängige Antigene beschränkt sondern verläuft ebenso bei Immunisierung mit T-Zellen-unabhängigen Antigenen (O'Neil et al. 1988).

\section{Genetischer Hintergrund}

Der Erbgang ist autosomal rezessiv. Heterozygote haben etwa $50 \%$ der bei normalen Hunden gemessenen C3-Konzentration. Das entspricht Werten innerhalb oder leicht unterhalb des unteren Grenzbereichs der normalen C3-Konzentration (Winkelstein et al. 1981). Das Gen befindet sich auf Chromosom 20 zwischen Position 56409575 und 56440977, das Transkript umfasst auf einer Länge von 4638 bp 39 Exons und codiert 
für ein 1564 Aminosäuren langes Protein (Ensembl-GeneID: ENSCAFG00000018625, Release 41, Oktober 2006). Die Genstruktur ist in Abb. 32 schematisch dargestellt.

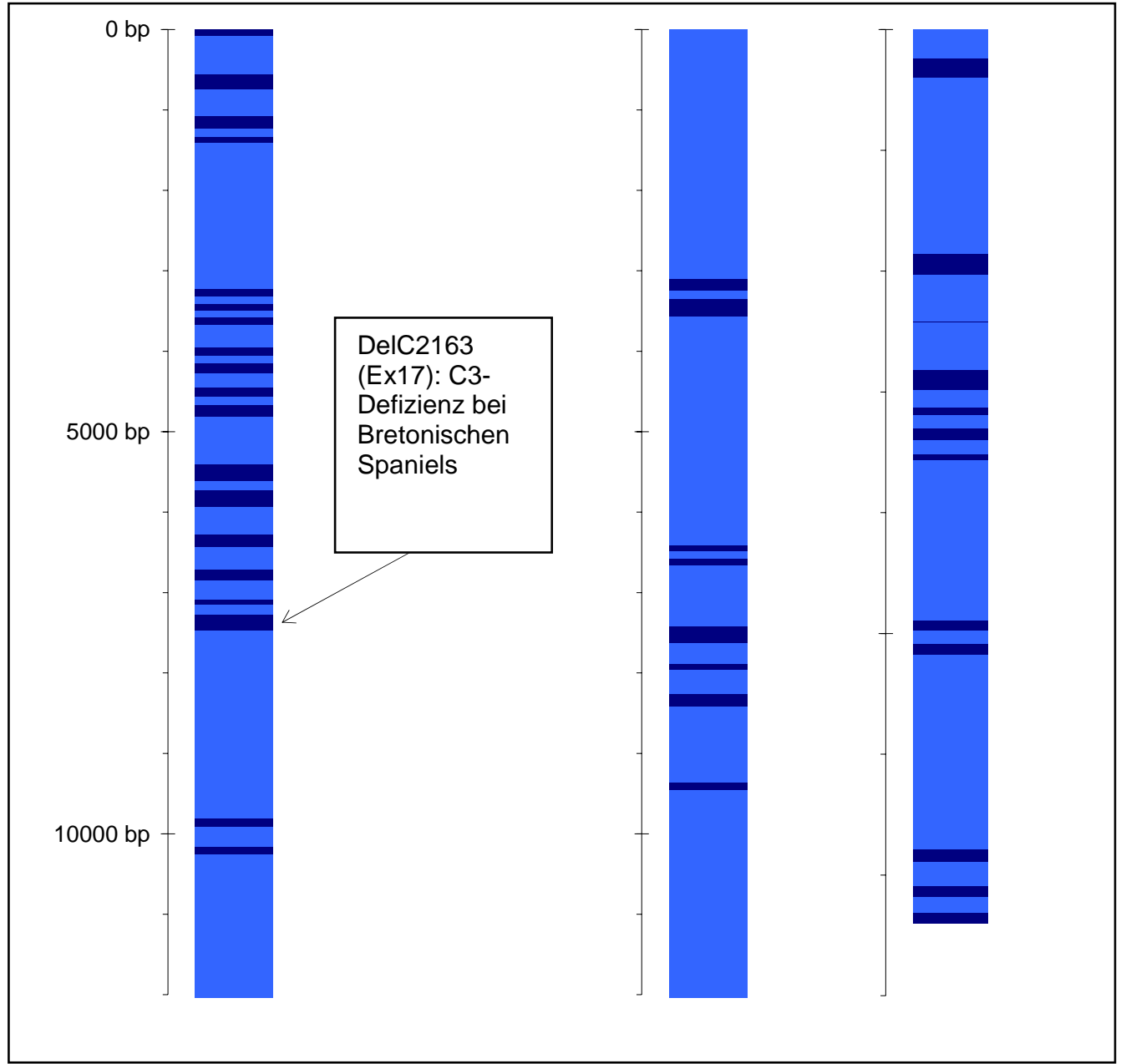

Abb. 32 Schematische Darstellung des caninen C3-Gens und Lage der bisher identifizierten Mutationen. Dunkelblau: codierende Sequenz, hellblau: Intronsequenz.

\section{Ursächliche Mutation der C3-Defizienz bei Bretonischen Spaniels}

Molekulargenetische Untersuchungen zeigten bei C3-defizienten Hunden eine auf $10 \%$ der normalen Konzentration reduzierte Menge an C3-mRNA. Sequenzvergleiche zwischen normaler und C3-defizienter cDNA ergaben bei kranken Hunden eine Deletion des Cytosins an Position 2136 der cDNA in Exon 17. Die Folge der Deletion ist eine Leserasterverschiebung und ein verfrühtes Stoppcodon, das 11 Codons in 3'Richtung der Deletion gelegen ist (Abb. 33). Das resultierende Protein müsste erwartungsgemäß aus der $\beta$-Kette und einem Teil der $\alpha$-Kette zusammengesetzt sein (Ameratunga et al. 1998). 


\section{Genotypisierung für C3-Defizienz bei Bretonischen Spaniels}

Der Nachweis der Mutation auf Basis von genomischer DNA kann über die Amplifikation eines 150-bp-Fragments aus Exon 17 und anschließende Analyse der Produkte mit allelspezifischen Oligonukleotid-Sonden (ASO) erfolgen (Ameratunga et al. 1998).

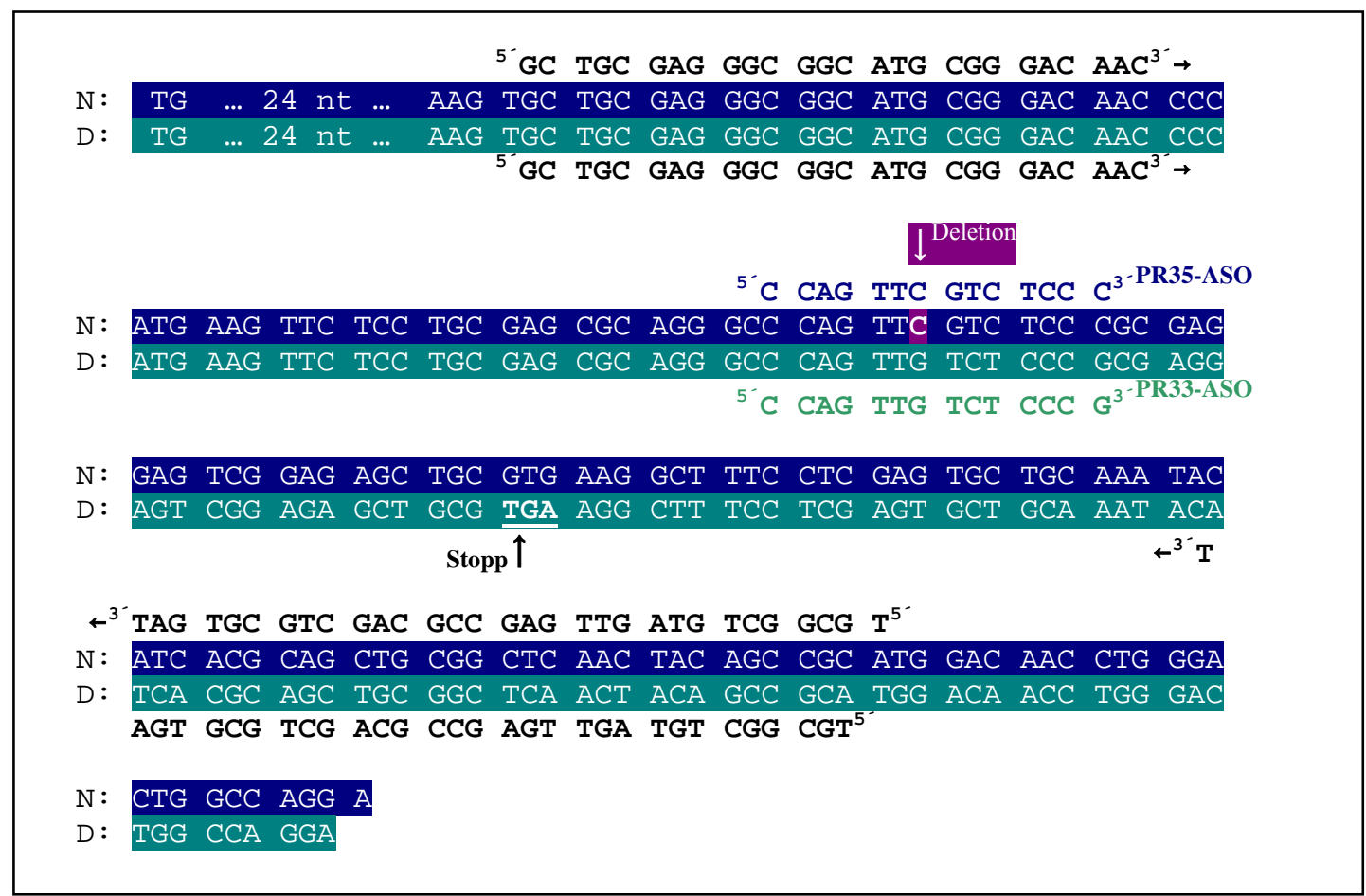

Abb. 33 Exon 17 des caninen C3 Gens. N: normale Sequenz, D: defekte Sequenz, von Deletion betroffenes Nukleotid in normaler Sequenz violett markiert, fett gedruckt und durch Pfeil gekennzeichnet, Stoppcodon in defekter Sequenz fett gedruckt, unterstrichen und durch Pfeil gekennzeichnet, dunkelblaue Schrift: PR35-ASO (für normale Sequenz spezifisches Oligonukleotid), dunkelgrüne Schrift: PR33-ASO (für defekte Sequenz spezifisches Oligonukleotid). 


\subsubsection{Primerliste}

Tabelle $5 \quad$ Liste der in Kapitel 3.2 genannten Primer

\begin{tabular}{|c|c|c|c|c|}
\hline $\begin{array}{l}\text { Krankheit/ } \\
\text { Merkmal }\end{array}$ & Zweck & Primer & $\begin{array}{l}\text { PCR- } \\
\text { Produkt } \\
{[\mathrm{bp}]}\end{array}$ & Quelle \\
\hline $\begin{array}{l}\text { Zyklische } \\
\text { Neutropenie } \\
\text { bei Collies }\end{array}$ & $\begin{array}{l}\text { diagnostische } \\
\text { Sequenzierung }\end{array}$ & $\begin{array}{l}\mathrm{V}:{ }^{5}{ }^{\prime} \text { ACCCAGGATTGAGTCCCATGTCAGG }{ }^{3} \\
\text { r: }{ }^{3} \text { CTACAAAGTGAAGATCTGGACCTAC }{ }^{\prime \prime}\end{array}$ & 341 & (Benson et al. 2004) \\
\hline $\begin{array}{l}\text { CLAD bei } \\
\text { Irischen } \\
\text { Settern }\end{array}$ & $\begin{array}{l}\mathrm{OLA} / \mathrm{RFLP} / \mathrm{Py}- \\
\text { rosequenzierung }\end{array}$ & $\begin{array}{l}\mathrm{V}:{ }^{\prime 5}{ }^{\prime} \text { CGTCCTGCCAGGAGTGCACCAAGTA }^{3^{\prime}} \\
\mathrm{r:}{ }^{3}{ }^{\prime} \mathrm{GCCGACGCGGACCACGGTCTTCG}^{5^{\prime}}\end{array}$ & 87 & $\begin{array}{l}\text { (Kijas et al. 1999; } \\
\text { Verfaillie et al. 2004; } \\
\text { Pfeiffer und Brenig } \\
\text { 2005) }\end{array}$ \\
\hline $\begin{array}{l}\text { SCID bei } \\
\text { Bassets }\end{array}$ & $\begin{array}{l}\text { PCR-Fragment- } \\
\text { größenanalyse }\end{array}$ & $\begin{array}{l}\mathrm{V}:{ }^{\prime}{ }^{\prime} \text { CTACACCCAGGGAACGAAGAGC }{ }^{3^{\prime}} \\
\mathrm{r}:{ }^{3}{ }^{\prime} \text { CCTTTGTACCCTGACCTTCCCC }{ }^{5^{\prime}}\end{array}$ & 169 & (Henthorn et al. 1994) \\
\hline $\begin{array}{l}\text { SCID bei } \\
\text { Cardigan } \\
\text { Welsh } \\
\text { Corgis }\end{array}$ & RFLP & $\begin{array}{l}\mathrm{V}:{ }^{5} \text { TGGAGCAACAGACACTTGGACC }{ }^{3^{\prime}} \\
\text { r: }{ }^{3} \text { GGACTGTGAGTGACTTGGGTCA }{ }^{5^{\prime}}\end{array}$ & 191 & (Somberg et al. 1995) \\
\hline $\begin{array}{l}\text { SCID bei } \\
\text { Jack Russel } \\
\text { Terriern }\end{array}$ & RFLP & $\begin{array}{l}\text { V: }{ }^{5}{ }^{\prime} \text { GCAAAAAACCCTGTTAATAAAAAA }{ }^{3 \prime} \\
\text { r: }{ }^{\prime}{ }^{\prime} \text { AGAAGGAGGTTTATTCAG }{ }^{5}\end{array}$ & 117 & (Ding et al. 2002) \\
\hline $\begin{array}{l}\text { C3- } \\
\text { Defizienz } \\
\text { bei Bretoni- } \\
\text { schen } \\
\text { Spaniels }\end{array}$ & ASO & 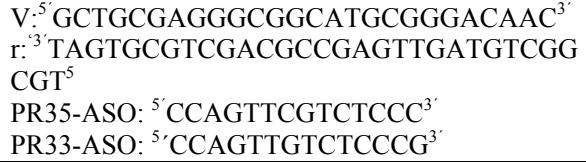 & 150 & $\begin{array}{l}\text { (Ameratunga et al. } \\
\text { 1998) }\end{array}$ \\
\hline
\end{tabular}

V: Vorwärtsprimer, 5'-3'-Richtung, r: reverser Primer, 3'-5'-Richtung, ASO: allelspezifisches Oligonukleotid 


\subsubsection{Literatur}

Ameratunga, R., Winkelstein, J.A., Brody, L., Binns, M., Cork, L.C., Colombani, P. und Valle, D. (1998): Molecular analysis of the third component of canine complement (C3) and identification of the mutation responsible for hereditary canine C3 deficiency. J Immunol, 160 (6), 2824-30.

Anderson, D.C., Schmalsteig, F.C., Finegold, M.J., Hughes, B.J., Rothlein, R., Miller, L.J., Kohl, S., Tosi, M.F., Jacobs, R.L., Waldrop, T.C. und et al. (1985): The severe and moderate phenotypes of heritable Mac-1, LFA-1 deficiency: their quantitative definition and relation to leukocyte dysfunction and clinical features. J Infect Dis, 152 (4), 668-89.

Anderson, D.C. und Springer, T.A. (1987): Leukocyte adhesion deficiency: an inherited defect in the Mac-1, LFA-1, and p150,95 glycoproteins. Annu Rev Med, 38, 17594.

Becherer, J., Alsenz, J. und Lambris, J. (1990): Molecular aspects of C3 interactions and structural/functional analysis of $\mathrm{C} 3$ from different species. In Lambris, J. (Herausgeber): The third component of complement: chemistry and biology. Springer, Berlin 1990, S. 45-72 ???

Bell, T.G., Butler, K.L., Sill, H.B., Stickle, J.E., Ramos-Vara, J.A. und Dark, M.J. (2002): Autosomal recessive severe combined immunodeficiency of Jack Russell terriers. J Vet Diagn Invest, 14 (3), 194-204.

Benson, K.F., Li, F.Q., Person, R.E., Albani, D., Duan, Z., Wechsler, J., Meade-White, K., Williams, K., Acland, G.M., Niemeyer, G., Lothrop, C.D. und Horwitz, M. (2003): Mutations associated with neutropenia in dogs and humans disrupt intracellular transport of neutrophil elastase. Nat Genet, 35 (1), 90-6.

Benson, K.F., Person, R.E., Li, F.Q., Williams, K. und Horwitz, M. (2004): Paradoxical homozygous expression from heterozygotes and heterozygous expression from homozygotes as a consequence of transcriptional infidelity through a polyadenine tract in the AP3B1 gene responsible for canine cyclic neutropenia. Nucleic Acids Res, 32 (21), 6327-33.

Blum, J.R., Cork, L.C., Morris, J.M., Olson, J.L. und Winkelstein, J.A. (1985): The clinical manifestations of a genetically determined deficiency of the third component of complement in the dog. Clin Immunol Immunopathol, 34 (3), 30415.

Calvete, J.J., Henschen, A. und Gonzalez-Rodriguez, J. (1991): Assignment of disulphide bonds in human platelet GPIIIa. A disulphide pattern for the betasubunits of the integrin family. Biochem J, 274 ( Pt 1), 63-71. 
Clark, R.H., Stinchcombe, J.C., Day, A., Blott, E., Booth, S., Bossi, G., Hamblin, T., Davies, E.G. und Griffiths, G.M. (2003): Adaptor protein 3-dependent microtubule-mediated movement of lytic granules to the immunological synapse. Nat Immunol, 4 (11), 1111-20.

Cork, L.C., Morris, J.M., Olson, J.L., Krakowka, S., Swift, A.J. und Winkelstein, J.A. (1991): Membranoproliferative glomerulonephritis in dogs with a genetically determined deficiency of the third component of complement. Clin Immunol Immunopathol, 60 (3), 455-70.

Dale, D.C., Rodger, E., Cebon, J., Ramesh, N., Hammond, W.P. und Zsebo, K.M. (1995): Long-term treatment of canine cyclic hematopoiesis with recombinant canine stem cell factor. Blood, 85 (1), 74-9.

Debenham, S.L., Millington, A., Kijast, J., Andersson, L. und Binns, M. (2002): Canine leucocyte adhesion deficiency in Irish red and white setters. J Small Anim Pract, 43 (2), 74-5.

Dell'Angelica, E.C., Shotelersuk, V., Aguilar, R.C., Gahl, W.A. und Bonifacino, J.S. (1999): Altered trafficking of lysosomal proteins in Hermansky-Pudlak syndrome due to mutations in the beta $3 \mathrm{~A}$ subunit of the AP-3 adaptor. Mol Cell, 3 (1), 11-21.

Dell'Angelica, E.C., Mullins, C., Caplan, S. und Bonifacino, J.S. (2000): Lysosomerelated organelles. Faseb J, 14 (10), 1265-78.

Deschenes, S.M., Puck, J.M., Dutra, A.S., Somberg, R.L., Felsburg, P.J. und Henthorn, P.S. (1994): Comparative mapping of canine and human proximal Xq and genetic analysis of canine X-linked severe combined immunodeficiency. Genomics, 23 (1), 62-8.

Ding, Q., Bramble, L., Yuzbasiyan-Gurkan, V., Bell, T. und Meek, K. (2002): DNAPKcs mutations in dogs and horses: allele frequency and association with neoplasia. Gene, 283 (1-2), 263-9.

Felsburg, P.J., Somberg, R.L. und Perryman, L.E. (1992): Domestic animal models of severe combined immunodeficiency: canine X-linked severe combined immunodeficiency and severe combined immunodeficiency in horses. Immunodefic Rev, 3 (4), 277-303.

Ford, L. (1956): A case history of two lethal silver-gray pups. Collie Genetics and Breeding, 15, 33-36.

Ford, L. (1969): Hereditary aspects of human and canine cyclic neutropenia. J Hered, 60 (5), 293-9.

Foureman, P., Whiteley, M. und Giger, U. (2002): Canine leukocyte adhesion deficiency: presence of the Cys36Ser beta-2 integrin mutation in an affected US Irish Setter cross-breed dog and in US Irish Red and White Setters. $J$ Vet Intern Med, 16 (5), 518-23. 
Giger, U., Boxer, L.A., Simpson, P.J., Lucchesi, B.R. und Todd, R.F., 3rd (1987): Deficiency of leukocyte surface glycoproteins Mo1, LFA-1, and Leu M5 in a dog with recurrent bacterial infections: an animal model. Blood, 69 (6), 1622-30.

Hammond, W.P., Engelking, E.R. und Dale, D.C. (1979): Cyclic hematopoiesis. Effects of endotoxin on colony-forming cells and colony-stimulating activity in grey collie dogs. J Clin Invest, 63 (4), 785-92.

Hammond, W.P., Rodger, E.R. und Dale, D.C. (1987): Lithium augments GM-CSA generation in canine cyclic hematopoiesis. Blood, 69 (1), 117-23.

Hammond, W.P., Boone, T.C., Donahue, R.E., Souza, L.M. und Dale, D.C. (1990): A comparison of treatment of canine cyclic hematopoiesis with recombinant human granulocyte-macrophage colony-stimulating factor (GM-CSF), G-CSF interleukin-3, and canine G-CSF. Blood, 76 (3), 523-32.

Henthorn, P.S., Somberg, R.L., Fimiani, V.M., Puck, J.M., Patterson, D.F. und Felsburg, P.J. (1994): IL-2R gamma gene microdeletion demonstrates that canine X-linked severe combined immunodeficiency is a homologue of the human disease. Genomics, 23 (1), 69-74.

Hirschhorn, R. (1993): Overview of biochemical abnormalities and molecular genetics of adenosine deaminase deficiency. Pediatr Res, 33 (1 Suppl), S35-41.

http://genome.ucsc.edu: Dog Genome Browser. aufgerufen am 15. Februar 2007

Huizing, M., Sarangarajan, R., Strovel, E., Zhao, Y., Gahl, W.A. und Boissy, R.E. (2001): AP-3 mediates tyrosinase but not TRP-1 trafficking in human melanocytes. Mol Biol Cell, 12 (7), 2075-85.

Huizing, M., Scher, C.D., Strovel, E., Fitzpatrick, D.L., Hartnell, L.M., Anikster, Y. und Gahl, W.A. (2002): Nonsense mutations in ADTB3A cause complete deficiency of the beta3A subunit of adaptor complex-3 and severe Hermansky-Pudlak syndrome type 2. Pediatr Res, 51 (2), 150-8.

Jezyk, P.F., Felsburg, P.J., Haskins, M.E. und Patterson, D.F. (1989): X-linked severe combined immunodeficiency in the dog. Clin Immunol Immunopathol, 52 (2), 173-89.

Jobling, A.I., Ryan, J. und Augusteyn, R.C. (2003): The frequency of the canine leukocyte adhesion deficiency (CLAD) allele within the Irish Setter population of Australia. Aust Vet J, 81 (12), 763-5.

Kijas, J.M., Bauer, T.R., Jr., Gafvert, S., Marklund, S., Trowald-Wigh, G., Johannisson, A., Hedhammar, A., Binns, M., Juneja, R.K., Hickstein, D.D. und Andersson, L. (1999): A missense mutation in the beta-2 integrin gene (ITGB2) causes canine leukocyte adhesion deficiency. Genomics, 61 (1), 101-7.

Kijas, J.M., Juneja, R.K., Gafvert, S. und Andersson, L. (2000): Detection of the causal mutation for canine leukocyte adhesion deficiency (CLAD) using pyrosequencing. Anim Genet, 31 (5), 326-8. 
Landegren, U., Kaiser, R., Sanders, J. und Hood, L. (1988): A ligase-mediated gene detection technique. Science, 241 (4869), 1077-80.

Li, F.Q. und Horwitz, M. (2001): Characterization of mutant neutrophil elastase in severe congenital neutropenia. J Biol Chem, 276 (17), 14230-41.

Lienhart, R. (1954): Les Robes bringees. Le Chien, 20, 6-8.

Löffler, G. (1998): Basiswissen Biochemie mit Pathobiochemie. (3. Auflage) SpringerVerlag, Berlin Heidelberg New York 1998.

Lund, J.E., Padgett, G.A. und Ott, R.L. (1967): Cyclic neutropenia in grey collie dogs. Blood, 29 (4), 452-61.

Markiewicz, S., DiSanto, J.P., Chelly, J., Fairweather, N., Le Marec, B., Griscelli, C., Graeber, M.B., Muller, U., Fischer, A., Monaco, A.P. und et al. (1993): Fine mapping of the human SCIDX1 locus at Xq12-13.1. Hum Mol Genet, 2 (6), 6514.

Meek, K., Kienker, L., Dallas, C., Wang, W., Dark, M.J., Venta, P.J., Huie, M.L., Hirschhorn, R. und Bell, T. (2001): SCID in Jack Russell terriers: a new animal model of DNA-PKcs deficiency. J Immunol, 167 (4), 2142-50.

Mimori, T., Akizuki, M., Yamagata, H., Inada, S., Yoshida, S. und Homma, M. (1981): Characterization of a high molecular weight acidic nuclear protein recognized by autoantibodies in sera from patients with polymyositis-scleroderma overlap. $J$ Clin Invest, 68 (3), 611-20.

Nyhan, W.L. (2005): Disorders of purine and pyrimidine metabolism. Mol Genet Metab, 86 (1-2), 25-33.

O'Neil, K.M., Ochs, H.D., Heller, S.R., Cork, L.C., Morris, J.M. und Winkelstein, J.A. (1988): Role of C3 in humoral immunity. Defective antibody production in C3deficient dogs. J Immunol, 140 (6), 1939-45.

Patt, H.M., Lund, J.E. und Maloney, M.A. (1973): Cyclic hematopoiesis in grey collie dogs: a stem-cell problem. Blood, 42 (6), 873-84.

Patterson, D.F., Haskins, M.E. und Jezyk, P.F. (1982): Models of human genetic disease in domestic animals. Adv Hum Genet, 12, 263-339.

Pfeiffer, I. und Brenig, B. (2005): Frequency of the canine leucocyte adhesion deficiency (CLAD) mutation among Irish red setters in Germany. J Anim Breed Genet, 122 (2), 140-2.

Puck, J.M., Conley, M.E. und Bailey, L.C. (1993): Refinement of linkage of human severe combined immunodeficiency (SCIDX1) to polymorphic markers in Xq13. Am J Hum Genet, 53 (1), 176-84. 
Pullen, R.P., Somberg, R.L., Felsburg, P.J. und Henthorn, P.S. (1997): X-linked severe combined immunodeficiency in a family of Cardigan Welsh corgis. J Am Anim Hosp Assoc, 33 (6), 494-9.

Renshaw, H.W., Chatburn, C., Bryan, G.M., Bartsch, R.C. und Davis, W.C. (1975): Canine granulocytopathy syndrome: neutrophil dysfunction in a dog with recurrent infections. J Am Vet Med Assoc, 166 (5), 443-7.

Renshaw, H.W., Davis, W.C. und Renshaw, S.J. (1977): Canine granulocytopathy syndrome: defective bactericidal capacity of neutrophils from a dog with recurrent infections. Clin Immunol Immunopathol, 8 (3), 385-95.

Renshaw, H.W. und Davis, W.C. (1979): Canine granulocytopathy syndrome: an inherited disorder of leukocyte function. Am J Pathol, 95 (3), 731-44.

Singer, L., Colten, H.R. und Wetsel, R.A. (1994): Complement C3 deficiency: human, animal, and experimental models. Pathobiology, 62 (1), 14-28.

Snyder, P.W., Kazacos, E.A. und Felsburg, P.J. (1993): Histologic characterization of the thymus in canine X-linked severe combined immunodeficiency. Clin Immunol Immunopathol, 67 (1), 55-67.

Somberg, R.L., Robinson, J.P. und Felsburg, P.J. (1994): T lymphocyte development and function in dogs with X-linked severe combined immunodeficiency. $J$ Immunol, 153 (9), 4006-15.

Somberg, R.L., Pullen, R.P., Casal, M.L., Patterson, D.F., Felsburg, P.J. und Henthorn, P.S. (1995): A single nucleotide insertion in the canine interleukin-2 receptor gamma chain results in X-linked severe combined immunodeficiency disease. Vet Immunol Immunopathol, 47 (3-4), 203-13.

Trowald-Wigh, G., Hakansson, L., Johannisson, A., Norrgren, L. und Hard af Segerstad, C. (1992): Leucocyte adhesion protein deficiency in Irish setter dogs. Vet Immunol Immunopathol, 32 (3-4), 261-80.

Trowald-Wigh, G., Ekman, S., Hansson, K., Hedhammar, A. und Hard af Segerstad, C. (2000): Clinical, radiological and pathological features of 12 Irish setters with canine leucocyte adhesion deficiency. J Small Anim Pract, 41 (5), 211-7.

Verfaillie, T., Verdonck, F. und Cox, E. (2004): Simple PCR-based test for the detection of canine leucocyte adhesion deficiency. Vet Rec, 154 (26), 821-3.

Weiden, P.L., Robinett, B., Graham, T.C., Adamson, J. und Storb, R. (1974): Canine cyclic neutropenia. A stem cell defect. J Clin Invest, 53 (3), 950-3.

Winkelstein, J.A., Cork, L.C., Griffin, D.E., Griffin, J.W., Adams, R.J. und Price, D.L. (1981): Genetically determined deficiency of the third component of complement in the dog. Science, 212 (4499), 1169-70. 
Yanay, O., Brzezinski, M., Christensen, J., Liggitt, D., Dale, D.C. und Osborne, W.R. (2006): An adult dog with cyclic neutropenia treated by lentivirus- mediated delivery of granulocyte colony-stimulating factor. Hum Gene Ther, 17 (4), 4649 . 


\subsection{Hereditäre Speicherdefekte}

Bei erblichen Speichererkrankungen wird generell durch die mangelnde Aktivität eines katabolen Enzyms ein metabolischer Block im Ab- bzw. Umbauprozess eines bestimmten Substrates verursacht. Die Folge ist eine pathologische Anreicherung des betreffenden Substrates im Gewebe. Die Einreihung einzelner Erkrankungen in diese Gruppe sowie deren Untergliederung unterliegt einem stetigen Wandel. Die hier vorgenommene Einteilung erfolgte in Anlehnung an eine Zusammenfassung von Haskins und Giger (1997).

Innerhalb der Gruppe der hereditären Speicherdefekte wird je nach Wirkungsort der betroffenen Enzyme und dem damit verbundenen Hauptanreicherungsort der jeweiligen Substrate zwischen lysosomalen und nicht lysosomalen Speicherdefekten unterschieden.

\subsubsection{Lysosomale Speicherdefekte}

Die Gruppe der lysosomalen Speicherdefekte beinhaltet eine Störung des Transports oder der Aktivität lysosomaler saurer Hydrolasen. Je nach Art des gespeicherten Substrats lässt sich zwischen Saccharidosen, Proteinosen und Lipidosen unterscheiden. Eine weitere Untergliederung erfolgt nach den jeweils betroffenen Enzymen unter Berücksichtigung des klinischen Erscheinungsbildes. Unterschiedliche Enzymdefekte verursachen zum Teil sehr ähnliche Symptome, wenn die gespeicherten Substrate ähnliche pathologische Effekte hervorrufen, so dass sie zu einer Gruppe zusammengefasst werden. Andererseits führen Defekte desselben Enzyms in einigen Fällen zu unterschiedlichen Krankheitserscheinungen, so dass eine weitere Untergliederung nötig wird. In solchen Fällen liegen in der Regel unterschiedliche Mutationen des betreffenden Enzyms vor. Es können aber auch Umwelteinflüsse oder Variationen des genetischen Hintergrundes sowohl zwischen verschiedenen Rassen als auch innerhalb einer Rasse eine Rolle spielen. Einige Erkrankungen werden lediglich aufgrund ihrer klinischen, pathologischen und histologischen Eigenschaften zur Gruppe der lysosomalen Speicherdefekte gezählt, obwohl das defekte Enzym nicht bekannt ist. Dazu gehören einige Unterformen der Ceroid-Lipofuscinose aus der Gruppe der 
Proteinosen. In einigen dieser Fälle ist auch der zugrunde liegende Gendefekt bekannt, ohne dass die Funktion des Genproduktes geklärt ist (Haskins und Giger 1997).

Die Diagnose lysosomaler Speicherdefekte erfolgt anhand der klinischen, pathologischen und histologischen Befunde sowie durch eine Bestimmung der Serumaktivität lysosomaler Enzyme, die in gewissem Rahmen Rückschlüsse auf die Aktivität der betreffenden Hydrolase in den Lysosomen zulässt. Dabei ist allerdings zu berücksichtigen, dass die gemessenen Werte von der ins Serum freigesetzten Menge und von der Stabilität der Enzyme im Plasma abhängen. Instabile Enzyme können trotz einer geringen Aktivität im Serum innerhalb der Lysosomen voll funktionsfähig sein. Auf der anderen Seite kann trotz einer hohen Serumaktivität die Aktivität eines Enzyms innerhalb der Zellen stark verringert sein, wenn beispielsweise der Haupttransportweg per Glykoproteinrezeptor vom Golgi-Apparat in die Lysosomen gestört ist und dadurch nur eine geringe Enzymmenge in den Lysosomen verfügbar ist.

Bei mangelnder lysosomaler Aktivität einer bestimmten Hydrolase wird die Menge des Endproduktes aus dem betreffenden, gestörten Abbauprozess reduziert. Die klinischen Erscheinungen bei lysosomalen Speichedefekten werden allerdings nicht durch diesen Effekt sondern durch die Akkumulation des Substrates in sekundären Lysosomen hervorgerufen. Diese Akkumulationen sind bei histologischen Untersuchungen als typische membranumgebene Einschlüsse im Zytoplasma zu sehen. In einigen Fällen zeigt die Histologie leere teilweise geschwollene Lysosomen. Dieses Bild kommt entweder durch einen Verlust der typischen Substrateinschlüsse im Zuge der Gewebepräparation zustande, oder das eingeschlossene Material ist wasserlöslich und hebt sich infolgedessen nicht von seiner Umgebung ab. Die Akkumulation des primären Substrates kann zur Beeinträchtigung weiterer lysosomaler Prozesse führen und damit eine sekundäre Akkumulation weiterer Substrate bedingen. Je nach primär und sekundär eingelagerten Substraten ergibt sich eine typische Ultrastruktur der Zelleinschlüsse, die in Verbindung mit Färbeeigenschaften des eingeschlossenen Materials Hinweise auf dessen biochemische Beschaffenheit liefert und zur Diagnose einer spezifischen Erkrankung beitragen kann.

Im Verlauf der Erkrankung nehmen die Lysosomen an Zahl und Größe zu. Innerhalb der Zellen kann es zur Verdrängung der Organellen und zur Deformation der Kernkonturen 
kommen. Teilweise sind betroffene Zellen geschwollen. Darauf beruht ein Großteil der Pathophysiologie lysosomaler Speicherdefekte, die durch die Ausdehnung von Zellen, Geweben und Organen gekennzeichnet ist. In den meisten Fällen liegen vor allem typische Veränderungen von Zellen des zentralen Nervensystems (ZNS) vor. Oft finden sich geschwollene Neuronen deren Lysosomen lamellare Einschlüsse aufweisen. Bei einigen Erkrankungen führt die Substrateinlagerung nicht zu einer Schwellung der betroffenen Zellen, sondern stattdessen zu einer Verdrängung der Zellorganellen. Zum Teil sind auch dendritische und axonale Fortsätze betroffen. Werden Axone zerstört, kommt es häufig an den Axonenden zur Bildung von Spheroiden, das heißt von kugelförmigen Kompartimenten, in denen ein Abbau von Zersetzungsprodukten aus der Zerstörung der Axone stattfindet. Bei primärer oder sekundärer Einlagerung von Gangliosiden kommt es außerdem zur Entstehung typischer Neuritensprosse. Betroffene Zellen des ZNS sind durch die Einlagerungen in ihrer Funktion gestört. Häufig kommt es zu Zellverlusten, die zu einer deutlich sichtbaren Atrophie bestimmter Hirnbereiche führen können. Sind extraneurale Zellen betroffen, zeigt sich in vielen Fällen eine Dilatation der Herzklappen mit der Folge von Herzgeräuschen. Bei einigen Erkrankungen liegen außerdem Organomegalien vor, die meistens Leber und Milz betreffen. In Zellen der Augenhornhaut kann die Einlagerung von Substrat zu veränderter Lichtbrechung und -reflexion und damit $\mathrm{zu}$ einer Eintrübung führen. Typisch sind weiterhin Gelenk- und Skelettabnormitäten einschließlich Missbildungen des Gesichtes, Deformationen der Rippen und Wirbel sowie der langen Knochen. Die beschriebenen Veränderungen verschiedener Zellen und Gewebe verursachen bestimmte klinische Anzeichen. Es kommt zu Störungen des Bewegungsapparates, die sowohl durch Schädigungen des Nervensystems als auch durch direkte Beeinträchtigungen der Muskulatur, der Gelenke und des Knochengerüstes verursacht sein können. Weitere Folgen sind Wachstums- und Entwicklungsstörungen sowie Nabelbrüche. Je nach Auftreten und Ausprägung der beschriebenen klinischen, pathologischen und histologischen Erscheinungen ergeben sich für die einzelnen Erkrankungen typische Befundmuster. Die Symptome sind jedoch auch bei Individuen, die von derselben Erkrankung betroffen sind, teilweise unterschiedlich deutlich ausgeprägt, so dass eine sichere Diagnose allein aufgrund der klinischen Erscheinungen nicht gestellt werden kann. Auch pathologische und histopathologische Befunde führen nicht immer zu einer absolut sicheren Klassifizierung einer Speichererkrankung. 
Die meisten lysosomalen Speicherdefekte werden autosomal rezessiv vererbt. Heterozygote Träger der verantwortlichen Gendefekte sind frei von Symptomen. Bei einigen Erkrankungen betragen die Werte für die Serumaktivität der jeweils defekten lysosomalen Hydrolasen bei heterozygoten Tieren etwa die Hälfte der bei homozygot normalen Tieren gemessenen Werte. Es besteht jedoch eine Überschneidung der Wertebereiche homozygot gesunder und heterozygoter Tiere, so dass eine eindeutige Identifizierung heterozygoter Defektträger auf Basis der Serumaktivität nicht in allen Fällen möglich ist. 


\subsubsection{Lysosomale Saccharidosen}

$\mathrm{Zu}$ den erblichen caninen lysosomalen Saccharidosen zählen verschiedene Mucopolysaccharidosen (MPS), die Fukosidose und die Lafora-Krankheit. Ursache der Mucopolysaccharidosen ist ein Mangel oder eine Funktionsminderung eines oder mehrerer spezifischer Enzyme zum Abbau von Glykosaminoglykanen (GAG). Dazu zählen Dermatansulfat und Heparansulfat sowie in einigen Fällen Keratansulfat. Die unvollständig abgebauten GAG lagern sich in den Lysosomen unterschiedlicher Zelltypen ab, außerdem wird ein gewisser Anteil über den Urin ausgeschieden (zusammengefasst bei McKusick und Neufeld 1983). Als Nebenerscheinung, deren Ursache noch nicht ganz geklärt ist, kommt es zur Ablagerung von Gangliosiden, die in einigen Fällen auf die Leber beschränkt ist, in anderen Fällen auch Nervenzellen des Gehirns und eine Vielzahl weiterer Zelltypen betrifft (Constantopoulos und Dekaban 1978). In Abhängigkeit von den jeweils akkumulierten Glykosaminoglykanen und vom Ausmaß des zugrunde liegenden Enzymdefektes kommt es zu verschiedenen Erkrankungen mit spezifischen und unterschiedlich stark ausgeprägten Symptomen, die in der Humanmedizin in sechs Typen mit mehreren Unterformen eingeteilt sind (zusammengefasst bei McKusick und Neufeld 1983). Bei Hunden sind bisher sechs verschiedene Mucopolysaccharidoseformen beschrieben worden: Typ I, II, IIIA und B, VI und VII. Der zugrunde liegende genetische Defekt ist bei den Typen I, IIIA, IIIB, VI und VII bekannt.

Die Fukosidose ist durch eine Ablagerung fukosehaltiger Glykoasparagine aufgrund eines $\alpha$-L-Fukosidase-Mangels gekennzeichnet (Kelly et al. 1983; Abraham et al. 1984).

Bei den verschiedenen Formen der Lafora-Krankheit kommt es aufgrund unterschiedlicher enzymatischer Störungen des Glukosestoffwechsels zur Ablagerung von Glukosanen (Chan et al. 2004; Gentry et al. 2005; Lohi et al. 2005a).

Die klinischen, pathologischen und histopathologischen Erscheinungen bei den einzelnen Saccharidosen sind im Folgenden tabellarisch dargestellt (Tabelle 6 und Tabelle 7). Im Anschluss an die Tabellen werden die einzelnen Erkrankungen nacheinander abgehandelt. Die in diesen Abhandlungen angegebenen Quellen sind auch Grundlage der in den Tabellen aufgelisteten Daten. 
Tabelle 6 Saccharidose: betroffene Rassen, klinische und pathologische Erscheinungen

\begin{tabular}{|c|c|c|c|c|c|c|c|}
\hline & MPS I & MPS IIIA & MPS IIIB & MPS VI & MPS VII & Fukosidose & Lafora-Krankheit \\
\hline Rassen & $\begin{array}{l}\text { Plotthound / Beagle- } \\
\text { Plotthound-Kolonie }\end{array}$ & $\begin{array}{l}\text { Rauhhaardackel, } \\
\text { Neuseeländischer } \\
\text { Huntaway }\end{array}$ & $\begin{array}{l}\text { Belgischer } \\
\text { Schifferspitz }\end{array}$ & $\begin{array}{l}\text { Zwergpinscher, Corgi, } \\
\text { Chesapeake Bay } \\
\text { Retriever, } \\
\text { Zwergschnauzer }\end{array}$ & $\begin{array}{l}\text { Mischling /Forschungs- } \\
\text { Kolonie /Deutscher } \\
\text { Schäferhund }\end{array}$ & $\begin{array}{l}\text { Englischer Springer } \\
\text { Spaniel }\end{array}$ & $\begin{array}{l}\text { Beagle, Basset, Corgi, } \\
\text { Zwergrauhaardackel }\end{array}$ \\
\hline $\begin{array}{l}\text { Alter bei } \\
\text { Ausbruch }\end{array}$ & 6-12 mo & $\begin{array}{l}\text { Dackel: } 3-4 \mathrm{yr}, \\
\text { Huntaway: } 18 \mathrm{mo}\end{array}$ & $3 \mathrm{yr}$ & $1 \mathrm{mo}$ & $4-8 \mathrm{wk}$ & $10-18 \mathrm{mo}$ & $\begin{array}{l}\text { Beagle-Kolonie: } 5 \mathrm{mo} \text {, } \\
\text { Dackel: } 6-9 \mathrm{yr}, \text { Basset: } \\
3 / 6 \mathrm{yr} \text {, Corgi: } 10 \mathrm{yr}\end{array}$ \\
\hline Verlauf & ca. $13 \mathrm{mo}$ & $\begin{array}{l}\text { Dackel: ca. } 2 \text { yr } \\
\text { Huntaway: } 1 \mathrm{mo}\end{array}$ & ca. $2 \mathrm{yr}$ & ca. $3 \mathrm{yr}$ & $\begin{array}{l}\text { Schäferhund/ Mischling: } \\
5-6 \text { wk, Kolonie: } 2 \text { yr }\end{array}$ & $7-30 \mathrm{mo}$ & $\begin{array}{l}\text { Dackel: ca. } 3 \text { yr Basset: } \\
1 \mathrm{mo} / 4 \text { yr, Corgi: } 3 \text { mo }\end{array}$ \\
\hline $\begin{array}{l}\text { Äußerliches } \\
\text { Krankheits- } \\
\text { bild }\end{array}$ & $\begin{array}{l}\text { Wachstumsrückstand, } \\
\text { Lahmheit, verlängerte, } \\
\text { heraushängende Zunge }\end{array}$ & $\begin{array}{l}\text { Schiefhaltung des } \\
\text { Kopfes, Ataxie, } \\
\text { Nystagmus, später } \\
\text { Tremor von Kopf und } \\
\text { Rumpf, } \\
\text { Huntaway weniger stark } \\
\text { betroffen als Dackel }\end{array}$ & $\begin{array}{l}\text { Appetitlosigkeit, } \\
\text { Lethargie, } \\
\text { Kopfwackeln, extreme } \\
\text { Gleichgewichtsstö- } \\
\text { rungen, Muskelzittern, } \\
\text { Farbwechsel (schwarz } \\
\text { zu rotbraun), in einigen } \\
\text { Fällen Nystagmus und } \\
\text { Starrkrampfepisoden }\end{array}$ & $\begin{array}{l}\text { Wachstumsrückstand, } \\
\text { disproportionaler Zwer- } \\
\text { genwuchs, kalottenför- } \\
\text { miger, breiter Schädel, } \\
\text { weitständige Augen, } \\
\text { Gang gespreizt und } \\
\text { abgehackt }\end{array}$ & $\begin{array}{l}\text { Wachstumsrückstand, } \\
\text { disproportionaler Zwer- } \\
\text { genwuchs: übergroßer } \\
\text { Kopf, Missbildungen, } \\
\text { Ataxie (nur beim Dt. } \\
\text { Schäferhund) }\end{array}$ & $\begin{array}{l}\text { Gewichtsverlust, gele- } \\
\text { gentliches Erbrechen } \\
\text { Depression, Verlust } \\
\text { erlernten Verhaltens, } \\
\text { Verhaltensänderung, } \\
\text { Ataxie, Hör- u. Seh- } \\
\text { vermögen, Koordina- } \\
\text { tion u. Gleichgewichts- } \\
\text { sinn beeinträchtigt, } \\
\text { Ptyalismus, Atemnot, } \\
\text { Schluckbeschwerden }\end{array}$ & $\begin{array}{l}\text { Beagle: epileptische } \\
\text { Anfälle, Dackel: } \\
\text { Muskelkontraktionen } \\
\text { Nacken + } \\
\text { Extremitäten, atonische } \\
\text { Attacken, generalisierte } \\
\text { Anfälle, später Ataxie, } \\
\text { Basset } 6 \text { yr: Stürze, } \\
\text { später generalisierte } \\
\text { Anfälle, } 3 \text { yr: erhöhtes } \\
\text { Schlafbe-dürfnis, } \\
\text { Lethargie, Steifheit, } \\
\text { keine Anfälle, Corgi: } \\
\text { Kopfzuckungen, später } \\
\text { myoklonische } \\
\text { Kontraktionen }\end{array}$ \\
\hline $\begin{array}{l}\text { Skelett/ } \\
\text { Gelenke/ } \\
\text { Muskulatur/ } \\
\text { ZNS/ Organe }\end{array}$ & $\begin{array}{l}\text { schwere degenerative } \\
\text { Gelenkerkrankung, } \\
\text { periartikuläre Knochen- } \\
\text { wucherungen, entzündete, } \\
\text { dunkel-braun verfärbte } \\
\text { Gelenkinnenhäute mit } \\
\text { zottigen Erhebungen, } \\
\text { intraartikuläre Bluter- } \\
\text { güsse, Katarakt, verdickte } \\
\text { Herzklappen, erweiterte } \\
\text { Ventrikel, Leber diffus- } \\
\text { blass verfärbt, } \\
\text { Lymphknotenschwellung, } \\
\text { Milzverstopfung }\end{array}$ & $\begin{array}{l}\text { Musculi interossii: } \\
\text { Fibrillationspotentiale, } \\
\text { Stell-, Beuge- u. vesti- } \\
\text { buloculare Reflexe } \\
\text { gestört, später krampf- } \\
\text { artig verstärkte myotak- } \\
\text { tische Reflexe, Atrophie } \\
\text { d. Kleinhirnrinde, Ven- } \\
\text { trikel erweitert, Calci- } \\
\text { umoxalat-Kristallurie, } \\
\text { Calciumoxalat-Urolith } \\
\text { in der Harnblase, sekun- } \\
\text { däre Calcifizierung } \\
\text { diverser Gewebe }\end{array}$ & $\begin{array}{l}\text { Stell- und } \\
\text { vestibulokulare } \\
\text { Reflexe gestört, } \\
\text { erweiterte Ventrikel, } \\
\text { Kleinhirnatrophie } \\
\text { Corneadystrophie, } \\
\text { Retinadegeneration, } \\
\text { Hepatomegalie, } \\
\text { Mangel an } \\
\text { retroperitonealem } \\
\text { Fettgewebe }\end{array}$ & $\begin{array}{l}\text { Degenerationen und } \\
\text { Deformationen des } \\
\text { Knochengerüsts, unter- } \\
\text { entwickelte Wirbel- } \\
\text { körper und Epiphysen, } \\
\text { Gelenkknirschen, } \\
\text { erweiterte Hirnventrikel } \\
\text { Katarakt, subepitheliale } \\
\text { Lipidoseherde in } \\
\text { Cornea, verdickte } \\
\text { Herzklappen }\end{array}$ & $\begin{array}{l}\text { deformierte Luftröhre, } \\
\text { schwere Gelenkerkran- } \\
\text { kungen: Luxuation, } \\
\text { Gelenkkapselschwellung } \\
\text { u. -fluktuation, zottige } \\
\text { Erhebungen auf Gelenk- } \\
\text { innenhäuten, leichte } \\
\text { Skelettmuskelatrophie, } \\
\text { Gelenkknirschen, } \\
\text { Katarakt }\end{array}$ & $\begin{array}{l}\text { Reflexüber- und - } \\
\text { unterfunktion, Nerven } \\
\text { grau verfärbt und } \\
\text { geschwollen, Hirn } \\
\text { verfestigt, } \\
\text { Sehvermögen gestört, } \\
\text { Lunge rot gesprenkelt, } \\
\text { dunkelbraun verfärbt + } \\
\text { verfestigt }\end{array}$ & $\begin{array}{l}\text { Degeneration der Herz- } \\
\text { u. Skelettmuskelfasern } \\
\text { Dackel: späte } \\
\text { Blindheit, Basset: } \\
\text { Glaukom, Herz: } \\
\text { Rhythmusstörungen, } \\
\text { Klappen: Insuffizienz, } \\
\text { entartete Innenhaut, } \\
\text { Ränder: fibröse } \\
\text { Knötchen }\end{array}$ \\
\hline
\end{tabular}


Tabelle 7 Saccharidosen: Enzymdefekt, eingelagertes Material und histologische Befunde

\begin{tabular}{|c|c|c|c|c|c|c|c|}
\hline & MPS I & MPS IIIA & MPS IIIB & MPS VI & MPS VII & Fukosidose & Lafora-Krankheit \\
\hline Enzym & $\alpha$-L-Iduronidase & $\begin{array}{l}\text { Heparansulfat- } \\
\text { Sulfamidase }\end{array}$ & $\begin{array}{l}\text { N-Acetyl- } \alpha \text {-D- } \\
\text { Glukosaminidase }\end{array}$ & Arylsulfatase B & $\beta$-Glukuronidase & $\alpha$-L-Fukosidase & $\begin{array}{l}\text { Malin (Dackel u. } \\
\text { Basset) }\end{array}$ \\
\hline $\begin{array}{l}\text { Speicher- } \\
\text { material }\end{array}$ & $\begin{array}{l}\text { Heparansulfat, Derma- } \\
\text { tansulfat, Ganglioside }\end{array}$ & $\begin{array}{l}\text { Heparansulfat, } \\
\text { Ganglioside }\end{array}$ & $\begin{array}{l}\text { Heparansulfat, } \\
\text { Glykosphingolipide }\end{array}$ & $\begin{array}{l}\text { Dermatansulfat, } \\
\text { Chondroitinsulfat }\end{array}$ & $\begin{array}{l}\text { Chondroitin-, Derma- } \\
\text { tan- u. Heparansulfat }\end{array}$ & $\begin{array}{l}\text { fukosehaltige } \\
\text { Glykoasparagine }\end{array}$ & $\begin{array}{l}\text { Glukosepolymere } \\
\text { (Glukosane) }\end{array}$ \\
\hline $\begin{array}{l}\text { neurales } \\
\text { Gewebe }\end{array}$ & $\begin{array}{l}\text { weiche Hirnhaut ver- } \\
\text { dickt durch Invasion } \\
\text { von Fibroblasten, keine } \\
\text { Nekrose oder Verlust } \\
\text { von Neuronen, } \\
\text { vakuolisiert: Neuronen } \\
\text { aller ZNS-Ebenen, pe- } \\
\text { rivascular akkumulierte } \\
\text { einkernige Zellen, } \\
\text { Astrozyten }\end{array}$ & $\begin{array}{l}\text { Degeneration und } \\
\text { Depletion von Purkinje- } \\
\text { zellen }\end{array}$ & $\begin{array}{l}\text { Verlust von } \\
\text { Purkinjezellen, des } \\
\text { Weiteren betroffen: } \\
\text { Gliazellen, Neuronen, } \\
\text { Ganglionzellen der } \\
\text { Netzhaut, myenterale } \\
\text { Plexuszellen }\end{array}$ & nicht betroffen & Neuronen vakuolisiert & $\begin{array}{l}\text { Waller-Degeneration, } \\
\text { Spheroide (dystrophier- } \\
\text { te Axone), phagozyten- } \\
\text { artige Zellen in Hirn- } \\
\text { haut- u. Hirngewebs- } \\
\text { lücken, vakuolisiert: } \\
\text { Neuronen u. Gliazellen } \\
\text { im ZNS, lose verteilte, } \\
\text { ödematöse Binde- } \\
\text { gewebsstücke }\end{array}$ & $\begin{array}{l}\text { vakuolisiert: Neuronen } \\
\text { und Dendriten, selten } \\
\text { Gliazellen (Dackel nie) } \\
\text { in Thalamus (Basset } \\
\text { nicht), Kleinhirn (Pur- } \\
\text { kinje- u. Molekularzell- } \\
\text { schicht), Kortex u. Hip- } \\
\text { pocampus (nur Beagle), } \\
\text { freie Einschlüsse im } \\
\text { Neuropil }\end{array}$ \\
\hline $\begin{array}{l}\text { extra- } \\
\text { neurales } \\
\text { Gewebe }\end{array}$ & $\begin{array}{l}\text { vakuolisiert: Fibroblas- } \\
\text { ten u. perivascular ak- } \\
\text { kumulierte, gewebefix- } \\
\text { ierte Makrophagen in } \\
\text { allen unters. Geweben } \\
\text { u. Interstitien, } \\
\text { Hepatozyten, Chondro- } \\
\text { u. Myozyten, Ovarien- } \\
\text { Follikelzellen, } \\
\text { Pigmentepithelzellen d. } \\
\text { Netzhaut, lymphoide } \\
\text { Blut- u. Lymphknotenz. }\end{array}$ & $\begin{array}{l}\text { vakuolisiert: Epithel- } \\
\text { zellen von Leber und } \\
\text { Niere, dermale Fibro- } \\
\text { blasten, Keratinozyten, } \\
\text { Monozyten, Thrombo- } \\
\text { zyten }\end{array}$ & $\begin{array}{l}\text { vakuolisiert: Leber, } \\
\text { Niere, Bauchspeichel- } \\
\text { drüse, Makrophagen, } \\
\text { Epithelzellen der Bron- } \\
\text { chien, Leukozyten } \\
\text { besonders betroffene } \\
\text { Gewebe: Leber und } \\
\text { Niere }\end{array}$ & $\begin{array}{l}\text { vakuolisiert: akkumu- } \\
\text { lierte Makrophagen in } \\
\text { vielen Geweben, Fi- } \\
\text { broblasten, weiche } \\
\text { Muskelzellen, Herz- u. } \\
\text { Skelettmuskelzellen, } \\
\text { umgebendes Epithel, } \\
\text { Chondrozyten } \\
\text { besonders betroffene } \\
\text { Gewebe: Knorpelmasse }\end{array}$ & $\begin{array}{l}\text { vakuolisiert: Keratozy- } \\
\text { ten, Fibroblasten, Gra- } \\
\text { nulozyten, Chondrozy- } \\
\text { ten, Lymphozyten, Z. } \\
\text { der Gelenkmembran, } \\
\text { Netz- u. Bindehaut, } \\
\text { Milz, Leber, } \\
\text { Herzklappen } \\
\text { besonders betroffene } \\
\text { Gewebe: Aorta, Klein- } \\
\text { hirn, Luftröhre, Hoden }\end{array}$ & $\begin{array}{l}\text { vakuolisiert: phagozy- } \\
\text { tenartige Zellen in Ton- } \\
\text { sillen, Lungenalveolen, } \\
\text { Interstitien, Zellen aus } \\
\text { Speicheldrüsenparen- } \\
\text { chym, Leberkanälchen, } \\
\text { Lymphknoten, Epithel } \\
\text { d. Gallengänge, Bauch- } \\
\text { speicheldrüsenparen- } \\
\text { chym, Nierentubuli, } \\
\text { alveolares und } \\
\text { bronchiales Epithel }\end{array}$ & $\begin{array}{l}\text { vakuolisiert: Kupffer- } \\
\text { zellen (Dackel nur } \\
\text { glukoneogenetische He- } \\
\text { patozyten), Lymphkno- } \\
\text { ten- u. Milzzellen, Myo- } \\
\text { epithelzellen im Bereich } \\
\text { apokriner Schweißdrü- } \\
\text { sen, Zellen d. Ausfüh- } \\
\text { rungsgänge merokriner } \\
\text { Schweißdrüsen, Skelett- } \\
\text { muskelzellen, Zellen der } \\
\text { Herzmuskelarterien }\end{array}$ \\
\hline $\begin{array}{l}\text { Zytoplasma/ } \\
\text { Ultrastruktur } \\
\text { des } \\
\text { eingeschloss } \\
\text { enen } \\
\text { Materials }\end{array}$ & $\begin{array}{l}\text { voluminös u. schaumig / } \\
\text { fein vakuolisiert / nicht } \\
\text { klar zu unterscheiden, } \\
\text { Organellen verdrängt, } \\
\text { Kerne verformt, } \\
\text { erweiterte Lysosomen: } \\
\text { leer / mit Einschlüssen } \\
\text { granulär, osmiophil / } \\
\text { lamellar (Zebrakörper) }\end{array}$ & $\begin{array}{l}\text { neurale Zellen: Zebra- } \\
\text { körperchen / freie glo- } \\
\text { bulär / wirbelartig la- } \\
\text { mellar; extraneurale } \\
\text { Zellen: membranum- } \\
\text { geben, fein, flockig }\end{array}$ & $\begin{array}{l}\text { Lymphozyten und } \\
\text { Purkinjezellen: freie } \\
\text { Granula, andere } \\
\text { Zelltypen: Vakuolen }\end{array}$ & $\begin{array}{l}\text { Vakuolen mit kleinen } \\
\text { Granula }\end{array}$ & $\begin{array}{l}\text { freie Granula (Alder- } \\
\text { Reilly bodies), leere } \\
\text { erweiterte Lysosomen } \\
\text { membranumgeben, } \\
\text { granulär oder lamellar }\end{array}$ & $\begin{array}{l}\text { neurale Zellen: } 1 \text { große } \\
\text { Vakuole/ viele kleine } \\
\text { Vakuolen, gr.Vakoule: } \\
\text { leer/ schaumig: amor- } \\
\text { phe Trümmer + Mem- } \\
\text { branen, kl.Vakuolen: } \\
\text { gebogene/ gerade/ kon- } \\
\text { zentrisch bilamelare } \\
\text { Stapel + Stränge/ gra- } \\
\text { nulär, Spheroide: granu- } \\
\text { lär/ durchsichtig/ form- } \\
\text { los, extraneurale Zellen: } \\
\text { schaumig vakuolisiert }\end{array}$ & $\begin{array}{l}\text { Laforakörper: Typ I: } \\
\text { gleichmäßig dicht, z. T. } \\
\text { konzentrisch gestreckt, } \\
\text { Typ II: aufgehelltes } \\
\text { radiales Muster umgibt } \\
\text { dichten Kern, Typ III: } \\
\text { dichter Ring um helles } \\
\text { Zentrum, Granula in } \\
\text { formloser Matrix: fibril- } \\
\text { lenartig verflochten/ } \\
\text { zentral zusammenge- } \\
\text { ballt/ gleichmäßig ver- } \\
\text { teilt/ Aggregate }\end{array}$ \\
\hline
\end{tabular}




\subsection{Mucopolysaccharidose I}

\begin{tabular}{|ll|}
\hline Chromosom: & CFA3 \\
Gen: & IDUA \\
NCBI: & GeneID: 488865, EMBL-EBI-ID: L01065 \\
DNA-Sequenz: & NW_876307, Position 54276792-54254339 \\
Mutationen: & G332A, Plotthound \\
\hline
\end{tabular}

\section{Krankheitsbild}

Erstmals bei Hunden beschrieben wurde die Mucopolysaccharidose I (MPS I) 1982 bei drei Plotthound Wurfgeschwistern (Shull et al. 1982). Der Erbgang ist autosomal rezessiv. Genauere klinische, pathologische und histopathologische Untersuchungen der caninen MPS I erfolgten an reinrassigen Nachkommen dieser Plotthounds (Shull et al. 1982; Shull et al. 1984; Constantopoulos et al. 1985; Breider et al. 1989) oder an Plotthound-Beagle-Mischlingen aus einer Forschungskolonie (Shull et al. 1994). Veröffentlichungen über weitere erkrankte Hunde der genannten oder anderer Rassen liege nicht vor, so dass von keiner weiten Verbreitung des Gendefektes auszugehen ist.

Biochemische Untersuchungen an Fibroblastenkulturen von gesunden und betroffenen Hunden zeigen bei betroffenen Hunden eine Verringerung der $\alpha$-L-IduronidaseAktivität auf höchstens $1 \%$ der normalen Aktivität. Entsprechende Befunde ergibt auch die Untersuchung von Lymphozyten. Der direkte Zusammenhang zwischen der Ablagerung von Substraten und der geringen $\alpha$-L-Iduronidase Aktivität konnte durch das folgende Experiment belegt werden: Eine übermäßige Akkumulation von ${ }^{35} \mathrm{~S}$ Mucopolysacchariden in Fibroblastenkulturen betroffener Hunde lässt sich durch Zusatz von $\alpha$-L-Iduronidase rückgängig machen. Die Konzentration von Glykosaminoglykanen im Urin ist auf die vier- bis fünfundzwanzigfache Menge der mittleren normalen Konzentration erhöht. Dabei wird vor allem Dermatansulfat und eine geringere Menge Heparansulfat ausgeschieden. Anhand der Ergebnisse dieser klinischen Untersuchungen lässt sich die Erkrankung eindeutig als Mucopolysaccharidose I identifizieren (Shull et al. 1982; Spellacy et al. 1983). Zwischen Verwandten der drei 1982 beschriebenen Wurfgeschwister (Shull et al. 1982) schwanken die Werte für $\alpha$-L-Iduronidase Aktivität stark. Ein für heterozygote Defektträger typischer Wertebereich lässt sich anhand der Messdaten nicht festlegen (Spellacy et al. 1983). 
Bei der humanen MPS I werden je nach auftretenden Symptomen und deren Ausprägung drei Typen unterschieden, von denen das Hurler-Syndrom den schwersten, das Scheie-Syndrom den am wenigsten schweren Verlauf hat, während das Hurler/Scheie-Syndrom einen intermediären Phänotyp bezeichnet. Der bei Plotthounds beschriebene Defekt wird dem Hurler/Scheie-Typ zugeordnet, da die betroffenen Hunde einerseits nicht die für das Hurler-Syndrom typische Hepatosplenomegalie aufweisen, andererseits aber an Symptomen wie schwerer Lahmheit, gestörtem Knochenwachstum und Wachstumsdefizit leiden, die beim Scheie-Syndrom nicht auftreten (Shull et al. 1982).

\section{Genetischer Hintergrund}

Die für $\alpha$-L-Iduronidase codierende cDNA umfasst 2,2 $\mathrm{kb}$. Bei MPS-I-Hunden fehlt dieses RNA-Fragment, stattdessen lässt sich ein 2,8-kb-RNA-Fragment nachweisen, das bei normalen Hunden nicht vorhanden ist (Stoltzfus et al. 1992). Das codierende Gen, bezeichnet als IDUA-Gen, erstreckt sich auf einer Länge von über $13 \mathrm{~kb}$ und enthält 14 Exons (Menon et al. 1992). Unter der EMBL-EBI-ID L01065 ist die Sequenz der ersten beiden Exons einschließlich 5'-UTR, die Sequenz des Introns 1 sowie der 5'-Bereich des Introns 2 veröffentlicht. Diese Sequenz entspricht der bei Menon et al. veröffentlichten Sequenz, stimmt allerdings weder mit der bei Ensembl veröffentlichten Sequenz noch mit der unter NCBI veröffentlichten Sequenzen überein (EnsemblGeneID: ENSCAFG00000016701, NCBI-GeneID: 488865). Eine chromosomale Lokalisierung wurde durch Menon et al. (1992) nicht vorgenommen. In den Datenbanken von Ensembl und NCBI wird das canine IDUA-Gen übereinstimmend auf Chromosom 3 lokalisiert. Abb. 34 basiert auf den Ergebnissen von Menon et al. (1992) und stellt die Struktur des caninen IDUA-Gens schematisch dar. 


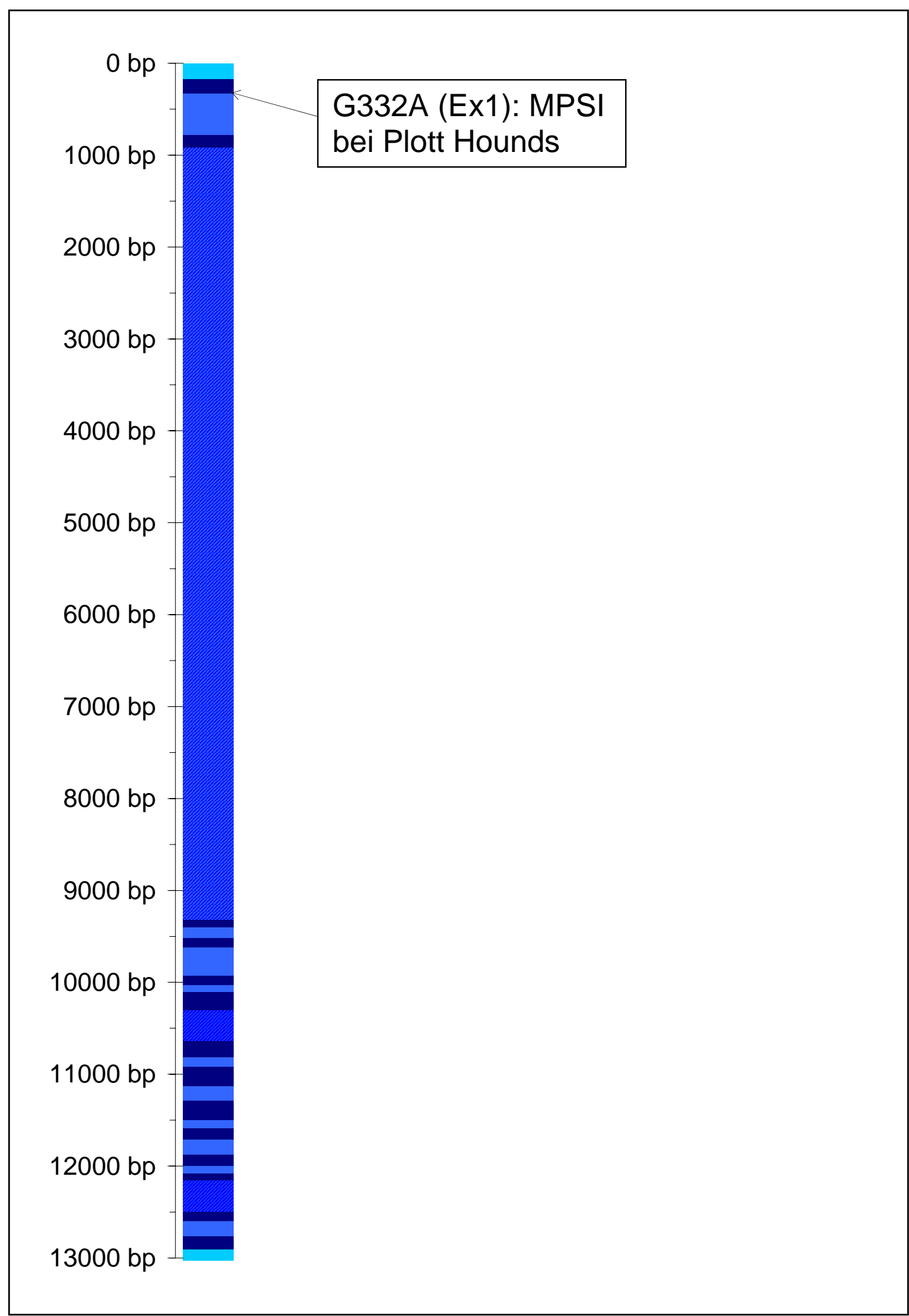

Abb. 34 Schematische Darstellung des caninen IDUA-Gens und Lage der bisher identifizierten Mutationen. Dunkelblau: codierende Sequenz, hellblau: Intronsequenz, hellblau schraffiert: Intron, dessen Grenzen auf Basis von Restriktionskartierung oder elektrophoretischer Analyse amplifizierter Fragmente geschätzt wurde. 


\section{Ursächliche Mutation für MPS I bei Plotthounds}

Die bei MPS-I-Hunden vorliegende Mutation betrifft die DonorSpleißerkennungssequenz von Exon 1 (Menon et al. 1992). Im Einzelnen handelt es sich um die Substitution eines Guanins durch Adenin an Position 332 der cDNA (Abb. 35). Neben dem Verlust der Spleißerkennungssequenz, der zu einer um die Intron-1Sequenz verlängerten mRNA bei MPS-I-Hunden führt, entsteht durch die Substitution ein verfrühtes Stoppcodon. Das resultierende Polypeptid hätte eine Länge von 51 Aminosäuren und liegt damit unterhalb der Mindestgröße von 64 Aminosäuren, die als Voraussetzung für die Transportfähigkeit durch die Membran des endoplasmatischen Retikulums gilt (Okun et al. 1990). Diese Überlegung wird durch die oben dargestellten Ergebnisse biosynthetischer Untersuchungen bestätigt, bei denen kein immunopräzipitierbares $\alpha$-L-Iduronidase-Protein gefunden wurde (Spellacy et al. 1983).

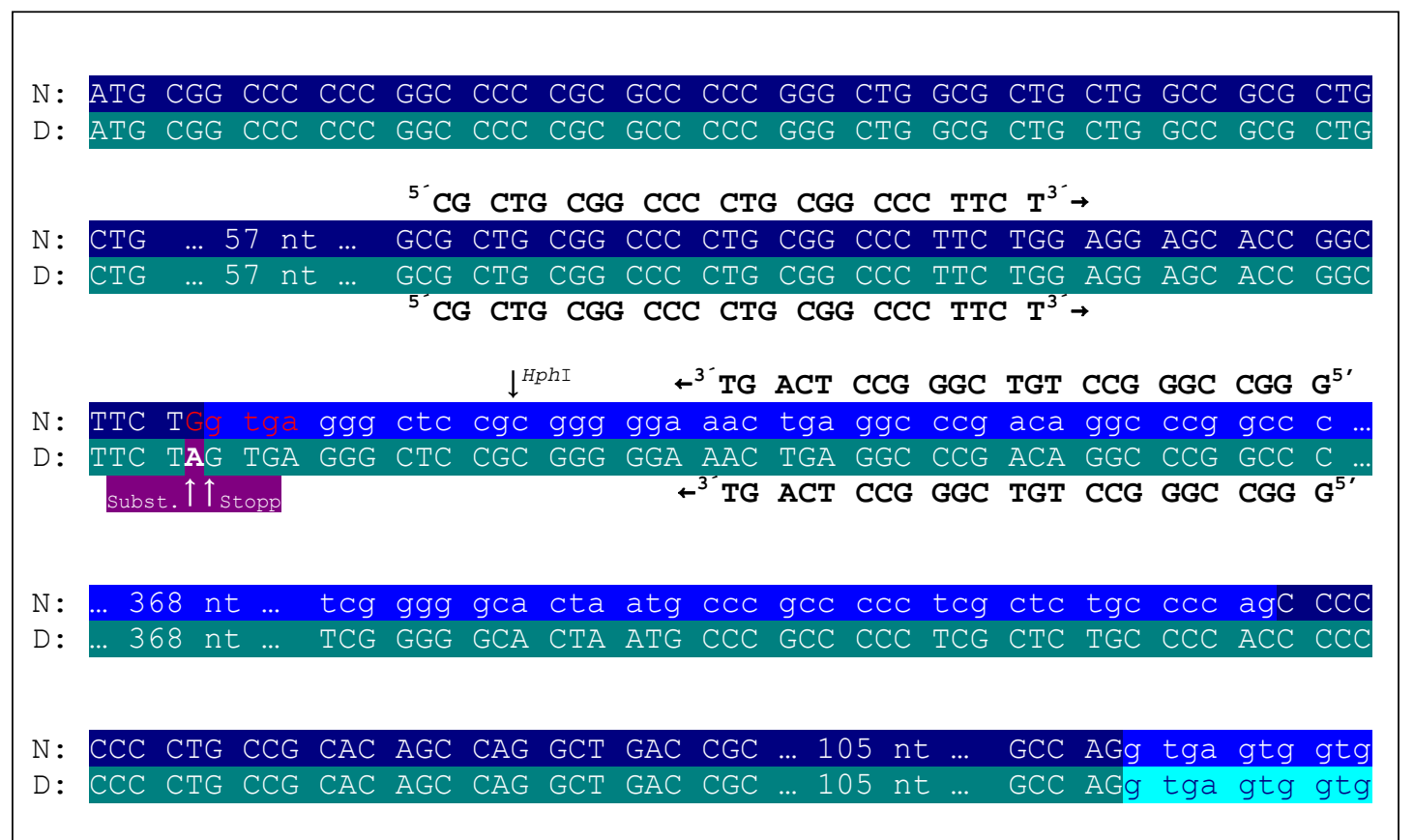

Abb. 35 Exons 1-2 des caninen IDUA Gens und angrenzende Intronsequenzen (EMBL-EBI ID: L01065). N: normale Sequenz, D: defekte Sequenz, dunkelblau: Exon normale Sequenz, dunkelgrün: Exon defekte Sequenz, hellblau: Intron normale Sequenz, türkis: Intron defekte Sequenz, rote Schrift: HphIErkennungssequenz, HphI-Schnittstelle durch Pfeil bezeichnet, Substitution und verfrühtes Stoppcodon in defekter Sequenz violett markiert und durch Pfeil bezeichnet.

\section{Genotypisierung für MPS I bei Plotthounds}

Der Nachweis der Substitution kann per Amplifikation eines 87-bp-Fragments aus genomischer DNA und anschließender RFLP-Typisierung erfolgen. Der RFLP beruht auf einer Restriktionserkennungssequenz für HphI im Wildtypallel, die im Defektallel augrund der Mutation nicht vorhanden ist (Menon et al. 1992). 


\subsection{Mucopolysaccharidose III}

Die Mucopolysaccharidose III (MPS III), in der Humanmedizin auch als SanfilippoSyndrom bezeichnet, ist durch Störungen des Heparansulfatstoffwechsels gekennzeichnet und in Abhängigkeit von dem ursächlichen Enzymdefekt in die Unterformen A, B, C und D unterteilt. Beim Hund sind bisher die Typen III A (Fischer et al. 1998) und III B (Ellinwood et al. 2003b) beschrieben worden. Charakteristisches Merkmal des Sanfilippo-Syndroms ist eine fortschreitende geistige Retardierung, die im Gegensatz zu anderen Mucopolysaccharidosen mit eher leichteren körperlichen Beeinträchtigungen einhergeht.

\subsection{Mucopolysaccharidose IIIA}

\begin{tabular}{ll}
\hline Chromosom: & CFA9 \\
Gen: & HSS (Heparansulfat Sulfamidase) \\
NCBI: & GeneID: 403707, GenBank: AF217203 \\
DNA-Sequenz: & NW_876328, Position 1529626-1536522 \\
Mutationen: & Ins708A709, Neuseeländischer Huntaway \\
& Del 737-739, Rauhaardackel \\
\hline
\end{tabular}

\section{Krankheitsbild}

Klinische, pathologische und histopathologische Erscheinungen der caninen MPS III A sind bisher bei Rauhaardackeln (Fischer et al. 1998; Aronovich et al. 2000) und bei Neuseeländischen Huntaway Hunden (Jolly et al. 2000) beschrieben worden. Bei einer Genotypisierung von 203 Neuseeländischen Huntaways unter Einsatz eines DNA-Tests wurden 15 heterozygote Träger des Gendefektes identifiziert. Das entspricht einer Genfrequenz von 3,8 \% (Yogalingam et al. 2002). Über die Häufigkeit der Erkrankung bei Rahaardackeln werden keine Angaben gemacht. MPS IIIA wurde bei zwei Wurfgeschwistern in den USA (Fischer et al. 1998) und bei einem einzelnen Dackel in Großbritannien (Jolly et al. 2001) diagnostiziert. Nur die US-amerikanischen Fälle wurden molekulargenetisch untersucht. Ob die Erkrankung des Rauhaardackels in Großbritannien auf demselben Gendefekt beruhte, ist nicht untersucht oder nicht veröffentlicht worden.

Der Erbgang ist in beiden Rassen autosomal rezessiv. Die beschriebenen klinischen Befunde entsprechen im Wesentlichen den beobachteten Erscheinungen bei humaner MPS IIIA. Als wichtigstes Kriterium für die Diagnose einer MPS III wird das Vorliegen 
einer auf Heparansulfat beschränkten Glykosaminoglykanurie gewertet. Das in Tabelle 6 und Tabelle 7 dargestellte Erscheinungsbild von membranumgebenen Einschlüssen in Leber- und Nierenzellen deutet auf die Ansammlung von Glykosaminoglykanen hin. Aus der Identifizierung der über den Urin ausgeschiedenen Glykosaminoglykane als Heparansulfat wird gefolgert, dass es sich auch bei den Glykosaminoglykaneinschlüssen in Leber- und Nierenzellen um Heparansulfat handelt (Fischer et al. 1998). Bei den nicht membranumgebenen Einschlüssen der Nervenzellen handelt es sich um eine Akkumulationen von Lipiden, die äußerlich starke Ähnlichkeiten mit Gangliosiden aufweisen. Als eine denkbare Erklärung für die Lipidakkumulation wird die Möglichkeit einer unspezifischen Reaktion der Nervenzellen auf die vorliegenden Stoffwechselstörungen angeführt. Des Weiteren wird ein Zusammenhang der Lipidakkumulation mit dem hohen Heparansulfatgehalt vermutetet. Die Möglichkeit eines hemmenden Effektes von Heparansulfat auf die Aktivität von Galaktosidasen wurde bereits in anderen Untersuchungen eingeräumt (Hara et al. 1984). Die Hemmung weiterer saurer Hydrolasen durch Heparansulfat ist experimentell erwiesen (Greenwood et al. 1978). Eine Calciumoxalat-Kristallurie und eine Urolithiasis wird ebenfalls als Folge der Heparansulfatablagerungen interpretiert, die in den Nierentubuli eine Störung der Calciumabsorption verursacht (Fischer et al. 1998). Auch die bei einigen Rauhaardackeln diagnostizierte schwere sekundäre Calcifizierung in verschiedenen Geweben, die auf eine gestörte Calcium-PhosphatHomöostase hindeutet, lässt sich auf die Anreicherung von Heparansulfat zurückführen. Als Ursachen kommen ein Blasenverschluss durch einen Calcium-Oxalat-Urolith und eine herabgesetzte Nierenfunktion in Frage. Es wird vermutet, dass es durch erhöhte Mengen an Heparansulfat zur Salzbildung in Verbindung mit einer Präzipitation von Calcium an Zellmembanen kommt (Jolly et al. 2001).

Im Lebergewebe betroffener Hunde beträgt die Aktivität des Enzyms HeparansulfatSulfamidase weniger als $2 \%$ des Normwertes, während andere lysosomale Enzyme in den untersuchten Zellen eine normale Aktivität aufweisen (Fischer et al. 1998). Bei einer Folgeuntersuchung an betroffenen Rauhaardackeln konnte in Leberhomogenaten keinerlei Heparansulfat-Sulfamidase-Aktivität gemessen werden. Aufgrund der stark reduzierten Heparansulfat-Sulfamidase-Aktivität lässt sich die Erkrankung eindeutig als MPS IIIA identifizieren (Aronovich et al. 2000). 


\section{Genetischer Hintergrund}

Molekularbiologische Untersuchungen ergeben eine Heparansulfat-Sulfamidase-cDNASequenz von 1850 bp Länge, die ein offenes Leseraster von 1521 bp einschließt und für ein 507 Aminosäuren langes Polypeptid codiert. Das Gen ist auf Chromosom 9 im genomischen Contig NW_876328 zwischen Nukleotid 1529626 und 1536522 lokalisiert (NCBI-GeneID: 403707) und enthält acht Exons (Aronovich et al. 2000). Die Genstruktur ist in Abb. 36 schematisch dargestellt. Die der MPS III A zugrunde liegenden Mutationen sind bei Rauhaardackeln und Neuseeländischen Huntaways verschieden.

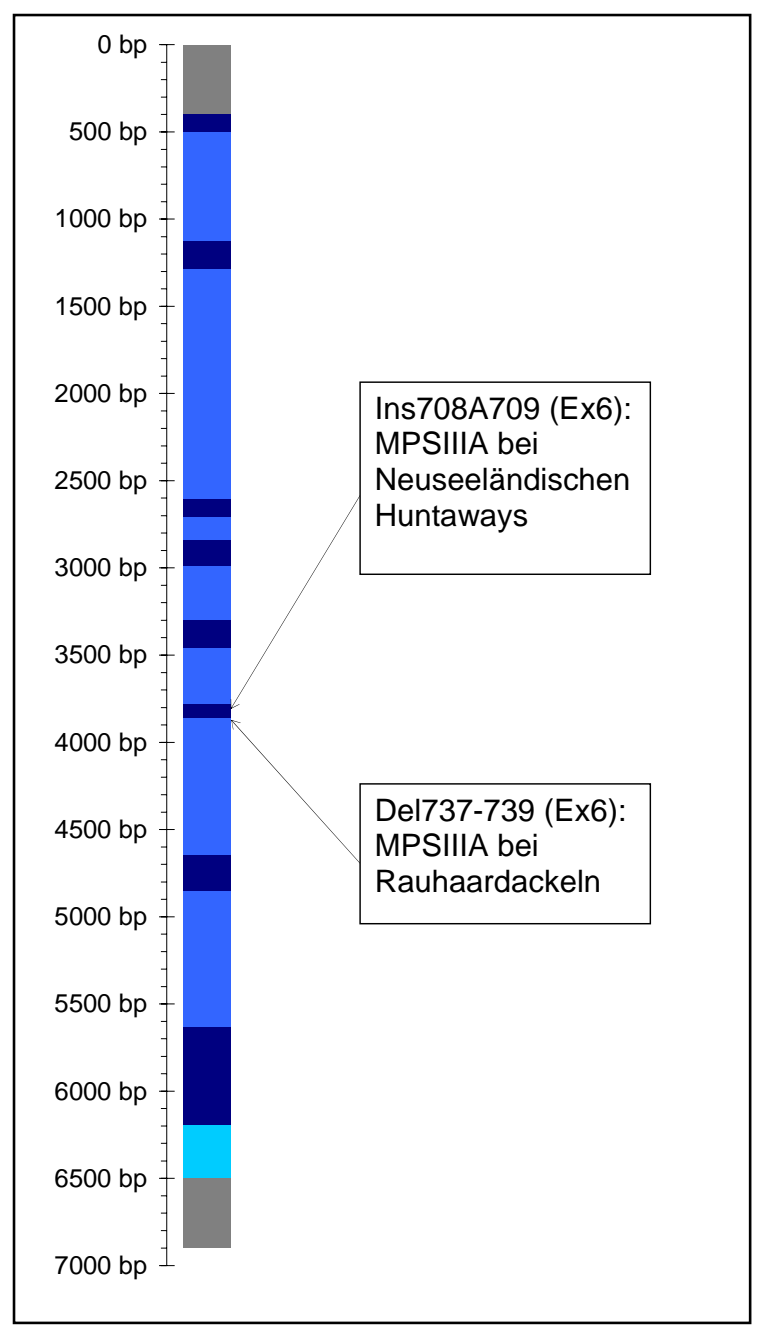

Abb. 36 Schematische Darstellung des caninen Heparansulfat-Sulfamidase-Gens und Lage der bisher identifizierten Mutationen. Dunkelblau: codierende Sequenz, hellblau: Intronsequenz, türkis: 3'-UTR, grau: intergenische Sequenz.

\section{III.a Ursächliche Mutation für MPS IIIA bei Rauhaardackeln}

Bei MPS III A Rauhaardackeln wurde eine 3-bp-Deletion von einschließlich Position 737 bis 739 der cDNA gefunden, die zu einer Deletion eines von zwei Threoninen an 
Aminosäurenposition 246 und 247 führt (Abb. 37). Die betroffenen Threonine sind Teil einer amphipathischen Oberflächen- $\alpha$-Helix, die sich von Aminosäure 238 bis 265 erstreckt. Die Deletion einer Aminosäure könnte eine Drehung dieser Helix verursachen, die zu einer verstärkten Überdeckung der hydrophilen langen Seitenketten führt und eine kompensatorische Verlagerung der benachbarten Loops nach sich zieht. Als Folge könnten Prozessierung und Steuerung des resultierenden Proteins gestört sein (Aronovich et al. 2000).

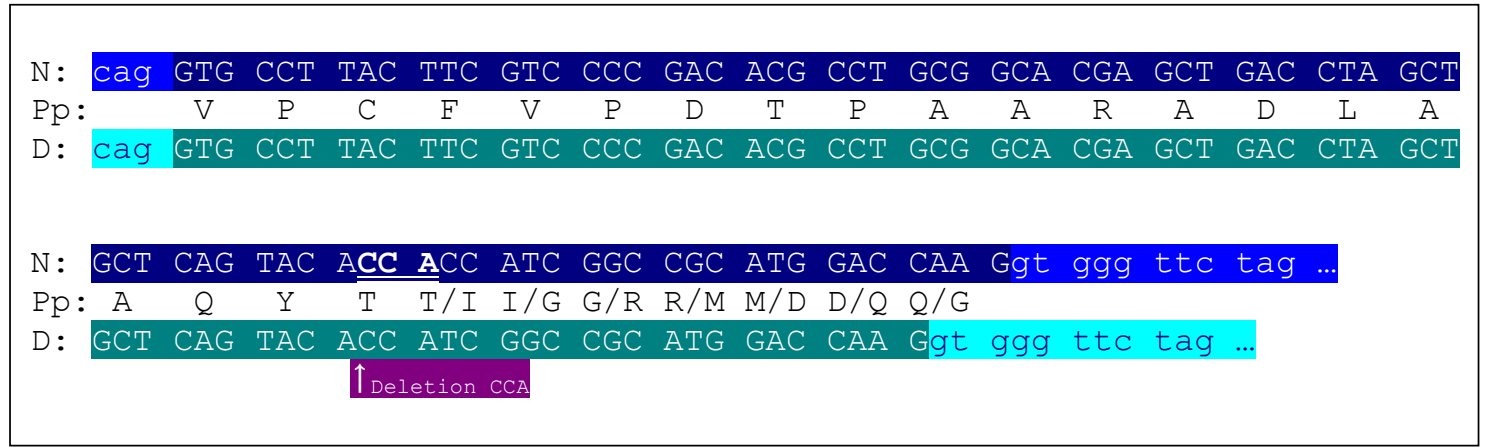

Abb. 37 Exon 6 des caninen Heparansulfat-Sulfamidase-Gens und angrenzende Intronsequenzen. N: normale Sequenz, D: defekte Sequenz, Pp: Polypeptidsequenz, hellblau: Intron normale Sequenz, türkis: Intron defekte Sequenz, dunkelblau: Exon normale Sequenz, dunkelgrün: Exon defekte Sequenz, von Deletion betroffene Sequenz in normaler Sequenz fett gedruckt, in defekter Sequenz durch violett unterlegten Pfeil markiert.

\section{III.b Ursächliche Mutation der MPS IIIA bei Neuseeländischen Huntaways}

Der MPS III A bei Neuseeländischen Huntaways liegt eine Adenosin-Insertion an Nukleotid Position 708-709 der cDNA zugrunde, die eine Verschiebung des Leserasters nach sich zieht und eine Terminierung des resultierenden Polypeptids nach Aminosäurenposition 228 zur Folge hat (Abb. 38) (Yogalingam et al. 2002).

Zur Analyse der Effekte der Mutationen bei Huntaway Hunden und Rauhaardackeln wurden Expressionsversuche durchgeführt, indem die jeweils mutierten caninen Sequenzbereiche in das humane Heparansulfat-Sulfamidase-Gen eingebaut wurden. Es konnten jedoch bei keiner der beiden Varianten Expressionsprodukte nachgewiesen werden. Bei Überexprimierung in CHO-KI-Zellen und anschließender Analyse mittels Immunopräzipitation mit polyklonalen Anti-Heparansulfat-Sulfamidaseseren wurde für die Huntaway-Variante weder im Medium noch in den Zelllysaten rekombinante Heparansulfat-Sulfamidase nachgewiesen. Das Expressionsprodukt der RauhaardackelVariante ließ sich in Form eines 82-kDa-Vorläufer-Polypeptids nachweisen. Eine Spaltung in die normale 56-kDa-Form findet nicht statt und es kommt nicht zur 
Sekretion ins Medium. Des Weiteren ist das 82-kDa-Vorläufer-Polypeptid nach $18 \mathrm{~h}$ vollständig abgebaut. Diese Ergebnisse stehen im Einklang $\mathrm{zu}$ den klinischen Beobachtungen der bei betroffenen Rauhaardackeln vorliegenden enzymatischen Restaktivität und dem etwas milderen Verlauf im Vergleich zu Neuseeländischen Huntaways (Yogalingam et al. 2002).

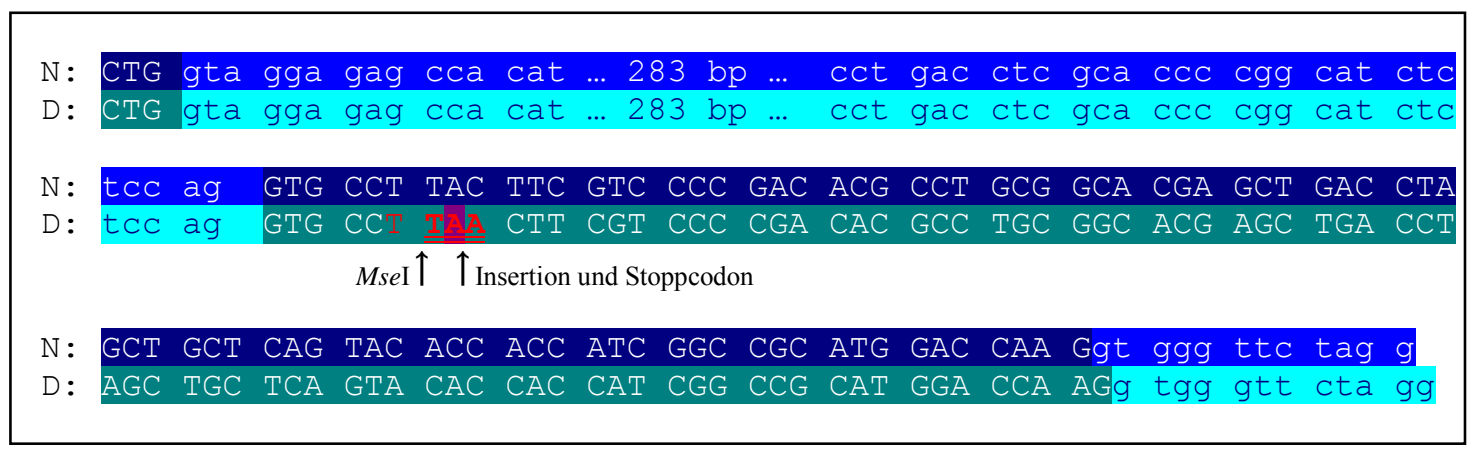

Abb. 38 Intron 5, Exon 6 und angrenzende Exon- bzw. Intronsequenzen des caninen HeparansulfatSulfamidase-Gens. N: normale Sequenz, D: defekte Sequenz, Pp: Polypeptidsequenz, hellblau: Intron normale Sequenz, türkis: Intron defekte Sequenz, dunkelblau: Exon normale Sequenz, dunkelgrün: Exon defekte Sequenz, Insertion und resultierendes Stopp Codon in der defekten Sequenz violett unterlegt, unterstrichen und durch Pfeil markiert, rote Schrift: MseI-Erkennungssequenz, MseI-Schnittstelle durch Pfeil markiert.

\section{IV.b Genotypisierung für MPS IIIA bei Neuseeländischen Huntaways}

Der Nachweis der Mutation kann über Amplifikation eines 264-bp-Fragments im Bereich des betroffenen DNA Abschnitts und anschließende RFLP-Typisierung erfolgen. Durch die Adenosin-Insertion entsteht im Defektallel eine MseIErkennungssequenz, die im Wildtypallel nicht vorhanden ist. Bei einem Screening von 203 Neuseeländischen Huntaways unter Einsatz der beschriebenen Testmethode wurden 15 heterozygote Träger des Gendefektes identifiziert. Das entspricht einer Genfrequenz von 3,8 \% (Yogalingam et al. 2002). 


\subsection{Mucopolysaccharidose III B}

\begin{tabular}{ll|}
\hline Chromosom: & CFA9 \\
Gen: & NAGLU \\
NCBI: & GeneID: 490965 \\
DNA-Sequenz: & NW_876332, Position 2226526-2218880 \\
Mutationen: & 2112Ins45A+13-bp-Dupl., Belgischer Schifferspitz \\
\hline
\end{tabular}

\section{Krankheitsbild}

Eine weitere Form caniner MPS III ist die MPS III B bei Belgischen Schifferspitzen (Schipperke Hunden). Zur Verbreitung der MPS IIIB in dieser Rasse werden keine Zahlen genannt. Die Krankheit wurde bei zwei über vier Generationen nicht miteinander verwandten Schifferspitzen in den USA diagnostiziert. Der Erbgang ist autosomal rezessiv (Giger et al. 2001; Ellinwood et al. 2003b). Betroffene Hunde zeigen erhöhte Heparansulfatwerte im Urin. In der Nierenrinde, im Nierenmark und in der Leber liegen erhöhte Glykosaminoglykanwerte vor, während die Werte in der Milz bei einem der Hunde gar nicht, beim anderen lediglich marginal erhöht sind. In Fibroblasten und Gewebehomogenaten von Nierenrinde, Nierenmark, Leber und Milz beträgt die Aktivität des Enzyms N-Acetyl- $\alpha$-D-Glukosaminidase (Naglu) zwischen 2,8\% und 9,2 \% der bei gesunden Kontrollhunden gemessenen Werte (Giger et al. 2001; Ellinwood et al. 2003b).

\section{Genetischer Hintergrund}

Das canine Naglu-Gen ist auf Chromosom 9 im genomischen Contig NW_876332 zwischen Position 2226526 und 2218880 lokalisiert (NCBI-GeneID: 490965). Es umfasst auf einer Gesamtlänge von 6520 bp sechs Exons, die für ein 741 Aminosäuren langes Polypeptid codieren. Abb. 39 zeigt schematisch die Lage der einzelnen Exons in der genomischen Sequenz. 


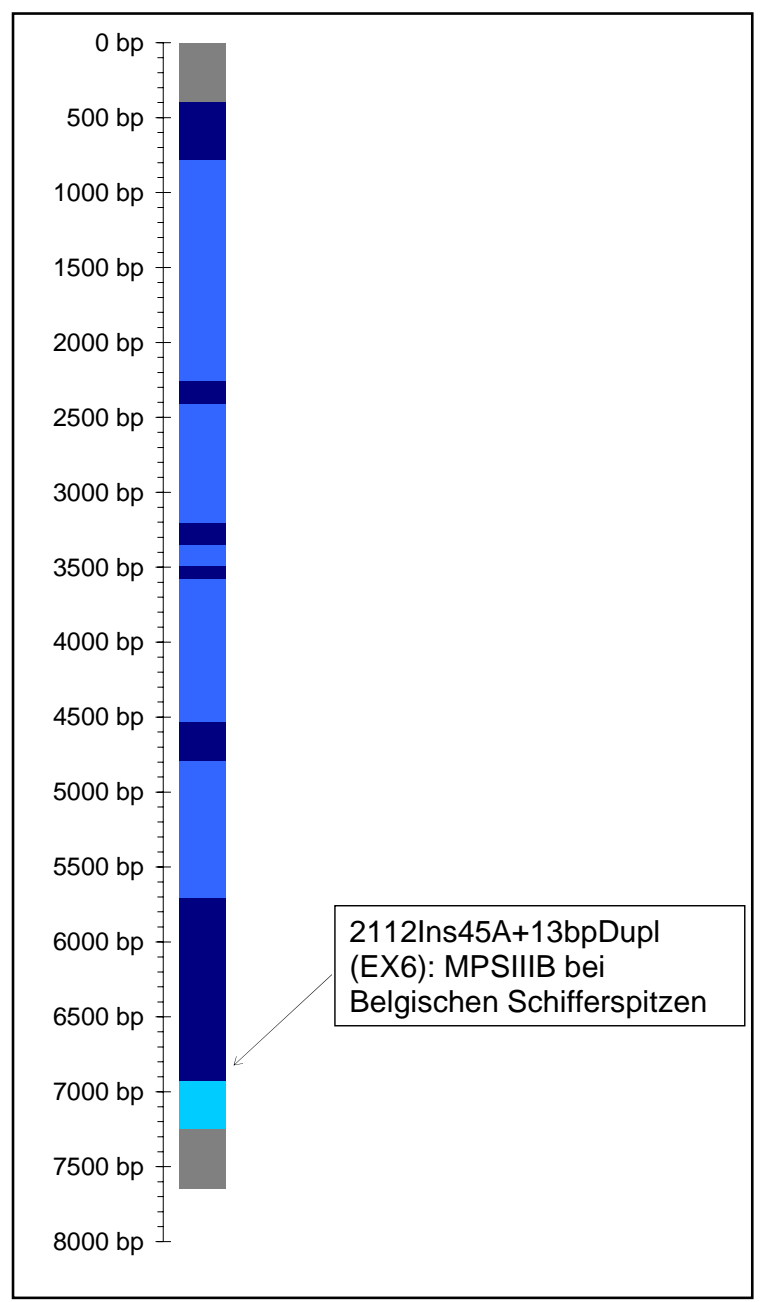

Abb. 39 Schematische Darstellung des caninen Naglu-Gens und Lage der bisher identifizierten Mutationen. Dunkelblau: codierende Sequenz, hellblau: Intronsequenz, türkis: UTR, grau: intergenische Sequenz.

\section{Ursächliche Mutation für MPS III B bei Belgischen Schifferspitzen}

Die für die Mucopolysaccharidose III B bei Belgischen Schifferspitzen verantwortliche Mutation ist in Exon 6 lokalisiert (Ellinwood et al. 2003a). Es handelt sich um eine ca. 45 Nukleotide umfassende Poly-Adenin-Insertion, die mit einer Duplikation der in 5'Richtung angrenzenden 13 bp (AG AAT GCC TTC CA) abschließt (Abb. 40). Die Anzahl der Adenin-Nukleotide in der Insertionssequenz schwankt individuell. Unabhängig von der Entstehung einer Leserasterverschiebung muss diese Mutation durch Einführen von ca. 15 Lysinresten nach Aminosäure 704 des resultierenden Polypeptids zu einer Störung der normalen Proteinaktivität führen. Aufgrund der flankierenden Duplikation und des Auftretens einer Poly-Adenin-Sequenz gehen die Autoren davon aus, dass diese Insertion durch ein LINE gesteuert wird (Ellinwood et al. 2003a). 


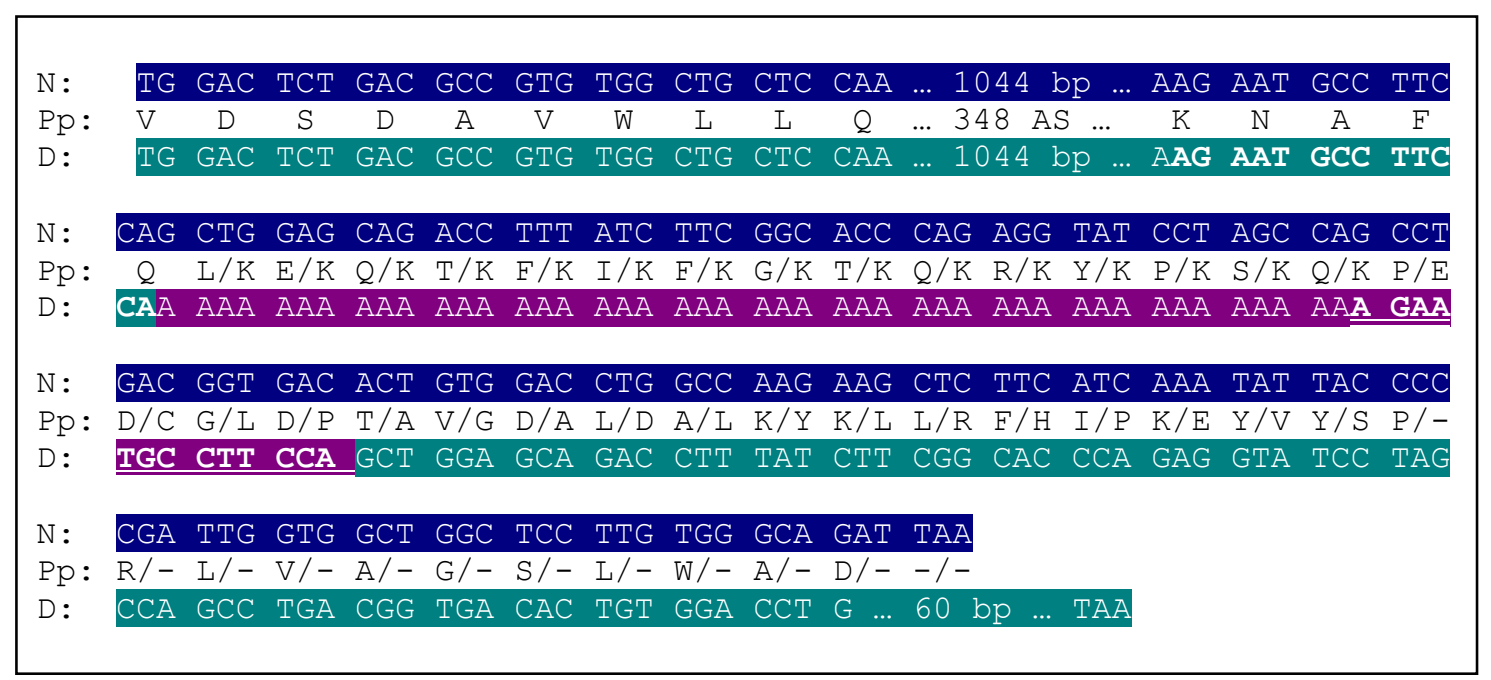

Abb. 40 Exon 6 des caninen Naglu-Gens. N: normale Sequenz, D: defekte Sequenz, Pp: Polypeptidsequenz, dunkelblau: Exon normale Sequenz, dunkelgrün: Exon defekte Sequenz, PolyAdenin-Insertion in defekter Sequenz violett unterlegt, 13-bp-Duplikation in defekter Sequenz dick gedruckt und unterstrichen.

\subsection{Mucopolysaccharidose VI}

\begin{tabular}{ll|}
\hline Chromosom: & CFA3 \\
Gen: & ASB \\
NCBI: & GeneID: 610364 \\
DNA-Sequenz: & NW_876308, Position 27752754-27917513 \\
Mutationen: & Del-26-30, Zwergschnauzer \\
& G?A(Position nicht veröffentlicht), Zwergpinscher \\
\hline
\end{tabular}

\section{Krankheitsbild}

Einzelheiten zur caninen MPS VI sind bei Zwergpinschern beschrieben worden (Neer et al. 1995; Foureman et al. 2004). Der Erbgang ist autosomal rezessiv. Bei einer Genotypisierung von 89 Zwergpinschern unter Einsatz eines DNA-Tests konnten zehn heterozygote Defektträger und ein erkrankter Hund identifiziert werden. Die Häufigkeit des Defektallels in der Zwergpinscherpopulation wird auf $7 \%$ geschätzt (Foureman et al. 2004). Weitere betroffene Rassen sind Zwergschnauzer, Corgis und Chesapeake Bay Retriever (Berman et al. 2004; Foureman et al. 2004). Über die Häufigkeit der MPS VI in diesen Rassen werden keine Angaben gemacht. Urinuntersuchungen zeigen eine Erhöhung der Dermatan- und Chondroitinsulfat-ausscheidung. In den Lysosomen der Fibroblasten und der Leukozyten ist die Aktivität des Enzyms Arylsulfatase B (ASB) deutlich herabgesetzt. Anhand dieser charakteristischen Befunde lässt sich eine eindeutige Diagnose der Mucopolysaccharidose VI stellen (Neer et al. 1995). 


\section{Genetischer Hintergrund}

Das canine ASB-Gen (NCBI-GeneID: 610364) ist im genomischen Contig NW_876308 auf Chromosom 3 lokalisiert und enthält insgesamt acht Exons, die für ein 535 Aminosäuren langes Polypeptid codieren. Exon 1 beginnt an Position 27752754, das Stoppcodon in Exon 8 endet an Position 27917513 (Abb. 41).

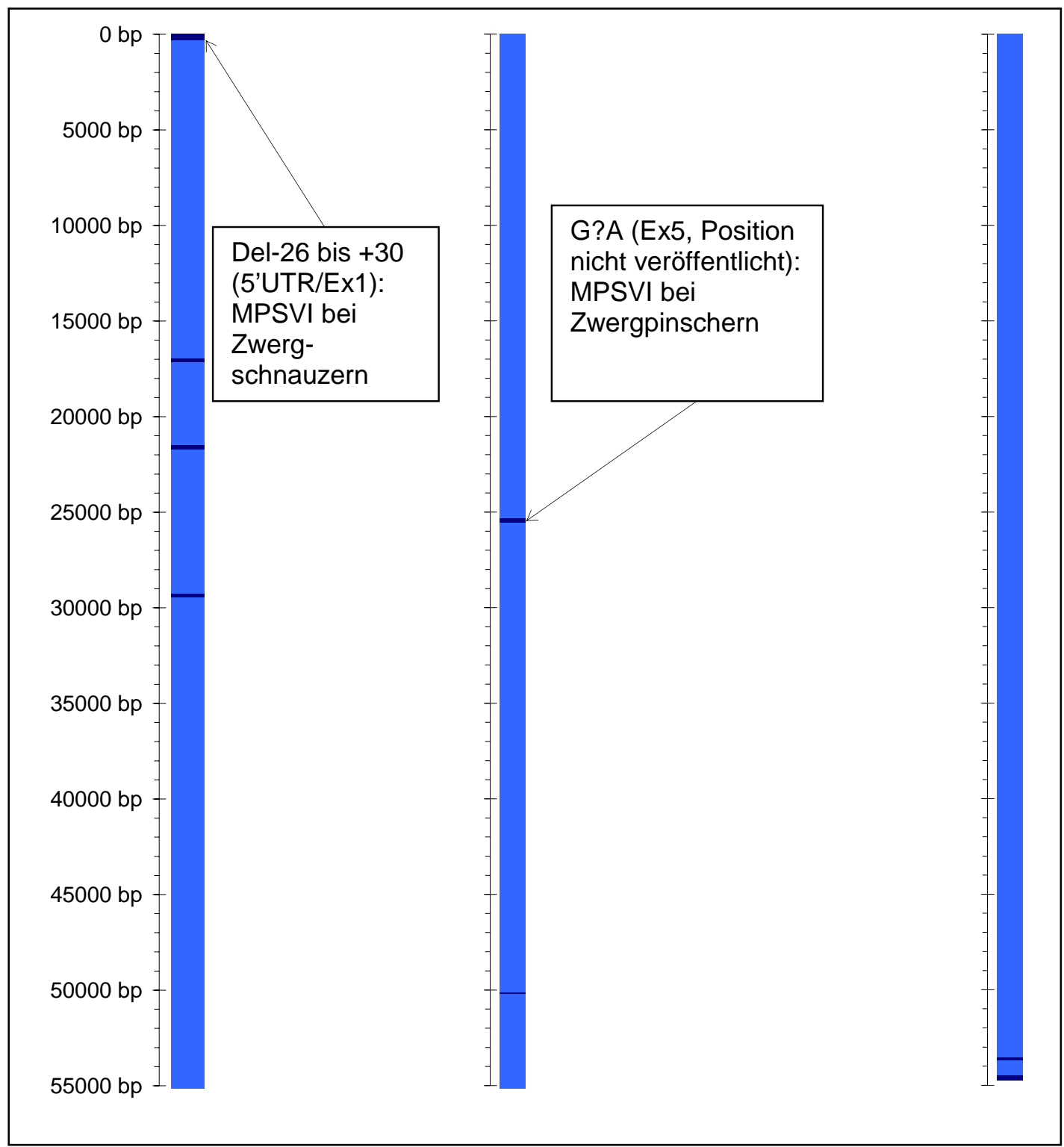

Abb. 41 Schematische Darstellung des caninen ASB-Gens und Lage der bisher identifizierten Mutationen. Dunkelblau: codierende Sequenz, hellblau: Intronsequenz.

\section{III.a Ursächliche Mutation der MPS VI bei Zwergschnauzern}

Bei der für MPS VI bei Zwergschnauzern verantwortliche Mutation handelt es sich um eine 56 bp lange Deletion im Arylsulfatase-B-Gen, die zu einem Verlust der letzten 26 bp der 5'-UTR sowie der ersten zehn Codons von Exon 1 führt (Abb. 42). Es wird 
erwartet, dass das resultierende verkürzte Polypeptid nicht funktionell und instabil ist (Berman et al. 2004).

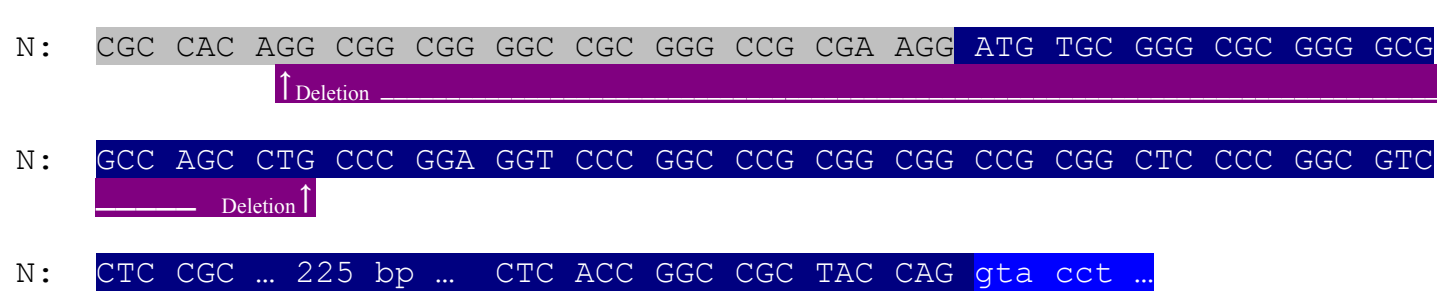

Abb. 42 Exon 1 des caninen Arylsulfatase B Gens und angrenzende 5'UTR- und Intronsequenz (NCBIGeneID: 610364). N: normale Sequenz, grau: UTR, dunkelblau: Exon normale Sequenz, hellblau: Intron normale Sequenz, deletierte Sequenz durch Pfeil gekennzeichnet.

\section{III.b Ursächliche Mutation der MPS VI bei Zwergpinschern}

Bei der für Mucopolysaccharidose VI bei Zwergpinschern verantwortlichen Mutation handelt es sich um eine Substitution von Guanin durch Adenin in Exon 5, die im resultierenden Protein zu einem Austausch von Glycin durch Arginin führt. Anhand der verfügbaren Informationen lässt sich die Lage der Substitution in Exon 5 nicht eindeutig bestimmen (Berman et al. 2004; Foureman et al. 2004).

\subsection{Mucopolysaccharidose VII}

\begin{tabular}{|ll|}
\hline Chromosom: & CFA6 \\
Gen: & GUSB \\
NCBI: & GeneID: 403831, GenBank: AF019759 \\
DNA-Sequenz: & NW_876317, Position 74279-731917 \\
Mutationen: & G559A, Mischlingshunde, Schäferhunde \\
\hline
\end{tabular}

\section{Krankheitsbild}

Die klinischen, pathologischen und histopathologischen Erscheinungen der caninen Form der MPS VII wurde erstmals 1984 bei einem männlichen Mischlingshund beschrieben (Haskins et al. 1984). Vertiefende Untersuchungen wurden an dessen Nachkommen in einer Forschungskolonie (Schuchman et al. 1989; Haskins et al. 1991; Ray et al. 1998b) sowie einem weiteren MPS-VII-Fall bei einem Deutschen Schäferhund (Silverstein Dombrowski et al. 2004) durchgeführt. Beim Deutschen Schäferhund konnte dasselbe Defektallel identifiziert werden wie in der Familie der Mischlingshunde. Über die Häufigkeit der MPS VII in der Rasse Deutscher Schäferhund werden keine Angaben gemacht. Stammbaumanalysen in der Familie der 
Mischlingshunde zeigen, dass der MPS VII ein autosomal rezessiver Erbgang zugrunde liegt (Ray et al. 1998a).

Biochemische Untersuchungen ergeben eine generelle Reduzierung der $\beta$ Glukuronidase-Aktivität, die sich jedoch in einzelnen Zelltypen graduell unterscheidet (Haskins et al. 1984; Haskins et al. 1991). So schwankt die Restaktivität der $\beta$ Glukuronidase in den untersuchten Geweben von MPS-VII-Hunden zwischen 0,2 und $1,7 \%$ des Normwertes, während im Serum eine Restaktivität von 6,4 \% und im Urin von 3,5-18,5 \% nachweisbar ist. Dementsprechend sind auch die Konzentrationen von Glykosaminoglykanen in einzelnen Zelltypen unterschiedlich (Schuchman et al. 1989). Zwischen der normalen und der bei MPS-VII-Hunden vorhandenen $\beta$-Glukuronidase bestehen hinsichtlich der Kinetik erhebliche Unterschiede. Die Michaeliskonstante (Maß für die Affinität eines Enzyms zu seinem Substrat) des normalen Enzyms beträgt 0,48 mmol/1, während dieser Wert bei MPS-VII-Hunden bei über 2,5 mmol/1 liegt. Demgegenüber sind die physikalischen Eigenschaften der $\beta$-Glukuronidase wie Thermo-, Cryo- und pH-Stabilität sowie pH-Optimum bei MPS-VII-Hunden und gesunden Hunden gleich. Möglicherweise beruht die Verringerung der $\beta$ Glukuronidase-Aktivität auf einer Mutation, die den Transport des Enzyms in die Lysosomen beeinträchtigt, so dass ein Großteil in den extrazellulären Raum abgegeben wird, in diesem Milieu instabil ist und denaturiert. Die relativ hohe Aktivität des mutierten Enzyms im Plasma und im Urin könnte hingegen mit einer höheren Stabilität in neutralem Milieu zusammenhängen (Schuchman et al. 1989). Während hinsichtlich der $\beta$-Glukuronidase-mRNA-Konzentration bei Untersuchungen an Netzhautzellen keinerlei Unterschiede zwischen klinisch gesunden und betroffenen Hunden feststellbar sind, ist das Protein mittels immunologischer Untersuchungen an Netzhautlysaten betroffener Hunde nicht nachweisbar. Der verwendete, gegen humane $\beta$-Glukuronidase gerichtete Antikörper bindet demgegenüber bei klinisch gesunden Hunden in der zu erwartenden Weise. Daraus lässt sich schließen, dass das Enzym bei betroffenen Hunden entweder instabil oder anfällig gegen proteolytischen Abbau ist oder durch die Mutation nicht mehr von den verwendeten Antikörpern erkannt wird (Ray et al. 1999). 


\section{Genetischer Hintergrund}

Pedigreeanalysen in einer Hundekolonie, die aus Nachkommen des oben erwähnten betroffenen Mischlingshundes gegründet wurde, sprechen für einen autosomal rezessiven Erbgang. Dabei zeichnen sich heterozygote Träger des mutierten Gens durch eine um etwa $50 \%$ verminderte $\beta$-Glukuronidase-Aktivität aus (Haskins et al. 1991).

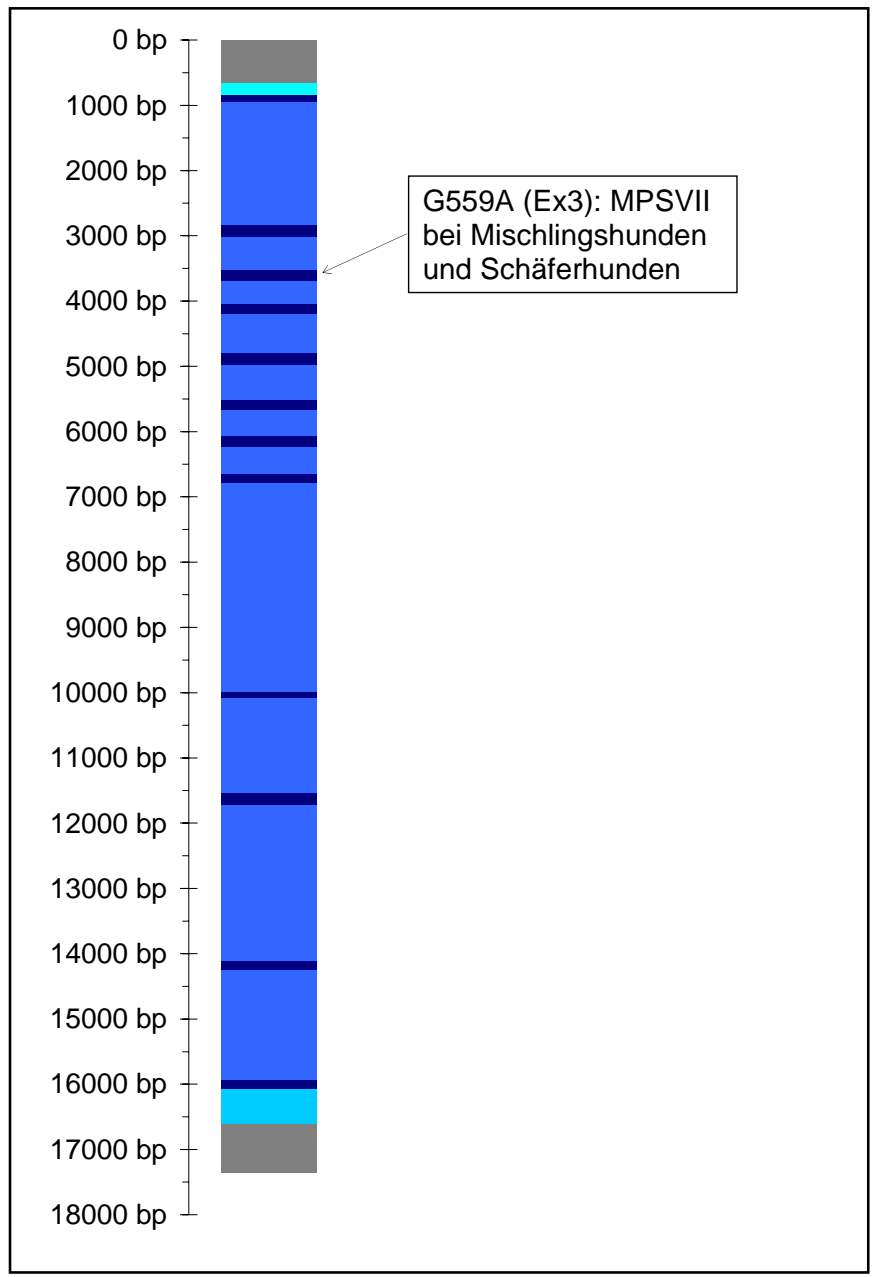

Abb. 43 Schematische Darstellung des caninen GUSB-Gens und Lage der bisher identifizierten Mutationen. Dunkelblau: codierende Sequenz, hellblau: Intronsequenz, türkis: 5'- und 3'-UTR, grau: intergenische Sequenz.

Das offene Leseraster der normalen caninen $\beta$-Glukuronidase-cDNA (cGUSB, NCBIGenBank: AF019759) hat eine Länge von 1956 bp. Daran schließt sich ein 14 bp langer Poly-Adenin-Schwanz an. Das $\beta$-Glukuronidase-Gen (GUSB) enthält 12 Exons und erstreckt sich im genomischen Contig NW_876317 auf dem revers komplementären Strang von Position 746279 bis 731917 (NCBI-GeneID: 403831). Das resultierende Polypeptid hat eine Länge von 651 Aminosäuren. In Abb. 43 ist die Lage der einzelnen Exons innerhalb der genomischen Sequenz schematisch dargestellt. 


\section{Ursächliche Mutation für Mucopolysaccharidose VII}

Die $\beta$-Glukuronidase-cDNA von MPS-VII-Mischlingshunden unterscheidet sich von der normalen cDNA durch einen Basenaustausch an Nukleotidposition 559 von Guanin durch Adenin. Dadurch kommt es beim resultierenden Enzym zu einem Aminosäurenaustausch von Arginin zu Histidin an Aminosäurenposition 166 (Abb. 44). Diese Mutation segregiert bei 30 untersuchten Mischlingshunden mit dem MPS-VIIPhänotyp (Ray et al. 1998a) und ist auch bei dem 2004 beschriebenen Deutschen Schäferhund mit MPS VII nachweisbar (Silverstein Dombrowski et al. 2004).

In der murinen Fibroblasten- Zelllinie 3521, die aufgrund einer vollständigen Deletion des GUSB-Gens $\beta$-Glukuronidase-defizient ist, führt die Einführung des retroviralen Vektors pLXSN, in den die mutierte $\beta$-Glukuronidase-cDNA einkloniert ist (pLcgusbXSN), zu einer $\beta$-Glukuronidase Expression, die gegenüber der Expression in 3521-Zellen ohne pLXSN-Vektor um das Vier- bis Fünffache erhöht ist. Im Verhältnis zu 3521-Zellen, die mit pLXSN-Vektor mit einklonierter, normaler cDNA transfiziert sind, ist die $\beta$-Glukuronidase-Expression in den mit pLcgusbXSN transfizierten Zellen um das Hundertfache geringer (Ray et al. 1998b). Diese Beobachtung ist mit der auf 0,2-1,7 \% reduzierten $\beta$-Glukuronidase-Aktivität in Geweben von MPS-VII-Hunden gut vereinbar und gibt einen weiteren Hinweis darauf, dass es sich bei der beschriebenen Mutation um die für MPS VII ursächliche Mutation handelt.

\section{Genotypisierung für MPS VII}

Drei veröffentlichte mögliche Verfahren zur Genotypisierung umfassen eine Heteroduplexanalyse (Abb. 44) (Ray et al. 1998a) und zwei Restriktionsanalysen, für die mit Hilfe von mismatch-Primern im Wildtypallel eine EagI- (Abb. 44) (Ray et al. 1998a) bzw. RsaI-Restriktionsschnittstelle (Abb. 45) (Silverstein Dombrowski et al. 2004) eingefügt wird. 


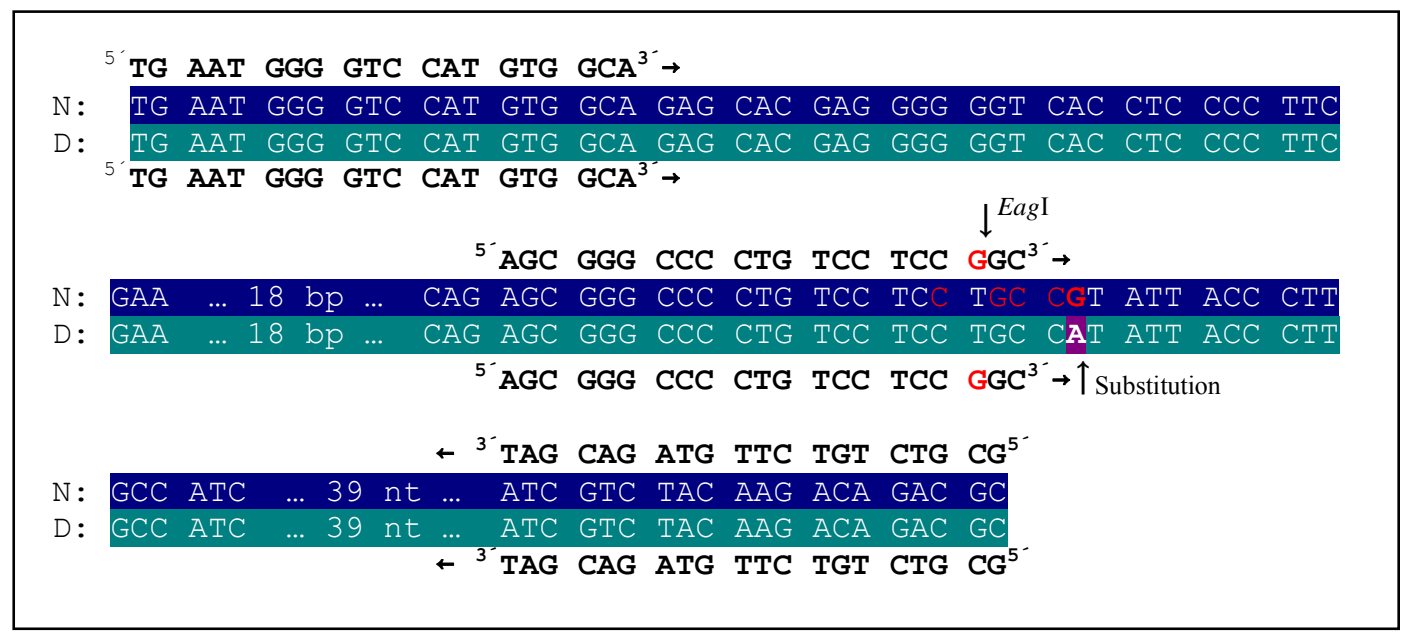

Abb. 44 Exon 3 des caninen $\beta$-Glukuronidase-Gens. N: normale Sequenz, D: defekte Sequenz, dunkelblau: Exon normale Sequenz, dunkelgrün: Exon defekte Sequenz, Substitution in der defekten Sequenz durch Pfeil gekennzeichnet und violett unterlegt, EagI Restriktionsschnittstelle durch Pfeil gekennzeichnet, rote Schrift: EagI Erkennungssequenz.

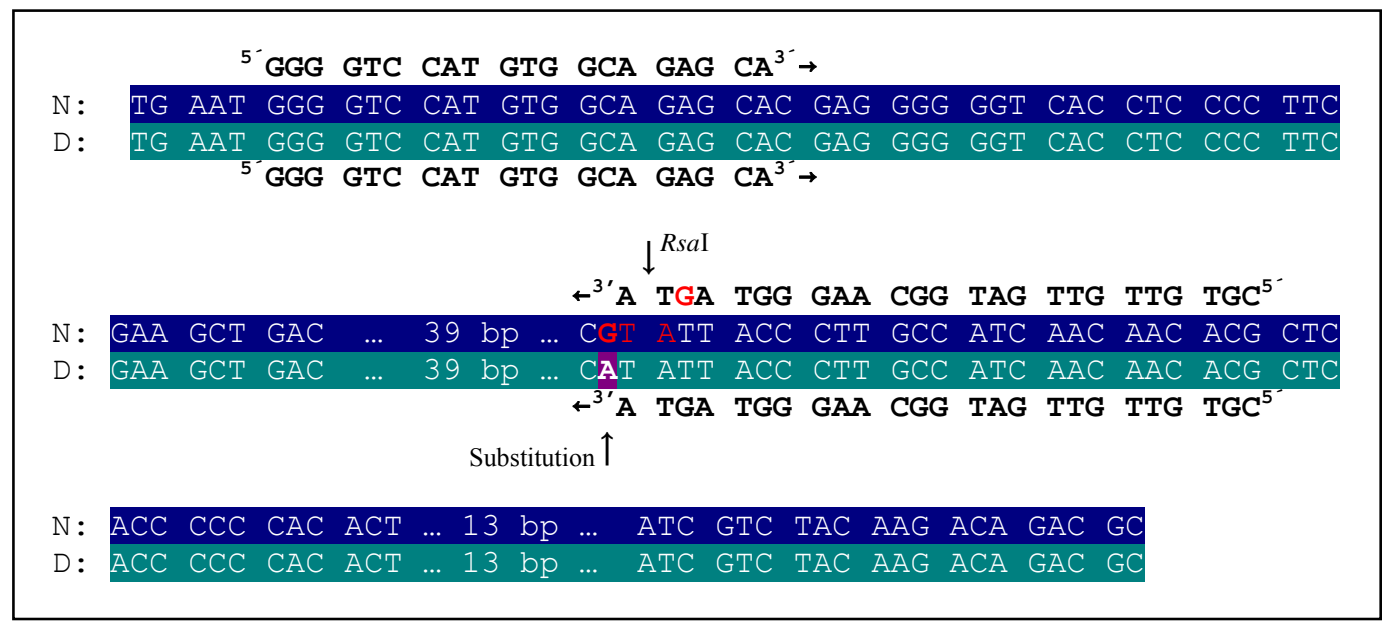

Abb. 45 Exon 3 des caninen $\beta$-Glukuronidase-Gens. N: normale Sequenz, D: defekte Sequenz, dunkelblau: Exon normale Sequenz, dunkelgrün: Exon defekte Sequenz, Substitution in der defekten Sequenz durch Pfeil gekennzeichnet und violett unterlegt, RsaI-Restriktionsschnittstelle durch Pfeil gekennzeichnet, rote Schrift: RsaI-Restriktionserkennungssequenz.

\subsection{Fukosidose}

\begin{tabular}{|ll|}
\hline Chromosom: & CFA2 \\
Gen: & FUCA1 \\
NCBI: & GeneID: 403929, GenBank: U29765 \\
DNA-Sequenz: & NW_876292, Position 41041253-41052867 \\
Mutationen: & Del398-441, Springer Spaniel \\
\hline
\end{tabular}

\section{Krankheitsbild}

Das Auftreten der caninen Fukosidose ist bisher auf Englische Springerspaniel beschränkt geblieben (Hartley et al. 1982; Kelly et al. 1983; Herrtage et al. 1985). Insgesamt scheint die Fucosidose innerhalb dieser Rasse nicht sehr stark verbreitet zu 
sein. Von 32 Springer Spaniels aus englischen Zuchtlinien, die mittels DNA-Test genotypisiert wurden, waren lediglich zwei Hunde Träger des Defektallels. Von 60 Springer Spaniels aus US-amerikanischen Zuchtlinien war keiner Träger des Defektallels (Skelly et al. 1999b). Ursache der Erkrankung ist ein Mangel an $\alpha$-LFukosidase, einem lysosomalen Enzym zum Abbau komplexer Verbindungen, in Folge dessen es zu Einlagerung fukosehaltiger Glykoasparagine in neurale und extraneurale Zellen kommt (Kelly et al. 1983; Abraham et al. 1984). Mittels Ionenaustauschchromatographie lässt sich im Hirn gesunder Hunde eine gebundene und eine ungebundene Fukosidase-Form unterscheiden. Im Hirn und im Rückenmark betroffener Hunde liegt eine deutliche Defizienz beider $\alpha$-L-Fukosidase-Typen vor (Abraham et al. 1984).

\section{Genetischer Hintergrund}

Pedigreeinformationen sprechen für einen autosomal rezessiven Erbgang (Kelly et al. 1983). Die Identifikation homozygot betroffener Hunde kann bereits in einem frühen Krankheitsstadium über die Messung der $\alpha$-L-Fukosidase-Aktivität in Plasma und extrahierten weißen Blutzellen erfolgen. Bis zu einem gewissen Grad lassen sich über diese Methode auch heterozygote Träger des Defektes identifizieren. Diese Diagnosemethode erfordert allerdings frisches Blut (Herrtage et al. 1985).

Eine 2040 bp lange canine $\alpha$-L-Fukosidase-cDNA-Sequenz mit einem offenen Leseraster von 1402 bp Länge, die von einer australischen Forschergruppe aus zwei Klonen hergeleitet wurde, codiert für ein 466 Aminosäuren langes Protein (Occhiodoro und Anson 1996). Die Eigenschaften der hergeleiteten 2040-bp-Sequenz bezüglich der vorhandenen Signalsequenzen stimmen mit den erwarteten Eigenschaften der $\alpha$-LFukosidase-cDNA-Sequenz überein. Es liegen typische Elemente eukaryotischer Promotorsequenzen in der 5'-UTR und eine Polyadenylierungs-Signalsequenz in der 3'UTR vor. Das Fehlen einer TATA-Box wird als typisch für konstitutiv exprimierte Gene bewertet. Start- und Stopp-Signalsequenzen für die Translation sind vorhanden. Ein Vergleich mit cDNA- und Protein-Sequenzen aus entsprechenden Datenbanken ergab außer der Übereinstimmung mit $\alpha$-L-Fukosidase keine weiteren Sequenzübereinstimmungen. Es bestehen hohe Homologien zur humanen und zur rodenten Nukleotid- und Aminosäurensequenz (Occhiodoro und Anson 1996). Das canine $\alpha$-L-Fucosidase-Gen ist auf Chromosom 2 im genomischen Contig NW_876292 
zwischen Position 41041253 und 41052867 lokalisiert (NCBI-GeneID: 403929) (Occhiodoro und Anson 1996). Die cDNA-Sequenz (NCBI-GenBank U29765) verteilt sich auf 9 Exons. Abb. 46 zeigt schematisch die Struktur des caninen $\alpha$-L-FukosidaseGens.

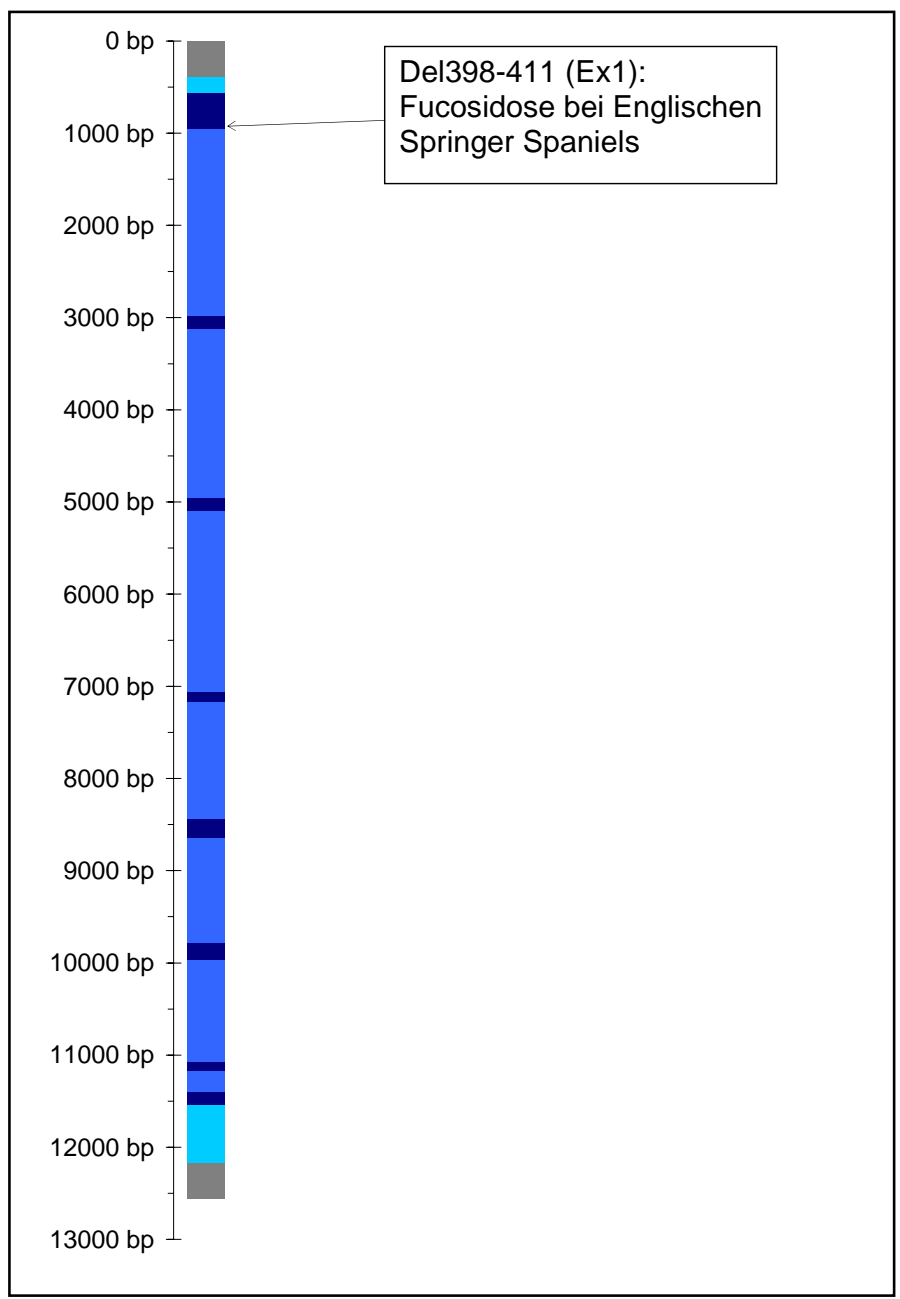

Abb. 46 Schematische Darstellung des caninen $\alpha$-L-Fukosidase-Gens und Lage der bisher identifizierten Mutationen. Dunkelblau: codierende Sequenz, hellblau: Intronsequenz, türkis: 5'- und 3'-UTR, grau: intergenische Sequenz.

Etwa zeitgleich zu Occhiodoro und Anson (1996) wurde von einer britischen Forschungsgruppe (Skelly et al. 1996) eine 2060-bp-cDNA-Sequenz der caninen $\alpha$-LFukosidase mit einem offenen Leseraster von 1398 bp ermittelt, die für ein 465 Aminosäuren langes Polypeptid codiert (NCBI-Sequence: X92448). Diese 465 Aminosäuren schließen ein hydrophobes Signalpeptid ein, das mutmaßlich vom reifen Protein abgespalten wird (Skelly et al. 1996). Die proteincodierenden Abschnitte der beiden Sequenzen stimmen an den ersten 38 Nukleotide zu $100 \%$ überein, zwischen den anschließenden 33 Basen (Occhiondoro-Sequenz) bzw. 30 Basen (Skelly-Sequenz) 
gibt es keinerlei Übereinstimmungen. Ab Nukleotid 72 bzw. 69 existiert zwischen den folgenden 1330 Nukleotiden bis zum Stoppcodon eine 99 \%ige Übereinstimmung. Insgesamt liegen nur 13 Sequenzunterschiede vor (ermittelt mit BLASTN, VERSION BLASTN 2.2.14 [May-07-2006]).

\section{Ursächliche Mutation der Fukosidose bei Englischen Springer Spaniels}

Northern-Blot-Untersuchungen ergaben bei mRNA-Proben von australischen, normalen Englischen Springer Spaniels ein 2,1 kb langes Molekül. Bei betroffenen Springer Spaniels misslang der Nachweis von $\alpha$-L-Fukosidase-mRNA. Bei der cDNA-Synthese aus den Proben betroffener Hunde konnte nur über den Einsatz von nested-Primern eine oberhalb der Nachweisgrenze liegende Menge erzielt werden (Occhiodoro und Anson 1996).

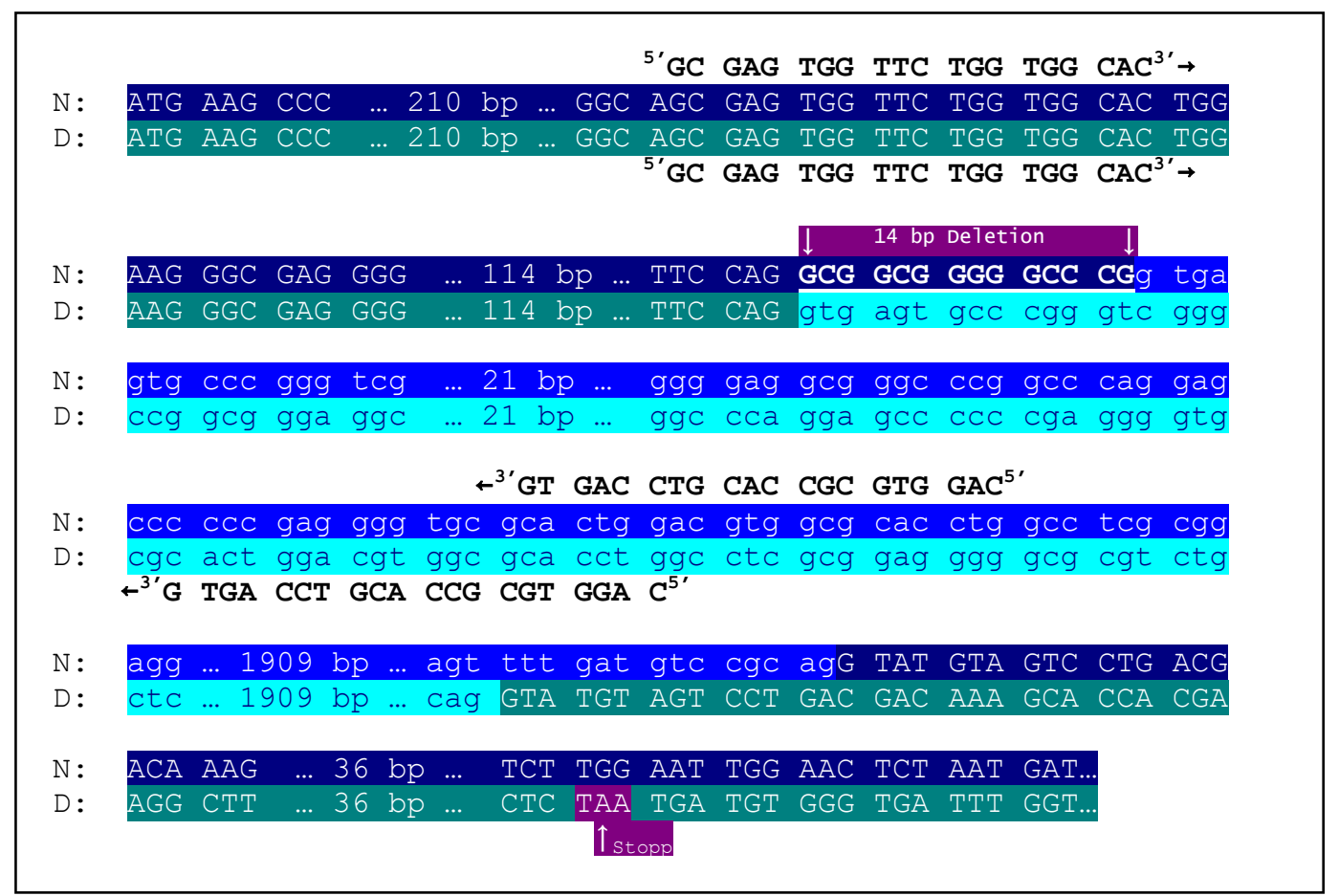

Abb. 47 Exon 1, Intron 1 und 5'-Bereich des Exons 2 des caninen $\alpha$-L-Fukosidase-Gens. N: normale Sequenz, D: defekte Sequenz, dunkelblau: Exon normale Sequenz, dunkelgrün: Exon defekte Sequenz, hellblau: Intron normale Sequenz, türkis: Intron defekte Sequenz, 14-bp-Deletion in normaler Sequenz unterstrichen und durch Pfeil gekennzeichnet, verfrühtes Stoppcodon in defekter Sequenz violett unterlegt und durch Pfeil gekennzeichnet.

Sowohl bei den australischen als auch bei den britischen Englischen Springer Spaniels mit Fukosidose liegt eine 14-bp-Deletion an der Grenze zwischen Exon 1 und Intron 1 vor. Dadurch ändert sich die Spleiß- Sequenz von CG/gt zu AG/gt. Trotz dieser Abweichung findet an dieser Position auch bei betroffenen Hunden ein Spleißereignis 
statt (Occhiodoro und Anson 1996; Skelly et al. 1996). Die 14-bp-Deletion führt zu einer Verschiebung des Leserasters ab Aminosäurenposition 127 und zur Entstehung eines verfrühten Stoppcodons an Position 152 (Abb. 47) (Occhiodoro und Anson 1996).

\section{Genotypisierung für Fukosidose bei Englischen Springer Spaniels}

Der Nachweis der Deletion kann per Amplifikation des betroffenen DNA-Abschnitts und anschließender PCR-Fragmentgrößenanalyse erfolgen. Die Amplifizierung des Sequenzabschnitts in der Umgebung der Mutation gestaltet sich aufgrund des hohen GC-Gehaltes problematisch. Zwei verschiedene PCR-Methoden zum Nachweis von Defektträgern auf der Basis von genomischer DNA (Occhiodoro und Anson 1996; Holmes et al. 1998) konnten in anderen Labors nur mit Schwierigkeiten reproduziert werden (Holmes et al. 1998; Skelly et al. 1999b). Eine dritte Methode erwies sich als stabiler (Skelly et al. 1999b).

\subsection{Lafora-Krankheit}

\begin{tabular}{|ll|}
\hline Chromosom: & CFA35 \\
Gen: & EPM2A (NHLRC1) \\
NCBI: & GeneID: 474161,GenBank: AY56095 \\
DNA-Sequenz: & NW_876302, Position 16940841-16939699 \\
Mutationen: & $(294-305)_{19-26}$, Zwergrauhaardackel, Basset \\
\hline
\end{tabular}

\section{Krankheitsbild}

Die Lafora-Krankheit ist durch massive Störungen des Bewegungsapparates in Verbindung mit dem Auftreten charakteristischer als Laforakörper bezeichneter Zelleinschlüsse gekennzeichnet. Die Laforakörper wurden erstmals 1911 beschrieben (Lafora und Glueck). Ihr Inhalt besteht zu 73-89 \% aus Glucosepolymeren, so genannten Glukosanen. Daraus lässt sich ableiten, dass die Pathologie der LaforaKrankheit mit einer Störung des Glukose- bzw. Glykogenstoffwechsels zusammenhängt (Sakai et al. 1970). Bei humanen Patienten zeigen sich erste Symptome im Alter zwischen 6 und 20 Jahren. Der Verlauf wird als progressiv beschrieben. Betroffene Patienten werden nicht älter als 35 Jahre (Van Hoof und Hageman-Bal 1967). Die Störungen des Bewegungsapparates treten vorrangig in Form von epileptischen Anfällen und Myoklonien zutage. Daher ist neben Lafora-Krankheit auch die Bezeichnung progressive Myoklonus Epilepsie (pME) gebräuchlich. Es sind jedoch 
auch pME-Formen beschrieben worden, bei denen keine Einlagerungen von Laforakörpern nachgewiesen werden konnte (Montgomery und Lee 1983). Auf der anderen Seite kann der Verlauf einer mit der Einlagerung von Laforakörpern verbundenen Erkrankung je nach betroffener Hirnregion vollständig frei von Epilepsie und Myoklonien sein (Seitelberger et al. 1964; Holland et al. 1970).

Bei der caninen Lafora-Krankheit liegt bezüglich des Alters betroffener Hunde beim Auftreten der ersten klinischen Anzeichen sowie bezüglich des Verlaufs und der beobachteten Symptome eine beträchtliche Variabilität vor. Ein einheitliches rassentypisches Krankheitsbild ergibt sich für betroffene Beagles aus einer Forschungskolonie (Tomchick 1973; Hegreberg und Padgett 1976) und für die britische Zwergrauhaardackelpopulation, in der 2005 eine relativ hohe Inzidenz von 5 \% vorlag (Lohi et al. 2005b). Bei Bassets sind zwei leicht voneinander abweichende Fälle beschrieben worden (Holland et al. 1970; Jian et al. 1990). Bei Corgis wurde bisher ein einzelner Fall bekannt (Davis et al. 1990).

\section{Genetischer Hintergrund}

Pedigreeinformationen betroffener Beagles (Hegreberg und Padgett 1976) und Zwergrauhaardackel (Lohi et al. 2005b) sprechen für einen autosomal rezessiven Erbgang. Eine Mikrosatellitenanalyse in einer Population von Zwergrauhaardackeln ergab unter anderem eine enge Koppelung der Lafora-Krankheit mit dem Mikrosatellitenmarker REN157J09. Aufgrund der Lage dieses Markers auf Chromosom 35 wurde bei der Überprüfung der humanen Kandidatengene Epm2a und Epm2b (auch NHLRC1, NHL repeat containig) ein Defekt im Epm2a-Gen als ursächlicher Gendefekt für die Lafora-Krankheit ausgeschlossen, nachdem es mittels Radiation-HybridMapping auf Chromosom 1 lokalisiert wurde (Lohi et al. 2005b). Das canine Epm2bGen weist dagegen eine enge Kopplung zu Mikrosatellitenmarker REN157J09 auf. Es enthält ein einzelnes Exon von 1200 bp Länge, das für ein 348 Aminosäuren langes Polypeptid codiert (NCBI-GenBank: AY560905). Im genomischen Contig NW_876302 erstreckt sich das canine Epm2b-Gen zwischen Position 16940841 und 16939699 (NCBI-GeneID: 474161). 


\section{Ursächliche Mutation für die Lafora Krankheit bei Zwergrauhaardackeln und Bassets}

In Exon 1 des Epm2b-Gens befindet sich in der normalen DNA-Sequenz eine Duplikation einer 12 bp langen Sequenz, die ausschließlich aus Cytosin- und Guaninukleotiden besteht. In der Sequenz von 14 untersuchten, betroffenen Zwergrauhaardackeln liegen anstelle der üblichen zwei Kopien dieser 12-bp-Sequenz 19 bis 26 Kopien vor. Auch bei einem betroffenen Basset konnte die beschriebene Mutation im Epm2b-Gen nachgewiesen werden (Abb. 48).

In der Skelettmuskulatur homozygot betroffener Zwergrauhaardackel beträgt die gegen Glycerinaldehydphosphat-Dehydrogenase (Gadph) normalisierte Menge an Epm2bmRNA zwischen 0,006 und 0,001. Demnach führt die Mutation zu einer vollständigen mRNA-Defizienz. Als Ursache wird eine Blockade der RNA-Polymerase aufgrund von im Bereich der Duplikation gebildeten Haarnadel-Sekundärstrukturen vermutet (Lohi et al. 2005b).

Das Epm2b-Gen codiert für das Protein Malin, das aufgrund seiner RING-FingerDomäne den E3-Ubiquitin-Ligasen zuzuordnen ist (Chan et al. 2003). Der Zusammenhang zwischen der Malindefizienz und der Pathologie der Lafora-Krankheit ist noch nicht im Detail geklärt. Unter anderem spielt Malin eine entscheidende Rolle für die Regulation von Laforin, das in Abhängigkeit von Malin ubiquitinisiert wird. Diese Ubiquitinisierung ist Voraussetzung für den Abbau von Laforin (Gentry et al. 2005). Laforin wird vom Epm2a-Gen codiert und scheint wesentlich zur Aufrechterhaltung eines intakten Glykogenanabolismus beizutragen. Mutationen am Laforin-Gen Epm2a führen ebenso zur Lafora-Krankheit wie Mutationen am Malin-Gen Epm2b. Die Funktion von Laforin innerhalb des Glykogenstoffwechsels ist noch nicht abschließend geklärt. Untersuchungen an transgenen Mäusen lassen auf eine Beteiligung von Laforin an der Regulation des Verhältnisses von Glykogensyntethase zu Glykosyl-4-6-Transferase (Verzweigungsenzym) schließen (Chan et al. 2004). Besteht zwischen diesen beiden Enzymen ein Ungleichgewicht im Sinne eines Glykogensyntethaseüberschusses, kommt es zur Bildung langer unverzweigter Polyglukosane mit deutlich herabgesetzter Löslichkeit. Neben der möglichen Funktion als Glykogensyntethaseregulator ist Laforin möglicherweise im Zusammenspiel mit 
Malin am Abbau unzureichend oder gar nicht verzweigter Polyglukosane beteiligt (Lohi et al. 2005a).

\section{Genotypisierung für die Lafora-Krankheit bei Zwergrauhaardackeln und Bassets}

Der Nachweis der Epm2b-Mutation bei Zwergrauhaardackeln und Bassets kann per PCR und anschließender diagnostischer Sequenzierung erfolgen (Abb. 48) (Lohi et al. 2005b).

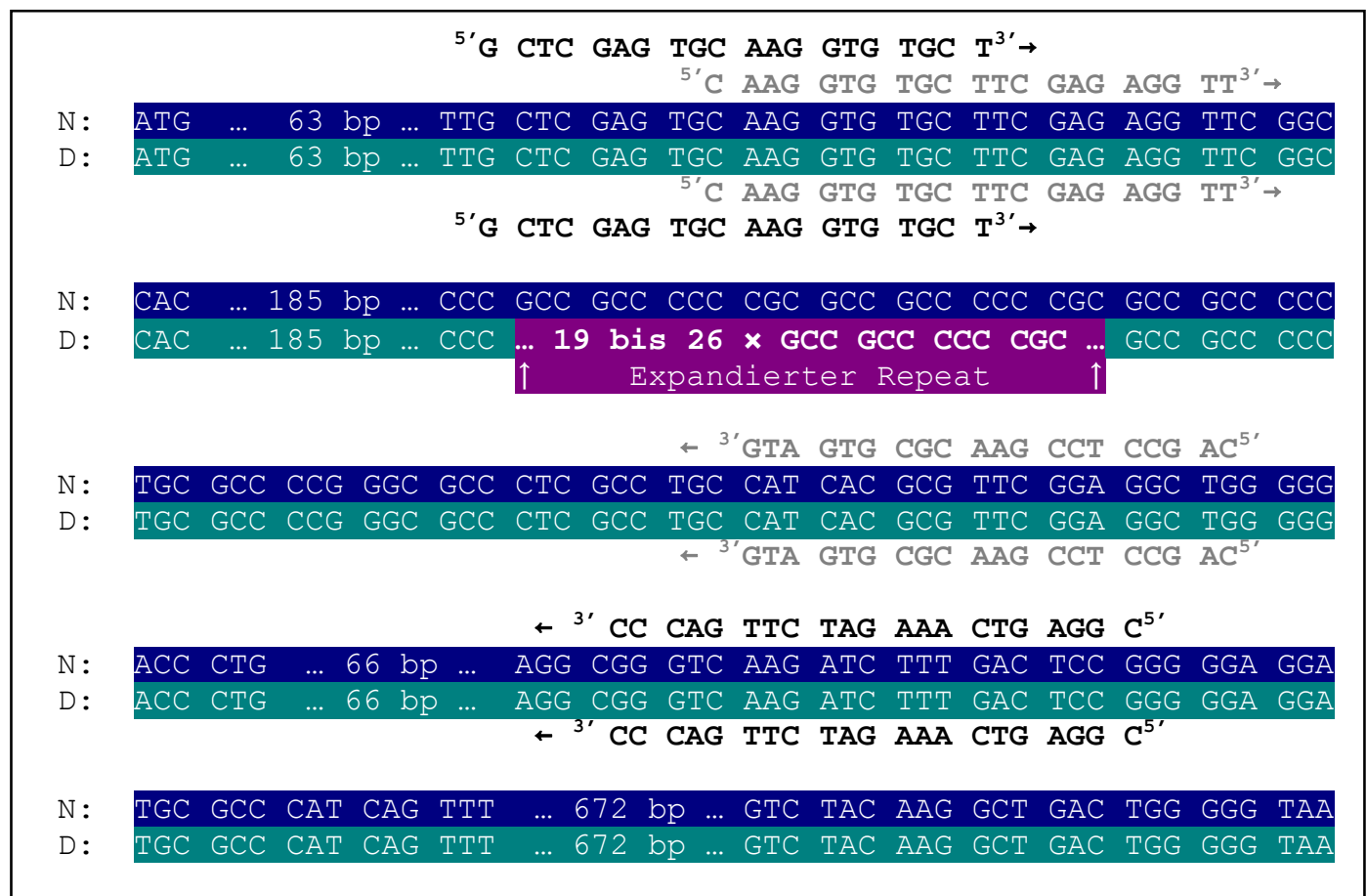

Abb. 48 Exon 1 des caninen Epm2b Gens. N: normale Sequenz, D: defekte Sequenz, dunkelblau: Exon normale Sequenz, dunkelgrün: Exon defekte Sequenz, Duplikation in defekter Sequenz violett unterlegt und durch Pfeil gekennzeichnet, schwarze Schrift und graue Schrift: alternative Primerpaare für die Sequenzierung. 


\subsubsection{Lysosomale Proteinosen: Ceroid-Lipofuscinosen}

Unter der Bezeichnung Ceroid-Lipofuscinose (CL) oder neuronale CL wird eine Gruppe von neurodegenerativen Erkrankungen zusammengefasst, die durch charakteristische, fluoreszierende Ablagerungen in den Lysosomen der Zellen des Nervengewebes und zum Teil auch in anderen Zelltypen gekennzeichnet sind. Diese Erkrankungen sind bisher die einzigen bekannten lysosomalen Proteinosen (Gupta und Hofmann 2002). In der Literatur finden sich häufig auch die Bezeichnungen Batten's Disease oder Amaurotische Familäre Idiotie. Die erste Beschreibung einer humanen Form der Ceroid-Lipofuscinose erfolgte 1826 (Stengel 1826). Über eine canine Form der Erkrankung wurde erstmals 1953 berichtet (Hagen 1953).

Der Name Ceroid-Lipofuscinose entstand aufgrund der Färbe- und TinktorialEigenschaften des abgelagerten Materials, die für die Lipofuscin- und CeroidLipopigmente typisch sind (Zeman und Dyken 1969). Lipofuscin gilt als typisches Alterspigment, das durch langsame Akkumulation nicht abbaubarer Stoffwechselzwischenprodukte entsteht. Der Name setzt sich aus dem griechischen Begriff „lipo“ für „Fett“ und dem lateinischen Begriff „fuscus“ für „dunkel“ zusammen. Neuere Analysen zeigen jedoch, dass Lipofuscin im Allgemeinen zu ca. zwei Dritteln aus Protein und nur zu etwa einem Drittel aus Lipiden zusammengesetzt ist Weitere Bestandteile sind Kohlenhydrate und Spuren von Metallen, darunter vorrangig Eisen. (Brunk und Terman 2002a; Brunk und Terman 2002b). Die Zusammensetzung scheint jedoch abhängig von der betroffenen Zelle zu variieren. In Retinapigmentepithelzellen abgelagertes Lipofuscin besteht beispielsweise zu $90 \%$ aus Retinoiden (Katz et al. 1986). Demnach fasst der Begriff Lipofuscin eine Reihe unterschiedlicher Lipopigmente zusammen (Seehafer und Pearce 2006). Ceroidpigmente sind als lipofuscinähnliche Lipopigmente definiert, deren Auftreten nicht auf normale physiologische Vorgänge zurückzuführen ist, sondern im Zusammenhang mit pathologischen Zuständen steht. Ceroidpigmente sind prinzipiell in allen Zelltypen zu finden, treten aber vorrangig in phagozytierenden Zellen auf. Das akkumulierte Material stammt demzufolge mit hoher Wahrscheinlichkeit von außerhalb der betroffenen Zellen, beispielsweise aus nekrotisierten Zellen oder von veränderten zirkulierenden Substanzen. Demgegenüber lagern sich Lipofuscinpigmente ausschließlich in 
Lysosomen ab, und ihre Vorläufersubstanzen stammen überwiegend aus derselben Zelle, in der die Pigmente abgelagert sind (Porta 1991).

Bei dem gespeicherten Material handelt es sich überwiegend um Proteine. Bei einigen Erkrankungsformen konnten spezifische Polypeptide identifiziert werden (Palmer et al. 1986). Daraus ergibt sich die Klassifizierung der CL als lysosomale Proteinose (Jolly et al. 1988).

Die biochemischen Eigenschaften des bei caniner CL eingeschlossenen Materials unterscheiden sich zwischen den einzelnen Typen der Erkrankung und konnten noch nicht bei allen Erkrankungstypen analysiert werden. In einigen Fällen handelt es sich bei einem Großteil des abgelagerten Materials um die Untereinheit $\mathrm{C}$ der mitochondrialen ATP-Synthase. In anderen Fällen bestehen die Zelleinschlüsse zu einem erheblichen Anteil aus den Sphingolipid-Aktivatorproteinen A und D. Bis heute wurde nicht bei allen beschriebenen CL-Typen der biochemische Charakter der Ablagerungen bestimmt. Der genaue physiologische Mechanismus der Erkrankungen ist in keinem der beschriebenen Fälle geklärt. Es sind inzwischen drei Gendefekte bekannt, die zu verschiedenen caninen CL Formen führen. Die Funktion der betroffenen Gene konnte bisher jedoch nicht entschlüsselt werden, so dass keine Verbindung $\mathrm{zu}$ den physiologischen Vorgängen bei erkrankten Individuen gezogen werden kann.

Klinische Anzeichen sind in allen Fällen motorische Störungen oder Ataxie, in den meisten Fällen kommt es außerdem auch zu Verhaltensstörungen, Wesensveränderungen und Beeinträchtigungen des Sehvermögens. Pathologische Merkmale sind häufig Hirnatrophie, teilweise gelblich-braune Verfärbungen des Kortex oder anderer Hirnbereiche und selten auch anderer Organe. In vielen Fällen sind nicht nur Zellen des Nervengewebes, sondern auch extraneurale Zellen von Ablagerungen betroffen. Degenerationen sind meistens auf Zellen des zentralen Nervensystems beschränkt. Teilweise kommt es auch zur Degeneration von Ganglien- und Rezeptorzellen, selten auch der Epithelzellen der Retina. Betroffene Zellen neigen bei einigen CL Formen aufgrund der Materialeinlagerung zum Anschwellen. Bei anderen Formen führt die Einlagerung stattdessen zum Verlust von Zellorganellen. Teilweise treten auch beide Phänomene parallel auf. Das typische Erscheinungsbild der Zelleinschlüsse umfasst beim überwiegenden Teil der Erkrankungen vor allem fingerabdruckartige und 
kurvilineare, außerdem zebraartig gestreifte, kristalloide oder granuläre Ultrastrukturen. In einigen Fällen überwiegen demgegenüber granuläre und lipoidale Strukturen.

Tabelle 8 Ceroid-Lipofuscinose: wesentliche Merkmale des frühadult-akuten Typs gegenüber der adulten Form

\begin{tabular}{|c|c|c|}
\hline & frühadult-akuter Typ & adulter Typ \\
\hline Rassen & $\begin{array}{l}\text { Englischer Setter (ES), Border Collie, } \\
\text { Langhaardackel }\end{array}$ & $\begin{array}{l}\text { American Bulldogs, Zwergschnauzer, Tibet } \\
\text { Terrier, Langhaardackel }\end{array}$ \\
\hline Alter bei Beginn & ES 12-18 mo, Collie 16-23 mo, Dackel 8-9 mo & $\begin{array}{l}\text { American Bulldogs 1-3 yr, Dackel } 5 \text { bzw. } 7 \text { yr, } \\
\text { Zwergschnauzer: } 2-3 \text { yr }\end{array}$ \\
\hline Verlauf & ES 9-17 mo, Collie 2-12 mo, Dackel 3 mo & mehrere Jahre, Dackel: $<1$ yr \\
\hline Allgemein & $\begin{array}{l}\text { ES: mentale Trägheit, Gewichtsverlust, Stolpern, } \\
\text { versteifte Gliedmaßen, Krämpfe, Ataxie, Collie und } \\
\text { Dackel: Demenz, Hyperaktivität, Dackel: } \\
\text { Aggressivität, tödliche Diarrhöe, Erbrechen }\end{array}$ & $\begin{array}{l}\text { Verstörtheit, Aggressivität, Depressionen, } \\
\text { Gedächtnisverlust }\end{array}$ \\
\hline ZNS & $\begin{array}{l}\text { verdickte Dura mater, fortschreitende Hirnatrophie } \\
\text { (Hirnmasse um } 30-40 \% \text { reduziert), feste } \\
\text { Hirnkonsistenz, graue Substanz gelblich verfärbt, } \\
\text { erweiterte Ventrikel, erhöhtes Liquorvolumen }\end{array}$ & $\begin{array}{l}\text { American Bulldog und Zwergschnauzer: v.a. } \\
\text { motorische Störungen, leicht braune Verfärbung } \\
\text { des Hirns, keine Atrophie, Dackel: epileptische } \\
\text { Anfälle, Hirnatrophie, erweiterte Ventrikel }\end{array}$ \\
\hline Auge/ Sehfähigkeit & $\begin{array}{l}\text { fortschreitende Blindheit aufgrund der ZNS- } \\
\text { Schädigung; Retinazellen unbeeinträchtigt }\end{array}$ & $\begin{array}{l}\text { American Bulldogs: Sehstörung, Zwergschnauzer: } \\
\text { schwere Retinadegeneration }\end{array}$ \\
\hline Herz/andere Organe & geschwollene Lymphknoten, ES: Herzversagen & \\
\hline $\begin{array}{l}\text { defektes Enzym } \\
\text { bzw. Gen }\end{array}$ & $\begin{array}{l}\text { ES: CLN8, Collie: CLN5, Dackel: Tripeptidyl } \\
\text { Peptidase I }\end{array}$ & American Bulldog: Cathepsin D \\
\hline Speichermaterial & $\begin{array}{l}\text { ES und Collie: hoher Anteil an Untereinheit C der } \\
\text { mitochondrialen ATP-Sythtase (Proteolipid), ES: } \\
\text { Plasma-Carnitin stark reduziert, Dackel: nicht } \\
\text { untersucht }\end{array}$ & $\begin{array}{l}\text { American Bulldog: nicht untersucht, Plasma- } \\
\text { Carnitin im Normbereich, Zwergschnauzer: } \\
\text { Sphingolipid-Aktivatorproteine A u. D, Dackel: } \\
\text { nicht untersucht }\end{array}$ \\
\hline neurales Gewebe & $\begin{array}{l}\text { in allen Zellen des ZNS viele Einschlüsse, } \\
\text { Verdrängung der Organellen, aber kein } \\
\text { Anschwellen, Pyknose und Nekrose u.a. von } \\
\text { Photorezeptorzellen }\end{array}$ & $\begin{array}{l}\text { American Bulldog und Dackel: Purkinjezellen } \\
\text { wenig betroffen, American Bulldog und } \\
\text { Zwergschnauzer: Spheroidbildung an Axonen } \\
\text { (neuroaxonale Dystrophie), Dackel: Glia- und } \\
\text { Mesenchymzellen nicht betroffen, Neuropil stark } \\
\text { vakuolisiert }\end{array}$ \\
\hline $\begin{array}{l}\text { extraneurales } \\
\text { Gewebe }\end{array}$ & $\begin{array}{l}\text { ES und Collie: Einschlüsse in diversen Gewebe- } \\
\text { und Zelltypen, Verdrängung von Organellen, keine } \\
\text { Zellzerstörung oder -schwellung; Dackel: nicht } \\
\text { untersucht }\end{array}$ & $\begin{array}{l}\text { American Bulldogs: nur Kupfferzellen betroffen } \\
\text { Dackel: keine Ablagerungen in extraneuralem } \\
\text { Gewebe, } \\
\text { Zwergschnauzer: schwere Degeneration der Retina }\end{array}$ \\
\hline $\begin{array}{l}\text { Material- } \\
\text { beschaffenheit, } \\
\text { Ultrastruktur }\end{array}$ & $\begin{array}{l}\text { Autofluoreszenz, ES und Collie: membranöse } \\
\text { Strukturen: fingerabdruckartig/ kurvilinear/ } \\
\text { zebrastreifenartig/ kristalloid durch Überschneidung } \\
\text { paralleler Membranstapel/ granulär bis homogen } \\
\text { ohne Lamellen/ Mischformen; Dackel: nur } \\
\text { kurvilinear }\end{array}$ & $\begin{array}{l}\text { American Bulldog: granulär oder lipoidal, nicht } \\
\text { kurvilinear oder fingerabdruckartig } \\
\text { Zwergschnauzer: keine membranösen Strukturen, } \\
\text { Dackel: Autofluoreszenz, Struktur wie bei } \\
\text { frühadult-akuter CL }\end{array}$ \\
\hline
\end{tabular}

Die einzelnen Typen der CL unterscheiden sich bezüglich Beginn, Ausmaß und zeitlicher Reihenfolge der auftretenden pathologischen Erscheinungen, Geschwindigkeit des neurodegenerativen Prozesses, Verteilung der Ablagerungen in einzelnen Zelltypen und Körperbereichen und Ultrastruktur der Zelleinschlüsse. Eine Einteilung der caninen Formen der CL findet sich bei Jolly et al. (1994). Es wird zwischen den drei Typen frühadult-akut, präpubertal-langwierig und adult unterschieden. Der genetische 
Hintergrund ist bisher nur für Formen des frühadult-akuten Typs und adulten Typs bekannt. Tabelle 8 zeigt die wesentlichen Merkmale dieser beiden CL-Typen.

\subsection{Frühadult-akute Form}

\begin{tabular}{ll|}
\hline Chromosom: & CFA37 \\
Gen: & CLN8 \\
NCBI: & GeneID: 488558 GenBank: U29765 \\
DNA-Sequenz: & NW_876304, Position 30879038-30897419 \\
Mutationen: & T491C, Englischer Setter \\
\hline
\end{tabular}

\begin{tabular}{ll|}
\hline Chromosom: & CFA22 \\
Gen: & CLN5 \\
NCBI: & GeneID: 484498, GenBank: AJ875418 \\
DNA-Sequenz: & NW_876274, Position 30514651-30533769 \\
Mutationen: & C619T, Border Collie \\
\hline
\end{tabular}

\begin{tabular}{|ll|}
\hline Chromosom: & CFA21 \\
Gen: & TPP1 \\
NCBI: & GeneID: 485227, GenBank: XM850520 \\
DNA-Sequenz: & NW_876273, Position 30114663-30108653 \\
Mutationen: & DelC325, Langhaardackel \\
\hline
\end{tabular}

\section{Krankheitsbild}

Die frühadult-akute Form der CL ist am besten beim Englischen Setter (Fankhauser 1965; Koppang 1973; Armstrong et al. 1982; Koppang 1987; Goebel 1992; Koppang 1992) und beim Border Collie (Taylor und Farrow 1988; Studdert und Mitten 1991; Taylor und Farrow 1992; Franks et al. 1999; Koie et al. 2004) untersucht worden. Auch die bei zwei Langhaardackeln (Awano et al. 2006b), Australian Cattle Dogs (Wood et al. 1987; Sisk et al. 1990), einem Queensland Blue Heeler (Cho et al. 1986), Chihuahuas (Rac und Giesecke 1975; Jolly und Hartley 1977), Salukis (Appleby et al. 1982), einem Spaniel (Fankhauser 1965), einem Jugoslawischen Schäferhund (Bichsel und Vandevelde 1982), einem Pudel (Cantile et al. 1996) und einem Spitz (Pickett et al. 1992) beschriebene Formen fallen unter diese Kategorie. 
Die ursächlichen Mutationen sind lediglich in den Rassen Englischer Setter, Border Collie und Langhaardackeln bekannt. Über die Häufigkeit der Erkrankung innerhalb der Rasse Englischer Setter sind keine Zahlen Veröffentlicht worden. Der überwiegende Anteil der Untersuchungen zur CL der Englischen Setter wurde an Hunden aus einer Forschungskolonie durchgeführt (Koppang 1973; Koppang 1987; Koppang 1992; Katz et al. 1994; Katz et al. 2005b). Die Frequenz des Defektallels innerhalb der Rasse Border Collie wird auf 3,5 \% geschätzt (Melville et al. 2005). Bei einer Genotypisierung der Eltern des betroffenen Langhaardackels, 77 nicht verwandter weiterer Dackel und 104 Hunden aus 104 verschiedenen Rassen waren lediglich die Eltern heterozygote Träger des defekten Allels. Bei keinem der 181 weiteren untersuchten Hunde konnte die Mutation nachgewiesen werden. Trotzdem ist die Mutation möglicherweise in bestimmten Zuchtlinien von Langhaardackeln relativ häufig. In dem vier Generationen umfassenden Pedigree des betroffenen Hundes tritt kein gemeinsamer Vorfahr der heterozygoten Eltern des Dackels auf. Die Einführung der Mutation in die Population muss also mindestens fünf Generationen zurückliegen. Es ist nicht ausgeschlossen, dass das Defektallel inzwischen unter den Nachfahren des unbekannten Vererbers eine gewisse Verbreitung erreicht hat (Awano et al. 2006b).

Isolierte Speicherkörper aus Hirngewebe von betroffenen Englischen Settern haben gegenüber Kontrollproben von normalen Englischen Settern einen deutlich erhöhten Proteingehalt, der $\mathrm{zu}$ einem überwiegenden Anteil von der Untereinheit $\mathrm{C}$ der mitochondrialen ATP-Synthetase (im Folgenden kurz als Untereinheit C bezeichnet) gebildet wird (Katz et al. 1994). In einer nicht veröffentlichten Studie wurde bei betroffenen Englischen Settern ein Anteil der Untereinheit C am gespeicherten Material von $36 \%$ nachgewiesen. Auch bei einem Border Collie mit frühadult-akuter CL ist die Untereinheit C eine Hauptkomponente des gespeicherten Materials (unveröffentlicht, zitiert bei Jolly et al. 1992; Jolly et al. 1994). Über biochemische Analysen des gespeicherten Materials bei Langhaardackeln mit frühadult-akuter CL ist nichts bekannt.

Mutmaßungen über die Ursachen der Speicherung von Untereinheit $\mathrm{C}$ beziehen sich auf eine mögliche Funktion der Untereinheit als Trimethyllysin-Quelle für die Carnitinbiosynthese. Trimethyllysin bildet die Grundlage der Carnitinbiosynthese. Die Synthese von Trimethyllysin erfolgt bei Säugetieren stets über die Methylierung von 
proteinständigem Lysin und dessen anschließende Freisetzung, da freies Lysin bei Säugetieren offenbar nicht methyliert werden kann. Die gespeicherte Untereinheit C weist abweichend vom normalen Proteolipid eine Trimethylierung der $\epsilon$-Aminogruppe an Lysin 43 auf. Sollte dieses Trimethyllysin tatsächlich für die Carnitinbiosynthese bestimmt sein, könnte die Ursache einer Ablagerung der Untereinheit $\mathrm{C}$ in einem unvollständigen Ablauf der Carnitinbiosynthese liegen. Diese These wird durch das Vorliegen signifikant verminderter Carnitin-Werte im Plasma betroffener Hunde unterstützt (Katz et al. 1994). Auch ein Diätversuch, bei dessen Bewertung allerdings die geringe Anzahl untersuchter Hunde zu berücksichtigen ist, lässt Rückschlüsse auf einen Zusammenhang zwischen Carnitinspiegel und den Symptomen der CL zu. So konnte durch eine Beimischung von Carnitin zum üblichen Laborfutter die Abnahme kognitiver Fähigkeiten bei Englischen Settern mit CL gebremst werden. Zwei betroffene Hunde, die mit Carnitinergänzung gefüttert wurden, zeigten im Gegensatz zu einem Kontrollhund und einem Hund, dessen Futterrationen mit Fisch- und Maisöl versetzt waren, im Alter von 22 Monaten keinerlei Beeinträchtigungen. Einer der beiden mit Carnitinergänzung gefütterten Hunde, der zusätzlich Fisch- und Maisölergänzung erhielt, erreichte gegenüber dem Kontrollhund eine um $10 \%$ verlängerte Lebensdauer (Siakotos et al. 2001). Carnitin spielt eine tragende Rolle als mitochondriales Protein für den Transport zur Oxidation bestimmter Fettsäuren durch die innere Mitochondrienmembran. Untersuchungen des ADP/O-Verhältnisses und der ADPinduzierten Respirationsraten von Mitochondrien aus Leberzellen betroffener Hunde deuten auf eine partielle Entkopplung der oxidativen Phosphorylierung hin. Das ADP/O-Verhältnis ist sowohl bei betroffenen Hunden als auch bei heterozygoten Trägern des Defektes signifikant reduziert, während ADP-induzierte Respirationsraten und der ADP-Gehalt der Mitochondrien erhöht sind. Die letztgenannten Befunde lassen sich als kompensatorische Reaktion auf die verminderte Effizienz der oxidativen Phosphorylierung deuten. Eine solche Effizienzverminderung kann durch Carnitinmangel verursacht werden (Siakotos et al. 1998). So könnte die Ablagerung der Untereinheit $\mathrm{C}$ die Folge einer gestörten Carnitinbiosynthese sein, die ihrerseits nachteilige Auswirkungen auf die oxidative Phosphorylierung nach sich zöge. Durch welche Voraussetzungen eine Blockade der Carnitinbiosynthese bei CeroidLipofuscinose-Erkrankungen verursacht sein könnte, ist unklar. 


\section{Genetischer Hintergrund}

Bisher sind in drei verschiedenen Genen Mutationen nachgewiesen worden, die verschiedene Unterformen der frühadult-akuten CL bei Englischen Settern (Katz et al. 2005b), Border Collies (Melville et al. 2005) und Langhaardackeln (Awano et al. 2006b) verursachen. Bei keinem dieser drei Gendefekte konnte bisher ein Zusammenhang zur Pathophysiologie der assoziierten Erkrankung hergestellt werden.

\section{II.a Genetischer Hintergrund bei Englischen Settern}

Bei einer Kopplungsanalyse an Englischen Settern wurde auf Chromosom 37 eine Gruppe von fünf Markern ermittelt, die mit der CL-Erkrankung segregieren (Lingaas et al. 1998). Eines von mehreren humanen Kandidatengenen für CL, CLN8 (für Ceroidlipofuscinose, neuronal 8), konnte ebenfalls auf dem caninen Chromosom 37 etwa drei Megabasen in telomerer Richtung entfernt von CL-Markerlokus ATH135 lokalisiert werden. Das CLN8-Gen (NCBI-GeneID: 488558) erstreckt sich im genomischen Contig NW_876304

von Position 30879038 bis 30897419 enthält auf einer Länge von 18382 bp drei Exons. Die proteincodierende Sequenz (NCBI-GenBank: U29765) umfasst 864 Nukleotide und erstreckt sich über die Exons 2 und 3. Abb. 49 stellt schematisch die Lage der einzelnen Exons in der genomischen Sequenz dar. 


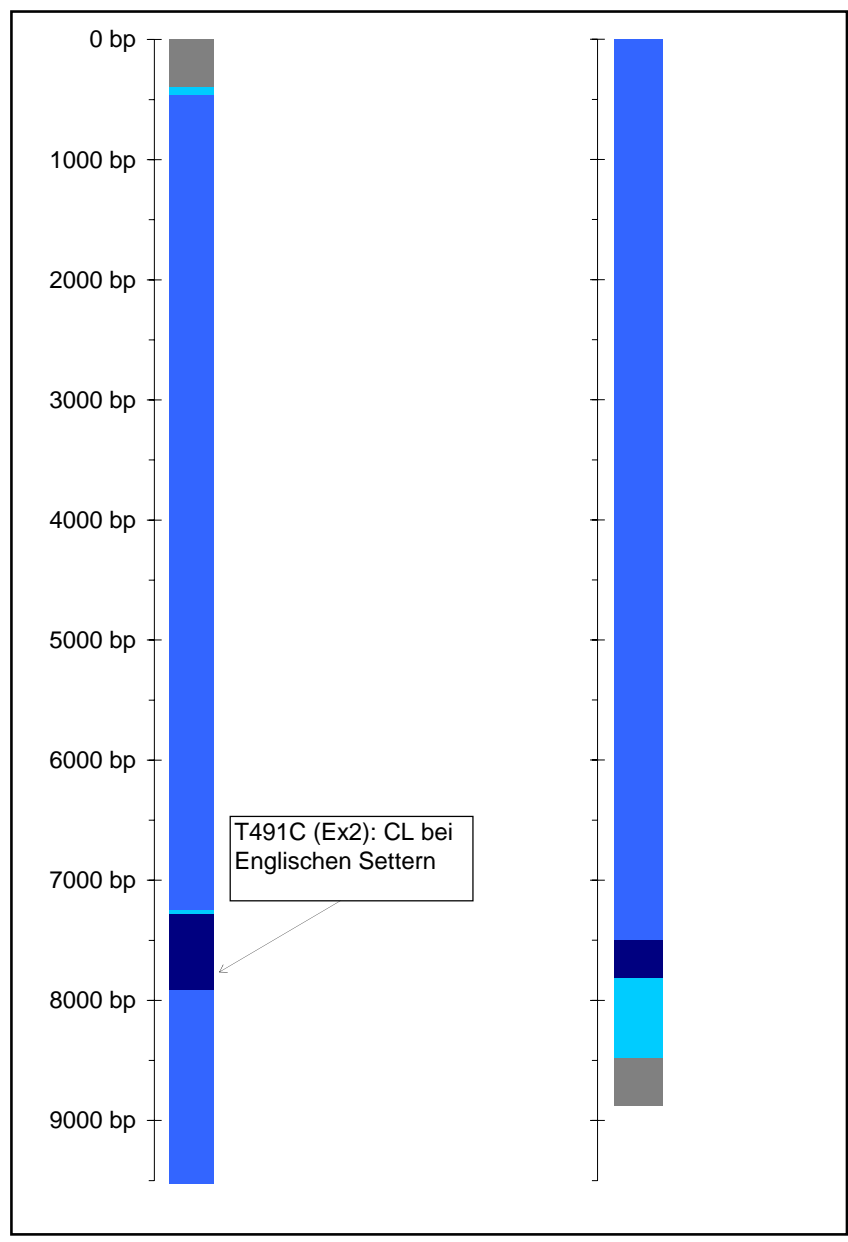

Abb. 49 Schematische Darstellung des caninen CLN8-Gens und Lage der bisher identifizierten Mutationen. Dunkelblau: coderende Sequenz, hellblau: Intronsequenz, türkis: UTR, grau: intergenische Sequenz.

\section{II.b Genetischer Hintergrund bei Border Collies}

Bei Border Collies konnte eine Mutation im CLN5-Gen (für Ceroidlipofuscinose, neuronal 5) mit CL assoziiert werden. Das canine CLN5-Gen ist auf Chromosom 22 lokalisiert und erstreckt sich im genomischen Contig NW_876274 von Position 30514651 bis 30533769 (NCBI-GeneID: 485498). Die mRNA (NCBI-GenBank: AJ875418) hat eine Länge von 1922 Nukleotiden und ist aus vier Exons zusammengesetzt. Abb. 50 stellt schematisch die Struktur des caninen CLN5-Gens dar. 


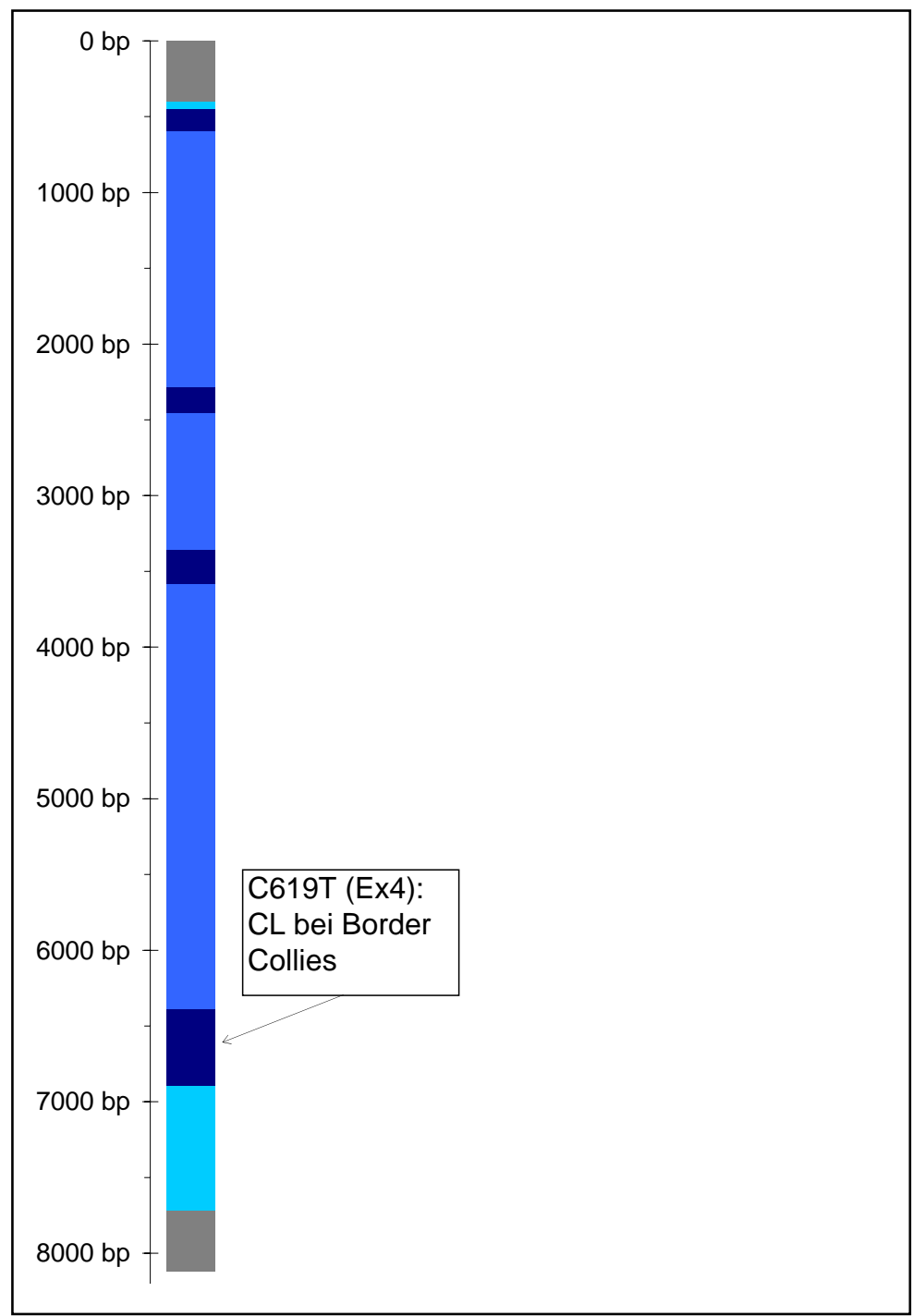

Abb. 50 Schematische Darstellung des caninen CLN5-Gens und Lage der bisher identifizierten Mutationen. Dunkelblau: codierende Sequenz, hellblau: Intronsequenz, türkis: UTR, grau: intergenische Sequenz.

\section{II.c Genetischer Hintergrund bei Langhaardackeln}

Bei einem Langhaardackel mit frühadult-akuter CL konnte eine Mutation im Tripeptidylpeptidase-I-Gen (TPP1) mit der Erkrankung assoziiert werden. Das canine TPP1-Gen ist auf Chromosom 21 lokalisiert (NCBI-GeneID: 485337), und erstreckt sich im genomischen Contig NW_876273 von Position 30114663 bis Position 30108653. Die mRNA (NCBI-GenBank: XM_850520) hat eine Länge von 1692 Nukleotiden und enthält 13 Exons, deren Lage in der genomischen Sequenz in Abb. 51 dargestellt ist. Das resultierende Enzym Tripeptdylpeptidase I hat eine Länge von 561 Aminosäuren (Awano et al. 2006b). 


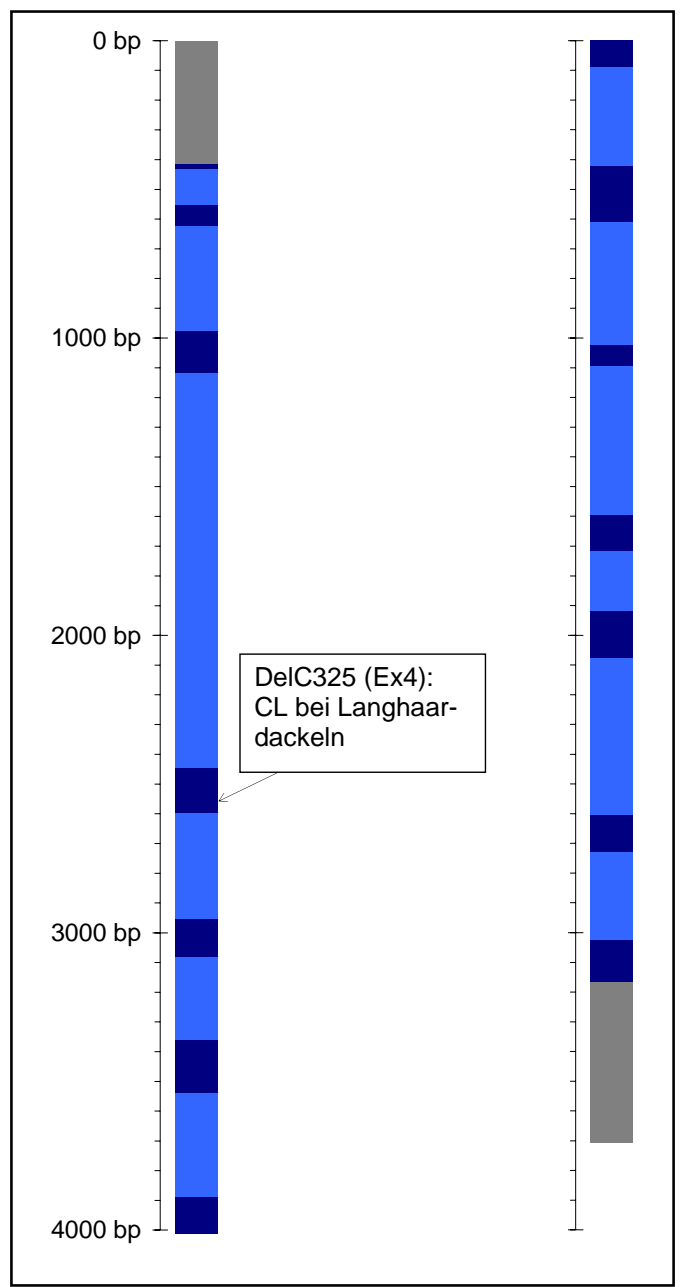

Abb. 51 Schematische Darstellung des caninen TPP1-Gens und Lage der bisher identifizierten Mutationen. Dunkelblau: codierende Sequenz, hellblau: Intronsequenz, grau: intergenische Sequenz.

\section{III.a Ursächliche Mutation der CL bei Englischen Settern}

CLN8-Segmente aus den Exons 2 und 3 von zwei betroffenen Englischen Settern zeigen bei einem Vergleich mit der entsprechenden Boxer-Sequenz aus dem caninen Genomprojekt, nur eine einzige Abweichung. Es handelt sich dabei um einen Basenaustausch von Thymin durch Cytosin an Position 491, der eine Proteinsubstitution von Leucin durch Prolin nach sich zieht (Abb. 52) (Katz et al. 2005b).

Bei einem Screening waren vier Englische Setter mit CL homozygot für das mutierte Allel. Vier verwandte, obligat heterozygote Englische Setter erwiesen sich als heterozygote Träger des Defektallels. Keiner von drei unverwandten Englischen Settern und 100 weiteren Hunden aus 100 verschiedenen Rassen war Träger des mutierten Allels. 
Da über die Funktion des von CLN8 codierten Polypeptids zurzeit nur Vermutungen angestellt werden können, lässt sich über Einzelheiten des pathogenen Effektes der gefundenen Mutation keine Aussage treffen. Aufgrund der folgenden Ergebnisse ist immerhin anzunehmen, dass die Mutation bei Englischen Settern $\mathrm{zu}$ einer Funktionsstörung des CLN8-Proteins führt. Das humane CLN8-Gen wird ubiquitär exprimiert. Bei dem resultierenden Polypeptid von 286 Aminosäuren Länge handelt es sich, nach seinen hydrophoben Eigenschaften zu urteilen, um ein Transmembranprotein mit mehreren Transmembrandomänen (Lonka et al. 2000). Strukturanalysen und multiple Sequenzabgleiche lassen auf fünf konservierte transmembrane $\alpha$-Helices schließen (Winter und Ponting 2002). Eine mutationsbedingte Änderung der Sekundärstruktur innerhalb einer dieser Domänen führt mit relativ hoher Wahrscheinlichkeit zu einer Funktionsstörung des Proteins. Unter Zugrundelegung des aktuellen Strukturmodells von CLN8 (Winter und Ponting 2002) lässt sich die Substitution von Leucin durch Prolin an Position 164 bei Englischen Settern mit CL in der vierten Transmembrandomäne des Proteins lokalisieren. Damit ist ein weiterer Hinweis darauf gegeben, dass es sich bei der gefundenen Substitution um die ursächliche Mutation für CL beim Englischen Setter handelt.

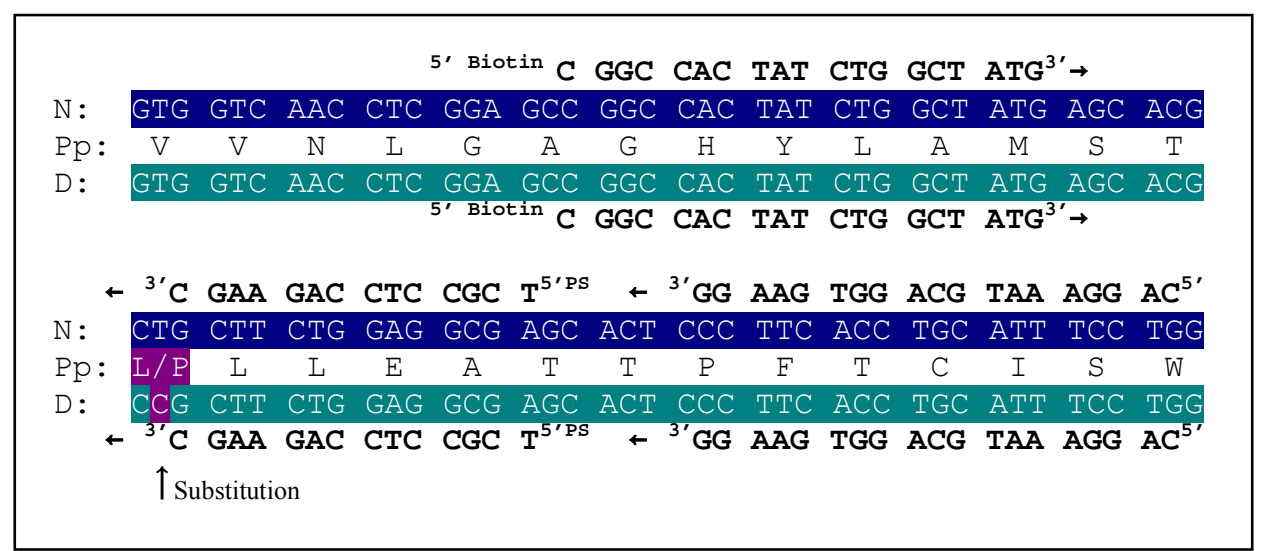

Abb. 52 Sequenzabschnitt aus Exon 2 des caninen CLN8 Gens. N: normale Sequenz, D: defekte Sequenz, Pp: Polypeptidsequenz, dunkelblau: Exon normale Sequenz, dunkelgrün: Exon defekte Sequenz, Substitution in defekter Sequenz violett unterlegt und durch Pfeil gekennzeichnet, PS: Primer für Pyrosequenzierung.

\section{IV.a Genotypisierung für CL bei Englischen Settern}

Ein Nachweis der beschriebenen Substitution kann mithilfe eines Gentests auf der Basis von Pyrosequenzierung erfolgen (Katz et al. 2005b). 


\section{III.b Ursächliche Mutation für CL bei Border Collies}

Bei betroffenen Border Collies liegt in Exon 4 des CLN5-Gens eine Substitution von Cytosin durch Thymin an Position 619 der codierenden Sequenz vor (Melville et al. 2005). Die Substitution führt zu einer Umcodierung des Codons 206 von Glycin in ein Stoppcodon, so dass das resultierende Protein auf eine Länge von 205 Aminosäuren verkürzt ist (Abb. 53).

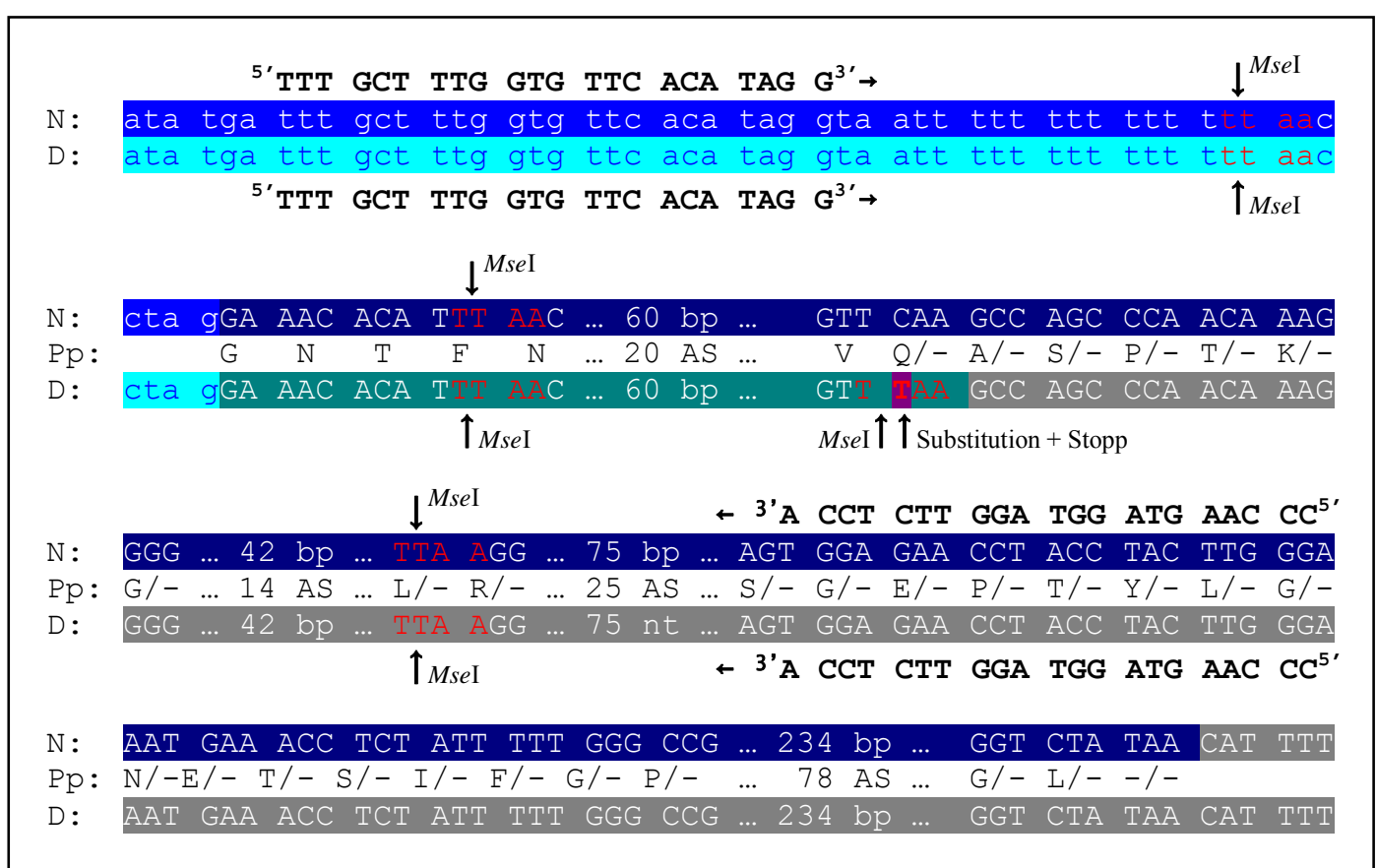

Abb. 53 Exon 4 des caninen CLN5-Gens und angrenzende Intron- bzw. UTR-Sequenz. N: normale Sequenz, D: defekte Sequenz, Pp: Polypeptidsequenz, hellblau: Intron normale Sequenz, türkis: Intron defekte Sequenz, dunkelblau: Exon normale Sequenz, dunkelgrün: Exon defekte Sequenz, grau: ${ }^{3}$ UTR, rote Schrift: MseI-Erkennungssequenz, MseI-Schnittstellen durch Pfeile gekennzeichnet, Substitution und Stoppcodon in defekter Sequenz violett unterlegt und durch Pfeil gekennzeichnet.

Das mutierte Allel ist mit 3,5 \% in der gesamten Border Collie Population relativ selten. Es wurde bei allen untersuchten Defektträgern nachgewiesen. Nur in einem von insgesamt 12 untersuchten Pedigrees betroffener Border Collies (1 japanisches, 11 australische) konnte das mutierte Allel nicht nachgewiesen werden. Dieses Pedigree enthielt nur ein betroffenes Tier, das nicht eng mit den anderen betroffenen Hunden verwandt war. Es wird nicht ausgeschlossen, dass es sich bei der Erkrankung dieses Border Collies um eine Phänokopie handelt. Die relativ geringe Häufigkeit des mutierten Allels in der gesamten Population und der Nachweis der Mutation bei allen untersuchten Defektträgern und bei fast allen untersuchten betroffenen Border Collies werden als deutliche Hinweise darauf gewertet, dass diese Mutation für CeroidLipofuscinose bei Border Collies verantwortlich ist oder zumindest sehr eng mit dem 
ursächlichen Allel gekoppelt ist. Die Länge des caninen CLN5-Proteins, über dessen Funktion nichts bekannt ist, beträgt nach bisherigem Kenntnisstand 349 Aminosäuren. Durch die Mutation in Exon 4 wird das Protein um 144 Aminosäuren verkürzt. Es ist zu erwarten, dass eine derartige Verkürzung einen schweren Effekt auf die Funktion des Proteins hat (Melville et al. 2005).

\section{IV.b Genotypisierung für CL bei Border Collies}

Eine Mögliche Methode zum Nachweis der Mutation ist die Genotypisierung per RFLP, der auf einer durch die Mutation im Defektallel entstehenden zusätzlichen MseIErkennungssequenz beruht (Melville et al. 2005).

\section{III.c Ursächliche Mutation für CL bei Langhaardackeln}

Bei einem Langhaardackel mit frühadult-akuter CL konnte eine Deletion in Exon 4 des TPP1-Gens an Position 325 der codierenden Sequenz identifiziert werden. Diese Deletion führt im resultierenden Polypeptid zu einer Leserasterverschiebung und zu einem verfrühten Stoppcodon an Aminosäurenposition 144 (Abb. 54) (Awano et al. 2006b). Das TPP1-Gen wird in allen bisher untersuchten Geweben exprimiert, ist essentiell für einen effizienten Proteinabbau in den Lysosomen verschiedener Zelltypen und kritisch für die Überlebensfähigkeit von Neuronen (Golabek und Kida 2006).

Die im cerebralen Kortex des betroffenen Dackels gemessene TPP1-Aktivität von weniger als $1 \%$ des normalen Wertes lässt sich durch einen Abbau mutierter mRNA durch körpereigene Kontrollmechanismen erklären (Awano et al. 2006b). 


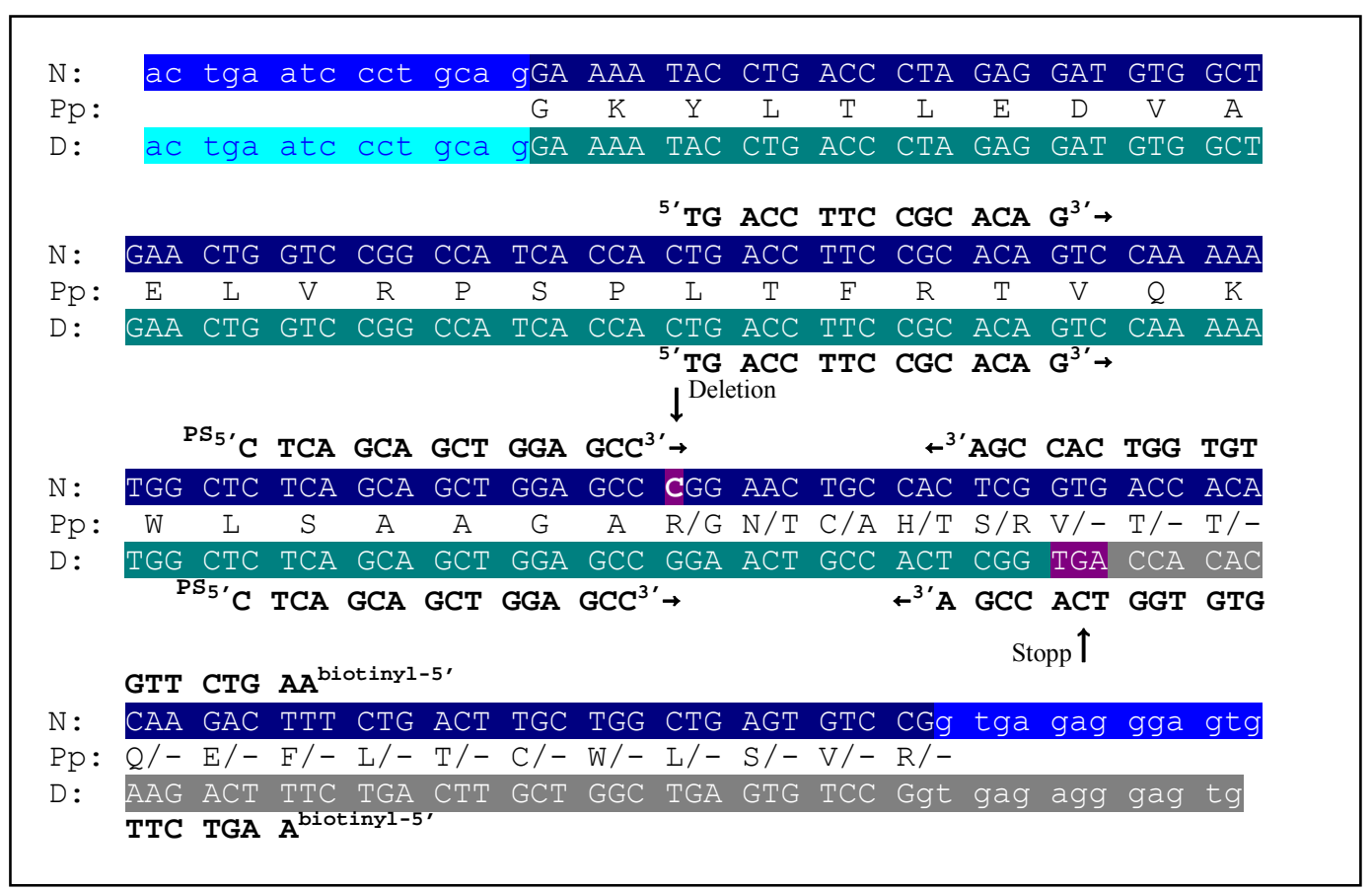

Abb. 54 Exon 4 und angrenzende Intronsequenz des caninen TPP1 Gens. N: normale Sequenz, D: defekte Sequenz, Pp: Polypeptidsequenz, hellblau: Intron normale Sequenz, türkis: Intron defekte Sequenz, dunkelblau: Exon normale Sequenz, dunkelgrün: Exon defekte Sequenz, grau: neue 3' UTR, von Deletion betroffenes Nukleotid in normaler Sequenz violett unterlegt und durch Pfeil bezeichnet, Stoppcodon in defekter Sequenz violett unterlegt und durch Pfeil bezeichnet, PS: Primer für Pyrosequenzierung.

\section{IV.c Genotypisierung für CL bei Langhaardackeln}

Die Genotypisierung für die beschriebene Mutation kann per Pyrosequenzierung erfolgen (Awano et al. 2006b).

\subsection{Präpubertär-langwierige Form}

Eine bei Dalmatinern auftretende CL-Form wird aufgrund des klinischen, pathologischen und histopathologischen Erscheinungsbildes der Gruppe der präpubertär-langwierigen CL zugeordnet. Besonderheiten gegenüber anderen CLFormen bestehen hinsichtlich der Ausprägung und der Reihenfolge des Auftretens der Symptome, der pathologischen Befunde und der Struktur des eingeschlossenen Materials. Die Färbeeigenschaften und die Autofluoreszenz des eingeschlossenen Materials weichen bei dieser CL-Form nicht vom typischen Erscheinungsbild bei CLErkrankungen ab. Die biochemische Zusammensetzung des eingeschlossenen Materials ist bei betroffenen Dalmatinern nicht untersucht worden. Weitere Beispiele dieses Erkrankungstyps in anderen Rassen sind nicht bekannt (Malkusch 1984; Goebel und Dahme 1985; Goebel et al. 1988). 


\subsection{Adulte Form}

\begin{tabular}{ll|}
\hline Chromosom: & CFA18 \\
Gen: & CTD \\
NCBI: & GeneID: 483662, GenBank: AM048627 \\
DNA-Sequenz: & NW_876266, Position 20725570-20715754 \\
Mutationen: & G597A, American Bulldog \\
\hline
\end{tabular}

\section{Krankheitsbild}

Adulte Formen der caninen CL sind in verschieden Rassen beschrieben worden und können bezüglich der klinischen, pathologischen und biochemischen Merkmale rassentypische Besonderheiten aufweisen. Betroffen sind American Bulldogs (Evans et al. 2005; Awano et al. 2006a), Zwergschnauzer (Jolly et al. 1997; Palmer et al. 1997), Tibet Terrier (Cummings et al. 1990; Riis et al. 1992; Katz et al. 2005a) und Langhaardackel (Vandevelde und Fatzer 1980). Eine bei einem Rauhaardackel als adulte CL beschriebene Erkrankung (Cummings und de Lahunta 1977) wurde später aufgrund der untypischen Ultrastruktur der beschriebenen Zelleinschlüsse als Fehldiagnose eingeschätzt und den Mucopolysaccharidosen zugeordnet (Awano et al. 2006b). Der ursächliche Gendefekt ist bisher nur bei American Bulldogs bekannt. Bei einer Genotypisierung von 123 American Bulldogs von privaten Besitzern unter Einsatz eines DNA-Tests konnte eine Frequenz des Defektallels von 0,28 ermittelt werden (Awano et al. 2006a).

\section{Genetischer Hintergrund}

Der heterogene Phänotyp der adulten CL lässt auf unterschiedliche zugrunde liegende Gendefekte in den einzelnen Rassen schließen. Neben den für verschiedene canine Formen der frühadult-akuten CL verantwortlichen Defektgenen CLN8, CLN5 und TPP1 kommen für weitere canine CL Formen auch die humanen Kandidatengene CLN2, CLN3 oder CLN6, das ovine oder murine Kandidatengen CTSD (Cathepsin D) oder die murinen Kandidatengene CLCN3 oder TPP2 (Awano et al. 2006a) in Frage. Bisher konnte erst in einem dieser Kandidatengene, im CTSD-Gen, eine Mutation mit caniner CL in Verbindung gebracht werden. Das canine CTSD-Gen (NCBI-GeneID: 483662) ist auf Chromosom 18 lokalisiert und erstreckt sich im genomischen Contig NW_876266 von Nukleotid 20725570 bis 20715754. Die mRNA (NCBI-GenBank: AM048627) hat 
eine Länge von 1524 bp und ist in neun Exons unterteilt, deren Lage in der genomischen Sequenz in (Abb. 55)dargestellt ist.

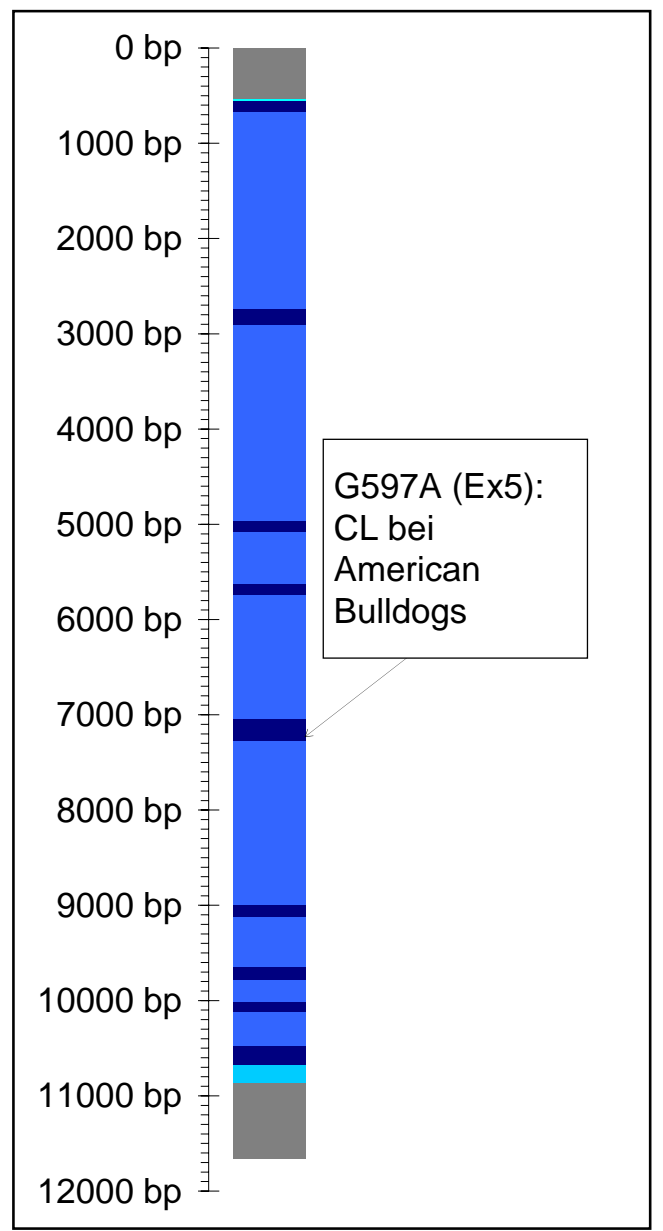

Abb. 55 Schematische Darstellung des caninen CTSD-Gens und Lage der bisher identifizierten Mutationen. Dunkelblau: codierende Sequenz, hellblau: Intronsequenz, türkis: UTR, grau: intergenische Sequenz.

\section{Ursächliche Mutation bei American Bulldogs}

Bei der ursächlichen Mutation für adulte CL bei American Bulldogs handelt es sich um eine Substitution von Guanin durch Adenin in Exon 5 des CTSD-Gens an Position 597 der codierenden Sequenz. Dieser Basenaustausch führt im resultierenden Polypeptid zu einer Substitution von Methionin durch Isoleucin an Position 199 (Abb. 56) (Awano et al. 2006a).

Bei der Genotypisierung von 131 zufällig ausgewählten Hunden aus 108 verschiedenen Rassen konnte in keiner der untersuchten Proben das mutierte Allel nachgewiesen werden. In einer Gruppe von 123 American Bulldogs, einschließlich acht Hunden mit klinischen Anzeichen von CL, betrug die Frequenz des defekten Allels 0,28. Zwölf 
dieser 123 genotypisierten American Bulldogs waren homozygot für das defekte Allel. Vier dieser Hunde zeigten keinerlei klinische Anzeichen. Da das typische Alter für das erste Auftreten klinischer Anzeichen bei American Bulldogs zwischen einem und drei Jahren liegt, schließt das Fehlen klinischer Anzeichen bei diesen vier homozygot mutierten Hunden das Vorliegen einer CL nicht aus (Awano et al. 2006a).

Cathepsin D gehört zur Familie der Pepsine, zählt zu den wichtigsten Asparaginproteinasen der Lysosomen und wird in allen bisher untersuchten Geweben exprimiert. Bevorzugte Substrate sind Peptidbrücken, die von umfangreichen Aminosäuren flankiert werden. Cathepsin-D-Knockout-Mäuse entwickeln im Alter von zwei Wochen eine tödliche Erkrankung, deren Symptome während des Endstadiums im Alter von drei bis vier Wochen mit den für CL typischen Symptomen übereinstimmen (Saftig et al. 1995). Die bei American Bulldogs von der Mutation betroffene Aminosäure Methionin an Position 199 ist mit den Cathepsin-Sequenzen von 18 Vertebraten konserviert. Die Folge der Substitution ist eine funktionelle Störung der Enzymaktivität. Es kommt jedoch bei homozygot betroffenen American Bulldogs zu keinem totalen Ausfall, sondern es bleibt eine Restaktivität von $36 \%$ erhalten. Dieser Wert ist nicht wesentlich geringer als die Cathepsin-D-Aktivität von $40 \%$ in Fibroblastenkulturen von klinisch gesunden Schafen, die heterozygote Träger des für ovine CL verantwortlichen Allels sind (Tyynela et al. 2000). Diese unterschiedlichen Effekte einer annähernd ähnlichen Cathepsin D Aktivität auf den Gesundheitszustand von Schafen und Hunden können nach heutigem Kenntnisstand nicht erschöpfend erklärt werden. Ein erheblicher Vorteil der heterozygoten Defektträger-Schafe gegenüber homozygot betroffenen Bulldogs liegt darin, dass die Restaktivität des Cathepsin D bei heterozygoten Schafen durch intaktes Cathepsin D bereitgestellt wird. Im Gegensatz dazu ist bei homozygot mutierten American Bulldogs das gesamte Cathepsin D verändert. Diese Veränderung könnte zu einer Störung des intrazellulären Transportes führen, so dass die vorhandene Restaktivität zwar in vitro messbar ist, in vivo aber nicht voll ausgenutzt werden kann (Awano et al. 2006a). 


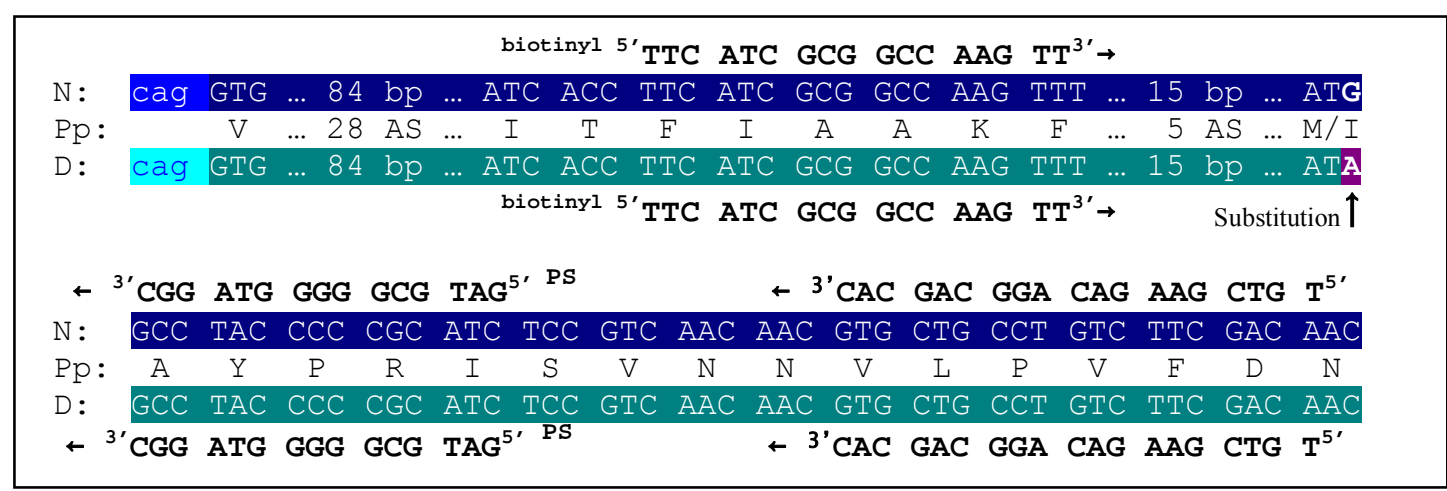

Abb. 56 Exon 5 des caninen Cathepsin D Gens. N: normale Sequenz, D: defekte Sequenz, Pp: Polypeptidsequenz, dunkelblau: Exon normale Sequenz, dunkelgrün: Exon defekte Sequenz, hellblau: Intron normale Sequenz, türkis: Intron defekte Sequenz, Substitution in defekter Sequenz violett unterlegt und durch Pfeil gekennzeichnet, PS: Primer für Pyrosequenzierung.

\section{Genotypisierung für CL bei American Bulldogs}

Der Nachweis der Mutation kann mittels Pyrosequenzierung erfolgen (Awano et al. 2006a). 


\subsubsection{Lysosomale Sphingolipidosen}

Sphingolipide stellen neben Cholesterol und Glycerophospholipiden den größten Anteil am Gesamtlipid des Nervengewebes. Als essentielle Membranbausteine sind die Sphingolipide zusammengesetzt aus dem hydrophoben, alkalischen Aminoalkohol Sphingosin, an dessen Aminogruppe eine Fettsäure von variabler Kettenlänge gebunden ist und einem variablen hydrophilen Teil. Dieser wird bei Glycosphingolipiden beispielsweise von Mono- oder Oligohexosiden gestellt, die N-Acetylneuraminsäure (Sialinsäure) enthalten, beim Phosphosphingolipid Sphingomyelin von Phosphorylcholin. Neben Sphingosin können auch Dihydrosphingosin oder ein Sphingosin mit 20 anstelle von 18 Kohlenstoffatomen die Basis des Moleküls bilden.

Der Katabolismus fast aller natürlich vorkommenden Sphingolipide findet mittels bestimmter Hydrolasen in den Lysosomen statt. Die verantwortlichen Enzyme sind meistens nicht spezifisch für ein bestimmtes Substrat, sondern für bestimmte Typen chemischer Verbindungen. Der schrittweise Abbau von Sphingolipiden beginnt am hydrophilen Ende und benötigt eine Reihe unterschiedlicher Enzyme. Eine aufgrund eines genetischen Defektes bestehende Enzymdefizienz ist überall messbar, wo das Enzym exprimiert wird, während die darauf beruhende Akkumulation der jeweiligen Substrate nur dort auftritt, wo diese in ausreichender Menge synthetisiert werden. Zu den humanen Sphingolipidosen zählen die Gangliosidosen (GM1-3), Trihexosylceramidose (Fabry's Disease), Galaktosylceramidose (GloboidzellLeukodystrophie), Sulfatidose (Metachromatische Leukodystrophie), Glukosylceramidose (Gaucher's Disease), Sphingomyelinose (Niemann-Pick Disease) und Ceramidose (Faber's Disease) (zusammengefasst bei Pilz et al. 1979). Eine Reihe dieser Defekte sind auch bei Hunden bekannt geworden. Die molekulargenetische Basis caniner Sphingolipidosen ist jedoch bisher nur bei der GM1-Gangliosidose und bei der Globoidzell-Leukodystrophie bekannt. 


\subsection{GM1-Gangliosidose}

\begin{tabular}{|ll|}
\hline Chromosom: & CFA23 \\
Gen: & BGAL $(\beta-$ Galaktosidase) \\
Ensembl: & GeneID: ENSCAFG00000004652 \\
DNA-Sequenz: & CFA23, Position 676327-6825190 \\
Mutationen: & G200A, Portugiesischer Wasserhund \\
& DelC1668, Shiba Hund \\
\hline
\end{tabular}

\section{Krankheitsbild}

Ganglioside spielen in neuronalen Plasmamembranen vor allem beim Aufbau einer negativen Ladung und als Rezeptoren für eine Reihe von Substanzen eine Rolle. Bei der pathologischen Akkumulation von Gangliosiden treten typischerweise multilamellare, konzentrische Partikel auf. Primär kommt es zu Veränderungen an den Neuronen. Als sekundäre Auswirkungen können auch Veränderungen von Myelin mit dem Verlust von Myelinlipiden zu beobachten sein (zusammengefasst bei Pilz et al. 1979). Bislang sind zwei Gruppen von erblichen Gangliosidosen bekannt. Die GM1-Gangliosidose ist auf einen Mangel an saurer $\beta$-Galaktosidase zurückzuführen, die durch Hydrolyse der terminalen Galaktose des GM1-Gangliosids den Abbau von GM1- zu GM2Gangliosiden katalysiert. Bei GM2-Gangliosidosen fehlt das Enzym $\beta$-AcetylGalaktosaminidase, das eine weitere Hydrolyse der Oligosaccharidkette katalysiert (O'Brien 1983).

Bei Hunden treten beide Formen erblicher Gangliosidosen auf. Die molekulargenetischen Ursachen sind bisher jedoch nur für zwei verschiedene Formen der GM1-Gangliosidose bei Portugiesischen Wasserhunden (Wang et al. 2000) und bei Shiba Hunden (Yamato et al. 2002) bekannt. Für keine der beiden Rassen sind Zahlen zur Häufigkeit der GM1-Gangliodsidose veröffentlicht. Bei Portugiesischen Wasserhunden wurde unter Einsatz eines DNA-Tests eine Genotypisierung von 115 Tieren durchgeführt. Dabei wurden fünf homozygot betroffene und 50 heterozygote Defektträger identifiziert. Inwieweit aus diesen Ergebnissen auf die Häufigkeit der Erkrankung innerhalb der gesamten Rasse geschlossen werden kann, wird nicht gesagt (Wang et al. 2000). Die veröffentlichten Untersuchungen der Gangliosidose bei Shiba Hunden beziehen sich alle auf Individuen aus einer einzigen Familie (Yamato et al. 2000; Yamato et al. 2002; Yamato et al. 2003). Der Erbgang ist in beiden Rassen autosomal rezessiv. Die Erkrankung wurde erstmals 1976 bei einem Beagle- 
Mischlingshund (BM) beschrieben (Read et al. 1976), der als Basis für den Aufbau einer Forschungskolonie zur weiteren Untersuchung der caninen GM1-Gangliosidose diente (Rodriguez et al. 1982). Weitere betroffene Rassen sind Englische Springer Spaniel (ESS) (Alroy et al. 1985; Alroy et al. 1992) Portugiesische Wasserhunde (PW) (Saunders et al. 1988; Shell et al. 1989; Alroy et al. 1992), Alaska Huskies (AH) (Muller et al. 1998) und Shiba Hunde (SH) (Yamato et al. 2000). Klinische, pathologische, histopathologische und biochemische Merkmale der caninen GM-Gangliosidose in den einzelnen betroffenen Rassen sind in Tabelle 9 aufgelistet.

Tabelle 9 Klinische, pathologische, histopathologische und biochemische Merkmale der caninen GM1Gangliosidose

\begin{tabular}{|c|c|}
\hline Alter bei Beginn & AH: 6W, BM: 2 M, ESS und PW: 4-5 M, SH: 5-6 M \\
\hline Verlauf & ESS und PW: 4-9 M, AH: 1-12 M, BM: 2-10 M, SH: 5-14 M \\
\hline Allgemeinzustand & AH: Gewichtsverlust, herabgesetzte Propriozeption \\
\hline ZNS & $\begin{array}{l}\text { Ataxie, Tremor, Kopfzittern, Nystagmus, AH und BM: Schielen, häufiges Stürzen und Schwanken, } \\
\text { AH: tonisch-klonische Anfälle, SH, PW, selten ESS: Hornhauteintrübung/gestörte Sehfähigkeit }\end{array}$ \\
\hline Skelett & $\begin{array}{l}\text { ESS und PW: Zwergenwuchs, Knorpelnekrose, retardierte Verknöcherung, ESS: weitständige Augen, } \\
\text { vorspringende Stirn, AH: weite Wirbelabstände, SH: keine Veränderungen }\end{array}$ \\
\hline Organe & $\begin{array}{l}\text { Infiltration von Thymus, Peyerschen Platten, Lymphknoten und Lunge durch vergrößerte } \\
\text { Makrophagen }\end{array}$ \\
\hline defektes Enzym & $\beta$-Galaktosidase \\
\hline Speichermaterial & (Asialo-) $\mathrm{G}_{\mathrm{M} 1}$-Ganglioside, Oligosaccharide, Polylaktosaminoglykane (nur Niere + Leber, nur PW) \\
\hline Pathologie/ Histologie & $\begin{array}{l}\text { neurales Gewebe: SH: Kortex von Cerebrum und Cerebellum gelblich verfärbt, ESS, PW, AH: } \\
\text { Einschlüsse in Neuronen bei AH bis in dendritische und axonale Fortsätze in Hirn, Rückenmark, } \\
\text { peripheren Ganglien, AH: Darm, Harnblase, Nebennieren, Spheroide an Axonen, Astrozytose, } \\
\text { Mikrogliose, Dys-/ Demyelinisierung), Waller-Degeneration }\end{array}$ \\
\hline & $\begin{array}{l}\text { extraneurales Gewebe: SH: Leber und Niere leicht geschwollen, ESS u. PW: Vakuolisierung von } \\
\text { Hepatozyten, Kupfferzellen, Chondrozyten, Keratozyten, Zellen in Pankreas-Inseln, Nebennieren, } \\
\text { Nierentubuli, Flimmerepithel, Schleimhaut der Speicheldrüsen }\end{array}$ \\
\hline $\begin{array}{l}\text { Ultrastruktur des } \\
\text { eingelagerten Materials }\end{array}$ & $\begin{array}{l}\text { ESS, PW, SH: schaumiges, blasses Zytoplasma (Ganglienzellen der Retina), lamellenartige, } \\
\text { membranöse Strukturen (Neuronen, Nebennierenzellen), Axone zusätzlich amorphes Material, leere } \\
\text { Vakuolen oder fibrillenartiges Material, vereinzelt membranöse Strukturen (Endothelzellen, Zellen } \\
\text { der Nierentubuli), verdrillte, tubuläre Strukturen (Glomeruli); AH: feines bis grobes granulares } \\
\text { Material und Vakuolen }\end{array}$ \\
\hline
\end{tabular}

AH: Alaska Husky, BM: Beagle-Mischlingshund, ESS: Englischer Springerspaniel, PW: Portugiesischer Wasserhund

\section{Genetischer Hintergrund}

Das canine $\beta$-Galaktosidase-Gen (BGAL) ist auf Chromosom 23 zwischen Position 6763274 und 6825190 lokalisiert (Ensembl GeneID: ENSCAFG00000004652). 


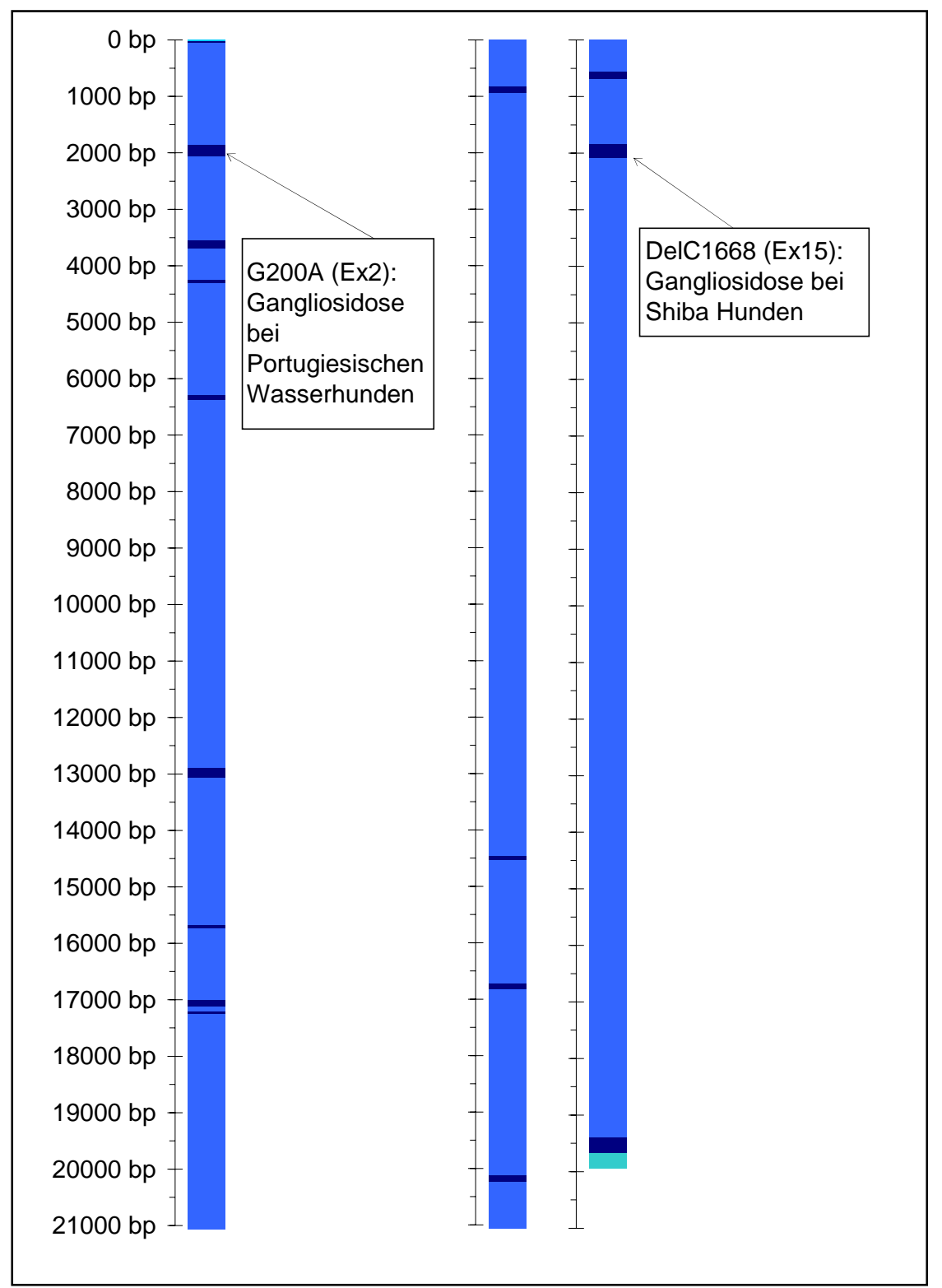

Abb. 57 Schematische Darstellung des caninen $\beta$-Galaktosidase-Gens und Lage der bisher identifizierten Mutationen. Dunkelblau: codierende Sequenz, hellblau: Intronsequenz, türkis: 5'- und 3'-UTR.

Die $\beta$-Galaktosidase-mRNA von gesunden Portugiesischen Wasserhunden hat eine Länge von 2322 Nukleotiden und setzt sich zusammen aus 21 Nukleotiden 5'-UTR, 297 Nukleotiden 3'-UTR und 2004 Nukleotiden codierender Sequenz, die in 16 Exons unterteilt ist. Das resultierende Protein hat eine Länge von 668 Aminosäuren (Wang et al. 2000). Es existieren vor allem in Exon 1 und hinsichtlich der Länge der 3' UTR einige Unterschiede zu den in der Ensembl-Datenbank veröffentlichten Daten. Bei der Ensembl-Sequenz wird zudem die 5'-UTR nicht dargestellt. Die in Abb. 57 schematisch gezeigte Struktur des $\beta$-Galaktosidase-Gens basiert vorrangig auf den Ensembl-Daten. Lediglich die Länge der 5'-UTR entspricht den von Wang et al. (2000) veröffentlichten Daten. 


\section{III.a Ursächliche Mutation für GM1-Gangliosidose bei Portugiesischen Wasserhunden}

Bei $\beta$-Galaktosidase-defizienten Portugiesischen Wasserhunden liegt an Position 200 der cDNA in Exon 2 ein Basenaustausch von Guanin durch Adenin vor, der zu einem Aminosäurenaustausch von Arginin zu Histidin führt (Abb. 58). Einzelheiten über den Einfluss dieser Mutation auf die $\beta$-Galaktosidase-Defizienz betroffener Hunde sind nicht untersucht worden (Wang et al. 2000).

Die Transkription des $\beta$-Galaktosidase-Gens scheint nicht beeinträchtigt zu sein, da die mRNA von betroffenen Portugiesischen Wasserhunden sich in ihrer Größe nicht von der mRNA normaler Kontrollhunde unterscheidet (Ahern-Rindell et al. 1996). Ursache der Erkrankung muss also eine gestörte Translation oder eine Funktionsstörung der mutierten $\beta$-Galaktosidase sein. Eine Untersuchung der Expression von normaler und mutierter $\beta$-Galaktosidase-cDNA in $\beta$-Galaktosidase-defizienten und normalen Fibroblastenkulturen zeigt, dass es sich bei der beschriebenen Mutation um den ursächlichen Defekt bei betroffenen Portugiesischen Wasserhunden handelt. In defizienten Fibroblasten mit einer stark herabgesetzten $\beta$-Galaktosidase-Aktivität lässt sich die $\beta$-Galaktosidase-Aktivität nach der Transfektion mit einem Vektor, in den normaler cDNA kloniert wurde, auf $86 \%$ des Normwertes steigern. Durch Transfektion der gleichen Zellen mit einem Wildtyp-Vektor oder mit einem Vektor, in den mutierte cDNA kloniert wurde, lässt sich kein Anstieg der $\beta$-Galaktosidase-Aktivität erzielen (Wang et al. 2000).

Bei insgesamt 115 untersuchten Proben von Portugiesischen Wasserhunden waren alle Hunde, die auf Grundlage der gemessenen $\beta$-Galaktosidase-Aktivität als homozygote oder heterozygote Defektträger eingestuft wurden, auch homozygot bzw. heterozygot für die beschriebene Mutation. Bei Proben von acht Portugiesischen Wasserhunden, die auf Grundlage der gemessenen $\beta$-Galaktosidase-Aktivität nicht eindeutig genotypisiert werden konnten, ermöglichten die Ergebnisse einer molekularbiologisch basierten Genotypisierung eine eindeutige Zuordnung. Bei einem betroffenen Englischen Springerspaniel konnte die Mutation nicht nachgewiesen werden. Trotz sehr ähnlicher Symptome scheint in dieser Rasse demnach eine andere Mutation für die Gangliosidose-Erkrankung verantwortlich zu sein (Wang et al. 2000). 


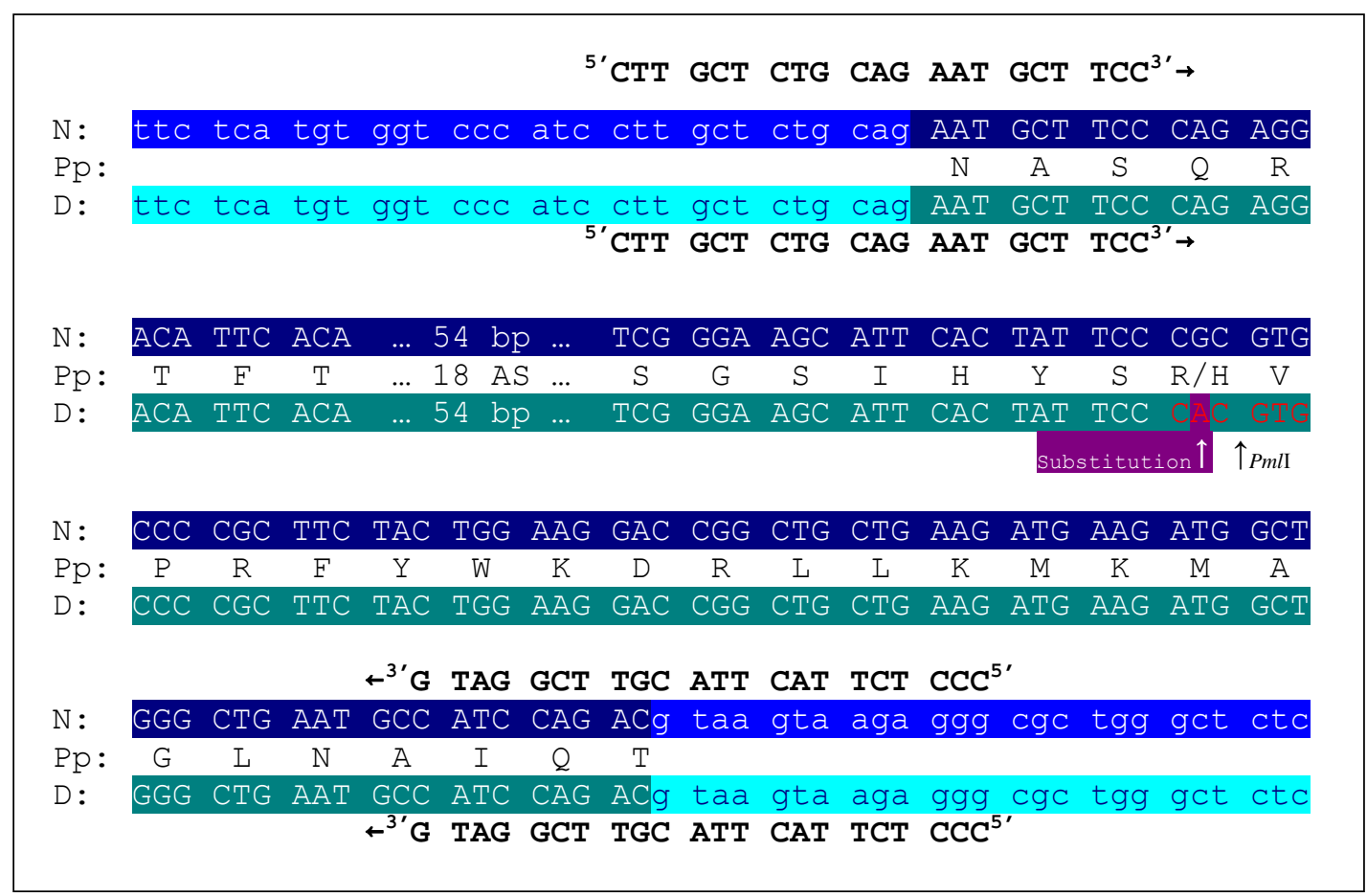

Abb. 58 Exon 2 des caninen $\beta$-Galaktosidase-Gens und angrenzende Intronsequenz. N: normale Sequenz, D: defekte Sequenz, Pp: Polypeptidsequenz, hellblau: Intron normale Sequenz, dunkelblau: Exon normale Sequenz, türkis: Intron defekte Sequenz, dunkelgrün: Exon defekte Sequenz, rote Schrift: PmlI-Erkennungssequenz, PmlI-Schnittstelle durch Pfeil markiert, Substitution violett unterlegt und durch Pfeil gekennzeichnet.

\section{IV.a Genotypisierung für GM1-Gangliosidose bei Portugiesischen Wasserhunden}

Der Nachweis der Substitution kann per Amplifikation eines 195-bp-Fragments und anschließender RFLP-Typisierung erfolgen. Der RFLP beruht auf einer Erkennungssequenz für PmlI, die im Defektallel durch die Mutation entsteht und im Wildtypallel nicht vorhanden ist (Wang et al. 2000).

\section{III.b Ursächliche Mutation der GM1-Gangliosidose bei Shiba Hunden}

Die Gegenüberstellung der Sequenz eines betroffenen Shiba Hundes und der Sequenz eines normalen Portugiesischen Wasserhundes zeigt beim Shiba Hund die Deletion eines Cytosins an Nukleotidposition 1668 in Exon 15 (Yamato et al. 2002). Durch diese Deletion kommt es zu einer Leserasterverschiebung und damit zu einer abweichenden Aminosäurensequenz nach Position 550, die nach 50 Aminosäuren in einem verfrühten Stoppcodon endet (Abb. 59). 


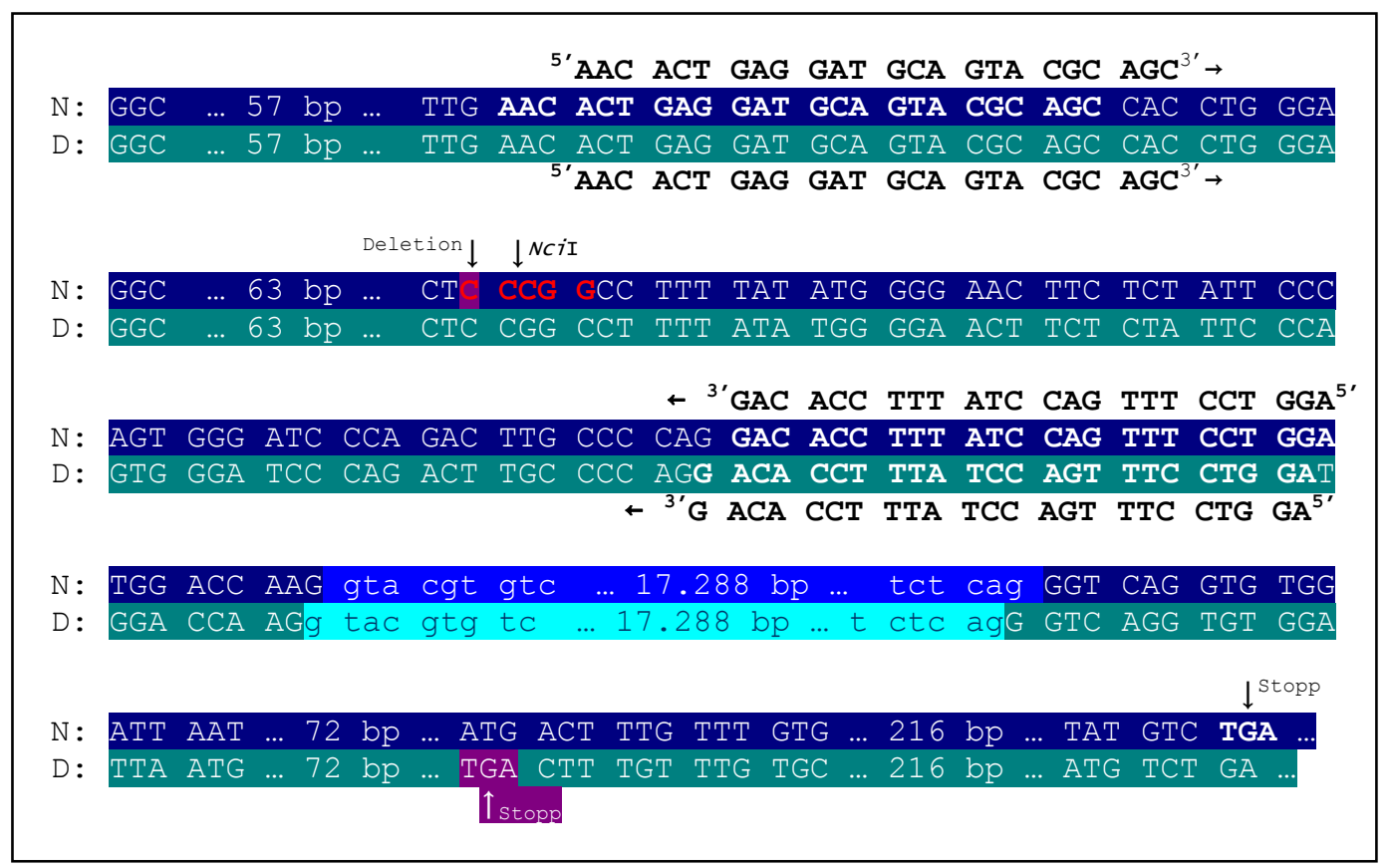

Abb. 59 Exon 15 Intron 15 und Exon 16 des caninen $\beta$-Galaktosidase-Gens. N: normale Sequenz, D: defekte Sequenz, dunkelblau: Exon normale Sequenz, dunkelgrün: Exon defekte Sequenz, hellblau: Intron normale Sequenz, türkis: Intron defekte Sequenz, von Deletion betroffenes Nukleotid in normaler Sequenz violett markiert und durch Pfeil gekennzeichnet, rote Schrift: NciI-Erkennungssequenz, NciISchnittstelle durch Pfeil gekennzeichnet, verfrühtes Stoppcodon in defekter Sequenz violett unterlegt und durch Pfeil gekennzeichnet, normales Stoppcodon in normaler Sequenz fett gedruckt und durch Pfeil gekennzeichnet.

\section{IV.b Genotypisierung für GM1-Gangliosidose bei Shiba Hunden}

Der Nachweis der Beschriebenen Mutation kann per Amplifikation eines 184-bpFragments und anschließender RFLP-Typisierung erfolgen. Der RFLP beruht auf einer Restriktionserkennungssequenz für NciI im Wildtypallel, die im Defektallel aufgrund der Mutation nicht enthalten ist (Yamato et al. 2002).

\subsection{Globoidzell-Leukodystrophie (Krabbe Disease)}

\begin{tabular}{ll|}
\hline Chromosom: & CFA8 \\
Gen: & GALC (Galaktosylcerebrosidase) \\
Ensembl: & GeneID: ENSCAFG00000017337 \\
DNA-Sequenz: & CFA8, Position 63206855-63263910 \\
Mutationen: & A473C, West Highland White Terrier, Cairn Terrier \\
& 832Ins78bp, Irischer Setter \\
\hline
\end{tabular}

\section{Krankheitsbild}

Aus der Gruppe der Leukodystrophien fallen zwei Erkrankungen unter die Sphingolipidosen. Es handelt sich um die metachromatische Leukodystrophie und die Globoidzell-Leukodystrophie. Die metachromatische Leukodystrophie beruht auf einem 
gestörten Abbau von Sulfatiden. Bei der Globoidzell-Leukodystrophie führt die Funktionsstörung einer oder mehrerer Galaktosyl- $\beta$-Galaktosidasen $\mathrm{zu}$ einer Beeinträchtigung des Abbaus der vier Substratgruppen oder Substrate Galaktosylceramide (Cerebroside) (Suzuki und Suzuki 1970), Galaktosylsphingosin (Psychosin) (Miyatake und Suzuki 1972b; Wenger et al. 1973), Monogalaktosyldiglycerid (Wenger et al. 1973) und Laktosylceramid (Wenger et al. 1974). Kennzeichen der Globoidzell-Leukodystrophie ist eine Zerstörung der Myelinscheiden in Hirn und Rückenmark in Verbindung mit der Akkumulation von typischen Globoidzellen, die vorrangig in den perivaskulären Bereichen der weißen Substanz auftreten und für die humane Form der Erkrankung bei Krabbe ausführlich beschrieben sind (Krabbe 1916). Daher tauchen in der Literatur auch häufig die Bezeichnungen „Krabbe Disease“ oder „Leukodystrophie Typus Krabbe“ auf.

Betroffene Hunderassen sind vor allem West Highland White Terrier (Fankhauser et al. 1963; Jortner und Jonas 1968; Fletcher et al. 1971) und Cairn Terrier (Fletcher et al. 1966; Hirth und Nielsen 1967; Jortner und Jonas 1968; Kurtz und Fletcher 1970; Fletcher et al. 1971; Howell und Palmer 1971). Fallberichte in weiteren Rassen betreffen einen Zwergpudel (Zaki und Kay 1973), Bluetick Coonhounds (Boysen et al. 1974), Beagles (Johnson et al. 1975, zitiert bei McGraw und Carmichael 2006), Dalmatiner (Bjerkas 1979, zitiert bei McGraw und Carmichael 2006) und Irische Setter (McGraw und Carmichael 2006). Die wesentlichen klinischen, pathologischen, histopathologischen und biochemischen Merkmale der caninen GloboidzellLeukodystrophie sind in Tabelle 10 zusammengefasst. 
Tabelle 10 Klinische, pathologische, histopathologische und biochemische Merkmale der caninen GloboidzellLeukodystrophie

\begin{tabular}{|c|c|}
\hline Alter bei Beginn & $2-6 \mathrm{mo}$ \\
\hline Verlauf & 3 wk -6 mo, im Mittel 2-3 mo \\
\hline Allgemein & mental unbeeinträchtigt, in einem Fall Appetitlosigkeit \\
\hline ZNS & $\begin{array}{l}\text { Kopfzittern, Lähmung der Extremitäten, Ataxie, Nystagmus, z. T. erscheint weiße Substanz grau bis } \\
\text { pink-grau und verfestigt, teilweise erweiterte Ventrikel, Schielen, Zuckungen der Augenlider und } \\
\text { Schnurrbarthaare }\end{array}$ \\
\hline \multicolumn{2}{|l|}{ Skelett } \\
\hline Auge/ Sehfähigkeit & z. T. Sehstörungen \\
\hline Herz/andere Organe & ohne Befund \\
\hline defektes Enzym & Galaktocerebrosidase (Galaktosylceramid- $\beta$-Galaktosidase) \\
\hline Speicher-material & Galaktocerebroside (Galaktosylceramid) und Psychosin (Galaktosylsphingosin) \\
\hline \multirow[t]{10}{*}{ neurales Gewebe } & $\begin{array}{l}\text { zunehmende Reduzierung der Myelinscheiden (Oligodendroglia) in Hirn und Rückenmark, in spätem } \\
\text { Stadium unregelmäßige Schwellung und Vakuolisierung der Myelinscheiden }\end{array}$ \\
\hline & $\begin{array}{l}\text { Gesamtlipidanteil der weißen Substanz bei betroffenen Hunden gegenüber gesunden Kontrollhunden auf } \\
\text { 31-45\% reduziert, entspricht Umfang des Myelinverlustes }\end{array}$ \\
\hline & Cerebrosidanteil gegenüber Kontrollwerten um 14-18 \% erhöht \\
\hline & Sphingomyelinanteil deutlich erhöht (165-304 \%) \\
\hline & $\begin{array}{l}\text { Anhäufung von Globoidzellen: rundlich, oval oder polygonal gegeneinander abgeplattet, nehmen } 40 \% \\
\text { der weißen Substanz ein, vorrangig in Wänden von Blutgefäßen und perivaskular lokalisiert, einzelne } \\
\text { Nester auch intervaskulär, oft von Retikulumzellen umgeben, }\end{array}$ \\
\hline & $\begin{array}{l}\text { perivaskulär z. T. massives Auftreten kleiner, rundkerniger Zellen (Leukozyten, Histiozyten, } \\
\text { Plasmazellen) gemischt mit Globoidzellen }\end{array}$ \\
\hline & $\begin{array}{l}\text { Zunahme von Zahl und Größe der Astrozyten: massiv in Regionen mit Globoidzellen, leicht in anderen } \\
\text { Regionen }\end{array}$ \\
\hline & $\begin{array}{l}\text { Axone in Umgebung von kleinen Globoidzell-Nestern unregelmäßig, geschwollen und blass, um größere } \\
\text { Nester herum auch dunkel gefärbte geschwollene Axone, innerhalb von Globoidzell-Nestern nur wenige } \\
\text { Axone, insgesamt reduziert }\end{array}$ \\
\hline & graue Substanz: weitgehend unverändert bis auf leichten Verlust von Neuronen \\
\hline & $\begin{array}{l}\text { von den beschriebenen Veränderungen sind Zellen des ZNS, periphere Nerven und einzelne } \\
\text { Spinalnervenwurzeln betroffen }\end{array}$ \\
\hline $\begin{array}{l}\text { Material- } \\
\text { beschaffenheit, } \\
\text { Ultrastruktur }\end{array}$ & $\begin{array}{l}\text { Globoidzellen: nicht fetthaltig a) blasses Zytoplasma, variabel strukturierte Einschlüsse und Vakuolen } \\
\text { mit degenerierten myelinisierten Fasern, b) osmiophiles Zytoplasma, unregelmäßig geformte Bläschen } \\
\text { mit Einschlüssen, kleine rundkernige Zellen (epitheloide Zellen): enthalten z.T. amorphes PAS positives } \\
\text { Material, Einschlüsse der Globoidzellen: rohrförmig, Lumen leer, Wände faserig, a) schlank und } \\
\text { gedreht, oft ineinander verflochten, runder Querschnitt, in unregelmäßig geformten Bläschen, b) breit, } \\
\text { gerade oder gebogen, eckiger Querschnitt, membranumgeben oder frei im Zytoplasma, c) selten: Packen } \\
\text { dichter Tubuli/ osmiophile Ringe o. Bögen/ Vakuolen mit degeneriertem Myelin }\end{array}$ \\
\hline
\end{tabular}

Die zugrunde liegenden Mutationen wurden bisher bei West Highland White und Cairn Terriern (Victoria et al. 1996) und bei Irischen Settern (McGraw und Carmichael 2006) charakterisiert. In den Rassen Cairn Terrier und West Highland White Terrier liegt derselbe ursächliche Gendefekt vor. Über die Frequenz des Defektallels kann anhand der bisher vorliegenden Ergebnisse keine Aussage getroffen werden (Victoria et al. 1996). Bei einer Untersuchung von 24 Irischen Settern aus verschiedenen Familien, die keine direkte Verwandtschaft $\mathrm{zu}$ den ursprünglich betroffenen Irischen Settern aufweisen, konnten mittels PCR-Test drei heterozygote Träger der beschriebenen 
Mutation identifiziert werden. Diese Ergebnisse deuten darauf hin, dass das mutierte Allel in der Population der Irischen Setter relativ häufig ist (McGraw und Carmichael 2006).

Ursache des gestörten Katabolismus von Cerebrosiden ist eine mangelnde Aktivität des lysosomalen Enzyms Galaktosylceramid- $\beta$-Galaktosidase (Suzuki et al. 1970; Suzuki und Suzuki 1971). Ob dieses Enzym auch für den Katabolismusdefekt des Psychosins (Galaktosylsphingosin) und der zwei weiteren Substrate verantwortlich ist, oder ob diese Störungen durch zusätzliche Enzymdefekte hervorgerufen werden, ist noch unklar (Miyatake und Suzuki 1972a). Dieses Enzym ist zusätzlich für die Spaltung von Galaktosylsphingosin (Psychosin) und Monogalaktosyldiglycerid verantwortlich und neben GM1- $\beta$-Galaktosidase am Abbau von Laktosylceramid beteiligt (Suzuki und Suzuki 1983). Als Ursache für die pathologischen Erscheinungen der GloboidzellLeukodystrophie spielen vor allem Cerebroside (Galaktosylceramide) und Galaktosylsphingosin (Psychosin) eine Rolle. So wird der gestörte Abbau von Cerebrosiden allgemein als Auslöser für die Entstehung sowohl von Globoidzellen als auch von rundkernigen, kleinen auch als epitheloid bezeichneten Zellen betrachtet (Austin 1963; Austin und Lehfeldt 1965). Die reduzierte Myelinisierung wird zum einen auf eine toxische Wirkung von Psychosin auf die myelinsynthetisierenden Oligodendrozyten (Miyatake und Suzuki 1972b), zum anderen auf einen gestörten Aufbau von Sulfomyelin (Bachhawat et al. 1967) zurückgeführt.

Experimentell lassen sich durch die intracerebrale Injektion von Cerebrosiden in der weißen Substanz von Ratten globoidzellartige Elemente erzeugen, innerhalb derer die injizierten Cerebroside über einen Zeitraum von sechs Monaten phagozytiert werden (Austin und Lehfeldt 1965). Oft wird daher auch von Globoidzellmakrophagen oder kurz Makrophagen gesprochen (Fletcher et al. 1971). Ein Rückgang der weißen Substanz wird durch die Injektion der Cerebroside nicht erzeugt (Austin und Lehfeldt 1965). Insgesamt ist bei betroffenen Patienten der Sphingolipidanteil in der weißen Substanz reduziert. Bei humanen Patienten besteht innerhalb der Sphingolipidfraktion eine Verschiebung der Anteile einzelner Sphingolipidgruppen, die durch einen relativen Zuwachs der Cerebroside gegenüber Sulfatiden und teilweise auch Sphingomyelin gekennzeichnet ist. Diese Tendenz zeigt sich in Bereichen mit starker Anhäufung von Globoidzellen, deren Cerebrosidgehalt gegenüber Sphingomyelin bis zu vierfach erhöht 
ist, besonders deutlich (Austin 1963). Enzymuntersuchungen sprechen dafür, dass dieses verschobene Verhältnis nicht nur auf dem blockierten Katabolismus von Cerebrosiden beruht sondern auch auf einem zusätzlichen Mangel an Cerebrosidsulfotransferase-Aktivität. Dieser Enzymdefekt führt zu einer Blockade des Aufbaus von Cerebrosidsulfaten und damit von Myelinsulfatiden. Eine dadurch verursachte Störung der Myelinisierung wird nicht ausgeschlossen (Bachhawat et al. 1967). Bezüglich des Sphingomyelingehaltes der weißen Substanz weichen betroffene Hunde von humanen Patienten ab. In der weißen Substanz liegt ein im Vergleich zu normalen Kontrollhunden ein um 165-304 \% erhöhter Sphingomyelinanteil vor, während der Cerebrosidanteil lediglich um 14-18 \% erhöht ist (Austin et al. 1968). Die biochemischen Verhältnisse bei der Globoidzell-Leukodystrophie scheinen demnach bei den betroffenen Spezies nicht vollständig übereinzustimmen. Daher können Theorien bezüglich des pathologischen Mechanismus nur unter Vorbehalt übertragen werden.

Neben der möglichen Störung des Aufbaus von Sulfomyelin wird ein erhöhter Psychosingehalt (Vanier und Svennerholm 1976; Svennerholm et al. 1980) und eine darauf beruhende toxische Wirkung auf Oligodendrozyten als Ursache für die Leukodystrophie in Betracht gezogen. Als mögliche Psychosinquelle kommt ein alternativer Abbau von Galaktosylceramid in Frage, bei dem durch Abspalten einer Fettsäure Psychosin entsteht. Die bei Suzuki (Suzuki 2003) entwickelte Vorstellung über den Ablauf dieses Stoffwechselweges ist in Abb. 60 vereinfacht dargestellt. Ob ein solcher Stoffwechselvorgang tatsächlich stattfindet, ist allerdings nicht erwiesen (Miyatake und Suzuki 1972b). Dafür sprechen massiv erhöhte Psychosingehalte in der weißen Substanz betroffener Patienten (Vanier und Svennerholm 1976; Svennerholm et al. 1980). Die zytotoxische Wirkung von Psychosin ist experimentell belegt (Taketomi und Nishimura 1964; Miyatake und Suzuki 1972b). Die Galaktosylceramid- $\beta$ Galaktosidase Defizienz begünstigt die Anreicherung des Substrates Psychosin (Miyatake und Suzuki 1972a; Miyatake und Suzuki 1972b; Suzuki et al. 1974; Svennerholm et al. 1980). Eine Zerstörung der Oligodendrozyten führt zum Abbau von Myelin und damit zu einer verstärkten Anreicherung von Cerebrosiden. Dadurch wird der gestörte Stoffwechselmechanismus zusätzlich belastet. 


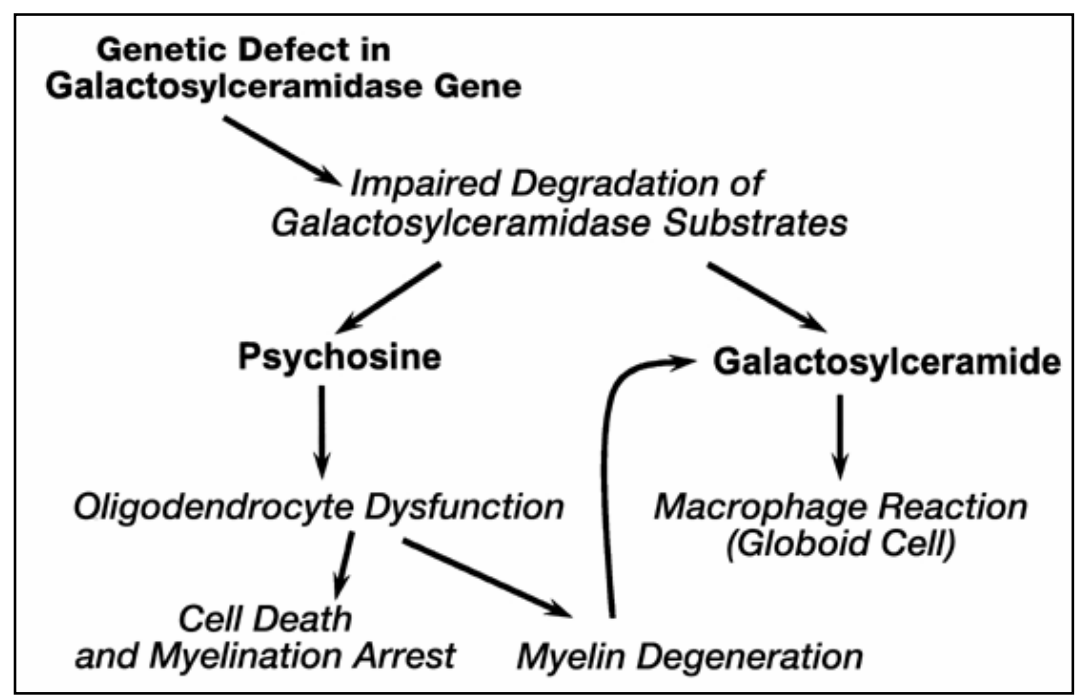

Abb. 60 Aktuelles Modell des pathogenen Mechanismus bei Globoidzell-Leukodystrophie (vereinfacht nach Suzuki 2003).

In Hirn, Leber und Niere sowie in peripheren Leukozyten von betroffenen West Highland White und Cairn Terriern ist die Galaktosylceramid- $\beta$-Galaktosidase-Aktivität im Vergleich $\mathrm{zu}$ klinisch gesunden Wurfgeschwistern oder klinisch gesunden unverwandten Hunden reduziert. Heterozygote Defektträger zeigen intermediäre Werte für die Galaktosylceramid- $\beta$-Galaktosidase-Aktivität in Leukozyten (Suzuki et al. 1970; McGraw und Carmichael 2006). Hinsichtlich der Serumaktivität der Galaktosylceramid- $\beta$-Galaktosidase scheint bei Hunden allerdings eine Besonderheit vorzuliegen. Es lassen sich keine Unterschiede zwischen Hunden mit klinischen Anzeichen einer Globoidzell-Leukodystrophie und obligat heterozygoten Hunden oder gesunden Hunden mit unbestimmtem Genotyp feststellen (Suzuki et al. 1972). Eine Elektrofokussierung der caninen Galaktosylcerebrosidase zeigt, dass dieses Enzym aus einer $\alpha$-Komponente mit einem isoelektrischen Punkt zwischen $\mathrm{pH}$ 5,0 und 5,1 und einer $\beta$-Komponente mit einem isoelektrischen Punkt zwischen $\mathrm{pH} 5,5$ und 5,4 zusammengesetzt ist (Suzuki et al. 1974). Diese Beobachtung erklärt möglicherweise die unbeeinträchtigte Aktivität der Galaktosylceramid- $\beta$-Galaktosidase im Serum. Unter der Annahme, dass die Expression der $\beta$-Komponente beim Hund möglicherweise auf Gewebe und Leukozyten beschränkt ist und im Serum eventuell nur die $\alpha$-Komponente exprimiert wird, bliebe der Effekt einer Funktionsstörung der $\beta$-Komponente auf Gewebe und Leukozyten reduziert. Im Serum wäre zwischen gesunden und kranken Hunden aufgrund der vollständigen Funktionsfähigkeit der $\alpha$-Komponente kein Unterschied in der Enzymaktivität messbar (Suzuki et al. 1972; Suzuki et al. 1974). 


\section{Genetischer Hintergrund}

Pedigreeinformationen aus einer Cairn-Terrier-Forschungskolonie sprechen für einen autosomal rezessiven Erbgang (Fletcher 1969).

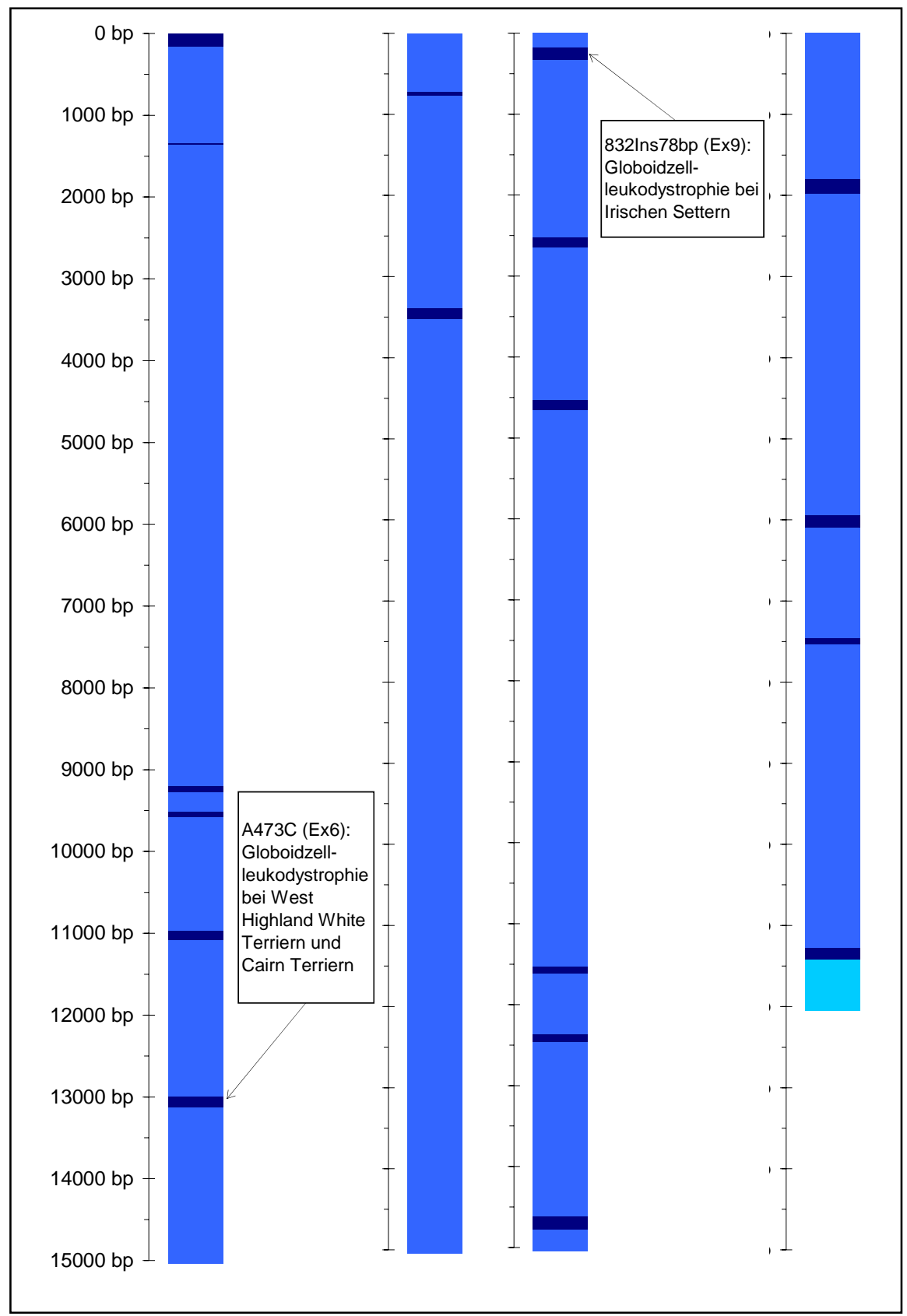

Abb. 61 Schematische Darstellung des caninen Galaktosylcerebrosidase-Gens und Lage der bisher identifizierten Mutationen. Dunkelblau: codierende Sequenz, hellblau: Intronsequenz, türkis: 3'-UTR.

Das canine Galaktosylcerebrosidase-Gen ist auf Chromosom 8 zwischen Position 62306855 und 62363910 lokalisiert und enthält 18 Exons (Ensembl-GeneID: ENSCAFG00000017337). Die von Victoria et al. (1996) klonierte cDNA hat eine Gesamtlänge von 2645 Nukleotiden mit einer etwa 600 bp langen 3'-UTR und einer 
codierenden Sequenz von 2007 bp Länge. Diese Daten stimmen ungefähr mit den bei Ensembl veröffentlichten Daten überein, anhand derer die Abb. 61 erstellt wurde.

\section{III.a Ursächliche Mutation für Globoidzell-Leukodystrophie bei West Highland White Terriern und Cairn Terriern}

Die mRNA-Sequenzen von zwei betroffenen West Highland White Terriern und zwei betroffenen Cairn Terriern zeigen zwei Abweichungen gegenüber der normalen Sequenz. Es handelt sich um einen Substitution von Adenin durch Cytosin an mRNAPosition 473 und eine Substitution von Cytosin durch Thymin an Position 1915 (Abb. 62). Beide Abweichungen führen zum Austausch konservierter Aminosäuren. Durch die erste Substitution wird an Aminosäurenposition 158 anstelle eines hydrophoben Thyrosinrestes ein hydrophiler Serinrest codiert. Die zweite Substitution führt zu einem Austausch von Prolin durch Serin an Aminosäurenposition 639. Expressionsstudien sprechen dafür, dass der Galaktocerebrosidasemangel bei betroffenen West Highland White Terriern ausschließlich durch die Substitution an Position 158 verursacht wird, während die Substitution an Position 639 keinen Einfluss auf den Galaktocerebrosidasespiegel in transfizierten COS-1 Zellen hat.

\section{IV.a Genotypisierung für Globoidzell-Leukodystrophie bei West Highland White Terriern und Cairn Terriern}

Der Nachweis der Mutation kann unter anderem per RFLP-Test erfolgen, der auf der Einführung einer MnlI-Restriktionserkennungssequenz in das Defektallel mit Hilfe eines mismatch-Vorwärtsprimers beruht. Diese Methode ermöglichte die Identifizierung von 19 Defektträgern innerhalb einer untersuchten Population von insgesamt 118 West Highland White und Cairn Terriern (Victoria et al. 1996). 


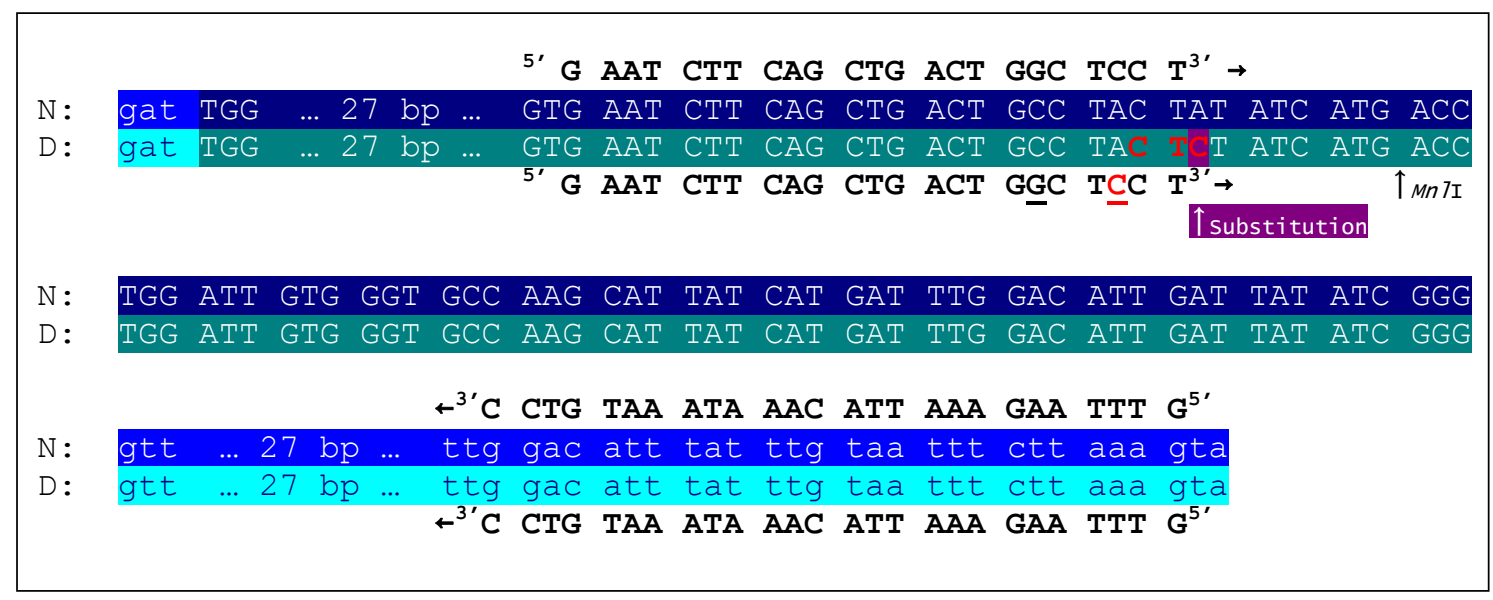

Abb. 62 Exon 6 des caninen Galaktosylceramid- $\beta$-Galaktosidase Gens und flankierende Intronsequenzen. N: normale Sequenz, D: defekte Sequenz, dunkelblau: Exon normale Sequenz, dunkelgrün: Exon defekte Sequenz, hellblau: Intron normale Sequenz, türkis: Intron defekte Sequenz, Substitution in defekter Sequenz violett unterlegt und durch Pfeil gekennzeichnet, rote Schrift: MnlIErkennungssequenz, Abweichungen der Primersequenz von der zu amplifizierenden Sequenz durch Unterstereichung hervorgehoben, MnlI-Restriktionsschnittstelle in defekter Sequenz durch Pfeil markiert.

\section{III.b Ursächliche Mutation für Globoidzell-Leukodystrophie bei Irischen Settern}

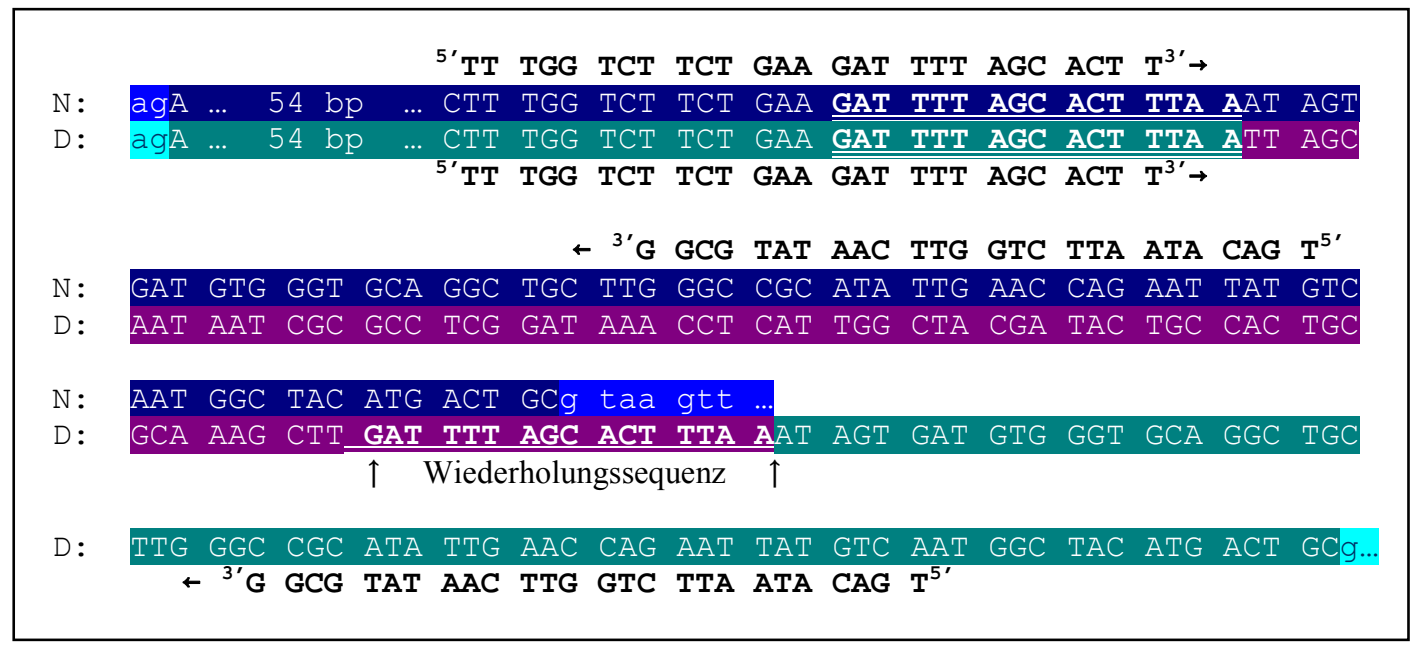

Abb. 63 Exon 9 des caninen Galaktosylceramid- $\beta$-Galaktosidase-Gens mit angrenzender Intronsequenz (Ensembl-GeneID: ENSCAFG00000017337). N: normale Sequenz, D: defekte Sequenz, dunkelblau: Exon normale Sequenz, dunkelgrün: Exon defekte Sequenz, hellblau: Intron normale Sequenz, türkis: Intron defekte Sequenz, 78 bp Insertion violett unterlegt und durch Pfeil gekennzeichnet, Duplikation in normaler und defekter Sequenz doppelt unterstrichen und fett gedruckt, in Insertsequenz zusätzlich durch Pfeil gekennzeichnet.

Bei Irischen Settern mit Globoidzell-Leukodystrophie liegt eine 78-bp-Insertion nach Position 832 in Exon 9 des Galaktosylceramid- $\beta$-Galaktosidase-Gens vor (Abb. 63) (McGraw und Carmichael 2006). Diese Insertion setzt sich zusammen aus einer Duplikation von $16 \mathrm{bp}$, die direkt in 5'-Richtung vor der Insertion lokalisiert sind, und einem Rest von 62 bp. 


\section{IV.b Genotypisierung für Globoidzell-Leukodystrophie bei Irischen Settern}

Der Nachweis der Mutation kann über eine Amplifikation des betroffenen Abschnitts aus Exon 9 und anschließende PCR-Fragmentlängenanalyse erfolgen (Abb. 63) (McGraw und Carmichael 2006). 


\subsubsection{Nicht lysosomale Speicherdefekte: Störungen des Glukose- und Glykogenstoffwechsels}

Unter den nicht lysosomalen Speicherdefekten sind Enzymdefekte mit der Folge von Substratanreicherungen zusammengefasst, bei denen die Ablagerung der unzureichend abgebauten Substrate nicht in den Lysosomen erfolgt. Hierzu zählen unter anderem Störungen des Glykogenstoffwechsels, deren weitere Unterteilung nach betroffenem Enzym und dessen Mutationen erfolgt.

Für vier canine Erkrankungen aus der Gruppe der nicht-lysosomalen Speicherdefekte sind die genetischen und biochemischen Grundlagen bekannt. Bei den betroffenen Enzymen handelt es sich um Muskel-Typ-Phosphofruktokinase (PFK) und erythrozytäre Pyruvatkinase (R-PK), die beide Schlüsselstellungen im Embden-Meyerhof-Zyklus, also in der anaeroben Glykolyse, einnehmen, den Pyruvatdehydrogenase-Komplex (PDH), der an der Umwandlung von Pyruvat als Produkt der Glykolyse in Acetylcoenzym A beteiligt ist, sowie Glucose-6-Phosphatase (G6Pase), die in der Glukoneogenese und in der Glykogenolyse den letzten Schritt zur Glukosebildung aus Glukose-6-Phosphat katalysiert. Je nach Expressionsmuster der defizienten Enzyme und je nach Grad der Abhängigkeit der betroffenen Zelltypen von der jeweiligen katalytischen Funktion der defizienten Enzyme haben die einzelnen Glucosestoffwechselstörungen unterschiedlich schwerwiegende Auswirkungen auf den betroffenen Organismus. Während die erythrozytäre PK-Defizienz ausschließlich die Erythrozyten betrifft, sind die Folgen der Muskel-Typ-PFK-Defizienz sowohl in der Muskulatur als auch in den Erythrozyten zu bemerken. Die Auswirkungen einer Störung der anaeroben Glykolyse sind in reifen Erythrozyten, die ihren Energiebedarf ausschließlich über den Embden-Meyerhof-Zyklus bestreiten, tief greifender als in Muskelzellen, die alternativ auf Energie aus dem Citratzyklus zurückgreifen können. Der Mangel einer Komponente des PDH-Komplexes bedingt eine Akkumulation von Pyruvat und Laktat im Serum und wirkt sich extrem leistungsmindernd auf die gesamte Muskulatur aus. Die durch G6Pase katalysierte Reaktion ist für die Umwandlung von Glucose-6-Phosphat in Glucose essentiell. Ein Fehlen dieses Enzyms hat deshalb schwerwiegende Folgen für den gesamten Organismus. 


\subsubsection{Erythrozytäre Pyruvatkinase Defizienz}

\begin{tabular}{ll|}
\hline Chromosom: & CFA7 \\
Gen: & PKLR \\
NCBI: & GeneID: 490425, GenBank: S71529 \\
DNA-Sequenz: & NW_876323, Position 40356359-40364802 \\
Mutationen: & DelC434, Basenji \\
& 1422Ins6bp/1425Ins6bp/1428Ins6bp/1431Ins6bp, \\
& West Highland White Terrier \\
\hline
\end{tabular}

\section{Krankheitsbild}

Die erythrozytäre Pyruvatkinase-Defizienz (R-PK) ist der bei Hunden am weitesten verbreitete Glykogenspeicherdefekt. Neben Basenjis sind auch Beagle (Prasse et al. 1975), Pudel (Randolph et al. 1986), West Highland White Terrier (Chapman und Giger 1990), Cairn Terrier (Schaer et al. 1992) und Langhaardackel (Kohn et al. 1999) betroffen. Veröffentlichungen des zugrunde liegenden genetischen Defekts liegen jedoch bisher nur bei West Highland White Terriern, Cairn Terriern (Skelly et al. 1999a) und Basenji Hunden (Whitney et al. 1994; Whitney und Lothrop 1995) vor. Zu den Häufigkeiten der Erkrankungen innerhalb der genannten Rassen sind keine Zahlen veröffentlicht.

Charakteristisches Merkmal der erythrozytären PK-Defizienz ist eine starke hämolytische Anämie. Erste Symptome sind blasse Schleimhäute, orangefarbiger Stuhl und gelb bis orange-brauner Urin, Erbrechen, Durchfall, plötzlicher Gewichtsverlust, Fieber sowie eine deutliche Splenomegalie, die auch äußerlich tastbar ist. Bei allen betroffenen Hunden fiel die Krankheit bereits innerhalb des ersten Lebensjahres auf. Betroffene Tiere gehen meist im Alter von drei bis fünf Jahren an den Folgen der hämolytischen Anämie oder an Leberversagen ein (Ewing 1969; Tasker et al. 1969; Searcy et al. 1971; Standerfer et al. 1974). Spätere Folgen der Erkrankung sind Myelofibrose und Osteosclerose (Searcy 1973; Prasse et al. 1975). Erstmals beschrieben wurde die Erkrankung 1969 in zwei verschiedenen Würfen von Basenji Hunden (Tasker et al. 1969). Im selben Jahr wurden drei weitere Fälle von hämolytischer Anämie in Basenji Würfen bekannt, bei denen jeweils mehrere Wurfgeschwister oder weitläufig verwandte Basenji Hunde betroffen waren (Ewing 1969). Diese Beobachtungen zeigen klar, dass es sich bei dieser Form einer hämolytischen Anämie um einen erblichen Defekt handelt. 
Differentialdiagnosen gegenüber der Pyruvatkinase-Defizienz als Ursache einer hämolytischen Anämie sind Blutverlust durch Trauma oder durch chronischen, gastrointestinalen Parasitenbefall, Knochenmarksdepression durch Harnvergiftung oder Neoplasie, Schilddrüsenunterfunktion, Ernährungsstörungen oder Knochenmarksinvasion durch Lymphosarkome oder Myelome. Gegenüber diesen Erkrankungen ist jedoch das Ausmaß der Zerstörung von Erythrozyten bei der PKDefizienz weitaus größer. Eine derartige hämolytische Anämie ist außer bei der seltenen PK-Defizienz in der Kleintierpraxis nur bei einer Autoimmunen Hämolytischen Anämie (Systemische Lupus Erythematodes) zu beobachten.

Befunde klinischer Routinelaboruntersuchungen erkrankter Basenji Hunde sind Makrozytose, Hypochromasie, Retikulozytose und große Mengen an kernhaltigen Erythrozyten im peripheren Blut sowie ein extrem geringes Myelozyten:ErythrozytenVerhältnis $(0,21: 1$ - 0,39:1 gegenüber Normwerten von 0,75:1 - 2,5:1). Die Lebensdauer der Erythrozyten ist stark reduziert (Ewing 1969). Normale Halbwertszeiten von Erythrozyten aus einer Transfusion gesunden Blutes im Kreislauf eines erkrankten Basenjis, sowie unverändert kurze Halbwertszeiten von Erythrozyten aus einer Transfusion kranken Basenji-Blutes im Kreislauf eines gesunden Hundes deuten klar auf einen intrakorpuskulären Defekt hin (Tasker et al. 1969).

Die Messung der PK-Aktivität erfolgt nach einer Methode (Tanaka et al. 1962), bei der in vitro die umgesetzte Menge an Phosphoenolpyruvat zu Pyruvat anhand einer durch Folgereaktionen verursachten Absorptionsänderung bestimmt wird. Eine Stunde nach der ersten Messung beträgt die PK-Aktivität bei homozygot betroffenen Basenjis nur noch durchschnittlich $40 \%$ bis ein Drittel des ursprünglichen Wertes, während bei gesunden und heterozygoten Hunden noch über zwei Drittel bis durchschnittlich $80 \%$ bzw. $75 \%$ der ursprünglichen Aktivität messbar sind. Eine eindeutige Unterscheidung zwischen heterozygoten und homozygot gesunden Hunden ist allein auf Basis der PKAktivitätsmessung nicht möglich. Zwar liegt die PK Aktivität bei heterozygoten Hunden etwa bei der Hälfte der Normwerte. Es ist allerdings keine klare Abgrenzung zum normalen Wertebereich möglich (Standerfer et al. 1974; Giger und Noble 1991; Whitney und Lothrop 1995). Die bei mutierten Hunden vorhandene erythrozytäre PK hat offenbar eine stark reduzierte Stabilität. Die Aktivität des Enzyms ist nicht beeinträchtigt. Die zu Beginn der Erkrankung überhöhten PK-Aktivitätswerte bei 
betroffenen Basenjis lassen sich durch die ständige Neubildung von Erythrozyten aufgrund der überhöhten Hämolyse erklären, da in jungen Erythrozyten und in Retikulozyten die Aktivität glykolytischer Enzyme generell höher ist als in älteren Blutzellen (Standerfer et al. 1974; Giger und Noble 1991). Eine weitere Erklärung von hohen PK-Aktivitäten bei betroffenen Basenjis hängt damit zusammen, dass sich die Aktivität der mutierten erythrozytären PK im Gegensatz zu normaler PK nicht durch Antikörper hemmen lässt, die gegen den in normalen Erythrozyten vorliegenden R-Typ der Pyruvatkinase gerichtet sind (Giger und Noble 1991). Insgesamt sind 4 verschiedene PK Typen bekannt. Der $\mathrm{M}_{1}$-Typ ist ausschließlich in der gestreiften Muskulatur und im Hirn zu finden, der $\mathrm{M}_{2}$-Typ ist im fetalen Gewebe vorherrschend und im erwachsenen Gewebe weit verbreitet, unter anderem in der Milz, in Lymphozyten, Thrombozyten und erythroiden Vorläuferzellen während des Proerythroblastenstadiums. Der L-Typ ist auf Hepatozyten und der R-Typ auf Erythrozyten beschränkt. Per Zelluloseacetat-Elektrophorese lassen sich $\mathrm{R}$ - und $\mathrm{M}_{2}$ Pyruvatkinase-Typen im caninen Blut unterscheiden. Erythrozyten von erkrankten Basenji Hunden enthalten statt des R-Typs nur den $\mathrm{M}_{2}$-Typ, der in normalen reifen Erythrozyten überhaupt nicht vorkommt. Die Expression des $\mathrm{M}_{2}$-Typs erklärt die hohe in vitro PK-Aktivität. In vivo kompensiert der $\mathrm{M}_{2}$-Typ jedoch den Mangel an Pyruvatkinase R-Typ absolut nicht, wie erhöhte Werte von glykolytischen Stoffwechselprodukten zeigen, die der Pyruvatkinase im Embden-Meyerhof-Zyklus vorgeschaltet sind. In den Erythrozyten heterozygoter Basenjis wird der $\mathrm{M}_{2}$-Typ nicht exprimiert (Giger und Noble 1991).

Pyruvatkinase (PK) katalysiert den letzten energieliefernden Schritt im EmbdenMeyerhof-Zyklus, die Umwandlung von Phosphoenolpyruvat zu Pyruvat. Ein gestörter Ablauf dieses Zyklus hat gerade in reifen Erythrozyten, die ihren Energiebedarf ausschließlich über anaerobe Glykolyse bestreiten und nicht auf den Citratzyklus ausweichen können, schwerwiegende Folgen. Es kommt zu vorzeitiger Zellalterung und Hämolyse (Yunis 1969).

\section{Genetischer Hintergrund}

Untersuchungen an humaner DNA und an Ratten-DNA zeigen, dass für die Codierung der vier PK-Typen zwei Gene verantwortlich sind, von denen eins die M-Typen und das andere den L- und den R-Typ codiert. Die Unterschiede zwischen den beiden M-Typen 
kommen durch gewebsspezifische Spleißereignisse zustande und sind auf ein Exon beschränkt (Noguchi et al. 1986).

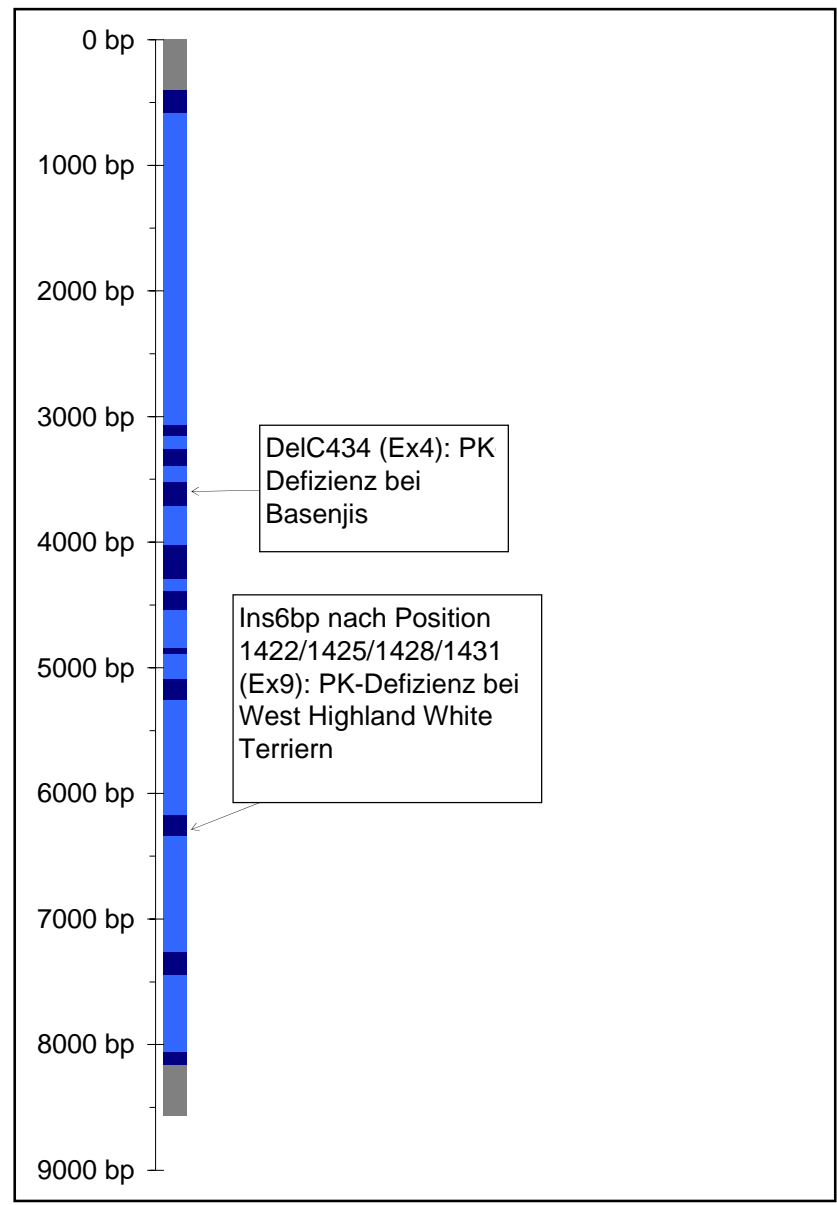

Abb. 64 Schematische Darstellung des caninen PKLR-Gens und Lage der bisher identifizierten Mutationen. Dunkelblau: codierende Sequenz, hellblau: Intronsequenz, grau: intergenischer Sequenzbereich.

Das für den L- und der R-Typ codierende Gen, oft bezeichnet als PKLR-Gen, ist auf Chromosom 7 lokalisiert (NCBI-GeneID: 490425) und erstreckt sich im genomischen Contig NW_876323 von Position 40356359 bis 40364802 . Je nach Gewebe werden die zwei verschiedenen Typen von unterschiedlichen Promotern aus transkribiert. Die beiden mRNAs weichen lediglich in Exon 1 voneinander ab (Noguchi et al. 1987). Die canine R-Typ cDNA-Sequenz (NCBI-GenBank: S71529) hat eine Länge von 1889 bp (Whitney et al. 1994). Die R-Typ-mRNA (NCBI-GenBank: XM_547547) hat eine Länge von 1725 Nukleotiden und ist aus elf Exons zusammengesetzt. Abb. 64 stellt die Lage der einzelnen Exons in der genomischen Sequenz dar. 


\section{III.a Ursächliche Mutation für PK-Defizienz bei Basenjis}

Bei betroffenen Basenji Hunden liegt an Position 434 in Exon 5 die Deletion eines Cytosins vor. Die Deletion führt zu einer Verschiebung des Leserasters und nach 65 Nukleotiden zur Entstehung eines verfrühten Stoppcodons (Whitney et al. 1994). Das resultierende Protein ist offenbar so instabil, dass das R-Typ-Enzym auf Basis immunologischer Untersuchungen in den Erythrozyten PK-defizienter Basenji Hunde nicht nachweisbar ist. Im NCBI-Modell des caninen PKLR-Gens liegt offenbar eine andere Lokalisierung und Unterteilung der mRNA-Sequenz in einzelne Exons zugrunde. In diesem Modell ist die Mutation in Exon 4 lokalisiert (Abb. 65).

\section{IV.a Genotypisierung für PK-Defizienz bei Basenjis}

Eine mögliche Methode zur Genotypisierung ist die Amplifikation eines 228-bpFragments bzw. bei Vorliegen der Deletion eines 227-bp-Fragments, das beginnend im Intron 3 das gesamte Exon 5 und 65 Basen des Introns 4 einschließt, und eine anschließende RFLP-Typisierung. Der RFLP beruht auf einer Restriktionserkennungssequenz für AciI im Wildtypallel, die aufgrund der Mutation im Defektallel fehlt (Whitney et al. 1994).

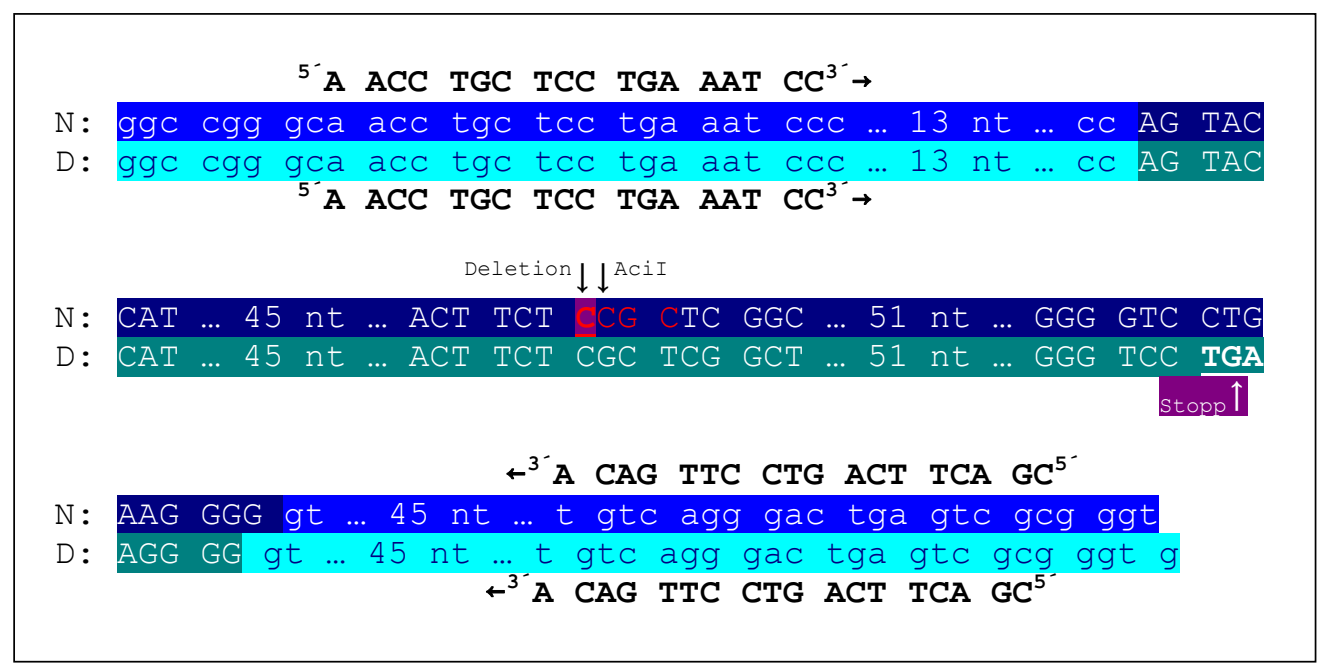

Abb. 65 Exon 4 des PKLR-Gens und angrenzende Intronsequenzen. N: normale Sequenz, D: defekte Sequenz, hellblau: Intron normale Sequenz, türkis: Intron defekte Sequenz, dunkelblau: Exon normale Sequenz, dunkelgrün: Exon defekte Sequenz, rote Schrift: AciI Erkennungssequenz, AciI Schnittstelle in normaler Sequenz durch Pfeil markiert, von Deletion betroffene Base (C) fett gedruckt, unterstrichen und durch Pfeil markiert, verfrühtes Stoppcodon in defekter Sequenz unterstrichen und fett gedruckt.

Auf Basis dieser Untersuchung konnten 24 Basenji Hunde, deren Genotyp aufgrund von Pedigreeanalysen bekannt war, eindeutig einzelnen Genotypen zugeordnet werden. Damit ist der molekulargenetische Test der Kombination aus parallel durchgeführten 
Untersuchungen der Hämatokritwerte, der Retikulozytenzahl und der erythrozytären PK Aktivität klar überlegen, die bei drei der 24 untersuchten Hunde keine klare Unterscheidung zwischen Defektträger- und Normalstatus ermöglichte (Whitney und Lothrop 1995).

\section{III.b Ursächliche Mutation für PK-Defizienz bei West Highland White Terriern}

Bei West Highland White Terriern mit erythrozytärer Pyruvatkinase-Defizienz liegt eine 6-bp-Insertion am 3' -Ende von Exon 9 vor (Skelly et al. 1999a).

Die Identifizierung dieser Mutation erfolgte anhand von Sequenzvergleichen der PKLR cDNA von einem phänotypisch gesunden West Highland White Terrier (WHWT) und drei betroffenen Wurfgeschwistern, zwölf weiteren WHWT aus dem selben Zwinger, vier gesunden nicht verwandten WHWT-Kontrollhunden, zwei PK-defizienten Basenjis, zwei PK-defizienten Beagles und vier phänotypisch gesunden Englischen Springer Spaniels.

In der normalen Sequenz flankieren zwischen Position 1422 und 1432 der mRNA zwei AAG-Triplets und ein ACC-Triplet. Bei PK-defizienten West Highland White Terriern findet sich in diesem Bereich eine von vier Insertionsvarianten. Entweder findet eine Insertion der Nukleotide „ACC AAG“ zwischen Position 1422 und 1423 oder 1425 und 1426 statt oder eine Insertion der Nukleotide „AAG ACC“ zwischen den Positionen 1428 und 1429 oder 1431 und 1432 (Abb. 66).

Exon 9 spielt eine Rolle für die Bildung der C-Domäne der Pyruvatkinase (Muirhead et al. 1986), ist durch Interaktion mit verschiedenen allosterischen Aktivatoren an der Steuerung der Aktivität der $\mathrm{M}_{2-}$, L- und R-Isoenzyme beteiligt (Imamura und Tanaka 1972) und nimmt eine Schlüsselstellung in der Interaktion zwischen C- und A-Domäne ein. Die korrekte räumliche Anordnung der C- und A-Domänen ist kritisch für die anschließende Aktivierung des reifen tetrameren Enzyms (van Solinge et al. 1997). Es ist also höchstwahrscheinlich, dass eine Insertion in diesem Bereich erhebliche Funktionsstörungen des Enzyms verursacht. 


\section{IV.b Genotypisierung für PK-Defizienz bei West Highland White Terriern}

Ein Nachweis der Mutation lässt sich beispielsweise über die Amplifikation des von der Insertion betroffenen Sequenzbereichs und anschließende PCR-Fragmentgrößenanalyse führen (Skelly et al. 1999a).

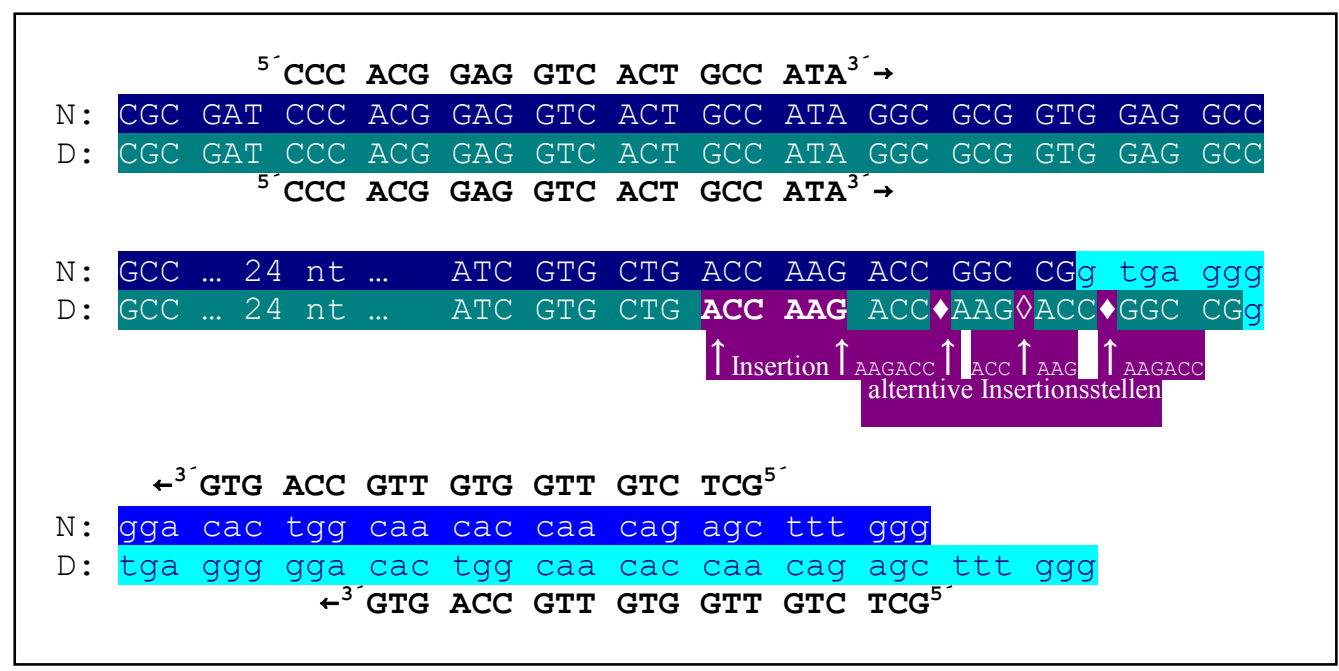

Abb. 66 3'Ende des Exons 9 und angrenzende Intronsequenz. N: normale Sequenz, D: defekte Sequenz, dunkelblau: Exon normale Sequenz, dunkelgrün: Exon defekte Sequenz, hellblau: Intron normale Sequenz, türkis: Intron defekte Sequenz, Insertion violett unterlegt und fett gedruckt, alternative Insertionen durch $\nabla$ für AAG ACC und $\nabla$ für ACC AAG und beschriftete Pfeile gekennzeichnet.

\subsubsection{Phosphofruktokinase-Defizienz}

\begin{tabular}{|ll|}
\hline Chromosom: & CFA27 \\
Gen: & PFK \\
Ensembl: & GeneID: ENSCAFG00000009035 \\
DNA-Sequenz: & CFA27, Position 9631859-9674173 \\
Mutationen: & G2228A, Endlischer Springer Spaniel \\
\hline
\end{tabular}

\section{Krankheitsbild}

Die canine Phosphofruktokinase (PFK)-Defizienz wurde erstmals 1985 bei Englischen Springer Spaniels beschrieben (Giger et al. 1985), eine weitere betroffene Rasse sind Amerikanische Cocker Spaniels (Giger et al. 1992). Der ursächliche Gendefekt ist bisher nur in der Rasse Englische Springer Spaniels bekannt. Bei einer Genotypisierung von fast 600 Hunden unter Einsatz eines DNA-Tests wurden $14 \%$ heterozygote Defektträger und $6 \%$ homozygot betroffene Hunde identifiziert. Die Untersuchung zufällig ausgewählter Zuchtschausieger ergab $4 \%$ heterozygote und $1 \%$ homozygote Defektträger (Giger et al. 2000 zitiert bei Skibild et al. 2001). 
Die Erkrankung äußert sich vor allem in Pigementurie und chronischer kompensierter hämolytischer Anämie. Nach Anstrengung oder Aufregung kommt es zu einer hämolytischen Krise, häufig in Verbindung mit Fieber, Appetitlosigkeit und Lethargie. Bei der physischen Untersuchung tritt ein leichter bis moderater Muskelschwund im Vergleich zu gesunden Familienmitgliedern zu Tage (Giger et al. 1985; Giger et al. 1986).

Weitere klinische Untersuchungen ergeben eine auf 8-20\% abgesenkte PFK-Aktivität im Serum (Giger et al. 1985; Giger et al. 1986) und eine auf $6 \%$ abgesenkte PFKAktivität im Muskel (Vora et al. 1985). Eingehendere Untersuchungen zeigen eine totale Defizienz von Muskeltyp PFK (Vora et al. 1985). Weitere Auffälligkeiten sind Makrozytose, Retikulozytose, eine variable Anzahl kernhaltiger roter Blutzellen, eine andauernde deutliche Bilirubinurie und zwischenzeitliche Hämoglobinurie, eine leicht erhöhte Kreatinphosphokinase- und Glukose-6-Phosphatdehydrogenase-Aktivität und eine abgesenkte 2,3-Diphosphoglycerat (DPG)-Konzentration. Die niedrige DPGKonzentration bedingt einen erhöhten Chlorid-Gehalt und dementsprechend eine hohe Hydroxylkonzentration der Erythrozyten. Dieser pH-Wert Anstieg in den Erythrozyten führt zu einer Verstärkung der ohnehin hohen Hämolyse-Empfindlichkeit caniner Erythrozyten im alkalischen Milieu (Giger et al. 1985; Giger et al. 1986).

Die Phosphofruktokinase in caninen Erythrozyten besteht zu ca. $83 \%$ aus Muskeltyp Phosphofruktokinase, den übrigen Anteil stellt Thrombozytentyp-PFK (Vora et al. 1985). Dementsprechend schwerwiegend wirkt sich der Defekt bei caniner PFK Defizienz auf die Erythrozyten aus.

\section{Genetischer Hintergrund}

Der Erbgang verläuft autosomal rezessiv. Heterozygote Defektträger sind anhand ihrer abgesenkten PFK-Aktivität identifizierbar, die bei etwa 38-51 \% des Normalwertes liegt (Giger et al. 1986). 


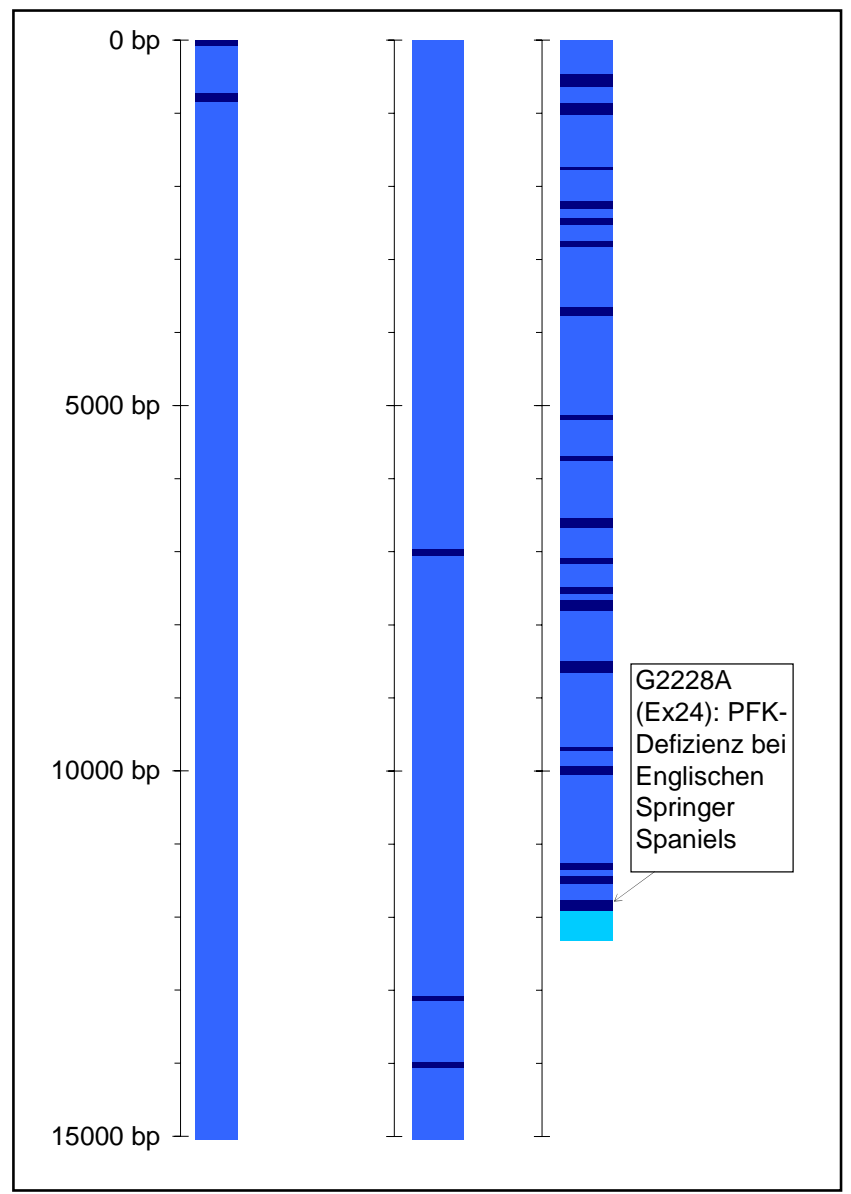

Abb. 67 Schematische Darstellung des caninen Phosphofruktokinase-Gens und Lage der bisher identifizierten Mutationen. Dunkelblau: codierende Sequenz, hellblau: Intronsequenz, türkis: 3'-UTR.

Die Sequenz der caninen Muskeltyp-PFK-cDNA ist seit 1996 bekannt (Smith et al. 1996a). Das PFK-Gen (Ensembl-GeneID: ENSCAFG00000009035) ist auf Chromosom 27 zwischen Position 9631859 und 9674173 lokalisiert und umfasst 24 Exons. Die Länge des Transkriptes beträgt 2960 Nukleotide. Abb. 67 zeigt die Lage der einzelnen Exons innerhalb der genomischen Sequenz.

\section{Ursächliche Mutation der PFK-Defizienz bei Englischen Springer Spaniels}

Der für die PFK-Defizienz bei Englischen Springer Spaniels verantwortliche Gendefekt besteht in einem Basenaustausch von Guanin durch Adenin an Position 2228 der codierenden Sequenz in Exon 24 und bedingt eine Umwandlung des Tryptophan Codons (TGG) zu einem Stoppcodon (TAG) und damit eine frühzeitige Terminierung der Translation 40 Aminosäuren vor dem normalen Stoppcodon (Abb. 68) (Smith et al. 1996b). 


\section{Genotypisierung für PFK-Defizienz bei Englischen Springer Spaniels}

Der Nachweis der Mutation kann per Amplifikation des betroffenen DNA-Abschnitts unter Verwendung eines mismatch-Primers, der im Wildtypallel eine BanIRestriktionsschnittstelle einführt, und anschließende RFLP-Typisierung erfolgen (Smith et al. 1996b).

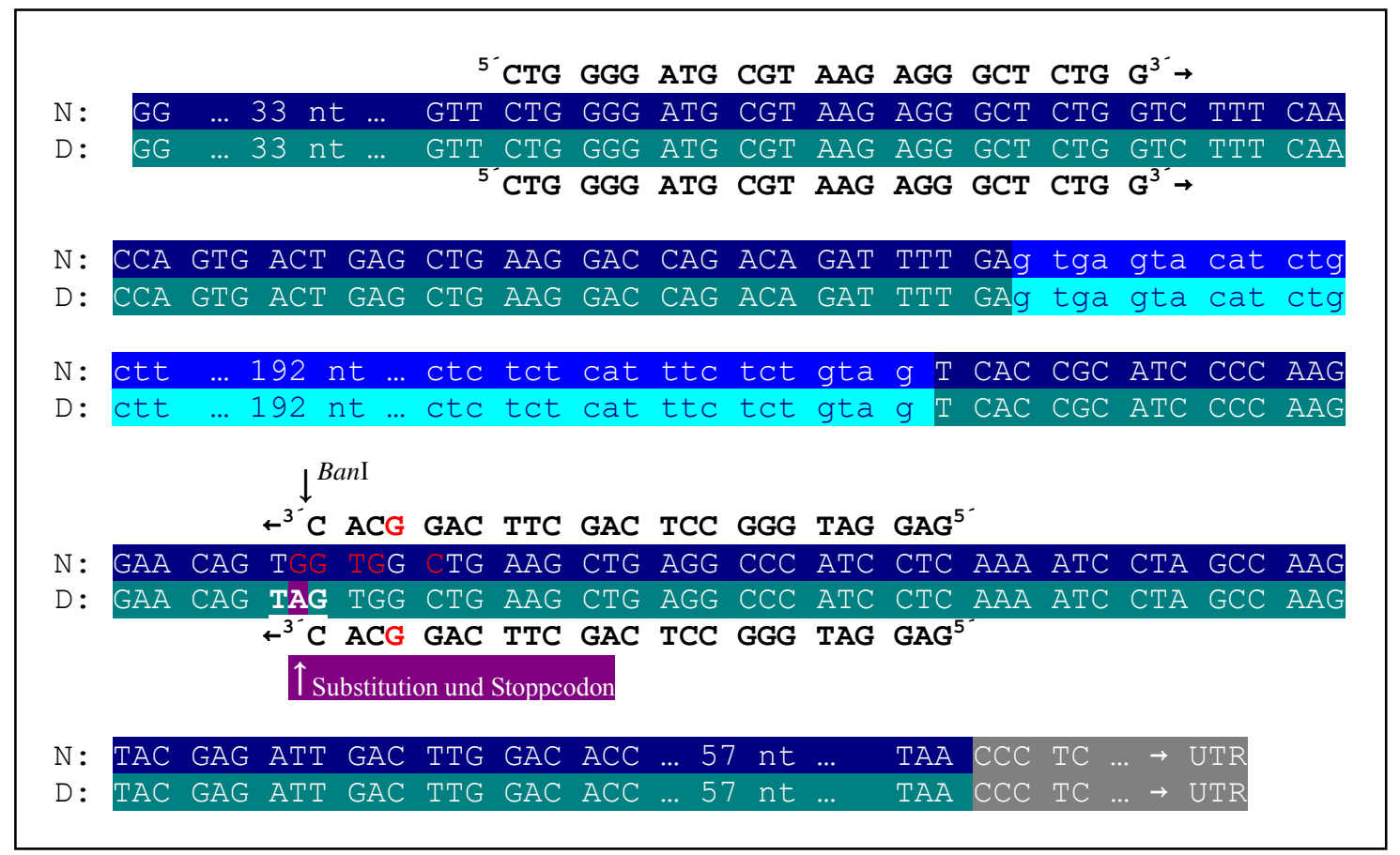

Abb. 68 Exon 23-24 des caninen Muskeltyp PFK-Gens. N: normale Sequenz, D: defekte Sequenz, dunkelblau: Exon normale Sequenz, dunkelgrün: Exon defekte Sequenz, hellblau: Intron normale Sequenz, türkis: Intron defekte Sequenz, grau unterlegt: 3'-UTR, Substitution und Stoppcodon in defekter Sequenz violett markiert und durch Pfeil bezeichnet, BanI-Schnittstelle in normaler Sequenz durch Pfeil bezeichnet, rote Schrift: BanI-Erkennungssequenz.

\subsubsection{Pyruvatdehydrogenase-Defizienz}

\begin{tabular}{ll}
\hline Chromosom: & CFA29 \\
Gen: & PDP1 (PPM2C, Proteinphosphatase 2C, \\
& magnesiumabhängig, kataytische Untereinheit) \\
NCBI: & GeneID: 477941 \\
DNA-Sequenz: & NW_876288, Position 38771840-38773520 \\
Mutationen: & C821T, Clumber Spaniel, Sussex Spaniel \\
\hline
\end{tabular}

\section{Krankheitsbild}

Charakteristisches klinisches Merkmal der autosomal rezessiv vererbten caninen Pyruvatdehydrogenase-Defizienz ist ein deutlich ausgeprägter Konditionsmangel. Beschrieben ist diese Erkrankung bisher in den Rassen Clumber und Sussex Spaniel (Houlton und Herrtage 1980; Shelton et al. 2000; Abramson et al. 2004). Bei der 
Genotypisierung von insgesamt 233 Clumber und elf Sussex Spaniels konnte das mutierte Allel homozygot bei einem Clumber Spaniel und heterozygot bei 61 Clumber und sieben Sussex Spaniels nachgewiesen werden. Dieser auffällige Überhang von heterozygoten gegenüber homozygoten Defektträgern wird mit unterschiedlichen Fähigkeiten betroffener Hunde zur Kompensation des krankheitsbedingten Energiemangels erklärt. Erwachsene betroffene Hunde zeigen unterschiedlich schwerwiegende Beeinträchtigungen, die teilweise im Alter von drei Jahren zum Tod führen, während andere Hunde ein Alter von sechs Jahren oder mehr erreichen. Das unterschiedliche Alter bei Auftreten erster klinischer Anzeichen spricht ebenfalls für das Vorliegen variabler Kompensationsfähigkeiten bei einzelnen betroffenen Hunden. Vor diesem Hintergrund wird es als wahrscheinlich angesehen, dass die erhöhte Anzahl von Totgeburten und perinatalem Verenden bei Nachkommen von heterozygoten Hündinnen durch die PDP1-Defizienz verursacht wird, so dass ein großer Anteil von homozygoten Defektträgern möglicherweise nicht diagnostiziert wird (Cameron et al. 2007).

Erste Anzeichen treten im Alter von drei Monaten bis ca. ein Jahr in Form von starker Erschöpfung bis hin zu Zusammenbrüchen bei geringsten körperlichen Belastungen auf. Je länger die körperliche Belastung andauert, desto häufiger finden episodische Zusammenbrüche statt und desto mehr Zeit benötigt der Hund, um sich zu erholen. Bis $\mathrm{zu}$ einem Alter von ca. einem Jahr bleiben physische und neurologische Untersuchungen ohne nennenswerte Befunde. Auch die histologische Untersuchung von Muskelbiopsien ergibt keinerlei Auffälligkeiten. Biochemische Untersuchungen an Muskelbiopsien zeigen eine deutlich herabgesetzte Konzentration von Carnitin, während im Urin erhöhte Mengen von Carnitin ausgeschieden werden. Serumuntersuchungen vor einem zehnminütigen Lauf sowie direkt danach und $10 \mathrm{~min}$ nach Beendigung des Laufs ergeben zu allen drei Zeitpunkten erhöhte Pyruvat- und Laktatkonzentrationen. Auch im Urin sind erhöhte Pyruvatwerte feststellbar. Ab einem Alter von zwei Jahren können neurologische Anomalien auftreten. Propriozeptive Reaktionen und Lidreflexe sind reduziert, und es kann zum Schielen kommen. Diese Befunde werden als Folge einer multifokalen Hirnschädigung als Folge der durch biochemische Befunde belegten Stoffwechselstörung interpretiert. Die Pyruvat- und Laktatkonzentrationen im Serum sind unverändert erhöht. Gasuntersuchungen des venösen Blutes im Anschluss an körperliche Belastung deuten auf das Vorliegen einer 
metabolischen Acidose in Verbindung mit einer respiratorischen Kompensation hin. (Abramson et al. 2004). Die Erkrankung führt zum Teil zu frühen Todesfällen aufgrund einer hypertrophischen Herzmuskelerkrankung. Bei betroffenen Hündinnen kommt es zu einer auffallend hohen Zahl von Totgeburten und schwachen Welpen, die wenige Tage nach der Geburt verenden. Pedigreeanalysen sprechen für das Vorliegen einer autosomal rezessiv vererbten Erkrankung (Cameron et al. 2007).

Die erhöhte Pyruvatkonzentration im Serum lässt auf das Vorliegen einer gestörten Funktion des Pyruvatdehydrogenasekomplexes schließen, der an der Umsetzung von Pyruvat zu Acetylcoenzym A beteiligt ist. Diese Vermutung bestätigt sich durch Enzymaktivitätsstudien (Cameron et al. 2007).

Die Aktivität des Pyruvatdehydrogenasekomplexes ist abhängig vom Phosphorylierungszustand der Untereinheit E1 $\alpha$. Bei geringem Energiebedarf und bei einer erhöhten Fettsäureoxidation ist die Untereinheit E1 $\alpha$ phosphoryliert und der Phosphodehydrogenasekomplex inaktiv (Yeaman et al. 1978; Gudi et al. 1995; Rowles et al. 1996). Steigt der Energiebedarf, wird die Untereinheit E1 $\alpha$ durch eine von zwei Pyruvatdehydrogenasephosphatasen (PDP1 und PDP2) dephosphoryliert und der Enzymkomplex ist aktiviert (Huang et al. 1998).

\section{Genetischer Hintergrund}

Aufgrund der biochemischen Befunde kommen als Kandidatengene unter anderem das Ea1-Gen sowie die für PDP1 und PDP2 codierenden Gene in Frage. Bei der Analyse der E1 $\alpha$-Sequenz betroffener und gesunder Hunde konnten keine Mutationen gefunden werden. Ähnlichkeiten des Phänotyps der caninen Erkrankung zu einer humanen Laktatacidose, die auf eine Mutation im PDP1-Gen zurückzuführen ist (Maj et al. 2005), führen zu der Einschätzung, dass PDP1 ein stärkeres Kandidatengen ist als PDP2.

Das canine PDP1-Gen (auch bezeichnet als PPM2C, Proteinphosphatase 2C, magnesiumabhängig, katalytische Untereinheit) ist im genomischen Contig NW_876288 auf Chromosom 29 lokalisiert und enthält wie das homologe humane Gen nur ein Exon, dessen offenes Leseraster auf dem revers komplementären Strang von 
Nukleotid 38771840 bis 38773520 reicht (NCBI-GeneID: 477941). Das resultierende Protein hat eine Länge von 538 Aminosäuren (Cameron et al. 2007).

\section{Ursächliche Mutation für Pyruvatdehydrogenase-Defizienz bei Clumber und Sussex Spaniels}

Eine Sequenzanalyse zeigte bei betroffenen Clumber und Sussex Spaniels eine Substitution von Cytosin durch Thymin in Codon 252, die zu einer Substitution von Glutamin durch ein verfrühtes Stoppcodons führt (Abb. 69).

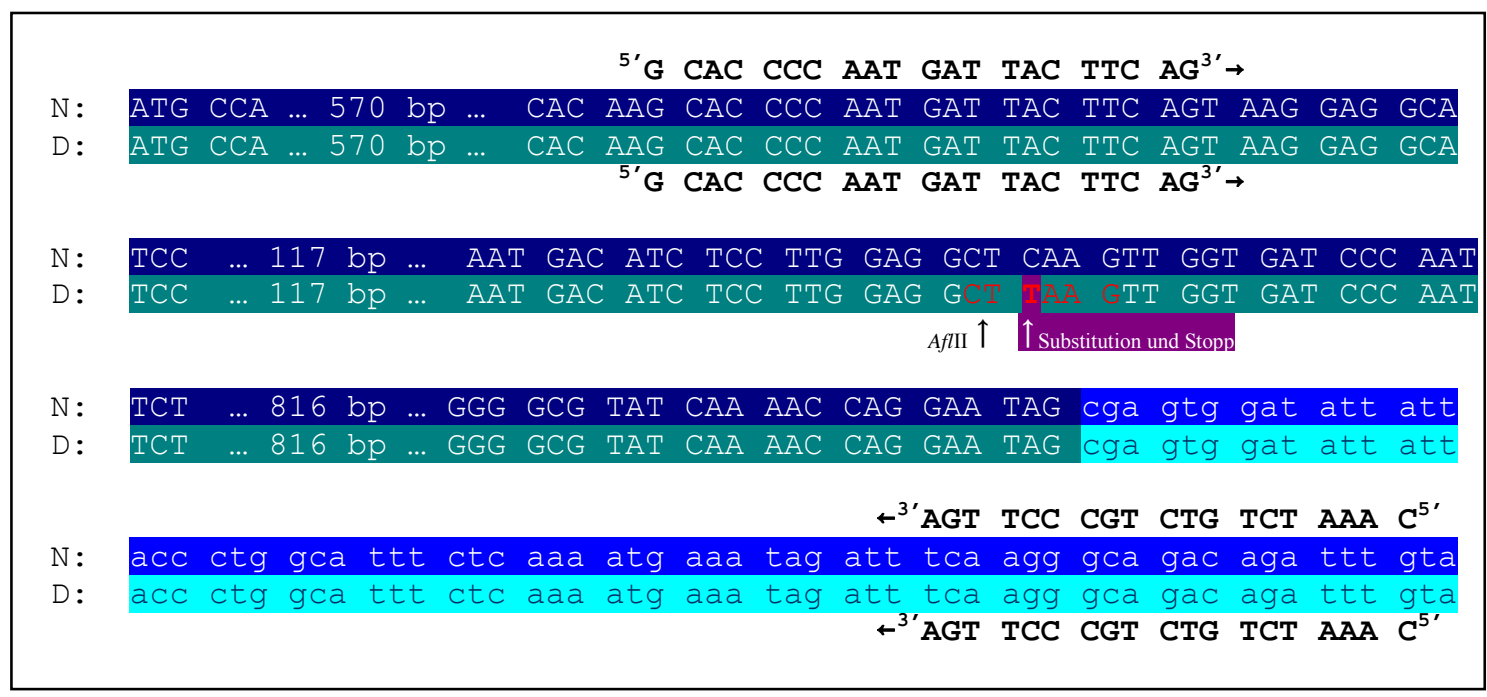

Abb. 69 Exon 1 des caninen PDP1-Gens und angrenzende Sequenz. N: normale Sequenz, D: defekte Sequenz, dunkelblau: Exon normale Sequenz, dunkelgrün: Exon defekte Sequenz, hellblau: Intron normale Sequenz, türkis: Intron defekte Sequenz, Substitution in defekter Sequenz violett unterlegt und durch Pfeil gekennzeichnet, verfrühtes Stoppcodon durch Pfeil gekennzeichnet, rote Schrift: AflIIErkennungssequenz, AflII-Restriktionsschnittstelle durch Pfeil gekennzeichnet.

Immunologische Untersuchungen von Mitochondrien betroffener Hunde zeigen einen vollständigen Verlust von PDP1-Protein ohne Anzeichen für einen Proteinabbau. Die Quantifizierung der Expression von PDP1-mRNA ergibt bei betroffenen Hunden bezogen auf die bei normalen Hunden detektierte PDP1-mRNA eine Expression von $80 \%$.

Der ursächliche Zusammenhang zwischen dem Mangel an PDP1 und der reduzierten Aktivität des Pyruvatdehydrogenasekomplexes wird durch zytologische Untersuchungen belegt. In Fibroblastenzellen betroffener Hunde lässt sich die Aktivität des Pyruvatdehydrogenasekomplexes durch Gabe von humanem PDP1 von 10-25 \% auf $50 \%$ der bei normalen Kontrollhunden gemessenen Aktivität anheben (Cameron et al. 2007). 


\section{Genotypisierung für Pyruvatdehydrogenase-Defizienz bei Clumber und Sussex Spaniels}

Der Nachweis der Mutation kann mittels Amplifikation eines 1097-bp-Fragments und anschließender RFLP-Typisierung erfolgen. Der zugrunde liegende RFLP beruht auf einer Restriktionserkennungssequenz für AfIII, die aufgrund der Mutation im Defektallel enthalten ist und im Wildtypallel fehlt (Cameron et al. 2007).

\subsubsection{Glukose-6-Phosphatase-Defizienz}

\begin{tabular}{|ll|}
\hline Chromosom: & CFA9 \\
Gen: & G6PC \\
NCBI: & GeneID: 403492 \\
DNA-Sequenz: & NW_876332, Position 1945477-1956141 \\
Mutationen: & G450C, Malteser \\
\hline
\end{tabular}

\section{Krankheitsbild}

Die Glukose-6-Phosphatase-Defizienz hat von allen Glykogenspeicherdefekten den schwerwiegendsten Verlauf. Betroffene Hunde sterben bereits im Alter von 35 bis 47 Lebenstagen. Bisher ist diese Erkrankung nur bei drei männlichen MalteserWurfgeschwistern beschrieben worden (Brix et al. 1995). Dieser Wurf scheint jedoch kein Einzelfall $\mathrm{zu}$ sein, da in der Zuchtlinie dieses Wurfes weitere Todesfälle von Welpen vor oder um das Absetzen herum beobachtet wurden, die jedoch keiner klinischen Untersuchung unterzogen wurden.

Bei den untersuchten Welpen wurden als auffälligste Symptome ein fortschreitender Wachstumsdefizit und im weiteren Verlauf eine deutliche mentale Depression, die Unfähigkeit zu Saugen und eine starke Verschlechterung des körperlichen Gesamtzustandes beobachtet. Alle drei Hunde wiesen deutliche Veränderungen der äußeren Erscheinung sowie des Gewebes von Niere, Leber, Milz, Lunge, Schilddrüse und Hirn auf. Dazu zählten eine akute tubuläre Nephrose, auffällig blasse Nieren, eine Mineralisierung der Tubuli, vor allem im Nierenbecken, zahlreiche teilweise von vakuolisierten Epithelzellen umgebene erweiterte und zystische Tubuli im kortikalen Bereich, eine interstitielle Fibrose in Verbindung mit mineralisierten Bereichen. Die Lebern waren vergrößert, blass und bröckelig, ohne erkennbare Struktur, wobei durch diffuse Vakuolisierungen und stark Schwellungen der Leberzellen und dadurch eine Kompression der Sinusoide verursachen. Auffälligkeiten der Milzen umfassten eine 
fleischige Struktur, Schwellungen und Anzeichen von extramedullarer Hämatopoese. Die Lungen zeigten eine splittartige Struktur mit mittelschwer bis schwerer multifokaler bis verschmelzender Mineralisierung der alveolaren Septen. Die Follikel der Schilddrüse waren klein, von Zylinderepithel umgeben und frei von Kolloid. Außerdem wiesen die Welpen leichte Anzeichen eines Wasserkopfes mit erweiterten lateralen Ventrikeln auf. Die Autoren weisen in diesem Zusammenhang darauf hin, dass die Wasserkopfbildung eine typische Erscheinung bei Malteserhunden ist und daher nicht als Folge des Glukose-6-Phosphatase-Mangels zu sehen ist. Sowohl in der Leber als auch in der Niere der betroffenen Welpen ist der Glukose-6-Phosphatase-Gehalt auf unter $10 \%$ des Normwertes reduziert, während sich die Konzentration weiterer glykogenolytischer Enzyme (4- $\alpha$-D-Glukanotransferase, Amylo- $\alpha-1,6-G l u k o s i d a s e$, Phosphorylase und Phosphorylase Kinase) in der Leber nicht von der bei Kontrollhunden gemessenen Konzentration unterscheidet. Die Leber betroffener Welpen weist erhöhte Glykogengehalte auf (Brix et al. 1995). Untersuchungen an sechs Glukose-6-Phosphatase-defizienten Malteser-Beagle-Welpen aus einer Zuchtkolonie ergaben sowohl hinsichtlich der pathologischen als auch der Enzym- und Glykogenanalyse übereinstimmende Ergebnisse (Kishnani et al. 2001).

Diese Beobachtungen deuten darauf hin, dass die Vakuolisierungen der Leberzellen und des Nierenepithels sowie die blasse Färbung dieser Organe durch Glykogenablagerungen verursacht werden und eine Unfähigkeit zur Nutzung von Glykogen als Glukosequelle vorliegt. Die Mineralisierungen in Niere und Lunge werden als mögliche Folgen einer Hypercalciurie gedeutet, wie sie bei humanen Glukose-6-Phosphatase-defizienten Patienten auftritt. Insgesamt entsprechen die Symptome bis auf geringe Abweichungen den Erscheinungen bei humanen Patienten mit der Glykogenspeicherkrankheit Ia (von Gierke's disease).

\section{Genetischer Hintergrund}

Unter Verwendung einer humanen Glukose-6-Phosphatase-Sonde ergaben sich bei Northern-Blot-Analysen an Leberzellen gesunder Kontrollhunde und Glukose-6Phosphatase-defizienter Hunde jeweils RNA-Banden von ca. 2,4 kb Länge. Die mRNABanden betroffener Hunde wiesen im Vergleich zu gesunden Kontrollhunden eine deutlich höhere Intensität auf. In weiterführenden Untersuchungen konnte eine cDNA von 2346 bp Länge generiert werden. Innerhalb dieser cDNA reicht die codierende 
Sequenz von Position 88 bis 1158. Daraus resultiert ein 357 aminosäuren langes Protein. Das Glukose-6-Phosphatase-Gen umfasst 10174 Nukleotide und ist aus fünf Exons zusammengesetzt (Kishnani et al. 1997). Im genomischen Contig NW_876332 auf Chomosom 9 ist das canine Glukose-6-Phosphatase-Gen (G6PC, glucose-6phosphatase catalytic subunit) zwischen Position 1956141 und 1945477 lokalisiert (NCBI-GeneID: 403492). Abb. 70 zeigt die Lage der einzelnen Exons innerhalb der genomischen Sequenz.

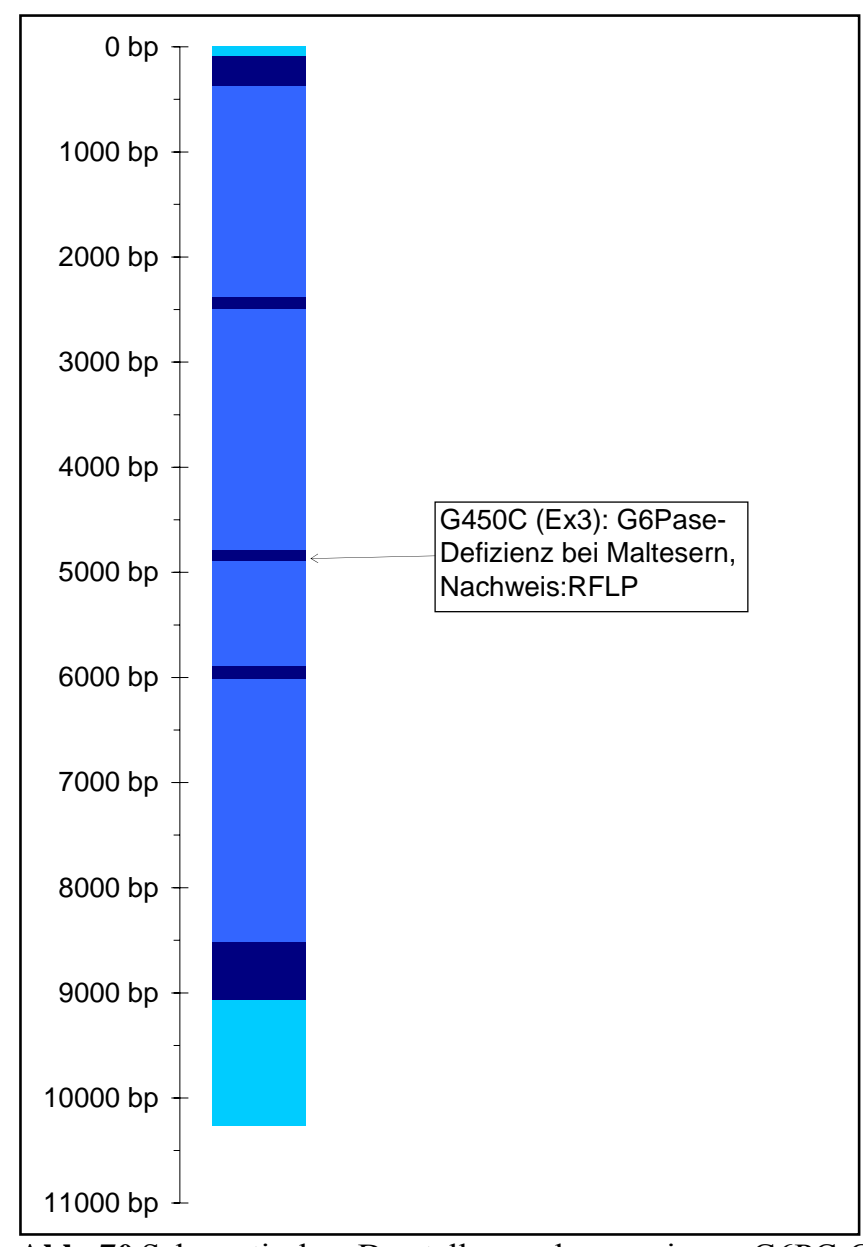

Abb. 70 Schematische Darstellung des caninen G6PC-Gens und Lage der bisher identifizierten Mutationen. Dunkelblau: codierende Sequenz, hellblau: Intronsequenz, türkis: 5'- und 3'-UTR.

Die Authentizität der definierten cDNA wurde über Expressionsstudien an COS-7Zellen (einer Affenzellinie) belegt. Diese Zellen weisen bei Transfektion mit caniner G6PC-Wildtyp-cDNA eine Glukose-6-Phosphatase-Aktivität von $289 \mathrm{nmol} / \mathrm{min} / \mathrm{mg}$ Protein auf, während mock-transfizierte Zellen lediglich eine Glukose-6-PhosphataseAktivität von $8,3 \mathrm{nmol} / \mathrm{min} / \mathrm{mg}$ Protein zeigen. 


\section{Ursächliche Mutation für Glucose-6-Phosphatase-Defizienz bei Maltesern}

Ein Vergleich der G6PC-cDNA-Sequenzen von gesunden Kontrollhunden und betroffenen Welpen zeigen als einzigen Unterschied einen Basenaustausch von Guanin durch Cytosin an Position 450 der cDNA in Exon 3, der im resultierenden Polypeptid zu einer Substitution von Methionin durch Isoleucin an Codon 121 führt (M121I) (siehe Abb. 71).

Eine Transfektion dieser mutierten M121I-cDNA in COS-7-Zellen führt zu einer Glukose-6-Phosphatase-Expression von 26,9 mmol/min/mg Protein (Kishnani et al. 1997). Dieser Wert entspricht etwa dem von Brix et al. (1995) gemessenen Glucose-6Phosphatase-Gehalt in Leberzellen betroffener Welpen von $<10 \%$ des Normwertes. Bei Northern-Blot-Analysen der RNA aus M121I-transfizierten COS-7-Zellen ergibt sich wie in Leberzellen betroffener Welpen ein deutlich erhöhter Glukose-6Phosphatase-mRNA Gehalt im Vergleich zu COS-7-Zellen, die mit normaler cDNA transfiziert wurden. Diese erhöhten Glukose-6-Phosphatase-mRNA-Gehalte bei betroffenen Welpen lassen sich als physiologische Reaktion auf eine Hypoglykämie erklären. Dafür sprechen Untersuchungen an gesunden Hunden, bei denen zwei Fütterungsgruppen gebildet wurden, von denen die eine normal versorgt wurde, die andere einer 48-stündigen Fastenperiode ausgesetzt wurde. In der anschließenden Northern Blot Analyse der Leberzellen-RNA zeigten die normal gefütterten Hunde eine deutlich geringere Glukose-6-Phosphatase-mRNA-Konzentration im Vergleich zu den Hunden, die der Fastenperiode ausgesetzt waren. Daraus lässt sich schließen, dass Hypoglykämie entweder zu einer Steigerung der Transkription von Glukose-6Phosphatase-mRNA führt oder deren Abbaugeschwindigkeit herabsetzt. Neben den Ergebnissen der beschriebenen Transfektionsversuche spricht eine Studie an 100 gesunden Kontrollhunden (50 Malteser Hunde und 50 Mischlingshunde), bei der kein einziger Hund mit der M121I-Mutation gefunden werden konnte, dafür, dass es sich bei dem beschriebenen Basenaustausch um die ursächliche Mutation für Glukose-6Phosphatase-Defizienz bei Malteser Hunden handelt. Vergleiche mit humaner, Rattenund Mäuse-cDNA zeigen, dass die von der Substitution betroffene Aminosäure Methionin 121 über alle vier Spezies konserviert ist. Ferner liegt Methionin 121 nur zwei Aminosäuren von einem hochkonservierten Histidin an Position 119 entfernt, das laut einer Struktur-Funktionsanalyse von humaner Glukose-6-Phosphatase als 
Phosphatrezeptor für die Glukose-6-Phosphatase-Katalyse fungiert (Lei et al. 1995). Dieser Zusammenhang wird als Erklärung für die deutlich reduzierte Glukose-6Phosphatase-Aktivität bei den betroffenen Malteserwelpen gewertet (Kishnani et al. 1997).

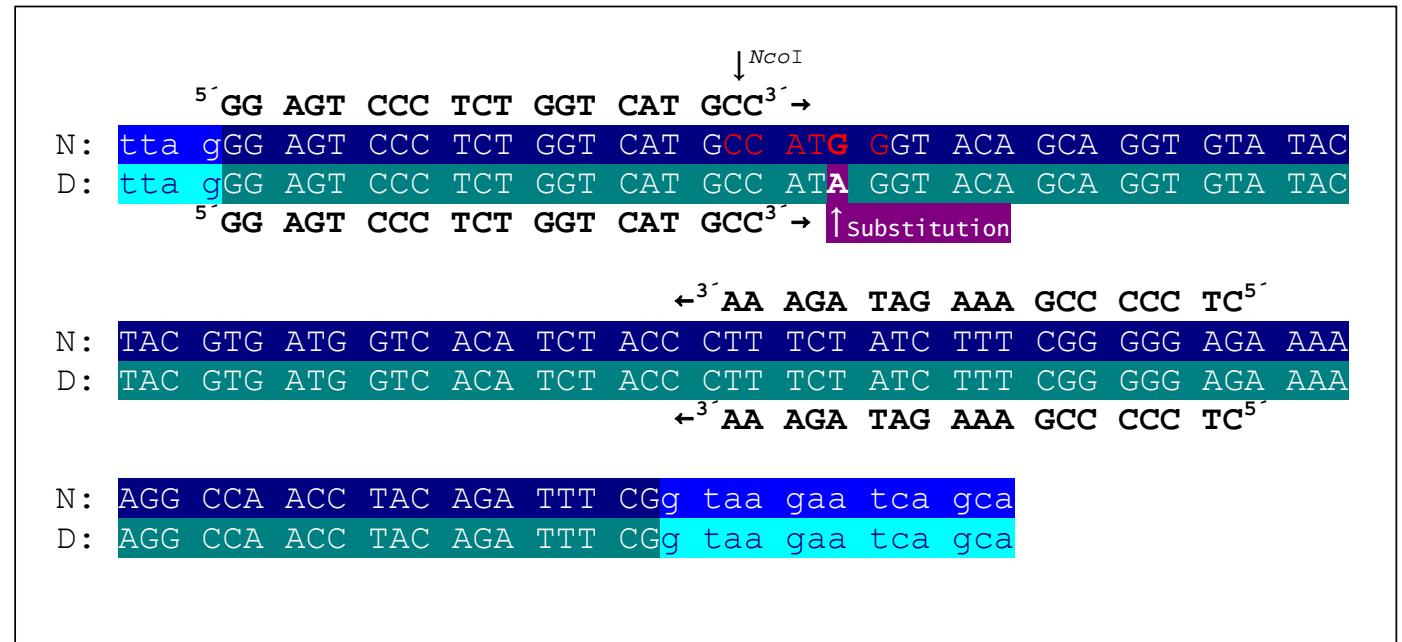

Abb. 71 Exon 3 des caninen G6PC-Gens mit flankierender Intronsequenz. N: normale Sequenz, D: defekte Sequenz, hellblau: Intron normale Sequenz, türkis: Intron defekte Sequenz, dunkelblau: Exon normale Sequenz, dunkelgrün: Exon defekte Sequenz, Substitution in defekter Sequenz violett markiert und durch Pfeil bezeichnet, NcoI-Schnittstelle in normaler Sequenz durch Pfeil bezeichnet, rote Schrift: NcoI-Erkennungssequenz.

\section{Genotypisierung für Glukose-6-Phosphatase-Defizienz bei Maltesern}

Der Nachweis der Mutation kann per Amplifikation eines 83-bp-Fragments aus genomischer DNA und anschließender RFLP-Typisierung erfolgen. Der zugruinde liegende RFLP beruht auf einer Restriktionserkennungssequenz für NcoI im Wildtypallel, die im Defektallel aufgrund der Mutation nicht vorhanden ist (Kishnani et al. 1997). 


\subsubsection{Primerliste}

Tabelle 11 Liste der in Kapitel 3.3 genannten Primer

\begin{tabular}{|c|c|c|c|c|}
\hline Krankheit/Merkmal & Zweck & Primer & $\begin{array}{l}\text { PCR- } \\
\text { Produkt } \\
\text { [bp] }\end{array}$ & Quelle \\
\hline MPS I bei Plotthounds & RFLP & $\begin{array}{l}\mathrm{V}:{ }^{5} \mathrm{CGCTGCGGCCCCTGCGGCCCTTCT}^{3^{\prime}} \\
\mathrm{r:}{ }^{3^{\prime}} \text { TGACTCCGGGCTGTCCGGGCCGGG }\end{array}$ & 87 & $\begin{array}{l}\text { (Menon et al. } \\
\text { 1992) }\end{array}$ \\
\hline \multirow[t]{2}{*}{$\begin{array}{l}\text { MPS VII bei Deutschen } \\
\text { Schäferhunden }\end{array}$} & $\begin{array}{l}\text { Heteroduplex- } \\
\text { analyse }\end{array}$ & $\begin{array}{l}\text { V: }{ }^{{ }^{\prime}} \text { TGAATGGGGTCCATGTGGCA }{ }^{3^{\prime}} \\
\text { r: }{ }^{3^{\prime}} \text { TAGCAGATGTTCTGTCTGCG }\end{array}$ & 172 & $\begin{array}{l}\text { (Ray et al. } \\
\text { 1998a) }\end{array}$ \\
\hline & RsaI-RFLP & $\begin{array}{l}\mathrm{V}:{ }^{5^{\prime}} \text { GGGGTCCATGTGGCAGAGCA }{ }^{3 \prime} \\
\mathrm{r}:{ }^{3^{\prime}} \text { ATGATGGGAACGGTAGTTGTTGTGC }\end{array}$ & 117 & $\begin{array}{l}\text { (Silverstein } \\
\text { Dombrowski } \\
\text { et al. 2004) }\end{array}$ \\
\hline $\begin{array}{l}\text { Fukosidose bei Englischen } \\
\text { Springer Spaniels }\end{array}$ & $\begin{array}{l}\text { PCR-Fragment- } \\
\text { längenanalyse }\end{array}$ & $\begin{array}{l}\text { v: }{ }^{5} \text { GCGAGTGGTTCTGGTGGCAC }{ }^{3} \text { ' } \\
\text { r: }{ }^{3} \text { GTGACCTGCACCGCGTGGAC }{ }^{3}\end{array}$ & $\begin{array}{l}248 \\
262\end{array}$ & $\begin{array}{l}\text { (Skelly et al. } \\
\text { 1999b) }\end{array}$ \\
\hline $\begin{array}{l}\text { Lafora-Krankheit bei } \\
\text { Bassets und } \\
\text { Zwergrauhaardackeln }\end{array}$ & $\begin{array}{l}\text { diagnostische } \\
\text { Sequenzierung }\end{array}$ & $\begin{array}{l}\mathrm{V}:{ }^{5}{ }^{\prime} \text { GCTCGAGTGCAAGGTGTGCT }{ }^{3}{ }^{\prime} \\
\text { r: }{ }^{3} \text { CCCAGTTCTAGAAACTGAGGC }\end{array}$ & 403 & $\begin{array}{l}\text { (Lohi et al. } \\
2005 b)\end{array}$ \\
\hline CL bei Border Collies & RFLP & $\begin{array}{l}\text { V: }{ }^{5} \text { 'TTTGCTTTGGTGTTCACATAGG } \\
\text { r: }{ }^{3} \text { 'ACCTCTTGGATGGATGAACCC }\end{array}$ & 190 & $\begin{array}{l}\text { (Melville et } \\
\text { al. 2005) }\end{array}$ \\
\hline CL bei Langhaardackeln & Pyrosequenzierung & $\begin{array}{l}\mathrm{V}:{ }^{5}{ }^{\prime} \mathrm{TGACCTTCCGCACAG}^{3}{ }^{\prime} \\
\text { r: }{ }^{3} \text { AGCCACTGGTGTGTTCTGAA }{ }^{\text {biotinyl-5' }} \\
\text { PS: }{ }^{5}{ }^{\prime} \text { CTCAGCAGCTGGAGCC }^{3}\end{array}$ & 79 & $\begin{array}{l}\text { (Awano et al. } \\
\text { 2006b) }\end{array}$ \\
\hline CL bei American Bulldogs & Pyrosequenzierung & $\begin{array}{l}\text { V: biotinyl 5' TTCATCGCGGCCAAGTT }{ }^{3}{ }^{\prime} \\
\text { r: }{ }^{3}{ }^{\prime} \text { CACGACGGACAGAAGCTGT }^{5} \\
\text { PS: }{ }^{\prime}{ }^{\prime} \text { CGGATGGGGGCGTAG }^{5}\end{array}$ & 82 & $\begin{array}{l}\text { (Awano et al. } \\
\text { 2006a) }\end{array}$ \\
\hline $\begin{array}{l}\text { GM1-Gangliosidose bei } \\
\text { Portugiesischen } \\
\text { Wasserhunden }\end{array}$ & RFLP & $\begin{array}{l}\text { V: }{ }^{5} \text { CTTGCTCTGCAGAATGCTTCC }{ }^{3} \text { ' } \\
\text { r: }{ }^{3} \text { GTAGGCTTGCATTCATTCTCCC }{ }^{5} \text { ' }\end{array}$ & 195 & $\begin{array}{l}\text { (Wang et al. } \\
\text { 2000) }\end{array}$ \\
\hline $\begin{array}{l}\text { GM1-Gangliosiose bei } \\
\text { Shiba Hunden }\end{array}$ & RFLP & $\begin{array}{l}\mathrm{V}:{ }^{5} \text { AACACTGAGGATGCAGTACGC AGC }{ }^{3} \text { ' } \\
\text { r: }{ }^{3} \text { GACACCTTTATCCAGTTTCCTGGA }\end{array}$ & 184 & $\begin{array}{l}\text { (Yamato et } \\
\text { al. 2002) }\end{array}$ \\
\hline $\begin{array}{l}\text { Globiodzell- } \\
\text { Leukodystrophie bei West } \\
\text { Highland White Terriern }\end{array}$ & RFLP & $\begin{array}{l}\mathrm{V}:{ }^{5} \text { 'GAATCTTCAGCTGACTGGCTCCT }{ }^{3}, \\
\mathrm{r:}^{3} \text { CCTGTAAATAAACATTAAAGAATTTG }\end{array}$ & 135 & $\begin{array}{l}\text { (Victoria et } \\
\text { al. 1996) }\end{array}$ \\
\hline
\end{tabular}

Highland White Terriern r: ${ }^{3}$ CCTGTAAATAAACATTAAAGAATTTG ${ }^{5}$ 
Fortsetzung Tabelle 11: Liste der genannten Primer

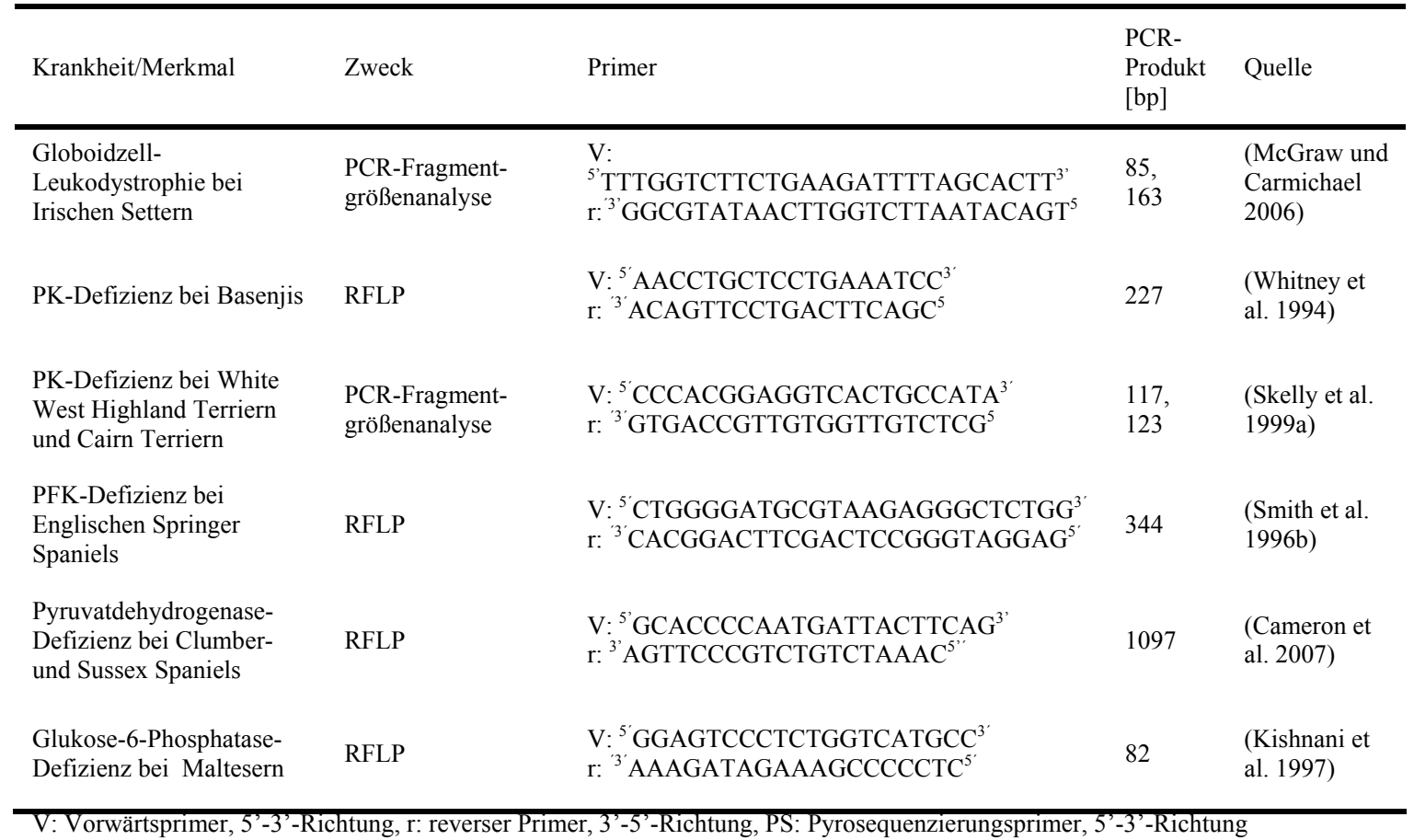




\subsubsection{Literatur}

Abraham, D., Blakemore, W.F., Dell, A., Herrtage, M.E., Jones, J., Littlewood, J.T., Oates, J., Palmer, A.C., Sidebotham, R. und Winchester, B. (1984): The enzymic defect and storage products in canine fucosidosis. Biochem J, 222 (1), 25-33.

Abramson, C.J., Platt, S.R. und Shelton, G.D. (2004): Pyruvate dehydrogenase deficiency in a Sussex spaniel. J Small Anim Pract, 45 (3), 162-5.

Ahern-Rindell, A.J., Kretz, K.A. und O'Brien, J.S. (1996): Comparison of the canine and human acid beta-galactosidase gene. Am J Med Genet, 63 (2), 340-5.

Alroy, J., Orgad, U., Ucci, A.A., Schelling, S.H., Schunk, K.L., Warren, C.D., Raghavan, S.S. und Kolodny, E.H. (1985): Neurovisceral and skeletal GM1gangliosidosis in dogs with beta-galactosidase deficiency. Science, 229 (4712), 470-2.

Alroy, J., Orgad, U., DeGasperi, R., Richard, R., Warren, C.D., Knowles, K., Thalhammer, J.G. und Raghavan, S.S. (1992): Canine GM1-gangliosidosis. A clinical, morphologic, histochemical, and biochemical comparison of two different models. Am J Pathol, 140 (3), 675-89.

Appleby, E.C., Longstaffe, J.A. und Bell, F.R. (1982): Ceroid-lipofuscinosis in two Saluki dogs. J Comp Pathol, 92 (3), 375-80.

Armstrong, D., Koppang, N. und Nilsson, S.E. (1982): Canine hereditary ceroid lipofuscinosis. Eur Neurol, 21 (3), 147-56.

Aronovich, E.L., Carmichael, K.P., Morizono, H., Koutlas, I.G., Deanching, M., Hoganson, G., Fischer, A. und Whitley, C.B. (2000): Canine heparan sulfate sulfamidase and the molecular pathology underlying Sanfilippo syndrome type A in Dachshunds. Genomics, 68 (1), 80-4.

Austin, J., Armstrong, D. und Margolis, G. (1968): Canine globoid leukodystrophy: a model demyelinating disorder. Trans Am Neurol Assoc, 93, 181-2.

Austin, J.H. (1963): Studies in Globoid (Krabbe) Leukodystrophy. Ii. Controlled ThinLayer Chromatographic Studies of Globoid Body Fractions in Seven Patients. $J$ Neurochem, 10, 921-30.

Austin, J.H. und Lehfeldt, D. (1965): Studies in Globoid (Krabbe) Leukodystrophy. 3. Significance of Experimentally-Produced Globoid-Like Elements in Rat White Matter and Spleen. J Neuropathol Exp Neurol, 24, 265-89.

Awano, T., Katz, M.L., O'Brien, D.P., Taylor, J.F., Evans, J., Khan, S., Sohar, I., Lobel, P. und Johnson, G.S. (2006a): A mutation in the cathepsin D gene (CTSD) in American Bulldogs with neuronal ceroid lipofuscinosis. Mol Genet Metab, 87 (4), 341-8. 
Awano, T., Katz, M.L., O'Brien, D.P., Sohar, I., Lobel, P., Coates, J.R., Khan, S., Johnson, G.C., Giger, U. und Johnson, G.S. (2006b): A frame shift mutation in canine TPP1 (the ortholog of human CLN2) in a juvenile Dachshund with neuronal ceroid lipofuscinosis. Mol Genet Metab, 89 (3), 254-60.

Bachhawat, B.K., Austin, J. und Armstrong, D. (1967): A cerebroside sulphotransferase deficiency in a human disorder of myelin. Biochem $J, 104$ (2), 15contd-17c.

Berman, L., Foureman, P., Stieger, K., Van Hoeven, M., Ellinwood, N., Henthorn, P.S., Thrall, M., Kirkness, E., Haskins, M. und Giger, U. (2004): Poster No 4: Mucopolysaccharidosis type VI caused by a Point Mutation in the Miniature Pinscher and deletion in the Miniature Schnauzer. In: 2nd International Conference: Advances in Canine and Feline Genomics, Utrecht, The Netherlands, Vol.

Bichsel, P. und Vandevelde, M. (1982): [A case of ceroid-lipofuscinosis in a Yugoslavian shepherd dog]. Schweiz Arch Tierheilkd, 124 (8), 413-8.

Bjerkas, I. (1979): Hereditary leukodystrophy in Dalmatian dogs in Norway. Norsk Veterinaertidsskrift, 91, 167-170.

Boysen, B.G., Tryphonas, L. und Harries, N.W. (1974): Globoid cell leukodystrophy in the bluetick hound dog. I. Clinical manifestations. Can Vet J, 15 (11), 303-8.

Breider, M.A., Shull, R.M. und Constantopoulos, G. (1989): Long-term effects of bone marrow transplantation in dogs with mucopolysaccharidosis I. Am J Pathol, 134 (3), 677-92.

Brix, A.E., Howerth, E.W., McConkie-Rosell, A., Peterson, D., Egnor, D., Wells, M.R. und Chen, Y.T. (1995): Glycogen storage disease type Ia in two littermate Maltese puppies. Vet Pathol, 32 (5), 460-5.

Brunk, U.T. und Terman, A. (2002a): The mitochondrial-lysosomal axis theory of aging: accumulation of damaged mitochondria as a result of imperfect autophagocytosis. Eur J Biochem, 269 (8), 1996-2002.

Brunk, U.T. und Terman, A. (2002b): Lipofuscin: mechanisms of age-related accumulation and influence on cell function. Free Radic Biol Med, 33 (5), 6119.

Cameron, J.M., Maj, M.C., Levandovskiy, V., MacKay, N., Shelton, G.D. und Robinson, B.H. (2007): Identification of a canine model of pyruvate dehydrogenase phosphatase 1 deficiency. Mol Genet Metab, 90 (1), 15-23.

Cantile, C., Buonaccorsi, A., Pepe, V. und Arispici, M. (1996): Juvenile neuronal ceroid-lipofuscinosis (Batten's disease) in a Poodle dog. Progress in Veterinary Neurology, 7 (3), 82-87. 
Chan, E.M., Ackerley, C.A., Lohi, H., Ianzano, L., Cortez, M.A., Shannon, P., Scherer, S.W. und Minassian, B.A. (2004): Laforin preferentially binds the neurotoxic starch-like polyglucosans, which form in its absence in progressive myoclonus epilepsy. Hum Mol Genet, 13 (11), 1117-29.

Chan, E.M., Young, E.J., Ianzano, L., Munteanu, I., Zhao, X., Christopoulos, C.C., Avanzini, G., Elia, M., Ackerley, C.A., Jovic, N.J., Bohlega, S., Andermann, E., Rouleau, G.A., Delgado-Escueta, A.V., Minassian, B.A. und Scherer, S.W. (2003): Mutations in NHLRC1 cause progressive myoclonus epilepsy. Nat Genet, 35 (2), 125-7.

Chapman, B. und Giger, U. (1990): Inherited erythrocyte pyruvate kinase deficiency in the West Highland white terrier. Journal of Small Animal Practice, 31, 610-611.

Cho, D.Y., Leipold, H.W. und Rudolph, R. (1986): Neuronal ceroidosis (ceroidlipofuscinosis) in a Blue Heeler dog. Acta Neuropathol (Berl), 69 (1-2), 161-4.

Constantopoulos, G. und Dekaban, A.S. (1978): Neurochemistry of the mucopolysaccharidoses: brain lipids and lysosomal enzymes in patients with four types of mucopolysaccharidosis and in normal controls. J Neurochem, $\mathbf{3 0}$ (5), 965-73.

Constantopoulos, G., Shull, R.M., Hastings, N. und Neufeld, E.F. (1985): Neurochemical characterization of canine alpha-L-iduronidase deficiency disease (model of human mucopolysaccharidosis I). J Neurochem, 45 (4), 12137.

Cummings, J.F. und de Lahunta, A. (1977): An adult case of canine neuronal ceroidlipofuscinosis. Acta Neuropathol, 39 (1), 43-51.

Cummings, J.F., deLahunta, A., Riis, R.C. und Loew, E.R. (1990): Neuropathologic changes in a young Tibetan terrier with subclinical neuronal ceroidlipofuscinosis. Progress in Veterinary Neurology, 1, 301-309.

Davis, K.E., Finnie, J.W. und Hooper, P.T. (1990): Lafora's disease in a dog. Aust Vet J, 67 (5), 192-3.

Ellinwood, N.M., Henthorn, P.S., Giger, U. und Haskins, M.E. (2003a):

Mucopolysaccharidosis type IIIB: Identification of the causative mutation in the canine model. Am J Hum Genet, 73, 449.

Ellinwood, N.M., Wang, P., Skeen, T., Sharp, N.J., Cesta, M., Decker, S., Edwards, N.J., Bublot, I., Thompson, J.N., Bush, W., Hardam, E., Haskins, M.E. und Giger, U. (2003b): A model of mucopolysaccharidosis IIIB (Sanfilippo syndrome type IIIB): N-acetyl-alpha-D-glucosaminidase deficiency in Schipperke dogs. J Inherit Metab Dis, 26 (5), 489-504.

Evans, J., Katz, M.L., Levesque, D., Shelton, G.D., de Lahunta, A. und O'Brien, D. (2005): A variant form of neuronal ceroid lipofuscinosis in American bulldogs. $J$ Vet Intern Med, 19 (1), 44-51. 
Ewing, G.O. (1969): Familial nonspherocytic hemolytic anemia of Basenji dogs. J Am Vet Med Assoc, 154 (5), 503-7.

Fankhauser, R. (1965): Degenerative, lipoidiotische Erkrankung des Zentralnervensystems bei zwei Hunden. Schweizer Archiv für Tierheilkunde, 107, 73-87.

Fankhauser, R., Luginbühl, H. und Hartley, W. (1963): Leukodystrophie vom Typus Krabbe beim Hund. Schweizer Archiv für Tierheilkunde, 105, 198-207.

Fischer, A., Carmichael, K.P., Munnell, J.F., Jhabvala, P., Thompson, J.N., Matalon, R., Jezyk, P.F., Wang, P. und Giger, U. (1998): Sulfamidase deficiency in a family of Dachshunds: a canine model of mucopolysaccharidosis IIIA (Sanfilippo A). Pediatr Res, 44 (1), 74-82.

Fletcher, T. (1969): Leukodystrophy in the dog. The Minnesota Veterinarian, 9, 19-22.

Fletcher, T.F., Kurtz, H.J. und Low, D.G. (1966): Globoid cell leukodystrophy (Krabbe type) in the dog. J Am Vet Med Assoc, 149 (2), 165-72.

Fletcher, T.F., Lee, D.G. und Hammer, R.F. (1971): Ultrastructural features of globoidcell leukodystrophy in the dog. Am J Vet Res, 32 (1), 177-81.

Foureman, P., Berman, L., Stieger, K., Van Hoeven, M., Ellinwood, N., Haskins, M., Kirkness, E. und Giger, U. (2004): Mucopolysaccharidosis type VI in Miniature Pinschers: Screening for the mutation. J Vet Intern Med, 18, 408-409.

Franks, J.N., Dewey, C.W., Walker, M.A. und Storts, R.W. (1999): Computed tomographic findings of ceroid lipofuscinosis in a dog. J Am Anim Hosp Assoc, 35 (5), 430-5.

Gentry, M.S., Worby, C.A. und Dixon, J.E. (2005): Insights into Lafora disease: malin is an E3 ubiquitin ligase that ubiquitinates and promotes the degradation of laforin. Proc Natl Acad Sci U S A, 102 (24), 8501-6.

Giger, U. und Noble, N.A. (1991): Determination of erythrocyte pyruvate kinase deficiency in Basenjis with chronic hemolytic anemia. J Am Vet Med Assoc, 198 (10), 1755-61.

Giger, U., Reilly, M.P., Asakura, T., Baldwin, C.J. und Harvey, J.W. (1986): Autosomal recessive inherited phosphofructokinase deficiency in English springer spaniel dogs. Anim Genet, 17 (1), 15-23.

Giger, U., Smith, B.F., Woods, C.B., Patterson, D.F. und Stedman, H. (1992): Inherited phosphofructokinase deficiency in an American cocker spaniel. J Am Vet Med Assoc, 201 (10), 1569-71.

Giger, U., Harvey, J.W., Yamaguchi, R.A., McNulty, P.K., Chiapella, A. und Beutler, E. (1985): Inherited phosphofructokinase deficiency in dogs with hyperventilation-induced hemolysis: increased in vitro and in vivo alkaline fragility of erythrocytes. Blood, 65 (2), 345-51. 
Giger, U., Kimmel, A., Overley, D.E., Schwartz, L.T., Smith, B.F. und Rajpurohit, Y. (2000): Frequency of phosphofructokinase (PFK) deficiency in English Springer Spaniels: a longitudinal and randomized study. ACVIM Proceedings, May, 737.

Giger, U., Wang, P., Ellinwood, N.M., Prociuk, U., Skeen, T., Bush, W., Edwards, N., Hardam, E. und Haskins, M.E. (2001): Mucopolysaccharidosis Type III B (Sanfilippo B Syndrome) in Schipperke Dogs. J Vet Intern Med, 15, 290.

Goebel, H.H. (1992): Retina in various animal models of neuronal ceroidlipofuscinosis. Am J Med Genet, 42 (4), 605-8.

Goebel, H.H. und Dahme, E. (1985): Retinal ultrastructure of neuronal ceroidlipofuscinosis in the dalmatian dog. Acta Neuropathol, 68 (3), 224-9.

Goebel, H.H., Bilzer, T., Dahme, E. und Malkusch, F. (1988): Morphological studies in canine (Dalmatian) neuronal ceroid-lipofuscinosis. Am J Med Genet Suppl, 5, 127-39.

Golabek, A.A. und Kida, E. (2006): Tripeptidyl-peptidase I in health and disease. Biol Chem, 387 (8), 1091-9.

Greenwood, R.S., Hillman, R.E., Alcala, H. und Sly, W.S. (1978): Sanfilippo A syndrome in the fetus. Clin Genet, 13 (3), 241-50.

Gudi, R., Bowker-Kinley, M.M., Kedishvili, N.Y., Zhao, Y. und Popov, K.M. (1995): Diversity of the pyruvate dehydrogenase kinase gene family in humans. $J$ Biol Chem, 270 (48), 28989-94.

Gupta, P. und Hofmann, S.L. (2002): Neuronal ceroid lipofuscinosis/Batten disease: the lysosomal proteinoses. Mol Psychiatry, 7 (5), 434-6.

Hagen, L.O. (1953): Lipid dystrophic changes in the central nervous system in dogs. Acta Pathol Microbiol Scand, 33 (1), 22-35.

Hara, A., Kitazawa, N. und Taketomi, T. (1984): Abnormalities of glycosphingolipids in mucopolysaccharidosis type III B. J Lipid Res, 25 (2), 175-84.

Hartley, W.J., Canfield, P.J. und Donnelly, T.M. (1982): A suspected new canine storage disease. Acta Neuropathol, 56 (3), 225-32.

Haskins, M.E. und Giger, U. (1997): Lysosomal Storage Diseases. In Bruce, M.L. (Herausgeber): Clinical Biochemistry in Domestic Animals. Academic Press, 1997, S. 741-753.

Haskins, M.E., Desnick, R.J., DiFerrante, N., Jezyk, P.F. und Patterson, D.F. (1984): Beta-glucuronidase deficiency in a dog: a model of human mucopolysaccharidosis VII. Pediatr Res, 18 (10), 980-4. 
Haskins, M.E., Aguirre, G.D., Jezyk, P.F., Schuchman, E.H., Desnick, R.J. und Patterson, D.F. (1991): Mucopolysaccharidosis type VII (Sly syndrome). Betaglucuronidase-deficient mucopolysaccharidosis in the dog. Am J Pathol, 138 (6), 1553-5.

Hegreberg, G.A. und Padgett, G.A. (1976): Inherited progressive epilepsy of the dog with comparisons to Lafora's disease of man. Fed Proc, 35 (5), 1202-5.

Herrtage, M.E., Palmer, A.C. und Blakemore, W.F. (1985): Canine fucosidosis. Vet Rec, 117 (17), 451-2.

Hirth, R.S. und Nielsen, S.W. (1967): A familial canine globoid cell leukodystrophy ("Krabbe Type"). J Small Anim Pract, 8 (10), 569-75.

Holland, J.M., Davis, W.C., Prieur, D.J. und Collins, G.H. (1970): Lafora's disease in the dog. A comparative study. Am J Pathol, 58 (3), 509-30.

Holmes, N.G., Acheson, T., Ryder, E.J. und Binns, M.M. (1998): A PCR-based diagnostic test for fucosidosis in English springer spaniels. Vet J, 155 (2), 113-4.

Houlton, J.E. und Herrtage, M.E. (1980): Mitochondrial myopathy in the Sussex spaniel. Vet Rec, 106 (9), 206.

Howell, J.M. und Palmer, A.C. (1971): Globoid cell leucodystrophy in two dogs. $J$ Small Anim Pract, 12 (11), 633-42.

Huang, B., Gudi, R., Wu, P., Harris, R.A., Hamilton, J. und Popov, K.M. (1998): Isoenzymes of pyruvate dehydrogenase phosphatase. DNA-derived amino acid sequences, expression, and regulation. J Biol Chem, 273 (28), 17680-8.

Imamura, K. und Tanaka, T. (1972): Multimolecular forms of pyruvate kinase from rat and other mammalian tissues. I. Electrophoretic studies. J Biochem (Tokyo), 71 (6), 1043-51.

Jian, Z., Alley, M.R., Cayzer, J. und Swinney, G.R. (1990): Lafora's disease in an epileptic Basset hound. N Z Vet J, 38 (2), 75-9.

Johnson, G.R., Oliver, J.E., Jr. und Selcer, R. (1975): Globoid cell leukodystrophy in a Beagle. J Am Vet Med Assoc, 167 (5), 380-4.

Jolly, R.D. und Hartley, W.J. (1977): Storage diseases of domestic animals. Aust Vet J, 53 (1), 1-8.

Jolly, R.D., Martinus, R.D. und Palmer, D.N. (1992): Sheep and other animals with ceroid-lipofuscinoses: their relevance to Batten disease. Am J Med Genet, 42 (4), 609-14.

Jolly, R.D., Sutton, R.H., Smith, R.I. und Palmer, D.N. (1997): Ceroid-lipofuscinosis in miniature Schnauzer dogs. Aust Vet J, 75 (1), 67. 
Jolly, R.D., Shimada, A., Craig, A.S., Kirkland, K.B. und Palmer, D.N. (1988): Ovine ceroid-lipofuscinosis II: Pathologic changes interpreted in light of biochemical observations. Am J Med Genet Suppl, 5, 159-70.

Jolly, R.D., Ehrlich, P.C., Franklin, R.J., Macdougall, D.F. und Palmer, A.C. (2001): Histological diagnosis of mucopolysaccharidosis IIIA in a wire-haired dachshund. Vet Rec, 148 (18), 564-7.

Jolly, R.D., Allan, F.J., Collett, M.G., Rozaklis, T., Muller, V.J. und Hopwood, J.J. (2000): Mucopolysaccharidosis IIIA (Sanfilippo syndrome) in a New Zealand Huntaway dog with ataxia. N Z Vet J, 48 (5), 144-8.

Jolly, R.D., Palmer, D.N., Studdert, V.P., Sutton, R.H., Kelly, W.R., Koppang, N., Dahme, G., Hartley, W.J., Patterson, J.S. und Riis, R.C. (1994): Canine ceroidlipofuscinoses: a review and classification. Journal of Small Animal Practice, 35, 299-306.

Jortner, B.S. und Jonas, A.M. (1968): The neuropathology of globoid-cell leucodystrophy in the dog. A report of two cases. Acta Neuropathol, 10 (3), 17182.

Katz, M.L., Drea, C.M. und Robison, W.G., Jr. (1986): Relationship between dietary retinol and lipofuscin in the retinal pigment epithelium. Mech Ageing Dev, 35 (3), 291-305.

Katz, M.L., Narfstrom, K., Johnson, G.S. und O'Brien, D.P. (2005a): Assessment of retinal function and characterization of lysosomal storage body accumulation in the retinas and brains of Tibetan Terriers with ceroid-lipofuscinosis. Am J Vet Res, 66 (1), 67-76.

Katz, M.L., Christianson, J.S., Norbury, N.E., Gao, C.L., Siakotos, A.N. und Koppang, N. (1994): Lysine methylation of mitochondrial ATP synthase subunit c stored in tissues of dogs with hereditary ceroid lipofuscinosis. J Biol Chem, 269 (13), 9906-11.

Katz, M.L., Khan, S., Awano, T., Shahid, S.A., Siakotos, A.N. und Johnson, G.S. (2005b): A mutation in the CLN8 gene in English Setter dogs with neuronal ceroid-lipofuscinosis. Biochem Biophys Res Commun, 327 (2), 541-7.

Kelly, W.R., Clague, A.E., Barns, R.J., Bate, M.J. und MacKay, B.M. (1983): Canine alpha-L-fucosidosis: a storage disease of Springer Spaniels. Acta Neuropathol, 60 (1-2), 9-13.

Kishnani, P.S., Bao, Y., Wu, J.Y., Brix, A.E., Lin, J.L. und Chen, Y.T. (1997): Isolation and nucleotide sequence of canine glucose-6-phosphatase mRNA: identification of mutation in puppies with glycogen storage disease type Ia. Biochem Mol Med, 61 (2), 168-77. 
Kishnani, P.S., Faulkner, E., VanCamp, S., Jackson, M., Brown, T., Boney, A., Koeberl, D. und Chen, Y.T. (2001): Canine model and genomic structural organization of glycogen storage disease type Ia (GSD Ia). Vet Pathol, 38 (1), 83-91.

Kohn, B., Freistedt, R., Pekrun, A., Wang, P. und Giger, U. (1999): Chronische hämolytische Anämie und Osteosklerose aufgrund einer ErythrozytenPyruvatkinase-Defizienz bei einem Langhaardackel. Kleintierpraxis, 44, 401486.

Koie, H., Shibuya, H., Sato, T., Sato, A., Nawa, K., Nawa, Y., Kitagawa, M., Sakai, M., Takahashi, T., Yamaya, Y., Yamato, O., Watari, T. und Tokuriki, M. (2004): Magnetic resonance imaging of neuronal ceroid lipofuscinosis in a border collie. $J$ Vet Med Sci, 66 (11), 1453-6.

Koppang, N. (1973): Canine ceroid-lipofuscinosis-a model for human neuronal ceroidlipofuscinosis and aging. Mech Ageing Dev, 2 (6), 421-45.

Koppang, N. (1987): Hereditary ceroid lipofuscinosis in English Setter dogs. A model for human neuronal ceroid lipofuscinosis and aging. Advances in Bioscience, 64, 185-195.

Koppang, N. (1992): English setter model and juvenile ceroid-lipofuscinosis in man. Am J Med Genet, 42 (4), 599-604.

Krabbe, K. (1916): A new familiar infantile form of diffuse brain sclerosis. Brain, 39, 74-114.

Kurtz, H.J. und Fletcher, T.F. (1970): The peripheral neuropathy of canine globoid-cell leukodystrophy (krabbe-type). Acta Neuropathol, 16 (3), 226-32.

Lafora, G. und Glueck, B. (1911): Beitrag zur Histopatholohgie der myoklonischen Epilepsie. Zeitschrift für die gesamte Neurologie und Psychiatrie/Originalien, 6, 1-14.

Lei, K.J., Pan, C.J., Liu, J.L., Shelly, L.L. und Chou, J.Y. (1995): Structure-function analysis of human glucose-6-phosphatase, the enzyme deficient in glycogen storage disease type 1a. J Biol Chem, 270 (20), 11882-6.

Lingaas, F., Aarskaug, T., Sletten, M., Bjerkas, I., Grimholt, U., Moe, L., Juneja, R.K., Wilton, A.N., Galibert, F., Holmes, N.G. und Dolf, G. (1998): Genetic markers linked to neuronal ceroid lipofuscinosis in English setter dogs. Anim Genet, 29 (5), 371-6.

Lohi, H., Ianzano, L., Zhao, X.C., Chan, E.M., Turnbull, J., Scherer, S.W., Ackerley, C.A. und Minassian, B.A. (2005a): Novel glycogen synthase kinase 3 and ubiquitination pathways in progressive myoclonus epilepsy. Hum Mol Genet, 14 (18), 2727-36. 
Lohi, H., Young, E.J., Fitzmaurice, S.N., Rusbridge, C., Chan, E.M., Vervoort, M., Turnbull, J., Zhao, X.C., Ianzano, L., Paterson, A.D., Sutter, N.B., Ostrander, E.A., Andre, C., Shelton, G.D., Ackerley, C.A., Scherer, S.W. und Minassian, B.A. (2005b): Expanded repeat in canine epilepsy. Science, 307 (5706), 81.

Lonka, L., Kyttala, A., Ranta, S., Jalanko, A. und Lehesjoki, A.E. (2000): The neuronal ceroid lipofuscinosis CLN8 membrane protein is a resident of the endoplasmic reticulum. Hum Mol Genet, 9 (11), 1691-7.

Maj, M.C., MacKay, N., Levandovskiy, V., Addis, J., Baumgartner, E.R., Baumgartner, M.R., Robinson, B.H. und Cameron, J.M. (2005): Pyruvate dehydrogenase phosphatase deficiency: identification of the first mutation in two brothers and restoration of activity by protein complementation. J Clin Endocrinol Metab, 90 (7), 4101-7.

Malkusch, F. (1984): Beitrag zur bioptischen Diagnose der neuronalen CeroidLipofuscinose des Hundes. München: 177.

McGraw, R.A. und Carmichael, K.P. (2006): Molecular basis of globoid cell leukodystrophy in Irish setters. Vet J, 171 (2), 370-2.

McKusick, V. und Neufeld, E. (1983): The Mucopolysaccharide Storage Diseases. In Brown, M. (Herausgeber): The Metabolic Basis of Inherited Diseases $\left(5^{\text {th }}\right)$. McGraw-Hill, New York 1983, S. 751-775.

Melville, S.A., Wilson, C.L., Chiang, C.S., Studdert, V.P., Lingaas, F. und Wilton, A.N. (2005): A mutation in canine CLN5 causes neuronal ceroid lipofuscinosis in Border collie dogs. Genomics, 86 (3), 287-94.

Menon, K.P., Tieu, P.T. und Neufeld, E.F. (1992): Architecture of the canine IDUA gene and mutation underlying canine mucopolysaccharidosis I. Genomics, 14 (3), 763-8.

Miyatake, T. und Suzuki, K. (1972a): Galactosylsphingosine galactosyl hydrolase. Partial purification and properties of the enzyme in rat brain. $J$ Biol Chem, 247 (17), 5398-403.

Miyatake, T. und Suzuki, K. (1972b): Globoid cell leukodystrophy: additional deficiency of psychosine galactosidase. Biochem Biophys Res Commun, 48 (3), 539-43.

Montgomery, D.L. und Lee, A.C. (1983): Brain damage in the epileptic beagle dog. Vet Pathol, 20 (2), 160-9.

Muirhead, H., Clayden, D.A., Barford, D., Lorimer, C.G., Fothergill-Gilmore, L.A., Schiltz, E. und Schmitt, W. (1986): The structure of cat muscle pyruvate kinase. Embo J, 5 (3), 475-81.

Muller, G., Baumgartner, W., Moritz, A., Sewell, A. und Kustermann-Kuhn, B. (1998): Biochemical findings in a breeding colony of Alaskan Huskies suffering from GM1-gangliosidosis. J Inherit Metab Dis, 21 (4), 430-1. 
Neer, T.M., Dial, S.M., Pechman, R., Wang, P., Oliver, J.L. und Giger, U. (1995): Clinical vignette. Mucopolysaccharidosis VI in a miniature pinscher. $J$ Vet Intern Med, 9 (6), 429-33.

Noguchi, T., Inoue, H. und Tanaka, T. (1986): The M1- and M2-type isozymes of rat pyruvate kinase are produced from the same gene by alternative RNA splicing. $J$ Biol Chem, 261 (29), 13807-12.

Noguchi, T., Yamada, K., Inoue, H., Matsuda, T. und Tanaka, T. (1987): The L- and Rtype isozymes of rat pyruvate kinase are produced from a single gene by use of different promoters. J Biol Chem, 262 (29), 14366-71.

O'Brien, J.S. (1983): The Gangliosidoses. In Brown, M.S. (Herausgeber): The metabolic basis of inherited diseases ( $5^{\text {th }}$ edition). McGraw-Hill, NewYork 1983, S. 945969.

Occhiodoro, T. und Anson, D.S. (1996): Isolation of the canine alpha-L-fucosidase cDNA and definition of the fucosidosis mutation in English Springer Spaniels. Mamm Genome, 7 (4), 271-4.

Okun, M.M., Eskridge, E.M. und Shields, D. (1990): Truncations of a secretory protein define minimum lengths required for binding to signal recognition particle and translocation across the endoplasmic reticulum membrane. J Biol Chem, 265 (13), 7478-84.

Palmer, D.N., Barns, G., Husbands, D.R. und Jolly, R.D. (1986): Ceroid lipofuscinosis in sheep. II. The major component of the lipopigment in liver, kidney, pancreas, and brain is low molecular weight protein. J Biol Chem, 261 (4), 1773-7.

Palmer, D.N., Tyynela, J., van Mil, H.C., Westlake, V.J. und Jolly, R.D. (1997): Accumulation of sphingolipid activator proteins (SAPs) A and D in granular osmiophilic deposits in miniature Schnauzer dogs with ceroid-lipofuscinosis. $J$ Inherit Metab Dis, 20 (1), 74-84.

Pickett, P., Dyer, K., Saunders, O. und Robertson, J. (1992): Ocular manifestation of ceroid-lipofuscinosis in a Spitz dog. Vet Pathol, 29, 469.

Pilz, H., Heipertz, R. und Seidel, D. (1979): Basic findings and current developments in sphingolipidoses. Hum Genet, 47 (2), 113-34.

Porta, E.A. (1991): Advances in age pigment research. Arch Gerontol Geriatr, 12 (2-3), 303-20.

Prasse, K.W., Crouser, D., Beutler, E., Walker, M. und Schall, W.D. (1975): Pyruvate kinase deficiency anemia with terminal myelofibrosis and osteosclerosis in a beagle. J Am Vet Med Assoc, 166 (12), 1170-5.

Rac, R. und Giesecke, P.R. (1975): Letter: Lysosomal storage disease in chihuahuas. Aust Vet J, 51 (8), 403-4. 
Randolph, J.F., Center, S.A., Kallfelz, F.A., Blue, J.T., Dodds, W.J., Harvey, J.W., Paglia, D.E., Walsh, K.M. und Shelly, S.M. (1986): Familial nonspherocytic hemolytic anemia in poodles. Am J Vet Res, 47 (3), 687-95.

Ray, J., Haskins, M.E. und Ray, K. (1998a): Molecular diagnostic tests for ascertainment of genotype at the mucopolysaccharidosis type VII locus in dogs. Am J Vet Res, 59 (9), 1092-5.

Ray, J., Scarpino, V., Laing, C. und Haskins, M.E. (1999): Biochemical basis of the beta-glucuronidase gene defect causing canine mucopolysaccharidosis VII. $J$ Hered, 90 (1), 119-23.

Ray, J., Bouvet, A., DeSanto, C., Fyfe, J.C., Xu, D., Wolfe, J.H., Aguirre, G.D., Patterson, D.F., Haskins, M.E. und Henthorn, P.S. (1998b): Cloning of the canine beta-glucuronidase cDNA, mutation identification in canine MPS VII, and retroviral vector-mediated correction of MPS VII cells. Genomics, 48 (2), 248-53.

Read, D.H., Harrington, D.D., Keenana, T.W. und Hinsman, E.J. (1976): Neuronalvisceral GM1 gangliosidosis in a dog with beta-galactosidase deficiency. Science, 194 (4263), 442-5.

Riis, R.C., Cummings, J.F., Loew, E.R. und de Lahunta, A. (1992): Tibetan terrier model of canine ceroid lipofuscinosis. Am J Med Genet, 42 (4), 615-21.

Rodriguez, M., O'Brien, J.S., Garrett, R.S. und Powell, H.C. (1982): Canine GM1 gangliosidosis. An ultrastructural and biochemical study. J Neuropathol Exp Neurol, 41 (6), 618-29.

Rowles, J., Scherer, S.W., Xi, T., Majer, M., Nickle, D.C., Rommens, J.M., Popov, K.M., Harris, R.A., Riebow, N.L., Xia, J., Tsui, L.C., Bogardus, C. und Prochazka, M. (1996): Cloning and characterization of PDK4 on 7q21.3 encoding a fourth pyruvate dehydrogenase kinase isoenzyme in human. $J$ Biol Chem, 271 (37), 22376-82.

Saftig, P., Hetman, M., Schmahl, W., Weber, K., Heine, L., Mossmann, H., Koster, A., Hess, B., Evers, M., von Figura, K. und et al. (1995): Mice deficient for the lysosomal proteinase cathepsin $\mathrm{D}$ exhibit progressive atrophy of the intestinal mucosa and profound destruction of lymphoid cells. Embo J, 14 (15), 3599-608.

Sakai, M., Austin, J., Witmer, F. und Trueb, L. (1970): Studies in myoclonus epilepsy (Lafora body form). II. Polyglucosans in the systemic deposits of myoclonus epilepsy and in corpora amylacea. Neurology, 20 (2), 160-76.

Saunders, G.K., Wood, P.A., Myers, R.K., Shell, L.G. und Carithers, R. (1988): GM1 gangliosidosis in Portuguese water dogs: pathologic and biochemical findings. Vet Pathol, 25 (4), 265-9. 
Schaer, M., Harvey, J.W., Calderwood-Mays, M. und Giger, U. (1992): Pyruvate kinase deficiency causing hemolytic anemia with secondary hemochromatosis in a Cairn Terrier. Journal of the American Animal Hospital Association, 28, 233239.

Schuchman, E.H., Toroyan, T.K., Haskins, M.E. und Desnick, R.J. (1989): Characterization of the defective beta-glucuronidase activity in canine mucopolysaccharidosis type VII. Enzyme, 42 (3), 174-80.

Searcy, G.P. (1973): Myelofibrosis and osteosclerosis as a sequelae to congenital hemolytic anemia in the Basenji dog. Bull Am Soc Vet Clin Pathol, 2, 9.

Searcy, G.P., Miller, D.R. und Tasker, J.B. (1971): Congenital hemolytic anemia in the Basenji dog due to erythrocyte pyruvate kinase deficiency. Can J Comp Med, 35 (1), 67-70.

Seehafer, S.S. und Pearce, D.A. (2006): You say lipofuscin, we say ceroid: defining autofluorescent storage material. Neurobiol Aging, 27 (4), 576-88.

Seitelberger, F., Jacob, H., Peiffer, J. und Colmant, H.J. (1964): [the Myoclonus Body Disease. A Congenital Disorder of the Carbohydrate Metabolism.

Clinicopathological Study of 5 Cases.]. Fortschr Neurol Psychiatr Grenzgeb, 32, 305-45.

Shell, L.G., Potthoff, A.I., Carithers, R., Katherman, A., Saunders, G.K., Wood, P.A. und Giger, U. (1989): Neuronal-visceral GM1 gangliosidosis in Portuguese water dogs. $J$ Vet Intern Med, 3 (1), 1-7.

Shelton, G., Van Ham, L., Bhatti, S., Cook-Olson, S., Johnson, K., Barshop, B., Tonne, J. und Applegarth, D. (2000): Pyruvate dehydrogenase deficiency in Clumber and Sussex Spaniels in the United States and Belgium. J Vet Intern Med, 14, 342.

Shull, R.M., Munger, R.J., Spellacy, E., Hall, C.W., Constantopoulos, G. und Neufeld, E.F. (1982): Canine alpha-L-iduronidase deficiency. A model of mucopolysaccharidosis I. Am J Pathol, 109 (2), 244-8.

Shull, R.M., Helman, R.G., Spellacy, E., Constantopoulos, G., Munger, R.J. und Neufeld, E.F. (1984): Morphologic and biochemical studies of canine mucopolysaccharidosis I. Am J Pathol, 114 (3), 487-95.

Shull, R.M., Kakkis, E.D., McEntee, M.F., Kania, S.A., Jonas, A.J. und Neufeld, E.F. (1994): Enzyme replacement in a canine model of Hurler syndrome. Proc Natl Acad Sci U S A, 91 (26), 12937-41.

Siakotos, A.N., Blair, P.S., Savill, J.D. und Katz, M.L. (1998): Altered mitochondrial function in canine ceroid-lipofuscinosis. Neurochem Res, 23 (7), 983-9.

Siakotos, A.N., Hutchins, G.D., Farlow, M.R. und Katz, M.L. (2001): Assessment of dietary therapies in a canine model of Batten disease. Eur J Paediatr Neurol, 5 Suppl A, 151-6. 
Silverstein Dombrowski, D.C., Carmichael, K.P., Wang, P., O'Malley, T.M., Haskins, M.E. und Giger, U. (2004): Mucopolysaccharidosis type VII in a German Shepherd Dog. J Am Vet Med Assoc, 224 (4), 553-7, 532-3.

Sisk, D.B., Levesque, D.C., Wood, P.A. und Styer, E.L. (1990): Clinical and pathologic features of ceroid lipofuscinosis in two Australian cattle dogs. J Am Vet Med Assoc, 197 (3), 361-4.

Skelly, B.J., Sargan, D.R., Herrtage, M.E. und Winchester, B.G. (1996): The molecular defect underlying canine fucosidosis. J Med Genet, 33 (4), 284-8.

Skelly, B.J., Wallace, M., Rajpurohit, Y.R., Wang, P. und Giger, U. (1999a): Identification of a 6 base pair insertion in West Highland White Terriers with erythrocyte pyruvate kinase deficiency. Am J Vet Res, 60 (9), 1169-72.

Skelly, B.J., Sargan, D.R., Winchester, B.G., Smith, M.O., Herrtage, M.E. und Giger, U. (1999b): Genomic screening for fucosidosis in English Springer Spaniels. Am $J$ Vet Res, 60 (6), 726-9.

Skibild, E., Dahlgaard, K., Rajpurohit, Y., Smith, B.F. und Giger, U. (2001): Haemolytic anaemia and exercise intolerance due to phosphofructokinase deficiency in related springer spaniels. J Small Anim Pract, 42 (6), 298-300.

Smith, B.F., Henthorn, P.S., Rajpurohit, Y., Stedman, H., Wolfe, J.H., Patterson, D.F. und Giger, U. (1996a): A cDNA encoding canine muscle-type phosphofructokinase. Gene, 168 (2), 275-6.

Smith, B.F., Stedman, H., Rajpurohit, Y., Henthorn, P.S., Wolfe, J.H., Patterson, D.F. und Giger, U. (1996b): Molecular basis of canine muscle type phosphofructokinase deficiency. J Biol Chem, 271 (33), 20070-4.

Spellacy, E., Shull, R.M., Constantopoulos, G. und Neufeld, E.F. (1983): A canine model of human alpha-L-iduronidase deficiency. Proc Natl Acad Sci U S A, 80 (19), 6091-5.

Standerfer, R.J., Templeton, J.W. und Black, J.A. (1974): Anomalous pyruvate kinase deficiency in the Basenji dog. Am J Vet Res, 35 (12), 1541-3.

Stengel, O. (1826): Account of a singular illness among four siblings in the vicinity of Roraas. In Rider, J. (Herausgeber): Ceroid-lipofuscinosis (Batten's Disease). Elsevier/North-Holland, Biomedical Press, Amsterdam 1826, S. 17-19.

Stoltzfus, L.J., Sosa-Pineda, B., Moskowitz, S.M., Menon, K.P., Dlott, B., Hooper, L., Teplow, D.B., Shull, R.M. und Neufeld, E.F. (1992): Cloning and characterization of cDNA encoding canine alpha-L-iduronidase. mRNA deficiency in mucopolysaccharidosis I dog. J Biol Chem, 267 (10), 6570-5.

Studdert, V.P. und Mitten, R.W. (1991): Clinical features of ceroid lipofuscinosis in border collie dogs. Aust Vet J, 68 (4), 137-40. 
Suzuki, K. (2003): Evolving perspective of the pathogenesis of globoid cell leukodystrophy (Krabbe disease). Proc Jpn Acad Ser B, 79 (1), 1-8.

Suzuki, K. und Suzuki, Y. (1970): Globoid cell leucodystrophy (Krabbe's disease): deficiency of galactocerebroside beta-galactosidase. Proc Natl Acad Sci U S A, 66 (2), 302-9.

Suzuki, K. und Suzuki, Y. (1983): Galactosylceramid lipidosis: globoid cell leukodystrophy (Krabbe's Disease). In Brown, M. (Herausgeber): Metabolic Basis of Inherited Diseases. McGraw-Hill, New York 1983, S. 857.

Suzuki, K., Suzuki, Y. und Fletcher, T. (1972): Galactocerebroside $\beta$-Galactosidase. In Aronson, S. (Herausgeber): Sphingolipids, Sphingolipidoses and Allied Disorders. Plenum Press, New York 1972, S.

Suzuki, Y. und Suzuki, K. (1971): Krabbe's globoid cell leukodystrophy: deficiency of glactocerebrosidase in serum, leukocytes, and fibroblasts. Science, 171 (966), 73-5.

Suzuki, Y., Miyatake, T., Fletcher, T.F. und Suzuki, K. (1974): Glycosphingolipid betagalactosidases. 3. Canine form of globoid cell leukodystrophy; comparison with the human disease. J Biol Chem, 249 (7), 2109-12.

Suzuki, Y., Austin, J., Armstrong, D., Suzuki, K., Schlenker, J. und Fletcher, T. (1970): Studies in globoid leukodystrophy: enzymatic and lipid findings in the canine form. Exp Neurol, 29 (1), 65-75.

Svennerholm, L., Vanier, M.T. und Mansson, J.E. (1980): Krabbe disease: a galactosylsphingosine (psychosine) lipidosis. J Lipid Res, 21 (1), 53-64.

Taketomi, T. und Nishimura, K. (1964): Physiological Activity of Psychosin. Jpn J Exp Med, 34, 255-65.

Tanaka, K.R., Valentine, W.N. und Miwa, S. (1962): Pyruvate kinase (PK) deficiency hereditary nonspherocytic hemolytic anemia. Blood, 19, 267-95.

Tasker, J.B., Severin, G.A., Young, S. und Gillette, E.L. (1969): Familial anemia in the Basenji dog. J Am Vet Med Assoc, 154 (2), 158-65.

Taylor, R.M. und Farrow, B.R. (1988): Ceroid-lipofuscinosis in border collie dogs. Acta Neuropathol, 75 (6), 627-31.

Taylor, R.M. und Farrow, B.R. (1992): Ceroid lipofuscinosis in the border collie dog: retinal lesions in an animal model of juvenile Batten disease. Am J Med Genet, 42 (4), 622-7.

Tomchick, T. (1973): Familial Lafora's Disease in the beagle dog. Federation Proceedings, 32, 821. 
Tyynela, J., Sohar, I., Sleat, D.E., Gin, R.M., Donnelly, R.J., Baumann, M., Haltia, M. und Lobel, P. (2000): A mutation in the ovine cathepsin D gene causes a congenital lysosomal storage disease with profound neurodegeneration. Embo J, 19 (12), 2786-92.

Van Hoof, F. und Hageman-Bal, M. (1967): Progressive familial myoclonic epilepsy with Lafora bodies. Electron microscopic and histochemical study of a cerebral biopsy. Acta Neuropathol, 7 (4), 315-36.

van Solinge, W.W., Kraaijenhagen, R.J., Rijksen, G., van Wijk, R., Stoffer, B.B., Gajhede, M. und Nielsen, F.C. (1997): Molecular modelling of human red blood cell pyruvate kinase: structural implications of a novel G1091 to a mutation causing severe nonspherocytic hemolytic anemia. Blood, 90 (12), 4987-95.

Vandevelde, M. und Fatzer, R. (1980): Neuronal ceroid-lipofuscinosis in older dachshunds. Vet Pathol, 17 (6), 686-92.

Vanier, M. und Svennerholm, L. (1976): Chemical Pathology of Krabbe Disease: The Occurrence of Psychosine and other neutral Sphingolipids. In Schenk, L. (Herausgeber): Current trends in sphingolipidoses and allied disorders: [proceedings of the Symposium on the Current Trends in Sphingolipidoses and Allied Disorders, held in Brooklyn, New York, October 20-21, 1975]. Plenum Press, New York 1976, S. 115 ff.

Victoria, T., Rafi, M.A. und Wenger, D.A. (1996): Cloning of the canine GALC cDNA and identification of the mutation causing globoid cell leukodystrophy in West Highland White and Cairn terriers. Genomics, 33 (3), 457-62.

Vora, S., Giger, U., Turchen, S. und Harvey, J.W. (1985): Characterization of the enzymatic lesion in inherited phosphofructokinase deficiency in the dog: an animal analogue of human glycogen storage disease type VII. Proc Natl Acad Sci U S A, 82 (23), 8109-13.

Wang, Z.H., Zeng, B., Shibuya, H., Johnson, G.S., Alroy, J., Pastores, G.M., Raghavan, S. und Kolodny, E.H. (2000): Isolation and characterization of the normal canine beta-galactosidase gene and its mutation in a dog model of GM1-gangliosidosis. J Inherit Metab Dis, 23 (6), 593-606.

Wenger, D.A., Satter, M. und Markey, J.P. (1973): Deficiency of monogalactosyl diglycerid beta-B-galactosidase activity in krabbe's disease. Biochem Biophys Res Commun, 53 (2), 680-5.

Wenger, D.A., Sattler, M. und Hiatt, W. (1974): Globoid cell leukodystrophy: deficiency of lactosyl ceramide beta-galactosidase. Proc Natl Acad Sci U S A, 71 (3), 854-7.

Whitney, K.M. und Lothrop, C.D., Jr. (1995): Genetic test for pyruvate kinase deficiency of Basenjis. J Am Vet Med Assoc, 207 (7), 918-21. 
Whitney, K.M., Goodman, S.A., Bailey, E.M. und Lothrop, C.D., Jr. (1994): The molecular basis of canine pyruvate kinase deficiency. Exp Hematol, 22 (9), 86674.

Winter, E. und Ponting, C.P. (2002): TRAM, LAG1 and CLN8: members of a novel family of lipid-sensing domains? Trends Biochem Sci, 27 (8), 381-3.

Wood, P.A., Sisk, D.B., Styer, E. und Baker, H.J. (1987): Animal model: ceroidosis (ceroid-lipofuscinosis) in Australian cattle dogs. Am J Med Genet, 26 (4), 891-8.

Yamato, O., Ochiai, K., Masuoka, Y., Hayashida, E., Tajima, M., Omae, S., Iijima, M., Umemura, T. und Maede, Y. (2000): GM1 gangliosidosis in shiba dogs. Vet Rec, 146 (17), 493-6.

Yamato, O., Endoh, D., Kobayashi, A., Masuoka, Y., Yonemura, M., Hatakeyama, A., Satoh, H., Tajima, M., Yamasaki, M. und Maede, Y. (2002): A novel mutation in the gene for canine acid beta-galactosidase that causes GM1-gangliosidosis in Shiba dogs. J Inherit Metab Dis, 25 (6), 525-6.

Yamato, O., Masuoka, Y., Yonemura, M., Hatakeyama, A., Satoh, H., Kobayashi, A., Nakayama, M., Asano, T., Shoda, T., Yamasaki, M., Ochiai, K., Umemura, T. und Maede, Y. (2003): Clinical and clinico-pathologic characteristics of Shiba dogs with a deficiency of lysosomal acid beta-galactosidase: a canine model of human GM1 gangliosidosis. J Vet Med Sci, 65 (2), 213-7.

Yeaman, S.J., Hutcheson, E.T., Roche, T.E., Pettit, F.H., Brown, J.R., Reed, L.J., Watson, D.C. und Dixon, G.H. (1978): Sites of phosphorylation on pyruvate dehydrogenase from bovine kidney and heart. Biochemistry, 17 (12), 2364-70.

Yogalingam, G., Pollard, T., Gliddon, B., Jolly, R.D. und Hopwood, J.J. (2002): Identification of a mutation causing mucopolysaccharidosis type IIIA in New Zealand Huntaway dogs. Genomics, 79 (2), 150-3.

Yunis, J. (1969): Biochemical Methods in Red Cell Genetics. Academic Press, New York 1969.

Zaki, F.A. und Kay, W.J. (1973): Globoid cell leukodystrophy in a miniature poodle. $J$ Am Vet Med Assoc, 163 (3), 248-50.

Zeman, W. und Dyken, P. (1969): Neuronal ceroid-lipofuscinosis (Batten's disease): relationship to amaurotic family idiocy? Pediatrics, 44 (4), 570-83. 


\subsection{Genetische Dispositionen für Vergiftungen oder Unverträglichkeiten}

\subsubsection{Kupfertoxikose}

\begin{tabular}{ll}
\hline Chromosom: & CFA10 \\
Gen: & MURR1 \\
Ensembl: & GeneID: ENSCAFE00000033576 \\
DNA-Sequenz: & CFA10, Position 65037469-65210770 \\
Mutationen: & 44133Del39,7kb, Bedlington Terrier \\
\hline
\end{tabular}

\begin{tabular}{ll|}
\hline Chromosom: & CFA10 \\
Mikrosatellit: & C04107 \\
DNA-Sequenz: & NW_876251, Position 45521335-45521495 \\
Allel 1: & $(\mathrm{GT})_{6} \mathrm{GA}(\mathrm{GT})_{11}$ \\
Allel 2: & $(\mathrm{GT})_{6} \mathrm{GA}(\mathrm{GT})_{13}$ \\
\hline
\end{tabular}

\section{Krankheitsbild}

Bei der caninen Kupfertoxikose kommt es vorrangig in der Leber zu einer übermäßigen Akkumulation von Kupfer, die zu schwerwiegenden Schädigungen der Hepatozyten führt. Betroffene Rassen sind vor allem Bedlington Terrier (Hardy et al. 1975; Johnson et al. 1980; Eriksson 1983). Weitere betroffene Rassen sind Dalmatiner (Noaker et al. 1999; Webb et al. 2002), West Highland White Terrier (Thornburg et al. 1986; Thornburg et al. 1996) und Skye Terrier (Haywood et al. 1988). Am besten untersucht ist die Kupfertoxikose bisher bei Bedlington Terriern. Aber auch in dieser Rasse sind die ursächlichen physiologischen Abläufe und die genetische Grundlage noch nicht im Einzelnen geklärt. Zwar ist ein mit der Erkrankung assoziierter Gendefekt gefunden worden, doch die Funktion des Genproduktes ist nicht bekannt und es besteht der Verdacht, dass möglicherweise weitere Defekte bei der Entwicklung der Kupfertoxikose eine Rolle spielen. In verschiedenen Untersuchungen zwischen 1978 und 1999 wurde der Anteil betroffener Bedlington Terrier in den USA mit 66 \% (Hardy und Stevens 1978 zitiert bei Coronado et al. 2003), in den Niederlanden mit $25 \%$, (Herrtage 1987 zitiert bei Coronado et al. 2003) und in Europa insgesamt mit 37 \% (Rothuizen et al. 1999) angegeben. In einer Untersuchung der Populationsdymamik der Kupfertoxikose bei Bedlington Terriern von 1977 bis 1997 konnte gezeigt werden, dass der Anteil homozygot betroffener Bedlington Terrier von $46 \%$ in den Jahren 1976 bis 1986 auf 11 \% in den Jahren 1990-1997 gesunken ist. Der Anteil heterozygoter 
Defektträger betrug in den Jahren 1990-1997 $43 \%$, die restlichen $46 \%$ der untersuchten Hunde waren homozygot gesund (Ubbink et al. 2000).

Das Krankheitsbild ist variabel. Der Verlauf der Erkrankung kann sowohl akut mit schweren, schnell fortschreitenden klinischen Erscheinungen als auch chronisch mit weniger deutlichen Symptomen oder asymptomatisch sein (Herrtage et al. 1987). Akute klinische Episoden treten vor allem bei Hunden unter sechs Jahren in Form von Appetitlosigkeit, allgemeiner Depression, Gewichtsverlust und Erbrechen auf. Einige dieser Hunde erholen sich innerhalb weniger Wochen und zeigen entweder für längere Zeiträume keine weiteren Krankheitsanzeichen oder leiden unter wiederkehrenden, akuten Episoden. In anderen Fällen kommt es innerhalb von 48 bis 72 Stunden zum Tod (Hardy 1984). Hunde mit einem chronischen Verlauf sind beim Auftreten der ersten Krankheitsanzeichen überwiegend älter als neun Jahre. Im Gegensatz zu akuten Episoden treten erste klinische Anzeichen über mehrere Wochen bis Monate eher sporadisch und in abgeschwächter Form auf. In einigen Fällen kann durch besondere Belastungen wie eine Geburt, eine einsetzende Laktation oder Schauauftritte eine akute, häufig auch tödliche Hämolyse ausgelöst werden. Auch bei einigen chronisch betroffenen Hunden liegt im Endstadium eine Hämolyse vor (Twedt et al. 1979). Bei der asymptomatischen Form zeigen betroffene Hunde trotz hoher Kupferleberwerte und teilweise geschädigten Lebergewebes keine äußerlichen Auffälligkeiten (Herrtage et al. 1987). Im Endstadium kommt es bei allen Verlaufsformen zu den typischen Anzeichen eingeschränkter Leberfunktion wie Gelbsucht, Ascites und teilweise auch zu hepatischer Enzephalopathie. Der Ausgang ist tödlich (Hardy et al. 1975; Twedt et al. 1979; Hardy 1984; Herrtage et al. 1987).

Der Grad der Leberschädigungen reicht von fokaler Hepatitis mit akuter oder subakuter Nekrose, teilweise leichter Fibrose und Infiltration durch einzelne Makrophagen und Neutrophile über eine chronische, aktive Hepatitis mit fokaler bis großräumiger Nekrose, Infiltration durch Lymphozyten und Plasmazellen, Gallenstauung und Fibrose bis hin zur mikro- und/oder makronodularen Zirrhose mit hepatozellulärer Regeneration, Hyperplasie der Gallengänge und Fibrose. Bei aktiver Hepatitis erscheint die Leber äußerlich leicht geschwollen mit abgerundeten Kanten. Eine Zirrhoseleber ist dunkelbraun und geringfügig verkleinert (Twedt et al. 1979). 
Weitere pathologische Befunde, überwiegend als Folge von Leberfunktionsstörungen, sind leichte Vergrößerung und die gelblich-braune Verfärbung der Lymphknoten, Milzvergrößerungen, das Auftreten dunkelgrüner Steine in den Nierenbecken. In der Bauchhöhle befindet sich eine klare gelbliche Flüssigkeit (Hardy et al. 1975).

Typische histopathologische Befunde sind pleomorphe Granula im Zytoplasma von Hepatozyten, die mit Fortschreiten der Erkrankung an Zahl und Größe zunehmen (Hardy et al. 1975). Bei Hunden mit Leberkupferwerten unter $2000 \mu \mathrm{g} / \mathrm{g}$ Trockengewicht sind Anzeichen von Kupferakkumulationen auf elektronendichte Lysosomen reduziert, ohne dass weitere zytoplasmatische Veränderungen vorliegen. Bei Hunden mit Kupferwerten über $7000 \mu \mathrm{g} / \mathrm{g}$ Trockengewicht zeigen sich Kupferakkumulationen in den Lysosomen, im Kern und im Zytoplasma. Die Leberzellen erscheinen geschrumpft mit kompaktierten, elektronendichten Organellen und geschrumpften verformten Kernen mit kondensiertem Chromatin und Fragmentierungen. In den Sinusoiden sind zum Teil Apoptosekörper nachweisbar (Haywood et al. 1996). In den Lymphknoten finden sich Schichten von Makrophagen mit PAS positivem, amorphem Material (Hardy et al. 1975). Bei älteren Hunden mit Kupfertoxikose können in Cerebrum, Cerebellum, Mesencephalon und Medulla Vakuolisierungen der weißen Substanz auftreten. In Hirn, Niere und Augenhornhaut liegen zum Teil erhöhte Kupferwerte vor (Hardy et al. 1975; Su et al. 1982b; Hunt et al. 1986; Herrtage et al. 1987).

Nach der derzeitigen Vorstellung von der Pathogenese wird in die Hepatozyten aufgenommenes Kupfer, das nicht in Ceruloplasmin eingebaut und zur Versorgung anderer Gewebe in den Blutkreislauf abgegeben wird, zunächst in den Lysosomen gespeichert. Durch Akkumulation von Kupfer in Lysosomen wird das Lebergewebe vor dessen toxischer Wirkung geschützt. Im Gegensatz zum gesunden Individuum erfolgt bei betroffenen Bedlington Terriern jedoch bei Erreichen der Kapazitätsgrenze der hepatischen Lysosomen kein unschädlicher Abtransport des überschüssigen Kupfers in die Gallenflüssigkeit. Darauf deutet vor allem der um ein Vielfaches geringere Kupfergehalt in der Gallenflüssigkeit betroffener Bedlington Terrier im Vergleich zu gesunden Kontrollhunden hin (Su et al. 1982a). Stattdessen kommt es zur Verlagerung von Kupfer in andere Zellbereiche, unter anderem in den Zellkern. Im Zusammenhang mit diesem Prozess treten Kernschäden auf (Haywood et al. 1996). 
Eine eindeutige Grenze für die Kupferkapazität der Lysosomen lässt sich nicht festlegen. Zwar ist ab einer Schwelle von über $2000 \mu \mathrm{g} / \mathrm{g}$ Trockengewicht ein zunehmendes Maß von Schäden an Hepatozyten zu beobachten (Twedt et al. 1979). Laut neueren Erkenntnissen scheint jedoch kein linearer Zusammenhang zwischen Kupferkonzentration und Schädigungsgrad des Lebergewebes zu bestehen. Bei einigen Hunden liegen trotz Kupferkonzentrationen bis $1000 \mu \mathrm{g} / \mathrm{g}$ Trockengewicht keinerlei sichtbare Veränderungen vor, während in einem Fall bei einem nur leicht erhöhtem Kupferwert von $403 \mu \mathrm{g} / \mathrm{g}$ Trockengewicht schwere Leberschäden auftraten (Haywood et al. 2001). Obwohl sich aus diesen Gründen kein Schwellenwert für eine pathologische Kupferkonzentration festlegen lässt, ist unbestritten, dass die Erkrankung auf einer Gewebeschädigung durch Kupfer beruht. Kupfer besitzt nachweislich einen destabilisierenden Effekt auf die DNA (Bryan und Frieden 1967), der möglicherweise mit einer durch eine $\mathrm{Cu}(\mathrm{II}) / \mathrm{Cu}(\mathrm{I})$ Redoxmechanismus verursachten Bildung freier Hydroxyl-Radikale zusammenhängt (Li und Trush 1993a; Li und Trush 1993b). Diese freien Radikale wirken möglicherweise extrem schädigend auf DNA-stabilisierende Histone. Zudem wird vermutet, dass freie Radikale als Signalmechanismus für die Aktivierung der Apoptosekaskade agieren (Haywood et al. 1996).

Seit der ersten Beschreibung der Kupfertoxikose sind verschiedene Versuche zur Definition von Kriterien für eine frühe Diagnose der Erkrankung unternommen worden. Anhand der Leberkupferwerte und des histochemischen Nachweises lysosomaler Granula lässt sich frühestens ab einem Alter von 12 Monaten das Vorliegen einer Kupfertoxikoseerkrankung mit ausreichender Sicherheit ausschließen oder diagnostizieren (Yuzbasiyan-Gurkan et al. 1997). Sehr hohe Kupferwerte von über $2000 \mu \mathrm{g} / \mathrm{g}$ und zahlreiche lysosomale Granula werden dabei allgemein als eindeutige Anzeichen einer Kupfertoxikose anerkannt (Twedt et al. 1979; Thornburg 2000). Kupferwerte unter $400 \mu \mathrm{g} / \mathrm{g}$ werden in den meisten Studien als nicht pathologisch eingeschätzt (Yuzbasiyan-Gurkan et al. 1997; Holmes et al. 1998; van de Sluis et al. 2000). Der Kupfertoxikosestatus von Hunden mit Werten zwischen 400 und 2000 pg/g wird von einzelnen Forschergruppen unterschiedlich beurteilt. Eine sichere Diagnose ist demnach bei diesen Hunden nicht möglich. 


\section{Genetischer Hintergrund}

An molekulargenetischen Methoden für die Diagnose der Kupfertoxikose bei Bedlington Terriern existiert ein Mikrosatelliten Markertest (Yuzbasiyan-Gurkan et al. 1997) und ein Test zum Nachweis einer Deletion im MURR1-Gen (neue Bezeichnung: COMMD1, copper metabolism domain 1) (van De Sluis et al. 2002). Der Rückschluss vom Genotypisierungsergebnis auf den Kupfertoxikosephänotyp ist allerdings bei beiden Testverfahren nur unter Vorbehalt $\mathrm{zu}$ ziehen. Es sind einzelne Fälle von Kupfertoxikose bei Bedlington Terriern bekannt geworden, die nach dem Ergebnis der Mikrosatelliten- und MURR1-Genotypisierung als kupfertoxikosefrei gelten (Coronado et al. 2003; Hyun et al. 2004). Demnach scheint zusätzlich zu dem bekannten Gendefekt mindestens ein weiterer noch unbekannter Gendefekt bei der Kupfertoxikose der Bedlington Terrier eine Rolle zu spielen (Haywood 2006). Im Folgenden werden die beiden bisher verfügbaren Gentests zur Diagnose von Kupfertoxikose bei Bedlington Terriern erläutert und bewertet.

Die Assoziation des MURR1-Gens mit der Kupfertoxikose bei Bedlington Terriern gelang schrittweise über die zytogenetische Lokalisierung des C04107-Markers auf dem caninen Chromosom 10q26 (van de Sluis et al. 1999) und die darauf aufbauende genauere Eingrenzung einer so genannten Kupfertoxikose-Kandidatenregion in einem Bereich von $42,3 \mathrm{cR}_{3000}$ (entspricht ca. $9 \mathrm{Mb}$ ) zwischen den Markern FH2523 und C10.602 (van de Sluis et al. 2000). Die Identifizierung des MURR1-Gens innerhalb der Kupfertoxikose-Kandidatenregion und die Entdeckung einer bei betroffenen Bedlington Terriern homozygot vorliegenden Deletion im MURR1-Gen sprechen für einen ursächlichen Zusammenhang zwischen der Deletion und der Kupfertoxikoseerkrankung bei Bedlington Terriern (van De Sluis et al. 2002). Unterstützt wird dieses Modell durch den Ausschluss verschiedener Kandidatengene, unter anderem des ATP7B-Gens, das mit einer verwandten humanen Kupferspeichererkrankung (Wilson Disease) assoziiert ist (van de Sluis et al. 1999; Coronado et al. 2003).

Das MURR1-Gen ist auf Chromosom 10 zwischen Position 65037469 und 65210770 lokalisiert (Ensembl-GeneID: ENSCAFE00000033576). Die mRNA hat eine Länge von 1478 Nukleotiden und ist in drei Exons unterteilt. Das resultierende Protein ist 188 Aminosäuren lang. Abb. 72 zeigt schematisch die Lage der einzelnen Exons in der genomischen Sequenz. 
Expressionsprofile in verschiedenen humanen Geweben zeigen die stärkste Expression in Lebergewebe (van De Sluis et al. 2002). Canine Gewebe mit deutlich messbarer Expression sind Niere, Nierenmark, Gallenblase, Thalamus, Fibroblasten, Hirn, Pankreas, Milz, periphere Leukozyten und die Leber. Es wird von einer ubiquitären Expression ausgegangen (van De Sluis et al. 2002; Klomp et al. 2003). Das canine MURR1-Gen weist hohe Homologien zum humanen und zum murinen MURR1-Gen auf. MURR1-orthologe Sequenzen finden sich außerdem bei Schweinen, Kühen und Ratten. $\mathrm{Zu}$ anderen Proteinen oder Domänen konnten jedoch keine Homologien festgestellt werden (van De Sluis et al. 2002). 


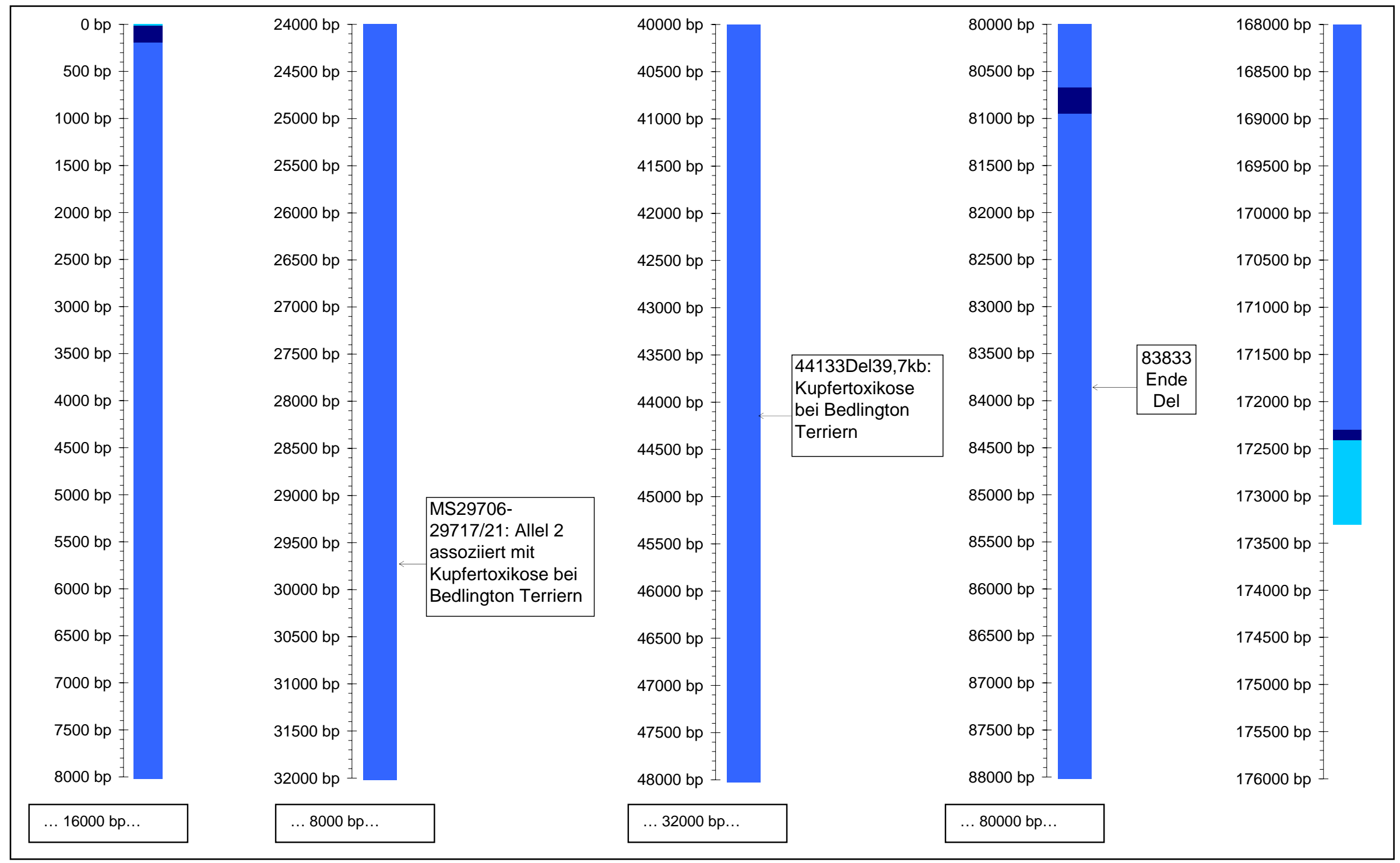

Abb. 72 Schematische Darstellung des caninen MURR1-Gens und Lage der bisher identifizierten Mutationen. Dunkelblau: codierende Sequenz, hellblau: Intronsequenz, türkis: 5'- und 3'-UTR. 


\section{III.a Assoziation eines Mikrosatellitenpolymorphismus mit Kupfertoxikose bei Bedlington Terriern}

Bei dem erwähnten Mikrosatellitenmarker handelt es sich um den Marker C04107, der auf Chromosom 10 lokalisiert ist und zwei Allele von 163 bp (Allel 1) bzw. 167 bp (Allel 2) Länge aufweist (Yuzbasiyan-Gurkan et al. 1997). Die Wiederholungssequenz lautet beim Bedlington Terrier entweder $(\mathrm{GT})_{6} \mathrm{GA}(\mathrm{GT})_{11}$ oder $(\mathrm{GT})_{6} \mathrm{GA}(\mathrm{GT})_{13}$ (Coronado et al. 2003). In der NCBI-Boxersequenz (Contig NW_876251 Position 45521335-45521495) tritt ein drittes Allel mit der Sequenz (GT)6GA(GT) $)_{10}$ auf. In zwei Untersuchungen in unabhängigen Populationen lag bei je 25 betroffenen Hunden mit Kupferwerten in der Leber von $>1000 \mu \mathrm{g} / \mathrm{g}$ (Yuzbasiyan-Gurkan et al. 1997) bzw. „pathologischen Kupferwerten“ (Rothuizen et al. 1999) Allel 2 homozygot vor. Dieses Kopplungsungleichgewicht bestätigt sich zum Teil auch in Folgeuntersuchungen in anderen Populationen (Proschowsky et al. 2000). In einigen Fällen in anderen Untersuchungen scheint jedoch stattdessen Allel 1 mit der Kupfertoxikoseerkrankung zu segregieren (Holmes et al. 1998; van de Sluis et al. 2000), bzw. haben Bedlington Terrier, die homozygot für Allel 2 sind, normale Kupferwerte und zeigen keinerlei Krankheitsanzeichen (Haywood et al. 2000; Haywood et al. 2001). Bei der Beurteilung der Ergebnisse ist allerdings $\mathrm{zu}$ berücksichtigen, dass in einzelnen Studien unterschiedliche Kriterien für die Zuordnung zum Status „Betroffen“ zugrunde gelegt wurden. Bei einem als „betroffen“ eingestuften C04107-heterozygoten Bedlington Terrier lag beispielsweise ein Kupferleberwert von $945 \mu \mathrm{g} / \mathrm{g}$ vor, für einen weiteren als betroffen bezeichneten Hund der homozygot für C04107-Allel 1 war, ist lediglich angegeben, dass der Kupferwert in der Leber $>400 \mu \mathrm{g} / \mathrm{g}$ betrug (Holmes et al. 1998). Ein Kupferleberwert von $370 \mu \mathrm{g} / \mathrm{g}$ und eine mäßige Anzahl von lysosomalen Granula bei einem für C04107-Allel 2 homozygoten Bedlington Terrier (Haywood et al. 2001) geben allerdings ein deutlicheres Beispiel für die Unvereinbarkeit von Mikrosatellitengenotyp und Kupfertoxikosestatus bei einzelnen Hunden. Diese Ergebnisse lassen sich am einfachsten durch das bei Markertests stets einzukalkulierende Auftreten einer Rekombination zwischen Marker und ursächlichem Gendefekt erklären. Damit ist eine Verwendung des C04107-Markertests zur Identifizierung von betroffenen Hunden und heterozygoten Defektträgern nur innerhalb einer Subpopulation zu empfehlen, innerhalb derer die Kupfertoxikose nachweislich mit 
dem C04107-Allel 2 segregiert. In einem solchen Fall wird der Test allgemein als zuverlässige Methode eingeschätzt (Holmes et al. 1998; Holmes et al. 2000).

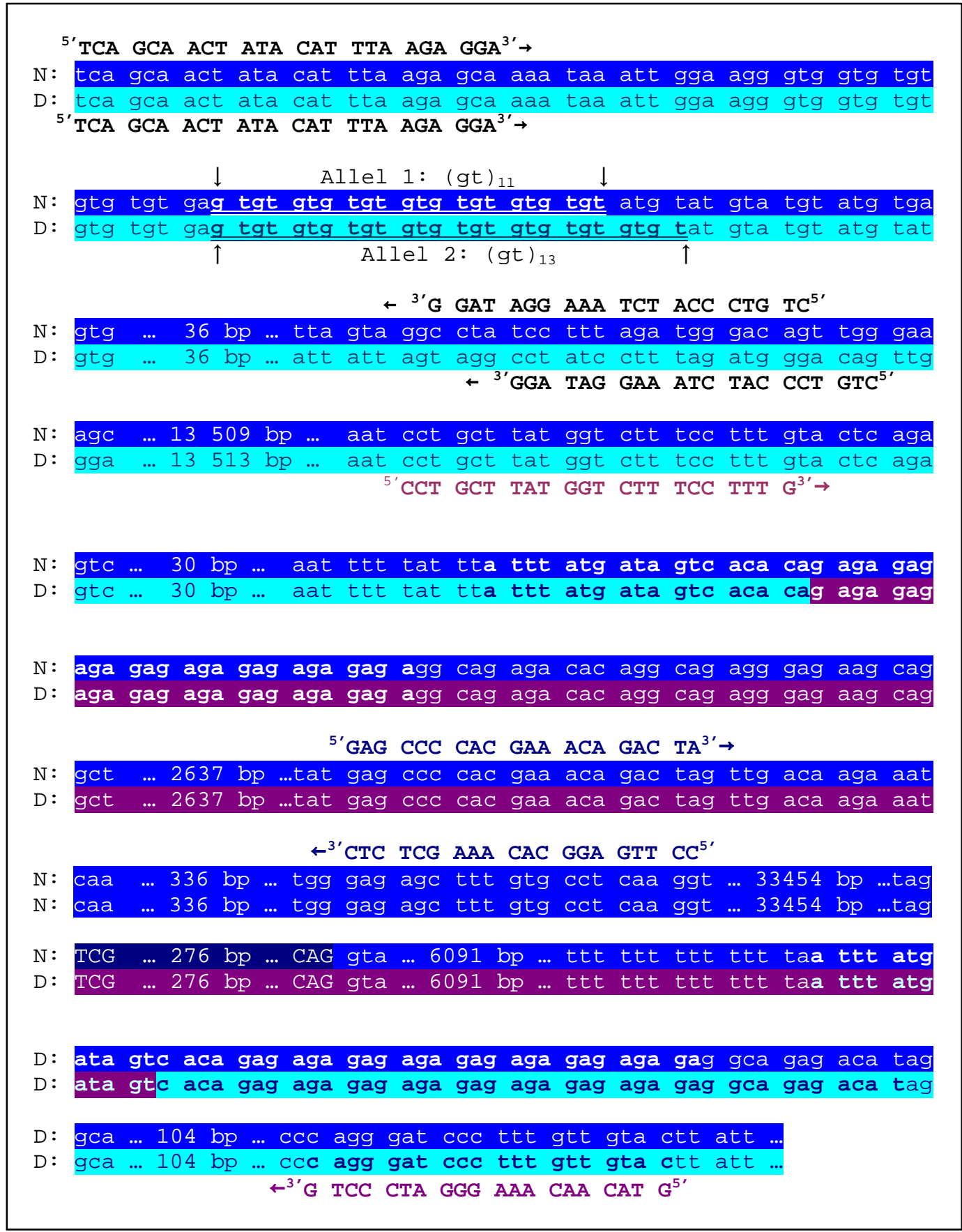

Abb. 73 Exon 2 des MURR1-Gens umgeben von Sequenzabschnitten aus Intron 1, beginnend beim C04107-Mikrosatellitenmarker, und Intron 2 (Ensembl-GeneID: ENSCAFE00000033576). N: normale Sequenz, D: defekte Sequenz, hellblau: Intron normale Sequenz, türkis: Intron defekte Sequenz, dunkelblau: Exon normale Sequenz, Sequenzunterschiede zwischen normalen Hunden und Defektträgern in der C04107-Markersequenz doppelt unterstrichen und durch Pfeile gekennzeichnet, deletierte Sequenz violett unterlegt, dunkelblaue Schrift: wildtypallelspezifischer Primer, violette Schrift: defektallelspezifischer Primer, die Deletion flankierende Sequenzen in normaler und defekter Sequenz fett gedruckt. 


\section{IV.a Genotypisierung für den mit Kupfertoxikose bei Bedlington Terriern assoziierten Mikrosatellitenpolymorphismus}

Die Bestimmung des C04107-Genotyps kann per Amplifikation der Mikrosatellitensequenz und anschließender PCR-Fragmentgrößenanalyse (YuzbasiyanGurkan et al. 1997) gegebenenfalls unter Einsatz eines automatische Sequenziergerätes (Holmes et al. 1998).

\section{III.b Ursächliche Mutation für Kupfertoxikose bei Bedlington Terriern}

Die bei betroffenen Bedlington Terriern gefundene Deletion betrifft Exon 2 des MURR1-Gens und angrenzende Intronbereiche (van De Sluis et al. 2002). Sie hat eine Länge von 39,7 kb. Die Grenzbereiche der Deletion weisen in der normalen Sequenz eine hohe Homologie auf. Im linken Grenzbereich lautet die Sequenz ATT-TAT-GATAGT-(CA) $)_{3}-(\mathrm{GA})_{13}$, im rechten Grenzbereich ATT-TAT-GAT-AGT-(CA) $)_{2}-(\mathrm{GA})_{13}$. Das 5'-Ende der gelöschten Sequenz befindet sich stromaufwärts der tripel-CAMultiplikation, das 3'-Ende stromaufwärts der CA-Duplikation. Möglicherweise ist die beobachtete Homologie die Ursache der 39,7-kb-Deletion als Folge einer fehlerhaften Rekombination (Abb. 73) (Forman et al. 2005).

Obwohl der überwiegende Teil der Untersuchungsergebnisse für einen ursächlichen Zusammenhang der Deletion im MURR1-Gen mit der Kupfertoxikose bei Bedlington Terriern sprechen, gibt es einige Widersprüche.

Als Folge der Deletion lässt sich eine Verkürzung des resultierenden Proteins von 188 auf 94 Aminosäuren vorhersagen (van De Sluis et al. 2002). Spätere Western-BlotAnalysen zeigen einen vollständigen Verlust der Expression von MURR1 in der Leber betroffener Bedlington Terrier. Diese Defizienz wird als Hinweis auf eine Funktion des MURR1-Proteins im Kupferstoffwechsel der Leber gedeutet (Klomp et al. 2003). Einzelheiten hierzu sind bisher nicht geklärt worden.

Da MURR1 unter anderem auch in Lysosomen lokalisiert werden konnte, ist eine mögliche Rolle bei der Regulation der lysosomalen Kupferabgabe nicht ausgeschlossen. Die ubiquitäre Expression von MURR1 spricht allerdings eher für eine pleiotrope Funktion. Die Expression und subzelluläre Lokalisation von MURR1 ist im Gegensatz zu dem Protein ATP7B unabhängig von der extrazellulären Kupferkonzentration 
(Klomp et al. 2003). ATP7B ist im trans-Golgi-Netzwerk von Hepatozyten lokalisiert und scheint essentiell für die Überführung überschüssigen Kupfers aus dem Zytosol in vesikuläre Kompartimente in der Umgebung der Gallenkanälchen zu sein. Bei erhöhter Kupferkonzentration verlagert sich die Verteilung von ATP7B in die Nähe der Membranen von Gallenkanälchen (Schaefer et al. 1999). Der genauere Ablauf dieses Prozesses ist nicht bekannt. Nähere Hinweise auf einen Zusammenhang zwischen der Deletion im MURR1-Gen und der gestörten Überführung von Kupfer aus den Hepatozyten in die Gallenflüssigkeit erbrachte der Nachweis einer spezifischen Interaktion zwischen dem ATP7B-Protein und dem MURR1-Protein. Als eine mögliche Funktion von MURR1 wird eine Beteiligung an der Bildung und Lokalisierung zellspezifischer Organellen vermutet, die möglicherweise Voraussetzung für eine Überführung von Kupfer in die Gallenflüssigkeit sein könnten (Tao et al. 2003).

Eine Gegenüberstellung von C04107- und MURR1-Genotypisierungsergebnissen spricht für eine eng gekoppelte Vererbung der MURR1-Deletion mit dem C04107-Allel 2. Alle untersuchten betroffenen Hunde aus einer finnischen Bedlington Terrier Population, die am C04107-Lokus homozygot für Allel 2 waren, zeigten auch homozygot die Deletion im MURR1-Gen (Coronado et al. 2003). Die enge Kopplung der beiden Genorte ergibt sich aus der Lokalisation von C04107 in Intron 1 des MURR1 Gens (van De Sluis et al. 2002). Die bereits diskutierte Entkopplung des C04107-Allels 2 vom Kupfertoxikoselokus scheint in einigen Fällen auch bei der gefundenen MURR1Deletion vorzuliegen. Zwei betroffene Hunde mit Kupferleberwerten über $1000 \mu \mathrm{g} / \mathrm{g}$, die am C04107-Lokus entweder heterozygot oder homozygot für Allel 1 typisiert wurden, waren auch heterozygot für die Exon 2 Deletion bzw. zeigten homozygot die komplette Exon 2 Sequenz im MURR1-Gen (Coronado et al. 2003). Eine enge Kopplung der Deletion im MURR1-Gen mit C04107-Allel 2 konnte auch in einer späteren Studie bestätigt werden (Forman et al. 2005). Allerdings ist auch durch die Lage des C04107-Markers im Intron 1 des MURR1-Gens eine Rekombination nicht ausgeschlossen. In mehreren Studien wurden Fälle von Rekombination zwischen der Deletion und dem C04107-Allel 2 nachgewiesen (van de Sluis et al. 2003; Hyun et al. 2004). In einer Studie an 8 Bedlington Terrier Pedigrees konnten in einem Pedigree sechs Hunde identifiziert werden, bei denen C04107-Allel 2 gekoppelt mit einem vollständigen Exon 2 vorlag. Alle sechs Hunde wiesen Leberkupferwerte über 
$1000 \mu \mathrm{g} / \mathrm{g}$ auf (Hyun et al. 2004). Neben dem Auftreten einer Rekombination zwischen Allel 2 und der Exon-2-Deletion zeigt dieses Ergebnis, dass die MURR1-Mutation nicht in allen Fällen von Kupfertoxikose bei Bedlington Terriern der ursächliche Gendefekt ist.

Abschließend muss festgestellt werden, dass der C04107-Marker in vielen Bedlington Terrier Subpopulationen eng mit dem Kupfertoxikoselokus gekoppelt ist. Der Einsatz des C04107-Markertests zur Identifizierung von heterozygoten Defektträgern ist aufgrund des Auftretens von Rekombinationen (Hyun et al. 2004) nur in Subpopulationen empfehlenswert, in denen bereits an verwandten betroffenen Hunden eine Kopplung von Allel 2 mit dem verantwortlichen Gendefekt nachgewiesen wurde.

Trotz zahlreicher Erkenntnisse, die eindeutig für einen ursächlichen Zusammenhang zwischen der Deletion im MURR1-Gen und der Kupfertoxikose sprechen, ist noch kein eindeutiger Beweis für diese These erbracht worden.

Die Kupfertoxikosefälle bei Bedlington Terriern mit mindestens einer vollständigen Kopie des Exons 2 lassen sich nach heutigem Kenntnisstand nicht erklären. Die Deletion im MURR1-Gen ist entweder nicht die ursächliche Mutation für Kupfertoxikose und eine noch unbekannte zusätzliche Mutation ist Voraussetzung für die Entwicklung der Erkrankung, oder die MURR1-Mutation ist nur in bestimmten Bedlington Terrier Subpopulationen Ursache der Kupfertoxikose, während der Krankheit in anderen Subpopulationen eine andere Mutation zugrunde liegt. Bis diese Fragen geklärt sind, bieten sowohl die C04107-Genotypisierung als auch der SouthernBlot-Nachweis der An- bzw. Abwesenheit von Exon 2 unter Berücksichtigung der genannten Einschränkungen eine geeignete Grundlage für die Selektion gegen Kupfertoxikose (Forman et al. 2005; Haywood 2006).

\section{IV.b Genotypisierung für Kupfertoxikose bei Bedlington Terriern}

Der Nachweis der Deletion kann per ASP erfolgen (Abb. 73) (Forman et al. 2005). 


\subsubsection{Erythrozytäre Hypokatalasie}

\begin{tabular}{ll|}
\hline Chromosom: & CFA18 \\
Gen: & CAT \\
NCBI: & GeneID: 403474 \\
DNA-Sequenz: & NW_876266 Position 8120979-8080736 \\
Mutationen: & G979A \\
\hline
\end{tabular}

\section{Krankheitsbild}

Die Hypo- oder Akatalasie, soll der Vollständigkeit halber erwähnt werden, auch wenn sie in der tierärztlichen Praxis nahezu keine Rolle spielt. Erstmals bei Hunden beschrieben wurde die Hypokatalasie 1982 in Japan (Fukuda et al. 1982; Tanase 1982, zitiert bei Nakamura; Nakamura et al. 2000). Generell zeigen akatalasemische Hunde keine Symptome, gelegentlich tritt allerdings eine gangräne, orale Erkrankung auf (Nakamura et al. 1999), die dem bei japanischen Akatalase Patienten beschriebenen Morbus Takahara ähnelt (Takahara und Miyamoto 1948, zitiert bei Nakamura et al. 1999). Katalase katalysiert den Abbau von Wasserstoffperoxid zu Wasser und Sauerstoff um die Zellen vor der toxischen Wirkung von Wasserstoffperoxid zu schützen. Kennzeichen der Hypokatalasie bei Hunden ist ein auf die Erythrozyten beschränkter Mangel an funktionsfähiger Katalase (Fukuda et al. 1982). Leber und Niere weisen bezüglich der Katalaseaktivität keinerlei Unterschiede zu gesunden Hunden auf und Katalase mRNA wird sowohl in Geweben und Organen als auch im Blut von Hypokatalase Hunden exprimiert (Nakamura et al. 1999). Auch in Retikulozyten von Hypokatalase-Hunden wird Katalase exprimiert, wenn auch zu einem geringeren Grad als in den Retikulozyten gesunder Hunde $(0,013 \%$ der gesamten Proteinexpression nach 30 min gegenüber 0,016 \% der gesamten Proteinexpression nach $30 \mathrm{~min}$ ) (Nakamura et al. 2000). Zudem wird Katalase in Hypokatalase Retikulozyten achtmal schneller abgebaut als in normalen Retikulozyten. Es ist also davon auszugehen, dass Katalase in allen Geweben von Hypokatalase Hunden auf einem normalen Level translatiert wird, aufgrund einer Mutation jedoch in Retikulozyten sehr schnell abgebaut wird, so dass in Erythrozyten betroffener Hunde keinerlei Katalase nachweisbar ist (Nakamura et al. 2000). Die besondere Anfälligkeit gegen proteolytischen Abbau von mutierter Katalase in Erythrozyten im Gegensatz zu mutierter Katalase in Leber- und Nierenzellen, hängt möglicherweise mit der Lokalisation von Katalase in den betreffenden Zellen zusammen. Während Katalase in Erythrozyten im Zytosol lokalisiert ist und damit dem proteolytischen System direkt 
zugänglich ist, ist Katalase in Nieren- und Leberzellen in der Matrix lokalisiert und dadurch vor dem Abbau geschützt (Nakamura et al. 2000).

\section{Genetischer Hintergrund}

Die canine cDNA-Sequenz und die daraus abgeleitete Aminosäurensequenz der Katalase wurden 1998 veröffentlicht (Nakamura et al. 1998). Das Katalase-Gen ist auf Chromosom 18 zwischen Position 8120979 und Position 8080736 im genomischen Contig NW_876266 lokalisiert und setzt sich aus 13 Exons zusammen (NCBI-GeneID: 403474). Bei der Mutation, die bei Beagles für die Ausbildung der Hypokatalasie verantwortlich ist, handelt es sich um einen Austausch von Guanin durch Adenin an Position 979 der cDNA, der zu einem Austausch von Alanin zu Threonin an Aminosäurenposition 327 führt (Nakamura et al. 2000).

\subsubsection{Ivermectin-Unverträglichkeit}

\begin{tabular}{|ll|}
\hline Chromosom: & CFA14 \\
Gen: & MDR1 \\
Ensembl: & TranscriptID: ENSCAFT00000002896 \\
DNA-Sequenz: & CFA14, Position 16594871-16692599 \\
& Del295-298, Collie, Australischer Schäferhund, \\
& Australischer Zwergschäferhund, Englischer \\
Mutationen: & Schäferhund, Langhaarwhippet, Shetland \\
& Schäferhund, Altenglischer Schäferhund, McNab, \\
& Silken Windhund \\
\hline
\end{tabular}

\section{Krankheitsbild}

Ivermectin ist ein semi-synthetisches Lacton aus der Familie der Avermectine, das in der Veterinärmedizin großräumig zur Behandlung von Nematoden- und ArthropodenInfektionen eingesetzt wird. Die antiparasitäre Wirkung von Ivermectin beruht auf einer Potenzierung der Leitfähigkeit von Glutamat- und/oder Gammaaminobuttersäure(GABA-) gesteuerten Chloridkanälen des Nervensystems mit der Folge einer tonischen Paralyse (Muskelerstarrung) (Fisher und Mrozik 1992). Eine solche Reaktion tritt bei allen wirbellosen Tieren auf, die über GABA-gesteuerte Chloridkanäle verfügen. Bei Wirbeltieren sind GABA-gesteuerte Chloridkanäle auf das zentrale Nervensystem beschränkt. Durch die Blut-Hirn-Schranke wird der Zugang von injiziertem Ivermectin zu diesen Chloridkanälen jedoch verhindert, so dass eine Ivermectin-Behandlung bei Wirbeltieren nicht zu unerwünschten Nebeneffekten führt (Tracy und Webster 1995). 
Als übliche Dosierung bei Hunden gelten $200 \mathrm{mcg} / \mathrm{kg}$. Bei einer großen Anzahl von Hunden traten bei dieser Dosierung keinerlei unerwünschte Nebenwirkungen auf. Bei Beagles sind bei Einzeldosen von bis $\mathrm{zu} 2000 \mathrm{mcg} / \mathrm{kg}$ keinerlei Vergiftungserscheinungen zu beobachten. Dosierungen zwischen 2500 und 20000 $\mathrm{mcg} / \mathrm{kg}$ führen zu zunehmenden neurologischen Störungen. Dosierungen über 40000 $\mathrm{mcg} / \mathrm{kg}$ sind tödlich (Campbell und Benz 1984). Bei Collies kann bereits 1/200 dieser Dosis tödliche Vergiftungserscheinungen hervorrufen. Demnach scheint das Auftreten der Unverträglichkeit abhängig von der Rasse zu sein. Weitere Rassen mit gehäuftem Auftreten von Ivermectin-Unverträglichkeit sind Border Collies, Shetland Schäferhunde, Altenglische Schäferhunde und Australische Schäferhunde. Typische Symptome sind Ataxie, Tremor, Mydriase (Pupillenerweiterung), Festliegen und Tod. Das rasseabhängige Auftreten der Empfindlichkeit spricht für das Vorliegen einer genetischen Disposition (Pulliam et al. 1985).

In Folgeuntersuchungen zeigten Hunde mit Überempfindlichkeit für Ivermectin auch Unverträglichkeiten für weitere Medikamente (Mealey et al. 2003; Sartor et al. 2004; Henik et al. 2006). Wirkstoffe, die bei betroffenen Hunden zu Überreaktionen führen können sind in Tabelle 12 aufgeführt.

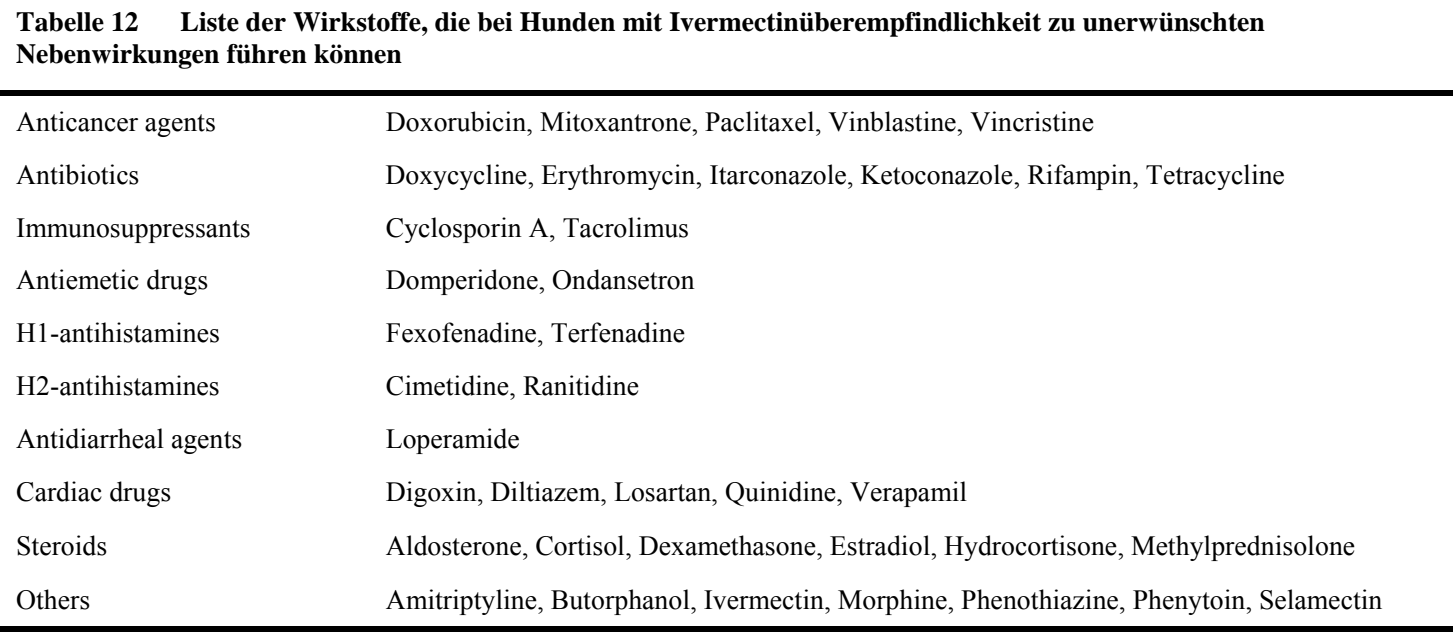

übernommen von (Henik et al. 2006)

Die beschriebene Überempfindlichkeit tritt vor allem bei Collies auf. Untersuchungen unter Einsatz eines DNA-Tests ergaben für diese Rasse einen Anteil von $42 \%$ heterozygoten Defektträgern und $35 \%$ betroffenen Hunden im Nordwesten der USA (Mealey et al. 2002), 31,2 \% homozygot betroffene und 46,8 \% heterozygote in den 
gesamten USA (Neff et al. 2004) und $24 \%$ homozygote und $64 \%$ heterozygote Defektträger in Australien (Mealey et al. 2005).

Weitere betroffene Rassen sind Australische Schäferhunde (1,7\% homozygote und $29,8 \%$ heterozygote Defektträger), Australische Zwergschäferhunde (3,6 \% homozygote und 44,6 \% heterozygote Defektträger), Englische Schäferhunde (keine homozygoten und 14,3 \% heterozygote Defektträger), Langhaarwhippet (15,7 \% homozygote und 51,7 \% heterozygote Defektträger), McNab (2,8\% homozygote und 28,6 \% heterozygote Defektträger), Altenglische Schäferhunde (keine homozygoten und $7,3 \%$ heterozygote Defektträger), Shetland Schäferhunde (1,1 \% homozygote und $14,7 \%$ heterozygote Defektträger) und Silken Windhunde (1,2\% homozygote und $33,3 \%$ heterozygote Defektträger) (Neff et al. 2004).

\section{Genetischer Hintergrund}

Die Ursache der hereditären Ivermectin-Unverträglichkeit wird auf eine Störung der Blut-Hirn-Schranke zurückgeführt. Normale Ivermectinkonzentrationen im ZNS behandelter Tiere betragen zwischen $1 / 10$ oder $1 / 100$ der Plasma- oder Leberkonzentrationen. Bei betroffenen Collies liegen die ZNS-Konzentrationen von Ivermectin deutlich höher (Pulliam et al. 1985). Verschiedene Untersuchungen an Mäusen zeigen einen Zusammenhang zwischen Defekten des MDR1 Gens und einer erhöhten Empfindlichkeit gegenüber Ivermectin (Schinkel et al. 1994; Schinkel et al. 1996; van Asperen et al. 1997; Kwei et al. 1999). MDR1 codiert für das PGlykoprotein, das als Transmembranproteinpumpe unter anderem in den Endothelzellen der Hirnkapillaren exprimiert wird. P-Glykoprotein ist an der Aufrechterhaltung der Blut-Hirn-Schranke beteiligt, indem es verschiedene Substrate, darunter auch Ivermectin, bindet und aus den Endothelzellen der Hirnkapillaren ins Kapillarlumen überführt (van Asperen et al. 1997).

Das canine MDR1-Gen ist auf Chromosom 14 lokalisiert und aus 30 Exons zusammengesetzt (ENSCAFT00000002896), die für ein 1281 bp langes Protein codieren (Roulet et al. 2003). Abb. 74 zeigt die Lage der einzelnen Exons innerhalb der genomischen Sequenz. 


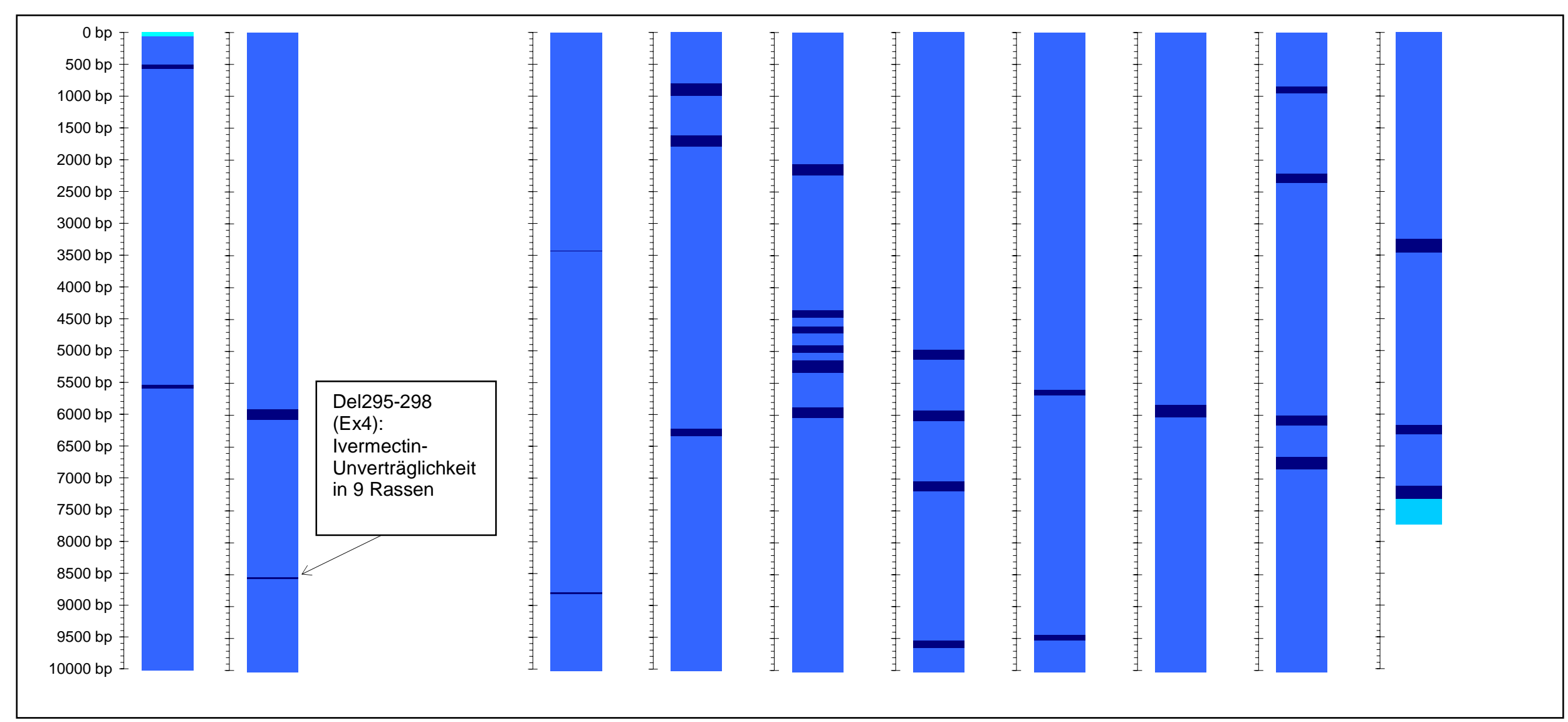

Abb. 74 Schematische Darstellung des caninen MDR1-Gens und bisher identifizierte Mutationen. Dunkelblau: codierende Sequenz, hellblau: Intron, türkis: 5'- und 3'UTR. 


\section{Ursächliche Mutation für Ivermectin-Unverträglichkeit in neun Rassen}

Bei betroffenen Collies wurde eine homozygote Mutation im MDR1-Gen identifiziert, die $\mathrm{zu}$ einer Verschiebung des Leserasters und der Entstehung eines verfrühten Stoppcodons führt. Es handelt sich um eine vier Nukleotide umfassende Deletion innerhalb der ersten $10 \%$ der mRNA (NCBI-GenBank AF045016) (Abb. 75) (Mealey et al. 2001).

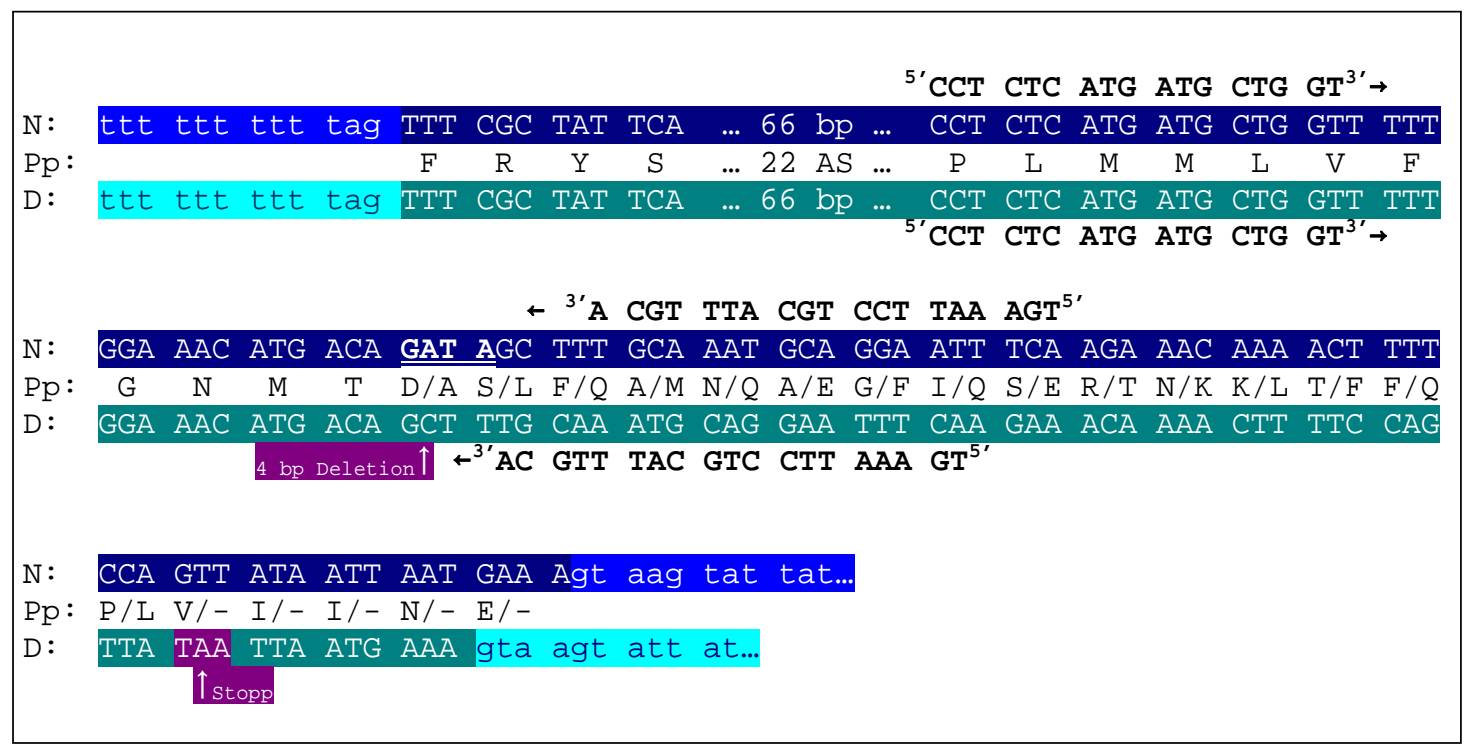

Abb. 75 Exon 4 des caninen MDR1 Gens und angrenzende Intronsequenzen. N: normale Sequenz, D: defekte Sequenz, Pp: Polypeptidsequenz, dunkelblau: Exon normale Sequenz, dunkelgrün: Exon defekte Sequenz, hellblau: Intron normale Sequenz, türkis: Intron defekte Sequenz, von Deletion betroffene Sequenz in der normalen Sequenz doppelt unterstrichen, Ort der Deletion in der defekte Sequenz durch Pfeil gekennzeichnet, verfrühtes Stoppcodon in defekter Sequenz violett unterlegt und durch Pfeil gekennzeichnet.

Aufgrund des verfrühten Stoppcodons an Position 91 ist das resultierende Protein auf 7,1 \% seiner ursprünglichen Länge reduziert und enthält keinerlei enzymatisch aktive Domänen. Bei Western-Blot-Untersuchungen von Lebergewebe betroffener und gesunder Hunde mit einem gegen das humane P-Glykoprotein gerichteten Antikörper, der im Gewebe normaler Hunde für einen P-Glykoprotein-Nachweis geeignet ist, konnte im Gewebe betroffener Hunde kein P-Glykoprotein nachgewiesen werden (Roulet et al. 2003). Die Ergebnisse sprechen dafür, dass es sich bei der Deletion um die ursächliche Mutation für die Ivermectin-Unverträglichkeit bei Collies handelt. Weitere Rassen, in denen die Mutation nachgewiesen wurde sind Australischer Schäferhund, Australischer Zwergschäferhund, Englischer Schäferhund, Langhaarwhippet, McNab, Altenglischer Schäferhund, Shetland Schäferhund und Silken Windhund. 


\section{Genotypisierung für Ivermectin-Unverträglichkeit in neun Rassen}

Der Nachweis der Mutation kann per Amplifikation des potentiell von der Deletion betroffenen Fragmentes aus Exon 4 und anschließender PCR-Fragmentgrößenanalyse erfolgen (Roulet et al. 2003).

\subsubsection{Varianten des caninen Arzneimittelstoffwechsels: CYP1A2- Polymorphismus}

\begin{tabular}{ll}
\hline Chromosom: & CFA30 \\
Gen: & CYP1A2 \\
Ensembl: & GeneID: ENSCAFG00000017941, TranscriptID: \\
DNA-Sequenz: & ENSCAFT00000028479 \\
Mutationen: & CFA30, Position 40815981-40821668 \\
\hline
\end{tabular}

\section{Phänotyp}

Die Isoenzyme des Cytochrom P450 spielen eine entscheidende Rolle beim oxidativen Abbau von Xenobiotoka und endogenen Substanzen (Rendic und Di Carlo 1997). Aus der Humanmedizin sind verschiedene Fälle bekannt, in denen Polymorphismen in Cytochrom-P450-Isoenzymen zu interindividuellen Unterschieden des Stoffwechsels und der Pharmakokinetik bestimmter Arzneimittel führen (http://www.cypalleles.ki.se/ 2001).

Beim Hund sind inzwischen verschiedene Isoenzyme des Cytochrom P450 kloniert und sequenziert worden, darunter CYP1A1/2 (Uchida et al. 1990) sowie verschiedene CYP2 Varianten (Graves et al. 1990; Uchida et al. 1990; Sakamoto et al. 1995; Blaisdell et al. 1998; Lankford et al. 2000) und eine CYP3 Variante (Uchida et al. 1990; Ciaccio et al. 1991). Der erste veröffentlichte stoffwechselwirksame Polymorphismus in einem der Cytochrom-P450-Isoenzyme betrifft das CYP1A2-Gen und beeinflusst den Abbau des kognitiven Enhancers AC-3933 (Mise et al. 2004a). AC-3933 wird zur Verbesserung des Erinnerungsvermögens eingesetzt. Diese Wirkung beruht auf einer Verringerung der Aktivität von $\gamma$-Aminobuttersäure über allosterische Mechanismen und einer dadurch bedingten Verstärkung der cholinergen Funktionen (Mise et al. 2004b).

Der Abbau von AC-3933 erfolgt vorrangig per Hydroxylierung zu SX-5745 und anschließender Reduktion zu SX-6088 sowie über einen Nebenabbauweg per Demethylierung zu SX-5773. Bei Hunden existieren zwei verschiedene AC-3933Stoffwechseltypen. Beim extensiven Typ (extensive metabolizer, EM) sind im Verlauf 
von $24 \mathrm{~h}$ nach Administration von AC-3933 die Serumkonzentrationen von SX-5745 ebenso hoch wie oder höher als die Werte für AC-3933. Der Abbau von AC-3933 erfolgt also zügig und in hohem Maße über Hydroxylierung. Beim schwachen Typ (poor metabolizer, PM) liegt die Serumkonzentration von SX-5745 im Verlauf von $24 \mathrm{~h}$ nach Administration von AC-3933 deutlich unterhalb der Konzentration von AC-3933. Die Hydroxylierung von AC-3933 erfolgt bei PM-Hunden also in deutlich geringerem Maße als bei EM-Hunden (Mise et al. 2004b).

Immunologische Versuche unter Einsatz spezifischer Inhibitoren gegen einzelne Cytochrom-P450-Isoenzyme ergaben, dass die Hydroxylierung von AC-3933 bei EMHunden mittels Antikörper gegen CYP1A2 deutlich gehemmt werden kann. Mittels Immunoblot ließ sich bei PM-Hunden im Gegensatz zu EM-Hunden keine Expression von CYP1A messen, während die Expression anderer Cytochrom-P450-Isoenzyme bei beiden Stoffwechseltypen übereinstimmte (Mise et al. 2004b).

\section{Genetischer Hintergrund}

Laut Ensembl-Datenbankeintrag (ENSCAFG00000017941) ist das CYP1A2-Gen auf Chromosom 30 zwischen Position 40815981 und 40821668 lokalisiert und enthält sieben Exons. Die Länge des offenen Leserasters beträgt bei EM-Hunden 1536 bp, das resultierende Protein hat eine Länge von 512 Aminosäuren (Mise et al. 2004a). Dieser Beschreibung entspricht am ehesten eine unter ENSCAFT00000028479 veröffentlichte Transkriptsequenz, deren offenes Leseraster eine Länge von 1557 bp aufweist und für ein 519 Aminosäuren langes Protein codiert. Dieses Transkript ist Grundlage der in Abb. 76 dargestellten Struktur des caninen CYP1A2-Gens. 


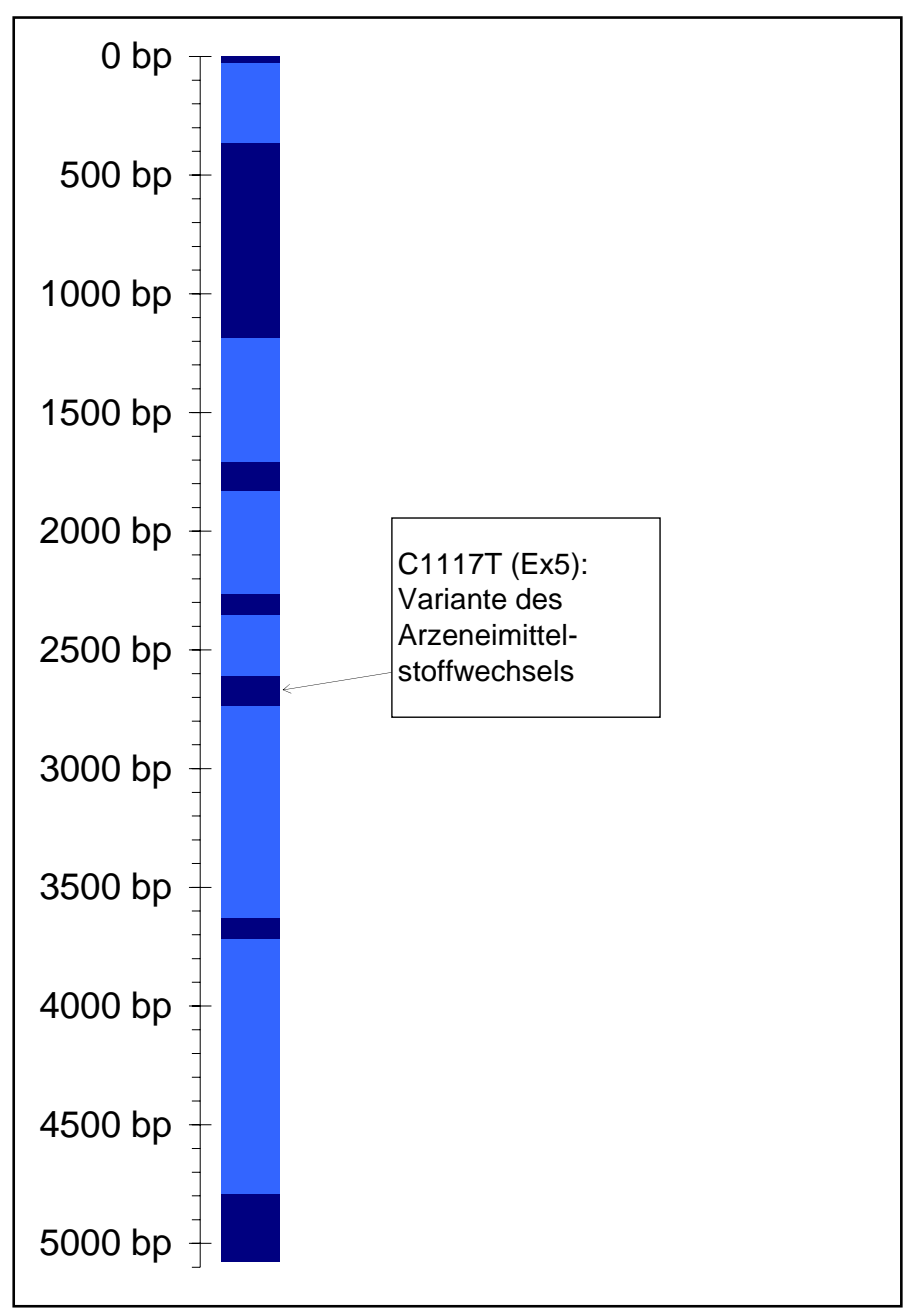

Abb. 76 Schematische Darstellung des caninen CYP1A2-Gens und Lage der bisher identifizierten Mutationen. Dunkelblau: codierende Sequenz, hellblau: Intron.

\section{Stoffwechselwirksame Mutation des Isoenzyms CYP1A2}

Bei PM-Hunden liegt eine Substitution von Cytosin durch Thymin an Position 1117 vor, die zur Entstehung eines verfrühten Stoppcodons führt (Abb. 77). Das resultierende Protein ist mit 373 Aminosäuren um 140 Aminosäuren kürzer als das CYP1A2-Protein von EM-Hunden. Durch den verfrühten Abbruch der Translation geht die HämBindungsstelle und damit die Monooxygenase Aktivität des Proteins verloren (Mise et al. 2004a). Die CYP1A2-cDNA-Sequenzen von EM- und PM-Hunden sind in der NCBI-Datenbank veröffentlicht (NCBI-GenBank: AB094347 bzw. AB094349) (Mise et al. 2004a). 


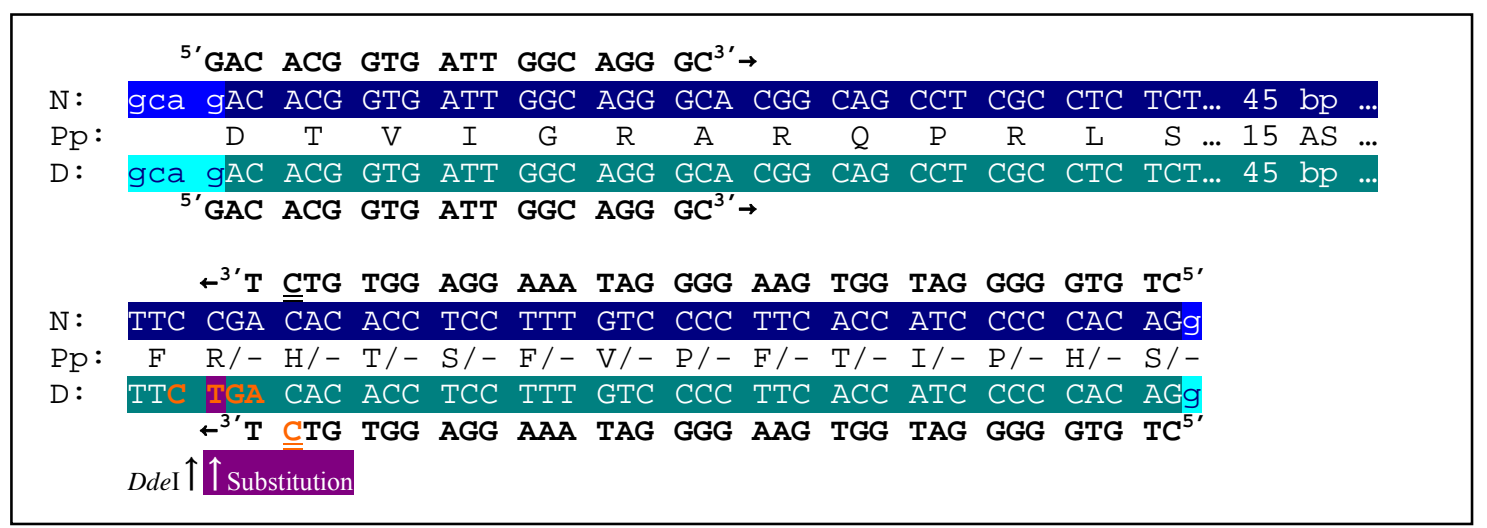

Abb. 77 Exon 5 des caninen CYP1A2-Gens und angrenzende Intronsequenzen. N: normale Sequenz, D: defekte Sequenz, hellblau: Intron normale Sequenz, dunkelblau: Exon normale Sequenz, türkis: Intron defekte Sequenz, dunkelgrün: Exon defekte Sequenz, rote Schrift: DdeI-Erkennungssequenz, Substitution in defekter Sequenz violett unterlegt und durch Pfeil gekennzeichnet, DdeI-Schnittstelle durch Pfeil gekennzeichnet, mismatch zur Konstruktion der DdeI-Erkennungssequenz im reversen Primer doppelt unterstrichen.

\section{Genotypisierung für den stoffwechselwirksamen CYP1A2-Polymorphismus}

Der Nachweis der Substitution kann über die Amplifikation eines 124-bp-Fragments unter Einsatz eines reversen mismatch-Primers, der für die Entstehung einer DdeIErkennungssequenz im Defektallel sorgt, und anschließender RFLP-Analyse erfolgen (Mise et al. 2004a). 


\subsubsection{Primerliste}

Tabelle 13 Liste der in Kapitel 3.4 genannten Primer

\begin{tabular}{|c|c|c|c|c|}
\hline Krankheit/Merkmal & Zweck & Primer & $\begin{array}{l}\text { PCR- } \\
\text { Produkt } \\
\text { [bp] }\end{array}$ & Quelle \\
\hline $\begin{array}{l}\text { Kupfertoxikose bei } \\
\text { Bedlington Terriern }\end{array}$ & ASP & 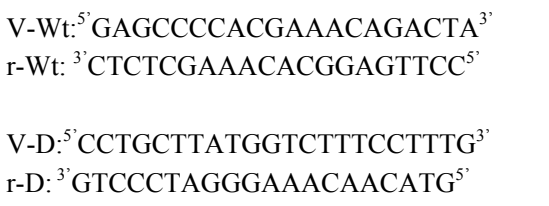 & 395 & $\begin{array}{l}\text { (Forman et al. } \\
\text { 2005) }\end{array}$ \\
\hline & $\begin{array}{l}\text { Mikrosatelliten- } \\
\text { polymorphismus }\end{array}$ & $\begin{array}{l}\text { V: 'TCAGCAACTATACATTTAAGAGGA }{ }^{3} \\
\text { r: }{ }^{3} \text { 'GGATAGGAAATCTACCCTGTC }\end{array}$ & & $\begin{array}{l}\text { (Yuzbasiyan- } \\
\text { Gurkan et al. } \\
\text { 1997) }\end{array}$ \\
\hline
\end{tabular}

V: Vorwärtsprimer, 5'-3'-Richtung, r: reverser Primer, 3'-5'-Richtung, V-Wt: wildtypallelspezifischer Vorwärtsprimer, r-Wt: wildtypallelspezifischer reverser Primer, V-D: defektallelspezifischer Vorwärtsprimer, r-D: defektallelspezifischer reverser Primer 


\subsubsection{Literatur}

Blaisdell, J., Goldstein, J.A. und Bai, S.A. (1998): Isolation of a new canine cytochrome P450 CDNA from the cytochrome P450 2C subfamily (CYP2C41) and evidence for polymorphic differences in its expression. Drug Metab Dispos, 26 (3), 27883.

Bryan, S.E. und Frieden, E. (1967): Interaction of copper(II) with deoxyribonucleic acid below 30 degrees. Biochemistry, 6 (9), 2728-34.

Campbell, W.C. und Benz, G.W. (1984): Ivermectin: a review of efficacy and safety. $J$ Vet Pharmacol Ther, 7 (1), 1-16.

Ciaccio, P.J., Graves, P.E., Bourque, D.P., Glinsmann-Gibson, B. und Halpert, J.R. (1991): cDNA and deduced amino acid sequences of a dog liver cytochrome P450 of the IIIA gene subfamily. Biochim Biophys Acta, 1088 (2), 319-22.

Coronado, V.A., Damaraju, D., Kohijoki, R. und Cox, D.W. (2003): New haplotypes in the Bedlington terrier indicate complexity in copper toxicosis. Mamm Genome, 14 (7), 483-91.

Eriksson, J. (1983): Copper toxicosis in Bedlington Terriers. Acta Vet Scand, 24 (2), 148-52.

Fisher, M.H. und Mrozik, H. (1992): The chemistry and pharmacology of avermectins. Annu Rev Pharmacol Toxicol, 32, 537-53.

Forman, O.P., Boursnell, M.E., Dunmore, B.J., Stendall, N., van den Sluis, B., Fretwell, N., Jones, C., Wijmenga, C., Rothuizen, J., van Oost, B.A., Holmes, N.G., Binns, M.M. und Jones, P. (2005): Characterization of the COMMD1 (MURR1) mutation causing copper toxicosis in Bedlington terriers. Anim Genet, 36 (6), 497-501.

Fukuda, K., Shindo, H., Yamashita, K. und Mizuhira, V. (1982): Catalase Activity of Erythrocytes from Beagle Dogs: An Appearance of Hereditary Acatalasemia. Acta Histochem Cytochem, 15 (5), 658-690.

Graves, P.E., Elhag, G.A., Ciaccio, P.J., Bourque, D.P. und Halpert, J.R. (1990): cDNA and deduced amino acid sequences of a dog hepatic cytochrome P450IIB responsible for the metabolism of 2,2',4,4',5,5'-hexachlorobiphenyl. Arch Biochem Biophys, 281 (1), 106-15.

Hardy, R.M. (1984): Copper-associated hepatitis in Bedlington terriers. Current Veterinary Therapy in Small Animal Practice, 834-836.

Hardy, R.M. und Stevens, J.B. (1978): Chronic progressive hepatitis in Bedlington terriers. Proc American Animal Hospital Association, 45, 187-190. 
Hardy, R.M., Stevens, J.B. und Stowe, C.M. (1975): Chronic progressive hepatitis in Bedlington terriers associated with elevated liver copper concentrations. Minn Vet, 15, 13-24.

Haywood, S. (2006): Copper toxicosis in Bedlington terriers. Vet Rec, 159 (20), 687.

Haywood, S., Rutgers, H.C. und Christian, M.K. (1988): Hepatitis and copper accumulation in Skye terriers. Vet Pathol, 25 (6), 408-14.

Haywood, S., Fuentealba, I.C. und Kemp, S.J. (2000): Copper toxicosis in Bedlington terriers. Vet Rec, 146 (13), 383-4.

Haywood, S., Fuentealba, I.C., Foster, J. und Ross, G. (1996): Pathobiology of copperinduced injury in Bedlington terriers: ultrastructural and microanalytical studies. Anal Cell Pathol, 10 (3), 229-41.

Haywood, S., Fuentealba, I.C., Kemp, S.J. und Trafford, J. (2001): Copper toxicosis in the Bedlington terrier: a diagnostic dilemma. J Small Anim Pract, 42 (4), 181-5.

Henik, R.A., Kellum, H.B., Bentjen, S.A. und Mealey, K.L. (2006): Digoxin and mexiletine sensitivity in a Collie with the MDR1 mutation. $J$ Vet Intern Med, 20 (2), 415-7.

Herrtage, M.E. (1987): Inherited copper toxicosis in the dog. Pedigree Digest, 14, 4-6.

Herrtage, M.E., Seymour, C.A., Jefferies, A.R., Blakemore, W.F. und Palmer, A.C. (1987): Inherited copper toxicosis in the Bedlington terrier: a report of two clinical cases. Journal of Small Animal Practice, 28, 1127-1140.

Holmes, N.G., Binns, M.M. und Herrtage, M.E. (2000): DNA testing for copper toxicosis in Bedlington terriers. Vet Rec, 146 (25), 739.

Holmes, N.G., Herrtage, M.E., Ryder, E.J. und Binns, M.M. (1998): DNA marker C04107 for copper toxicosis in a population of Bedlington terriers in the United Kingdom. Vet Rec, 142 (14), 351-2.

http://www.cypalleles.ki.se/: Home Page of the Human Cytochrome P450 (CYP) Allele Nomenclature Committee. (Ingelman-Sundberg, M.

Daly, A.K.

Nebert, D.W.), aufgerufen am 02. Februar 2007 zuletzt akzualisiert: 01. Dezember 2006

Hunt, D.M., Wake, S.A., Mercer, J.F. und Danks, D.M. (1986): A study of the role of metallothionein in the inherited copper toxicosis of dogs. Biochem J, 236 (2), 409-15.

Hyun, C., Lavulo, L.T. und Filippich, L.J. (2004): Evaluation of haplotypes associated with copper toxicosis in Bedlington Terriers in Australia. Am J Vet Res, 65 (11), 1573-9. 
Johnson, G.F., Sternlieb, I., Twedt, D.C., Grushoff, P.S. und Scheinberg, I. (1980): Inheritance of copper toxicosis in Bedlington terriers. Am J Vet Res, 41 (11), 1865-6.

Klomp, A.E., van de Sluis, B., Klomp, L.W. und Wijmenga, C. (2003): The ubiquitously expressed MURR1 protein is absent in canine copper toxicosis. $J$ Hepatol, 39 (5), 703-9.

Kwei, G.Y., Alvaro, R.F., Chen, Q., Jenkins, H.J., Hop, C.E., Keohane, C.A., Ly, V.T., Strauss, J.R., Wang, R.W., Wang, Z., Pippert, T.R. und Umbenhauer, D.R. (1999): Disposition of ivermectin and cyclosporin A in CF-1 mice deficient in mdr1a P-glycoprotein. Drug Metab Dispos, 27 (5), 581-7.

Lankford, S.M., Bai, S.A. und Goldstein, J.A. (2000): Cloning of canine cytochrome P450 2E1 cDNA: identification and characterization of two variant alleles. Drug Metabolism and Disposition, 28 (8), 981-6.

Li, Y. und Trush, M.A. (1993a): Oxidation of hydroquinone by copper: chemical mechanism and biological effects. Arch Biochem Biophys, 300 (1), 346-55.

Li, Y. und Trush, M.A. (1993b): DNA damage resulting from the oxidation of hydroquinone by copper: role for a $\mathrm{Cu}(\mathrm{II}) / \mathrm{Cu}(\mathrm{I})$ redox cycle and reactive oxygen generation. Carcinogenesis, 14 (7), 1303-11.

Mealey, K.L., Bentjen, S.A. und Waiting, D.K. (2002): Frequency of the mutant MDR1 allele associated with ivermectin sensitivity in a sample population of collies from the northwestern United States. Am J Vet Res, 63 (4), 479-81.

Mealey, K.L., Northrup, N.C. und Bentjen, S.A. (2003): Increased toxicity of Pglycoprotein-substrate chemotherapeutic agents in a dog with the MDR1 deletion mutation associated with ivermectin sensitivity. J Am Vet Med Assoc, 223 (10), 1453-5, 1434.

Mealey, K.L., Munyard, K.A. und Bentjen, S.A. (2005): Frequency of the mutant MDR1 allele associated with multidrug sensitivity in a sample of herding breed dogs living in Australia. Vet Parasitol, 131 (3-4), 193-6.

Mealey, K.L., Bentjen, S.A., Gay, J.M. und Cantor, G.H. (2001): Ivermectin sensitivity in collies is associated with a deletion mutation of the mdrl gene.

Pharmacogenetics, 11 (8), 727-33.

Mise, M., Hashizume, T., Matsumoto, S., Terauchi, Y. und Fujii, T. (2004a): Identification of non-functional allelic variant of CYP1A2 in dogs. Pharmacogenetics, 14 (11), 769-73.

Mise, M., Yadera, S., Matsuda, M., Hashizume, T., Matsumoto, S., Terauchi, Y. und Fujii, T. (2004b): Polymorphic expression of CYP1A2 leading to interindividual variability in metabolism of a novel benzodiazepine receptor partial inverse agonist in dogs. Drug Metab Dispos, 32 (2), 240-5. 
Nakamura, K., Watanabe, M. und Ikeda, T. (1998): cDNA and deduced amino acid sequences of dog catalase. DNA Seq, 9 (5-6), 347-52.

Nakamura, K., Watanabe, M., Ikeda, T., Sasaki, Y. und Matsunuma, N. (1999): Tissue and organ expression of catalase in acatalasemic beagle dogs. Exp Anim, 48 (4), 229-34.

Nakamura, K., Watanabe, M., Takanaka, K., Sasaki, Y. und Ikeda, T. (2000): cDNA cloning of mutant catalase in acatalasemic beagle dog: single nucleotide substitution leading to thermal-instability and enhanced proteolysis of mutant enzyme. Int J Biochem Cell Biol, 32 (11-12), 1183-93.

Neff, M.W., Robertson, K.R., Wong, A.K., Safra, N., Broman, K.W., Slatkin, M., Mealey, K.L. und Pedersen, N.C. (2004): Breed distribution and history of canine mdr1-1Delta, a pharmacogenetic mutation that marks the emergence of breeds from the collie lineage. Proc Natl Acad Sci U S A, 101 (32), 11725-30.

Noaker, L.J., Washabau, R.J., Detrisac, C.J., Heldmann, E. und Hendrick, M.J. (1999): Copper associated acute hepatic failure in a dog. J Am Vet Med Assoc, 214 (10), 1502-6, 1495.

Proschowsky, H.F., Jepsen, B., Jensen, H.E., Jensen, A.L. und Fredholm, M. (2000): Microsatellite marker C04107 as a diagnostic marker for copper toxicosis in the Danish population of Bedlington terriers. Acta Vet Scand, 41 (4), 345-50.

Pulliam, J.D., Seward, R.L., Henry, R.T. und Steinberg, S.A. (1985): Investigating ivermectin toxicity in Collies. Vet Med, 80, 33-40.

Rendic, S. und Di Carlo, F.J. (1997): Human cytochrome P450 enzymes: a status report summarizing their reactions, substrates, inducers, and inhibitors. Drug Metab Rev, 29 (1-2), 413-580.

Rothuizen, J., Ubbink, G.J., van Zon, P., Teske, E., van den Ingh, T.S. und YuzbasiyanGurkan, V. (1999): Diagnostic value of a microsatellite DNA marker for copper toxicosis in West-European Bedlington terriers and incidence of the disease. Anim Genet, 30 (3), 190-4.

Roulet, A., Puel, O., Gesta, S., Lepage, J.F., Drag, M., Soll, M., Alvinerie, M. und Pineau, T. (2003): MDR1-deficient genotype in Collie dogs hypersensitive to the P-glycoprotein substrate ivermectin. Eur J Pharmacol, 460 (2-3), 85-91.

Sakamoto, K., Kirita, S., Baba, T., Nakamura, Y., Yamazoe, Y., Kato, R., Takanaka, A. und Matsubara, T. (1995): A new cytochrome P450 form belonging to the CYP2D in dog liver microsomes: purification, cDNA cloning, and enzyme characterization. Arch Biochem Biophys, 319 (2), 372-82.

Sartor, L.L., Bentjen, S.A., Trepanier, L. und Mealey, K.L. (2004): Loperamide toxicity in a collie with the MDR1 mutation associated with ivermectin sensitivity. $J$ Vet Intern Med, 18 (1), 117-8. 
Schaefer, M., Hopkins, R.G., Failla, M.L. und Gitlin, J.D. (1999): Hepatocyte-specific localization and copper-dependent trafficking of the Wilson's disease protein in the liver. American Journal of Physiology - Gastrointestinal and Liver Physiology, 276 (3), G639-G646.

Schinkel, A.H., Wagenaar, E., Mol, C.A. und van Deemter, L. (1996): P-glycoprotein in the blood-brain barrier of mice influences the brain penetration and pharmacological activity of many drugs. J Clin Invest, 97 (11), 2517-24.

Schinkel, A.H., Smit, J.J., van Tellingen, O., Beijnen, J.H., Wagenaar, E., van Deemter, L., Mol, C.A., van der Valk, M.A., Robanus-Maandag, E.C., te Riele, H.P. und et al. (1994): Disruption of the mouse mdrla P-glycoprotein gene leads to a deficiency in the blood-brain barrier and to increased sensitivity to drugs. Cell, 77 (4), 491-502.

Su, L.C., Owen, C.A., Zollmann, P.E. und Hardy, R.M. (1982a): A defect of biliary excretion of copper in copper-laden Bedlington terriers. Am J Physiol Gastrointest Liver Physiol, 243 (6), G231-G236.

Su, L.C., Ravanshad, S., Owen, C.A., Jr., McCall, J.T., Zollman, P.E. und Hardy, R.M. (1982b): A comparison of copper-loading disease in Bedlington terriers and Wilson's disease in humans. Am J Physiol, 243 (3), G226-30.

Takahara, S. und Miyamoto, H. (1948): Clinical and experimental studies on the odontogenous progressive necrotic ostitis due to lack of blood catalase. $J$ Otorhinol Soc Jpn, 51, 163-164.

Tanase, H. (1982): Hereditary acatalasemia in dogs. Jikken Dobutsu, 31 (4), 323-325.

Tao, T.Y., Liu, F., Klomp, L., Wijmenga, C. und Gitlin, J.D. (2003): The copper toxicosis gene product Murrl directly interacts with the Wilson disease protein. J Biol Chem, 278 (43), 41593-6.

Thornburg, L. (2000): A perspective on copper and liver disease in the dog. J Vet Diagn Invest, 12, 101-110.

Thornburg, L.P., Rottinghaus, G., Dennis, G. und Crawford, S. (1996): The relationship between hepatic copper content and morphologic changes in the liver of West Highland White Terriers. Vet Pathol, 33 (6), 656-61.

Thornburg, L.P., Shaw, D., Dolan, M., Raisbeck, M., Crawford, S., Dennis, G.L. und Olwin, D.B. (1986): Hereditary copper toxicosis in West Highland white terriers. Vet Pathol, 23 (2), 148-54.

Tracy, J.W. und Webster, L.T.J. (1995): Drugs used in the chemotherapy of helminthes. In Limbird, L.E. (Herausgeber): Goodman \& Gilman's The Pharmacological Basis of Therapeutics $\left(9^{\text {th }}\right)$. McGraw-Hill, 1995, S. 1009-1026.

Twedt, D.C., Sternlieb, I. und Gilbertson, S.R. (1979): Clinical, morphologic, and chemical studies on copper toxicosis of Bedlington Terriers. J Am Vet Med Assoc, 175 (3), 269-75. 
Ubbink, G.J., Van den Ingh, T.S., Yuzbasiyan-Gurkan, V., Teske, E., Van de Broek, J. und Rothuizen, J. (2000): Population dynamics of inherited copper toxicosis in Dutch Bedlington terriers (1977-1997). J Vet Intern Med, 14 (2), 172-6.

Uchida, T., Komori, M., Kitada, M. und Kamataki, T. (1990): Isolation of cDNAs coding for three different forms of liver microsomal cytochrome P-450 from polychlorinated biphenyl-treated beagle dogs. Mol Pharmacol, 38 (5), 644-51.

van Asperen, J., Mayer, U., van Tellingen, O. und Beijnen, J.H. (1997): The functional role of P-glycoprotein in the blood-brain barrier. J Pharm Sci, 86 (8), 881-4.

van de Sluis, B., Peter, A.T. und Wijmenga, C. (2003): Indirect molecular diagnosis of copper toxicosis in Bedlington terriers is complicated by haplotype diversity. $J$ Hered, 94 (3), 256-9.

van De Sluis, B., Rothuizen, J., Pearson, P.L., van Oost, B.A. und Wijmenga, C. (2002): Identification of a new copper metabolism gene by positional cloning in a purebred dog population. Hum Mol Genet, 11 (2), 165-73.

van de Sluis, B., Kole, S., van Wolferen, M., Holmes, N.G., Pearson, P.L., Rothuizen, J., van Oost, B.A. und Wijmenga, C. (2000): Refined genetic and comparative physical mapping of the canine copper toxicosis locus. Mamm Genome, 11 (6), 455-60.

van de Sluis, B.J., Breen, M., Nanji, M., van Wolferen, M., de Jong, P., Binns, M.M., Pearson, P.L., Kuipers, J., Rothuizen, J., Cox, D.W., Wijmenga, C. und van Oost, B.A. (1999): Genetic mapping of the copper toxicosis locus in Bedlington terriers to dog chromosome 10 , in a region syntenic to human chromosome region 2p13-p16. Hum Mol Genet, 8 (3), 501-7.

Webb, C.B., Twedt, D.C. und Meyer, D.J. (2002): Copper-associated liver disease in Dalmatians: a review of 10 dogs (1998-2001). J Vet Intern Med, 16 (6), 665-8.

Yuzbasiyan-Gurkan, V., Blanton, S.H., Cao, Y., Ferguson, P., Li, J., Venta, P.J. und Brewer, G.W. (1997): Linkage of a microsatellite marker to the canine copper toxicosis locus in Bedlington Terriers. Am J Vet Res, 58 (1), 23-27. 


\subsection{Hereditäre Erkrankungen innerer und äußerer Organe}

\subsubsection{Erkrankungen der Haut}

\subsubsection{Ektodermale Dysplasie}

\begin{tabular}{ll|}
\hline Chromosom: & CFAX \\
Gen: & EDA \\
NCBI: & GeneID: 491935 \\
DNA-Sequenz: & NW_879563, Position 5648845-5772159 \\
Mutationen: & G1862A, Deutscher Schäferhund \\
\hline
\end{tabular}

\section{Krankheitsbild}

Die wichtigsten äußerlichen Anzeichen der caninen ektodermalen Dysplasie sind Alopezie (Haarausfall) und Hypotrichose (spärlicher Haarwuchs). Diese Störungen betreffen in der Regel etwa drei Viertel des gesamten Körpers und treten bilateral symmetrisch auf. Bei jungen Hunden sind unbehaarte Hautbereiche meist dünn, rosagrau oder grau-braun gefärbt und lassen die Gefäße durchscheinen. Mit fortschreitendem Alter der betroffenen Hunde sind diese Partien zunehmend pigmentiert. Bei einigen Hunden bleibt der Haarbestand auf das Primärhaar beschränkt, das dünner erscheint als bei normalen Hunden und keinen Glanz zeigt. Bei anderen Hunden wächst auch Sekundärhaar, die Haare sind jedoch spröde und unvollständig. Oft kommt es stellenweise zu oberflächlicher, orthokeratotischer Hyperkeratose, phasenweise treten außerdem Schuppenbildung und Bläschenbildungen (Spongiose) auf. Weitere charakteristische Befunde sind Störungen des Zahnwuchses wie Oligodontie, dentale Hypoplasie, persistierende Milchzähne, verspäteter Durchbruch der bleibenden Zähne und Auftreten konisch fehlgeformter Zähne. In histopathologischen Untersuchungen sind Haarfollikel, Musculi arrector pili und Schweißdrüsen deutlich reduziert oder fehlen vollständig. Die beschriebenen Haut- und Zahndefekte sind nicht lebensbedrohlich, stellen jedoch eine erhebliche Beeinträchtigung der Lebensqualität dar (Thomsett 1961; Kràl und Schwartzman 1964; Selmanowitz et al. 1970; Selmanowitz et al. 1977; Kunkle 1984; Chastain und Swayne 1985; Grieshaber et al. 1986; Casal et al. 1997; Moura und Cirio 2004).

Neben einigen Berichten über Einzelfälle bei einem Whippet-Rüden (Thomsett 1961), einem Cocker Spaniel Rüden (Kràl und Schwartzman 1964), einer Labrador Hündin 
(Kunkle 1984) und einem Bichon-Frise-Rüden (Grieshaber et al. 1986) kommt es auch zur Häufung von Fällen in Familien der Rassen Zwergpudel (Selmanowitz et al. 1970; Selmanowitz et al. 1977) und Bassets (Chastain und Swayne 1985). Des Weiteren wurde eine ektodermale Dysplasie bei einem Rüden der Rasse Deutscher Schäferhund beschrieben. Die Nachkommen aus Anpaarungen dieses Rüden mit Riesenschnauzer-, Wolfsspitz- und Basset/Beagle-Mischlingshündinnen bildeten 1997 die Basis einer Forschungskolonie (Casal et al. 1997). Zur Häufigkeit der ektodermalen Dysplasie innerhalb dieser Rassen sind keine Zahlen veröffentlicht.

\section{Genetischer Hintergrund}

Die ektodermale Dysplasie betrifft überwiegend Rüden. Betroffene Hündinnen zeigen Symptome häufig nur in abgeschwächter Form. Diese Beobachtungen sowie die Ergebnisse aus Pedigreestudien bei Zwergpudeln lassen auf eine rezessive $\mathrm{X}$ chromosomal gekoppelte Vererbung schließen. Die Daten reichen jedoch nicht aus, um das Vorliegen eines autosomal rezessiven Erbgangs sicher auszuschließen (Selmanowitz et al. 1977). Innerhalb der 1997 gegründeten Forschungskolonie aus den Nachkommen eines betroffenen Deutschen Schäferhundes liegt eindeutig ein eine rezessiv X-chromosomal gekoppelte Vererbung vor (Casal et al. 1997).

Aufgrund von Ähnlichkeiten zu humanen Erkrankungen, deren genetischer Hintergrund bereits bekannt ist, kommen als Kandidatengene die X-chromosomalen Gene IKBKG (nuclear factor $\mathrm{KB}$ essential modulator protein gene) (Zonana et al. 2000) und EDA (Ektodysplasin-Gen) (Zonana et al. 1993; Kere et al. 1996; Monreal et al. 1998) in Frage.

Die ursächliche Mutation konnte im EDA-Gen identifiziert werden. Das canine EDAGen enthält acht Exons, die mit Exon 1 und 3-9 benannt werden, da sie zu den humanen Exons 1 und 3-9 eine hohe Homologie aufweisen. Ein dem humanen Exon 2 homologer Sequenzabschnitt fehlt in der caninen cDNA. Durch alternatives Spleißen an der DonorSpleißstelle am 3'-Ende von Exon 8 entstehen die zwei verschiedenen Isoformen EDA1 und EDA-2. Die codierende Sequenz von EDA-1 hat eine Länge von 1161 Nukleotiden, die codierende Sequenz von EDA-2 ist um 6 bp kürzer. Das resultierende Protein Ektodysplasin hat eine Länge von 386 bzw. 384 Aminosäuren (Casal et al. 2005). 
Hinsichtlich der in der Originalveröffentlichung angegebenen Exonlängen kommen die in der NCBI-Datenbank dargestellten Positionen der einzelnen cDNA-Abschnitte im genomischen Contig NW_879563 zwischen Position 5648845 und 5772159 (NCBIGeneID: 491935) den in der Originalveröffentlichung beschriebenen Verhältnissen am nächsten. Die Exonlängen stimmen überein, allerdings ist das erste der bei Casal et al. (2005) beschriebenen acht Exons in der NCBI-Datenbank nicht eingetragen. Die in Abb. 78 dargestellte Struktur des caninen EDA-Gens basiert auf dem NCBIDatenbankeintrag. Folglich ist das erste Exon nicht abgebildet.

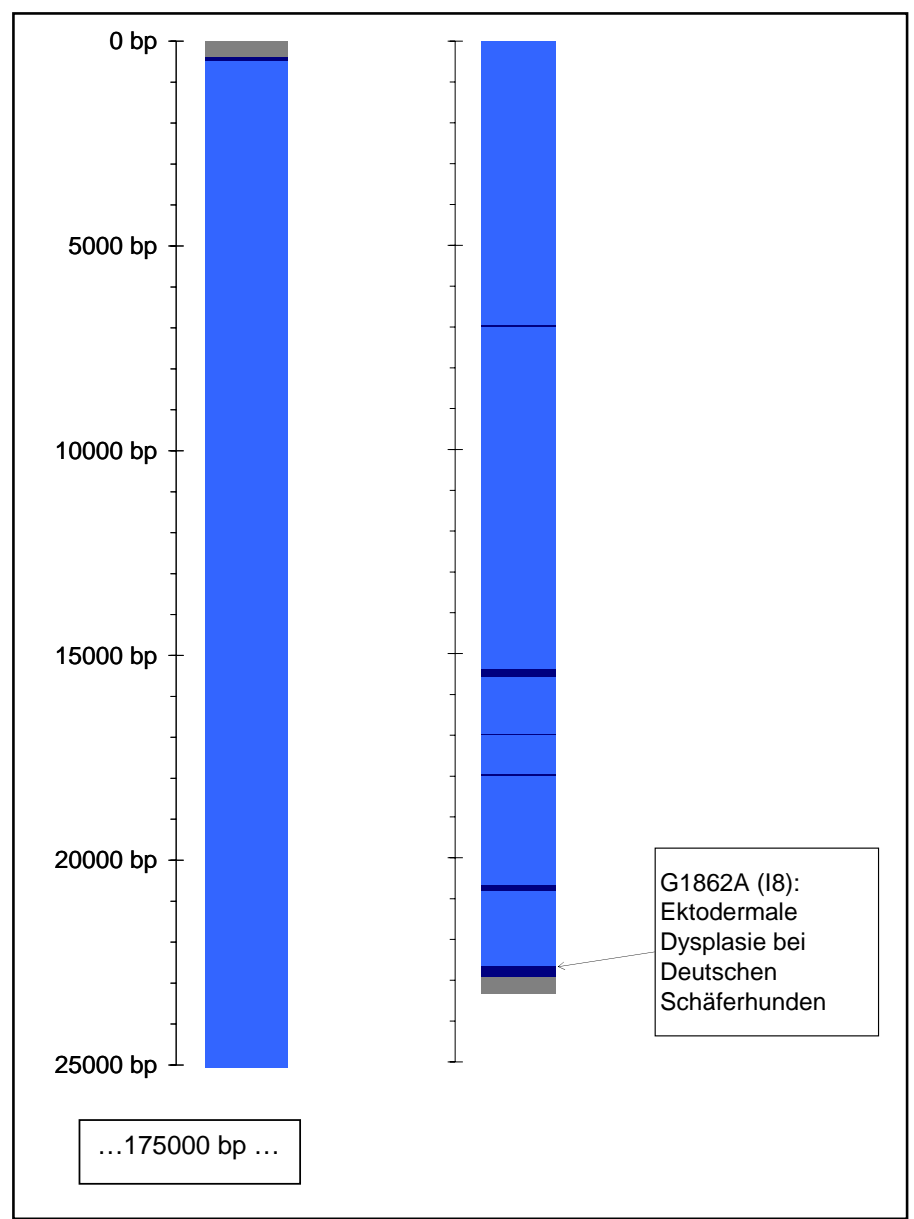

Abb. 78 Schematische Darstellung des caninen EDA-Gens und Lage der bisher identifizierten Mutationen. Dunkelblau: codierende Sequenz, hellblau: Intronsequenz, grau: intergenische Sequenz.

\section{Ursächliche Mutation für ektodermale Dysplasie bei Deutschen Schäferhunden}

Mithilfe von Kopplungsanalysen sowie durch Sequenzieren der cDNA- und Genabschnitte und Vergleich der Sequenzen gesunder und betroffener Wurfgeschwister konnte bei betroffenen Hunden eine Substitution von Guanin durch Adenin in der konservierten Akzeptor-Spleißkonsensussequenz $\mathrm{AG}$ in Intron 8 des EDA-Gens 
gefunden werden (Abb. 79). Als Folge wird nicht an der ursprünglichen Spleißstelle sondern an einer in 3'-Richtung gelegenen alternativen Spleißstelle gespleißt. In dem dadurch um 32 Nukleotide verkürzten Exon 9 kommt es $\mathrm{zu}$ einer Leserasterverschiebung und zur Entstehung eines verfrühten Stoppcodons drei Basenpaare abwärts der neuen Spleißstelle. Die Folgen der Mutation betreffen sowohl EDA-1 als auch EDA-2 (Casal et al. 2005).

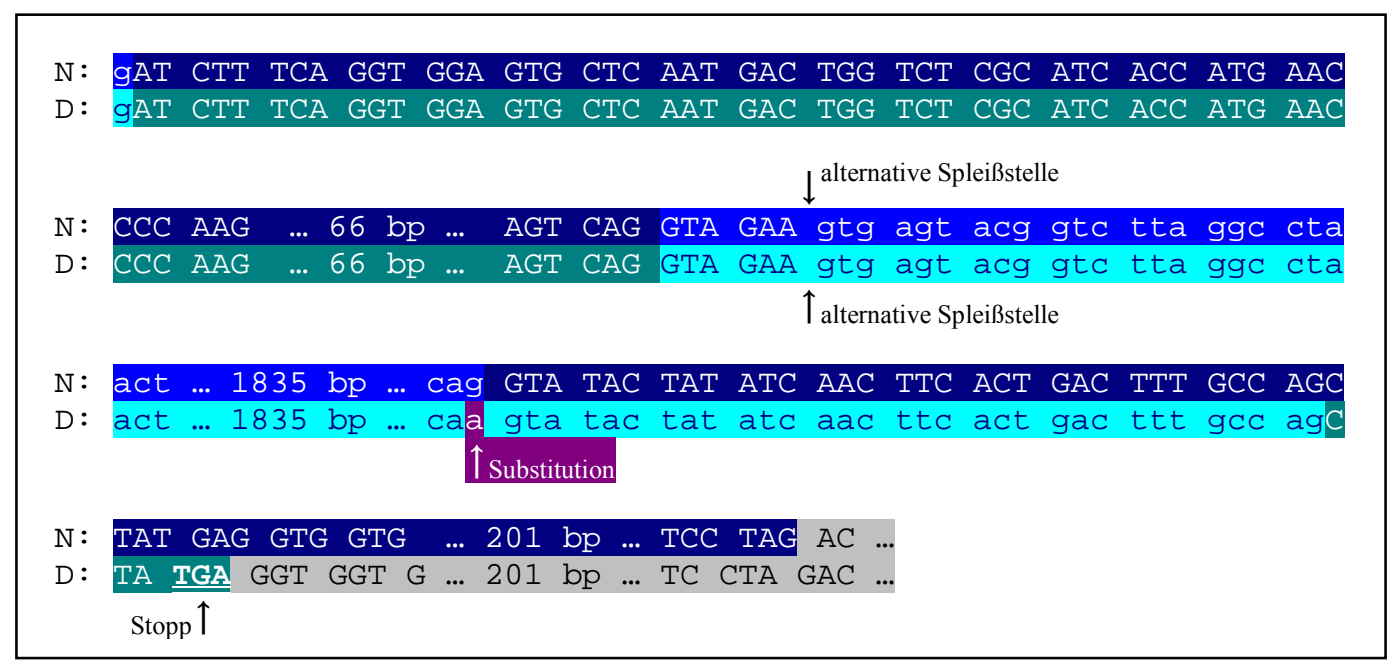

Abb. 79 Exon 8 und Exon 9 des caninen EDA-Gens mit angrenzenden Intronsequenzen und 3'-UTR. N: normale Sequenz, D: defekte Sequenz, hellblau: Intron normale Sequenz, dunkelblau: Exon normale Sequenz, hellgrün: Intron defekte Sequenz, dunkelgrün: Exon defekte Sequenz, grau unterlegt: UTR, alternative Spleißstelle in Exon 8 mit Pfeil gekennzeichnet, Substitution in defekter Sequenz violett unterlegt und durch Pfeil gekennzeichnet, verfrühtes Stoppcodon in defekter Sequenz fett gedruckt und durch Pfeil gekennzeichnet.

Anhand von Strukturanalysen an acht humanen EDA-Isoformen, die durch alternatives Spleißen entstehen, werden die Ektodysplasin-Proteine der Gruppe der Klasse-IITransmembranproteine zugeordnet (Bayes et al. 1998). Mittels in situ Hybridisierung ist eine Expression unter anderem in Keratinozyten, Haarfollikeln und Schweißdrüsen nachweisbar. Zahlreiche Mutationen im humanen EDA-Gen treten wie die beschriebene Mutation im caninen EDA-Gen im Zusammenhang mit einer gestörten Ausbildung von Hautanhängen wie Schweißdrüsen, Talgdrüsen und Haaren auf. Demnach scheint Ektodysplasin eine entscheidende Rolle für die Interaktion zwischen Mesenchym und Epithel zur Regulation der Ausbildung epidermaler Anhänge zu spielen (Kere et al. 1996). Einzelheiten zum Ablauf dieses Mechanismus sind noch nicht geklärt. 


\subsubsection{Epidermolysis bullosa}

\begin{tabular}{ll|}
\hline Chromosom: & CFA7 \\
Gen: & LAMA3 \\
NCBI: & GeneID: 480173, GenBank: AF236865 \\
DNA-Sequenz: & NW_876324, Position 840748-590765 \\
Mutationen: & 207Ins6,5kb, junktionale EB, Deutsch Kurzhaar \\
& Vorstehhund \\
\hline
\end{tabular}

\begin{tabular}{|ll|}
\hline Chromosom: & CFA20 \\
Gen: & COL7A1 \\
NCBI: & GeneID: 403467 \\
DNA-Sequenz: & NW_876272, Position 15335076-15366372 \\
Mutationen: & A516G, dystrophische EB, Golden Retriever \\
\hline
\end{tabular}

Die Bezeichnung Epidermolysis bullosa (EB) umfasst eine Gruppe von Hautkrankheiten, bei denen es aufgrund von Defekten innerhalb der kutanen Basalmembranzone durch minimale Reibungen oder Traumata zur blasenförmigen Spaltbildung zwischen Dermis und Epidermis kommt. Die erblichen Formen der Epidermolysis bullosa beruhen auf einem Mangel oder einer gestörten Funktion bestimmter Komponenten des Netzwerks zwischen dem intrazellularen Milieu der basalen Keratinozyten, der dermoepidermalen Basalmembran und der darunter liegenden Dermis. Betroffene Komponenten sind je nach genetischem Defekt das Zytoskelett der Keratinozyten, die Hemidesmosomen, die Ankerfilamente oder die Ankerfibrillen. Je nach betroffener Komponente ist die Ebene, in der es zur Aufspaltung des stabilisierenden Netzwerkes kommt, intraepidermal in der Ebene der Keratinozyten (EB simplex), zwischen basalen Keratinozyten und der Basalmembran (hemidesmosomale EB), innerhalb der Lamina lucida (junktionale EB) oder unterhalb der Lamina densa in der Ebene der Ankerfibrillen (dystrophische EB) lokalisiert. Die einzelnen Unterformen sind je nach phänotypischen Besonderheiten, dem Schweregrad und den zugrunde liegenden Mutationen weiter untergliedert (Pulkkinen und Uitto 1999).

Bei Hunden sind in unterschiedlichen Rassen verschiedene Unterformen von Epidermolysis bullosa beschrieben worden, darunter die erblichen Formen EB simplex (Scott und Schultz 1977; Muller et al. 1983), junktionale EB (Dunstan et al. 1988; Guaguere et al. 1997; Nagata et al. 1997; Capt et al. 2005) und dystrophische EB (Nagata et al. 1995; Palazzi et al. 2000; Magnol et al. 2005). Dabei handelt es sich 
überwiegend um Einzelfälle ohne Informationen $\mathrm{zu}$ möglicherweise ebenfalls erkrankten Familienmitgliedern. Insgesamt scheint die Epidermolysis bullosa bei Hunden keine sehr große Rolle zu spielen. In den meisten Veröffentlichungen zu caniner EB steht die Eignung betroffener Hunde als Tiermodell zur Entwicklung gentechnischer Therapiemaßnahmen für die Humanmedizin im Vordergrund. Bisher sind zwei canine Gendefekte bekannt, die mit Unterformen der junktionalen bzw. der dystrophischen EB zusammenhängen.

\subsection{Junktionale Epidermolysis bullosa}

\section{Krankheitsbild der junktionalen Epidermolysis bullosa bei Deutsch Kurzhaar Vorstehhunden}

Formen von caniner junktionaler EB sind bisher bei einem Toy Pudel (Dunstan et al. 1988), einem Mischlingshund (Nagata et al. 1997), einer Familie von Deutschen Bracken (Guaguere et al. 1997) und in einer Familie von Deutsch Kurzhaar Vorstehhunden (Olivry et al. 1997; Capt et al. 2005) beschrieben worden. In allen Fällen treten erste Krankheitsanzeichen bereits direkt nach der Geburt auf. Je nach Erkrankungsform nehmen die Symptome mit zunehmendem Alter in unterschiedlich starkem Maße zu. Weiterhin unterscheiden sich die einzelnen Formen hinsichtlich der betroffenen Hautbereiche und dem Schweregrad der Erkrankung. Die ursächliche Mutation ist bisher nur bei deutsch Kurzhaar Vorstehhunden bekannt (Capt et al. 2005).

Bei Deutsch Kurzhaar Vorstehhunden treten Erosionen und Verkrustungen im Bereich der Ballen, an Druckpunkten der Extremitäten wie Knie, Ellenbogen, Sprunggelenken, Handwurzelknochen und Hüften, im Inneren der Ohrmuscheln sowie in Bereichen des Zahnfleisches, der Zunge und der Lippen auf (Olivry et al. 1997; Capt et al. 2005). Einige Hunde zeigen zudem einen körnigen Zahnschmelz (Capt et al. 2005). Histologische Untersuchungen zeigen eine Spaltung oberhalb der Lamina densa. Die Hemidesmosomen sind im Gegensatz zu früher beschriebenen caninen Fällen von junktionaler EB (Dunstan et al. 1988; Nagata et al. 1997) in normaler Anzahl vorhanden und zeigen keinerlei Abweichungen hinsichtlich Morphologie, Fokalkontakten und Verbindungen zum intermediären Filamentsystem (Olivry et al. 1997). 
In zwei unabhängigen immunologischen Untersuchungen an Deutsch Kurzhaarhunden aus einer Familie ergeben sich teilweise widersprüchliche Befunde (Olivry et al. 1997; Capt et al. 2005).

In einer älteren Studie wurden Gewebeproben von erkrankten Hunden aus betroffenen und gesunden Hautbereichen sowie aus Übergangszonen mit dem gegen Kollagen XVII gerichteten Antikörper J17 gefärbt und mit ebenso behandelten Gewebeproben gesunder Hunde verglichen. Die Ergebnisse lassen auf einen Defekt von Kollagen XVII bei betroffenen Hunden schließen, da Kollagen XVII in keiner der untersuchten Gewebeproben erkrankter Tiere mit Antikörper J17 gefärbt werden konnte, unabhängig davon, ob es sich um Proben aus einer gesunden oder betroffenen Hautregion handelte. Demgegenüber erfolgte bei gesunden Hunden eine lineare und gleichmäßige Färbung der Basalmembran (Olivry et al. 1997). In einer späteren Untersuchung lässt sich unter Verwendung des Antikörpers mAb233 gegen Kollagen XVII dagegen kein Unterschied zwischen Proben von gesunden und betroffenen Hunden feststellen (Capt et al. 2005).

Des Weiteren ergibt in der älteren Untersuchung eine Immunofärbung von Laminin 5 unter Verwendung des Antikörpers J18 sowie der gegen die Laminin-5-Ketten $\beta 3$ und $\gamma 2$ gerichteten Antikörper SE288 und SE 144 keinerlei Unterschiede zwischen gesunden und betroffenen Hunden (Olivry et al. 1997). In der späteren Untersuchung ergibt demgegenüber eine Immunofärbung der Laminin-5-Ketten $\alpha 3, \beta 3$ und $\gamma 2$, bei der neben zwei neuen Antikörpern (SE 85 und $\beta 3 \mathrm{~B}$ ) auch einer der Antikörper aus der älteren Untersuchung zum Einsatz kommt (SE144), bei betroffenen Hunden eine reduzierte Reaktion für alle drei Laminin-5-Ketten (Capt et al. 2005). Diese Widersprüche werden nicht diskutiert. Allerdings liefern weiterführende molekularbiologische Untersuchungen aus der neueren Studie Ergebnisse, die deutlich für einen ursächlichen Zusammenhang zwischen der junktionalen Epidermolysis bullosa bei Deutsch Kurzhaar Vorstehhunden und einem genetischen Defekt einer Untereinheit des Laminin 5 sprechen (Capt et al. 2005).

\section{Genetischer Hintergrund}

Eine Northern-Blot-Analyse der gesamten Keratinozyten-mRNA mit ${ }^{32} \mathrm{P}$-markierten cDNA-Sonden für die Laminin-5-Ketten $\alpha 3, \beta 3$ und $\gamma 2$ ergibt bei betroffenen Hunden ein deutlich reduziertes Signal für die Laminin-5- $\alpha 3-K e t t e$, das auf einen 
Zusammenhang der Erkrankung mit einem Defekt im die Laminin-5- $\alpha 3-K e t t e$ codierenden lama3-Gen hindeutet. Der Zusammenhang der junktionalen Epidermolysis bullosa bei Deutsch Kurzhaar Vorstehhunden mit einem lama3-Gendefekt bestätigt sich durch Vergleiche zwischen $\alpha 3$-cDNAs von normalen und betroffenen Hunden (Capt et al. 2005).

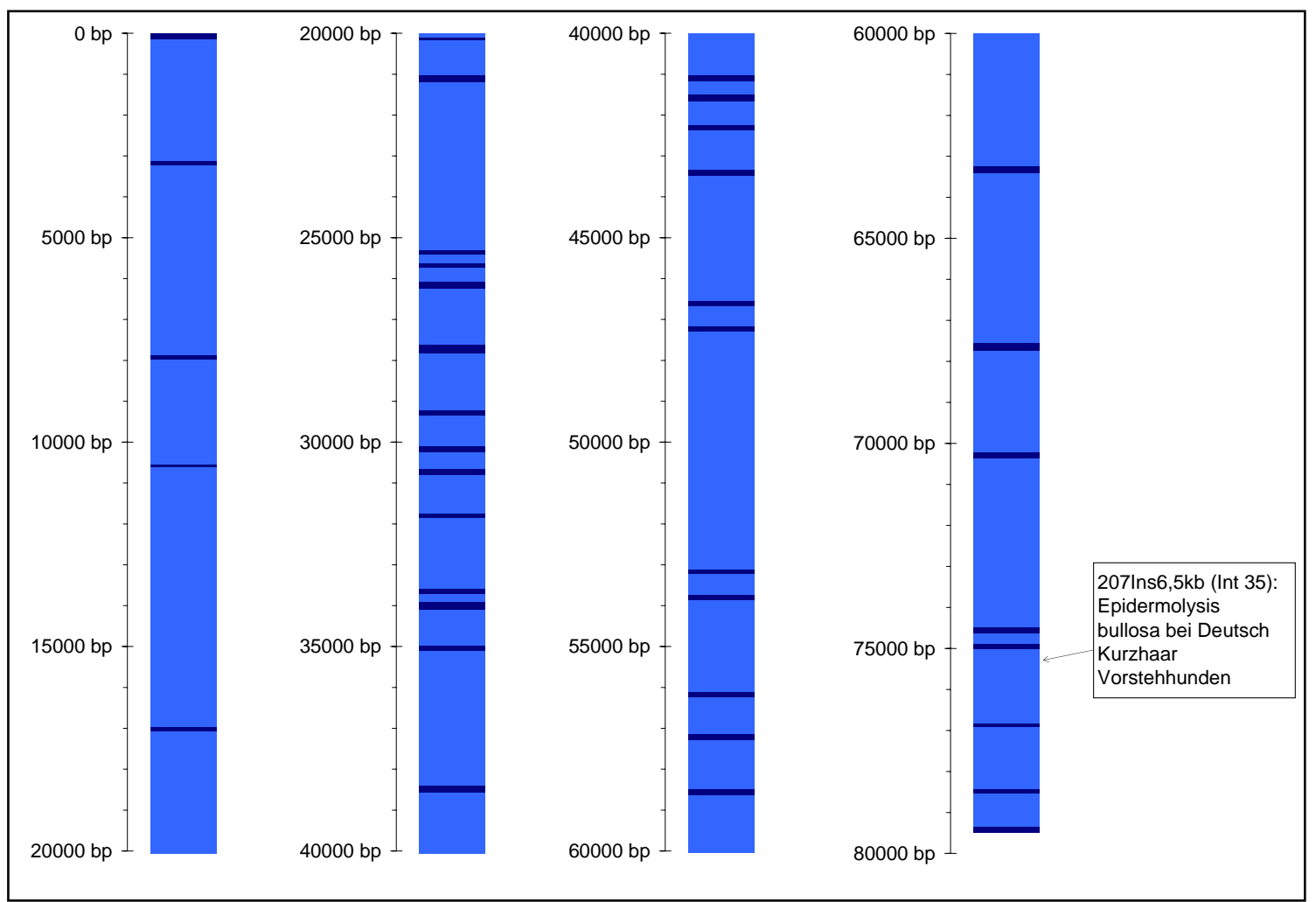

Abb. 80 Schematische Darstellung der ersten 38 Exons des caninen LAMA3-Gens und Lage der bisher identifizierten Mutationen. Dunkelblau: codierende Sequenz, hellblau: Intronsequenz.

Das canine LAMA3-Gen (Laminin, alpha 3) ist auf Chromosom 7 lokalisiert (Capt et al. 2003) und erstreckt sich im genomischen Contig NW_876324 zwischen Position 840748 und 590765. Die ersten 5176 bp der caninen $\alpha 3$-cDNA (NCBI-GenBank: AF236865) sind in 38 Exons unterteilt (NCBI-GeneID: 480173) und codieren für ein 1725 Aminosäuren langes Polypeptid. Die Lage der einzelnen Exons innerhalb der genomischen Sequenz ist in Abb. 80 schematisch dargestellt. Die N-terminale Domäne enthält zwei EGF (epidermal growth factor)-ähnliche Multiplikationen. Daran schließen sich ein stäbchenartiger Arm und die C-terminale globuläre Domäne (G-Domäne) an, die fünf Finger (G1-G5) bildet (Capt et al. 2005). 


\section{Ursächliche Mutation für Epidermolysis bullosa bei Deutsch Kurzhaar Vorstehhunden}

Vergleiche der cDNA-Sequenzen normaler und betroffener Hunde ergeben bei betroffenen Hunden das Vorliegen einer 227 bp langen Insertion zwischen Exon 35 und 36 an Position 4818. Dadurch kommt es zu einer Verschiebung des Leserasters und zur Entstehung eines verfrühten Stoppcodons 33 bp stromabwärts von der Insertionsposition (Capt et al. 2005).

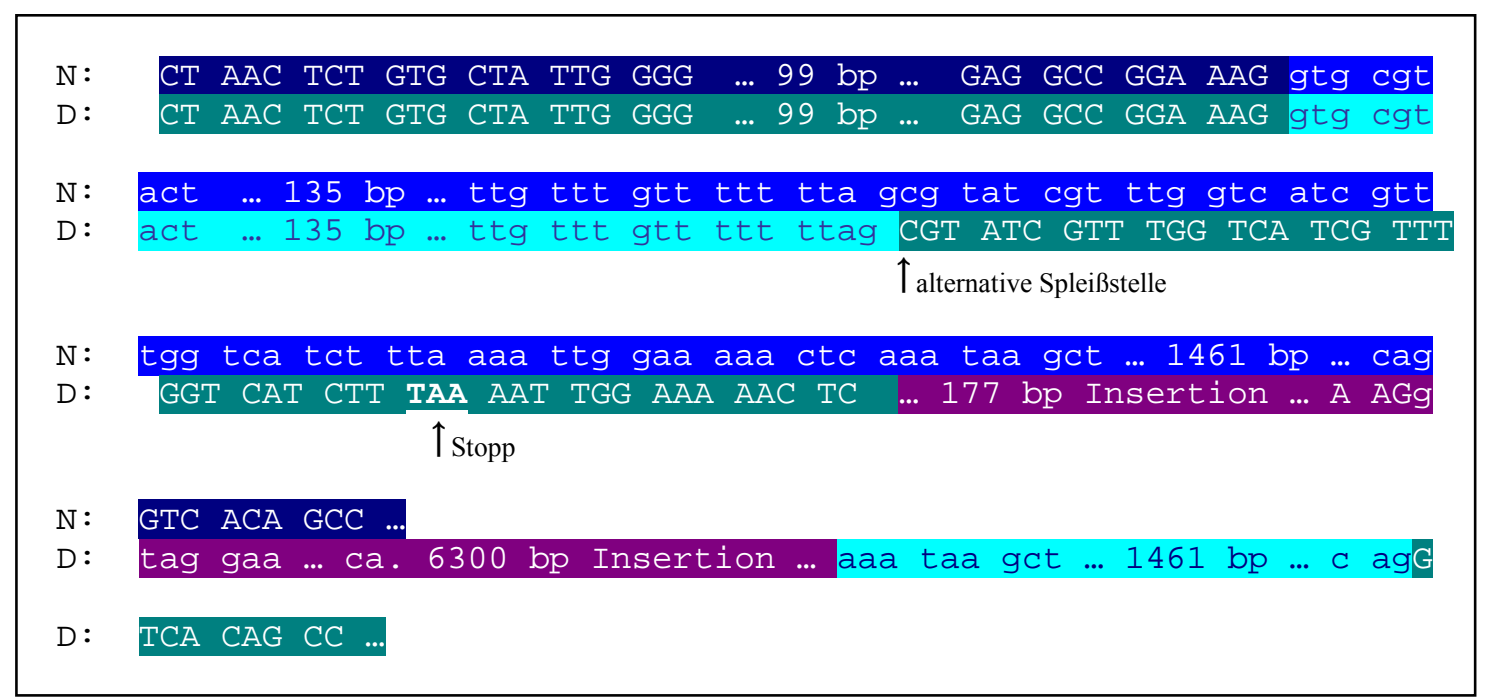

Abb. 81 Exon 35, Intron 35 und 5'-Sequenz von Exon 36 des caninen lama3-Gens. N: normale Sequenz, D: defekte Sequenz, dunkelblau: Exon normale Sequenz, dunkelgrün: Exon defekte Sequenz, hellblau: Intron normale Sequenz, hellgrün: Intron defekte Sequenz, 6,5-kb-Insertion in defekter Sequenz violett unterlegt, Großbuchstaben in Insertionssequenz: mRNA-Sequenz, Kleinbuchstaben in Insertionssequenz: intronische Sequenz, alternative Spleißstelle und verfrühtes Stoppcodon in defekter Sequenz durch Pfeil gekennzeichnet.

Weiterführende Untersuchungen an genomischer DNA ergeben für Intron 35 bei normalen Hunden eine Länge von 1680 bp. Unter Einsatz von Primern, die von normaler caniner genomischer DNA ein 114-bp-Fragment aus Intron 35 des Laminin-5a3-Gens amplifizieren, ergibt sich bei der Amplifikation von genomischer DNA betroffener Hunde ein DNA-Fragment von ca. 6,5 kb Länge. Die Sequenzierung zeigt, dass bei betroffenen Hunden in einer adenin- und threoninreichen Region des Introns 35 im Anschluss an Position 207 eine ca. 6,5 kb lange Insertion vorliegt. Die Insertion enthält eine Spleißstelle, die im Zusammenspiel mit einer kryptischen Spleißstelle 5' der Insertion in Intron 35 für die Generierung der 227 Nukleotide umfassenden Insertion in der $\alpha 3-m R N A$ verantwortlich ist und ein Poly-Adenin-Ende. Die vollständige Sequenz der 6,5-kb-Insertion ist nicht veröffentlicht. Es sind lediglich zehn Nukleotide aus dem Bereich der 3'-Spleißstelle der 227 Nukleotide umfassenden 
Insertion in der mutierten mRNA angegeben. Die ersten 47 Nukleotide dieser 227 Nukleotide entsprechen Position 160-207 des Introns 35. Bei den 180 weiteren Nukleotiden handelt es sich um das 5'-Ende der 6,5-kb-Insertion (Abb. 81) (Capt et al. 2005).

Die 6,5-kb-Insertion zeigt Übereinstimmungen mit einer repetitiven caninen SatellitenDNA-Sequenz, die signifikante Homologien zu humanen LINE-Sequenzen aufweist. Der in der 6,5-kb-Insertion enthaltene Poly-Adenin-Schwanz spricht für die Entstehung der Mutation durch eine Retrotransposition. Die geringe Restmenge an funktionsfähigem Laminin 5, die in den Keratinozyten betroffener Hunde exprimiert wird, ist unzureichend für die Gewährleistung einer stabilen Zelladhäsion und der Proliferation (Capt et al. 2005). Eine Methode zur Genotypisierung für die beschriebene Mutation ist nicht veröffentlicht.

\subsection{Dystrophische Epidermolysis bullosa}

\section{Krankheitsbild}

Die canine dystrophische Epidermolysis bullosa (DEB) ist bisher bei einem Akita Inu (Nagata et al. 1995) und in einer Familie von stark ingezüchteten Golden Retrievern (Palazzi et al. 2000) beschrieben worden. Das Erscheinungsbild der beiden Erkrankungen stimmt lediglich hinsichtlich der Lage der Spaltebene unterhalb der Lamina densa überein. Äußere Anzeichen, betroffene Hautregionen, Ultrastruktur der betroffenen Hautschichten und Immunofluoreszenzreaktion auf den Antikörper LH2:7, der spezifisch gegen die NC1-Domäne des Kollagen-Typ-VII gerichtet ist, unterscheiden sich zwischen den beiden Rassen. Demnach scheint bei der betroffenen Akita-Inu-Hündin eine andere Hautkomponente betroffen zu sein als bei betroffenen Golden Retrievern oder ein anderer Schädigungsgrad derselben Hautkomponente vorzuliegen.

Der ursächliche genetische Defekt ist bisher nur in der Golden-Retriever-Familie identifiziert worden. Daher konzentriert sich die Beschreibung des Krankheitsbildes auf Besonderheiten dieser Rasse. Für Informationen zur DEB bei Akita-Inu-Hunden sei auf die entsprechende Literatur verwiesen (Nagata et al. 1995). Eine Genotypisierung von zwei betroffenen und acht weiteren phänotypisch gesunden Golden Retrievern aus 
demselben Zwinger spricht für das Vorliegen eines rezessiven Erbgangs (Magnol et al. 2005).

Die typischen klinischen Erscheinungen sind für einen weiblichen und einen männlichen Golden Retriever aus zwei unterschiedlichen Würfen beschrieben worden. Beide Hunde gehörten zu einer Familie mit gehäuftem Auftreten eines autosomal rezessiv vererbten Bläschenausschlags. Vorrangig betrifft die Erkrankung die Schleimhäute des oberen Verdauungstraktes einschließlich der Speiseröhre und der Lippen. Die übrige Haut ist weniger schwerwiegend geschädigt. Zum Zeitpunkt der Geburt zeigen sich punktförmige Blutergüsse unter der Zunge und im harten Gaumen, die sich zu großen, multifocalen Geschwüren und blutgefüllten Blasen entwickeln. Neben einer generalisierten Neigung zur Blasenbildung zeigen sich vor allem im ventralen Abdominalbereich Hautgrieß und Hautrötungen. Während die aktiven Blasenbildungen sowie Grieß und Läsionen mit zunehmendem Alter zurückgehen, bleiben die Erosionen in der Mundhöhle und der Speiseröhre auch im Alter von dreieinhalb Jahren bestehen und führen zu Schwierigkeiten bei der Futteraufnahme mit der Folge eines Wachstums- und Gewichtsrückstandes. Die Funktion des Mageneingangs ist durch das Vorliegen fibröser Narbenbildungen schwer gestört, so dass die betroffenen Hunde an einem ständigen Reflux leiden. Des Weiteren ist in regelmäßigen Abständen ein Ausfallen der Krallen zu beobachten. Es kann zur Entwicklung eines Hornhautgeschwürs mit der Folge eines Lidkrampfs kommen (Palazzi et al. 2000; Magnol et al. 2005).

In histopathologischen Untersuchungen zeigen sich Spaltbildungen zwischen Dermis und Epidermis unterhalb der Lamina densa mit geringgradigen Entzündungen der umliegenden Zellen in perivascularen und periadnexalen Bereichen. Die Basalmembran ist vorrangig im Dach der von Spaltung betroffenen Abschnitte lokalisiert. In zwei unabhängigen Untersuchungen der beiden betroffenen Golden Retriever wurden hinsichtlich der Ankerfibrillen abweichende Beobachtungen dokumentiert. Im Alter von zwei Monaten konnten keinerlei Besonderheiten in der Ultrastruktur der Ankerfibrillen und der Hemidesmosomen nachgewiesen werden (Palazzi et al. 2000). In späteren Untersuchungen derselben betroffenen Hunde im Alter von dreieinhalb Jahren konnten jedoch Anomalien der Ankerfibrillen beobachtet werden. Die Fibrillen sind kürzer und weniger deutlich zu erkennen als beim Menschen. 
Hinsichtlich der immunohistochemischen Reaktivität gegenüber dem spezifisch gegen Kollagen-Typ-VII gerichteten Antikörper LH2:7 zeigen betroffene Golden Retriever im Gegensatz zu normalen Kontrollhunden eine beim Rüden deutliche, bei der Hündin leicht verminderte Reaktivität im dermoepidermalen Grenzbereich. Kollagen-Typ-VIIHomotrimere lagern sich zu Ankerfibrillen zusammen, die zur Anheftung der basalen Keratinozyten an das Mesenchym beitragen. Die veränderte Reaktion auf den Antikörper LH2:7 deutet klar auf einen Mangel von Kollagen-Typ-VII in den Ankerfibrillen hin. Demnach liegt die Ursache der Spaltbildung unterhalb der Lamina densa bei den beiden Golden Retrievern in einer Anomalie der Ankerfibrillen, wie histologische Befunde bei älteren Golden Retrievern in Form von nicht im Einzelnen beschriebenen Abweichungen zeigen (Palazzi et al. 2000; Magnol et al. 2005).

Die Reduzierung des Kollagen-Typ-VII im Grenzbereich zwischen Dermis und Epidermis bei Golden Retrievern scheint auf eine Retention des Kollagen-Typ-VIIMolekülen in den basalen Keratinozyten zurückzuführen zu sein. Darauf lassen starke LH7:2-Floureszenzreaktionen in einzelnen basalen Keratinozyten der betroffenen Hunde schließen (Palazzi et al. 2000).

\section{Genetischer Hintergrund}

Die veränderte Verteilung von Kollagen Typ-VII-Molekülen bei betroffenen Golden Retrievern spricht für das Vorliegen eines Defektes im Kollagen-Typ-VII-Gen (COL7A1). Ein Kollagen-Typ-VII-Molekül ist aus drei $\alpha$-Ketten mit der typischen kollagenen Gly-X-Y-Wiederholungsabfolge zusammengesetzt, die von je zwei nichtkollagenen Domänen, NC1 und NC2 flankiert werden. Beim Hund hat die kollagene Domäne eine Länge von 1523 Aminosäuren und wird etwa mittig von einer nicht kollagenen Abfolge von 36 Aminosäuren unterbrochen. Die beiden kollagenen Abschnitte werden mit P1 und P2 bezeichnet (Baldeschi et al. 2003).

Das canine COL7A1-Gen ist auf Chromosom 20 im genomischen Contig NW_876272 zwischen Position 15335076 und 15366372 lokalisiert (GeneID: 403467). Die cDNA (NCBI-GenBank: AY183408) hat eine Länge von 8811 bp und ist in 119 Exons unterteilt. Das resultierende Protein umfasst 2936 Aminosäuren (Baldeschi et al. 2003). Abb. 82 zeigt schematisch die Lage der einzelnen Exons innerhalb der genomischen Sequenz. 


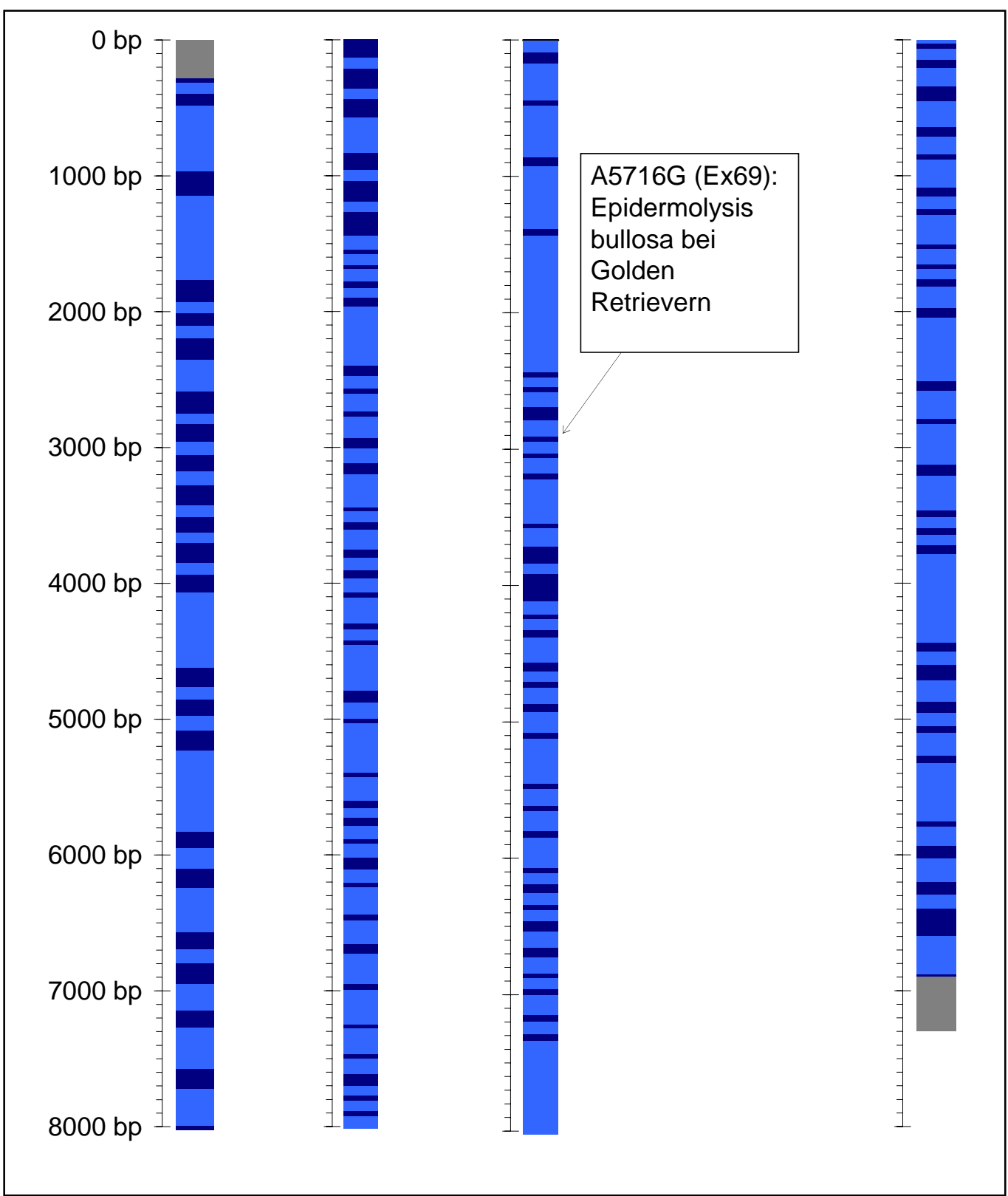

Abb. 82 Schematische Darstellung des caninen COL7A1-Gens und Lage der bisher identifizierten Mutationen. Dunkelblau: codierende Sequenz, hellblau: Intronseqenz, grau: intergenische Sequenz.

\section{Ursächliche Mutation der dystrophischen Epidermolysis bullosa bei Golden Retrievern}

Bei betroffenen Golden Retrievern liegt an Position 5716 der Kollagen-Typ-VII-cDNA in Exon 68 eine homozygote Substitution von Guanin durch Adenin vor (Abb. 83). Der von Baldeschi et al. (Baldeschi et al. 2003) mit Exon 68 bezeichnete Sequenzbereich entspricht Exon 69 im NCBI-Modell (NCBI-GeneID: 403467) Die Folge ist ein Austausch von Glycin durch Serin an Position 1906 der Aminosäurensequenz in der kollagenen P2-Domäne (Baldeschi et al. 2003). 
In Keratinozyten von betroffenen Golden Retrievern wird in vitro ein 320-kDa-Protein exprimiert, das immunoreaktiv auf den LH2:7-Antikörper reagiert und bezüglich seines Molekulargewichtes mit dem normalem Kollagen Typ VII übereinstimmt. Demnach ist die Expression des Kollagen-Typ-VII-Proteins durch die Mutation nicht beeinträchtigt. Im Vergleich zu normalen caninen Keratinozyten ist die in mutierten Keratinozyten exprimierte Menge an Kollagen Typ VII deutlich erhöht. Demnach scheint die Substitution eine Retention von Kollagen-Typ-VII-Molekülen in den basalen Keratinozyten $\mathrm{zu}$ verursachen. Die Autoren gehen aufgrund der Lokalisation der Substitution in der P2-Domäne von einer Beeinträchtigung des Aufbaus der Homotrimere und daraus resultierender Störung der Formation von Ankerfbrillen aus (Baldeschi et al. 2003).

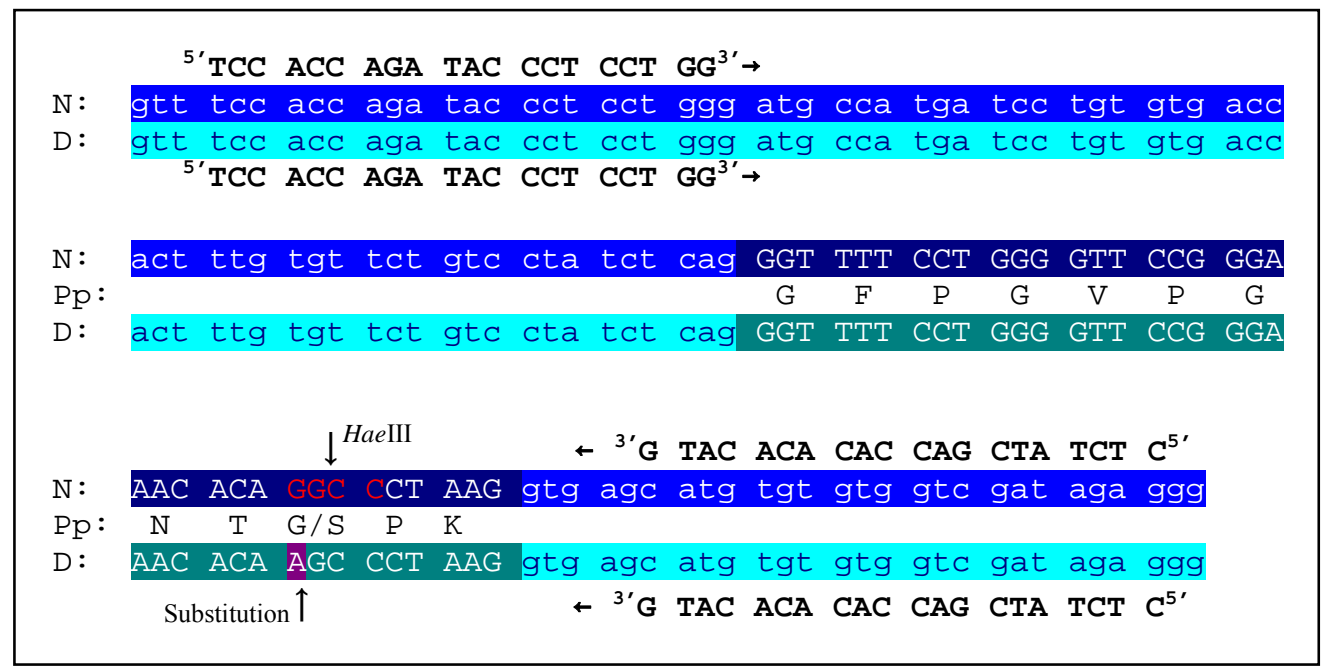

Abb. 83 Exon 69 des caninen Kollagen-Typ-VII-Gens und angrenzende Intronsequenzen. N: normale Sequenz, D: defekte Sequenz, Pp: Polypeptidsequenz, dunkelblau: Exon normale Sequenz, dunkelgrün: Exon defekte Sequenz, hellblau: Intron normale Sequenz, hellgrün: Intron defekte Sequenz, Substitution in defekter Sequenz violett unterlegt und durch Pfeil gekennzeichnet, rote Schrift: HaeIIIErkennungssequenz, HaeIII-Restriktionsschnittstelle durch Pfeil gekennzeichnet.

\section{Genotypisierung für dystrophische Epidermolysis bullosa bei Golden Retrievern}

Eine Genotypisierung kann per Amplifikation eines 127-bp-Fragments, das Exon 68 und angrenzende Intronsequenzen umspannt, und anschließender RFLP-Typisierung erfolgen. Der zugrunde liegende RFLP beruht auf einer HaeIIIRestriktionserkennungssequenz im Wildtypallel, die im Defektallel aufgrund der Mutation nicht vorhanden ist (Baldeschi et al. 2003). 


\subsubsection{Epidermolytische Hyperkeratose}

\begin{tabular}{ll|}
\hline Chromosom: & CFA9 \\
Gen: & KRT10 \\
NCBI: & GeneID: 491009, GenBank: AY318944 \\
DNA-Sequenz: & NW_876332, Position 3686456-3691710 \\
Mutationen: & G1T (Intron 1), Norfolk Terrier \\
\hline
\end{tabular}

\section{Krankheitsbild}

Die canine epidermolytische Hyperkeratose ist am besten bei Norfolk Terriern beschrieben. Kennzeichen der Erkrankung sind eine generalisierte, pigmentierte Hyperkeratose in Verbindung mit epidermaler Instabilität. Erste Anzeichen treten bereits wenige Stunden nach der Geburt in Form von Häutung der obersten Epidermisschicht als Folge geringer mechanischer Belastungen auf. Bei erwachsenen Hunden kommt es zusätzlich zu Hyperpigmentierung in Verbindung mit generalisierter dunkelgrauer Hyperkeratose. Besonders betroffen sind intertriginöse Hautpartien. Hautrötungen treten nicht auf. Fußsohlen, Nägel, Haare und Zähne sind nicht betroffen (Credille et al. 2005). Histopathologisch zeigen sich in der Körnerzellschicht Epidermolysis und intragranulare Risse in Verbindung mit großen Keratohyalingranula, einer leichten Verdickung der Hornschicht mit verdünnten Hornzellen und leichter warzenartiger epidermaler Hyperplasie. Der immunohistochemische Nachweis von Keratin 10 unter Verwendung des Antikörpers DE-K10 ergibt bei normalen und heterozygoten Hunden in der suprabasalen Epidermis stark positive Reaktionen, während in Hautbiopsien von betroffenen Hunden keine Kertain-10-Expression zu detektieren ist (Barnhart et al. 2004). Elektronenmikroskopisch sind bei betroffenen Hunden eine Zytolyse, eine verringerte Anzahl von Tonofilamenten und abnorme Verklumpungen der Tonofilamente zu erkennen (Credille et al. 2005).

Analysen eines acht-Generationen-Pedigrees bestehend aus 108 Norfolk Terriern sprechen für einen autosomal rezessiven Erbgang. Heterozygote Hunde sind phänotypisch gesund. Zahlen zur Verbreitung der Erkrankung innerhalb der Rasse Norfolk Terrier sind nicht veröffentlicht. Für sieben in der Literatur beschriebene erkrankte Hunde konnte die Quelle des Defektallels auf einen sieben Generationen zurückliegenden gemeinsamen Vorfahren zurückgeführt werden. Bei einer Genotypisierung von 50 Norfolkterriern aus einer anderen Zuchtlinie unter Einsatz eines DNA-Tests konnte das Defektallel nicht nachgewiesen werden (Credille et al. 
2005). Weitere Fälle von hyperkeratotischer Epidermolysis (August et al. 1988) sind bei einem Cocker-Spaniel-Terrier-Mischling, zwei Cavalier-King-Charles-SpanielWurfgeschwistern (Alhaidari et al. 1994) und einer Labradorhündin (Mecklenburg et al. 2000) beschrieben worden. Die Symptome sind in allen Rassen sehr ähnlich.

\section{Genetischer Hintergrund}

Im Zusammenhang mit der humanen epidermolytischen Hyperkeratose sind inzwischen zahlreiche Mutationen in Genen für die Oberflächenkeratine Keratin 1, 10 und 2e bekannt (Corden und McLean 1996).

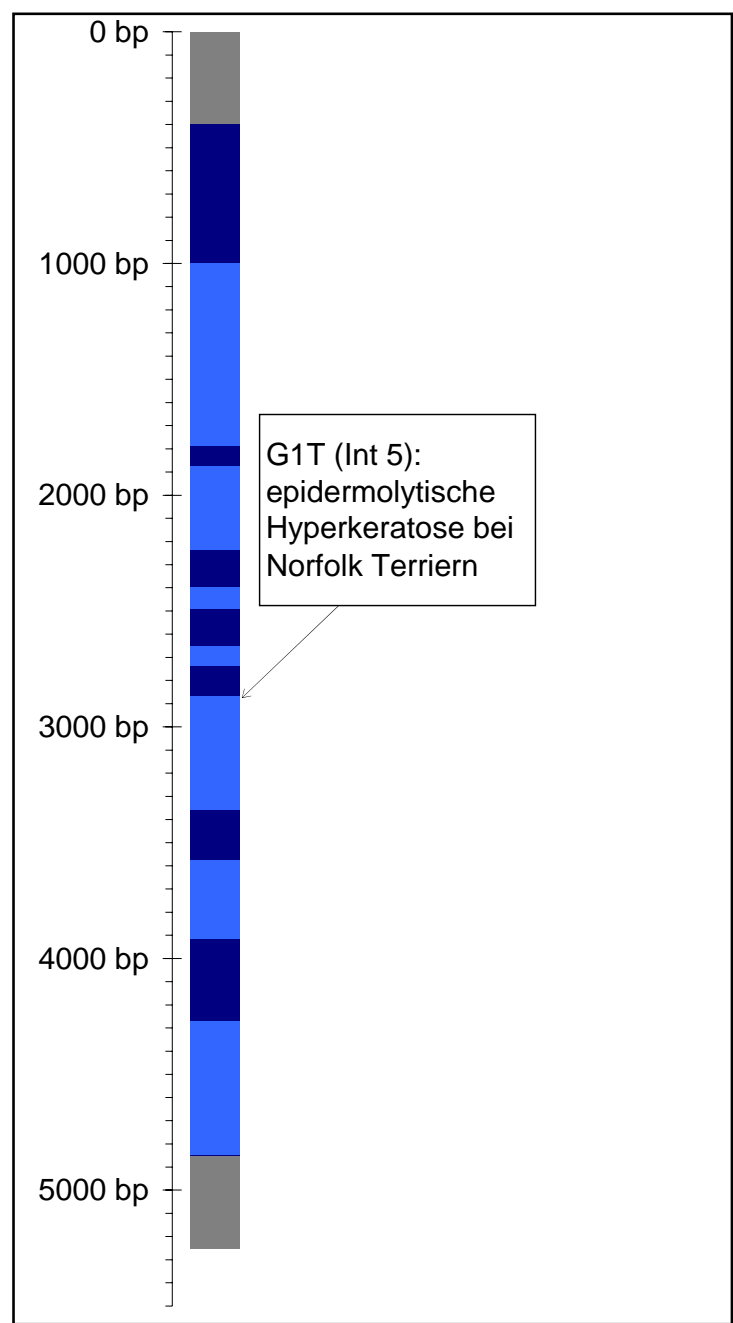

Abb. 84 Schematische Darstellung des caninen Keratin-10-Gens und Lage der bisher identifizierten Mutationen. Dunkelblau: cosierende Sequenz, hellblau: Intron, grau: intergenische Sequenz.

Aufgrund der immunohistochemischen Befunde kommt als Kandidatengen für die epidermolytische Hyperkeratose bei Norfolk Terriern vor allem das Keratin-10-Gen (KRT10) in Frage (Barnhart et al. 2004). Das canine Keratin-10-Gen ist auf Chromosom 9 innerhalb des Typ-I-Keratin-Genclusters lokalisiert (NCBI-GeneID: 
491006) und erstreckt sich im genomischen Contig NW_876332 zwischen Position 3686456 und 3691710. Die codierende Sequenz umfasst $1707 \mathrm{bp}$ und ist in acht Exons unterteilt, deren Lage innerhalb der genomischen Sequenz in Abb. 84 schematisch dargestellt ist (NCBI-GenBank: AY318944) (Minor et al. 2005).

\section{Ursächliche Mutation für Epidermolytische Hyperkeratose bei Norfolk Terriern}

Bei betroffenen Norfolk Terriern liegt im Keratin-10-Gen an der Donor-Spleißstelle von Intron 5 eine Substitution von Guanin durch Thymin vor (0) (Credille et al. 2005). Mittels spezifischer Primer lässt sich von normaler caniner cDNA ein 359-bp-Fragment beginnend in Exon 4 und endend in Exon 6 amplifizieren. Bei einer Amplifikation von cDNA-Proben betroffener Hunde ergeben sich unter Einsatz derselben Primer stattdessen mehrere kürzere oder längere Fragmente. Sequenzanalysen von drei dieser Fragmente zeigen alternative Spleißstellen. So entsteht ein 230-bp-Fragment durch ein leserasterkonformes Überspringen von Exon 5. Ein 330-bp-Fragment scheint durch die Aktivierung einer kryptischen Spleißstelle in Exon 5 (GTCTG) zustande zu kommen. Anhand der Stärke der diesem Fragment zugehörigen Bande schließen die Autoren, dass diese kryptische Spleißstelle von allen alternativen Spleißstellen am häufigsten genutzt wird. Die Folge dieses alternativen Spleißvorganges ist eine Leserasterverschiebung und die Insertion von 114 Nukleotiden, an die sich ein verfrühtes Stoppcodon anschließt. Ein drittes, 450 bp langes Fragment enthält eine 95bp-Insertion am 5'-Ende von Intron 5, deren Ursache der Aktivierung einer kryptischen Spleißstelle in Intron 5 (GTAAG) zugeschrieben wird. Die Folge ist eine Leserasterverschiebung und die Entstehung eines verfrühten Stoppcodons am Ende von Exon 5. Alle bei betroffenen Hunden untersuchten abnormen Keratin-10-Transkripte würden bei einer Translation zur Entstehung mutierter Keratin-10-Moleküle mit unvollständigen 2B-Domänen führen. Mithilfe einer quantitativen ReverseTranskriptase-PCR lässt sich bei betroffenen Hunden ein signifikanter Rückgang der Keratin-10-mRNA-Expression nachweisen. Diese Ergebnisse werden durch die histologischen Befunde bestätigt, indem eine Reduzierung der Tonofilamente vorliegt und abnorme Filamentaggregate zu beobachten sind, die offenbar durch die Translation von falsch gespleißten, leserasterkonformen Transkripten zustande kommen. 


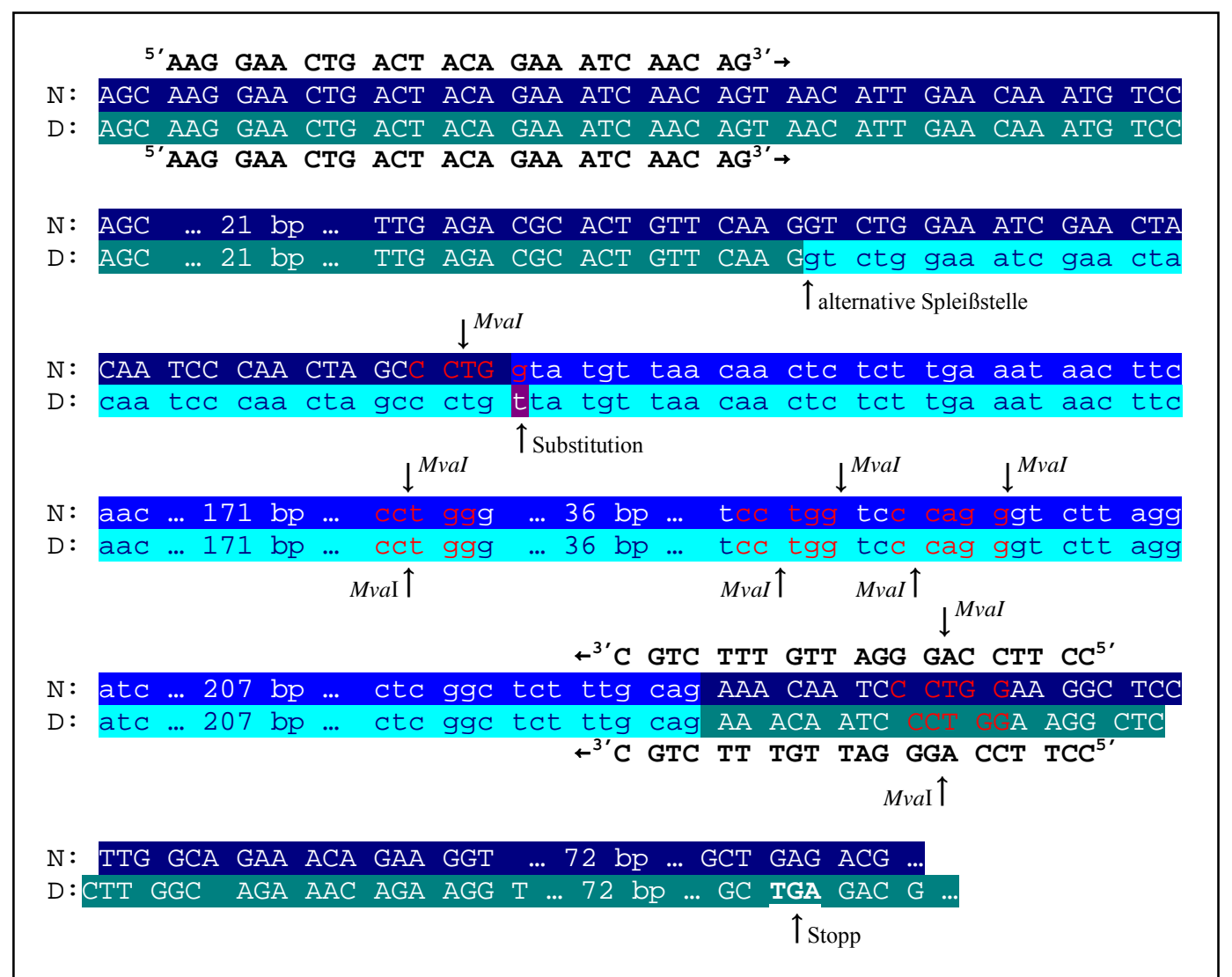

Abb. 85 Intron 5 des caninen Keratin-10-Gens und angrenzende Exonsequenzen. N: normale Sequenz, D: defekte Sequenz, dunkelblau: Exon normale Sequenz, dunkelgrün, Exon defekte Sequenz, hellblau: Intron normale Sequenz, hellgrün: Intron defekte Sequenz, Substitution in defekter Sequenz violett unterlegt und durch Pfeil gekennzeichnet, Beispiel für ein alternatives Spleißen der defekten Sequenz durch Pfeil gekennzeichnet, daraus resultierendes verfrühtes Stoppcodon in defekter Sequenz fett gedruckt, unterstrichen und durch Pfeil gekennzeichnet, rote Schrift: MvaI-Erkennungssequenz, MvaIRestriktionsschnittstellen durch Pfeile gekennzeichnet.

\section{Genotypisierung für epidermolytische Hyperkeratose bei Norfolk Terriern}

Die Genotypisierung kann per Amplifikation eines 660-bp-Fragments und anschließender RFLP-Typisierung erfolgen. Der zugrunde liegende RFLP beruht auf einer von insgesamt fünf Restriktionserkennungssequenzen für MvaI im WildtypallelPCR-Produkt, die aufgrund der Mutation im Defektallel-PCR-Produkt nicht vorhanden ist (Credille et al. 2005). 


\subsubsection{Hereditäre ophthalmologische Defekte}

Eine grobe Unterteilung der erblichen caninen ophthalmologischen Erkrankungen erfolgt nach den jeweils primär betroffenen Funktionseinheiten.

$\mathrm{Zu}$ den Retinadefekten gehört unter anderem eine große Gruppe von Erkrankungen, die als progressive Retinaatrophien (PRA) zusammengefasst sind. Je nachdem, in welcher Komponente und in welchem Entwicklungsstadium der Retina die ersten pathologischen Prozesse einsetzen, erfolgt eine weitere Klassifikation einzelner Unterformen. Die meisten PRAs betreffen primär die Photorezeptorzellen. Innerhalb dieser Gruppe wird weiterhin unterschieden zwischen primären Stäbchen- gegenüber primären Zapfenzelldefekten und Erkrankungen, bei denen beide Rezeptorzelltypen gleichermaßen betroffen sind, sowie zwischen Störungen der Entwicklung (Dysplasien) gegenüber rein degenerativen Erkrankungen. Photorezeptoratrophien werden auch als generalisierte PRAs bezeichnet, da pathologische Veränderungen schon zu Beginn fokal über die gesamte Retinafläche verteilt auftreten.

Neben den Photorezeptorzellatrophien zählen auch einige Formen von Pigmentepithelatrophien zu den PRAs. Erkrankungen aus dieser Gruppe werden auch als zentrale PRAs bezeichnet, da erste Gewebeschädigungen im zentralen Bereich der Retina lokalisiert sind und sich erst im Krankheitsverlauf über die gesamte Fläche der Retina ausbreiten. Die genetischen Ursachen sind bisher nur für eine als kongenitale stationäre Nachtblindheit oder hereditäre Retinadystrophie bezeichnete Erkrankung in der Rasse Briard bekannt.

Abgesehen von dieser zu den PRAs gehörigen Erkrankung des Retinapigmentepithels ist kürzlich die genetische Ursache einer als canine multifokale Retinopathie bezeichneten Erkrankung identifiziert worden. Dieser Defekt ist durch eine multifokale Ablösung der Retina oder des Retinapigmentepithels charakterisiert und führt in der Regel nicht zu schwerwiegenden visuellen Komplikationen.

Eine weitere canine Retinaerkrankung, deren genetische Ursache bekannt ist, ist die Achromatopsie-3 oder Hemeralopie. Bei dieser Erkrankung handelt es sich um einen spezifischen Defekt der Zapfenphotorezeptorzellen, der im Gegensatz zu den verschiedenen Defekten bei PRAs keine Kollateralschäden in anderen 
Retinakomponenten verursacht. Betroffene Hunde sind lediglich tagblind, während die Sehfähigkeit bei Dämmerungslicht vollständig erhalten bleibt.

Weitere hereditäre ophthalmologische Defekte, deren genetische Ursachen ermittelt werden konnten, betreffen wie die Collie Eye Anomalie die Aderhaut oder wie die primäre hereditäre Katarakt die Linsenepithelzellen (Millichamp 1990; Curtis et al. 1991).

Tabelle 14 bietet einen Überblick über alle bisher in der Gruppe der ophthalmologischen Erkrankungen identifizierten Gendefekte, die jeweils assoziierten Erkrankungstypen und die betroffenen Rassen. 
Tabelle 14 Typen hereditärer ophthalmologischer Erkrankungen, betroffene Rassen und assoziierte Defektgene

\begin{tabular}{|c|c|c|c|c|}
\hline Bezeichnung & Typ & Rasse & Gen & Erbgang \\
\hline red-PRA & Stäbchen-Zapfen-Dysplasie & Irischer Setter & PDE6B & autosomal rezessiv \\
\hline rcd-PRA & Stäbchen-Zapfen-Dysplasie & Sloughi & PDE6B & autosomal rezessiv \\
\hline red-PRA & Stäbchen-Zapfen-Dysplasie & Corgi & PDE6A & autosomal rezessiv \\
\hline pd-PRA & Photorezeptorzelldysplasie & Zwergschnauzer & Phosducin & autosomal rezessiv \\
\hline red-XLPRA1 & Photorezeptorzelldysplasie & Sibirischer Husky & RPGR & X-chromosomal \\
\hline red-XLPRA1 & Photorezeptorzelldysplasie & Samoyede & RPGR & $\mathrm{X}$-chromosomal \\
\hline pred-PRA & Stäbchen-Zapfen-Degeneration & $\begin{array}{l}\text { Am. Cocker Spaniel, Engl. Cocker } \\
\text { Spaniel, Am. Eskimohund, } \\
\text { Australian Cattle Dog, Australischer } \\
\text { Schäferhund, Australian Stumpy } \\
\text { Tail Cattle Dog, Chesapeake Bay } \\
\text { Retriever, Chinesischer Schopfhund, } \\
\text { Entlebucher Sennenhund, Finnischer } \\
\text { Lappenhund, Kuvasz, Labradoodle, } \\
\text { Labrador, Lappischer Hütehund, } \\
\text { Toy- und Zwergpudel, Nova Scotia } \\
\text { Duck Tolling Retriever, } \\
\text { Portugiesischer Wasserhund, } \\
\text { Spanischer Wasserhund, } \\
\text { Schwedischer Lappenhund, Golden } \\
\text { Retriever }\end{array}$ & PRCD & autosomal rezessiv \\
\hline $\begin{array}{l}\text { späte rcd- } \\
\text { PRA }\end{array}$ & Photorezeptorzelldegeneration & Schapendoes & Marker & autosomal rezessiv \\
\hline $\begin{array}{l}\text { multifokale } \\
\text { PRA }\end{array}$ & Photorezeptorzelldegeneration & Englischer Mastiff, Bullmastiff & Rhodopsin & autosomal dominant \\
\hline red-XLPRA2 & Photorezeptorzelldegeneration & Mischling & RPGR & autosomal rezessiv \\
\hline crd-PRA & Photorezeptorzelldegeneration & Zwerglanghaardackel & RPGRIP1 & autosomal rezessiv \\
\hline CSNB & Retinaepitheldefekt & Briard & RPE65 & autosomal rezessiv \\
\hline $\begin{array}{l}\text { multifokale } \\
\text { Netzhaut- } \\
\text { ablösung }\end{array}$ & Retinaepitheldefekt & $\begin{array}{l}\text { Englischer Mastiff, Bullmastiff, } \\
\text { French Mastiff, Dogue de Bordeaux, } \\
\text { Pyrenäenberghund, Coton de Tulear }\end{array}$ & FLJ2610 & autosomal rezessiv \\
\hline $\begin{array}{l}\text { Achromatop- } \\
\text { sie }\end{array}$ & Zapfendysplasie & Alaskan Malamute & CNGB3 & autosomal rezessiv \\
\hline $\begin{array}{l}\text { Achromatop- } \\
\text { sie }\end{array}$ & Zapfendysplasie & Deutsch Kurzhaar Vorstehhund & CNGB3 & autosomal rezessiv \\
\hline $\mathrm{CEA} / \mathrm{CH}$ & Aderhautdefekt & $\begin{array}{l}\text { Australischer Schäferhund, Border } \\
\text { Collie, Lancashire Heeler, Nova } \\
\text { Scotia Duck Tolling Retriever, } \\
\text { Lang- und Kurzhaar-Collie, Shetland } \\
\text { Schäferhund, Langhaarwhippet }\end{array}$ & CEA & autosomal rezessiv \\
\hline Katarakt & Linsendefekt & $\begin{array}{l}\text { Boston Terrier, Staffordshire } \\
\text { Bullterrier }\end{array}$ & HSF4 & autosomal rezessiv \\
\hline Katarakt & Linsendefekt & Australischer Schäferhund & HSF4 & autosomal dominant \\
\hline
\end{tabular}




\subsubsection{Photorezeptor-PRAs}

Alle Photorezeptor-PRAs beruhen auf dem Defekt einer der Komponenten der visuellen Signaltransduktionskaskade, sind durch eine fortschreitende Zerstörung der gesamten Netzhaut gekennzeichnet und münden stets in einem vollständigen oder nahezu vollständigen Verlust des Sehvermögens. Erste klinische Anzeichen bestehen in Verhaltensauffälligkeiten, die auf eine Störung des Sehvermögens hindeuten. Im Verlauf der Erkrankung nimmt die Sehfähigkeit fortschreitend ab. Parallel dazu kommt es zu einer zunehmenden Verzögerung des Pupillenreflexes und einer Erweiterung der Pupillen. Im Gegensatz zur Blindheit bleibt jedoch bei der PRA auch im Endstadium ein geringer Pupillenreflex erhalten. Charakteristische Befunde einer Untersuchung des Augenhintergrundes betreffen unter anderem eine erhöhte Reflexion und einen Verlust des granularen Erscheinungsbildes. Zurückzuführen sind diese Veränderungen auf ein Abnehmen des Retinadurchmessers. Mit zunehmender Atrophie der Retina geht auch der Durchmesser der Retinagefäße zurück bis sie mit bloßem Auge nicht mehr zu erkennen sind. Weitere erkrankungsbedingte Veränderungen umfassen die lückenhafte Verteilung von Retinapigmenten im Pigmentepithel sowie ein Verblassen und eine Verflachung der Papilla optica aufgrund von Degenerationen der Gefäße und Nerven. Im fortgeschrittenen Stadium liegt fast in allen Fällen eine Katarakt vor. Die Ursache der Kataraktbildung konnte bisher nicht eindeutig ermittelt werden. Es wird davon ausgegangen, dass die Trübung durch Produkte der Lipidperoxidation zustande kommt, die bei der Degeneration der äußeren Photorezeptorsegmente entstehen (Curtis et al. 1991). Die Grundlage für diese These bilden Ergebnisse aus Studien an Ratten mit einer erblichen Retinadegeneration. Dabei wurde eine zeitliche Kopplung der Kataraktbildung mit einem deutlichen Anstieg der Konzentration von Lipidperoxidationsprodukten im Glaskörper festgestellt (Ziegler und Hess 1985).

Eine Übersicht einzelner Photorezeptoratrophien, deren genetische Ursachen bekannt sind, sowie typische klinische, ophthalmologische, elektroretinographische, biochemische und histopathologische Befunde sind in Tabelle 15 zusammengestellt. 
Tabelle 15 Photorezeptoratrophien: Übersicht über zugrunde liegende Gendefekte, klinische, elektroretinographische, biochemische und histolopathologische Befunde

\begin{tabular}{|c|c|c|c|c|c|c|c|c|}
\hline & rcd-PRA & pd-PRA & rcd-XLPRA1 & PRCD & späte PRA & $\begin{array}{l}\text { multifokale } \\
\text { PRA }\end{array}$ & rcd-XLPRA2 & crd-PRA \\
\hline $\begin{array}{l}\text { Gen/ } \\
\text { Unter- } \\
\text { form }\end{array}$ & $\begin{array}{l}\text { PDE6B/ Irischer Setter } \\
\text { PDE6B/ Sloughi } \\
\text { PDE6A/ Corgi }\end{array}$ & Phosducin & $\begin{array}{l}\text { RPGR/ Husky } \\
\text { RPGR/ Samoyede }\end{array}$ & PRCD & $\begin{array}{l}\text { Marker-Haplotyp/ } \\
\text { Schapendoes }\end{array}$ & Rhodopsin & RPGR & RPGRIP1 \\
\hline $\begin{array}{l}\text { Klinik u. } \\
\text { Ophthal- } \\
\text { moskopie } \\
\text { (Os) }\end{array}$ & $\begin{array}{l}\text { Setter: Nacht-blindheit ab 4-6 } \\
\text { mo, Tagblindheit: bei einigen } \\
\text { Hunden ab } 1 \text { yr, z.T. bleibt } \\
\text { geringe Sehfähigkeit bei } \\
\text { Tageslicht bis } 6 / 7 \text { yr erhalten, } \\
\text { ab } 4 \text { mo häufig Katarakt, Os: } \\
\text { ab 6-8 wk erhöhte Reflexion } \\
\text { des Tapetum lucidum, Sloughi: } \\
\text { Details nicht publiziert, wie } \\
\text { PRA der Irischen Setter, Corgi: } \\
\text { typische Zeichen einer PRA }\end{array}$ & $\begin{array}{l}\text { ab } 3 \text { yr: vollständige } \\
\text { Nachtblindheit. } \\
\text { Tagblindheit: ab 4-5 yr } \\
\text { Os: ab } 3 \text { yr erhöhte } \\
\text { Reflexion des Tapetum } \\
\text { lucidum }\end{array}$ & $\begin{array}{l}\text { typische Anzeichen } \\
\text { einer PRA, } \\
\text { Samoyede: nicht } \\
\text { publiziert, entspr. } \\
\text { Husky }\end{array}$ & $\begin{array}{l}\text { rassenabhängig } \\
\text { sehr variabel: } \\
\text { offensichtliche } \\
\text { visuelle Defizite } \\
\text { ab ca. 2-5 yr zu } \\
\text { Beginn: Nacht- } \\
\text { blindheit, später } \\
\text { tagblind }\end{array}$ & $\begin{array}{l}\text { ab 2-5 yr } \\
\text { beginnende } \\
\text { Nachtblindheit, } \\
\text { später Tagblindheit }\end{array}$ & $\begin{array}{l}\text { Os: ab 6-12 mo } \\
\text { erhöhte } \\
\text { Reflexion des } \\
\text { Tapetum } \\
\text { lucidum }\end{array}$ & $\begin{array}{l}\text { typische } \\
\text { Anzeichen } \\
\text { einer PRA }\end{array}$ & $\begin{array}{l}\text { erste offensichtliche Seh- } \\
\text { störungen zwischen } 6 \text { mo } \\
\text { u. } 3 \text { yr beginnen mit } \\
\text { Nachtblindheit, variabler } \\
\text { Verlauf: Einzelfälle ab } 17 \\
\text { mo vollständig blind, Os: } \\
\text { ab } 25-26 \text { wk erhöhte } \\
\text { Reflexion des Tapetum } \\
\text { lucidum }\end{array}$ \\
\hline ERG & $\begin{array}{l}\text { bis } 2 \text { wk: normale Befunde, zu } \\
\text { keiner Zeit Reaktion auf } \\
\text { skotopische blaue Stimulation, } \\
\text { ab } 6 \text { wk keine Reaktion auf } \\
\text { skotopische rote und auf weiße } \\
\text { Stimulation, Stäbchenzell- } \\
\text { reaktion zu Beginn stärker } \\
\text { beeinträchtigt, später } \\
\text { allmählicher Verlust der } \\
\text { Zapfenreaktion, Sloughi und } \\
\text { Corgi: nicht publiziert }\end{array}$ & $\begin{array}{l}\text { ab } 8 \text { wk: reduzierte } \\
\text { Reaktion auf skotopische } \\
\text { blaue und rote und auf } \\
\text { weiße Stimulation, beide } \\
\text { Rezeptorzelltypen } \\
\text { gleichmäßig beeinträchtigt, } \\
\text { im weiteren Verlauf extrem } \\
\text { schnelle Verschlechterung } \\
\text { der Reaktionen, steht im } \\
\text { Widerspruch zu langem } \\
\text { Erhalt der Sehfähigkeit }\end{array}$ & $\begin{array}{l}\text { ab } 6 \text { mo Abnehmen } \\
\text { der Stäbchenzell- } \\
\text { amplituden auch } \\
\text { bei heterozygoten } \\
\text { Hündinnen, Zap- } \\
\text { fenzellamplituden } \\
\text { bleiben länger } \\
\text { normal, im } \\
\text { weiteren Verlauf } \\
\text { schneller Rückgang } \\
\text { der Funktion beider } \\
\text { Rezeptorzelltypen, } \\
\text { Samoyede: nicht } \\
\text { publiziert, entspr. } \\
\text { Husky }\end{array}$ & $\begin{array}{l}\text { Alter rassen- } \\
\text { spezifisch u. } \\
\text { individuell } \\
\text { variabel, Zwerg- } \\
\text { pudel zeigt ab } \\
9,5 \text { wk-10 mo, } \\
\text { Cocker Spaniel } \\
\text { ab } 1 \text { yr erste } \\
\text { reduzierte Am- } \\
\text { plituden, zu Be- } \\
\text { ginn spezifischer } \\
\text { Verlust der Stäb- } \\
\text { chenfunktion, } \\
\text { später auch } \\
\text { Rückgang der } \\
\text { Zanfenfunktion }\end{array}$ & nicht publiziert & $\begin{array}{l}\text { erste Auffällig- } \\
\text { keiten bei hete- } \\
\text { rozygoten ab } \\
12-18 \text { mo, bei } \\
\text { homozygoten } \\
\text { ab } 3 \text { mo betref- } \\
\text { fen zu Beginn } \\
\text { v.a. Stäbchen- } \\
\text { zellfunktion, } \\
\text { Besonderheit: } \\
\text { verzögerte } \\
\text { Dunkeladap- } \\
\text { tation }\end{array}$ & $\begin{array}{l}\text { erste Auffällig- } \\
\text { keiten ab 5-6 } \\
\text { wk: kleine } \\
\text { Amplituden, } \\
\text { abnorme } \\
\text { Wellenform, } \\
\text { zuerst Stäb- } \\
\text { chen- später } \\
\text { auch Zapfen- } \\
\text { zellreaktion } \\
\text { beeinträchtigt }\end{array}$ & $\begin{array}{l}\text { Rückgang der Amplituden } \\
\text { ab } 9 \text { mo, keine Hinweise } \\
\text { auf selektiven Verlust der } \\
\text { Stäbchenzellfunktion }\end{array}$ \\
\hline
\end{tabular}


Fortsetzung Tabelle 15

\begin{tabular}{|c|c|c|c|c|c|c|c|c|}
\hline & rcd-PRA & pd-PRA & rcd-XLPRA1 & PRCD & späte PRA & multifokale PRA & rcd-XLPRA2 & crd-PRA \\
\hline $\begin{array}{l}\text { Gen/ } \\
\text { Unter- } \\
\text { form }\end{array}$ & $\begin{array}{l}\text { PDE6B/ Irischer Setter } \\
\text { PDE6B/ Sloughi } \\
\text { PDE6A/ Corgi }\end{array}$ & Phosducin & $\begin{array}{l}\text { RPGR/ Husky } \\
\text { RPGR/ Samoyede }\end{array}$ & PRCD & $\begin{array}{l}\text { Marker- } \\
\text { Haplotyp/ } \\
\text { Schapendoes }\end{array}$ & Rhodopsin & RPGR & RPGRIP1 \\
\hline $\begin{array}{l}\text { Bio- } \\
\text { chemie }\end{array}$ & $\begin{array}{l}\text { ab 10-12 d: erhöhte cGMP- } \\
\text { Werte, reduzierte cGMP- } \\
\text { PED-Aktivität, Sloughi und } \\
\text { Corgi: nicht publiziert }\end{array}$ & $\begin{array}{l}\text { cGMP-Werte im } \\
\text { Referenzbereich }\end{array}$ & nicht untersucht & $\begin{array}{l}\text { Hinweise auf Störung } \\
\text { des Fettstoffwechsels }\end{array}$ & nicht publiziert & nicht untersucht & nicht untersucht & nicht untersucht \\
\hline $\begin{array}{l}\text { histo- } \\
\text { logische } \\
\text { Verän- } \\
\text { derungen } \\
\text { einzelner } \\
\text { Retina- } \\
\text { schichten }\end{array}$ & $\begin{array}{l}\text { 2-3 wk: Pyknose von } \\
\text { Stäbchenrezeptorzellkernen, } \\
\text { unterentwickelte innerer u. } \\
\text { äußerer Segmente der } \\
\text { Stäbchenzellen, später } \\
\text { Degeneration der Zapfen- } \\
\text { zellrezeptoren, schrittweise } \\
\text { Degeneration der Gefäße u. } \\
\text { des Pigmentepithels, } \\
\text { Tapetum lucidum: bleibt } \\
\text { erhalten, morphologisch } \\
\text { veränderte Zellen, Stäbchen- } \\
\text { zellkerne werden vollständig } \\
\text { resorbiert, Zapfenzellkerne } \\
\text { bleiben mehrere yr erhalten, } \\
\text { Sloughi und Corgi: nicht } \\
\text { publiziert }\end{array}$ & $\begin{array}{l}\text { ab } 24 \text { d: Unterent- } \\
\text { wicklung der } \\
\text { äußeren Segmente } \\
\text { der Zapfen- u. } \\
\text { Stäbchenzellen u. } \\
\text { der inneren Seg- } \\
\text { mente der Stäb- } \\
\text { chenzellen, ab } 8 \\
\text { wk: beginnende } \\
\text { Degeneration v.a. } \\
\text { Stäbchenzellen, ab } \\
6 \text { mo enthält } \\
\text { Retina vorrangig } \\
\text { Zapfenz., weiterer } \\
\text { Verlauf wie bei } \\
\text { rcd-PRA }\end{array}$ & $\begin{array}{l}\text { heterozygote Hündinnen } \\
\text { o.B., betroffene Rüden: } \\
\text { erste morphologische } \\
\text { Veränderungen nach } \\
\text { Erreichen des jungen } \\
\text { Erwachsenenalters, } \\
\text { Beginn: äußere Segmente } \\
\text { der Stäbchenzellen, } \\
\text { später Übergang auf } \\
\text { Zapfenzellen, im Endsta- } \\
\text { dium ab ca. } 4 \text { yr besteht } \\
\text { Retina aus dünner } \\
\text { Schicht Gliazellen u. } \\
\text { Resten d. Pigmentepi- } \\
\text { thels, Samoyede: nicht } \\
\text { publiziert, wie bei Husky }\end{array}$ & $\begin{array}{l}\text { ab 13-14 wk verzö- } \\
\text { gerte Erneuerung der } \\
\text { membranösen Schei- } \\
\text { ben der äußeren Seg- } \\
\text { mente der Stäbchen- } \\
\text { zellen, Degeneration } \\
\text { unter Anwesenheit } \\
\text { phagozytierender } \\
\text { Zellen betrifft } \\
\text { zunächst innere, dann } \\
\text { äußere Segmente, } \\
\text { später proximale } \\
\text { Retinaschichten, } \\
\text { Zwergpudel: typische } \\
\text { Vesikel, Endphase } \\
\text { entspr. rcd-PRA }\end{array}$ & $\begin{array}{l}\text { binnen } 2 \text { yr } \\
\text { kommt es zur } \\
\text { vollständige } \\
\text { Degeneration } \\
\text { der Photo- } \\
\text { rezeptorzellen }\end{array}$ & $\begin{array}{l}\text { unregelmäßige } \\
\text { Degeneration } \\
\text { der } \\
\text { Stäbchenzellen } \\
\text { ab 6-12 mo, } \\
\text { Zapfen-zellen } \\
\text { erst ab ca. } 4 \text { yr } \\
\text { betroffen }\end{array}$ & $\begin{array}{l}\text { heterozygote } \\
\text { Hündinnen wie } \\
\text { Rüden betroffen, } \\
\text { veränderte Morpho- } \\
\text { genese der äußeren } \\
\text { Photorezeptor- } \\
\text { segmente, ab } 4 \text { mo } \\
\text { Beginn des degene- } \\
\text { rativen Prozesses, } \\
\text { Endstadium ab ca. } 2 \\
\text { yr wie XLPRA1 }\end{array}$ & $\begin{array}{l}\text { ab } 6 \text { wk marginale } \\
\text { Veränderungen der äußeren } \\
\text { Stäbchensegmente, ab } 10 \\
\text { wk deutlichere Verände- } \\
\text { rungen, Zapfenzellen und } \\
\text { Retinapigmentepithel o.B., } \\
\text { ab } 25 \text { wk beginnende } \\
\text { Degeneration, im } \\
\text { Widerspruch zu ERG } \\
\text { Hinweise auf primäre } \\
\text { Stäbchendegeneration, laut } \\
\text { nicht publizierter. Studien } \\
\text { handelt es sich trotzdem } \\
\text { um primäre } \\
\text { Zapfendegeneration }\end{array}$ \\
\hline $\begin{array}{l}\text { Vertei- } \\
\text { lungs- } \\
\text { muster } \\
\text { der } \\
\text { Läsionen }\end{array}$ & $\begin{array}{l}\text { gleichmäßige Verbreitung in } \\
\text { der gesamten Retina, } \\
\text { Sloughi und Corgi: nicht } \\
\text { publiziert }\end{array}$ & $\begin{array}{l}\text { gleichmäßige } \\
\text { Verbreitung in der } \\
\text { gesamten Retina }\end{array}$ & $\begin{array}{l}\text { geht von peripheren auf } \\
\text { zentrale Bereiche über, } \\
\text { Samoyede: nicht } \\
\text { publiziert, wie bei Husky }\end{array}$ & $\begin{array}{l}\text { geht von inferioren } \\
\text { Bereichen auf } \\
\text { superiore und } \\
\text { temporale Bereiche } \\
\text { über }\end{array}$ & & $\begin{array}{l}\text { mosaikartig, } \\
\text { Beginn im } \\
\text { Bereich der } \\
\text { Papilla optica }\end{array}$ & & \\
\hline
\end{tabular}




\subsection{Photorezeptordysplasie bei Irischen Settern und Sloughis}

\begin{tabular}{ll|}
\hline Chromosom: & CFA3 \\
Gen: & PDE6B \\
Ensembl: & GeneID: ENSCAFG00000016782, NCBI-GenBank: \\
DNA-Sequenz: & AJ277998 \\
Mutationen: & GFA3, Position 94573287-94601397 \\
& 24472A, Irischer Setter \\
\hline
\end{tabular}

\section{I.a Krankheitsbild bei Irischen Settern}

Auf der Grundlage von klinischen, elektroretinographischen und histopathologischen Befunden wird die Photorezeptordysplasie der Irischen Setter als eine primäre Entwicklungsstörung der Stäbchenrezeptorzellen eingestuft. Daraus ergibt sich die Bezeichnung als rcd-PRA (rod-cone-degenerative PRA), die auf die Reihenfolge des Auftretens degenerativer Erscheinungen in den beiden Rezeptorzelltypen hinweist (Hodgman et al. 1949; Parry 1953; Buyukmihci et al. 1980; Chader et al. 1985).

Biochemische Untersuchungen von Retinahomogenaten ergeben bereits bei 10-12 Tage alten betroffenen Hunden, vor dem Auftreten erster klinischer Anzeichen deutlich erhöhte Konzentrationen von zyklischem Guanosinmonophosphat (cGMP) (Aguirre et al. 1982b). Bei acht bis zwölf Wochen alten betroffenen Irischen Settern beträgt die cGMP-Konzentration in der Retina etwa das Zehnfache der cGMP-Konzentration normaler Altersgenossen (Aguirre et al. 1978). Während der Hauptphase visueller Degeneration, während derer eine Reduzierung der äußeren Körnerschicht um $60 \%$ stattfindet, bleiben die cGMP-Konzentrationen in der Retina um das 10- bis 15 fache der Werte bei normalen Altersgenossen erhöht. Erst wenn die Photorezeptorschichten und die äußere Körnerschicht weitgehend degeneriert sind, sinken die cGMPKonzentrationen in der Retina auf annähernd normale Werte ab (Aguirre et al. 1982b). Der cGMP-Spiegel reguliert die $\mathrm{Na}^{+}$-Kanäle in der Membran der StäbchenPhotorezeptorzellen und nimmt damit eine entscheidende Steuerungsfunktion bei der Weiterleitung von Lichtreizen ein (Miller und Nicol 1979). Vor diesem Hintergrund lässt sich ein ursächlicher Zusammenhang zwischen der abweichenden cGMPKonzentration und der reduzierten Sehfähigkeit herstellen.

Die Ursache der erhöhten cGMP-Konzentration scheint in einer reduzierten Aktivität von cGMP-Phosphodiesterase (cGMP-PDE) zu liegen. Dieses Enzym wird als Folge 
einer Stimulierung der Photorezeptoren der Stäbchen aktiviert und hydrolysiert cGMP zu 5'-GMP. Bereits bei neun Tage alten betroffenen Irischen Settern liegt in der Retina eine im Vergleich zu gesunden Altersgenossen reduzierte Aktivität von cGMP-PDE vor (Liu et al. 1979). Auch in späteren Untersuchungen im Alter von fünf und sieben Wochen bleibt die cGMP-PDE-Aktivität bei betroffenen Hunden im Vergleich zu gesunden Kontrollhunden reduziert. Sowohl bei gesunden Kontrollhunden als auch bei betroffenen Irischen Settern lässt sich im Alter von neun Tagen die cGMP-PDEAktivität durch Zugabe von bovinem Hirn-Calmodulin erhöhen. Bei Calmodulin handelt es sich um ein calciumabhängiges Aktivatorprotein. In Retinas von gesunden Hunden nimmt der Effekt des Aktivatorproteins auf die cGMP-PDE-Aktivität mit zunehmendem Alter ab und ist bei Untersuchungen von fünf und sieben Wochen alten Hunden nicht mehr erkennbar. Demgegenüber ist bei betroffenen Hunden auch im Alter von fünf und sieben Wochen durch Zugabe von bovinem Calmodulin eine messbare Erhöhung der cGMP-PDE-Aktivität $\mathrm{zu}$ erzielen. Die Konzentrationen von retinaeigenem Calmodulin sind bei gesunden Hunden generell höher als bei betroffenen Hunden. Sowohl bei gesunden als auch bei betroffenen Hunden werden die höchsten Werte im Alter von neun Tagen gemessen. Bei späteren Untersuchungen im Alter von fünf und sieben Wochen liegen jeweils deutlich geringere Konzentrationen vor. Dieser Konzentrationsrückgang ist bei betroffenen Hunden stärker als bei gesunden Hunden (Liu et al. 1979).

Mithilfe einer Technik zur biochemischen Untersuchung einzelner Schichten der Retina (Lowry und Passoneau 1972) konnte zudem bereits bei zehn Tage alten betroffenen Welpen eine Verschiebung in der Verteilung von cGMP und cGMP-PDE in den einzelnen Retinaschichten im Verlauf der Entwicklung der Retina zwischen normalen und betroffenen Hunden nachgewiesen werden. Die Guanylatcyclase-Aktivität in den einzelnen Schichten der Retina unterscheidet sich nicht von der bei normalen Hunden gemessenen Aktivität. Es wird als wahrscheinlich eingeschätzt, dass eine normale Guanylatcyclase-Aktivität in Verbindung mit einer reduzierten cGMP-PDE-Aktivität eine Akkumulation von cGMP verursachen kann (Barbehenn et al. 1988).

\section{I.b Krankheitsbild bei Sloughis}

Bei der PRA der Sloughis sind detaillierte elektrophysiologische, histopathologische und biochemische Untersuchungen bisher nicht durchgeführt worden. Betroffene Hunde 
zeigen ähnlich wie Irischen Setter mit PRA bereits früh erste Symptome. Beobachtet wurde die Erkrankung im Verlauf der letzten 20 Jahre von verschiedenen deutschen und niederländischen Züchtern (Dekomien et al. 2000).

\section{Genetischer Hintergrund}

Die Beobachtung einer auffälligen Häufung von PRA-Fällen bei Roten Irischen Settern in Großbritannien in den 1920er Jahren und Studien von rund 200 Pedigrees betroffener Irischer Setter sprechen für das Vorliegen eines autosomal rezessiven Erbgangs (Gray 1925 zitiert nach Hodgman et al. 1949; Rasbridge 1944 zitiert nach Hodgman et al. 1949). Spätere Studien bestätigen diese Ergebnisse (Parry 1953). Die Frequenz des Defektallels innerhalb der Rasse Irischer Setter wurde anhand einer Genotypisierung von 436 Hunden unter Einsatz eines DNA-Tests zwischen 1994 und 1997 auf 7,8 \% geschätzt (Aguirre et al. 1999). Auch bei Sluoghis liegt ein autosomal rezessiver Erbgang vor. Bei der Genotypisierung von 88 verwandten Sloughis aus sieben Generationen wurden 26 heterozygote und zwei homozygote Defektträger identifiziert (Dekomien et al. 2000). Über die Verbreitung der Erkrankung in anderen Zuchtlinien sind keine Zahlen veröffentlicht.

Bei einer Untersuchung der mRNAs verschiedener an der Phototransduktion beteiligter Retinaproteine ergibt sich bei betroffenen Irischen Settern eine deutliche Reduzierung der cGMP-PDE $\beta$-mRNA (Farber et al. 1992). Bei einem Western Immunoblot unter Verwendung spezifischer Antikörper gegen die $\alpha$ - und $\beta$-Untereinheiten des cGMPPDE-Proteins lassen sich bei gesunden Kontrollhunden beide Untereinheiten nachweisen, während bei betroffenen Hunden nur ein Polypeptid von etwas höherer Molekülmasse als die $\alpha$-Untereinheit und mehrere weitere Polypeptide von deutlich höherer oder deutlich geringerer Molekülmasse als die $\alpha$ - oder $\beta$-Untereinheit zu detektieren sind (Suber et al. 1993).

Die annähernd vollständige cDNA-Sequenz des caninen cGMP-PDE $\beta$-Gens beinhaltet auf einer Länge von 2746 Nukleotiden 16 terminale Nukleotide der 5'-UTR, die codierende Sequenz, die vollständige 3'-UTR und das Polyadenylierungssignal. Das resultierende Polypeptid umfasst 856 Aminosäuren und zeigt eine hohe Konservierung aller typischen Eigenschaften einer Photorezeptor PDE wie der cGMP- und $\gamma$ - 
Untereinheits-Bindungsstellen, der C-terminalen CAAX-Box und weiterer homologer Domänen (Clements et al. 1993).

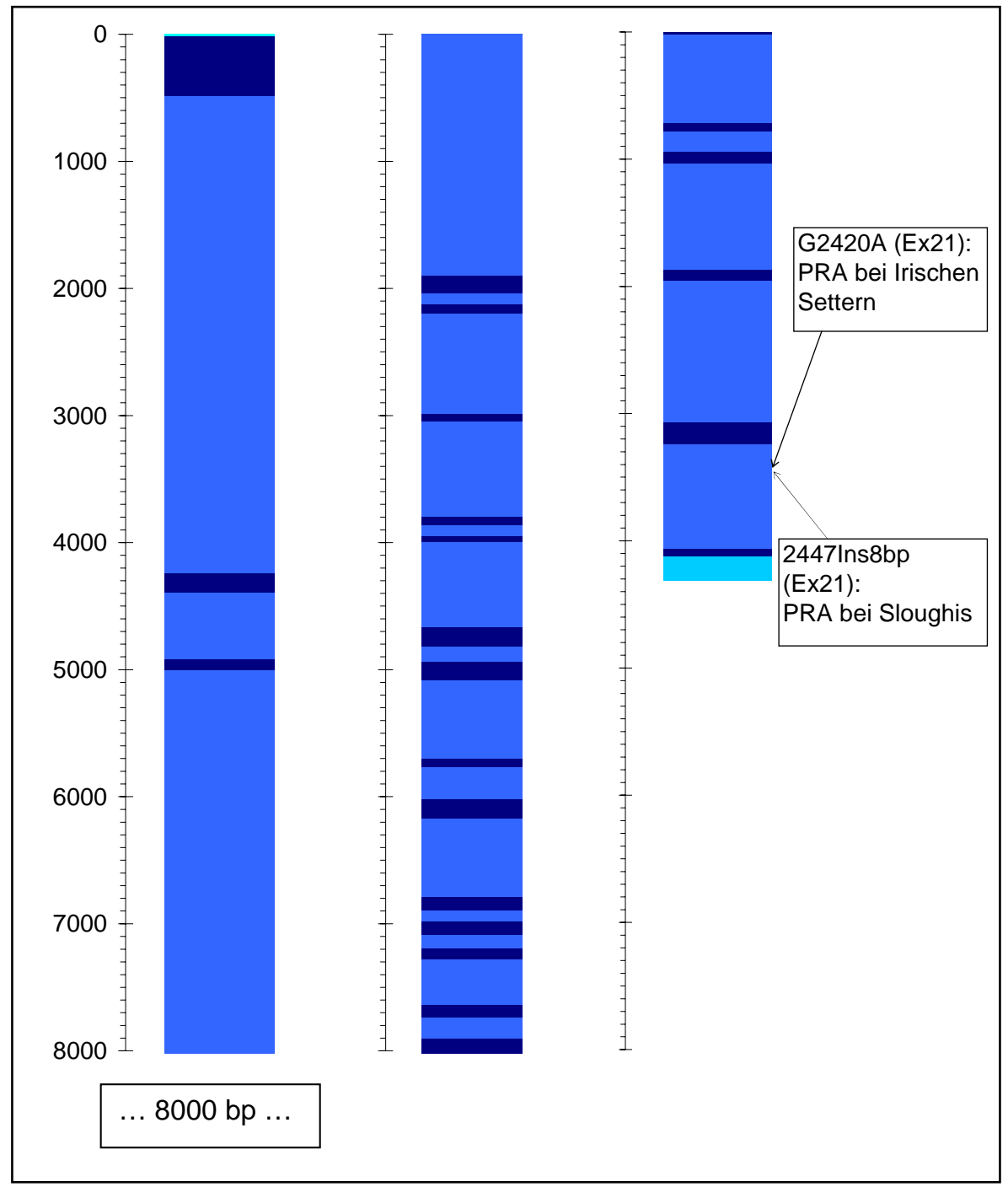

Abb. 86 Schematische Darstellung des caninen PDE6B-Gens und Lage der bisher identifizierten Mutationen. Dunkelblau: codierende Sequenz, hellblau: Intronsequenz, türkis: UTR.

Die C-terminale CAAX-Box signalisiert die posttranslationale Isoprenylierung, die Voraussetzung für die korrekte Funktion des Proteins ist. CAAX steht für Cystein gefolgt von zwei alipathischen Aminosäuren und einer beliebigen weiteren Aminosäure. Diese Sequenz signalisiert die posttranslationale Isoprenylierung von Cystein, die proteolytische Entfernung der drei folgenden Aminosäuren AAX und die Carboxylmethylierung. Dabei bestimmt die letzte Aminosäure X den Prenylrest, der als Thioether an Cystein gebunden wird. Bei Irischen Settern handelt es sich bei dieser letzten Aminosäure um Leucin, das an dieser Stelle für die Assoziation von Geranylgeranyl signalisiert. Geranylgeranyl dient als Anker für die Assoziation an die 
Membran der äußeren Stäbchensegmente (Maltese 1990). Das cGMP-PDE $\beta-G e n$ ist aus 22 Exons zusammengesetzt (Dekomien et al. 2000) und auf Chromosom 3 lokalisiert (Ensembl-GeneID: ENSCAFG00000016782, NCBI-GenBank: AJ277998). Die Lage der einzelnen Exons innerhalb der genomischen Sequenz ist in Abb. 86 dargestellt.

\section{III.a Ursächliche Mutation für PRA bei Irischen Settern}

Bei betroffenen Irischen Settern liegt im cGMP-PDE $\beta-G e n$ in Codon 807 in Exon 21 eine Substitution von Guanin durch Adenin vor, die zur Codierung eines verfrühten Stopp-Signals und damit zur Verkürzung des resultierenden Polypeptids um 49 Aminosäuren führt (Abb. 87).

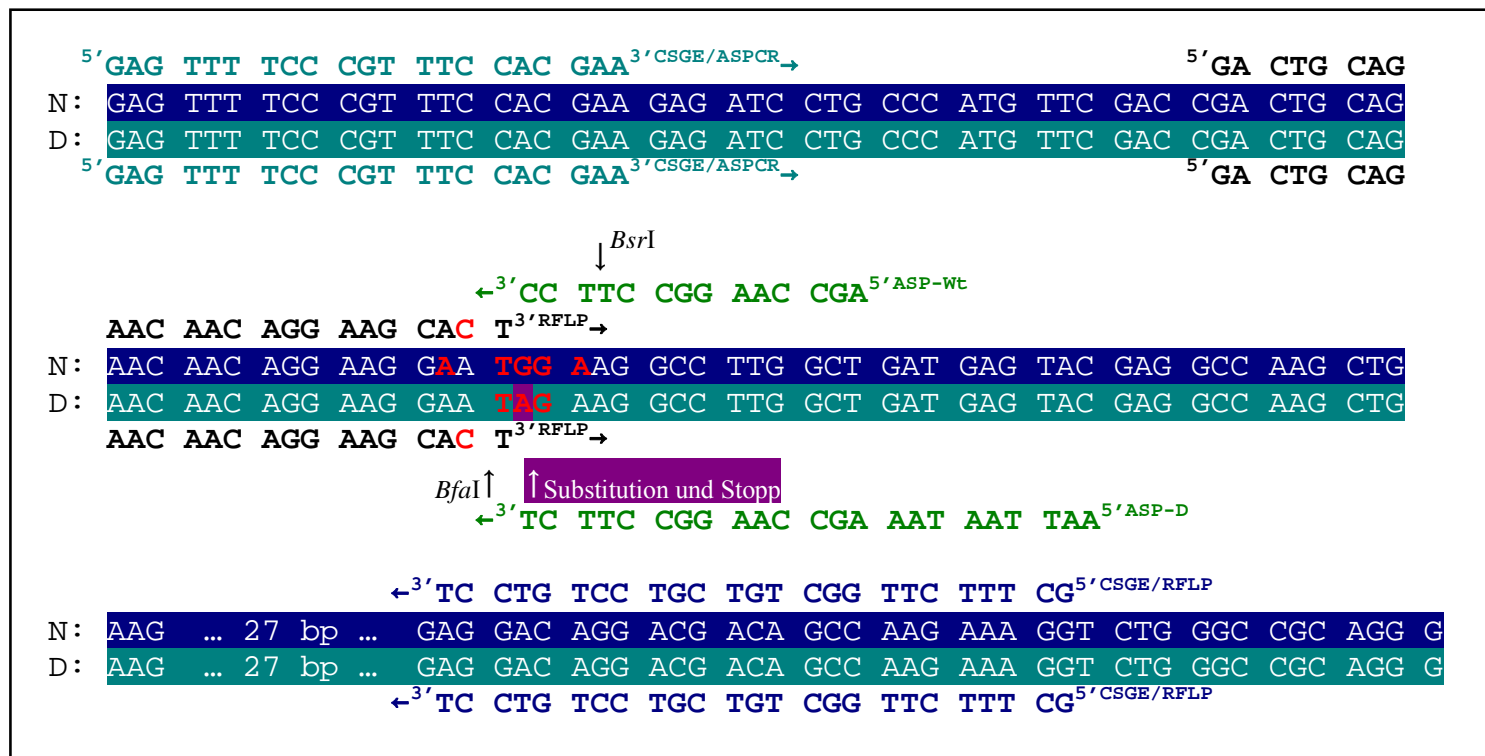

Abb. 87 Exon 21 des canine cGMP-PDEß-Gens. N: normale Sequenz, D: defekte Sequenz, dunkelblau: Exon normale Sequenz, dunkelgrün: Exon defekte Sequenz, Substitution in defekter Sequenz violett unterlegt und durch Pfeil gekennzeichnet, verfrühtes Stoppcodon in defekter Sequenz durch Pfeil gekennzeichnet, rote Schrift: BsrI- bzw. BfaI-Erkennungssequenzen, Restriktionsschnittstellen für BsrI bzw. BfaI durch Pfeil gekennzeichnet, RFLP: Primer für Restriktionsfragmentlängenpolymorphismus, ASPCR: Vorwärtsprimer für ASP, ASR-Wt: wildtypallelspezifischer reverser Primer, ASP-D: defektallelspezifischer reverser Primer, CSGE (Conformation Sensitive Gel Electrophoresis): Primer für Heteroduplexanalyse.

Dadurch kommt es zum Verlust der C-terminalen CAAX-Box (Suber et al. 1993). Die beschriebene Mutation kosegregiert in drei untersuchten US-amerikanischen Pedigrees Irischer Setter mit der progressiven Retinaatrophie (Ray et al. 1994) und konnte auch bei betroffenen Irischen Settern aus einer britischen Forschungskolonie nachgewiesen werden (Clements et al. 1993). Auch bei drei von vier Irischen Settern mit einem atypisch langsamen Krankheitsverlauf konnte ein homozygotes Vorliegen der Mutation nachgewiesen werden (Ray et al. 1994). Bei einzelnen untersuchten Hunden aus neun 
verschiedenen Rassen mit verschiedenen anderen erblichen degenerativen Retinaerkrankungen konnte die Mutation nicht nachgewiesen werden (Suber et al. 1993; Ray et al. 1994). Auch in einer weiteren Studie konnte die beschriebene Mutation bei Hunden mit erblichen degenerativen Retinaerkrankungen aus 23 verschiedenen Rassen nicht nachgewiesen werden (Aguirre et al. 1999).

\section{IV.a Genotypisierung für PRA bei Irischen Settern}

Zum Nachweis der Mutation sind drei verschiedene Gentests entwickelt worden (Abb. 87). Die älteste veröffentlichte Methode zur Genotypisierung beruht auf einer RFLPAnalyse. Dazu wird bei der Amplifikation eines 114-bp-Fragments unter Einsatz eines mismatch-Vorwärtsprimers im Defektallel eine BfaI-Restriktionsschnittstelle eingeführt, die im Wildtypallel nicht vorhanden ist (Clements et al. 1993). Dieser Test erwies sich aufgrund des sporadischen Auftretens unvollständiger Restriktionsspaltungen als bedingt zuverlässig für die Unterscheidung zwischen homozygoten und heterozygoten Defektträgern. Dieses Problem ließ sich trotz intensiver Optimierungsexperimente nicht vollständig beheben. Der für den ersten Gentest entwickelte mismatch-Primer (Clements et al. 1993) generiert im Wildtypallel eine BsrI-Restriktionsschnittstelle. Durch die Restriktionsspaltung eines $\mathrm{zu}$ untersuchenden PCR-Produktes mit beiden Restriktionsendonukleasen kann die Zuverlässigkeit des Gentests erheblich erhöht werden. Zudem wird aufgrund vergleichender Untersuchungen die Wahrscheinlichkeit für das Auftreten unvollständiger Spaltungen bei Einsatz von BsrI als geringer eingeschätzt (Ray et al. 1995). Eine weitere mögliche Methode zur Genotypisierung basiert auf der amplifikation eines 157-bp-Fragmentes und anschließender Heteroduplexanalyse (Ray et al. 1995). Bei der vierten veröffentlichten Methode zur Detektion heterozygoter und homozygoter Defektträger handelt es sich um einen ASPTest (Ray et al. 1996).

\section{III.b Ursächliche Mutation für PRA bei Sloughis}

Wie bei Irischen Settern ist der ursächliche Gendefekt auch bei der PRA der Sloughis im cGMP-PDE $\beta$-Gen lokalisiert. Im Zuge einer SSCP-Analyse des cGMP-PDE $\beta$-Gens von insgesamt 349 Hunden aus 14 verschiedenen Rassen einschließlich 75 Hunden mit generalisierter PRA konnte bei zwei betroffenen Sloughis eine Mutation in Exon 21 nachgewiesen werden. Es handelt sich hierbei um eine 8-bp-Insertion in Codon 816, die 
ein Stoppcodon beinhaltet (Abb. 88). Das resultierende Polypeptid ist um 40 Aminosäuren verkürzt. Damit weist die Mutation hinsichtlich ihres Effektes auf das resultierende Polypeptid eine große Ähnlichkeit $\mathrm{zu}$ der bei Irischen Settern beobachteten Mutation (Suber et al. 1993) auf, so dass ähnliche physiologische Effekte zu erwarten sind. Abgesehen von zwei homozygot betroffenen Sloughis konnte das heterozygote Vorliegen der Mutation bei 26 von 88 untersuchten verwandten Sloughis nachgewiesen werden. Bis auf einen dieser 26 Hunde, der eine von PRA abweichende Augenerkrankung zeigte, waren alle heterozygoten Hunde frei von Krankheitsanzeichen. Bei keinem der weiteren untersuchten Hunde konnte eine Mutation im cGMP-PDE $\beta$-Gen mit der PRA-Erkrankung in Verbindung gebracht werden (Dekomien et al. 2000).

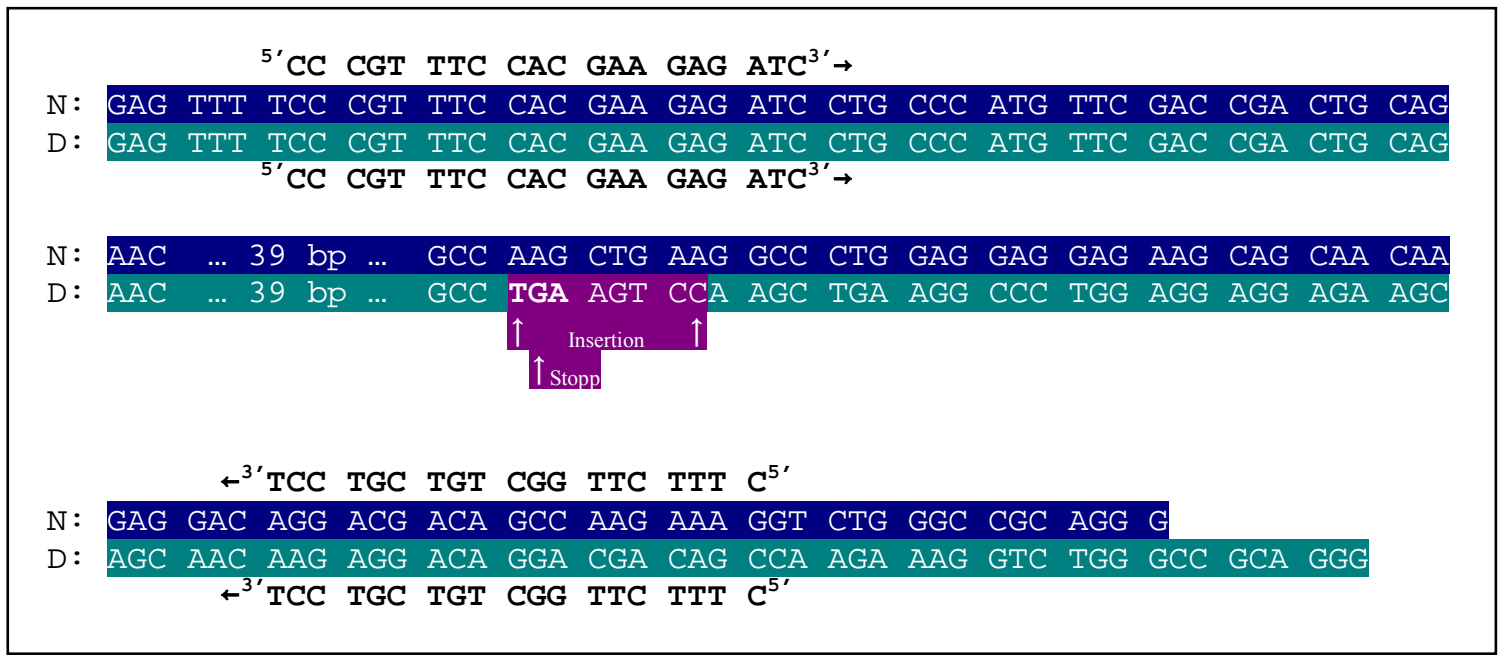

Abb. 88 Exon 21 des caninen cGMP-PDE $\beta$-Gens. N: normale Sequenz, D: defekte Sequenz, dunkelblau: Exon normale Sequenz, dunkelgrün: Exon defekte Sequenz, Insertion in defekter Sequenz violett unterlegt und durch Pfeil gekennzeichnet, verfrühtes Stoppcodon in defekter Sequenz fett gedruckt und durch Pfeil gekennzeichnet.

\section{IV.b Genotypisierung für PRA bei Sloughis}

Der Nachweis der Mutation kann per diagnostischer Sequenzierung erfolgen (Dekomien et al. 2000). 


\subsection{Photorezeptordysplasie bei Cardigan Welsh Corgis}

\begin{tabular}{ll|}
\hline Chromosom: & CFA4 \\
Gen: & PDE6A \\
Ensembl: & GeneID: ENSCAFG00000018251, TranscriptID: \\
DNA-Sequenz: & ENSCAFT00000028993 \\
Mutationen: & CFA4, Position 62307499-62367393 \\
\hline
\end{tabular}

\section{Krankheitsbild}

Auch bei Cardigan Welsh Corgis mit autosomal rezessiv vererbter PRA treten erste Anzeichen wie bei Irischen Settern schon im Welpenalter zwischen sechs und 16 Wochen auf und es kommt oft bereits im Alter von einem Jahr zur Blindheit (Keep 1972). Detaillierte elektrophysiologische, histopathologische und biochemische Untersuchungen sind bisher nicht durchgeführt worden. Bei einer Genotypisierung von 500 Corgis unter Einsatz eines DNA-Tests konnte ein Anteil an heterozygoten Defektträgern von 8,6 \% ermittelt werden (Petersen-Jones und Zhu 2000).

\section{Genetischer Hintergrund}

Eine Analyse des cGMP-PDE $\alpha$-Gens betroffener, heterozygoter und gesunder Corgis mittels SSCP ergab Hinweise auf die Existenz unterschiedlicher Allele, die mit der Erkrankung segregieren (Petersen-Jones et al. 1999). Das cGMP-PDE $\alpha-G e n$ ist auf Chromosom 4 zwischen Nukleotid 62307499 und 62367393 lokalisiert (Ensembl GeneID: ENSCAFG00000018251) (Petersen-Jones et al. 1999). Die mRNA umfasst 3176 Nukleotide, ist in 22 Exons unterteilt und codiert für ein 861 Aminosäuren langes Polypeptid (Ensembl-Trancript ID: ENSCAFT00000028993). Abb. 89 zeigt schematisch die Lage der einzelnen Exons innerhalb der genomischen Sequenz. 


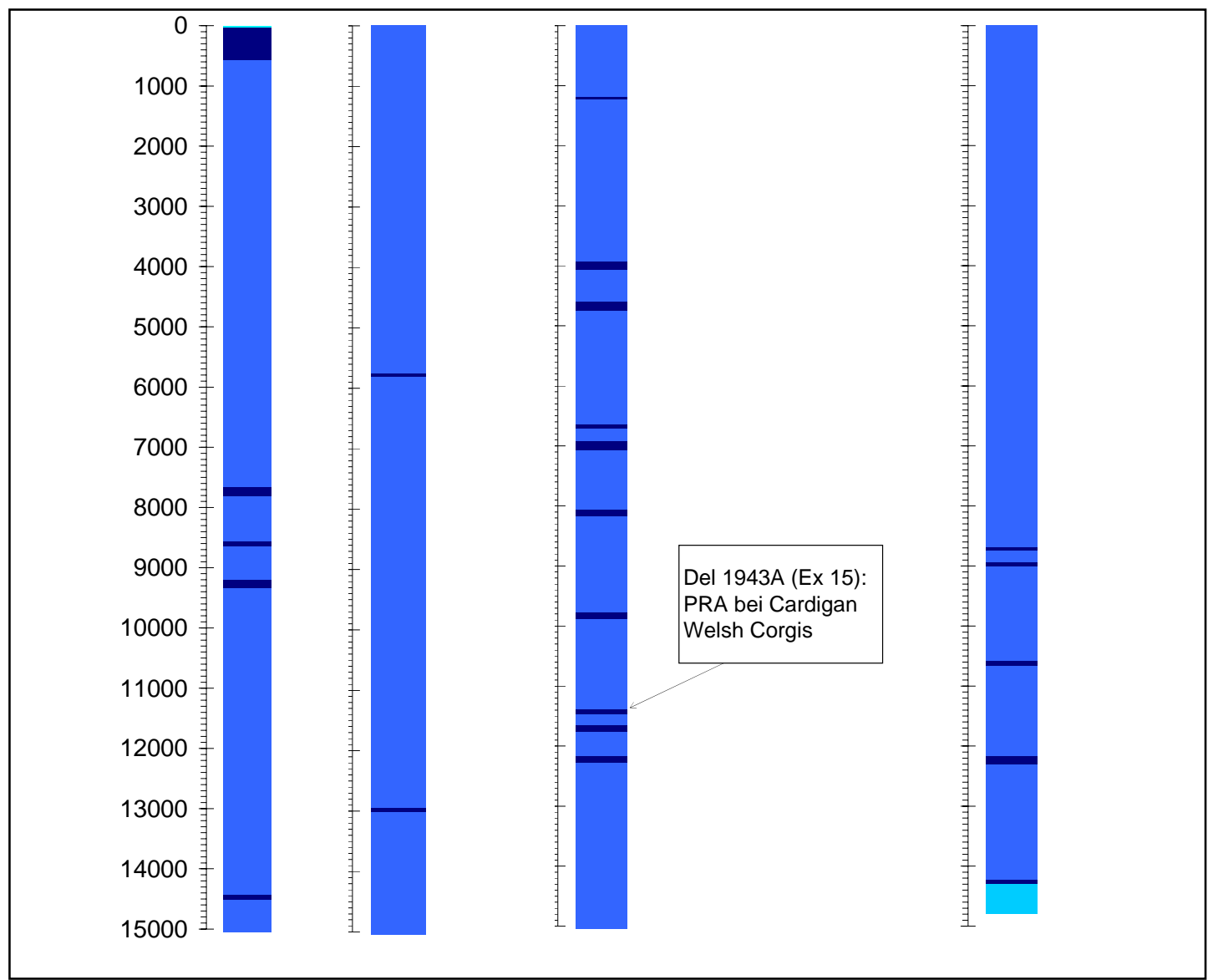

Abb. 89 Schematische Darstellung des caninen PDE6A-Gens und Lage der bisher identifizierten Mutationen. Dunkelblau: codierende Sequenz, hellblau: Intron, türkis: 5'- und 3'-UTR.

\section{Ursächliche Mutation für PRA bei Cardigan Welsh Corgis}

Ein Sequenzvergleich zwischen betroffenen und gesunden Hunden ergab unter anderem das Vorliegen einer 1 bp Deletion in Exon 15, die zu einer Leserasterverschiebung und der Entstehung eines verfrühten Stoppcodons führt (Abb. 90). Das resultierende Polypeptid wird um 218 Aminosäuren verkürzt (Petersen-Jones et al. 1999). Wie bereits für die $\beta$-Untereinheit beschrieben (s.o. PRA bei Irischen Settern) enthält auch die $\alpha$ Untereinheit des cGMP-PDE-Proteins ein CAAX-Motiv, das als Signal für eine posttranslationale Modifizierung als Voraussetzung für eine korrekte Funktion des Polypeptids dient (Baehr et al. 1991). Es ist zu erwarten, dass der Verlust dieser Signalsequenz in der $\alpha$-Untereinheit ähnliche pathophysiologische Konsequenzen hat wie die bei Irischen Settern (Suber et al. 1993) und Sloughis (Dekomien et al. 2000) beschriebenen Mutationen in der $\beta$-Untereinheit der cGMP-Phosphodiesterase. 


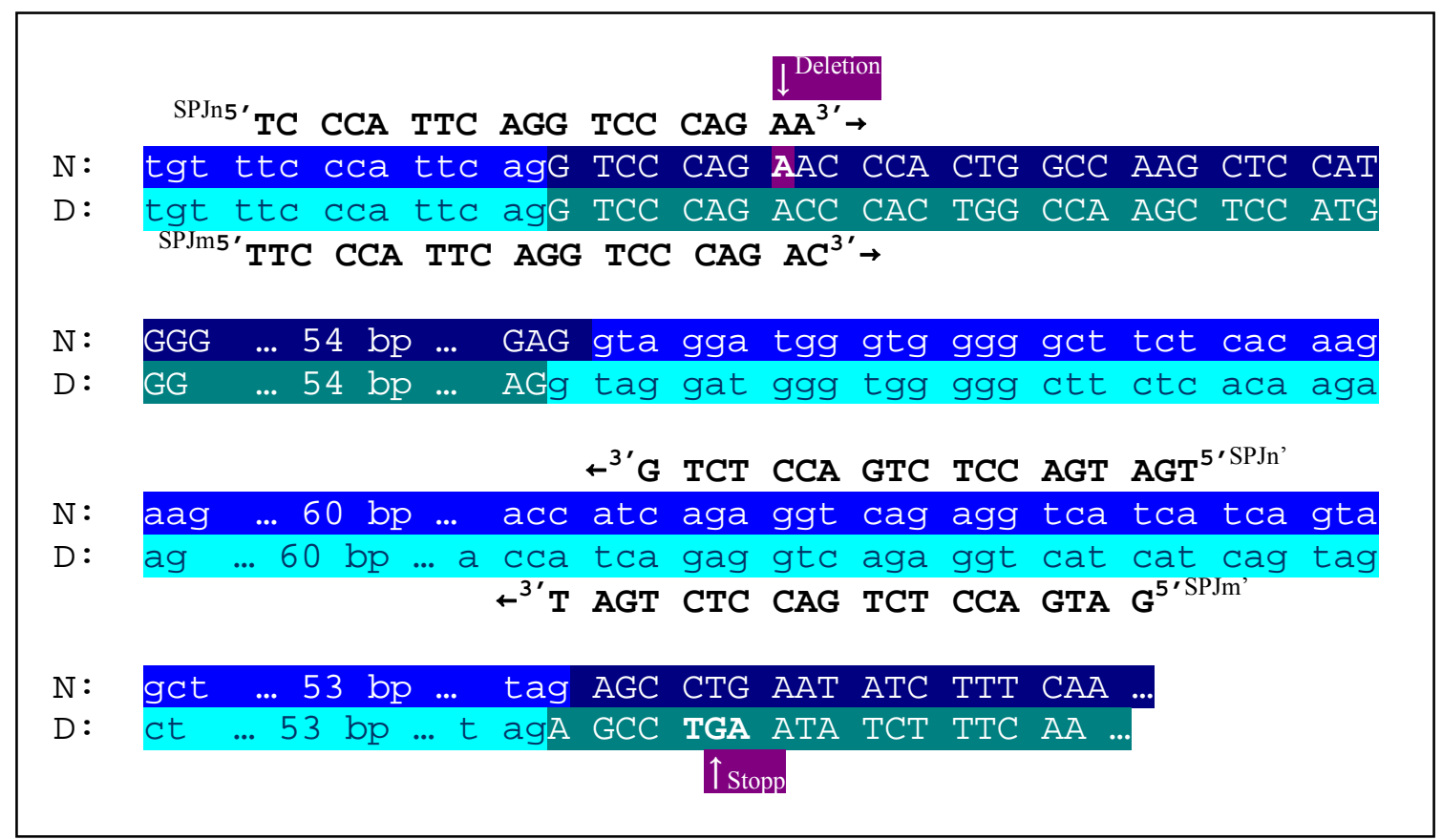

Abb. 90 Exon 15 und Intron 15 sowie angrenzende Intron- und Exonsequenzen des caninen cGMPPDE $\alpha$-Gens. N: normale Sequenz, D: defekte Sequenz, hellblau: Intron normale Sequenz, hellgrün: Intron defekte Sequenz, dunkelblau: Exon normale Sequenz, dunkelgrün: Exon defekte Sequenz, Deletion in normaler Sequenz violett unterlegt und durch Pfeil gekennzeichnet, verfrühtes Stoppcodon in defekter Sequenz fett gedruckt und durch Pfeil gekennzeichnet, SPJn/SPJn': wildtypallelspezifisches Primerpaar, SPJm/SPJm': defektallelspezifisches Primerpaar.

\section{Genotypisierung für PRA bei Cardigan Welsh Corgis}

Der Nachweis der Mutation kann beispielsweise per ASP erfolgen (Abb. 90) (PetersenJones und Zhu 2000).

\subsection{Photorezeptordysplasie bei Zwergschnauzern}

\begin{tabular}{ll|}
\hline Chromosom: & CFA7 \\
Gen: & PDC \\
NCBI: & GeneID: 403624, GenBank: AF046874 \\
DNA-Sequenz: & NW_876323, Position17598663-17582422 \\
Mutationen: & C244G, Zwergschnauzer \\
\hline
\end{tabular}

\section{Krankheitsbild}

Eine weitere Erkrankung aus der Gruppe der Photorezeptordysplasien tritt bei Zwergschnauzern auf. Aufgrund des relativ langsamen Krankheitsverlaufs wurde diese PRA-Form ursprünglich als degenerative Erkrankung eingestuft. Elektroretinographische und histologische Untersuchungen deuten jedoch auf das Vorliegen einer Entwicklungsstörung der Photorezeptorzellen hin, die aus noch nicht geklärten Zusammenhängen klinisch und ophthalmoskopisch erst bei älteren Hunden in Erscheinung tritt. Im Unterschied zu den Photorezeptordysplasien bei Irischen Settern, 
Sloughis und Cardigan Welsh Corgis sind beide Rezeptorzelltypen gleichermaßen betroffen. Daraus ergibt sich die Bezeichnung als pd-PRA (PhotorezeptordyplasiePRA). Auch auf biochemischer Ebene unterscheidet sich die PRA bei Zwergschnauzern von den oben beschriebenen rcd-PRAs. Im Gegensatz zu betroffenen Irischen Settern sind in der Retina betroffener Zwergschnauzer keine erhöhten cGMP-Werte nachweisbar (Parshall et al. 1991). Laut den Ergebnissen nicht veröffentlichter Studien liegen innerhalb der Rasse der Zwergschnauzer zwei genetisch verschiedene Formen der pd-PRA vor, die mit Typ A und Typ B bezeichnet werden und die zwar hinsichtlich des klinischen Erscheinungsbildes übereinstimmen, aber auf Defekten in unterschiedlichen Allelen beruhen. Bisher ist erst eine dieser beiden genetischen Ursachen identifiziert worden (Zhang et al. 1998). Bei klinischen Untersuchungen von 287 Zwergschnauzern in den Jahren 1982 bis 1985 wurden 66 erkrankte Hunde identifiziert (Parshall et al. 1991). Studien über die Verbreitung der identifizierten Mutation innerhalb der Zwergschnauzerpopulation sind nicht veröffentlicht.

\section{Genetischer Hintergrund}

Die Suche nach dem zugrunde liegenden genetischen Defekt für die mit Typ A bezeichnete Form erfolgte zunächst über die Evaluierung verschiedener für photorezeptorspezifische Strukturproteine codierender Kandidatengene, darunter Opsin, RDS/Peripherin, ROM1 und drei Untereinheiten des Transducins (Zhang et al. 1999). Zur Identifizierung weiterer Kandidatengene diente die Analyse zweier SubtraktionsBibliotheken, die aus Retinagewebe eines normalen und eines betroffenen Zwergschnauzers generiert wurden (Zhang et al. 1998). Eine BLAST-Analyse der Subtraktionsbibliothek mit cDNA-Fragmenten, die bei dem betroffenen Zwergschnauzer häufiger vorliegen als bei gesunden Hunden, identifiziert unter anderem Fragmente des caninen Homologon zum humanen Phosducin-Gen (Zhang et al. 1998).

Dieses Gen codiert für ein zytosolisches Phosphoprotein, das in den Photorezeptorzellen der Retina exprimiert wird (Lee et al. 1990; Abe et al. 1994) und in der visuellen Signaltransduktionskaskade eine regulatorische Funktion erfüllt. Über die Bindung an $\beta$ - und $\gamma$-Transducin steuert Phosducin die Interaktion dieser beiden Transducinuntereinheiten mit $\alpha$-Transducin und beeinflusst damit transducinabhängige 
Signalprozesse. Aufgrund dieser Eigenschaften wird Phosducin als starkes Kandidatengen für die PRA bei Zwergschnauzern eingestuft (Zhang et al. 1998).

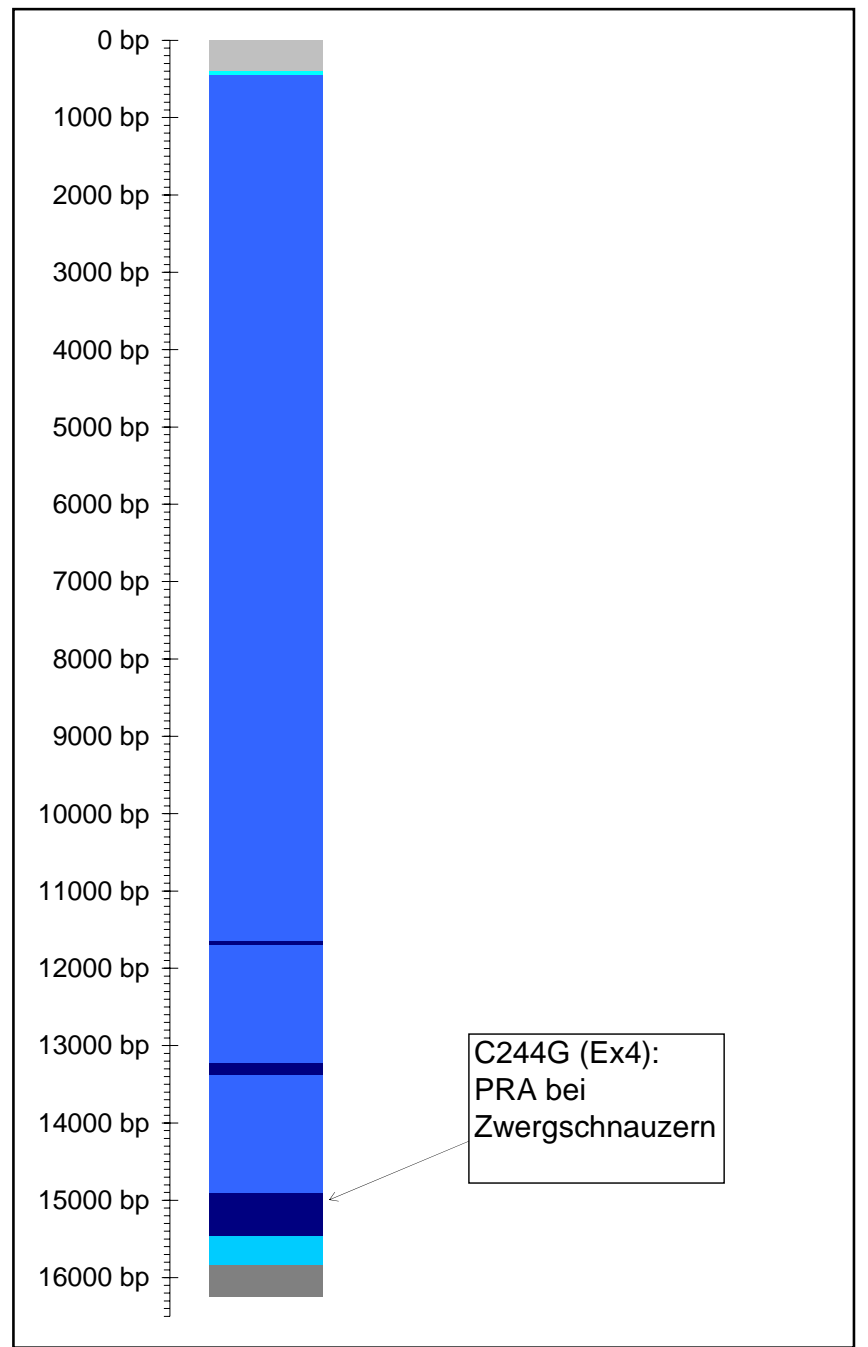

Abb. 91 Schematische Darstellung des caninen Phosducin-Gens und Lage der bisher identifizierten Mutationen. Dunkelblau: codierende Sequenz, hellblau: Intronsequenz, türkis: 5'- und 3'-UTR, grau: intergenische Sequenz.

Für die Evaluierung des caninen Phosducin-Gens (PDC) als Kandidatengen für die PRA bei Zwergschnauzern wurden aus einer caninen Retina cDNA-Bibliothek (Stratagene La Jolla, CA) überlappende Fragmente der Phosducin-cDNA amplifiziert. Die auf diesem Wege ermittelte 1258 bp umfassende Sequenz setzt sich aus dem 738 bp langen offenen Leseraster sowie 93 bp 5'-UTR und 427 bp 3'-UTR einschließlich Polyadeninregion zusammen (NCBI-GenBank: AF046874) (Zhang et al. 1998). Abb. 91 zeigt die Lage der einzelnen Exons innerhalb der genomischen Sequenz

Das canine Phosducin-Gen (NCBI-GeneID 403624) ist auf Chromosom 7 im genomischen Contig NW_876323 zwischen Position 17598663 und 17582422 
lokalisiert und enthält vier Exons (Dekomien und Epplen 2002). Das resultierende Protein hat eine Länge von 245 Aminosäuren.

\section{Ursächliche Mutation für PRA bei Zwergschnauzern}

Ein Vergleich der Phosducin-cDNA aus Retinas gesunder Zwergschnauzer mit der cDNA-Sequenz eines betroffenen Zwergschnauzers ergab das Vorliegen einer Substitution von Cytosin durch Guanin an Nukleotidposition 244 des offenen Leserasters in Exon 4. Die Folge ist ein Aminosäurenaustausch von Arginin durch Glycin an Aminosäurenposition 82 (Abb. 92) (Zhang et al. 1998). Die substituierte Aminosäure liegt in einer Region die nach bisherigen Erkenntnissen über die Struktur des Phosducins mit den $\beta$ - und $\gamma$-Untereinheiten von Transducin interagiert (Gaudet et al. 1996).

Immunozytochemische Untersuchungen einer normalen caninen Retina unter Verwendung eines bovinen polyklonalen Antikörpers gegen Stäbchenzell-Phosducin zeigen eine deutliche Konzentration des Proteins in den inneren Segmenten, dem perinuklearen Zytoplasma und den synaptischen Enden der Stäbchenphotorezeptorzellen, während Phosducin in Zapfenzellen nicht detektiert werden kann. Für betroffene Hunde liegen keine immunozytochemischen Befunde vor.

Mittels Northern Blot lassen sich in der normalen caninen Retina zwei Transkripte des Phosducin-Gens von 1,9 und 3,5 kb nachweisen, wobei das kleinere Transkript deutlich vorherrschend ist. In der Retina betroffener Zwergschnauzer liegt eine um das ca. 1,5fache höhere Expression der Phosducin-mRNA vor. Die Möglichkeit einer daraus resultierenden kompetetiven Hemmung der Interaktion von $\beta / \gamma$-Transducin mit $\alpha$ Transducin mit der Folge einer Störung der transducinabhängigen Signaltransduktion wird in Betracht gezogen. $\mathrm{Ob}$ und in welcher Weise die beschriebene Substitution mit der leicht erhöhten mRNA-Expression in der Retina betroffener Zwergpudel zusammenhängt, ist nicht geklärt. Der Austausch der polaren Aminosäure Arginin durch das unpolare Glycin in einer funktionell bedeutenden Region wird als ausreichend für die Verursachung einer Störung der Retinafunktion eingestuft. Des Weiteren sprechen Genotypisierungsergebnisse für einen ursächlichen Zusammenhang zwischen der Mutation und der PRA bei Zwergschnauzern. Alle untersuchten Hunde mit homozygot mutiertem Genotyp sind phänotypisch von PRA betroffen. In 48 Proben von 
Kontrollhunden aus 20 verschiedenen Rassen konnte die Mutation nicht detektiert werden.

Allerdings weisen einige der betroffenen untersuchten Zwergschnauzer einen heterozygoten Genotyp auf oder sind homozygot für das Wildtypallel. Als mögliche Ursache für dieses Ergebnis wird auf das Vorliegen einer weiteren, nicht allelischen PRA innerhalb der Zwergschnauzerpopulation verwiesen, die bei nicht veröffentlichten Anpaarungsexperimenten entdeckt wurde. Aus diesen Studien ergeben sich auch Hinweise auf das mögliche Auftreten digenischer Fälle (Zhang et al. 1998).

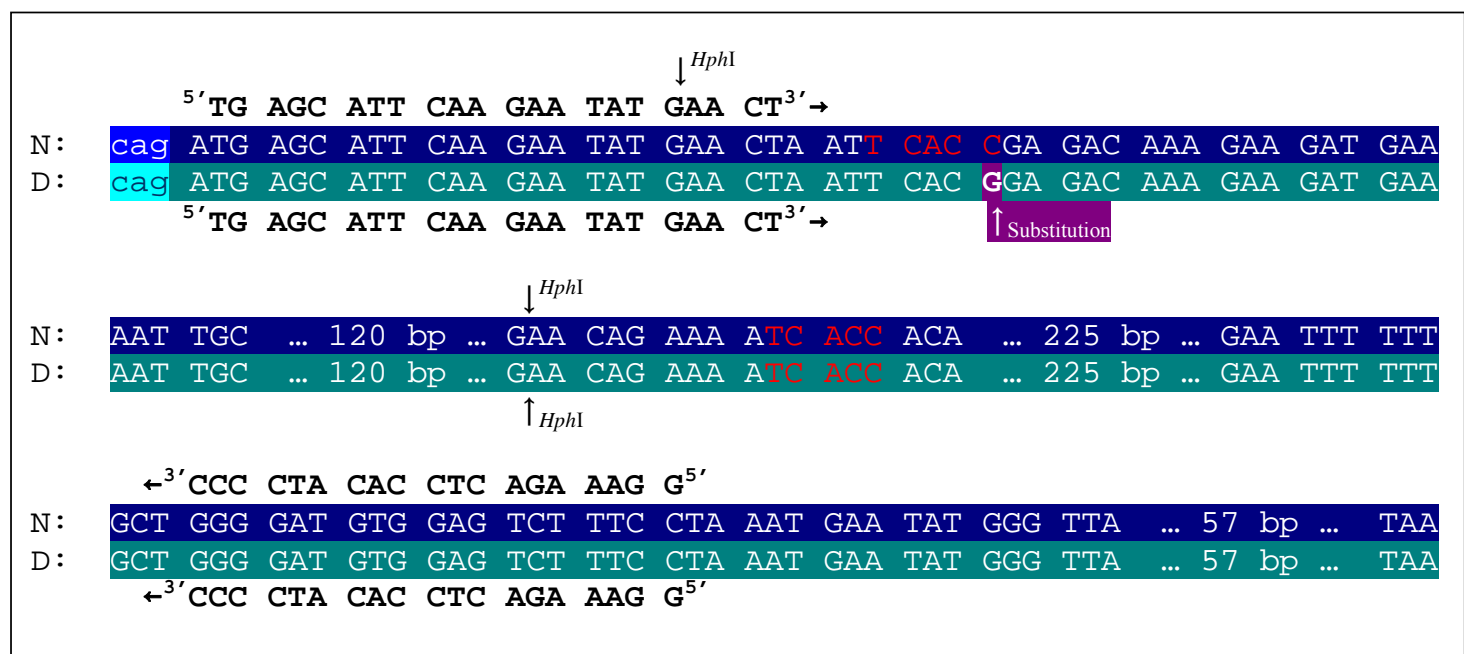

Abb. 92 Exon 4 des caninen Phosducin Gens. N: Normale Sequenz, D: defekte Sequenz, dunkelblau: Exon normale Sequenz, dunkelgrün: Exon defekte Sequenz, hellblau: Intron normale Sequenz, hellgrün: Intron defekte Sequenz, Substitution in defekter Sequenz violett unterlegt und durch Pfeil gekennzeichnet, rote Schrift: HphI-Restriktionserkennungssequenz, HphI-Restriktionsschnittstellen durch Pfeil gekennzeichnet.

\section{Genotypisierung für PRA bei Zwergschnauzern}

Der Nachweis der Mutation kann per Amplifikation eines 447-bp-Fragments und anschließender RFLP-Analyse erfolgen (Abb. 92). Der zugrunde liegende RFLP basiert auf einer von insgesamt zwei Restriktionserkennungssequenzen für HphI im Wildtypallel-PCR-Produkt, die aufgrund der Mutation im Defektallel-PCR-Produkt nicht enthalten ist (Zhang et al. 1998). 


\subsection{X-chromosomal gekoppelte PRA 1 und 2}

\begin{tabular}{|ll|}
\hline Chromosom: & CFAX \\
Gen: & RPGR \\
NCBI: & GeneID: 403726, GenBank: AF385629 \\
DNA-Sequenz: & NW_876562, Position 32959690-32911022 \\
Mutationen: & ORF15, Del1028-1032, Sibirischer Husky, \\
& Samoyede \\
& ORF15, Del1084-1085, Mischling \\
\hline
\end{tabular}

\section{Krankheitsbild}

Die canine X-chromosomal gekoppelte PRA (XLPRA) ist in die zwei Unterformen XLPRA1 und XLPRA2 unterteilt. Während es sich bei der ersten Form um eine degenerative PRA handelt, zählt die zweite Form zur Gruppe der dystrophischen Retinaerkrankungen. Die wesentlichen klinischen Merkmale entsprechen den typischen Erscheinungen einer PRA (Zhang et al. 2002).

Die XLPRA1 wurde erstmals bei einem männlichen Sibirischen Husky beschrieben. Stammbaumuntersuchungen sowie die Ergebnisse von Kreuzungsexperimenten mit phänotypisch normalen Beagle Hündinnen deuten klar auf eine X-chromosomale Vererbung hin. Die Kreuzung des betroffenen Sibirischen-Husky-Rüden mit gesunden Beagle-Hündinnen bildete die Basis einer Forschungskolonie die als Grundlage für alle weiterführenden Untersuchungen der klinischen, elektroretinographischen und histopathologischen Erscheinungen diente. Die Häufigkeit der Erkrankung innerhalb der Rasse Sibirischer Husky scheint nicht näher untersucht worden zu sein. Heterozygote Hündinnen des XLPRA1 Genotyps weisen fokale Degenerationen von Photorezeptorzellen auf. Außerhalb dieser betroffenen Bereiche bleiben die Photorezeptorzellen unversehrt. (Acland et al. 1994; Zeiss et al. 1999; Zhang et al. 2002). Eine klinisch ähnliche Form von XLPRA tritt bei Samoyeden auf. Einzelheiten sind nicht veröffentlicht (Zhang et al. 2002).

XLPRA2 ist eine seltene Unterform der X-chromosomal gekoppelten PRAs, die bisher nur in einer Familie von Mischlingshunden beobachtet wurde. Im Gegensatz zu der häufiger auftretenden XLPRA1 handelt es sich bei der zweiten Form der XLPRA um eine Entwicklungsstörung der Retina, die auch heterozygote Hündinnen betrifft. Abweichend von der für viele X-chromosomal gekoppelte Erbkrankheiten typischen mosaikartigen Verteilung von mutationsbedingten Läsionen betrifft die Dysplasie bei heterozygoten XLPRA2-Hündinnen die gesamte Retina. Als eine mögliche Erklärung 
für dieses untypische Erscheinungsbild wird das Vorliegen eines mit der Degeneration mutierter Photorezeptorzellen zusammenhängenden Prozesses angenommen, der zu schweren kollateralen Schädigungen der normalen Photorezeptorzellen führt (Zhang et al. 2002).

\section{Genetischer Hintergrund}

Hinsichtlich des Krankheitsbildes und des Erbganges existieren Parallelen der caninen XLPRA zu einer Gruppe von X-chromosomal gekoppelten humanen Retinaerkrankungen aus der Familie der Retinitis pigmentosa (XLRP). Kopplungsanalysen ergaben eine hohe Homologie zwischen einer 500-600 kb großen Region auf dem kleinen Arm des humanen X-Chromosoms, die mit 60-90\% aller humanen Retinitis-pigmentosa-3 (RP3)-Fällen assoziiert ist (Meindl et al. 1996; Vervoort et al. 2000), und einem $1 \mathrm{cM}$ umfassenden Abschnitt auf dem kurzen Arm des caninen X-Chromosoms, der zu 100 \% mit XLPRA segregiert (Zeiss et al. 2000; Zhang et al. 2001). Von vier innerhalb dieser Region gelegenen, bekannten Genen kommt als Kandidatengen vor allem das Retinitis-pigmentosa-GTPase-Regulator-Gen (RPGR) in Betracht, das in zahlreichen humanen RP3-Familien pathogene Mutationen aufweist (Meindl et al. 1996; Vervoort et al. 2000).

Sowohl XLPRA1 bei Sibirischen Huskys und Samoyeden als auch XLPRA2 bei Mischlingshunden können auf Mutationen in dem so genannten Exon ORF15 (für open reading frame 15) des caninen RPGR Gens zurückgeführt werden (Zhang et al. 2002). Das Gen enthält insgesamt 19 Exons (Zhang et al. 2002). Durch alternatives Spleißen kommt es zur Expression verschiedener mRNA-Varianten (Zeiss et al. 1998; Zhang et al. 2002). Das in der Retina vorherrschende Transkript hat eine Länge von ca. 5000 Nukleotiden und resultiert aus dem Überspringen der Spleißstellen für Intron 14 und Intron 15. Daraus ergibt sich in der mRNA die folgende Fragmentabfolge: Exon $14-$ Exon 14a (ursprünglich Intron 14) - Exon 15 - Exon ORF15 (ca. 2800 Nukleotide der an Exon 15 anschließenden Intron-15-Sequenz). An Position 1717-1719 des Exons ORF15 ist ein alternatives Stoppsignal lokalisiert. Ca. 1000 Nukleotide aufwärts, zwischen Position 2805 und 2810, befindet sich eine Polyadenylierungssequenz. Die Exons 16-19 werden bei dieser Spleißvariante nicht transkribiert. Exon ORF15 weist mit $70 \%$ einen ungewöhnlich hohen Gehalt an Purinbasen auf und enthält zahlreiche repetitive Sequenzen. Die C-terminalen 35 Aminosäuren sind zwischen dem caninen 
und dem humanen Exon ORF15 des 5000 Nukleotide umfassenden Transkripts stark konserviert (Zhang et al. 2002).

A $54,2,3,4,6,7,8,9,11,12,13,15,16,17,18,19-3^{\prime}$

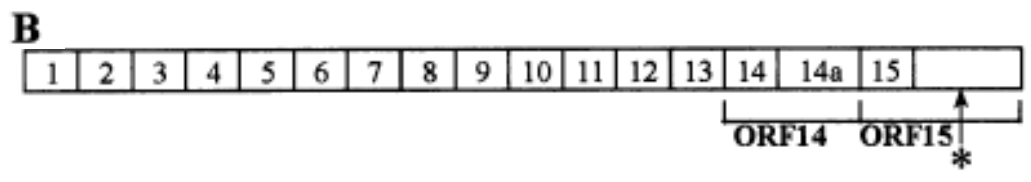

Abb. 93 Gegenüberstellung der genomischen Struktur des caninen RPGR-Gens (A) und der in der Retina exprimierten mRNA (B) (nichtmaßstäblich). ORF14: zusammengesetzt aus Exon 14 und Exon 14a (entspricht Intron 14), ORF15: zusammengesetzt aus Exon 15 und dem 5'Bereich von Intron 15, Stern*:ungefähre Position der mit XLPRA1 bei und XLPRA2 bei assoziierten Deletionen leicht abgewandelt nach (Zhang et al. 2002).

Eine maßstabgetreue schematische Darstellung der Lage der einzelnen Exons des in der Retina exprimierten Transkriptes innerhalb der genomischen Sequenz ist anhand der verfügbaren Informationen nicht $\mathrm{zu}$ erstellen.Abb. 93 zeigt nichtmaßstäblich die genomische Struktur und die in der Rettina exprimierte mRNA. Im genomischen Contig NW_879562 ist das canine RPGR-Gen zwischen Position 32959690 und 32911022 auf dem revers komplementären Strang lokalisiert. Die Exon-ORF15-Sequenz (NCBIGenBank AF385629) ist in dieser Sequenz jedoch nicht enthalten.

\section{Ursächliche Mutation der XLPRA1 bei Sibirischen Huskys und Samoyeden und XLPRA2}

Bei Sibirischen Huskys und Samoyeden des XLPRA1-Phänotyps liegt im RPGR-Gen in Exon ORF15 zwischen Position 1028 und 1032 eine 5-bp-Deletion vor (Abb. 94). Dadurch kommt es zu einer Leserasterverschiebung und zur Entstehung eines direkt an die Deletion anschließenden, verfrühten Stoppcodons. Das resultierende Protein ist am C-Terminus um 230 Aminosäuren verkürzt.

Mischlingshunde des XLPRA2-Phänotyps weisen im RPGR-Gen eine Deletion von 2 bp zwischen Position 1084-1085 des Exons ORF15 auf. Die Folge ist eine Leserasterverschiebung, die zur Codierung von 34 abweichenden Aminosäuren und der Entstehung eines verfrühten Stoppcodons 71 Aminosäuren abwärts der Deletion führt. 
Unter Einsatz spezifischer Sonden für die Exons 3-10 bzw. ORF15 kann bei betroffenen XLRP1- und XLRP2-Hunden im Alter von vier bis sechs Wochen, das heißt vor Beginn der Degeneration, ein deutliches Signal für das 5-kb-Transkript detektiert werden. Bei XLPRA2-mutierten Hunden fällt das Signal etwas schwächer aus als bei gesunden und XLRRA1-mutierten Hunden. Mittels in situ Hybridisierung kann das Transkript in Retinagewebe von normalen und XLPRA1-mutierten Hunden im retinalen Pigmentepithel, in den inneren Segmenten der Photorezeptorzellen sowie in der inneren und äußeren Körnerschicht nachgewiesen werden. Dabei sind hinsichtlich Intensität und Verteilung des 5-kb-Transkriptes keine Unterschiede zwischen normalen und XLPRA1mutierten Hunden feststellbar. Gewebe von XLPRA2-mutierten Hunden wurde nicht untersucht. Auch Western-Blot-Untersuchungen unter Verwendung der Antikörper DR39, RPGR-254 und RPGR-33606 ergeben keinerlei Unterschiede zwischen Retinagewebe von XLPRA1-mutierten, XLPRA2-mutierten und gesnden Hunden. Die Autoren gehen davon aus, dass die verwendeten Antikörper nicht für den Nachweis von Exon-ORF15-RPGR-Proteinvarianten geeignet sind.

Für die Analyse der intrazellularen Verteilung des Exons ORF15 bei gesunden, XLPRA1- und XLPRA2-mutierten Individuen wurden COS7-Zellen mit GFP-Vektoren transfiziert, die jeweils mit der zu untersuchenden Exon-ORF15-Variante ligiert waren. Während das resultierende Polypeptid in GFP/WildtypExonORF15 und GFP/XLPRA1ExonORF15 transfizierten Zellen vorrangig im Zytoplasma lokalisiert ist, ergibt sich bei GFP/XLPRA2ExonORF15 transfizierten Zellen eine Akkumulation des resultierenden Polypeptids in einer eindeutig perinuklearen subzellularen Region. Eine zusätzliche Färbung mit einem spezifisch für die Detektion von endoplasmatischem Retikulum konstruierten Marker zeigt das Vorliegen einer Kolokalisierung des XLPRA2-mutierten Exon ORF15 Polypeptids mit dem Endoplasmatischen Retikulum (Zhang et al. 2002).

Diese Ergebnisse stehen im Einklang zu den phänotypischen Besonderheiten der beiden XLPRA Formen und sprechen dafür, dass es sich bei den gefundenen Deletionen um die ursächlichen Mutationen für die canine XLPPA1 und 2 handelt. Die durch die XLPRA1-Mutation nicht translatierten 230 C-terminalen Aminosäuren scheinen für die Entwicklung der Photorezeptorzellen keine Rolle zu spielen, erfüllen aber offenbar bei der Aufrechterhaltung der Lebensfähigkeit dieser Zellen eine wesentliche Funktion. 
Demgegenüber führt die XLPRA2-Mutation aufgrund der Codierung von 34 abweichenden Aminosäuren zu schwerwiegenderen Störungen der Proteinfunktion, die auch die Entwicklung der Photorezeptoren beeinträchtigen.

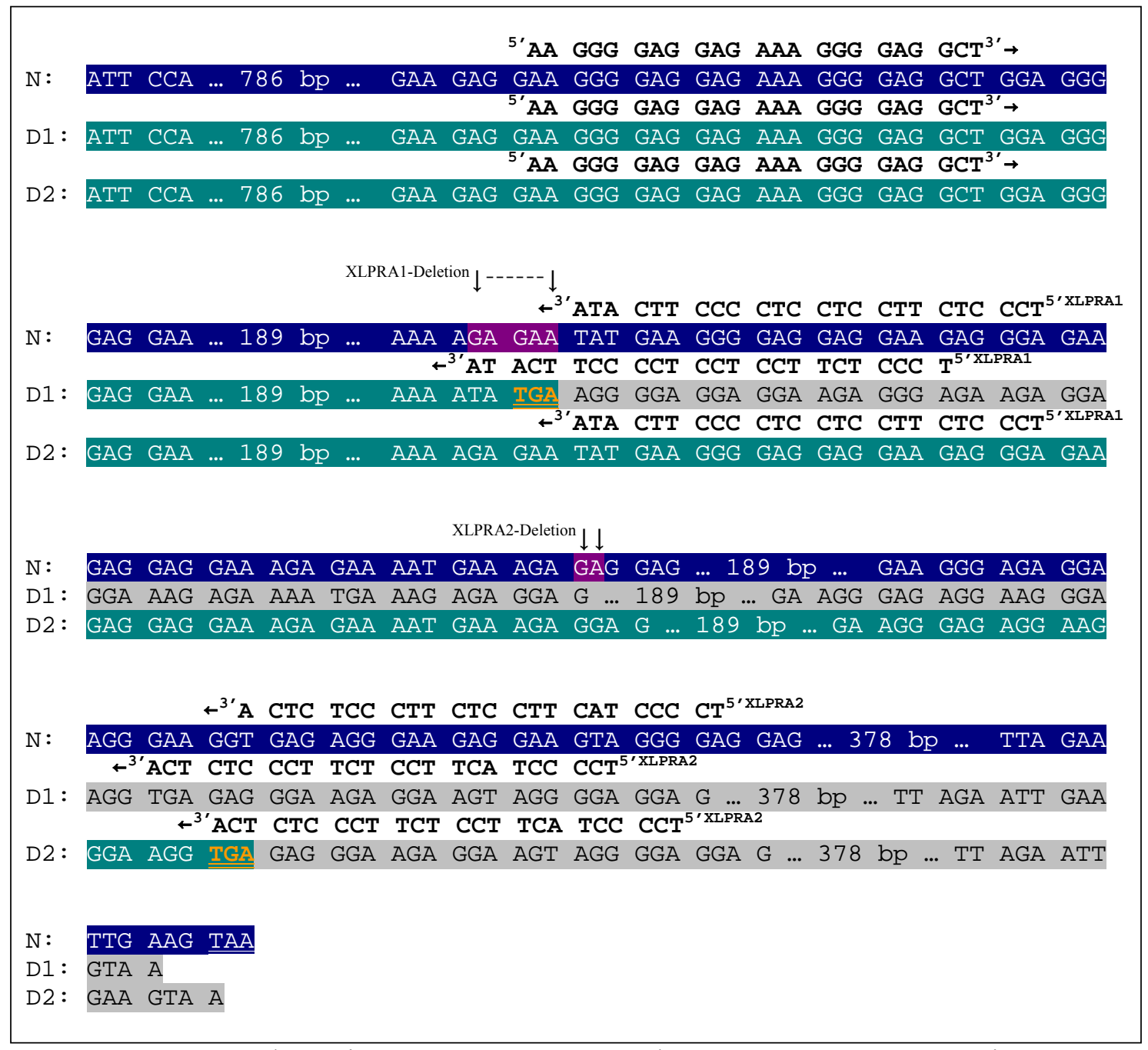

Abb. 94 Exon ORF15 des caninen RPGR-Gens. N: normale Sequenz, D1: XLPRA1-mutierte Sequenz, D2: XLPRA2-mutierte Sequenz, dunkelblau: Exon normale Sequenz, dunkelgrün: Exon defekte Sequenz, grau: nicht transkribierte Sequenz, XLPRA1-5-bp-Deletion und XLPRA2-2-bp-Deletion in normaler Sequenz violett unterlegt und durch Pfeil gekennzeichnet, verfrühte Stoppcodons in XLPRA1- bzw. XLPRA2-Sequenz fett und orange gedruckt.

Die Ergebnisse der Transfektionsstudien sprechen für das Vorliegen einer Fehlfaltung des XLPRA2-mutierten RPGR-Proteins, die eine Aggregation im Endoplasmatischen Retikulum und damit eine gestörte intrazellulare Lokalisation bedingt.

Ein weiterer Beleg für den Zusammenhang der gefundenen Deletionen mit der XLPRA1- bzw. XLPRA2-Erkrankung ergibt sich aus einer Genotypisierung von 137 Rüden und Hündinnen aus 20 verschiedenen Rassen. Die XLPRA1-Mutation konnte lediglich bei Defektträgern oder betroffenen Samoyeden und Sibirischen Huskys 
gefunden werden, die XLPRA2-Mutation lag ausschließlich bei Defektträgern und betroffenen Hunden aus der XLPRA2-Mischlingshundefamilie vor (Zhang et al. 2002).

\section{Genotypisierung für XLPRA 1 und 2}

Der Nachweis der XLPRA1- und XLPRA2-Mutation kann beispielsweise per diagnostischer Sequenzierung erfolgen (Zhang et al. 2002).

\subsection{Fortschreitende Stäbchen-Zapfen-Degenerations-PRA (PRCD-PRA)}

\begin{tabular}{ll|}
\hline Chromosom: & CFA9 \\
Gen: & PRCD \\
NCBI: & GeneID: GenBank: DQ390330 \\
DNA-Sequenz: & CFA9: ca. 7187000-7180000 \\
Mutationen: & G5A, 34 Rassen \\
\hline
\end{tabular}

\section{Krankheitsbild}

Bei der PRCD-PRA (fortschreitende Stäbchen-Zapfen Degeneration, progressive rodcone degeneration) handelt es sich um eine in über 20 verschiedenen Rassen verbreitete degenerative Form der PRA. Bezüglich des Krankheitsbildes unterscheidet sich diese Erkrankung kaum von den beschriebenen Photorezeptordysplasien oder degenerationen. Bei betroffenen Hunden aus verschiedenen Rassen liegen relativ einheitliche klinische, histopathologische und elektroretinographische Befunde vor (Aguirre und Rubin 1972; Buyukmihci et al. 1980; Aguirre et al. 1982a; Sandberg et al. 1986; Aguirre und Acland 1988; Curtis et al. 1991), die jedoch keine klare Abgrenzung gegenüber anderen PRAs mit ähnlich spätem Beginn und langsamem Verlauf ermöglichen. Das Alter bei Manifestierung der Erkrankung und die Geschwindigkeit des Verlaufs können sowohl innerhalb einer Rasse als auch zwischen einzelnen Rassen deutlich schwanken. Diese Schwankungen und die Existenz weiterer ähnlicher PRAFormen führen dazu, dass die PRCD-PRA anhand des Krankheitsbildes nicht eindeutig diagnostizierbar ist.

\section{Genetischer Hintergrund}

Kreuzungsexperimente zwischen betroffenen Individuen aus verschiedenen Rassen deuten darauf hin, dass die ursächlichen Mutationen für diese PRA-Form in mehreren Rassen am selben, im Folgenden mit „PRCD“ bezeichneten Genort lokalisiert sind. Dabei handelt es sich um die Rassen Zwergpudel, Englischer Cocker Spaniel und Amerikanischer Cocker Spaniel (Aguirre und Acland 1988) sowie Labrador Retriever, 
Australian Cattle Dog, Portugiesischer Wasserhund und Nova Scotia Duck Tolling Retriever(Pearce-Kelling et al. 2002). Die Ergebnisse dieser Experimente sprechen außerdem für das Vorliegen eines autosomal rezessiven Erbgangs (Aguirre und Acland 1988; Pearce-Kelling et al. 2002; Goldstein et al. 2006).

Rassentypische Besonderheiten werden auf einen möglichen Einfluss des genetischen Hintergrundes in Form von so genannten Moderatorgenen oder auf unterschiedliche allelische Mutationen am selben Genort zurückgeführt (Curtis et al. 1991).

Über die Identifizierung bestimmter Markerallele und eine anschließende Kopplungsanalyse ließ sich in mehreren betroffenen Zwergpudelfamilien ein mit PRCD-PRA gekoppelter Genort am centromeren Ende von Chromosom 9 lokalisieren. Die identifizierte Region wird von den Mikrosatellitenmarkern MYL4 und TK1 flankiert und weist eine konservierte Homologie $\mathrm{zu}$ einem Abschnitt des humanen Chromosoms 17 auf. Unter der Hypothese einer vollständig konservierten Syntenie zwischen den homologen Regionen entspricht die canine PRCD-Region einer ca. $30 \mathrm{Mb}$ großen Region auf dem humanen Chromosom 17 (Acland et al. 1998). Eine detaillierte Charakterisierung der caninen PRCD-Region bestätigte die Hypothese einer Konservierung der enthaltenen Gene, deckte aber auch mehrere Abweichungen in der Reihenfolge der Gene zwischen den beiden homologen Regionen auf. Eine 1,5 Mb umfassende physikalische Karte, die unter anderem die eng mit PRCD-PRA gekoppelte Marker GALK1 und GRB2 enthält, bildete die Grundlage für weiterführende Untersuchungen (Sidjanin et al. 2003). Parallel zu diesen Untersuchungen wurden verschiedene Kandidatengene auf Polymorphismen hin überprüft, darunter rom-1, ein Strukturprotein der Photorezeptoren (Gould et al. 1997), Phosducin (Lin et al. 1998) und Apolipoprotein H (Gu et al. 1999), ohne jedoch einen Zusammenhang mit PRCDPRA herstellen zu können. Eine Revision der physischen Karte und eine Identifizierung mehrerer SNPs und kleiner Insertionen und Deletionen bildeten die Grundlage für die Aufstellung eines Haplotyps. Dadurch ließ sich die PRCD-Region auf ein 106 kb langes Fragment eingrenzen. Dieser Haplotyp konnte bei betroffenen Hunden aus insgesamt 14 Rassen nachgewiesen werden. Im Einzelnen handelt es sich um die Rassen Zwerg- und Toy Pudel, Amerikanischer und Englischer Cocker Spaniel, Labrador, Chesapeake Bay Retriever, Portugiesischer Wasserhund, Australian Cattle Dog, Nova Scotia Duck Tolling Retriever, Amerikanischer Eskimohund, Entlebucher Sennenhund, Chinese 
Crested, Silky Terrier und Finnischer Lappenhund. Drei innerhalb dieser 106 kb Region enthaltene bekannte Gene wurden als Kandidatengene für PRCD-PRA ausgeschlossen (Goldstein et al. 2006). Zur Identifizierung weiterer Kandidatengene für PRCD-PRA innerhalb der $106 \mathrm{~kb}$ Region wurde eine Retina-EST-Bibliothek erstellt. Durch Kombination von Expressions- und Sequenzdaten konnten in der untersuchten Region mehrere bekannte und neue Gene identifiziert werden. Bei der Anwendung dieser Methode auf den PRCD-PRA-Haplotyp wurde in einem neuen Gen mit unbekannter Funktion eine Mutation identifiziert. Dieses neue Gen ist auf Chromosom 9 im Bereich zwischen Position 7187000 und 7180000 lokalisiert und wird im Folgenden als PRCDGen bezeichnet (Zangerl et al. 2006).

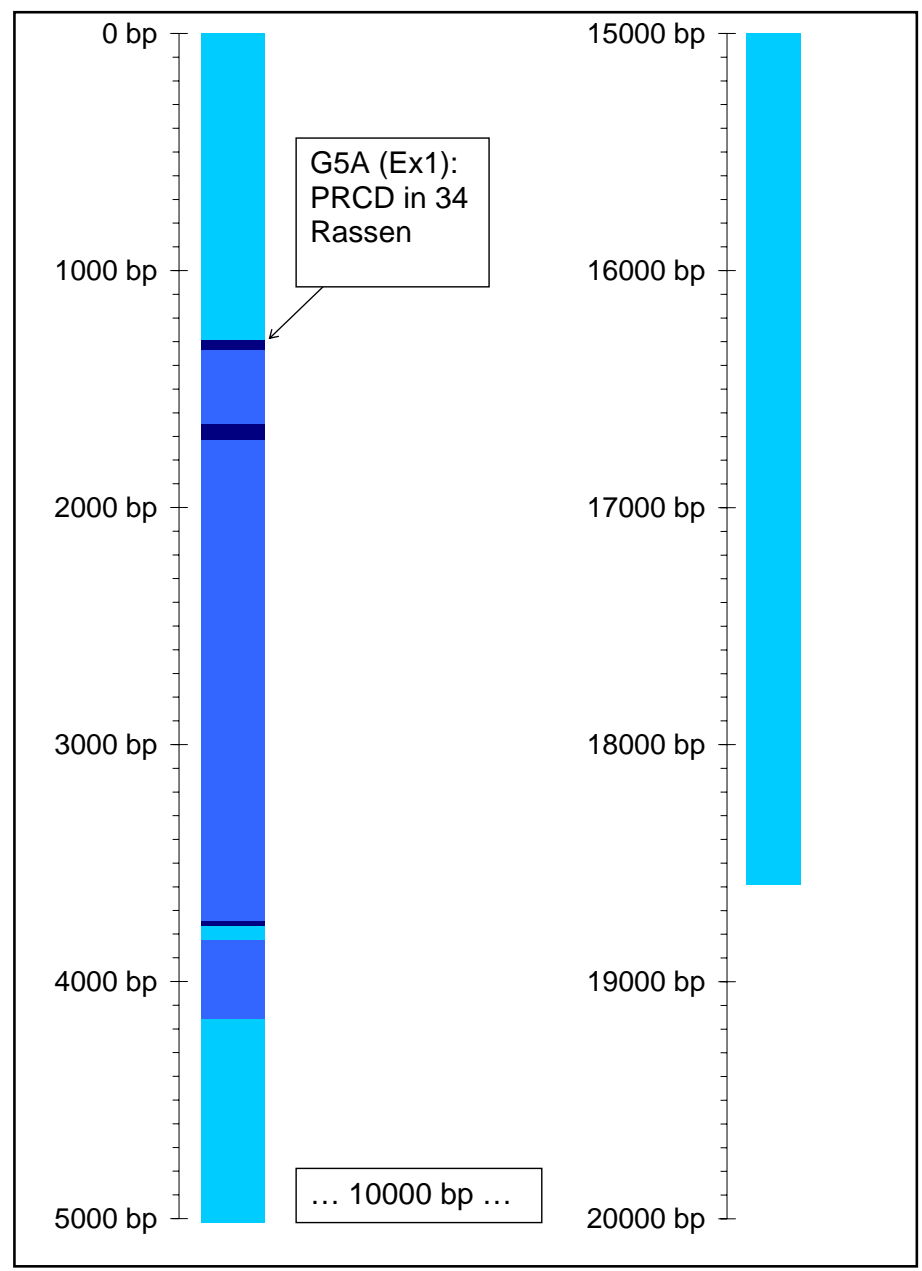

Abb. 95 Schematische Darstellung des caninen PRCD-Gens und Lage der bisher identifizierten Mutationen. Dunkelblau: codierende Sequenz, hellblau: Intronsequenz, türkis: 5'- und 3'-UTR.

Das häufigste retinale Transkript des PRCD-Gens (NCBI-GenBank DQ390339) hat eine Länge von 695 bp und wird von vier Exons codiert. Die Lage der vier Exons in der genomischen Sequenz ist in Abb. 95 dargestellt. Grundlage dieser Darstellung sind Angaben aus einer US-Patentschrift von 2005 (US-Patent-Application 2005). Das 
resultierende Polypeptid ist 54 Aminosäuren lang und weist voraussichtlich eine $\alpha$ helikale Struktur auf. Aufgrund des Konservierungsprofils bei einer Gegenüberstellung des humanen, murinen und caninen Proteins scheint nur den ersten 24 von Exon 1 codierten Aminosäuren eine besonders hervorzuhebende funktionelle Bedeutung zuzukommen. Eine potentielle Spaltstelle zwischen den Aminosäuren 20 und 21 spricht für eine mögliche Funktion als Signalpeptid mit einer C-terminalen Transmembrandomäne (Zangerl et al. 2006).

\section{Ursächliche Mutation für PRCD PRA in 34 Rassen}

Bei der identifizierten Mutation handelt es sich um einen Basenaustausch von Guanin durch Adenin an Position 5 der codierenden Sequenz. Die Folge ist eine Aminosäurensubstitution von Cystin durch Tyrosin an Aminosäurenposition 2 des PRCD-Proteins (Abb. 96).

Expressionsstudien zeigen eine relativ gleichmäßige Expression von PRCD in vielen retinalen Zelltypen. Eine Konzentration auf die Photorezeptorzellen ist nicht zu erkennen. Offenbar liegen keinerlei Schwankungen der Expression in Abhängigkeit vom Alter oder vom Krankheitsstadium der untersuchten gesunden und betroffenen Hunde vor. Da die Funktion des PRCD-Proteins bislang noch ungeklärt ist, kann der Zusammenhang zwischen der Aminosäurensubstitution und der Pathogenese der PRCD auf physiologischer Ebene nicht hergestellt werden. Genotypisierungsergebnisse in verschiedenen caninen Populationen sprechen jedoch dafür, dass es sich bei dem gefundenen Gendefekt tatsächlich um die ursächliche Mutation für PRCD handelt (Zangerl et al. 2006).

Bei der Substitution handelt es sich um einen der 98 Polymorphismen des bereits erwähnten PRCD-Haplotyps, der in einer Referenzkolonie aus hauptsächlich Zwergund Toy Pudeln sowie eingekreuzten Englischen Cocker Spaniels, Portugiesischen Wasserhunden, Nova Scotia Duck Tolling Retriever, Australian Cattle Dogs und Labrador Retrievern in vollständiger Übereinstimmung mit dem PRCD-Phänotyp vererbt wird (Goldstein et al. 2006).

Auch in unabhängigen Pedigrees dieser sieben Rassen außerhalb der Referenzkolonie konnte die Mutation bei allen von PRCD betroffenen Hunden homozygot nachgewiesen 
werden. Andere Hunde aus diesen Pedigrees, die entweder gesund waren oder an degenerativen Retinaerkrankungen litten, deren Symptome deutlich von den typischen Anzeichen für PRCD abwichen, waren entweder homozygot negativ oder heterozygot für die Mutation. In Pedigrees aus den vier Rassen, Amerikanischer Cocker Spaniel, Chesapeake Bay Retriever, Entenbuchler Sennenhund und Amerikanischer Eskimohund konnte bis auf eine Ausnahme eine vollständige Übereinstimmung zwischen dem PRCD-Phänotyp und dem homozygot mutierten Genotyp nachgewiesen werden. Bei der Ausnahme handelt es sich um einen Amerikanischen Eskimohund, der trotz homozygoten Vorliegens der Mutation im Alter von 13 Jahren keinerlei Anzeichen für eine PRCD zeigte. Da sich die Erkrankung in dieser Rasse häufig erst spät klinisch manifestiert, müssen die Ergebnisse histologischer Untersuchungen nach dem Tod des Hundes abgewartet werden, um ein subklinisches Vorliegen von PRCD vollständig auszuschließen.

In ausgewählten Proben von PRA-Fällen aus weiteren Rassen, die phänotypisch mit PRCD-PRA übereinstimmen, konnte das homozygote Vorliegen der Mutation nachgewiesen werden. Es handelt sich um die Rassen Chinesischer Schopfhund, Seidenterrier, Finnischer Lappenhund, Schwedischer Lappenhund, Lappischer Rentierhund und Kuvasz. Des Weiteren wurden 1120 Proben von Hunden aus 91 verschiedenen Rassen genotypisiert, darunter 1007 Proben von Hunden aus 37 verschiedenen Rassen, bei denen eine phänotypisch von PRCD-PRA abweichende Retinadegeneration vorlag, sowie 113 Proben von Hunden aus 54 verschiedenen Rassen ohne bekannte Retinaerkrankung. Alle 1120 Hunde waren homozygot für das Wildtypallel (Zangerl et al. 2006). 


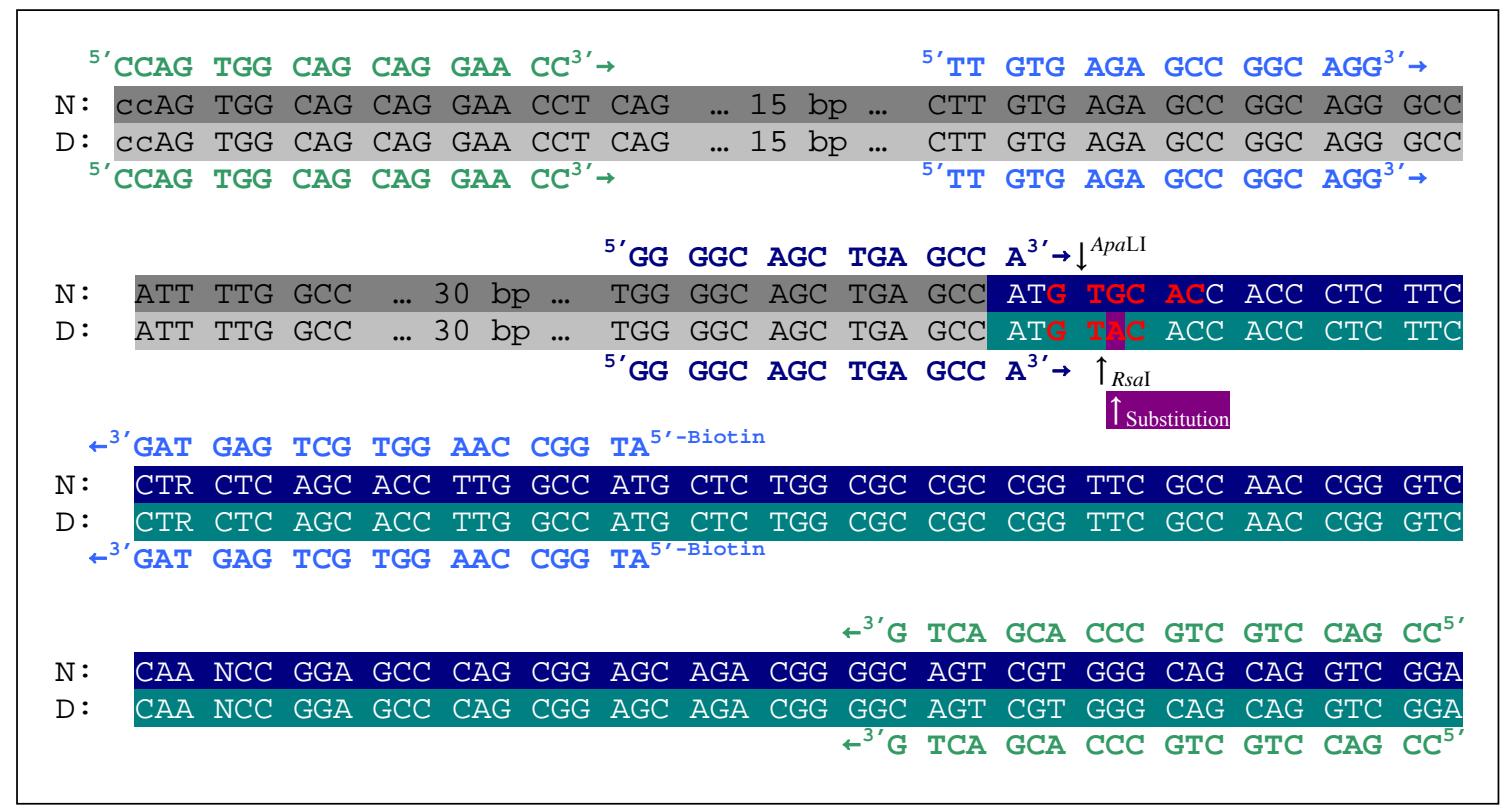

Abb. 96 5'-UTR, aufwärts angrenzende Sequenz und Sequenzanfang von Exon 1 des caninen PRCDGens. N: normale Sequenz, D: defekte Sequenz, dunkelgrau: UTR normale Sequenz, hellgrau: UTR defekte Sequenz, dunkelblau: Exon normale Sequenz, dunkelgrün: Exon defekte Sequenz, Substitution in defekter Sequenz violett unterlegt und durch Pfeil markiert, rote Schrift: Restriktionserkennungssequenzen, Restriktionsschnittstellen für RsaI bzw. ApaLI durch Pfeil gekennzeichnet, grüne Schrift: Primer für RFLP-Typisierung, hellblaue Schrift: Primer für Pyrosequenzierung, dunkelblaue Schrift: Sequenzierungsprimer.

\section{Genotypisierung}

Der Nachweis der Mutation kann beispielsweise über eine RFLP-Typisierung oder mittels Pyrosequenzierung erfolgen. Der RFLP beruht auf einer Restriktionserkennungssequenz für ApaLI im Wildtypallel, die im Defektallel aufgrund der Substitution nicht vorhanden ist sowie auf einer Restriktionsschnittstelle für RsaI, die durch die Mutation im Defektallel entsteht und die im Wildtypallel nicht vorhanden ist (Zangerl et al. 2006).

Die genannten Nachweismethoden sind für die Anwendung bei insgesamt 31 verschiedenen Rassen unter der US-Patentnummer 20050282212 zum Patent angemeldet. Es handelt sich um die Rassen Akita, Amerikanischer Cocker Spaniel, Amerikanischer Eskimohund, Australian Cattle Dog, Australian Stumpy Tail Cattle Dog, Basenji, Bernersennenhund, Border Collie, Chesapeake Bay Retriever, Chinesischer Schopfhund, Englischer Cocker Spaniel, Englischer Mastiff, Englischer Springerspaniel, Entlebucher Sennenhund, Finnischer Lappenhund, Deutsch Kurzhaar Vorstehhund, Riesenschnauzer, Havanese, Labrador Retriever, Löwchen, Zwergpudel, Zwergschnauzer, Nova Scotia Duck Tolling Retriever, Portugiesischer Wasserhund, Samoyede, Seidenterrier, Spitz, Standardpudel, Rauhaardackel, Tibet Terrier, Toy Pudel 
(US-Patent-Application 2005). Ob in allen diesen Rassen bereits PRCD-Fälle per Genotypisierung nachgewiesen wurden, geht aus der Patentschrift nicht hervor. Der zum Patent angemeldete Test wird von der US-amerikanischen Firma OptiGen vertrieben. Für die in der obigen Aufzählung unterstrichenen Rassen werden auf der OptiGen-Homepage PRCD-PRA-Gentests angeboten. Weitere Rassen in denen bei Untersuchungen der Firma OptiGen Fälle von PRCD-PRA per Genotypisierung eindeutig nachgewiesen werden konnten, sind Australischer Schäferhund, Cockapoos, Golden Retriever, Kuvacz, Labradoodle, Lappischer Hütehund, Spanischer Wasserhund und Schwedischer Lappenhund. Für einige der genannten Rassen finden sich entweder in der Patentschrift oder auf der Homepage der Firma OptiGen zusätzliche Informationen über die geschätzte rassenspezifische Prävalenz der PRCD-PRA im Vergleich zu anderen PRA-Formen sowie Schätzungen der Häufigkeit von Defektträgern. Die verfügbaren Informationen sind in Tabelle 16 zusammengefasst.

Tabelle 16 Häufigkeit der PRCD-PRA bei verschiedenen Rassen

\begin{tabular}{ll}
\hline Rasse & Kategorie \\
\hline $\begin{array}{l}\text { Nova Scotia Duck Tolling Retriever, Entlebucher Sennenhund, } \\
\text { Amer. Eskimohund }\end{array}$ & bisher keine anderen PRA-Formen bekannt \\
Zwergpudel & $75 \%$ aller PRA-Fälle sind PRCD-PRAs \\
Australian Cattle Dog, Australian Stumpy Tail Cattle Dog & PRCD-PRA ist häufigste von mehreren PRA-Formen \\
$\begin{array}{l}\text { Finnischer Lappenhund, Schwedischer Lappenhund, Lappischer } \\
\text { Hütehund }\end{array}$ & nicht PRCD-PRAs sind selten \\
Chinesischer Schopfhund & PRCD-PRA ist nicht die häufigste erbliche PRA-Form \\
Golden Retriever & PRA insgesamt unter 1\%, bei OptiGen bisher nur 1 PRCD- \\
Portugiesischer. Wasserhund & PRA Fall \\
Cocker Spaniel, Zwergpudel & Defektträgeranteil 40\% \\
Labrador & Defektträgeranteil >24\% \\
\hline
\end{tabular}

Grundlage dieser Daten sind Genotypisierungen von freiwillig von Züchtern und Tierärzten eingesandten Proben, die nicht nach statistischen Gesichtspunkten ausgewählt wurden. Des Weiteren gehen in die Schätzungen zum Teil Daten aus ophthalmologischen Untersuchungen des American College of Veterinary Ophthalmologists (A.C.V.O.) ein, bei denen nicht alle gestellten PRCD-PRA Diagnosen mittels Gentest bestätigt sind. Alle Daten beziehen sich vorrangig auf Populationen aus dem US-amerikanischen Raum und Großbritannien (http://www.optigen.com; US- 
Patent-Application 2005). Diese Punkte schränken die Übertragbarkeit der Informationen auf europäische oder deutsche Populationen erheblich ein.

\subsection{Degenerative PRA bei Schapendoes}

\section{Krankheitsbild}

In der Rasse Schapendoes tritt eine weitere Retinaerkrankung mit den typischen Anzeichen einer degenerativen PRA auf. Klinische, ophthalmoskopische und elektroretinographische Einzelheiten sind nicht veröffentlicht (Lippmann et al. 2007). Das Ausgangsmaterial für die Suche nach dem ursächlichen genetischen Defekt stammt von 57 Schapendoes aus fünf informativen Pedigrees einschließlich 13 betroffener Schapendoes. Als gesunde Kontrolle dienten Proben von Saarloos/Wolfshounds.

\section{II./III. Genetischer Hintergrund und assoziierter Haplotyp}

Es wurde eine Untersuchung des gesamten Genoms (WGS, Whole Genome Scan) per Typisierung für 165 gleichmäßig über die Chromosomen 1-20 und 24-26 verteilte Marker aus einer als MSS-2 (minimal screening set 2) bezeichneten Zusammenstellung (Guyon et al. 2003) durchgeführt (Lippmann et al. 2007). Daraus ergab sich innerhalb der untersuchten Population eine enge Kopplung des Markers REN93E07 auf dem caninen Chromosom 20 mit der PRA bei Schapendoes (Lippmann et al. 2007). Für die Feinkartierung des PRA-Lokus bei Schapendoes wurden anschließend 9 weitere Marker von Chromosom 20 zwischen REN100J13 und TL195IIMS bei allen 57 Schapendoes typisiert. Ein auf diesem Wege ermittelter, insgesamt sieben Marker umfassender Haplotyp (REN149D232 ${ }^{\text {Allel-2 }}$ - REN316E232 $2^{\text {Allel-2 }}$ - TL335MS ${ }^{\text {Allel-3 }}-$ REN93E071 $1^{\text {Allel-2 }}$

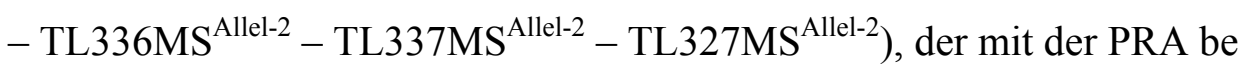

i Schapendoes segregiert, tritt in den untersuchten Pedigrees mit einer Frequenz von 50 \% auf. Die Länge der einzelnen Allele ist nicht angegeben. Die Lage der in diesem Haplotyp enthaltenen Marker lässt sich auf eine 5,6 Mb umfassende Region eingrenzen. Ein Vergleich mit dem humanen Genom zeigt das Vorliegen einer Homologie zwischen der 5,6-Mb-Region mit dem kurzen Arm des humanen Chromosoms 3. Eine Evaluierung mittels Sequenzierung und mRNA-Expressionsstudien von verschiedenen Kandidatengenen für PRA aus dieser Region, darunter CACNA2D3, HT017 und WNT5A, ergab keinerlei Hinweise auf das Vorliegen einer mit PRA assoziierten 
Mutation. Es sind anhand der Homologie zum humanen Chromosom 3p weitere Kandidatengene identifiziert, die noch nicht evaluiert sind.

\section{Haplotypisierung}

Bis zur Entdeckung der ursächlichen Mutation ist eine Detektion von Defektträgern mittels Typisierung für den ermittelten Haplotyp möglich. Zur Beurteilung der Zuverlässigkeit der Haplotypisierung bezüglich der Identifizierung homozygoter und heterozygoter Vererber der PRA wurden insgesamt 600 Schapendoes im Alter von über fünf Jahren typisiert. Die Altersvorgabe stellt sicher, dass die untersuchten Hunde aufgrund klinischer Befunde relativ sicher als betroffen oder gesund beurteilt werden können, da das typische Alter für das Auftreten erster Anzeichen einer PRA bei Schapendoes zwischen zwei und fünf Jahren liegt. In dieser Untersuchung wurden alle 18 untersuchten betroffenen Hunde homozygot für den ermittelten Haplotyp typisiert, und bei allen gesunden obligaten Defektträgern konnte das heterozygote Vorliegen des PRA-Haplotyps nachgewiesen werden. Anhand dieser Ergebnisse wird die Defektträgeridentifizierung über die Haplotypisierung bis zum Vorliegen eines Gentests als sinnvolles Werkzeug für Zuchtentscheidungen in der Rasse Schapendoes eingeschätzt (Lippmann et al. 2007).

In der veröffentlichten Methode zur Haplotypisierung erfolgt die Amplifikation der Markersequenzen unter Verwendung verlängerter Vorwärtsprimer (Lippmann et al. 2007). Die Oligonukleotidsequenz der am 5'-Ende der Vorwärtsprimer angehängten Verlängerung ( ${ }^{5}$ CATCGCTGATTCGCACAT ${ }^{3}$ ) wurde aus einer anderen Studie derselben Arbeitsgruppe übernommen (Jagiello et al. 2004). Zusätzlich zu den verlängerten Vorwärtsprimern werden ein reverser Primer sowie ein fluoreszenzmarkierter dritter Primer, der mit der Primerverlängerung hybridisiert, eingesetzt (Abb. 97). 
REN149D23: $37.609 .209-37.609 .376$
5'GACAGAAGAGCCCATCGAG ${ }^{{ }^{\prime}} \rightarrow$

GACAGAAGAGCCCATCGAGGACTTTTGTTGGAGGACAGATTTGGGGTGAGGGGGATGAGTTTTGTCCTTT AGCAATGTGCCTGTGGTTTGCTGAGGGAGCAGATGGGCTGGGGCAACCTGTGTGTGTGTGTGTGTGTGTG TGAGCGTGCATTGGTGGGTGTGACTATG

$\leftarrow$ 'GTAACCACCCACACTGATAC ${ }^{5}$

REN316E23: 38.133.160 - 38.133.313

${ }^{5}$ 'AAAAAGAGGATGGGATGGAG ${ }^{3 \prime} \rightarrow$

AAAAAGAGGATGGGATGGAGGAGGAGAAACAAGTGGGTTTTTTCCTCTATTAGGACAGGAGT

CAGTGTGTGTGTGTGTGTGTGTGTGTGTGTGTGTGTGTGTGTGTGTGCTGGTGGTGCAGGGG

AAAGTTGCGGCAGCAAATGATCTATCTGA

$\leftarrow^{3}$ CCGTCGTTTACTAGATAGACT $^{5}$

TL335MS: 38.313.482-38.313.607

$5^{\prime}$ CCCATAGAAAAGGGACTG $^{3} \rightarrow$

CCCATAGAAAAGGGACTGAGAAAATAAAGTCAAGCCAGAGACAGGAAGAAAAGTGTGTGTGTGTGTGT GTGTGTGTGTGTGTGTGTGTGTGATGGAGGAGGAGGAGCAGAGGGGGAGAGAAAGTG

$\leftarrow^{3 \prime}$ GTCTCCСССTCTCTTTCAC $^{5}$

REN93E071: $38.525 .708-38.525 .877$

$5^{\prime}$ GGCCCCCTCACCACTCC $^{3 \prime} \rightarrow$

GGCCCССTCACСАСTCССTCAAAGACTGCACTGCCCCCACTGGGCTCTGAGCATCTGCTTCCTGGTTGT CCCCACACCCAACACACACACACACACACACACACACACACACAATTCAAGGTTCACAGGAGAGGACAA TCTGTCTTCCGTATTTACAGTGGCAGCCCTCA

${ }^{3 \prime}$ ATAAATGTCACCGTCGGGAGT ${ }^{\prime \prime}$

TL336MS: 38.727.171-38.727.303

$5^{\prime}$ TCACTGGTACAGGCATTGTTC $^{3 \prime \rightarrow}$

TCACTGGTACAGGCATTGTTCTCTGGTTCATTTTATCTTAGCTCATCAAGCCTGAGCAGACACACACAC ACACACACACACACACACACACACACATACGCGTGCATGCTCAGGGATGGGGATGGACATAAGG $\leftarrow^{3 \prime}$ CTACCCCTACCTGTATTCC ${ }^{\prime \prime}$

TL337MS: 38.956.429 - 38.956.763

${ }^{5}$ AAGGCTACTTTTGGGACCC ${ }^{3}{ }^{\rightarrow}$

AAGGCTACTTTTGGGACCCCCTGGGTGGCTCAGCGGTTAAGCATCTGTCTTTGGCTCAGGGTGTGATCC TGGAGTCCCAGGATCGAGTCCCACATCGGGCTCCCTGCATGGAGCCTGTTTCTCTCTCTGCCATGTCTC TGCCTCGTGTGTGTGTGTGTGTGTGTGTGTGTGTGTGTGTGTGTGTGTGTGTCTCATGAATAAATAAAT AAAATCTTAAAAAAAGAAAAGAAGAGGAAGCTGCTTTTAAAAGTCAACATCTACAAGTTCTGTTACAAA AATTCAATAGCTCCCCTATACCTCAGTCTTCCTGCTCCTCCAGCATCTCTCACCTCTCA

${ }^{3}{ }^{\prime}$ GGTCGTAGAGAGTGGAGAGT $^{5}$

TL327MS: 39.812.660 - 39.812.826

$5^{\prime}$ TGGCTTGTTATGAAGTTGGCC ${ }^{3^{\prime}} \rightarrow$

TGGCTTGTTATGAAGTTGGCCATTCTGATTATTGATCAGTAGTTAGTGAAAAACACACCTCCCTTGTTG GAGGATTGTGTATGTGTGTGTGTGTGTGTGTGTGTGTGTGTGTGTATGGTATTCCTGTTACCCCTCCGA TCAGGTATATCTCCATAGCACCTGGGGCT

$\leftarrow{ }^{\prime}$ GAGGTATCGTGGACCCCGA ${ }^{5}$

Abb. 97 Marker des PRA-Haplotyps bei Schapendoes (Ensembl Dog Contig View Release 44 - April 2007 - Chromosom 20). Hinter dem Markernamen ist jeweils die Position der Sequenz auf Chromosom 20 angegeben, Wiederholungssequenzen sind blau gedruckt. 


\subsection{Multifokale PRA bei Englischen Mastiffs und Bullmastiffs}

\begin{tabular}{|ll|}
\hline Chromosom: & CFA20 \\
Gen: & Rhodopsin \\
Ensembl: & TranscriptID: ENSCAFT00000007461 \\
DNA-Sequenz: & CFA20, Position 86362128641466 \\
Mutationen: & G11C, Englischer Mastiff, Bullmastiff \\
\hline
\end{tabular}

\section{Krankheitsbild}

Bei Englischen Mastiffs tritt eine autosomal dominante Form progressiver Retinaatrophie auf, die wie die PRCD zu den degenerativen PRAs gehört (Kijas et al. 2002). In den wesentlichen Grundzügen entspricht das Krankheitsbild den bereits beschriebenen typischen Erscheinungen einer PRA. Besonderheiten, die die PRA bei Mastiffs von anderen PRAs abgrenzen, betreffen das Vorliegen einer verzögerten Dunkeladaptation und die multifokale Verteilung der erkrankungsbedingten Läsionen in der Retina betroffener Mastiffs (Kijas et al. 2002). Im Hinblick auf diese Befunde existiert allerdings eine deutliche Übereinstimmung mit mehreren humanen degenerativen Retinaerkrankungen, die durch verschiedene Mutationen im RhodopsinGen verursacht werden (Cideciyan et al. 1998).

Rhodopsin ist eine Verbindung aus Opsin, das $90 \%$ der Gesamtproteinmasse in den membranösen Scheiben der äußeren Segmente der Stäbchenzellen stellt, und 11-cisRetinal (Aldehyd des Vitamin A), das kovalent an Opsin gebunden ist. Durch Absorption von Licht wird 11-cis-Retinal in die all-trans-Konfiguration überführt. Dadurch wird das Lichtsignal in ein elektrochemisches Signal übersetzt, das die Umwandlung von GDP-Transducin zu GTP-Transducin bewirkt und damit die visuelle Signaltransduktionskaskade in Gang setzt. Wie alle guaninnukleotidregulierenden Proteine (G-Proteine) enthält Rhodopsin sieben Transmembranhelices, die durch unterschiedlich lange extrazelluläre oder zytoplasmatische Schleifen verbunden sind, sowie einen extrazellulären N-Terminus und einen intrazellulären C-Terminus (zusammengefasst bei Gärtner 2001).

\section{Genetischer Hintergrund}

Die canine Rhodopsin-cDNA hat eine Länge von 1107 bp und umfasst fünf Exons. Das resultierende Polypeptid hat eine Länge von 368 Aminosäuren. Das Gen ist auf Chromosom 20 zwischen Position 8636212 und 8641466 lokalisiert (Ensembl 
Transcript ID: ENSCAFT00000007461) (Petersen-Jones et al. 1994; Gould et al. 1995; Kijas et al. 2002). Abb. 98 zeigt die Lage der einzelnen Exons innerhalb der genomischen Sequenz.

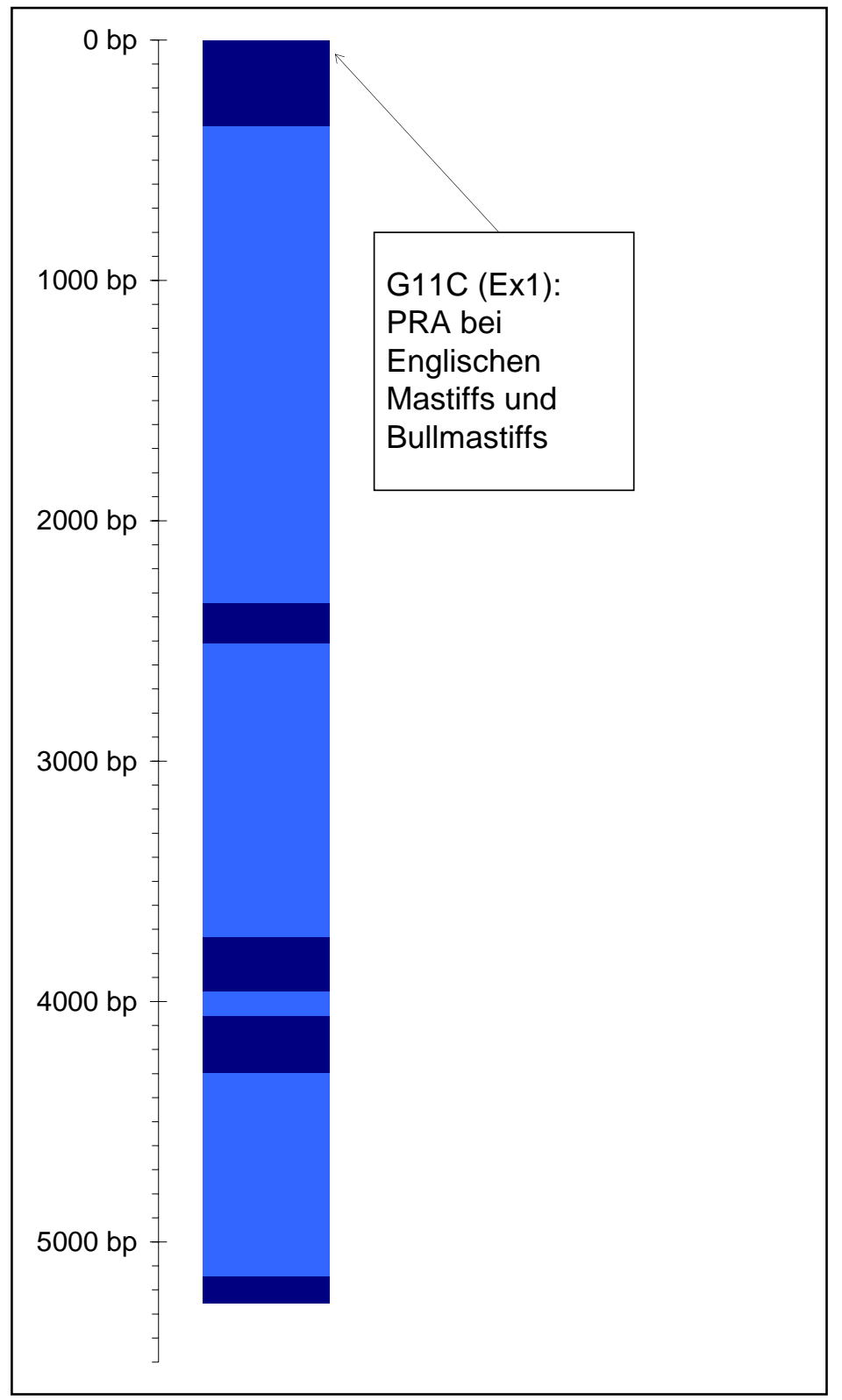

Abb. 98 Schematische Darstellung des caninen Rhodopsin-Gens und Lage der bisher identifizierten Mutationen. Dunkelblau: codierende Sequenz, hellblau: Intronsequenz.

\section{Ursächliche Mutation für PRA bei Englischen Mastiffs und Bullmastiff}

Bei betroffenen Englischen Mastiffs liegt in Exon 1 des Rhodopsin Gens eine Substitution von Guanin durch Cytosin an Nukleotidposition 11 vor, die zu einem Aminosäurenaustausch von Threonin durch Arginin an Aminosäurenposition 4 führt (Abb. 99). In einer Genotypisierung waren 23 von 26 betroffenen Hunden heterozygot für die Mutation. Bei den übrigen drei Hunden lag die Mutation homozygot vor. Bei 
keinem der 21 normalen verwandten Mastiffs und 156 weiteren klinisch normalen Hunden aus 17 verschiedenen Rassen konnte das mutierte Allel nachgewiesen werden.

Einzelheiten des Zusammenhangs zwischen der Mutation und der PRA sind noch nicht abschließend geklärt. Immunozytochemische Untersuchungen zeigen eine hinsichtlich Lokalisation, Quantität und Größe der mRNA normale Expression des Rhodopsin-Gens (Kijas et al. 2002).

Die Substitution ist in der extrazellulären Domäne des Proteins lokalisiert, die für die Bindung der Retinal-Isomere sowie weiterer Moleküle wie Phosphatgruppen oder Arrestin zuständig ist. Die einzelnen Rhodopsin-Zwischenprodukte, die im Verlauf der Phototransduktionskaskade gebildet werden, erfüllen zum Teil wichtige regulatorische Funktionen im Ablauf der Hell- oder Dunkeladaptation. Die detaillierten molekularen Abläufe innerhalb dieses Systems sind noch nicht abschließend untersucht. Demnach kann der Effekt der bei betroffenen Mastiffs vorliegenden Substitution nicht im Einzelnen vorhergesagt werden. Vor dem Hintergrund der bisher bekannten Zusammenhänge wird eine Veränderung der Bindungseigenschaften des RhodopsinMoleküls mit der Folge eines Mangels oder eines gestörten Abbaus einer oder mehrerer Zwischenprodukte des Rhodopsins für die Störung der Dunkeladaptation bei betroffenen Mastiffs verantwortlich gemacht. Aufgrund der Komplexität des Systems und der zentralen Rolle des Rodopsin-Moleküls wird als Konsequenz der Substitution einer einzelnen Aminosäure eine schwerwiegende Störung der einzelnen Abläufe als relativ wahrscheinlich beurteilt, auch wenn die Substitution nur heterozygot vorliegt. Welche Mechanismen in diesem Zusammenhang zur Degeneration der Photorezeptorzellen führen ist nicht geklärt. Des Weiteren existieren bisher nur spekulative Vorstellungen über die Ursache des fokalen Charakters der Degeneration. Als mögliche Erklärung wird eine ungleichmäßige Lichtabsorption innerhalb der verschiedenen Regionen der Retina in Betracht gezogen. In Übereinstimmung mit dieser These sind die ersten von Degeneration betroffenen Photorezeptorzellen im temporalen Bereich des Tapetum lokalisiert. In dieser Region ist beim Hund der Bereich des zentralen Sehens mit der höchsten Photorezeptordichte gelegen. Eine dadurch bedingte höhere Lichtabsorption in diesem Bereich im Vergleich zu anderen Regionen der Retina wird als mögliche Ursache für eine beschleunigte Degeneration in Erwägung gezogen (Kijas et al. 2002). Eine gezielte Untersuchung der Wirkung verschiedener 
Lichtintensitäten auf das Retinagewebe betroffener Mastiffs ergibt eine weitere Bestätigung dieser These. Es konnte gezeigt werden, dass eine punktuelle Stimulation mit moderater Lichtintensität an den stimulierten Stellen sowohl in Bereichen mit als auch in Arealen ohne Tapetum lucidum zu deutlich sichtbaren Schädigungen des Retinagewebes führen, die sich gegenüber den nicht stimulierten Regionen der Retina abheben. Mit schwachen Lichtreizen lässt sich keine derartige Veränderung erzielen. Es wird von der Existenz eines Reparaturmechanismus ausgegangen, der in schwach stimulierten Zonen einer nachhaltigen Gewebeschädigung entgegenwirkt, während er die Folgen einer stärkeren Lichtstimulation nicht aufheben kann (Cideciyan et al. 2005). Für ein abschließendes Verständnis der pathophysiologischen Zusammenhänge sind weitere Untersuchungen erforderlich (Kijas et al. 2002; Cideciyan et al. 2005).

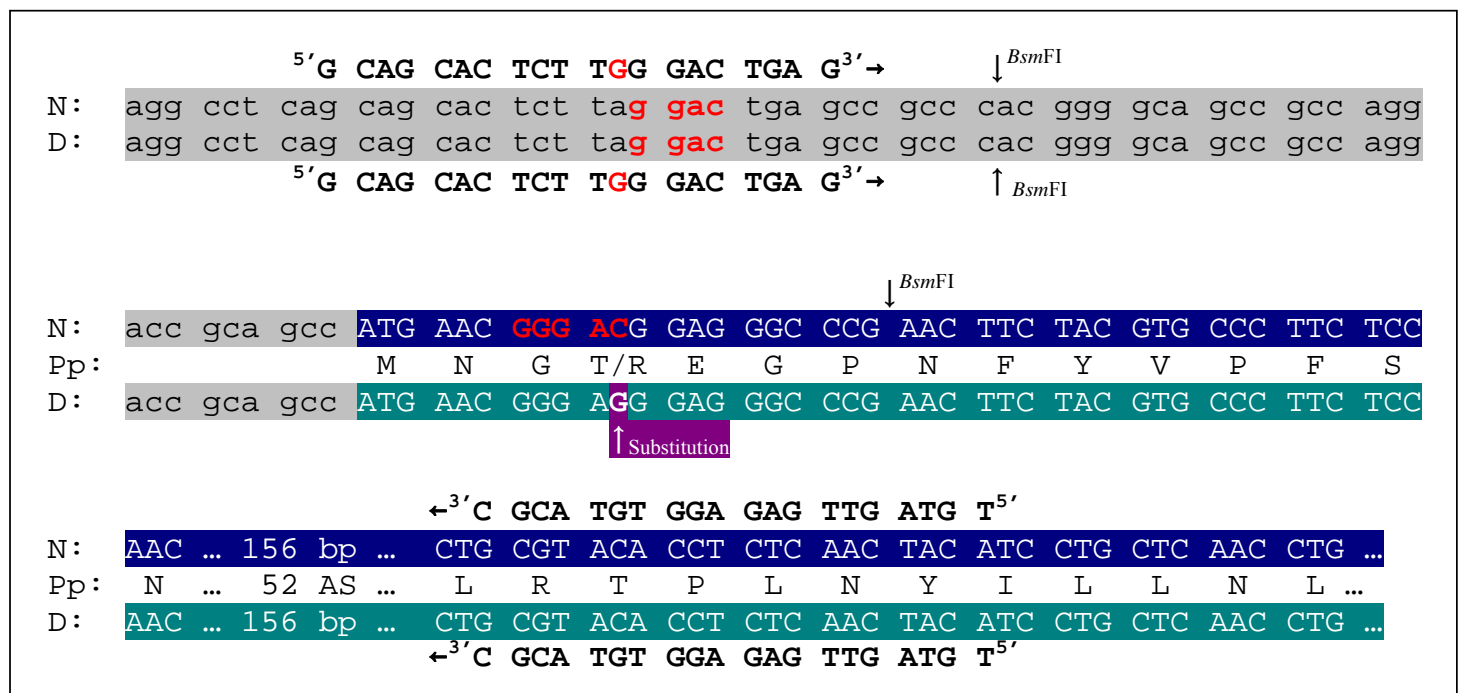

Abb. 99 Sequenzabschnitt aus Exon 1 des caninen Rhodopsin-Gens und der angrenzende 5' UTR. N: normale Sequenz, D: defekte Sequenz, Pp: Polypeptidsequenz, grau: 5'UTR, dunkelblau: Exon normale Sequenz, dunkelgrün: Exon defekte Sequenz, Substitution in defekter Sequenz violett unterlegt und durch Pfeil gekennzeichnet, rote Schrift: BmsFI-Erkennungssequenzen, BmsFI-Restriktionsschittstellen durch Pfeil gekennzeichnet.

Nach Angaben der Firma OptiGen ist die beschriebene Mutation auch bei Bullmastiffs mit einer ähnlichen PRA-Form assoziiert. Für keine der beiden betroffenen Rassen sind Zahlen zur Häufigkeit der Erkrankung angegeben. Defektträger können mit demselben Gentest identifiziert werden (http://www.optigen.com).

\section{Genotypisierung für PRA bei Englischen Mastiffs und Bullmastiff}

Der Nachweis der Substitution kann anhand einer RFLP-Typisierung erfolgen. Der zugrunde liegende RFLP basiert auf einer Erkennungssequenz für BmsFI im 
Wildtypallel, die aufgrund der Substitution im Defektallel nicht vorhanden ist (Kijas et al. 2002).

\subsection{Primäre Zapfenphotorezeptoratrophie bei Zwerglanghaardackeln}

\begin{tabular}{|ll|}
\hline Chromosom: & CFA15 \\
Gen: & RPGRIP1 \\
Ensembl: & GeneID: ENSCAFG00000005511, TranscriptID: \\
& ENSCAFT00000008883 \\
DNA-Sequenz: & CFA15, Position 21338682-21394473 \\
Mutationen: & Exon2, Position 24Ins44bp, Zwerglanghaardackel \\
\hline
\end{tabular}

\section{Krankheitsbild}

Die primäre Zapfenphotorezeptoratrophie ist eine degenerative Erkrankung die offenbar vorrangig die Zapfenphotorezeptoren betrifft. Der Erbgang ist autosomal rezessiv (Curtis und Barnett 1993). Bei einer Genotypisierung von 38 Zwerglanghaardackeln unter Einsatz eines DNA-Tests wurde ein Anteil heterozygoter Defektträger von $36,84 \%$ ermittelt. Obwohl die untersuchten Hunde keinesfalls als repräsentative Stichprobe für die Population der Zwerglanghaardackel zu bewerten sind, schließen die Autoren aus diesem Ergebnis auf eine relativ starke Verbreitung des Defektallels in der Rasse Zwerglanghaardackel (Mellersh et al. 2006a). Erste Anzeichen eines beeinträchtigten Sehvermögens treten bei betroffenen Zwerglanghaardackeln üblicherweise im Alter zwischen einem und drei Jahren auf. In Einzelfällen sind bereits im Alter von sechs Monaten Sehstörungen zu bemerken. Funduskopisch sind bereits im Alter zwischen 25 und 26 Wochen die für PRA typischen Veränderungen des Tapetum lucidum, der Pupillen und des Pupillenreflexes zu erkennen. Zu diesem Zeitpunkt lässt sich in einem Hindernisparcours bei schwachen Lichtverhältnissen bereits eine beginnende Nachtblindheit nachweisen, während die Sehfähigkeit bei Tageslicht in keiner Weise gestört $\mathrm{zu}$ sein scheint. Hinsichtlich der Geschwindigkeit der Krankheitsentwicklung bestehen zwischen einzelnen betroffenen Individuen erhebliche Unterschiede. Zwei von vier betroffenen Wurfgeschwistern waren im Alter von 17 Monaten bereits nahezu vollständig blind und zeigten fortgeschrittene Hyperreflexion des Tapetum lucidum, Verlust der retinalen Gefäße, eine Pigmentverarmung der peripher zum Tapetum lucidum gelegenen Fundusbereiche und deutliche Atrophie der Papilla optica. Demgegenüber war bei den übrigen zwei betroffenen Welpen desselben Wurfes eine geringe Sehfähigkeit erhalten, die Hyperreflexion weniger weit fortgeschritten und die retinalen Gefäße waren wenig, die Papilla optica und die 
peripher zum Tapetum lucidum gelegenen Fundusbereiche gar nicht betroffen. Eine Kataraktbildung konnte bei betroffenen Langhaardackeln auch in einem späteren Stadium der Erkrankung nicht beobachtet werden.

Elektroretinographische Auffälligkeiten treten bei allen untersuchten betroffenen Zwerglanghaardackeln ab einem Alter von neun Monaten beginnend mit einem Rückgang der Amplituden auf. Später kommt es zu einem Rückgang der retinalen Empfindlichkeit und einer Verringerung der implizierten Zeitintervalle. Vergleiche zwischen der Reaktion auf skotopische Blaulicht- und skotopische Rotlichtstimuli ergeben keinerlei Hinweise auf einen selektiven Verlust von Stäbchenphotorezeptoren.

Histopathologisch lassen sich im Alter von sechs Wochen ausschließlich in den äußeren Stäbchensegmenten marginale Veränderungen feststellen. Die Stäbchen haben eine normale Länge und erscheinen vollständig entwickelt weisen jedoch leichte Unregelmäßigkeiten hinsichtlich des Durchmessers auf. Sehr vereinzelt sind die membranösen Scheiben der äußeren Segmenten desorganisiert und desorientiert angeordnet. Im Alter von zehn Wochen ist der Durchmesser und die Anzahl von Kernen in der äußeren Körnerschicht reduziert. Bei normaler Länge ist der Durchmesser der inneren und äußeren Photorezeptorsegmente unregelmäßig und in den äußeren Segmenten der Stäbchenzellen ist bei generell regelmäßiger Anordnung der membranösen Scheiben eine deutliche Desorganisation und -orientierung $\mathrm{zu}$ beobachten. die Zapfenzellen und das Retinapigmentepithel sind unverändert. Im Alter von 25 Wochen ist die Dicke der äußeren plexiformen Schicht und der äußeren Körnerschicht deutlich verringert und es liegt eine fortgeschrittene Degeneration der äußeren Photorezeptorsegmente sowie Atrophie der inneren Segmente vor. Die histopathologischen Befunde sprechen für das Vorliegen einer primären Stäbchendystrophie, während die Ergebnisse der elektroretinographischen Untersuchungen diese Einschätzung nicht bestätigten (Curtis und Barnett 1993). Spätere elektrophysiologische, morphologische und immunohistochemische Untersuchungen sowie Lectinbindungsstudien (Turney et al. 2007) werden von verschiedenen Autoren als Beleg für das Vorliegen einer primären Zapfendegeneration mit sekundärer Degeneration der Stäbchen und der übrigen Retinakomponenten angeführt (Mellersh et al. 2006a; Ropstad et al. 2007). Einzelheiten sind noch nicht veröffentlicht. 


\section{Genetischer Hintergrund}

Die Ergebnisse von Zuchtexperimenten deuten auf eine autosomal rezessive Vererbung der PRA bei Zwerglanghaardackeln hin (Curtis und Barnett 1993).

Mithilfe von Kopplungsanalysen gelang es, den für progressive Retinaatrophie bei Zwerglanghaardackeln verantwortlichen Genort, bezeichnet als cord1 (cone-rod dystrophy 1), zwischen den Mikrosatelliten FH3833 und Ren265M23 auf dem caninen Chromosom 15 zu kartieren. Damit lässt sich unter Zugrundelegung der Genkarte „full Ensembl gene build for Canis familiaris“ (CanFam 1.0: http://www.ensembl.org/Canis familiaris/) (Breen et al. 2004) die Lage des cord1Genorts auf eine 14,15 Mb große Region eingrenzen (Mellersh et al. 2006a). Des Weiteren konnte eine enge Kopplung des cord1-Genorts mit den drei Mikrosatelliten Ren06C11, R61G2_E2 und 61G2_E7 nachgewiesen werden. Die Sequenzierung von 96 Subklonen des BAC 61G2, der alle drei Mikrosatelliten enthält, ergab das Vorliegen einer Syntenie zwischen der cord1-Region auf dem caninen Chromosom 15 und dem humanen Chromosom 14q11.

Innerhalb dieser Region ist das RPGRIP1-Gen lokalisiert, das für das RetinitisPigmentosa-GTPase-Regulator-interagierende-Protein 1 codiert. Die Funktion dieses Proteins ist noch nicht abschließend geklärt. Neben einer C-terminalen RPGRinteragierenden Domäne besitzt RPGRIP1 eine coiled-coil Domäne (CC), die homolog zu Proteinen des vesikularen Transports ist. Diese Eigenschaft wird als Hinweis auf eine Beteiligung von RPGRIP1 an vesikulären Transportprozessen gedeutet. Hinsichtlich der Lokalisierung bestehen speziesspezifische Unterschiede. Studien an humanem RPGRIP1 ergeben Hinweise auf eine Kolokalisation mit RPGR in den äußeren Segmenten der Photorezeptorzellen. Bei Mäusen wurde eine Kolokalisation von RPGRIP1 und RPGR in den Verbindungscilien zwischen den inneren und den äußeren Photorezeptorsegmenten gefunden und daraus auf eine Funktion von RPGRIP1 als Strukturkomponente der Cilien und als Anker für RPGR geschlossen. Eine kritische Rolle von RPGRIP1 im zielgerichteten Transport entstehender Proteine aus den inneren in die äußeren Photorezeptorsegmente wird in Betracht gezogen. Zudem wird RPGRIP1 in den Amakrin-Zellen exprimiert, die an der retinalen Entwicklung und an der Adaptation des Auges an schlechte Lichtverhältnisse (Urschel et al. 2006) beteiligt sind. Studien an Mäusen deuten auf eine wesentliche Rolle von RPGRIP1 bei der 
Morphogenese der membranösen Scheiben der Photorezeptoren hin (zusammengefasst bei Koenekoop 2005).

Aufgrund der offensichtlich maßgeblichen Beteiligung von RPGRIP1 an der Entwicklung der Photorezeptorzellen und an der visuellen Signaltransduktionskaskade und aufgrund des Zusammenhangs zweier Mutationen im humanen RPGRIP1-Gen mit Retinadystrophieerkrankungen (Dryja et al. 2001; Gerber et al. 2001) wird das RPGRIP1-Gen als starkes Kandidatengen für progressive Retinaatrophie bei Zwerglanghaardackeln betrachtet. Bei einem Sequenzvergleich zwischen obligat homozygot normalen, obligat heterozygoten und homozygot betroffenen Zwerglanghaardackeln wurde bei betroffenen Hunden eine 44-bp-Insertion nachgewiesen, die nach bisherigen Erkenntnissen eine erhebliche Funktionsstörung des RPGRIP1 Gens verursacht (Mellersh et al. 2006a).

Das canine RPGRIP1-Gen ist noch nicht abschließend charakterisiert. Grundlage der Untersuchung der Zwerglanghaardackel ist eine aus verschiedenen caninen Whole Genome Shotgun (WGS) Sequenzen öffentlicher Datenbanken erstellte vorläufige Sequenz. Zur Orientierung dienten signifikante Homologien zu den 24 bekannten humanen RPGRIP1 Exons (Koenekoop 2005), die unter Ensembl veröffentlichte vorläufige canine Sequenz (Transcript ID: ENSCAFT00000008883) sowie weitere bekannte cDNA-Sequenzen verschiedener Spezies. Anhand dieser Sequenz wurden Primer für die Amplifikation der einzelnen Exons einschließlich ca. 100 bp der flankierenden Intronsequenzen aus genomischer DNA der $\mathrm{zu}$ untersuchenden Zwerglanghaardackel generiert. Von den Sequenzen der so amplifizierten Fragmente sind lediglich die als Exons 2 und Exon 3 bezeichneten Abschnitte veröffentlicht. Die verfügbaren Informationen sind als Grundlage für eine Darstellung der genomischen Struktur des RPGRIP1-Gens nicht ausreichend. Die in der Ensembl-Datenbank veröffentlichte Version (Transcript ID: ENSCAFT00000008883) unterscheidet sich in einigen Punkten von den bei Mellersh und Kollegen (2006a) veröffentlichten Ergebnissen. 5'-UTR und Startsignal sind nicht enthalten. Die codierende Sequenz ist nicht auf 24, sondern auf 27 Exons aufgeteilt. Die in der Untersuchung von Mellersh und Kollegen (2006a) als Exons 2 und Exon 3 bezeichneten Sequenzfragmente sind in der Ensembl-Sequenz in Exon1 bzw. Exon 4 lokalisiert. 
Laut Ensembl-Datenbankeintrag ist das canine RPGRIP1-Gen auf Chromosom 15 zwischen Position 21338682 und 21394473 lokalisiert. Die 27 Exons bilden ein 4089 bp langes Transkript. Die Länge des resultierenden Proteins beträgt 1313 Aminosäuren.

\section{Ursächliche Mutation für primäre Zapfenphotorezeptoratrophie bei Zwerglanghaardackeln}

Die bei betroffenen Zwerglanghaardackeln homozygot vorliegende 44-bp-Insertion ist in der zugrunde gelegten Sequenz des RPGRIP1-Gens in Exon 2 lokalisiert. Es handelt sich um eine Aneinanderreihung von 29 Adeninnukleotiden gefolgt von einer perfekten Duplikation der vorausgehenden 15 bp (Abb. 100). Die Folge ist eine Verschiebung des Leserasters und die Entstehung eines verfrühten Stoppcodons 80 Nukleotide abwärts der Insertion. Der Polyadeninabschnitt sowie die 15-bp-Duplikation entsprechen den typischen Eigenschaften einer SINE-Insertion (Mellersh et al. 2006a).

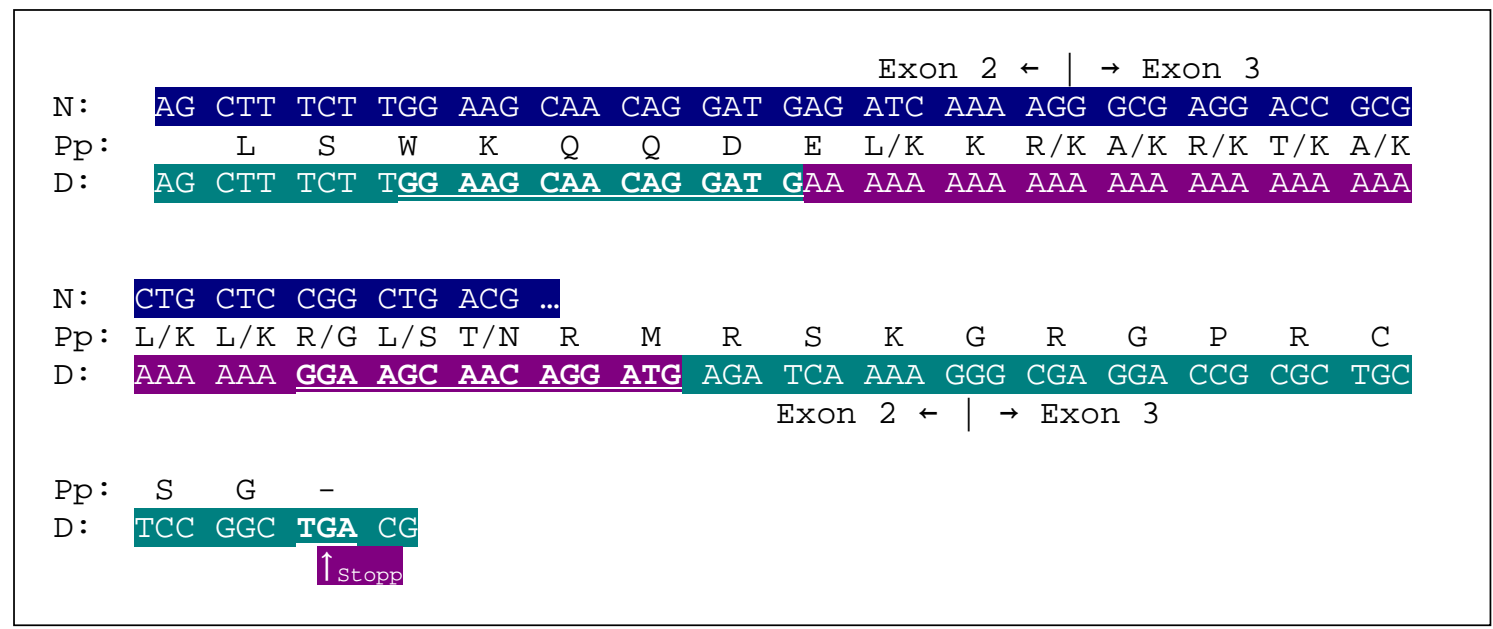

Abb. 100 Exons 2 und 3 des caninen RPGRIP1-Gens (Mellersh et al. 2006a). N: normale Sequenz, D: defekte Sequenz, Pp: Polypeptidsequenz, 44-bp-Insertion in defekter Sequenz violett unterlegt, duplizierte 15-bp-Sequenz in defekter Sequenz und in Insertion doppelt unterstrichen und fett gedruckt, Exongrenzen durch Pfeil gekennzeichnet.

Die Insertion konnte homozygot bei 15 betroffenen verwandten Zwerglanghaardackeln sowie zwölf betroffenen nicht verwandten Zwerglanghaardackeln nachgewiesen werden. Bei zwei weiteren für das mutierte Allel homozygoten Zwerglanghaardackeln lagen keinerlei Anzeichen für eine generalisierte PRA vor. Für einen dieser Hunde lagen ophthalmologische Befunde nur bis zu einem Alter von zwei Jahren vor. Die weitere Entwicklung des Hundes wurde nicht beobachtet. Der zweite Hund zeigte bis zu einem Alter von über zehn Jahren keinerlei Anzeichen für eine PRA. Aufgrund dieser Ausnahmen sowie der bereits erwähnten erheblichen Variationen in der Geschwindigkeit des Krankheitsverlaufs zwischen einzelnen betroffenen Hunden wird 
die Existenz eines weiteren Gens in Erwägung gezogen, das neben dem RPGRIP1-Gen mit der Erkrankung assoziiert ist.

\subsubsection{Achromatopsie/Hemeralopie}

\begin{tabular}{ll|}
\hline Chromosom: & CFA29 \\
Gen: & CNGB3 \\
NCBI: & GeneID: 403554, GenBank: AF490511 \\
DNA-Sequenz: & NW_876288, Position 32896548-32752479 \\
Mutationen: & G784A, Deutsch Kurzhaar Vorstehhund \\
& vollständige Deletion des Gens, Alaskan Malamute \\
\hline
\end{tabular}

\section{Krankheitsbild}

Die als canine Achromatopsie (Farbenblindheit) oder Hemeralopie (Tagblindheit) bezeichnete Erkrankung ist durch das Vorliegen einer vollständigen Sehunfähigkeit bei Tageslicht in Verbindung mit unbeeinträchtigter Sehfähigkeit bei Dämmerlicht gekennzeichnet. Beschrieben wurde die Erkrankung bisher in den Rassen Alaskan Malamute, Zwergpudel, Deutsch Kurzhaar (Sidjanin et al. 2002), Deutsch Drahthaar (McElroy 2006), Chihuahua und Australian Cattle Dog sowie bei einem Rhodesian Ridgeback Mischling (Hurn et al. 2003).

Der ursächliche Gendefekt ist bisher nur in den Rassen Alaskan Malamute und Deutsch Kurzhaar Vorstehhund identifiziert worden. Zahlen zur Häufigkeit der Erkrankung in diesen beiden Rassen sind offenbar nicht veröffentlicht. Am besten untersucht ist die Erkrankung bei Alaskan Malamutes. Betroffene Hunde zeigen oft bereits im Alter von acht Wochen Anzeichen für das Vorliegen einer Tagblindheit, während im Dämmerlicht eine normale Sehfähigkeit vorzuliegen scheint (Rubin et al. 1967). Bei einem Wechsel von Dämmerlicht zu Tageslicht tritt ein sofortiger Verlust der Sehfähigkeit ein. Dagegen stellt sich bei einem Wechsel von Tageslicht zu Dämmerlicht erst nach einigen Minuten eine normale Sehfähigkeit ein. Mittels Ophthalmoskopie lassen sich auch bei älteren betroffenen Hunden keine pathologischen Veränderungen feststellen. Die beschriebenen Befunde bleiben während des gesamten Lebens betroffener Hunde unverändert bestehen. Elektroretinographische Untersuchungen deuten klar auf einen Verlust der Zapfenzellfunktion hin. Ab einer Frequenz von über $10 \mathrm{~Hz}$ lassen sich mittels Blitzlichtstimulation bei einer hohen Lichtintensität keinerlei Reaktionen hervorrufen, während gesunde Altersgenossen auch bei Frequenzen von über $75 \mathrm{~Hz}$ Reaktionen zeigen (Rubin 1971). Eine gestörte Zapfenfunktion zeigt sich bereits im 
Alter von acht Wochen. Ab einem Alter von sechs Monaten lassen sich zapfenzellspezifische Reaktionen nicht mehr evozieren (Aguirre und Rubin 1975). Histologische Routineuntersuchungen sind ohne Befund. Allerdings zeigen die Retinas betroffener erwachsener Alaskan Malamutes eine signifikant reduzierte Anzahl von Zapfenphotorezeptorzellkernen (Koch und Rubin 1971). Elektronenmikroskopisch ist bereits bei sieben Wochen alten betroffenen Alaskan Malamutes in den äußeren Segmenten an einigen Zapfenzellen eine Desorganisation der lamellaren Scheiben zu erkennen. Die inneren Segmente einiger Zapfenzellen enthalten Bündel unverzweigter Filamente, die häufig von einer erhöhten Anzahl polyribosomaler Aggregationen umgeben sind. Morphologisch identische Filamentbündel sind gelegentlich in geringer Anzahl auch in normalen caninen Photorezeptorzellen $\mathrm{zu}$ beobachten. Im Krankheitsverlauf nimmt sowohl die Anzahl und die Größe der Filamentbündel als auch die Anzahl der polyribosomalen Aggregationen zu. Da die Tagblindheit bereits bei sieben Wochen alten betroffenen Hunden zu beobachten ist, die Zapfenzellen zu diesem Zeitpunkt jedoch nur teilweise betroffen sind, wird das Auftreten der Filamentbündel als Folge des degenerativen Prozesses eingestuft und die Existenz eines noch unbekannten anderen Ereignisses, das zur Entstehung der Filamente führt und dadurch den degenerativen Prozess auslöst, als unwahrscheinlich verworfen. Die beschriebenen Veränderungen greifen allmählich auf alle Zapfenzellen über. Die Stäbchenzellen und andere Komponenten der Retina bleiben auch in späteren Krankheitsstadien unbeeinträchtigt. Im weiteren Verlauf kommt es zunächst zu einer Reduzierung der inneren Segmente einiger Zapfenzellen auf ca. 1/3 der normalen Größe. Die Desorganisation der äußeren Segmente nimmt zu. Nach und nach degenerieren die Zapfenzellen nahezu vollständig. In älteren Studien konnten bereits bei vier Jahre alten betroffenen Alaskan Malamutes keine Zapfenzellen mehr nachgewiesen werden (Aguirre und Rubin 1974; Aguirre und Rubin 1975). In jüngeren Untersuchungen konnte bei neun bis zehn Jahre alten betroffenen Hunden eine Präsenz weniger Zapfenzellen dokumentiert werden. Die Zellen wiesen jedoch ausnahmslos morphologische Veränderungen auf. Die Zellkerne der Zapfenrezeptorzellen werden mit fortschreitender Degeneration in die Interzellularschicht verlagert. Einige der Kerne degenerieren nicht sondern bleiben in der Interzellularschicht erhalten und produzieren weiterhin spezifische Zapfenzellproteine (Long und Aguirre 1991). In immunologischen Untersuchungen betroffener Alskan Malamutes zeigt sich ein Mangel an 
zapfenzellspezifischem Transducin- $\beta 3$ (Gropp et al. 1996) sowie an zapfenzellspezifischem $\gamma$-Transducin (Akhmedov et al. 1998). Nukleotidsequenzen und mRNA-Expression in der Retina betroffener Hunde unterscheiden sich jedoch bei keinem der beiden codierenden Gene von normalen Kontrollhunden (Akhmedov et al. 1997; Akhmedov et al. 1998). Als mögliche Ursache für diese Diskrepanz zwischen immunologischen und molekularbiologischen Befunden wird das Vorliegen einer gestörten posttranslationellen Prozessierung einer oder beider TransducinUntereinheiten in Betracht gezogen, die auf dem Mangel, einer Funktions- oder einer Transportstörung eines der dafür zuständigen Enzyme beruhen könnte (Akhmedov et al. 1998).

\section{Genetischer Hintergrund}

Die Ergebnisse von weiterführenden Untersuchungen zur Aufklärung dieses Zusammenhangs liegen nicht vor. Parallel zur Analyse dieser funktionellen Kandidatengene wurde nach positionellen Kandidatengenen gesucht. Über Markeranalysen in sechs informativen Alaskan Malamute Pedigrees konnte eine enge Kopplung der Achromatopsie mit einem Abschnitt des Chromosoms 29 ermittelt werden, der von den Markern RH86C11 und FH3366 flankiert wird (Sidjanin et al. 2002). In einer auf der Basis von acht caninen Referenzpedigrees erstellten RadiationHybrid-Karte umfasst diese Region 4,8 cM (Mellersh et al. 1997), in der auf Basis der untersuchten sechs Achromatopsie-informativen Pedigrees erstellten Markerordnung ist das Intervall zwischen den beiden Markern 6,1 cM lang (Sidjanin et al. 2002). Aus den vorliegenden Ergebnissen verschiedener Studien zur Kartierung caniner Gene und Marker ist das Vorliegen einer Syntenie zwischen dem caninen Chromosoms 29 und dem langen Arm des humanen Chromosoms 8 bekannt (Priat et al. 1998; Breen et al. 1999; Yang et al. 1999; Sargan et al. 2000). Eines der auf dem humanen Chromosom 8q lokalisierten Gene ist das CNGB3-Gen, das für die $\beta$-Untereinheit des cGMPgesteuerten Zapfenphotorezeptorkanals codiert (cyclic nucleotide gated channel $\beta$ subunit). Verschiedene Mutationen im CNGB3-Gen konnten mit einer humanen Form von Achromatopsie, der Achromatopsie-3, in Verbindung gebracht werden (Kohl et al. 2000), einer Erkrankung, die starke Parallelen zur caninen Achromatopsie aufweist. Daraus ergibt sich die Einschätzung von CNGB3 als starkes Kandidatengen für die canine Achromatopsie. 
Die Schließung cGMP-abhängiger Kanäle spielt eine wesentliche Rolle in der visuellen Phototransduktionskaskade. Aufgrund von Sequenzverwandtschaften mit spannungsabhängigen Kanälen wird angenommen, dass cGMP-abhängige Kanäle in Form von Heterotetrameren aus je zwei $\alpha$ - und zwei $\beta$-Untereinheiten vorliegen. Bei einer reinen Expression der $\alpha$-Untereinheit in Xenopus Oozyten werden Ionenkanäle gebildet, die wesentlich längere Öffnungs- und Schließzeiten aufweisen als normale cGMP-gesteuerte Kanäle. Eine reine Expression der $\beta$-Untereinheit ist nicht möglich. Bei einer Koexpression beider Untereinheiten kommt es zur Bildung von Kanälen mit den für cGMP-gesteuerte Kanäle typischen blitzartigen Öffnungs- und Schließzeiten. Zudem wird die Empfindlichkeit der Kanäle gegenüber blockierenden Einflüssen externer, bivalenter Kationen deutlich reduziert (Zagotta und Siegelbaum 1996).

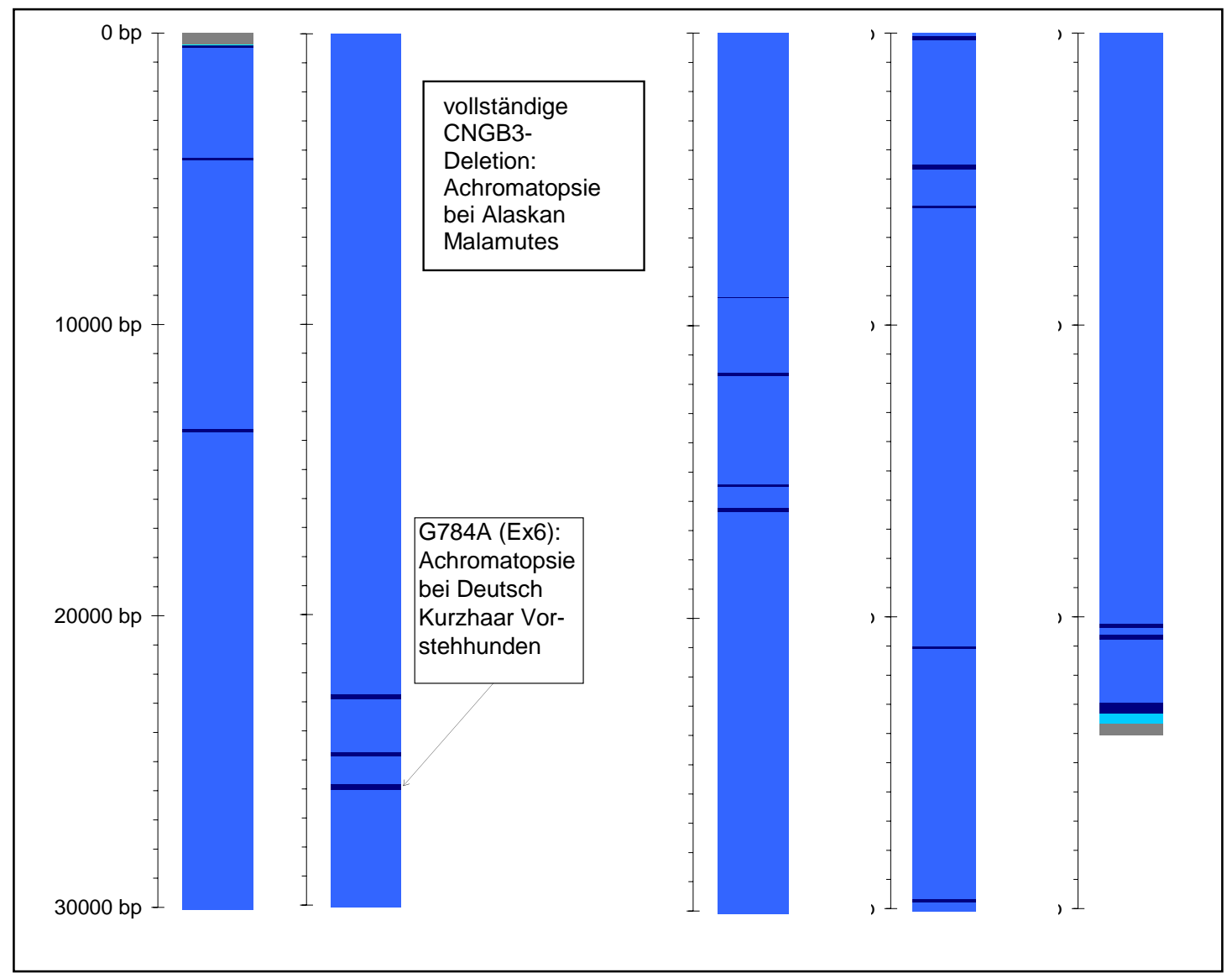

Abb. 101 Schematische Darstellung des caninen CNGB3-Gens und bisher identifizierte Mutationen. Dunkelblau: codierende Sequenz, hellblau: Intronsequenz, türkis: 5'- und 3'-UTR, grau: intergenische Sequenz.

Für die Evaluierung des CNGB3-Gens als Kandidatengen für die canine Achromatopsie wurden zunächst aus einer caninen genomischen BAC-Bibliothek in Anlehnung an die bekannte humane Gensequenz die Exons 1 und 4-18 des CNGB3 Gens einschließlich 
ca. 50 bp angrenzender Intronsequenz amplifiziert. Die 3'-Spleißstelle von Exon 2 sowie die 5'- und 3'-Spleißstellen von Exon 3 konnten nicht eindeutig identifiziert werden. Die auf diesem Wege ermittelte codierende Sequenz (NCBI-GenBank: AF490511) umfasst 2349 bp und dient als Referenzsequenz für die Suche nach Mutationen in der Sequenz betroffener Alaskan Malamutes und Deutsch Kurzhaar Vorstehhunde. Das resultierende Protein ist 782 Aminosäuren lang und weist eine 75,7 \%ige Homologie zur humanen Sequenz auf.

Im genomischen Contig NW_ 876288 ist das canine CNGB3-Gen zwischen Nukleotid 32896548 und 32752479 lokalisiert (NCBI-GeneID: 403554) und enthält 18 Exons. Abb. 101 zeigt schematisch die Lage der einzelnen Exons innerhalb der genomischen Sequenz.

\section{III.a Ursächliche Mutation für Achromatopsie bei Alaskan Malamutes}

Sequenzanalysen bei betroffenen Alaskan Malamutes ergeben deutliche Hinweise auf das Vorliegen einer vollständigen Deletion von CNGB3. Während bei homozygot gesunden und heterozygoten Hunden eine erfolgreiche Amplifikation überlappender Fragmente des CNGB3-Gens aus mRNA erreicht wird, schlägt die Amplifikation bei betroffenen Hunden für alle Fragmente des CNGB3-Gens fehl.

Das Vorliegen einer vollständigen CNGB3-Deletion bei betroffenen Alaskan Malamutes bestätigt sich in weiteren Untersuchungen. Mittels Northern Blot unter Verwendung einer spezifischen Sonde für die Exons 5-7 lässt sich bei betroffenen Hunden kein CNGB3-Transkrip ermitteln, während bei homozygot gesunden Hunden ein prominentes und bei heterozygoten Hunden ein weniger deutliches Signal für ein 5 kb Transkript detektiert werden kann. Auch in genomischer DNA lässt sich bei betroffenen Hunden mittels Southern Blot unter Verwendung einer Sonde für Exon 18 und einen Abschnitt der 3'UTR kein Fragment von der erwarteten Größe ermitteln, während bei homozygot gesunden und heterozygoten Hunden jeweils ein $6,5 \mathrm{~kb}$ großes Fragment detektiert werden kann. Das Vorliegen einer genomischen Deletion bei betroffenen Hunden wird durch die Ergebnisse einer Fluoreszenz in situ Hybridisierung bestätigt. Bei der Verwendung des caninen BAC-Klons BAC 100-O2 (Li et al. 1999) als Sonde, der sowohl das CNGB3-Gen als auch einen großen Abschnitt eines zum humanen Copin III (CPNE3) homologen Gens enthält, ist bei homozygot gesunden 
Hunden auf beiden Chromosomen 29 ein Signal zu detektieren, während heterozygote Hunde nur auf einem Chromosom ein Signal zeigen und bei betroffenen Hunden kein Signal erkennbar ist. Das $140 \mathrm{~kb}$ große BAC100-O2 Insert ist innerhalb des mit Achromatopsie gekoppelten Intervalls auf Chromosom 29 lokalisiert. Die Größe der Deletion ist nicht genau bekannt. Da nicht nur das CNGB3-Gen sondern auch ein großer Bereich des CPNE3-Gens von der Deletion betroffen ist, wird die Länge der Deletion auf mindestens $140 \mathrm{~kb}$ geschätzt. Aufgrund des Fehlens von zytogenetisch sichtbaren Veränderungen des Chromosoms 29 bei betroffenen Hunden wird eine maximale Größe von 0,5 - $1 \mathrm{Mb}$ angenommen. Das Fehlen physiologischer Hinweise auf weitere Gendeletionen spricht ebenfalls dafür, dass die Größe der betroffenen Sequenz das angegebene Intervall nicht überschreitet und neben dem CNGB3-Gen und dem Copin-III-Gen keine weiteren Gene betroffen sind. Das Copin-III-Gen gehört zur Familie der Copin-Gene, deren Funktion bisher nicht spezifiziert werden konnte. Aufgrund der dargestellten Ergebnisse wird die Funktion des caninen Copin-III-Gens als ausreichend redundant eingeschätzt, so dass der Verlust des Gens keine offensichtlichen Konsequenzen nach sich zieht (Sidjanin et al. 2002).

Neuere Untersuchungen zeigen, dass die Deletion des CNGB3-Gens nicht die einzige Mutation ist, die bei Alaskan Malamutes zu einer Achromatopsie führt. Bei sechs von 15 untersuchten betroffenen Alaskan Malamutes konnte mittels erfolgreicher Amplifikation von Exon 6 ein Vorliegen der beschriebenen Deletion ausgeschlossen werden. Bei Sequenzanalysen des CNGB3-Gens zweier betroffener Hunde und zweier Vergleichshunde konnten keine Mutationen identifiziert werden, die mit der Achromatopsie segregieren. Die ursächliche Mutation für die sechs AchromatopsieFälle konnte nicht ermittelt werden (Seddon et al. 2006).

\section{III.b Ursächliche Mutation bei Deutsch Kurzhaar Vorstehhunden}

Bei betroffenen Deutsch Kurzhaar Vorstehhunden lässt sich die Achromatopsie auf einen Defekt im CNGB3-Gen zurückführen. Anhand eines Kreuzungsexperimentes lässt sich belegen, dass die zugrunde liegende Mutation beim Deutsch Kurzhaar allelisch zur Alaskan Malamute Mutation ist. Nicht veröffentlichte Pedigreeanalysen sprechen für das Vorliegen einer autosomal rezessiven Vererbung von Achromatopsie bei Deutsch Kurzhaar Vorstehhunden. Bei einem von zwei Nachkommen aus der Anpaarung eines betroffenen Alaskan Malamutes mit einem obligat heterozygoten 
Deutsch Kurzhaar kann das Vorliegen einer Achromatopsie mittels Elektroretinographie und anhand des Phänotyps eindeutig diagnostiziert werden.

Die Sequenzierung der einzelnen CNGB3-Exons aus genomischer DNA eines betroffenen Deutsch Kurzhaar und der Vergleich dieser Sequenzen mit der Referenzsequenz ergeben das Vorliegen eines Basenaustauschs von Guanin durch Adenin an Position 784 der codierenden Sequenz mit der Folge einer Aminosäurensubstitution von Asparaginsäure durch Asparagin an Aminosäurenposition 262 in Exon 6. In keinem der Exons 1, 4-5 und 7-18 oder in den ermittelten Sequenzfragmenten im Bereich der Exons 2 und 3 konnten weitere Abweichungen von der Referenzsequenz festgestellt werden.

Die beschriebene Mutation liegt bei allen acht untersuchten betroffenen Deutsch Kurzhaar Vorstehhunden vor. Alle verfügbaren obligat heterozygoten Hunde zeigen einen heterozygoten Genotyp für die Substitution in Exon 6. In keiner der DNA-Proben von 101 gesunden oder von anderen Retinadefekten betroffenen Kontrollhunden aus 17 verschiedenen Hunderassen konnte die Substitution detektiert werden (Sidjanin et al. 2002).

\section{IV.b Genotypisierung für Achromatopsie bei Deutsch Kurzhaar Vorstehhunden}

Der Nachweis der Mutation kann per RFLP-Analyse erfolgen. Dazu wird unter Verwendung eines mismatch-Primers, der im Wildtypallel eine zusätzliche Sau3AIRestriktionsschnittstelle generiert, ein 258-bp-Fragment amplifiziert (Sidjanin et al. 2002).

\subsubsection{Defekte des Retinapigmentepithels}

Erbliche Defekte des Retinapigmentepithels treten in unterschiedlicher Form bei einer Vielzahl von Hunderassen auf. Am weitesten verbreitet ist eine als zentrale PRA oder Retinapigmentepitheldystrophie (RPED) bezeichnete Erkrankung, die unter anderem in den Rassen Labrador, Golden Retriever, Collie, Border Collie, Englischer Springerspaniel, Englischer Cockerspaniel, Chesapeake Bay Retriever und Shetland Schäferhund auftritt. Bei Briards in Großbritannien ist eine besondere Häufung von RPED-Fällen festgestellt worden (Bedford 1984; Lightfoot et al. 1996; Narfstrom und Ekesten 1999). In einer Fünfjahresstudie (Bedford 1984) waren ca. $70 \%$ aller 
untersuchten Briards im Alter von über 18 Monaten klinisch betroffen. Offensichtliche Sehstörungen sind üblicherweise nicht vor Erreichen eines mäßig fortgeschrittenen Stadiums zu bemerken. Ophthalmoskopisch ist bereits vor dem Auftreten von Sehstörungen eine Akkumulation ungleichmäßig verteilter, hellbrauner Pigmentflecken feststellbar, die zu Beginn der Erkrankung auf den zentralen Fundus konzentriert sind. Im Krankheitsverlauf kommt es zur Vergrößerung der einzelnen Flecke und zu einer Ausbreitung über die gesamte Retina. Des Weiteren treten in der neuralen Retina atrophische Veränderungen auf. In den meisten Fällen kommt es im fortgeschrittenen Stadium zur Bildung von Katarakten. Unterschiede zwischen betroffenen Hunden aus verschiedenen Rassen bestehen unter anderem hinsichtlich des zugrunde liegenden Erbgangs sowie der Geschwindigkeit des Krankheitsverlaufs (Bedford 1984; Lightfoot et al. 1996; Narfstrom und Ekesten 1999). Bisher konnte in keiner der genannten Rassen der ursächliche Gendefekt für RPED ermittelt werden.

Bei Briards tritt neben der RPED eine weitere als Kongenitale Stationäre Nachtblindheit (Congenital Stationary Night Blindness, CSNB) oder Hereditäre Retinadystrophie bezeichnete Erkrankung des Retinapigmentepithels auf, deren Erscheinungsbild deutlich von den typischen RPED-Fällen abweicht. Betroffene Briards sind offensichtlich von Geburt an nachtblind. Im Verlauf eines 1,5 jährigen Beobachtungszeitraumes sind keine Veränderungen dieses Zustands feststellbar (Narfstrom et al. 1989). Weiterführende Untersuchungen zeigen einen langsam fortschreitenden degenerativen Prozess, der zum partiellen oder vollständigen Verlust des Sehvermögens bei Tageslicht führen kann (Wrigstad et al. 1992; Wrigstad et al. 1994). Vor diesem Hintergrund ist die Bezeichnung als „Stationäre Nachtblindheit“ etwas irreführend. Im Folgenden wird trotzdem die Bezeichnung CSNB verwendet, da die zweite mögliche Bezeichnung als „Hereditäre Retinadystrophie“ sehr allgemein ist und die Erkrankung nicht ausreichend deutlich von anderen Defekten des Retinapigmentepithels abgrenzt. Die CSNB konnte auf einen Defekt im RPE65-Gen zurückgeführt werden, der offenbar sowohl in der schwedischen als auch in der USamerikanischen Briard-Population für CNSB verantwortlich ist. Aus dieser Beobachtung schließen die Autoren auf eine relativ starke Verbreitung des Defektallels (Aguirre et al. 1998). 
Eine weitere hereditäre Erkrankung des Retinapigmentepithels ist die multifokale Retinopathie bei Pyrenäenberghunden (Grahn et al. 1998), die durch multifokale seröse Ablösungen der Netzhaut und des Pigmentepithels gekennzeichnet ist und autosomal rezessiv vererbt wird. Einzelheiten $\mathrm{zu}$ klinischen, ophthalmoskopischen, elektroretinographischen und histopathologischen Befunden sind bei Pyrenäenberghunden beschrieben. Weitere betroffene Rassen sind English Mastiff, Bullmastiff, Dogue de Bordeaux und Coton de Tulear. Zur Häufigkeit der Erkrankung in den einzelnen Rassen werden keine Angaben gemacht. Auch wenn diese Erkrankung bei betroffenen Hunden zu keiner offensichtlichen Beeinträchtigung des Sehvermögens führten, können betroffene Hunde von der Zucht disqualifiziert werden. Ähnlichkeiten des Krankheitsbildes mit der humanen Vitelliformen Maculadystrophie (VMD) oder Morbus Best führten zur Identifizierung und Evaluierung des caninen VMD2-Gens als Kandidatengen und zur Entdeckung zweier Mutationen, die mit der caninen multifokalen Retinopathie assoziiert sind (Guziewicz et al. 2007).

\subsection{Kongenitale Stationäre Nachtblindheit / Hereditäre Retinadystrophie bei Briards}

\begin{tabular}{ll}
\hline Chromosom: & CFA6 \\
Gen: & RPE65 \\
NCBI: & GeneID: 403803 \\
DNA-Sequenz: & NW_876321, Position 59209258-59232992 \\
Mutationen: & Del447-450, Briard \\
\hline
\end{tabular}

\section{Krankheitsbild}

Mittels Ophthalmoskopie und Biomikroskopie lassen sich bei zehn Monate alten betroffenen Hunden keine Auffälligkeiten feststellen (Narfstrom et al. 1989). In histopathologischen Untersuchungen zeigen bereits fünf Wochen alte betroffene Briards Desorientierungen der membranösen Scheiben in den äußeren Segmenten der Stäbchenzellen (Wrigstad et al. 1994). Ab einem Alter von dreieinhalb bis vier Monaten sind in den basalen Bereichen der Retinapigmentepithelzellen große elektronentransparente Einschlüsse sichtbar, die vorrangig Pigmentepithelzellen in der zentralen Retina und im Bereich des Tapetum lucidum betreffen. Das Erscheinungsbild dieser Einschlüsse ist vergleichbar mit Lipideinschlüssen. Um welches Material es sich tatsächliche handelt, ist nicht aufgeklärt. In der zentralen Retina zeigen die äußeren Segmente bei 60-80 \% der Stäbchenzellen keine Auffälligkeiten. Nur in einigen Bereichen treten Gruppen von Stäbchenzellen mit desorganisierten und desorientierten 
äußeren Segmenten auf. Die inneren Segmente erscheinen normal. Die Zapfenzellen sind ohne Befund. In der Tapetum lucidum Zone sind 40-50\% der äußeren Stäbchenzellsegmente desorientiert und desorganisiert. Einzelne äußere Segmente der Zapfenzellen weisen Deformationen auf. Die Tapetumschicht ist nicht verändert. Die peripheren Bereiche sind deutlich weniger betroffen und weisen nur leichte Veränderungen auf (Wrigstad et al. 1992; Wrigstad et al. 1994). Ab einem Alter von sieben Monaten kommt es vor allem im peripheren Bereich der Retina zu Degenerationen der Stäbchenzellen. Ein sieben Jahre alter betroffener Briard weist in der zentralen Retina und in der Tapetum lucidum Zone eine reduzierte Anzahl von Photorezeptorzellen auf. Im peripheren Bereich liegt eine fast vollständige Photorezeptorzelldegeneration vor. Offenbar besteht keine anatomische Korrelation zwischen den Veränderungen der Photorezeptor- und Pigmentepithelzellen (Wrigstad et al. 1994).

Im Elektroretinogramm (ERG) zeigen sich deutliche Abweichungen von normalen Altersgenossen, die im Einklang zu den histopathologischen Befunden stehen. Im dunkeladaptierten ERG ist lediglich bei Erreichen der vollen Lichtintensität eine kaum messbare Amplitude hervorzubringen, die auf eine reduzierte Reaktion der Zapfenzellen und das vollständige Fehlen einer Stäbchenzellreaktion zurückgeführt wird. Auch die durch Blitzlichtstimuli ausgelösten Amplituden fallen deutlich niedriger aus als bei normalen Hunden (Narfstrom et al. 1989; Nilsson et al. 1992). Außerdem erscheint spät eine langsame negative Amplitude, die bei schlechten Lichtverhältnissen relativ klein, bei hellem Licht sehr deutlich zu Tage tritt. Diese Beobachtung wird als Folge eines Verlustes der positiven Komponente der c-Amplitude gedeutet. Die bei Hunden generell sehr niedrige c-Amplitude wird allgemein als die Summe eines langsamen negativen Potentials der Müllerzellen und eines positiven Potentials mit Ursprung im Retinapigmentepithel gedeutet. Die späte langsame negative Amplitude im Elektroretinogramm betroffener Briards lässt sich in einen ursächlichen Zusammenhang mit den histologischen Veränderungen der Retina stellen (Nilsson et al. 1992; Wrigstad et al. 1992).

\section{Genetischer Hintergrund}

Erstmals beschrieben wurde die Erkrankung bei Briards in Schweden und in den USA. Pedigreeanalysen deuten auf einen autosomal rezessiven Erbgang hin und identifizieren 
gemeinsame Vorfahren der betroffenen schwedischen und US amerikanischen Briards (Narfstrom et al. 1989). Verschiedene bekannte Gene, die für photorezeptorspezifische Proteine codieren, konnten im Zuge einer systematischen Kanidatengenuntersuchung anhand von SSCP-Analysen (Single Strand Conformation Polymorphisms) oder cDNASequenzanalysen als CSNB-Kandidatengene ausgeschlossen werden (Veske et al. 1997a; Veske et al. 1997b; Veske et al. 1998).

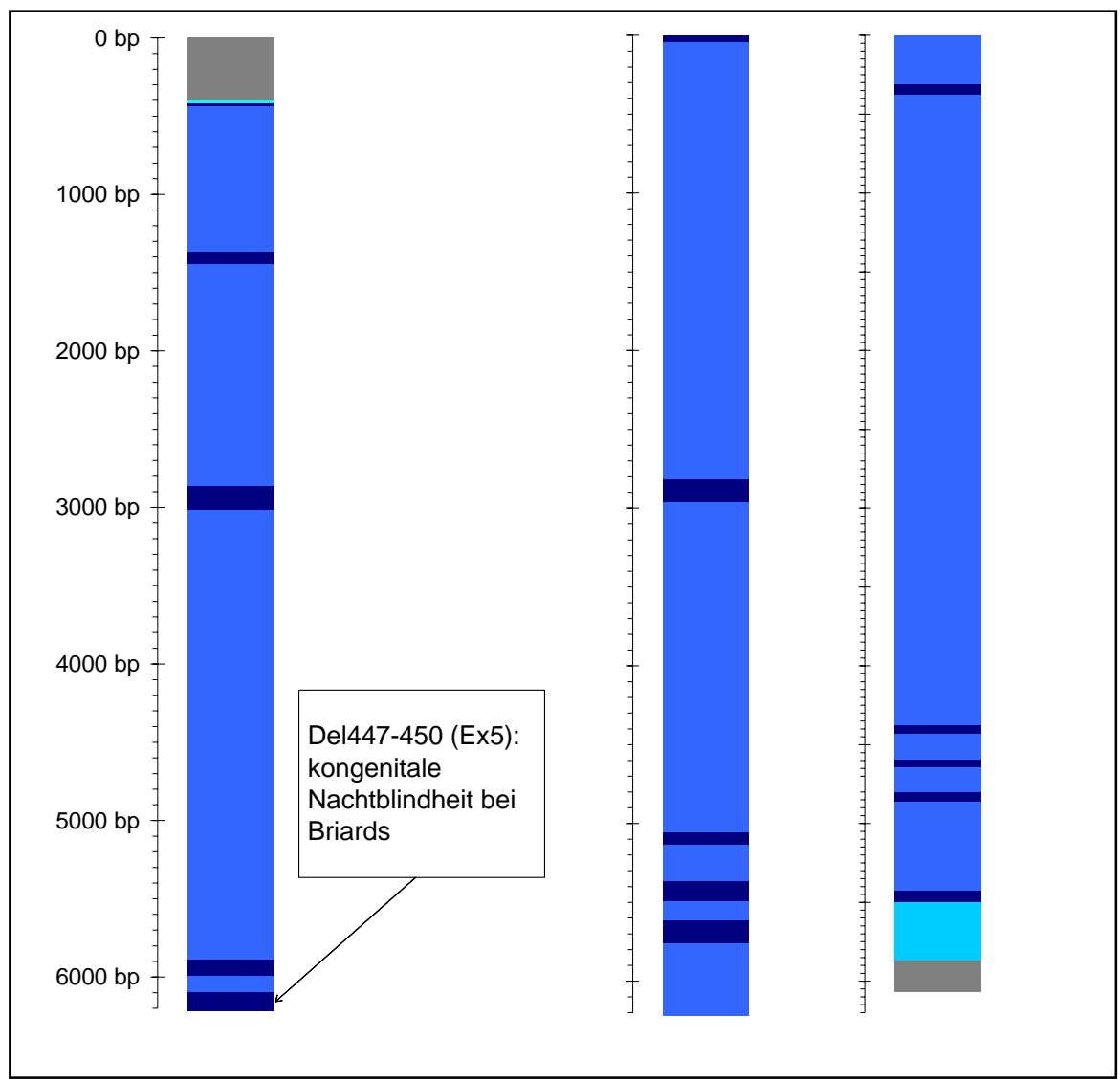

Abb. 102 Schematische Darstellung des caninen RPE65-Gens und Lage der bisher identifizierten Mutationen. Dunkelblau: codierende Sequenz, hellblau: Intronsequenz, türkis: 5'- und 3'-UTR, grau: intergenische Sequenz.

Im Rahmen der Untersuchungen von Veske et al. (1999) und in einer unabhängigen weiteren Studie (Aguirre et al. 1998) konnte bei betroffenen Briards eine Mutation im RPE65-Gen nachgewiesen werden. RPE65 codiert für ein mikrosomales Protein, das ausschließlich im Retinapigmentepithel exprimiert wird (Bavik et al. 1993; Hamel et al. 1993; Nicoletti et al. 1995). Das canine RPE65-Gen ist im genomischen GenBank Contig NW_876321 auf Chromosom 6 lokalisiert. Die codierende Sequenz umfasst 1602 bp. Das resultierende Protein ist 533 Aminosäuren lang und weist eine Homologie von 97,9 \% zum bovinen (Bavik et al. 1993; Hamel et al. 1993) und 98,5 \% zum humanen (Nicoletti et al. 1995) RPE65-Protein auf. Die Exon/Intron Grenzen stimmen 
mit dem humanen RPE65-Gen überein (Dekomien und Epplen 2003). Demnach enthält das canine RPE65-Gen 14 Exons. Abb. 102 zeigt die Lage der Exons innerhalb der genomischen Sequenz.

\section{Ursächliche Mutation für kongenitale Nachtblindheit bei Briards}

Bei der nachgewiesenen Mutation im RPE65-Gen handelt es sich um eine 4-bpDeletion in Exon 5. Die Folge ist eine Leserasterverschiebung, die Codierung von 52 abweichenden Aminosäuren und die Entstehung eines verfrühten Stoppcodons. Das resultierende Polypeptid ist auf 205 Aminosäuren verkürzt (Abb. 103).

Einzelheiten zur Funktion von RPE65 sind noch nicht bekannt. RPE65-knockout-Mäuse weisen in den Stäbchenzellen dunkeladaptierter Retinas kein Rhodopsin auf und akkumulieren all-trans-Retinylester im Pigmentepithel. Daraus lässt sich auf eine wesentliche Rolle von RPE65 im Umwandlungsprozess von all-trans-Retinol zu 11-cisRetinol schließen (Redmond et al. 1998). Dafür sprechen auch biochemische Experimente, in denen eine Assoziation von RPE65 mit Plasmaretionol bindendem Protein und mit 11-cis Retinol Dehydrogenase gefunden wurde (Bavik et al. 1993; Simon et al. 1995). Wie Untersuchungen des Vitamin A (Retinol) Stoffwechsels in Froschretinas zeigen, ist das bedeutendste Speicherdepot für Vitamin A in der Retina in Öltröpfchen lokalisiert (Bridges 1976). Vor diesem Hintergrund und im Zusammenhang mit der bei RPE65-knockout-Mäusen beobachteten Akkumulation von all-transRetinylestern sowie dem Auftreten von lipidartigen Einschlüssen in der Retina betroffener Briards wird als Folge der Deletion ein ähnlicher pathogener Mechanismus wie bei RPE65-knockout-Mäusen in Betracht gezogen (Aguirre et al. 1998).

Die Deletion segregiert bei acht untersuchten Proben aus einem US-amerikanischen Briard Pedigree zu 100\% mit CSNB. Bei vier Briardwurfgeschwistern mit progressiver Retinaatrophie (PRA) konnte die Deletion nicht nachgewiesen werden (Aguirre et al. 1998). Auch in einem schwedischen Briard Pedigree waren alle betroffenen Hunde homozygot und alle gesunden obligaten Defektträger heterozygot für die 4 bp Deletion. Bei keinem von 38 untersuchten Kontrollhunden konnte die beschriebene Mutation nachgewiesen werden (Veske et al. 1999). Des Weiteren konnte das homozygote Vorliegen der Mutation bei Briards mit CSNB in Genotypisierungsstudien der 
Briardpopulation Großbritanniens (Gould 2001; Thomas et al. 2001) und Polens (Switonski et al. 2002) nachgewiesen werden.

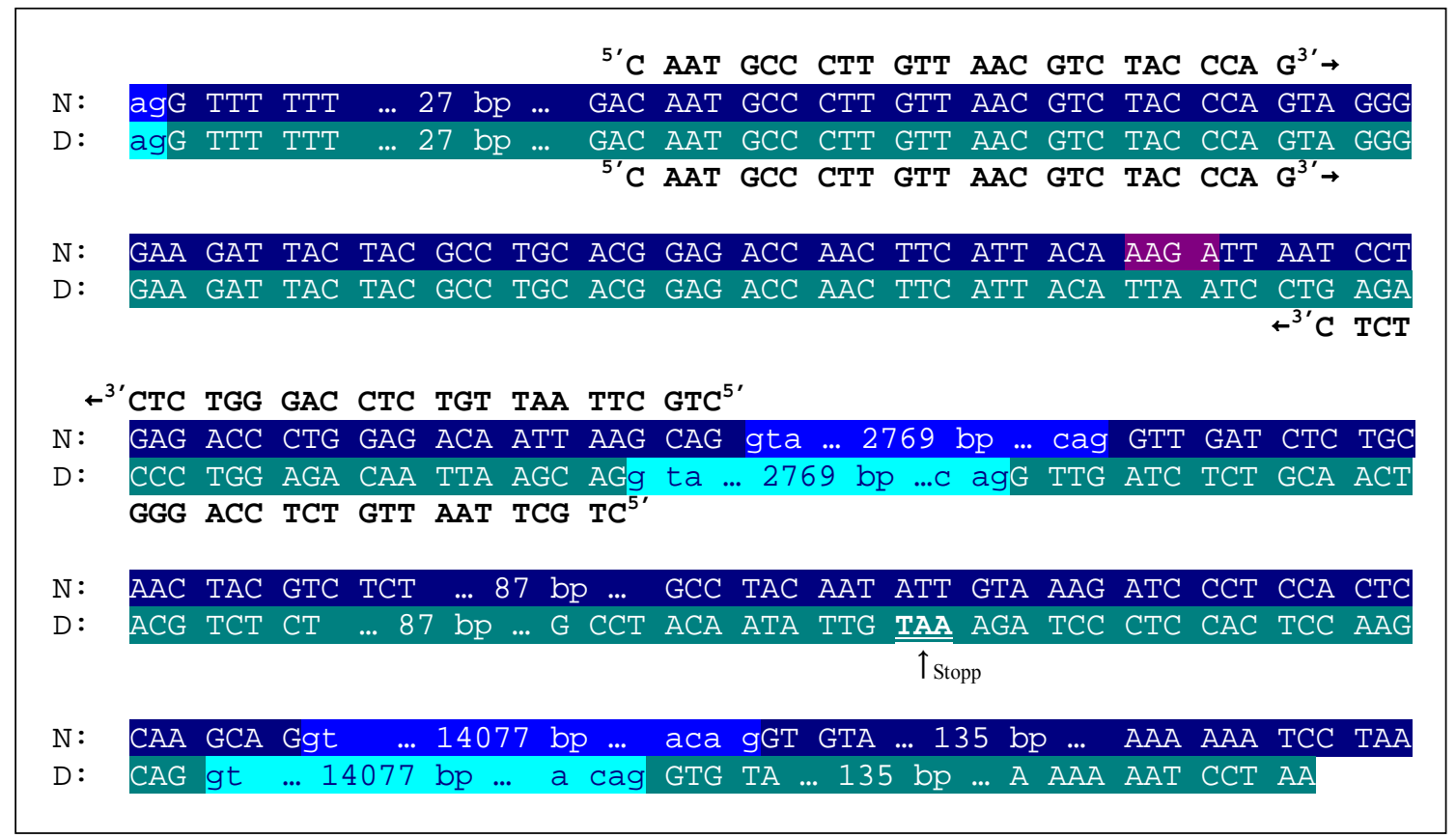

Abb. 103

Exon 5 und 6, sowie Exon 14 des caninen RPE65-Gens. N: normale Sequenz, D: defekte Sequenz, dunkelblau: Exon normale Sequenz, dunkelgrün: Exon defekte Sequenz, hellblau: Intron normale Sequenz, hellgrün: Intron defekte Sequenz, 4 bp Deletion in normaler Sequenz violett unterlegt, verfrühtes Stoppcodon in defekter Sequenz durch Pfeil gekennzeichnet.

\section{Genotypisierung für kongenitale Nachtblindheit bei Briards}

Der Nachweis der Mutation kann beispielsweise per Amplifikation eines 109 bzw. bei Vorliegen der Mutation 105 bp langen Fragments aus Exon 5 und anschließende Sequenzierung erfolgen (Aguirre et al. 1998). Die Methode für die Identifizierung von homozygoten und heterozygoten Defektträgern ist patentiert (US-Patent 6428958).

\subsection{Multifokale Retinopathie}

\begin{tabular}{ll}
\hline Chromosom: & CFA18 \\
Gen: & VMD2 \\
Ensembl: & GeneID: ENSCAFG00000015909 \\
DNA-Sequenz: & CFA18, 57499607-57508030 \\
Mutationen: & C73T, Englischer Mastiff, Bullmastiff, \\
& Prenäenberghund \\
& G482A, Coton de Tulear \\
\hline
\end{tabular}

\section{Krankheitsbild}

Auch bei der multifokalen Retinopathie treten wie bei der RPED und bei der CSNB der Briards Flecken im Augenhintergrund auf. Gelegentlich ist eine Katarakt, ein Kolobom oder ein Conus peripapillaris (direkt an die Papilla optica angrenzende ringförmige 
Aufhellung der Netzhaut) zu beobachten. Ophthalmoskopische Untersuchungen zeigen bei betroffenen Hunden zwischen drei bis sechs Monaten mehrere graubraune runde bis ovale Verdunklungen im Augenhintergrund, die Erhebungen der Netzhaut darstellen. Histopathologische Untersuchungen zeigen, dass es sich um seröse Retinaablösungen handelt. Innerhalb eines halben Jahres nehmen die Läsionen eine dunklere, braun-pinke Färbung an. Diese Erscheinungen lassen sich mittels Fluoreszenzangiographie als fokale Hypertrophie und verstärkte Pigmentierung des Retinapigmentepithels identifizieren. Im weiteren Verlauf lassen sich über einen Zeitraum von drei Jahren keinerlei Veränderungen dieses Zustandes feststellen. Elektroretinographische Untersuchungen zeigen keinerlei Unterschiede zwischen betroffenen und gesunden Welpen oder ausgewachsenen Hunden. Anhand des Verhaltens lassen sich keinerlei Rückschlüsse auf das Vorliegen visueller Störungen ziehen. Neben serösen Netzhautund Pigmentepithelablösungen, Hypertrophie, Hyperplasie sowie verstärkter Pigmentierung zeigen histopathologische Untersuchungen fokale Vakuolisierungen des Pigmentepithels sowie fokale Degenerationen der äußeren Segmente der Photorezeptoren. Pedigreeanalysen deuten auf das Vorliegen einer autosomal rezessiven Erbkrankheit hin (Grahn et al. 1998). In einer Folgeuntersuchung lässt sich bereits vor dem Auftreten ophthalmoskopisch detektierbarer Läsionen bei betroffenen Welpen im Alter von sieben Wochen mittels Floureszenzangiographie eine fokale Blockierung der Fluoreszenz feststellen. Diese Beobachtung wird als erstes Anzeichen für die Entwicklung einer Retinopathie gedeutet. Zudem ist in histopathologischen Untersuchungen eine regional unterschiedliche Verteilung verschiedener Läsionstypen zu detektieren. Während im Bereich der Papilla optica relativ großflächige seröse Retinaablösungen vorliegen, sind im peripheren Bereich kleinere Läsionen zu sehen, bei denen es sich überwiegend um Pigmentepithelablösungen und nur zu einem geringen Anteil um kleinflächigere Retinaablösungen handelt (Grahn und Cullen 2001).

Erbliche Defekte mit übereinstimmendem Erscheinungsbild treten in den Rassen English Mastiff, Bullmastiff und Coton de Tulear auf (Guziewicz et al. 2007).

\section{Genetischer Hintergrund}

Ähnlichkeiten der beschriebenen caninen Erkrankung mit einer humanen Form der vitelliformen Maculadystrophie (VMD) oder Morbus Best, die durch eine Mutation im VMD2-Gen verursacht wird, veranlassen eine Evaluierung des caninen VMD2-Gens als 
Kandidatengen für die Multifokale Retinopathie. Das canine VMD2-Gen ist auf Chromosom 18 zwischen Position 57498216 und 57511980 lokalisiert und enthält elf Exons. Das offene Leseraster hat eine Länge von 1740 Nukleotiden. In diesem Punkt stimmen die Ergebnisse von Guziewicz, Zangerl et al. (2007) mit den in der EnsemblDatenbank veröffentlichten Daten überein (Ensembl GeneID: ENSCAFG00000015909). Allerdings deckt diese Version nur den Bereich von Position 57499607 bis 57508030 ab. Exon 1 und Exon 11 liegen außerhalb dieses Bereiches. Die genaue Position dieser Exons ist nicht bekannt, in Abb. 104 sind daher nur die Bereiche gezeigt, innerhalb derer Exon 1 und Exon 11 lokalisiert sind. Exon1 beinhaltet offenbar die 5'-UTR, Exon 11 beinhaltet codierende Sequenz.

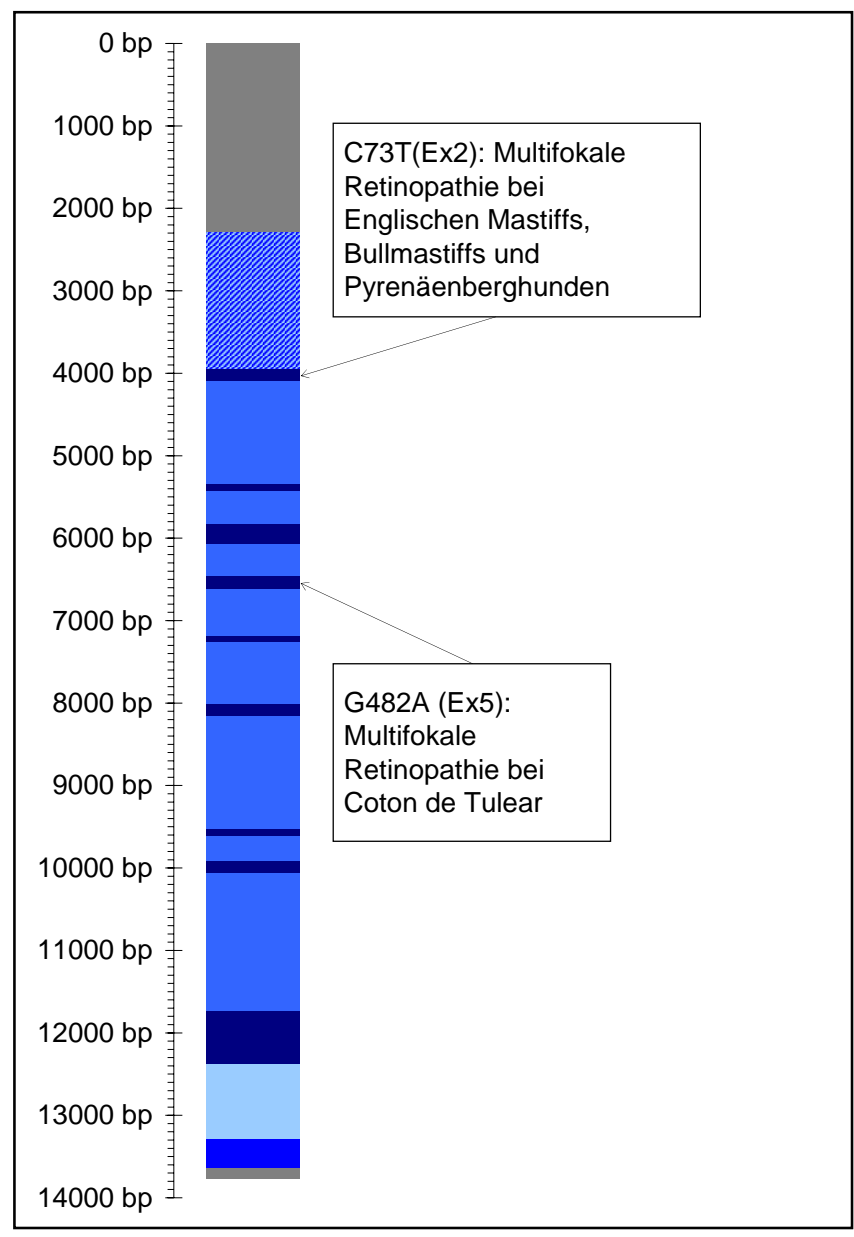

Abb. 104 Schematische Darstellung des caninenVMD2-Gens und Lage der bisher identifizierten Mutationen. Dunkelblau: codierende Sequenz, hellblau: Intronsequenz, mittelblau: ungefähre Lage von Exon 11, lichtblau: ungefähre Lage von Intron10, lichtblau-mittelblau schraffiert: ungefähre Lage von Exon 1 und Intron 1, grau: intergenische Sequenz.

Das resultierende Protein Bestrophin umfasst 580 Aminosäuren und hat ein geschätztes Molekulargewicht von $66 \mathrm{kDa}$ (Guziewicz et al. 2007). Immunozytochemische Untersuchungen unter Verwendung des humanen monoklonalen Antikörpers E6-6 
(Marmorstein et al. 2000) zeigen in der normalen caninen Retina eine spezifische Lokalisierung von Bestrophin in den basolateralen Plasmamembranen der Retinapigmentepithelzellen (Guziewicz et al. 2007). Einzelheiten zur Funktion von Bestrophin sind nicht geklärt. Laut neueren Erkenntnissen ist Bestrophin entweder an der Bildung von calciumabhängigen Chloridkanälen beteiligt oder spielt eine wesentliche Rolle für die Regulation von Calciumkanälen. Als Folge einer Störung oder eines Verlusts dieser Funktion in den Membranen der Retinapigmentepithelzellen wird eine Akkumulation von Ionen im Interzellularraum zwischen Zellen des Retinapigmentepithels und der neuralen Retina erwartet (Kunzelmann et al. 2007). Ein durch diese Akkumulation bedingtes osmotisches Gefälle würde einen Flüssigkeitszustrom in den Interzellularraum nach sich ziehen und dadurch eine Erweiterung des Interzellularraums bedingen. Diese Überlegungen zur Pathogenese der multifokalen Retinopathie stehen mit dem histopathologisch erwiesenen Vorliegen seröser Ablösungen des Retinapigmentepithels im Einklang (Guziewicz et al. 2007).

\section{III.a Ursächliche Mutation der Multifokalen Retinopathie bei Pyrenäenberghunden, English Mastiffs und Bullmastiffs}

Sequenzanalysen der Exons und der Exon/Intron Grenzen ergeben das Vorliegen einer Substitution von Cytosin durch Thymin an Position 73 des offenen Leserasters im Exon 2 des VMD2-Gens mit der Folge einer Substitution der Aminosäure Arginin an Position 25 durch ein verfrühtes Stoppcodon (Abb. 105). Genotypisierungsergebnisse zeigen, dass diese Mutation im caninen VMD2-Gen sowohl in der Rasse Pyrenäenberghund als auch in den verwandten Rassen Englischer Mastiff und Bullmastiff mit der multifokalen Retinopathie segregiert. Es wird als höchstwahrscheinlich angesehen, dass die Verkürzung des offenen Leserasters auf 25 von 580 Codons zu einem Abbau der mutierten mRNA führt und somit eine Translation nicht stattfinden kann (Guziewicz et al. 2007).

\section{IV.a Genotypisierung für Multifokale Retinopathie bei Pyrenäenberghunden, Englischen Mastiffs und Bullmastiffs}

Der Nachweis der Mutation kann mittels RFLP-Analyse eines 212-bp-Fragments beginnend in Exon 2 und endend in Intron 2 erfolgen. Der RFLP beruht auf einer Erkennungssequenz für $H p h I$ die aufgrund der Substitution im Defektallel entsteht und im Wildtypallel nicht enthalten ist (Guziewicz et al. 2007). 


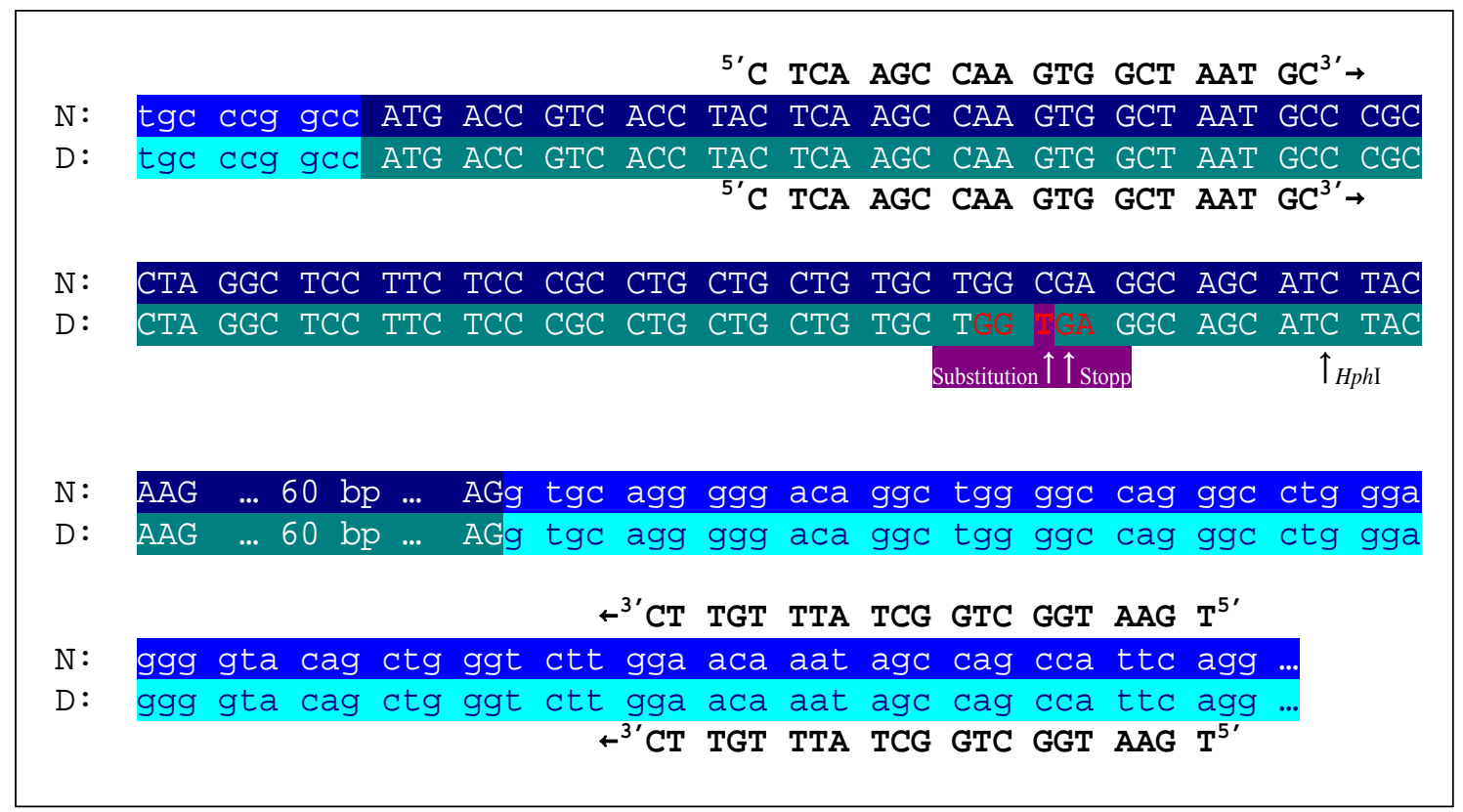

Abb. 105

Exon 2 des caninen VMD2-Gens und angrenzende Intronsequenzen. N: normale Sequenz, D: defekte Sequenz, dunkelblau: Exon normale Sequenz, dunkelgrün: Exon defekte Sequenz, hellblau: Intron normale Sequenz, hellgrün: Intron defekte Sequenz, Substitution in defekter Sequenz fett gedruckt, violett unterlegt und durch Pfeil gekennzeichnet, verfrühtes Stoppcodon durch Pfeil gekennzeichnet, rote Schrift: HphI-Erkennungssequenz, HphI-Restriktionsschnittstelle durch Pfeil gekennzeichnet.

\section{III.b Ursächliche Mutation der Multifokalen Retinopathie bei Coton de Tulear}

Bei betroffenen Coton de Tulear konnte im VMD2-Gen eine Substitution von Guanin durch Adenin an Position 482 des offenen Leserasters in Exon 5 nachgewiesen werden (Abb. 106), die bei allen sieben untersuchten betroffenen Hunden homozygot vorlag. Die Folge ist eine Aminosäurensubstitution von Glycin durch Asparaginsäure an Position 121. Glycin ist an dieser Position evolutionär hochkonserviert. Der Effekt einer Substitution der hydrophoben, unpolaren Aminosäure Glycin gegen die negativ geladene Asparaginsäure auf die Proteineigenschaften wird als ausreichend bedeutsam eingeschätzt, um eine Erkrankung hervorzurufen, die phänotypisch nicht von der multifokalen Retinopathie der Pyrenäenberghunde zu unterscheiden ist (Guziewicz et al. 2007).

\section{IV.b Genotypisierung für Multifokale Retinopathie bei Coton de Tulear}

Der Nachweis der Mutation kann per ASP erfolgen (Abb. 106)(Guziewicz et al. 2007). 


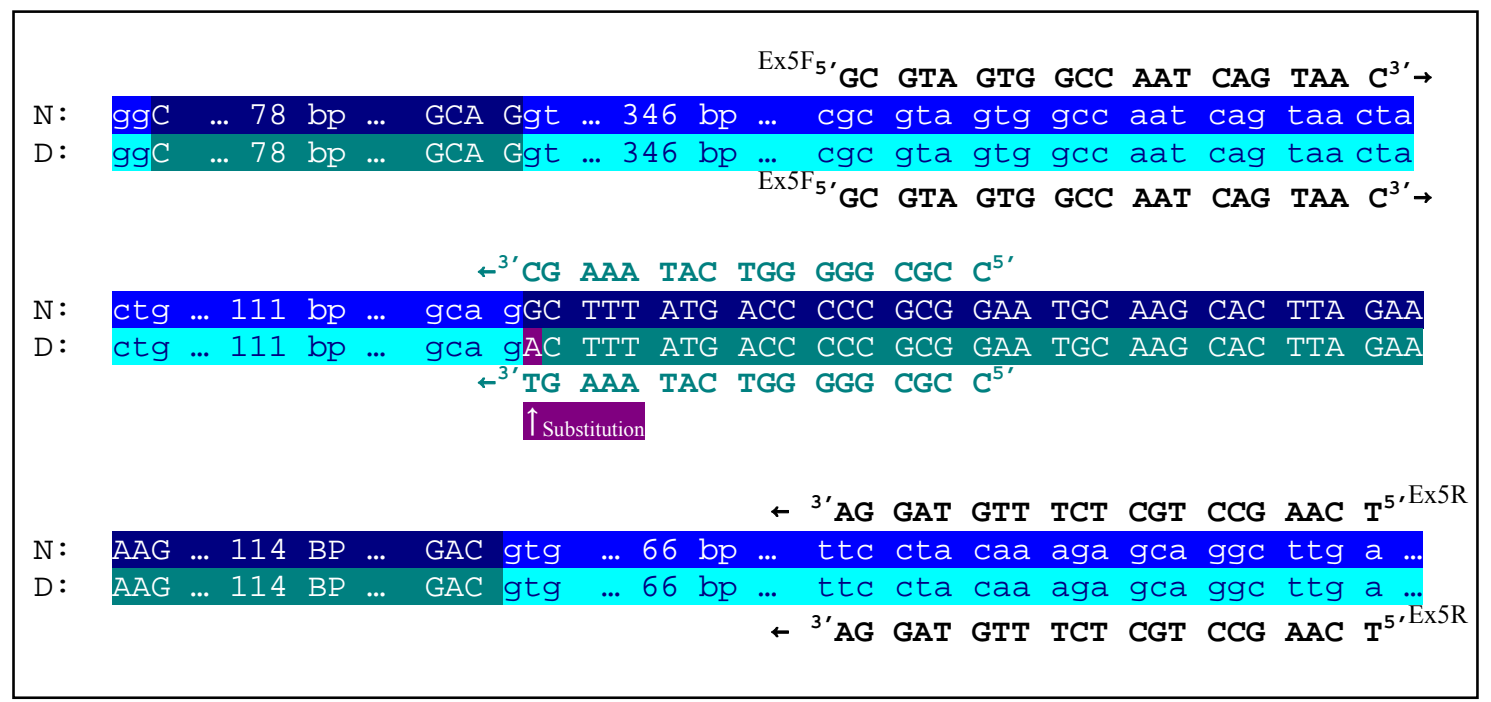

Abb. 106 Exon 4, Intron 4 und Exon 5 des caninen VMD2-Gens und angrenzende Intronsequenzen. N: normale Sequenz, D: defekte Sequenz, dunkelblau: Exon normale Sequenz, dunkelgrün: Exon defekte Sequenz, hellblau: Intron normale Sequenz, hellgrün: Intron defekte Sequenz, Substitution in defekter Sequenz fett gedruckt, violett unterlegt und durch Pfeil gekennzeichnet, blaugrüne Schrift: Allelspezifische Primer.

\subsubsection{Aderhautdefekt: Collie Eye Anomalie (CEA)}

\begin{tabular}{|c|c|}
\hline $\begin{array}{l}\text { Chromosom: } \\
\text { Potentielles Gen: } \\
\text { DNA-Sequenz: } \\
\text { Mutationen: }\end{array}$ & $\begin{array}{l}\text { CFA37 } \\
\text { FLJ2610 } \\
\text { CFA37, Position 28694530-28676390 } \\
\text { CFA37Del28677428-28685226, Langhaarcollie, } \\
\text { Kurzhaarcollie, Border Collie, Australischer } \\
\text { Schäferhund, Lancashire Heeler, Shetland } \\
\text { Schäferhund, Nova Scotia Duck Tolling Retriever } \\
\text { und Langhaarwhippet }\end{array}$ \\
\hline
\end{tabular}

\section{Krankheitsbild}

Die Collie Eye Anomalie ist durch eine regionale Hypoplasie der Aderhaut gekennzeichnet, die in unterschiedlich schwerwiegender Form zu Tage tritt. Typisches klinisches Anzeichen ist eine ophthalmoskopisch erkennbare, temporal der Papilla optica gelegene blasse Region im Augenhintergrund. Bei leicht bis mittelschwer betroffenen Hunden treten zusätzlich keine weiteren Schädigungen auf, und die Sehfähigkeit bleibt für die gesamte Lebensdauer erhalten. Stärker betroffene Hunde weisen kolobomartige Läsionen der Lederhaut in Form von Vertiefungen im Bereich der Papilla optica oder des angrenzenden Fundus auf. Gelegentlich sind übermäßig gewundene Retinagefäße und die Bildung mehrerer Falten in der Retina zu beobachten. Bei schwerwiegenden Fällen kommt es zu Netzhautablösungen, Neovaskularisierung und Blutungen und als Folge dieser Erscheinungen zur Erblindung (Roberts 1960; Roberts und Dellaporta 1965; Roberts et al. 1966). 
Histopathologische Untersuchungen zeigen im Pigmentepithel im Bereich der blassen Region ein Fehlen oder einen Rückgang der Pigmentierung. Die aufliegende Retina weist in diesen Bereichen keinerlei Auffälligkeiten auf. Dafür zeigt sich in der Aderhaut eine deutliche Unterentwicklung des Kapillarnetzes. Es wird von einer angeborenen Unterentwicklung ausgegangen. Auch die kolobomartigen Läsionen in der Lederhaut entpuppen sich als Folgen einer unvollständigen embryonalen Entwicklung. Die Faltenbildung scheint nach histologischen Befunden durch eine unvollständige Schließung der optischen Fissur während der Embryonalentwicklung verursacht zu sein, die zu einer zystischen Erweiterung führt. Die Retinaablösungen sind zumeist am Rand der kolobomartigen Schädigungen der Lederhaut lokalisiert. Erste ophthalmoskopisch erkennbare Anzeichen sind bereits bei drei Wochen alten Welpen nachzuweisen.

\section{Genetischer Hintergrund}

Pedigreeanalysen sprechen für das Vorliegen eines autosomal rezessiven Erbganges. Bei Collies wurde die Prävalenz Ende der 60er Jahre auf $75 \%$ der gesamten reingezüchteten Population geschätzt (Donovan et al. 1969; Roberts 1969). Verschiedene Studien aus den 80er und 90er Jahren zur Häufigkeit der Erkrankung in einigen europäischen Ländern ergaben die folgenden absoluten Häufigkeiten betroffener Hunde: Großbritannien: 64 von 2000 untersuchten Collies, Schweden: 55 von 2136 untersuchten Collies, Italien: 51 von 361 untersuchten Hunden, für Holland: 41 von 160 untersuchten Hunden, Norwegen: 41 von 741 untersuchten Hunden, Deutschland 37 von 248 untersuchten Hunden, Schweiz: 31 von 77, Finnland: 31 von 3577 und Österreich: 20 von 152 (zusammengefasst bei Wallin-Hakanson et al. 2000).

Neben Langhaarcollies und Kurzhaarcollies sind die Rassen Border Collie, Australischer Schäferhund, Lancashire Heeler und Shetland Schäferhund, Nova Scotia Duck Tolling Retriever und Langhaarwhippet sowie weitere Rassen betroffen. Kreuzungsexperimente mit betroffenen Kurzhaarcollies, Langhaarcollies, Border Collies und Australischen Schäferhunden sprechen für das Vorliegen einer allelischen Mutation in den genannten Rassen (Lowe et al. 2003). Bei Australischen Schäferhunden betrug die Inzidenz Ende der 70er Jahre in den Niederlanden 48 \% (Barnett und Stades 1979). 
Eine Analyse des gesamten Genoms von 104 Hunden aus insgesamt 15 CEAinformativen Pedigrees per Typisierung für Marker aus dem Minimal Screening Set I (Richman et al. 2001) ergab eine hohe Kopplung der Erkrankung mit dem Marker FH2532 auf Chromosom 37 (Lowe et al. 2003). In weiterführenden Untersuchungen gelang es, die potentielle Lage der ursächlichen Mutation für CEA auf eine 3,9 cM umfassende Region auf Chromosom 37 einzugrenzen und die Homologie dieser Region zu einem Abschnitt auf dem langen Arm des humanen Chromosoms 2q35 festzustellen (Lowe et al. 2003).

\section{Ursächliche Mutation für CEA bei Langhaarcollies, Kurzhaarcollies, Border Collies, Australischen Schäferhunden, Lancashire Heelers, Shetland Schäferhunden, Nova Scotia Duck Tolling Retrievern und Langhaarwhippets}

Aufbauend auf diese Erkenntnisse konnte in einer nicht veröffentlichten Untersuchung das homozygote Vorliegen einer 7,8-kb-Deletion auf Chromosom 37 nachgewiesen werden. Im UCSC Whole Genome Shotgun Assembly v.1.0 (Juli 2004) ist die Deletion zwischen Position 28677428 und 28685226 lokalisiert. Für die Identifizierung homozygoter und heterozygoter Träger des Defekts steht ein Test auf der Basis von genomischer DNA zu Verfügung. Die Genotypisierungsmethode ist unter der Nummer 20060115843 beim US-Amerikanischen Patentamt zum Patent angemeldet (US-PatentApplication 2006).

Die identifizierte Deletion befindet sich in Intron 4 eines als FLJ2610 bezeichneten potentiellen Gen, das auf Chromosom 37 zwischen Position 28694530-28676390 auf dem revers komplementären Strang lokalisiert ist. Da weder eine vollständige Charakterisierung des FLJ12610-Gens veröffentlicht ist, noch Hinweise auf eine mögliche Funktion vorliegen, kann auf dieser Ebene kein Zusammenhang zwischen der Deletion und den pathologischen Erscheinungen der Collie Eye Anomalie hergestellt werden. Der ursächliche Zusammenhang zwischen der Deletion und der CEA wird anhand einer Genotypisierung von insgesamt 20 Hunden mit per Testanpaarung ermittelten Genotypen belegt. Das Ergebnis des DNA-Tests stimmt in allen untersuchten Fällen mit den per Testanpaarung ermittelten Genotypen überein (USPatent-Application 2006). Laut Fa. Optigen ist die beschriebene Mutation in den Rassen Langhaarcollie, Kurzhaarcollie, Border Collie, Australischer Schäferhund, Lancashire 
Heeler, Shetland Schäferhund, Nova Scotia Duck Tolling Retriever und Langhaarwhippet mit CEA assoziiert.

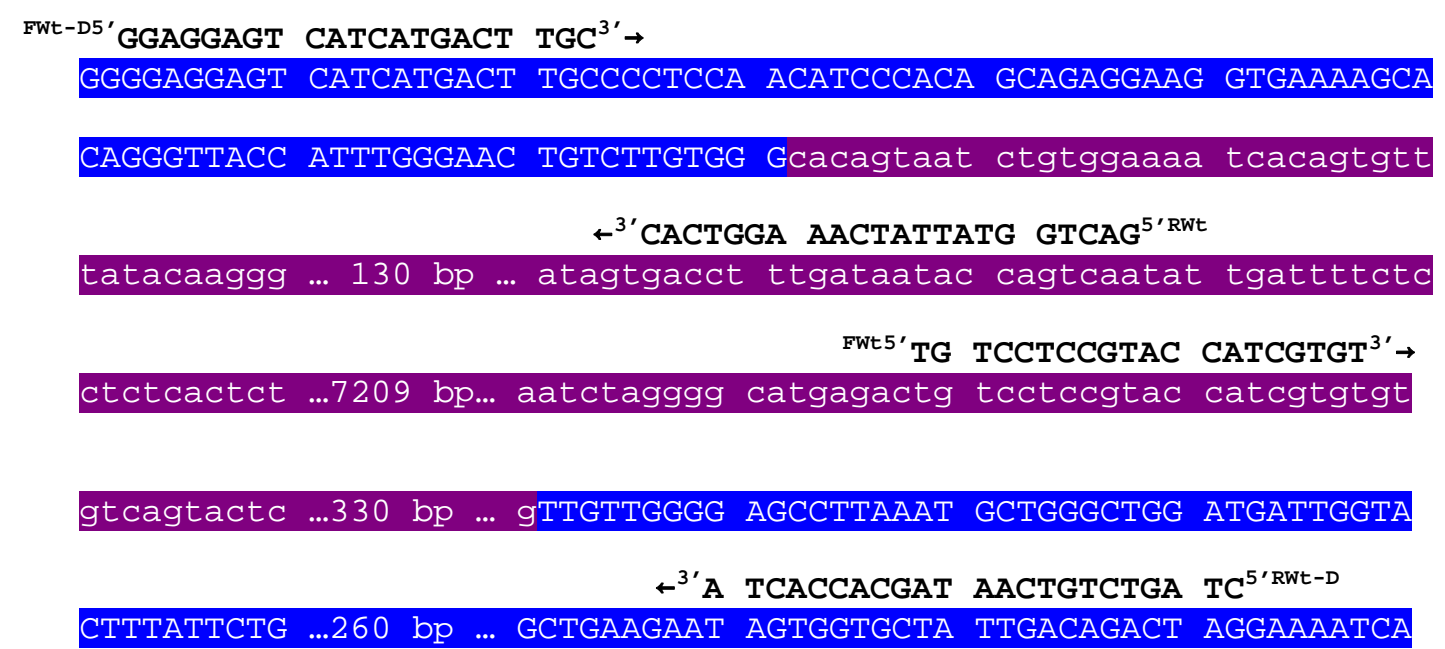

Abb. 107 Sequenzabschnitt des caninen FLJ12610-Gens (UCSC-WGS-Assembly v.1.0, Juli 2004: Chr.37 28685294 - 28677118). Blau unterlegt: übereinstimmende Sequenzabschnitte zwischen normalen und betroffenen Hunden, violett unterlegt: Deletion.

IV. Genotypisierung für CEA bei Langhaarcollies, Kurzhaarcollies, Border Collies, Australischen Schäferhunden, Lancashire Heelers, Shetland Schäferhunden, Nova Scotia Duck Tolling Retrievern und Langhaarwhippets

Der Nachweis der Deletion kann in den Rassen Langhaarcollie, Kurzhaarcollie, Border Collie, Australischer Schäferhund, Lancashire Heeler, Shetland Schäferhund, Nova Scotia Duck Tolling Retriever und Langhaarwhippet per ASP erfolgen (Abb. 107) (USPatent-Application 2006).

\subsubsection{Linsendefekt: Die Katarakt}

$\begin{array}{ll}\text { Chromosom: } & \text { CFA5 } \\ \text { Gen: } & \text { HSF4 } \\ \text { NCBI: } & \text { GeneID: 489766 } \\ \text { DNA-Sequenz: } & \text { NW_876316, Position 15747613-15742268 } \\ \text { Mutationen: } & \text { 982InsC, Staffordshire Bullterrier, Boston Terrier } \\ & \text { Del982, Australischer Schäferhund }\end{array}$

\section{Krankheitsbild}

Die Katarakt zählt zu den häufigsten caninen Augenerkrankungen und ist eine der wichtigsten Ursachen für Blindheit. Die Erkrankung ist in über 97 verschiedenen Rassen beschrieben worden. Es handelt sich um eine Eintrübung der Linse, die unterschiedliche Ursachen haben kann (Mellersh et al. 2006b). 
Man unterscheidet zwischen primärer und sekundärer Katarakt. Während sekundäre Formen Folgeerscheinungen anderer Augenerkrankungen sind, tritt die primäre Katarakt unabhängig von anderen Erkrankungen auf. Es sind sowohl erbliche als auch nichterbliche Formen bekannt (Barnett 1976; Barnett 1978).

Erbliche Formen der primären Katarakt zeichnen sich durch ein rassenspezifisches Erscheinungsbild hinsichtlich der ophthalmologischen Befunde, des Alters beim Auftreten klinischer Erscheinungen, der Verlaufsgeschwindigkeit und des Grades bilateraler Symmetrie aus. Es sind sowohl unilaterale als auch bilaterale Formen beschrieben worden. In einigen Fällen ist die Linse lediglich partiell betroffen, in anderen kommt es zu einer vollständigen Eintrübung. Der Verlauf variiert zwischen stationär, fortschreitend und, sofern es zu einer Resorption kommt, vorübergehend (Barnett 1976; Barnett 1978). Die ursächlichen genetischen Defekte sind bisher nur in den Rassen Staffordshire Bullterrier, Boston Terrier und Australischer Schäferhund bekannt.

Die Katarakt bei Boston Terriern ist durch eine stets symmetrisch bilaterale Ausprägung gekennzeichnet (Barnett 1976). Der Verlauf ist fortschreitend. Per direkter Ophthalmoskopie ist die Linseneintrübung bereits im Alter von acht Wochen zu erkennen. In diesem Stadium erscheinen die Umrisse der Faserzellen des Linsenepithels als feine schwarze Linien. Die Durchsichtigkeit im Bereich des Linsenkerns ist leicht beeinträchtigt, die Peripherie ist klar. Im weiteren Verlauf kommt es ausgehend von den Begrenzungslinien der Faserzellen zur Ausbreitung eingetrübter Bereiche. Bis zu diesem Zeitpunkt ist bei betroffenen Hunden keine offensichtliche Beeinträchtigung des Sehvermögens zu bemerken. Ab einem Alter von sechs Monaten ist der größte Teil der Linse eingetrübt, wobei der Grad der Eintrübung regional schwankt. Unter Einsatz einer Spaltlampe ist eindeutig zu erkennen, dass es sich um eine subkapsulare Eintrübung handelt. Der Grad der Eintrübung nimmt stetig zu. Im Alter von neun bis 15 Monaten treten erste offensichtliche Sehstörungen auf und die Katarakt ist mit bloßem Auge erkennbar. Im Alter von zwei bis vier Jahren ist die Linse vollständig und dicht eingetrübt und die betroffenen Hunde sind blind (Barnett 1978). Die Katarakt bei Staffordshire Bullterriern hinsichtlich des Verlaufs und der ophthalmologischen Befunde mit der beschriebenen Katarakt bei Boston Terriern überein (Barnett 1976; 
Barnett 1978). Über die Krankheitserscheinungen der Katarakt bei Australischen Schäferhunden liegen keine Veröffentlichungen vor.

\section{Genetischer Hintergrund}

Bei Boston Terriern und bei Staffordshire Bullterriern liegt der Katarakt ein autosomal rezessiver Erbgang zugrunde (Barnett 1976; Barnett 1978).

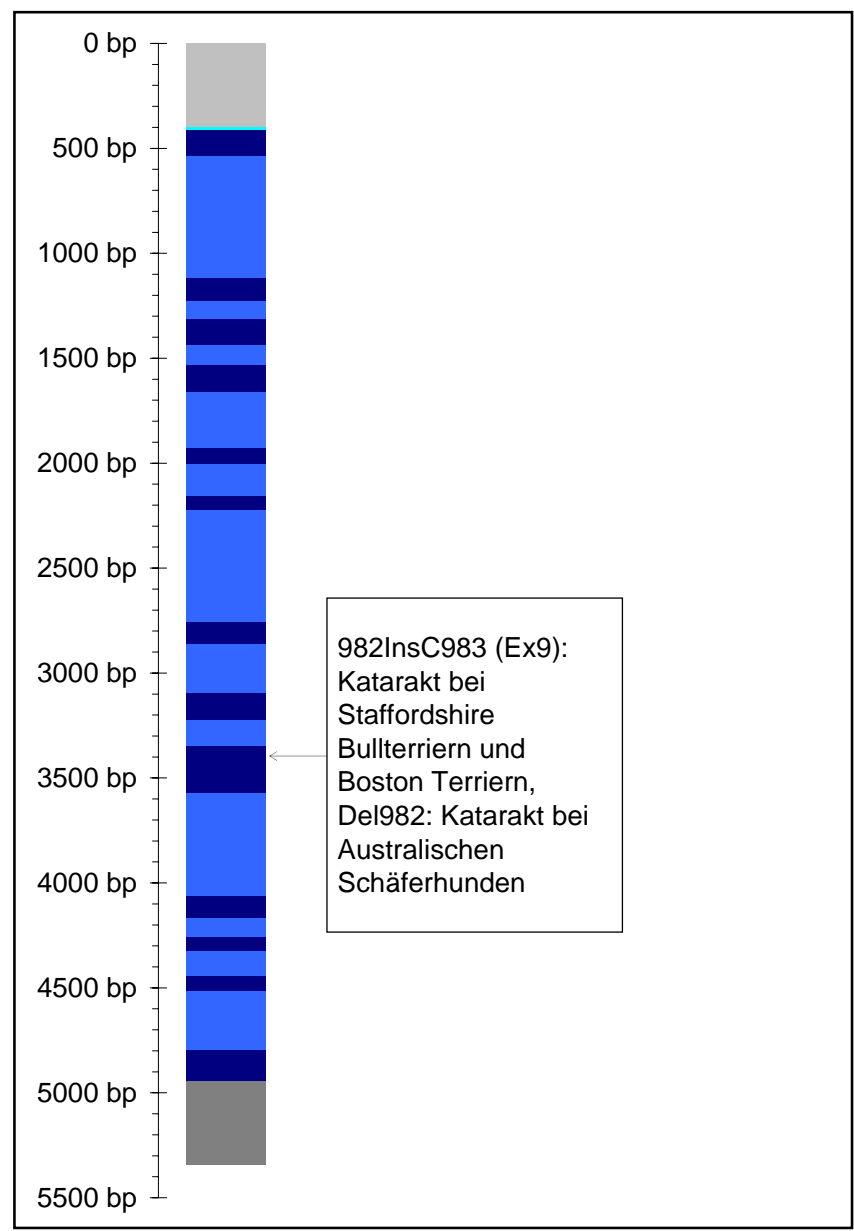

Abb. 108 Schematische Darstellung des caninen HSF4-Gens und Lage der bisher identifizierten Mutationen. Dunkelblau: codierende Sequenz, hellblau: Intronsequenz, türkis: 5'-UTR, grau: intergenische Sequenz

Der Erbgang der Katarakt bei Australischen Schäferhunden blieb lange Zeit unklar. Nach der Entdeckung der ursächlichen Mutation wurden mehrere betroffene Hunde genotypisiert. Die Ergebnisse lassen auf einen autosomal dominanten Erbgang schließen (Mellersh et al. 2006b).

Die Analyse von Markern aus den angrenzenden genomischen Regionen von 20 funktionellen Kandidatengenen ergab in einer betroffenen Staffordshire Bullterrier Familie deutliche Hinweise auf eine Beteiligung des HSF4-Gens an der Entwicklung 
der Katarakt (Mellersh et al. 2006b). Das canine HSF4-Gen (NCBI-GeneID: 489766) ist auf Chromosom 5 im genomischen Contig NW_876316 zwischen Position 15747613 und 15742268 lokalisiert. Die codierende Sequenz befindet sich auf dem revers komplementären Strang.

In der caninen Linse sind drei verschiedene Transkripte des HSF4-Gens mit Längen von 1479 Basen (a), 1377 Basen (b) und 1251 Basen (c) nachweisbar. Transkript b entsteht durch die Aktivität einer alternativen Spleißstelle in Exon 9. Dadurch bleiben nur 123 Basen des 3'Endes von Exon 9 in der mRNA erhalten. Transkript $\mathrm{c}$ entsteht durch das vollständige Überspringen von Exon 9 während des Spleißvorgangs. Abb. 108 zeigt die Lage der insgesamt 13 Exons innerhalb der genomischen Sequenz. Exon 9 ist vollständig dargestellt.

\section{Ursächliche Mutation für Katarakt bei Staffordshire Bullterriern, Boston Terriern und Australischen Schäferhunden}

Bei Staffordshire Bullterriern und bei Boston Terriern mit Katarakt liegt in Exon 9 des HSF4-Gens nach Position 982 der mRNA homozygot eine Insertion eines Cytosins vor. Die Folge ist eine Verschiebung des Leserasters, die zur Codierung 27 abweichender Aminosäuren und eines verfrühten Stoppsignals führt (Abb. 109) (Mellersh et al. 2006b).

Bei Australischen Schäferhunden mit Katarakt liegt in Exon 9 die Deletion eines Cytosins an Position 982 der cDNA vor. Die dadurch verursachte Leserasterverschiebung führt zur Codierung 86 abweichender Aminosäuren und eines verfrühten Stoppsignals (Abb. 109) (Mellersh et al. 2006b). 


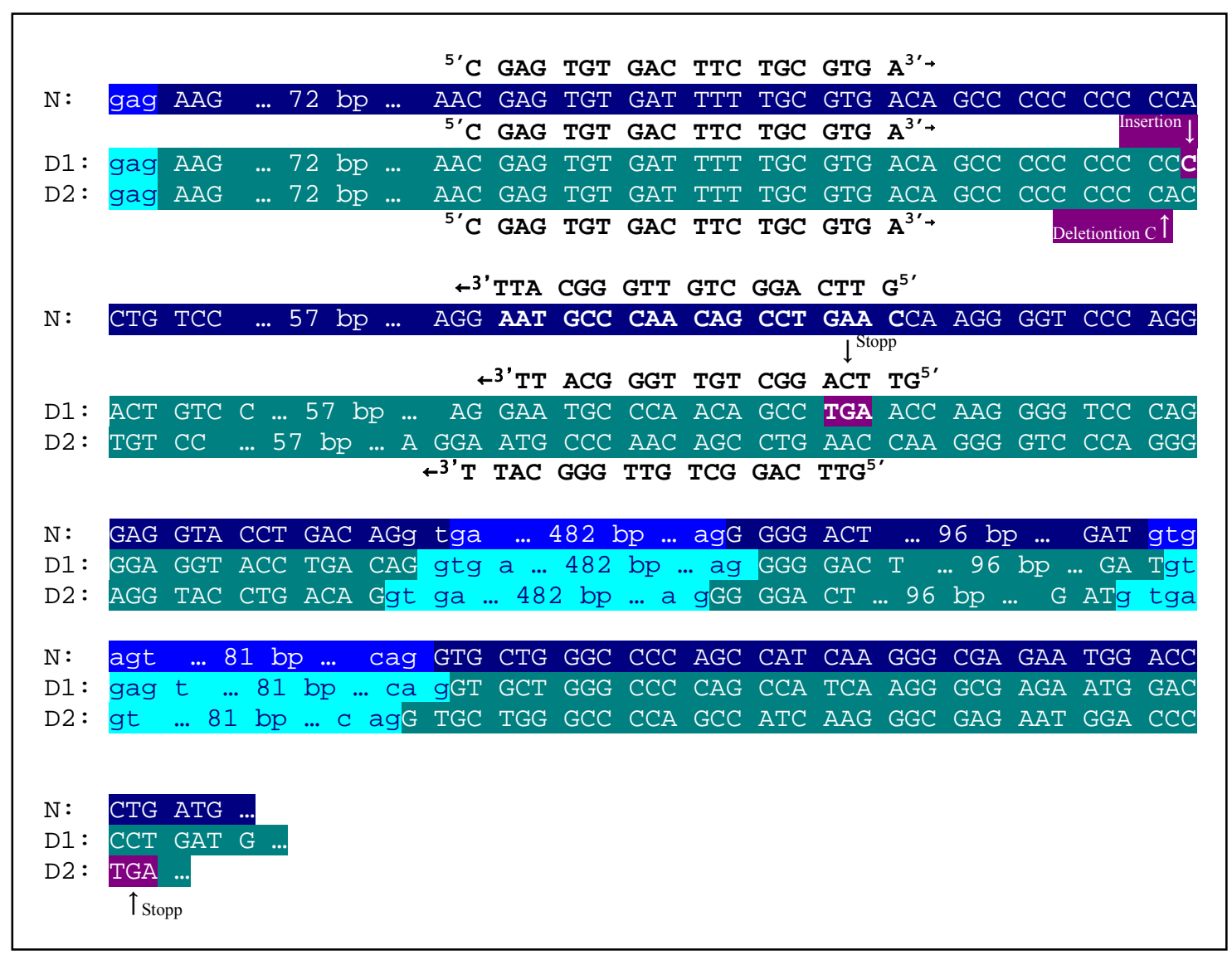

Abb. 109 Exon 9 - 11 des caninen HSF-Gens und angrenzende Intronsequenzen. N: normale Sequenz, D1: defekte Sequenz bei Staffordshire Bullterriern und Boston Terriern, D2: defekte Sequenz bei Australischen Schäferhunden, dunkelblau: Exon normale Sequenz, dunkelgrün: Exon defekte Sequenz, hellblau: Intron normale Sequenz, hellgrün: Intron defekte Sequenz, Insertion bzw. Deletion violett markiert und durch Pfeil gekennzeichnet, verfrühte Stoppcodons violett unterlegt und durch Pfeil gekennzeichnet.

Alle untersuchten betroffenen Staffordshire Bullterrier und Boston Terrier waren homozygot für die beschriebene Mutation. Es wird jedoch darauf hingewiesen, dass zur Absicherung des Zusammenhangs zwischen der Insertion und der Katarakt bei Boston Terriern in Anbetracht der relativ geringen Anzahl typisierter Hunde (zwei betroffene und drei heterozygote Boston Terrier) weitere Studien nötig sind. Zudem sind bei Boston Terriern neben der juvenilen Katarakt auch später einsetzende Formen der Katarakt beobachtet worden. Daher ist außerdem zu klären, ob alle auftretenden Formen der Katarakt mit der Insertion in Exon 9 des HSF4-Gens assoziiert sind.

Sechs von sieben untersuchten betroffenen Australischen Schäferhunden waren heterozygot für die beschriebene Mutation, einer wies einen homozygot mutierten Genotyp auf. Diese Beobachtung lässt auf einen dominanten Effekt der Mutation bei Australischen Schäferhunden schließen (Mellersh et al. 2006b). 
Die Mutationen im HSF4-Gen sind sowohl bei Boston Terriern und Staffordshire Bullterriern als auch bei Australischen Schäferhunden an Position 982 der cDNA lokalisiert. Trotzdem ist der Effekt der Mutation bei Staffordshire Bullterriern und Boston Terriern im Gegensatz zu Australischen Schäferhunden rezessiv. Als mögliche Erklärung wird ein stärkerer Effekt der Mutation bei Australischen Schäferhunden aufgrund der größeren Abweichung des mutierten Proteins vom normalen Protein in Betracht gezogen. Bei betroffenen Australischen Schäferhunden werden 86 abweichende Aminosäuren codiert, während bei Staffordshire Bullterriern und Boston Terriern lediglich 27 abweichende Aminosäuren codiert werden (Mellersh et al. 2006b).

Das HSF4-Gen codiert für den Hitzeschockfaktor 4, ein Protein aus der Familie der Hitzeschocktranskriptionsfaktoren, und ist somit an der Regulation der Expression von Hitzeschockproteinen beteiligt. Die Expression der Hitzeschockproteine erfolgt in Reaktion auf verschiedene Stressfaktoren wie Oxidantien, Schwermetalle, hohe Temperaturen sowie bakterielle und virale Infektionen (Nakai et al. 1997).

Beim Menschen sind zahlreiche Mutationen im HSF4-Gen mit kongenitaler Katarakt assoziiert (Bu et al. 2002; Forshew et al. 2005). Auch bei $\mathrm{HSF}^{0 / 0}{ }^{-M a ̈ u s e n ~ t r i t t ~ e i n e ~}$ kongenitale Katarakt auf. Wesentliche Merkmale dieser murinen Katarakt sind abnorme Faserzellen mit einschlussartigen Strukturen, die möglicherweise mit einer verringerten Expression von $\gamma$-Crystallin zusammenhängen, vermehrte Zellteilung im Linsenepithel und verfrühte Differenzierung der Linsenepithelzellen in Verbindung mit erhöhter Expression von Wachstumsfaktoren. Diese Beobachtungen sprechen für eine kritische Funktion des HSF4-Proteins in der Linsenentwicklung durch Beeinflussung der Expression von $\gamma$-Crystallinen und Wachstumsfaktoren (Fujimoto et al. 2004).

Im Gegensatz zu humanen und murinen HSF4-assoziierten Katarakt-Formen kommt es bei den beschriebenen caninen HSF-4-assoziierten Katarakt-Formen erst nach der Geburt zur Entwicklung der Linseneintrübung. Da alle beschriebenen Mutationen in Exon 9 lokalisiert sind, werden nur zwei der drei in der caninen Linse exprimierten HSF4-Transkripte (a und b) betroffen. Transkript $\mathrm{c}$ bleibt durch die Mutation unverändert. Möglicherweise spielen die von Transkript a und b translatierten Formen erst nach Ablauf der Embryonalentwicklung eine wesentliche Rolle, so dass der Effekt der Mutationen erst nach der Geburt zu Tage tritt (Mellersh et al. 2006b). 
Bei Golden Retrievern und Amerikanischen Cocker Spaniels mit Katarakt konnte keine der beschriebenen Mutationen nachgewiesen werden.

\section{Genotypisierung für Katarakt bei Boston Terriern, Staffordshire Bullterriern und Australischen Schäferhunden}

Der Nachweis der beschriebenen Mutationen kann per diagnostischer Sequenzierung erfolgen (Abb. 109) (Mellersh et al. 2006b). 


\subsubsection{Hereditäre Nierenfunktionsstörungen}

\subsubsection{Cystinurie}

\begin{tabular}{|ll|}
\hline Chromosom: & CFA10 \\
Gen: & SLC3A1 \\
Ensembl: & GeneID: ENSCAFG00000002538 \\
DNA-Sequenz: & CFA10, Position 49826797-49862068 \\
Mutationen: & C663T, Neufundländer \\
\hline
\end{tabular}

\section{Krankheitsbild}

Die canine Cystinurie ist durch das Auftreten von Cystinkristallen in der Blase meist in Verbindung mit einer erhöhten Cystinausscheidung über den Urin gekennzeichnet.

Betroffen sind mindestens 20 verschiedene Hunderassen. Unter den veröffentlichten Fällen stellen Dackel einen besonders hohen Anteil, gefolgt von Bassets, Beagles, Bulldoggen, Chihuahuas, Welsh Corgis, Zwergschnauzern, Pudeln und Mischlingshunden. Eine Bewertung des Risikos von Cystinblasensteinbildung in verschiedenen Rassen anhand epidemiologischer Daten aus einem Zeitraum von neun Jahren deutet auf ein besonders hohes Erkrankungsrisiko für Mastiffs (5 \%), Australische Cattledogs, Englische Bulldoggen (20\%), Chihuahuas Bullmastiffs, Neufundländer (5\%), Dackel (10\%), Basenjis, Australische Schäferhunde, Schottische Hirschhunde, Staffordshire Bullterrier (3\%), Zwergpinscher, Pitbullterrier, Welsh Corgis, Silky Terrier und Bichon Frises. Ein signifikant geringeres Risiko ergab sich für Deutsche Schäferhunde, Pudel, Schnauzer und Mischlingshunde (Case et al. 1992). Prozentuale Angaben zur Häufigkeit von Cystinurie sind für die Rassen Englische Bulldogge (20\%), Dackel (10\%), Mastiffs (5\%), Neufundländer (5\%), Staffordshire Bullterrier (3 \%) und Französische Bulldogge veröffentlicht (Osborne et al. 1999). Erste Hinweise auf die Erblichkeit der Erkrankung ergaben Pedigreeuntersuchungen von Brand und Mitarbeitern sowie Morris und Mitarbeitern (Brand und Cahill 1936; Green et al. 1936; Brand und Cahill 1938).

Äußerliche Anzeichen für das Vorliegen einer Cystinurie sind auf Folgeerscheinungen von Cystinblasensteinen beschränkt (Bovee 1986). Es handelt sich dabei um Harnverhaltung, Harnzwang, Hämaturie und Cystinkristallurie (Bovee 1986; Casal et al. 1995). Nach einer chirurgischen Entfernung der Blasensteine verschwinden die Symptome, allerdings kommt es oft bereits innerhalb eines Jahres erneut zur 
Cystinsteinbildung. Das Durchschnittsalter beim ersten Auftreten von Blasensteinen liegt zwischen vier und fünf Jahren. In Einzelfällen kann es bereits im Alter von eineinhalb Jahren zu Cystinsteinbildung kommen (Bovee 1986; Ling et al. 1998). Erhöhte Cystinausscheidung über den Urin tritt sowohl bei Rüden als auch bei Hündinnen auf. Bei Hündinnen kommt es allerdings nur selten zur Bildung von Cystinkristallen, so dass unter den klinisch auffälligen Hunden die Rüden deutlich überwiegen (Bovee et al. 1974; Case et al. 1992; Ling et al. 1998). In der überwiegenden Zahl der Fälle ist die Entstehung von Cystinsteinen mit erhöhter Cystinausscheidung über den Urin gekoppelt. In Ausnahmefällen kommt es jedoch bei einigen Hunden trotz einer extrem hohen Cystinausscheidung nicht zur Bildung von Cystinkristallen oder es entstehen Cystinblasensteine trotz normaler Cystinwerte im Urin (Treacher 1964).

Hinsichtlich der biochemischen Befunde bei betroffenen Hunden existieren verschiedene Varianten. Zudem kommt es zu Überlappungen zwischen Werten von normalen Kontrollhunden und Werten betroffener Hunde. Unterschiede zwischen den einzelnen Erkrankungsformen bestehen unter anderem hinsichtlich des Ausmaßes der erhöhten Cystinausscheidung über den Urin (Bovee et al. 1974). So beträgt bei einigen betroffenen Hunden die Cystinausscheidung über den Urin bezogen auf die glomeruläre Filtration zwischen ca. 10 und $60 \%$. Andere Hunde scheiden annähernd genauso viel Cystin über den Urin aus, wie bei der glomerulären Filtration in den Primärharn aufgenommen wurde. Einzelne Hunde weisen im Urin ein Vielfaches der Cystinmenge auf, die nach der glomerulären Filtrationsrate maximal zu erwarten wäre (Bovee et al. 1974). Neben der Variabilität der ausgeschiedenen Cystinmenge zeigen betroffene Hunde Unterschiede im sonstigen Aminosäurenmuster des Urins. Während bei einigen eine reine Cystinurie vorliegt (Bovee et al. 1974), zeigen andere zusätzlich eine erhöhte Exkretion weiterer Aminosäuren (Hoppe et al. 1993). Besonders hervorgehoben werden hierbei vor allem die drei zweibasischen Aminosäuren Lysin, Ornithin und Arginin sowie Glutamat, Threonin und Citrullin (Bovee et al. 1974; Hoppe et al. 1993).

Es ist unsicher, ob die Entstehung von Cystinsteinen ausschließlich auf die erhöhte Cystinausscheidung zurückzuführen ist. Dagegen sprechen die Überlappung der Urincystinwerte zwischen gesunden und betroffenen Hunden und die genannten Ausnahmefälle, bei denen unabhängig vom Urincystingehalt eine Kristallbildung 
beobachtet wurde. Trotz dieser Ausnahmefälle besteht jedoch zwischen den Mittelwerten des Urincystingehaltes bei normalen und betroffenen Hunden ein signifikanter Unterschied, aufgrund dessen zumindest bei einem Teil der betroffenen Hunde von einem ursächlichen Effekt des Urincystingehaltes auf die Erkrankung auszugehen ist (Treacher 1964).

Die erhöhte Cystinausscheidung betroffener Hunde wird dem Defekt eines oder mehrerer spezifischer Proteine zugeschrieben, die bei gesunden Hunden für den Transport von Cystin und weiteren Aminosäuren durch die Epithelzellen der Nierentubuli und des Darmtraktes zuständig sind (Rosenberg et al. 1965). Bei gesunden Hunden werden nahezu $100 \%$ des per glomerulärer Filtration in den Primärharn übertretenden Cystins reabsorbiert (Bovee et al. 1974). Bei erkrankten Hunden kommt es je nach Schweregrad des Defektes zur Verminderung oder vollständigen Blockade der Reabsorption von Cystin und gegebenenfalls weiterer Aminosäuren. Die sehr geringe Löslichkeit von Cystin im Urin führt daraufhin zur Kristallbildung mit den sich daraus ergebenden gesundheitlichen Schwierigkeiten. Ein solcher Zusammenhang erklärt allerdings nur Cystinexkretionen, die mengenmäßig unterhalb der glomerulären Filtrationsrate liegen. Urincystingehalte oberhalb der glomerulären Filtrationsrate müssen durch zusätzliche Cystinquellen verursacht werden. Eine direkte Abgabe von Cystin durch das Nierengewebe wird als unwahrscheinlich angesehen, da Cystin in der Niere vorrangig in reduzierter Form (Cystein) vorliegt und insgesamt gering konzentriert ist (Holtzapple et al. 1971). Untersuchungen an Mäusen mit experimentell induzierter Cystinurie deuten auf einen möglichen Zusammenhang extrem hoher Cystingehalte im Urin mit einer erhöhten Exkretion von Glutathion hin. Dieses aus Glutaminsäure, Cystein und Glycin zusammengesetzte Tripeptid wird intrazellular synthetisiert und im Ablauf des normalen Stoffwechsels in die Nierentubuli transportiert. Bei einer dort stattfindenden Oxidation $\mathrm{zu}$ Glutathiondisulfid und anschließendem enzymatischem Abbau wird Cystin freigesetzt. Bei Mäusen mit experimentell induzierter Cystinurie führt eine Hemmung der Glutathionsynthese zu einer signifikanten Reduzierung der Cystinexkretion. Diese Beobachtung spricht dafür, dass es sich bei einem nicht unerheblichen Teil des im Urin ausgeschiedenen Cystins um ein Produkt des Glutathionstoffwechsels handelt. Ein solcher Zusammenhang würde Urincystinwerte oberhalb der glomerulären Filtration erklären (Griffith 1981). 
Die molekulargenetische Basis der caninen Cystinurie ist bisher nur bei Neufundländern identifiziert worden. Das Krankheitsbild bei betroffenen Neufundländern ist einheitlich. Männliche Hunde zeigen im Alter zwischen sechs und 48 Monaten urethrale Störungen, die eine operative Entfernung von Cystinsteinen erforderlich machen. Die Bildung von Cystinsteinen findet sowohl in der Blase als auch in der Niere statt. Im Vergleich zu anderen Rassen kommt es bei Neufundländern zu einer extrem schnellen Neubildung von Cystinsteinen. Weibliche Hunde zeigen vorübergehende Phasen von Hämaturie und teilweise ultrasonographisch sichtbare Blasensteine ohne Erfordernis eines operativen Eingriffs. Alle betroffenen Hunde weisen erhöhte Urinwerte von Cystin, Lysin, Arginin und Ornithin auf. Normale Vergleichshunde zeigen diesbezüglich keinerlei Auffälligkeiten. Die bei betroffenen Hunden gemessenen Urincystinwerte übersteigen teilweise deutlich die per globulärer Filtration aufgenommene Menge. Es ergeben sich Reabsorptionswerte zwischen -92 und $7 \%$, so dass von einer aktiven Exkretion von Cystin auszugehen ist (Casal et al. 1995).

\section{Genetischer Hintergrund der Cystinurie}

Der Erbgang für Cystinurie kann in den meisten betroffenen Rassen nicht eindeutig bestimmt werden. Pedigreeanalysen sprechen teilweise für eine X-chromosomal gekoppelte Vererbung und teilweise für einen autosomal rezessiven Erbgang (Bovee 1986).

Bei Neufundländern wird der Erbgang für Cystinurie als eindeutig autosomal rezessiv beschrieben (Casal et al. 1995). Der ursächliche Defekt konnte im SLCA1-Gen lokalisiert werden, das für die rBAT Untereinheit eines heterodimeren Aminosäurentransporterproteins codiert, das vorrangig in den proximalen Nierentubuli und in den Schleimhautzellen des Darms exprimiert wird (Bertran et al. 1992b).

Das canine SLC3A1-Gen auf Chromosom zwischen Position 49826797 und 49862068 lokalisiert (Ensembl-GeneID: ENSCAFG00000002538). Auf einer Gesamtlänge von ca. $35 \mathrm{~kb}$ befinden sich 10 Exons (Abb. 110). Die codierende Sequenz ist 2103 Nukleotide lang und codiert für ein 700 Aminosäuren langes Polypeptid. 


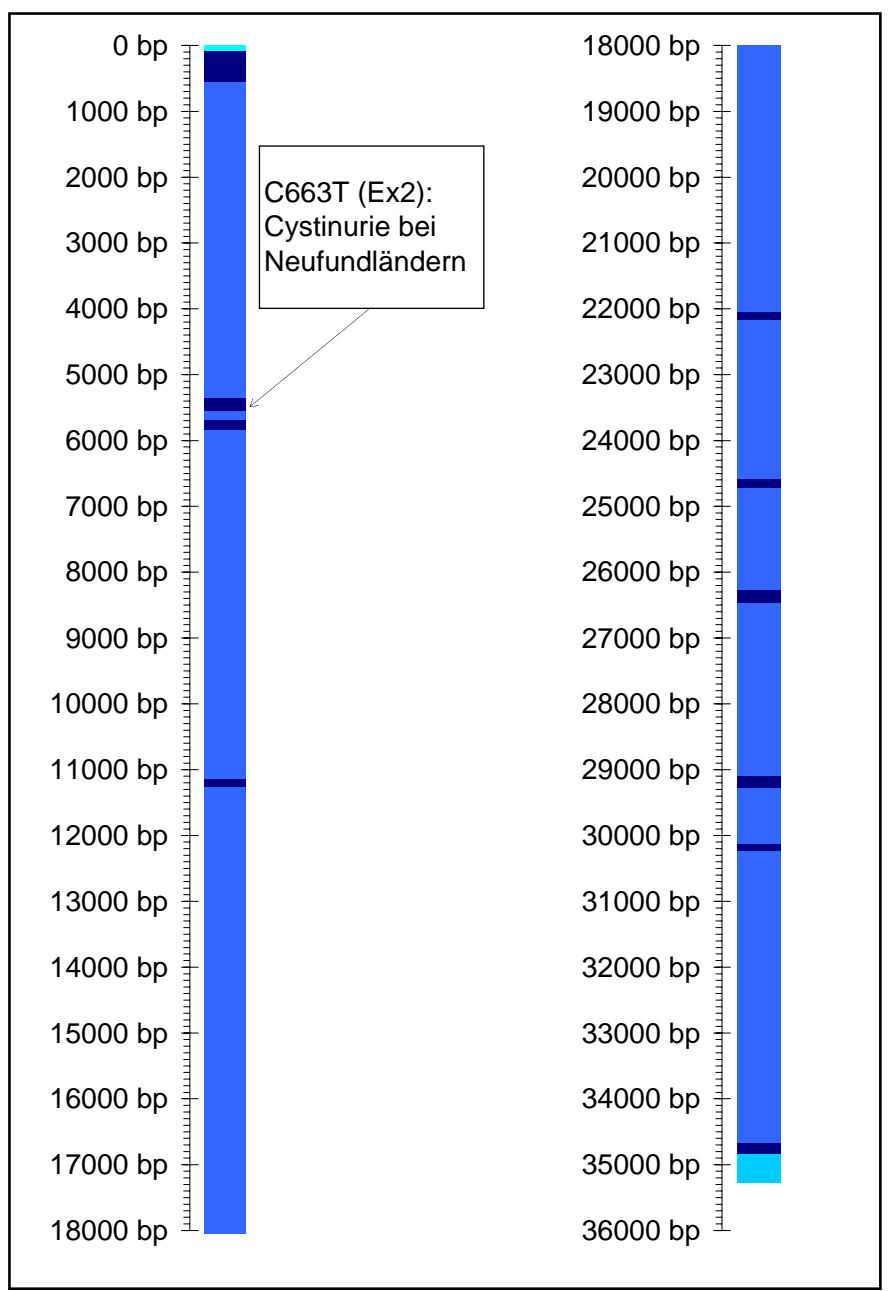

Abb. 110 Schematische Darstellung des caninen SLC3A1-Gens und Lage der bisher identifizierten Mutationen. Dunkelblau: Exon, hellblau: Intron, türkis: UTR.

Der als rBAT-b ${ }^{0,+}$-AT bezeichnete Proteinkomplex (Feliubadalo et al. 1999) transportiert in der Niere Cystin und die zweibasischen Aminosäuren Lysin, Arginin und Ornithin aus dem Lumen in die Zellen der proximalen Tubuli und ist im Darm für die Aufnahme der genannten Aminosäuren aus der Nahrung zuständig (Bertran et al. 1992b). Es handelt sich um ein Membranglykoprotein mit einer kurzen intrazellularen N-terminalen Domäne, einer einzelnen Transmembranhelix und einer großen extrazellularen Domäne (Bertran et al. 1992a; Broer und Wagner 2002).

Beim Menschen sind zahlreiche Mutationen sowohl des SLC3A1-Gens als auch des SLC7A9-Gens, das für die zweite als $b^{0,+}$-AT bezeichnete Untereinheit des Transportproteins codiert, als Ursachen verschiedener Formen der Cystinurie bekannt geworden (Calonge et al. 1994; Font et al. 2001; Harnevik et al. 2001; Bauch und Verrey 2002; Harnevik et al. 2003; Font-Llitjos et al. 2005). Bei Hunden konnte bisher außer der Neufundländer-Mutation trotz Untersuchungen in zehn weiteren Rassen 
(Englische und Französische Bulldogge, Dackel, Tibet Spaniel, Cardigan Welsh Corgi, Border Collie, Irischer Terrier, Schottischer Terrier, Schottischer Hirschhund und Labrador Retriever) kein weiterer Gendefekt mit der Cystinurie in Verbindung gebracht werden (Harnevik et al. 2006)

\section{Ursächliche Mutation für Cystinurie bei Neufundländern}

Bei dem zugrunde liegenden genetischen Defekt handelt es sich um eine Substitution von Cytosin durch Thymin in Exon 2 an Position 663 der mRNA des SLC3A1-Gens (Henthorn et al. 2000). Die Substitution führt zur Entstehung eines verfrühten Stoppcodons und $\mathrm{zu}$ einem verkürzten Polypeptid, das anstelle der üblichen 700 Aminosäuren lediglich 197 Aminosäuren lang ist (Abb. 111). Alle zwölf untersuchten betroffenen Neufundländer waren homozygot für den beschriebenen Defekt, während alle elf verfügbaren obligaten Defektträger einen heterozygoten Genotyp aufwiesen.

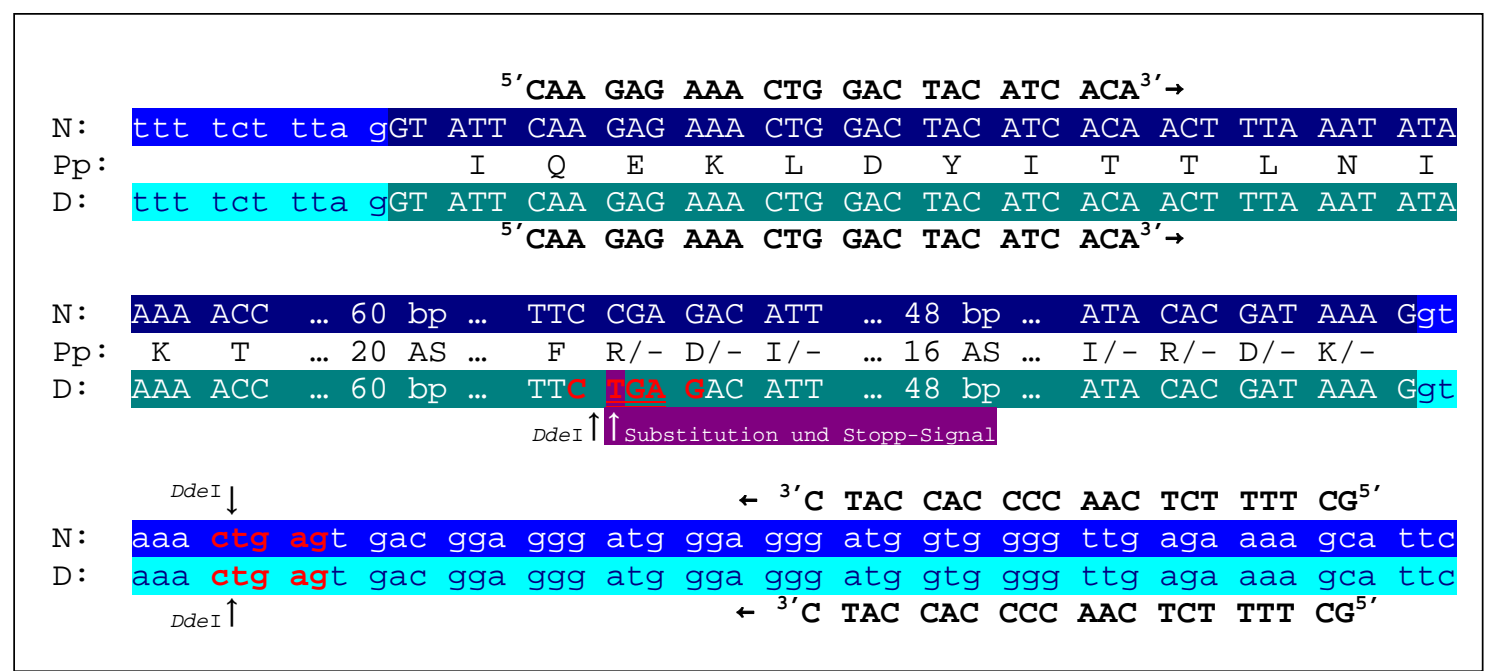

Abb. 111 Exon 2 des caninen SLC3A1 Gens und angrenzende Intronsequenzen. N: normale Sequenz, Pp: Polypeptidsequenz, D: defekte Sequenz, Substitution und in defekter Sequenz violett markiert und durch Pfeil gekennzeichnet, verfrühtes Stoppsignal doppelt unterstrichen und durch Pfeil gekennzeichnet, rote Schrift: DdeI-Erkennungssequenz, DdeI-Restriktionsschnittstellen durch Pfeil gekennzeichnet.

\section{Genotypisierung für Cystinurie bei Neufundländern}

Der Nachweis der Mutation kann beispielsweise über die Amplifikation eines 223-bpFragments aus Exon 2 und angrenzender Intronsequenz und anschließende RFLPAnalyse erfolgen. Der zugrunde liegende RFLP beruht auf einer Restriktionserkennungssequenz für DdeI im Defektallel, die aufgrund der Substitution entsteht und im Wildtypallel nicht enthalten ist (Henthorn et al. 2000). 


\subsubsection{Nierenzystadenokarzinom und nodulare Dermatofibrose des Deutschen Schäferhundes}

\begin{tabular}{|ll|}
\hline Chromosom: & CFA17 \\
Gen: & BHD \\
Ensembl: & GeneID: ENSCAFG00000018469 \\
DNA-Sequenz: & CFA17, Position 45182073-45195854 \\
Mutationen: & A764G, Deutscher Schäferhund \\
\hline
\end{tabular}

\section{Krankheitsbild}

Zystadenokarzinome sind vom Epithelgewebe der Drüsen ausgehende Karzinome mit zystischer Aufweitung der veränderten Drüsenschläuche. Bei Deutschen Schäferhunden (Henthorn et al. 2000) tritt eine offenbar erbliche Form von Zystadenokarzinomen in der Niere in Verbindung mit knotiger Dermatofibrose auf. Von allen 1174 Deutschen Schäferhunden, die zwischen den Jahren 1967 und 1983 bei Nekropsien untersucht wurden, waren $43(3,7 \%)$ von Nierenzystadenokarzinomen betroffen. Der Anteil der Deutschen Schäferhunde an allen in diesem Zeitraum diagnostizierten primären Neoplasmen in der Niere betrug 79 \% (45 von 54 insgesamt diagnostizierten Neoplasmen). Anhand von Pedigreeanalysen ließen sich 37 der 43 betroffenen Hunde auf einen gemeinsamen männlichen Vorfahren zurückführen, wobei in den meisten Fällen nur eines der Elterntiere mit diesem Rüden verwandt war (Lium und Moe 1985).

Das Alter betroffener Hunde liegt zwischen fünf und elf Jahren. Äußere Anzeichen betreffen zahlreiche sehr feste Knoten in der Haut, Erweiterungen des Abdominalbereiches und vergrößerte unregelmäßig geformte Nieren. Des Weiteren zeigen betroffene Hunde Appetitlosigkeit, Schwäche, übermäßigen Durst, Erbrechen, Verstopfung oder Diarrhöe sowie Hautentzündungen. Bei einigen Hunden treten eine wiederkehrende heftige Hämaturie und erhöhte Harnstoffwerte im Blut auf. Die Nieren betroffener Hunde weisen eine unebene Oberfläche auf und sind häufig von einer extrem dicken Bindegewebskapsel umgeben. Das Gewicht reicht vom Normalgewicht (95 g) bis zu 2950 g. Die Nieren können erheblich vergrößert sein. Neben mehreren kleinen finden sich auf der Niere bis zu fünf große Zysten von $>1 \mathrm{~cm}$ Durchmesser. Während die kleinen Zysten mit einer klaren serösen oder koagulierten Flüssigkeit gefüllt sind, enthalten die größeren Zysten dunkelbraune trübe und breiige Flüssigkeit oder Blutgerinnsel. In einigen Zysten findet sich eine graubraune schlammige Masse. Wucherungen von Tumorgewebe reichen in das Lumen der Zysten hinein. Einzelne 
neoplasmatische Wucherungen sind über das gesamte Nierenparenchym verteilt. Die Größe variiert zwischen wenigen Millimetern bis $4 \mathrm{~cm}$ Durchmesser. In einigen Fällen erreichen die neoplasmatischen Wucherungen Größen von bis zu $10 \mathrm{~cm}$ Durchmesser. Die Eigenschaften dieser Wucherungen variieren zwischen weich und bröckelig bis extrem fest. Einige Bereiche sind von Blutergüssen und Nekrose betroffen. Im fortgeschrittenen Stadium wird das Nierengewebe nahezu vollständig durch verschiedene Zysten und Tumoren ersetzt. Metastasen treten meistens in Form von kleinen festen Knoten oder Zysten auf. Am häufigsten betroffen sind die Lymphknoten von Niere und Brustbein. Zudem finden sich teilweise Wucherungen im Bauch- und Rippenfell sowie in Leber, Lunge, Milz und Knochen. Im Unterschied zu sporadischen Nierentumoren, die in der Regel einzeln und unilateral auftreten, sind die erblichen Nierentumoren bei Deutschen Schäferhunden stets bilateral und multifokal lokalisiert.

Alle betroffenen Hunde weisen feste, kugel- oder linsenförmige Knoten in der Haut und Unterhaut des gesamten Körpers auf. In den meisten Fällen sind die Knoten zwischen wenigen Millimetern und $1 \mathrm{~cm}$ groß, können jedoch auch Durchmesser von bis zu $4 \mathrm{~cm}$ erreichen. Im Durchschnitt finden sich 30-50 Knoten pro Hund, im fortgeschrittenen Stadium kann die Anzahl der Knoten jedoch auch mehrere Hundert betragen. Meist sind die Knoten von gesunder Epidermis überzogen, größere Knoten zeigen jedoch gelegentlich Geschwüre und Entzündungen. Bei betroffenen Hündinnen liegen häufig Tumoren der Gebärmutter von wenigen Millimetern bis zu $10 \mathrm{~cm}$ Durchmesser vor. Größere Tumore sind nekrotisch und zeigen Blutergüsse. Weitere Befunde sind Hämoperitoneum und Peritonitis ausgelöst durch Brüche der Nierenzysten. Als Folgeerscheinung von Hämoperitoneum und metastatischen Tumoren der Leber kann es zu leichten, gelbsuchtartigen Verfärbungen kommen.

In histopathologischen Untersuchungen zeigen sich kleine unregelmäßige Erweiterungen der Nierentubuli mit Übergängen zu Zysten, die von kubisch bis zylindrischem Epithel mit papillären Vorsprüngen ins Lumen der Zysten überzogen sind. Die meisten Zellen dieser Wucherungen ähneln stark normalen Tubulizellen, wobei einige der Zellen vergrößert sind und erweiterte Kerne enthalten (Lium und Moe 1985). Als Ursache der Zystenbildung wird eine mechanische Blockierung einzelner Bereiche durch wuchernde Epithelzellen und eine dadurch herbeigeführte Entstehung 
zystischer Erweiterungen einzelner Segmente vermutet. Der exakte Ursprung der neoplastischen Zellen ist noch nicht ermittelt worden (Lium und Moe 1985).

\section{Genetischer Hintergrund}

Mehrere unabhängige Pedigreeanalysen betroffener Deutscher Schäferhunde sowie die eingangs beschriebenen epidemiologischen Daten sprechen eindeutig dafür, dass es sich bei dieser Erkrankung um einen erblichen Defekt handelt. Der erste Schritt bei der Entdeckung des für Zystadenokarzinome der Niere und nodulare Dermatofibrose (Renal Cystadenocarcioma and Nodular Dermatofibrosis, RCND) verantwortlichen Genorts war die Lokalisierung auf Chromosom 5. Über Mikrosatellitenanalysen konnte eine enge Kopplung des RCND-Gens mit insgesamt sechs caninen Mikrosatellitenmarkern auf Chromosom 5 ermittelt werden. Nach Ergebnissen einer Multipoint-Analyse liegt die Position des RCND-Gens zwischen den Markern C02608 und C05.771 in ca. 2 cM Entfernung von Marker C02608. Zudem gelang die Identifizierung verschiedener konservierter Chromosomsegmente zwischen dem caninen und dem humanen Genom. Im Bereich des Mikrosatellitenmarkers C02608, der dem RCND-Gen laut Kartierungsergebnissen am nächsten liegen soll, bestehen hohe Homologien zu den humanen Chromosomen 17p und $1 \mathrm{p}$ (Jonasdottir et al. 2000a). Auf dieser Informationsgrundlage konnten verschiedene humane Kandidatengene, die beim Menschen im Zusammenhang mit RCND ähnlichen Krebserkrankungen stehen, aufgrund ihrer Lokalisation auf der caninen Genkarte als verantwortliche RCND-Gene ausgeschlossen werden. Es handelt sich um die Gene TP53, TSC1, TSC2, KRT9, WT1, FH, NF1 und PKD1 (Priat et al. 1998; Werner et al. 1999; Jonasdottir et al. 2000a; Jonasdottir et al. 2000b; Breen et al. 2001; Guyon et al. 2003).

Über weiterführende Mikrosatellitenanalysen gelang es, die potentielle Lage des RCND-Gens auf eine Region des Chromosom 5 zwischen den Markern FH4160 und FH4442 einzugrenzen, die Homologie zu einer $12 \mathrm{Mb}$ großen Region des humanen Chromosoms 17p aufweist (Lingaas et al. 2003). In dieser Region befindet sich neben 85 weiteren Genen das humane BHD-Gen, das mit dem humanen Nierenkrebs Syndrom Birt-Hogg-Dubé (BHD) in Zusammenhang steht (Nickerson et al. 2002). Aufgrund besonderer Ähnlichkeiten zwischen dem humanen BHD-Syndrom und der caninen RCND wurde das BHD-Gen als Kandidatengen näher untersucht. Das canine BHD-Gen umfasst laut Ensembl Datenbank 11 Exons und codiert für ein 579 Aminosäuren langes 
Protein (Ensembl GeneID: ENSCAFG00000018469). Die Länge der mRNA beträgt laut Ensembl-Vorhersage 2245 Nukleotide, laut Expressionsstudien ca. 3800 Nukleotide (Nickerson et al. 2002). Grundlage der Abb. 112 ist die unter Ensembl veröffentlichte Genstruktur.

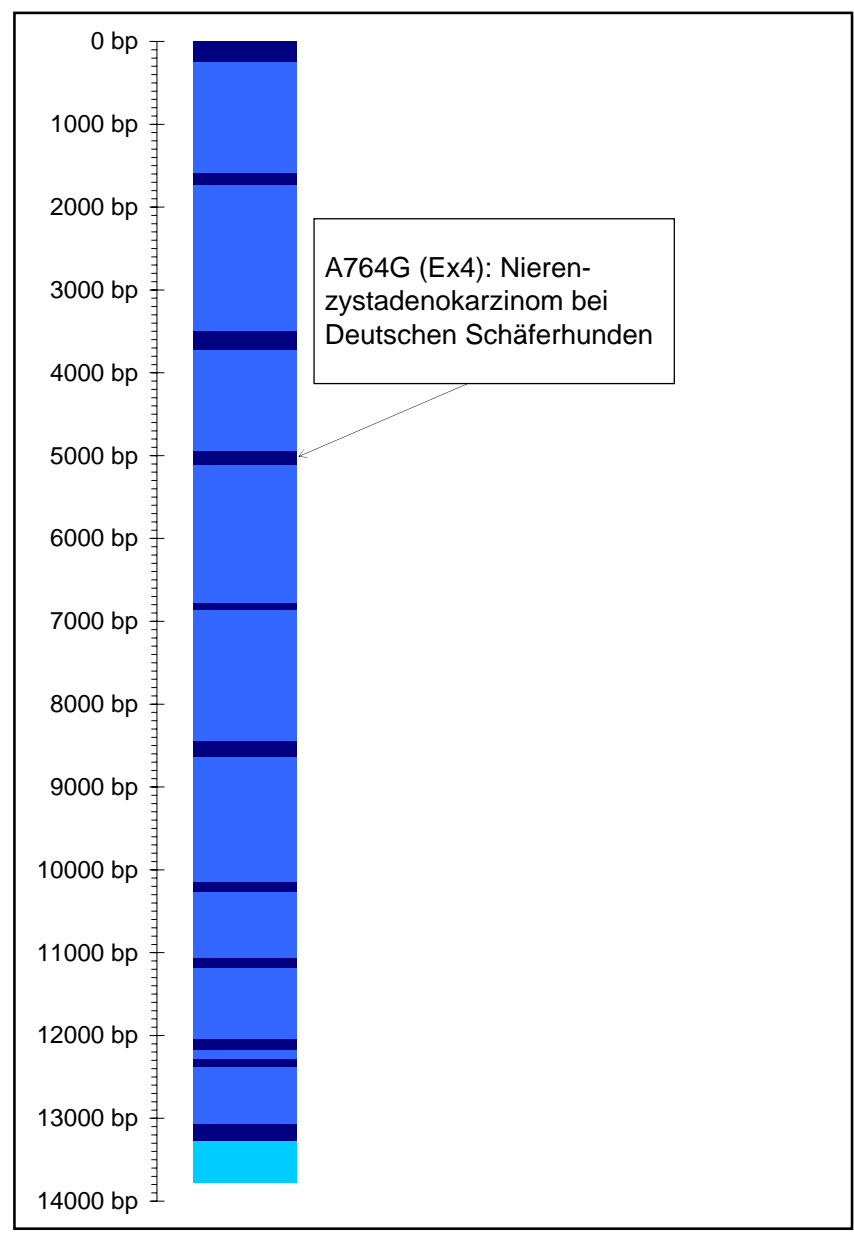

Abb. 112 Schematische Darstellung des caninen BHD-Gens und Lage der bisher identifizierten Mutationen. Dunkelblau: codierende Sequenz, hellblau: Intronsequenz, türkis: 5'-UTR

\section{Ursächliche Mutation für Nierenzystadenokarzinome beim Deutschen Schäferhund}

Vergleiche der cDNA-Sequenzen von normalen Hunden und RCND-Hunden ergaben bei betroffenen Hunden eine Substitution von Adenin durch Guanin in Exon 7 (Abb. 113) mit der Folge eines Aminosäurenaustausches von Histidin durch Arginin an Aminosäurenposition 255 (Lingaas et al. 2003). Die bei Lingaas et al. (2003) als Exon 7 veröffentlichte Sequenz entspricht der Sequenz von Exon 4 in der Ensembl Gensequenz (Ensembl GeneID: ENSCAFG00000018469). 
Die Funktion des vom BHD-Gen codierten Proteins Folliculin ist noch nicht geklärt. Allgemeinen Vermutungen zufolge handelt es sich um ein Tumor-Suppressor-Gen. Eindeutige Beweise dieser Vermutungen liegen zur Zeit nicht vor (Adley et al. 2006). Daher konnte bisher kein physiologischer Zusammenhang zwischen der beschriebenen Substitution und der Pathogenese des RCND-Syndroms hergestellt werden. Ergebnissen von Expressionsstudien zufolge scheinen Länge und Quantität der mRNA von der Mutation nicht beeinflusst zu sein, da sowohl bei gesunden als auch bei betroffenen Hunden in der Niere die gleiche Menge eines 3800 Nukleotide umfassenden Transkripts nachgewiesen werden konnte. Trotz dieser Ergebnisse gibt es deutliche Anzeichen für einen engen Zusammenhang der RCND-Erkrankung mit der Substitution in Exon 7, die, falls es sich nicht um die ursächliche Mutation handelt, eine enge Kopplung zum verantwortlichen Genort aufweist (Lingaas et al. 2003).

Es existiert eine hohe Konservierung der von Exon 7 codierten Aminosäurensequenz über zwölf verschiedene Spezies, die für eine hohe funktionelle Bedeutung der betreffenden Region spricht. Zudem scheint ein homozygotes Vorliegen der Substitution zum Verlust der fetalen Lebensfähigkeit zu führen. Dafür sprechen Genotypisierungsergebnisse von insgesamt 19 Nachkommen aus Anpaarungen zweier heterozygoter RCND-Hunde, die nicht wie erwartet ein Verhältnis der einzelnen Genotypen von 1:2:1 aufwiesen. Stattdessen trat der homozygot betroffene Genotyp überhaupt nicht auf. Diese Beobachtung legt nahe, dass die beschriebene Substitution einen homozygot letalen Effekt hat (Lingaas et al. 2003).

Die Substitution konnte bei allen 15 untersuchten Deutschen Schäferhunden mit RCND nachgewiesen werden, während keiner der 264 genotypisierten gesunden Hunde aus insgesamt 58 verschiedenen Rassen einschließlich 63 gesunden Deutschen Schäferhunden die Mutation aufwies. Zudem gelang der Nachweis eines $3 \mathrm{Mb}$ umfassenden typischen Haplotyps bei allen betroffenen Hunden. Diese Beobachtung spricht für das Vorliegen eines so genannten Founder- oder Gründer-Ereignisses. Darunter versteht man die Einführung eines Gendefektes und dessen Verbreitung innerhalb einer Population über einen in vielen Zuchtlinien einer Rasse eingesetzten Rüden. Der Nachweis eines gemeinsamen Haplotyps bei betroffenen Hunden lässt außerdem darauf schließen, dass die für RCND verantwortliche Mutation, falls es sich nicht um die Substitution im BHD-Gen handeln sollte, innerhalb dieses Haplotyps liegt 
und eng gekoppelt mit der BHD-Mutation vererbt wird. Es wird nicht ausgeschlossen, dass neben der beschriebenen BHD-Mutation weitere Mutationen innerhalb des 3-MbHaplotyps bei der Pathogenese der RCND eine Rolle spielen. Abschließend lässt sich feststellen, dass es sich bei der Substitution in Exon 7 um einen zuverlässigen genetischen Marker für eine RCND-Disposition handelt (Lingaas et al. 2003).

\section{Genotypisierung für Nierenzystadenokarzinom beim Deutschen Schäferhund}

Der Nachweis der Mutation kann per diagnostischer Sequenzierung erfolgen (Abb. 113) (Lingaas et al. 2003).

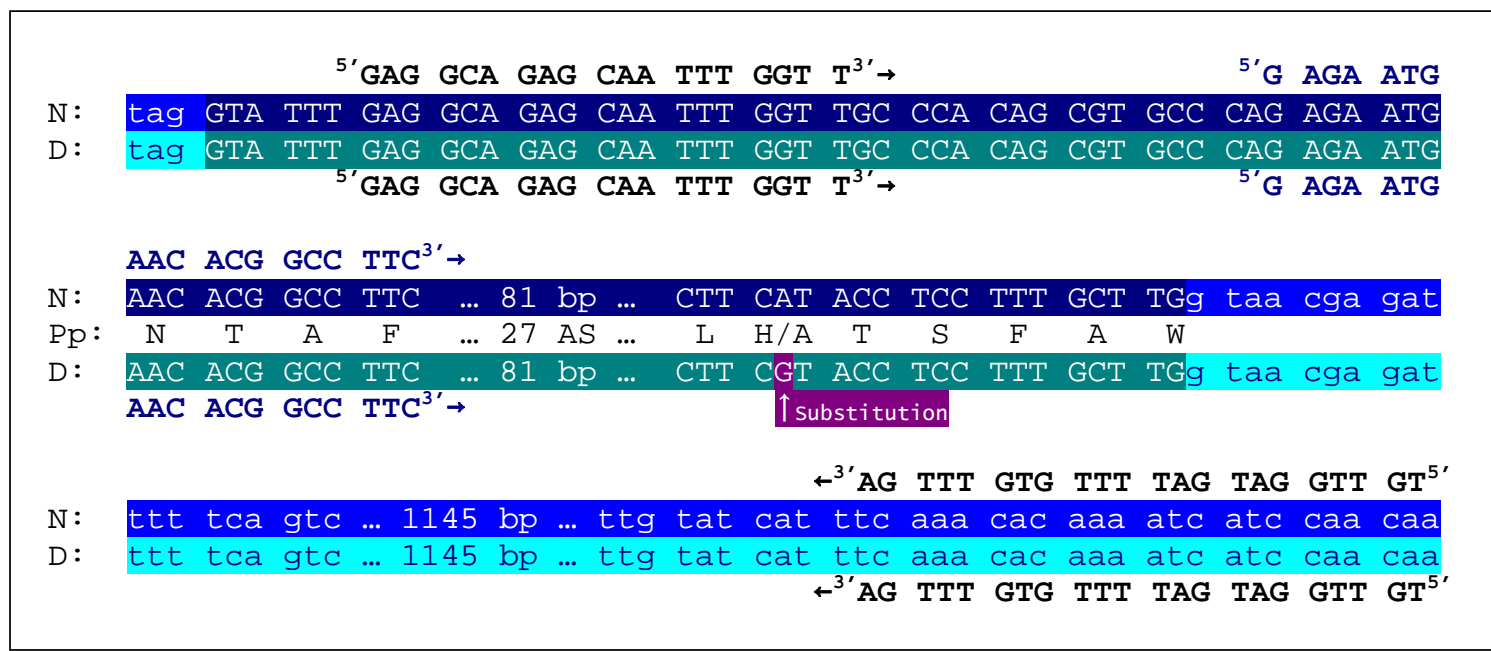

Abb. 113 Exon 4 des caninen BHD-Gens und angrenzende Intronsequenzen (Ensembl GeneID: ENSCAFG00000018469 entspricht Exon 7 und angrenzenden Intronsequenzen bei Lingaas et al. (Lingaas et al. 2003)). N: normale Sequenz, D: defekte Sequenz, dunkelblau: Exon normale Sequenz, dunkelgrün: Exon defekte Sequenz, hellblau: Intron normale Sequenz, hellgrün: Intron defekte Sequenz, Substitution in defekter Sequenz violett unterlegt und durch Pfeil gekennzeichnet, blaue Schrift: Sequenzierungsprimer.

\subsubsection{X-chromosmal gekoppelte Nephritis}

$\begin{array}{ll}\text { Chromosom: } & \text { CFAX } \\ \text { Gen: } & \text { COL4A5 } \\ \text { NCBI: } & \text { GeneID: 403466 } \\ \text { DNA-Sequenz: } & \text { NW_879563, Position 33485264-33649082 } \\ \text { Mutationen: } & \text { Del432-441, Navasota Hund } \\ & \text { G2083T, Samoyede }\end{array}$

\section{Krankheitsbild}

Canine hereditäre Nephritis ist durch einen im Alter von ca. drei Monaten einsetzenden, fortschreitenden Verlust der Nierenfunktion gekennzeichnet, der sich in zunehmender Proteinurie äußert und zu chronischem Nierenversagen im Endstadium führt. Betroffene Rassen sind Samoyeden (Bloedow 1981; Jansen et al. 1986a; Jansen et al. 1986b), Bull 
Terrier (Hood et al. 1995), Englische Cocker Spaniel (Lees et al. 1997; Lees et al. 1998a; Lees et al. 1998b) und so genannte Navasota-Hunde, bei denen es sich um eine Familie von Mischlingshunden aus Navasota in Kanada handelt (Lees et al. 1999).

Während der Erbgang bei Englischen Cocker Spaniels (Lees et al. 1997; Lees et al. 1998a; Lees et al. 1998b) und bei Bull Terriern (Hood et al. 1995) autosomal rezessiv bzw. dominant ist, deuten Pedigreeuntersuchungen bei Samoyeden (Jansen et al. 1986b) und Navasota-Hunden (Lees et al. 1999) klar auf eine X-chromosomal vererbte Vererbung hin. Zur Häufigkeit der Erkrankung innerhalb der Rasse Samoyeden werden keine Zahlen genannt. Berichte über X-chromosomal vererbte Nephritis bei Samoyeden beziehen sich ausschließlich auf Nachkommen von fünf 1977 (Bernard und Valli) beschriebenen Fälle in einer Forschungskolonie (Bloedow 1981). Die zugrunde liegenden Gendefekte konnten bisher nur bei den X-chromosomal vererbte Formen der caninen hereditären Nephritis gefunden werden (Zheng et al. 1994; Cox et al. 2003).

Klinische Anzeichen treten frühestens ab einem Alter von vier bis 13 Monaten auf und umfassen Appetitlosigkeit, Lethargie, plötzlichen Gewichtsverlust sowie gelegentliches Erbrechen. Häufig verenden betroffene Hunde bereits drei bis sechs Wochen nach dem Auftreten erster klinischer Anzeichen (Bloedow 1981; Lees et al. 1998a).

Messbar ist die Störung der Nierenfunktion anhand von Urinuntersuchungen bei einigen Hunden bereits im Alter von vier Monaten und spätestens im Alter von fünf Monaten in Form einer erhöhten Proteinkonzentration im Urin (urine protein-to-creatinine ratio, UPC). Das Vorliegen einer Proteinurie wird über UPC-Werten von $\geq 2$ definiert (Lees et al. 1999). UPC-Werte betroffener Navasota-Hunde können zwischen 2,1 und 17,0 schwanken und in Einzelfällen bis zu 33,0 betragen. Weitere Befunde sind fortschreitende Azotämie, erhöhte Phosphorkonzentration im Serum und reduzierte Gesamt- $\mathrm{CO}_{2}$-Konzentration im Serum. In Ultraschalluntersuchungen ist ab einem Alter von sechs Monaten bei betroffenen Hunden eine Nierenvergrößerung feststellbar. Störungen der Sehfähigkeit und Hörschäden konnten bei keinem der betroffenen Navasota-Hunde gefunden werden.

In pathologischen Untersuchungen zeigen betroffene Hunde ungleichgroße Nieren mit unregelmäßigen Konturen und kantiger Kortexoberfläche. Die Nieren sind blassbraun bis braun gesprenkelt und verfestigt. Das kantige Erscheinungsbild der Oberfläche wird 
durch dichte Bindegewebsbänder verursacht, die ausgehend von der Kapsel bis in äußere Bereiche der Medulla reichen. Die betroffenen Regionen sind infarktähnlich verändert und zeichnen sich durch eine verminderte Anzahl von Glomeruli und Tubuli sowie eine Akkumulation von Lymphozyten und Makrophagen aus. Mikroskopisch sind in ca. $75 \%$ der Glomeruli Ausdehnungen des Mesangiums sichtbar. $10 \%$ der Glomeruli sind zudem abschnittsweise von Fibrose betroffen oder zeigen eine vollständige Sklerose. Im kortikalen Interstitium zeigen sich eine ungleichmäßige Fibrose und eine Infiltration durch lymphozytäre und histiozytäre Entzündungszellen. Die Tubuli sind teils atrophiert, teils erweitert und mit Proteinen gefüllt.

Weitere charakteristische Befunde betreffen die Ultrastruktur der Glomeruli. Vorherrschend sind hierbei Verdickungen der glomerulären Basalmembran. In einigen Bereichen sind allerdings auch extrem dünne Abschnitte dieser Membran zu sehen. In Bereichen mit verdickter Basalmembran zeigt sich eine Spaltung der Lamina densa in zwei oder mehrere Schichten. Es kommt zu fokalen Fusionen der Fußfortsätze der Podozyten. Im Verlauf der Erkrankung kommt es zur Verstärkung aller beschriebenen Befunde (Jansen et al. 1986a; Lees et al. 1999).

Bei obligat heterozygoten Hündinnen ergibt sich ein variables Bild. In einer Studie an 37 heterozygoten Hündinnen aus einer Forschungskolonie von Mischlingshunden zeigten alle bis zum Alter von fünf Jahren keinerlei äußerliche Anzeichen einer Nierenfunktionsstörung, obwohl bei allen Hündinnen ab einem Alter von zwei bis drei Monaten Proteinurie auftrat. Von 13 dieser Hündinnen erreichten vier ein Alter zwischen sechs und elf Jahren, ohne Anzeichen einer Erkrankung zu zeigen. Vier weitere Hündinnen wurden aufgrund anderer Erkrankungen im Alter zwischen sechs und 13 Jahren getötet. Fünf Hündinnen mussten im Alter zwischen fünf und neun Jahren aufgrund einer Nierenfunktionsstörung eingeschläfert werden (Baumal et al. 1991). Ein ähnliches Bild ergab sich bei heterozygoten Navasota Hündinnen (Lees et al. 1999).

Die Lamina densa der Basalmembranen ist aus Typ IV Kollagen $\alpha$-Ketten zusammengesetzt. Die Gruppe der Typ-IV-Kollagene umfasst sechs verschiedene $\alpha$ Ketten $(\alpha 1-\alpha 6)$. Je nach Entwicklungsstadium und Organsystem sind zwei bis vier verschiedene Typen von Kollagen-IV- $\alpha$-Ketten, die untereinander Netzwerke bilden, 
am Aufbau der Lamina densa beteiligt. Es existieren drei verschiedene Netzwerke:

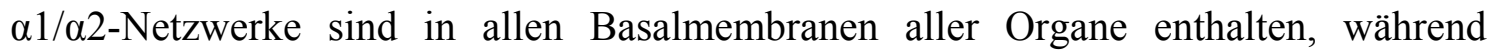
$\alpha 3 / \alpha 4 / \alpha 5-N e t z w e r k e$ und $\alpha 1 / \alpha 2 / \alpha 5 / \alpha 6-N e t z w e r k e$ nur in speziellen Bereichen auftreten. Die Verteilung der $\alpha 3 / \alpha 4 / \alpha 5$ - und $\alpha 1 / \alpha 2 / \alpha 5 / \alpha 6-N e t z w e r k e$ ist über zahlreiche Säugetierarten bemerkenswert konstant (zusammengefasst bei Zheng et al. 2005). Die Proteinstruktur ist bei allen Kollagen-IV- $\alpha$-Ketten ähnlich. An eine amino-terminale ca. 25 Aminosäuren umfassende nichtkollagene Sequenz schließt sich eine längere, ca. 1400 Aminosäuren umfassende kollagene Sequenz bestehend aus Gly-X-YMultiplikationen und eine carboxyl-terminale, ca. 230 Aminosäuren umfassende nichtkollagene Sequenz, bezeichnet als NC1-Domäne, an. Die kollagene Sequenz bildet mit zwei weitren $\alpha$-Ketten Tripel-Helix-Moleküle. Nachgewiesen wurden sowohl Heterotrimere wie $(\alpha 1)_{2} \alpha 2$ oder $(\alpha 3)_{2} \alpha 4$ als auch Homotrimere wie $(\alpha 1)_{3}$ oder $(\alpha 3)_{3}$. Einzelne Trimere sind untereinander mit stabilisierenden Disulfidbrücken verbunden (Hudson et al. 1993).

Im Verlauf der glomerulären Entwicklung findet beim gesunden Organismus ein Wechsel in der Zusammensetzung der Basalmembran statt. In immunologischen Studien konnte die Verteilung der einzelnen $\alpha$-Ketten in den einzelnen Nierenbereichen bei gesunden und betroffenen Hunden im Verlauf der Entwicklung ermittelt werden. Bei jungen Hunden im Alter von ca. sechs Tagen ist die glomeruläre Basalmembran ausschließlich aus $\alpha 1 / \alpha 2-N e t z w e r k e n$ zusammengesetzt. Des Weiteren finden sich $\alpha 1$ und a2-Ketten in Geweben, die sich in Entwicklung zu mesangialem Gewebe und Epithel der Bowmanschen Kapsel befinden, und in den Podozyten. Hingegen sind $\alpha 3-$, a4- $\alpha 5$ - und $\alpha 6$-Ketten in keiner der untersuchten Membranen nachweisbar. Nach Abschluss der glomerulären Entwicklung im Alter von ca. drei Monaten sind weiterhin $\alpha 1$ - und $\alpha 2-$ Ketten in allen untersuchten Basalmembranen nachweisbar, nehmen jedoch in der glomerulären Basalmembran mit Zunahme des Anteils anderer $\alpha$-Ketten anteilmäßig ab. $\alpha 3$ - und $\alpha 4$ - Ketten sind auf glomeruläre Basalmembranen und Membranen der distalen Tubuli beschränkt, $\alpha 5-$ Ketten treten gemeinsam mit $\alpha 3$ - und a4- Ketten in der Basalmembran der Glomeruli und den distalen Tubuli auf und sind außerdem gemeinsam mit $\alpha 1-, \alpha 2-$ und $\alpha 6-K e t t e n$ in der Basalmembran der Bowmanschen Kapsel nachweisbar (Harvey et al. 1998; Lees et al. 1999). 
Bei betroffenen Hunden sind ab einem Alter von vier Monaten, also nach Abschluss der glomerulären Entwicklung und mit Einsetzen erster Anzeichen für eine Nierenerkrankung, $\alpha 1$ - und $\alpha 2-$ Ketten in der glomerulären Basalmembran im Vergleich zu normalen Hunden verstärkt nachweisbar. $\alpha 5$-Ketten sowie $\alpha 3$ - und $\alpha 4-$ Ketten sind bei betroffenen Rüden weder in der glomerulären Basalmembran noch in der Membran der distalen Tubuli nachweisbar. In der Membran der Bowmanschen Kapsel treten ausschließlich $\alpha 1$ - und $\alpha 2$-Ketten auf, $\alpha 5$ - und $\alpha 6$-Ketten sind nicht nachweisbar. Einige heterozygote Hündinnen zeigen in einigen Abschnitten der glomerulären und tubulären Basalmembranen einen Mangel an $\alpha 3-$, $\alpha 4-$ und $\alpha 5$-Ketten, während andere Membranabschnitte eine normale Zusammensetzung aufweisen. Andere heterozygote Hündinnen zeigen eine vollständig normale Zusammensetzung glomerulärer und tubulärer Basalmembranen (Harvey et al. 1998; Lees et al. 1999).

Offenbar ist das $\alpha 1 / \alpha 2-N e t z w e r k$ für eine normale glomeruläre Entwicklung notwendig. Die im späteren Entwicklungsstadium erforderliche langfristige Stabilität der Membran und die Aufrechterhaltung der glomerulären Funktion sind jedoch nur bei einer Zusammensetzung der Membran aus $\alpha 3 / \alpha 4 / \alpha 5-N e t z w e r k$ gewährleistet. Findet dieser Wechsel in der Zusammensetzung der Membran nicht statt, kommt es zu fortschreitenden Schädigungen der Membran und damit zu allmählichem Verlust der Nierenfunktion (Harvey et al. 1998; Lees et al. 1999).

\section{Genetischer Hintergrund}

Sowohl bei betroffenen Samoyeden als auch bei betroffenen NavasotaMischlingshunden liegen Mutationen im Kollagen-IV-a5-Gen (COL4A5) vor (Zheng et al. 1994; Cox et al. 2003). Verschiedene Untersuchungen der Expression der Kollagen IV Gene geben Hinweise darauf, dass es sich bei den gefundenen COL4A5-Mutationen um die ursächlichen Mutationen handelt. Außerdem sprechen die Ergebnisse gegen eine Beteiligung zusätzlicher Mutationen an weiteren Kollagen-IV-Genen (Thorner et al. 1996; Harvey et al. 1998; Zheng et al. 2005).

Im Nierengewebe von betroffenen Hunden beträgt die nachgewiesene Menge an COL4A5-mRNA nur ca. $10 \%$ der bei normalen Hunden nachweisbaren Menge bzw. ist fast keine Expression der COL4A5-mRNA nachweisbar. Auch im Hodengewebe betroffener Hunde ist die Expression von COL4A5 nur in sehr geringem Maße zu 
detektieren. Die Folgen der gefundenen Mutationen scheinen sich also im gesamten Körper auszuwirken. Die Mengen der COL4A3- und COL4A4-mRNA im Nierengewebe unterscheiden sich bei jungen betroffenen Hunden nicht von den bei normalen Hunden nachgewiesenen Mengen. Ab einem Alter von ca. drei Monaten nehmen die Mengen beider mRNAs bei betroffenen Hunden auf weniger als 25\% der bei normalen Hunden nachgewiesenen Mengen ab. Die Expression der COL4A3- und COL4A4-Gene scheint nach diesen Untersuchungsergebnissen in den ersten Lebensmonaten normal zu sein. Das Einsetzen einer anormalen Expression fällt mit dem Auftreten erster Anzeichen einer Nephritis zusammen. Daraus lässt sich schließen, dass die anormale Expression durch die Erkrankung ausgelöst wird und nicht durch Defekte der COL4A3 und COL4A4 Gene verursacht wird. Dafür spricht weiterhin der Nachweis einer normalen Expression von COL4A3 und COL4A4 in untersuchtem Hodengewebe betroffener Hunde. Demnach scheint es sich bei der abweichenden Expression dieser beiden Kollagen IV Gene um einen organspezifischen Effekt zu

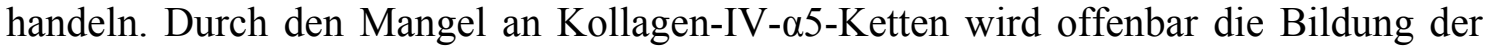
$\alpha 3 / \alpha 4 / \alpha 5$-Netzwerke verhindert. Es wird vermutet, dass die Steuerung der Expression von COL4A3 und COL4A4 in der Niere über einen Rückkopplungsmechanismus erfolgt, der bei Überschuss von Kollagen-IV- $\alpha 3$ - und - $\alpha 4-K e t t e n$, wie er bei einer gestörten Bildung von $\alpha 3 / \alpha 4 / \alpha 5-N e t z w e r k e n$ vorliegt, für eine Hemmung der COL4A3und COL4A4-Expression sorgt. Im Hodengewebe findet auch bei betroffenen Hunden eine normale Expression von COL4A3 und COL4A4 statt, da hier die Verwertung der $\alpha 3$ - und $\alpha 4$-Ketten offenbar nicht von der Verfügbarkeit der $\alpha 5$-Kette abhängt. Auch die Steuerung der COL4A1- und COL4A2-Expression scheint in ähnlicher Weise organspezifisch gesteuert zu werden. Während im Nierengewebe bei betroffenen Hunden ab einem Alter von vier Monaten zunehmend erhöhte Mengen an COL4A1und COL4A2-mRNAs nachweisbar sind, unterscheidet sich die COL4A1- und COL4A2-Expression im Hodengewebe zwischen betroffenen und normalen Hunden nicht. Für die erhöhte Expression im Nierengewebe wird ein erhöhter Bedarf an $\alpha 1$ - und $\alpha 2$-Ketten aufgrund der gestörten Bildung von $\alpha 3 / \alpha 4 / \alpha 5-N e t z w e r k e n$ verantwortlich gemacht. Nähere Einzelheiten zu der Steuerung der Expression von Kollagen -IVGenen sind nicht bekannt (Thorner et al. 1996; Zheng et al. 2005). 
Die Länge der COL4A5-mRNA beträgt 5681 Nukleotide und ist offenbar in 53 Exons unterteilt. Das resultierende Protein hat eine Länge von 1692 Aminosäuren. Die Exons 2-53 des caninen COL4A5-Gens sind im genomischen Contig NW_879563 zwischen Position 33485264 und 33649082 lokalisiert (NCBI-GeneID: 403466, Stand: 04.Oktober 2007). Die ersten 257 Nukleotide der mRNA (Exon 1) konnten offenbar nicht lokalisiert werden. Abb. 114 zeigt die genomische Struktur der 52 lokalisierten Exons. 


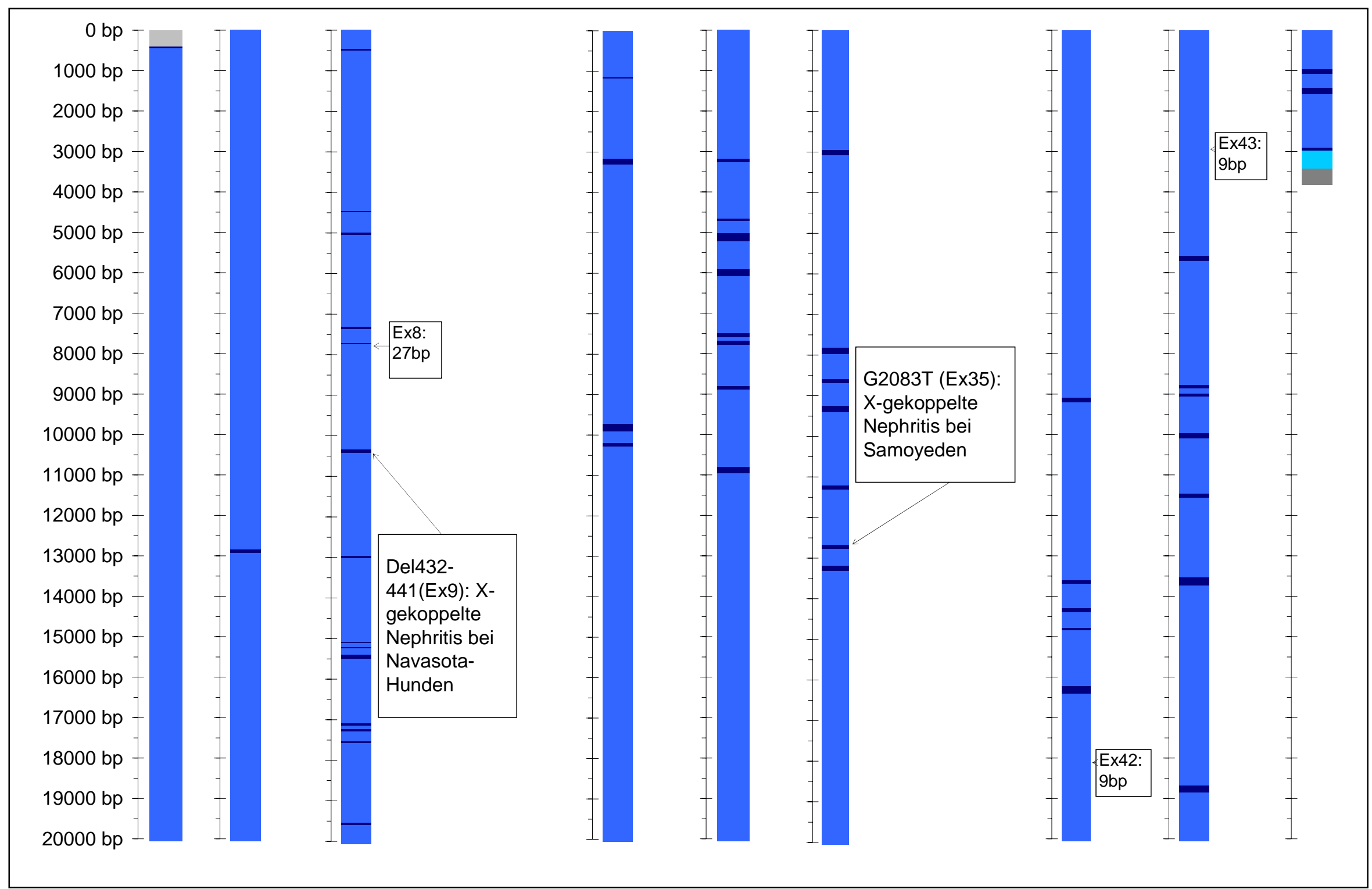

Schematische Darstellung des caninen COL4A5-Gens (Exon 2-53) und Lage der bisher identifizierten Mutationen. Dunkelblau: codierende Sequenz, hellblau: Intronsequenz, türkis: 3'-UTR, grau: intergenische Sequenz. 


\section{III.a Ursächliche Mutation bei Samoyeden}

Vergleiche der cDNA-Sequenzen der NC1-Domäne von betroffenen und normalen Samoyeden ergaben bei betroffenen Hunden in Exon 35 eine Substitution von Guanin durch Thymin (Abb. 115). Dadurch wird die Aminosäure Glycin 695 Aminosäuren aufwärts des C-Terminus durch ein verfrühtes Stoppcodon ersetzt (Zheng et al. 1994). Die bei Zheng et al. (1994) als Exon 35 veröffentlichte Sequenz entspricht Exon 34 in der unter NCBI-GeneID 403466 veröffentlichten Sequenz.

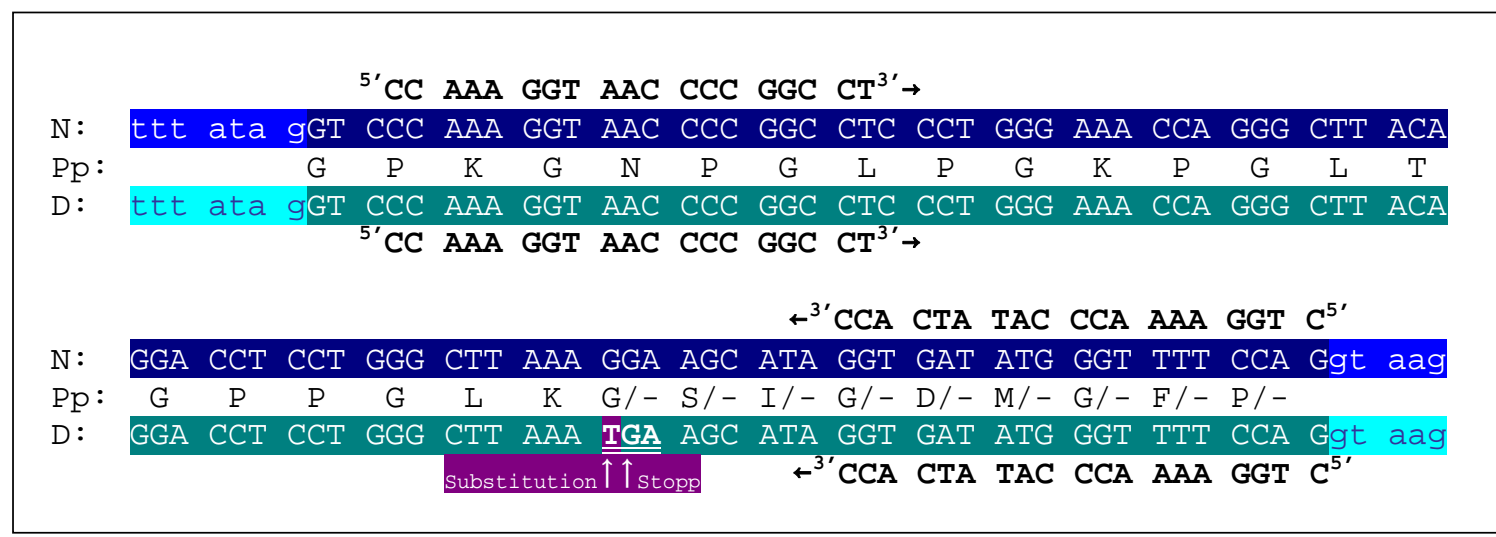

Abb. 115 Exon 34 des caninen COL4A5-Gens und angrenzende Intronsequenzen. N: normale Sequenz, D: defekte Sequenz, Pp: Polypeptidsequenz, dunkelblau: Exon normale Sequenz, dunkelgrün, Exon defekte Sequenz, hellblau: Intron normale Sequenz, hellgrün: Intron defekte Sequenz, Substitution in defekter Sequenz violett unterlegt und durch Pfeil gekennzeichnet, verfrühtes Stoppcodon in defekter Sequenz unterstrichen und durch Pfeil gekennzeichnet.

\section{IV.a Genotypisierung bei Samoyeden}

Der Nachweis der Mutation kann per diagnostischer Sequenzierung erfolgen (Zheng et al. 1994).

\section{III.b Ursächliche Mutation bei Navasota Hunden}

Bei betroffenen Navasota-Hunden liegen in Exon 35 des COL4A5-Gens keinerlei Abweichungen von der normalen caninen Sequenz vor (Lees et al. 1999). Die vollständige Sequenzierung der normalen caninen COL4A5-cDNA einschließlich 5'und 3'- UTR und ein anschließender Vergleich mit der cDNA-Sequenz betroffener Navasota-Hunde führten zur Entdeckung einer 10-bp-Deletion in Exon 9 bei betroffenen Navasota-Hunden (Abb. 116) (Cox et al. 2003).

Die Mutation führt $\mathrm{zu}$ einer Leserasterverschiebung. Dadurch wird die für Kollagendomänen typische Gly-X-Y-Aminosäurenmultiplikation unterbrochen, und es kommt zur Entstehung eines verfrühten Stoppcodons in Exon 10. Das resultierende 
Protein ist um 85\% des Carboxyl-Terminus verkürzt. Der Verlust umfasst den überwiegenden Teil der Kollagenregion sowie die gesamte NC1-Domäne. Die Autoren gehen davon aus, dass diese Mutation ebenso wie die COL4A5-Mutation bei Samoyeden die Bildung von $\alpha 3 / \alpha 4 / \alpha 5-N e t z w e r k e n$ in der glomerulären Basalmembran verhindert (Cox et al. 2003).

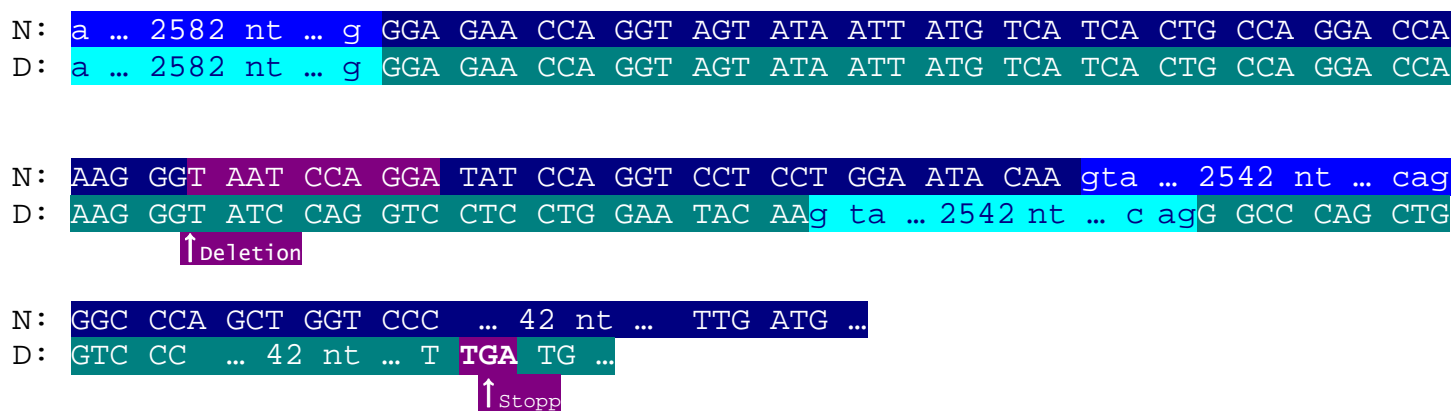

Abb. 116 Exon 9 und 10 des caninen COL4A5 Gens und angrenzende Intronsequenzen (GeneID 403466). N: normale Sequenz, D: defekte Sequenz, dunkelblau: Exon normale Sequenz, dunkelgrün, Exon defekte Sequenz, hellblau: Intron normale Sequenz, hellgrün: Intron defekte Sequenz, Deletion in normaler Sequenz violett unterlegt und durch Pfeil gekennzeichnet, verfrühtes Stoppcodon in defekter Sequenz violett unterlegt und durch Pfeil gekennzeichnet. 


\subsubsection{Hereditäre Schilddrüsenunterfunktion}

\begin{tabular}{ll|}
\hline Chromosom: & CFA17 \\
Gen: & TPO \\
NCBI: & GeneID: 403521 \\
DNA-Sequenz: & NW_876263, Position 751087-787972 \\
Mutationen: & C331T, Toy Foxterrier \\
\hline
\end{tabular}

\section{I.a Krankheitsbild allgemein}

Die zahlreichen verschiedenen Formen der erblichen caninen Schilddrüsenunterfunktion können nach bestimmten Kriterien unterteilt werden. Zunächst wird zwischen primärer, sekundärer und tertiärer Schilddrüsenunterfunktion unterschieden. Primäre Formen beruhen auf einem Defekt, der direkt zu einer reduzierten oder fehlenden Bildung der Schilddrüsenhormone Thyroxin (T4) und Trijodthyronin (T3) führt. Bei sekundären Formen ist der Mangel an Schilddrüsenhormonen durch eine reduzierte Freisetzung des Thyroid stimulierenden Hormons (TSH, Thyreotropin) aus der Hypophyse bedingt. Tertiäre Formen, die durch einen Mangel an Thyreotropin releasing Hormon (TRH) des Hypothalamus verursacht werden, sind beim Hund bisher nicht beschrieben worden (McKeown 2002).

Primäre Schilddrüsenunterfunktionen gehören $\mathrm{zu}$ den häufigsten endokrinen Erkrankungen des Hundes. Das Alter betroffener Hunde ist variabel. Es sind sowohl kongenitale Fälle als auch später auftretende Formen beschrieben worden. Am häufigsten scheinen mittelgroße Hunde im Alter zwischen vier und acht Jahren betroffen zu sein (Scarlett 1994). Bezogen auf die Gesamtheit der caninen Fälle von Schilddrüsenunterfunktion macht der Anteil der kongenitalen Fälle lediglich 3,6 \% aus (Greco 1997). Mögliche Ursachen erblicher primärer Schilddrüsenunterfunktionen umfassen angeborenes Fehlen, Unterentwicklung oder Verlagerung der Schilddrüse, Dyshormonogenese und autoimmune Thyreoiditis (Greco 1997). Eine Dyshormonogenese kann durch Störungen der Jodaufnahme oder -speicherung, der Thyreoglobulinsynthese sowie der Jodkonservierung durch Dejodierung ungenutzter Jodthyronine hervorgerufen werden oder durch Organifizierungsdefekte bedingt sein. Unter Organifizierung versteht man die kovalente Bindung von Jod an Thyreoglobulin, die durch ein Zusammenspiel der Thyroidperoxidase mit Thyroidoxidase gesteuert wird. Bei der Thyroidoxidase handelt es sich um einen Enzymkomplex, der in 
Abhängigkeit von reduziertem Nikotinamid-Adenindinukleotid eine Generierung von $\mathrm{H}_{2} \mathrm{O}_{2}$ bewirkt (Fyfe et al. 2003).

In Abhängigkeit vom ursächlichen Defekt kommt es zu variablen klinischen, histologischen und biochemischen Befunden. Eine eindeutige Diagnose wird durch diese Variabilität erschwert. Typische Anzeichen einer kongenitalen Schilddrüsenunterfunktion sind unproportionierter Zwergenwuchs, Störungen des zentralen und peripheren Nervensystems sowie geistige Unterentwicklung (Greco 1997). Weitere klinische Erscheinungen treten sowohl bei kongenitalen Unterfunktionen als auch bei Erkrankungen mit einem späteren Beginn auf und umfassen Haut- und Haarveränderungen, metabolische Anzeichen wie Trägheit und Gewichtszunahme sowie neurologische, oculare, hämatologische und kardiovaskulare Störungen (Scarlett 1994). Allerdings ist weder das Vorliegen eines einzelnen noch einer Gruppe dieser Symptome ausreichend für eine eindeutige Diagnose (Scarlett 1994; Greco 1997).

Auch eine Messung der Serumkonzentrationen von T4 oder T3 wird nicht als sichere Methode für den Nachweis oder den Ausschluss einer Schilddrüsenunterfunktion beurteilt. Die Serumkonzentration von T3 weicht bei betroffenen Hunden häufig entgegen den Erwartungen nicht von den Werten normaler Kontrollhunde ab, da das Vorliegen einer gestörten Schilddrüsenfunktion häufig einen kompensatorischen Mechanismus auslöst der zur erhöhten Freisetzung von T3 führt. Auch die Gesamtserumkonzentration von T4 ist kein zuverlässiger Indikator. Zum Teil liegen auch bei gesunden Hunden aufgrund von normalen Fluktuationen des Serum-T4Gehaltes reduzierte Konzentrationen vor. Daneben kann es durch nicht thyreoidale Erkrankungen sowie in Abhängigkeit von Rasse und Alter und durch den Einfluss bestimmter Medikamente zu reduzierten Konzentrationen kommen. Zudem zeigen Hunde mit immunologisch bedingter Schilddrüsenunterfunktion und Autoantikörpern gegen T4 -je nach Messverfahren- gegebenenfalls erhöhte T4-Gesamtkonzentrationen. Eine Messung freier T4-Gehalte sowie der Nachweis einer erhöhten TSH-Konzentration erhöhen die Sicherheit der Diagnose. Allerdings sind zuverlässige Messverfahren für nicht proteingebundenes T4 technisch relativ aufwendig. Allgemein werden niedrige freie T4-Werte in Verbindung mit hohen TSH-Konzentrationen als Indikatoren gedeutet, die mit einer hohen Wahrscheinlichkeit für das Vorliegen einer 
Schilddrüsenunterfunktion sprechen. Bei immunologisch bedingten Schilddrüsenunterfunktionen lassen sich Autoimmunantikörper nachweisen, die in den meisten Fällen gegen Thyreoglobulin, in einigen Fällen auch gegen T3 oder T4 gerichtet sind (Kemppainen und Behrend 2001).

Histologische Befunde können in unterschiedlich schwerwiegenden atrophischen Veränderungen des Schilddrüsengewebes bestehen. Es kann zum vermehrten Auftreten von Lymphozyten und Makrophagen kommen. Gelegentlich ist eine fokale oder generalisierte Hyperplasie des Schilddrüsenepithels zu beobachten.

Ein Zusammenhang der Erkrankung mit spezifischen molekulargenetischen Eigenschaften konnte bisher nur für eine immunologisch bedingte Schilddrüseunterfunktion bei Dobermännern (Kennedy et al. 2006a) und für eine kongenitale Schilddrüsenunterfunktion mit Kropfbildung bei Toy Foxterriern (Fyfe et al. 2003) hergestellt werden.

Die Beteiligung einer genetischen Komponente an der Pathogenese immunologisch bedingter Schilddrüsenunterfunktionen wird durch die Beobachtung einer Disposition bestimmter Zuchtlinien in verschiedenen Forschungskolonien sowie durch das gehäufte Auftreten der Erkrankung in bestimmten Rassen belegt.

Tabelle 17 Häufigkeit autoimmuner Thyroiditis in verschiedenen Rassen (leicht abgewandelt nach http://www.offa.org/thystatbreed.html 2006)

\begin{tabular}{|c|c|c|}
\hline Rasse & $\begin{array}{l}\text { Anzahl untersuchter } \\
\text { Hunde }\end{array}$ & $\begin{array}{c}\text { Häufigkeit autimmuner Thyroiditis } \\
{[\%]}\end{array}$ \\
\hline Englischer Setter & 268 & 27,6 \\
\hline Deutsch Drahthaar Vorstehhund & 135 & 14,8 \\
\hline Shetland Schäferhund & 452 & 13,1 \\
\hline Akita & 246 & 12,2 \\
\hline Boxer & 405 & 11,6 \\
\hline Irischer Setter & 187 & 11,2 \\
\hline Rhodesian Ridgeback & 1461 & 11,0 \\
\hline Kuvasz & 173 & 11,0 \\
\hline Amerikanischer Pit Bullterrier & 56 & 10,7 \\
\hline Dalmatiner & 189 & 10,6 \\
\hline Welsh Springer Spaniel & 221 & 9,5 \\
\hline
\end{tabular}


Fortsetzung Tabelle 17: Häufigkeit autoimmuner Thyroiditis in verschiedenen Rassen (leicht abgewandelt nach http://www.offa.org/thystatbreed.html 2006)

\begin{tabular}{|c|c|c|}
\hline Rasse & $\begin{array}{c}\text { Anzahl untersuchter } \\
\text { Hunde }\end{array}$ & $\begin{array}{c}\text { Häufigkeit autimmuner Thyroiditis } \\
{[\%]}\end{array}$ \\
\hline Nova Scotia Duck Tolling Retriever & 207 & 9,2 \\
\hline Flat-Coated Retriever & 69 & 8,7 \\
\hline Havanese & 92 & 8,7 \\
\hline Riesenschnauzer & 133 & 8,3 \\
\hline Englischer Springer Spaniel & 78 & 7,7 \\
\hline Leonberger & 303 & 7,6 \\
\hline Borzoi & 424 & 7,5 \\
\hline Golden Retriever & 1358 & 7,5 \\
\hline Amerikanischer Staffordshire Bullterrier & 122 & 7,4 \\
\hline Basenji & 124 & 7,3 \\
\hline Bluthund & 86 & 7,0 \\
\hline Afghane & 69 & 5,8 \\
\hline Keeshond & 140 & 5,7 \\
\hline Cocker Spaniel & 111 & 5,4 \\
\hline Dobermann Pinscher & 616 & 5,2 \\
\hline Dänische Dogge & 1053 & 4,9 \\
\hline Border Collie & 81 & 4,9 \\
\hline Gordon Setter & 63 & 4,8 \\
\hline Altenglischer Schäferhund & 62 & 4,8 \\
\hline Petit Basset Griffons Vendeen & 67 & 4,5 \\
\hline Coton de Tulear & 250 & 4,4 \\
\hline Bullmastiff & 170 & 4,1 \\
\hline Collie & 101 & 4,0 \\
\hline
\end{tabular}

\section{II.a Genetischer Hintergrund der hereditären Schilddrüsenunterfunktion bei Dobermännern}

Bei Dobermännern konnte kürzlich eine Form immunologisch bedingter Schilddrüsenunterfunktion mit einem bestimmten Haplotyp dreier polymorpher DLAGene (Dog-Leucocyte Antigen) in Verbindung gebracht werden. DLA bezeichnet die 
canine Entsprechung des humanen MHC-Komplex (major histocompatibility complex). Es handelt sich um die Gene DLA-DRB1, -DQA1 und -DQB1. Insgesamt konnten sechs Haplotypen identifiziert werden, von denen einer in der untersuchten Gruppe betroffener Hunde mit 55,6 \% etwa doppelt so häufig auftrat wie in der Gruppe normaler Kontrollhunde mit nur 29,46 \%. Bezogen auf die Gesamthundepopulation scheint es sich um einen eher seltenen Haplotyp zu handeln. In einer Typisierung von insgesamt 3014 Hunden konnte der betreffende Haplotyp nur bei 30 Hunden und ausschließlich in den Rassen Dobermann und Labrador nachgewiesen werden. Ferner ist unklar, ob die identifizierten Polymorphismen ursächlich mit der Schilddrüsenunterfunktion zusammenhängen oder ob es sich lediglich um Surrogatmarker handelt (Kennedy et al. 2006a). In einer Folgestudie zeigt ein Vergleich der Allelfrequenzen des DQA1-Gens zwischen 173 Hunden mit klinischen Anzeichen einer Schilddrüsenunterfunktion und 873 gesunden Kontrollhunden eine deutliche Erhöhung des DQA1*00101-Allels bei betroffenen Hunden der Rassen Dobermann, Rhodesian Ridgeback und Englische Setter. Das Allel DQA1*00101 ist Teil des bei Dobermännern mit Schilddrüsenunterfunktion assoziierten Haplotyps. Bei betroffenen Boxern konnte keine Erhöhung dieses Allels festgestellt werden. Stattdessen ist in dieser Rasse eine von dem zuvor bei Dobermännern identifizieren Haplotyp verschiedene Allelkombination mit der Erkrankung assoziiert (Kennedy et al. 2006b). Beide Studien sprechen für einen möglichen Zusammenhang immunologisch basierter Schilddrüsenunterfunktionen mit Mutationen in DLA-Genen. Die Erkenntnisse bieten jedoch keine ausreichende Grundlage für die Entwicklung von Zuchtstrategien.

\section{I.b Krankheitsbild der hereditären Schilddrüsenunterfunktion bei Toy Foxterriern}

Bei Toy Foxterriern tritt eine offenbar autosomal rezessiv vererbte kongenitale Schilddrüsenunterfunktion mit Kropfbildung auf, die durch exzessive Schläfrigkeit, mangelhaftes Säugeverhalten und verzögertes Öffnen der Augen und der Ohrkanäle gekennzeichnet ist (Fyfe et al. 2003). Es sind offenbar keine repräsentativen Untersuchungen der Häufigkeit der Erkrankung innerhalb der Rasse Toy Foxterrier durchgeführt worden. Es wird auf mehrere Einzelberichte von Züchtern über betroffene

Welpen verwiesen. Demnach scheinen in gewisser Regelmäßigkeit einzelne erkrankte Toy Foxterrier aufzutreten (Fyfe et al. 2004). Ohne Therapie verenden betroffene 
Welpen meist im Alter von drei Wochen oder werden eingeschläfert. Neben den beschriebenen klinischen Anzeichen sind kurze, dicke Hälse, struppiges Fell ohne Leithaare oder langes, flauschiges Fell, eine Verdickung des subkutanen Gewebes sowie eine kurze, untersetzte Schnauze zu beobachten. Zudem ist eine Schwellung des ventralen Halsbereichs palpierbar. Histopathologisch zeigt sich eine Vergrößerung der Schilddrüse, die durch eine schwerwiegende diffuse Hyperplasie des Follikelepithels hervorgerufen wird. Eine Serumuntersuchung ergibt reduzierte Konzentrationen des Gesamtthyroxins sowie des freien Thyroxins.

Eine im Alter von drei Wochen beginnedne Therapie mit synthetischem Thyroxin führt nach zwei Wochen zu einer Verbesserung der Lebhaftigkeit und Aktivität. Andere klinische Erscheinungen wie die ödemartige Verdickung der Unterhaut sowie die verlängerten, flauschigen Haare und die verkürzten und stumpfen Unterkiefer bleiben unverändert. Zudem kommt es trotz der Thyroxintherapie zu einer langsamen stetigen Vergrößerung der Schilddrüse. Die Serumwerte von Thyroxin und TSH sind bei therapierten Welpen normal, die T3-Werte bleiben reduziert. Nach dreitägigem Aussetzen der Thyroxintherapie liegen im Serum erhöhte TSH-Werte und reduzierte Thyroidwerte vor. Im Alter von 22 Wochen liegen bei therapierten Hunden keinerlei Auffälligkeiten des Fells oder des Unterhautgewebes mehr vor. Der Wuchs ist zwar insgesamt etwas kleiner als bei normalen Altersgenossen, aber proportioniert. Fünf Stunden nach der regelmäßigen Thyroxinadministration liegen bei einem untersuchten Rüden die Serumkonzentrationen von Gesamtthyroxin und freiem Thyroxin im Referenzbereich. Abweichend von der Norm liegen reduzierte Trijodthyroninwerte und erhöhte TSH-Werte im Serum vor. Bei einer untersuchten Hündin sind alle Thyroidhormonwerte reduziert und es liegt eine erhöhte TSH-Konzentration im Serum vor.

Befunde der histopathologischen Untersuchung der Schilddrüsen eines 22 Wochen alten betroffenen Rüden und einer ebenso alten betroffenen Hündin umfassen das Vorliegen einer schwerwiegenden, diffusen Hyperplasie der Follikel, eine quader- oder säulenartige Verformung der Epithelzellen. Die Follikel erscheinen überwiegend klein, sind unregelmäßig geformt und enthalten wenig Kolloid. 
Ein Radiojodidaufnahme- und ein Perchlorattest im Alter von acht Wochen nach siebentägiger Aussetzung der Thyroxintherapie zeigt bei einem betroffenen Toy Foxterrier vier Stunden nach Radiojodidadministration eine mit $33 \%$ der Gesamtdosis um das Elffache höhere Aufnahme von Radiojodid als bei einem normalen Kontrollhund. Vierundzwanzig Stunden nach Administration ergibt sich demgegenüber bei dem betroffenen Foxterrier eine um 50 \% reduzierte Radioaktivität, während beim normalen Kontrollhund ein Anstieg um 120 \% vorliegt. Innerhalb einer Stunde nach Perchloridgabe sinkt die verbliebene Menge an Radiojodid bei dem betroffenen Toy Foxterrier um 80 \%, während bei normalen Hunden lediglich ein Rückgang um $10 \%$ stattfindet. Die Ergebnisse sprechen für das Vorliegen eines intakten Jodidaufnahmemechanismus.

Aufschluss über den Transport von Jodid innerhalb der Schilddrüse gibt eine Untersuchung der Pendrinfunktion anhand des BAER (Brainstem Auditory Evoked Responses)-Tests. Pendrin ist in den Follikelepithelzellen der Schilddrüse essentiell am Transport von Jodid durch die Apikalmembran beteiligt. Zudem spielt Pendrin eine wesentliche Rolle für die Funktionsfähigkeit des Corti-Organs, die mit einer möglichen Beteiligung am Ionentransport in Zusammenhang gebracht wird. Bei betroffenen elf Wochen alten Toy Foxterriern unter Thyroxintherapie liegen die im BAER-Test gemessenen Reaktionen im Referenzbereich. Demnach ist die Pendrinfunktion zumindest im Corti-Organ nicht beeinträchtigt.

Insgesamt deuten die Untersuchungsergebnisse auf eine Störung der Jodidoxidation und der Bindung von Jodid an Thyreoglobulin und damit auf einen Defekt der Thyroidperoxidase oder des Thyroidoxidasekomplexes hin.

Eine Western Blot Untersuchung von Schilddrüsengewebe unter Verwendung eines polyklonalen Antikörpers gegen canines Thyreoglobulin betroffener Toy Foxterrier und gesunder Kontrollhunde spricht ebenfalls für eine gestörte Jodierung von Thyreoglobulin. Während bei normalen Hunden drei immunoreaktive Thyreoglobulinproteine zu $200 \mathrm{kDa}, 300 \mathrm{kDa}$ und $600 \mathrm{kDa}$ vorliegen, können bei betroffenen Hunden nur die zwei kleineren Thyreoglobulinproteine nachgewiesen werden. Die 200 und $300 \mathrm{kDa}$ großen Proteine werden als unglykosylierte bzw. glykosylierte Thyreoglobulinmonomere interpretiert. Das 600 kDa große Protein in der 
Schilddrüse normaler Hunde wird als Thyreoglobulindimer gedeutet (Fyfe et al. 2003). Die Formation von Thyreoglobulindimeren ist abhängig von einer intakten Jodierung von Thyreoglobulin (Seed und Goldberg 1965).

\section{II.b Genetischer Hintergrund der hereditären Schilddrüsenunterfunktion bei Toy Foxterriern}

Die Ergebnisse einer Untersuchung der Jodidoxidierungsaktivität von Thyroidperoxidase nach einer Methode von Nakashima und Taurog (1978) sprechen für das Vorliegen einer Funktionsstörung dieses Proteins. Bei betroffenen Hunden ist im Gegensatz zu normalen Kontrollhunden keine Thyroidperoxidase-Aktivität nachweisbar (Fyfe et al. 2003).

Die Bestimmung der caninen Thyroidperoxidase (TPO)-cDNA-Sequenz erfolgte anhand der Sequenzierung eines $3 \mathrm{~kb}$ großen TPO-Inserts eines Klons aus einer caninen Bakteriophage-Lambda-gt11-Schilddrüsen-cDNA-Bibliothek (Lefort et al. 1989) und anschließender Identifizierung des 5'-Endes mittels RACE (rapid amplification of cDNA ends) unter Einsatz von Schilddrüsen-mRNA eines gesunden Kontrollhundes. Das offene Leseraster umfasst 2799 bp und codiert für ein 933 Aminosäuren langes Polypeptid. Die Länge der 3'-UTR beträgt 145 bp einschließlich eines Polyadenylierungssignals 22 bp aufwärts der Polyadenylierungssequenz. Die für TPO anderer Spezies typischen Proteindomänen, darunter ein N-terminales Signalpeptid für den Transport in das rauhe endoplasmatische Retikulum, eine C-terminale Transmembrandomäne sowie funktionelle Domänen für Peroxidase, Sushi und den epidermalen Wachstumsfaktor sind vorhanden. Die identifizierte mRNA-Sequenz (Fyfe et al. 2003) hat eine Länge von 2944 Nukleotiden (NCBI-GenBank: AY094504) und ist offenbar in 17 Exons unterteilt. Exon 2-17 sind auf Chromosom 17 im GenBank Contig NW_876263 zwischen Position 751087 und Position 787972 lokalisiert (NCBIGeneID: 403521). Die Lage des ersten Exons, das die 5'-UTR und die ersten zwei Nukleotide der codierenden Sequenz beinhaltet, ist nicht veröffentlicht. Abb. 117 stellt schematisch die Lage der Exons 2-17 in der genomischen Sequenz dar. 


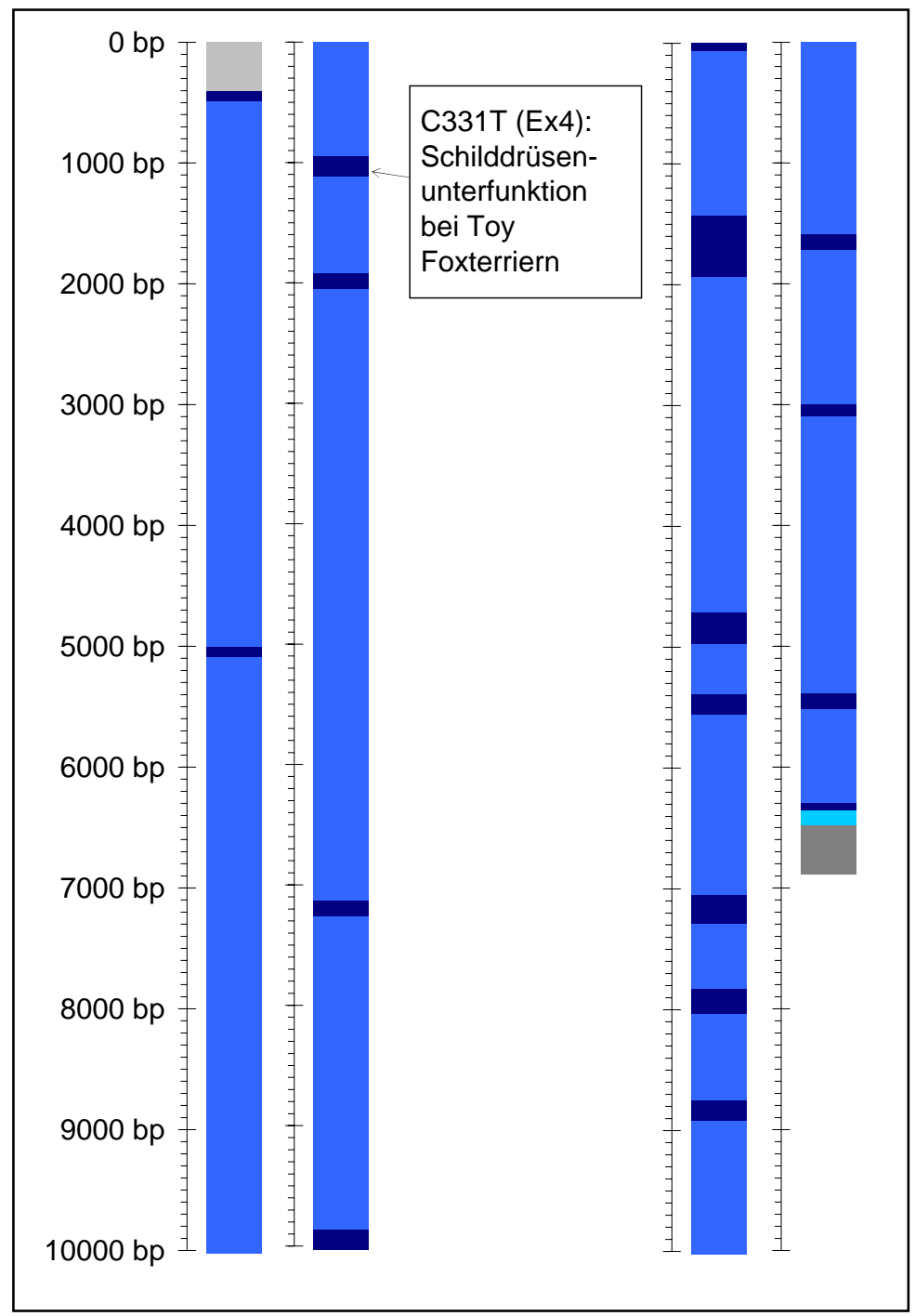

Abb. 117 Schematische Darstellung des caninen TPO-Gens (Exon 2-Exon 17) und Lage der bisher identifizierten Mutationen. Dunkelblau: codierende sequenz, hellblau: Intronsequenz, türkis: 3'UTR, grau: intergenische Sequenz.

\section{III.b Ursächliche Mutation für hereditäre Schilddrüsenunterfunktion bei Toy Foxterriern}

Ein Vergleich der cDNA-Sequenz betroffener Hunde mit dieser Referenzsequenz ergibt das Vorliegen einer Substitution von Cytosin durch Thymin an Position 331 der mRNA (GenBank: AY094504) mit der Folge einer Substitution der Aminosäure Arginin an Position 111 durch ein verfrühtes Stoppcodon (Abb. 118). Dadurch kommt es zu einer Verkürzung des resultierenden Polypeptids auf 110 Aminosäuren und zum Verlust der Peroxidase-Domäne (Fyfe et al. 2003). 


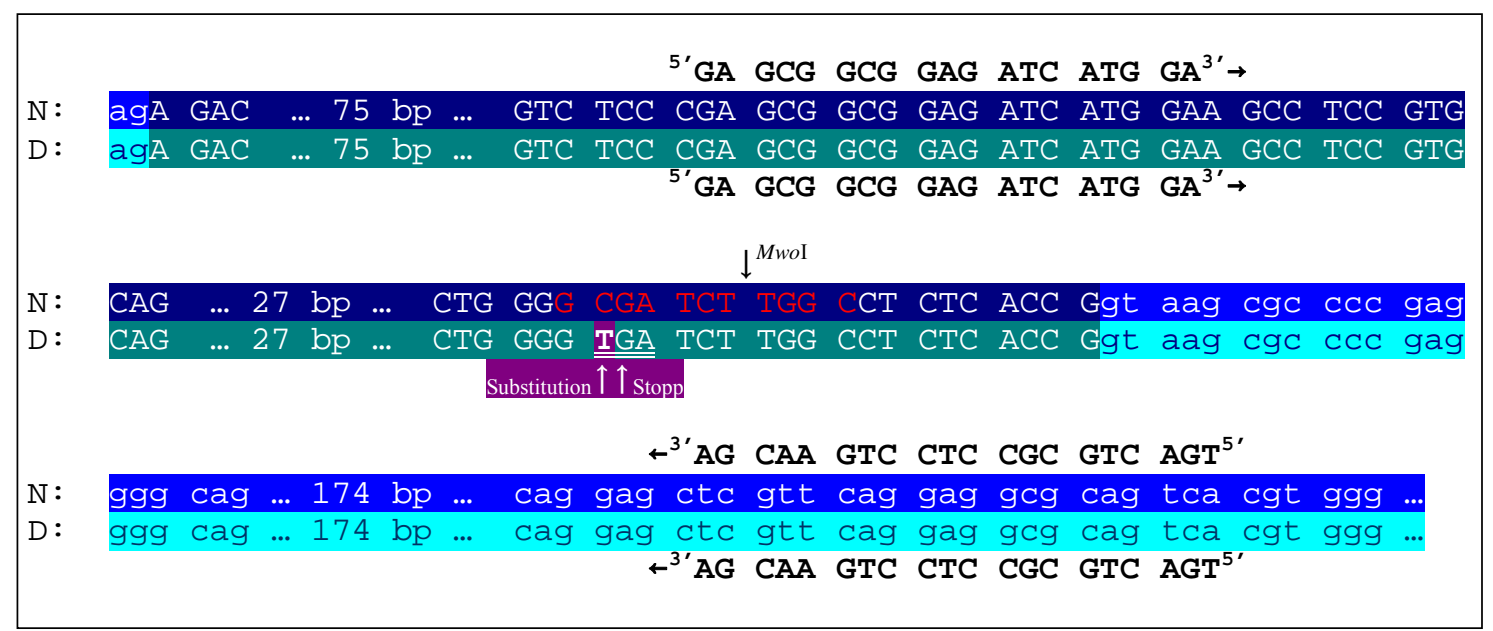

Abb. 118 Exon 4 des caninen TPO-Gens und angrenzende Intronsequenzen. N: normale Sequenz, D: defekte Sequenz, dunkelblau: Exon normale Sequenz, dunkelgrün: Exon defekte Sequenz, hellblau: Intron normale Sequenz, hellgrün: Intron defekte Sequenz, rote Schrift: MwoI-Erkennungssequenz, MwoI-Restriktionsschnittstelle in normaler Sequenz durch Pfeil gekennzeichnet, Substitution in defekter Sequenz violett unterlegt und durch Pfeil gekennzeichnet, verfrühtes Stoppcodon durch Pfeil gekennzeichnet.

\section{IV.b Genotypisierung für hereditäre Schilddrüsenunterfunktion bei Toy Foxterriern}

Der Nachweis der Mutation kann per Amplifikation eines 305-bp-Fragments und anschließender RFLP-Typisierung erfolgen. Der RFLP beruht auf einer MwoIErkennungssequenz im Wildtypallel, die aufgrund der Mutation im Defektallel nicht enthalten ist (Fyfe et al. 2003). 


\subsubsection{Primer}

Tabelle 18 Liste der in Kapitel 3.5 genannten Primer

\begin{tabular}{|c|c|c|c|c|}
\hline Krankheit/Merkmal & Zweck & Primer & $\begin{array}{l}\text { PCR- } \\
\text { Produkt } \\
{[\text { bp }]}\end{array}$ & Quelle \\
\hline $\begin{array}{l}\text { dystrophische } \\
\text { Epidermolysis bullosa bei } \\
\text { Golden Retrievern }\end{array}$ & RFLP & $\begin{array}{l}\text { V: }{ }^{5 \prime} \text { 'TCCACCAGATACCCTCCTGG }{ }^{3} \\
\text { r: }{ }^{3} \text { GTACACACACCAGCTATCTC }\end{array}$ & 127 & $\begin{array}{l}\text { (Baldeschi et } \\
\text { al. 2003) }\end{array}$ \\
\hline $\begin{array}{l}\text { epidermolytische } \\
\text { Hyperkeratose bei Norfolk } \\
\text { Terriern }\end{array}$ & RFLP & $\begin{array}{l}\text { V: }:^{5^{\prime}} \text { AAGGAACTGACTACAGAAATCAAC } \\
\text { AG }^{3^{\prime}} \\
\text { r: }{ }^{3^{\prime}} \text { CGTCTTTGTTAGGGACCTTCC }{ }^{5}\end{array}$ & 660 & $\begin{array}{l}\text { (Credille et } \\
\text { al. 2005) }\end{array}$ \\
\hline \multirow[t]{3}{*}{ PRA bei Irischen Settern } & RFLP & $\begin{array}{l}\mathrm{V}:{ }^{5^{\prime}} \text { GACTGCAGAACAACAGGAAGCACT } \\
\text { r: }{ }^{3}{ }^{3} \text { TCCTGTCCTGCTGTCGGTTCTTTCG }\end{array}$ & 114 & $\begin{array}{l}\text { (Clements et } \\
\text { al. 1993) }\end{array}$ \\
\hline & $\begin{array}{l}\text { Heteroduplex- } \\
\text { analyse }\end{array}$ & $\begin{array}{l}\text { V: }:^{5^{\prime}} \text { GAGTTTTCCCGTTTCCACGAA }{ }^{3 \prime} \\
\text { r: }{ }^{3} \text { TCCTGTCCTGCTGTCGGTTCTTTCG }\end{array}$ & 157 & $\begin{array}{l}\text { (Ray et al. } \\
\text { 1995) }\end{array}$ \\
\hline & ASP & 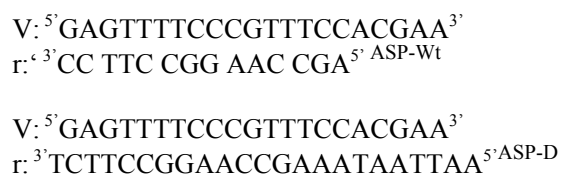 & 90 & $\begin{array}{l}\text { (Ray et al. } \\
\text { 1996) }\end{array}$ \\
\hline PRA bei Sloughis & Sequenzierung & $\begin{array}{l}\text { v: }:^{5^{\prime} \text { CCCGTTTCCACGAAGAGATC }}{ }^{3^{\prime}} \\
\text { r: }{ }^{3^{\prime}} \text { TCCTGCTGTCGGTTCTTTC }{ }^{\prime \prime}\end{array}$ & 150 & $\begin{array}{l}\text { (Dekomien et } \\
\text { al. 2000) }\end{array}$ \\
\hline PRA bei Corgis & ASP & 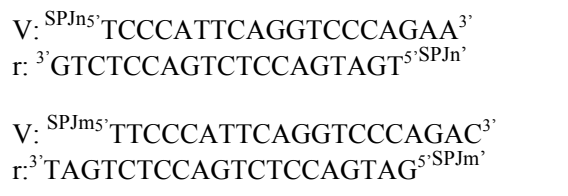 & 213 & $\begin{array}{l}\text { (Petersen- } \\
\text { Jones et al. } \\
\text { 1999) }\end{array}$ \\
\hline $\begin{array}{l}\text { pd-PRA bei } \\
\text { Zergschnauzern }\end{array}$ & RFLP & $\begin{array}{l}\text { V: }{ }^{5^{\prime}} \text { TGAGCATTCAAGAATATGAACT } \\
\text { r: }{ }^{3}{ }^{3} \text { CCCCTACACCTCAGAAAGG }\end{array}$ & 447 & $\begin{array}{l}\text { (Zhang et al. } \\
\text { 1998) }\end{array}$ \\
\hline $\begin{array}{l}\text { XLPRA-1 bei Sibirischen } \\
\text { Huskys und Samoyeden }\end{array}$ & Sequenzierung & $\begin{array}{l}\mathrm{V}:{ }^{5 \prime} \text { AAGGGGAGGAGAAAGGGGAGGCT, }{ }^{3,} \\
\text { r: }{ }^{3} \text { ATACTTCCCCTCCTCCTTCTCCCT }{ }^{5} \text { “ }\end{array}$ & $\begin{array}{l}257 / \\
252\end{array}$ & $\begin{array}{l}\text { (Zhang et al. } \\
\text { 2002) }\end{array}$ \\
\hline XLPRA-2 & Sequenzierung & $\begin{array}{l}\mathrm{V}:{ }^{5} \text { AAGGGGAGGAGAAAGGGGAGGCT }{ }^{3} \\
\mathrm{r:}{ }^{3} \text { ACTCTCCCTTCTCCTTCATCCCCT }\end{array}$ & $\begin{array}{l}523 / \\
521\end{array}$ & $\begin{array}{l}\text { (Zhang et al. } \\
\text { 2002) }\end{array}$ \\
\hline \multirow[t]{2}{*}{ PRCD in 34 Rassen } & RFLP & $\begin{array}{l}\text { V: }{ }^{5^{\prime} C C A G T G G C A G C A G G A A C C}{ }^{3 \prime} \\
\text { r: }{ }^{\prime} \text { 'GTCAGCACCCGTCGTCCAGCC }\end{array}$ & 512 & $\begin{array}{l}\text { (Zangerl et al. } \\
\text { 2006) }\end{array}$ \\
\hline & Pyrosequenzierung & $\begin{array}{l}\text { V: }{ }^{5 \prime} \text { TTGTGAGAGCCGGCAGG }{ }^{3} \\
\text { r: }^{3^{\prime}} \text { GATGAGTCGTGGAACCGGTA } \\
\text { S: }:^{5} \text { 'BGGGCAotin }\end{array}$ & 52 & $\begin{array}{l}\text { (Zangerl et al. } \\
2006)\end{array}$ \\
\hline
\end{tabular}


Fortsetzung Tabelle 18

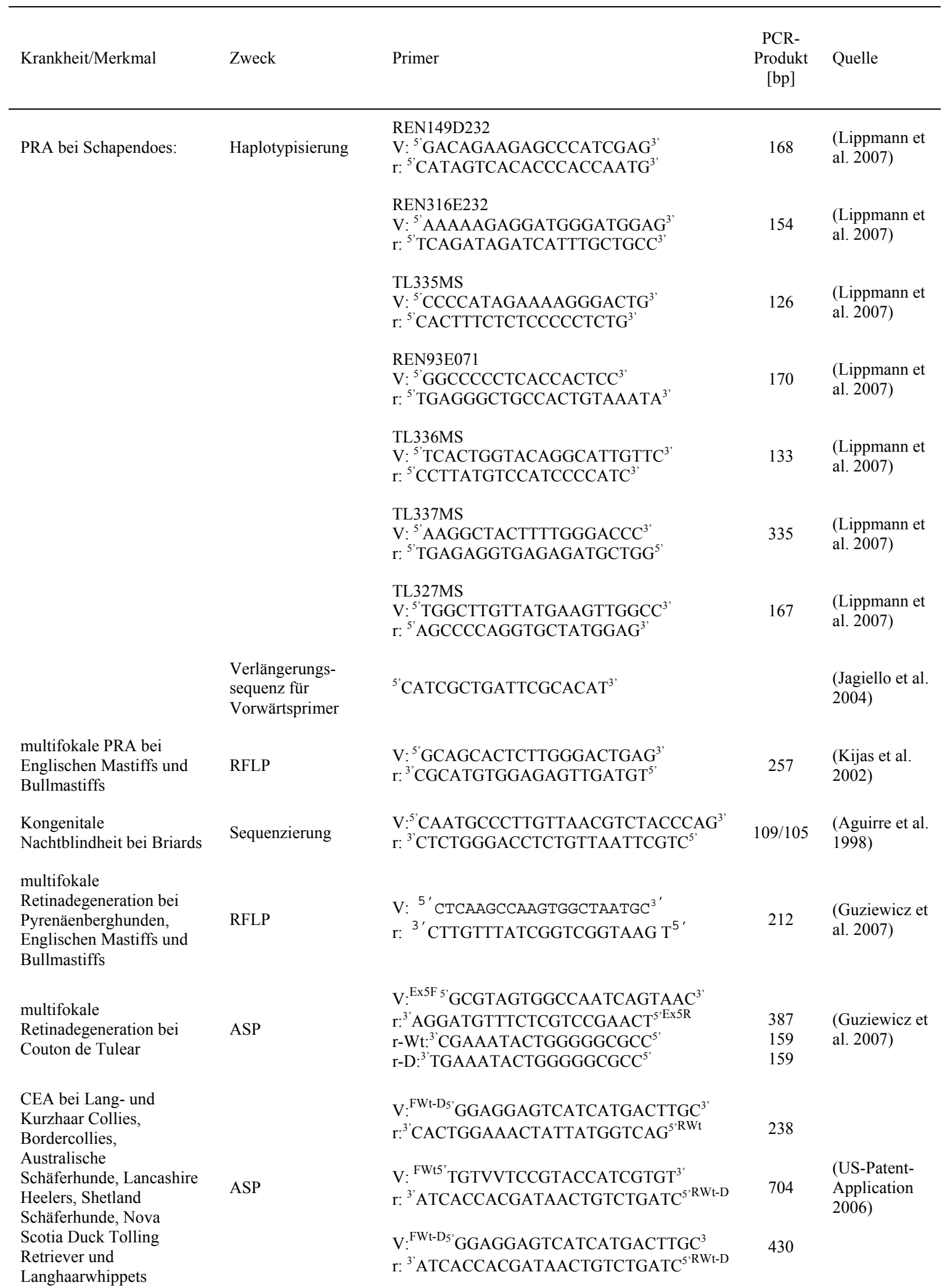


Fortsetzung Tabelle 18

\begin{tabular}{|c|c|c|c|c|}
\hline Krankheit/Merkmal & Zweck & Primer & $\begin{array}{l}\text { PCR- } \\
\text { Produkt } \\
\text { [bp] }\end{array}$ & Quelle \\
\hline $\begin{array}{l}\text { Katarakt bei Boston } \\
\text { Terriern Staffordshire } \\
\text { Bullterriern und } \\
\text { Australischen } \\
\text { Schäferhunden }\end{array}$ & Sequenzieruing & $\begin{array}{l}\text { V: }:^{5^{\prime}} \text { CGAGTGTGACTTCTGCGTGA, } \\
\text { r: }{ }^{3} \text { TTACGGGTTGTCGGACTTG }{ }^{\prime \prime}\end{array}$ & 112 & $\begin{array}{l}\text { (Mellersh et } \\
\text { al. 2006b) }\end{array}$ \\
\hline $\begin{array}{l}\text { Cystinurie bei } \\
\text { Neufundländern }\end{array}$ & RFLP & $\begin{array}{l}\text { V: }{ }^{5} \text { CAAGAGAAACTGGACTACATCACA }{ }^{3} \\
\text { r: }{ }^{3} \text { CTACCACCCCAACTCTTTTCG }{ }^{5}\end{array}$ & 181 & $\begin{array}{l}\text { (Henthorn et } \\
\text { al. 2000) }\end{array}$ \\
\hline Nierencystadenokarzinom & Sequenzierung & $\begin{array}{l}\text { V: }:^{5^{\prime}} \text { GAGGCAGAGCAATTTGGTT }{ }^{3} \\
\text { r: }{ }^{3} \text { AGTTTGTGTTTTAGTAGGTTGT } \\
\text { S: }{ }^{5^{\prime}} \text { GAGAATGAACACGGCCTTC }{ }^{3}\end{array}$ & 1500 & $\begin{array}{l}\text { (Lingaas et } \\
\text { al. 2003) }\end{array}$ \\
\hline $\begin{array}{l}\text { X-chromosomal } \\
\text { gekoppelte Nephritis bei } \\
\text { Samoyedeb }\end{array}$ & Sequenzierung & $\begin{array}{l}\text { V: }:^{5}{ }^{\prime} \text { CCAAAGGTAACCCCGGCCT T' } \\
\text { r: }{ }^{3} \text { CCACTATACCCAAAAGGTC }\end{array}$ & 87 & $\begin{array}{l}\text { (Zheng et al. } \\
\text { 1994) }\end{array}$ \\
\hline $\begin{array}{l}\text { Schilddrüsenunterfunktion } \\
\text { bei Toy Foxterriern }\end{array}$ & RFLP & $\begin{array}{l}\text { V: ' }{ }^{\prime} \text { GAGCGGCGGAGATCATGGA }{ }^{3} \text { ' } \\
\text { r: }{ }^{3} \text { AGCAAGTCCTCCGCGTCAGT }\end{array}$ & 305 & $\begin{array}{l}\text { (Fyfe et al. } \\
2003 \text { ) }\end{array}$ \\
\hline
\end{tabular}

V: Vorwärtsprimer, 5'-3'-Richtung, r: reverser Primer, 3'-5'-Richtung, S: Sequenzierungsprimer, 5'-3'-Richtung 


\subsubsection{Literatur}

Abe, T., Kikuchi, T. und Shinohara, T. (1994): The sequence of the human phosducin gene (PDC) and its 5'-flanking region. Genomics, 19 (2), 369-72.

Acland, G.M., Blanton, S.H., Hershfield, B. und Aguiree, G.D. (1994): XLPRA: a canine retinal degeneration inherited as an X-linked trait. Am J Med Genet, 52 (1), 27-33.

Acland, G.M., Ray, K., Mellersh, C.S., Gu, W., Langston, A.A., Rine, J., Ostrander, E.A. und Aguirre, G.D. (1998): Linkage analysis and comparative mapping of canine progressive rod-cone degeneration (prcd) establishes potential locus homology with retinitis pigmentosa (RP17) in humans. Proc Natl Acad Sci U S A, 95 (6), 3048-53.

Adley, B.P., Smith, N.D., Nayar, R. und Yang, X.J. (2006): Birt-Hogg-Dube syndrome: clinicopathologic findings and genetic alterations. Arch Pathol Lab Med, 130 (12), 1865-70.

Aguirre, G., Farber, D., Lolley, R., Fletcher, R.T. und Chader, G.J. (1978): Rod-cone dysplasia in Irish setters: a defect in cyclic GMP metabolism in visual cells. Science, 201 (4361), 1133-4.

Aguirre, G., Alligood, J., O'Brien, P. und Buyukmihci, N. (1982a): Pathogenesis of progressive rod-cone degeneration in miniature poodles. Invest Ophthalmol Vis Sci, 23 (5), 610-30.

Aguirre, G., Farber, D., Lolley, R., O'Brien, P., Alligood, J., Fletcher, R.T. und Chader, G. (1982b): Retinal degeneration in the dog. III. Abnormal cyclic nucleotide metabolism in rod-cone dysplasia. Exp Eye Res, 35 (6), 625-42.

Aguirre, G.D. und Rubin, L.F. (1972): Progressive retinal atrophy in the Miniature Poodle: an electrophysiologic study. J Am Vet Med Assoc, 160, 191-201.

Aguirre, G.D. und Rubin, L.F. (1974): Pathology of hemeralopia in the Alaskan malamute dog. Invest Ophthalmol, 13 (3), 231-5.

Aguirre, G.D. und Rubin, L.F. (1975): The electroretinogram in dogs with inherited cone degeneration. Invest Ophthalmol, 14 (11), 840-7.

Aguirre, G.D. und Acland, G.M. (1988): Variation in retinal degeneration phenotype inherited at the prcd locus. Exp Eye Res, 46 (5), 663-87.

Aguirre, G.D., Baldwin, V., Pearce-Kelling, S., Narfstrom, K., Ray, K. und Acland, G.M. (1998): Congenital stationary night blindness in the dog: common mutation in the RPE65 gene indicates founder effect. Mol Vis, 4, 23. 
Aguirre, G.D., Baldwin, V., Weeks, K.M., Acland, G.M. und Ray, K. (1999):

Frequency of the codon 807 mutation in the cGMP phosphodiesterase betasubunit gene in Irish setters and other dog breeds with hereditary retinal degeneration. J Hered, 90 (1), 143-7.

Akhmedov, N.B., Piriev, N.I., Ray, K., Acland, G.M., Aguirre, G.D. und Farber, D.B. (1997): Structure and analysis of the transducin beta3-subunit gene, a candidate for inherited cone degeneration (cd) in the dog. Gene, 194 (1), 47-56.

Akhmedov, N.B., Piriev, N.I., Pearce-Kelling, S., Acland, G.M., Aguirre, G.D. und Farber, D.B. (1998): Canine cone transducin-gamma gene and cone degeneration in the cd dog. Invest Ophthalmol Vis Sci, 39 (10), 1775-81.

Alhaidari, Z., Ortonne, J.P. und Pisani, A. (1994): Congenital ichthyosis in two Cavalier King Charles spaniel littermates. Vet Dermatol, 5 (3), 117-121.

August, J.R., Chickering, W.R. und Rikihisa, Y. (1988): Congenital ichthyosis in a dog: comparison with the human ichthyosiform dermatoses. Compendium on Continuing Education for the Practicing Veterinarian, 10 (1), 40-45.

Baehr, W., Champagne, M.S., Lee, A.K. und Pittler, S.J. (1991): Complete cDNA sequences of mouse rod photoreceptor cGMP phosphodiesterase alpha- and beta-subunits, and identification of beta'-, a putative beta-subunit isozyme produced by alternative splicing of the beta-subunit gene. FEBS Lett, 278 (1), 107-14.

Baldeschi, C., Gache, Y., Rattenholl, A., Bouille, P., Danos, O., Ortonne, J.P., Bruckner-Tuderman, L. und Meneguzzi, G. (2003): Genetic correction of canine dystrophic epidermolysis bullosa mediated by retroviral vectors. Hum Mol Genet, 12 (15), 1897-905.

Barbehenn, E., Gagnon, C., Noelker, D., Aguirre, G. und Chader, G. (1988): Inherited rod-cone dysplasia: abnormal distribution of cyclic GMP in visual cells of affected Irish setters. Exp Eye Res, 46 (2), 149-59.

Barnett, K.C. (1976): Comparative aspects of canine hereditary eye disease. Adv Vet Sci Comp Med, 20, 39-67.

Barnett, K.C. (1978): Hereditary cataract in the dog. J Small Anim Pract, 19 (2), 10920.

Barnett, K.C. und Stades, F.C. (1979): Collie eye anomaly in the Shetland sheepdog in the Netherlands. J Small Anim Pract, 20 (6), 321-9.

Barnhart, K.F., Credille, K.M., Ambrus, A. und Dunstan, R.W. (2004): A heritable keratinization defect of the superficial epidermis in norfolk terriers. $J$ Comp Pathol, 130 (4), 246-54.

Bauch, C. und Verrey, F. (2002): Apical heterodimeric cystine and cationic amino acid transporter expressed in MDCK cells. Am J Physiol - Renal Physiol, 283 (1), F181-9. 
Baumal, R., Thorner, P., Valli, V.E., McInnes, R., Marrano, P., Jacobs, R., Binnington, A. und Bloedow, A.G. (1991): Renal disease in carrier female dogs with Xlinked hereditary nephritis. Implications for female patients with this disease. Am J Pathol, 139 (4), 751-64.

Bavik, C.O., Levy, F., Hellman, U., Wernstedt, C. und Eriksson, U. (1993): The retinal pigment epithelial membrane receptor for plasma retinol-binding protein. Isolation and cDNA cloning of the 63-kDa protein. $J$ Biol Chem, 268 (27), 20540-6.

Bayes, M., Hartung, A.J., Ezer, S., Pispa, J., Thesleff, I., Srivastava, A.K. und Kere, J. (1998): The anhidrotic ectodermal dysplasia gene (EDA) undergoes alternative splicing and encodes ectodysplasin-A with deletion mutations in collagenous repeats. Hum Mol Genet, 7 (11), 1661-9.

Bedford, P.G.C. (1984): Retinal pigment epithelial dystrophy (CPRA): a study of the disease in the Briard. J Small Anim Pract, 25, 129-138.

Bernard, M.A. und Valli, V.E. (1977): Familial renal disease in Samoyed dogs. Can Vet $J, 18$ (7), 181-9.

Bertran, J., Magagnin, S., Werner, A., Markovich, D., Biber, J., Testar, X., Zorzano, A., Kuhn, L.C., Palacin, M. und Murer, H. (1992a): Stimulation of system y(+)-like amino acid transport by the heavy chain of human 4F2 surface antigen in Xenopus laevis oocytes. Proc Natl Acad Sci U S A, 89 (12), 5606-10.

Bertran, J., Werner, A., Moore, M.L., Stange, G., Markovich, D., Biber, J., Testar, X., Zorzano, A., Palacin, M. und Murer, H. (1992b): Expression cloning of a cDNA from rabbit kidney cortex that induces a single transport system for cystine and dibasic and neutral amino acids. Proc Natl Acad Sci U S A, 89 (12), 5601-5.

Bloedow, A.G. (1981): Familial renal disease in samoyed dogs. Vet Rec, 108 (8), 167-8.

Bovee, K.C., Thier, S.O., Rea, C. und Segal, S. (1974): Renal clearance of amino acids in canine cystinuria. Metabolism, 23 (1), 51-8.

Bovee, K.C. (1986): Canine cystine urolithiasis. Vet Clin North Am Small Anim Pract, 16 (2), 211-5.

Brand, E. und Cahill, G. (1936): Caninen Cystinuria III. J Biol Chem, 114, Scientific Proceedings XV.

Brand, E. und Cahill, G. (1938): Canine Cystinuria IV. J Biol Chem, 123, Scientific Proceedings xvi.

Breen, M., Thomas, R., Binns, M.M., Carter, N.P. und Langford, C.F. (1999): Reciprocal chromosome painting reveals detailed regions of conserved synteny between the karyotypes of the domestic dog (Canis familiaris) and human. Genomics, 61 (2), 145-55. 
Breen, M., Jouquand, S., Renier, C., Mellersh, C.S., Hitte, C., Holmes, N.G., Cheron, A., Suter, N., Vignaux, F., Bristow, A.E., Priat, C., McCann, E., Andre, C., Boundy, S., Gitsham, P., Thomas, R., Bridge, W.L., Spriggs, H.F., Ryder, E.J., Curson, A., Sampson, J., Ostrander, E.A., Binns, M.M. und Galibert, F. (2001): Chromosome-specific single-locus FISH probes allow anchorage of an 1800marker integrated radiation-hybrid/linkage map of the domestic dog genome to all chromosomes. Genome Res, 11 (10), 1784-95.

Breen, M., Hitte, C., Lorentzen, T.D., Thomas, R., Cadieu, E., Sabacan, L., Scott, A., Evanno, G., Parker, H.G., Kirkness, E.F., Hudson, R., Guyon, R., Mahairas, G.G., Gelfenbeyn, B., Fraser, C.M., Andre, C., Galibert, F. und Ostrander, E.A. (2004): An integrated 4249 marker FISH/RH map of the canine genome. BMC Genomics, 5 (1), 65.

Bridges, C.D. (1976): Vitamin A and the role of the pigment epithelium during bleaching and regeneration of rhodopsin in the frog eye. Exp Eye Res, 22 (5), 435-55.

Broer, S. und Wagner, C.A. (2002): Structure-function relationships of heterodimeric amino acid transporters. Cell Biochem Biophys, 36 (2-3), 155-68.

Bu, L., Jin, Y., Shi, Y., Chu, R., Ban, A., Eiberg, H., Andres, L., Jiang, H., Zheng, G., Qian, M., Cui, B., Xia, Y., Liu, J., Hu, L., Zhao, G., Hayden, M.R. und Kong, X. (2002): Mutant DNA-binding domain of HSF4 is associated with autosomal dominant lamellar and Marner cataract. Nat Genet, 31 (3), 276-8.

Buyukmihci, N., Aguirre, G. und Marshall, J. (1980): Retinal degenerations in the dog. II. Development of the retina in rod-cone dysplasia. Exp Eye Res, 30 (5), 57591.

Calonge, M.J., Gasparini, P., Chillaron, J., Chillon, M., Gallucci, M., Rousaud, F., Zelante, L., Testar, X., Dallapiccola, B., Di Silverio, F. und et al. (1994): Cystinuria caused by mutations in rBAT, a gene involved in the transport of cystine. Nat Genet, 6 (4), 420-5.

Capt, A., Spirito, F., Guyon, R., Andre, C., Ortonne, J.P. und Meneguzzi, G. (2003): Cloning of laminin gamma $2 \mathrm{cDNA}$ and chromosome mapping of the genes for the dog adhesion ligand laminin 5. Biochem Biophys Res Commun, 312 (4), 1256-65.

Capt, A., Spirito, F., Guaguere, E., Spadafora, A., Ortonne, J.P. und Meneguzzi, G. (2005): Inherited junctional epidermolysis bullosa in the German Pointer: establishment of a large animal model. J Invest Dermatol, 124 (3), 530-5.

Casal, M.L., Giger, U., Bovee, K.C. und Patterson, D.F. (1995): Inheritance of cystinuria and renal defect in Newfoundlands. J Am Vet Med Assoc, 207 (12), $1585-9$.

Casal, M.L., Jezyk, P.F., Greek, J.M., Goldschmidt, M.H. und Patterson, D.F. (1997): X-linked ectodermal dysplasia in the dog. J Hered, 88 (6), 513-7. 
Casal, M.L., Scheidt, J.L., Rhodes, J.L., Henthorn, P.S. und Werner, P. (2005): Mutation identification in a canine model of X-linked ectodermal dysplasia. Mamm Genome, 16 (7), 524-31.

Case, L.C., Ling, G.V., Franti, C.E., Ruby, A.L., Stevens, F. und Johnson, D.L. (1992): Cystine-containing urinary calculi in dogs: 102 cases (1981-1989). J Am Vet Med Assoc, 201 (1), 129-33.

Chader, G., Aguirre, G., Sanyal, S., Acland, G. und Stramm, L. (1985): Mechanisms of Hereditary Visual Cell Disease. In Hilfer, S.R. (Herausgeber): Cell and Developmental Biology of the Eye - Heredity and Visual Development. Springer Verlag, New York 1985, S. 1-30.

Chastain, C.B. und Swayne, D.E. (1985): Congenital hypotrichosis in male basset hound littermates. J Am Vet Med Assoc, 187 (8), 845-6.

Cideciyan, A.V., Hood, D.C., Huang, Y., Banin, E., Li, Z.Y., Stone, E.M., Milam, A.H. und Jacobson, S.G. (1998): Disease sequence from mutant rhodopsin allele to rod and cone photoreceptor degeneration in man. Proc Natl Acad Sci U S A, 95 (12), 7103-8.

Cideciyan, A.V., Jacobson, S.G., Aleman, T.S., Gu, D., Pearce-Kelling, S.E., Sumaroka, A., Acland, G.M. und Aguirre, G.D. (2005): In vivo dynamics of retinal injury and repair in the rhodopsin mutant dog model of human retinitis pigmentosa. Proc Natl Acad Sci U S A, 102 (14), 5233-8.

Clements, P.J., Gregory, C.Y., Peterson-Jones, S.M., Sargan, D.R. und Bhattacharya, S.S. (1993): Confirmation of the rod cGMP phosphodiesterase beta subunit (PDE beta) nonsense mutation in affected rcd-1 Irish setters in the UK and development of a diagnostic test. Curr Eye Res, 12 (9), 861-6.

Corden, L.D. und McLean, W.H. (1996): Human keratin diseases: hereditary fragility of specific epithelial tissues. Exp Dermatol, 5 (6), 297-307.

Cox, M.L., Lees, G.E., Kashtan, C.E. und Murphy, K.E. (2003): Genetic cause of Xlinked Alport syndrome in a family of domestic dogs. Mamm Genome, 14 (6), 396-403.

Credille, K.M., Barnhart, K.F., Minor, J.S. und Dunstan, R.W. (2005): Mild recessive epidermolytic hyperkeratosis associated with a novel keratin 10 donor splice-site mutation in a family of Norfolk terrier dogs. Br J Dermatol, 153 (1), 51-8.

Curtis, R., Barnett, K.C. und Leon, A. (1991): Diseases of the canine posterior segment. In Gelatt, K.N. (Herausgeber): Veterinary Ophthalmology ( ${ }^{\text {nd }}$ Edn.). Lea \& Febinger, Philadelphia, 1991, S. 461-525.

Curtis, R. und Barnett, K.C. (1993): Progressive retinal atrophy in miniature longhaired dachshund dogs. Br Vet J, 149 (1), 71-85. 
Dekomien, G., Runte, M., Godde, R. und Epplen, J.T. (2000): Generalized progressive retinal atrophy of Sloughi dogs is due to an 8-bp insertion in exon 21 of the PDE6B gene. Cytogenet Cell Genet, 90 (3-4), 261-7.

Dekomien, G. und Epplen, J.T. (2002): The canine Phosducin gene: characterization of the exon-intron structure and exclusion as a candidate gene for generalized progressive retinal atrophy in 11 dog breeds. Mol Vis, 8, 138-42.

Dekomien, G. und Epplen, J.T. (2003): Evaluation of the canine RPE65 gene in affected dogs with generalized progressive retinal atrophy. Mol Vis, 9, 601-5.

Donovan, R.H., Freeman, H.M. und Schepens, C.L. (1969): Anomaly of the collie eye. J Am Vet Med Assoc, 155 (6), 872-7.

Dryja, T.P., Adams, S.M., Grimsby, J.L., McGee, T.L., Hong, D.H., Li, T., Andreasson, S. und Berson, E.L. (2001): Null RPGRIP1 alleles in patients with Leber congenital amaurosis. Am J Hum Genet, 68 (5), 1295-8.

Dunstan, R.W., Sills, R.C., Wilkinson, J.E., Paller, A.S. und Hashimoto, K.H. (1988): A disease resembling junctional epidermolysis bullosa in a toy poodle. Am $J$ Dermatopathol, 10 (5), 442-7.

Farber, D.B., Danciger, J.S. und Aguirre, G. (1992): The beta subunit of cyclic GMP phosphodiesterase mRNA is deficient in canine rod-cone dysplasia 1. Neuron, 9 (2), 349-56.

Feliubadalo, L., Font, M., Purroy, J., Rousaud, F., Estivill, X., Nunes, V., Golomb, E., Centola, M., Aksentijevich, I., Kreiss, Y., Goldman, B., Pras, M., Kastner, D.L., Pras, E., Gasparini, P., Bisceglia, L., Beccia, E., Gallucci, M., de Sanctis, L., Ponzone, A., Rizzoni, G.F., Zelante, L., Bassi, M.T., George, A.L., Jr., Manzoni, M., De Grandi, A., Riboni, M., Endsley, J.K., Ballabio, A., Borsani, G., Reig, N., Fernandez, E., Estevez, R., Pineda, M., Torrents, D., Camps, M., Lloberas, J., Zorzano, A. und Palacin, M. (1999): Non-type I cystinuria caused by mutations in SLC7A9, encoding a subunit (bo,+AT) of rBAT. Nat Genet, 23 (1), $52-7$.

Font, M.A., Feliubadalo, L., Estivill, X., Nunes, V., Golomb, E., Kreiss, Y., Pras, E., Bisceglia, L., d'Adamo, A.P., Zelante, L., Gasparini, P., Bassi, M.T., George, A.L., Jr., Manzoni, M., Riboni, M., Ballabio, A., Borsani, G., Reig, N., Fernandez, E., Zorzano, A., Bertran, J. und Palacin, M. (2001): Functional analysis of mutations in SLC7A9, and genotype-phenotype correlation in nonType I cystinuria. Hum Mol Genet, 10 (4), 305-16.

Font-Llitjos, M., Jimenez-Vidal, M., Bisceglia, L., Di Perna, M., de Sanctis, L., Rousaud, F., Zelante, L., Palacin, M. und Nunes, V. (2005): New insights into cystinuria: 40 new mutations, genotype-phenotype correlation, and digenic inheritance causing partial phenotype. J Med Genet, 42 (1), 58-68. 
Forshew, T., Johnson, C.A., Khaliq, S., Pasha, S., Willis, C., Abbasi, R., Tee, L., Smith, U., Trembath, R.C., Mehdi, S.Q., Moore, A.T. und Maher, E.R. (2005): Locus heterogeneity in autosomal recessive congenital cataracts: linkage to $9 \mathrm{q}$ and germline HSF4 mutations. Hum Genet, 117 (5), 452-9.

Fujimoto, M., Izu, H., Seki, K., Fukuda, K., Nishida, T., Yamada, S., Kato, K., Yonemura, S., Inouye, S. und Nakai, A. (2004): HSF4 is required for normal cell growth and differentiation during mouse lens development. Embo J, 23 (21), 4297-306.

Fyfe, J.C., Kampschmidt, K., Dang, V., Poteet, B.A., He, Q., Lowrie, C., Graham, P.A. und Fetro, V.M. (2003): Congenital hypothyroidism with goiter in toy fox terriers. J Vet Intern Med, 17 (1), 50-7.

Fyfe, J.C., Kampschmidt, K. und Dang, V. (2004): Congenital Hypothyroidism in Toy Fox Terriers. Small Animal Clinical Endocrinology, 14 (1), 7.

Gärtner, W. (2001): Das Licht weise den Weg \pm oder: die Konformationsänderungen des

Retinalchromophors im Sehpigment Rhodopsin nach Lichtanregung. Angewandte Chemie, 113 (16), 3065-3069.

Gaudet, R., Bohm, A. und Sigler, P.B. (1996): Crystal structure at 2.4 angstroms resolution of the complex of transducin betagamma and its regulator, phosducin. Cell, 87 (3), 577-88.

Gerber, S., Perrault, I., Hanein, S., Barbet, F., Ducroq, D., Ghazi, I., Martin-Coignard, D., Leowski, C., Homfray, T., Dufier, J.L., Munnich, A., Kaplan, J. und Rozet, J.M. (2001): Complete exon-intron structure of the RPGR-interacting protein (RPGRIP1) gene allows the identification of mutations underlying Leber congenital amaurosis. Eur J Hum Genet, 9 (8), 561-71.

Goldstein, O., Zangerl, B., Pearce-Kelling, S., Sidjanin, D.J., Kijas, J.W., Felix, J., Acland, G.M. und Aguirre, G.D. (2006): Linkage disequilibrium mapping in domestic dog breeds narrows the progressive rod-cone degeneration interval and identifies ancestral disease-transmitting chromosome. Genomics, 88 (5), 541-50.

Gould, D. (2001): Congenital stationary night blindness in briards in the UK. Vet Rec, 148 (11), 351-2.

Gould, D.J., Petersen-Jones, S.M., Sohal, A., Barnett, K.C. und Sargan, D.R. (1995): Investigation of the role of opsin gene polymorphism in generalized progressive retinal atrophies in dogs. Anim Genet, 26 (4), 261-7.

Gould, D.J., Petersen-Jones, S.M., Lin, C.T. und Sargan, D.R. (1997): Cloning of canine rom-1 and its investigation as a candidate gene for generalized progressive retinal atrophies in dogs. Anim Genet, 28 (6), 391-6. 
Grahn, B.H., Philibert, H., Cullen, C.L., Houston, D.M., Semple, H.A. und Schmutz, S.M. (1998): Multifocal retinopathy of Great Pyrenees dogs. Vet Ophthalmol, 1 (4), 211-221.

Grahn, B.H. und Cullen, C.L. (2001): Retinopathy of Great Pyrenees dogs: fluorescein angiography, light microscopy and transmitting and scanning electron microscopy. Vet Ophthalmol, 4 (3), 191-9.

Gray, H., Ed. (1925). Nicholas's Veterinary Ophthalmology. London, H \& W Brown.

Greco, D. (1997): Congenital Canine Hypothyroidism. Canine Practice, 22 (1), 23-24.

Green, D.F., Morris, M.L., Cahill, G.F. und Brand, E. (1936): Canine Cystinuria. II. Analysis of cystine calculi and sulfur distribution in the unrine. J Biol Chem, 114 (1), 91-94.

Grieshaber, T.L., Blakemore, J.C. und Yaskulski, S. (1986): Congenital alopecia in a Bichon Frise. J Am Vet Med Assoc, 188 (9), 1053-4.

Griffith, O.W. (1981): The role of glutathione turnover in the apparent renal secretion of cystine. J Biol Chem, 256 (23), 12263-8.

Gropp, K.E., Szel, A., Huang, J.C., Acland, G.M., Farber, D.B. und Aguirre, G.D. (1996): Selective absence of cone outer segment beta 3-transducin immunoreactivity in hereditary cone degeneration (cd). Exp Eye Res, 63 (3), 285-96.

Gu, W., Ray, K., Pearce-Kelling, S., Baldwin, V.J., Langston, A.A., Ray, J., Ostrander, E.A., Acland, G.M. und Aguirre, G.D. (1999): Evaluation of the APOH gene as a positional candidate for pred in dogs. Invest Ophthalmol Vis Sci, 40 (6), 122937.

Guaguere, E., Olivry, T., Poujade-Delverdier, A. und Magnol, J.P. (1997):

Epidermolyse bulleuse jonctionnelle familiale avec absence d'expression de collagene XVII (BPAG2, BP180) chez le Braque Allemand: a propos de deux cas. Pratique medicale et chirurgicale de l'animal de compagnie, 32, 471-480.

Guyon, R., Lorentzen, T.D., Hitte, C., Kim, L., Cadieu, E., Parker, H.G., Quignon, P., Lowe, J.K., Renier, C., Gelfenbeyn, B., Vignaux, F., DeFrance, H.B., Gloux, S., Mahairas, G.G., Andre, C., Galibert, F. und Ostrander, E.A. (2003): A 1-Mb resolution radiation hybrid map of the canine genome. Proc Natl Acad Sci U S A, 100 (9), 5296-301.

Guziewicz, K.E., Zangerl, B., Lindauer, S.J., Mullins, R.F., Sandmeyer, L.S., Grahn, B.H., Stone, E.M., Acland, G.M. und Aguirre, G.D. (2007): Bestrophin gene mutations cause canine multifocal retinopathy: a novel animal model for best disease. Invest Ophthalmol Vis Sci, 48 (5), 1959-67. 
Hamel, C.P., Tsilou, E., Pfeffer, B.A., Hooks, J.J., Detrick, B. und Redmond, T.M. (1993): Molecular cloning and expression of RPE65, a novel retinal pigment epithelium-specific microsomal protein that is post-transcriptionally regulated in vitro. J Biol Chem, 268 (21), 15751-7.

Harnevik, L., Fjellstedt, E., Molbaek, A., Tiselius, H.G., Denneberg, T. und Soderkvist, P. (2001): Identification of 12 novel mutations in the SLC3A1 gene in Swedish cystinuria patients. Hum Mutat, 18 (6), 516-25.

Harnevik, L., Fjellstedt, E., Molbaek, A., Denneberg, T. und Soderkvist, P. (2003): Mutation analysis of SLC7A9 in cystinuria patients in Sweden. Genet Test, 7 (1), 13-20.

Harnevik, L., Hoppe, A. und Soderkvist, P. (2006): SLC7A9 cDNA cloning and mutational analysis of SLC3A1 and SLC7A9 in canine cystinuria. Mamm Genome, 17 (7), 769-76.

Harvey, S.J., Zheng, K., Sado, Y., Naito, I., Ninomiya, Y., Jacobs, R.M., Hudson, B.G. und Thorner, P.S. (1998): Role of distinct type IV collagen networks in glomerular development and function. Kidney Int, 54 (6), 1857-66.

Henthorn, P.S., Liu, J., Gidalevich, T., Fang, J., Casal, M.L., Patterson, D.F. und Giger, U. (2000): Canine cystinuria: polymorphism in the canine SLC3A1 gene and identification of a nonsense mutation in cystinuric Newfoundland dogs. Hum Genet, 107 (4), 295-303.

Hodgman, S.F.J., Parry, H.B., Rasbridge, W.J. und Steel, J.D. (1949): Progressive retinal atrophy in dogs. 1. The disease in Irish Setters (Red). Vet Rec, 61 (15), 185-189.

Holtzapple, P.G., Rea, C., Bovee, K. und Segal, S. (1971): Characteristics of cystine and lysine transport in renal jejunal tissue from cystinuric dogs. Metabolism, 20 (11), 1016-22.

Hood, J.C., Savige, J., Hendtlass, A., Kleppel, M.M., Huxtable, C.R. und Robinson, W.F. (1995): Bull terrier hereditary nephritis: a model for autosomal dominant Alport syndrome. Kidney Int, 47 (3), 758-65.

Hoppe, A., Denneberg, T., Jeppsson, J.O. und Kagedal, B. (1993): Urinary excretion of amino acids in normal and cystinuric dogs. Br Vet $J, 149$ (3), 253-68.

http://www.ensembl.org/Canis_familiaris/: full Ensembl gene build for Canis familiaris. aufgerufen am 15. April 2007

http://www.offa.org/thystatbreed.html: OFFA Thyroid Statistics. (Orthopedic Foundation for Animals Inc., a not-for-profit organization), aufgerufen am 30. November 2007

http://www.optigen.com: OptiGen for genetic advantage. (OptiGen), aufgerufen am 28. April 2007 
Hudson, B.G., Reeders, S.T. und Tryggvason, K. (1993): Type IV collagen: structure, gene organization, and role in human diseases. Molecular basis of Goodpasture and Alport syndromes and diffuse leiomyomatosis. J Biol Chem, 268 (35), 26033-6.

Hurn, S.D., Hardman, C. und Stanley, R.G. (2003): Day-blindness in three dogs: clinical and electroretinographic findings. Vet Ophthalmol, 6 (2), 127-30.

Jagiello, P., Gencik, M., Arning, L., Wieczorek, S., Kunstmann, E., Csernok, E., Gross, W.L. und Epplen, J.T. (2004): New genomic region for Wegener's granulomatosis as revealed by an extended association screen with 202 apoptosis-related genes. Hum Genet, 114 (5), 468-77.

Jansen, B., Thorner, P., Baumal, R., Valli, V., Maxie, M.G. und Singh, A. (1986a): Samoyed hereditary glomerulopathy (SHG). Evolution of splitting of glomerular capillary basement membranes. Am J Pathol, 125 (3), 536-45.

Jansen, B., Tryphonas, L., Wong, J., Thorner, P., Maxie, M.G., Valli, V.E., Baumal, R. und Basrur, P.K. (1986b): Mode of inheritance of Samoyed hereditary glomerulopathy: an animal model for hereditary nephritis in humans. J Lab Clin Med, 107 (6), 551-5.

Jonasdottir, T.J., Mellersh, C.S., Moe, L., Heggebo, R., Gamlem, H., Ostrander, E.A. und Lingaas, F. (2000a): Genetic mapping of a naturally occurring hereditary renal cancer syndrome in dogs. Proc Natl Acad Sci U S A, 97 (8), 4132-7.

Jonasdottir, T.J., Mellersh, C.S., Moe, L., Vignaux, F., Ostrander, E.A. und Lingaas, F. (2000b): Chromosomal assignment of canine TSC2, PKD1 and CLN3 genes by radiation hybrid- and linkage analyses. Animal Genetics, 31 (2), 123-6.

Keep, J.M. (1972): Clinical aspects of progressive retinal atrophy in the Cardigan Welsh Corgi. Aust Vet J, 48 (4), 197-9.

Kemppainen, R.J. und Behrend, E.N. (2001): Diagnosis of canine hypothyroidism. Perspectives from a testing laboratory. Vet Clin North Am Small Anim Pract, 31 (5), 951-62, vii.

Kennedy, L.J., Huson, H.J., Leonard, J., Angles, J.M., Fox, L.E., Wojciechowski, J.W., Yuncker, C. und Happ, G.M. (2006a): Association of hypothyroid disease in Doberman Pinscher dogs with a rare major histocompatibility complex DLA class II haplotype. Tissue Antigens, 67 (1), 53-6.

Kennedy, L.J., Quarmby, S., Happ, G.M., Barnes, A., Ramsey, I.K., Dixon, R.M., Catchpole, B., Rusbridge, C., Graham, P.A., Hillbertz, N.S., Roethel, C., Dodds, W.J., Carmichael, N.G. und Ollier, W.E. (2006b): Association of canine hypothyroidism with a common major histocompatibility complex DLA class II allele. Tissue Antigens, 68 (1), 82-6. 
Kere, J., Srivastava, A.K., Montonen, O., Zonana, J., Thomas, N., Ferguson, B., Munoz, F., Morgan, D., Clarke, A., Baybayan, P., Chen, E.Y., Ezer, S., Saarialho-Kere, U., de la Chapelle, A. und Schlessinger, D. (1996): X-linked anhidrotic (hypohidrotic) ectodermal dysplasia is caused by mutation in a novel transmembrane protein. Nat Genet, 13 (4), 409-16.

Kijas, J.W., Cideciyan, A.V., Aleman, T.S., Pianta, M.J., Pearce-Kelling, S.E., Miller, B.J., Jacobson, S.G., Aguirre, G.D. und Acland, G.M. (2002): Naturally occurring rhodopsin mutation in the dog causes retinal dysfunction and degeneration mimicking human dominant retinitis pigmentosa. Proc Natl Acad Sci U S A, 99 (9), 6328-33.

Koch, S.A. und Rubin, L.F. (1971): Distribution of cones in the hemeralopic dog. J Am Vet Med Assoc, 159 (10), 1257-9.

Koenekoop, R.K. (2005): RPGRIP1 is mutated in Leber congenital amaurosis: a minireview. Ophthalmic Genet, 26 (4), 175-9.

Kohl, S., Baumann, B., Broghammer, M., Jagle, H., Sieving, P., Kellner, U., Spegal, R., Anastasi, M., Zrenner, E., Sharpe, L.T. und Wissinger, B. (2000): Mutations in the CNGB3 gene encoding the beta-subunit of the cone photoreceptor cGMPgated channel are responsible for achromatopsia (ACHM3) linked to chromosome 8q21. Hum Mol Genet, 9 (14), 2107-16.

Kràl, F. und Schwartzman, R. (1964): J.B. Lippincott Co., Philadelphia 1964.

Kunkle, G.A. (1984): Congenital hypotrichosis in two dogs. J Am Vet Med Assoc, 185 (1), 84-5.

Kunzelmann, K., Milenkovic, V.M., Spitzner, M., Soria, R.B. und Schreiber, R. (2007): Calcium-dependent chloride conductance in epithelia: is there a contribution by Bestrophin? Pflugers Arch,

Lee, R.H., Fowler, A., McGinnis, J.F., Lolley, R.N. und Craft, C.M. (1990): Amino acid and cDNA sequence of bovine phosducin, a soluble phosphoprotein from photoreceptor cells. J Biol Chem, 265 (26), 15867-73.

Lees, G.E., Wilson, P.D., Helman, R.G., Homco, L.D. und Frey, M.S. (1997): Glomerular ultrastructural findings similar to hereditary nephritis in 4 English cocker spaniels. J Vet Intern Med, 11 (2), 80-5.

Lees, G.E., Helman, R.G., Homco, L.D., Millichamp, N.J., Hunter, J.F. und Frey, M.S. (1998a): Early diagnosis of familial nephropathy in English cocker spaniels. $J$ Am Anim Hosp Assoc, 34 (3), 189-95.

Lees, G.E., Helman, R.G., Kashtan, C.E., Michael, A.F., Homco, L.D., Millichamp, N.J., Ninomiya, Y., Sado, Y., Naito, I. und Kim, Y. (1998b): A model of autosomal recessive Alport syndrome in English cocker spaniel dogs. Kidney Int, 54 (3), 706-19. 
Lees, G.E., Helman, R.G., Kashtan, C.E., Michael, A.F., Homco, L.D., Millichamp, N.J., Camacho, Z.T., Templeton, J.W., Ninomiya, Y., Sado, Y., Naito, I. und Kim, Y. (1999): New form of X-linked dominant hereditary nephritis in dogs. Am J Vet Res, 60 (3), 373-83.

Lefort, A., Lecocq, R., Libert, F., Lamy, F., Swillens, S., Vassart, G. und Dumont, J.E. (1989): Cloning and sequencing of a calcium-binding protein regulated by cyclic AMP in the thyroid. Embo J, 8 (1), 111-6.

Li, R., Mignot, E., Faraco, J., Kadotani, H., Cantanese, J., Zhao, B., Lin, X., Hinton, L., Ostrander, E.A., Patterson, D.F. und de Jong, P.J. (1999): Construction and characterization of an eightfold redundant dog genomic bacterial artificial chromosome library. Genomics, 58 (1), 9-17.

Lightfoot, R.M., Cabral, L., Gooch, L., Bedford, P.G. und Boulton, M.E. (1996):

Retinal pigment epithelial dystrophy in Briard dogs. Res Vet Sci, 60 (1), 17-23.

Lin, C.T., Petersen-Jones, S.M. und Sargan, D.R. (1998): Isolation and investigation of canine phosducin as a candidate for canine generalized progressive retinal atrophies. Exp Eye Res, 67 (4), 473-80.

Ling, G.V., Franti, C.E., Ruby, A.L., Johnson, D.L. und Thurmond, M. (1998): Urolithiasis in dogs. I: Mineral prevalence and interrelations of mineral composition, age, and sex. Am J Vet Res, 59 (5), 624-9.

Lingaas, F., Comstock, K.E., Kirkness, E.F., Sorensen, A., Aarskaug, T., Hitte, C., Nickerson, M.L., Moe, L., Schmidt, L.S., Thomas, R., Breen, M., Galibert, F., Zbar, B. und Ostrander, E.A. (2003): A mutation in the canine BHD gene is associated with hereditary multifocal renal cystadenocarcinoma and nodular dermatofibrosis in the German Shepherd dog. Hum Mol Genet, 12 (23), 304353 .

Lippmann, T., Jonkisz, A., Dobosz, T., Petrasch-Parwez, E., Epplen, J.T. und Dekomien, G. (2007): Haplotype-defined linkage region for gPRA in Schapendoes dogs. Mol Vis, 13, 174-80.

Liu, Y.P., Krishna, G., Aguirre, G. und Chader, G.J. (1979): Involvement of cyclic GMP phosphodiesterase activator in an hereditary retinal degeneration. Nature, 280 (5717), 62-4.

Lium, B. und Moe, L. (1985): Hereditary multifocal renal cystadenocarcinomas and nodular dermatofibrosis in the German shepherd dog: macroscopic and histopathologic changes. Vet Pathol, 22 (5), 447-55.

Long, K.O. und Aguirre, G.D. (1991): The cone matrix sheath in the normal and diseased retina: cytochemical and biochemical studies of peanut agglutininbinding proteins in cone and rod-cone degeneration. Exp Eye Res, 52 (6), 699713. 
Lowe, J.K., Kukekova, A.V., Kirkness, E.F., Langlois, M.C., Aguirre, G.D., Acland, G.M. und Ostrander, E.A. (2003): Linkage mapping of the primary disease locus for collie eye anomaly. Genomics, 82 (1), 86-95.

Lowry, O.H. und Passoneau, J.V. (1972): A Flexible System of Enzymatic Analysis. Academic Press, New York 1972.

Magnol, J.P., Pin, D., Palazzi, X., Lacour, J.P., Gache, Y. und Meneguzzi, G. (2005): [Characterization of a canine model of dystrophic bullous epidermolysis (DBE). Development of a gene therapy protocol]. Bull Acad Natl Med, 189 (1), 107-19; discussion 119-21.

Maltese, W.A. (1990): Posttranslational modification of proteins by isoprenoids in mammalian cells. Faseb J, 4 (15), 3319-28.

Marmorstein, A.D., Marmorstein, L.Y., Rayborn, M., Wang, X., Hollyfield, J.G. und Petrukhin, K. (2000): Bestrophin, the product of the Best vitelliform macular dystrophy gene (VMD2), localizes to the basolateral plasma membrane of the retinal pigment epithelium. Proc Natl Acad Sci U S A, 97 (23), 12758-63.

McElroy, R.P. (2006): Day blindness in a German wirehaired pointer. Vet Rec, 158 (5), 175.

McKeown, H.M. (2002): Hypothyroidism in a boxer dog. Can Vet J, 43 (7), 553-5.

Mecklenburg, L., Hetzel, U. und Ueberschar, S. (2000): Epidermolytic ichthyosis in a dog: clinical, histopathological, immunohistochemical and ultrastructural findings. J Comp Pathol, 122 (4), 307-11.

Meindl, A., Dry, K., Herrmann, K., Manson, F., Ciccodicola, A., Edgar, A., Carvalho, M.R., Achatz, H., Hellebrand, H., Lennon, A., Migliaccio, C., Porter, K., Zrenner, E., Bird, A., Jay, M., Lorenz, B., Wittwer, B., D'Urso, M., Meitinger, T. und Wright, A. (1996): A gene (RPGR) with homology to the RCC1 guanine nucleotide exchange factor is mutated in X-linked retinitis pigmentosa (RP3). Nat Genet, 13 (1), 35-42.

Mellersh, C.S., Langston, A.A., Acland, G.M., Fleming, M.A., Ray, K., Wiegand, N.A., Francisco, L.V., Gibbs, M., Aguirre, G.D. und Ostrander, E.A. (1997): A linkage map of the canine genome. Genomics, 46 (3), 326-36.

Mellersh, C.S., Boursnell, M.E., Pettitt, L., Ryder, E.J., Holmes, N.G., Grafham, D., Forman, O.P., Sampson, J., Barnett, K.C., Blanton, S., Binns, M.M. und Vaudin, M. (2006a): Canine RPGRIP1 mutation establishes cone-rod dystrophy in miniature longhaired dachshunds as a homologue of human Leber congenital amaurosis. Genomics, 88 (3), 293-301.

Mellersh, C.S., Pettitt, L., Forman, O.P., Vaudin, M. und Barnett, K.C. (2006b): Identification of mutations in HSF4 in dogs of three different breeds with hereditary cataracts. Vet Ophthalmol, 9 (5), 369-78. 
Miller, W.A. und Nicol, G.D. (1979): Evidence that cyclic GMP regulates membrane potential in rod photoreceptors. Nature, 280 (5717), 64-66.

Millichamp, N.J. (1990): Retinal degeneration in the dog and cat. Vet Clin North Am Small Anim Pract, 20 (3), 799-835.

Minor, J., Dunstan, R., Guyon, R., Andre, C., Barnhart, K. und Credille, K. (2005): Comparative sequence analysis and radiation hybrid mapping of the canine keratin 10 gene. DNA Sequence, 16 (2), 89-95.

Monreal, A.W., Zonana, J. und Ferguson, B. (1998): Identification of a new splice form of the EDA1 gene permits detection of nearly all X-linked hypohidrotic ectodermal dysplasia mutations. Am J Hum Genet, 63 (2), 380-9.

Moura, E. und Cirio, S.M. (2004): Clinical and genetic aspects of X-linked ectodermal dysplasia in the dog -- a review including three new spontaneous cases. Vet Dermatol, 15 (5), 269-77.

Muller, G.H., Kirk, R.W. und Scott, D.W. (1983): Congenital and Hereditary Defects Epidermolysis Bullosa. In Scott, D.W. (Herausgeber): Small Animal Dermatology (3rd). Saunders, Philadelphia, Pa. 1983, S. 583-586.

Nagata, M., Shimizu, H., Masunaga, T., Nishikawa, T., Nanko, H., Kariya, K., Washizu, T. und Ishida, T. (1995): Dystrophic form of inherited epidermolysis bullosa in a dog (Akita Inu). Br J Dermatol, 133 (6), 1000-3.

Nagata, M., Iwasaki, T., Masuda, H. und Shimizu, H. (1997): Non-lethal junctional epidermolysis bullosa in a dog. Br J Dermatol, 137 (3), 445-9.

Nakai, A., Tanabe, M., Kawazoe, Y., Inazawa, J., Morimoto, R.I. und Nagata, K. (1997): HSF4, a new member of the human heat shock factor family which lacks properties of a transcriptional activator. Mol Cell Biol, 17 (1), 469-81.

Nakashima, T. und Taurog, A. (1978): Improved assay procedures for thyroid peroxidase; application to normal and adenomatous human thyroid tissue. Clin Chim Acta, 83 (1-2), 129-40.

Narfstrom, K., Wrigstad, A. und Nilsson, S.E. (1989): The Briard dog: a new animal model of congenital stationary night blindness. Br J Ophthalmol, 73 (9), 750-6.

Narfstrom, K. und Ekesten, B. (1999): Diseases of the canine fundus. In Gelatt, K.N. (Herausgeber): Veterinary Ophthalmology $\left(3^{\text {rd }}\right)$. Lipincott Williams \&Wilkins, Philadelphia 1999, S. 869-933.

Nickerson, M.L., Warren, M.B., Toro, J.R., Matrosova, V., Glenn, G., Turner, M.L., Duray, P., Merino, M., Choyke, P., Pavlovich, C.P., Sharma, N., Walther, M., Munroe, D., Hill, R., Maher, E., Greenberg, C., Lerman, M.I., Linehan, W.M., Zbar, B. und Schmidt, L.S. (2002): Mutations in a novel gene lead to kidney tumors, lung wall defects, and benign tumors of the hair follicle in patients with the Birt-Hogg-Dube syndrome. Cancer Cell, 2 (2), 157-64. 
Nicoletti, A., Wong, D.J., Kawase, K., Gibson, L.H., Yang-Feng, T.L., Richards, J.E. und Thompson, D.A. (1995): Molecular characterization of the human gene encoding an abundant $61 \mathrm{kDa}$ protein specific to the retinal pigment epithelium. Hum Mol Genet, 4 (4), 641-9.

Nilsson, S.E., Wrigstad, A. und Narfstrom, K. (1992): Changes in the DC electroretinogram in Briard dogs with hereditary congenital night blindness and partial day blindness. Exp Eye Res, 54 (2), 291-6.

Olivry, T., Poujade-Delverdier, A., Dunston, S.M., Fine, J.D. und Ortonne, J.P. (1997): Absent expression of collagen XVII (BPAG", BP180) in canine familial localized junctional epidermolysis bullosa. Veterinary Dermatology, 8 (3), 203212.

Osborne, C.A., Sanderson, S.L., Lulich, J.P., Bartges, J.W., Ulrich, L.K., Koehler, L.A., Bird, K.A. und Swanson, L.L. (1999): Canine cystine urolithiasis. Cause, detection, treatment, and prevention. Vet Clin North Am Small Anim Pract, 29 (1), 193-211, xiii.

Palazzi, X., Marchal, T., Chabanne, L., Spadafora, A., Magnol, J.P. und Meneguzzi, G. (2000): Inherited dystrophic epidermolysis bullosa in inbred dogs: A spontaneous animal model for somatic gene therapy. J Invest Dermatol, 115 (1), $135-7$.

Parry, H.B. (1953): Degenerations of the dog retina. II. Generalized progressive atrophy of hereditary origin. Br J Ophthalmol, 37 (8), 487-502.

Parshall, C.J., Wyman, M., Nitroy, S., Acland, G. und Aguirre, G. (1991): Photoreceptor dysplasia: An inherited progressive retinal atrophy of miniature schnauzer dogs. Progress in Veterinary and Comparative Ophthalmology, 1 (3), 187-203.

Pearce-Kelling, S., Nickle, A., Kijas, J., Sidjanin, D.J., Miller, B., Aguirre, G.D. und Acland, G.M. (2002): Test matings confirm allelism of prcd across many dog breeds. Invest Ophthalmol Vis Sci, 43, E3673 (Abstract).

Petersen-Jones, S.M., Sohal, A.K. und Sargan, D.R. (1994): Nucleotide sequence of the canine rod-opsin-encoding gene. Gene, 143 (2), 281-4.

Petersen-Jones, S.M., Entz, D.D. und Sargan, D.R. (1999): cGMP phosphodiesterasealpha mutation causes progressive retinal atrophy in the Cardigan Welsh corgi dog. Invest Ophthalmol Vis Sci, 40 (8), 1637-44.

Petersen-Jones, S.M. und Zhu, F.X. (2000): Development and use of a polymerase chain reaction-based diagnostic test for the causal mutation of progressive retinal atrophy in Cardigan Welsh Corgis. Am J Vet Res, 61 (7), 844-6.

Priat, C., Hitte, C., Vignaux, F., Renier, C., Jiang, Z., Jouquand, S., Cheron, A., Andre, C. und Galibert, F. (1998): A whole-genome radiation hybrid map of the dog genome. Genomics, 54 (3), 361-78. 
Pulkkinen, L. und Uitto, J. (1999): Mutation analysis and molecular genetics of epidermolysis bullosa. Matrix Biol, 18 (1), 29-42.

Rasbridge, W. (1944): Our Dogs,

Ray, K., Baldwin, V.J., Acland, G.M., Blanton, S.H. und Aguirre, G.D. (1994): Cosegregation of codon 807 mutation of the canine rod cGMP phosphodiesterase beta gene and rcd1. Invest Ophthalmol Vis Sci, 35 (13), 42919.

Ray, K., Baldwin, V.J., Acland, G.M. und Aguirre, G.D. (1995): Molecular diagnostic tests for ascertainment of genotype at the rod cone dysplasia $1(\mathrm{rcd} 1)$ locus in Irish setters. Curr Eye Res, 14 (3), 243-7.

Ray, K., Tejero, M.D., Baldwin, V.J. und Aguirre, G.D. (1996): An improved diagnostic test for rod cone dysplasia 1 (rcd1) using allele-specific polymerase chain reaction. Curr Eye Res, 15 (5), 583-7.

Redmond, T.M., Yu, S., Lee, E., Bok, D., Hamasaki, D., Chen, N., Goletz, P., Ma, J.X., Crouch, R.K. und Pfeifer, K. (1998): Rpe65 is necessary for production of 11 cis-vitamin A in the retinal visual cycle. Nat Genet, 20 (4), 344-51.

Richman, M., Mellersh, C.S., Andre, C., Galibert, F. und Ostrander, E.A. (2001): Characterization of a minimal screening set of 172 microsatellite markers for genome-wide screens of the canine genome. J Biochem Biophys Methods, 47 (12), 137-49.

Roberts, S.R. (1960): Congenital posterior ectasia of the sclera in collie dogs. Am J Ophthalmol, 50, 451-65.

Roberts, S.R. und Dellaporta, A. (1965): Congenital Posterior Ectasia of the Sclera in Collie Dogs. I. Clinical Features. Am J Ophthalmol, 59, 180-6.

Roberts, S.R., Dellaporta, A. und Winter, F.C. (1966): The collie ectasia syndrome. Pathology of eyes of young and adult dogs. Am J Ophthalmol, 62 (4), 728-52.

Roberts, S.R. (1969): The collie eye anomaly. J Am Vet Med Assoc, 155 (6), 859-65.

Ropstad, E.O., Bjerkas, E. und Narfstrom, K. (2007): Clinical findings in early onset cone-rod dystrophy in the Standard Wire-haired Dachshund. Vet Ophthalmol, 10 (2), 69-75.

Rosenberg, L.E., Durant, J.L. und Holland, J.M. (1965): Intestinal absorption and renal extraction of cystine and cysteine in cystinuria. N Engl J Med, 273 (23), 123945 .

Rubin, L.F., Bourns, T.K. und Lord, L.H. (1967): Hemeralopia in dogs: heredity of hemeralopia in Alaskan Malamutes. Am J Vet Res, 28 (123), 355-7.

Rubin, L.F. (1971): Clinical features of hemeralopia in the adult Alaskan malamute. $J$ Am Vet Med Assoc, 158 (10), 1696-8. 
Sandberg, M.A., Pawlyk, B.S. und Berson, E.L. (1986): Full-field electroretinograms in miniature poodles with progressive rod-cone degeneration. Invest Ophthalmol Vis Sci, 27 (7), 1179-84.

Sargan, D.R., Yang, F., Squire, M., Milne, B.S., O'Brien, P.C. und Ferguson-Smith, M.A. (2000): Use of flow-sorted canine chromosomes in the assignment of canine linkage, radiation hybrid, and syntenic groups to chromosomes: refinement and verification of the comparative chromosome map for dog and human. Genomics, 69 (2), 182-95.

Scarlett, J.M. (1994): Epidemiology of thyroid diseases of dogs and cats. Vet Clin North Am Small Anim Pract, 24 (3), 477-86.

Scott, D.W. und Schultz, R.D. (1977): Epidermolysis bullosa simplex in the Collie dog. J Am Vet Med Assoc, 171 (8), 721-7.

Seddon, J.M., Hampson, E.C., Smith, R.I. und Hughes, I.P. (2006): Genetic heterogeneity of day blindness in Alaskan Malamutes. Anim Genet, 37 (4), 40710 .

Seed, R.W. und Goldberg, I.H. (1965): Iodination in relation to thyroglobulin maturation and subunit aggregation. Science, 149 (690), 1380-2.

Selmanowitz, V.J., Kramer, K.M. und Orentreich, N. (1970): Congenital ectodermal defect in miniature poodles. $J$ Hered, 61 (5), 196-9.

Selmanowitz, V.J., Markofsky, J. und Orentreich, N. (1977): Heritability of an ectodermal defect. A study of affected dogs. J Dermatol Surg Oncol, 3 (6), 6236.

Sidjanin, D.J., Lowe, J.K., McElwee, J.L., Milne, B.S., Phippen, T.M., Sargan, D.R., Aguirre, G.D., Acland, G.M. und Ostrander, E.A. (2002): Canine CNGB3 mutations establish cone degeneration as orthologous to the human achromatopsia locus ACHM3. Hum Mol Genet, 11 (16), 1823-33.

Sidjanin, D.J., Miller, B., Kijas, J., McElwee, J., Pillardy, J., Malek, J., Pai, G., Feldblyum, T., Fraser, C., Acland, G. und Aguirre, G. (2003): Radiation hybrid map, physical map, and low-pass genomic sequence of the canine prcd region on CFA9 and comparative mapping with the syntenic region on human chromosome 17. Genomics, 81 (2), 138-48.

Simon, A., Hellman, U., Wernstedt, C. und Eriksson, U. (1995): The retinal pigment epithelial-specific 11-cis retinol dehydrogenase belongs to the family of short chain alcohol dehydrogenases. J Biol Chem, 270 (3), 1107-12.

Suber, M.L., Pittler, S.J., Qin, N., Wright, G.C., Holcombe, V., Lee, R.H., Craft, C.M., Lolley, R.N., Baehr, W. und Hurwitz, R.L. (1993): Irish setter dogs affected with rod/cone dysplasia contain a nonsense mutation in the rod cGMP phosphodiesterase beta-subunit gene. Proc Natl Acad Sci U S A, 90 (9), 396872. 
Switonski, M., Konieczny, P., Klukowska, J., Janyga, B. und Aguirre, G.D. (2002): Microdeletion in the RPE65 gene causing hereditary retinal dystrophy (HRD) disease segregates in the Polish ppulation of Briards. Medycyna Wet, 58 (12), 946-949.

Thomas, R., Holmes, N. und Binns, M. (2001): Congenital stationary night blindness in briards in the UK. Vet Rec, 148 (15), 488.

Thomsett, L.R. (1961): Congenital hypotrichia in the dog. Vet Rec, 73, 915-917.

Thorner, P.S., Zheng, K., Kalluri, R., Jacobs, R. und Hudson, B.G. (1996): Coordinate gene expression of the alpha3, alpha4, and alpha5 chains of collagen type IV. Evidence from a canine model of X-linked nephritis with a COL4A5 gene mutation. J Biol Chem, 271 (23), 13821-8.

Treacher, R.J. (1964): The aetiology of canine cystinuria. Biochem J, 90 (3), 494-8.

Turney, C., Chong, N.H., Alexander, R.A., Hogg, C.R., Fleming, L., Flack, D., Barnett, K.C., Bird, A.C., Holder, G.E. und Luthert, P.J. (2007): Pathological and electrophysiological features of a canine cone-rod dystrophy in the miniature longhaired dachshund. Invest Ophthalmol Vis Sci, 48 (9), 4240-9.

Urschel, S., Hoher, T., Schubert, T., Alev, C., Sohl, G., Worsdorfer, P., Asahara, T., Dermietzel, R., Weiler, R. und Willecke, K. (2006): Protein kinase A-mediated phosphorylation of connexin 36 in mouse retina results in decreased gap junctional communication between AII amacrine cells. J Biol Chem, 281 (44), 33163-71.

US-Patent (6428958): Identification of congenital stationary night blindness in dogs. US Patent \& Trademark Office: Patent Full-Text and Image Database, http://patft.uspto.gov/netacgi/nph-

Parser?Sect $1=$ PTO $2 \&$ Sect $2=$ HITOFF $\& p=1 \& u=\% 2$ Fnetahtml $\% 2 F P T O \% 2 F$ sear ch-

$\underline{\text { bool.html } \& \mathrm{r}=1 \& \mathrm{f}=\mathrm{G} \& \mathrm{l}=50 \& \mathrm{col}=\mathrm{AND} \& \mathrm{~d}=\mathrm{PTXT} \& \mathrm{~s} 1=6428958 . \mathrm{PN} . \& O S=\mathrm{PN} /}$ 6428958\&RS=PN/6428958

US-Patent-Application (2005): Identification of the gene and mutation for progressive rod-cone degeneration in the dog and a method for testing the same. US Patent \& Trademark Office: Patent Full-Text and Image Database, No: 20050282212, http://appft1.uspto.gov/netacgi/nphParser?Sect $1=$ PTO2\&Sect $2=$ HITOFF $\& u=\% 2$ Fnetahtml $\% 2$ FPTO $\% 2$ Fsearchadv.html\&r=61\&f=G\&l=50\&d=PG01\&s1=Aguirre $\& \mathrm{p}=2 \& O S=$ Aguirre $\& \mathrm{RS}=\mathrm{A}$ guirre

US-Patent-Application (2006): Diagnostic test for Collie Eye Anomaly. US Patent \& Trademark Office - Patent Application Full-Text And Image Database, No: 20060115843, http://appft1.uspto.gov/netacgi/nphParser?Sect $1=$ PTO1\&Sect $2=$ HITOFF $\& d=$ $=$ G01\&p $=1 \& u=\% 2 F n e t a h t m 1 \% 2 F P T$ O\%2Fsrchnum.html\&r=1\&f=G\&l=50\&s1=\%2220060115843\%22.PGNR.\&OS $=\mathrm{DN} / 20060115843 \& \mathrm{RS}=\mathrm{DN} / 20060115843$ 
Vervoort, R., Lennon, A., Bird, A.C., Tulloch, B., Axton, R., Miano, M.G., Meindl, A., Meitinger, T., Ciccodicola, A. und Wright, A.F. (2000): Mutational hot spot within a new RPGR exon in X-linked retinitis pigmentosa. Nat Genet, 25 (4), 462-6.

Veske, A., Narfstrom, K., Finckh, U., Sargan, D.R., Nilsson, S.E. und Gal, A. (1997a): Isolation of canine retinal arrestin cDNA and exclusion of three candidate genes for Swedish Briard retinal dystrophy. Curr Eye Res, 16 (3), 270-4.

Veske, A., Nilsson, S.E. und Gal, A. (1997b): Characterization of canine rod photoreceptor cGMP-gated cation channel alpha-subunit gene and exclusion of its involvement in the hereditary retinal dystrophy of Swedish Briards. Gene, 202 (1-2), 115-9.

Veske, A., Nilsson, S.E. und Gal, A. (1998): Organization of the canine gene encoding the $\mathrm{E}$ isoform of retinal guanylate cyclase (cGC-E) and exclusion of its involvement in the inherited retinal dystrophy of the Swedish Briard and Briardbeagle dogs. Biochim Biophys Acta, 1372 (1), 69-77.

Veske, A., Nilsson, S.E., Narfstrom, K. und Gal, A. (1999): Retinal dystrophy of Swedish briard/briard-beagle dogs is due to a 4-bp deletion in RPE65. Genomics, 57 (1), 57-61.

Wallin-Hakanson, B., Wallin-Hakanson, N. und Hedhammar, A. (2000): Influence of selective breeding on the prevalence of chorioretinal dysplasia and coloboa in the rough collie in Sweden. J Small Anim Pract, 41, 56-59.

Werner, P., Mellersh, C.S., Raducha, M.G., DeRose, S., Acland, G.M., Prociuk, U., Wiegand, N., Aguirre, G.D., Henthorn, P.S., Patterson, D.F. und Ostrander, E.A. (1999): Anchoring of canine linkage groups with chromosome-specific markers. Mamm Genome, 10 (8), 814-23.

Wrigstad, A., Nilsson, S.E. und Narfstrom, K. (1992): Ultrastructural changes of the retina and the retinal pigment epithelium in Briard dogs with hereditary congenital night blindness and partial day blindness. Exp Eye Res, 55 (6), 80518.

Wrigstad, A., Narfstrom, K. und Nilsson, S.E. (1994): Slowly progressive changes of the retina and retinal pigment epithelium in Briard dogs with hereditary retinal dystrophy. A morphological study. Doc Ophthalmol, 87 (4), 337-54.

Yang, F., O'Brien, P.C., Milne, B.S., Graphodatsky, A.S., Solanky, N., Trifonov, V., Rens, W., Sargan, D. und Ferguson-Smith, M.A. (1999): A complete comparative chromosome map for the dog, red fox, and human and its integration with canine genetic maps. Genomics, 62 (2), 189-202.

Zagotta, W.N. und Siegelbaum, S.A. (1996): Structure and function of cyclic nucleotide-gated channels. Annu Rev Neurosci, 19, 235-63. 
Zangerl, B., Goldstein, O., Philp, A.R., Lindauer, S.J., Pearce-Kelling, S.E., Mullins, R.F., Graphodatsky, A.S., Ripoll, D., Felix, J.S., Stone, E.M., Acland, G.M. und Aguirre, G.D. (2006): Identical mutation in a novel retinal gene causes progressive rod-cone degeneration in dogs and retinitis pigmentosa in humans. Genomics, 88 (5), 551-63.

Zeiss, C.J., Acland, G., Aguirre, G. und Ray, K. (1998): Cloning of RPGR in a canine model of XLRP and characterization of novel splice variants (ARVO Abstract). Invest Ophthalmol Vis Sci, 39 (4), S881, Abstract 4082.

Zeiss, C.J., Acland, G.M. und Aguirre, G.D. (1999): Retinal pathology of canine Xlinked progressive retinal atrophy, the locus homologue of RP3. Invest Ophthalmol Vis Sci, 40 (13), 3292-304.

Zeiss, C.J., Ray, K., Acland, G. und Aguirre, G. (2000): Mapping of X-linked progressive retinal atrophy (XLPRA), the canine homolog of retinitis pigmentosa 3 (RP3). Hum Mol Genet, 9 (4), 531-537.

Zhang, Q., Acland, G.M., Parshall, C.J., Haskell, J., Ray, K. und Aguirre, G.D. (1998): Characterization of canine photoreceptor phosducin cDNA and identification of a sequence variant in dogs with photoreceptor dysplasia. Gene, 215 (2), 231-9.

Zhang, Q., Baldwin, V.J., Acland, G.M., Parshall, C.J., Haskel, J., Aguirre, G.D. und Ray, K. (1999): Photoreceptor dysplasia (pd) in miniature schnauzer dogs: evaluation of candidate genes by molecular genetic analysis. $J$ Hered, 90 (1), 5761.

Zhang, Q., Acland, G.M., Zangerl, B., Johnson, J.L., Mao, Z., Zeiss, C.J., Ostrander, E.A. und Aguirre, G.D. (2001): Fine mapping of canine XLPRA establishes homology of the human and canine RP3 intervals. Invest Ophthalmol Vis Sci, 42 (11), 2466-71.

Zhang, Q., Acland, G.M., Wu, W.X., Johnson, J.L., Pearce-Kelling, S., Tulloch, B., Vervoort, R., Wright, A.F. und Aguirre, G.D. (2002): Different RPGR exon ORF15 mutations in Canids provide insights into photoreceptor cell degeneration. Hum Mol Genet, 11 (9), 993-1003.

Zheng, K., Thorner, P.S., Marrano, P., Baumal, R. und McInnes, R.R. (1994): Canine X chromosome-linked hereditary nephritis: a genetic model for human X-linked hereditary nephritis resulting from a single base mutation in the gene encoding the alpha 5 chain of collagen type IV. Proc Natl Acad Sci U S A, 91 (9), 398993.

Zheng, K., Perry, J., Harvey, S.J., Sado, Y., Ninomiya, Y., Jefferson, B., Jacobs, R., Hudson, B.G. und Thorner, P.S. (2005): Regulation of collagen type IV genes is organ-specific: evidence from a canine model of Alport syndrome. Kidney Int, 68 (5), 2121-30.

Ziegler, J. und Hess, H. (1985): Cataracts in the Royal College of Surgeons Rat: Evidence for Initiation by Lipid Peroxidation Products. Exp Eye Res, 41, 67-76. 
Zonana, J., Gault, J., Davies, K.J., Jones, M., Browne, D., Litt, M., Brockdorff, N., Rastan, S., Clarke, A. und Thomas, N.S. (1993): Detection of a molecular deletion at the DXS732 locus in a patient with X-linked hypohidrotic ectodermal dysplasia (EDA), with the identification of a unique junctional fragment. Am J Hum Genet, 52 (1), 78-84.

Zonana, J., Elder, M.E., Schneider, L.C., Orlow, S.J., Moss, C., Golabi, M., Shapira, S.K., Farndon, P.A., Wara, D.W., Emmal, S.A. und Ferguson, B.M. (2000): A novel X-linked disorder of immune deficiency and hypohidrotic ectodermal dysplasia is allelic to incontinentia pigmenti and due to mutations in IKKgamma (NEMO). Am J Hum Genet, 67 (6), 1555-62. 


\subsection{Hereditäre Erkrankungen des Skelettsystems, der Muskulatur und des Nervensystems}

\subsubsection{Erkrankungen des Skelettsystems}

\subsubsection{Osteogenesis imperfecta}

\begin{tabular}{ll|}
\hline Chromosom: & CFA9 \\
Gen: & COL1A1 \\
NCBI: & GeneID: 403651 \\
DNA-Sequenz: & NW_876332, Position 8019358-8002483 \\
Mutationen: & G1276A, Golden Retriever \\
\hline
\end{tabular}

\begin{tabular}{|ll|}
\hline Chromosom: & CFA14 \\
Gen: & COL1A2 \\
NCBI: & GeneID: 40824 \\
DNA-Sequenz: & NW_876258, Position 19830577-19867173 \\
Mutationen: & Del3991-3994+3990Ins9bp, Beagle \\
\hline
\end{tabular}

\section{Krankheitsbild}

Osteogenesis imperfecta beschreibt eine Gruppe von erblichen Erkrankungen des Skelettsystems, die durch eine mangelhafte Knochenbildung und einer damit verbundenen Neigung zu Knochenbrüchen und -verbiegungen gekennzeichnet sind. In der Humanmedizin werden je nach Schweregrad vier Unterformen unterschieden.

Bei Hunden scheint die Osteogenesis imperfecta relativ selten zu sein. Zahlen über die Häufigkeit der Erkrankung in einzelnen Rassen werden nicht genannt Es liegen Berichte über betroffene Würfe in den Rassen Pudel und Norwegischer Elchhund (Calkins et al. 1956), Collie (Holmes und Price 1957), Bedlington Terrier (Lettow und Dämmrich 1960), Golden Retriever (Campbell et al. 1997), American Cream Dogs (Lazar et al. 2000) und Dackel (Seeliger et al. 2003) vor. Einzelne Fälle wurden des Weiteren in den Rassen Pudel und Beagle (Campbell et al. 1997) beschrieben.

Erste Anzeichen zeigen sich in der Regel im Verlauf der ersten Lebenswochen. Betroffene Welpen lahmen, können zum Teil gar nicht laufen und leiden offenbar unter Schmerzen. Vorrangig sind die Hinterextremitäten betroffen. In einigen Fällen sind die Welpen im Vergleich zu normalen Altersgenossen sehr klein. Klinische Befunde umfassen Knochenverbiegungen und -brüche. Röntgenuntersuchungen zeigen eine 
herabgesetzte Knochendichte. Weiterhin fällt an den Röhrenknochen durchgängig eine dünne Kompakta auf. Im Bereich von Frakturen ist eine sehr geringe Kallusbildung zu beobachten. Sowohl Becken als auch Thorax sind stark deformiert. Dadurch ist die Darmpassage behindert und die Lungenfläche verkleinert. Es kann zu Sekundärerscheinungen wie gestörtem Absetzen von Kot und Harn und in Verbindung damit zum Auftreten auffallend dicker Bäuche kommen. Auch die Entwicklung einer Dyspnoe ist möglich. Der Krankheitsverlauf ist variabel. Bei einigen Tieren verschlechtert sich der Zustand zunehmend, so dass sie im Alter zwischen zwei und vier Monaten verenden oder eingeschläfert werden müssen. Bei anderen Hunden tritt mit Einsetzen der Pubertät eine Spontanheilung ein, wobei eine Neigung zu schlecht heilenden Knochenbrüchen und zum Teil eine geringere Körpergröße im Vergleich zu normalen Altersgenossen bestehen bleibt.

Anzeichen für das Vorliegen eines übermäßigen Knochenabbaus treten nicht auf. Die Ursache liegt demnach in einem gestörten Aufbau von Knochensubstanz. Auch die histologischen Befunde deuten auf eine Störung der Knochenentwicklung und des Knochenwachstums hin. Es sind sowohl die desmale als auch die chondrale Knochenbildung betroffen. Bei gleichmäßiger Verkalkung der inneren Knorpelschichten und regelmäßiger Eröffnung der Knorpelzellhöhlen durch Markgefäße sowie abschnittsweise gut ausgebildeter Osteoblastenbesätze erfolgt die Anlagerung von Osteoid und dessen Weiterentwicklung $\mathrm{zu}$ Spongiosabälkchen unregelmäßig und in geringem Maße. In einigen Abschnitten fehlt auch der Osteoblastenbesatz. Auch an der Kortikalis ist der Anbau von Knochensubstanz reduziert, Knochenlamellen sind nur in geringer Anzahl vorhanden und sehr dünn, unregelmäßig geformt und häufig unterbrochen. Radiärlamellen sind nur spärlich ausgebildet. Im Kambium des Periosts befinden sich zum Teil keine Osteoblasten. Auch in Abschnitten mit vorhandenen Osteoblasten werden keine oder extrem schmale Knochenbälkchen gebildet. Teilweise fehlt das Kambium vollständig. Die Umwandlung des embryonalen geflechtartigen Knochenbaus in den adulten lamellaren Knochenbau findet verzögert oder gar nicht statt. Abschnittsweise kann diese Störung auf das Fehlen von Osteoblasten zurückgeführt werden. Der Defekt tritt jedoch auch in Regionen auf, die ausreichend Osteoblasten enthalten. Die Zähne sind histologisch nicht auffällig. Allerdings könnte das gelegentliche Auftreten kleiner, stummelförmiger 
Milchschneidezähne im Oberkiefer mit der Erkrankung zusammenhängen (Calkins et al. 1956; Holmes und Price 1957; Lettow und Dämmrich 1960).

In den einzelnen Rassen liegen zum Teil Besonderheiten vor. Bei einem zwölf Wochen alten Golden Retriever Rüden zeigte sich zusätzlich zu den typischen klinischen Befunden eine Pinkfärbung der Zähne. Röntgenuntersuchungen ergaben eine reduzierte Knochendichte. Milchzähne und bleibende Zähne zeigten eine auffällig dünne Dentinschicht, bleibende Zähne wiesen zahlreiche Brüche auf. Histologische Untersuchungen der Knochen ergaben die für Osteogenesis imperfecta charakteristischen Befunde: In den Zähnen traten Odontoblasten nur spärlich auf und erschienen atrophiert, während Ameloblasten morphologisch normal waren. Im Alter von drei Monaten wurde der Rüde eingeschläfert. Drei Wurfgeschwister des betroffenen Welpen verendeten kurz nach der Geburt. Über weitere betroffene Verwandte wird nicht berichtet. Eine Pudelhündin zeigte $a b$ einem Alter von elf Monaten ähnliche Symptome wie der Golden Retriever Rüde. Allerdings erreichte die Pudelhündin eine normale Körpergröße, wies weniger Knochenbrüche auf als der betroffene Golden Retriever Welpe und hatte weiße Zähne. Die Hündin erreichte ein Alter von mindestens zwei Jahren. Die weitere Krankengeschichte ist nicht dargelegt. Ebenfalls betroffene Verwandte werden nicht erwähnt.

Die Symptome einer drei Monate alten Beaglehündin stimmen mit den beim Golden Retriever beschriebenen Auffälligkeiten überein. Im Alter von vier Monaten wurde die Hündin eingeschläfert. Ebenfalls betroffene Verwandte werden nicht erwähnt (Campbell et al. 1997).

Die Diagnose von Osteogenesis imperfecta erfolgte bei allen drei Hunden unter Nutzung zweier in der Humanmedizin entwickelten Methoden über den Nachweis einer abweichenden Proteinstruktur (de Vries und de Wet 1986) oder Proteinprozessierung (Minor et al. 1986) des Kollagen I.

Kollagen I ist Hauptbestandteil der organischen Knochenmatrix und bildet das strukturelle Gerüst für die Mineralisierung. Das Typ-I-Prokollagen setzt sich aus zwei pro- $\alpha 1-K e t t e n$ und einer pro- $\alpha 2-K e t t e$ zusammen, die sich im Anschluss an die Hydroxylierung von ca. $50 \%$ der Lysinreste und 25-35\% der Prolinreste zu einem Prokollagenmolekül aufdrillen. Verdrillte Prokollagen- $\alpha 1-$ und - $\alpha 2-K e t t e n$ werden in 
die extrazelluläre Matrix abgegeben. Dort werden sie durch Spaltung mit ProkollagenN- bzw. Prokollagen-C-Proteinase in N- bzw. C-Prokollagen und durch Spaltung mit beiden Proteinasen in Kollagen umgewandelt. Einzelne Kollagenmonomere polymerisieren zu Kollagenfibrillen und bilden untereinander Querverbindungen aus. Die beiden Kollagen-I- $\alpha-K e t t e n$ werden von den Genen COL1A1 und COL1A2 codiert. Über $90 \%$ aller humanen Osteogenesis imperfecta Erkrankungen sind auf Mutationen in einem dieser beiden Gene zurückzuführen (Kuivaniemi et al. 1991).

Das Vorliegen einer abweichenden Proteinstruktur von Kollagen Typ I lässt sich nach einer Auftrennung der einzelnen pro- $\alpha$ - bzw. $\alpha$-Ketten per Pepsin-Spaltung anhand der Analyse des Wanderungsverhaltens in einer SDS-Polyacrylamidgelelektrophorese erkennen (de Vries und de Wet 1986; Minor et al. 1986). Hinweise auf eine abweichende Prozessierung von Kollagen I ergeben sich aus der Detektion von markiertem Prokollagen I und Kollagen I in der Zellschicht und im Zellmedium von Fibroblastenzellkulturen im Verlauf von acht Stunden. Nach elektrophoretischer Auftrennung lassen sich Störungen der Prozessierung anhand der Menge des prozessierten Kollagens sowie des $\mathrm{N}$ - und C-Prokollagens erkennen. Vergleiche zwischen der Zellschicht und dem Zellmedium ermöglichen des Weiteren Rückschlüsse darauf, ob eine Mutationen intrazellulares oder lösliches Kollagen betrifft (Minor et al. 1986). (Bei der Kollagensynthese in Fibroblasten wird nicht das gesamte Prokollagen in den Extrazellularraum abgegeben. Ein geringer Teil verbleibt in der Zelle und wird dort zu membranständigem Kollagen prozessiert (Fernandez-Madrid et al. 1981).) Die Ergebnisse dieser Untersuchungen lassen bei allen drei Hunden auf das Vorliegen von Mutationen in einem der beiden Kollagen I Gene schließen.

\section{Genetischer Hintergrund der Osteogenesis imperfecta beim Golden Retriever und beim Beagle}

Der molekulargenetische Hintergrund der Osteogenesis imperfecta ist bisher nur bei dem beschriebenen Golden Retriever Rüden und bei der Beaglehündin geklärt worden.

Beim Golden Retriever liegt eine Mutation im COL1A1-Gen vor. Das canine CO11A1Gen ist auf Chromosom 9 im genomischen Contig NW_876332 zwischen Position 8019358 und 8002483 lokalisiert (NCBI-GeneID 403651). Die Länge des offenen Leserasters beträgt 4383 bp. Es bestehen hohe Homologien zur humanen cDNA und 
noch höhere zur Aminosäurensequenz, die sich insgesamt nur durch 34 Aminosäuren unterscheidet. Unter der Voraussetzung, dass die caninen Exon-Intron-Grenzen mit den humanen übereinstimmen, enthält das canine COL1A1-Gen 51 Exons (Campbell et al. 2000). Die Lage der einzelnen Exon innerhalb der genomischen Sequenz ist in Abb. 119 dargestellt.

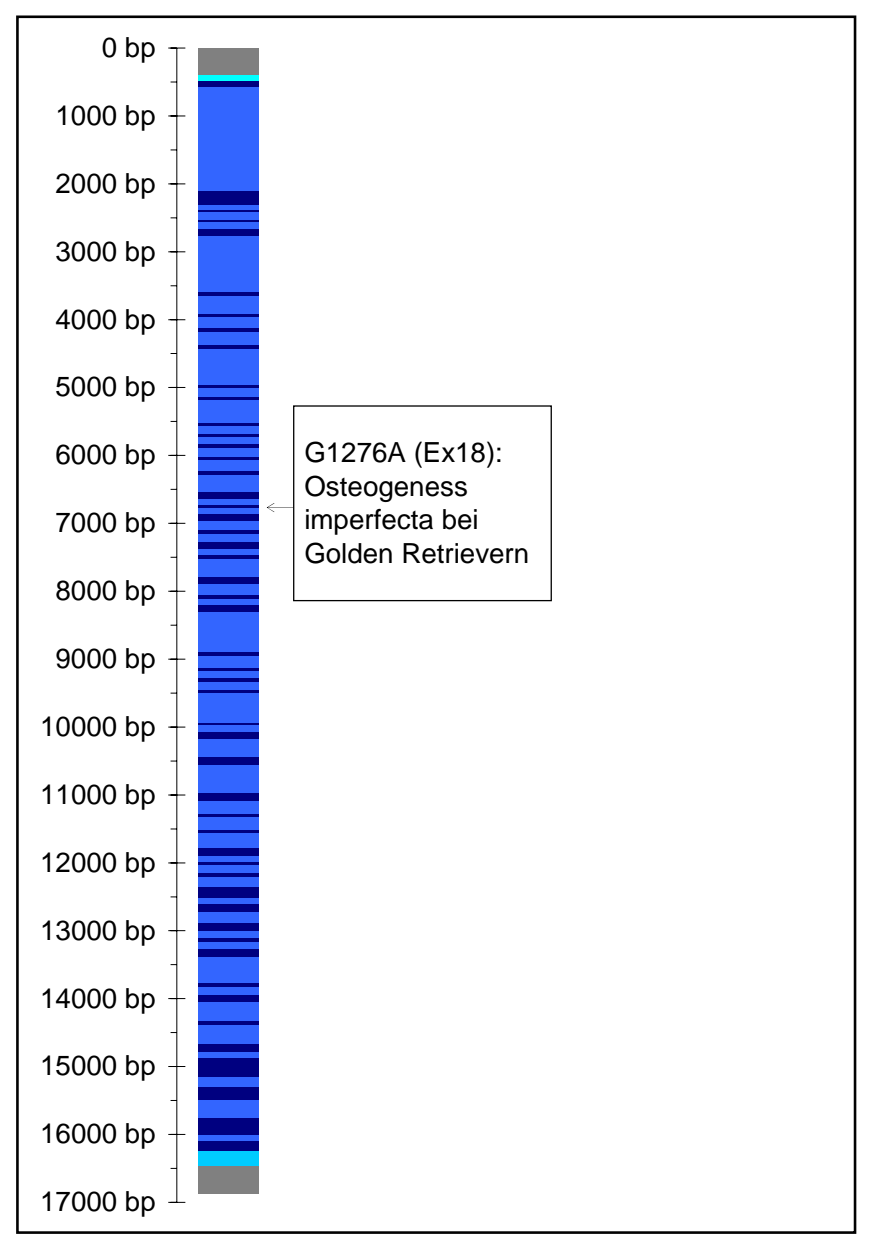

Abb. 119 Schematische Darstellung des caninen COL1A1-Gens und Lage der bisher identifizierten Mutationen. Dunkelblau: codierende Sequenz, hellblau: Intronsequenz, türkis: 5'- und 3'UTR, grau: intergenische Sequenz.

Beim Beagle betrifft die ursächliche Mutation für Osteogenesis imperfecta das COL1A2-Gen (Campbell et al. 2001). Das canine COL1A2-Gens ist auf Chromosom 14 im genomischen Contig NW_876258 zwischen Nukleotid 19830577 und 19867173 lokalisiert (NCBI-GeneID 40824) und enthält 52 Exons. Die canine COL1A2-cDNA setzt sich zusammen aus 136 bp 5'-UTR, 4097 bp translatierter Sequenz und 324 bp 3'UTR (Campbell et al. 1998). Die Lage der einzelnen Exon innerhhalb der genomischen Sequenz ist in Abb. 120 dargestellt. 


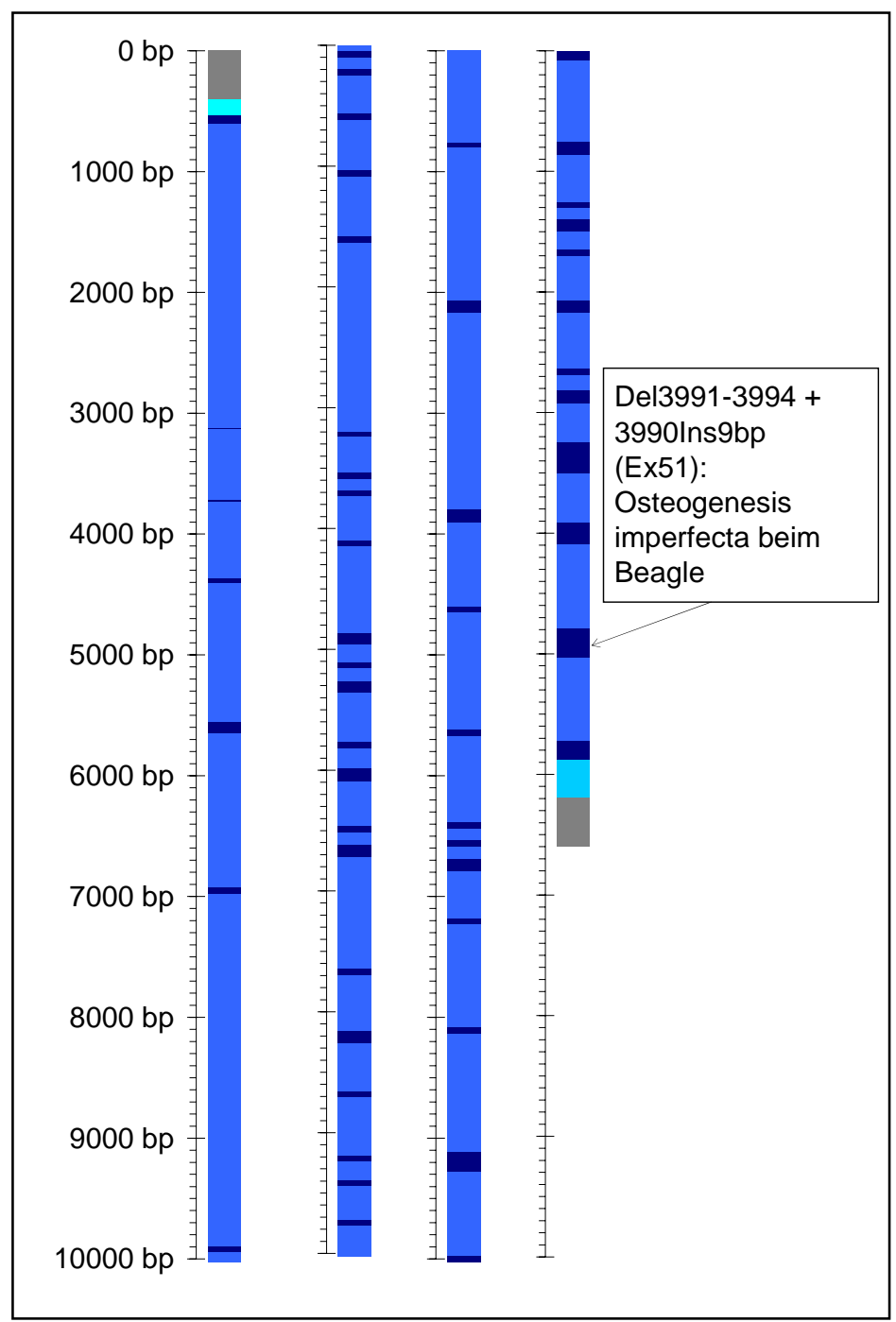

Abb. 120 Schematische Darstellung des caninen COL1A2-Gens und Lage der bisher identifizierten Mutationen. Dunkelblau: codierende Sequenz, hellblau: Intronsequenz, türkis: 5'- und 3'UTR, grau: intergenische Sequenz.

\section{III.a Ursächliche Mutation der Osteogenesis imperfecta bei Golden Retrievern}

Bei der Mutation im COL1A1-Gen des betroffenen Golden Retrievers handelt es sich um eine Substitution von Guanin durch Adenin an Position 1276 der cDNA, die im ersten Codon von Exon 18 lokalisiert ist und $\mathrm{zu}$ einem Aminosäurenaustausch von Glycin durch Alanin führt (Abb. 121). 


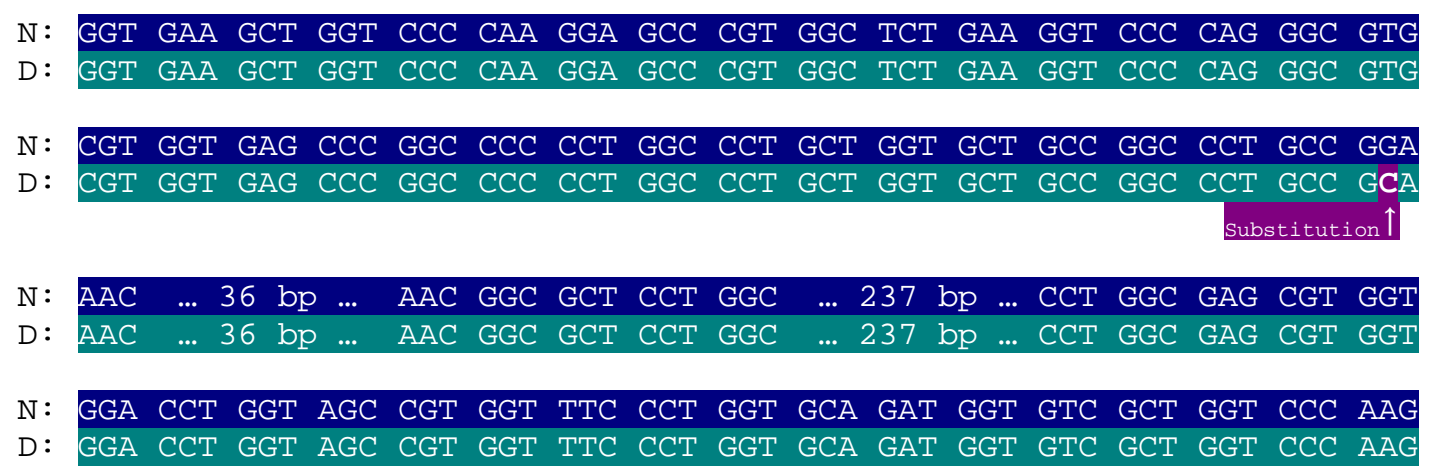

Abb. 121 cDNA-Abschnitt von Exon 17 bis Exon 22 des caninen COL1A1 Gens. N: normale Sequenz, D: defekte Sequenz, dunkelblau: Exon normale Sequenz, dunkelgrün: Exon defekte Sequenz, Substitution in defekter Sequenz violett unterlegt und durch Pfeil gekennzeichnet.

Dadurch kommt es $\mathrm{zu}$ einer Unterbrechung des typischen Gly-X-YAminosäurenmusters, das für die Formation der Tripelhelix essentiell ist (Campbell et al. 2000). Studien zur Auswirkung von Glycinsubstitutionen in Kollagenketten untermauern die Hypothese, dass Glycinmutationen eine Unterbrechung der Tripelhelixformation bewirken. Der Schweregrad der durch die jeweilige Mutation verursachten Störungen hängt davon ab, wie leicht es in der aminoterminal zur Mutation gelegenen Region zur Repolymerisation kommt. Die Polymerisationsfähigkeit wiederum hängt von der Stabilität der Aminosäuren innerhalb der betroffenen Region ab (Bachinger und Davis 1991). Laut einer Kartierung der relativen Stabilität der Aminosäuren in einzelnen Tripeptideinheiten des humanen Prokollagen I fällt die beim Golden Retriever detektiere Substitution in eine als relativ instabil eingestufte Region (Bachinger und Davis 1991). Aufgrund der hohen Homologie zwischen caninem und humanem Kollagen erscheint es vertretbar, die Ergebnisse der Analysen von humanem Kollagen I auf die caninen Verhältnisse zu übertragen. Demnach lassen sich die relativ schwerwiegenden Krankheitserscheinungen des betroffenen Golden Retrievers durch die geringe Stabilität der Aminosäuren im Bereich der Mutation erklären (Campbell et al. 2000).

\section{III.b Ursächliche Mutation für Osteogenesis imperfecta beim Beagle}

Bei der betroffenen Beagle Hündin konnte eine Mutation im COL1A2-Gen identifiziert werden (Campbell et al. 2001). Bei der identifizierten Mutation handelt es sich um eine Deletion der vier Nukleotide CTGA an Position 3991-3994 der cDNA in Exon 51, die durch eine Insertion von neun Nukleotiden (TGTCATTGG) ersetzt wird. Die ersten 
sieben Nukleotide dieser Insertion stellen eine Wiederholung der Sequenz $11 \mathrm{bp}$ abwärts der Deletion dar (Abb. 122). Die Folgen dieser Mutation betreffen das CPropeptid. Es kommt zu einer Verschiebung des Leserasters, die zu einer Translation von 30 abweichenden Aminosäuren und der Entstehung eines verfrühten Stoppcodons führt, so dass das resultierende Protein um 51 Aminosäuren verkürzt wird.

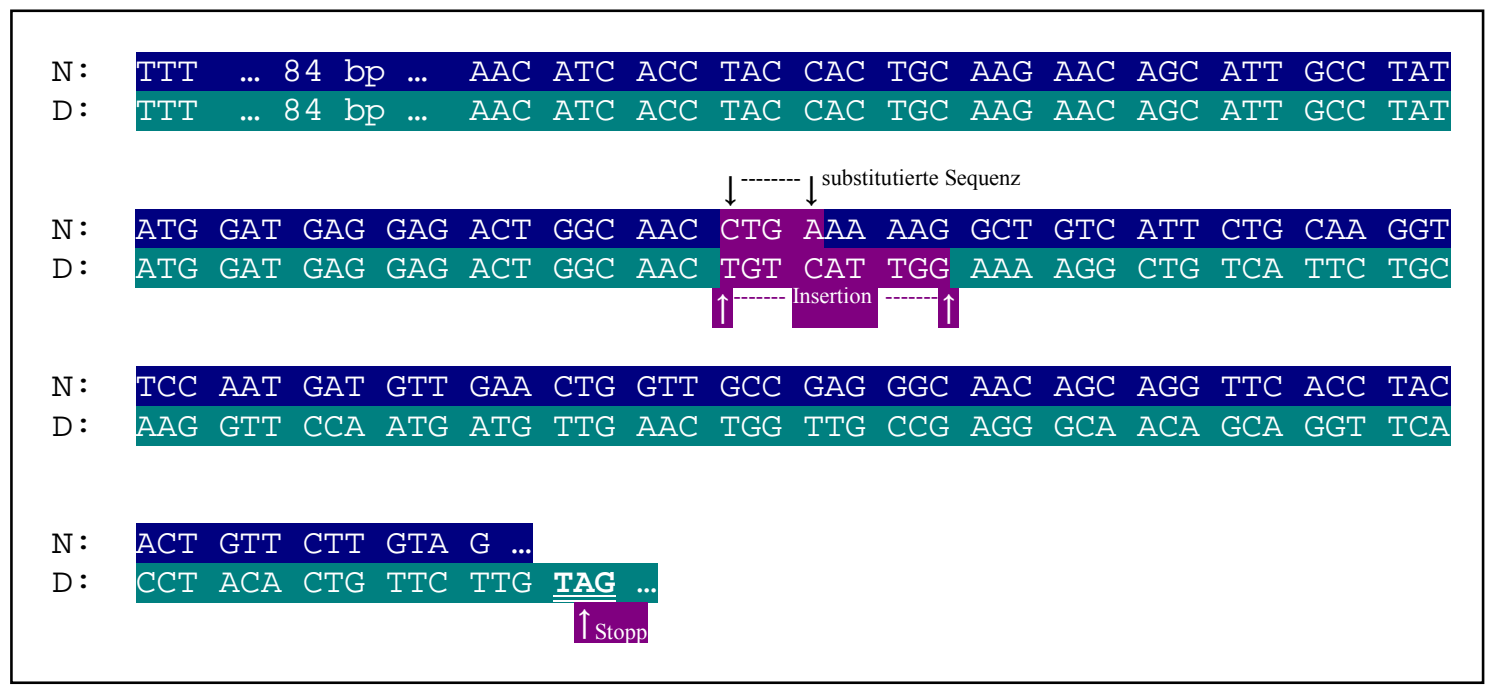

Abb. 122 Exon 51 des COL1A2 Gens. N: normale Sequenz, D: defekte Sequenz, dunkelblau: Exon normale Sequenz, dunkelgrün: Exon defekte Sequenz, 4 bp Deletion in normaler Sequenz violett unterlegt und durch Pfeil gekennzeichnet, 9-bp-Insertion in defekter Sequenz violett unterlegt und durch Pfeil gekennzeichnet, verfrühtes Stoppcodon in defekter Sequenz dick gedruckt und durch Pfeil gekennzeichnet.

Bei Mäusen mit einer ähnlichen Mutation im C-Terminus des $\alpha 2$-Propeptids schwankt die phänotypische Ausprägung bei heterozygoten Tieren extrem. Heterozygote Mäuse können sowohl klinisch gesund oder leicht erkrankt sein, als auch schwerwiegende Symptome zeigen, so dass sie phänotypisch nicht von homozygot betroffenen Mäusen $\mathrm{zu}$ unterscheiden sind. Aufgrund welcher Einflüsse es $\mathrm{zu}$ diesen phänotypischen Varianten kommt, ist nicht näher untersucht (Camacho et al. 1998).

Aufgrund der exzessiven Strukturänderung des a2-C-Propeptid-Transkriptes wird der Einbau von mutiertem $\alpha 2$-C-Propeptid in eine Tripelhelix als unwahrscheinlich beurteilt (Campbell et al. 2001). Untersuchungen an Fibroblastenkulturen eines homozygot betroffenen humanen Patienten mit einer ähnlichen Mutation im COL1A2-Gen zeigen, dass es bei einem Mangel an einbaufähigem $\alpha 2$-C-Propeptid zur Bildung von $\alpha 1$ Homotrimeren kommt. Die Homotrimere lagern sich wie normale Heterotrimere zu Fibrillen mit typischer, quer gestreifter Musterung zusammen, wobei die Effizienz der 
Fibrillenbildung aus Homotrimeren deutlich unter der Effizienz der Fibrillenbildung aus Heterotrimeren liegt (McBride et al. 1992).

Bei der heterozygot mutierten Beagle Hündin liegt ein erhöhtes $\alpha 1: \alpha 2$ Verhältnis vor. Dieser Befund ist mit dem bei einem heterozygoten Individuum $\mathrm{zu}$ erwartenden gemeinsamen Auftreten von $(\alpha 1)_{3}$-Homotrimeren und $(\alpha 1)_{2}(\alpha 2)$-Heterotrimeren vereinbar (Campbell et al. 2001). Möglicherweise führt eine Fibrillenbildung aus Homotrimeren und Heterotrimeren zum generalisierten Aufbau instabiler KollagenTyp-I-Fibrillen, so dass dadurch die Dominanz der Mutation zu erklären ist.

\subsubsection{Brachyury (Kurzschwänzigkeit)}

\begin{tabular}{|ll|}
\hline Chromosom: & CFA1 \\
Gen: & T \\
NCBI: & GeneID: 403653 \\
DNA-Sequenz: & NW_876269, Position 54237728-54228892 \\
Mutationen: & C295G, Pembroke Welsh Corgi \\
\hline
\end{tabular}

\section{Krankheitsbild}

Die Länge der Rute bei Hunden ist ein hochvariables Merkmal und schwankt zwischen sechs und 23 Wirbeln. In einigen Rassen, darunter Pembroke Welsh Corgi, Beagle und Cocker Spaniel tritt in sehr geringer Frequenz eine erbliche Rutenlosigkeit (Anury) oder eine starke Verkürzung der Rute (Brachyury) auf, die in einigen Fällen mit weiteren, teilweise schwerwiegenden Missbildungen im Steißbereich einhergeht. Außerdem liegen Anzeichen für einen Zusammenhang zwischen diesem Merkmal und frühembryonaler Sterblichkeit vor (Pullig 1953; Burns und Fraser 1966; Haworth et al. 2001).

Der genetische Hintergrund ist bisher nur bei Pembroke Welsh Corgis bekennt. In dieser Rasse besteht offenbar keine Assoziation zwischen der Brachyury und weiteren Defekten im Steißbereich (Indrebo und Langeland 1997).

\section{Genetischer Hintergrund}

Der Erbgang kann sowohl rezessiv, als auch dominant oder semidominant sein (Pullig 1953; Burns und Fraser 1966; Haworth et al. 2001). In Rasse Pembroke Welsh Corgi bekannt liegt ein dominanter Defekt im T-Box-Transkriptionsfaktor-T-Gen (kurz: TGen) vor (Haworth et al. 2001). Das als T-Protein bezeichnete Produkt dieses Gens wird 
ausschließlich während der Embryogenese und begrenzt auf den Primitivstreifen, das pränotochordale Mesoderm und die Chorda dorsalis exprimiert (Smith 1999). Es spielt offensichtlich eine zentrale Rolle für die mesodermale Determination und in der Entwicklung der Chorda dorsalis. Untersuchungen an Mäuseembryonen zeigen, dass bei einer homozygot vorliegenden vollständigen Deletion des T-Gens, keine Chorda dorsalis ausgebildet wird. Betroffene Embryonen weisen schwerwiegende Anomalien des posterioren Segmentes auf, die schon früh im Verlauf der Entwicklung zum Absterben der Embryonen führen (Wilson et al. 1995).

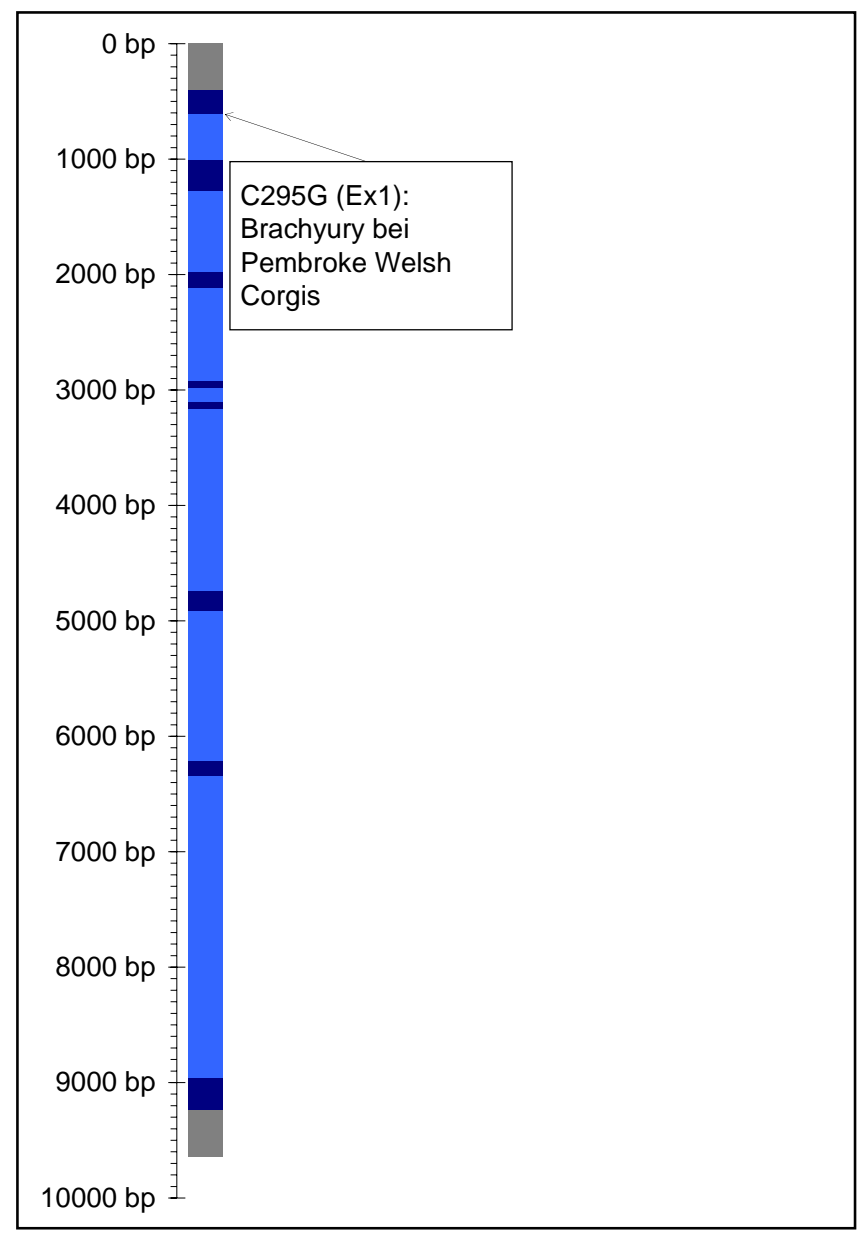

Abb. 123 Schematische Darstellung des caninen T-Gens und Lage der bisher identifizierten Mutationen. Dunkelblau: codierende Sequenz, hellblau: Intronsequenz, grau: intergenische Sequenz.

Das canine T-Gen ist auf dem langen Arm des Chromosoms 1 in Bande 23 lokalisiert (Haworth et al. 2001). Einzelheiten zur Charakterisierung der mRNA sind nicht veröffentlicht. Die Länge der codierenden Sequenz beträgt 1308 Nukleotide (NCBIGenBank: AJ245513). Im genomischen Contig NW_876269 ist die codierende Sequenz des T-Gens unterteilt in acht Exons zwischen Position 54237728 und 54228892 lokalisiert. Das offene Leseraster befindet sich auf dem revers komplementären Strang 
(NCBI-GeneID: 403653). Die Lage der einzelnen Exons der codierenden Sequenz innerhalb der genomischen Sequenz sind in Abb. 123 dargestellt.

\section{Ursächliche Mutation für Brachyury bei Pembroke Welsh Corgis}

Als ursächliche Mutation für die verkürzte Rute bei Pembroke Welsh Corgis konnte eine Substitution von Cytosin durch Guanin an Position 295 der cDNA identifiziert werden (Haworth et al. 2001). Das entspricht Position 189 in Exon 1 der codierenden Sequenz (Abb. 124) (NCBI-GeneID: 403653). Die Folge ist eine Aminosäurensubstitution von Isoleucin durch Methionin an Aminosäurenposition 63 (Haworth et al. 2001).

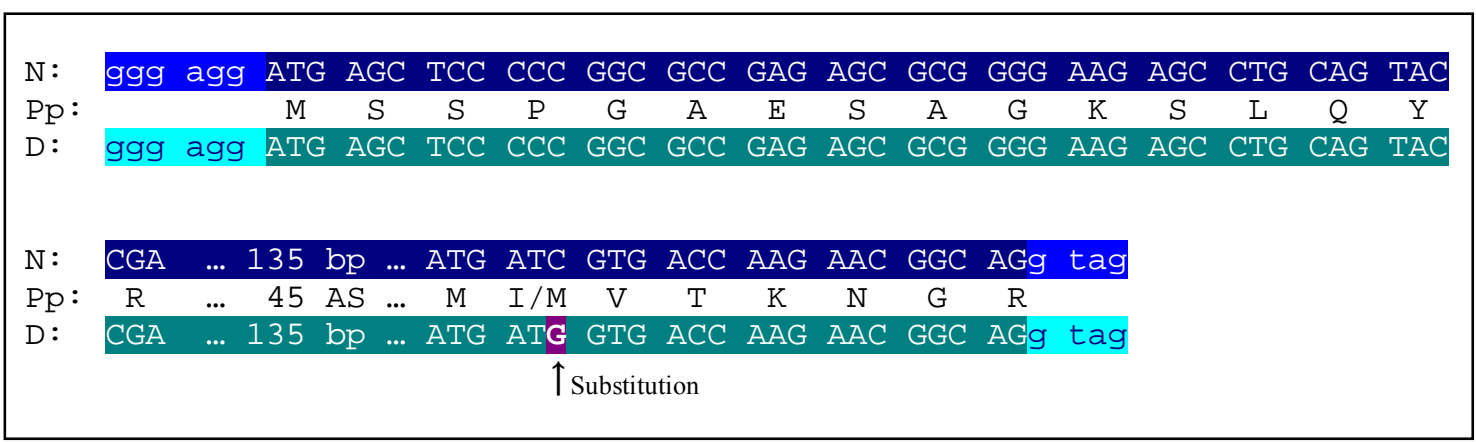

Abb. 124 Exon 1 des caninen T-Gens. N: normale Sequenz, D: defekte Sequenz, Pp: Polypeptidsequenz, dunkelblau: Exon normale Sequenz, hellblau: Intron normale Sequenz, dunkelgrün: Exon defekte Sequenz, türkis: Intron defekte Sequenz, Substitution in defekter Sequenz violett unterlegt und durch Pfeil gekennzeichnet.

Diese Mutation lag bei allen untersuchten Pembroke Welsh Corgis und PembrokeWelsh-Corgi-Kreuzungen mit verkürzter Rute heterozygot vor. Bei 30 untersuchten Hunden aus 19 weiteren Rassen konnte die Mutation nicht nachgewiesen werden (Haworth et al. 2001).

Diese Beobachtungen sprechen dafür, dass es sich bei der beschriebenen Mutation um den ursächlichen Gendefekt für die verkürzte Rute handelt. Offenbar liegt ein dominanter Erbgang vor. Als weitere wichtige Erkenntnis konnte festgestellt werden, dass bei der Anpaarung zweier heterozygot mutierter Elterntiere keine homozygoten Nachkommen geboren werden. Diese Beobachtung spricht dafür, dass homozygot mutierte Embryonen bereits zu einem frühen Zeitpunkt in ihrer Entwicklung absterben (Haworth et al. 2001).

Eine Untersuchung, in der die DNA-Bindungsfähigkeit mutierter und normaler TProteine sowie einer 1:1-Mischung aus mutierten und normalen T-Proteinen verglichen 
wurde, zeigt beim mutierten T-Protein einen vollständigen Verlust der DNABindungsfähigkeit. Für die Mischung aus mutierten und normalen T-Proteinen konnte eine gegenüber dem Wildtyp-Protein um 50 \% reduzierte Bindungsfähigkeit festgestellt werden. $\mathrm{Ob}$ es zur Formation von Heterodimeren aus mutierten und Wildtyp-Proteinen kommt, konnte nicht eindeutig geklärt werden. Allerdings liegt zwischen den Mengen an DNA-gebundenen Monomeren und Dimeren für reines Wildtyp-Protein und für die 1:1-Mutanten-Wildtyp-Mischung dasselbe Verhältnis vor. Daraus lässt sich schließen, dass entweder keine Heterodimere gebildet werden, oder dass, falls Heterodimere gebildet werden, diese eine geringere DNA-Bindungsfähigkeit aufweisen. Würden 100 \%ig funktionelle Heterodimere gebildet, müsste das Verhältnis zwischen DNAgebundenen Monomeren und Dimeren in der 1:1-Wildtyp-Mutanten-Mischung zugunsten der Dimere verschoben sein (Haworth et al. 2001).

Neben den dargestellten Untersuchungsergebnissen sprechen außerdem Parallelen zu TProtein-Mutationen bei Mäusen dafür, dass es sich bei der beschriebenen Substitution um den ursächlichen Gendefekt für Kurzschwänzigkeit bei Pembroke Welsh Corgis handelt. So ist bei Mäusen ein ähnlicher Phänotyp wie bei betroffenen Corgis zu beobachten. Heterozygote Mäuse weisen einen verkürzten Schwanz auf, während homozygote Mäuse von schwerwiegenden Defekten in posterioren mesodermalen Geweben betroffen sind und 10,5 Tage post coitum im Uterus absterben (Beddington et al. 1992; Wilson et al. 1993). 


\subsubsection{Erkrankungen des Nervensystems}

\subsubsection{Narkolepsie}

\begin{tabular}{|ll|}
\hline Chromosom: & CFA12 \\
Gen: & HCRTR2 \\
Ensembl: & GeneID: ENSCAFG00000002328 \\
DNA-Sequenz: & CFA12, Position 25519537-25625347 \\
Mutationen: & G160A, Dackel \\
& Int3Pos750Ins226-bp-SINE, Dobermann \\
& Int6G5A, Labrador Retriever \\
\hline
\end{tabular}

\section{Krankheitsbild}

Das Auftreten einer Narkolepsie ist in vielen Rassen beschrieben worden. Betroffen sind unter anderem die Rassen Dobermann, Labrador, Zwergpudel, Beagle, Dackel, Griffon und Cockapoo sowie Mischlingshunde (Baker et al. 1982). Hinweise auf einen genetischen Hintergrund liegen jedoch nur bei Dobermann und Labrador sowie bei Kreuzungen dieser beiden Rassen (Foutz et al. 1979; Baker et al. 1982) und bei Dackeln, Pudeln und Beagles (Cederberg et al. 1998; Hungs et al. 2001) vor. In allen übrigen Rassen sowie in einzelnen Fällen bei Dackeln, Pudeln, Labrador Retrievern und Chihuahuas lässt sich kein genetischer Hintergrund erkennen (Mitler et al. 1974; Babcock et al. 1976; Baker et al. 1982; vanHeerden und Eckersley 1989; Nishino et al. 1994; Hungs et al. 2001; Tonokura et al. 2003). Studien zur Häufigkeit der Narkolepsie in den genannten Rassen sind nicht veröffentlicht. Das klinische Erscheinungsbild ist bei allen betroffenen Hunden dasselbe. Unterschiede zwischen den einzelnen Rassen beziehungsweise zwischen spontanen und ererbten Erkrankungen bestehen lediglich hinsichtlich des Alters bei Ausbruch der Krankheit sowie des Schweregrades der Symptome.

Das auffälligste klinische Anzeichen der caninen Narkolepsie ist Kataplexie. Darunter versteht man das plötzliche Auftreten einer vorübergehenden schlaffen Lähmung einzelner Muskelgruppen (partielle Lähmung) oder der gesamten Skelettmuskulatur (totale Lähmung). Spontane kataplektische Anfälle treten stets im Zusammenhang mit einem erregenden Ereignis wie der Futteraufnahme oder Spielen auf. Beginnend mit einer Schwäche der Hinterbeine kommt es zu plötzlichem Hinsetzen (partielle Lähmung) oder Hinfallen (totale Lähmung) mit anschließender Bewegungsunfähigkeit. Der Lähmungszustand hält von wenigen Sekunden bis zu fünf Minuten an, lässt sich 
durch Berühren oder lautes Ansprechen des Hundes in den meisten Fällen sofort aufheben und ist vollständig reversibel (Knecht et al. 1973; Mitler et al. 1976; Baker et al. 1982). Im Elektroenzephalogramm (EEG) sind kataplektische Episoden narkoleptischer Hunde von normalen rapid-eye-movement (REM)-Phasen nur anhand des vorhergehenden Zustandes zu unterscheiden. Normalen REM-Phasen geht eine Tiefschlafphase voraus, während kataplektische Episoden übergangslos aus dem Wachzustand heraus stattfinden (Mitler und Dement 1977).

Als weiteres klinisches Merkmal wird in einigen Untersuchungen Hypersomnolenz angeführt. Von humanen Narkolepsie-Patienten wird diese extreme Tagesmüdigkeit mit Einschlafneigung als die am stärksten beeinträchtigende klinische Erscheinung empfunden (Kaitin et al. 1986). Vergleiche der EEG-Muster von narkoleptischen und gesunden Hunden sprechen gegen das Auftreten von Hypersomnolenz bei betroffenen Hunden. Es zeigt sich bezüglich des Gesamtanteils von wachen Episoden (überwiegend Beta-Wellen), leichtem Schlaf (überwiegend Theta-Wellen, Muskelzuckungen), Tiefschlaf (überwiegend Delta-Wellen) und REM-Schlaf (überwiegend Theta-Wellen, geringer Muskeltonus) im Verlauf einer 48-h-Erhebung kein signifikanter Unterschied zwischen narkoleptischen und gesunden Hunden (Mitler und Dement 1977). Die Summe der Non-REM-Schlaf Phasen sowie die Summe von Non-REM-Schlaf und REM-Schlaf Phasen, die im Verlauf einer 24-h-Erhebung auftreten, unterscheiden sich zwischen narkoleptischen und gesunden Hunden nicht (Kaitin et al. 1986). Allerdings gibt eine der Studien Hinweise auf eine erhöhte Schläfrigkeit bei narkoleptischen Hunden, indem sich im Verlauf einer 24-h-Erhebung eine signifikante Reduzierung der Summe aller Wachphasen und eine signifikant erhöhte Summe aller Dösephasen zeigt (Kaitin et al. 1986).

Der Schweregrad der Erkrankung ist über die Häufigkeit kataplektischer Episoden innerhalb einer bestimmten Zeitspanne definiert und wird mit einem Verhaltenstest, dem so genannten FECT (Food-Elicited Cataplexy Test) ermittelt (Babcock et al. 1976). Dabei wird der zu untersuchende Hund in einen Raum geführt, in dem zehn Futterstücke in gleichmäßigen Abständen auf dem Fußboden aufgereiht sind. Maß für die Schwere der Erkrankung ist die Zeit, die der Hund benötigt um alle zehn Futterstückchen zu fressen. Die gemessene Zeit schließt durch kataplektische Anfälle 
hervorgerufene Unterbrechungen ein. Dieser Test bildet auch die Grundlage zum Vergleich der Wirkung verschiedener Medikamente.

Allgemein scheinen ererbte Erkrankungen weniger schwer zu verlaufen als spontane Erkrankungen. Häufig sind die Symptome in der Anfangsphase, die meist im präpubertären Alter liegt, deutlich schwerer als beim erwachsenen Hund. Bei spontanen Erkrankungen kann der Schweregrad zwischen einzelnen Fällen sehr unterschiedlich sein. Zudem erkranken Hunde kleinerer Rassen häufig stärker als größere Hunde. Möglicherweise besteht zwischen diesen beiden Beobachtungen ein Zusammenhang, da spontane Narkolepsie-Fälle im Wesentlichen kleinere Rassen betreffen, während ererbte Narkolepsie-Fälle vor allem bei Dobermännern und Labrador Retrievern (Foutz et al. 1979; Baker et al. 1982) und nur einer geringen Anzahl kleinerer Hunde (Hungs et al. 2001) auftreten. Das Alter beim Auftreten erster Symptome liegt bei größeren Rassen unter sechs Monaten. Zu ersten kataplektischen Episoden kommt es bei Dobermännern im Alter zwischen einem und vier Monaten, bei Labrador Retrievern zwischen 14 und 24 Wochen, bei Kreuzungen zwischen acht und zehn Wochen. Bei kleinern Rassen schwankt das Alter bei erstmaligem Auftreten kataplektischer Episoden zwischen vier und 16 Monaten bei Zwergpudeln, vier Monaten bis drei Jahren bei Beagles, fünf Monaten bis sieben Jahren beim Dackel und sieben Wochen bis sieben Jahren in anderen Rassen. Eine Abhängigkeit des Schweregrades der Erkrankung vom Alter bei Auftreten erster Symptome scheint nicht vorzuliegen (Baker et al. 1982).

Histopathologische Untersuchungen an betroffenen Dobermännern zeigen im Vergleich zu normalen Kontrollhunden ein erhöhtes Auftreten von axonalen Degenerationen. Diese Degenerationen sind vor allem auf Hirnbereiche konzentriert, die mit der Reaktion auf Schrecken und mit der Steuerung des Schlafes in Verbindung gebracht werden (Siegel et al. 1999).

Pharmakologische Untersuchungen geben Hinweise auf die an der Pathogenese der Narkolepsie beteiligten Neurotransmittersysteme. Wie die REM-Schlaf-Phase scheinen auch bei kataplektischen Episoden cholinerge Mechanismen eine Rolle zu spielen. Die Injektion von Acetylcholinagonisten führt bei Hunden zur signifikanten Erhöhung kataplektischer Zustände, während muscarine Blocker zur Verminderung von Kataplexie führen (Delashaw et al. 1979). 


\section{Genetischer Hintergrund}

Inzwischen konnten in den Rassen Dobermann, Labrador und Dackel drei verschiedene Mutationen gefunden werden, die mit der Narkolepsie in Zusammenhang stehen (Lin et al. 1999; Hungs et al. 2001). Alle drei Defekte betreffen das Hypocretin-Rezeptor-2Gen (HCRTR2).

In einem untersuchten Pudel Pedigree konnte keine Segregation der Narkolepsie mit HCRTR2-oder Hypocretin (HCRT)-Markern nachgewiesen werden, demnach scheint bei Pudeln ein anderer Genort für die erbliche Narkolepsie verantwortlich zu sein (Hungs et al. 2001).

Die Assoziation zwischen dem HCRTR2-Gen und der caninen Narkolepsie wurde über positionelles Klonen ermittelt. Innerhalb einer Forschungskolonie betroffener heterozygoter und normaler Dobermänner und Labrador Retriever konnte über eine Analyse zufällig verteilter Marker eine enge Kopplung des Narkolepsie-Lokus mit einer Immunglobulin- $\mu$-Switch-ähnlichen Sequenz ermittelt werden (Mignot et al. 1991). Unter Verwendung einer genomischen caninen BAC-Bibliothek mit Inserts von durchschnittlich $155 \mathrm{~kb}$ Länge gelang die Erstellung eines 1,8 Mb langen Contigs, das den Narkolepsie-Lokus enthalten sollte ( $\mathrm{Li}$ et al. 1999). Mittels FISH konnten verschiedene BAC-Klone aus dem 1,8-Mb-Contig auf dem caninen Chromosom 12 innerhalb eines 30-Mb-Bereiches mit hoher Homologie zum humanen Chromosom 6 lokalisiert werden. Mikrosatellitenanalysen ermöglichten eine weitere Eingrenzung der relevanten Region im ursprünglichen 1,8-Mb-Contig auf eine $800 \mathrm{~kb}$ große Region. Innerhalb dieser Region war das HCRTR2-Gen das einzige bereits identifizierte Gen. Eine RFLP-Analyse ergab deutliche Hinweise auf das Vorliegen genomischer Veränderungen in der Nachbarschaft oder innerhalb des HCRTR2 Gens (Lin et al. 1999).

Das canine HCRTR2-Gen (ENSCAFG00000002328) ist auf Chromosom 12 lokalisiert und reicht von Position 25519537 - 25625347. Die mRNA hat eine Länge von 1802 Nukleotiden und enthält insgesamt sieben Exons. Die Länge des resultierenden Proteins beträgt 444 Aminosäuren. Die Lage der einzelnen Exons innerhalb der genomischen Sequenz ist in Abb. 125 dargestellt. 


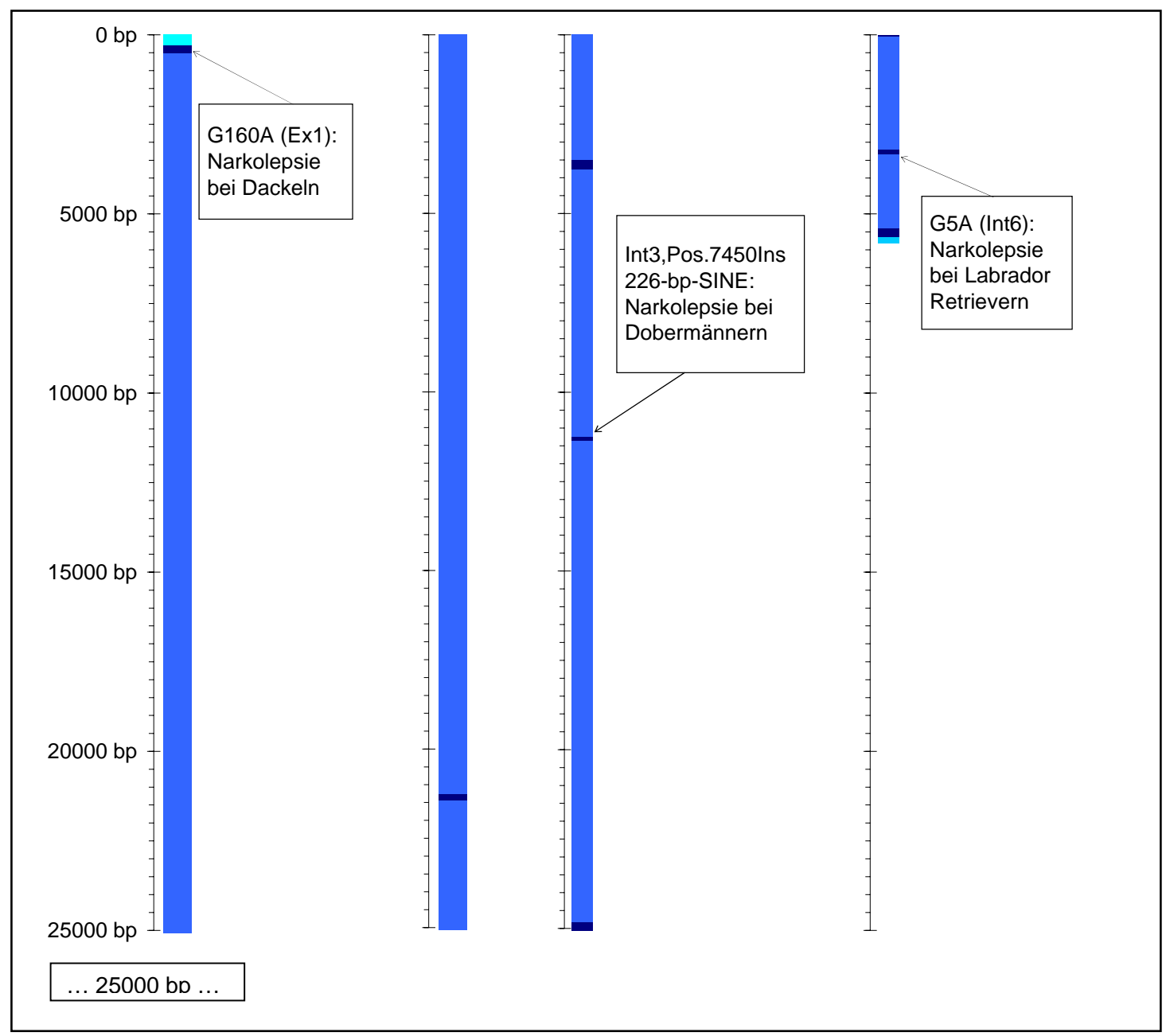

Abb. 125 Schematische Darstellung des caninen HCRTR2-Gens und Lage der bisher identifizierten Mutationen. Dunkelblau: codierende Sequenz, hellblau: Intronsequenz, türkis: 5'- und 3'UTR

Hypocretine, auch als Orexine bezeichnet, sind hypothalamusspezifische Neuropeptide, die an verschiedenen durch den Hypothalamus kontrollierten Funktionen beteiligt sind. Neben einer Stimulierung der Nahrungsaufnahme (Sakurai et al. 1998) betreffen weitere Funktionen dieser Neuropeptide die Regulation von Schlaf, Energiehomöostase sowie neuroendokrine und autonome Nervenfunktionen (Sakurai 2002).

Western-Blot-Analysen der HCRTR-Proteine von narkoleptischen Dackeln, Dobermännern und Labrador Retrievern sowie gesunden Vergleichshunden ergeben für mutierte Dackel- und Wildtyp- HCRTR-Proteine eine Größe von 78 kDa, während die Größen der mutierten Proteine von Dobermännern und Labrador Retrievern lediglich 55 kDa bzw. $65 \mathrm{kDa}$ betragen. In Expressionsstudien zeigen sich weitere Unterschiede. Während Wildtyp- und mutierte Dackel-HCRTR-Proteine vorrangig auf der Zellmembran exprimiert werden, sind mutierte Proteine von Dobermännern und 
Labrador Retrievern vor allem intrazytoplasmatisch lokalisiert. In Radiorezeptorbindungsstudien erfolgt erwartungsgemäß bei mutierten Labrador- und Dobermann-Rezeptoren keine spezifische Bindung. Auch bei mutierten Dackelrezeptoren ist trotz einer korrekten Expression auf der Zellmembran auch bei gesättigter Konzentration des radiomarkierten Liganden keine spezifische Bindung nachweisbar. Weitere Hinweise auf eine gestörte Funktion des mutierten Dackelrezeptors liefern Ergebnisse von Messungen des $\mathrm{Ca}^{2+}$-Influx in Reaktion auf verschiedene HCRT1- und HCRT2-Konzentrationen in Wildtyp-HCRTR- bzw. mutanten HCRTR- transfizierten Zellen. Der $\mathrm{Ca}^{2+}$-Influx dient als Maß für den Aktivierungslevel des zu untersuchenden Rezeptors. In Zelllinien, die mit mutierten Dobermann- und Labrador-Rezeptoren transfiziert sind, ist keine Reaktion zu erkennen. In Zelllinien, die mit mutierten Dackelrezeptoren transfiziert sind, erfolgt bei gleicher HCRT-Konzentration $(1 \mu \mathrm{M})$ eine im Vergleich zu Wildtyp-transfizierten Zelllinien um das Tausendfache reduzierte Reaktion. Physiologische Konzentrationen von bis zu 4 nM HCRT lösen in Dackelmutanten-transfizierten Zelllinien keine Reaktion aus (Hungs et al. 2001).

Diese Ergebnisse deuten auf das Vorliegen einer vollständigen Hemmung bzw. erheblichen Störung des HCRT-Rezeptors bei narkoleptischen Dobermännern, Labrador Retrievern und Dackeln hin. Der physiologische Zusammenhang zwischen diesen Ergebnissen und dem klinischen Erscheinungsbild der Narkolepsie konnte noch nicht vollständig aufgeklärt werden (Lin et al. 1999).

Hypocretin 1 und 2 und HCRTR2 scheinen in Interaktion mit dem aminergen und cholinergen System zu den wichtigsten Neuromodulatoren des Schlafes zu gehören. Möglicherweise ist diese Interaktion vor allem während der Entwicklungsphase wirksam. Eine im Verlauf der Entwicklung abnehmende Bedeutung von HCRTR2 könnte die Ursache für die besonders schwerwiegenden Symptome bei Hunden mit erblicher Narkolepsie im Alter zwischen vier und sechs Monaten und der im weiteren Verlauf der Erkrankung zu beobachtende leichte Rückgang in der Heftigkeit der klinischen Anzeichen sein (Lin et al. 1999). Für einen solchen Zusammenhang sprechen auch pharmakologische Untersuchungen, im Zuge derer bei jungen Hunden mit heterozygotem Narkolepsie-Genotyp durch Gaben von cholinergen Agonisten in Kombination mit Medikamenten zur Hemmung der monoaminergen Aktivität 
kataplektische Episoden ausgelöst werden konnten. Bei älteren heterozygoten Hunden ließ sich ein solches Ergebnis nicht erzielen (Mignot et al. 1993).

\section{III.a Ursächliche Mutation für Narkolepsie bei Dobermännern}

Bei betroffenen Dobermännern konnte in der HCRTR2-cDNA eine 116-bp-Deletion identifiziert werden, bei der es sich um Exon 4 handelt (Lin et al. 1999). Ursache für diese Deletion ist ein gestörtes Spleißen aufgrund einer 226-bp-Insertion in Intron 3, die 35 bp aufwärts der Intron-3-Exon-4-Grenze gelegen ist (Abb. 126). Bei dieser Insertion handelt es sich um ein bekanntes canines SINE Element.

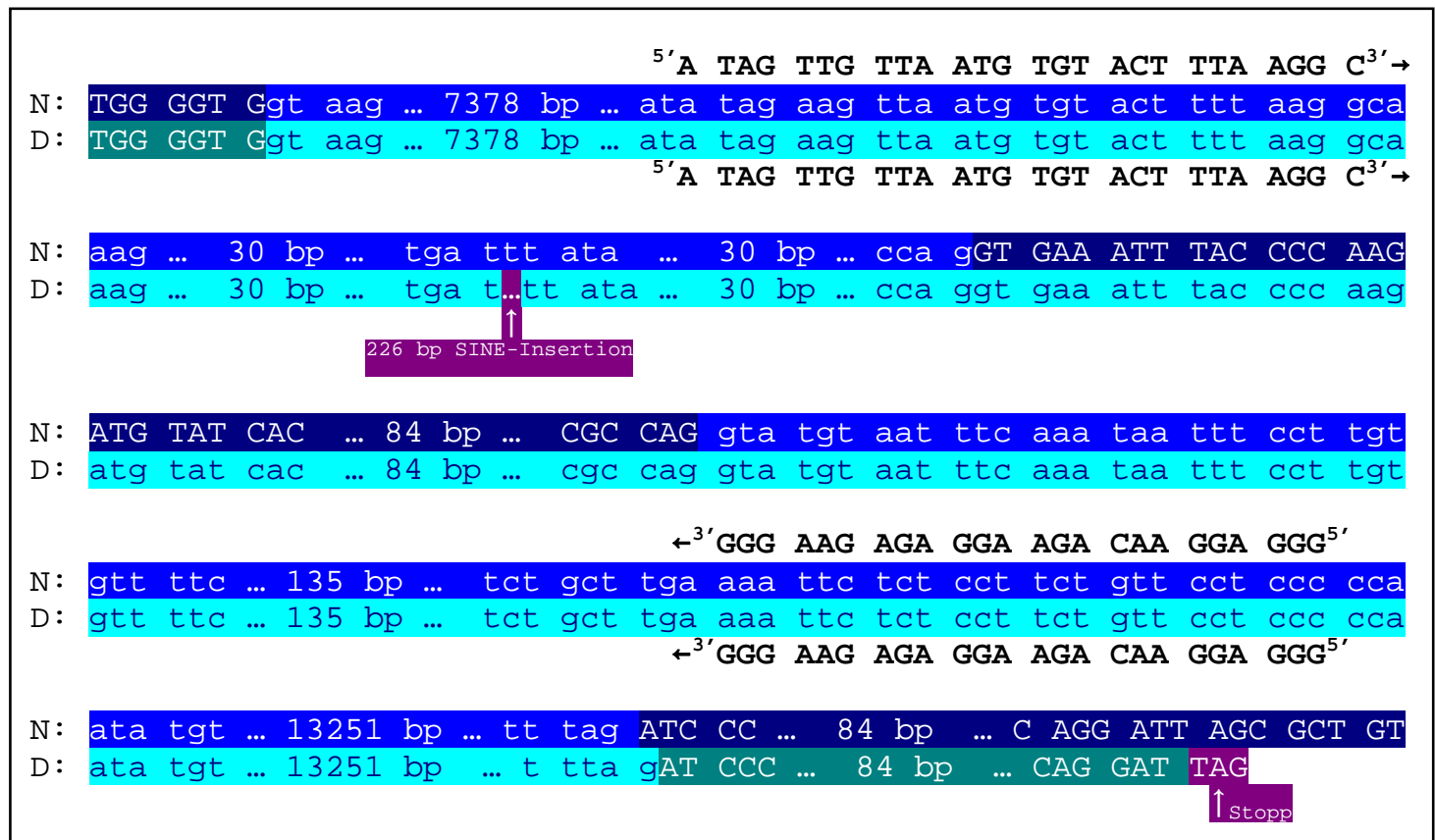

Abb. 126 Intron 3, Exon 4, Intron 4 und angrenzende Exonsequenzen des caninen HCRTR2Gens. N: normale Sequenz, D: defekte Sequenz, dunkelblau: Exon normale Sequenz, dunkelgrün: Exon defekte Sequenz, hellblau: Intron normale Sequenz, türkis: Intron defekte Sequenz, Insertion und verfrühtes Stoppcodon in defekter Sequenz violett unterlegt und durch Pfeil gekennzeichnet.

Durch diese Insertion wird eine mutmaßliche Lariat-Verzweigungssequenz (Branchpoint Sequenz - BPS), die in der normalen caninen Sequenz von 40 bp bis 46 bp aufwärts der Intron-3/Exon-4-Grenze gelegen ist, verschoben. Die BPSKonsensussequenz (PyXPyTPuAPy) ist bei Säugetieren nicht sehr hoch konserviert. Auch die übliche Lage der BPS zwischen 18 und 40 Nukleotiden aufwärts der 3'Spleißstelle kann erheblich variieren. Trotz dieser scheinbar geringen Voraussetzungen für die Funktionsfähigkeit einer BPS können Mutationen innerhalb dieser Sequenz zu einer nahezu vollständigen Verhinderung von Spleißvorgängen an der assoziierten Exon-Intron-Grenze führen (Reed und Maniatis 1985; Reed und Maniatis 1988). Daher 
ist es wahrscheinlich, dass die bei narkoleptischen Dobermännern gefundene SINEInsertion die Ursache für das gestörte Spleißen von Exon 4 ist. Durch das Fehlen von Exon 4 kommt es in der codierenden Sequenz zu einer Leserasterverschiebung, die zu Abweichungen der ersten 32 von Exon 5 codierten Aminosäuren führt, an die sich ein verfrühtes Stoppcodon anschließt.

\section{IV.a Genotypisierung für Narkolepsie bei Dobermännern}

Der Nachweis der Mutation kann per Amplifikation der potentiell von der Insertion betroffenen Region von genomischer DNA und anschließender PCRFragmentgrößenanalyse erfolgen. Bei allen 17 untersuchten narkoleptischen Dobermännern konnte die SINE-Insertion nachgewiesen werden, während keiner der 36 untersuchten gesunden Kontrollhunde aus den Rassen Dobermann, Labrador und Dackel und keiner der vier narkoleptischen Kontrollhunde aus den Rassen Labrador und Dackel die Insertion aufwies (Lin et al. 1999).

\section{III.b Ursächliche Mutation für Narkolepsie bei Labrador Retrievern}

Bei narkoleptischen Labrador Retrievern konnte durch cDNA-Amplifikation und Sequenzierung eine 122-bp-Deletion identifiziert werden, bei der es sich um Exon 6 handelt. Eine Analyse der Intron-Exon-Grenzen anhand von genomischer DNA zeigte in der Konsensussequenz der 5'-Spleißstelle von Intron 6 eine Substitution von Guanin zu Adenin an Position +5 (Abb. 127). Nach Shapiro und Senapathy (1987) beträgt die relative Häufigkeit von Guanin an dieser Position 84 \%. Die Substitution von Guanin durch Adenin verringert die Wahrscheinlichkeit für ein korrektes Spleißen von 88,4 \% auf $74,8 \%$ (Shapiro und Senapathy 1987). Aus anderen Untersuchungen sind Fälle bekannt, bei denen Mutationen an Position +5 der 5'-Spleißstelle zu 100 \%igem ExonSkipping geführt haben (Krawczak et al. 1992; McGrory und Cole 1999; Teraoka et al. 1999). Diese Ergebnisse sprechen dafür, dass es sich bei der beschriebenen Substitution um die Ursache für das Fehlen von Exon 6 handelt (Lin et al. 1999). Das gestörte Spleißen von Exon 6 führt zu einer Leserasterverschiebung. Dadurch kommt es zu Abweichungen der ersten drei von Exon 7 codierten Basen und ein daran anschließendes verfrühtes Stoppcodon (Lin et al. 1999). 


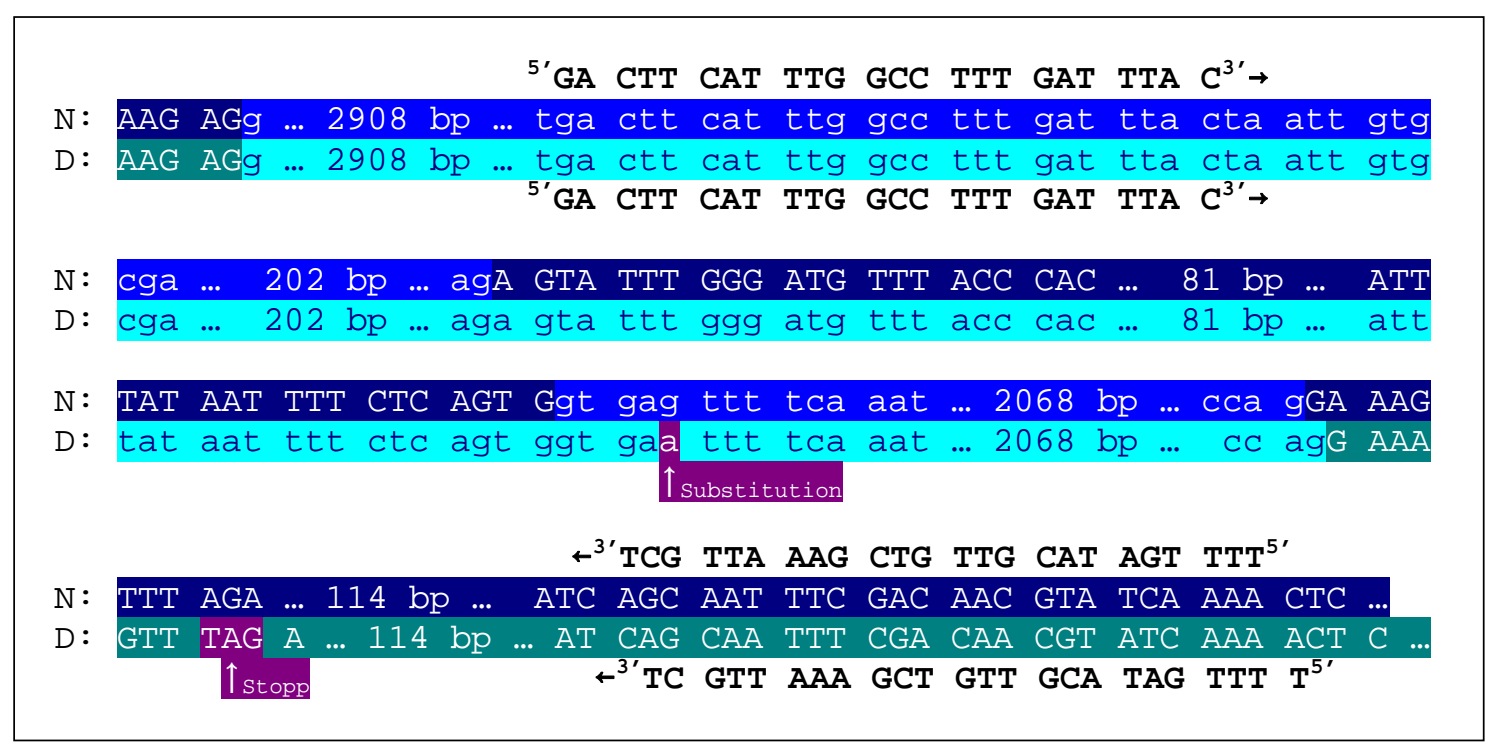

Abb. 127 Intron 5, Exon 6, Intron 6 und angrenzende Exonsequenzen des caninen HCRTR2 Gens. N: normale Sequenz, D: defekte Sequenz, dunkelblau: Exon normale Sequenz, dunkelgrün: Exon defekte Sequenz, hellblau: Intron normale Sequenz, türkis: Intron defekte Sequenz, Substitution und verfrühtes Stoppcodon in defekter Sequenz violett unterlegt und durch Pfeil gekennzeichnet.

\section{IV.b Genotypisierung für Narkolepsie bei Labrador Retrievern}

Der Nachweis der Substitution kann beispielsweise per diagnostischer Sequenzierung erfolgen (Lin et al. 1999).

Bei allen drei narkoleptischen Labrador Retrievern konnte das homozygote Vorliegen der beschriebenen Substitution nachgewiesen werden, während keiner der untersuchten 24 gesunden Hunde aus den Rassen Labrador, Dobermann und Dackel und keiner der untersuchten elf narkoleptischen Hunde aus den Rassen Dobermann und Dackel die Substitution aufwies (Lin et al. 1999).

\section{III.c Ursächliche Mutation für Narkolepsie bei Dackeln}

Bei drei narkoleptischen Dackeln konnte eine Substitution von Guanin durch Adenin in Codon 54 in Exon 1 nachgewiesen werden. Die Folge ist eine Aminosäurensubstitution von Glutamat zu Lysin (Abb. 128). Die Aminosäure 54 ist die letzte Aminosäure der Nterminalen Region des Hcrt2-Rezeptors, an die sich direkt die erste Transmembrandomäne anschließt (Hungs et al. 2001). 


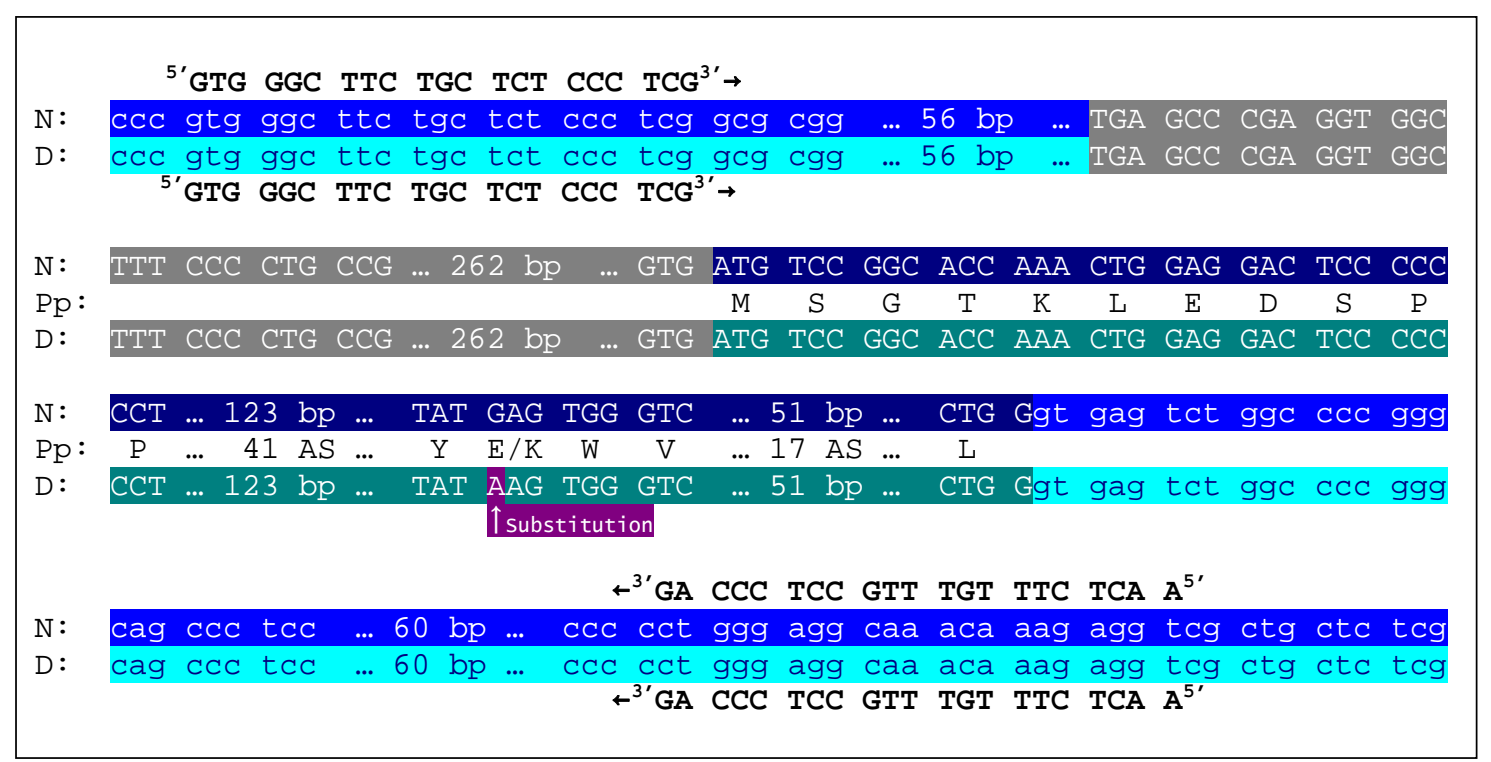

Abb. 128 5'UTR, Exon 1 und angrenzende genomische Sequenz bzw. Intronsequenz des caninen HCRTR2 Gens. N: normale Sequenz, D: defekte Sequenz, Pp: Polypeptidsequenz, dunkelblau: Exon normale Sequenz, dunkelgrün: Exon defekte Sequenz, hellblau: Intron normale Sequenz, türkis: Intron defekte Sequenz, Substitution in defekter Sequenz violett unterlegt und durch Pfeil gekennzeichnet.

\section{IV.c Genotypisierung für Narkolepsie bei Dackeln}

Der Nachweis der Substitution kann beispielsweise per diagnostischer Sequenzierung erfolgen (Hungs et al. 2001).

In einer betroffenen Dackelfamilie konnte bei drei narkoleptischen Wurfgeschwistern homozygot die Substitution nachgewiesen werden. Sowohl die Mutter als auch die zwei verbleibenden gesunden Wurfgeschwister waren heterozygot für die Substitution (Hungs et al. 2001).

\subsubsection{Spongiforme Leukoenzephalomyelopathie}

\begin{tabular}{ll}
\hline Chromosom: & CFAMT \\
Gen: & CYB \\
Ensembl: & GeneID: ENSCAFG00000022742 \\
DNA-Sequenz: & CFAmt, Position 14183-15322 \\
Mutationen: & G14474A, Australian Cattle Dog, Shetland \\
& Schäferhund \\
\hline
\end{tabular}

\section{Krankheitsbild}

Die Spongiforme Leukoenzephalomyelopathie gehört $\mathrm{zu}$ einer Reihe von Erkrankungen, die in Verbindung mit fehlerhaftem reduziertem oder blockiertem Aufbau von Myelin auftreten. Die Folge ist ein Rückgang der weißen Substanz des ZNS, der je nach Erkrankung aus unterschiedlichen histopathologischen Erscheinungen hervorgeht. Von anderen Erkrankungen aus dieser Gruppe hebt sich die spongiforme 
Degeneration vor allem durch eine charakteristische Vakuolisierung des Myelins ab, die das schwammartige histopathologische Erscheinungsbild der weißen Substanz bei betroffenen Individuen verursacht.

Zahlreiche Hunderassen sind von unterschiedlichen Erkrankungen aus der Gruppe der Leukoenzephalomyelopathien betroffen. Ein typisches spongiformes Erscheinungsbild ist jedoch bisher nur bei Silky Terriern (Richards und Kakulas 1978), Samoyeden (Mason et al. 1979), Labrador Retrievern (O'Brien und Zachary 1985; Zachary und O'Brien 1985; Neer und Kornegay 1995), Shetland Schäferhunden (Wood und Patterson 2001; Li et al. 2006) und Australian Cattle Dogs (Li et al. 2006) beobachtet worden. In allen genannten Rassen gibt es deutliche Hinweise darauf, dass es sich um erbliche Defekte handelt. Eine Identifizierung des verantwortlichen Gendefekts gelang bisher bei Shetland Schäferhunden und Australian Cattle Dogs (Li et al. 2006). Studien zur Häufigkeit der Erkrankung in den genannten Rassen sind nicht veröffentlicht.

Das klinische und histopathologische Erscheinungsbild ist abgesehen von einigen Abweichungen bezüglich des Alters zu Beginn der klinischen Erscheinungen und der Heftigkeit und Reihenfolge der Symptome bei allen betroffenen Rassen relativ ähnlich. Bei betroffenen Australian Cattle Dogs treten überwiegend im Alter von vier bis sechs Wochen, teilweise auch später (neun Wochen) typische neurologische Störungen auf, wobei hinsichtlich der einzelnen Symptome eine leichte Variabilität zwischen den einzelnen betroffenen Tieren vorliegt. Als erstes Anzeichen wird häufig ein Tremor des gesamten Körpers beobachtet, weitere Anzeichen sind Unregelmäßigkeiten des Ganges, die sich im Krankheitsverlauf zur Ataxie steigern, Wachstumsstörungen, spastische Erscheinungen an allen vier Gliedmaßen, Festliegen, Kiefersperre, Störungen des Nervus hypoglossus, Nystagmus, Dysphagie und übermäßiges Speicheln (Li et al. 2006). Auch bei betroffenen Shetland Schäferhunden sind entsprechende Symptome zu beobachten. Allerdings treten klinische Anzeichen in dieser Rasse teilweise bereits im Alter von einer Woche bis drei Wochen auf, und einige Welpen verenden bereits im Alter von sieben Wochen (Wood und Patterson 2001).

Pathologische Befunde zeigen sich ausschließlich im zentralen Nervensystem. Andere Organe wie Lunge, Herz, Dünndarm, Jejunum, Milz, Leber und Niere zeigen keinerlei Auffälligkeiten. Typisch sind eine diffuse Hypomyelinisierung der weißen Substanz 
und eine weiträumige Vakuolisierung von Myelin in der subkortikalen weißen Substanz sowie im Cerebellum, im Stammhirn und im Rückenmark. In stark betroffenen Regionen kommt es zur vollständigen Demyelinisierung der Axone bis hin zu axonalem Verlust und Gliose. Lichtmikroskopische Untersuchungen zeigen, dass die Vakuolisierung des Myelins durch eine Spaltung der Myelinhülle im Bereich der Zwischenlinie (Linea intermedia, intraperiod line) verursacht wird. Innerhalb der Myelinlamellen scheint sich zudem Flüssigkeit einzulagern (Wood und Patterson 2001; Li et al. 2006).

Eine biochemische Analyse der Cerebrospinalflüssigkeit bei betroffenen American Cattle Dogs ergibt erhöhte Gehalte an Laktat, Pyruvat und $\beta$-Hydroxybuttersäure sowie eine Verschiebung des Verhältnisses von $\beta$-Hydroxybuttersäure zu Acetoessigsäure. Western Blot Analysen von Hirnproben betroffener Shetland Schäferhunde zeigen erhöhte Konzentrationen der so genannten Core-Proteine I und II und eine reduzierte Konzentration von Cytochrom $\mathrm{c}_{1}$ des Ubichinol-Cytochrom c-Reduktase-Komplexes (Komplex III) der Atmungskette sowie eine reduzierte Konzentration der Cytochrom cOxidase (COX) (Komplex IV) (Li et al. 2006). Diese Ergebnisse deuten wie auch die verschobenen Konzentrationsverhältnisse von Endprodukten der Glykolyse und der $\beta$ Oxidation in der Cerebrospinalflüssigkeit, die als Substrate in den Citratzyklus eingehen, auf einen mitochondrialen Defekt hin (Li et al. 2006).

\section{Genetischer Hintergrund}

Der Erbgang lässt sich anhand der vorliegenden Pedigreeinformationen nicht eindeutig bestimmen. Ein gleichmäßiges Geschlechterverhältnis bei betroffenen Hunden schließt das Vorliegen eines X-chromosomalen Erbgangs aus. In drei Würfen einer klinisch normalen Shetland Schäferhündin von zwei unterschiedlichen ebenfalls gesunden Rüden sind 14 von insgesamt 19 Welpen betroffen. Die große Anzahl betroffener Welpen lässt einen autosomal rezessiven Erbgang für spongiforme Leukoenzephalomyelopathie bei Shetland Schäferhunden als unwahrscheinlich erscheinen (Wood und Patterson 2001). Bei Australian Cattle Dogs liegen ähnliche Verhältnisse vor. Drei Würfe mit betroffenen Welpen stammen von derselben Hündin und zwei verschiedenen Rüden ab. Auch hier liegt ein ausgeglichenes Geschlechterverhältnis vor, das gegen einen X-chromosomalen Erbgang spricht. 
Trotzdem gibt es Hinweise auf eine maternale Vererbung, denn beide Rüden haben in Würfen von anderen Hündinnen nur gesunde Nachkommen.

Sowohl die Pedigreeinformationen als auch die Ergebnisse der biochemischen Analyse von Cerebrospinalflüssigkeit und Hirngewebsproben deuten darauf hin, dass der ursächliche genetische Defekt in der mitochondrialen DNA lokalisiert ist. Anhand von Sequenzvergleichen konnte bei betroffenen Hunden eine Mutation im CYB-Gen identifiziert werden, das für Cytochrom b codiert (Li et al. 2006). Das canine CYB-Gen ist im mitochondrialen Chromosom zwischen Position 14183 und 15322 lokalisiert und enthält ein Exon. Die Länge der mRNA beträgt 1140 Nukleotide. Das resultierende Protein ist 380 Aminosäuren lang (ENSCAFG00000022742).

\section{Ursächliche Mutation für Spongiforme Leukoenzephalomyelopathie bei Australian Cattle Dogs und Shetland Schäferhunden}

Ein Sequenzvergleich der mitochondrialen DNA eines betroffenen Australian Cattle Dogs mit der normalen caninen Sequenz ergab einen Basenaustausch von G zu A an Position 14474 mit der Folge eines Aminosäurenaustauschs von Valin zu Methionin an Aminosäurenposition 98 des mitochondrial codierten Cytochrom b (MTCYB) (Abb. 129). Die Substitution verursacht den Verlust einer NspIRestriktionserkennungssequenz. Ein darauf basierender Gentest weist bei allen betroffenen Australian Cattle Dogs und Shetland Schäferhunden dieselbe Substitution von Guanin durch Adenin nach (Li et al. 2006).

Cytochrom b ist eine der Hauptkomponenten des Ubichinol-Cytochrom-c-ReduktaseKomplexes (Komplex III) der Atmungskette. Dieser Komplex spielt eine tragende Rolle bei der Aufrechterhaltung des Protonengradienten an der inneren Mitochondrienmembran, der eine essentielle Voraussetzung für die ATP-Synthese darstellt. Cytochrom b ist nach einem weithin anerkannten Modell im Zusammenspiel mit Cytochrom c1 am Elektronentransfer und der Verlagerung von Protonen über den so genannten Q-Zyklus beteiligt. Dabei werden 2 Elektronen von Ubichinol von Hämzentrum-b-566 auf Hämzentrum-b-560 übertragen, währen 4 Protonen aus dem mitochondrialen Matrixraum in den Intermembranraum verlagert werden. Die Folge der beschriebenen Substitution ist ein Aminosäurenaustausch von Valin zu Methionin an Aminosäurenposition 98. Diese Substitution liegt in direkter Nachbarschaft zu 
Hämzentrum-b-566 an Aminosäurenposition 97. Es wird vermutet, dass ein Austausch des sehr hydrophoben Valins gegen das deutlich weniger hydrophobe Methionin die Bindungseigenschaften des benachbarten Hämzentrums verändert und dadurch die Übertragung von Elektronen gestört und der Ablauf der ATP-Synthese blockiert wird. Im Anschluss an die durch Komplex III katalysierte Reaktion findet im gesunden Organismus eine durch Cytochrom-c-Oxidase (COX/Komplex IV) katalysierte energieliefernde Reaktion statt. Die deutlich reduzierte Konzentration der Cytochrom-cOxidase in Hirngewebsproben betroffener Shetland Schäferhunde lässt den Schluss auf einen verminderten Ablauf der durch COX katalysierten Reaktion zu. Diese Beobachtung steht im Einklang mit der vermuteten Funktionsstörung des UbichinolCytochrom-c-Reduktasekomplexes (Komplex III) (Li et al. 2006). Auch die erhöhte Konzentration der so genannten Core-Proteine I und II lässt sich mit einer Funktionsstörung von Komplex III in Zusammenhang bringen. Core I und II sind an der Aktivierung der mitochondrialen Prozessierungspeptidase (MPP) beteiligt. MPP ist für die Prozessierung des im Zytosol synthetisierten Vorläuferpeptides einer wichtigen Untereinheit von Komplex III beteiligt. Dabei handelt es sich um das Rieskeprotein. Die Aktivität der Prozessierungspeptidase wird gestoppt, wenn Core I, Core II und das prozessierte Rieskeprotein im Verhältnis 1:1:1 vorliegen. Aus einer erhöhten Konzentration von Core I und II schließen die Autoren auf eine exzessive Prozessierung des Prä-Rieskeproteins, die durch ein geringes ATP-Angebot verursacht sein könnte (Li et al. 2006).

Diese Überlegungen sprechen dafür, dass bei der Leukoenzephalomyelopathie der Australian Cattle Dogs und der Shetland Schäferhunde eine mitochondriale Störung vorliegt. Eine solche Störung scheint auch bei der humanen Van Bogaert-Bertrand Disease (Gambetti et al. 1969) sowie bei der Leukodystrophie der Labrador Retriever (Zachary und O'Brien 1985) vorzuliegen. Bei beiden Erkrankungen konnten in den Astrozyten Mitochondrien mit abnormer Struktur sowie Einschlüsse von parakristallinem Material gefunden werden, die als Überreste degenerierter Mitochondrien gedeutet werden (Gambetti et al. 1969; Zachary und O'Brien 1985). Der Zusammenhang dieser mitochondrialen Störung mit der Vakuolisierung von Myelin ist bisher noch unklar (Li et al. 2006). 


\section{Genotypisierung für Spongiforme Leukoenzephalomyelopathie bei Australian Cattle Dogs und Shetland Schäferhunden}

Der Nachweis kann per Amplifikation eines 584-bp-Fragments der mitochondrialen DNA und anschließende RFLP-Typisierung erfolgen (Abb. 129).

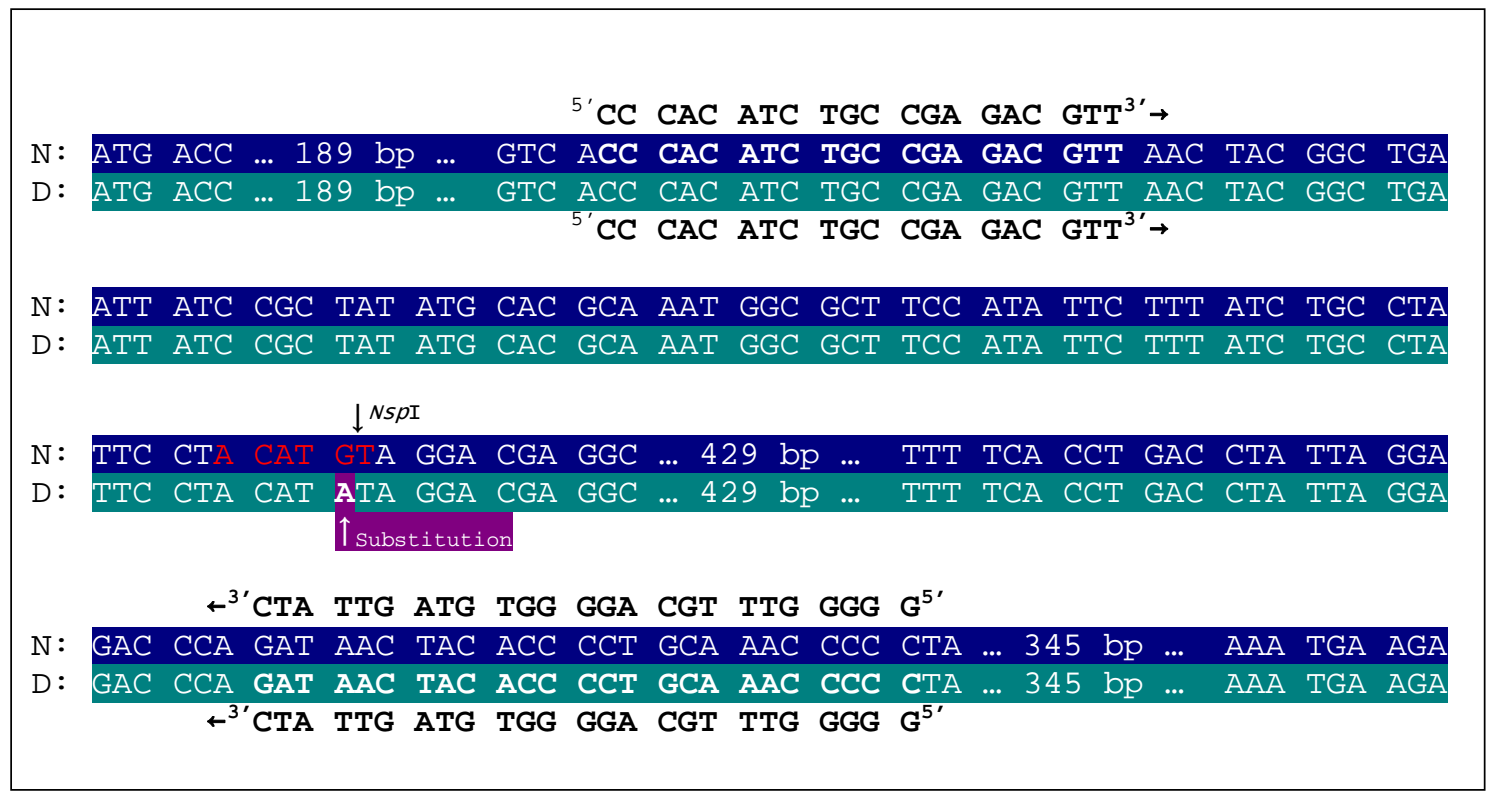

Abb. 129 Sequenz des caninen Cytochrom-b-Gens. N: normale Sequenz, D: defekte Sequenz, rote Schrift: NspI Erkennungssequenz, NspI Schnittstelle in normaler Sequenz durch Pfeil gekennzeichnet, Substitution in defekter Sequenz violett unterlegt und durch Pfeil gekennzeichnet.

Tabelle 19 Sequenz der Primer für die Amplifikation mitochondrialer DNA, Lage der Primer in der mitochondrialen DNA, Länge des amplifizierten Fragments, nicht amplifizierter DNA-Bereich

\begin{tabular}{lllll}
\hline Primer & Sequenz & $\begin{array}{l}\text { Lage in mt- } \\
\text { DNA [nt] }\end{array}$ & Fragmentlänge [bp] & $\begin{array}{l}\text { nicht amplifizierter Bereich der mt- } \\
\text { DNA [nt] }\end{array}$ \\
\hline $\begin{array}{l}\text { mt1 (Vor- } \\
\text { wärtsprimer) }\end{array}$ & $\begin{array}{l}\text { 5'GCCATCTTCAGCAA- } \\
\text { ACCCTCAAAAG }{ }^{3}\end{array}$ & $685-709$ & & $129-685$ \\
$\begin{array}{l}\mathrm{mt2} \text { (Rück- } \\
\text { wärtsprimer) }\end{array}$ & 5'TGGAGGCTTGCATGT- & $129-105$ & & \\
\hline
\end{tabular}

Der zugrunde liegende RFLP beruht auf einer Erkennungssequenz für NspI im Wildtypallel, die im Defektallel aufgrund der Mutation nicht enthalten ist ( $\mathrm{Li}$ et al. 2006). Um die Spezifität der Amplifikation des 584-bp-Fragments zu gewährleisten, wird in einer vorgeschalteten PCR unter Verwendung eins speziellen Primerpaares (Tabelle 19) ein 16727-bp-Fragment amplifiziert (Li et al. 2006). 


\subsubsection{X-chromosomal gekoppelter Tremor (shaking pup)}

\begin{tabular}{ll|}
\hline Chromosom: & CFAX \\
Gen: & PLP \\
Ensembl: & GeneID: ENSCAFG00000017811 \\
DNA-Sequenz: & CFAX, Position 80257960-80272972 \\
Mutationen: & A219C, Englischer Springer Spaniel \\
\hline
\end{tabular}

\section{Krankheitsbild}

Tremor-Syndrome betreffen die verschiedensten Hunderassen und können vielfältige Ursachen haben. Idiopathische Fälle der so genannten white shaker disease betreffen vor allem kleine, weiße Hunderassen wie Malteser Terrier und West Highland White Terrier sowie Beagles, Yorkshire Terrier, Australische Seidenterrier und Zwergpinscher. Als Ursache wird eine entzündliche Hirnerkrankung vermutet. Ein Erreger konnte bisher jedoch nicht gefunden werden. Des Weiteren tritt Tremor als Folge von Vergiftungen oder als sekundäre Erscheinung bei einigen erblichen Speichererkrankungen auf (Bagley 1992).

Ursache des shaking pup Syndroms bei Englischen Springer Spaniels ist eine genetisch bedingte Störung der Myelinisierung im zentralen Nervensystem (Griffiths et al. 1981a; Griffiths et al. 1981b). Angaben zur Häufigkeit dieser Erkrankung bei Springer Spaniels werden nicht gemacht. Betroffene Hunde zeigen im Alter von zehn bis zwölf Tagen einen generalisierten Tremor, der Rumpf, Extremitäten, Kopf und Augen betrifft. Im schlafenden Zustand nimmt der Tremor deutlich ab oder verschwindet, setzt aber sofort nach dem Erwachen intensiv wieder ein. Die Welpen sind unfähig, zu stehen oder koordinierte Bewegungen auszuführen. Die Fortbewegung erfolgt rückwärts oder seitwärts. Eine Untersuchung der Reflexe ergibt keinerlei Auffälligkeiten. Die Nahrungsaufnahme ist nur mit Hilfestellung möglich. Gewicht und Größe betroffener Hunde beträgt etwa die Hälfte der Maße normaler Wurfgeschwister. Betroffene Hunde überleben meist nicht länger als fünf bis acht Wochen.

Die weiße Substanz ist grau und gelatineartig und hebt sich dadurch deutlich von den weiß gefärbten Nervenwurzeln, peripheren und kranialen Nerven ab. Im gesamten zentralen Nervensystem (ZNS) ist lichtmikroskopisch ein deutlicher Myelinmangel erkennbar. Die Myelinisierung des peripheren Nervensystems (PNS) ist normal. Am stärksten betroffen ist die cerebrale weiße Substanz. In betroffenen Bereichen sind die Axone entweder nackt oder von dünnen Myelinscheiden umgeben. Im Verlauf der 
Entwicklung nimmt der Durchmesser der Myelinscheiden zwar zu, bleibt aber gegenüber der Norm stets reduziert (Griffiths et al. 1981b). Zudem sind die Myelinscheiden betroffener Hunde häufig nicht kompaktiert (Griffiths et al. 1981a). Myelinisierte Internodien sind deutlich kürzer als bei normalen Welpen. Des Weiteren fallen eine große Anzahl von Heminodien und eine vergleichsweise geringere Anzahl Ranvier'scher Schnürringe auf. Im Gegensatz zum Ranvier'schen Schnürring trennt ein Heminodium nicht zwei myelinisierte Axonabschnitte voneinander, sondern beschreibt den Übergang von einem myelinisierten Axonabschnitt zu einem nichtmyelinisierten Abschnitt (Griffiths et al. 1981b). Weitere Befunde lassen vermuten, dass die Oligodendrozyten betroffener Hunde nur zu einer limitierten Bildung von Myelin in der Lage sind. Das schließen die Autoren aus der Beobachtung eines Zusammenhangs zwischen dem Durchmesser der Myelinscheiden und der Länge der Internodien. Je dicker die Myelinscheiden sind, desto kürzer sind die Internodien. Lange Myelinscheiden sind stets dünn (Duncan et al. 1983).

Angrenzend an Nervenfasern und teilweise im Zytoplasma von Gliazellen treten kleine Vakuolen auf, die zum Teil zusammengelagert sind. Die Häufigkeit dieser Vakuolen ist bei Welpen im Alter von einem Monat größer als bei zwei Monate alten Hunden (Griffiths et al. 1981b). Einige dieser Vakuolen sind leer, während andere elektronendichtes granulares Material enthalten (Griffiths et al. 1981a). Die Autoren vermuten aufgrund von Parallelen zu Mäusen mit einer ähnlichen Erkrankung (Watanabe und Bingle 1972), dass es sich bei den Vakuolen um sekundäre Lysosomen handelt, in denen anormales oder übermäßig instabiles Myelin abgebaut wird (Griffiths et al. 1981a).

Makrophagen treten im Bereich der Vakuolen nicht auf. Diese Beobachtung spricht gegen einen übermäßigen Abbau von Myelin (Griffiths et al. 1981b). Auch weitere Befunde deuten eher auf eine Störung des Myelinisierungsprozesses als Ursache der mangelhaften Myelinisierung hin als auf übermäßigen Myelinabbau. Bei betroffenen Hunden im Alter von zwei Monaten befinden sich im Vergleich zu normalen Altersgenossen in den lateralen Myelinschleifen sowie in internodialen oder paranodialen zytoplasmatischen Taschen der Oligodendrozyten und in den außenseitig terminierten lateralen Myelinschleifen erhöhte Mengen an Zytoplasma. Ein ebensolches Bild ergibt sich bei normalen, noch nicht vollständig entwickelten Myelinscheiden 
(Hildebrand 1971; Fraher 1978). Auch die bei zwei Monate alten betroffenen Hunden auftretende internodiale Terminierung von Myelinschleifen ist in ähnlicher Form in frühen Stadien der Myelinisierung bei normalen Individuen zu finden, wie z.B. im ZNS einwöchiger Katzen (Hildebrand 1971) oder bei der Remyelinisierung peripherer Nerven (Hall 1973; King et al. 1975). Diese Parallelen zwischen Befunden bei zwei Monate alten betroffenen Hunden und Befunden $\mathrm{zu}$ Beginn einer normalen Myelinscheidenentwicklung sprechen für das Vorliegen einer Entwicklungsstörung der Oligodendrozyten bei betroffenen Hunden (Griffiths et al. 1981a).

Mittels Gefrierschnitt-Elektronenmikroskopie lassen sich weitere zytologische Besonderheiten im ZNS betroffener Hunde erkennen (Bray et al. 1983). Dabei handelt es sich um das Auftreten spiralförmiger, zytoplasmatischer Fortsätze, die hypomyelinisierte Axone im Bereich der Ranvier'schen Schnürringe umschließen. Die spiralförmigen Fortsätze haben eine deutliche Ähnlichkeit mit paranodialen, dem Myelin anliegenden Zytoplasmaschleifen. Diese Beobachtung legt die Vermutung nahe, dass es sich um Ausdehnungen oligodendrozytischen Zytoplasmas handelt. Bei neugeborenen Katzen finden sich ähnliche Spiralfortsätze (Hildebrand 1971). Es wird daher in Betracht gezogen, dass die bei betroffenen Hunden beobachteten Spiralfortsätze Reste eines Übergangsstadiums innerhalb der paranodialen Entwicklung sind. Daraus schließen die Autoren weiterhin, dass der zugrunde liegende Defekt spezifisch die Myelinsynthese betrifft, während die Regulationsmechanismen für die Ausdehnung und Spiralbildung der Oligodendrozytenfortsätze nicht beeinträchtigt sind. Zudem zeigt sich hier eine weitere Parallele der Oligodendroglia betroffener Hunde zu frühen Entwicklungsstadien von Oligodendrozyten normaler Individuen (Bray et al. 1983).

Quantitative Untersuchungen an betroffenen Hunden ergeben eine Reduzierung der Gesamtanzahl der Oligodendroglia gegenüber normalen Altersgenossen (Duncan und Griffiths 1981; Duncan et al. 1983). Als Ursache wird eine Störung der Stammzellproliferation vermutet. Eine weitere mögliche Ursache, ein frühes Absterben von Oligodendroglia, wird als unwahrscheinlich eingeschätzt, da bei betroffenen Hunden kein deutlich erhöhtes Zellsterben der Oligodendrozyten feststellbar ist (Duncan et al. 1983). Zudem kommt es zum Auftreten anormaler Oligodendroglia mit deutlicher Ausdehnung des rauen endoplasmatischen Retikulums (RER) und der 
perinuklearen Hülle. Die erweiterten Regionen enthalten flockenartiges Material. Als mögliche Ursache dieser Akkumulation wird die erhöhte Syntheserate eines Proteins im RER oder der gestörte Transport eines Proteins im Zytoplasma oder die Synthese eines abnormalen Sekretionsproduktes vermutet (Duncan et al. 1983). In späteren Experimenten gelingt die immunologische Identifizierung dieses flockigen Materials in einigen aber nicht allen veränderten Oligodendrozyten als myelinassoziiertes Glykoprotein (Inuzuka et al. 1986).

Bezüglich der Proteinzusammensetzung existieren bei betroffenen Hunden sowohl in Gewebehomogenaten aus verschiedenen Bereichen des ZNS als auch in isolierten Myelinfraktionen einige Besonderheiten. Insgesamt sind die Anteile von myelinassoziierten Proteinen sowohl bezüglich des gesamten Gewebes als auch in der Myelinfraktion bei betroffenen Hunden gegenüber Kontrollhunden deutlich reduziert. Es handelt sich dabei um die Proteine MBP (Myelinbasisprotein), CNP (2'3'-Zyklische Nukleotidphosphodiesterase), MAG (myelinassoziiertes Glykoprotein), PLP (Proteolipid Protein) und DM-20, wobei PLP am stärksten reduziert ist (Inuzuka et al. 1986; Yanagisawa et al. 1987). In isolierten Myelinfraktionen ist MBP bei betroffenen Hunden im gleichen Maße reduziert wie in den Gewebehomogenaten, während CNP und MAG in isolierten Myelinfraktionen etwas höher konzentriert sind als im Gesamthomogenat. CNP und MAG sind Komponenten nicht kompaktierter Myelinscheiden, während MBP eine Hauptkomponente kompaktierter, vollständig entwickelter Myelinscheiden ist. Die biochemische Zusammensetzung stimmt mit früheren Beobachtungen eines verringerten Anteils kompaktierten Myelins und demgegenüber erhöhten Anteils nichtkompaktierten Myelins überein. Die geringere Reduzierung von CNP und MAG gegenüber MBP lässt sich also als sekundärer Effekt einer unvollständigen Myelinreifung erklären (Inuzuka et al. 1986).

Bezüglich der Myelinkomponente PLP gibt es neben der Beobachtung, dass dieses Protein bei betroffenen Hunden am stärksten reduziert ist, eine weitere Besonderheit. Es existiert eine Verschiebung im Mengenverhältnis von PLP zu DM-20. Bei gesunden Kontrollhunden beträgt das Verhältnis von PLP zu DM-20 etwa 0,06. Im Gegensatz dazu liegen beide Proteine bei betroffenen Hunden sowohl im Rückenmark als auch im Hirn zu etwa gleichen Anteilen vor (Yanagisawa et al. 1987). Die gefundenen Proteinmengenverhältnisse spiegeln sich auch auf mRNA-Ebene wieder. Insgesamt sind 
PLP und DM-20 mRNA bei betroffenen Hunden gegenüber normalen Hunden in Hirn und Rückenmark während der Embryonalentwicklung und der ersten zehn Lebenswochen deutlich reduziert. Mit fortschreitender Entwicklung scheint sich die mRNA-Menge betroffener Hunde allmählich wieder der Norm zu nähern. Im Hirn nimmt der Anstieg der mRNA-Menge zwischen vier und zehn Wochen deutlich zu, im Rückenmark erreichen betroffene Hunde im Alter von zwei Jahren die selben mRNAWerte wie normale Hunde. Ab einem Alter von zehn Wochen bewegen sich die mRNAMengen beider Proteine etwa im selben Bereich. Das Verhältnis von DM-20-mRNA zu PLP-mRNA während der ersten zwei Lebensjahre hat bei normalen und betroffenen Hunden einen ähnlichen Verlauf, indem die Menge an DM-20-mRNA gegenüber der Menge an PLP-mRNA stetig abnimmt. Bei gesunden Hunden übersteigt die Menge an DM-20-mRNA im Hirn nur innerhalb der Embryonalentwicklung die Menge an PLPmRNA. Im Rückenmark besteht bereits in diesem Entwicklungsstadium ein DM20/PLP-mRNA Verhältnis $<1$, das ab dem ersten Lebenstag auch im Hirn vorliegt. Bei betroffenen Hunden liegt hingegen im Verlauf der ersten zehn Lebenswochen sowohl im Hirn als auch im Rückenmark ein deutlicher Überhang an DM-20-mRNA vor (Nadon et al. 1990). Damit ergibt sich eine weitere Parallele der Myelineigenschaften betroffener Hunde zu den Myelineigenschaften im ZNS vor Abschluss der Entwicklung.

PLP ist ein hydrophobes integrales Membranprotein, das in den Myelinscheiden des ZNS etwa die Hälfte der gesamten Proteinfraktion stellt. DM-20 unterscheidet sich von PLP nur durch eine Deletion von ca. 40 Aminosäuren (Trifilieff et al. 1985). Offenbar werden PLP und DM-20 vom selben Gen codiert. Das Verhältnis der Expression von PLP zur Expression von DM-20 wird durch alternatives Spleißen der PLP mRNA nach der Transkription bestimmt (Hudson et al. 1987). Im peripheren Nervensystem (PNS) sind die Proteine PLP und DM-20 in den Myelinscheiden nicht vertreten, sondern treten lediglich im Zellkörper der Schwann'schen Zellen auf (Puckett et al. 1987).

Erste Untersuchungen an Welpen mit dem shaking pup Syndrom beziehen sich auf vier von insgesamt sechs betroffenen männlichen Englische Springer Spanielwelpen aus drei verschiedenen Würfen einer klinisch normalen Hündin und zweier gesunder Rüden (Griffiths et al. 1981b). Auch spätere Fälle betreffen ausschließlich Rüden, so dass allgemein von einer X-gekoppelten Vererbung des shaking pup Syndroms ausgegangen wird. In Einzelfällen zeigen weibliche Nachkommen von Defektträgerhündinnen 
innerhalb des ersten Lebensmonats übergangsweise ebenfalls Symptome, die jedoch nur kurze Zeit anhalten. Untersuchungen von Hirn und Rückenmark dieser weiblichen Defektträger zeigen einen so genannten Myelin-Mosaizismus. Das bedeutet, dass in einigen Zellen das mutierte X-Chromosom aktiviert ist, so dass es in wenigen zufällig verteilten Bereichen zum Auftreten der typischen Myelindefekte kommt. Es sind jedoch bisher keine Fälle bekannt geworden, in denen das shaking pup Syndrom bei heterozygoten Defektträgerhündinnen zu nachhaltigen Störungen geführt hätte. Daher ist davon auszugehen, dass trotz des Myelin-Mosaizismus heterozygoter Hündinnen noch vor Ablauf der neonatalen Periode eine vollständige Myelinisierung erfolgt (Duncan et al. 1987; Cuddon et al. 1998).

\section{Genetischer Hintergrund}

Sowohl das humane als auch das murine PLP-Gen sind auf dem X-Chromosom lokalisiert (Willard und Riordan 1985). Vor diesem Hintergrund in Verbindung mit deutlichen Hinweisen auf eine X-chromosomal gekoppelte Vererbung des shaking pup Syndroms und der abnormalen Expression von PLP und DM-20 wird ein primärer Zusammenhang der Erkrankung mit einer Mutation im PLP-Gen als wahrscheinlich angesehen (Yanagisawa et al. 1987; Nadon et al. 1990).

Das canine PLP-Gen ist auf dem X-Chromosom zwischen Position 80257960 und 80272972 lokalisiert und enthält auf einer Länge von 18 kb sieben Exons. Die Länge der mRNA beträgt 1264 Nukleotide (ENSCAFG00000017811). Die Intron-ExonGrenzen entsprechen den bereits bei Mensch und Maus identifizierten Positionen. Zwischen den einzelnen Spezies bestehen lediglich geringe Unterschiede hinsichtlich der Intronlänge. Das resultierende canine Protein hat eine Länge von 276 Aminosäuren und unterscheidet sich lediglich durch einen Isoleucinrest an Position 591 anstelle eines Valinrestes vom murinen und humanen PLP (Nadon et al. 1990). Abb. 130 zeigt die Lage der einzelnen Exons innerhalb der genomischen Sequenz. 


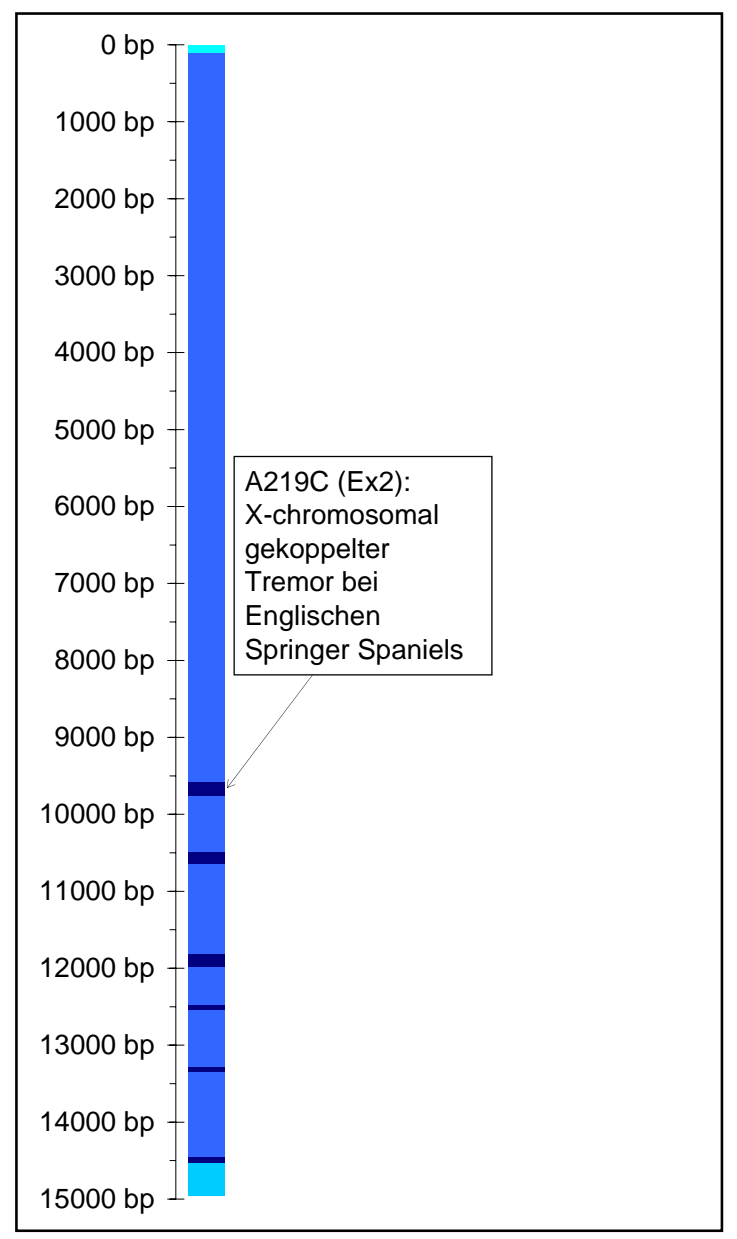

Abb. 130 Schematische Darstellung des caninen PLP-Gens und Lage der bisher identifizierten Mutationen. Dunkelblau: codierende Sequenz, hellblau: Intronsequenz, türkis: 5'- und 3'UTR.

\section{Ursächliche Mutation für X-chromosomal gekoppelten Tremor bei Englischen Springer Spaniels}

Bei betroffenen Englischen Springer Spaniels liegt eine Substitution von Adenin durch Cytosin an Position 219 der codierenden Sequenz in Exon 2 vor (Abb. 131). Die Folge ist eine Aminosäurensubstitution von Histidin zu Prolin. Bei dieser Mutation handelt es sich um die einzige Abweichung der Sequenz betroffener Hunde von der normalen Sequenz einschließlich Spleißstellen, 200 bp der 3'-UTR und der gesamten 5'-UTR (Nadon et al. 1990).

Der Effekt der Mutation ist einerseits eine Reduzierung der mRNA- und ProteinMengen von PLP und DM-20. Es wird vermutet, dass die mutierten Proteine zudem einen hemmenden Effekt auf die Entwicklung der Oligodendrozyten haben. Sowohl auf histologischer als auch auf biochemischer Ebene existieren deutliche Hinweise auf eine Blockade in der Oligodendrozytenentwicklung (Duncan et al. 1983; Inuzuka et al. 1986; Yanagisawa et al. 1987; Song et al. 2006). Einzelheiten über den Mechanismus dieser 
Blockade sind nicht bekannt. Der Aminosäurenaustausch von Histidin zu Prolin ist in der ersten Transmembrandomäne des Proteins lokalisiert (Nadon et al. 1990). Da bekannt ist, dass Prolin in der Lage ist die Richtung einer Aminosäurekette zu verändern und deshalb generell nicht in Intramembranregionen von Proteinen auftritt (Brandl und Deber 1986), ist eine Veränderung der Proteinstruktur aufgrund der beschriebenen Mutation nicht ausgeschlossen. Eine mögliche Folge ist die Störung des intrazellulären Transports vom RER über den Golgi-Apparat zur Membran. Diese Vermutung wird durch die Beobachtung einer abweichenden Verteilung von PLP und DM-20 in Oligodendrozyten betroffener Hunde unterstützt. Mittels immunohistochemischer Untersuchungen konnte eine Ansammlung von PLP und DM20 im perinuklearen Zytoplasma und in den proximalen Fortsätzen der Oligodendrozyten nachgewiesen werden, während für andere myelinassoziierte Proteine wie MBP, MAG und CNP keine derartige Akkumulation festgestellt werden konnte. Die PLP- und DM-20-Akkumulationen fallen mit Bereichen zusammen, in denen Aufweitungen des RER vorliegen. Diese bereits in früheren Untersuchungen beschriebenen RER Aufweitungen (Duncan et al. 1983) gelten als spezifische Reaktion des RER auf Ansammlungen ungefalteter Proteine (Kaufman 1999), die so genannte „unfolded protein response“. Warum die Akkumulation fehlgefalteter Proteine in einigen Oligodendrozyten eine Blockade in der Entwicklung verursacht, während andere Oligodendrozyten sich normal entwickeln, konnte bisher noch nicht geklärt werden (Song et al. 2006).

\section{Genotypisierung für X-chromosomal gekoppelten Tremor bei Englischen Springer Spaniels}

Der Nachweis der Mutation kann per Amplifikation eines 322-bp-Fragments, das Exon 2 einschließt, und anschließender RFLP-Typisierung erfolgen. Der zugrunde liegende RFLP basiert auf einer AvaII-Restriktionserkennungssequenz, die durch die Mutation im Defektallel entsteht und im Wildtypallel nicht vorhanden ist (Nadon et al. 1990). 


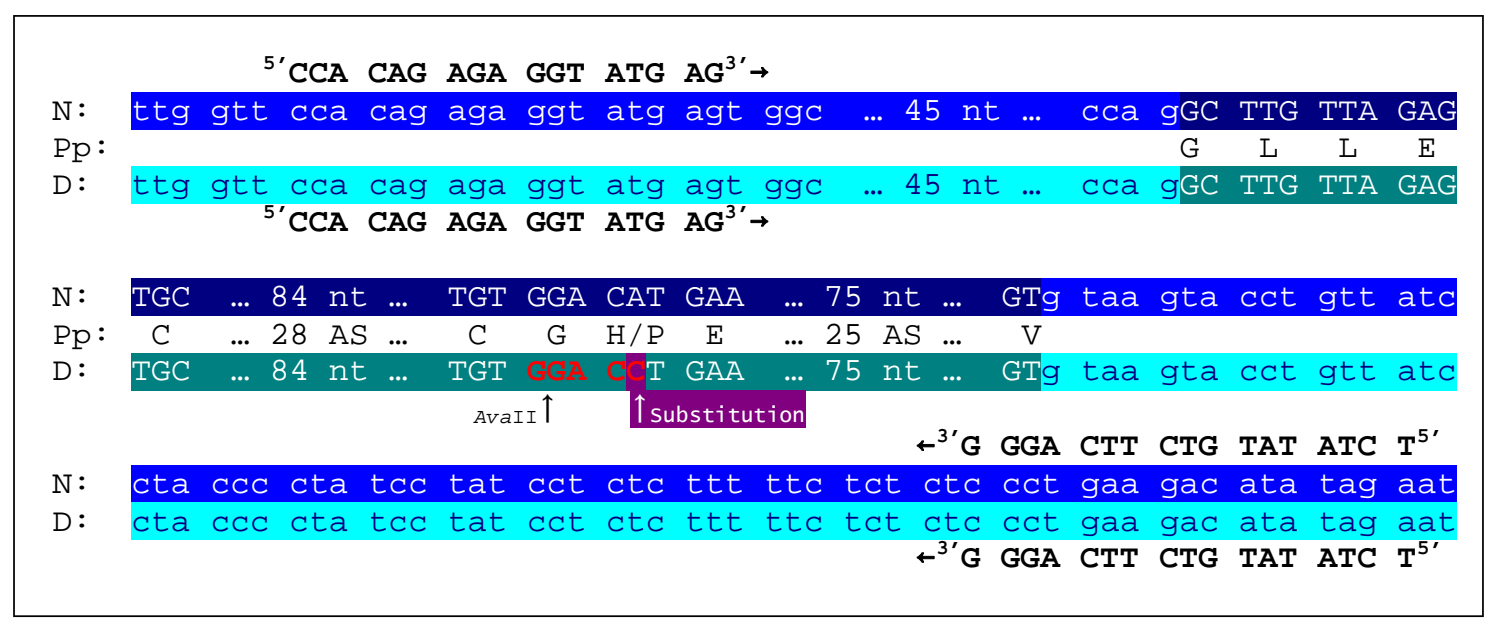

Abb. 131 Exon 2 des caninen PLP-Gens und angrenzende Intronsequenz. N: normale Sequenz, D: defekte Sequenz, Pp: Polypeptidsequenz, hellblau: Intron normale Sequenz, türkis: Intron defekte Sequenz, dunkelblau: Exon normale Sequenz, dunkelgrün: Exon defekte Sequenz, Substitution in defekter Sequenz violett unterlegt und durch Pfeil gekennzeichnet, rote Schrift: AvaII Erkennungssequenz, AvaII Restriktionsschnittstelle durch Pfeil gekennzeichnet. 


\subsubsection{Muskelerkrankungen}

\subsubsection{Das Maligne Hyperthermie Syndrom (MHS)}

\begin{tabular}{ll|}
\hline Chromosom: & CFA1 \\
Gen: & RYR1 \\
NCBI: & GeneID: 606491,GenBank: AF302128 bzw. \\
DNA-Sequenz: & AF302129 \\
Mutationen: & T1640C, Dobermann-Deutscher-Schäferhund- \\
\hline
\end{tabular}

\section{Krankheitsbild}

Beim Maligne Hyperthermie Syndrom (MHS) kommt es als Folge einer Verabreichung von flüchtigen Anästhetika und depolarisierenden Muskelrelaxantien sowie ausgelöst durch starke Kraftanstrengungen oder Hitzestress zu einer pathologisch erhöhten Calciumkonzentration in der Skelettmuskulatur.

Bei Hunden äußert sich MHS durch Sinken des Blutdrucks, eine erhöhte Herzfrequenz (Tachykardie), ein Ansteigen der Körpertemperatur und eine erhöhte $\mathrm{CO}_{2}$-Produktion. Es kann, bevor im Verlauf der Narkose die Muskelentspannung einsetzt, zu besonders intensiven lang andauernden Faszikulationen kommen. Ohne die Ergreifung geeigneter Gegenmaßnahmen kommt es auch nach Abschalten der auslösenden Faktoren zu einem weiteren Blutdruckabfall, unregelmäßigem Puls und Asystolie mit tödlichem Ausgang. Nach dem Verenden tritt innerhalb kürzester Zeit (nach weniger als 2-15 min) die Totenstarre ein. Durch Gabe von Dantrolen lassen sich die beschriebenen Erscheinungen aufheben. (Bagshaw et al. 1978; Bagshaw et al. 1981; Duncan et al. 1997). Blutuntersuchungen während einer akuten malignen Hyperthermie ergeben unter anderem erhöhte Creatinkinase-Werte (Kirmayer et al. 1984). In einem Vergleich der Blutlaktatkonzentration nach Halothanadmnistration bei betroffenen und nicht betroffenen Hunden zeigten sich in beiden untersuchten Gruppen erhöhte Laktatkonzentrationen im Blut. Zwar lagen die Laktatwerte bei betroffenen Hunden durchschnittlich leicht über den Werten normaler Hunde. Die Unterschiede zwischen beiden Gruppen erwiesen sich jedoch als nicht signifikant. Eine Muskelstarre wie sie bei Schweinen und bei humanen Patienten mit akuter maligner Hyperthermie zu beobachten ist, tritt bei betroffenen Hunden in der Regel nicht auf (Nelson 1991). 
Eine Reihe von Berichten über canine maligne Hyperthermie bezieht sich auf Greyhounds (Bagshaw et al. 1978; Bagshaw et al. 1981; Bjotvedt et al. 1983; Kirmayer et al. 1984; Cosgrove et al. 1992; Dickinson und Sullivan 1994; Duncan et al. 1997). Weitere Rassen, in denen ein oder mehrere MHS-Fälle beobachtet wurden sind Bernhardiner, Border Collie, Vorstehhunde, Spaniels (zusammengefasst bei O'Brien et al. 1983) und Labrador Retriever (Otto 1992; Brunson et al. 1997). Außerdem wurde MHS bei einem Dobermann-Deutscher-Schäferhund-Mischling beobachtet. Dieser Fall diente als Basis für die Gründung einer Forschungskolonie (Nelson 1991; Roberts et al. 2001). Die ursächliche Mutation für MHS in dieser Forschungskolonie ist identifiziert (Roberts et al. 2001). Die Verbreitung dieser Mutation innerhalb der caninen Population ist nicht bekannt (Brunson und Hogan 2004).

\section{Genetischer Hintergrund}

Die Untersuchung mehrerer Nachkommen aus Anpaarungen zweier betroffener Dobermann-Deutscher Schäferhund-Mischlingen mit nicht anfälligen Mischlingshündinnen spricht für eine autosomal dominante Vererbung des caninen Maligne-Hyperthermie-Syndroms (Nelson 1991; Roberts et al. 2001). Auch bei Labrador Retrievern konnte ein autosomal dominanter Erbgang festgestellt werden (Brunson et al. 1997)

Da alle porcinen und mehr als $50 \%$ der humanen Fälle von Maligner Hyperthermie mit Defekten des Ryanodinrezeptor-1-Gens (RYR1) in Verbindung gebracht werden (McCarthy et al. 2000), gilt RYR1 als starkes Kandidatengen für die canine Maligne Hyperthermie. In einer integrierten Kopplungs-RH-Karte ist das canine Ryanodinrezeptor-1-Gen auf Chromosom 1 zwischen den Markern REN143K19 und FH2294 lokalisiert (Mellersh et al. 2000). Die genomische Struktur des caninen RYR1Gens scheint noch nicht im Detail untersucht worden $\mathrm{zu}$ sein. Es wird allerdings von einer hohen Homologie zum humanen RYR1-Gen ausgegangen (Roberts et al. 2001). Die humane cDNA hat eine Länge von 15393 bp, die in 106 Exons unterteilt in einer $158 \mathrm{~kb}$ großen genomischen Region lokalisiert ist. Das resultierende Protein hat eine Länge von 5035 Aminosäuren. Bisher ist die Sequenz zweier Abschnitte der caninen cDNA veröffentlicht. Es handelt sich um Fragmente, die den humanen cDNAPositionen 22-1982 und 5946-7927 homolog sind (NCBI-GenBank: AF302128 bzw. AF302129). Das in der Ensembl-Datenbank veröffentlichte Modell der genomischen 
Sequenz des caninen RYR1 Gens (Ensembl Transcript ID: ENSCAFT00000009509) enthält keinerlei Übereinstimmungen mit diesen beiden Sequenzen. In der NCBIDatenbank ist kein Modell der genomischen Sequenz des caninen RYR1-Gens verfügbar (GeneID: 606491).

Zur Untersuchung eines möglichen Zusammenhangs zwischen der caninen malignen Hyperthermie und RYR1 wurde zunächst innerhalb eines informativen Pedigrees eine Typisierung für sechs verschiedene mit dem RYR1-Gen gekoppelte Marker durchgeführt. Es lässt sich ein spezifischer Haplotyp ermitteln, der innerhalb der untersuchten Population mit MHS segregiert (Roberts et al. 2001). Die Ergebnisse mehrerer Kopplungsanalysen belegen, dass die Positionen des RYR1-Gens und des MHS-Genortes im Verhältnis zu sechs untersuchten Markern aus einer integrierten Kopplungs-RH-Karte übereinstimmen (Mellersh et al. 2000; Roberts et al. 2001). Diese Ergebnisse sprechen für einen Zusammenhang zwischen RYR1 und der caninen malignen Hyperthermie (Roberts et al. 2001).

\section{Ursächliche Mutation für MHS bei Dobermann-Deutscher Schäferhund- Mischlingen}

Die mit MHS bei Schweinen assoziierte Mutation konnte bei betroffenen Hunden nicht nachgewiesen werden. Die weitere Suche nach dem verantwortlichen Gendefekt für die canine Maligne Hyperthermie konzentrierte sich auf zwei Bereiche des RYR1-Gens, in denen im homologen humanen Gen 21 mit maligner Hyperthermie assoziierte Mutationen lokalisiert sind. Dabei handelt es sich um den Bereich zwischen Nukleotid 22 und 1982 sowie den Bereich zwischen Nukleotid 5946 und 7927 der humanen cDNA (McCarthy et al. 2000; Roberts et al. 2001). Die Amplifikation dieser zwei Bereiche aus der cDNA zweier gesunder und zweier betroffener Hunde unter Verwendung homologer, humaner Primer und anschließender Sequenzvergleiche führten zur Identifizierung einer bei betroffenen Hunden heterozygot vorliegenden Substitution von Thymin durch Cytosin an Position 1640 der cDNA in Exon 15. Diese Angaben gelten unter der Voraussetzung übereinstimmender Exon-Intron-Grenzen und Exonlängen zwischen caniner und humaner RYR1-cDNA (Roberts et al. 2001).

Die Folge der beschriebenen Substitution ist ein Aminosäurenaustausch von Valin durch Alanin an Aminosäurenposition 547. Vergleiche der Aminosäurensequenz im 
Bereich der Substitution zwischen dem normalen caninen Protein sowie den humanen, porcinen, murinen, Kaninchen- und Ratten-Proteinen zeigen, dass die substituierte Aminosäure Valin an Position 547 phylogenetisch konserviert ist (Roberts et al. 2001).

Bei einer Genotypisierung aller 52 Hunde des der Untersuchung zugrunde liegenden Pedigrees konnte bei allen betroffenen Hunden das Defektallel heterozygot oder homozygot nachgewiesen werden, während keiner der gesunden Hunde ein Defektallel aufwies. Zudem konnte die beschriebene Substitution bei keinem von 24 typisierten, nicht verwandten Kontrollhunden nachgewiesen werden (Roberts et al. 2001).

Einzelheiten zum physiologischen Zusammenhang zwischen der Mutation und der caninen Malignen Hyperthermie sind nicht geklärt. Ursache der pathologischen Erscheinungen ist eine erhöhte Calciumkonzentration mit der Folge einer Aktivierung von Phosphorylase und einer Erhöhung des Katabolismus von Glykogen zu Wärmeenergie, $\mathrm{CO}_{2}$ und Laktat. Laktat wird in die Leber abtransportiert und dort entweder zu Glucose umgebaut oder unter Freisetzung von Wärmeenergie zu $\mathrm{CO}_{2}$ und $\mathrm{H}_{2} \mathrm{O}$ katabolisiert. Ein weiterer Effekt erhöhter Calciumkonzentrationen im Myoplasma ist die Auslösung einer Muskelkontraktion durch Bewirken einer Konformationsänderung an Myosinfilamenten und durch Aktivierung der MyosinATPase, die durch Hydrolyse von ATP die Energie für Muskelkontraktion bereitstellt. Bei anhaltend hohen Calciumkonzentrationen kann es zu einem übermäßigen Verbrauch von ATP und schließlich in Ausnahmefällen auch zu einem Mangel mit der Folge einer Muskelversteifung kommen. Hyperthermie, Sauerstoffmangel und erhöhte Laktatwerte führen im weiteren Verlauf zu einem herabgesetzten Zusammenhalt der Zellwände, einem Verlust von Muskelzellen und einer Störung des Elektrolytgleichgewichts. Es kommt zu Herzrhythmusstörungen, die einen tödlichen Ausgang haben können (Kirmayer et al. 1984).

Der durch das RYR1-Gen codierte Ryanodinrezeptor 1 gehört zu einer Gruppe von Calciumfreisetzungskanälen des sarkoplasmatischen bzw. endoplasmatischen Retikulums. Die Bezeichnung als Ryanodinrezeptor beruht auf der Interaktion dieser Familie von Calciumkanälen mit dem pflanzlichen Alkaloid Ryanodin, das als Indikator für die Aktivität dieser Calciumkanäle verwendet werden kann, da Aktivität und Interaktion mit Ryanodin in derselben Weise durch Antagonisten und Agonisten des 
Calciumkanals bestimmt werden (Coronado et al. 1994). Insgesamt sind drei Isoformen ryanodinsensitiver Calciumkanäle bekannt. Der Ryanodinrezeptor 1 wird in der Skelettmuskulatur und in der Speiseröhre exprimiert. Ryanodinrezeptor-2-mRNA findet sich im Herzmuskel, in der Aorta und ebenfalls in der Speiseröhre. Ryanodinrezeptor-3mRNA ist in der Skelett- und Herzmuskulatur, in der Speiseröhre, in der Aorta, in den Nebennieren, im Dünndarm und in der Lunge nachweisbar. Alle drei Isoformen sind außerdem in vielen Bereichen des Gehirns verbreitet (Ledbetter et al. 1994). Die Steuerung der Aktivität des Ryanodinrezeptors 1 erfolgt entweder direkt durch Calcium oder durch die Interaktion mit Plasmamembranproteinen wie der $\alpha 1$-Untereinheit des spannungsgesteuerten Dihydropyridin-Rezeptors, dem G-Proteinen oder dem Inositol1,3,4,5-Tetrakisphosphat-Rezeptor, oder durch Signalsubstanzen wie Inositol-1,3,5Trisphosphat, Stickoxide, reaktive Sauerstoffderivate oder zyklische ADP-Ribose (MacKrill 1999).

Offensichtlich führt die Substitution der Aminosäure Valin durch Alanin zu einer gestörten Funktion des Ryanodinrezeptors, so dass bei ohnehin durch Anästhetika oder aufgrund von Hitzestress oder starker Muskelarbeit erhöhten Calciumkonzentrationen im Myoplasma kein Gleichgewicht mehr hergestellt werden kann (Roberts et al. 2001).

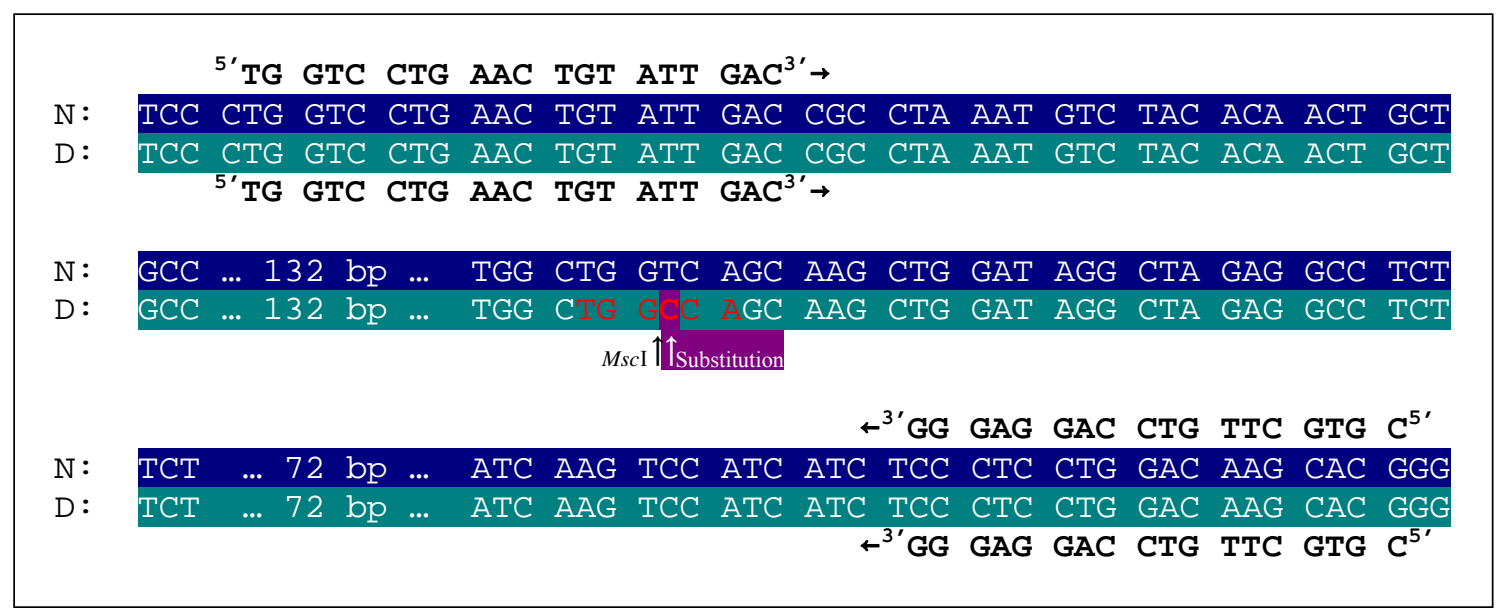

Abb. 132 cDNA-Abschnitt des caninen RYR1-Gens (GenBank AF302128: 1262-1592, entspricht Exon 15 und Teilen von Exon 14 und 16). N: normale Sequenz, D: defekte Sequenz, Substitution in defekter Sequenz violett unterlegt und durch Pfeil gekennzeichnet, rote Schrift: MscIErkennungssequenz, MscI-Restriktionsschnittstelle in defekter Sequenz durch Pfeil gekennzeichnet.

\section{Genotypisierung für Maligne Hyperthermie bei Dobermann-Deutscher Schäferhund Mischlingen}

Der Nachweis der Mutation kann beispielsweise per Amplifikation eines 487-bpFragments aus genomischer DNA beginnend in Exon 14 und endend in Exon 16 und 
anschließende RFLP-Tyisierung erfolgen (Abb. 132). Der zugrunde liegende RFLP beruht auf einer MscI-Restriktionserkennungssequenz, die duch die substitution im Defektallel entsteht und die im Wildtypallel nicht enthalten ist (Roberts et al. 2001). Diese und andere Methoden zur Detektion der Mutation sind patentiert (US-Patent 6664059).

\subsubsection{Muskeldystrophie}

\begin{tabular}{|ll|}
\hline Chromosom: & CFAX \\
Gen: & DMD \\
NCBI: & GeneID: 606758 \\
DNA-Sequenz: & NW_879562, Position 27832124-26147619 \\
& Int6A6950G, Golden Retriever \\
Mutationen: & vollständige DMD-Deletion, Deutsch Kurzhaar \\
& Vorstehhund \\
\hline
\end{tabular}

\section{Krankheitsbild}

Bei der caninen Muskeldystrophie handelt es sich um eine fortschreitende, degenerative Muskelerkrankung, die in den Rassen Golden Retriever (Cardinet und Holliday 1979), Labrador Retriever, Alaskan Malamute (Cardinet und Holliday 1979), Irischer Terrier, Samoyede, Rottweiler (Cooper, nicht publiziert, zitiert bei (Valentine et al. 1992)) und Deutsch Kurzhaar auftritt (Schatzberg et al. 1999b). Der Schweregrad der klinischen Erscheinungen ist abhängig von der Rasse und kann zudem zwischen den Nachkommen desselben betroffenen Rüden stark variieren. Allgemein scheint der Verlauf der Erkrankung bei großen Rassen schwerwiegender zu sein als bei kleineren Hunden. Zudem sind die Erscheinungen bei Hündinnen etwas weniger stark ausgeprägt als bei Rüden. Erste klinische Anzeichen treten bei den meisten Hunden im Alter zwischen zwei und fünf Monaten auf. Die Hunde sind allgemein schwach, zeigen einen steifen Gang und haben Schwierigkeiten, die Schnauze vollständig zu öffnen. Im weiteren Verlauf findet ein fortschreitender Verlust der Muskelmasse statt, und es treten Versteifungen und Schrumpfungen auf. Die Futteraufnahme wird durch Störungen der Speiseröhre und des Rachenraums stark beeinträchtigt. Die Kontraktilität des Herzmuskels kann abnehmen. Es kommt zu Kyphose und Lordose. Das Endstadium wird meist im Alter zwischen einem und sechs Jahren erreicht und ist gekennzeichnet durch extreme Schwäche, Atemschwierigkeiten, Dehydrierung und Herzversagen. In einzelnen Fällen kommt es bereits im Alter von zehn Wochen in einem wesentlich früheren Stadium zu Todesfällen (Kornegray et al. 1988; Valentine et al. 1988). Bei 
Deutsch Kurzhaar treten neben den beschriebenen Schädigungen der Muskulatur Auffälligkeiten am Skelettsystem wie ein abnorm kleiner Unterkiefer (Brachygnethie), angezogene Sprunggelenke und Einfallen des Brustkorbs im Bereich des Sternums auf. Zudem kann es zu einem Wachstumsrückstand kommen (Schatzberg et al. 1999b). Bei einzelnen Golden Retrievern kommt es bereits kurz nach der Geburt zu einem heftigen Ausbruch der Erkrankung, der durch schwerwiegende Schädigungen bestimmter Muskeln wie der Zunge, des Deltamuskels, des Trapezmuskels, des Zwerchfells und des Schneidermuskels gekennzeichnet ist. Weitere Erscheinungen sind extreme Schwäche, Dehydrierung und Hypothermie. Welpen, die von dieser fulminanten Form der Muskeldystrophie betroffen sind, werden nicht älter als zehn Tage (Valentine et al. 1988).

Bei allen betroffenen Welpen kann das Vorliegen einer Muskeldystrophie bereits in der ersten Lebenswoche anhand von deutlich erhöhten Creatinkinasewerten im Serum nachgewiesen werden (Kornegray et al. 1988; Valentine et al. 1988).

Histopathologisch zeigt sich zunächst eine erhöhte Variabilität der Fasergröße. Es liegen zahlreiche runde, vergrößerte Fasern mit hyalinem Erscheinungsbild vor, die intensiv durch Hämatoxilin-Eosin und Trichrom gefärbt werden. Einige der größeren Fasern weisen quer verlaufende Fissuren auf. Daneben sind nekrotische Fasern mit blassem homogenem Zytoplasma und kleinere, leicht basophile Fasern mit großen vesikulären Kernen zu beobachten, die als regenerative Fasern gedeutet werden. Nekrotische Fasern sind häufig von Makrophagen infiltriert. Im späteren Verlauf der Erkrankung kommt es zu einer perimysialen und epimysialen Fibrose. Angrenzend an große, runde, hyaline Fasern sind häufig vollständig mineralisierte Fasern zu finden. Sowohl die großen, runden als auch die nekerotischen Fasern zeigen bei Färbung mit ARS generell einen erhöhten Calciumgehalt. In Ultrastrukturuntersuchungen erscheinen viele der vergrößerten Fasern hyperkontrahiert und weisen verklumpte Myofibrillen, Erweiterungen des sarkoplasasmatischen Retikulums und Lysis der Myofibrillen auf. In nekrotischen Fasern liegt ein vollständiger Verlust myofibrillärer Strukturen vor, und das Zytoplasma ist von fein granularer Struktur (Valentine et al. 1986; Cooper et al. 1988b; Valentine et al. 1990). 


\section{Genetischer Hintergrund}

Kreuzungsexperimente zwischen einem betroffenen Golden Retriever Rüden und drei klinisch normalen Hündinnen sowie Rückkreuzungen und Auskreuzungen der sich daraus ergebenden Nachkommen deuten klar auf eine X-chromosomal gekoppelte Vererbung der caninen Muskeldystrophie hin. Untersuchungen des Karyogramms einer obligat heterozygoten Hündin und eines betroffenen Rüden sprechen gegen das Vorliegen einer zytogenetisch detektierbaren Mutation (Cooper et al. 1988a). Auch bei Deutsch Kurzhaar Vorstehhunden liegt ein X-chromosomal gekoppelter Erbgang vor, während die Erkrankung bei Labrador Retrievern autosomal rezessiv vererbt wird (Kramer et al. 1981). Die genetischen Ursachen konnten bisher nur für zwei Xchromosomal gekoppelte Muskeldystrophieformen in den Rassen Golden Retriever und Deutsch Kurzhaar identifiziert werden, die auf verschiedenen Mutationen im Dystrophin-Gen (DMD, Duchenne Muscular Dystrophy) beruhen. Zur Häufigkeit der Muskeldystrophie bei Golden Retrievern und bei Deutsch Kurzhaar Vorstehhunden sind keine Untersuchungen veröffentlicht.

Im genomischen Contig NW_879562 zwischen Position 27832124 und 26147619 sind auf dem revers komplementären Strang 78 Exons des canine Dystrophin-Gens lokalisiert (NCBI-GeneID 606758), die die Nukleotide 381-13887 der cDNA abdecken (AF070485). Southern-Blot-Analysen von caniner und humaner genomischer DNA sprechen für das Vorliegen übereinstimmender Exon-Intron-Grenzen im DystrophinGen (Sharp et al. 1992). Die in der Literatur (Sharp et al. 1992; Bartlett et al. 1996; Honeyman et al. 1999) als Exon 7 und Exon 8 angegebenen Genabschnitte entsprechen in der unter NCBI Gene ID 606758 veröffentlichten Sequenz den Exons 5 und 6. Demnach scheinen die in der NCBI-Datenbankversion fehlenden 381 Nukleotide der cDNA in zwei Exons unterteilt zu sein und das canine Dystrophin-Gen insgesamt 80 Exons zu enthalten. 


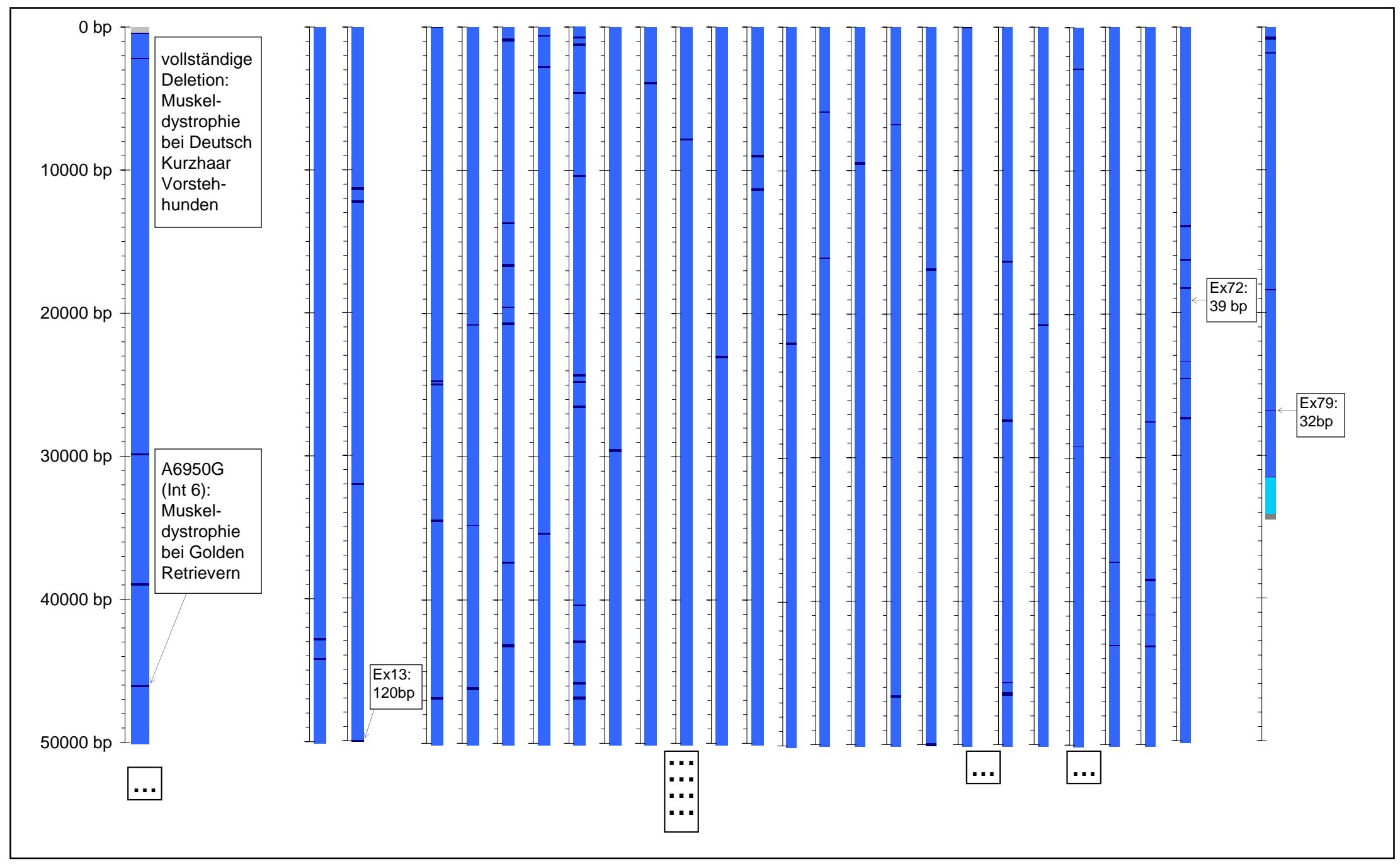

Abb. 133 Schematische Darstellung des caninen Dystrophin-Gens (Exon 3-80) und Lage der bisher identifizierten Mutationen. Dunkelblau: codierende Sequenz, hellblau: Intronsequenz, türkis 3'-UTR, grau: intergenische Sequenz, ,.'“‘: 50000 bp Intronsequenz 
Abb. 133 zeigt basierend auf dem NCBI-Datenbankeintrag schematisch die Lokalisierung der Exons 2 bis 80 in der genomischen Sequenz.

Es wird von einer Übereinstimmung der chromosomalen Lage und der Regulation der Expression des caninen Dystrophin-Gens mit dem auf dem langen Arm des XChromosoms in Bande 21 lokalisierten humanen Dystrophin-Gen ausgegangen. Die Regulation der Expression erfolgt zellspezifisch und wird durch mindestens acht verschiedene Promotoren gesteuert. In der Skelett- und Herzmuskulatur spielt vor allem der M-Promotor eine Rolle. Auf geringem Niveau ist in der caninen Muskulatur außerdem der überwiegend kortikal aktive C-Promotor transkriptionell aktiv (Schatzberg et al. 1999a).

Der direkte Zusammenhang zwischen Mutationen im Dystrophin-Gen und den pathologischen Erscheinungen bei Muskeldystrophie ist nicht abschließend geklärt. Dystrophin ist Bestandteil des dystrophinassoziierten Proteinkomplexes, der mit weiteren Proteinen wie Spectrin, Desmin und Vinculin rippenförmige Netzstrukturen, so genannte Costamere, bildet. Diese Costamere überziehen die zytoplasmatische Oberfläche des Sarkolemmas und verankern das Zytoskelett in der extrazellulären Matrix. Ein Mangel an Dystrophin führt zur Instabilität dieses Costamernetzes (Deconinck und Dan 2007).

Die Auswirkung dieser mechanischen Störung der Muskelzellen wird möglicherweise durch einen erhöhten Calciumeintrag durch die defekte Zellmembran verstärkt, indem erhöhte Calciumkonzentrationen zu einer erhöhten Aktivität von Proteasen wie zum Beispiel Calpainen führen, die die Zellmembran zusätzlich angreifen. Zudem gibt es Hinweise auf eine Beteiligung des dystrophinassoziierten Proteinkomplexes an der Steuerung der muskelaktivitätsabhängigen Genexpression. Weitere Hypothesen zur Pathophysiologie der X-gekoppelten Muskeldystrophie betreffen gestörte Glykosylierung von Komponenten des dystrophinassoziierten Proteinkomplexes, eine mögliche sekundäre Funktionsstörung des Enzyms Stickoxidsynthase und eine mögliche verschärfende Rolle von entzündlichen Prozessen. Einzelheiten zu diesen Zusammenhängen sind noch nicht bekannt (Deconinck und Dan 2007). 


\section{III.a Ursächliche Mutation für Muskeldystrophie bei Golden Retrievern}

Die canine Dystrophin-mRNA lässt sich unter Verwendung von anhand der humanen cDNA-Sequenz konstruierten Primern vollständig amplifizieren. Größenvergleiche einzelner amplifizierter cDNA-Fragmente aus der Skelettmuskulatur von betroffenen und gesunden Golden Retrievern ergeben für den Bereich zwischen Exon 1 und Exon 5 keinerlei Unterschiede. Der cDNA-Abschnitt zwischen Exon 1 und Exon 8 ist bei betroffenen Golden Retrievern um ca. 120 bp kürzer als bei normalen Kontrollhunden. Sequenzierungsergebnisse zeigen das Vorliegen einer Substitution von Adenin durch Guanin an der Spleißakzeptorposition von Intron 6. Die Folge ist eine abweichende Prozessierung der Dystrophin-mRNA betroffener Golden Retriever, die zum Verlust des Exons 7, zu einer Leserasterverschiebung in Exon 8 und zur Entstehung eines verfrühten Stoppsignals in Codon 8 des neuen Leserasters führt (Abb. 134) (Sharp et al. 1992). Die beschriebenen Ergebnisse stehen in Einklang mit Ergebnissen von NorthernBlot-Untersuchungen, bei denen in Skelettmuskelproben von betroffenen Golden Retrievern keinerlei Dystrophin-mRNA nachgewiesen werden kann (Cooper et al. 1988b; Sharp et al. 1992). Lediglich mittels PCR ist bei betroffenen Golden Retrievern eine geringe Menge an Dystrophin-mRNA nachweisbar (Sharp et al. 1992).

Mit humanen Antikörpern gegen Dystrophin lässt sich im Western Blot bei normalen Kontrollhunden ein Protein von etwa $400 \mathrm{kDa}$ nachweisen, während in der Muskelprobe eines betroffenen Rüden nur mit einem hochsensitiven Chemilumineszenzverfahren ein sehr schwaches Signal in der Höhe von $400 \mathrm{kDa}$ detektierbar ist (Cooper et al. 1988b; Cooper et al. 1990). Bei heterozygoten Hündinnen liegt kurz nach der Geburt sowohl in der Herz- als auch in der Skelettmuskulatur eine mosaikartige Dystrophinexpression vor. Zwischen acht und 24 Wochen steigt der Dystrophingehalt in der Skelettmuskulatur auf normale Werte an, während im Herzmuskel das mosaikartige Expressionsmuster lebenslänglich erhalten bleibt (Cooper et al. 1990). 


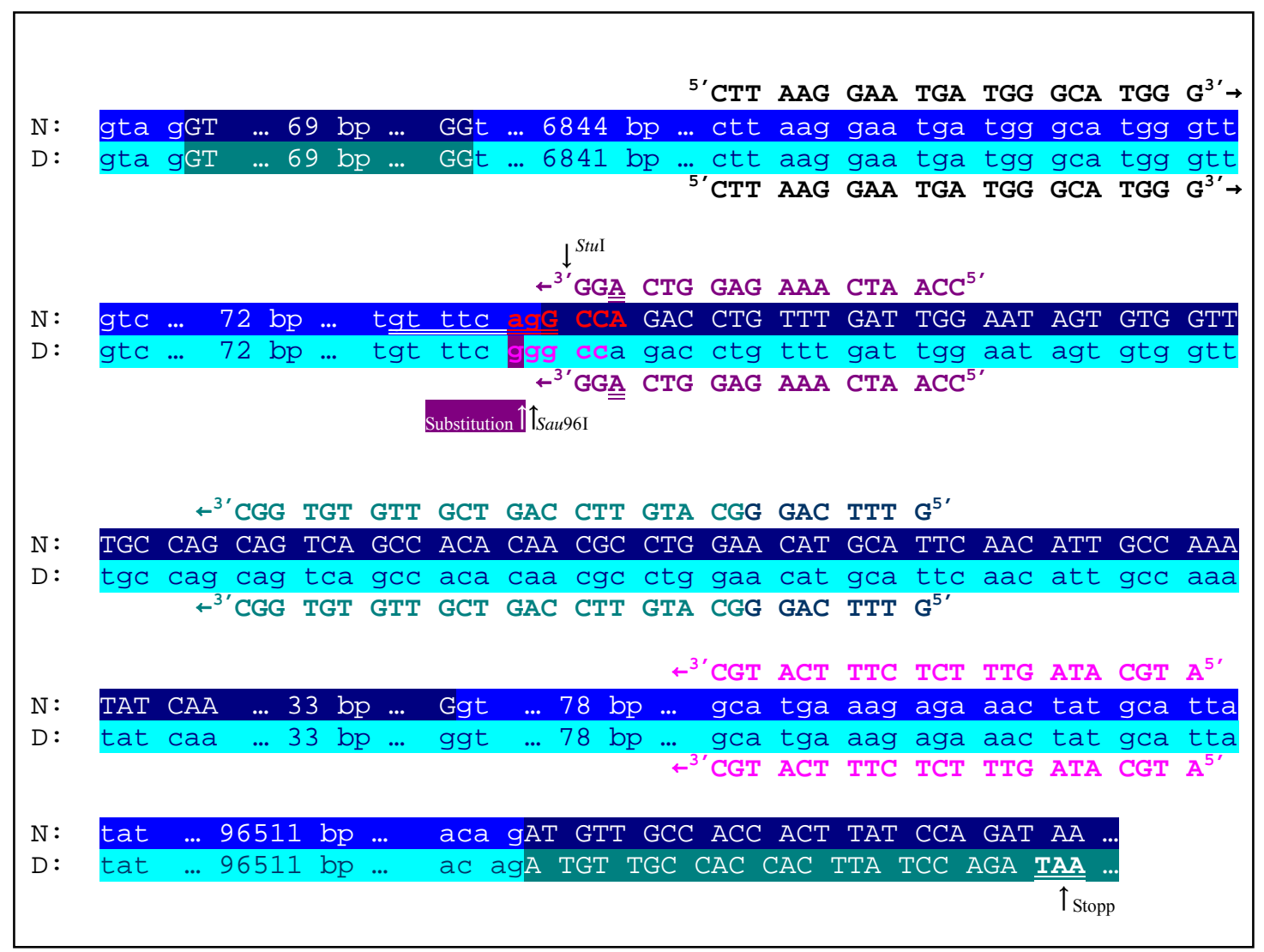

Abb. 134 Exon 6 bis Exon 8 des caninen Dystrophin-Gens und angrenzende Intronsequenzen. N: normale Sequenz, D: defekte Sequenz, dunkelblau: Exon normale Sequenz, dunkelgrün: Exon defekte Sequenz, hellblau: Intron normale Sequenz, türkis: Intron defekte Sequenz, Substitution in defekter Sequenz violett unterlegt und durch Pfeil gekennzeichnet, rote Schrift: Sau96I-Erkennungssequenz, Sau96I-Restriktionsschnittstelle in defekter Sequenz durch Pfeil gekennzeichnet.

\section{IV.a Genotypisierung für Muskeldystrophie bei Golden Retrievern}

Der Nachweis der beschriebenen Substitution kann mittels Amplifikation eines 328-bpFragments aus genomischer DNA und anschließender RFLP-Analyse erfolgen. Der zugrunde liegene RFLP basiert auf einer Erkennungssequenz für Sau96I im DefektallelPCR-Produkt, die im Wildtypallel-PCR-Produkt nicht enthalten ist. Für eine Absicherung des Ergebnisses kann eine zusätzliche RFLP-Typisierung durchgeführt werden. Dazu wird aus dem ursprünglichen PCR-Fragment unter Verwendung eines reversen mismatch-Primers, der im Wildtypallel-PCR-Produkt durch eine abweichende Base eine StuI Restriktionserkennungssequenz einführt, die im Defektallel-PCRProdukt nicht enthalten ist, ein 126-bp-Fragment amplifiziert (Bartlett et al. 1996).

Ein weitere Möglichkeit zur Identifizierung von Defektträgern beruht auf einer Rückschnapp-SSCP (snapback single strand conformation polymorphism)Analyse(Abb. 134) (Honeyman et al. 1999). 


\section{III.b Ursächliche Mutation für Muskeldystrophie bei Deutsch Kurzhaar Vorstehhunden}

Bei Deutsch Kurzhaar Vorstehhunden mit X-chromosomal gekoppelter Muskeldystrophie liegt eine vollständige Deletion des Dystrophin-Gens einschließlich Promotorregion vor (Schatzberg et al. 1999b). Weder der M- oder der C-Promotor noch die Exons 1, 7-9, 21 und 79 des Dystrophin-Gens lassen sich aus genomischer DNA betroffener Deutsch Kurzhaar amplifizieren. Unter der Voraussetzung einer Größenübereinstimmung des caninen und humanen Dystrophin Gens beträgt die Länge der deletierten Sequenz demnach mindestens 2,4 Mb. Eine Fluoreszenz in situ Hybridisierung (FISH) von insgesamt vier Klonen, von denen zwei innerhalb der Xp21Region in dem bei betroffenen Deutsch Kurzhaar deletierten Sequenzabschnitt lokalisiert sind und zwei weitere die deletierte Sequenz flankieren und Untersuchungen DAPI gefärbter verlängerter Metaphasen lassen weitere Rückschlüsse auf die Größe der deletierten Region zu. Die Signale der beiden innerhalb der deletierten Sequenz gelegenen Klone sind mittels FISH auf den X-Chromosomen normaler Kontrollhunde deutlich zu unterscheiden. Demnach beträgt der Abstand der beiden klonierten Fragmente mindestens $2 \mathrm{Mb}$. Des Weiteren sind die von der Deletion betroffenen $\mathrm{X}$ Chromosomen durchgängig um rund $2 \%$ kleiner als normale X-Chromosomen. Bei einer geschätzten Größe des caninen X-Chromosoms von $137 \mathrm{Mb}$ entspricht der fehlende Bereich demnach ca. 2,7 Mb (Schatzberg et al. 1999b).

\subsubsection{Kongenitale Myotonie}

\begin{tabular}{ll|}
\hline Chromosom: & CFA16 \\
Gen: & CLCN1 \\
Ensembl: & GeneID: ENSCAFG00000003619, TranscriptID: \\
& ENSCAFT00000020333 \\
DNA-Sequenz: & CFA16, Position 9322725-9353533 \\
Mutationen: & C894T, Zwergschnauzer \\
\hline
\end{tabular}

\section{Krankheitsbild}

Die canine kongenitale Myotonie beruht auf einem Defekt der Erregbarkeit des Sarkolemmas mit der Folge einer verzögerten Relaxation der Skelettmuskulatur nach Kontraktionen. Am besten untersucht ist die Erkrankung bei Zwergschnauzern (Vite et al. 1998; Vite et al. 1999; Bhalerao et al. 2002). Weitere betroffene Rassen sind Fox Terrier (Griffiths und Duncan 1973), Chow-Chow (Jones et al. 1977), Staffordshire Bull 
Terrier (Shires et al. 1983), Cocker Spaniel (Hill et al. 1995), Silky Terrier und Malteser (Swinney et al. 1998).

$\mathrm{Zu}$ den ersten Krankheitsanzeichen zählen ein steifbeiniger Gang und hoppelnde Bewegungen beim Rennen. Die Stellreflexe, die segmentalen Reflexe, das Gefühl und die kranialen Nerven sind normal. Die Steifheit wird offensichtlich durch eine Dauerkontraktion der Muskulatur verursacht. Zudem lässt sich anhand der Atemgeräusche auf eine Verengung und Verschleimung der Atemwege schließen (Vite et al. 1998; Vite et al. 1999).

Die genetische Ursache der Myotonie ist bisher nur in der Rasse Zwergschnauzer untersucht und identifiziert worden (Rhodes et al. 1999). Der Erbgang ist autosomal rezessiv (Vite et al. 1999). Bei einer Genotypisierung von 372 Zwergschnauzern aus den USA, Kanada, Großbritannien, der Schweiz, Dänemark, Schweden und Australien wurden 76 heterozygote Defektträger (20,4 \%) und vier homozygot betroffene Hunde (1 $\%$ ) identifiziert (Bhalerao et al. 2002).

\section{Genetischer Hintergrund}

Es handelt sich um einen Defekt des spannungsabhängigen Chloridkanals ClC-1. Der spannungsabhängige ClC-1 Kanal steuert in der Sarkolemmamembran von Skelettmuskelzellen die Aufrechterhaltung des Ruheleitwertes von Chlorid, der ca. 80

$\%$ des Gesamtruheleitwertes der Plasmamembran ausmacht. Dieser Leitwert ist entscheidend für die Stabilisierung des Ruhepotentials der Skelettmuskelzellmembranen und trägt entscheidend zur Repolarisation und zur Terminierung von Aktionspotentialen bei. Die Steuerung der Kanalaktivität erfolgt über Inhibitoren, die in Abhängigkeit von der interzellulären Cl-Konzentration bei negativen Spannungen eine reduzierende Wirkung auf die Stromstärke ausüben, während die Stromstärke bei positiven Spannungen kaum durch die Inhibitoren beeinflusst wird. Diese Spannungsabhängigkeit resultiert aus statusabhängiger Bindung der Inhibitoren an die Chloridkanäle, indem geschlossene Kanäle eine deutlich höhere Affinität für Inhibitoren aufweisen als geöffnete Kanäle (Aromataris und Rychkov 2006; Pusch et al. 2006).

Das canine ClC-1-Gen (CLCN1, Chloride Channel Protein 1) ist auf Chromosom 16 zwischen Position 9322725 und 9353533 beginnend in Contig 35454 lokalisiert und 
enthält 24 Exons. Die beschriebene Substitution befindet sich in Exon 7 (Ensembl Transcript ID: ENSCAFT00000020333). Die Lage der einzelnen Exons innerhalb der genomischen Sequenz ist in Abb. 135 schematisch dargestellt.

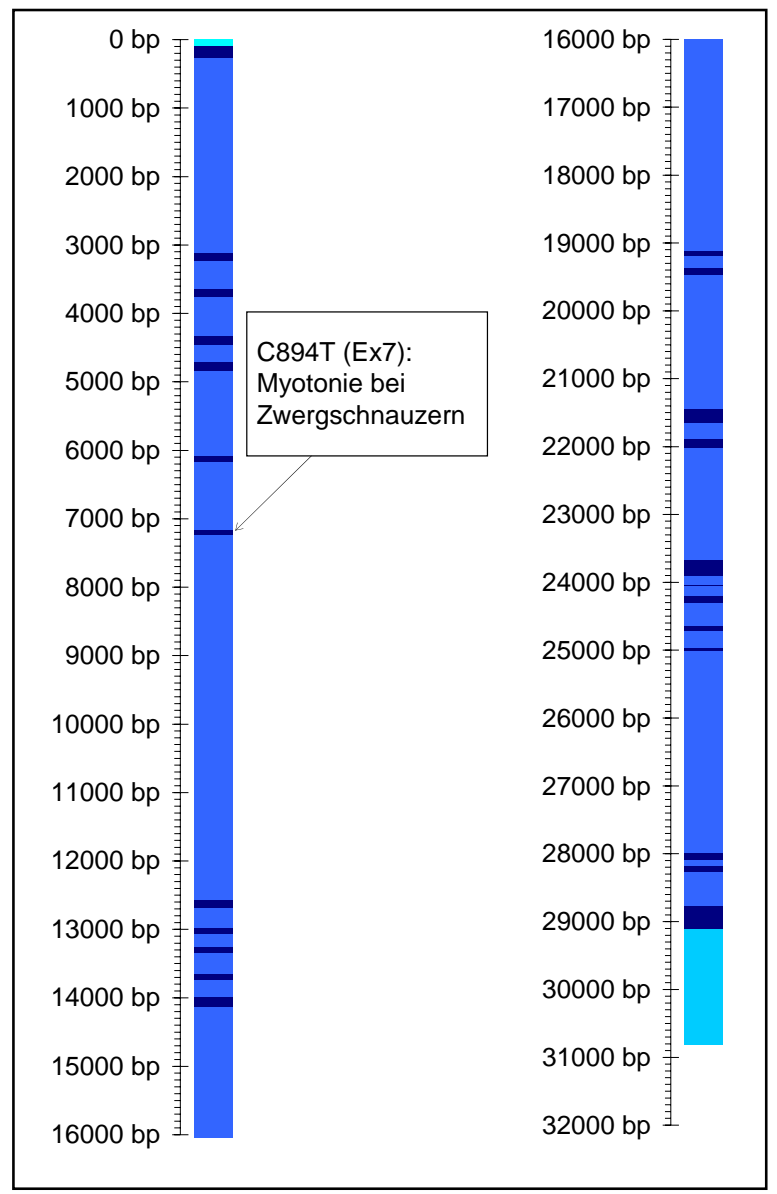

Abb. 135 Schematische Darstellung des caninen CLCN1-Gens und Lage der bisher identifizierten Mutationen. Dunkelblau: codierende Sequenz, hellblau: Intronsequenz, türkis: 5'- und 3'-UTR-

\section{Ursächliche Mutation für Kongenitale Myotonie bei Zwergschnauzern}

Als ursächliche Mutation konnte ein Basenaustausch von Cytosin durch Thymin an Position 894 der cDNA in Exon 7 identifiziert werden (Abb. 136). Die Folge ist ein Aminosäurenaustausch von Threonin durch Methionin an Aminosäurenposition 268 (Rhodes et al. 1999).

Die Substitution an Aminosäurenposition 268 des ClC-1 Proteins führt offenbar zu einer Veränderung der Spannungsabhängigkeit des ClC-1 Kanals. Funktionsstudien an tsA210 Zellen, die entweder mit wildtyp- oder mit mutierter ClC-1-cDNA transfiziert wurden, zeigen nach Impulsen im Ruhepotentialbereich der Skelettmuskulatur eine verringerte Öffnungswahrscheinlichkeit des ClC-1-Kanals. Im physiologischen Zusammenhang führt dieser biophysikalische Defekt des ClC-1 Kanals zu einer 
verringerten Chloridleitfähigkeit des Sarkolemmas bei physiologischen Spannungswerten mit der Folge einer Übererregbarkeit des Sarkolemmas und bedingt so eine Verlängerung von Muskelkontraktionszeiten und Muskelversteifungen. Die Folge der Substitution bei heterozygoten Individuen ließ sich ebenfalls mittels Funktionsstudien an tsA210-Zellen ermitteln. Da der ClC-1-Kanal durch ein Dimer des ClC-1-Proteins gebildet wird (Fahlke et al. 1997), wurden zu diesem Zweck ein Konkatamer aus Wildtyp- und defekter cDNA hergestellt und exprimiert. Die Ergebnisse stimmen mit dem rezessiven Erbgang bei der Myotonie bei Zwergschnauzern überein, indem kein dominanter negativer Effekt der mutierten Dimeruntereinheit auf die Aktivität des ClC-1 Kanals zu beobachten war (Rhodes et al. 1999).

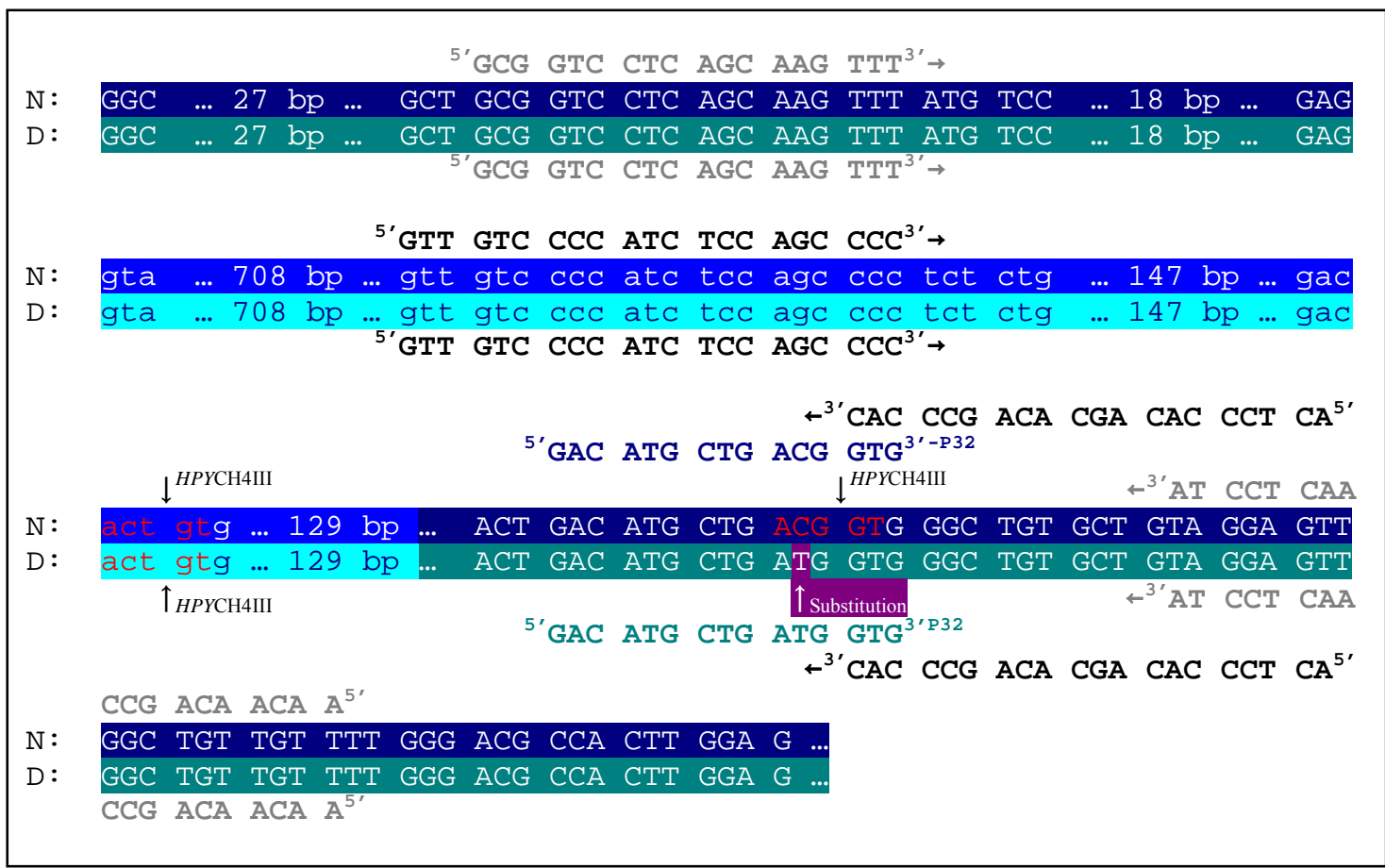

Abb. 136 Exon 6 und 7 des caninen ClC-1 Gens und angrenzende Intronsequenzen. N: normale Sequenz, D: defekte Sequenz, dunkelblau: Exon normale Sequenz, dunkelgrün: Exon defekte Sequenz, hellblau: Intron normale Sequenz, türkis: Intron defekte Sequenz, rote Schrift: HPYCH4IIIRestriktionserkennungssequenz, HPYCH4III-Schnittstellen durch Pfeil gekennzeichnet, Substitution in defekter Sequenz violett markiert und durch Pfeil gekennzeichnet, dunkelblaue Schrift: $\mathrm{P}^{32}$-markierter wildtypallelspezifischer Hybridisierungsprimer, dunkelgrüne Schrift: $\mathrm{P}^{32}$-markierter defektallelspezidfischer Hybridisierungsprimer, hellgrau: Primerpaar für Hybridisierungsnachweis, schwarz: Primerpaar für RFLP-Typisierung.

\section{Genotypisierung für Kongenitale Myotonie bei Zwergschnauzern}

Der Nachweis der Mutation kann unter anderem über eine ASO-Untersuchung (Rhodes et al. 1999) oder über eine RFLP-Typisierung (Bhalerao et al. 2002) erfolgen. 
Der zugrunde liegende RFLP basiert auf einer Erkennungssequenz für HPYCH4III, die aufgrund der Mutation im Defektallel entsteht, und die im Wildtypallel nicht vorhanden ist (Bhalerao et al. 2002).

\subsubsection{Zentronukleäre Myopathie}

\begin{tabular}{|ll|}
\hline Chromosom: & CFA2 \\
Gen: & PTPLA \\
NCBI: & GeneID: 574011 \\
DNA-Sequenz: & NW_876291, Position 976338-997851 \\
Mutationen: & 203Ins236-bp-SINE, Labrador Retriever \\
\hline
\end{tabular}

\section{Krankheitsbild}

Bei der zentronukleären Myopathie der Labrador Retriever handelt es sich um eine kongenitale Erkrankung der Muskulatur, die durch Hypotonie, allgemeine Muskelschwäche, anormale Körperhaltung, überdehnte Karpalgelenke und einen steifen hüpfenden Gang charakterisiert ist (Kramer et al. 1976). Das Auftreten der Erkrankung wird als „relativ häufig“ eingestuft. Studien zur Häufigkeit der Erkrankung bei Labrador Retrievern sind nicht veröffentlicht (Bley et al. 2002). Die klinischen Anzeichen treten meist vor Erreichen des sechsten Lebensmonats auf und werden durch Kälte, Bewegung oder Aufregung verstärkt. Betroffene Hunde brechen häufig zusammen. Es gibt keinerlei Anzeichen für ein Auftreten von Schmerzen. Weitere klinische Merkmale sind eine Muskelatrophie, die vor allem die Kopfmuskulatur betrifft, und eine Areflexie der Sehnen. Histologische Untersuchungen zeigen einen Mangel an Typ-2-Muskelzellen und ein Vorherrschen von atrophierten oder hypertrophierten Typ-1-Zellen. Außerdem besteht eine ungewöhnlich hohe Variabilität in der Größe der einzelnen Muskelfasern, die von 5 bis $150 \mu \mathrm{m}$ Durchmesser schwanken kann. Die Autoren interpretieren diese Beobachtung als mögliche kompensatorische Reaktion der Muskelzellen auf die offenbar vorliegende Funktionsstörung (Kramer et al. 1976; Watson et al. 1988; Gortel et al. 1996; Bley et al. 2002). In bestimmten Phasen des Krankheitsverlaufs kann es zu Kreatinurie und außerdem zu niedrigen bzw. erhöhten Kreatinphosphokinaseaktivitäten im Serum kommen (Kramer et al. 1976; Watson et al. 1988; Gortel et al. 1996). Eine erhöhte Kreatinphosphokinaseaktivität ist häufig die Folge einer aktiven Muskelfaserdegeneration, die offenbar in frühen Krankheitsstadien stattfindet. In späteren Phasen der Erkrankung ist möglicherweise die Anzahl der Typ-2-Muskelzellen als Hauptspeicher- und dehydrationsort von Kreatin bereits so stark reduziert, dass eine 
Senkung der Kreatinphosphokinaseaktivität im Serum verursacht wird (Kramer et al. 1976; Watson et al. 1988).

Die Erkrankung zeigt sowohl Merkmale einer Denervation wie Hyporeflexie und Fibrillationspotentiale als auch Anzeichen für eine primäre Myopathie wie das Auftreten zentralisierter Myonuklei, morphologische Veränderungen von Muskelzellen, Nekrose, Phagozytose, Regeneration und Fibrose (Watson et al. 1988). Die Ergebnisse elektromyographischer Untersuchungen sprechen für das Vorliegen eines myotonischen Defekts, also einer krankhaft verlängerten tonischen Muskelanspannung (Kramer et al. 1976). Trotz intensiver Untersuchungen des Nervensystems betroffener Hunde konnten keinerlei Besonderheiten festgestellt werden (Watson et al. 1988; Bley et al. 2002; Tiret et al. 2003). Neben der beschriebenen klinischen Form der Zentronukleären Myopathie existiert bei Labrador Retrievern auch eine subklinische Form, die durch das Auftreten typischer histologischer Befunde bei Fehlen von klinischen Anzeichen gekennzeichnet ist (Bley et al. 2002).

\section{Genetischer Hintergrund}

Canine zentronukleäre Myopathie wird autosomal rezessiv vererbt (Kramer et al. 1981). Mittels Kopplungsanalyse wurde ein assoziierter Genort in einer 18,1 cM großen Region im centromeren Bereich von Chromosom 2 kartiert (Tiret et al. 2003).

Die betreffende Region auf Chromosom 2 ist ortholog zum kurzen Arm des humanen Chromosoms 10. Bezüglich der klinischen und histologischen Befunde besteht eine deutliche Ähnlichkeit der caninen zentronukleären Myopathie zur humanen Xchromosomal gekoppelten myotubulären Myopathie (Tiret et al. 2003). Diese Erkrankung wird durch Defekte des für Myotubularin codierenden Gens MTM1 (Myotubuläre Myopathie 1) hervorgerufen. Annähernd 200 verschiedene Mutationen des MTM1-Gens konnten inzwischen mit der myotubulären Mypathie in Verbindung gebracht werden (Laporte et al. 1996). Myotubularin zählt zu einer 14 Mitglieder umfassenden Familie von Phosphatasen. Auf dem orthologen kurzen Arm des humanen Chromosoms 10 ist jedoch kein Mitglied dieser Genfamilie identifiziert worden, so dass diese Gruppe von Genen als Kandidatengen für canine zentronukleäre Myopathie ausgeschlossen werden kann (Tiret et al. 2003). In der orthologen Region auf dem humanen Chromosom 10 sind insgesamt 208 Gene bekannt. Zur Identifizierung des 
ursächlichen Gendefektes für die canine zentronukleäre Myopathie wurden aus diesen 208 Genen Kandidaten ausgewählt.

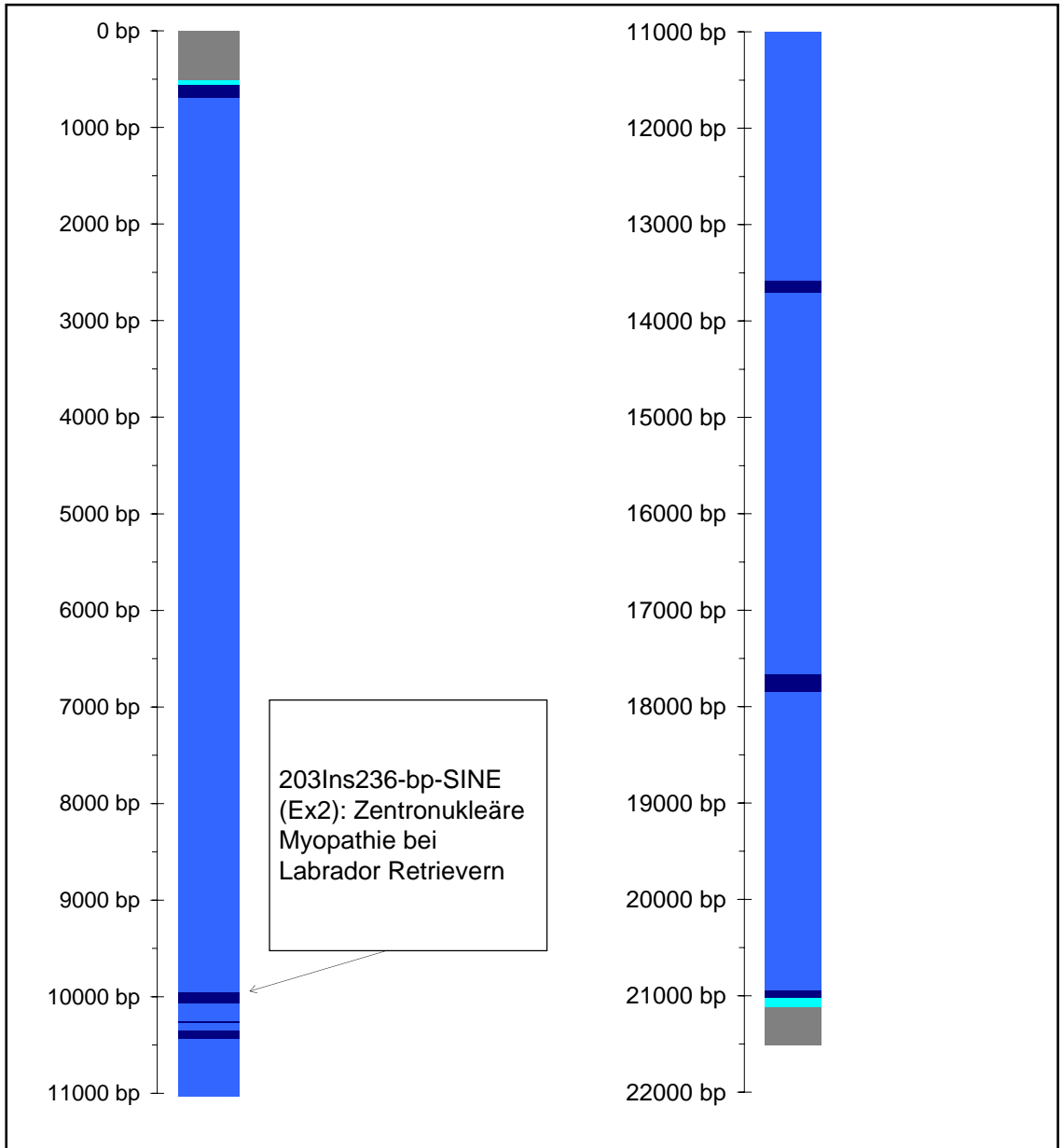

Abb. 137 Schematische Darstellung des caninen PTPLA-Gens und Lage der bisher identifizierten Mutationen. Dunkelblau: codierende Sequenz, hellblau: Intron, türkis: 5'- und 3'-UTR, grau: intergenische Sequenz.

Auswahlkriterien waren Expression in der Skelettmuskulatur und Expression während einer Entwicklungsstufe, die mit den frühen klinischen Anzeichen bei caniner zentronukleärer Myopathie in Einklang steht. Unter den nach diesem Kriterium ausgewählten Genen kam das PTPLA-Gen (Protein Tyrosine Phosphatase-Like, member A) am ehesten als Kandidatengen in Frage. PTPLA enthält eine proteaseähnliche Domäne, die in der katalytischen Region anstelle eines Arginins ein Prolin enthält. Bezüglich dieses Motivs stimmt PTPLA mit Myotubularin überein, das mit der humanen Form der zentronukleären Myopathie assoziiert ist (Pele et al. 2005).

Das canine PTPLA-Gen umfasst ca. $20 \mathrm{~kb}$ und enthält sieben Exons. Im caninen Skelettmuskel werden zwei Isoformen exprimiert. Isoform PTPLAfl (EMBL AJ876904) ergibt sich mit einer Länge von 249 Aminosäuren aus der Translation der vollen Länge 
der codierenden Sequenz und enthält vier Transmembrandomänen sowie die Tyrosinphosphatase-ähnliche katalytische Site. Bei der Translation von Isoform PTPLAd5 (EMBL AJ876905) wird Exon 5 übersprungen. Dadurch kommt es zu einer Leserasterverschiebung und $\mathrm{zu}$ einer verfrühten Terminierung der Translation. PTPLAd5 enthält zwei Transmembrandomänen und die katalytische Tyrosinphosphatase-ähnliche Site. In den ersten 125 Aminosäuren stimmen beide Isoformen überein. Im C-Terminus, der bei PTPLAfl 124 Aminosäuren lang ist und bei PTPLAd5 lediglich 11 Aminosäuren umfasst, unterscheiden sich die Aminosäurensequenzen vollständig (Pele et al. 2005).

Im genomischen NCBI-Contig NW_876291.1 auf Chromosom 2 ist das PTPLA-Gen zwischen den Basen 976338 und 997851 lokalisiert (NCBI-GeneID: 574011). Abb. 137 zeigt die Lage der einzelnen Exons innerhalb der genomischen Sequenz.

\section{Ursächliche Mutation für kongenitale Zentronukleäre Myopathie bei Labrador Retrievern}

Nach näheren Untersuchungen des caninen PTPLA Gens ergab sich bei betroffenen Labrador Retrievern das Vorliegen einer 236 bp umfassenden t-RNA-ähnlichen SINEInsertion (EMBL AJ 876906). Die Leserichtung des SINE-Elementes verläuft revers komplementär zur Orientierung des PTPLA Gens. Die Insertion ist zwischen den Basen 203 und 204 der cDNA-Sequenz lokalisiert und schließt mit einer 13-bp-Sequenz ab, die eine direkte Wiederholung der 13 der Insertion vorausgehenden Basen darstellt (Abb. 138).

Die SINE-Insertion in Exon 2 führt zur Entstehung von fünf zusätzlichen Spleißvarianten. Eine mRNA-Untersuchung ergibt bei betroffenen Hunden das Vorliegen von PTPLAfl- als auch von -d5-mRNA. Diese Beobachtung lässt darauf schließen, dass zumindest gelegentlich ein Spleißen des SINE-Elementes erfolgt, so dass ein geringer Anteil intakter mRNA produziert wird. Von den fünf zusätzlichen Spleißvarianten sind vier durch das Überspringen von Exon 2 bzw. Exon 2 und 3, Exon 2,3 und 4 oder Exon 2,3,4 und 5 charakterisiert. Eine fünfte Spleißvariante ergibt sich aus der Aktivität kryptischer Spleißstellen, die zur Deletion von 25 bp aus Exon 2 und der Integration von 154 bp der 3' Region des SINE-Elementes in die codierende Sequenz führt. 


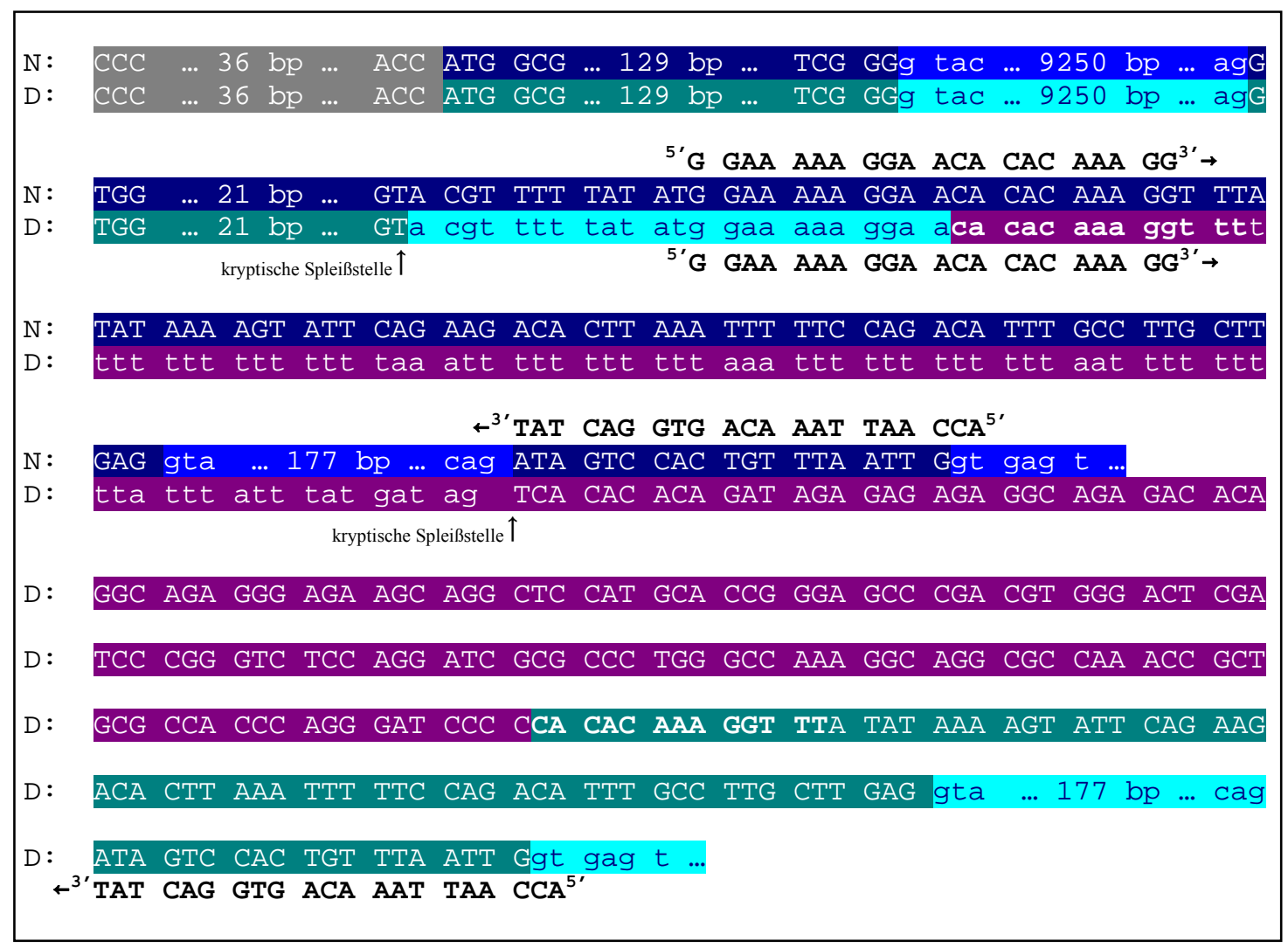

Abb. 138 Exon 1-3 des caninen PTPLA-Gens und angrenzende Intronsequenzen. N: normale Sequenz, D: defekte Sequenz, dunkelblau: Exon normale Sequenz, dunkelgrün: Exon defekte Sequenz, hellblau: Intron normale Sequenz, türkis: Intron defekte Sequenz, SINE-Insertion violett unterlegt, repetierte Sequenz: fett gedruckt, kryptische Spleißstellen in defekter Sequenz für eine von insgesamt 6 Spleißvarianten durch Pfeil gekennzeichnet, in codierende Sequenz integrierter Bereich der SINEInsertion: Großbuchstaben.

Einzelheiten zur Funktion des PTPLA-Proteins sind nicht bekannt, so dass auch kein direkter Zusammenhang zwischen dem Gendefekt und den Symptomen bei zentronukleärer Myopathie hergestellt werden kann.

Vermutungen über den pathogenen Mechanismus beziehen sich auf eine mögliche Beteiligung von PTPLA an denselben Signalprozessen, an denen auch Myotubularin beteiligt ist. Zwar liegen keinerlei Sequenzübereinstimungen mit dem MyotubularinGen vor. Allerdings enthält PTPLA eine phosphataseähnliche katalytische Region. Myotubularin wirkt als spezifische Phosphatase zur Dephosphorylierung von Phosphatidylinositolen, die an einer Reihe von zellulären Prozessen beteiligt sind. Die wesentlichen Wirkungsbereiche von Phosphatidylinositolen in der Zelle umfassen die Proliferation, den Zelltod, die Motilität, regulatorische Funktionen des Zytoskeletts und den intrazellulären Vesikeltransport. Möglicherweise führt die bei Labrador Retrievern identifizierte Mutation im PTPLA-Gen zu einer Störung dieser Prozesse. Die beschriebenen Symptome stehen mit einer derartigen ursächlichen Verknüpfung in 
Einklang. Zur endgültigen Klärung des Zusammenhangs zwischen der Mutation im PTPLA-Gen und der Myopathie bei Labrador Retrievern sind weiterführende Untersuchungen notwendig (Pele et al. 2005).

\section{Genotypisierung für zentronukleäre Myopathie bei Labrador Retrievern}

Der Nachweis der Insertion kann per Amplifikation eines genomischen Sequenzabschnitts der einen großen Teil von Exon 2, Intron 2 und die 5'-Region von Exon 3 umfasst, und anschließender PCR-Fragmentgrößenanalyse erfolgen (Pele et al. 2005). 


\subsubsection{Primerliste}

Tabelle 20 Liste der in Kapitel 3.6 genannten Primer

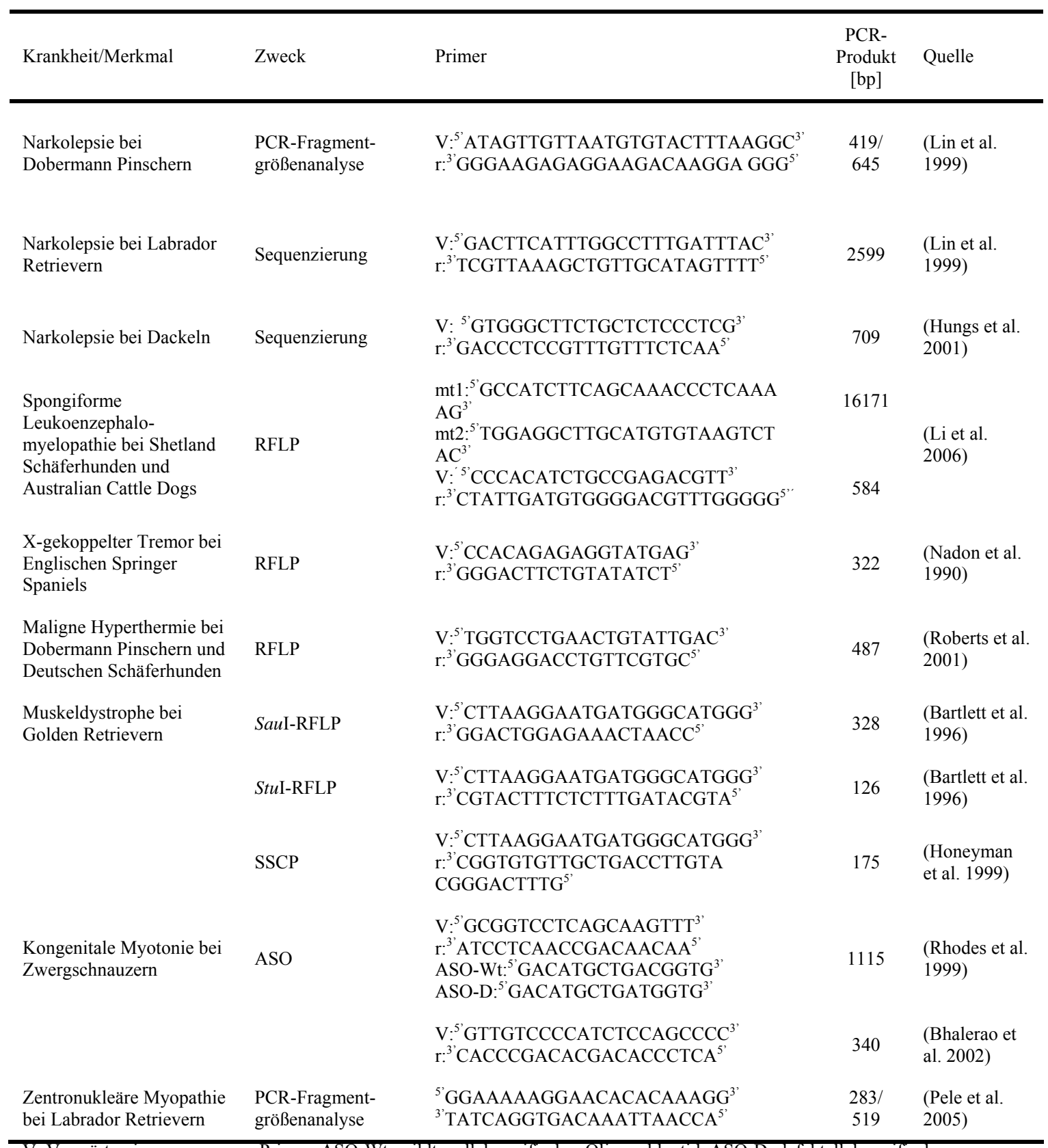

V: Vorwärtsprimer, r: reverser Primer, ASO-Wt: wildtypallelspezifisches Oligonukleotid, ASO-D: defektallelspezifisches

Oligonukleotid 


\subsubsection{Literatur}

Aromataris, E.C. und Rychkov, G.Y. (2006): ClC-1 chloride channel: Matching its properties to a role in skeletal muscle. Clin Exp Pharmacol Physiol, 33 (11), 1118-23.

Babcock, D.A., Narver, E.L., Dement, W.C. und Mitler, M.M. (1976): Effects of imipramine, chlorimipramine, and fluoxetine on cataplexy in dogs. Pharmacol Biochem Behav, 5 (6), 599-602.

Bachinger, H.P. und Davis, J.M. (1991): Sequence specific thermal stability of the collagen triple helix. Int J Biol Macromol, 13 (3), 152-6.

Bagley, R. (1992): Tremor syndromes in dogs: Diagnosis and treatment. J Small Anim Pract, 33, 485-490.

Bagshaw, R.J., Cox, R.H., Knight, D.H. und Detweiler, D.K. (1978): Malignant hyperthermia in a Greyhound. J Am Vet Med Assoc, 172 (1), 61-2.

Bagshaw, R.J., Cox, R.H. und Rosenberg, H. (1981): Dantrolene treatment of malignant hyperthermia. J Am Vet Med Assoc, 178 (10), 1129.

Baker, T.L., Foutz, A.S., McNerney, V., Mitler, M.M. und Dement, W.C. (1982): Canine model of narcolepsy: genetic and developmental determinants. Exp Neurol, 75 (3), 729-42.

Bartlett, R.J., Winand, N.J., Secore, S.L., Singer, J.T., Fletcher, S., Wilton, S., Bogan, D.J., Metcalf-Bogan, J.R., Bartlett, W.T., Howell, J.M., Cooper, B.J. und Kornegay, J.N. (1996): Mutation segregation and rapid carrier detection of Xlinked muscular dystrophy in dogs. Am J Vet Res, 57 (5), 650-4.

Beddington, R.S., Rashbass, P. und Wilson, V. (1992): Brachyury--a gene affecting mouse gastrulation and early organogenesis. Dev Suppl, 157-65.

Bhalerao, D.P., Rajpurohit, Y., Vite, C.H. und Giger, U. (2002): Detection of a genetic mutation for myotonia congenita among Miniature Schnauzers and identification of a common carrier ancestor. Am J Vet Res, 63 (10), 1443-7.

Bjotvedt, G., Hendricks, G.M. und Weems, C.W. (1983): Exertional rhabdomyolysis in a racing Greyhound / a case report. Veterinary Medicine / Small Animal Clinician, August, 1215-1220.

Bley, T., Gaillard, C., Bilzer, T., Braund, K.G., Faissler, D., Steffen, F., Cizinauskas, S., Neumann, J., Vogtli, T., Equey, R. und Jaggy, A. (2002): Genetic aspects of Labrador Retriever myopathy. Res Vet Sci, 73 (3), 231-6. 
Brandl, C.J. und Deber, C.M. (1986): Hypothesis about the function of membraneburied proline residues in transport proteins. Proc Natl Acad Sci U S A, 83 (4), 917-21.

Bray, G.M., Duncan, I.D. und Griffiths, I.R. (1983): 'Shaking pups': a disorder of central myelination in the spaniel dog. IV. Freeze-fracture electron microscopic studies of axons, oligodendrocytes and astrocytes in the spinal cord white matter. Neuropathol Appl Neurobiol, 9 (5), 369-78.

Brunson, D.B., Hogan, K., Powers, P., Gregg, R. und Nelson, T. (1997): Investigation of the casual mutation for malignant hyperthermia in black Labrador Retrievers. Canine Practice, 23, 48.

Brunson, D.B. und Hogan, K.J. (2004): Malignant hyperthermia: a syndrome not a disease. Vet Clin North Am Small Anim Pract, 34 (6), 1419-33.

Burns, M. und Fraser, M. (1966): Genetics of the dog. The basis of successful breeding. (2nd Edition) Oliver \& Boyd, Edinburg 1966.

Calkins, E., Kalm, D. und Diner, W.C. (1956): Idiopathic familial osteoporosis in dogs: Osteogenesis Imperfecta. Annals of the New York Academy of Science, 64, 410423.

Camacho, N.P., Dow, D., Toledano, T.R., Buckmeyer, J.K., Gertner, J.M., Brayton, C.F., Raggio, C.L., Root, L. und Boskey, A.L. (1998): Identification of the oim mutation by dye terminator chemistry combined with automated direct DNA sequencing. J Orthop Res, 16 (1), 38-42.

Campbell, B.G., Wootton, J.A., Krook, L., DeMarco, J. und Minor, R.R. (1997): Clinical signs and diagnosis of osteogenesis imperfecta in three dogs. J Am Vet Med Assoc, 211 (2), 183-7.

Campbell, B.G., Wootton, J.A., MacLeod, J.N. und Minor, R.R. (1998): Sequence of canine COL1A2 cDNA: nucleotide substitutions affecting the cyanogen bromide peptide map of the alpha 2(I) chain. Arch Biochem Biophys, 357 (1), 67-75.

Campbell, B.G., Wootton, J.A., MacLeod, J.N. und Minor, R.R. (2000): Sequence of normal canine COL1A1 cDNA and identification of a heterozygous alpha1(I) collagen Gly208Ala mutation in a severe case of canine osteogenesis imperfecta. Arch Biochem Biophys, 384 (1), 37-46.

Campbell, B.G., Wootton, J.A., Macleod, J.N. und Minor, R.R. (2001): Canine COL1A2 mutation resulting in C-terminal truncation of pro-alpha2(I) and severe osteogenesis imperfecta. J Bone Miner Res, 16 (6), 1147-53.

Cardinet, G.H., 3rd und Holliday, T.A. (1979): Neuromuscular diseases of domestic animals: a summary of muscle biopsies from 159 cases. Ann N Y Acad Sci, 317, 290-313.

Cederberg, R., Nishino, S., Dement, W.C. und Mignot, E. (1998): Breeding history of the Stanford colony of narcoleptic dogs. Vet Rec, 142 (2), 31-6. 
Cooper, B.J., Valentine, B.A., Wilson, S., Patterson, D.F. und Concannon, P.W. (1988a): Canine muscular dystrophy: confirmation of X-linked inheritance. $J$ Hered, 79 (6), 405-8.

Cooper, B.J., Winand, N.J., Stedman, H., Valentine, B.A., Hoffman, E.P., Kunkel, L.M., Scott, M.O., Fischbeck, K.H., Kornegay, J.N., Avery, R.J. und et al. (1988b): The homologue of the Duchenne locus is defective in X-linked muscular dystrophy of dogs. Nature, 334 (6178), 154-6.

Cooper, B.J., Gallagher, E.A., Smith, C.A., Valentine, B.A. und Winand, N.J. (1990): Mosaic expression of dystrophin in carriers of canine X-linked muscular dystrophy. Lab Invest, 62 (2), 171-8.

Coronado, R., Morrissette, J., Sukhareva, M. und Vaughan, D.M. (1994): Structure and function of ryanodine receptors. Am J Physiol, 266 (6 Pt 1), C1485-504.

Cosgrove, S.B., Eisele, P.H., Martucci, R.W. und Gronert, G.A. (1992): Evaluation of greyhound susceptibility to malignant hyperthermia using halothanesuccinylcholine anesthesia and caffeine-halothane muscle contractures. Lab Anim Sci, 42 (5), 482-5.

Cuddon, P.A., Lipsitz, D. und Duncan, I.D. (1998): Myelin mosaicism and brain plasticity in heterozygous females of a canine X-linked trait. Ann Neurol, 44 (5), 771-9.

de Vries, W.N. und de Wet, W.J. (1986): The molecular defect in an autosomal dominant form of osteogenesis imperfecta. Synthesis of type I procollagen containing cysteine in the triple-helical domain of pro-alpha 1(I) chains. J Biol Chem, 261 (19), 9056-64.

Deconinck, N. und Dan, B. (2007): Pathophysiology of duchenne muscular dystrophy: current hypotheses. Pediatr Neurol, 36 (1), 1-7.

Delashaw, J.B., Jr., Foutz, A.S., Guilleminault, C. und Dement, W.C. (1979): Cholinergic mechanisms and cataplexy in dogs. Exp Neurol, 66 (3), 745-57.

Dickinson, P.J. und Sullivan, M. (1994): Exercise induced hyperthermia in a racing greyhound. Vet Rec, 135 (21), 508.

Duncan, I.D. und Griffiths, I. (1981): Qualitative and quantitative studies of the CNS of the canine mutant shaking pup. J Neuropathol Exp Neurol, 40 (Abstracts of the $57^{\text {th }}$ Annual Meeting of the American Association of Neuropathologists), 303.

Duncan, I.D., Griffiths, I.R. und Munz, M. (1983): 'Shaking pups': a disorder of central myelination in the spaniel dog. III. Quantitative aspects of glia and myelin in the spinal cord and optic nerve. Neuropathol Appl Neurobiol, 9 (5), 355-68.

Duncan, I.D., Hammang, J.P. und Jackson, K.F. (1987): Myelin mosaicism in female heterozygotes of the canine shaking pup and myelin-deficient rat mutants. Brain Res, 402 (1), 168-72. 
Duncan, K.L., Hare, W.R. und Buck, W.B. (1997): Malignant hyperthermia-like reaction secondary to ingestion of hops in five dogs. J Am Vet Med Assoc, 210 (1), 51-4.

Fahlke, C., Knittle, T., Gurnett, C.A., Campbell, K.P. und George, A.L., Jr. (1997): Subunit stoichiometry of human muscle chloride channels. J Gen Physiol, 109 (1), 93-104.

Fernandez-Madrid, F., Noonan, S. und Riddle, J. (1981): The "spindle-shaped" body in fibroblasts: intracellular collagen fibrils. J Anat, 132 (Pt 2), 157-66.

Foutz, A.S., Mitler, M.M., Cavalli-Sforza, L.L. und Dement, W.C. (1979): Genetic factors in canine narcolepsy. Sleep, 1 (4), 413-21.

Fraher, J.P. (1978): Quantitative studies on the maturation of central and peripheral parts of individual ventral motoneuron axons. I. Myelin sheath and axon calibre. J Anat, 126 (Pt 3), 509-33.

Gambetti, P., Mellman, W.J. und Gonatas, N.K. (1969): Familial spongy degeneration of the central nervous system (Van Bogaert-Bertrand disease). An ultrastructural study. Acta Neuropathol, 12 (2), 103-15.

Gortel, K., Houston, D.M., Kuiken, T., Fries, C.L. und Boisvert, B. (1996): Inherited myopathy in a litter of Labrador retrievers. Can Vet J, 37 (2), 108-10.

Griffiths, I.R. und Duncan, I.D. (1973): Myotonia in the dog: a report of four cases. Vet Rec, 93 (7), 184-8.

Griffiths, I.R., Duncan, I.D. und McCulloch, M. (1981a): Shaking pups: a disorder of central myelination in the spaniel dog. II. Ultrastructural observations on the white matter of the cervical spinal cord. $J$ Neurocytol, 10 (5), 847-58.

Griffiths, I.R., Duncan, I.D., McCulloch, M. und Harvey, M.J. (1981b): Shaking pups: a disorder of central myelination in the Spaniel dog. Part 1. Clinical, genetic and light-microscopical observations. J Neurol Sci, 50 (3), 423-33.

Hall, S.M. (1973): Some aspects of remyelination after demyelination produced by the intraneural injection of lysophosphatidyl choline. J Cell Sci, 13 (2), 461-77.

Haworth, K., Putt, W., Cattanach, B., Breen, M., Binns, M., Lingaas, F. und Edwards, Y.H. (2001): Canine homolog of the T-box transcription factor T; failure of the protein to bind to its DNA target leads to a short-tail phenotype. Mamm Genome, 12 (3), 212-8.

Hildebrand, C. (1971): Ultrastructural and light-microscopic studies of the developing feline spinal cord white matter. I. The nodes of Ranvier. Acta Physiol Scand Suppl, 364, 81-109.

Hill, S.L., Shelton, G.D. und Lenehan, T.M. (1995): Myotonia in a cocker spaniel. J Am Anim Hosp Assoc, 31 (6), 506-9. 
Holmes, J.R. und Price, C.H.G. (1957): Multiple Fractures in a Collie: Osteogenesis Imperfecta. Vet Rec, 69, 1047-1052.

Honeyman, K., Carville, K.S., Howell, J.M., Fletcher, S. und Wilton, S.D. (1999): Development of a snapback method of single-strand conformation polymorphism analysis for genotyping Golden Retrievers for the X-linked muscular dystrophy allele. Am J Vet Res, 60 (6), 734-7.

Hudson, L.D., Berndt, J.A., Puckett, C., Kozak, C.A. und Lazzarini, R.A. (1987): Aberrant splicing of proteolipid protein mRNA in the dysmyelinating jimpy mutant mouse. Proc Natl Acad Sci U S A, 84 (5), 1454-8.

Hungs, M., Fan, J., Lin, L., Lin, X., Maki, R.A. und Mignot, E. (2001): Identification and functional analysis of mutations in the hypocretin (orexin) genes of narcoleptic canines. Genome Res, 11 (4), 531-9.

Indrebo, A. und Langeland, M. (1997): Is there a connection between natural occurring bobtails and defects in the spinal vertebrae in Welsh Corgi Pembroke? "Corgi Post", the Annual of Norwegian Welsh Corgi Club, 4, 28-29.

Inuzuka, T., Duncan, I.D. und Quarles, R.H. (1986): Myelin proteins in the CNS of 'shaking pups'. Brain Res, 392 (1-2), 43-50.

Jones, B.R., Anderson, L.J., Barnes, G.R., Johnstone, A.C. und Juby, W.D. (1977): Myotonia in related Chow Chow dogs. N Z Vet J, 25 (8), 217-20.

Kaitin, K.I., Kilduff, T.S. und Dement, W.C. (1986): Evidence for excessive sleepiness in canine narcoleptics. Electroencephalogr Clin Neurophysiol, 64 (5), 447-54.

Kaufman, R.J. (1999): Stress signaling from the lumen of the endoplasmic reticulum: coordination of gene transcriptional and translational controls. Genes Dev, 13 (10), 1211-33.

King, R., Pollard, J. und Thomas, P. (1975): Aberrant remyelination in chronic relapsing experimental allergic neuritis. Neuropathology and Applied Neurobiology, 1, 367-378.

Kirmayer, A.H., Klide, A.M. und Purvance, J.E. (1984): Malignant hyperthermia in a dog: case report and review of the syndrome. J Am Vet Med Assoc, 185 (9), 97882 .

Knecht, C.D., Oliver, J.E., Redding, R., Selcer, R. und Johnson, G. (1973): Narcolepsy in a dog and a cat. $J$ Am Vet Med Assoc, 162 (12), 1052-3.

Kornegray, J., Tuler, S., Miller, D. und Levesque, D. (1988): Muscular Dystrophy in a Litter of Golden Retriever Dogs. Muscle and Nerve, 11, 1056-1064.

Kramer, J.W., Hegreberg, G.A., Bryan, G.M., Meyers, K. und Ott, R.L. (1976): A muscle disorder of Labrador retrievers characterized by deficiency of type II muscle fibers. J Am Vet Med Assoc, 169 (8), 817-20. 
Kramer, J.W., Hegreberg, G.A. und Hamilton, M.J. (1981): Inheritance of a neuromuscular disorder of Labrador retriever dogs. J Am Vet Med Assoc, 179 (4), 380-1.

Krawczak, M., Reiss, J. und Cooper, D.N. (1992): The mutational spectrum of single base-pair substitutions in mRNA splice junctions of human genes: causes and consequences. Hum Genet, 90 (1-2), 41-54.

Kuivaniemi, H., Tromp, G. und Prockop, D.J. (1991): Mutations in collagen genes: causes of rare and some common diseases in humans. Faseb J, 5 (7), 2052-60.

Laporte, J., Hu, L.J., Kretz, C., Mandel, J.L., Kioschis, P., Coy, J.F., Klauck, S.M., Poustka, A. und Dahl, N. (1996): A gene mutated in X-linked myotubular myopathy defines a new putative tyrosine phosphatase family conserved in yeast. Nat Genet, 13 (2), 175-82.

Lazar, T., deHaan, J., Peck, J., Campbell, B.G., Ginn, P., Phillips, L., Suero, A. und Chase, J. (2000): Osteogenesis imperfecta in Three Dogs from a Single Litter. Vet Comp Orthop Traumatol, 13, 23-27.

Ledbetter, M.W., Preiner, J.K., Louis, C.F. und Mickelson, J.R. (1994): Tissue distribution of ryanodine receptor isoforms and alleles determined by reverse transcription polymerase chain reaction. J Biol Chem, 269 (50), 31544-51.

Lettow, E. und Dämmrich, K. (1960): Beitrag zur Klinik und Pathologie der Osteogenesis imperfecta bei Junghunden. Zentralblatt für Veterinärmedizin, 7, 936-966.

Li, F.Y., Cuddon, P.A., Song, J., Wood, S.L., Patterson, J.S., Shelton, G.D. und Duncan, I.D. (2006): Canine spongiform leukoencephalomyelopathy is associated with a missense mutation in cytochrome b. Neurobiol Dis, 21 (1), 3542 .

Li, R., Mignot, E., Faraco, J., Kadotani, H., Cantanese, J., Zhao, B., Lin, X., Hinton, L., Ostrander, E.A., Patterson, D.F. und de Jong, P.J. (1999): Construction and characterization of an eightfold redundant dog genomic bacterial artificial chromosome library. Genomics, 58 (1), 9-17.

Lin, L., Faraco, J., Li, R., Kadotani, H., Rogers, W., Lin, X., Qiu, X., de Jong, P.J., Nishino, S. und Mignot, E. (1999): The sleep disorder canine narcolepsy is caused by a mutation in the hypocretin (orexin) receptor 2 gene. Cell, 98 (3), 365-76.

MacKrill, J.J. (1999): Protein-protein interactions in intracellular Ca2+-release channel function. Biochem J, 337 ( Pt 3), 345-61.

Mason, R.W., Hartley, W.J. und Randall, M. (1979): Spongiform degeneration of the white matter in a Samoyed pup. Aust Vet Practit, 9 (1), 11-13.

McBride, D.J., Jr., Kadler, K.E., Hojima, Y. und Prockop, D.J. (1992): Self-assembly into fibrils of a homotrimer of type I collagen. Matrix, 12 (4), 256-63. 
McCarthy, T.V., Quane, K.A. und Lynch, P.J. (2000): Ryanodine receptor mutations in malignant hyperthermia and central core disease. Hum Mutat, 15 (5), 410-7.

McGrory, J. und Cole, W.G. (1999): Alternative splicing of exon 37 of FBN1 deletes part of an 'eight-cysteine' domain resulting in the Marfan syndrome. Clin Genet, 55 (2), 118-21.

Mellersh, C.S., Hitte, C., Richman, M., Vignaux, F., Priat, C., Jouquand, S., Werner, P., Andre, C., DeRose, S., Patterson, D.F., Ostrander, E.A. und Galibert, F. (2000): An integrated linkage-radiation hybrid map of the canine genome. Mamm Genome, 11 (2), 120-30.

Mignot, E., Wang, C., Rattazzi, C., Gaiser, C., Lovett, M., Guilleminault, C., Dement, W.C. und Grumet, F.C. (1991): Genetic linkage of autosomal recessive canine narcolepsy with a mu immunoglobulin heavy-chain switch-like segment. Proc Natl Acad Sci U S A, 88 (8), 3475-8.

Mignot, E., Nishino, S., Sharp, L.H., Arrigoni, J., Siegel, J.M., Reid, M.S., Edgar, D.M., Ciaranello, R.D. und Dement, W.C. (1993): Heterozygosity at the canarc-1 locus can confer susceptibility for narcolepsy: induction of cataplexy in heterozygous asymptomatic dogs after administration of a combination of drugs acting on monoaminergic and cholinergic systems. J Neurosci, 13 (3), 1057-64.

Minor, R.R., Sippola-Thiele, M., McKeon, J., Berger, J. und Prockop, D.J. (1986): Defects in the processing of procollagen to collagen are demonstrable in cultured fibroblasts from patients with the Ehlers-Danlos and osteogenesis imperfecta syndromes. J Biol Chem, 261 (21), 10006-14.

Mitler, M.M., Boysen, B.G., Campbell, L. und Dement, W.C. (1974): Narcolepsycataplexy in a female dog. Exp Neurol, 45 (2), 332-40.

Mitler, M.M., Soave, O. und Dement, W.C. (1976): Narcolepsy in seven dogs. J Am Vet Med Assoc, 168 (11), 1036-8.

Mitler, M.M. und Dement, W.C. (1977): Sleep studies on canine narcolepsy: pattern and cycle comparisons between affected and normal dogs. Electroencephalogr Clin Neurophysiol, 43 (5), 691-9.

Nadon, N.L., Duncan, I.D. und Hudson, L.D. (1990): A point mutation in the proteolipid protein gene of the 'shaking pup' interrupts oligodendrocyte development. Development, 110 (2), 529-37.

Neer, T.M. und Kornegay, J.N. (1995): Leucoencephalomalacia and cerebral white matter vacuolar degeneration in two related Labrador retriever puppies. $J$ Vet Intern Med, 9 (2), 100-4.

Nelson, T.E. (1991): Malignant hyperthermia in dogs. J Am Vet Med Assoc, 198 (6), 989-94.

Nishino, S., Reid, M.S., Dement, W.C. und Mignot, E. (1994): Neuropharmacology and neurochemistry of canine narcolepsy. Sleep, 17 (8 Suppl), S84-92. 
O'Brien, D.P. und Zachary, J.F. (1985): Clinical features of spongy degeneration of the central nervous system in two Labrador retriever littermates. J Am Vet Med Assoc, 186 (11), 1207-10.

O'Brien, P.J., Cribb, P.H., White, R.J., Olfert, E.D. und Steiss, J.E. (1983): Canine Malignant Hyperthermia: Diagnosis of Susceptibility in a Breeding Colony. Can Vet J, 24 (6), 172-177.

Otto, K. (1992): [Malignant hyperthermia as a complication of anesthesia in the dog]. Tierarztl Prax, 20 (5), 519-22.

Pele, M., Tiret, L., Kessler, J.L., Blot, S. und Panthier, J.J. (2005): SINE exonic insertion in the PTPLA gene leads to multiple splicing defects and segregates with the autosomal recessive centronuclear myopathy in dogs. Hum Mol Genet, 14 (11), 1417-27.

Puckett, C., Hudson, L., Ono, K., Friedrich, V., Benecke, J., Dubois-Dalcq, M. und Lazzarini, R.A. (1987): Myelin-specific proteolipid protein is expressed in myelinating Schwann cells but is not incorporated into myelin sheaths. $J$ Neurosci Res, 18 (4), 511-8.

Pullig, T. (1953): Anury in cocker spaniels. J Hered, 44, 105-107.

Pusch, M., Zifarelli, G., Murgia, A.R., Picollo, A. und Babini, E. (2006): Channel or transporter? The CLC saga continues. Exp Physiol, 91 (1), 149-52.

Reed, R. und Maniatis, T. (1985): Intron sequences involved in lariat formation during pre-mRNA splicing. Cell, 41 (1), 95-105.

Reed, R. und Maniatis, T. (1988): The role of the mammalian branchpoint sequence in pre-mRNA splicing. Genes Dev, 2 (10), 1268-76.

Rhodes, T.H., Vite, C.H., Giger, U., Patterson, D.F., Fahlke, C. und George, A.L., Jr. (1999): A missense mutation in canine $\mathrm{C} 1 \mathrm{C}-1$ causes recessive myotonia congenita in the dog. FEBS Lett, 456 (1), 54-8.

Richards, R.B. und Kakulas, B.A. (1978): Spongiform leucoencephalopathy associated with congenital myoclonia syndrome in the dog. J Comp Pathol, 88 (2), 317-20.

Roberts, M.C., Mickelson, J.R., Patterson, E.E., Nelson, T.E., Armstrong, P.J., Brunson, D.B. und Hogan, K. (2001): Autosomal dominant canine malignant hyperthermia is caused by a mutation in the gene encoding the skeletal muscle calcium release channel (RYR1). Anesthesiology, 95 (3), 716-25.

Sakurai, T., Amemiya, A., Ishii, M., Matsuzaki, I., Chemelli, R.M., Tanaka, H., Williams, S.C., Richardson, J.A., Kozlowski, G.P., Wilson, S., Arch, J.R., Buckingham, R.E., Haynes, A.C., Carr, S.A., Annan, R.S., McNulty, D.E., Liu, W.S., Terrett, J.A., Elshourbagy, N.A., Bergsma, D.J. und Yanagisawa, M. (1998): Orexins and orexin receptors: a family of hypothalamic neuropeptides and $\mathrm{G}$ protein-coupled receptors that regulate feeding behavior. Cell, 92 (4), 573-85. 
Sakurai, T. (2002): Roles of orexins in regulation of feeding and wakefulness. Neuroreport, 13 (8), 987-95.

Schatzberg, S., Olby, N., Steingold, S., Keene, B., Atkins, C., Meurs, K., Solomon, G., Goedegebuure, S.A., Wilton, S. und Sharp, N. (1999a): A polymerase chain reaction screening strategy for the promoter of the canine dystrophin gene. Am J Vet Res, 60 (9), 1040-6.

Schatzberg, S.J., Olby, N.J., Breen, M., Anderson, L.V., Langford, C.F., Dickens, H.F., Wilton, S.D., Zeiss, C.J., Binns, M.M., Kornegay, J.N., Morris, G.E. und Sharp, N.J. (1999b): Molecular analysis of a spontaneous dystrophin 'knockout' dog. Neuromuscul Disord, 9 (5), 289-95.

Seeliger, F., Leeb, T., Peters, M., Brugmann, M., Fehr, M. und Hewicker-Trautwein, M. (2003): Osteogenesis imperfecta in two litters of dachshunds. Vet Pathol, 40 (5), $530-9$.

Shapiro, M.B. und Senapathy, P. (1987): RNA splice junctions of different classes of eukaryotes: sequence statistics and functional implications in gene expression. Nucleic Acids Res, 15 (17), 7155-74.

Sharp, N.J., Kornegay, J.N., Van Camp, S.D., Herbstreith, M.H., Secore, S.L., Kettle, S., Hung, W.Y., Constantinou, C.D., Dykstra, M.J., Roses, A.D. und et al. (1992): An error in dystrophin mRNA processing in golden retriever muscular dystrophy, an animal homologue of Duchenne muscular dystrophy. Genomics, 13 (1), 115-21.

Shires, P.K., Nafe, L.A. und Hulse, D.A. (1983): Myotonia in a Staffordshire terrier. $J$ Am Vet Med Assoc, 183 (2), 229-32.

Siegel, J.M., Nienhuis, R., Gulyani, S., Ouyang, S., Wu, M.F., Mignot, E., Switzer, R.C., McMurry, G. und Cornford, M. (1999): Neuronal degeneration in canine narcolepsy. J Neurosci, 19 (1), 248-57.

Smith, J. (1999): T-box genes: what they do and how they do it. Trends Genet, 15 (4), 154-8.

Song, J., Goetz, B.D. und Duncan, I.D. (2006): His36Pro point-mutated proteolipid protein retained in the endoplasmic reticulum of oligodendrocytes in the shaking pup. Glia, 53 (3), 257-65.

Swinney, G.R., Foster, S.F., Church, D.B. und Malik, R. (1998): Myotonia associated with hyperadrenocorticism in two dogs. Aust Vet J, 76 (11), 722-4.

Teraoka, S.N., Telatar, M., Becker-Catania, S., Liang, T., Onengut, S., Tolun, A., Chessa, L., Sanal, O., Bernatowska, E., Gatti, R.A. und Concannon, P. (1999): Splicing defects in the ataxia-telangiectasia gene, ATM: underlying mutations and consequences. Am J Hum Genet, 64 (6), 1617-31. 
Tiret, L., Blot, S., Kessler, J.L., Gaillot, H., Breen, M. und Panthier, J.J. (2003): The cnm locus, a canine homologue of human autosomal forms of centronuclear myopathy, maps to chromosome 2. Hum Genet, 113 (4), 297-306.

Tonokura, M., Fujita, K., Morozumi, M., Yoshida, Y., Kanbayashi, T. und Nishino, S. (2003): Narcolepsy in a hypocretin/orexin-deficient chihuahua. Vet Rec, 152 (25), 776-9.

Trifilieff, E., Skalidis, G., Hélynck, G., Lepage, P., Sorokine, O., Van Drosselaer, A. und Luu, B. (1985): Donées structurales sur le protéolipide de la myélinede masse moléculaire apparente $20 \mathrm{kDa}$. Comptes Rendus de l'Academie des Sciences, Paris, Série III, 300 (7), 241-246.

US-Patent (6664059): Assay for propensity for canine malignant hyperthermia. US Patent \& Trademark Office: Patent Full-Text and Image Database, http://patft.uspto.gov/netacgi/nphParser?Sect $1=$ PTO1\&Sect $2=$ HITOFF $\& d=$ PALL $\& p=1 \& u=\% 2 F n e t a h t m 1 \% 2 F P T$ $\mathrm{O} \% 2 \mathrm{Fsrchnum} . \mathrm{htm} \& \mathrm{r}=1 \& \mathrm{f}=\mathrm{G} \& \mathrm{l}=50 \& \mathrm{~s} 1=6664059 . \mathrm{PN} . \& \mathrm{OS}=\mathrm{PN} / 6664059 \& \mathrm{RS}$ $=\mathrm{PN} / 6664059$

Valentine, B.A., Cooper, B.J., Cummings, J.F. und deLahunta, A. (1986): Progressive muscular dystrophy in a golden retriever dog: light microscope and ultrastructural features at 4 and 8 months. Acta Neuropathol, 71 (3-4), 301-10.

Valentine, B.A., Cooper, B.J., de Lahunta, A., O'Quinn, R. und Blue, J.T. (1988): Canine X-linked muscular dystrophy. An animal model of Duchenne muscular dystrophy: clinical studies. J Neurol Sci, 88 (1-3), 69-81.

Valentine, B.A., Cooper, B.J., Cummings, J.F. und de Lahunta, A. (1990): Canine Xlinked muscular dystrophy: morphologic lesions. J Neurol Sci, 97 (1), 1-23.

Valentine, B.A., Winand, N.J., Pradhan, D., Moise, N.S., de Lahunta, A., Kornegay, J.N. und Cooper, B.J. (1992): Canine X-linked muscular dystrophy as an animal model of Duchenne muscular dystrophy: a review. Am J Med Genet, 42 (3), 352-6.

vanHeerden, J. und Eckersley, G. (1989): Narcolepsy in a long-haired dachshund. Tydskr S Afr vet Ver, 60 (3), 151-153.

Vite, C.H., Cozzi, F., Rich, M., Klide, A.K., Volk, S.W. und Lombardo, R. (1998): Myotonic myopathy in a miniature Schnauzer: case report and data suggesting abnormal chloride conductance across the muscle membrane. J Vet Intern Med, 12 (5), 394-7.

Vite, C.H., Melniczek, J., Patterson, D. und Giger, U. (1999): Congenital myotonic myopathy in the miniature schnauzer: an autosomal recessive trait. J Hered, 90 (5), 578-80.

Watanabe, I. und Bingle, G.J. (1972): Dysmyelination in "quaking" mouse. Electron microscopic study. J Neuropathol Exp Neurol, 31 (2), 352-69. 
Watson, A.J.D., Farrow, B., Middleton, D.J. und Smyth, J.B.A. (1988): Myopathy in a Labrador retriever. Aust Vet J, 65 (7), 226-227.

Willard, H.F. und Riordan, J.R. (1985): Assignment of the gene for myelin proteolipid protein to the $\mathrm{X}$ chromosome: implications for X-linked myelin disorders. Science, 230 (4728), 940-2.

Wilson, V., Rashbass, P. und Beddington, R.S. (1993): Chimeric analysis of T (Brachyury) gene function. Development, 117 (4), 1321-31.

Wilson, V., Manson, L., Skarnes, W.C. und Beddington, R.S. (1995): The T gene is necessary for normal mesodermal morphogenetic cell movements during gastrulation. Development, 121 (3), 877-86.

Wood, S.L. und Patterson, J.S. (2001): Shetland Sheepdog leukodystrophy. J Vet Intern Med, 15 (5), 486-93.

Yanagisawa, K., Moller, J.R., Duncan, I.D. und Quarles, R.H. (1987): Disproportional expression of proteolipid protein and DM-20 in the X-linked, dysmyelinating shaking pup mutant. J Neurochem, 49 (6), 1912-7.

Zachary, J.F. und O'Brien, D.P. (1985): Spongy degeneration of the central nervous system in two canine littermates. Vet Pathol, 22 (6), 561-71. 


\subsection{Farbvarianten}

Die verschiedenartige Ausprägung der einzelnen Fellfarbvarianten beim Hund wird anhand von zahlreichen Anpaarungsexperimenten auf das Zusammenspiel von mindestens zehn verschiedenen Genorten zurückgeführt. Dabei kann derselbe Phänotyp sogar innerhalb einer Rasse durch den Effekt von unterschiedlichen Allelen und Allelwechselwirkungen zustande kommen. Beispielsweise existiert neben einer dominant vererbten vollständig schwarzen Grundfärbung außerdem eine vollständige Schwarzfärbung mit rezessivem Erbgang, die auf dem Effekt eines anderen Genortes beruht. Als grundlegende Arbeiten zur Analyse der an der der Farbvererbung beim Hund beteiligten Genorte sowie deren jeweiliger Allele gelten die Untersuchungen von Little $(1914 ; 1934 ; 1957)$ sowie von Burns und Fraser (1966). Eine Übersicht über die wesentlichen Erkenntnisse bis 1989 findet sich bei Willis (1989). Im Folgenden soll nur auf diejenigen Genorte eingegangen werden, die bis heute auf molekularer Ebene identifiziert und charakterisiert werden konnten. Zu den Merkmalen, die bisher mit bestimmten Genotypen assoziiert werden konnten, gehören neben der Fellgrundfarbe die Farbe der Nase und bestimmte Fellzeichnungen. Tabelle 21 listet alle bisher mit der Farbgebung assoziierten Gene und deren Polymorphismen auf.

Grundsätzlich hängt die Farbgebung von Eigenschaften der in den Mark- und Faserzellen der Haare lokalisierten Farbpigmente ab. Zu diesen für die Fellfärbung entscheidenden Eigenschaften zählt zunächst die Farbe der Pigmentgranula, die auf der Menge, Ausdehnung und Verteilung der beiden Melanine Eumelanin und Pheomelanin beruht. Dabei führt die Expression von Pheomelanin zu einer hellgelben bis roten Fellfarbe, während die Expression von Eumelanin eine braune bis schwarze Färbung bedingt. Des Weiteren spielen die Form und die Größe, die Menge an Granula in den einzelnen Mark- und Faserzellen sowie die Anordnung zueinander und innerhalb der Zellen eine entscheidende Rolle. Diese Erkenntnisse beruhen zwar auf einer Untersuchung an Mäusen (Russell 1946), es wird jedoch allgemein als angemessen beurteilt, auch bei anderen Säugetieren von ähnlichen Verhältnissen auszugehen (Willis 1989). 
Tabelle 21 Liste der bisher identifizierten Mutationen mit Einfluss auf die Fellfarbe

\begin{tabular}{|c|c|c|c|c|}
\hline Gen & Polymorphismus & Rassen & Fellfarbe/ Zeichnung/ Schattierung & Erbgang \\
\hline \multirow[t]{3}{*}{ MC1R } & R306ter & $\begin{array}{l}\text { Labrador Retriever, Golden Retriever, } \\
\text { Irischer Setter, }\end{array}$ & reine Expression von Pheomelanin & rezessiv \\
\hline & M264V & $\begin{array}{l}\text { Akita, Boxer, Bullmastiff, Dänische } \\
\text { Dogge, Greyhound, Rhodesian } \\
\text { Ridgeback, Deutscher Schäferhund }\end{array}$ & $\begin{array}{l}\text { regional variable Expression von } \\
\text { Eu- und Pheomelanin: dunkle } \\
\text { Maske }\end{array}$ & dominant \\
\hline & S90G & $\begin{array}{l}\text { Labrador Retriever, Flat Coated } \\
\text { Retriever, Neufundländer }\end{array}$ & reine Expression von Eumelanin & dominant \\
\hline \multirow[t]{3}{*}{ Agouti } & Wildtyp & & $\begin{array}{l}\text { regional variable Expression von } \\
\text { Eu- und Pheomelanin } \\
\text { a) gebänderte Rückenhaare und } \\
\text { helle Bauchhaare } \pm \text { Zobel } \\
\text { b) Zweifarbigkeit (schwarz mit } \\
\text { gelben oder braunen Flecken) }\end{array}$ & \\
\hline & R96C & $\begin{array}{l}\text { Deutscher Schäferhund, Shetland } \\
\text { Schäferhund, Belgischer Schäferhund, }\end{array}$ & reine Expression von Eumelanin & $\begin{array}{l}\text { rezessiv } \\
\text { gegenüber } \\
\text { dem ange- } \\
\text { stammten } \\
\text { Agouti- } \\
\text { Allel, } \\
\text { dominant } \\
\text { gegenüber } \\
\text { A82S+R83 } \\
\text { H }\end{array}$ \\
\hline & $\mathrm{A} 82 \mathrm{~S}+\mathrm{R} 83 \mathrm{H}$ & $\begin{array}{l}\text { Dackel, Cardigan Welsh Corgi, } \\
\text { Pembroke Welsh Corgi, Dänische } \\
\text { Dogge, Pekinese, Französische } \\
\text { Bulldogge, Mops, Staffordshire } \\
\text { Bullterrier, Rhodesian Ridgeback, } \\
\text { Shetland Schäferhund, Belgischer } \\
\text { Tervuren, Belgischer Laekenois, } \\
\text { Belgischer Malinois, Rauhaarcollie, } \\
\text { Afghane, Chow-Chow, Shar-Pei, } \\
\text { Akita, Mastiff, Bullmastiff, Boxer } \\
\text { NICHT: Deutscher Schäferhund, } \\
\text { Wolf, Coyote }\end{array}$ & $\begin{array}{l}\text { überwiegende Expression von } \\
\text { Pheomelanin } \\
\text { a) einheitlich gelb-braun }+ \text { ggf. } \\
\text { leicht dunklerer Schattierung auf } \\
\text { dem Rücken } \pm \text { Zobel } \\
\text { b) rein Zobel } \\
\text { c) Zobel mit weiß } \\
\text { d) gescheckt }\end{array}$ & $\begin{array}{l}\text { dominant } \\
\text { gegenüber } \\
\text { dem } \\
\text { angestammt } \\
\text { en } \\
\text { Agoutiallel, } \\
\text { rezessiv } \\
\text { gegenüber } \\
\text { Agouti-96C }\end{array}$ \\
\hline TYRP1 & $\begin{array}{l}\text { Q331ter + P345del } \\
+ \text { S41C }\end{array}$ & $\begin{array}{l}\text { Großer Münsterländer, Kleiner } \\
\text { Münsterländer, Portugiesischer } \\
\text { Wasserhund, Englischer Pointer, } \\
\text { Deutsch Langhaar Vorstehhund, } \\
\text { Chesapeake Bay Retriever, Deutsch } \\
\text { Drahthaar Vorstehhund, Griffon, } \\
\text { Deutsch Kurzhaar Vorstehhund, } \\
\text { Pudelpointer, Neufundländer, } \\
\text { Labrador Retriever, Deutsch Drahthaar } \\
\text { Vorstehhund, Feldspaniel, } \\
\text { Australischer Schäferhund, Deutsch } \\
\text { Kurzhaar Vorstehhund, Zwergpudel, } \\
\text { Weimaraner }\end{array}$ & $\begin{array}{l}\text { braunes statt schwarzes Eumelanin } \\
\text { Fell: braun-weiß, braun, } \\
\text { schokolade, leber, Australian- } \\
\text { Shepherd-rot tricolor und merle, } \\
\text { braun-grau, silber braun, silber- } \\
\text { grau } \\
\text { Nase: braun/ fleisch-farben }\end{array}$ & $\begin{array}{l}\text { rezessiv, } \\
\text { Effekt auf } \\
\text { Phänotyp, } \\
\text { wenn eine } \\
\text { Mutation } \\
\text { homozygot } \\
\text { oder zwei } \\
\text { heterozygot } \\
\text { vorliegen }\end{array}$ \\
\hline
\end{tabular}




\begin{tabular}{|c|c|c|c|c|}
\hline Gen & Polymorphismus & Rassen & Fellfarbe/ Zeichnung/ Schattierung & Erbgang \\
\hline MLPH & G165A & $\begin{array}{l}\text { Dobermann Pinscher, Deutscher } \\
\text { Pinscher, Rhodesian Ridgeback, } \\
\text { Beagle, Großer Münsterländer, } \\
\text { Amerikanischer Staffordshire } \\
\text { Bullterrier, Zwergpinscher }\end{array}$ & $\begin{array}{l}\text { gleichmäßige Aufhellung } \\
\text { schwarzer und brauner Fellfarben, } \\
\text { assoziiert mit CDA }\end{array}$ & rezessiv \\
\hline SILV & $\begin{array}{l}\text { SINE-Insertion } 3 \text { bp } \\
\text { vor Ex } 11\end{array}$ & $\begin{array}{l}\text { Shetland Schäferhund, Collie, Border } \\
\text { Collie, Australischer Schäferhund, } \\
\text { Cardigan Welsh Corgi, Dackel, } \\
\text { American Pit Bull Terrier, Catahoula } \\
\text { Leopard Dog, Chihuahua, } \\
\text { Zwergpudel, Pyrenäenschäferhund }\end{array}$ & $\begin{array}{l}\text { Merle-Phänotyp, assoziiert mit } \\
\text { Hör-u. Sehbeeinträchtigungen und } \\
\text { falls homozygot mit }\end{array}$ & $\begin{array}{l}\text { dominant } \\
\text { mit } \\
\text { unvollständi } \\
\text { ger } \\
\text { Penetranz }\end{array}$ \\
\hline
\end{tabular}

\subsubsection{Varianten des MC1R-Gens}

\begin{tabular}{|ll}
\hline Chromosom: & CFA5 \\
Gen: & MC1R \\
Ensembl: & GeneID: ENSCAFG00000023902 \\
DNA-Sequenz: & CFA5, Position 66692398-66693351 \\
Polymorphismen: & C916T (R306ter), reine Pheomelaninexpression \\
& G790A (M264V), schwarze Maske \\
& G268A (S90G), reine Eumelaninexpression \\
\hline
\end{tabular}

Das offene Leseraster des caninen MC1R-Gens, das für den Melanocortin 1 bindenden Rezeptor codiert, hat eine Länge von 951 bp und ist in einem einzigen Exon auf Chromosom 5 zwischen Position 66692398 und 66693351 lokalisiert (EnsemblGeneID: ENSCAFG00000023902) (Schmutz et al. 2001).

Der Melanocortin-1-bindende Rezeptor ist an der Plasmamembran der Melanozyten lokalisiert und nimmt die entscheidende Bedeutung bei der Steuerung der Tyrosinaseaktivität ein. Das Enzym Tyrosinase ist am Syntheseprozess von Eu- oder Pheomelanin aus Tyrosin beteiligt und bestimmt das Ausmaß der Expression dieser beiden Melanine. Eine geringe Tyrosinaseaktivität führt zur bevorzugten Bildung von Pheomelanin, während eine hohe Tyrosinaseaktivität die Eumelaninsynthese stimuliert. $\mathrm{MC1R}$ ist einer von fünf melanocortinbindenden Rezeptoren, die zur Familie der GProtein-gekoppelten Rezeptoren zählen. Die Aktivierung dieses Rezeptors, die unter anderem durch das $\alpha$-Melanozytenstimulierende Hormon ( $\alpha-\mathrm{MSH})$ erfolgt, führt zu einer Stimulierung der Eumelaninsynthese. Eine Inaktivierung des Rezeptors durch Mutationen im MC1R-Gen oder durch den Effekt weiterer Gene führt demgegenüber zu einer bevorzugten Synthese von Pheomelanin (Everts et al. 2000). 
Bei Hunden sind im MC1R-Gen bisher drei Mutationen mit einem offensichtlichen bzw. wahrscheinlichen Einfluss auf die Fellfarbe gefunden worden (Abb. 139).

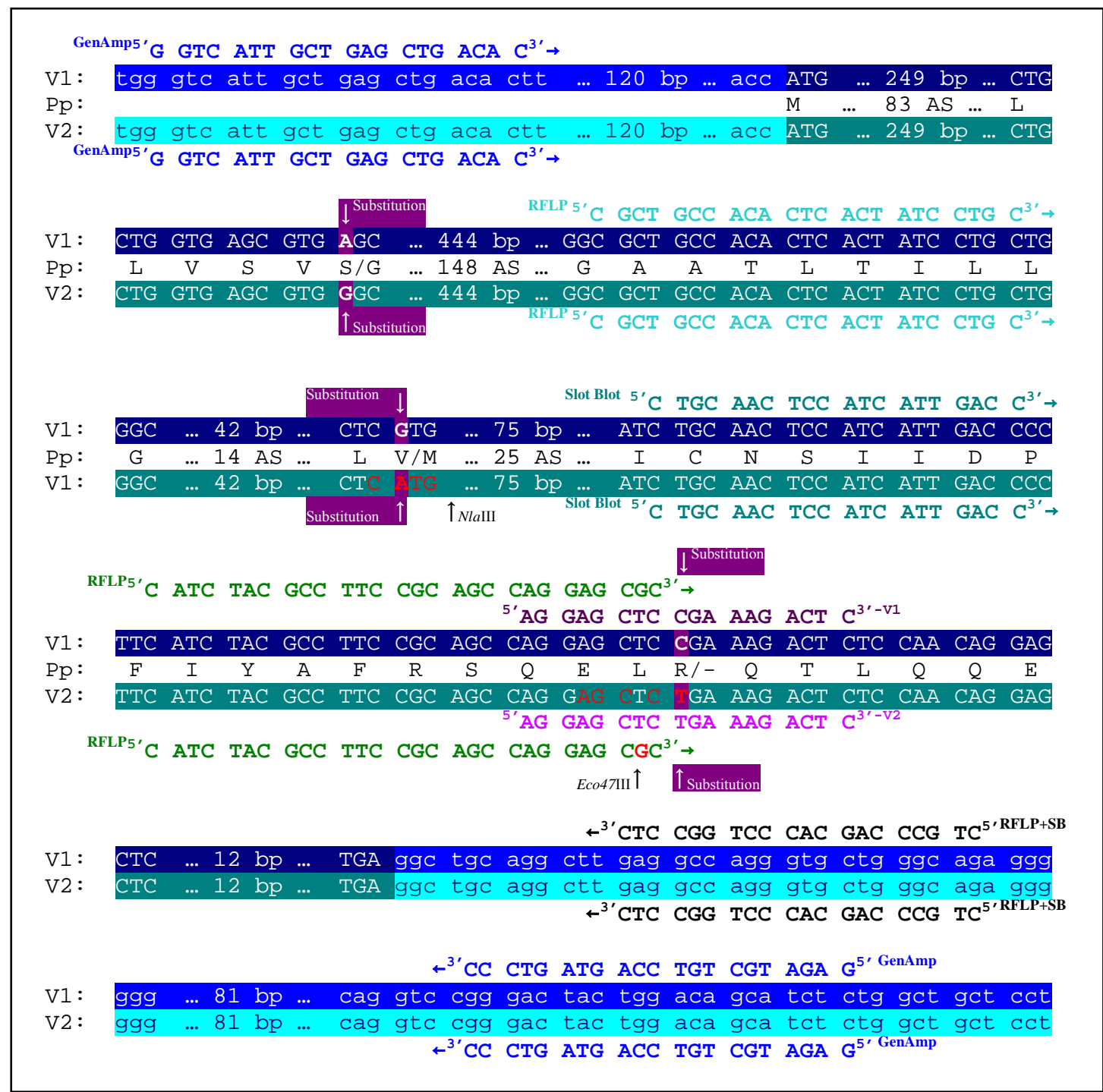

Abb. 139 MC1R-Gen und flankierende Sequenzen. V1: Variante 1, V2: Variante 2, Pp: Polypeptidsequenz, dunkelblau: Exon Variante 1, dunkelgrün: Exon Variante 2, hellblau: flankierende Sequenz Variante 1, hellgrün: flankierende Sequenz Variante 2, Substitutionen jeweils durch Pfeil bezeichnet und violett unterlegt, dunkelblaue Schrift: Primerpaar zur Amplifikation der gesamten codierenden Sequenz, blaugrüne Schrift: Vorwärtsprimer zur Amplifikation des 120-bp-Fragmentes für die R306ter-Genotypisierung per Slot-Blot, dunkelviolett: V1-spezifische Oligonukleotidsonde, hellviolett: V2-spezifische Oligonukleotidsonde, grüne Schrift: Vorwärtsprimer zur Amplifikation des 90bp-Fragmentes für die R306ter-Genotypisierung per RFLP, hellgrüne Schrift: Vorwärtsprimer zur Amplifikation des 270-bp-Fragmentes für die V264M Genotypisierung, schwarze Schrift: reverser Primer für beide RFLP-Tests und die Slot-Blot-Genotypisierung.

Es handelt sich um eine Substitution an Nukleotidposition 916 von Cytosin durch Thymin mit der Folge der Entstehung eines verfrühten Stoppcodons an Aminosäurenposition 306 (R306ter) (Everts et al. 2000; Newton et al. 2000), um eine Substitution von Guanin durch Adenin an Nukleotidposition 790 mit der Folge einer 
Aminosäurensubstitution von Methionin durch Valin an Position 264 (M264V) (Schmutz et al. 2003), sowie um eine Substitution von Guanin durch Adenin an Nukleotidposition 268 mit der Folge eines Aminosäurenaustauschs von Serin durch Glycin an Aminosäurenposition 90 (S90G) (Newton et al. 2000).

\section{I.a Der Polymorphismus R306ter}

Die Substitution von Cytosin durch Thymin an Position 916 des MC1R Gens führt in den Rassen Labrador Retriever, Golden Retriever und Irischer Setter zu einer rezessiv vererbten Gelbfärbung des Fells (Everts et al. 2000; Newton et al. 2000). Alle untersuchten gelben Labrador Retriever sowie alle untersuchten Golden Retriever wiesen im MC1R-Gen homozygot die beschriebene Substitution auf. Schwarze Labrador Retriever mit gelben und schwarzen Nachkommen sind heterozygot für die Aminosäurensubstitution (Everts et al. 2000). Neben Labrador Retrievern und Golden Retrievern konnte die beschriebene Substitution außerdem bei roten Irischen Settern, zwei sandfarbenen Cocker Spaniels und einem cremefarbenen Samoyeden nachgewiesen werden. Ein schwarzer Cocker Spaniel war heterozygot für die beschriebene Substitution (Newton et al. 2000). Diese Ergebnisse sprechen für einen ursächlichen Zusammenhang der Mutation mit der Gelb- oder Rotfärbung in den genannten Rassen. Bei Cocker Spaniels und Samoyeden wird jedoch vermutet, dass ein weiteres Gen bei der Ausprägung der Pheomelaninfärbung beteiligt ist (Newton et al. 2000). Bei einer nicht genannten Anzahl von Cocker Spaniels konnte die Substitution nicht nachgewiesen werden. Allerdings ist die Fellfärbung der untersuchten Hunde nicht angegeben (Everts et al. 2000). Bei zwei roten Chow-Chows konnte die Ursache der vorherrschenden Pheomelaninexpression dagegen nicht auf die beschriebene Substitution zurückgeführt werden. Die Autoren vermuten, dass die Fellfarbe in dieser Rasse durch ein oder mehrere andere Gene bestimmt wird (Newton et al. 2000). In 16 weiteren Rassen (Airdale Terrier, Berner Sennenhund, Dobermann, Rottweiler, Zwergschnauzer, Deutsch Drahthaar Vorstehhund, Deutscher Schäferhund, Greyhound, Yorkshire Terrier, Cocker Spaniel, Drentscher Hühnerhund, Irischer Wolfshund, Welsh Corgi, Cairn Terrier, Boxer und Dackel) konnte die Mutation ebenfalls nicht nachgewiesen werden (Everts et al. 2000).

Die Substitution R306ter führt zu einem verfrühten Abbruch der Translation und zum Verlust von 12 C-terminalen Aminosäuren. Trotz dieses relativ geringen Verlustes wird 
davon ausgegangen, dass das Stoppcodon zu einem vollständigen Verlust der MC1Rezeptorfunktion führt. Offensichtlich sind im C-terminalen Ende des Proteins wesentliche Funktionen lokalisiert. Dafür spricht die starke Konservierung der Carboxyl-Termini aller bekannten MC1R-Proteine. Das Stoppcodon bewirkt den Verlust eines Cysteinrestes. In anderen G-Protein-gekoppelten Rezeptoren spielen ein oder zwei Cysteinreste im C-terminalen Bereich häufig eine Rolle für die Bindung an Membranen (Everts et al. 2000).

\section{I.b Der Polymorphismus M264V}

Der Polymorphismus M264V wird mit der Ausprägung einer dunklen Maske über der Schnauze in Verbindung gebracht, die häufig bis über die Ohren ausgedehnt ist. Eine solche Zeichnung ist typisch für die Rassen Akita, Bullmastiff, Boxer, Deutscher Schäferhund, Dänische Dogge, Greyhound, Wolfsspitz, Leonberger, Mastiff, Pekinese, Mops, Rhodesian Ridgeback, Sloughi, Tibet Spaniel und Whippet. Der Farbton der dunklen Maske variiert zwischen schwarzen, dunkelbraunen oder dunkelgrauen Schattierungen. Weder die Schattierung der Maske noch die der Nase scheint mit der M264V- oder der R360ter-Variante des MC1R-Gens zusammenzuhängen.

Bei einer Genotypisierung von insgesamt 43 Hunden waren alle 17 Hunde aus den Rassen Akita, Boxer, Bullmastiff, Dänische Dogge, Greyhound, Rhodesian Ridgeback und Deutscher Schäferhund mit eindeutig ausgeprägter dunkler Maske homozygot oder heterozygot für die Substitution. Bei fünf weiteren Hunden mit heterozygotem oder homozygot mutiertem Genotyp aus den Rassen Deutscher Schäferhund, Schottischer Hirschhund und Toypudel ließ sich aufgrund einer vollständigen Schwarz- bzw. Braunfärbung bzw. aufgrund grau gescheckter Fellfärbung in Verbindung mit langem Haar die Ausprägung einer dunklen Maske nicht eindeutig bestimmen. Lediglich in zwei Fällen war trotz homozygot oder heterozygot nachgewiesener Substitution eindeutig keine dunkle Maske ausgeprägt. Der Phänotyp der betroffenen Hunde deutet allerdings laut Autoren darauf hin, dass bei diesen Tieren insgesamt ein Mangel an Melanozyten vorliegt, so dass der Effekt der Mutation M264V nicht offensichtlich wird. Alle 19 untersuchten Hunde der Rassen Bouvier, Greyhound, Whippet Englischer Setter, Dackel, Dobermann, Cocker Spaniel, Zwergpudel und Irischer Setter, bei denen eindeutig keine dunkle Maske ausgeprägt war, waren homozygot für Methionin an Position 264 (Schmutz et al. 2003). 
Auf welche Weise es durch die beschriebene Mutation $\mathrm{zu}$ einer regional deutlich begrenzten Expression von Eu- bzw. Pheomelanin kommt ist noch nicht geklärt. Möglicherweise wird die Fellzeichnung durch die Anzahl von Melanozyten je Haarfollikel gesteuert, oder es liegen in verschiedenen Körperzonen unterschiedliche Schwellenwerte für die Umschaltung zwischen Eumelanin- und Pheomelaninsynthese vor (Schmutz et al. 2003).

\section{I.c Der Polymorphismus S90G}

Mehrere weitere Mutationen an den Aminosäurenpositionen 17, 105, 159 und 311 des MC1R-Proteins, die bei einer Typisierung von Dobermann Pinschern, Neufundländern, Flat Coated Retrievern, schwarzen und gelben Labrador Retrievern, Golden Retrievern und Irischen Settern gefunden wurden, scheinen die Funktion des Rezeptors nicht zu beeinflussen (Newton et al. 2000). Untersuchungen an Labrador Retrievern, Flat Coated Retrievern und Neufundländern deuten auf die Existenz einer weiteren funktionellen Mutation in der zweiten Transmembrandomäne an Aminosäureposition 90 hin. Es handelt sich um einen Basenaustausch an Nukleotidposition 268, wobei Adenin durch Guanin ersetzt wird, mit der Folge einer Aminosäuresubstitution von Serin durch Glycin, die bei schwarzen Labrador Retrievern, Flat Coated Retrievern und Neufundländern vorliegt. In Übereinstimmung mit bekannten Mutationen in identischen Domänen bei Mäusen (Robbins et al. 1993), Rindern (Klungland et al. 1995) und Schweinen (Kijas et al. 1998) scheint die beschriebene Substitution zu einer konstitutiven Aktivierung des MC1-Rezeptors und damit zu einer dominant vererbten Schwarzfärbung des Fells zu führen. Es wird vermutet, dass die beschriebene Substitution eine veränderte Hydrophobizität der Seitenketten bewirkt. Dadurch könnten Kontakte zwischen Transmembranhelices beeinträchtigt werden. Bei Mäusen führt eine Mutation in der zweiten Transmembrandomäne des MC1R-Proteins zu einer Unempfindlichkeit des MC1-Rezeptors gegenüber Melanocortinagonisten (Robbins et al. 1993).

Allerdings konnte die S90G-Substitution auch bei einem gelben Labrador Retriever festgestellt werden. Daraus schließen die Autoren, dass die konstitutive Aktivierung des MC1R-Proteins durch die R306ter-Substitution überlagert wird (Newton et al. 2000). 


\section{II.a Genotypisierung für den Polymorphismus R306ter}

Der Nachweis kann per Amplifikation eines 122-bp-Fragmentes aus genomischer DNA und anschließender Slot Blot Hybridisierung mit allelspezifischen Sonden (ASO) erfolgen (Newton et al. 2000).

Eine alternative Methode ist die Amplifikation eines 99-bp-Fragments unter Verwendung eines mismatch-Primers, der im Defektallel-PCR-Produkt die Entstehung einer Eco47III-Restriktionsschnittstelle bewirkt, die im Wildtypallel nicht vorhanden ist, und anschließende RFLP-Typisierung (Schmutz et al. 2002).

\section{II.b Genotypisierung für den Polymorphismus M264V}

Der Nachweis der Substitution an Aminosäureposition 264 kann über die Amplifikation eines 270-bp-Fragments und eine anschließende RFLP-Analyse erfolgen. Die Substitution führt zur Entstehung einer neuen NlaIII-Restriktionserkennungssequenz im Defektallel, die im Wildtypallel nicht enthalten ist (Schmutz et al. 2003).

\section{II.c Genotypisierung für den Polymorphismus S90G}

Der Nachweis der Substitution an Aminosäureposition 90 kann per diagnostischer Sequenzierung erfolgen (Newton et al. 2000).

\subsubsection{Varianten des Agouti-Gens}

\begin{tabular}{|ll|}
\hline Chromosom: & CFA24 \\
Gen: & Agouti \\
NCBI: & GeneID: 492296 \\
DNA-Sequenz: & NW_876277, Position 23327360-23366322 \\
Polymorphismen: & G375T+G379A (A82S+R83H), überwiegende \\
& Pheomelaninexpression \\
& C427A (R96C), reine Eumelaninexpression \\
\hline
\end{tabular}

Das canine Agouti-Gen ist auf Chromosom 24 lokalisiert (Kerns et al. 2004). Es konnte eine cDNA von 788 bp Länge isoliert werden, die in vier Exons unterteilt ist (NCBIGenBank: AY714374). Die 131 Codons umfassende proteincodierende Sequenz beginnt in Exon 2 und endet in Exon 4 (Kerns et al. 2004). Die Lage der einzelnen Exons innerhalb der genomischen Sequenz scheint noch nicht abschließend geklärt zu sein. Bisher sind nur vorläufige genomische Sequenzen veröffentlicht, die nicht vollständig mit der Dobermann-cDNA-Sequenz (NCBI-GenBank: AY714374 (Kerns et al. 2004)) in Einklang zu bringen sind. Im genomischen Contig NW_876277 erstreckt sich das 
Agouti-Gen zwischen Position 23327360 und 23366322 (NCBI-GeneID: 492296). Diese Version ist Grundlage der schematischen Darstellung des caninen Agouti-Gens in Abb. 140.

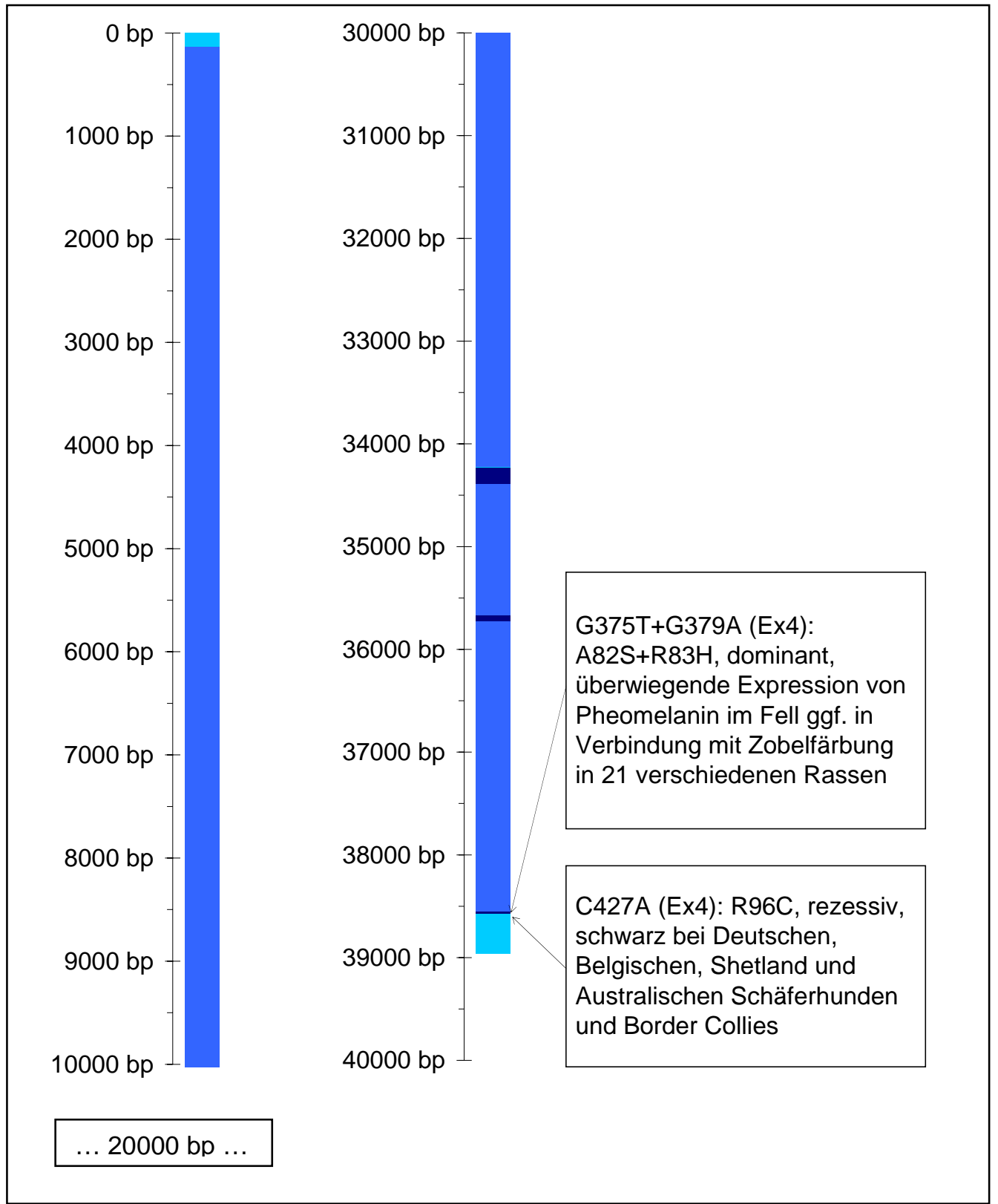

Abb. 140 Schematische Darstellung des caninen Agoutigens und Lage der bisher identifizierten Mutationen. Dunkelblau: codierende Sequenz, hellblau: Intronsequenz, türkis: 3' - und 5'-UTR.

Das Agouti-Protein zählt $\mathrm{zu}$ den parakrinen Signalmolekülen und begünstigt die Synthese von Pheomelanin gegenüber Eumelanin. Dieser Funktion liegen im Wesentlichen zwei Mechanismen zugrunde. Einerseits besetzt das Agouti-Protein gesteuert durch N-terminale Domänen die $\alpha$-MSH-Bindungsstellen am MC1-Rezeptor 
und hemmt dadurch die MC1R-Aktivität. Andererseits sorgen C-terminale Domänen des Agouti-Proteins für eine Drosselung der MC1R-Signalfunktion (Barsh et al. 2000).

Für die Wechselwirkungen zwischen dem MC1R-Gen und dem Agouti-Gen gilt, dass funktionssteigernde MC1R-Mutationen und funktionsmindernde Agouti-Mutationen zu einer überwiegenden Expression von Eumelanin führen, während umgekehrt funktionssteigernde Agouti-Mutationen und funktionsmindernde MC1R-Mutatinen eine überwiegende Pheomelaninexpression zur Folge haben. Treten Agouti- und MC1RAllele mit gegensätzlichen Effekten nebeneinander auf, so wird der Phänotyp des betreffenden Individuums durch das MC1R-Allel bestimmt. MC1R ist also gegenüber dem Agouti-Gen epistatisch (zusammengefasst bei Berryere et al. 2005).

Bis heute sind bei Hunden die molekularen Eigenschaften einer als angestammtes Agoutiallel bezeichneten und zwei weiterer Varianten bekannt, die mit bestimmten Fellfärbungen in Verbindung gebracht werden.

\section{I.a Das angestammte Agouti-Allel}

Als Effekt des angestammten Agouti-Allels gilt eine bei einigen Wölfen, Schakalen und Füchsen sowie einzelne Individuen aus domestizierte Rassen wie Deutschen Schäferhunden und Sibirischen Huskys zu beobachtende Färbung mit gebänderten Rückenhaaren und einem hellen Bauch. Diese Grundfärbung kann in Verbindung mit einer Zobelfärbung, also der Ausprägung unterschiedlicher Mengen an einzelnen schwarzen, nicht gebänderten Haaren auftreten.

Eine weitere Grundfärbung, die ebenfalls mit dem angestammten Agoutiallel segregiert, ist die so genannte black-and-tan-Färbung, die entweder in Form einer Zweifarbigkeit oder einer Sattelzeichnung auftritt. Zweifarbigkeit beschreibt eine schwarze Grundfärbung mit einzelnen gelben bis roten Abzeichen wie sie zum Beispiel in den Rassen Dobermann Pinscher oder Rottweiler auftritt. Die Sattelzeichnung ist durch die Ausprägung einer schwarzen Decke bei gelber bis roter Färbung von Bauch und Beinen gekennzeichnet und tritt zum Beispiel in den Rassen Deutscher Schäferhund, Airdale Terrier und Dackel auf (Kerns et al. 2004; Berryere et al. 2005). 
Der molekulare Mechanismus, der hinter der Ausprägung einer Zobelfärbung gegenüber einer Sattelzeichnung oder einer Zweifarbigkeit steht, ist bisher nicht identifiziert.

Die beschriebenen Fellzeichnungen entstehen offenbar im Fall der black-and-tanFärbung durch regional unterschiedlich gesteuerte Expression bzw. im Fall der gebänderten Haare durch zeitlich unterschiedlich gesteuerte Expression von Eu-und Pheomelanin. Als mögliche Erklärung für diese Erscheinung kommen sowohl eine zeitlich oder räumlich variable Expression unterschiedlicher Transkripte in Frage als auch ein regulierender Effekt weiterer noch nicht identifizierter Gene. Für den ersteren Mechanismus gibt es ein murines Beispiel. Bei Mäusen führt die alternative Translation der ersten Exons des Agoutigens zu verschiedenen Isoformen, die entweder ventralspezifisch exprimiert werden, wie bei weiß- oder hellbäuchigen Mäusen, oder haarzyklus-spezifisch auftreten und für eine gebänderte Musterung einzelner Haare sorgen (Vrieling et al. 1994; Chen et al. 1996).

\section{I.b Der Polymorphismus R96C}

In den Rassen Deutscher Schäferhund, Belgischer Schäferhund, Shetland Schäferhund, Australischer Schäferhund und Border Collie tritt an Position 427 der cDNA in Exon 4 eine Substitution von Cytosin durch Thymin mit der Folge einer Aminosäuresubstitution von Arginin durch Cystein in Codon 96 auf (Abb. 141). Betroffene Hunde zeigen eine gegenüber der angestammten Agouti-Färbung, der Zweifarbigkeit und der Sattelzeichnung rezessiv vererbte, vollständige Schwarzfärbung. Während bei Deutschen Schäferhunden bisher nur rezessiv vererbte Fälle von vollständiger Schwarzfärbung bekannt sind, tritt in den anderen Rassen auch eine dominante Schwarzfärbung auf, die offenbar mit einem anderen Gen assoziiert ist (Kerns et al. 2004).

Für einen Zusammenhang der identifizierten Mutation mit der vollständigen Schwarzfärbung spricht zunächst die hohe Konservierung der betroffenen Aminosäure Arginin 96 in allen Spezies, bei denen die Sequenz des Agouti-Proteins bisher bekannt ist. Zudem ist die betroffene Aminosäure innerhalb der Domäne lokalisiert, die direkt mit dem MC1-Rezeptor interagiert. 
Anhand von Studien des Agouti-verwandten Proteins Agrp, das im C-terminalen Bereich ein ähnliches Verteilungsmuster von Cysteinresten aufweist wie das AgoutiProtein, und dessen dreidimensionale Struktur bekannt ist, können die Folgen der beschriebenen Mutation eingeschätzt werden. Höchstwahrscheinlich bilden die Cterminalen Cysteinreste des Agouti-Proteins ein so genanntes inhibitorisches Cysteinknoten (ICK)- Motiv. Das durch das mutierte Triplet codierte zusätzliche Cystein führt möglicherweise zu einer gestörten Bildung dieses Motivs (Kerns et al. 2004)

\section{I.c Der Polymorphismus A82S+R83H}

Ein drittes Allel mit einem Aminosäureaustausch von Alanin durch Serin an Position 82 und einem weiteren Aminosäureaustausch von Arginin durch Histidin an Position 83 (Abb. 141), führt offenbar dominant zur Ausbildung von vollständig sand- oder beigefarbenem Fell, das in Verbindung mit Zobelfärbung auftreten kann (Berryere et al. 2005).

Ursache der Aminsäurensubstitutionen ist eine Nukleotidsubstitution von Guanin durch Thymin an Position 375 der cDNA und eine Substitution von Guanin durch Adenin an Position 79 der cDNA. Diese Mutation tritt den folgenden Rassen auf: Dackel, Cardigan Welsh Corgi, Pembroke Welsh Corgi, Dänische Dogge, Pekinese, Französische Bulldogge, Mops, Staffordshire Bullterrier, Rhodesian Ridgeback, Shetland Schäferhund, Belgischer Tervuren, Belgischer Laekenois, Belgischer Malinois, Rauhaarcollie, Afghane, Chow-Chow, Shar-Pei, Akita, Mastiff, Bullmastiff und Boxer. Nicht nachweisbar ist die Mutation hingegen in den Rassen Deutscher Schäferhund, Wolf, Coyote.

Wie die beschriebenen Substitutionen im Einzelnen mit der veränderten Funktion des Agouti-Gens zusammenhängen, ist nicht geklärt. Die Möglichkeit, dass eine oder beide Mutationen direkt für eine Funktionsänderung verantwortlich sind, wird als ebenso wahrscheinlich angesehen wie die Möglichkeit, dass ein über diese beiden Substitutionen hinausgehender Haplotyp vorliegt. In diesem Fall könnte bei Hunden vom 82S-83H-Genotyp eine noch nicht identifizierte weitere Mutation vorliegen, die möglicherweise die Expression einer oder mehrerer Agouti-mRNA-Isoformen beeinflusst (Berryere et al. 2005). 


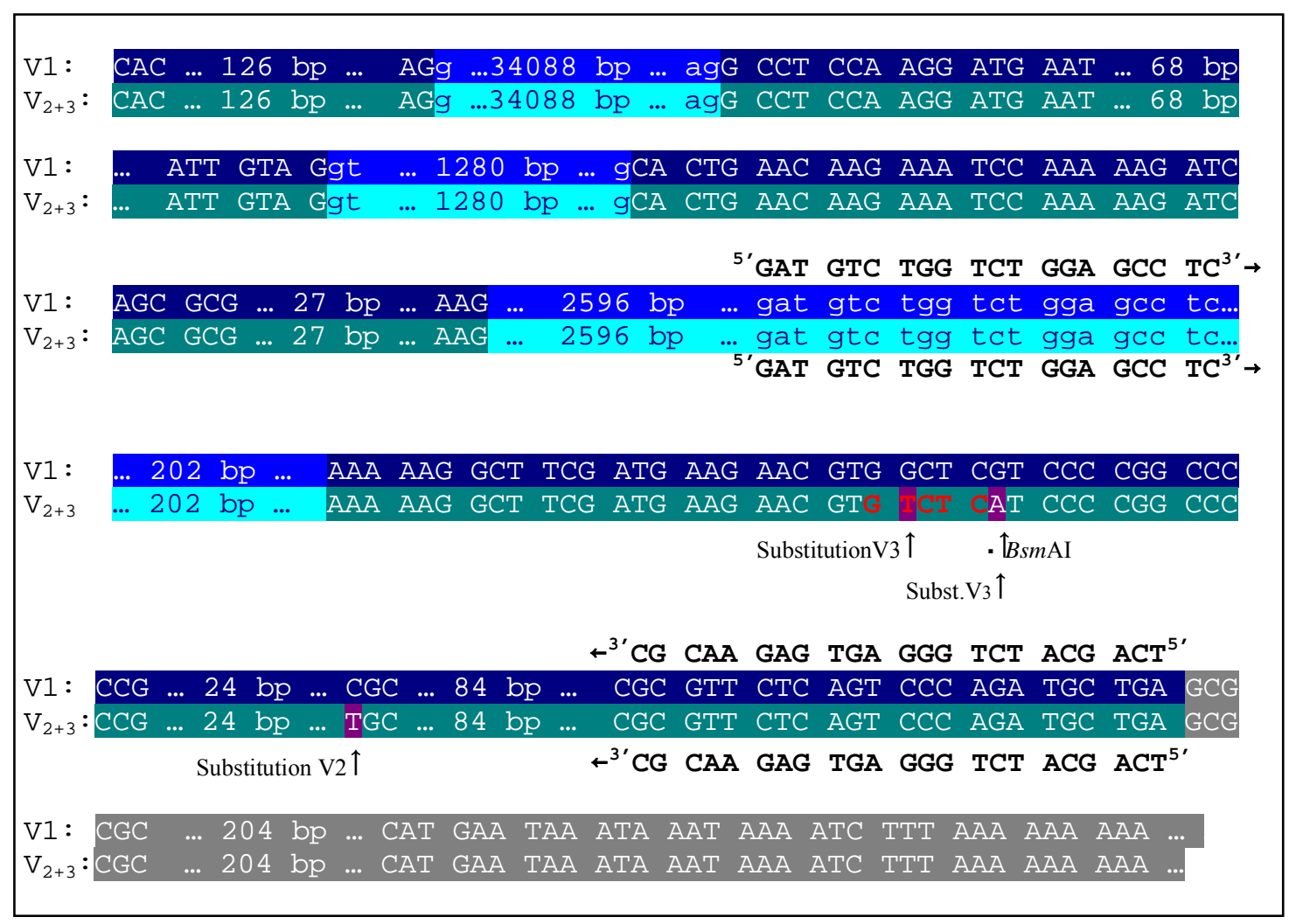

Abb. 141 Exons 1-4 des caninen Agoutigens und angrenzende Intronsequenzen. V1: angestammtes Agoutiallel, V2: R96C-Allel, V3: A82S+R83H-Allel, grau: UTR, dunkelblau: Exon V1, dunkelgrün: Exon V2 und V3, hellblau: Intron V1, hellgrün: Intron V2 und V3, Substitutionen violett markiert und durch Pfeil gekennzeichnet, rote Schrift: BsmAI-Restriktionserkennungssequenz, BsmAIRestriktionsschnittstelle durch Pfeil gekennzeichnet

\section{II.b Genotypisierung für den Polymorphismus R96C}

Eine mögliche Nachweismethode für die Substitution an Codon 96, die in der Rasse Deutscher Schäferhund mit einer rezessiv vererbten vollständigen Schwarzfärbung einhergeht, ist die Amplifikation von Exon 4 und eine anschließende Sequenzierung (Kerns et al. 2004; Berryere et al. 2005).

\section{II.c Genotypisierung für den Polymorphismus A82S+R83H}

Da ein vollständiges Kopplungsungleichgewicht zwischen Codon 82 und 83 vorliegt, reicht der Nachweis einer der beiden Substitutionen zur Genotypisierung für beide Polymorphismen aus. Die Typisierung für den A82S+R83H-Polymorphismus kann per RFLP-Test erfolgen. Der zugrunde liegende RFLP beruht auf einer BsmAIRestriktionserkennungssequenz im Defektallel, die durch die Substitution in Codon 82 verursacht wird (Abb. 141) (Berryere et al. 2005). 


\subsubsection{Varianten des TYRP1-Gens}

\begin{tabular}{|ll|}
\hline Chromosom: & CFA11 \\
Gen: & TYRP1 \\
NCBI: & GeneID: 403479, GenBank: XM_531934, XM_ \\
& 859433, XM_859450 \\
DNA-Sequenz: & NW_876253, Position 24283092 - 24303787 \\
Polymorphismen: & G536C (S41C), Braunfärbung \\
& C1399T (Q331ter), Braunfärbung \\
& G1413C (C336S), Braunfärbung \\
& Del1441-1443 (P345del), Braunfärbung \\
\hline
\end{tabular}

Ein weiteres Gen mit einem wesentlichen Einfluss auf die Farbgebung bei Hunden ist das TYRP1-Gen, das für das Tyrosinase-verwandte (tyrosinase-related) Protein 1 (TYRP1) codiert. Unter bestimmten Voraussetzungen verhindern verschiedene Polymorphismen des TYRP1-Gens die Bildung von schwarzen Farbpigmenten in Fell und Nase sowie der Haut der Fußsohlen. Dadurch kommt es zur Ausprägung verschiedener brauner Schattierungen im Fell, und braunen oder fleischfarbenen Nasen und Fußsohlen.

Das canine TYRP1-Gen ist auf Chromosom 11 lokalisiert (Schmutz et al. 2002) und erstreckt sich im genomischen Contig NW_876253 zwischen Position 24283092 und 24303787 (NCBI-GeneID: 403479). Es sind drei verschiedene mRNA-Varianten bekannt (NCBI-GenBank: XM_531934, XM_859433 und XM_859450). Variante 1 setzt ist in acht Exons unterteilt und hat eine Länge von 3212 Nukleotiden. Die Länge der codierenden Sequenz beträgt 1614 Nukleotide. Variante 2 enthält drei zusätzliche Nukleotide die zwischen den Exons 2 und 3 lokalisiert sind und für ein zusätzliches Exon codieren. Die Gesamtlänge beträgt 3215 Nukleotide, davon 1617 Nukleotide codierende Sequenz. Variante 3 hat ebenfalls eine Länge von 3215 Nukleotiden mit 1617 Nukleotiden codierender Sequenz und enthält drei zusätzliche Nukleotide, die für ein zusätzliches Exon zwischen den Exon 6 und 7 codieren. Für die Lokalisierung der im Folgenden beschriebenen Mutationen in der mRNA-Sequenz wird Variante 1 zugrunde gelegt. Die Lage der einzelnen Exons in der genomischen Sequenz ist in Abb. 142 schematisch dargestellt. 


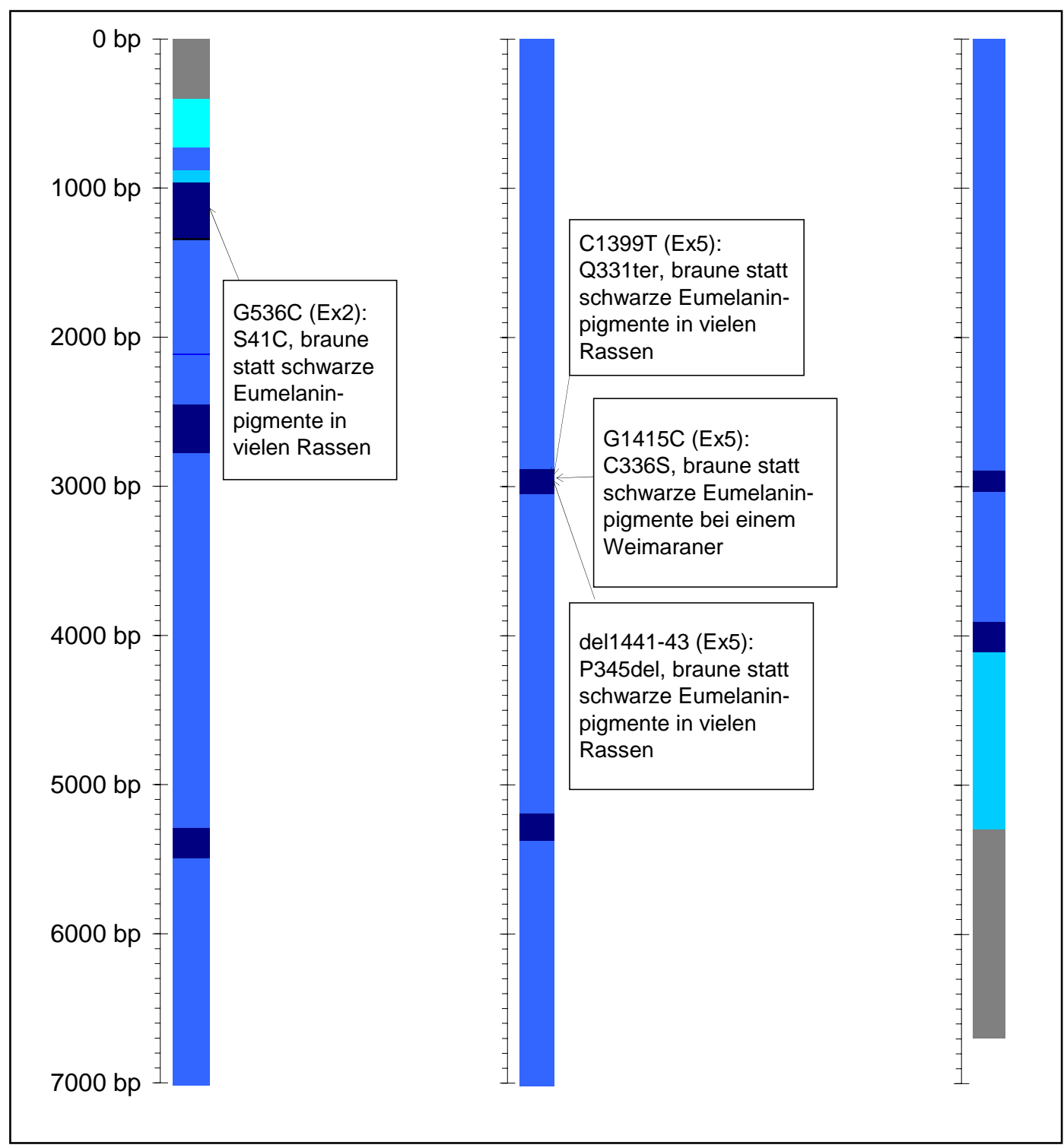

Abb. 142 Schematische Darstellung des caninen TYRP1-Gens und Lage der bisher identifizierten Mutationen. Dunkelblau: codierende Sequenz der Transkripte 1,2 und 3, mittelblau: zusätzliches Exon des Transkriptes 2 (zwischen Exon 1 und 2) bzw. 3 (zwischen Exon 6 und 7), dunkelblau-schwarz schraffiert: 10 bp am 3'-Ende von Exon 2, die bei Transkript 2 nicht transkribiert werden, hellblau: Intron, türkis: 5'- und 3'-UTR, grau: intergenische Sequenz.

\section{I.a Die Polymorphismen Q331ter, P345del und S41C}

Es sind drei Polymorphismen des caninen TYRP1-Gens beschrieben worden, die mit einer Braunfärbung des Fells und der Nase assoziiert sind. Diese drei Polymorphismen werden bezeichnet als Q331ter, P345del und S41C. Sowohl der Q331terPolymorphismus als auch der P345del-Polymorphismus sind in Exon 5 lokalisiert. Im Einzelnen handelt es sich um eine Substitution von Cytosin durch Thymin an Position 1399 der mRNA, die zur Substitution der Aminosäure Glutamin an Position 331 durch ein Stoppsignal führt, sowie um eine Deletion von drei Nukleotiden zwischen Position 
1415 und 1419 der mRNA, die, ohne das Leseraster zu verändern, zu einem Verlust der Aminosäure Prolin an Position 435 führt (Abb. 143).

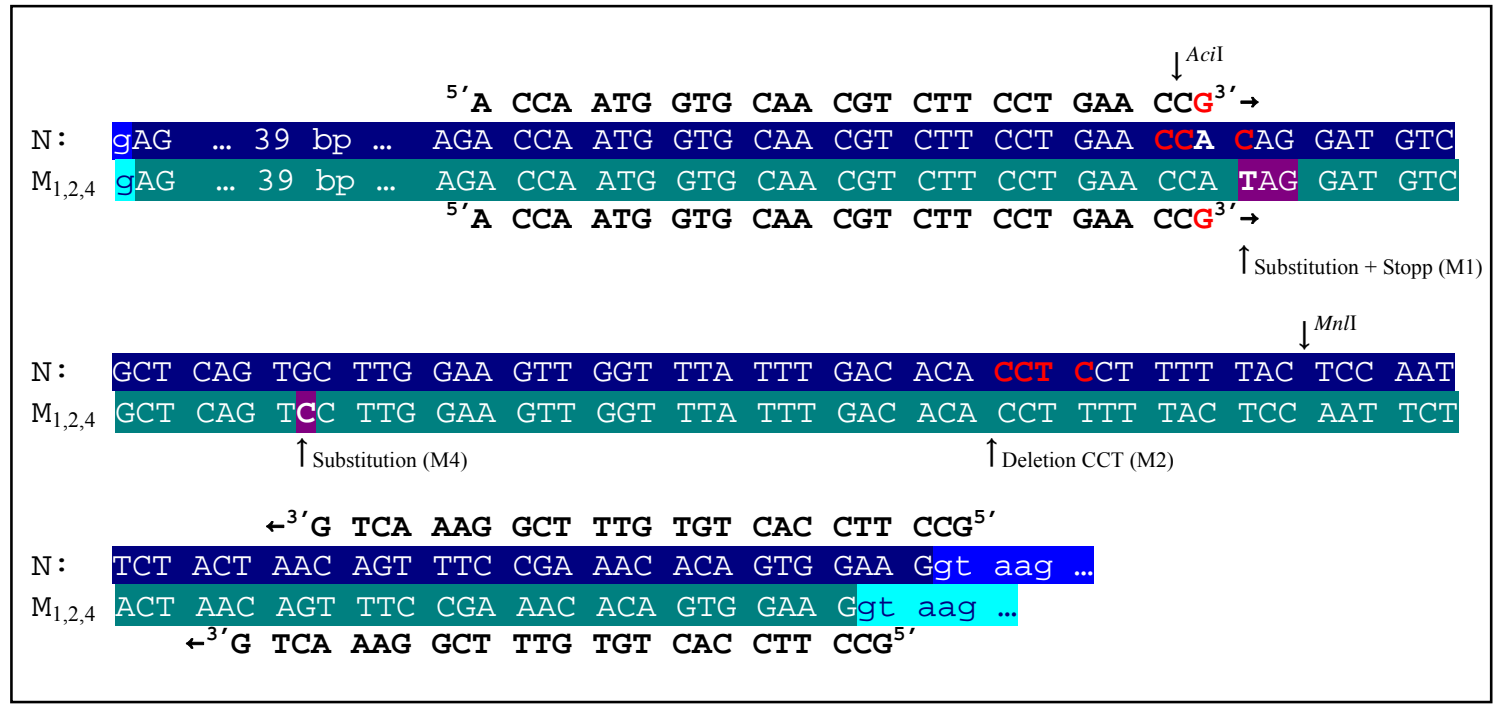

Abb. 143 Exon 5 des caninen TYRP1-Gens und angrenzende Intronsequenzen. N: normale Sequenz, $\mathrm{M}_{1 / 2 / 3}$ : mutierte Sequenz mit Polymorphismus 1,2 und 3, dunkelblau: Exon normale Sequenz, dunkelgrün: Exon mutierte Sequenz, hellblau: Intron normaler Sequenz, hellgrün: Intron mutiere Sequenz, Substitutionen bei Polymorphismus Q331ter (M1) und C336S (M2) violett unterlegt und durch Pfeil gekennzeichnet, Position der 3-bp-Deletion bei Polymorphismus P345del (M3) durch Pfeil gekennzeichnet, rote Schrift: Restriktionserkennungssequenzen für AciI- und MnlI, AciI- und MnlIRestriktionsschnittstelle durch Pfeil gekennzeichnet.

Der S41C-Polymorphismus, ein Aminosäureaustausch von Serin durch Cytosin an Aminosäureposition 41 wird durch eine Substitution von Guanin durch Cytosin an cDNA-Position 536 in Exon 2 verursacht (Abb. 144).

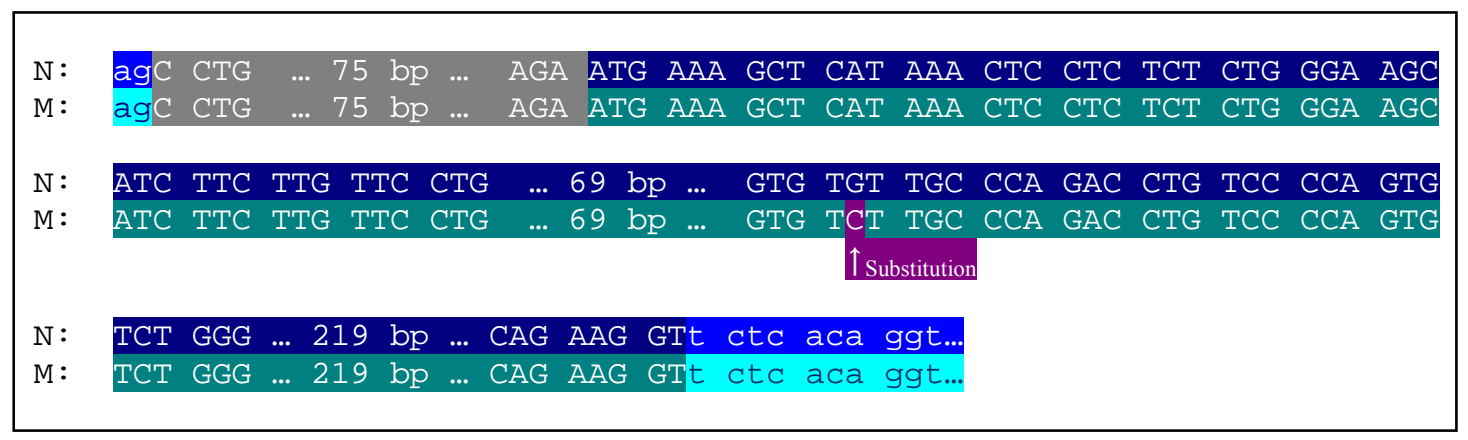

Abb. 144 Exon 2 des caninen TYRP1-Gens und angrenzende Intronsequenzen. N: Allel 1, M: Allel 2, grau: UTR, dunkelblau: Exon Allel 1, dunkelgrün: Exon Allel 2, hellblau: Intron Allel 1, hellgrün: Intron Allel 2, Substitution in Allel 2 violett unterlegt und durch Pfeil gekennzeichnet.

Ein Effekt auf die Fell- und Nasenfarbe entsteht, wenn eine der drei Mutationen homozygot vorliegt, oder wenn zwei Mutationen heterozygot vorliegen und unterschiedliche Kopien des TYRP1-Gens betreffen (Schmutz et al. 2002). Tabelle 22 verdeutlicht diesen Zusammenhang. 


\begin{tabular}{cccc}
\hline Aminosäurenposition & 331 & 345 & 41 \\
\hline & ter/ter & $*$ & $*$ \\
& Qer/Q & P/del & $*$ \\
Allel 1/Allel 2 & der/Q $/$ P & $*$ & $*$ \\
& Q/ter & $*$ & $\mathrm{C} / \mathrm{S}$ \\
$*$ & $\mathrm{Sel} / \mathrm{del}$ & $*$ \\
& $*$ & $\mathrm{P} / \mathrm{del}$ & $\mathrm{S} / \mathrm{C}$ \\
& $*$ & $\mathrm{C} / \mathrm{S}$ \\
& $*$ & del/P & $\mathrm{S} / \mathrm{S}$ \\
\hline
\end{tabular}

*: Allelkombination unerheblich, ter: Stoppcodon, del: Deletion

Bei allen insgesamt 48 untersuchten braunen Hunden lag entweder einer der Polymorphismen homozygot oder mindestens zwei Polymorphismen heterozygot vor. Alle braunen Hunde hatten entweder braune oder fleischfarbene Nasen und Fußsohlen (Schmutz et al. 2002).

Die jeweiligen Schattierungen der braunen Fellfarbe variieren individuell und in Abhängigkeit von der Rasse. Es konnte kein Zusammenhang zwischen einzelnen Brauntönen und bestimmten Allelen des TYRP1-Gens hergestellt werden. Offensichtlich sind an der Ausprägung individueller Farbschattierungen weitere, noch nicht identifizierte Gene beteiligt. Auch die Variabilität bezüglich brauner oder fleischfarbener Nasen scheint nicht vom TYRP1-Gen abzuhängen sondern von einem oder mehreren weiteren Genen gesteuert zu werden (Schmutz et al. 2002). Eines dieser weiteren steuernden Gene ist das MLPH-Gen (Drogemuller et al. 2005), das für den so genannten Dilute-Effekt oder Aufheller-Effekt verantwortlich ist und im nächsten Kapitel besprochen wird .

Die jeweiligen Effekte der genannten TYRP1-Polymorphismen auf die Fell- und Nasenfarbe bei Hunden aus verschiedenen Rassen, sind in Tabelle 23 dargestellt. In der Rasse Australischer Schäferhund tritt eine als „rot“ bezeichnete Fellfarbe auf, die 
jedoch nach der allgemeinen Ansicht durch Eumelaninexpression hervorgerufen wird (Schmutz et al. 2002).

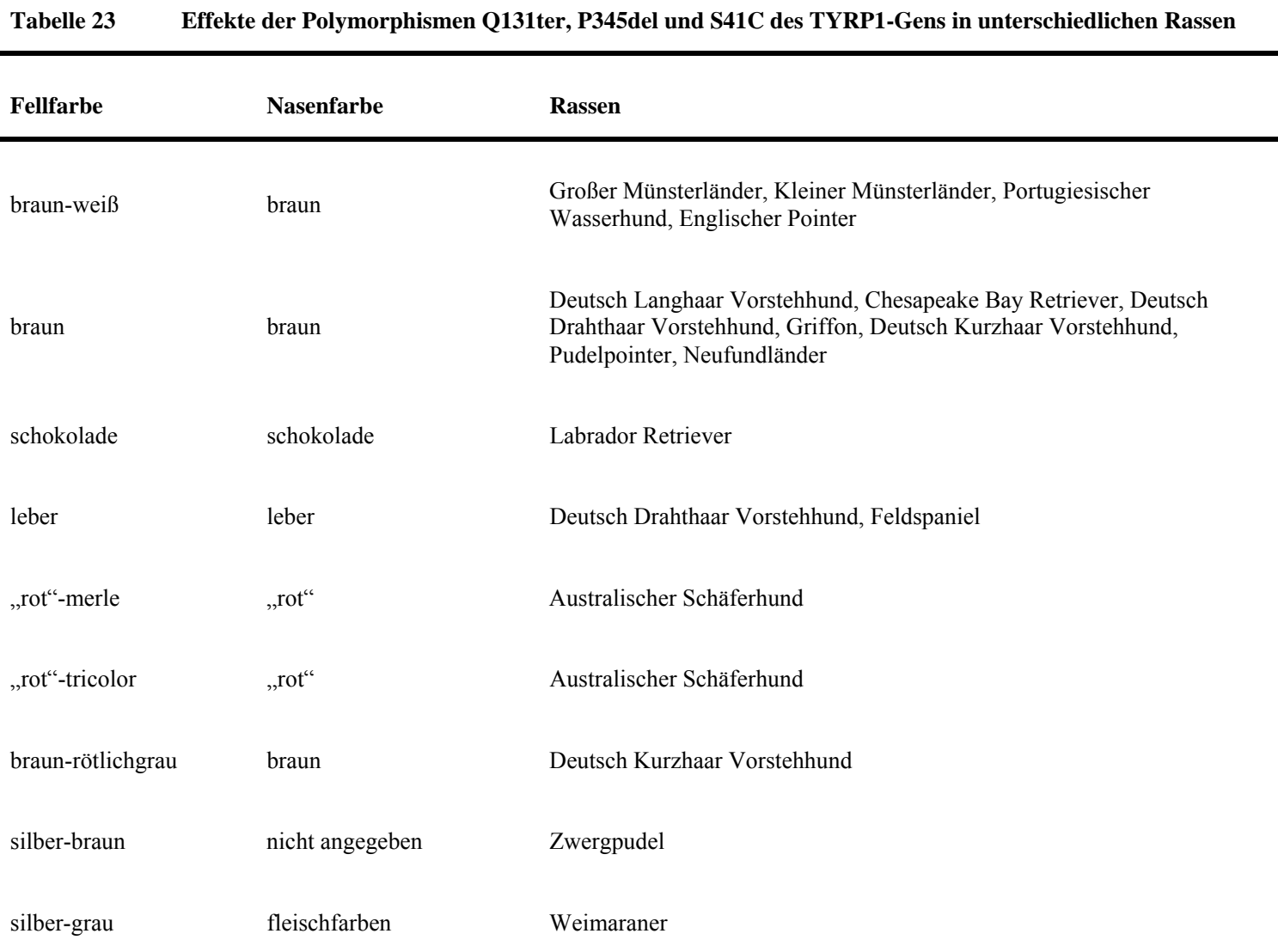

Bei Hunden mit homozygotem Genotyp für das MC1R-306ter-Allel kommt es aufgrund der reinen Pheomelaninexpression im Fell zu keinem Effekt durch TYRP1Polymorphismen. Allerdings lässt sich bei diesen Hunden ein Zusammenhang der TYRP1-Polymorphismen mit der Farbe der Nase und der Fußsohlen beobachten (Schmutz et al. 2002).

\section{I.b Der Polymorphismus C336S}

Eine vierte Mutation, eine Substitution von durch an Position 1415 in Exon 5 mit der Folge einer Aminosäurensubstitution von Cystin durch Serin an Aminosäurenposition 336 (Abb. 143), konnte nur bei einem einzelnen Weimaraner nachgewiesen werden. Ein funktioneller Zusammenhang dieser Mutation mit der Fellfarbe der Weimaraner ist nicht bewiesen, wird jedoch als wahrscheinlich angesehen. Eine Methode zur Typisierung für diesen Polymorphismus ist nicht entwickelt worden (Schmutz et al. 2002). 


\section{II.a Genotypisierung für die Polymorphismen Q331ter und P345del}

Die Typisierung für den Q331ter-Polymorphismus kann mittels RFLP-Test erfolgen. Dazu wird aus genomischer DNA ein 121-bp-Fragment aus Exon 5 amplifiziert. Dabei wird ein mismatch-Primer eingesetzt, der im Wildtypallel-PCR-Produkt für die Entstehung einer AciI-Restriktionsschnittstelle sorgt, die im Defektallel-PCR-Produkt nicht vorhanden ist. Auch die Typisierung für den P345del-Polymorphismus kann per RFLP-Test erfolgen. Dazu wird dasselbe Fragment amplifiziert wie bei der Typisierung für den Q331ter-Polymorphismus. Grundlage des RFLP ist eine MnlIRestriktionserkennungssequenz im Wildtypallel, die aufgrund der Mutation im Defektallel nicht enthalten ist (Schmutz et al. 2002).

\subsubsection{Der Aufhellungsfaktor (Dilute-Faktor)}

\begin{tabular}{ll|}
\hline Chromosom: & CFA25 \\
Gen: & MLPH \\
EMBL: & ID: BN000728 \\
DNA-Sequenz: & CFA25q24 \\
Polymorphismen: & G165A \\
\hline
\end{tabular}

\section{Phänotyp}

Die einzelnen Schattierungen der Fellfärbung sind weder bei brauner oder schwarzer Grundfärbung noch auf der Palette möglicher Färbungen zwischen hellgelb und rot abhängig vom TYRP1-Gen sondern unterliegen dem Effekt eines oder mehrerer weiterer Gene. Bei schwarzer und bei brauner Grundfärbung scheinen verschiedene Schattierungen vom so genannten Dilute-Gen oder Aufhellungsfaktor-Gen gesteuert zu werden.

In einer Reihe verschiedener Rassen tritt der Aufhellungsfaktor häufig in Verbindung mit einer als CDA (colour dilution alopecia) oder BHFD (black hair follicualer dysplasia) bezeichneten Hauterkrankung auf. Leitsymptom ist eine Alopezie, die häufig mit Follikelentzündungen einhergeht. Erste äußerliche Anzeichen sind im Alter zwischen vier und 18 Monaten erkennbar. Die Haut der betroffenen Hunde ist nur spärliche mit kurzen, brüchigen Haaren besetzt. Ingesamt nimmt die Behaarung in caudaler Richtung stetig ab. Die Haut erscheint schuppig. Ein Juckreiz scheint nicht vorzuliegen, da üblicherweise keinerlei Kratzspuren auftreten. Histologische Untersuchungen der Epidermis zeigen in aufgehellt schwarzen Hautbereichen eine 
Hyperpigmentierungen. Entlang der Basalmembran fallen in regelmäßigen Abständen große Klumpen aus zusammengeballten Melaningranula auf. In der oberen Dermis und in den perifollikulären Bereichen treten zahlreiche melaninhaltige Makrophagen auf. Einzelne Follikel erscheinen leicht erweitert und hyperkeratotisch, Medulla, Kortex und Kutikula vieler Haarschäfte enthalten große Melaninaggregate. Auch in Papilla, Matrix und inneren und äußeren Wurzelscheiden sind übermäßig viele Melaninpigmente enthalten. In einigen Fällen liegt eine zystische Erweiterung der Haarfollikel sowie eine sekundäre Follikelentzündung und Furunkelblidung vor, die zu einem papulopustularen Erscheinungsbild der Haut führt (Muller et al. 1989; Finnie und Tham 1993; Roperto et al. 1995; Beco et al. 1996; Kim et al. 2005).

Betroffene Rassen sind blaue, rote und beige Dobermann Pinscher, beige Irische Setter, blaue Dackel, blaue Chow-Chows, blaue Standardpudel, blaue Dänische Doggen, blaue Italienische Greyhounds, blaue Whippets (zusammengefasst bei Muller et al. 1989), Kelpies, Border Collies (Finnie und Tham 1993), Yorkshire Terrier (Roperto et al. 1995), Salukis, Neufundländer, Pinscher, Chihuahuas, Bernersennenhunde, Shetland Schäferhunde, Belgische Schifferspitze (zusammengefasst bei Beco et al. 1996), Deutsche Schäferhunde (Castellano und Idiart 1999) und Weimaraner (Laffort-Dassot et al. 2002).

\section{Genetischer Hintergrund}

Sowohl die Aufhellung des Fells als auch die CDA werden autosomal rezessiv vererbt (Muller et al. 1989; Finnie und Tham 1993; Roperto et al. 1995; Beco et al. 1996; Kim et al. 2005).

Bei Mäusen sind inzwischen mehrere Mutationen in den drei Genen MYO5A, RAB27A und MLPH mit verschiedenen Farbaufhellungsphänotypen assoziiert. Alle drei Gene codieren für Proteine aus dem Melanosomentransportkomplex, und die betreffenden Mutationen sind alle mit Akkumulationen von Melaningranula in der Zellkernumgebung oder großen Pigmentklumpen im Haarschaft assoziiert. Mutationen im MYO5A-Gen, das für Myosin Va codiert, und im RAB27A-Gen sind sowohl bei Menschen als auch bei Mäusen mit einer Aufhellung von Haut- und Haarfarbe assoziiert, die in fast allen bekannten Fällen mit schwerwiegenden neurologischen bzw. immunlogischen Defekten einhergeht (Mercer et al. 1991; Pastural et al. 1997; 
Menasche et al. 2000; Wilson et al. 2000). Mutationen im MLPH-Gen, das für Melanophilin codiert, führen dagegen in den bisher bekannten Fällen zu Farbaufhellungen, ohne weitere Beeinträchtigungen $\mathrm{zu}$ verursachen (Matesic et al. 2001; Menasche et al. 2003). Aus diesen Überlegungen heraus erschien das MLPH-Gen als das wahrscheinlichste Kandidatengen für den Farbaufhellungs- oder DilutePhänotyp beim Hund (Philipp et al. 2005a).

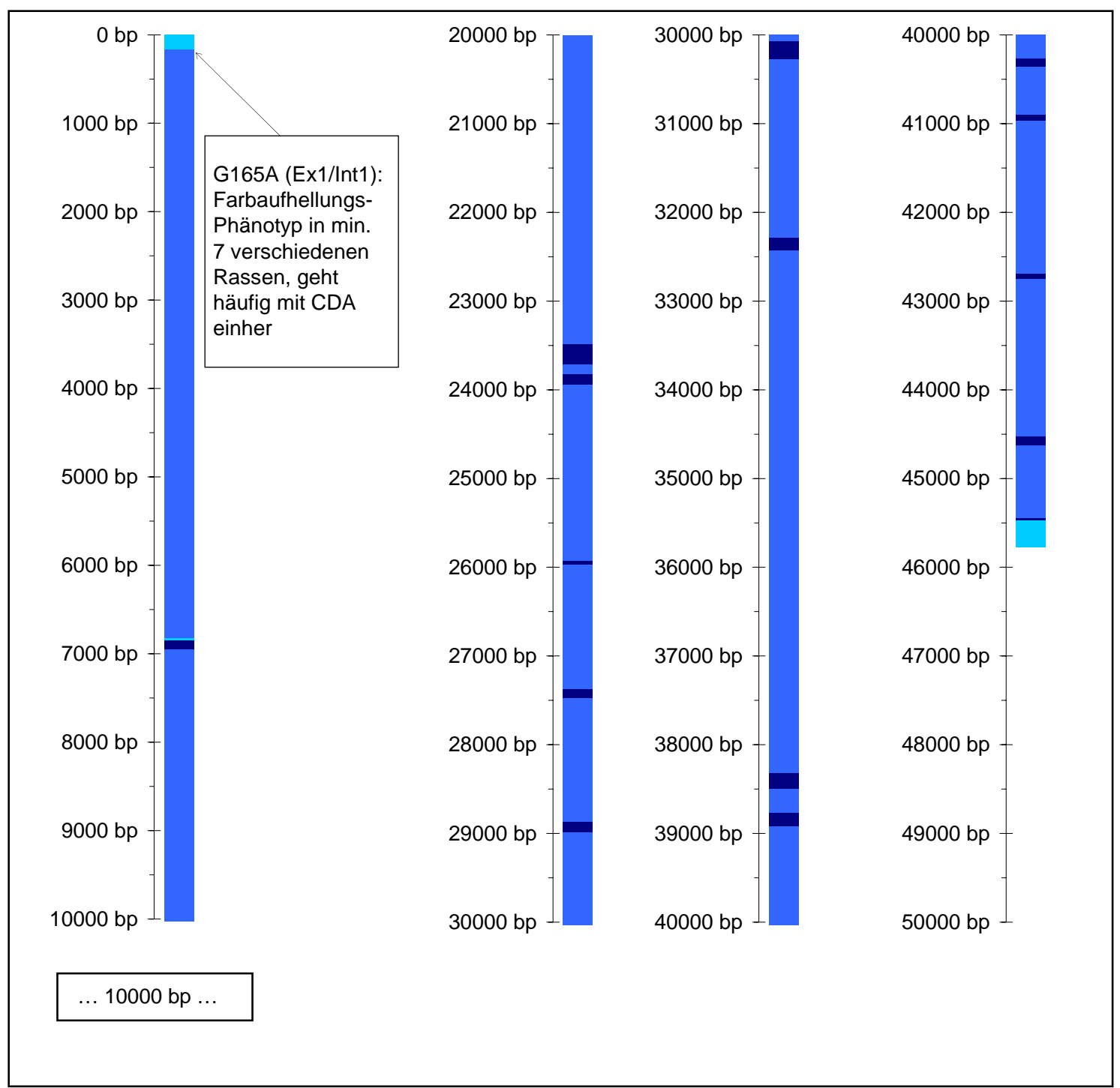

Abb. 145 Schematische Darstellung des caninen MLPH-Gens und Lage der bisher identifizierten Mutationen. Türkis: 5'- und 3'-UTR, dunkelblau: codierende Sequenz, hellblau: Intronsequenz.

Das canine MLPH-Gen konnte mittels FISH auf Chromosom 25q24 lokalisiert werden (Philipp et al. 2005a) und erstreckt sich über ca. 48 kb genomischer Sequenz (EMBLID: BN000728). Die mRNA enthält 1746 Basen codierende Sequenz und ist in 16 Exons unterteilt. Das resultierende Protein hat eine Länge von 581 Aminosäuren 
(Philipp et al. 2005b). Abb. 145 zeigt die Lage der einzelnen Exons innerhalb der genomischen Sequenz basierend auf dem EMBL-Datenbankeintrag BN000728.

\section{Potentiell ursächliche Mutation für den Farbaufhellungsphänotyp in mindestens sieben Rassen}

Im Zuge der Bewertung zahlreicher Polymorphismen im MLPH-Gen bezüglich der Wahrscheinlichkeit eines ursächlichen Zusammenhangs mit dem Farbaufhellungsphänotyp konnte ein Basenaustausch am 3'-Ende von Exon 1 als die wahrscheinlich ursächliche Mutation in sieben Rassen identifiziert werden (Dobermann Pinscher, Deutscher Pinscher, Rhodesian Ridgeback, Beagle, Großer Münsterländer, Amerikanischer Staffordshire Bullterrier und Zwergpinscher).

Der Basenaustausch beinhaltet einen Austausch von Guanin durch Adenin an Position 165 der cDNA (EMBL-ID: BN000728) in der Donor-Spleißerkennungssequenz von Exon 1 (Abb. 146).

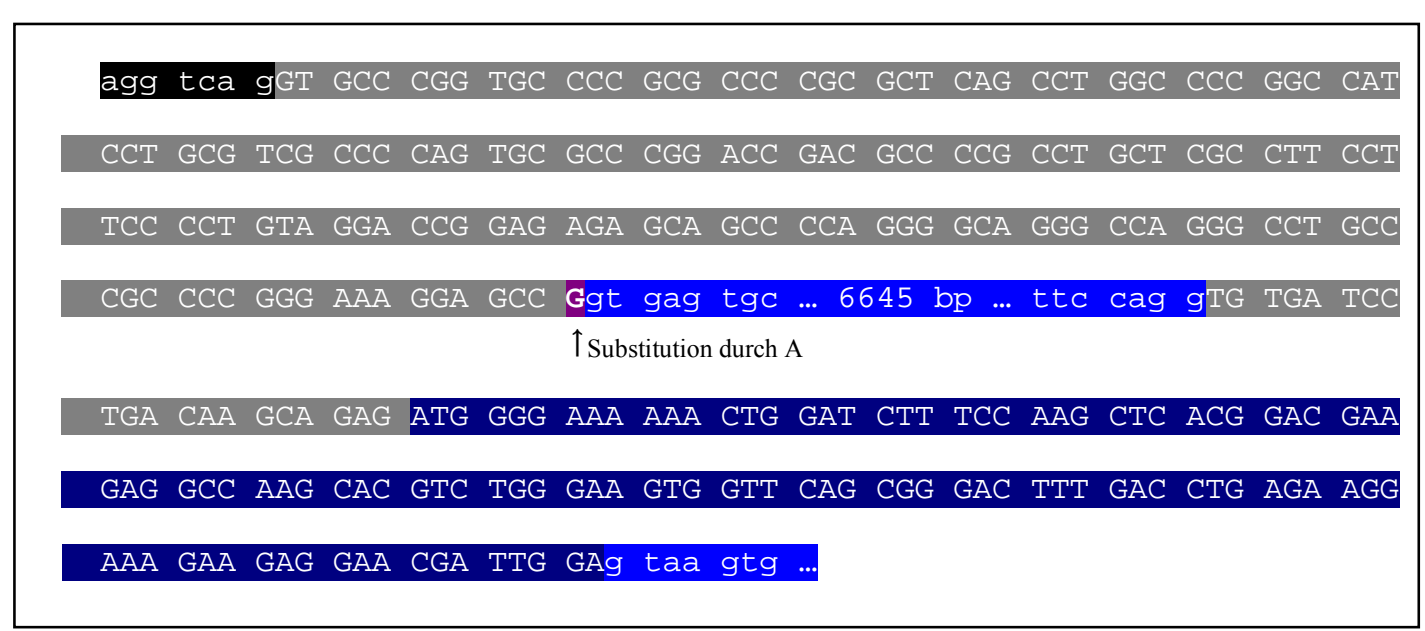

Abb. 146 5'-UTR und Exon 2 des caninen MLPH-Gens und angrenzende Sequenzen. Schwarz: intergenische Sequenz, grau: UTR, hellblau: Intron, dunkelblau: Exon, Substitution violett unterlegt und durch Pfeil gekennzeichnet.

Die Substitution führt laut einer automatischen Spleißstellenanalyse zu einer gegenüber der ursprünglichen Sequenz auf unter $12 \%$ reduzierten Wahrscheinlichkeit für ein korrektes Spleißen von Intron 1. Die Folgen eines inkorrekten Spleißens für die Sequenz der mRNA sind nicht genau absehbar. Eine mRNA-Expressionsstudie anhand von Hautbiopsien zeigt allerdings bei homozygot mutierten Hunden eine im Vergleich zu homozygot normalen Hunden auf durchschnittlich $25 \%$ reduzierte MLPH-mRNAKonzentration. Bei heterozygoten Hunden liegen die mRNA-Konzentrationen im Bereich zwischen normalen Werten und den Werten homozygot mutierter Hunde. Diese 
Überlegungen und Beobachtungen sowie die Lage des Polymorphismus innerhalb der mRNA sprechen dafür, dass es sich um die ursächliche Mutation für den Farbaufhellungsphänotyp handelt. Die Hintergründe des Mechanismus, der bei Vorliegen des Farbaufhellungsphänotyps in einigen Fällen für die Entwicklung der oben beschriebenen Hauterkrankung CDA sorgt, sind noch nicht näher untersucht worden (Drogemuller et al. 2007).

\subsubsection{Die Merlefärbung}

\begin{tabular}{|ll|}
\hline Chromosom: & CFA10 \\
Gen: & SILV \\
NCBI: & Gene-ID: 481102 \\
DNA-Sequenz: & NW_876250, Position 281774-273485 \\
Polymorphismen: & Int10-336InsSINE (3 bp stromaufwärts von Ex11) \\
\hline
\end{tabular}

\section{Phänotyp}

Hunde vom Merle-Phänotyp zeichnen sich durch eine Aufhellung der Grundfellfarbe mit oder ohne die Ausprägung weißer Flecken aus. Zusätzlich treten stets einige oder zahlreiche Fellregionen auf, in denen die Grundfellfarbe in normaler Intensität erscheint. Bei Hunden mit heller Fellgrundfärbung ist die visuelle Unterscheidung zwischen Merle- und Nichtmerle-Phänotyp unter umständen problematisch (Mitchell 1935; Schaible und Brumbaugh 1976; Clark et al. 2006).

Der Erbgang wird als autosomal dominant mit unvollständiger Penetranz beschrieben. Heterozygote Hunde zeigen den oben beschriebenen Phänotyp, homozygote Hunde sind überwiegend weiß (Mitchell 1935). Bei Anpaarungen von homozygoten Trägern der Merlemutation mit Nichtmerle-Hunden entstehen gelegentlich trotz der Dominanz der Merlemutation phänotypische Nichtmerle-Nachkommen. Bei den Nachkommen dieser als kryptische Merle-Hunde bezeichneten Individuen tritt allerdings der Merle-Phänotyp gelegentlich wieder auf (Schaible und Brumbaugh 1976).

Für einige Rassen wie Shetland Schäferhund, Australischer Schäferhund, Cardigan Welsh Corgi und Dackel ist der Merle-Phänotyp vom American Kennel Club (Zuchtverband) als Standardfarbe anerkannt. In der Rasse Dänische Dogge ist dieser Phänotyp zwar nicht akzeptiert, der mit dem Merle-Phänotyp assoziierte Genort ist jedoch in Interaktion mit einem weiteren Genort $(\mathrm{H})$ für die Ausprägung eines erwünschten Harlekin-Musters verantwortlich. In zahlreichen weiteren Rassen wie zum 
Beispiel Catahoula Leopard Dog, Bergamasco Schäferhund und Pyrenäen Schäferhund ist der Merle-Phänotyp von anderen Zuchtverbänden akzeptiert (Clark et al. 2006).

Neben der besonderen Fellfarbe weisen Hunde vom Merle-Phänotyp häufig weitere besondere Merkmale auf. Betroffene Hunde sind typischerweise blauäugig und leiden häufig an verschiedene Formen auditorischer und ophthalmologischer Defekte. Betroffene Rassen sind unter anderem Dackel, Collies, Dänische Doggen, Norwegische Dunkerhounds, Foxhounds, Englische Schäferhunde, Shetland Schäferhunde (Sorsby und Davey 1954; Schaible und Brumbaugh 1976) und Australische Schäferhunde(Sponenberg 1984; Sponenberg und Lamoreux 1985).

In einer Untersuchung des Hörvermögens bei Dackeln konnte beispielsweise bei 54,6 \% aller homozygoten und 36,8 \% aller heterozygoten Träger der Merle-Mutation eine Beeinträchtigung des Hörvermögens festgestellt werden. Dabei reichte die Spanne der diagnostizierten Hörschädigungen von einer leichten Beeinträchtigung bis zu schwerwiegender Taubheit (Reetz et al. 1977).

In einer anderen, ebenfalls bei Dackeln durchgeführten Studie konnte bei homozygoten und heterozygoten Trägern der Merle-Mutation eine signifikant erhöhte Häufigkeit okularer Anomalien festgestellt werden, darunter Erhöhungen des Innenaugendrucks und Ametrophie (Klinckmann et al. 1987; Klinckmann und Wegner 1987).In allen Rassen liegt für homozygote Träger der Merlemutation ein hohes Risiko für das Auftreten subletaler Störungen vor (Sorsby und Davey 1954).

\section{Genetischer Hintergrund}

Über Markeranalysen unter Zugrundelegung des Minimal Screening Sets 2 (Guyon et al. 2003; Clark et al. 2004) konnte der Merle-Genort bei Shetland Schäferhunden in einer Region auf Chromosom 10 lokalisiert werden, die eine konservierte Syntenie mit dem humanen Chromosom 12q13 aufweist (Clark et al. 2006). Das in dieser Region enthaltene SILV-Gen wurde aus verschiedenen Gründen als Kandidatengen für den Merle-Phänotyp ausgewählt: Bei Mäusen sind Mutationen in dem auch als Silber-Lokus bezeichneten SILV-Gen mit einem rezessiv vererbten Phänotyp assoziiert, der durch eine silbrige Aufhellung der Haarfarbe gekennzeichnet ist (Kwon et al. 1995). Dem 
SILV-Protein scheint eine Reihe von Funktionen zuzukommen, die noch nicht abschließend untersucht sind.

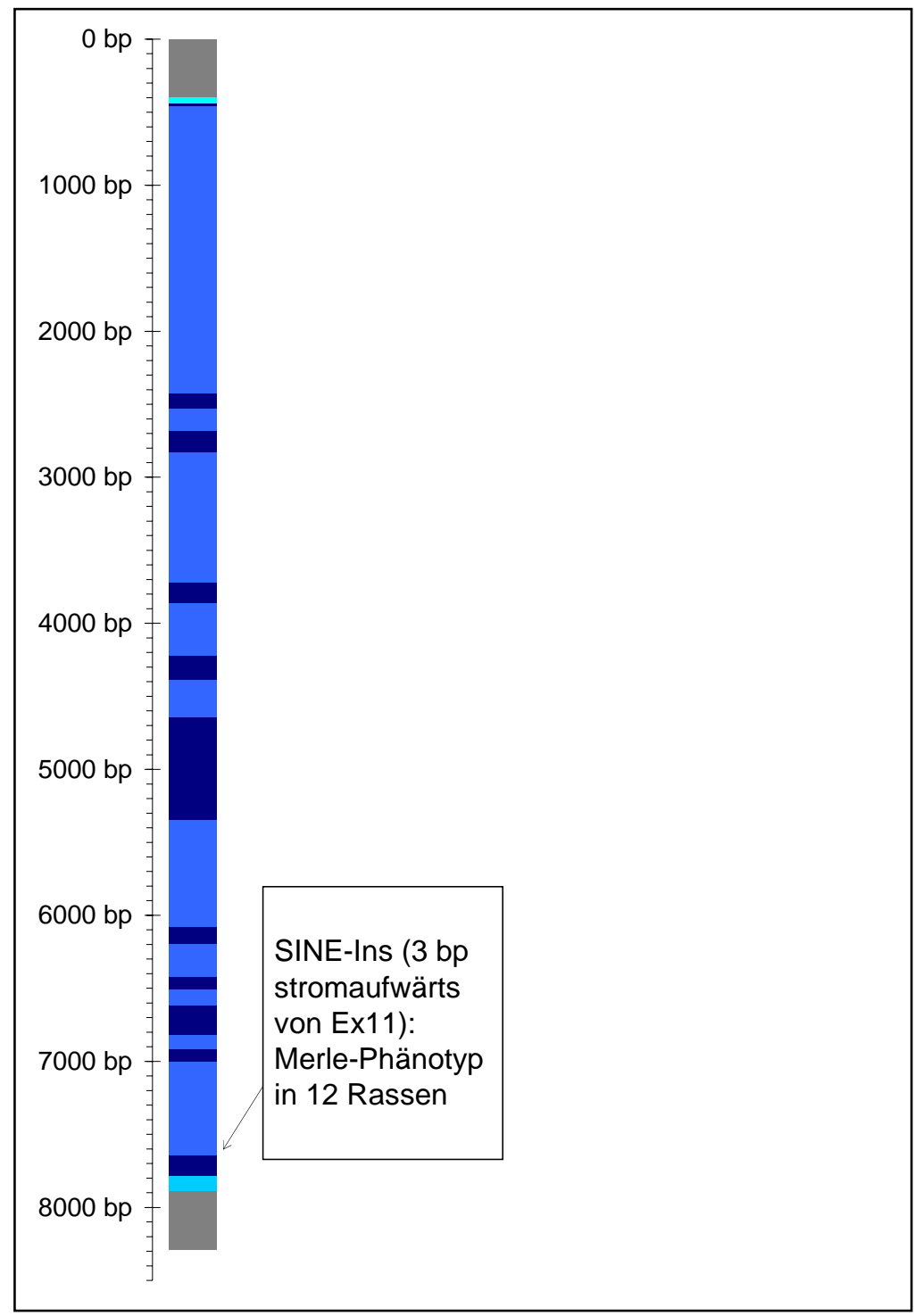

Abb. 147 Schematische Darstellung des caninen SILV-Gens und Lage der bisher identifizierten Mutationen. Dunkelblau: codierende Sequenz hellblau: Intronsequenz, türkis: 5'- und 3'-UTR, grau: intergenische Sequenz

Die Expression des SILV-Gens ist fast ausschließlich auf das Auge und die Haut beschränkt. Offenbar ist das SILV-Protein an der Bildung einer Fibrillenmatrix beteiligt, in der im Verlauf der Reifung der Melaningranula Zwischenprodukte der Melaninbildung abgelagert werden (Theos et al. 2005). Zudem wird dem SILV-Protein eine katalytische Funktion bei der Melaninbiosynthese zugesprochen (Chakraborty et al. 1996; Lee et al. 1996). Eingehende Untersuchungen bei Shetland Schäferhunden führten zur Identifizierung einer SINE-Insertion im caninen SILV-Gen, die mit dem Merle-Phänotyp assoziiert ist (Clark et al. 2006). 
Das canine SILV-Gen enthält 11 Exons (Clark et al. 2006), deren Lage in der genomischen Sequenz in Abb. 147 schematisch dargestellt ist. Im genomischen Contig NW_876250 erstreckt sich das SILV-Gen in revers komplementärer Richtung zwischen Position 281774 und 273485 (NCBI-GeneID: 481102).

\section{Ursächliche Mutation für den Merle-Phänotyp in mindestens zwölf Rassen}

Bei Shetland Schäferhunden mit Merle-Phänotyp liegt im SILV-Gen an der Grenze zwischen Intron 10 und Exon 11 eine im Durchschnitt 235 bp große SINE-Insertion vor, die von einer $15 \mathrm{bp}$ umfassenden target site duplication flankiert wird und in reverser Richtung orientiert ist (Abb. 148). Das heißt, das 5'-Ende der SINE-Insertion grenzt an Exon 11, das 3'-Ende an Intron 10. Die Insertion enthält ein Poly-Adenin-Ende mit einer variierenden Länge zwischen 91 und 101 Adeninnukleotiden (Clark et al. 2006). Die Insertion weist starke Ähnlichkeiten zu einem offenbar nur in der Spezies canis familiaris auftretenden transponiblen Element auf (Minnick et al. 1992).

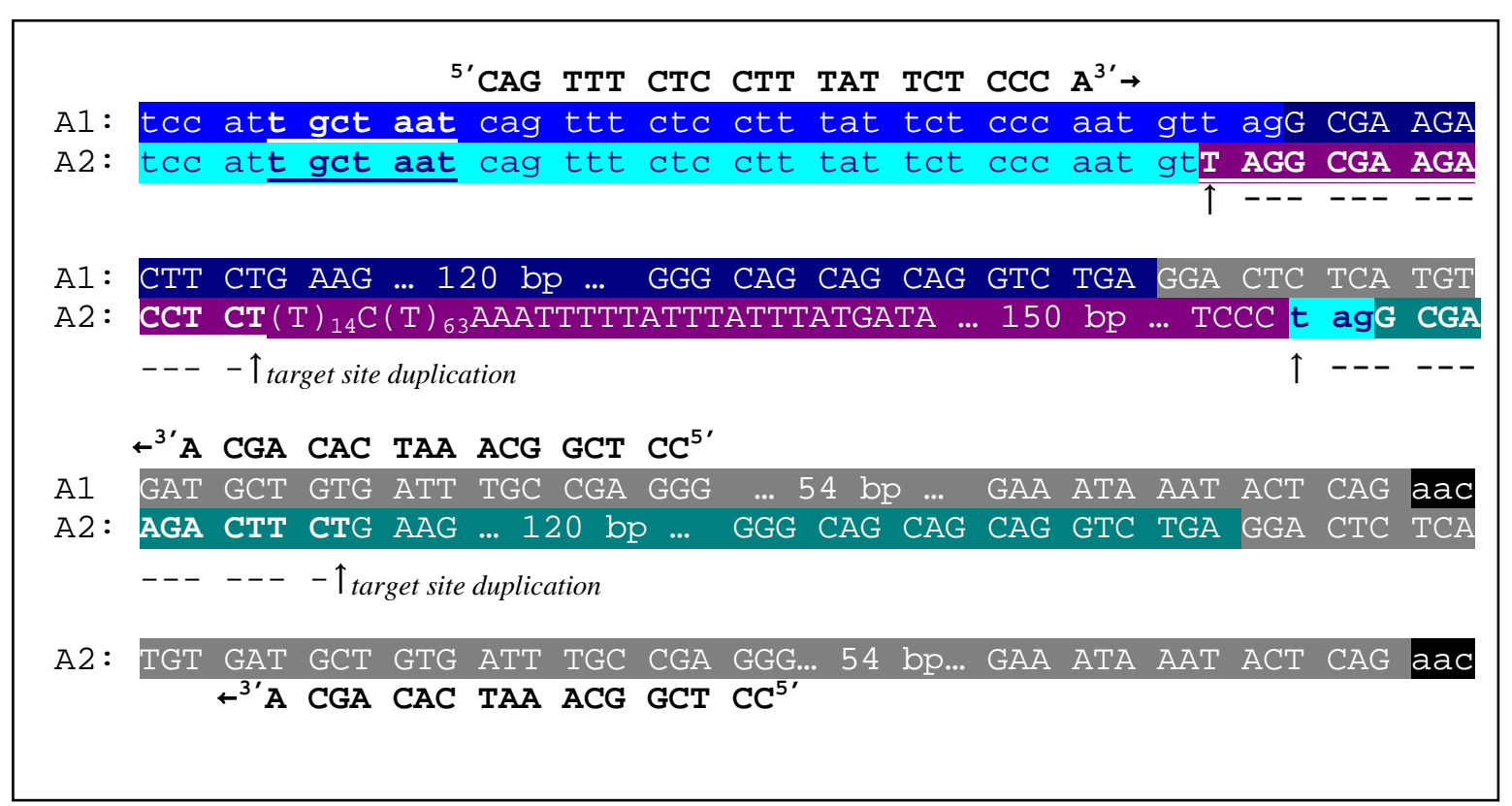

Abb. 148 Exon 11 und 3'-UTR des caninen SILV-Gens und angrenzende Intronsequenz. A1: Sequenz Nichtmerle-Allelsequenz, A2: Merle-Allelsequenz, dunkelblau: Exon Allel 1, dunkelgrün: Exon Allel 2, hellblau: Intron Allel 1, hellgrün: Intron Allel 2, grau: UTR, schwarz unterlegt: angrenzende genomische Sequenz, SINE-Insertion in Allel 2 violett unterlegt, target site duplication in SINE-Sequenz und Allel-2-Sequenz fett gedruckt und durch Pfeil gekennzeichnet.

Als Folge der Insertion ist eine Störung des Spleißvorgangs von Exon 11 zu erwarten. Nähere Untersuchungen in Form einer Analyse von cDNA-Transkripten sind noch nicht erfolgt (Clark et al. 2006). Bei allen zwölf untersuchten Shetland Schäferhunden des Merle-Phänotyps lag die Insertion heterozygot vor, bei zwei untersuchten weißen 
Merle-Shetland-Schäferhunden lag die Insertion homozygot vor. Von 35 untersuchten Nichtmerle-Shetland-Schäferhunden waren 31 frei von der beschriebenen Insertion, die vier übrigen waren Träger einer kleineren SINE-Insertion, die im Gegensatz zu den Merle-Hunden ein verkürztes Poly-Adenin-Ende von variabler Länge zwischen 54 und 65 Adeninnukleotiden aufwiesen. Die beschriebene Insertion konnte außerdem bei Merle-Hunden aus den Rassen Collie, Border Collie, Australischer Schäferhund, Cardigan Welsh Corgi, Dackel, American Pit Bull Terrier, Catahoula Leopard Dog, Chihuahua, Zwergpudel und Pyrenäenschäferhund nachgewiesen werden. Bei Dänischen Doggen vom Harlekin-Phänotyp liegt die Insertion stets entweder homozygot oder heterozygot vor. Diese Beobachtung spricht dafür, dass dieser Phänotyp durch den Effekt eines zusätzlichen weiteren Gens bestimmt wird, und dass das Harlekin-Allel dieses Gens gegenüber dem Merle-Allel dominant ist. Bei 29 Nichtmerle-Hunden aus 26 verschiedenen Rassen konnte die Insertion nicht nachgewiesen werden. Diese Ergebnisse sprechen dafür, dass es sich bei der identifizierten SINE-Insertion um die ursächliche Mutation für den Merle-Phänotyp handelt.Ursache für die Variation in der Länge des Poly-Adenin-Endes ist offenbar das Auftreten einer sekundären Mutation. Die beschriebenen Ergebnisse sprechen für einen Einfluss der Länge des Poly-Adenin-Endes auf die phänotypischen Auswirkungen der SINE-Insertion. Es wird vermutet, dass bei kryptischen Merle-Hunden mit MerleNachkommen eine Keimzellmutation stattfindet, bei der das Poly-Adenin-Ende wieder verlängert wird, so dass es bei den Nachkommen zur Ausprägung des Merle-Phänotyps kommen kann. Zur Bestätigung dieser Vermutung sind weitere Untersuchungen erforderlich (Clark et al. 2006).

\section{Genotypisierung für die Merle-Mutation in mindestens zwölf Rassen}

Der Nachweis der Mutation kann per Amplifikation eines ca. 200-bp-Fragments bzw. bei Vorliegen der Insertion eines 500 bp langen Fragments beginnend in Intron 10 und endend in der 3'-UTR (Abb. 148) und anschließende Fragmentgrößenanalyse erfolgen (Clark et al. 2006).

Für Züchter lässt sich diese Methode nutzen, um bei Hunden mit heller Grundfarbe zwischen Merle- und Nichtmerle-Phänotyp zu unterscheiden, um bei Dänischen Doggen mit Harlekin-Färbung zwischen homozygoten und heterozygoten Trägern der Merlemutation zu unterscheiden und um kryptische Merle-Hunde zu identifizieren. 
Dadurch kann die Zucht von homozygoten Trägern der Merlemutation unterbunden werden, bei denen in allen Rassen ein hohes Risiko für das Auftreten subletaler Störungen vorliegt. (Clark et al. 2006).

Die Methode ist patentiert (Clark et al. 2006; WO/ 2007/022335). 


\subsubsection{Primerliste}

Tabelle 24

Liste der in Kapitel 3.7 genannten Primer

\begin{tabular}{|c|c|c|c|c|}
\hline Krankheit/Merkmal & Zweck & Primer & $\begin{array}{l}\text { PCR- } \\
\text { Produkt } \\
\text { [bp] }\end{array}$ & Quelle \\
\hline \multirow[t]{2}{*}{ MC1R: R306ter } & ASO & 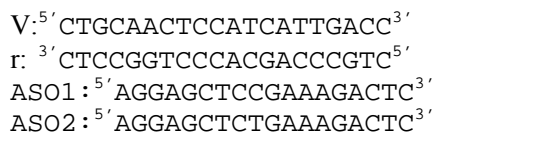 & 122 & $\begin{array}{l}\text { (Newton et } \\
\text { al. 2000) }\end{array}$ \\
\hline & RFLP & 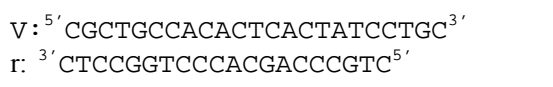 & 99 & $\begin{array}{l}\text { (Schmutz et } \\
\text { al. 2003) }\end{array}$ \\
\hline MC1R: S90G & Sequenzierung & $\begin{array}{l}\mathrm{V}:{ }^{5} \text { GGTCATTGCTGAGCTGACAC }{ }^{3}, \\
\mathrm{r:}{ }^{3} \text { CCCTGATGACCTGTCGTAGAG }\end{array}$ & & $\begin{array}{l}\text { (Newton et } \\
\text { al. 2000) }\end{array}$ \\
\hline Agouti: R96C & Sequenzierung & $\begin{array}{l}\mathrm{V}:{ }^{5} \text { GATGTCTGGTCTGGAGCCTC } \\
\text { r: }:^{3} \text { CGCAAGAGTGAGGGTCTACGACT }\end{array}$ & & $\begin{array}{l}\text { (Kerns et al. } \\
\text { 2004) }\end{array}$ \\
\hline Agouti: A82S & RFLP & $\begin{array}{l}\mathrm{V}: 5^{\prime} \text { GATGTCTGGTCTGGAGCCTC }{ }^{3}, \\
\mathrm{r}^{3}{ }^{\prime} \text { CGCAAGAGTGAGGGTCTACGACT }\end{array}$ & 285 & $\begin{array}{l}\text { (Berryere et } \\
\text { al. 2005) }\end{array}$ \\
\hline TYRP1: Q331ter & RFLP & $\begin{array}{l}\mathrm{V}: 5^{\prime} \text { ACCAATGGTGCAACGTCTTCCTGAAC } \\
\mathrm{CG}^{3} \text { ' } \\
\text { r: }{ }^{3} \text { GTCAAAGGCTTTGTGTCACCTTCCG }{ }^{5}\end{array}$ & 121 & $\begin{array}{l}\text { (Schmutz et } \\
\text { al. 2002) }\end{array}$ \\
\hline
\end{tabular}

V: Vorwärtsprimer, r: reverser Primer, ASO1: spezifisches Oligonukleotid für Allel 1, ASO2: spezifisches Oligonukleotid für Allel 2 


\subsubsection{Literatur}

Barsh, G., Gunn, T., He, L., Schlossman, S. und Duke-Cohan, J. (2000): Biochemical and genetic studies of pigment-type switching. Pigment Cell Res, 13 Suppl 8, 48-53.

Beco, L., Fontaine, J., Gross, T. und Charlier, G. (1996): Colour dilution alopecia in seven Dachshunds. A clinical study and the hereditary, microscopical and ultrastructural aspect of the disease. Veterinary Dermatology, 7, 91-97.

Berryere, T.G., Kerns, J.A., Barsh, G.S. und Schmutz, S.M. (2005): Association of an Agouti allele with fawn or sable coat color in domestic dogs. Mamm Genome, 16 (4), 262-72.

Burns, M. und Fraser, M. (1966): Genetics of the dog. The basis of successful breeding. (2nd Edition) Oliver \& Boyd, Edinburg 1966.

Castellano, M. und Idiart, J. (1999): Colour Dilution Alopecia in a German Shepherd Dog. Canine Practice, 24 (5), 6-7.

Chakraborty, A.K., Platt, J.T., Kim, K.K., Kwon, B.S., Bennett, D.C. und Pawelek, J.M. (1996): Polymerization of 5,6-dihydroxyindole-2-carboxylic acid to melanin by the pmel 17/silver locus protein. Eur J Biochem, 236 (1), 180-8.

Chen, Y., Duhl, D.M. und Barsh, G.S. (1996): Opposite orientations of an inverted duplication and allelic variation at the mouse agouti locus. Genetics, 144 (1), 265-77.

Clark, L.A., Wahl, J.M., Rees, C.A. und Murphy, K.E. (2006): Retrotransposon insertion in SILV is responsible for merle patterning of the domestic dog. Proc Natl Acad Sci U S A, 103 (5), 1376-81.

Clark, L.A., Tsai, K.L., Steiner, J.M., Williams, D.A., Guerra, T., Ostrander, E.A., Galibert, F. und Murphy, K.E. (2004): Chromosome-specific microsatellite multiplex sets for linkage studies in the domestic dog. Genomics, 84 (3), 550-4.

Drogemuller, C., Wohlke, A. und Distl, O. (2005): Characterization of candidate genes for neuronal ceroid lipofuscinosis in dog. J Hered, 96 (7), 735-8.

Drogemuller, C., Philipp, U., Haase, B., Gunzel-Apel, A.R. und Leeb, T. (2007): A noncoding melanophilin gene (MLPH) SNP at the splice donor of exon 1 represents a candidate causal mutation for coat color dilution in dogs. $J$ Hered, 98 (5), 468-73.

Everts, R.E., Rothuizen, J. und van Oost, B.A. (2000): Identification of a premature stop codon in the melanocyte-stimulating hormone receptor gene (MC1R) in Labrador and Golden retrievers with yellow coat colour. Anim Genet, 31 (3), 194-9. 
Finnie, J.W. und Tham, V.L. (1993): Colour mutant alopecia in a kelpie x border collie dog. Aust Vet J, 70 (10), 388-9.

Guyon, R., Lorentzen, T.D., Hitte, C., Kim, L., Cadieu, E., Parker, H.G., Quignon, P., Lowe, J.K., Renier, C., Gelfenbeyn, B., Vignaux, F., DeFrance, H.B., Gloux, S., Mahairas, G.G., Andre, C., Galibert, F. und Ostrander, E.A. (2003): A 1-Mb resolution radiation hybrid map of the canine genome. Proc Natl Acad Sci U S A, 100 (9), 5296-301.

Kerns, J.A., Newton, J., Berryere, T.G., Rubin, E.M., Cheng, J.F., Schmutz, S.M. und Barsh, G.S. (2004): Characterization of the dog Agouti gene and a nonagoutimutation in German Shepherd Dogs. Mamm Genome, 15 (10), 798808.

Kijas, J.M., Wales, R., Tornsten, A., Chardon, P., Moller, M. und Andersson, L. (1998): Melanocortin receptor 1 (MC1R) mutations and coat color in pigs. Genetics, 150 (3), 1177-85.

Kim, J.H., Kang, K.I., Sohn, H.J., Woo, G.H., Jean, Y.H. und Hwang, E.K. (2005): Color-dilution alopecia in dogs. J Vet Sci, 6 (3), 259-61.

Klinckmann, G. und Wegner, W. (1987): [Tonometry in Merle dogs]. Dtsch Tierarztl Wochenschr, 94 (6), 337-8.

Klinckmann, G., Koniszewski, G. und Wegner, W. (1987): [Light microscopy studies of the cornea of Merle dachshunds]. Dtsch Tierarztl Wochenschr, 94 (6), 338-41.

Klungland, H., Vage, D.I., Gomez-Raya, L., Adalsteinsson, S. und Lien, S. (1995): The role of melanocyte-stimulating hormone (MSH) receptor in bovine coat color determination. Mamm Genome, 6 (9), 636-9.

Kwon, B.S., Halaban, R., Ponnazhagan, S., Kim, K., Chintamaneni, C., Bennett, D. und Pickard, R.T. (1995): Mouse silver mutation is caused by a single base insertion in the putative cytoplasmic domain of Pmel 17. Nucleic Acids Res, 23 (1), 154-8.

Laffort-Dassot, C., Beco, L. und Carlotti, D.N. (2002): Follicular dysplasia in five Weimaraners. Vet Dermatol, 13 (5), 253-60.

Lee, Z.H., Hou, L., Moellmann, G., Kuklinska, E., Antol, K., Fraser, M., Halaban, R. und Kwon, B.S. (1996): Characterization and subcellular localization of human Pmel 17/silver, a 110-kDa (pre)melanosomal membrane protein associated with 5,6,-dihydroxyindole-2-carboxylic acid (DHICA) converting activity. $J$ Invest Dermatol, 106 (4), 605-10.

Little, C. (1914): Inheritance of coat color in Pointer dogs. Journal of Heredity, 5, 244248.

Little, C. (1934): Inheritance in Toy Griffons. Journal of Heredity, 25, 198-200.

Little, C. (1957): The inheritance of coat color in dogs. Howell, New York 1957. 
Matesic, L.E., Yip, R., Reuss, A.E., Swing, D.A., O'Sullivan, T.N., Fletcher, C.F., Copeland, N.G. und Jenkins, N.A. (2001): Mutations in Mlph, encoding a member of the Rab effector family, cause the melanosome transport defects observed in leaden mice. Proc Natl Acad Sci U S A, 98 (18), 10238-43.

Menasche, G., Ho, C.H., Sanal, O., Feldmann, J., Tezcan, I., Ersoy, F., Houdusse, A., Fischer, A. und de Saint Basile, G. (2003): Griscelli syndrome restricted to hypopigmentation results from a melanophilin defect (GS3) or a MYO5A Fexon deletion (GS1). J Clin Invest, 112 (3), 450-6.

Menasche, G., Pastural, E., Feldmann, J., Certain, S., Ersoy, F., Dupuis, S., Wulffraat, N., Bianchi, D., Fischer, A., Le Deist, F. und de Saint Basile, G. (2000): Mutations in RAB27A cause Griscelli syndrome associated with haemophagocytic syndrome. Nat Genet, 25 (2), 173-6.

Mercer, J.A., Seperack, P.K., Strobel, M.C., Copeland, N.G. und Jenkins, N.A. (1991): Novel myosin heavy chain encoded by murine dilute coat colour locus. Nature, 349 (6311), 709-13.

Minnick, M.F., Stillwell, L.C., Heineman, J.M. und Stiegler, G.L. (1992): A highly repetitive DNA sequence possibly unique to canids. Gene, 110 (2), 235-8.

Mitchell, A. (1935): Dominant dilution and other color factors in collie dogs. Journal of Heredity, 26 (10), 425-30.

Muller, G., Kirk, R. und Scott, D. (1989): Small animal dermatology. (4th) Saunders, Philadelphia, 1989.

Newton, J.M., Wilkie, A.L., He, L., Jordan, S.A., Metallinos, D.L., Holmes, N.G., Jackson, I.J. und Barsh, G.S. (2000): Melanocortin 1 receptor variation in the domestic dog. Mamm Genome, 11 (1), 24-30.

Pastural, E., Barrat, F.J., Dufourcq-Lagelouse, R., Certain, S., Sanal, O., Jabado, N., Seger, R., Griscelli, C., Fischer, A. und de Saint Basile, G. (1997): Griscelli disease maps to chromosome $15 \mathrm{q} 21$ and is associated with mutations in the myosin-Va gene. Nat Genet, 16 (3), 289-92.

Philipp, U., Quignon, P., Scott, A., Andre, C., Breen, M. und Leeb, T. (2005a):

Chromosomal assignment of the canine melanophilin gene (MLPH): a candidate gene for coat color dilution in Pinschers. J Hered, 96 (7), 774-6.

Philipp, U., Hamann, H., Mecklenburg, L., Nishino, S., Mignot, E., Gunzel-Apel, A.R., Schmutz, S.M. und Leeb, T. (2005b): Polymorphisms within the canine MLPH gene are associated with dilute coat color in dogs. BMC Genet, 6, 34.

Reetz, I., Stecker, M. und Wegner, W. (1977): Deutsche Tierärztliche Wochenschrift, 84, 273-277. 
Robbins, L.S., Nadeau, J.H., Johnson, K.R., Kelly, M.A., Roselli-Rehfuss, L., Baack, E., Mountjoy, K.G. und Cone, R.D. (1993): Pigmentation phenotypes of variant extension locus alleles result from point mutations that alter MSH receptor function. Cell, 72 (6), 827-34.

Roperto, F., Cerundolo, R., Restucci, B., Vincensi, M., DeCaprariis, D., DeVico, G. und Maiolino, P. (1995): Colour Dilution Alopecia (CDA) in Ten Yorkshire Terriers. Veterinary Dermatology, 6 (4), 171.178.

Russell, E.S. (1946): A Quantitative Histological Study of the Pigment Found in the Coat-Color Mutants of the House Mouse. I. Variable Attributes of the Pigment Granules. Genetics, 31 (3), 327-46.

Schaible, R.H. und Brumbaugh, J.A. (1976): Electron Microscopy of Pigment Cells in Variegated and Nonvariegated, Piebald-Spotted Dogs. Pigment Cell, 3, 191-200.

Schmutz, S.M., Berryere, T.G. und Goldfinch, A.D. (2002): TYRP1 and MC1R genotypes and their effects on coat color in dogs. Mamm Genome, 13 (7), 380-7.

Schmutz, S.M., Moker, J.S., Berryere, T.G., Christinson, K.M. und Dolf, G. (2001): A SNP is used to map MC1R to dog chromosome 5. Anim Genet, 32, 40-53.

Schmutz, S.M., Berryere, T.G., Ellinwood, N.M., Kerns, J.A. und Barsh, G.S. (2003): MC1R studies in dogs with melanistic mask or brindle patterns. J Hered, 94 (1), 69-73.

Sorsby, A. und Davey, J. (1954): Ocular associations of dappling (or merling) in the coat colour of dogs. J Genet, 52, 425-440.

Sponenberg, D.P. (1984): Germinal reversion of the merle allele in Australian shepherd dogs. J Hered, 75 (1), 78.

Sponenberg, D.P. und Lamoreux, M.L. (1985): Inheritance of tweed, a modification of merle, in Australian shepherd dogs. J Hered, 76 (4), 303-4.

Theos, A.C., Truschel, S.T., Raposo, G. und Marks, M.S. (2005): The Silver locus product Pmel17/gp100/Silv/ME20: controversial in name and in function. Pigment Cell Res, 18 (5), 322-36.

Vrieling, H., Duhl, D.M., Millar, S.E., Miller, K.A. und Barsh, G.S. (1994): Differences in dorsal and ventral pigmentation result from regional expression of the mouse agouti gene. Proc Natl Acad Sci U S A, 91 (12), 5667-71.

Willis, M.B. (1989): Genetics of the dog. H.F.\&G. Witherby LTD, London 1989.

Wilson, S.M., Yip, R., Swing, D.A., O'Sullivan, T.N., Zhang, Y., Novak, E.K., Swank, R.T., Russell, L.B., Copeland, N.G. und Jenkins, N.A. (2000): A mutation in Rab27a causes the vesicle transport defects observed in ashen mice. Proc Natl Acad Sci U S A, 97 (14), 7933-8. 
WO/ (2007/022335): Methods for identification of merle gen. World Intellectual Property Organization,

http://www.wipo.int/patentscopedb/en/fetch.jsp?LANG=ENG\&DBSELECT $=\mathrm{P}$ CT\&SERVER TYPE $=19 \&$ SORT $=1222069-$

KEY\&TYPE FIELD $=256 \& I D B=0 \& I D O C=1305254 \& C=10 \& E L E M E N T$ SET $=$ B \&RESULT $=1 \&$ TOTAL $=2 \&$ START $=1 \& D I S P=25 \& F O R M=$ SEP-

0/HITNUM,B-ENG,DP,MC,AN,PA,ABSUM-

ENG\&SEARCH IA=US2006032100\&QUERY $=\% 28 \mathrm{FP} \% 2 \mathrm{f} 708589 \% 29$ 


\section{Zusammenfassung/Abstract}

\subsection{Zusammenfassung}

Ziel der vorliegenden Arbeit war die Erstellung einer Übersicht über alle monogenen Erbkrankheiten und -merkmale bei Hunden, deren molekulargenetische Ursachen bisher (Stand: Oktober 2007) identifiziert werden konnten. Ein besonderer Schwerpunkt lag dabei auf der Darstellung der verfügbaren Genotypisierungsmethoden.

Im Vergleich zu anderen Spezies herrscht auf dem Gebiet der Genomanalyse bei Hunden eine auffallend hohe Forschungsaktivität. Die erste Kopplungskarte wurde 1997 veröffentlicht und ist seitdem stetig erweitert worden. Seit 2001 steht eine integrierte Kopplungskarte zu Verfügung. Ein weiterer Meilenstein war die erste Assemblierung der Sequenz des gesamten caninen Genoms CanFam1.0 im Juli 2004. Seit Mai 2005 ist eine überarbeitete Version (CanFam2.0, Mai 2005) verfügbar. Das große Interesse an der Spezies Canis familiaris in diesem Zusammenhang ist vor allem durch die besondere Eignung des Hundes als Modelltier für humane Erbkrankheiten und -merkmale begründet. Die relativ starke Inzucht innerhalb von Rassen führt zum Auftreten zahlreicher monogener Erbkrankheiten, die phänotypisch und, wie die Forschungsergebnisse der letzten Jahre zeigen, häufig auch genotypisch homolog zu Erkrankungen des Menschen sind. Die Zahl der beim Hund im Zusammenhang mit Erbkrankheiten oder bestimmten morphologischen Merkmalen identifizierten Genmutationen ist in den letzten Jahren rapide angestiegen.

Die Nutzung der ständig wachsenden Menge an Daten, die sich aus der beschriebenen Entwicklung ergeben, ist nicht nur für die humanmedizinische Forschung von Interesse, sondern bietet Hundezüchtern die Möglichkeit, über den Einsatz molekulargenetischer Genotypisierungsmethoden mit einer hohen Effizienz gegen Erbkrankheiten und unerwünschte morphologische Merkmale zu selektieren.

Inzwischen konnten 86 pathogene Mutationen in 64 Genen als Ursache für bestimmte canine Erbkrankheiten identifiziert werden. Für 66 Mutationen sind DNA-Tests etabliert worden. Ein weiterer DNA-Test zum Nachweis einer pathogenen Mutation beruht auf der Assoziation eines Haplotyps mit der nachzuweisenden Erkrankung. 
Außerdem sind neun Polymorphismen in fünf Genen beschrieben worden, die mit bestimmten Farbvarianten des Fells und der Nase assoziiert sind. Für sieben dieser Polymorphismen sind DNA-Tests entwickelt worden. (Stand: Oktober 2007)

Trotz zahlreicher Quellen (OMIA, Liste der Universität Bern: „Gentests beim Hund“, Internetseiten verschiedener Firmen und Einrichtungen, die Gentests anbieten und Patentschriften) sind die wesentlichen Detailinformationen oft erst nach längerem Suchen auffindbar. Die vorliegende Arbeit bietet die Grundlage für die Erstellung eines Handbuches, um Tierärzten und Hundezüchtern den Zugang zu verfügbaren DNA-Tests bei Hunden zu erleichtern. 


\subsection{Abstract}

The objective of the present thesis was to compile all monogenic hereditary diseases and traits whose molecular genetic causes have been identified to date (status quo in October 2007). Special emphasis was placed on the characterization of existing genotyping methods.

Compared to other species there is strikingly intense research activity in the field of dog genome analysis. The first linkage map was published in 1997 and has been continuously expanded ever since. An integrated linkage map has been available since 2001. A further milestone was the first compilation of the complete dog genome sequence CanFam1.0 in July 2004, and a revised version of it was released in May 2005 (CanFam2.0, May 2005). In this context, the extraordinary interest in the species Canis familiaris is primarily due to dog's particular suitability as animal models in the investigation of human hereditary diseases and traits. The relatively intense inbreeding within dog breeds has resulted in the occurrence of numerous monogenic hereditary diseases which are homologous to human diseases with regard to both the phenotype and, as scientific results of the last several years have demonstrated, frequently the genotype as well. In the course of the last few years the number of identified genetic mutations in the dog associated with hereditary diseases or certain morphological traits has risen rapidly.

The utilization of the steadily increasing quantity of data resulting from the developments described here is not only of interest to human medical science but also gives dog breeders the possibility to select against hereditary diseases or undesirable morphological traits in a highly efficient manner by applying molecular genetic genotyping methods.

By now 86 pathogenic mutations in 64 genes have been identified as causes of certain canine hereditary diseases. Direct DNA-tests have been established for the detection of 66 of these mutations. An additional pathogenic mutation is associated with a specific haplotype that can be detected by a DNA-test. Additionally, nine polymorphisms in five genes that are associated with certain coat and skin colours have been described. DNAtests have been developed for seven of these polymorphisms. 
Despite the existence of numerous sources (OMIA, the University of Bern's list: “Gentests beim Hund”, patent specifications and homepages of different companies or organizations offering DNA-tests) fundamental detailed information frequently cannot be found without time-consuming research. The present thesis provides a basis for the preparation of a manual to facilitate veterinarians and dog breeders' access to available dog DNA-tests. 